UNIVERSIDAD POLITÉCNICA DE MADRID

Escuela Técnica Superior de Edificación

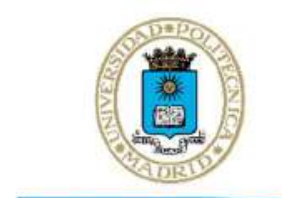

POLITÉCNICA

\title{
COMPORTAMIENTO SULFÁTICO Y MECÁNICO- RESISTENTE DE CEMENTOS PORTLAND CON ELEVADOS CONTENIDOS DE PUZOLANAS (> 40\%): SU FUNDAMENTO QUÍMICO Y JUSTIFICACIÓN DE OTRAS CONSECUENCIAS POSIBLES
}

\author{
M E M O R I A \\ de Tesis Doctoral para optar al grado de \\ DOCTOR por la UNIVERSIDAD POLITÉCNICA DE MADRID \\ en el programa de doctorado Innovación Tecnológica en Edificación
}

\section{CARLOS HERNANDO ARAMBURO VARELA \\ Ingeniero Mecánico}

Realizada bajo la DIRECCIÓN de:

D. RAFAEL TALERO MOLARES

Doctor en Química Industrial y Doctor en Farmacia

D. MARIANO GONZÁLES CORTINA

Doctor Arquitecto 

Al Cementero, Investigador y/o Docente para que encuentre en esta investigación una ampliación de su conocimiento y una puerta abierta hacia los desempeños y prestaciones de los diferentes cementos mezclados al trabajar con materiales puzolánicos y haga de esta información una contribución a la sostenibilidad de la Industria.

"No puede impedirse el viento pero hay que saber hacer molinos"

Miguel de Cervantes Saavedra (1547 - 1616) 



\section{AGRADECIMIENTOS}

Al inspirador de esta Tesis, Rafael Talero Morales Dr. En Química Industrial y Licenciado en Farmacia, que con su incansable pasión imprimió en mí la fuerza para decidir enfrentar este cometido. Por su ejemplo de tenacidad de un ser humano que a la edad de 73 años presenta su segunda Tesis Doctoral y por permitir en su calidad de Codirector, enriquecer mi carrera en cemento con su amplio conocimiento.

A la constante presencia y acompañamiento intelectual y moral de mi mentor y amigo Dr. Cesar Pedrajas Nieto-Márquez que con su permanente aliento impulsó el día a día de este arduo proceso.

Al Codirector de esta Tesis Doctoral Dr. Mariano González Cortina por su guía y aportes en el deber ser.

Al voto de confianza que depositó en mí Dr. Juan Esteban Calle, Presidente de Cementos Argos S.A., quien permitió el desarrollo e implementación de nuevas tecnologías de producción de puzolanas naturales calcinadas y la aplicación de todo lo aprendido y demostrado en esta Tesis Doctoral.

Al Instituto de Ciencias de la Construcción "Eduardo Torroja" del CSIC en la persona de su Director, Dr. Ángel Castillo Talavera, por todas las facilidades que me brindó para poder llevar a cabo y materializar esta Tesis Doctoral cuyos análisis químicos, ensayos físicos y mecánicos se realizaron en su totalidad en sus Laboratorios y demás instalaciones y técnicas analíticas avanzadas que se requirieron.

Al apoyo de la Universidad Politécnica de Madrid en la persona de su Subdirector de Investigación, Doctorado y Postgrado de la Escuela Técnica de Edificación, Dr Joaquin Santiago y su equipo de trabajo, por contribuir en mi formación de investigador y en especial por la comprensión de mi situación semi-presencial y apoyo en las diferentes actividades.

Al apoyo definitivo de mi esposa Piedad González Guzmán en esos momentos que sentía ya casi desfallecer y abandonar.

Al apoyo emocional incondicional de mis hijos Sara, Lina y Santiago que siempre han creído en mí. 

RESUMEN 

Esta tesis Doctoral surge como una línea futura de Investigación a partir de los resultados obtenidos por Talero (1986), donde la dependencia del grado de RS o RM a edades iniciales de un Cemento de mezcla constituido por Portland y Puzolana, única y exclusivamente y con un contenido de esta última del $20 \%, 30 \%$ ó $40 \%$, en peso, de la puzolana que lo constituye, no hacen que el grado de RS ó RM a edades iniciales de sus cementos de mezcla respectivos, resulte ser siempre superior al correspondiente de su Cemento Portland P o PY, constitutivo solo, y viceversa, sino tan sólo las adecuadas para cada fin.

Sin embargo, el aumento de RS, que poseen un grado de RS superior al de su CPM constitutivo sólo, se originó por lo común en los correspondientes cementos de mezcla 60/40, o sea, con un $40 \%$ en peso de puzolana. Siendo además por ello calificados de moderada o elevada RS en todos los casos, mientras que los 80/20 no lo fueron.

Tales generalizaciones anteriores se verificaron con mayor razón cuanto más alumínica que silícica era la puzolana constitutiva.

Por lo tanto, cabe la posibilidad de podernos hacer las siguientes preguntas con fundamento:

$1^{\text {a }} \quad$ ¿Es posible que una puzolana dada que ha demostrado no sólo no impedir el ataque de los iones sulfatos al cemento Portland que la acompaña, pueda llegar a comportarse de forma totalmente contraria ante dicho ataque agresivo al serle añadida en cantidades superiores al $40 \%$ haciéndolo incluso sulfato-resistente en mayor o menor grado al nuevo cemento de mezcla?

$2^{\underline{a}} \quad$ ¿Es posible que la idea anterior se puede hacer extensiva cualitativamente y en 
idéntica medida, al resto de las puzolanas naturales y artificiales ensayadas, con diferentes cantidades presentes de cada puzolana, según sea su carácter químico?

$3^{\text {a }} \quad$ En el supuesto posible de que la mayor presencia de puzolana en detrimento de cemento Portland y consecuentemente de portlandita $\mathrm{Ca}(\mathrm{OH})_{2}$ proveniente de su hidratación, pudiera ser el motivo del aparente mejor comportamiento de dicha puzolana por alumínica que sea a partir de una cantidad presente de la misma en adelante en el cemento de mezcla ¿Cómo se comportaría en el ensayo correspondiente de RMC y RMF en mortero normalizado RC-75?

Estos cuestionamientos dan origen a esta Tesis Doctoral y se propone evaluar experimentalmente la resistencia sulfática de los cementos Puzolánicos de la vigente Instrucción para la Recepción de Cementos RC-16 y de la norma UNE-EN 197-1:2011 o cementos tipo CEM IV/A-SR y IV/B-SR, constituidos por cualquier cemento Portland ordinario (CPO) y cualquier puzolana natural* y/o artificial*, esté contemplada o no incluso por dicha Instrucción, pero adicionada al mismo desde un nivel de reemplazo superior al 40\%, y determinar por qué motivo son más resistentes aún al ataque de los sulfatos cuanto mayor es su nivel de reemplazo. De igual manera evaluar la afectación de las resistencias mecánicas a Compresión y Flexotracción de dichos cementos adicionados y su comportamiento frente al ataque del $\mathrm{CO}_{2}$ del aire o Carbonatación Negativa, en condiciones favorables de humedad relativa y a temperatura ambiente, en ambos casos determinar la razón de su comportamiento.

Los resultados obtenidos confirman la tesis descrita en los Objetivos de esta Investigación del aumento de la RS y de la carbonatación negativa y disminución de las RM de un cemento Portland cuando se reemplaza por puzolana en cantidades mayores del $40 \%$, este resultado es consecuencia del efecto químico derivado de la actividad puzolánica que logra generar y desarrollar la considerable cantidad de puzolana con la que se mezcló ocasionando adicionalmente un descenso considerable de la portlandita en la fase líquida de su pasta que es la que provoca en definitiva, el aumento de RS y la disminución de RM además de promoverle su mayor degradación ulterior por carbonatación negativa.

Estos resultados de la presente TD, difieren del mal comportamiento mostrado por los cementos de mezcla en la Tesis Doctoral de Talero (1986) cuando su reemplazo no superó el 40\%. 
ABSTRACT 

This $\mathrm{PhD}$ dissertation emerges as a future research guideline taken from the results obtained by Talero (1986) where the different RS or RM grades in a blended cement formed by Portland cement and pozzolan at early age did not imply superior results when compared with the corresponding Portland P or PY. The different pozzolan percentages added to Portland were $20 \%, 30 \%, 40 \%$ by weight.

Moderate or elevated RS began to show when the RS increased for blended cement of $60 / 40$ that is, $40 \%$ pozzolan by weight while the $80 / 20$ were not RS.

The above conclusions were verified more obviously when the given pozzolan was more aluminic than silicic in character.

The following questions arose:

1. Is it possible that a given pozzolan that shows not to avoid sulfate ions action to Portland cement can change to an opposite behavior when increased over $40 \%$, turning even sulfate resistant in the resulting blended cement?

2. Can this idea be qualitatively extended in the same measure to the rest of either natural or artificial pozzolans tested, taking in consideration quantity and chemical character of every pozzolan?

3. Could the higher pozzolan content in the Portland cement detriment along with the less portlandite content $\mathrm{Ca}(\mathrm{OH})_{2}$ resulting from its hydration, be the reason for better pozzolan performance in addition to its aluminic character, How would the performance be in the RMC and RMF test in a normalized mortar RC-75? 
The above questions were the objective of this dissertation. It was proposed to experimentally determine the sulfatic resistance of pozzolanic cements, from the Cement Reception Instruction RC-16, the UNE-EN-197-1:2011 or cements type CEM IV/A-SR and IV/B$\mathrm{SR}$, given to any ordinary Portland Cement (OPC) and any natural or artificial pozzolan. The pozzolan replacement was higher than $40 \%$. It was also determined why the new blended cement were more SR at higher replacement level. It evaluated the performance of mechanical resistance to compression and flex traction of the cements, and performance of negative carbonation under convenient relative humidity and temperature.

The obtained results confirmed the Thesis objectives. That is, RS increase, negative carbonation and RM decrease of Portland cement occur when replaced by pozzolan in quantities over $40 \%$. This chemical effect from the pozzolanic activity, the less amount of Portland cement and consequently the lower level of portlandite in its paste liquid phase, bring RS increase and RM decrease with further degradation by negative carbonation.

The present Thesis results differ with the bad performance shown in the cement mixtures in Talero's (1986) where the pozzolan replacement was not higher than $40 \%$. 


\section{ÍNDICE DE CONTENIDOS}





\section{CAPÍTULO 1. INTRODUCCIÓN}

1.1.- Perspectiva histórica de la construcción con materiales de base cemento Cemento Portland .59

1.2.- Proceso Industrial y las Emisiones de Gases Efecto Invernadero ……………………...........61

1.2.1.-Efecto Invernadero y el proceso de fabricación del Clinker Generalidades..........................61

1.3.- Gestión de residuos. Aprovechamiento material y energético ……………............................63

1.4- La valorización material en el ciclo productivo del cemento .....................................................64

1.5.- Adiciones minerales que se le incorporan al cemento Portland..............................................67

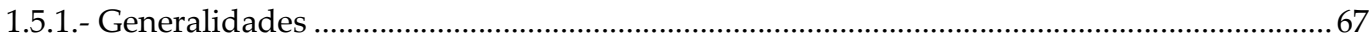

1.5.2.- Composición química de las adiciones puzolánicas................................................................ 68

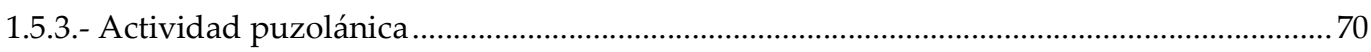

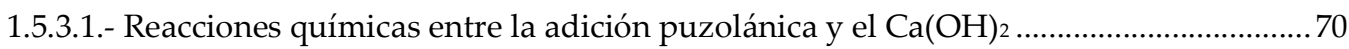

1.6.- Comportamiento del cemento Portland con adiciones minerales inorgánicas frente al

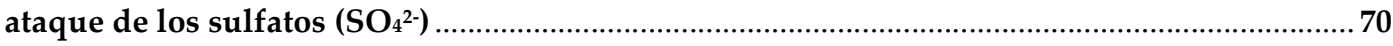

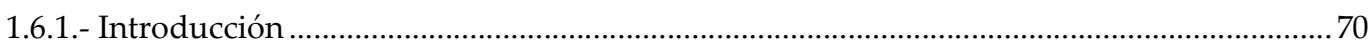

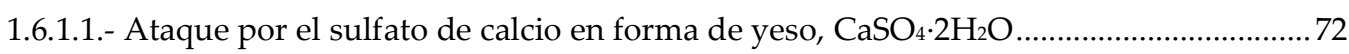

CAPÍTULO 2 ESTADO DEL ARTE

2.1.- Estudio bibliográfico de las últimas investigaciones sobre cementos con adiciones de

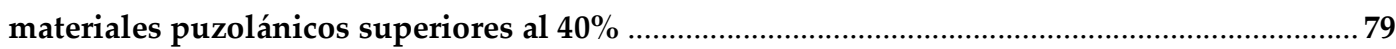

2.1.1.- Resistencia Sulfática ........................................................................................................ 79

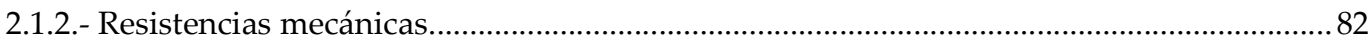

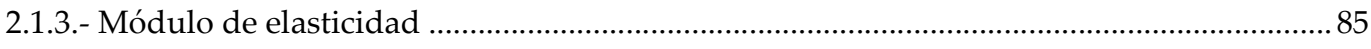

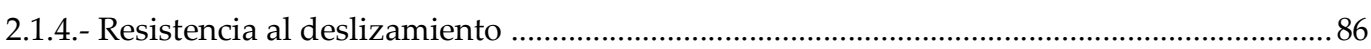

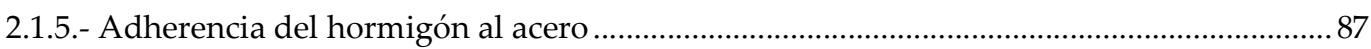

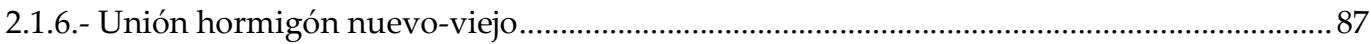

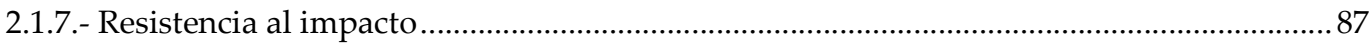

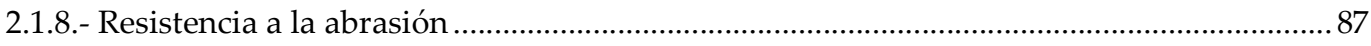

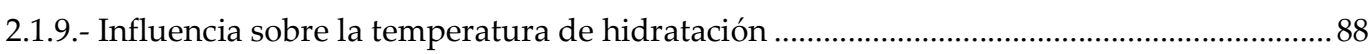

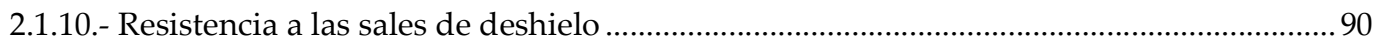


COMPORTAMIENTO SULFÁTICO Y MECÁNICO-RESISTENTE DE CEMENTOS PORTLAND CON ELEVADOS CONTENIDOS DE PUZOLANAS (> 40\%): SU FUNDAMENTO QUÍMICO Y JUSTIFICACIÓN DE OTRAS CONSECUENCIAS POSIBLES

2.1.11.- Permeabilidad (porosidad) y protección contra la corrosión .......................................... 90

2.1.12.- Retracción hidráulica. Retracción por secado ó "Drying shrinkage".............................. 93

2.1.13.- Resistencia química a ambientes marinos..................................................................... 95

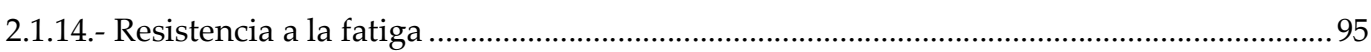

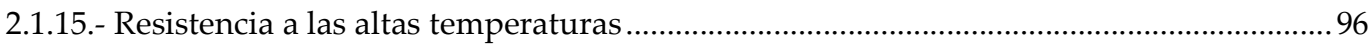

2.2- Conclusión obtenida del estudio bibliográfico realizado de los cementos Portland con

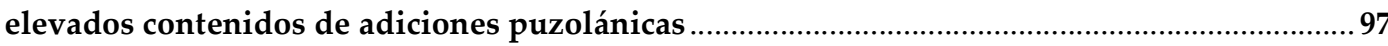

CAPÍTULO 3 JUSTIFICACIÓN DE LA TESIS DOCTORAL

CAPÍTULO 4 OBJETIVOS

\section{CAPÍTULO 5. FUNDAMENTOS}

5.1.- Fundamentos Teóricos 112

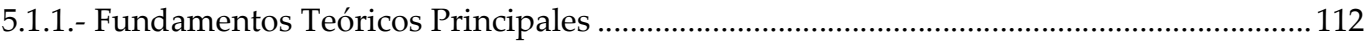

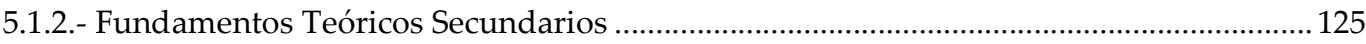

5.2.- Fundamentos Prácticos.

125

5.2.1.- Fundamentos Prácticos: Selección de materiales hidráulicos. Razones cualitativas y

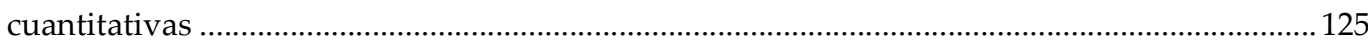

5.2.2.- Fundamentos prácticos: Razones cualitativas y cuantitativas de la misma ...................128

5.2.3.- Fundamentos Prácticos: Selección de otros materiales ................................................... 129

5.2.4.- Definición y Estudio, en su caso, de los diversos materiales seleccionados para la realización de esta investigación

5.2.4.1.- Características de los cementos Portland seleccionados, con y sin las Adiciones

Puzolánicas que se han seleccionado para la realización de esta investigación...................129

5.2.4.2.- Características de las Adiciones Puzolánicas seleccionadas ................................... 130

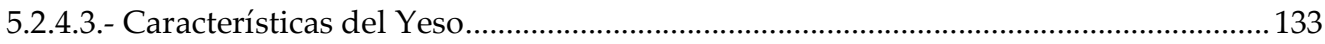

\section{CAPÍTULO 6. SELECCIÓN Y CARACTERIZACIÓN DE MATERIALES}

6.1.- Selección de Materiales. 137

6.1.1.- Selección de los cementos Portland ............................................................................ 137

6.1.2.- Selección de las adiciones minerales puzolánicas ........................................................ 139 
6.2.1.- Análisis químico y composición mineralógica potencial.....

6.2.2.- Análisis mineralógico por DRX

6.2.3.- Determinación de la densidad real, superficie específica y distribución de tamaños de partícula

6.2.4.-Determinación de la cantidad de agua necesaria para la pasta de consistencia normal, tiempos de fraguado y estabilidad de volumen

6.2.5.- Determinación de las resistencias mecánicas a compresión en probetas de mortero normalizado.

6.2.6.- Determinación, mediante el ensayo de Frattini, de la [CaO] y [OH-]de la fase líquida en contacto con la pasta de cada cemento Portland seleccionado.

6.3.- Caracterización de las adiciones minerales puzolánicas seleccionadas.

6.3.2.- Análisis mineralógico por DRX de las SEIS adiciones minerales puzolánicas seleccionadas

6.3.3.- Determinación de la densidad real, superficie específica y distribución de tamaños de partícula

6.3.4.- Determinación del contenido de sílice reactiva, $\mathrm{SiO}_{2}{ }^{\mathrm{r}-}$, de cada una de las puzolanas seleccionadas

6.3.5.- Determinación del contenido de alúmina reactiva, $\mathrm{Al}_{2} \mathrm{O}_{3}{ }^{\mathrm{r}-}$, de cada una de las puzolanas seleccionadas

6.3.6.- Determinación, mediante el ensayo de Frattini, de la actividad puzolánica de todas y cada una de las seis puzolanas seleccionadas

6.3.7.- Determinación del Índice de actividad resistente en probetas de mortero normalizado

\section{CAPÍTULO 7. METODOLOGÍA Y PROCEDIMIENTO EXPERIMENTAL}

7.1.- Dosificación de los materiales. Cementos de mezcla propuestos

7.1.1.- Pastas de cemento. Dosificación de componentes

7.2.- Ensayo de resistencia química a los sulfatos: Método de ensayo acelerado (MAE) Le Chatelier-Anstett

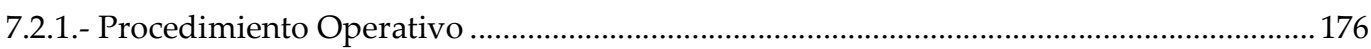

7.2.2.- Parámetros característicos del ensayo de Le Chatelier Anstett...................................... 178

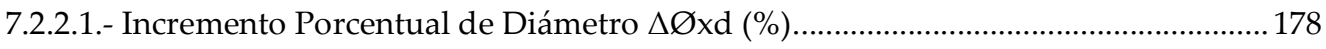

7.2.2.2.- Velocidad de Incremento Diametral VC $\varnothing(\Delta \varnothing(\%) /$ día $)$.......................................... 179

7.2.2.3.- Incremento porcentual de diámetro por unidad de masa de puzolana " $Z$ ", $\Delta \varnothing \times \mathrm{d}(\%) / " \mathrm{Z}^{\prime \prime}$ 
COMPORTAMIENTO SULFÁTICO Y MECÁNICO-RESISTENTE DE CEMENTOS PORTLAND CON ELEVADOS CONTENIDOS DE PUZOLANAS ( $>40 \%$ ): SU FUNDAMENTO QUÍMICO Y JUSTIFICACIÓN DE OTRAS CONSECUENCIAS POSIBLES

7.2.2.4.- Penetración de la Aguja de Vicat", P.A.V. (mm).................................................... 179

7.2.2.5.- Evolución de las Características Orgánicas, ECO, de la probeta L-A..................... 180

7.2.3.- Caracterización microestructural de las pastas Le Chatelier-Anstett ............................ 181

7.2.3.1.- Determinación cualitativa y semicuantitativa mediante DRX de los compuestos de hidratación formados en las pastas frescas de cemento ..................................................... 181

7.2.3.2.- Descripción del equipo y condiciones analíticas de la determinación realizada ... 181

7.2.3.3.- Preparación de las pastas Le Chatelier Anstett para su análisis por DRX.............. 182

7.3.- Determinación del comportamiento mecánico-resistente de los cementos de mezcla en mortero normalizado tipo EN 196-1 183

7.4.- Ensayo de puzolanicidad o ensayo de Frattini. Determinación de la [CaO] y [OH-] de la fase líquida en contacto con cada pasta ................................................................................... 184

7.4.1.- Fundamento 185

7.4.2.- Determinación de la basicidad de la fase líquida en contacto con cada pasta fresca de los cementos de mezcla anteriores: el $\mathrm{pH}$.

7.5.- Determinación de la velocidad de penetración de la carbonatación en probetas de mortero normalizado. Interrelación con el comportamiento mecánico-resistente

7.5.1.- Preparación de las probetas de mortero .......................................................................... 190

7.5.2.- Conservación y curado de las probetas de mortero .......................................................... 191

7.5.3.- Equipo y ambiente del proceso de carbonatación ......................................................... 192

7.5.4.- Determinación de la RMF de las probetas carbonatadas ................................................. 193

7.5.5.- Determinación de la profundidad de carbonatación en los morteros endurecidos ........ 193

7.5.6.- Determinación de la R.M.C. de las probetas carbonatadas ............................................ 195

CAPÍTULO 8. RESULTADOS OBTENIDOS: SU ANÁLISIS, ESTUDIO Y DISCUSIÓN

\section{1.- Ensayo de resistencia química a los sulfatos: Método de ensayo acelerado (MAE) Le}

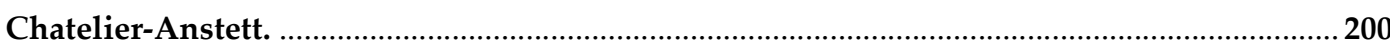

8.1.1.- Para los cementos Portland de referencia 201

8.1.2.- De los cementos de mezcla preparados y dosificados que figuran en el apartado 7.1. del Capítulo 7 201

8.1.2.1.- A igualdad de puzolana seleccionada "Z" y cantidad de su reemplazo por CP

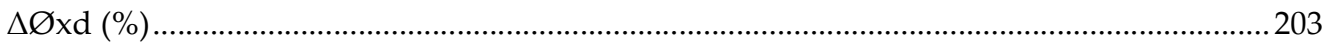

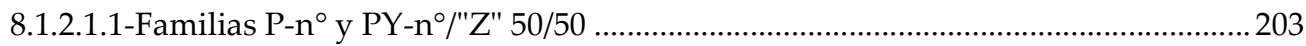

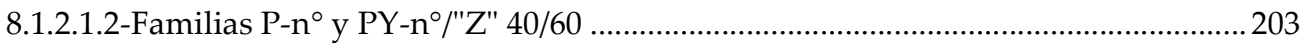

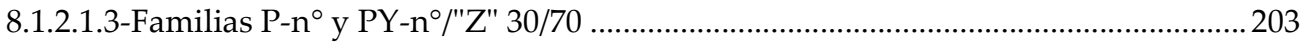

8.1.2.1.4-Familias P-n ${ }^{\circ}$ y PY-n"Z" 50/50 + CH ("Z"/CH=4) ................................................2 204

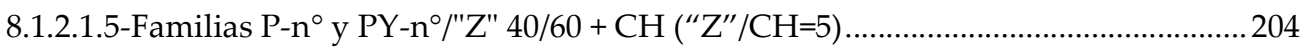




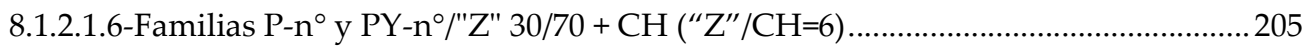

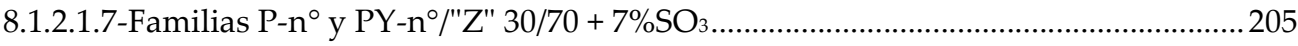

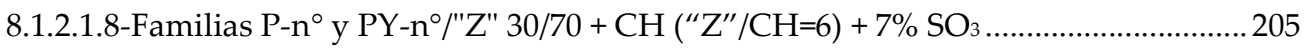

8.1.2.2- Interpretaciones de los comportamientos encontrados en el apartado 8.1.2.1........ 206

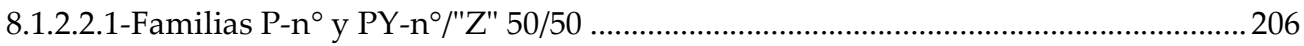

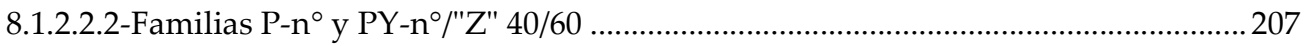

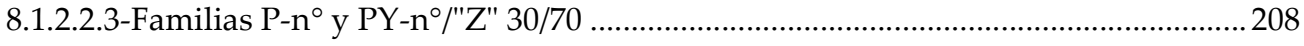

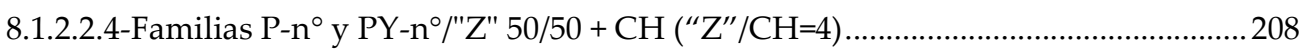

8.1.2.2.5-Familias P-nº y PY-n/"Z" 40/60 + CH ("Z"/CH=5) ................................................... 208

8.1.2.2.6-Familias P-nº y PY-n/"Z" 30/70 + CH ("Z"/CH=6) ..................................................209

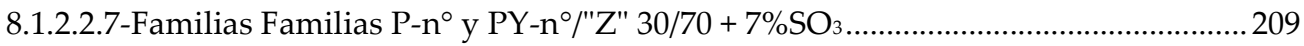

8.1.2.3-Análisis, Estudio, Discusión e Interpretación mediante las figuras obtenidas con los

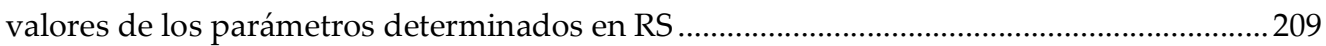

8.1.2.3.1-Figuras obtenidas con valores del parámetro $\Delta \varnothing$........................................................ 209

8.1.2.3.1.1- Discusión e Interpretación General .................................................................... 209

8.1.2.3.1.2-Discusión e Interpretación de las Familias P-nº y PY-nº/"Z" 50/50 ................. 211

8.1.2.3.1.3-Discusión e Interpretación de las Familias P-nº y PY-nº/"Z" 50/50 + CH ...... 224

8.1.2.3.1.4-Discusión e Interpretación de las Familias de CM P-nº y PY-no/("Z"+CH) 40/60

8.1.2.3.1.5- Discusión e Interpretación de las Familias de CM P-nº y PY-nº/(M+CH)

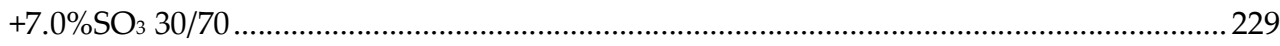

8.1.2.3.1.6- Discusión e Interpretación de las Familias de CM PY-6/(M+CH) +7.0\% $\mathrm{SO}_{3}$

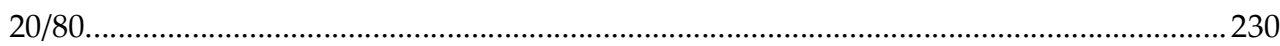

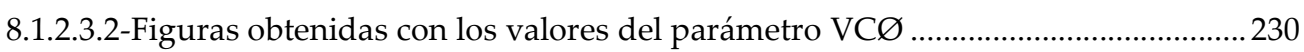

8.1.2.3.2.1- Discusión e Interpretación de las Familias de CM P-nº y PY-nº/"Z" 50/50 ... 230

8.1.2.3.2.2-Discusión e Interpretación de las Familias P-nº y PY-no/"Z" 50/50 + CH ....... 237

8.1.2.3.2.3-Discusión e Interpretación de las Familias de CM P-nº y PY-no/("Z"+CH) 40/60

8.1.2.3.2.4-Discusión e Interpretación de las Familias de CM P-nº y PY-

$\mathrm{n} \%(\mathrm{M}+\mathrm{CH})+7.0 \% \mathrm{SO}_{3} 30 / 70$ .241

8.1.2.3.2.5- Discusión e Interpretación de las Familias de CM P-nº y PY-nº/(M+CH)

$+7.0 \% \mathrm{SO}_{3} 30 / 70$.

8.1.2.4-A igualdad de cemento Portland y cantidad de adición adición puzolánica.

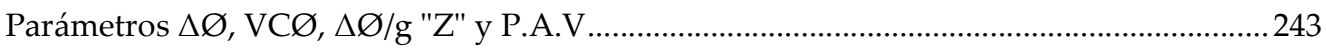

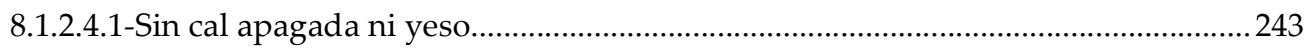

8.1.2.4.1.1-Discusión e Interpretación de las Familias P-noํㅡ y PY-no/"Z" 50/50 .................. 243

8.1.2.4.1.2-Discusión e Interpretación de las Familias P-no y PY-no/"Z" 40/60 ................... 245

8.1.2.4.1.3-Discusión e Interpretación de las Familias P-no y PY-no/"Z" 30/70 .................. 246 
COMPORTAMIENTO SULFÁTICO Y MECÁNICO-RESISTENTE DE CEMENTOS PORTLAND CON ELEVADOS CONTENIDOS DE PUZOLANAS (> 40\%): SU FUNDAMENTO QUÍMICO Y JUSTIFICACIÓN DE OTRAS CONSECUENCIAS POSIBLES

8.1.2.4.1.4-Discusión e Interpretación de las Familia PY-6/M 20/80................................ 247

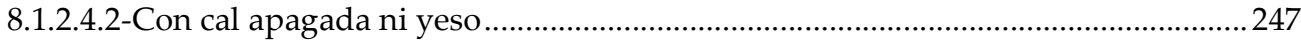

8.1.2.4.2.1-Discusión e Interpretación de las Familias P-nº y PY-nº/("Z"+CH) 50/50

$(" \mathrm{Z} " / \mathrm{CH})=4$. 247

8.1.2.4.2.2-Discusión e Interpretación de las Familias P-n/("Z"+CH) 40/60, ("Z"/CH = 5)

8.1.2.4.2.3-Discusión e Interpretación de las Familias P-nํy PY-nº/("Z"+CH) 30/70, ("Z"/CH=6) 250

8.1.2.4.2.4-Discusión e Interpretación de las Familias PY-6/(M+CH) 20/80, ("Z"/CH = 7) 250

8.1.2.4.3-Sin cal apagada y con yeso. 251

8.1.2.4.3.1-Discusión e Interpretación de las Familias (P-1 y PY-6/M 30/70) +7.0\%SO3) 251

8.1.2.4.3.2-Discusión e Interpretación de las Familias (PY-6/M 20/80) +7.0\% SO 3 ) ......... 251

8.1.2.4.4- Con cal apagada y yeso, 365 y 730 días del ensayo .............................................2 251

8.1.2.4.4.1-Discusión e Interpretación de las Familias (P-1 y PY-6/(M+CH) 30/70) +7.0\%

$\left.\mathrm{SO}_{3}\right)$ 251

8.1.2.4.4.2-Discusión e Interpretación de las Familias PY-6/(M+CH) 20/80) +7.0\% SO3) 251

8.1.2.5- Interpretaciones de los comportamientos encontrados en el apartado 8.1.2.4........252

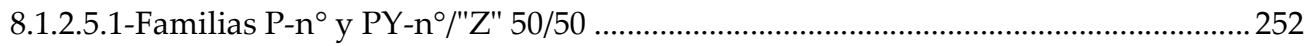

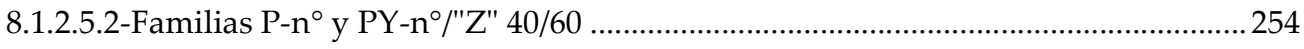

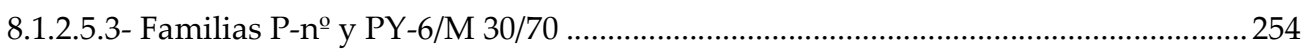

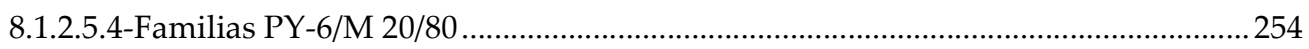

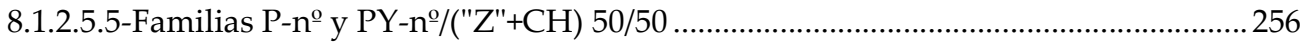

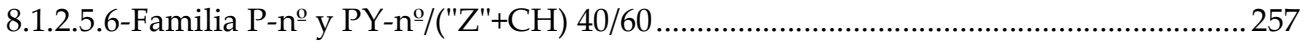

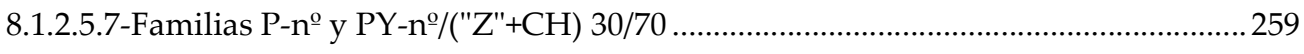

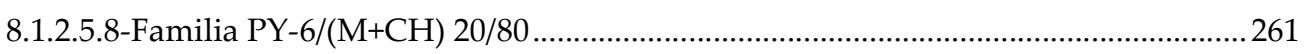

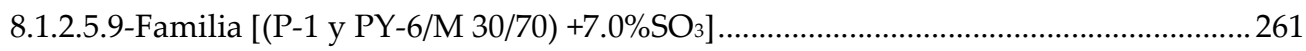

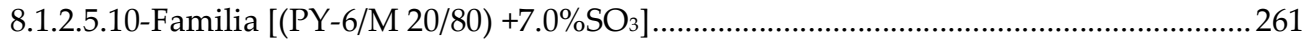

8.1.2.5.11-Familia [P-1 y PY-6/(M+CH) 30/70] +7.0\% SO $]$................................................ 261

8.1.2.6-A igualdad de CM y derivados con cal apagada y/o yeso: Análisis y Estudio Comparativo, Discusión e Interpretación en RS, EXTERNO e INTERNO ...........................261

8.1.2.6.1-Análisis y Estudio Comparativo en RS, EXTERNO .............................................261

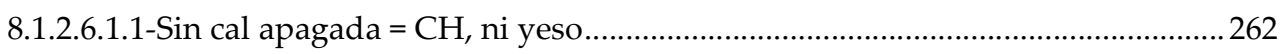

8.1.2.6.1.1.1-Caso de que el CP constitutivo era de elevado $(\geq 8 \%$, el P-1 $=14.11 \%$ C $3 \mathrm{~A}$ y el P-2 $=11.09 \%$ C $3 \mathrm{~A})$ o moderado (= 8\%, el P-31 = 7.62\% C3A) contenido de

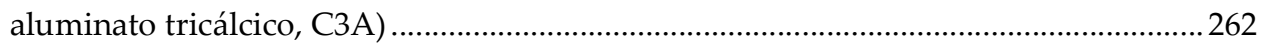

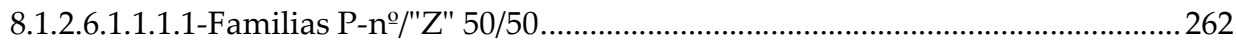

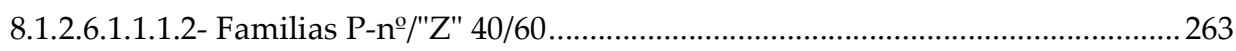


8.1.2.6.1.1.1.3- Familias P-no/"Z" 30/70. 264

8.1.2.6.1.1.2- Caso de que el CP constitutivo era de nulo contenido de aluminato tricálcico, C3A, el PY-4 y el PY-6 264

8.1.2.6.1.1.2.1-Familias PY-no/"Z" 50/50 264

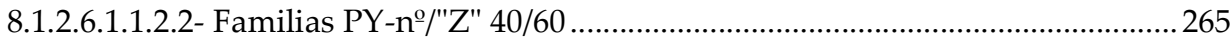

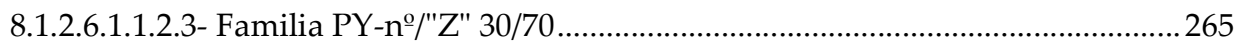

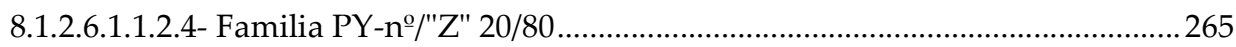

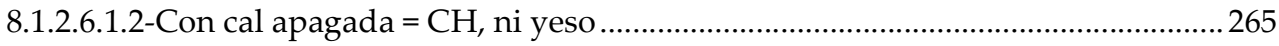

8.1.2.6.1.2.1-Caso de que el CP constitutivo era de elevado o moderado contenido de

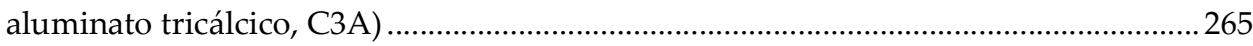

8.1.2.6.1.2.1.1-Familias P-no/"Z" 50/50, [("Z"/CH) = 4] ............................................... 266

8.1.2.6.1.2.1.2- Familias P-nº/("Z"+CH) 40/60; [("Z"/CH) = 5] ....................................... 266

8.1.2.6.1.2.1.3- Familia P-nº/("Z"+CH) 30/70; [("Z"/CH) = 6] ......................................... 267

8.1.2.6.1.2.2-Caso de que el CP constitutivo era de nulo contenido de C3A, el PY-4 y el

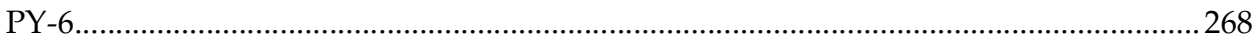

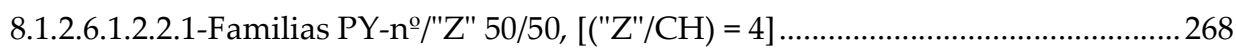

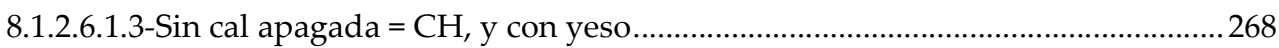

8.1.2.6.1.3.1-Caso de que el CP constitutivo era de elevado o nulo contenido de

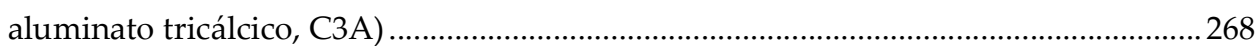

8.1.2.6.1.3.1.1-Familias [(P-1 ó PY-6/M 30/70) +7.0\% SO3)] ........................................ 268

8.1.2.6.1.3.1.2-Familias [(PY-6/M 20/80) +7.0\% SO3)] …............................................ 269

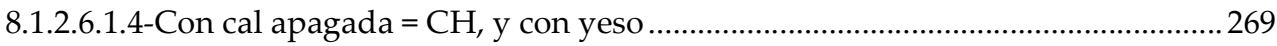

8.1.2.6.1.4.1-Caso de que el CP constitutivo era de elevado o nulo contenido de

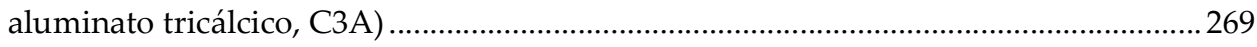

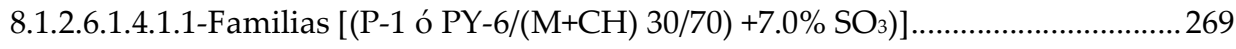

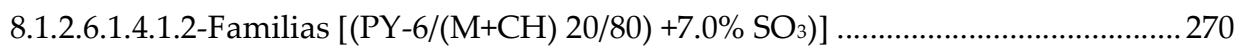

8.1.2.6.2-Análisis y Estudio Comparativo en RS, INTERNO.............................................220

8.1.2.6.2.1-A igualdad de familia de cementos mixtos y derivados con cal apagada de CP P-no ó PY-nº común. Parámetros $\Delta \varnothing$, VCØ, $\Delta \varnothing / g$ "Z" y P.A.V. ........................................ 270

8.1.2.7-Análisis, Estudio, Discusión e Interpretación de los parámetros $\Delta \varnothing$, y P.A.V ........ 271

8.1.2.7.1- De la Discusión 8.1.2.6.1.1.1.1.: Familias de CM P-no/"Z" 50/50 ..........................2271

8.1.2.7.2-De la Discusión 8.1.2.6.1.1.1.2.: Familias de CM P-nㅇ"Z" 40/60 ............................274

8.1.2.7.3-De la Discusión 8.1.2.6.1.1.1.3.: Familias de CM P-no/"Z" 30/70 ............................. 276

8.1.2.7.4-De la Discusión 8.1.2.6.1.1.2.1-Familias PY-no/"Z" 50/50 .......................................277

8.1.2.7.5-De la Discusión 8.1.2.6.1.1.2.2-Familias PY-no /"Z" 40/60 .......................................2279

8.1.2.7.6-De la Discusión 8.1.2.6.1.1.2.3-Familias PY6/M 30/70 ...........................................279

8.1.2.7.7-De la Discusión 8.1.2.6.1.1.2.4-Familias PY6/M 20/80......................................... 279 
COMPORTAMIENTO SULFÁTICO Y MECÁNICO-RESISTENTE DE CEMENTOS PORTLAND CON ELEVADOS CONTENIDOS DE PUZOLANAS (> 40\%): SU FUNDAMENTO QUÍMICO Y JUSTIFICACIÓN DE OTRAS CONSECUENCIAS POSIBLES

8.1.2.7.8-De la Discusión8.1.2.5.1.2.1.1-Familia P-nº/("Z"+CH) 50/50, con relación [("Z"/CH) $=4]$.

8.1.2.7.9-De la Discusión 8.1.2.6.1.2.1.2-Familia P-nº/("Z"+CH) 40/60, con relación

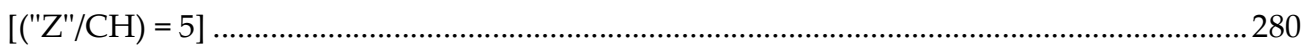

8.1.2.7.10-De la Discusión8.1.2.6.1.2.1.3- Familias P-nº/("Z"+CH) 30/70............................. 281

8.1.2.7.11-De la Discusión 8.1.2.6.1.2.2.1-Familias PY-nㅇ("Z"+CH) 50/50, [("Z"/CH) = 4]. 282 8.1.2.7.12-De la Discusión 8.1.2.6.1.2.2.2-Familias PY-nำ("Z"+CH) 40/60, [("Z"/CH) = 5]. 283 8.1.2.7.13-De la Discusión 8.1.2.6.1.2.2.3- Familia PY-6/(M+CH) 30/70, [("Z"/CH) = 6] ..... 283 8.1.2.7.14-De la Discusión 8.1.2.6.1.2.2.4- Familia PY-6/(M+CH) 20/80;("Z"/CH) = 7 ......... 284 8.1.2.7.15-De la Discusión 8.1.2.4.3.1-Familias [(P-1 ó PY-6/M 30/70) + 7.0\%SO3] ............. 284 8.1.2.7.16-De la Discusión 8.1.2.6.1.3.1.2- Familia [(PY-6/M 20/80)+7.0\%SO3] ................... 285 8.1.2.6.17-De la Discusión Familias [P-1 ó PY-6/(M+CH) 30/70+7.0\%SO3] ........................ 286

\section{2.- Determinación del comportamiento mecánico-resistente de los cementos de mezcla en}

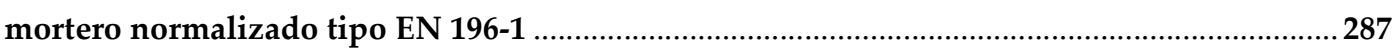

8.2.1.- Para los cementos Portland de referencia ....................................................................28

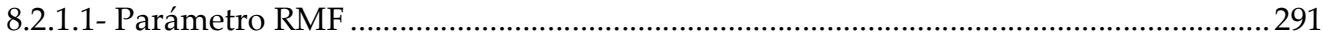

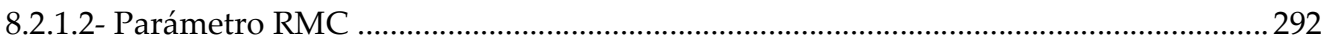

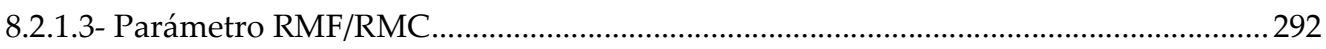

8.2.2.-De los cementos de mezcla preparados y dosificados que figuran en el apartado 7.1. del

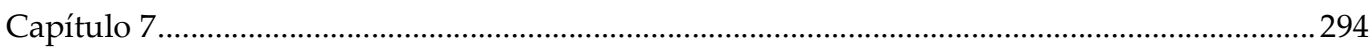

8.2.2.1-A igualdad de puzolana seleccionada "Z" y cantidad de su reemplazo por CP ......... 294

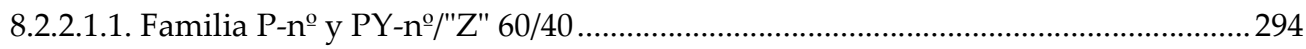

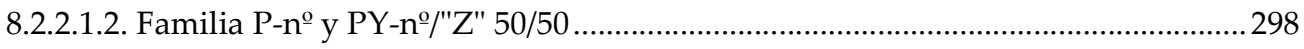

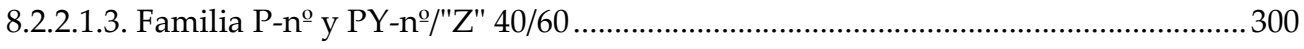

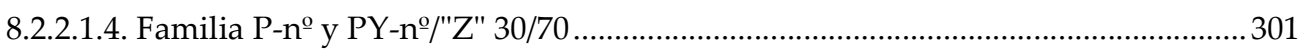

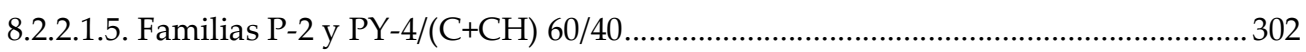

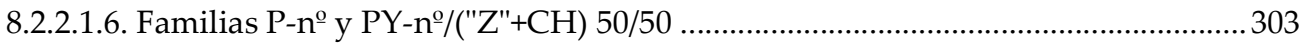

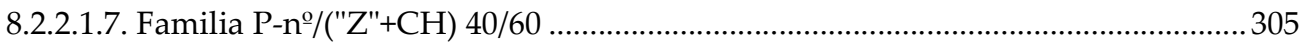

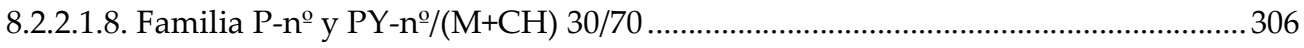

8.2.2.1.9. Familias P1 y PY6/M 30/70 +7.0\% SO

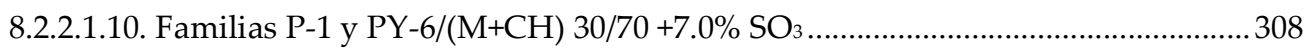

8.2.2.2-A igualdad de cemento Portland de referencia y cantidad de este ............................310

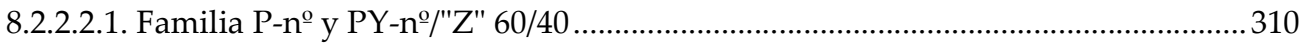

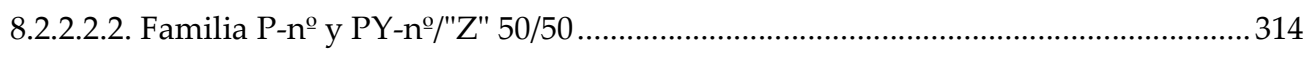

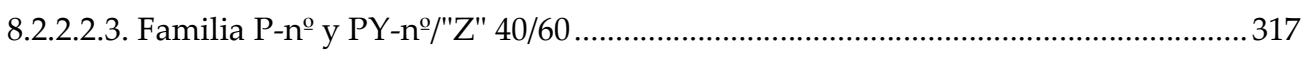

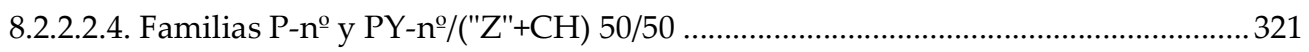

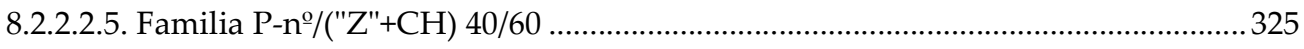


8.2.2.2.6. Familia P-nº y PY-no/"Z" 30/70. 328

8.3.- Ensayo de puzolanicidad o ensayo de Frattini. Determinación de la [CaO] y [OH-] de la fase líquida en contacto con cada pasta de cemento ................................................................ 330

8.3.1.- De los cementos Portland de referencia 330

8.3.2.- De los cementos de mezcla del cemento Portland P1 con cada una de las adiciones puzolánicas

8.4.- Determinación de la velocidad de penetración de la carbonatación en probetas de mortero normalizado. Interrelación con el comportamiento mecánico-resistente 341

8.4.1.- De los cementos de mezcla P1/M 40/60 y P1/M 40/60+CH ............................................ 342

8.4.1.1.- Resultados obtenidos en la medida del perfil de carbonatación.................................342

8.4.1.2.- Resultados obtenidos en la determinación de las RMF y RMC .................................345

8.4.2.- De los cementos de mezcla P1/O 50/50 y P1/O 50/50+CH ...............................................347

8.4.2.1.- Resultados obtenidos en la medida del perfil de carbonatación................................347

8.4.2.2.- Resultados obtenidos en la determinación de las RMF y RMC ...............................350

CAPÍTULO 9. CONCLUSIONES 355

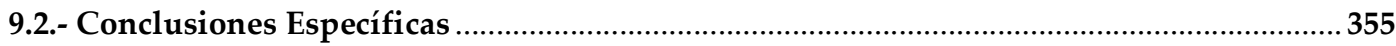

9.2.1.- Del comportamiento Sulfático de los cementos de mezcla..............................................356

9.2.2.- Del comportamiento Mecánico resistente de los cementos de mezcla............................356

9.2.3.- Del Comportamiento frente al ataque por Carbonatación de los cementos de mezcla.357

9.2.4- Confirmación de la reversión de las reacciones químicas de hidratación selenitosa al adicionar cal apagada a cada uno de los cementos puzolánicos preparados: su efecto sobre las RMC y RMF así como la carbonatación negativa.....

CAPÍTULO 10. FUTURAS LÍNEAS DE INVESTIGACIÓN

10.1.- Primer punto de análisis: Adoptar incrementos mayores de adición puzolánica como solución a la sostenibilidad y reglamentar su mínima RMC. 361

10.2.- Segundo punto de análisis: Promover la activación térmica de Arcillas calcinables para la producción de Puzolanas naturales calcinadas. 362

REFERENCIAS 
COMPORTAMIENTO SULFÁTICO Y MECÁNICO-RESISTENTE DE CEMENTOS PORTLAND CON ELEVADOS CONTENIDOS DE PUZOLANAS ( $>40 \%$ ): SU FUNDAMENTO QUÍMICO Y JUSTIFICACIÓN DE OTRAS CONSECUENCIAS POSIBLES

ANEJOS 
ÍNDICE DE TABLAS 

TABLA 1-1.- COMPOSICIÓN QUÍMICA DE LAS ADICIONES PUZOLÁNICAS (EN PARÉNTESIS: VALORES MEDIOS).

CAPÍTULO 5. FUNDAMENTOS

TABLA 5-1.- ENTORNOS DE VARIABILIDAD DE LOS CONTENIDOS DE ÓXIDOS ÁCIDOS Y BÁSICOS FUNDAMENTALES DE LAS ESCORIAS GRANULADAS DE ALTO HORNO ... 116

TABLA 5-2.- COMPOSICIÓN QUÍMICA, CUALI Y CUANTITATIVA (\%), DE POSIBLES ESCORIAS SIDERÚRGICAS "TEÓRICAS" RESULTANTES AL AÑADIRLE 45.25\% EN MASA DE CAL APAGADA, CA $(\mathrm{OH}) 2(\approx 35 \%$ EN MASA DE CAL VIVA, CaO) A LAS SEIS PUZOLANAS UTILIZADAS EN ESTA INVESTIGACIÓN .117

TABLA 5-3.- RELACIÓN PUZOLANA "Z" / CAL APAGADA Ó RELACIÓN AP "Z" / CH .....119 TABLA 5-4.- RELACIÓN PUZOLANA "Z" / CAL APAGADA Ó RELACIÓN AP "Z" / CH, ENTRE 3 Y 7 A LO SUMO 126

\section{CAPÍTULO 6. SELECCIÓN Y CARACTERIZACIÓN DE MATERIALES}

TABLA 6-1.- COMPOSICIÓN QUÍMICA Y MINERALÓGICA POTENCIAL DE LOS CEMENTOS PORTLAND.

TABLA 6-2.- DENSIDAD REAL Y SUPERFICIE ESPECÍFICA BLAINE (SEB) DE DOS DE LOS CINCO CEMENTOS PORTLAND. 145

TABLA 6-3.- RESULTADOS DE LA CANTIDAD DE AGUA PARA LA PASTA DE CONSISTENCIA NORMAL, TIEMPOS DE FRAGUADO Y ESTABILIDAD DE VOLUMEN .. 147

TABLA 6-4.- RESISTENCIAS MECÁNICAS A COMPRESIÓN (SEGÚN NORMA UNE-EN 1961), A 2, 7, 28 DÍAS DE EDAD, DE LOS CEMENTOS PORTLAND SELECCIONADOS. 148

TABLA 6-5.- ENSAYO DE FRATTINI: RESULTADOS DE LA [CaO] Y [OH-] DE LA FASE LÍQUIDA EN CONTACTO CON LA PASTA DE CADA CEMENTO PORTLAND SELECCIONADO

TABLA 6-6.- RESULTADOS DEL ANÁLISIS QUÍMICO DE LAS SEIS PUZOLANAS SELECCIONADAS. .150

TABLA 6-7.- DENSIDAD REAL, SUPERFICIE ESPECÍFICA BLAINE (SEB) O SUPERFICIE ESPECÍFICA BET (SE-BET) DE LAS SEIS PUZOLANAS SELECCIONADAS. 
COMPORTAMIENTO SULFÁTICO Y MECÁNICO-RESISTENTE DE CEMENTOS PORTLAND CON ELEVADOS CONTENIDOS DE PUZOLANAS ( $>$ 40\%): SU FUNDAMENTO QUÍMICO Y JUSTIFICACIÓN DE OTRAS CONSECUENCIAS POSIBLES

TABLA 6-8.- CONTENIDO DE SÍLICE TOTAL Y SÍLICE REACTIVA DE CADA UNA DE LAS PUZOLANAS SELECCIONADAS 156

TABLA 6-9.- CONTENIDO DE ALÚMINA TOTAL Y ALÚMINA REACTIVA DE CADA UNA DE LAS PUZOLANAS SELECCIONADAS 156

TABLA 6-10.- ENSAYO DE FRATTINI DE LOS CEMENTOS DE MEZCLA DEL CP P1 CON CADA PUZOLANA SELECCIONADA: RESULTADOS A LAS EDADES DE 2, 7 Y 28 DÍAS.. 159

TABLA 6-11.- ENSAYO DE FRATTINI DE LOS CEMENTOS DE MEZCLA DEL CP PY6 CON CADA PUZOLANA SELECCIONADA: RESULTADOS A LAS EDADES DE 2, 7 Y 28 DÍAS.. 160 TABLA 6-12.- ÍNDICE DE ACTIVIDAD RESISTENTE, IAR, DE CADA UNA DE LAS ADICIONES PUZOLÁNICAS SELECCIONADAS MEZCLADAS CON EL CEMENTO PORTLAND P1 EN PROPORCIÓN 80/20 EN MASA. EDAD: 28 DÍAS 162

\section{CAPÍTULO 7. METODOLOGÍA Y PROCEDIMIENTO EXPERIMENTAL}

TABLA 7-1.- DOSIFICACIÓN DE COMPONENTES PARA LA PREPARACIÓN DE LOS CEMENTOS DE MEZCLA EN FUNCIÓN DEL PORCENTAJE DE REEMPLAZO PARA LA DETERMINACIÓN DE SU EXPANSIÓN EN PROBETAS DE PASTA TIPO LE CHATELIERANSTETT.

TABLA 7-2.- PARÁMETROS QUÍMICOS Y COMPOSICIÓN MINERALÓGICA DE LA PIEDRA DE YESO NATURAL MOLIDA UTILIZADA PARA ESTE ENSAYO DE DURABILIDAD

TABLA 7-3.- DOSIFICACIÓN DE COMPONENTES PARA LA PREPARACIÓN DE LOS CEMENTOS DE MEZCLA EN FUNCIÓN DEL PORCENTAJE DE REEMPLAZO PARA LA DETERMINACIÓN DEL PH DE LA FASE LÍQUIDA DE SU PASTA FRESCA.

TABLA 7-4.- DOSIFICACIÓN DE COMPONENTES PARA LA PREPARACIÓN DE LOS CEMENTOS DE MEZCLA EN FUNCIÓN DEL PORCENTAJE DE REEMPLAZO PARA SU ENSAYO ACELERADO DE DURABILIDAD FRENTE A LA CARBONATACIÓN

TABLA 7-5.- RELACIÓN A/C DE CADA UNO DE LOS MORTEROS PREPARADOS. 190

CAPÍTULO 8. RESULTADOS OBTENIDOS: SU ANÁLISIS, ESTUDIO Y DISCUSIÓN

TABLA 8-1.- CLASIFICACIÓN DE LOS DISTINTOS CEMENTOS PORTLAND DE REFERENCIA A IGUALDAD DE PUZOLANA EN EL ENSAYO L-A. CEMENTO DE MEZCLA P-N ${ }^{\circ}$ Y PY-N'/"Z" 50/50 204

TABLA 8-2.- CLASIFICACIÓN DE LOS DISTINTOS CEMENTOS PORTLAND DE REFERENCIA A IGUALDAD DE PUZOLANA EN EL ENSAYO L-A. CEMENTO DE MEZCLA P-N ${ }^{\circ}$ Y PY-No/"Z" 40/60 + CH 205 
TABLA 8-3.- CLASIFICACIÓN DE LOS DISTINTOS CEMENTOS PORTLAND DE REFERENCIA A IGUALDAD DE PUZOLANA EN EL ENSAYO L-A. CEMENTO DE MEZCLA P-N ${ }^{\circ}$ Y PY-N ${ }^{\circ} / Z " 30 / 70+C H$

TABLA 8-4.- CLASIFICACIÓN DE LOS DISTINTOS CEMENTOS PORTLAND DE REFERENCIA A IGUALDAD DE PUZOLANA EN EL ENSAYO L-A. CEMENTO DE MEZCLA P-N ${ }^{\circ}$ Y PY-N ${ }^{\circ} / Z "$ 30/70 + 7\% $\mathrm{SO}_{3}$

205

TABLA 8-5.- CLASIFICACIÓN DE LOS DISTINTOS CEMENTOS PORTLAND DE REFERENCIA A IGUALDAD DE PUZOLANA EN EL ENSAYO L-A. CEMENTO DE MEZCLA P-N ${ }^{\circ}$ Y PY-N ${ }^{\circ} " Z " 30 / 70+\mathrm{CH}+7 \% \mathrm{SO}_{3}$ 206

TABLA 8-6.- EJEMPLO PRACTICO DEL ESE PRODUCIDO EN EL CEMENTO DE MEZCLA P$1 / \mathrm{O} 50 / 50$

218

TABLA 8-7.- EJEMPLO PRACTICO DEL ESE PRODUCIDO EN EL CEMENTO DE MEZCLA P$1 /$ A $50 / 50$ 218

TABLA 8-8.- EJEMPLO PRACTICO DEL ESE PRODUCIDO EN EL CEMENTO DE MEZCLA P31/O 50/50 218

TABLA 8-9.- EJEMPLO PRACTICO DEL ESE PRODUCIDO EN EL CEMENTO DE MEZCLA P31/A 50/50 218

TABLA 8-10.- EJEMPLO PRACTICO DEL ESE PRODUCIDO EN EL CEMENTO DE MEZCLA9P-2/O 50/50 219

TABLA 8-11.- EJEMPLO PRACTICO DEL ESE PRODUCIDO EN EL CEMENTO DE MEZCLA $\mathrm{P}-2 / \mathrm{O} 50 / 50$ 219

TABLA 8-12.- EJEMPLO PRACTICO DEL ESE PRODUCIDO EN EL CEMENTO DE MEZCLA P-1/C 50/50. 222

TABLA 8-13.- EJEMPLO PRACTICO DEL ESE PRODUCIDO EN EL CEMENTO DE MEZCLA $\mathrm{P}-1 /(\mathrm{C}+\mathrm{CH}) 50 / 50$ 222

TABLA 8-14.- EJEMPLO PRACTICO DEL ESE PRODUCIDO EN EL CEMENTO DE MEZCLA P-1/CV10 50/50 222

TABLA 8-15.- EJEMPLO PRACTICO DEL ESE PRODUCIDO EN EL CEMENTO DE MEZCLA $\mathrm{P}-1 /(\mathrm{CV} 10+\mathrm{CH}) 50 / 50$. 222

TABLA 8-16.- EJEMPLO PRACTICO DEL ESE PRODUCIDO EN EL CEMENTO DE MEZCLA P-1/M 50/50 222

TABLA 8-17.- EJEMPLO PRACTICO DEL ESE PRODUCIDO EN EL CEMENTO DE MEZCLA P-1/CV19 50/50 223

TABLA 8-18.- EJEMPLO PRACTICO DEL ESE PRODUCIDO EN EL CEMENTO DE MEZCLA P-31/CV19 50/50 223

TABLA 8-19.- EJEMPLO PRACTICO DEL ESE PRODUCIDO EN EL CEMENTO DE MEZCLA P-31/CV19 50/50 
COMPORTAMIENTO SULFÁTICO Y MECÁNICO-RESISTENTE DE CEMENTOS PORTLAND CON ELEVADOS CONTENIDOS DE PUZOLANAS ( $>40 \%$ ): SU FUNDAMENTO QUÍMICO Y JUSTIFICACIÓN DE OTRAS CONSECUENCIAS POSIBLES

TABLA 8-20.- EJEMPLO PRACTICO DEL ESE PRODUCIDO EN EL CEMENTO DE MEZCLA P-31/CV19 50/50 223

TABLA 8-21.- COMPARATIVA ENTRE $\triangle \varnothing 1 D$ (\%) P-NNo Y PY-6/"Z" 50/50 DE LAS PUZOLANAS C Y CV10 228

TABLA 8-22.- CLASIFICACIÓN DE LAS DICTINTAS PUZOLANAS A IGUALDAD DE CEMENTO PORTLAND DE REFERENCIA EN EL ENSAYO L-A DE LOS CEMENTOS P1/"Z" $50 / 50$

TABLA 8-23.- CLASIFICACIÓN DE LAS DICTINTAS PUZOLANAS A IGUALDAD DE CEMENTO PORTLAND DE REFERENCIA EN EL ENSAYO L-A DE LOS CEMENTOS P2/"Z" $50 / 50$.

TABLA 8-24.- CLASIFICACIÓN DE LAS DICTINTAS PUZOLANAS A IGUALDAD DE CEMENTO PORTLAND DE REFERENCIA EN EL ENSAYO L-A DE LOS CEMENTOS P31/"Z" $50 / 50$

TABLA 8-25.- CLASIFICACIÓN DE LAS DICTINTAS PUZOLANAS A IGUALDAD DE CEMENTO PORTLAND DE REFERENCIA EN EL ENSAYO L-A DE LOS CEMENTOS PY4/"Z" $50 / 50$

TABLA 8-26.- CLASIFICACIÓN DE LAS DICTINTAS PUZOLANAS A IGUALDAD DE CEMENTO PORTLAND DE REFERENCIA EN EL ENSAYO L-A DE LOS CEMENTOS PY6/"Z" $50 / 50$

TABLA 8-27.- CLASIFICACIÓN DE LAS DICTINTAS PUZOLANAS A IGUALDAD DE CEMENTO PORTLAND DE REFERENCIA EN EL ENSAYO L-A DE LOS CEMENTOS P1/"Z" $40 / 60$.

TABLA 8-28.- CLASIFICACIÓN DE LAS DICTINTAS PUZOLANAS A IGUALDAD DE CEMENTO PORTLAND DE REFERENCIA EN EL ENSAYO L-A DE LOS CEMENTOS P31/"Z" $40 / 60$.

TABLA 8-29.- CLASIFICACIÓN DE LOS DISTINTOS CEMENTOS A IGUALDAD DE PUZOLANA M DE REFERENCIA EN EL ENSAYO L-A DE LOS CEMENTOS P-№ Y PY№/"M"

TABLA 8-30.- CLASIFICACIÓN DE LOS DISTINTOS CEMENTOS A IGUALDAD DE PUZOLANA M DE REFERENCIA EN EL ENSAYO L-A DE LOS CEMENTOS PY6/"M"..

TABLA 8-31.- CLASIFICACIÓN DE LAS DISTINTAS PUZOLANAS A IGUALDAD DE CEMENTO PORTLAND DE REFERENCIA EN EL ENSAYO L-A DE LOS CEMENTOS $\mathrm{P} 1 /(" \mathrm{Z}+\mathrm{CH})$ 50/50

TABLA 8-32.- CLASIFICACIÓN DE LAS DISTINTAS PUZOLANAS A IGUALDAD DE CEMENTO PORTLAND DE REFERENCIA EN EL ENSAYO L-A DE LOS CEMENTOS $\mathrm{P} 2 /(" \mathrm{Z}+\mathrm{CH})$ 50/50

TABLA 8-33.- CLASIFICACIÓN DE LAS DISTINTAS PUZOLANAS A IGUALDAD DE CEMENTO PORTLAND DE REFERENCIA EN EL ENSAYO L-A DE LOS CEMENTOS $\mathrm{P} 31 /(" \mathrm{Z}+\mathrm{CH})$ 50/50 
TABLA 8-34.- CLASIFICACIÓN DE LAS DISTINTAS PUZOLANAS A IGUALDAD DE CEMENTO PORTLAND DE REFERENCIA EN EL ENSAYO L-A DE LOS CEMENTOS PY4/("Z"+CH) 50/50 Y PY6/("Z"+CH) 50/50

TABLA 8-35.- CLASIFICACIÓN DE LAS DISTINTAS PUZOLANAS A IGUALDAD DE CEMENTO PORTLAND DE REFERENCIA EN EL ENSAYO L-A DE LOS CEMENTOS PY4/("Z"+CH) 50/50 Y PY6/("Z"+CH) 50/50

TABLA 8-36.- CLASIFICACIÓN DE LAS DISTINTAS PUZOLANAS A IGUALDAD DE CEMENTO PORTLAND DE REFERENCIA EN EL ENSAYO L-A DE LOS CEMENTOS P-1 Y P$31^{*} /(" \mathrm{Z}+\mathrm{CH}) 40 / 60$

TABLA 8-37.- CLASIFICACIÓN DE LAS DISTINTAS PUZOLANAS A IGUALDAD DE CEMENTO PORTLAND DE REFERENCIA EN EL ENSAYO L-A DE LOS CEMENTOS P-№ Y PY-No/("Z"+CH) 30/70.

TABLA 8-38.- CLASIFICACIÓN DE LAS DISTINTAS PUZOLANAS A IGUALDAD DE CEMENTO PORTLAND DE REFERENCIA EN EL ENSAYO L-A DE LOS CEMENTOS PY$6 /(\mathrm{M}+\mathrm{CH}) 20 / 80$

TABLA 8-39.- CLASIFICACIÓN DE LAS DISTINTAS PUZOLANAS A IGUALDAD DE CEMENTO PORTLAND DE REFERENCIA EN EL ENSAYO L-A DE LOS CEMENTOS P-1 Y $\mathrm{PY}-6 / \mathrm{M} 30 / 70)+7.0 \% \mathrm{SO}_{3}$

TABLA 8-40.- CLASIFICACIÓN DE LAS DISTINTAS PUZOLANAS A IGUALDAD DE CEMENTO PORTLAND DE REFERENCIA EN EL ENSAYO L-A DE LOS CEMENTOS (PY-6/M $20 / 80)+7.0 \% \mathrm{SO}_{3}$

TABLA 8-41.- CLASIFICACIÓN DE LAS DISTINTAS PUZOLANAS A IGUALDAD DE CEMENTO PORTLAND DE REFERENCIA EN EL ENSAYO L-A DE LOS CEMENTOS P-1 Y $\mathrm{PY}-6 /(\mathrm{M}+\mathrm{CH}) 30 / 70)+7.0 \% \mathrm{SO}_{3}$

TABLA 8-42.- CLASIFICACIÓN DE LAS DISTINTAS PUZOLANAS A IGUALDAD DE CEMENTO PORTLAND DE REFERENCIA EN EL ENSAYO L-A DE LOS CEMENTOS PY$6 /(\mathrm{M}+\mathrm{CH}) 20 / 80)+7.0 \% \mathrm{SO}_{3}$

TABLA 8-43.- VALORES DE LOS PARÁMETROS $\triangle \varnothing$, VCØ, $\triangle \varnothing / G$ "Z" Y P.A.V. DE LOS CEMENTOS MIXTOS DERIVADOS CON CH SOBRE LOS CORRESPONDIENTES SIN CH . 270

TABLA 8-44.- VALORES DE RMC Y RMF EN PROBETAS DE 4X4X16 CM DE MORTERO NORMALIZADO TIPO RC-75, DE LOS CEMENTOS PORTLAND DE REFERENCIA: RELACIÓN CON SU COMPOSICIÓN POTENCIAL Y FINURA DE MOLIDO.

TABLA 8-45.- CLASIFICACIÓN MECÁNICO-RESISTENTE DE LOS CEMENTOS PORTLAND.ANÁLISIS Y ESTUDIO COMPARATIVO CON SU COMPOSICIÓN POTENCIAL Y FINURA DE MOLIDO 289

TABLA 8-46.- ESTUDIO COMPARATIVO DE LOS CEMENTOS PORTLAND A CADA UNA DE LAS 3 EDADES DEL ENSAYO, EN FUNCIÓN DE LA RMF DE SUS MEZCLAS 60/40 CON CADA PUZOLANA SELECCIONADA 
TABLA 8-47.- ESTUDIO COMPARATIVO DE LOS CEMENTOS PORTLAND A CADA UNA DE LAS 3 EDADES DEL ENSAYO, EN FUNCIÓN DE LA RMC DE SUS MEZCLAS 60/40 CON CADA PUZOLANA SELECCIONADA

TABLA 8-48.- ESTUDIO COMPARATIVO DE LA RELACIÓN RMF/RMC DE LOS CEMENTOS DE MEZCLA 60/40 EN FUNCIÓN DEL CEMENTO PORTLAND DE REFERENCIA UTILIZADO, CON IDÉNTICA PUZOLANA SELECCIONADA... 296

TABLA 8-49.- ESTUDIO COMPARATIVO DE LA RMC DE LOS CEMENTOS DE MEZCLA 60/40 EN FUNCIÓN DEL CEMENTO PORTLAND DE REFERENCIA UTILIZADO CON APORTE DE CAL APAGADA, CON IDÉNTICA PUZOLANA SELECCIONADA 297

TABLA 8-50.- ESTUDIO COMPARATIVO DE LA RELACIÓN RMF/RMC DE LOS CEMENTOS DE MEZCLA 60/40 EN FUNCIÓN DEL CEMENTO PORTLAND DE REFERENCIA UTILIZADO CON APORTE DE CAL APAGADA, CON IDÉNTICA PUZOLANA SELECCIONADA

TABLA 8-51.- ESTUDIO COMPARATIVO DE LA RMC DE LOS CEMENTOS DE MEZCLA 50/50 EN FUNCIÓN DEL CEMENTO PORTLAND DE REFERENCIA UTILIZADO, CON IDÉNTICA PUZOLANA SELECCIONADA

TABLA 8-52.- ESTUDIO COMPARATIVO DE LA RMF DE LOS CEMENTOS DE MEZCLA 50/50 EN FUNCIÓN DEL CEMENTO PORTLAND DE REFERENCIA UTILIZADO, CON IDÉNTICA PUZOLANA SELECCIONADA

TABLA 8-53.- ESTUDIO COMPARATIVO DE LA RELACIÓN RMF/RMC DE LOS CEMENTOS DE MEZCLA 50/50 EN FUNCIÓN DEL CEMENTO PORTLAND DE REFERENCIA UTILIZADO, CON IDÉNTICA PUZOLANA SELECCIONADA. 300

TABLA 8-54.- ESTUDIO COMPARATIVO DE LA RMF DE LOS CEMENTOS DE MEZCLA 40/60 EN FUNCIÓN DEL CEMENTO PORTLAND DE REFERENCIA UTILIZADO, CON IDÉNTICA PUZOLANA SELECCIONADA, A Y M .

TABLA 8-55.- ESTUDIO COMPARATIVO DE LA RMC DE LOS CEMENTOS DE MEZCLA 40/60 EN FUNCIÓN DEL CEMENTO PORTLAND DE REFERENCIA UTILIZADO, CON IDÉNTICA PUZOLANA SELECCIONADA, A Y M .

TABLA 8-56.- ESTUDIO COMPARATIVO DE LA RELACIÓN RMF/RMC LOS CEMENTOS DE MEZCLA 40/60 EN FUNCIÓN DEL CEMENTO PORTLAND DE REFERENCIA UTILIZADO, CON IDÉNTICA PUZOLANA SELECCIONADA, A Y M 301

TABLA 8-57.- ESTUDIO COMPARATIVO DE LA RMF DE LOS CEMENTOS DE MEZCLA 30/70 EN FUNCIÓN DEL CEMENTO PORTLAND DE REFERENCIA UTILIZADO, CON LA PUZOLANA SELECCIONADA M

TABLA 8-58.- ESTUDIO COMPARATIVO DE LA RMF DE LOS CEMENTOS DE MEZCLA 30/70 EN FUNCIÓN DEL CEMENTO PORTLAND DE REFERENCIA UTILIZADO, CON LA PUZOLANA SELECCIONADA M. 
TABLA 8-59.- ESTUDIO COMPARATIVO DE LA RMF DE LOS CEMENTOS DE MEZCLA 30/70 EN FUNCIÓN DEL CEMENTO PORTLAND DE REFERENCIA UTILIZADO, CON LA PUZOLANA SELECCIONADA M

TABLA 8-60.- ESTUDIO COMPARATIVO DE LA RMF DE LOS CEMENTOS DE MEZCLA P2/C 60/40+CH, PY4/C 60/40+CH EN FUNCIÓN DEL CEMENTO PORTLAND DE REFERENCIA UTILIZADO, P2 Y PY4

TABLA 8-61.- ESTUDIO COMPARATIVO DE LA RMC DE LOS CEMENTOS DE MEZCLA P2/C 60/40 +CH, PY4/C 60/40+CH EN FUNCIÓN DEL CEMENTO PORTLAND DE REFERENCIA UTILIZADO, P2 Y PY4.

TABLA 8-62.- ESTUDIO COMPARATIVO DE LA RMF/RMC DE LOS CEMENTOS DE MEZCLA P2/C 60/40+CH, PY4/C 60/40+CH EN FUNCIÓN DEL CEMENTO PORTLAND DE REFERENCIA UTILIZADO, P2 Y PY4. 303

TABLA 8-63.- ESTUDIO COMPARATIVO DE LA RMF DE LOS CEMENTOS DE MEZCLA EN FUNCIÓN DEL CEMENTO PORTLAND DE REFERENCIA UTILIZADO CON APORTE DE CAL APAGADA, CON IDÉNTICA PUZOLANA SELECCIONADA 304

TABLA 8-64.- ESTUDIO COMPARATIVO DE LA RMC DE LOS CEMENTOS DE MEZCLA EN FUNCIÓN DEL CEMENTO PORTLAND DE REFERENCIA UTILIZADO CON APORTE DE CAL APAGADA, CON IDÉNTICA PUZOLANA SELECCIONADA 304

TABLA 8-65.- ESTUDIO COMPARATIVO DE LA RELACIÓN RMF/RMC DE LOS CEMENTOS DE MEZCLA EN FUNCIÓN DEL CEMENTO PORTLAND DE REFERENCIA UTILIZADO CON APORTE DE CAL APAGADA, CON IDÉNTICA PUZOLANA SELECCIONADA...........305

TABLA 8-66.- ESTUDIO COMPARATIVO DE LA RMF DE LOS CEMENTOS DE MEZCLA EN FUNCIÓN DEL CEMENTO PORTLAND DE REFERENCIA UTILIZADO, P1 Y P31, CON APORTE DE CAL APAGADA, CON LA PUZOLANA SELECCIONADA A. .305

TABLA 8-67.- ESTUDIO COMPARATIVO DE LA RMC DE LOS CEMENTOS DE MEZCLA EN FUNCIÓN DEL CEMENTO PORTLAND DE REFERENCIA UTILIZADO, P1 Y P31, CON APORTE DE CAL APAGADA, CON LA PUZOLANA SELECCIONADA A ……………..............306

TABLA 8-68.- ESTUDIO COMPARATIVO DE LA RELACIÓN RMF/RMC DE LOS CEMENTOS DE MEZCLA EN FUNCIÓN DEL CEMENTO PORTLAND DE REFERENCIA UTILIZADO, P1 Y P31, CON APORTE DE CAL APAGADA, CON LA PUZOLANA SELECCIONADA A .........306

TABLA 8-69.- ESTUDIO COMPARATIVO DE LA RMF DE LOS CEMENTOS DE MEZCLA EN FUNCIÓN DEL CEMENTO PORTLAND DE REFERENCIA UTILIZADO CON APORTE DE CAL APAGADA, CON LA PUZOLANA SELECCIONADA M TABLA. 306

TABLA 8-70.- ESTUDIO COMPARATIVO DE LA RMF DE LOS CEMENTOS DE MEZCLA EN FUNCIÓN DEL CEMENTO PORTLAND DE REFERENCIA UTILIZADO CON APORTE DE CAL APAGADA, CON LA PUZOLANA SELECCIONADA M .307

TABLA 8-71.- ESTUDIO COMPARATIVO DE LA RELACIÓN RMF/RMC DE LOS CEMENTOS DE MEZCLA EN FUNCIÓN DEL CEMENTO PORTLAND DE REFERENCIA UTILIZADO CON APORTE DE CAL APAGADA, CON LA PUZOLANA SELECCIONADA M.... 
TABLA 8-72.- ESTUDIO COMPARATIVO DE LA RMF DE LOS CEMENTOS DE MEZCLA EN FUNCIÓN DEL CEMENTO PORTLAND DE REFERENCIA UTILIZADO, P1 Y PY6 CON APORTE DE 7\% DE SO3, CON LA PUZOLANA SELECCIONADA M. 307

TABLA 8-73.- ESTUDIO COMPARATIVO DE LA RMC DE LOS CEMENTOS DE MEZCLA EN FUNCIÓN DEL CEMENTO PORTLAND DE REFERENCIA UTILIZADO, P1 Y PY6 CON APORTE DE 7\% DE SO3, CON LA PUZOLANA SELECCIONADA M. .308

TABLA 8-74.- ESTUDIO COMPARATIVO DE LA RELACIÓN RMF/RMC DE LOS CEMENTOS DE MEZCLA EN FUNCIÓN DEL CEMENTO PORTLAND DE REFERENCIA UTILIZADO, P1 Y PY6 CON APORTE DE 7\% DE SO3, CON LA PUZOLANA SELECCIONADA M. .308

TABLA 8-75.- ESTUDIO COMPARATIVO DE LA RMF DE LOS CEMENTOS DE MEZCLA EN FUNCIÓN DEL CEMENTO PORTLAND DE REFERENCIA UTILIZADO, P1 Y PY6 CON APORTE DE 7\% DE SO3 Y HIDRÓXIDO DE CALCIO, CON LA PUZOLANA SELECCIONADA M .308

TABLA 8-76.- ESTUDIO COMPARATIVO DE LA RMC DE LOS CEMENTOS DE MEZCLA EN FUNCIÓN DEL CEMENTO PORTLAND DE REFERENCIA UTILIZADO, P1 Y PY6 CON APORTE DE 7\% DE SO3 Y HIDRÓXIDO DE CALCIO, CON LA PUZOLANA SELECCIONADA M 309

TABLA 8-77.- ESTUDIO COMPARATIVO DE LA RELACIÓN RMF/RMC DE LOS CEMENTOS DE MEZCLA EN FUNCIÓN DEL CEMENTO PORTLAND DE REFERENCIA UTILIZADO, P1 Y PY6 CON APORTE DE 7\% DE SO3 Y HIDRÓXIDO DE CALCIO, CON LA PUZOLANA SELECCIONADA M .309

TABLA 8-78.- ESTUDIO COMPARATIVO DE LA RMF DE LOS CEMENTOS DE MEZCLA 60/40 EN FUNCIÓN DE LA PUZOLANA SELECCIONADA UTILIZADA, CON UN MISMO CEMENTO PORTLAND DE REFERENCIA

TABLA 8-79.- ESTUDIO COMPARATIVO DE LA RMC DE LOS CEMENTOS DE MEZCLA 60/40 EN FUNCIÓN DE LA PUZOLANA SELECCIONADA UTILIZADA, CON UN MISMO CEMENTO PORTLAND DE REFERENCIA

TABLA 8-80.- ESTUDIO COMPARATIVO DE LA RELACIÓN RMF/RMC DE LOS CEMENTOS DE MEZCLA 60/40 EN FUNCIÓN DE DE LA PUZOLANA SELECCIONADA UTILIZADA, CON UN MISMO CEMENTO PORTLAND DE REFERENCIA

TABLA 8-81.- ESTUDIO COMPARATIVO DE LA RMF DE LOS CEMENTOS DE MEZCLA 50/50 EN FUNCIÓN DE LA ADICIÓN MINERAL UTILIZADA, CON UN MISMO CEMENTO PORTLAND DE REFERENCIA .314

TABLA 8-82.- ESTUDIO COMPARATIVO DE LA RMC DE LOS CEMENTOS DE MEZCLA 50/50 EN FUNCIÓN DE LA ADICIÓN MINERAL UTILIZADA, CON UN MISMO CEMENTO PORTLAND DE REFERENCIA 315

TABLA 8-83.- ESTUDIO COMPARATIVO DE LA RELACIÓN RMF/RMC DE LOS CEMENTOS DE MEZCLA 50/50 EN FUNCIÓN DE LA ADICIÓN MINERAL UTILIZADA, CON UN MISMO CEMENTO PORTLAND DE REFERENCIA 317 
TABLA 8-84.- ESTUDIO COMPARATIVO DE LA RMF DE LOS CEMENTOS DE MEZCLA 40/60 EN FUNCIÓN DE LA ADICIÓN MINERAL UTILIZADA (M, A, C Y S4), CON UN MISMO CEMENTO PORTLAND DE REFERENCIA (P1 Y P31)

TABLA 8-85.- ESTUDIO COMPARATIVO DE LA RMC DE LOS CEMENTOS DE MEZCLA 40/60 EN FUNCIÓN DE LA ADICIÓN MINERAL UTILIZADA (M, A, C Y S4), CON UN MISMO CEMENTO PORTLAND DE REFERENCIA (P1 Y P31).

TABLA 8-86.- ESTUDIO COMPARATIVO DE LA RELACIÓN RMF/RMC DE LOS CEMENTOS DE MEZCLA 40/60 EN FUNCIÓN DE LA ADICIÓN MINERAL UTILIZADA (M, A, C Y S4), CON UN MISMO CEMENTO PORTLAND DE REFERENCIA (P1 Y P31). 319

TABLA 8-87.- ESTUDIO COMPARATIVO DE LA RMF DE LOS CEMENTOS DE MEZCLA EN FUNCIÓN DE LA ADICIÓN MINERAL UTILIZADA, CON UN MISMO CEMENTO PORTLAND DE REFERENCIA, UTILIZADO CON APORTE DE CAL APAGADA .321

TABLA 8-88.- ESTUDIO COMPARATIVO DE LA RMC DE LOS CEMENTOS DE MEZCLA EN FUNCIÓN DE LA ADICIÓN MINERAL UTILIZADA, CON UN MISMO CEMENTO PORTLAND DE REFERENCIA, UTILIZADO CON APORTE DE CAL APAGADA. 322

TABLA 8-89.- ESTUDIO COMPARATIVO DE LA RELACIÓN RMF/RMC DE LOS CEMENTOS DE MEZCLA EN FUNCIÓN DE LA ADICIÓN MINERAL UTILIZADA, CON UN MISMO CEMENTO PORTLAND DE REFERENCIA, UTILIZADO CON APORTE DE CAL APAGADA

TABLA 8-90.- ESTUDIO COMPARATIVO DE LA RMF DE LOS CEMENTOS DE MEZCLA EN FUNCIÓN EN FUNCIÓN DE LA ADICIÓN MINERAL UTILIZADA, CON UN MISMO CEMENTO PORTLAND DE REFERENCIA UTILIZADO, CON APORTE DE CAL APAGADA

TABLA 8-91.- ESTUDIO COMPARATIVO DE LA RMC DE LOS CEMENTOS DE MEZCLA EN FUNCIÓN EN FUNCIÓN DE LA ADICIÓN MINERAL UTILIZADA, CON UN MISMO CEMENTO PORTLAND DE REFERENCIA UTILIZADO, CON APORTE DE CAL APAGADA

TABLA 8-92.- ESTUDIO COMPARATIVO DE LA RELACIÓN RMF/RMC DE LOS CEMENTOS DE MEZCLA EN FUNCIÓN EN FUNCIÓN DE LA ADICIÓN MINERAL UTILIZADA, CON UN MISMO CEMENTO PORTLAND DE REFERENCIA UTILIZADO, CON APORTE DE CAL APAGADA. 326

TABLA 8-93.- RESULTADOS DEL GRADO DE SATURACIÓN DE CAO DE LA FASE LÍQUIDA EN CONTACTO CON LOS CEMENTOS DE REFERENCIA P1 Y PY6 .330

TABLA 8-94.- RESULTADOS DEL GRADO DE SATURACIÓN DE CAO DE LA FASE LÍQUIDA EN CONTACTO CON LOS CEMENTOS DE MEZCLA PREPARADOS CON EL CEMENTO PORTLAND P1 Y TODAS LAS ADICIONES MINERALES PUZOLÁNICAS .........333

TABLA 8-95.- RESULTADOS DE LA MEDIDA DEL PERFIL DE CARBONATACIÓN DE LOS CEMENTOS DE MEZCLA PREPARADOS CON EL CEMENTO PORTLAND P1 Y LA PUZOLANA M EN PROPORCIÓN 40/60 
COMPORTAMIENTO SULFÁTICO Y MECÁNICO-RESISTENTE DE CEMENTOS PORTLAND CON ELEVADOS CONTENIDOS DE PUZOLANAS (> 40\%): SU FUNDAMENTO QUÍMICO Y JUSTIFICACIÓN DE OTRAS CONSECUENCIAS POSIBLES

TABLA 8-96.- RESULTADOS DE RMFY RMC DE LOS CEMENTOS DE MEZCLA P1/M 40/60 SOMETIDOS AL ENSAYO DE CARBONATACIÓN ACELERADA. EDADES: 14, 28, 60, 120 Y 180 DÍAS

TABLA 8-97.- RESULTADOS DE LA MEDIDA DEL PERFIL DE CARBONATACIÓN DE LOS CEMENTOS DE MEZCLA PREPARADOS CON EL CEMENTO PORTLAND P1 Y LA PUZOLANA O EN PROPORCIÓN 50/50

TABLA 8-98.- RESULTADOS DE RMF Y RMC DE LOS CEMENTOS DE MEZCLA P1/M 40/60 SOMETIDOS AL ENSAYO DE CARBONATACIÓN ACELERADA. EDADES: 14, 28, 60, 120 Y 180 DÍAS 


\section{ÍNDICE DE FIGURAS}



FIGURA 1-1.- ESQUEMA DEL PROCESO DE FABRICACIÓN DEL CEMENTO .64

FIGURA 1-2.- EVOLUCIÓN DEL CONSUMO TOTAL EN ESPAÑA DE LOS DIFERENTES TIPOS DE MATERIAS PRIMAS ALTERNATIVAS DURANTE EL PERIODO 2004-2011 (Tm) (Fundación CEMA, 2011)

FIGURA 1-3.- MICROFOTOGRAFÍAS DE MICROSCOPÍA ELECTRÓNICA DE BARRIDO (X1000); (A) ETTRINGITA DE LENTA FORMACIÓN, DE ORIGEN CEMENTO PORTLAND; (B) ETTRINGITA DE RÁPIDA FORMACIÓN DE ORIGEN PUZOLÁNICO.

\section{CAPÍTULO 6. SELECCIÓN Y CARACTERIZACIÓN DE MATERIALES}

FIGURA 6-1.- RESULTADOS DEL ANÁLISIS POR DRX DEL CEMENTO PORTLAND P1....144 FIGURA 6-2.- RESULTADOS DEL ANÁLISIS POR DRX DEL CEMENTO PORTLAND PY6.145 FIGURA 6-3.- DISTRIBUCIÓN DE TAMAÑOS DE PARTÍCULA DEL CEMENTO PORTLAND P1 146

FIGURA 6-4.- DISTRIBUCIÓN DE TAMAÑOS DE PARTÍCULA DEL CEMENTO PORTLAND PY6 146

FIGURA 6-5.- RESULTADOS DEL ANÁLISIS POR DRX. (A) PUZOLANA O; (B) PUZOLANA A; (C) PUZOLANA C 152

FIGURA 6-6.- RESULTADOS DEL ANÁLISIS POR DRX. (A) PUZOLANA CV10; (B) PUZOLANA CV19; (C) PUZOLANA M. 153

FIGURA 6-7.- DISTRIBUCIÓN DE TAMAÑOS DE PARTÍCULA. (A) PUZOLANA O; (B) PUZOLANA A; (C) PUZOLANA C. .154

FIGURA 6-8.- DISTRIBUCIÓN DE TAMAÑOS DE PARTÍCULA. (A) PUZOLANA CV10; (B) PUZOLANA CV19; (C) PUZOLANA M. 155

\section{CAPÍTULO 7. METODOLOGÍA Y PROCEDIMIENTO EXPERIMENTAL}

FIGURA 7-1.- REPRESENTACIÓN ESQUEMÁTICA CON EL RESUMEN DEL PLAN EXPERIMENTAL DE ENSAYOS Y ANÁLISIS REALIZADOS A LAS DIFERENTES PASTAS Y MORTEROS OBJETO DE INVESTIGACIÓN. .168

FIGURA 7-2.- TORTA CARACTERÍSTICA DEL ENSAYO LE CHATELIER-ANSTETT. 178 
COMPORTAMIENTO SULFÁTICO Y MECÁNICO-RESISTENTE DE CEMENTOS PORTLAND CON ELEVADOS CONTENIDOS DE PUZOLANAS (> 40\%): SU FUNDAMENTO QUÍMICO Y JUSTIFICACIÓN DE OTRAS CONSECUENCIAS POSIBLES

FIGURA 7-3.- APARATO DE VICAT TÍPICO (EXTRAIDO DE UNE EN 196-3) 180

FIGURA 7-4.- AGUJA PARA LA DETERMINACIÓN DEL PRINCIPIO Y FINAL DE FRAGUADO (EXTRAIDO DE UNE EN 196-3). 181

FIGURA 7-5.- IMAGEN DEL MEZCLADOR TUBULAR WAB. 183

FIGURA 7-6.- GRÁFICA DEL ENSAYO DE FRATTINI 186

FIGURA 7-7.- PHMETRO UTILIZADO EN ESTA INVESTIGACIÓN 189

FIGURA 7-8.- ESQUEMA GENERAL DE LA CÁMARA DE ENSAYO (EXTRAÍDO DE UNE 83993-2) .192

FIGURA 7-9.- REPRESENTACIÓN GRÁFICA DE UN FRENTE HOMOGÉNEO DE CARBONATACIÓN (EXTRAÍDO DE UNE 112011). .194

FIGURA 7-10.- REPRESENTACIÓN GRÁFICA DE UN FRENTE IRREGULAR DE CARBONATACIÓN (EXTRAÍDO DE UNE 112011) .194

FIGURA 7-11.- REPRESENTACIÓN GRÁFICA DE UN FRENTE SINGULAR DE CARBONATACIÓN (EXTRAÍDO DE UNE 112011) .195

FIGURA 7-12- MEDIDAS DE PROFUNDIDAD DE CARBONATACIÓN (EXTRAÍDO DE UNE 83993-2) 195

CAPÍTULO 8. RESULTADOS OBTENIDOS: SU ANÁLISIS, ESTUDIO Y DISCUSIÓN

FIGURA 8-1.- RESULTADOS OBTENIDOS DE $\triangle$ Ø EN EL ENSAYO LE CHATELIER ANSTETT PARA TODOS LOS CEMENTOS DE MEZCLA PREPARADOS CON CP P1 Y TODAS LAS PUZOLANAS UTILIZADAS EN ESTA INVESTIGACIÓN 212

FIGURA 8-2.- RESULTADOS OBTENIDOS DE $\triangle \varnothing$ EN EL ENSAYO LE CHATELIER ANSTETT PARA TODOS LOS CEMENTOS DE MEZCLA PREPARADOS CON CP P2 Y TODAS LAS PUZOLANAS UTILIZADAS EN ESTA INVESTIGACIÓN .213

FIGURA 8-3.- RESULTADOS OBTENIDOS DE $\triangle$ Ø EN EL ENSAYO LE CHATELIER ANSTETT PARA TODOS LOS CEMENTOS DE MEZCLA PREPARADOS CON CP P31 Y TODAS LAS PUZOLANAS UTILIZADAS EN ESTA INVESTIGACIÓN .214

FIGURA 8-4.- RESULTADOS OBTENIDOS DE $\triangle \varnothing$ EN EL ENSAYO LE CHATELIER ANSTETT PARA TODOS LOS CEMENTOS DE MEZCLA PREPARADOS CON CP PY4 Y TODAS LAS PUZOLANAS UTILIZADAS EN ESTA INVESTIGACIÓN .215

FIGURA 8-5.- RESULTADOS OBTENIDOS DE $\triangle \varnothing$ EN EL ENSAYO LE CHATELIER ANSTETT PARA TODOS LOS CEMENTOS DE MEZCLA PREPARADOS CON CP PY6 Y TODAS LAS PUZOLANAS UTILIZADAS EN ESTA INVESTIGACIÓN 217

FIGURA 8-6.- RESULTADOS OBTENIDOS DE VCØ EN EL ENSAYO LE CHATELIER ANSTETT PARA TODOS LOS CEMENTOS DE MEZCLA PREPARADOS CON CP P1 Y TODAS LAS PUZOLANAS UTILIZADAS EN ESTA INVESTIGACIÓN 
FIGURA 8-7.- RESULTADOS OBTENIDOS DE VCØ EN EL ENSAYO LE CHATELIER ANSTETT PARA TODOS LOS CEMENTOS DE MEZCLA PREPARADOS CON CP P2 Y TODAS LAS PUZOLANAS UTILIZADAS EN ESTA INVESTIGACIÓN

FIGURA 8-8.- RESULTADOS OBTENIDOS DE VCØ EN EL ENSAYO LE CHATELIER ANSTETT PARA TODOS LOS CEMENTOS DE MEZCLA PREPARADOS CON CP P31 Y TODAS LAS PUZOLANAS UTILIZADAS EN ESTA INVESTIGACIÓN

FIGURA 8-9.- RESULTADOS OBTENIDOS DE VCØ EN EL ENSAYO LE CHATELIER ANSTETT PARA TODOS LOS CEMENTOS DE MEZCLA PREPARADOS CON CP PY4 Y TODAS LAS PUZOLANAS UTILIZADAS EN ESTA INVESTIGACIÓN

FIGURA 8-10.- RESULTADOS OBTENIDOS DE VCØ EN EL ENSAYO LE CHATELIER ANSTETT PARA TODOS LOS CEMENTOS DE MEZCLA PREPARADOS CON CP PY6 Y TODAS LAS PUZOLANAS UTILIZADAS EN ESTA INVESTIGACIÓN

FIGURA 8-11.- RESULTADOS OBTENIDOS DE $\triangle \varnothing / \mathrm{g}$ “Z” EN EL ENSAYO LE CHATELIER ANSTETT PARA TODOS LOS CEMENTOS DE MEZCLA PREPARADOS CON CP P1 Y TODAS LAS PUZOLANAS UTILIZADAS EN ESTA INVESTIGACIÓN ....

FIGURA 8-12.- RESULTADOS OBTENIDOS DE $\triangle \varnothing / \mathrm{g}$ “Z” EN EL ENSAYO LE CHATELIER ANSTETT PARA TODOS LOS CEMENTOS DE MEZCLA PREPARADOS CON CP P2 Y TODAS LAS PUZOLANAS UTILIZADAS EN ESTA INVESTIGACIÓN

FIGURA 8-13.- RESULTADOS OBTENIDOS DE $\triangle \varnothing / \mathrm{g}$ “Z” EN EL ENSAYO LE CHATELIER ANSTETT PARA TODOS LOS CEMENTOS DE MEZCLA PREPARADOS CON CP P31 Y TODAS LAS PUZOLANAS UTILIZADAS EN ESTA INVESTIGACIÓN

FIGURA 8-14.- RESULTADOS OBTENIDOS DE $\triangle \varnothing / \mathrm{g}$ “Z” EN EL ENSAYO LE CHATELIER ANSTETT PARA TODOS LOS CEMENTOS DE MEZCLA PREPARADOS CON CP PY4 Y TODAS LAS PUZOLANAS UTILIZADAS EN ESTA INVESTIGACIÓN

FIGURA 8-15.- RESULTADOS OBTENIDOS DE $\triangle \varnothing / \mathrm{g}$ “Z” EN EL ENSAYO LE CHATELIER ANSTETT PARA TODOS LOS CEMENTOS DE MEZCLA PREPARADOS CON CP PY6 Y TODAS LAS PUZOLANAS UTILIZADAS EN ESTA INVESTIGACIÓN

FIGURA 8-16.- RESULTADOS OBTENIDOS DE P.A.V. EN EL ENSAYO LE CHATELIER ANSTETT PARA TODOS LOS CEMENTOS DE MEZCLA PREPARADOS CON CP P1 Y TODAS LAS PUZOLANAS UTILIZADAS EN ESTA INVESTIGACIÓN

FIGURA 8-17.- RESULTADOS OBTENIDOS DE P.A.V. EN EL ENSAYO LE CHATELIER ANSTETT PARA TODOS LOS CEMENTOS DE MEZCLA PREPARADOS CON CP P2 Y TODAS LAS PUZOLANAS UTILIZADAS EN ESTA INVESTIGACIÓN

FIGURA 8-18.- RESULTADOS OBTENIDOS DE P.A.V. EN EL ENSAYO LE CHATELIER ANSTETT PARA TODOS LOS CEMENTOS DE MEZCLA PREPARADOS CON CP P31 Y TODAS LAS PUZOLANAS UTILIZADAS EN ESTA INVESTIGACIÓN

FIGURA 8-19.- RESULTADOS OBTENIDOS DE P.A.V. EN EL ENSAYO LE CHATELIER ANSTETT PARA TODOS LOS CEMENTOS DE MEZCLA PREPARADOS CON CP PY4 Y TODAS LAS PUZOLANAS UTILIZADAS EN ESTA INVESTIGACIÓN 
COMPORTAMIENTO SULFÁTICO Y MECÁNICO-RESISTENTE DE CEMENTOS PORTLAND CON ELEVADOS CONTENIDOS DE PUZOLANAS (> 40\%): SU FUNDAMENTO QUÍMICO Y JUSTIFICACIÓN DE OTRAS CONSECUENCIAS POSIBLES

FIGURA 8-20.- RESULTADOS OBTENIDOS DE P.A.V. EN EL ENSAYO LE CHATELIER ANSTETT PARA TODOS LOS CEMENTOS DE MEZCLA PREPARADOS CON CP PY6 Y TODAS LAS PUZOLANAS UTILIZADAS EN ESTA INVESTIGACIÓN 260

FIGURA 8-21.-REPRESENTACIÓN GRÁFICA DE LAS RMF Y RMC DE LOS CEMENTOS DE MEZCLA CONSTITUIDOS POR EL CEMENTO PORTLAND P1 Y CADA UNA DE LAS ADICIONES PUZOLÁNICAS SELECCIONADAS EN PROPORCIÓN 60/40. EDADES: 7, 28 Y 90 DÍAS 311

FIGURA 8-22.-REPRESENTACIÓN GRÁFICA DE LAS RMF Y RMC DE LOS CEMENTOS DE MEZCLA CONSTITUIDOS POR EL CEMENTO PORTLAND P2 Y CADA UNA DE LAS ADICIONES PUZOLÁNICAS SELECCIONADAS EN PROPORCIÓN 60/40. EDADES: 7, 28 Y 90 DÍAS

FIGURA 8-23.-REPRESENTACIÓN GRÁFICA DE LAS RMF Y RMC DE LOS CEMENTOS DE MEZCLA CONSTITUIDOS POR EL CEMENTO PORTLAND P31 Y CADA UNA DE LAS ADICIONES PUZOLÁNICAS SELECCIONADAS EN PROPORCIÓN 60/40. EDADES: 7, 28 Y 90 DÍAS .313

FIGURA 8-24.-REPRESENTACIÓN GRÁFICA DE LAS RMF Y RMC DE LOS CEMENTOS DE MEZCLA CONSTITUIDOS POR EL CEMENTO PORTLAND PY4 Y CADA UNA DE LAS ADICIONES PUZOLÁNICAS SELECCIONADAS EN PROPORCIÓN 60/40. EDADES: 7, 28 Y 90 DÍAS .313

FIGURA 8-25.-REPRESENTACIÓN GRÁFICA DE LAS RMF Y RMC DE LOS CEMENTOS DE MEZCLA CONSTITUIDOS POR EL CEMENTO PORTLAND PY6 Y CADA UNA DE LAS ADICIONES PUZOLÁNICAS SELECCIONADAS EN PROPORCIÓN 60/40. EDADES: 7, 28 Y 90 DÍAS .314

FIGURA 8-26.-REPRESENTACIÓN GRÁFICA DE LAS RMF Y RMC DE LOS CEMENTOS DE MEZCLA CONSTITUIDOS POR EL CEMENTO PORTLAND P1 Y CADA UNA DE LAS ADICIONES PUZOLÁNICAS SELECCIONADAS EN PROPORCIÓN 50/50. EDADES: 7, 28 Y 90 DÍAS

FIGURA 8-27.-REPRESENTACIÓN GRÁFICA DE LAS RMF Y RMC DE LOS CEMENTOS DE MEZCLA CONSTITUIDOS POR EL CEMENTO PORTLAND P2 Y CADA UNA DE LAS ADICIONES PUZOLÁNICAS SELECCIONADAS EN PROPORCIÓN 50/50. EDADES: 7, 28 Y 90 DÍAS .316

FIGURA 8-28.-REPRESENTACIÓN GRÁFICA DE LAS RMF Y RMC DE LOS CEMENTOS DE MEZCLA CONSTITUIDOS POR EL CEMENTO PORTLAND P31 Y CADA UNA DE LAS ADICIONES PUZOLÁNICAS SELECCIONADAS EN PROPORCIÓN 50/50. EDADES: 7, 28 Y 90 DÍAS .316

FIGURA 8-29.-REPRESENTACIÓN GRÁFICA DE LAS RMF Y RMC DE LOS CEMENTOS DE MEZCLA CONSTITUIDOS POR EL CEMENTO PORTLAND PY4 Y CADA UNA DE LAS ADICIONES PUZOLÁNICAS SELECCIONADAS EN PROPORCIÓN 50/50. EDADES: 7, 28 Y 90 DÍAS 316 
FIGURA 8-30.-REPRESENTACIÓN GRÁFICA DE LAS RMF Y RMC DE LOS CEMENTOS DE MEZCLA CONSTITUIDOS POR EL CEMENTO PORTLAND PY6 Y CADA UNA DE LAS ADICIONES PUZOLÁNICAS SELECCIONADAS EN PROPORCIÓN 50/50. EDADES: 7, 28 Y 90 DÍAS .317

FIGURA 8-31.-REPRESENTACIÓN GRÁFICA DE LAS RMF Y RMC DE LOS CEMENTOS DE MEZCLA CONSTITUIDOS POR EL CEMENTO PORTLAND P1 Y CADA UNA DE LAS ADICIONES PUZOLÁNICAS SELECCIONADAS EN PROPORCIÓN 50/50. EDADES: 7, 28 Y 90 DÍAS 319

FIGURA 8-32.-REPRESENTACIÓN GRÁFICA DE LAS RMF Y RMC DE LOS CEMENTOS DE MEZCLA CONSTITUIDOS POR EL CEMENTO PORTLAND P2 Y CADA UNA DE LAS ADICIONES PUZOLÁNICAS SELECCIONADAS EN PROPORCIÓN 50/50. EDADES: 7, 28 Y 90 DÍAS 319

FIGURA 8-33.-REPRESENTACIÓN GRÁFICA DE LAS RMF Y RMC DE LOS CEMENTOS DE MEZCLA CONSTITUIDOS POR EL CEMENTO PORTLAND P31 Y CADA UNA DE LAS ADICIONES PUZOLÁNICAS SELECCIONADAS EN PROPORCIÓN 50/50. EDADES: 7, 28 Y 90 DÍAS 320

FIGURA 8-34.-REPRESENTACIÓN GRÁFICA DE LAS RMF Y RMC DE LOS CEMENTOS DE MEZCLA CONSTITUIDOS POR EL CEMENTO PORTLAND PY4 Y CADA UNA DE LAS ADICIONES PUZOLÁNICAS SELECCIONADAS EN PROPORCIÓN 50/50. EDADES: 7, 28 Y 90 DÍAS .320

FIGURA 8-35.-REPRESENTACIÓN GRÁFICA DE LAS RMF Y RMC DE LOS CEMENTOS DE MEZCLA CONSTITUIDOS POR EL CEMENTO PORTLAND PY6 Y CADA UNA DE LAS ADICIONES PUZOLÁNICAS SELECCIONADAS EN PROPORCIÓN 50/50. EDADES: 7, 28 Y 90 DÍAS .321

FIGURA 8-36.-REPRESENTACIÓN GRÁFICA DE LAS RMF Y RMC DE LOS CEMENTOS DE MEZCLA CONSTITUIDOS POR EL CEMENTO PORTLAND P1 Y CADA UNA DE LAS ADICIONES PUZOLÁNICAS SELECCIONADAS EN PROPORCIÓN 50/50 CON APORTE EXTRA DE CH. EDADES: 7, 28 Y 90 DÍAS

FIGURA 8-37.-REPRESENTACIÓN GRÁFICA DE LAS RMF Y RMC DE LOS CEMENTOS DE MEZCLA CONSTITUIDOS POR EL CEMENTO PORTLAND P2 Y CADA UNA DE LAS ADICIONES PUZOLÁNICAS SELECCIONADAS EN PROPORCIÓN 50/50 CON APORTE EXTRA DE CH. EDADES: 7, 28 Y 90 DÍAS

FIGURA 8-38.-REPRESENTACIÓN GRÁFICA DE LAS RMF Y RMC DE LOS CEMENTOS DE MEZCLA CONSTITUIDOS POR EL CEMENTO PORTLAND P31 Y CADA UNA DE LAS ADICIONES PUZOLÁNICAS SELECCIONADAS EN PROPORCIÓN 50/50 CON APORTE EXTRA DE CH. EDADES: 7, 28 Y 90 DÍAS

FIGURA 8-39.-REPRESENTACIÓN GRÁFICA DE LAS RMF Y RMC DE LOS CEMENTOS DE MEZCLA CONSTITUIDOS POR EL CEMENTO PORTLAND PY4 Y CADA UNA DE LAS ADICIONES PUZOLÁNICAS SELECCIONADAS EN PROPORCIÓN 50/50 CON APORTE EXTRA DE CH. EDADES: 7, 28 Y 90 DÍAS. 
COMPORTAMIENTO SULFÁTICO Y MECÁNICO-RESISTENTE DE CEMENTOS PORTLAND CON ELEVADOS CONTENIDOS DE PUZOLANAS (> 40\%): SU FUNDAMENTO QUÍMICO Y JUSTIFICACIÓN DE OTRAS CONSECUENCIAS POSIBLES

FIGURA 8-40.-REPRESENTACIÓN GRÁFICA DE LAS RMF Y RMC DE LOS CEMENTOS DE MEZCLA CONSTITUIDOS POR EL CEMENTO PORTLAND PY6 Y CADA UNA DE LAS ADICIONES PUZOLÁNICAS SELECCIONADAS EN PROPORCIÓN 50/50 CON APORTE EXTRA DE CH. EDADES: 7, 28 Y 90 DÍAS

FIGURA 8-41.-REPRESENTACIÓN GRÁFICA DE LAS RMF Y RMC DE LOS CEMENTOS DE MEZCLA CONSTITUIDOS POR EL CEMENTO PORTLAND P1 Y CADA UNA DE LAS ADICIONES PUZOLÁNICAS SELECCIONADAS EN PROPORCIÓN 40/60 CON APORTE EXTRA DE CH. EDADES: 7, 28 Y 90 DÍAS. .326

FIGURA 8-42.-REPRESENTACIÓN GRÁFICA DE LAS RMF Y RMC DE LOS CEMENTOS DE MEZCLA CONSTITUIDOS POR EL CEMENTO PORTLAND P2 Y CADA UNA DE LAS ADICIONES PUZOLÁNICAS SELECCIONADAS EN PROPORCIÓN 40/60 CON APORTE EXTRA DE CH. EDADES: 7, 28 Y 90 DÍAS

FIGURA 8-43.-REPRESENTACIÓN GRÁFICA DE LAS RMF Y RMC DE LOS CEMENTOS DE MEZCLA CONSTITUIDOS POR EL CEMENTO PORTLAND P31 Y CADA UNA DE LAS ADICIONES PUZOLÁNICAS SELECCIONADAS EN PROPORCIÓN 40/60 CON APORTE EXTRA DE CH. EDADES: 7, 28 Y 90 DÍAS

FIGURA 8-44.-REPRESENTACIÓN GRÁFICA DE LAS RMF Y RMC DE LOS CEMENTOS DE MEZCLA CONSTITUIDOS POR EL CEMENTO PORTLAND PY4 Y CADA UNA DE LAS ADICIONES PUZOLÁNICAS SELECCIONADAS EN PROPORCIÓN 50/50 CON APORTE EXTRA DE CH. EDADES: 7, 28 Y 90 DÍAS

FIGURA 8-45.-REPRESENTACIÓN GRÁFICA DE LAS RMF Y RMC DE LOS CEMENTOS DE MEZCLA CONSTITUIDOS POR EL CEMENTO PORTLAND PY6 Y CADA UNA DE LAS ADICIONES PUZOLÁNICAS SELECCIONADAS EN PROPORCIÓN 50/50 CON APORTE EXTRA DE CH. EDADES: 7, 28 Y 90 DÍAS.

FIGURA 8-46.-REPRESENTACIÓN GRÁFICA DE LAS RMF Y RMC DE LOS CEMENTOS DE MEZCLA CONSTITUIDOS POR EL CEMENTO PORTLAND P1 Y CADA UNA DE LAS ADICIONES PUZOLÁNICAS SELECCIONADAS EN PROPORCIÓN 30/70. EDADES: 7, 28 Y 90 DÍAS

FIGURA 8-47.-REPRESENTACIÓN GRÁFICA DE LAS RMF Y RMC DE LOS CEMENTOS DE MEZCLA CONSTITUIDOS POR EL CEMENTO PORTLAND P2 Y CADA UNA DE LAS ADICIONES PUZOLÁNICAS SELECCIONADAS EN PROPORCIÓN 30/70. EDADES: 7, 28 Y 90 DÍAS

FIGURA 8-48.- REPRESENTACIÓN GRÁFICA DE LAS RMF Y RMC DE LOS CEMENTOS DE MEZCLA CONSTITUIDOS POR EL CEMENTO PORTLAND P31 Y CADA UNA DE LAS ADICIONES PUZOLÁNICAS SELECCIONADAS EN PROPORCIÓN 30/70. EDADES: 7, 28 Y 90 DÍAS

FIGURA 8-49.- REPRESENTACIÓN GRÁFICA DE LAS RMF Y RMC DE LOS CEMENTOS DE MEZCLA CONSTITUIDOS POR EL CEMENTO PORTLAND PY6 Y CADA UNA DE LAS ADICIONES PUZOLÁNICAS SELECCIONADAS EN PROPORCIÓN 30/70. EDADES: 7, 28 Y 90 DÍAS 
FIGURA 8-50.- REPRESENTACIÓN GRÁFICA DEL GRADO DE SATURACIÓN DEL CAO DE LA FASE LÍQUIDA EN CONTACTO CON LOS CEMENTOS DE REFERENCIA P1 Y PY6 .... 331

FIGURA 8-51.- REPRESENTACIÓN GRÁFICA DEL GRADO DE SATURACIÓN DE CAO DE LA FASE LÍQUIDA EN CONTACTO CON LOS CEMENTOS DE MEZCLA DEL CEMENTO PORTLAND P1 CON LA PUZOLANA C .334

FIGURA 8-52.- REPRESENTACIÓN GRÁFICA DEL GRADO DE SATURACIÓN DEL CAO DE LA FASE LÍQUIDA EN CONTACTO CON LOS CEMENTOS DE MEZCLA DEL CEMENTO PORTLAND P1 CON LA PUZOLANA A .335

FIGURA 8-53.- REPRESENTACIÓN GRÁFICA DEL GRADO DE SATURACIÓN DEL CAO DE LA FASE LÍQUIDA EN CONTACTO CON LOS CEMENTOS DE MEZCLA DEL CEMENTO PORTLAND P1 CON LA PUZOLANA O .336

FIGURA 8-54.- REPRESENTACIÓN GRÁFICA DEL GRADO DE SATURACIÓN DEL CAO DE LA FASE LÍQUIDA EN CONTACTO CON LOS CEMENTOS DE MEZCLA DEL CEMENTO PORTLAND P1 CON LA CENIZA VOLANTE CV10 337

FIGURA 8-55.- REPRESENTACIÓN GRÁFICA DEL GRADO DE SATURACIÓN DEL CAO DE LA FASE LÍQUIDA EN CONTACTO CON LOS CEMENTOS DE MEZCLA DEL CEMENTO PORTLAND P1 CON LA CENIZA VOLANTE CV19 .338

FIGURA 8-56.- REPRESENTACIÓN GRÁFICA DEL GRADO DE SATURACIÓN DEL CAO DE LA FASE LÍQUIDA EN CONTACTO CON LOS CEMENTOS DE MEZCLA DEL CEMENTO PORTLAND P1 CON EL METACAOLÍN M

FIGURA 8-57.- EVOLUCIÓN DEL PERFIL DE CARBONATACIÓN EN LAS PROBETAS CORRESPONDIENTES AL CEMENTO DE MEZCLA P1/M 40/60 CURADAS DURANTE 28 DÍAS EN AMBIENTE DEL LABORATORIO

FIGURA 8-58.- EVOLUCIÓN DEL PERFIL DE CARBONATACIÓN EN LAS PROBETAS CORRESPONDIENTES AL CEMENTO DE MEZCLA P1/M 40/60 CURADAS DURANTE 28 DÍAS BAJO AGUA.

FIGURA 8-59.- EVOLUCIÓN DEL PERFIL DE CARBONATACIÓN EN LAS PROBETAS CORRESPONDIENTES AL CEMENTO DE MEZCLA P1/M 40/60+CH CURADAS DURANTE 28 DÍAS EN AMBIENTE DE LABORATORIO

FIGURA 8-60.- EVOLUCIÓN DEL PERFIL DE CARBONATACIÓN EN LAS PROBETAS CORRESPONDIENTES AL CEMENTO DE MEZCLA P1/M 40/60+CH CURADAS DURANTE 28 DÍAS BAJO AGUA

FIGURA 8-61.- RESULTADOS DE RMF DE LOS CEMENTOS DE LOS CEMENTOS DE MEZCLA P1/M 40/60 SOMETIDOS AL ENSAYO DE CARBONATACIÓN ACELERADA. EDADES: 14, 28, 60, 120 Y 180 DÍAS.

FIGURA 8-62.- RESULTADOS DE RMC DE LOS CEMENTOS DE LOS CEMENTOS DE MEZCLA P1/M 40/60 SOMETIDOS AL ENSAYO DE CARBONATACIÓN ACELERADA. EDADES: 14, 28, 60, 120 Y 180 DÍAS. 
COMPORTAMIENTO SULFÁTICO Y MECÁNICO-RESISTENTE DE CEMENTOS PORTLAND CON ELEVADOS CONTENIDOS DE PUZOLANAS (> 40\%): SU FUNDAMENTO QUÍMICO Y JUSTIFICACIÓN DE OTRAS CONSECUENCIAS POSIBLES

FIGURA 8-63.- EVOLUCIÓN DEL PERFIL DE CARBONATACIÓN EN LAS PROBETAS CORRESPONDIENTES AL CEMENTO DE MEZCLA P1/O50/50 CURADAS DURANTE 28 DÍAS EN AMBIENTE DEL LABORATORIO.

FIGURA 8-64.- EVOLUCIÓN DEL PERFIL DE CARBONATACIÓN EN LAS PROBETAS CORRESPONDIENTES AL CEMENTO DE MEZCLA P1/O50/50 CURADAS DURANTE 28 DÍAS BAJO AGUA

FIGURA 8-65.- EVOLUCIÓN DEL PERFIL DE CARBONATACIÓN EN LAS PROBETAS CORRESPONDIENTES AL CEMENTO DE MEZCLA P1/O50/50+CH CURADAS DURANTE 28 DÍAS EN AMBIENTE DE LABORATORIO

FIGURA 8-66.- EVOLUCIÓN DEL PERFIL DE CARBONATACIÓN EN LAS PROBETAS CORRESPONDIENTES AL CEMENTO DE MEZCLA P1/O50/50+CH CURADAS DURANTE 28 DÍAS BAJO AGUA 349

FIGURA 8-67.- RESULTADOS DE RMF DE LOS CEMENTOS DE LOS CEMENTOS DE MEZCLA P1/O50/50 SOMETIDOS AL ENSAYO DE CARBONATACIÓN ACELERADA. EDADES: 14, 28, 60, 120 Y 180 DÍAS. 351

FIGURA 8-68.- RESULTADOS DE RMC DE LOS CEMENTOS DE LOS CEMENTOS DE MEZCLA P1/O50/50 SOMETIDOS AL ENSAYO DE CARBONATACIÓN ACELERADA. EDADES: 14, 28, 60, 120 Y 180 DÍAS. 352 
NOMENCLATURA Y GLOSARIO 



\section{NOMENCLATURA Y GLOSARIO}

La Química del cemento posee una formulación y nomenclatura muy particular en todos los sentidos, en cuanto a sus compuestos mineralógicos y productos de hidratación del cemento Portland, la cual consiste en la abreviación de los óxidos que los componen. Esta nomenclatura surge a consecuencia de investigaciones preliminares llevadas a cabo sobre el sistema ternario de óxidos $\mathrm{CaO}-\mathrm{Al}_{2} \mathrm{O}_{3}-\mathrm{SiO}_{2}$ en la década de 1910, pero fue John Johnston cinco años más tarde quien estableció una nomenclatura para la descripción de los compuestos mineralógicos del cemento Portland y que continúa como referencia en nuestros días.

Con el transcurso del tiempo y basados en el estilo propuesto por Johnston, han ido surgiendo abreviaturas para la mayor parte de los componentes mineralógicos y productos de hidratación del cemento. A continuación, se facilitan las abreviaturas de los principales óxidos propios de la química del cemento (Bogue, 1947):

- $\mathrm{CaO}$ - óxido de calcio - C

- $\mathrm{SiO}_{2}$ - óxido de silicio - $\mathrm{S}$

- $\mathrm{Al}_{2} \mathrm{O}_{3}$ - óxido de aluminio - $\mathbf{A}$

- $\mathrm{Fe}_{2} \mathrm{O}_{3}$ - óxido de hierro (III) - F

- $\mathrm{MgO}$ - óxido de magnesio - M
- $\mathrm{K}_{2} \mathrm{O}$ - óxido de potasio - $\mathrm{K}$

- $\mathrm{Na}_{2} \mathrm{O}$ - óxido de sodio - $\mathbf{N}$

- $\mathrm{H}_{2} \mathrm{O}$ - agua - $\mathbf{H}$

- $\mathrm{SO}_{4}{ }^{2-}$ - ión sulfato - $\overline{\mathbf{S}}$

- $\mathrm{CO}_{3}{ }^{2-}$ - ión carbonato - $\overline{\overline{\mathbf{C}}}$

Mediante abreviaturas, también es posible expresar las principales fases mineralógicas del clínker, así como el resto de componentes que lo acompañan en un cemento Portland y algunos parámetros que lo caracterizan, tales como:

- $3 \mathrm{CaO} \bullet \mathrm{SiO}_{2}$ - silicato tricálcico - $\mathrm{C}_{3} \mathrm{~S}$, comúnmente denominado como alita.

- $2 \mathrm{CaO} \bullet \mathrm{SiO}_{2}$ - silicato bicálcico - $\mathrm{C}_{2} \mathrm{~S}$, comúnmente denominado como belita.

- $3 \mathrm{CaO} \bullet \mathrm{Al}_{2} \mathrm{O}_{3}$ - aluminato tricálcico $-\mathrm{C}_{3} \mathrm{~A}$, comúnmente denominado como celita.

- $2 \mathrm{CaO} \bullet \mathrm{Fe}_{2} \mathrm{O}_{3}-6 \mathrm{CaO} \cdot 2 \mathrm{Al}_{2} \mathrm{O}_{3} \bullet \mathrm{Fe}_{2} \mathrm{O}_{3}$ - fase ferrito-aluminato (solución sólida) - $\mathrm{C}_{2} \mathrm{~F}-$ $\mathrm{C}_{6} \mathrm{~A}_{2} \mathrm{~F}^{1}$.

- $\mathrm{CaO}$ libre - cal libre, se encuentra como componente del clínker Portland en pequeña proporción, y algunas adiciones minerales inorgánicas, tanto de origen la natural como artificial, en mayor o menor cantidad.

- $\mathrm{CaSO}_{4} \bullet 2 \mathrm{H}_{2} \mathrm{O}$ - yeso $-\mathrm{CSH}_{2}$, el cual también recibe el nombre de regulador de fraguado por su acción específica sobre el fenómeno del fraguado.

- Pérdida al fuego, P.F.

${ }^{1}$ En la mayoría de las ocasiones a lo largo de esta MEMORIA aparecerán como $\mathrm{C}_{4} \mathrm{AF}$ ó $\mathrm{C}_{4} \mathrm{AF}\left(+\mathrm{C}_{2} \mathrm{~F}\right)$, cuyo nombre mineralógico es brownmillerita, puesto que para la mayor parte del cemento de los cementos Portland, la composición química de esta fase suele estar muy cercana a la de la composición asumida por Bogue, la del $4 \mathrm{CaO} \cdot \mathrm{Al}_{2} \mathrm{O}_{3} \cdot \mathrm{Fe}_{2} \mathrm{O}_{3}$. 
- $\quad$ Residuo Insoluble, R.I.

Mediante abreviaturas, también es habitual expresar todos y cada uno de los factores hidráulicos constituyentes, que se encuentran en estado físico amorfo y/o vítreo, de aquellos materiales inorgánicos naturales o artificiales que pueden ser considerados como puzolanas, y que tienen la propiedad de generar productos insolubles en combinación con el hidróxido de calcio de cualquier origen, tales como:

- $\quad \mathrm{SiO}_{2}{ }^{\mathrm{r}-}-$ sílice reactiva.

- $\mathrm{Al}_{2} \mathrm{O}_{3^{\mathrm{r}-}}$-alúmina reactiva.

- $\mathrm{Fe}_{2} \mathrm{O}_{3}{ }^{\mathrm{r}-}$ óxido de hierro reactivo.

Con respecto a los principales productos de hidratación del cemento Portland y su nomenclatura, los siguientes:

- gel CSH - silicatos de calcio hidratados, sin fórmula química definida y comúnmente representado como una solución sólida de composición variable $(\mathrm{CaO})_{x} \bullet\left(\mathrm{SiO}_{2}\right)_{\mathrm{y}} \bullet\left(\mathrm{H}_{2} \mathrm{O}\right)_{z}$, de los cuales aparecen a lo largo de esta Tesis Doctoral los siguientes tipos:

- en función de su localización en relación a la partícula de donde se originaron:

$\checkmark$ gel $\mathrm{CSH}^{\mathrm{E}}$, de carácter externo a las partículas del clínker Portland, y

$\checkmark$ gel CSH', de carácter interno a las partículas del clínker Portland.

- en función de la morfología de sus partículas:

$\checkmark$ gel CSH de tipo I, de morfología en forma de agujas o varillas, y

$\checkmark$ gel CSH de tipo II, de morfología reticular

- en función de las propiedades mecánico-elásticas:

$\checkmark$ gel CSH de alta densidad, cuyo módulo elástico está comprendido entre 26 y 39 GPa, y

$\checkmark$ gel CSH de baja densidad, cuyo módulo elástico está comprendido entre 13 y $26 \mathrm{GPa}$

- $\mathrm{Ca}(\mathrm{OH})_{2}$ - portlandita - $\mathrm{CH}$, que precipita a partir de la fase líquida sobresaturada en ella de la pasta de cemento Portland, a consecuencia de su hidratación,

- $4 \mathrm{CaO} \bullet \mathrm{Al}_{2} \mathrm{O}_{3} \bullet \mathrm{SO}_{3} \bullet 12 \mathrm{H}_{2} \mathrm{O}$ - Fase AFm o monosulfoaluminato de calcio hidratado $\mathrm{C}_{4} \mathrm{~A} \overline{\mathrm{S}} \mathrm{H}_{12}$ aunque, en realidad, también se utiliza la notación $\mathrm{C}_{4}(\mathrm{~A}, \mathrm{~F}) \mathrm{SH}_{12}$, donde el óxido de hierro 'puede sustituir al de aluminio,

- $6 \mathrm{CaO} \bullet \mathrm{Al}_{2} \mathrm{O}_{3} \bullet 3 \mathrm{SO}_{3} \bullet 32 \mathrm{H}_{2} \mathrm{O}-\mathrm{Fase} \mathrm{AFt}$, trisulfoaluminato de calcio hidratado o ettringita $-\mathrm{C}_{6} \mathrm{AS}_{3} \mathrm{H}_{32}$, y por idéntico motivo que en el caso anterior, también se emplea $\mathrm{C}_{6}(\mathrm{~A}, \mathrm{~F}) \overline{\mathrm{S}}_{3} \mathrm{H}_{12}$. De este producto de hidratación, y a consecuencia de investigaciones previas (Talero, (1986)), aparecerán a lo largo del texto los siguientes tipos:

- Ettringita de rápida formación - ett-rf, se trata de la ettrigita formada de origen alúmina reactiva, $\mathrm{Al}_{2} \mathrm{O}_{3}{ }^{\mathrm{r}}$, de las puzolanas, cuya velocidad de formación es significativamente mayor que cualquier otra de distinto origen.

- Ettringita de lenta formación - ett-lf, se trata de la ettringita formada que proviene de la hidratación de la fase $\mathrm{C}_{3} \mathrm{~A}$ del clínker Portland, cuya velocidad de formación es menor que la de origen $\mathrm{Al}_{2} \mathrm{O}_{3}{ }^{\mathrm{r}-}$ de las adiciones puzolánicas. 
- Ettringita de muy lenta formación - ett-mlf, se trata de la ettringita formada que proviene de la hidratación de la fase $\mathrm{C}_{4} \mathrm{AF}$ del clínker Portland, cuya velocidad de formación es sustancialmente menor que la de origen $\mathrm{Al}_{2} \mathrm{O}_{3}{ }^{\mathrm{r}-}$ de las adiciones puzolánicas y la de origen $\mathrm{C}_{3} \mathrm{~A}$ del mismo clínker.

Además, en relación a los productos de hidratación, y concretamente respecto al gel CSH, se mencionan a continuación los siguientes compuestos mineralógicos que se asemejan con su composición y estructura cristalina:

- $\quad \mathrm{T}$ - tobermorita, cuyas fórmulas químicas varían en función de su tamaño: la de $9 \AA$ $\left(\mathrm{Ca}_{5} \mathrm{Si}_{6} \mathrm{O}_{16}(\mathrm{OH})_{2}\right)$, la de $11 \AA\left(\mathrm{Ca}_{4} \mathrm{Si}_{6} \mathrm{O}_{15}(\mathrm{OH})_{2} \cdot 5 \mathrm{H}_{2} \mathrm{O}\right)$ y la de $14 \AA\left(\mathrm{Ca}_{5} \mathrm{Si}_{6} \mathrm{O}_{16}(\mathrm{OH})_{2} \cdot 7 \mathrm{H}_{2} \mathrm{O}\right)$, siendo esta última las más importante de todas.

- J - jennita, cuya fórmula química es $\mathrm{Ca}_{9} \mathrm{Si}_{6} \mathrm{O}_{18}(\mathrm{OH})_{6} \cdot 8 \mathrm{H}_{2} \mathrm{O}$.

De la misma forma, se considera necesario dar explicación de ciertas convenciones adoptadas a la hora de escribir varios términos que aparecen en esta MEMORIA de Tesis Doctoral. Estos términos son los siguientes:

- Materiales de construcción base cemento Portland: comprende a aquellos morteros, hormigones, gunitas y hormigones proyectados que incluyen entre sus componentes cemento Portland.

- Materiales de construcción base cemento: comprende la misma serie de materiales anteriormente citados, pero incluyendo al resto de los mismos que contienen cualquier cemento.

- Cemento Portland: se ha decidido ésta forma de denotar a este tipo de cemento como la más acertada y adecuada, y no similares denominaciones que se pueden encontrar en bibliografía tales como portland, pórtland o Pórtland.

- Clínker: se ha optado por esta denominación como la más adecuada, y no tales como clinker, clinquer o clínquer.

En relación a las técnicas analíticas instrumentales se ha tomado como convención utilizar sus acrónimos española, por ser el uso de los mismos el más ampliamente utilizado por la comunidad científica y técnica y, en casos concretos, por no disponer de un acrónimo equivalente en lengua castellana para ciertas técnicas. En cada caso, y cuando proceda, a lo largo de esta MEMORIA se dará cuenta del acrónimo correspondiente.

Por otra parte, se ha adoptado y utilizado a lo largo de la presente MEMORIA de Tesis Doctoral el Sistema Internacional de unidades, excepto en muy contadas ocasiones debido a que el orden de magnitud así lo aconsejaba o bien por el uso más frecuente y extendido de otro sistema específico.

Y por último, a continuación se recogen las principales variables matemáticas y propiedades físicas:

- Las denotadas con caracteres griegos:

$\checkmark \quad \alpha, \beta, \gamma$ : ángulos de la red cristalográfica

$\checkmark \quad \varepsilon$ : índice de refracción óptica.

$\checkmark \quad \omega$ : índice de refracción óptica.

$\checkmark \quad \theta$ : ángulo de difracción.

$\checkmark \Delta \varnothing$ : incremento de crecimiento diametral de la probeta Le-Chatelier-Anstett. 
$\checkmark \quad \varnothing$ : diámetro de la probeta Le-Chatelier-Anstett.

$\checkmark \varnothing_{\mathrm{m}}$ : diámetro interno del molino de bolas empleado para ajustar el tamaño de partícula de los materiales empleados en esta Tesis Doctoral.

$\checkmark \quad \varnothing_{0}$ : diámetro inicial de la probeta Le-Chatelier-Anstett.

$\checkmark \Delta \varnothing x \mathrm{x}(\%) / " Z "$ ": Incremento porcentual de diámetro por unidad de masa de puzolana.

- Las denotadas con caracteres latinos:

$\checkmark \quad a / c$ : relación entre el agua y el cemento que constituyen una pasta fresca.

$\checkmark$ A/F: relación entre la alúmina $\left(\mathrm{Al}_{2} \mathrm{O}_{3}\right)$ y el óxido de hierro $\left(\mathrm{Fe}_{2} \mathrm{O}_{3}\right)$ propio del clínker.

$\checkmark$ AP: Adiciones puzolánicas.

$\checkmark$ BET: Superficie específica de una partícula determinada por el método BET.

$\checkmark \mathrm{CA}: \mathrm{CaO} \bullet \mathrm{Al}_{2} \mathrm{O}_{3}$ - aluminato monocálcico, propio de las escorias siderúrgicas.

$\checkmark$ CP: Cemento Portland. Todo aquel cemento con un contenido mínimo del 95\% de clínker en su composición.

$\checkmark$ CPO: Cemento Portland Ordinario. Todo aquel cemento Portland que no es resistente a los sulfatos, es decir, que su composición cristalográfica cumpla los siguientes requisitos: contenido de $\mathrm{C}_{3} \mathrm{~A} \geq 5 \%$ y contenido de $\mathrm{C}_{3} \mathrm{~A}+\mathrm{C}_{4} \mathrm{AF} \geq 22 \%$.

$\checkmark$ CPSR: Cemento Portland Resistente a los Sulfatos. Todo aquel cemento Portland que es resistente a los sulfatos, es decir, que su composición cristalográfica cumpla los siguientes requisitos: contenido de $\mathrm{C}_{3} \mathrm{~A} \leq 5 \%$ y contenido de $\mathrm{C}_{3} \mathrm{~A}+$ $\mathrm{C}_{4} \mathrm{AF} \leq 22 \%$.

$\checkmark C / S$ : Cociente entre la cal $(\mathrm{CaO})$ y la sílice $\left(\mathrm{SiO}_{2}\right)$ característico del gel CSH y de las tobermoritas.

$\checkmark \quad d k$ : término que expresa la profundidad de carbonatación, si el proceso presenta un frente homogéneo.

$\checkmark \quad d_{k}$ máx: término que expresa la profundidad de carbonatación máxima, si el proceso presenta un frente irregular.

$\checkmark \quad d_{k}$ min.: término que expresa la profundidad de carbonatación mínima, si el proceso presenta un frente irregular.

$\checkmark C_{3} A_{e q}$ : suma ponderada del contenido de fase $C_{3} A$ del cemento y del contenido de $\mathrm{Al}_{2} \mathrm{O}_{3}{ }^{\mathrm{r}-}$ de la puzolana.

$\checkmark$ ECO: Evolución de las Características Orgánicas de la probeta Le ChatelierAnstett.

$\checkmark \quad E_{i}$ : Diferencia de potencial entre el electrodo de referencia y el electrodo de medida; que será igual a la diferencia de potencial existente entre la parte interior y exterior de la membrana de vidrio del electrodo de medida, si la referencia externa (electrodo de referencia) es la misma que la referencia interna del electrodo de medida.

$\checkmark$ ESE: Efecto Sinérgico Expansivo.

$\checkmark \quad f_{1}$ : factor la disolución EDTA.

$\checkmark \quad f_{2}$ : factor de la disolución de ácido clorhídrico.

$\checkmark f(K a)$ : es la función de Henry

$\checkmark$ G: módulo de Young. 
$\checkmark \quad h$ : altura de la probeta Le-Chatelier-Anstett.

$\checkmark \quad h_{m}$ : altura interna del molino de bolas empleado para ajustar el tamaño de partícula de los materiales empleados en esta Tesis Doctoral de la probeta LeChatelier-Anstett.

$\checkmark \quad h_{0}$ : altura inicial de la probeta Le-Chatelier-Anstett

$\checkmark$ HCPA: Hormigón de cemento Portland con adiciones.

$\checkmark$ HCP: Hormigón de cemento Portland.

$\checkmark$ HR: Humedad Relativa.

$\checkmark I A R_{x d}$ : Indice de actividad resistente de un mortero respecto al mortero de referencia a una edad determinada.

$\checkmark \quad$ ITZ: zona transición interfacial árido-pasta de cemento.

$\checkmark \quad$ IUPAC: Unión Internacional de Química Pura y Aplicada, más conocida por sus siglas en inglés IUPAC (International Union of Pure and Applied Chemistry), es un grupo de trabajo que tiene como miembros a las sociedades nacionales de química.

$\checkmark \quad$ K1: Longitud de onda del Cu, material del ánodo del equipo de DRX.

$\checkmark \quad$ K2: Longitud de onda del $\mathrm{Cu}$, material del ánodo del equipo de DRX.

$\checkmark$ MAE: Método de ensayo acelerado

$\checkmark M R$ : Categoría otorgada a todo cemento común que sea Resistente al Agua de Mas. Todo aquel cemento común que es resistente al agua de mar, su composición cristalográfica debe cumplir los siguientes requisitos: contenido de $\mathrm{C} 3 \mathrm{~A} \leq 8 \%$ y contenido de $\mathrm{C} 3 \mathrm{~A}+\mathrm{C} 4 \mathrm{AF} \leq 24 \%$.

$\checkmark \quad m_{1}$ : masa de carbonato de calcio, en gramos.

$\checkmark \quad m_{2}$ : masa de carbonato de sodio, en gramos.

$\checkmark \quad N$ : Factor del Nernst.

$\checkmark \quad N M A Q V H$ : nuevo método de análisis químico por vía húmeda para determinar el contenido de alúmina reactiva, $\mathrm{Al}_{2} \mathrm{O}_{3}{ }^{\mathrm{r}-}$ de una adición puzolánica.

$\checkmark \quad \mathrm{Na}$ Oeq: Según la norma ASTM C150, la concentración equivalente de álcalis, $\mathrm{Na}_{2} \mathrm{O}$ eq se expresa: $\mathrm{Na} 2 \mathrm{O}+0,658 \cdot \mathrm{K}_{2} \mathrm{O}$.

$\checkmark \quad P A$ : cemento Portland con adiciones puzolánicas, de acuerdo con el Pliego General de condiciones para la Recepción de los Conglomerantes Hidráulicos PCCH-64.

$\checkmark \quad p H$ : exponente de hidrógeno que determina el grado de hidrólisis de los iones hidrolizables.

$\checkmark \quad$ pHi: pH conocido de la solución interna del electrodo de medida.

$\checkmark \quad p H p: \mathrm{pH}$ de la disolución que se quiere determinar.

$\checkmark$ PAS: cementos Portland Resistente a las Aguas Selenitosas, de acuerdo con el Pliego General de condiciones para la Recepción de los Conglomerantes Hidráulicos PCCH-64.

$\checkmark$ PAS-PUZ: cementos con adiciones puzolánicas Resistente a las Aguas Selenitosas, de acuerdo con la denominación seguida en el Pliego General de condiciones para la Recepción de los Conglomerantes Hidráulicos PCCH-64.

$\checkmark \quad P A V$ : penetración de la aguja de Vicat, en el ensayo Le Chatelier-Anstett.

$\checkmark$ POP: 
$\checkmark \quad$ PUZ: cemento Puzolánico, de acuerdo con el Pliego General de condiciones para la Recepción de los Conglomerantes Hidráulicos PCCH-64.

$\checkmark \quad$ PY: cemento Portland Resistente al Yeso, de acuerdo con el Pliego de Recepción de Cementos RC-75.

$\checkmark \quad R M$ : resistencia mecánica de un cemento.

$\checkmark R S$ : resistencia. ante el ataque de los iones sulfato de un cemento.

$\checkmark$ SEB: Superficie específica de una partícula determinada por el método del permeabilímetro Blaine.

$\checkmark S / A$ : Cociente entre la sílice $\left(\mathrm{SiO}_{2}\right)$ y la alúmina $\left(\mathrm{Al}_{2} \mathrm{O}_{3}\right)$ índice característico de los minerales de la arcilla y depende del "grado de descomposición" de los feldespatos originales.

$\checkmark \quad t$ : tiempo o edad del ensayo.

$\checkmark \quad T$ : temperatura.

$\checkmark \quad V_{1}$ : volumen de la disolución de EDTA utilizado en la valoración, en mililitros.

$\checkmark \quad V_{2}$ : volumen de ácido clorhídrico utilizado en la valoración, en mililitros.

$\checkmark \quad V_{3}$ : volumen de disolución de ácido clorhídrico 0,1 mol/l utilizado en la valoración, en mililitros.

$\checkmark \quad V_{4}$ : volumen de disolución de EDTA 0,01 mol/l utilizado en la valoración, en mililitros.

$\checkmark \quad$ Vcø: velocidad de crecimiento diametral de la probeta Le Chatelier-Anstett.

$\checkmark$ Z: puzolana cualquiera.

En cuanto a las diferentes referencias que aparecen en esta edición digital de esta MEMORIA de Tesis Doctoral se ha adoptado la siguiente convención:

- Los artículos en revistas, contribuciones a congresos y capítulos de libro a aparecen con la tipografía normal, por ejemplo, Yahia y cols. (2001) en referencia a: Yahia A., Khayat K.H., (2001) "Analytical model for estimating yield stress of high-performance pseudoplastic groud". - Cement and Concrete Research, 31, pp. 731-738.

- Las Tesis Doctorales aparecen en tipografía normal subrayada, por ejemplo, Talero (1986) en referencia a: Talero R., (1986) “Contribución al Estudio Analítico y Físico-Químico del Sistema: Cementos Puzolánicos-Yeso-Agua $\left(\right.$ a $\left.20 \pm 2{ }^{\circ} \mathrm{C}\right)$ ". - Tesis Doctoral - Facultad de Ciencias Químicas, Universidad Complutense de Madrid, España.

- Los libros aparecen en tipografía cursiva, por ejemplo, Bogue (1947) en referencia a: Bogue R.H., (1947) "The Chemistry of Portland Cement", 1 ${ }^{\text {st }}$ Edition, Reinhold Publishing Corporation, Nueva York, Estados Unidos.

- Los documentos técnicos aparecen también en tipografía normal, por ejemplo, UNE-EN 197-1 en referencia a: UNE-EN 197-1:2011 “Cemento. Parte 1: Composición, especificaciones y criterios de conformidad de los cementos comunes".-AENOR. 


\section{CAPÍTULO 1}

INTRODUCCIÓN 



\section{1- Perspectiva histórica de la construcción con materiales de base cemento}

El progresivo cambio de las primitivas sociedades prehistóricas hacia una forma de vida sedentaria, abandonando el nomadismo, hizo que, en paralelo a la creación de los primeros asentamientos permanentes, surgiera la necesidad de encontrar y elaborar materiales para su construcción. Así, surgieron grandes civilizaciones que utilizaron diferentes materiales para la construcción de sus edificios y monumentos; de este modo y hasta nuestros días, se nos han legado diversas construcciones de piedra de ciertas culturas prehistóricas -los dólmenes de Antequera, Stonehenge, etc.-, continuando con el uso del mismo material, los egipcios, griegos e incas y Mayas -América Precolombina-, o los Persas con el adobe y las civilizaciones más orientales con el bambú (Lara (2000); Demeude y col. (2001); Wildung (2001)). No fue hasta el imperio romano -o los Mayas en el caso de la referida América precolombina-, cuando empezaron a usarse los primeros conglomerantes basados fundamentalmente en la cal apagada, a los que se les incorporaron posteriormente diferentes materias primas naturales que les llegaban a conferir al conjunto cierto carácter hidráulico, lo que les permitió realizar construcciones de ingeniería civil inéditas hasta ese momento (Davies (1997); Stierlin (2001)). Estos materiales de construcción han evolucionado hasta los que hoy conocemos, pasando por el hito decisivo del descubrimiento del primer conglomerante hidráulico: el cemento Portland. Fue Smeatone quien lo descubrió en el año 1756 al cual llamó piedra de Portland, por su semejanza con las formaciones 
rocosas de dicha región, aunque se debe citar que no patentó el material ni el nombre (Lea y col. (1956); Bogue (1959)).

De este modo, se llegó a la Ilustración en el siglo XIX, en el que se desarrolló por primera vez la fabricación industrial del cemento Portland. Sus materias primas son simples y abundantes, caliza y arcilla, ya que son de composición química específica. Ambas dosificadas y calcinadas adecuadamente a elevada temperatura, con adecuados fundentes o mineralizadores bauxita, hematite, magnetita, limonita, pirita, etc.-, forman el clínker (del holandés kliken = resonar, Bussagli, 2(001)) del cemento Portland, mediante reacciones químicas de tipo sólidosólido a muy elevada temperatura (de 1400 a $1500{ }^{\circ} \mathrm{C}$ ) por las cuales dichas materias primas producen la cristalización de sus compuestos sintéticos más característicos: alita, belita, celita y brownmillerita, de los cuales se hablará con detalle más adelante.

En la actualidad, la importancia del sector de la construcción en todos los países, desde el punto de vista económico y social, junto con la disponibilidad de recursos naturales y artificiales necesarios, y su desarrollo sostenible, hacen que desde hace varias décadas a esta parte se haya tenido que aumentar, en cantidad y tipos, la incorporación de adiciones minerales al cemento Portland. La interacción que se genera entre ambos y con el resto de los materiales que componen el hormigón, el mortero o la pasta, sumada al resto de variables que intervienen en cada producto derivado, tanto en el momento de su dosificación, fabricación y primeras edades de su hidratación, como en sus prestaciones futuras, es decir, su durabilidad, constituye una materia muy extensa de investigación y desarrollo. Lo que ha motivado la organización de numerosos eventos internacionales donde se discute, valida o invalida, según sea el caso, la aptitud o no de uso de tales adiciones minerales en determinados tipos de obras y/o en determinados medios, a la par que se intercambian experiencias. Todo ello, se ha visto además acelerado en la actualidad al tratar de conseguir dos objetivos fundamentales:

- El primero, exclusivo de la industria del cemento, que es el de reducir los costes de producción mediante la sustitución parcial del cemento Portland o del Clinker por dichas adiciones minerales, obteniendo así un ahorro considerable por menor uso de Clinker.

- El segundo, de carácter medioambiental y de efecto doble:

- Disminuir la relación Clinker / Cemento aumentando la capacidad de producción de Cemento con menor cantidad de producción de Clinker Portland, lo que conlleva a una menor emisión global de gases efecto Invernadero, estando alineados con las directrices definidas en el Protocolo de Kioto del año 1997 y el "Acuerdo de Paris" de la Convención Marco sobre el cambio Climático de Diciembre del 2015.

- El uso de Residuos Industriales por la que se lleva a cabo además la valorización material de diferentes subproductos de otros sectores que antes eran residuos y que eran destinados a vertederos, botaderos o escombreras.

Por todo ello, no es de extrañar que una de las líneas de investigación con más proyección en este sector sea la búsqueda, detección y consecución de nuevos materiales cemeticios suplementarios para adicionárselos al cemento Portland, previa su caracterización y validación de la compatibilidad físico-química de todos y cada uno de ellos con el cemento Portland, ya sean de origen natural o artificial. Es aquí donde se enmarca este trabajo de investigación, y para 
contextuarlo se hace obligatorio explicar antes de todo el impacto medioambiental que conlleva la producción industrial de clínker Portland, además de algunos conceptos fundamentales sobre el cemento Portland y las adiciones minerales más comunes, para lo cual recomendamos leer el ANEXO I y en particular para este caso, de aquellas que son activas y que se denominan "adiciones puzolánicas". Y llamaremos la atención sobre la investigación de Talero (1986) profundizando su estudio sobre las adiciones Puzolánicas en cementos Portland con niveles de sustitución del Clinker inferiores al $40 \%$ revisando los resultados obtenidos que son base de esta Tesis Doctoral, como lo podrán leer en el ANEXO II.

\section{2- Proceso Industrial y las Emisiones de Gases Efecto Invernadero.}

La contaminación es uno de los principales problemas que la Humanidad tiene planteados en la actualidad surgida como consecuencia de la explotación intensiva de los recursos naturales y del desarrollo de grandes concentraciones industriales y urbanas. La Naturaleza, al ser incapaz de asimilar los cambios que continuamente se está produciendo y, por lo tanto, de regenerarse, sufre perturbaciones, en algunos casos irreversibles, cuyas consecuencias a largo plazo son impredecibles.

Uno de los sistemas más susceptibles de sufrir contaminación es la atmósfera. La contaminación atmosférica afecta a millones de personas de todo el mundo y especialmente a aquellas que viven en los grandes núcleos urbanos con áreas fuertemente industrializadas.

Tanto los óxidos de nitrógeno, como los óxidos de azufre y el monóxido de carbono, son importantes contaminantes atmosféricos que originan graves problemas medioambientales, como el efecto invernadero, la lluvia ácida, el "smog" fotoquímico y el aumento del agujero de la capa de ozono. Estos compuestos químicos en estado gaseoso se generan junto a otros contaminantes sólidos y líquidos, cuando se queman combustibles fósiles para producir energía tanto en las grandes centrales industriales, como en los automóviles particulares y en las calefacciones de los edificios.

De todo ellos, el fenómeno de mayor relevancia dentro del sector de la industria del cemento es el efecto invernadero el cual se trata de un fenómeno atmosférico natural que permite mantener la temperatura del planeta, al retener parte de la energía proveniente del Sol. A finales del siglo XIX, Svante August Arrhenius (1896) enunció que el equilibrio térmico de la Tierra dependía en gran medida de la capa protectora de $\mathrm{CO}_{2}$.

\subsection{1.- Efecto Invernadero y el proceso de fabricación del Clinker.}

El Efecto Invernadero es, en definitiva, un proceso en el que la radiación térmica emitida por la superficie planetaria es absorbida por los gases de efecto invernadero atmosféricos y es reirradiada en todas las direcciones.

Se llama Efecto Invernadero al fenómeno por el cual determinados gases de la atmósfera planetaria retienen parte de la energía que el suelo emite por haber sido calentado por la radiación solar. Es un proceso normal que evita que la energía del Sol recibida constantemente por la Tierra, 
vuelva inmediatamente al espacio, produciendo a escala planetaria un efecto similar al observado en un invernadero.

Los Gases de Efecto Invernadero:

- Vapor de Agua, su cantidad en la atmósfera no está influida directamente por la acción del hombre. La cantidad de vapor de agua en la atmósfera depende fundamentalmente de la temperatura de la superficie del océano. La mayor parte se origina como resultado de la evaporación natural, en la que no interviene la acción del hombre.

- $\mathrm{CO}_{2}$, supone el 70\% de los gases de Efecto Invernadero. La concentración en la atmosfera es debido al uso de combustibles fósiles para generación de energía, procesos industriales y medios de transporte.

- Metano $\left(\mathrm{CH}_{4}\right)$, contribuye en un $24 \%$ al efecto invernadero. Se genera a partir del tratamiento de aguas residuales, la industria Agropecuaria, fertilizantes agrícolas, incineradoras de residuos, etc.

- Óxido nitroso $\left(\mathrm{N}_{2} \mathrm{O}\right)$ contribuye en un $6 \%$, también utilizado en aerosoles.

- Hidrocarburos (HFC) por el uso de los PFC.

La actual Concentración atmosférica de $\mathrm{CO}_{2}$ y $\mathrm{CH}_{4}$ excede de forma exponencial la variación natural de los gases a lo largo de los últimos 650.000 años. Su aumento se debe a la acción industrial del hombre y a la destrucción de áreas verdes:

- Quema de combustibles fósiles.

- Producción Industrial.

- Cambios en el uso de la tierra, especialmente por quema de bosques y deforestación.

Los problemas anteriormente mencionados, han generado una creciente preocupación por el medio ambiente que ha llevado a aprobar acuerdos a escala mundial iniciados con el referido Protocolo de Kyoto, y seguidos ahora último por el Acuerdo de Paris.

Ahora bien, la Industria cementera contribuye con el 7\% de las emisiones totales de $\mathrm{CO}_{2}$ al ambiente. Estos compromisos afectan sustancialmente a la industria cementera, puesto que produce aproximadamente $0,72 \mathrm{t}$ de $\mathrm{CO}_{2} / \mathrm{t}$ de cemento, de las cuales $0,46 \mathrm{t}$ son debidas a los procesos de descarbonatación de la Caliza y $0,26 \mathrm{t}$ son debidas a la utilización de combustibles Fósiles en el horno de clinkerización.

Por consiguiente, la industria cementera debe de ser sensible al grave problema derivado de la emisión de $\mathrm{CO}_{2}$ en la fabricación del clínker Portland, ya que es responsable de la producción del $7 \%$ de las emisiones globales totales de dióxido de carbono a nivel mundial. En este sentido, en el sector cementero se han introducido diferentes líneas de investigación encaminadas a la introducción de diferentes subproductos industriales, que antes eran considerados como residuos, y dentro del ciclo productivo del cemento a través de procesos de valorización de estos, tanto material como energético. 


\section{3- Gestión de residuos. Aprovechamiento material y energético}

La valorización energética en hornos de cemento ofrece un alto potencial de reducción de las emisiones globales de gases de efecto invernadero. Estos residuos sustituyen a combustibles fósiles, evitando sus emisiones directas de $\mathrm{CO}_{2}$ de origen fósil, y evitando también el consumo energético derivado de su obtención, trasporte y molienda. Además, cuando se utilizan residuos con biomasa, las emisiones de $\mathrm{CO}_{2}$ son neutras con respecto al clima, porque el $\mathrm{CO}_{2}$ emitido por la combustión de la biomasa está en equilibrio con la cantidad de $\mathrm{CO}_{2}$ que han fijado las plantas del aire en el proceso de fotosíntesis, por lo que no se contabilizan a efectos de los compromisos estatales de contención de las emisiones. Por otra parte, los residuos y subproductos no reciclables, de no ser valorizados energéticamente, se destinarían a vertederos o a incineradoras, y producirían emisiones de gases de efecto invernadero. En vertederos, la fermentación de la materia orgánica produce metano, un gas con un potencial de calentamiento 21 veces mayor que el del $\mathrm{CO}_{2}$. Los vertederos son causantes del 3\% de las emisiones de gases de efecto invernadero.

Para obtener el clínker es necesario calentar las materias primas minerales (caliza y arcillas) en grandes hornos rotatorios hasta su fusión parcial, a $1.450^{\circ} \mathrm{C}$. Este proceso requiere una gran cantidad de combustibles y aporta la posibilidad de valorizar ciertos residuos utilizándolos como combustibles alternativos en sustitución de los tradicionales. Para llegar al horno, el mineral molido finamente va cayendo a través de la torre de ciclones. Mientras, los gases de combustión circulan en sentido contrario, por lo que este contacto directo entre gases y material proporciona una limpieza de estos, neutralizando los gases ácidos, y arrastrando otros contaminantes como metales hacia la parte baja del horno, donde se solidifican con el clínker. El horno cementero presenta significativas características que lo constituyen como el mejor incinerador asegurando combustión completa:

- Los compuestos orgánicos de los residuos quedan destruidos, desapareciendo su peligrosidad. La combustión de residuos en el horno clínker destruye de manera completa la materia orgánica contenida en los mismos.

- Altas temperaturas de llama del orden de $2.000^{\circ} \mathrm{C}$ en el quemador principal

- Largo tiempo de residencia, los gases permanecen a muy alta temperatura, entre 3 y 4 segundos por encima de $850^{\circ} \mathrm{C}$ en el precalcinador, y entre 5 y 6 segundos por encima de $1.800^{\circ}$ en la llama principal. La legislación europea exige 2 segundos por encima de $850^{\circ} \mathrm{C}$.

- Atmósfera oxidante; la combustión se realiza con exceso de aire, por lo que toda la materia orgánica reacciona con el oxígeno formando $\mathrm{CO}_{2}$ y $\mathrm{H}_{2} \mathrm{O}$.

- Los gases se limpian a través de la materia prima entrante al horno. El propio material mineral presente en el horno (mayoritariamente cal) y en los ciclones, constituye un potente sistema de filtrado de los gases de combustión. Posteriormente los gases son filtrados nuevamente en equipos de limpieza de gases (filtros).

- No se producen cenizas volantes o residuos de la valorización. En general, en la combustión de los residuos queda un resto mineral, denominado "cenizas", pero en el horno de cemento estas cenizas quedan fundidas en el clínker, de forma permanente e inocua. (Puertas y col, (2004)). Las partículas emitidas por el horno de cemento no son cenizas volantes del combustible, como en otras instalaciones, sino que son partículas de la materia prima, 
arrastrada por los gases a su paso por los ciclones superiores, por los que está entrando el mineral. Por todo ello cuando los gases del horno llegan a la atmósfera, no presentan una composición que conlleve mayor impacto sobre el medio ambiente que cuando se ha empleado un combustible tradicional (Puertas y col, (2004)).

La flexibilidad de los hornos cementeros para cambiar de combustible hace que las cantidades empleadas puedan variar, por ejemplo, si se desarrollan otras vías de recuperación o reciclaje para un residuo. (Fundación CEMA, (2012))

Pese a la tendencia al crecimiento, existe un amplio potencial de incremento de la valorización energética hasta llegar a los porcentajes de otros países europeos como Holanda que sustituye más del 80\% de los combustibles por residuos, Alemania y Austria superan el 60\% entre otros.

\section{4- La valorización material en el ciclo productivo del cemento.}

A la vista de las características del proceso de fabricación del cemento (Figura 1-1), existen una serie de residuos o subproductos procedente de otras industrias que pueden ser utilizados como materiales secundarios en cada una de las fases de dicho proceso: como materia prima en la composición del crudo, como combustible en la fase de cocción, o bien, como materia prima de adición al clínker Portland en la fase final de su molienda.

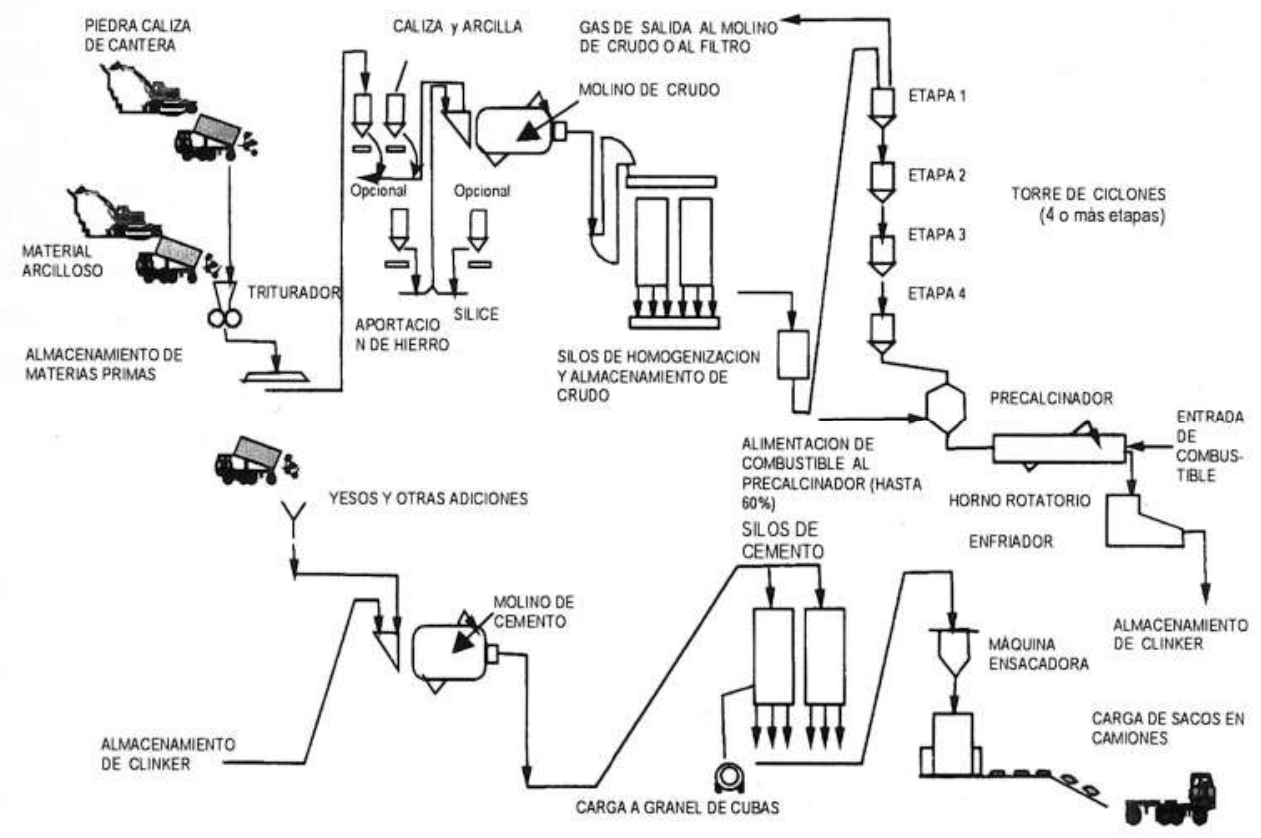

FIGURA 1-1.- ESQUEMA DEL PROCESO DE FABRICACIÓN DEL CEMENTO.

Cuando se emplean como materias primas, tanto en la composición del crudo como en la fase de molienda del clínker, se está realizando un reciclaje de materiales como materias primas en la industria del cemento. El aprovechamiento de estos residuos está siempre sometido al aseguramiento y mantenimiento de un nivel de calidad y durabilidad especialmente en los 
productos obtenidos, tanto del clínker como del cemento, a que su manipulación no complique el proceso, y a que no se produzcan emisiones contaminantes como consecuencia directa de su empleo. Para garantizar el cumplimiento de estas condiciones y de la legislación ambiental vigente, todos estos materiales alternativos deben pasar un proceso muy riguroso de caracterización antes de ser utilizados en las fábricas de cemento el cual abarca, la caracterización químico-física y mecánico-resistente del residuo para identificar su aptitud o rechazo para ser utilizado, la identificación de las condiciones técnico-económicas que hagan viable su utilización en las instalaciones, así como la concesión de la autorización pertinente con sus correspondientes controles asociados: emisiones atmosféricas, análisis y estudio de los lixiviados del residuo, calidad del producto, etc.

De este modo, existe ya un gran número de residuos tales como arenas de fundición con un elevado contenido en óxidos de silicio, cascarillas de laminación para el aporte de óxidos de hierro, lodos o materiales calizos provenientes de la industria papelera con un importante contenido en caolín, caliza y Aluminio, escorias de acería con un aporte de $\mathrm{CaO}$ y $\mathrm{SiO}_{2}$ o la cascarilla y paja del arroz por su elevado contenido de óxido de silicio y además por su también elevado contenido de materia orgánica (celulosa, combustible), que en la actualidad se están empleando para sustituir los recursos naturales tradicionales utilizados para fabricar el clínker Portland como son: calizas o margas, arenas, pizarras, arcillas o minerales de hierro, que normalmente se extraen de canteras aledañas a las fábricas de cemento, o que se transportan de otros centros fabriles no tan cercanos. Asimismo, en el proceso de molienda del cemento se pueden introducir materiales diversos, que sin modificar las características propias de cada tipo de cemento, permiten reducir el consumo de recursos naturales, entre los que cabe destacar las escorias granuladas de horno alto, las cenizas volantes de centrales térmicas, los sulfatos de calcio de origen industrial como reguladores de fraguado, etc.

Las fábricas de cemento presentan grandes posibilidades para aprovechar parte de los residuos minerales generados por otros procesos industriales:

- Por tener composición similar a la de sus materias primas. En este caso los residuos se emplean en la preparación inicial de las materias primas o "crudo".

- Por mejorar las prestaciones de los cementos. Estos residuos se pueden añadir como adiciones en la molienda del clínker junto con otros minerales, para dar lugar al cemento.

Se ha considerado como materias primas alternativas, tanto aquellos residuos empleados como sustitutos del crudo (materia prima que entra al horno), como aquellos utilizados para moler junto con el clínker (como componentes del cemento), estando estos últimos normalizados según Norma UNE-EN 197-1:2011 (cenizas volantes, escorias de alto horno, etc.)

Para los residuos o subproductos que tradicionalmente se han empleado como materia prima alternativa no se considera necesario establecer limitaciones en su composición. Es el caso de adiciones como cenizas volantes, escoria granulada de alto horno y otros materiales normalizados. (Figura 1-2).

En cualquier caso, se trata de una actividad a seguir desarrollando, dado el potencial de esta, autorizadas en las Autorizaciones Ambientales Integradas otorgadas. Las cenizas volantes 
para cemento fueron las más empleadas, junto con las escorias granuladas de alto horno como adición al cemento. (Fundación CEMA, 2011).

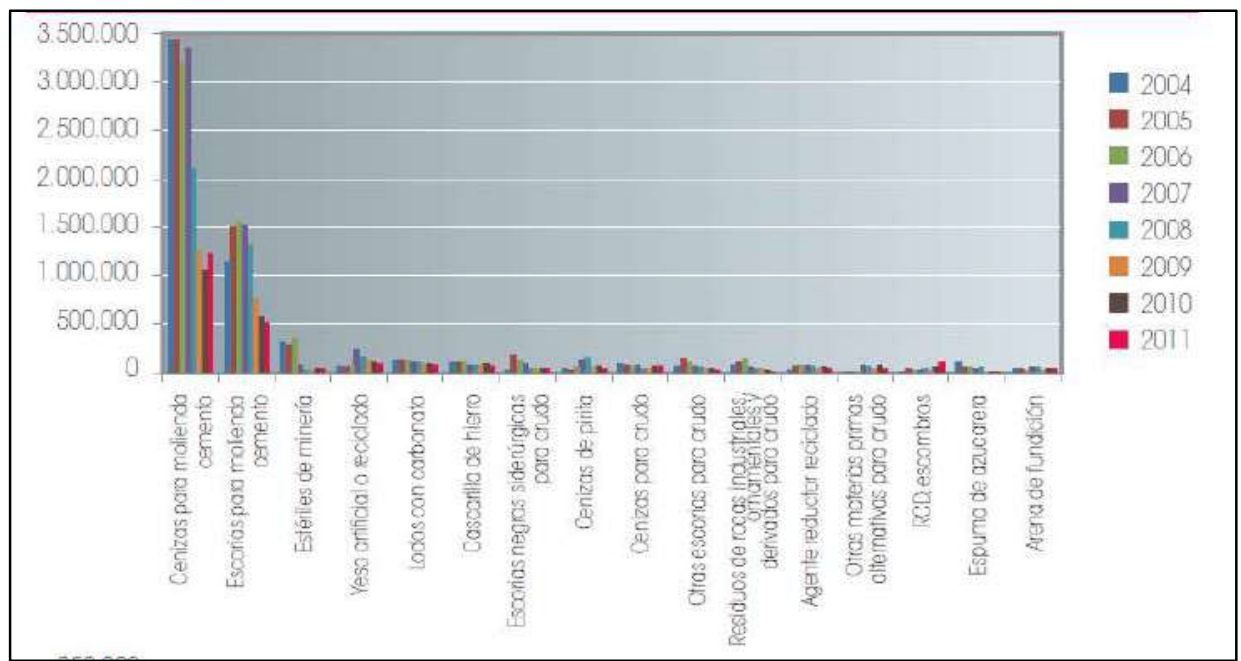

FIGURA 1-2. EVOLUCIÓN DEL CONSUMO TOTAL EN ESPAÑA DE LOS DIFERENTES TIPOS DE MATERIAS PRIMAS ALTERNATIVAS DURANTE EL PERIODO 2004-2011 (TONELADAS). (Fundación CEMA, 2011).

En consecuencia disminuir la relación Clinker / Cemento aumentando la capacidad de producción de Cemento con menor cantidad de producción de Clinker Portland, busca una menor emisión global de gases efecto Invernadero, permitiendo estar alineados con las directrices de Sostenibilidad definidas en el Acuerdo de Paris de la Convención Marco sobre el cambio Climático de Diciembre del 2015, además de lograr reducción de costes de producción y permitir mejorar su durabilidad y/o prestaciones en la particularidad o exigencias de los diferentes tipos de cemento dependiendo del uso para el cuál vaya determinado.

A continuación retomo algunos conceptos básicos y fundamentales de las Puzolanas descritas en el Anexo I, por considerarlas importantes para el entendimiento de esta Investigación ser el objeto de esta Tesis Doctoral y dentro del marco acabado de tratar, pues conociendo su potencial y carácter químico de las mismas podremos contribuir de una mejor manera a la adición de estos materiales cementicios suplementarios como un factor de suma importancia para reducir el factor Clinker / Cemento tan importante en la Industria del Cemento. No sin antes dejar de destacar que ante la limitada oferta de estos materiales en especial los provenientes de residuos industriales como las Escorias y Cenizas volantes, y llamando la atención en especial sobre esta últimas en cuanto a su disminución de oferta en un futuro cercano precisamente por las mismas exigencias ambientales de reducción de las emisiones de $\mathrm{CO}_{2}$ al ambiente en los diferentes Protocolos y Acuerdos y más aun teniendo en consideración que ya varios países han definido fechas últimas de terminación de la generación eléctrica con base en Carbón, es muy claro entonces que la oferta de cenizas Volantes disminuirá en el orden de estas implementaciones. Por tanto cobra con gran fuerza la producción de Puzolanas naturales calcinadas a partir de las arcillas susceptibles de ser calcinadas, por su gran existencia en el globo terráqueo, siendo consideradas el futuro de los materiales cementicios suplementarios. Adicionalmente con grandes ventajas ya que se podrá controlar su producción y calidad de las mismas a diferencia de ser un residuo industrial como las cenizas donde no puedes controlar ni el uno ni el otro. 


\section{5.- Adiciones minerales que se le incorporan al cemento Portland.}

\subsection{1.- Generalidades.}

En el mundo de los materiales de construcción de base cemento Portland (CP), se entiende por adiciones minerales, los materiales inorgánicos amorfos y/o vítreos y cristalinos, naturales o artificiales, de diferente origen, que incorporados al $\mathrm{CP}$ en cantidades apropiadas son capaces de generar los mismos productos de hidratación que el propio cemento Portland, si bien, únicamente los amorfos y/o vítreos nada más. La mejor cualidad de estos materiales es el ahorro energético que reporta su utilización en la fabricación de cemento Portland, al poder reemplazarlo, en parte, hasta un límite máximo permitido para cada tipo, lo que también conlleva apreciables beneficios medioambientales y de costes.

Entre dichos materiales inorgánicos aptos para ser adicionadas al $\mathrm{CP}$, se pueden destacar principalmente los siguientes:

Adiciones minerales activas: puzolanas naturales y artificiales y escorias siderúrgicas, las cuales están constituidas por cierta fracción cristalina, la menor, por lo general, dispersa en una matriz amorfa y/o vítrea, la mayor, por lo general también, y esta última, a su vez y en el caso de las puzolanas, está constituida por componentes reactivos, llamados factores hidráulicos (sílice reactiva, alúmina reactiva, etc.) (Calleja, 1969) entre los cuales cabe destacar por su abundancia, de mayor a menor, la sílice reactiva, $\mathrm{SiO}_{2}{ }^{\mathrm{r}}$, la alúmina reactiva, $\mathrm{Al}_{2} \mathrm{O}_{3^{\mathrm{r}}}$, y el óxido de hierro (III) reactivo, $\mathrm{Fe}_{2} \mathrm{O}_{3^{\mathrm{r}}}$, (asimismo y entre las cenizas volantes especialmente, existen algunas, las de la combustión de lignitos, que también contienen óxido de calcio reactivo, y sulfatos, etc.), los cuales, por su marcado carácter químico ácido, poseen la capacidad de reaccionar químicamente, a temperatura ambiente y en medio acuoso, con la cal apagada y/o con la portlandita liberada por el CP tras su hidratación, para formar silicatos y aluminatos de calcio hidratados semejantes a los del propio cemento Portland, contribuyendo, por ello, a las resistencias mecánicas finales del material endurecido que las contiene. Este comportamiento tan peculiar de estas adiciones minerales es el que se ha dado en llamar actividad puzolánica. Entre este tipo de adiciones minerales activas se tienen las puzolanas naturales (rocas sedimentarias fósiles de naturaleza silícea como diatomeas, rocas volcánicas vítreas, etc.) y artificiales (cenizas volantes de las centrales térmicas, el humo de sílice, la nanosílice, las arcillas activadas térmicamente, los metacaolines, los esquistos calcinados, los residuos inquemados de la incineración adecuada de la paja y de la cáscara de arroz o del bagazo de la caña de azúcar, etc.).

Todas las escorias siderúrgicas son, en cambio, productos artificiales provenientes de la industria de la siderurgia integral, las cuales mediante su enfriamiento brusco desde temperaturas elevadas, con agua (el método más común utilizado) o con aire (el menos común), se vitrifican, necesitando a continuación, una vez molidas a la finura del cemento Portland, un activador alcalino (disolución acuosa de pH básico o muy básico: cal apagada, portlandita, sosa, potasa, etc.) para poder formar así también los compuestos hidráulicos estables e insolubles en agua como los del propio cemento Portland. 
Adiciones minerales cristalinas o mal llamadas "inertes" (Rahhal y cols., 2012): son unos materiales inorgánicos igualmente de origen natural o artificial, que a diferencia de las adiciones minerales activas, se comportan con el cemento Portland durante su hidratación inicial y ulterior, de manera totalmente distinta, lo que justifica que no se las pueda considerar totalmente "inertes", bajo ningún concepto, pero sin que por ello se les pueda adscribir tampoco nunca propiedad hidráulica alguna. Su nombre común es filler y son de origen silíceo o calizo especialmente. Su incorporación requiere cierto proceso de preparación física (homogeneización, secado, molienda, etc.) y en ningún caso debería afectar negativamente la demanda del agua de amasado. Y ni mucho menos tampoco a las resistencias mecánicas y químicas del hormigón resultante ni a su durabilidad prevista, lo que puede resultar sumamente difícil, según sea la naturaleza del fíller y/o la cantidad que se incorpore (Rahhal y cols., 2012).

En España y desde el año 1975, casi todas las construcciones de edificación y obra civil, se han realizado y se continuarán realizando con hormigones que, por lo común, contienen cantidades diversas de adiciones puzolánicas naturales y artificiales (su estado físico es vítreo y/o amorfo en su mayor parte, es decir, no cristalino) por ser este tipo de adiciones minerales activas las que más abundan. En determinadas regiones de España abundan bastante más las cenizas volantes, mientras que en otras las que abundan son las puzolanas naturales. En cambio, la adición de escorias siderúrgicas molidas (su estado físico es vítreo) al $\mathrm{CP}$ ha estado circunscrita finalmente a las plantas de cemento de la región cantábrica, en general, y, posteriormente, a la asturiana y sus provincias colindantes, en particular, aunque últimamente se ha sumado a ellas alguna otra ubicada en el sureste de España. Antes de esa fecha, los hormigones utilizados para construir, eran en su mayoría, de cemento Portland puro.

En todos los países de la UE está permitido también incorporarle en fábrica de cemento al CP adiciones minerales cristalinas muy molidas tipo filler.

\subsection{2.- Composición química de las adiciones puzolánicas.}

Un importante parámetro, para diferenciar una puzolana de los demás materiales que pudieran estar también incluidos en la definición dada antes de adiciones minerales activas, es la composición química de sus componentes, así como también, las proporciones en las que se encuentren. De aquí las normas vigentes (UNE EN 197-1; ASTM C 311; ASTM C 618; UNE EN 450-1) que las contemplan tienen las siguientes especificaciones de obligado cumplimiento para todas ellas:

- $\quad$ que el contenido de la suma de $\mathrm{SiO}_{2}(\%), \mathrm{Al}_{2} \mathrm{O}_{3}(\%)$ y $\mathrm{Fe}_{2} \mathrm{O}_{3}(\%)$ sea $\geq 70 \%$ (ASTM C 618),

- $\quad$ que el contenido de sílice reactiva $\left(\mathrm{SiO}_{2}{ }^{\mathrm{r}}\right)$ (UNE 80225) no sea inferior al $25 \%$ (Calavera, 1996), es decir, que sea $\geq 25 \%$.

En consecuencia, las adiciones puzolánicas, en principio, se pueden clasificar también por su composición química tomando de referencia su contenido en óxidos ácidos. Lo que no es de mucha utilidad en cuanto a su capacidad de reaccionar químicamente a temperatura ambiente y 
en medio acuoso, con la cal apagada ni con la portlandita y, en definitiva, para poder discernir su utilidad o no para la construcción.

Por todo ello, de acuerdo con Calleja (1969), más descriptiva en este aspecto resulta su composición mineralógica, mientras que para Talero (1986), lo que las caracteriza es su adecuación o no para un fin determinado para la construcción: fabricar hormigones, morteros y pastas de cemento que resistan a unos medios agresivos determinados y/o que proporcionen elevadas resistencias mecánicas a edades iniciales o no, o proporcionar ambas características a un mismo tiempo. Lo que ineludiblemente está relacionado con sus contenidos de $\mathrm{SiO}_{2^{-}}{ }^{\mathrm{r}}, \mathrm{Al}_{2} \mathrm{O}_{3}{ }^{\mathrm{r}-} \mathrm{y}$ $\mathrm{Fe}_{2} \mathrm{O}_{3}{ }^{\mathrm{r}-}$.

A continuación, en la Tabla 1-1 se muestran valores entre los que varían las composiciones químicas de las adiciones puzolánicas que se le incorporan a los cementos Portland.

TABLA 1-1.- COMPOSICIÓN QUÍMICA DE LAS ADICIONES PUZOLÁNICAS (EN PARÉNTESIS: VALORES MEDIOS).

\begin{tabular}{|c|c|c|c|c|c|c|c|c|c|}
\hline Constituyentes & $\mathrm{SiO}_{2}$ & $\mathrm{Al}_{2} \mathrm{O}_{3}$ & $\mathrm{Fe}_{2} \mathrm{O}_{3}$ & $\mathrm{CaO}$ & $\mathrm{MgO}$ & $\mathrm{Na}_{2} \mathrm{O}$ & $\mathrm{K}_{2} \mathrm{O}$ & $\mathrm{SO}_{3}$ & PF \\
\hline Porcentajes & $28-100$ & $0-45$ & $0-20$ & $0-34$ & $0-11$ & $0-7$ & $0-8$ & $0-14$ & $0-15$ \\
\hline \multirow{2}{*}{$\begin{array}{l}\text { Puzolanas de origen } \\
\text { mineral }\end{array}$} & $42-73$ & $10-20$ & $1-14$ & $0-12$ & $0-11$ & $1-5$ & $1-5$ & $0-0.05$ & $0-15$ \\
\hline & $(57,0)$ & $(15,0)$ & $(5,0)$ & $(5,0)$ & $(2,0)$ & $(3,0)$ & $(3,0)$ & $(0,025)$ & $(7,0)$ \\
\hline \multirow{2}{*}{$\begin{array}{c}\text { Puzolanas de origen } \\
\text { orgánico }\end{array}$} & $65-85$ & 5-15 & $1-10$ & $0-5$ & $1-2$ & $0-0.5$ & $0-1$ & $0-1$ & $1-10$ \\
\hline & $(75,0)$ & $(10,0)$ & $(5,0)$ & $(2,0)$ & $(2,0)$ & $(0,5)$ & $(0,5)$ & $(0,5)$ & $(5,0)$ \\
\hline \multirow{2}{*}{$\begin{array}{c}\text { Puzolanas en } \\
\text { general }\end{array}$} & $42-85$ & $5-20$ & $1-14$ & $0-12$ & $0-11$ & $0-5$ & $0-5$ & $0-1$ & $0-15$ \\
\hline & $(65,0)$ & $(12,5)$ & $(5,0)$ & $(3,5)$ & $(1,5)$ & $(2,0)$ & $(2,0)$ & $(0,5)$ & $(6,0)$ \\
\hline
\end{tabular}

Toda adición puzolánica de cualquier origen, posee una parte, generalmente la mayor, amorfa, y otra, generalmente la menor, cristalina. Además, la parte amorfa es la que más la caracteriza y posee un estado físico que puede ser un compendio de vítreo, amorfo, gel, pseudogel, numolítico, pseudo-cristalino, etc.

Consecuentemente, dicha parte amorfa puede llegar a originar con el tiempo minerales más o menos argilizados, tales como, augita, $(\mathrm{Ca}, \mathrm{Mg}, \mathrm{Fe})_{2}(\mathrm{Si}, \mathrm{Al})_{2} \mathrm{O}_{6}$, herschelita o chabazita- $\mathrm{Na}$, $\mathrm{NaAISi}_{2} \mathrm{O}_{6} \cdot \mathrm{H}_{2} \mathrm{O}$, feldespatos, etc., productos todos ellos que suelen provenir de una mayor o menor meteorización de sus vidrios volcánicos originales. La parte cristalina suele ser, en cambio, lo que más diferencia a las adiciones puzolánicas (Calavera, 1996) y está representada, por lo general, por sílico-aluminatos cristalinos, naturales o no, bastante estables e inatacables por ácidos fuertes, y quizás menos, por bases fuertes. Por lo común, las mencionadas estructuras ordenadas se obtienen por síntesis mediante calentamientos, fusiones y/o recristalizaciones de diverso grado y cantidad, que dan por resultado mullita o porcelanita, $\mathrm{Al}_{4+2 x} \mathrm{Si}_{2-2 x} \mathrm{O}_{10-x}(\mathrm{x} \approx 0.4)$, sillimanita, $\mathrm{Al}_{2} \mathrm{SiO}_{5}$, cuarzo, $\mathrm{SiO}_{2}$, tridimita, $\mathrm{SiO}_{2}$, cristobalita, $\mathrm{SiO}_{2}$, andalucita, $\mathrm{Al}_{2} \mathrm{SiO}_{5}$, disteno, $\mathrm{Al}_{2} \mathrm{SiO}_{5}$, o cianita, $\mathrm{Al}_{2} \mathrm{SiO}_{5}$, hematita, $\mathrm{Fe}_{2} \mathrm{O}_{3}$, magnetita, $\mathrm{Fe}_{3} \mathrm{O}_{4}$, maghemita, $\mathrm{Fe}_{2.67} \mathrm{O}_{4}$, etc., aunque por 
ser su cantidad escasa, son las que menos influencian o caracterizan la adición. En cambio, la parte amorfa y/o vítrea (o parte reactiva) es la que más.

\subsection{3.- Actividad puzolánica.}

\subsubsection{1.- Reacciones químicas entre la adición puzolánica y el $\mathrm{Ca}(\mathrm{OH})_{2}$}

Teniendo en cuenta que los constituyentes minerales de las adiciones puzolánicas pueden ser múltiples y variados, además de encontrarse en diferentes cantidades, a continuación, se presentan las reacciones químicas (r12, r13, r14, r15) que pueden producirse entre el hidróxido de calcio y los tres principales factores hidráulicos (Uzal y cols., 2007) de las adiciones puzolánicas mencionadas antes, que son la sílice reactiva, $\mathrm{SiO}_{2}{ }^{\mathrm{r}}$, la alúmina reactiva, $\mathrm{Al}_{2} \mathrm{O}_{3}{ }^{\mathrm{r}-}$, y el óxido de hierro reactivo, $\mathrm{Fe}_{2} \mathrm{O}_{3^{\mathrm{r}}}$, sin despreciar los álcalis, que aunque no son factores hidráulicos, propiamente dichos, pueden llegar a estar también presentes con apreciable influencia sobre las resistencias mecánicas y la durabilidad del material resultante (Talero y col., 1991; Rahhal, 2002).

$$
\begin{aligned}
& \mathrm{SiO}_{2}{ }^{\mathrm{r}-}+\mathrm{CaO}+\mathrm{H}_{2} \mathrm{O}=\mathrm{C}-\mathrm{S}-\mathrm{H}+\mathrm{Q} \\
& \mathrm{Al}_{2} \mathrm{O}_{3}{ }^{\mathrm{r}-}+\mathrm{CaO}+\mathrm{H}_{2} \mathrm{O}=\mathrm{C}_{3} \mathrm{AH}_{6}, \mathrm{C}_{4} \mathrm{AH}_{13}, \mathrm{C}_{4} \mathrm{AH}_{19}+\mathrm{Q} \\
& \mathrm{C}_{4} \mathrm{AH}_{13}+\mathrm{H}_{2} \mathrm{O}+\text { yeso }=\mathrm{AFm}+\mathrm{Q} \\
& \mathrm{AFm}+\mathrm{H}_{2} \mathrm{O}+\text { yeso }=\mathrm{AFt}+\mathrm{Q}
\end{aligned}
$$

Y los productos de reacción resultantes de las reacciones químicas mencionadas dependerán de la naturaleza de la adición mineral de que se trate (su composición mineral y constitución química), por lo que se formarán los compuestos químicos hidratados hidráulicamente estables o inestables. Finalmente, la naturaleza, el carácter químico y/o el tamaño medio de partícula de la adición mineral determinarán, en cambio, su comportamiento frente al ataque de un medio agresivo o no, determinado, del hormigón, mortero o pasta de cemento del que forme parte.

\section{6.- Comportamiento del cemento Portland con adiciones minerales inorgánicas frente al ataque de los sulfatos $\left(\mathrm{SO}_{4}{ }^{2-}\right)$}

\subsection{1.- Introducción.}

El problema existente relacionado con el ataque de los cementos Portland por los iones sulfato, se abordó en un principio en EEUU tratando de disminuir cuantitativamente el contenido de $\mathrm{C}_{3} \mathrm{~A}$ procedente del cemento Portland, en el conjunto de la masa del hormigón. Con este objetivo parte de aquél se sustituía físicamente, hasta los límites máximos permisibles, por determinados materiales, generalmente inorgánicos, más ó menos rocosos y molidos, y de contenidos variable en silicatos. A dichos materiales se les denominó genéricamente adiciones, inertes ó activas; a su vez a estas últimas se las denominó de un modo general, con el término puzolanas ó escorias siderúrgicas.

En general los resultados que se obtuvieron vinieron a ser tan heterogéneos e inconexos, a veces, como las adiciones empleadas 
Obviamente la ingeniería civil y la arquitectura, ambos campos prácticos fundamentales de utilización de todos estos materiales, no podían hacer recaer su responsabilidad y ejecutoria en la "casualidad" del buen ó mal comportamiento de tal ó cual adición con tal ó cual cemento Portland, dilucidado siempre, en su caso, merced a largas investigaciones previas, no carentes de metodología pragmática, y si por el contrario y como es lógico en la casualidad metodológica del mismo. Por todo lo cual, paralelamente a estas investigaciones y posiblemente por los resultados proporcionados por las mismas, se hizo imprescindible y necesario abordar además el problema, estudiando con detenimiento el comportamiento de una gran variedad de cementos Portland y más concretamente de sus correspondientes clínkeres, seleccionados por las cantidades respectivas de sus componentes fundamentales ("alita", "belita", "celita", "bronwmillerita" y "ferritas", más ó menos cristalinos), frente a la acción de los diversos sulfatos.

Fruto de todo ello fue la puesta en marcha de varias investigaciones (Miller, 1928, 1942; Wolochow, 1952; Santarelli, 1941) a veces solapadas en el tiempo con las anteriores, de la que se obtuvieron un gran número de resultados en las últimas décadas.

Por otra parte Kalousek, Porter y Benton (Kalousedy cols. 1972), señalaron que las limitaciones normalizadas actualmente sobre los contenidos porcentuales potenciales calculados de $\mathrm{C}_{3} \mathrm{~A}$ y $\mathrm{C}_{4} \mathrm{AF}+\mathrm{C}_{3} \mathrm{~A}$ de los cementos Portland de elevada resistencia al ataque de los iones sulfato (CEM IV/B) no son la única y mejor respuesta al problema del ataque sulfático, ya que según ellos, la esperanza de vida media ante un ataque sulfático, de algunos hormigones de elevada calidad preparados con tales cementos, es de menos de 50 años.

Estos fenómenos están también relacionados con:

- Las aseveraciones realizadas, mucho antes, por Santarelli (1941), en el sentido de que no se puede olvidar la posibilidad de ataque sulfático adicional, aunque más lento, de la fase "ferrítica", cuya composición es variable según la saturación de $\mathrm{Al}_{2} \mathrm{O}_{3}$ del $\mathrm{MF}, \% \mathrm{Al}_{2} \mathrm{O}_{3}$ / $\% \mathrm{Fe}_{2} \mathrm{O}_{3}$ y su proporción en el clínker.

- Lo afirmado por Thorwaldson (1952) de que las probetas carentes de $\mathrm{C}_{3} \mathrm{~A}$, en las que el $\mathrm{Al}^{3+}$ está, todo él, como $\mathrm{C}_{4} \mathrm{AF}$, fueron atacadas por disoluciones al $2 \%$ de $\mathrm{Na}_{2} \mathrm{SO}_{4}$ ó $\mathrm{MgSO}_{4}$, con intensidad menor de lo que lo fueron las probetas de mortero hechas con $\mathrm{C}_{3} \mathrm{~A}$ puro, pero mayor que sus homónimas de $\mathrm{C}_{3} \mathrm{~S}$ puro, $\mathrm{y}$

- Lo afirmado por Bogue (1959) de que probetas de mortero de cemento con 15\% de $\mathrm{C}_{4} \mathrm{AF}$, permanecieron más de 10 años en disolución de $\mathrm{NaSO}_{4}$, y no mostraron señal alguna de expansiones,, por el contrario y en contra de lo que cabría esperar, sus homónimas del $24 \%$ al $27 \%$ de $\mathrm{C}_{4} \mathrm{AF}$, se destruyeron a los 2 años.

Y volviendo de nuevo a la temática primitiva, se observa que como resultado de los trabajos llevados a cabo por entonces, se obtuvo la primera gran conclusión sobre la misma, circunscrita única y exclusivamente a los cementos Portland, y es que "la resistencia potencial de un cemento Portland al ataque de los iones sulfato era y es función inversa, principalmente, de su contenido de $C_{3} A$ ". Por cuya razón se hizo patente la gran vulnerabilidad de los cementos cuyos contenidos respectivos de $\mathrm{C}_{3} \mathrm{~A}$ y $\mathrm{C}_{4} \mathrm{AF}$ estuviesen por encima de unos límites que actualmente ya se encuentran como especificaciones y/o limitaciones diversas en los distintos países con tecnología avanzada. 
Tales cementos, calificados genéricamente como "cementos Portland Resistentes a los Sulfatos", en España pasarían a denominarse, en principio, "cementos Portland Resistentes a las Aguas Selenitosas o Cementos PAS" (Pliego PCCH-64). En este sentido conviene señalar los trabajos previos realizados al efecto en el IETCC por Soria (1966). Posteriormente, y a partir de 1975, a tales cementos se les denominó "cementos Portland Resistentes al Yeso", PY (Pliego RC$75)$.

Estos cementos, clasificados siempre dentro de los cementos Portland, aunque diferenciados, como se verá, de ellos, se caracterizan en todos los países por tener limitados los contenidos porcentuales ponderales calculados de $\mathrm{C}_{3} \mathrm{~A}$ y $\mathrm{C}_{4} \mathrm{AF}$, solos o en conjunto, siendo para España el máximo del $5 \%$ para el primero y el máximo del $22 \%$ para la suma de ambos (Instrucción RC-16).

\subsubsection{1.- Ataque por el sulfato de calcio en forma de yeso, $\mathrm{CaSO}_{4} \cdot 2 \mathrm{H}_{2} \mathrm{O}$.}

Este tipo de ataque químico es el que se le produce en presencia de agua, a los elementos de hormigón en contacto con terrenos yesíferos y selenitosos, principalmente. Se debe entender, en el caso de los suelos, que el ataque del hormigón por los iones sulfato de los mismos se produce si éstos se movilizan por su disolución previa en el agua, teniendo lugar en uno u otro grado de intensidad -débil, medio o fuerte- según la concentración en sulfato que se alcance. Los efectos negativos de este ataque químico se producen con rapidez, y se traducen en agrietamiento y pérdida de resistencia mecánica, debido al gran incremento de volumen que se produce en la pasta endurecida del cemento constitutivo del hormigón.

Este ataque químico se produce mediante una serie de reacciones químicas expansivas entre determinadas fases y productos de hidratación del cemento Portland (con o sin adiciones puzolánicas y escorias siderúrgicas), y los aniones sulfato, $\mathrm{SO}_{4}{ }^{2}$. Fundamentalmente, estas reacciones químicas expansivas son la formación de monosulfoaluminato de calcio hidratado o Fase $A F m$, a partir del aluminato tricálcico, $C_{3} A$, del cemento Portland $(\mathrm{CP})$ o a partir de la alúmina reactiva, $\mathrm{Al}_{2} \mathrm{O}_{3^{r}}{ }^{-}$, o alúmina tetra o penta-coordinada (Talero, 1986; Trusilewicz, y cols. 2012) de las adiciones puzolánicas (AP), las de carácter alumínico o alumínico-silícico principalmente (Talero, 1986, Talero, 1993b; 1996; Talero y cols. 1999) o a partir del aluminato monocálcico vítreo, $C A$, de las escorias siderúrgicas. No obstante, tales fuentes de aluminato también originan el trisulfoaluminato de calcio hidratado o Fase AFt o ettringita, o "bacilo del cemento" (su estructura fue establecida en 1970 por Moore y col. (1970)), mucho más expansiva que el monosulfoaluminato. La Fase AFt se forma siempre antes que la Fase AFm, pudiéndose incluso mantener como tal si la cantidad de sulfatos presentes es al menos tres veces mayor que la de aluminatos, como así ocurre en el caso de las referidas aguas yesíferas o selenitosas, y transformándose total o parcialmente en Fase AFm en los casos contrarios. Éste es el motivo por el cual las aguas con sulfato de calcio son tan agresivas para el cemento Portland ordinario o común, es decir, para aquellos cementos que no poseen la característica SR. Adicionalmente, en estas condiciones de exceso de iones sulfato también se puede producir neo-formación de yeso a partir de la portlandita o a partir de elevadas concentraciones de $\mathrm{Ca}^{2+}$ provenientes de nuevos procesos de hidratación de las fases que permanecían anhidras, lo que también lleva aparejado un aumento relativo del volumen. 
Las reacciones químicas de formación de ambos sulfoaluminatos y las relaciones de volumen con sus respectivos aluminatos originarios son las que se recogen a continuación:

$$
\begin{aligned}
& \text { CP- Fase AFm: } \quad \mathrm{C}_{3} \mathrm{~A}+\mathrm{CaSO}_{4} \cdot 2 \mathrm{H}_{2} \mathrm{O}+10 \mathrm{H}_{2} \mathrm{O} \rightarrow \mathrm{C}_{3} \mathrm{~A} \cdot \mathrm{CaSO}_{4} \cdot 12 \mathrm{H}_{2} \mathrm{O} \\
& \begin{array}{lll}
\text { Vol. Molar } & 88,8 & 319,1
\end{array} \\
& \begin{array}{lll}
\text { Rel. Volumen } & 1 & 3,6
\end{array} \\
& \text { AP-Fase AFm: } \quad \mathrm{Al}_{2} \mathrm{O}_{3}^{r-}+3 \mathrm{CaO}+\mathrm{CaSO}_{4} \cdot 2 \mathrm{H}_{2} \mathrm{O}+10 \mathrm{H}_{2} \mathrm{O} \rightarrow \mathrm{C}_{3} \mathrm{~A} \cdot \mathrm{CaSO}_{4} \cdot 12 \mathrm{H}_{2} \mathrm{O} \\
& \text { Vol. Molar } \quad 29,1 \text { (Volumen molar del } \gamma-\mathrm{Al}_{2} \mathrm{O}_{3} \text { ) } \quad 319,1 \\
& \begin{array}{lll}
\text { Rel. Volumen } & 1 & 10,9
\end{array} \\
& \text { CP- Fase AFt: } \quad \mathrm{C}_{3} \mathrm{~A}+3 \mathrm{CaSO}_{4} \cdot 2 \mathrm{H}_{2} \mathrm{O}+25 \mathrm{H}_{2} \mathrm{O} \rightarrow \mathrm{C}_{3} \mathrm{~A} \cdot 3 \mathrm{CaSO}_{4} \cdot 31 \mathrm{H}_{2} \mathrm{O} \\
& \begin{array}{lll}
\text { Vol. Molar } \quad 88,8 & 714,7
\end{array} \\
& \begin{array}{lll}
\text { Rel. Volumen } 1 & 8,0
\end{array} \\
& \text { AP- Fase AFt: } \quad \mathrm{Al}_{2} \mathrm{O}_{3}^{r-}+3 \mathrm{CaO}+3 \mathrm{CaSO}_{4} \cdot 2 \mathrm{H}_{2} \mathrm{O}+25 \mathrm{H}_{2} \mathrm{O} \rightarrow \mathrm{C}_{3} \mathrm{~A} \cdot 3 \mathrm{CaSO}_{4} \cdot 31 \mathrm{H}_{2} \mathrm{O} \\
& \text { Vol. Molar } \left.\quad 29,1 \text { (Volumen molar del } \gamma-\mathrm{Al}_{2} \mathrm{O}_{3}\right) \quad 714,7 \\
& \begin{array}{lll}
\text { Rel. Volumen } & 1 & 28,3
\end{array}
\end{aligned}
$$

En el caso de las reacciones (r1.7) y (r1.9), las relaciones de volumen deben ser mayores aún, ya que se ha supuesto que el volumen molecular de la alúmina reactiva de las adiciones puzolánicas, $\mathrm{Al}_{2} \mathrm{O}_{3}{ }^{r-}$, es el de la $\gamma-\mathrm{Al}_{2} \mathrm{O}_{3}$, y con toda seguridad dicha suposición es errónea, ya que debe ser menor lógicamente. Por otra parte, se ha demostrado también que la velocidad de formación de la ettringita de este último origen, es decir, de la $\mathrm{Al}_{2} \mathrm{O}_{3^{r}}$ de las puzolanas, ya sean naturales o artificiales, es aproximadamente diez veces mayor que la de formación de la ettringita de origen $C_{3} A$ del cemento Portland, y en justa correspondencia, el tamaño de aquélla es alrededor de diez veces menor que el de ésta (Talero, 2002; 2003a; 2003b; 2005a; 2007; 2009). Véanse al efecto ambas ettringitas en las Figura 1-3. La razón estriba en que la $\mathrm{Al}_{2} \mathrm{O}_{3}{ }^{r^{-}}$se encuentra en el estado físico-químico ideal para que se lleve cabo dicha reacción química (r1.7), y del mismo modo la (r1.4). En cambio, el $C_{3} A$ de los cementos Portland se encontraría en situación diferente, es decir, en el estado físico-químico no ideal, o, al menos, en la forma menos ideal para obtener el mismo resultado. De aquí que la velocidad de formación de la ettringita de este origen sea sensiblemente menor. Consecuentemente, el $C_{4} A F$ forma ettringita mucho más lentamente todavía. Por todo ello, han venido a denominarse ettringita de rápida formación (ett-rf), ettringita de lenta formación (ett-lf) y ettringita de muy lenta formación (ett-vlf), respectivamente.

Pero es que además, en vista de que todas las adiciones activas, en general, y las puzolánicas, en particular, se utilizan habitualmente incorporadas al cemento Portland en fábrica o al hormigón en planta, cuando se lleva a cabo el ataque de los sulfatos, ya sea en el laboratorio o en obra real, dichos sulfatos reaccionan al mismo tiempo con la alúmina reactiva, $\mathrm{Al}_{2} \mathrm{O}{ }^{r-}$ de la fracción puzolana y con el $C_{3} A$ de la fracción cemento Portland del cemento de mezcla correspondiente (Talero, 2010). De manera que la formación conjunta de ambas ettringitas, ett-rf 
y ett-lf, en dicho medio sulfático común, no se realiza de una manera independiente sino interdependiente, combinada e interactiva entre las dos (Talero, 2005a; 2007; 2009). Además, cuanto más próximas entre sí se encuentren las partículas de $\mathrm{Al}_{2} \mathrm{O}_{3}{ }^{r-}$ y de $C_{3} A$, caso de los cementos de mezcla cemento Portland/puzolana, con elevado porcentaje de sustitución, más interdependiente es su formación conjunta o co-precipitación. Esto significa que ambas ettringitas se forman en mayor o menor medida, aunque el producto de reacción final de dichos cementos de mezcla esté más próximo a la ett-rf que a la ett-lf, y al contrario, en el caso del cemento de mezcla de menor porcentaje de sustitución (Talero, 2005a; 2007; 2009).

(a)

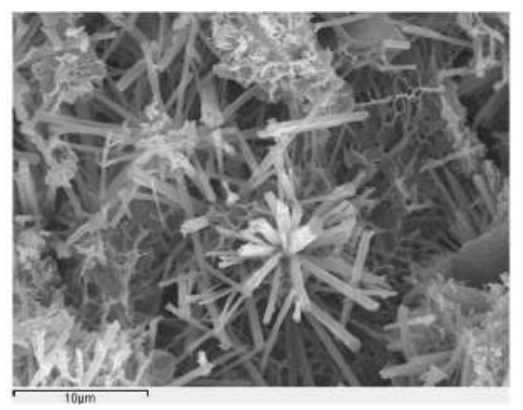

(b)

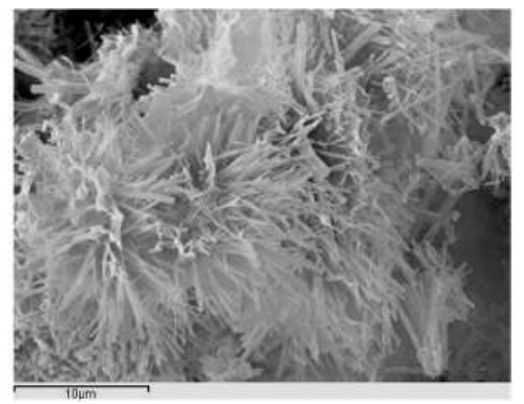

FIGURA 1-3.- MICROFOTOGRAFÍAS DE MICROSCOPÍA ELECTRÓNICA DE BARRIDO (X1000); (A) ETTRINGITA DE LENTA FORMACIÓN, DE ORIGEN CEMENTO PORTLAND; (B) ETTRINGITA DE RÁPIDA FORMACIÓN DE ORIGEN PUZOLÁNICO.

El efecto expansivo resultante de esta interdependencia entre la ett-rf y ett-lf durante su co-precipitación conjunta en un medio sulfático común, es siempre más sinérgico que aditivo, por cuyo motivo ha sido denominado "Efecto Sinérgico Expansivo", ESE (Talero, 2010), cuya consecuencia final es que a igualdad de todo lo demás y tanto en el laboratorio como en la realidad, el ataque sulfático agresivo a tales cementos de mezcla (con tales puzolanas alumínicas y alumínico-silícicas principalmente) se lleva a cabo siempre más pronto que a su propio cemento Portland puro, siendo además este efecto tan deletéreo para el hormigón y tan rápido, que ha justificado también haberle podido denominar con fundamento "ataque rápido del yeso". Lógicamente y por el contrario, la formación de la ett-rf y la ett-vlf, o de origen $C_{4} A F$ del cemento Portland, no es combinada, sino independiente.

Por todo ello, se ha puesto de manifiesto, de forma clara, el papel tan importante que pueden llegar a jugar en el ataque de los sulfatos, las fracciones de sílice reactiva, $\mathrm{SiO}_{2}{ }^{\mathrm{r}-}$, y alúmina reactiva, $\mathrm{Al}_{2} \mathrm{O}_{3}{ }^{\mathrm{r}}$, especialmente, que forman parte de la composición de las adiciones puzolánicas en mayor o menor medida. Y tanto, si su estado físico es vítreo, caso de las cenizas volantes, el humo de sílice y las diatomeas, cuanto más si es amorfo, caso de los metacaolines y demás arcillas activadas, o si su estado físico es una mezcla aleatoria de ambos estados físicos, caso de la puzolana natural canaria, la cual incluso posee además una fracción apreciable zeolítica, que es cristalina, aunque también puzolánica, no obstante.

La razón de tan importante papel estriba en que la $\mathrm{Al}_{2} \mathrm{O}_{3}{ }^{\mathrm{r}-}$ de las puzolanas posee la capacidad cierta de reaccionar químicamente, en medio acuoso, con la portlandita (y con la cal apagada) y los sulfatos, para originar también ettringita a mayor velocidad, y de menor tamaño, lógicamente, pero no por ello menos expansiva, sino todo lo contrario porque es más expansiva 
incluso, que la que forma el $\mathrm{C}_{3} \mathrm{~A}$ de los $\mathrm{CPO}$. Es decir, posee la capacidad cierta de participar de forma explícita en dicho ataque agresivo y promoverlo por ello, hasta el punto de poder acelerarlo y de forma muy notable incluso, por la estimulación de la hidratación selenitosa que le provoca al $\mathrm{C}_{3} \mathrm{~A}$, que no en cambio al $\mathrm{C}_{3} \mathrm{~S}$, de la fracción del CPO con el que se ha mezclado la puzolana, como consecuencia de la actividad puzolánica tan específica, por elevada, temprana y rápida que logra desarrollar previamente, desde el inicio de la hidratación. En definitiva, la $\mathrm{Al}_{2} \mathrm{O}_{3}{ }^{r-}$ comienza siendo promotora del ataque de los sulfatos y termina siendo facilitadora del mismo, es decir, es "pro-ataque" de los sulfatos.

$\mathrm{La} \mathrm{SiO}_{2}{ }^{\mathrm{r}}$, en cambio, no posee la capacidad de originar ettringita como la $\mathrm{Al}_{2} \mathrm{O}_{3}{ }^{\mathrm{r}}$, aunque no por ello deja de ejercer, no obstante, su influencia también en dicho ataque agresivo, pero de forma implícita nada más. En función de las propiedades físicas de la puzolana los resultados finales, pueden llegar a ser totalmente diferentes por contrarios u opuestos, pero acordes, en cualquier caso, al tamaño medio y la morfología de sus partículas:

- si son del tipo diatomeas, rocas opalinas y similares, no poseen la misma capacidad estimuladora, por vía indirecta, de las reacciones de hidratación selenitosa que la $\mathrm{Al}_{2} \mathrm{O}_{3}{ }^{\mathrm{r}-}$ promueve de forma explícita. En cambio, promueve el efecto protector de dilución física derivado del reemplazo, junto con el de dilución química de la portlandita originada inicialmente merced a la elevada succión capilar de agua de amasado y de cualquier otro tipo, que ejercen sus partículas, lo que, sin duda alguna, facilita el ingreso muy rápido de los sulfatos al interior del hormigón, el mortero o la pasta que las contiene. Finalmente llegan a generar geles C-S-H en cantidad suficiente para conferir la protección necesaria, aunque para entonces, la expansión que se ha producido, a igualdad de todo lo demás, sea algo mayor que la de su propio CPO puro, cuyas probetas continuarán expandiendo si aún hay cantidad de sulfatos en exceso; sin embargo, aquellas que contienen estas puzolanas, no porque habían dejado de expandir mucho antes (Talero 2012; 2013), puesto que habrían generado ya para entonces y pese a todo, cantidades de geles C-S-H suficientes y necesarios para impedir totalmente dicha expansión.

- si son del tipo humo de sílice, la estimulación de la hidratación selenitosa por vía indirecta sí la pueden ejercer (Talero 2012; 2013), pero únicamente y en el mejor de los casos, hasta las primeras 16 horas a lo sumo (Talero y col. 2009), puesto que a partir de esa edad tan temprana deja de ejercerla (es decir, el tiempo que ha necesitado el humo de sílice para generar cantidad de gel C-S-H suficiente para comenzar a actuar en sentido contrario o "protector" frente al ataque de los sulfatos, desde el punto de vista físico-químico). Además, tanto más deja de ejercerla cuanto más progresa la hidratación selenitosa, es decir, cuanto mayor cantidad de gel C-S-H ha logrado generar, hasta el punto de llegar a tornarse en la opuesta, por llegar a desestimularla e, incluso, a dificultarla e impedirla en su totalidad, es decir, termina por ser también "protectora", en las mismas circunstancias del ataque de los sulfatos. No obstante, la estimulación por vía directa también la debe de ejercer, y algo más allá incluso quizás de los 28 días de edad (Talero 2012; 2013), puesto que hasta esas edades dicho efecto "protector" ha sido menor con el aumento del porcentaje de reemplazo, mientras que a partir de esas edades fue mayor, y fue incluso bastante mayor que el de las diatomeas visto con anterioridad, aunque en cualquier caso ambos fueron de tal magnitud que pudieron ser calificados de "anti-ataque de los 
COMPORTAMIENTO SULFÁTICO Y MECÁNICO-RESISTENTE DE CEMENTOS PORTLAND CON ELEVADOS CONTENIDOS DE PUZOLANAS ( $>40 \%$ ): SU FUNDAMENTO QUÍMICO Y JUSTIFICACIÓN DE OTRAS CONSECUENCIAS POSIBLES

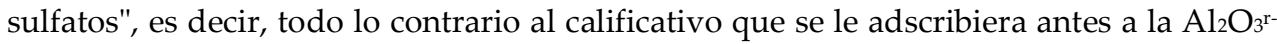
en las mismas circunstancias. 


\section{CAPÍTULO 2}

ESTADO DEL ARTE 



\subsection{Estudio bibliográfico de las últimas investigaciones sobre cementos con adiciones de materiales puzolánicos superiores al 40\%.}

Las siguientes investigaciones sobre diferentes propiedades y características de los hormigones y/o morteros preparados con cementos que contenían elevadas cantidades (más del $40 \%$ en peso) de cenizas volantes muestran los siguientes avances:

\subsubsection{Resistencia Sulfática}

Henager y cols. (1984) y Pierce (1982), establecen que ciertas CV utilizadas en el hormigón bajo condiciones húmedas o secas incrementan sensiblemente las resistencias sulfáticas del hormigón cualquiera que fuera el tipo de cemento.

Goma (1983) indica que un hormigón con altas proporciones de CV (60\%) de clase C que contiene alto contenido de sulfatos $\left(5 \%\right.$ de $\left.\mathrm{SO}_{3}\right)$ no muestra expansiones, ni significantes cambios de longitud de las probetas. Indica que posee un método en el que mediante la determinación del contenido de $\mathrm{Ca}(\mathrm{OH})_{2}$ puede establecer la vida de un hormigón cuantitativamente.

Una indicación de la resistencia sulfática de una CV viene dada por el "Valor R", desarrollada empíricamente por Dunstan (1986)- que viene expresado por el cociente entre el contenido de cal y el porcentaje de óxido férrico, indicando que para hormigones con un contenido de CV entre $15-25 \%$ que den lugar a valores de $\mathrm{R}$ menores o igual a 3.0, mejoran las resistencias sulfáticas y un valor de R mayor de 3.0 las empeora. 
En resumen, la máxima resistencia sulfática será alcanzada en una situación y exposición dada, con el empleo de una relación agua/cemento baja, con un cemento resistente a los sulfatos y con CV que tengan buenas cualidades de resistencia sulfática. La elección de las CV puede ser realizadas atendiendo, en principio, al valor $\mathrm{R}$, sin olvidar un estudio previo en laboratorios especializados. Este mismo autor, propone que el empeoramiento de las resistencias sulfáticas se debe al contenido de calcio de las CV superior al 5\% y asume que el incremento de las mismas es directamente proporcional al contenido de hierro de la $\mathrm{CV}$.

Este factor $\mathrm{R}$ ha dado lugar a enormes controversias debido, entre otras cosas, a que no tiene en cuenta el contenido de alúmina reactiva de la CV. Si ésta es tan alta, después de la hidratación de la mezcla cemento Portland-CV, se producen cantidades variables de $\mathrm{C}_{4} \mathrm{ASH}_{12}$ y CA-H directamente responsables del fenómeno de ataque de los sulfatos, independientemente de que el factor $\mathrm{R}$ pudiese ser menor de 1.5. Así se ha corroborado en las investigaciones de Mehta (1986) en las que CV con un factor R muy bajo e incluso negativo, han dado lugar a peores resistencias sulfáticas de las esperadas según Dunstan (1986) debido a la naturaleza de la alúmina reactiva que contenía cada CV. Asimismo, se comprobó también que $\mathrm{CV}$ con altos contenidos de $\mathrm{Fe}_{2} \mathrm{O}_{3}$, que implican bajos valores de $\mathrm{R}$, dieron lugar a grandes pérdidas de resistencias mecánicas en ensayos de inmersión en sulfatos. De la misma manera, se comprobó que CV con un factor R > 4 dieron lugar a una notable mejoría de las resistencias sulfáticas, incluso conteniendo cantidades significativas de sulfato sódico y cálcico, de sulfoaluminato cálcico, $\mathrm{CaO}$ cristalina y periclasa, debido a que antes de la exposición a los sulfatos era la ettringita el producto estable de la hidratación del cemento.

Así pues, es el tipo de compuestos de hidratación originados por la mezcla cemento Portland-CV, lo que determina la capacidad de una CV a mejorar la resistencia sulfática del cemento Portland sin adición y no la composición química resultante de su análisis químico por fusión alcalina. Por otra parte, el mecanismo de ataque de los sulfatos al cemento con o sin adición de CV es similar: Ataque inicial al aluminato cálcico hidratado produciendo las fases AFt y AFm y a continuación, el ataque al hidróxido de calcio, resultando la formación de yeso. Por tanto, la incorporación de las CV reduce el ataque sulfático, debido a la mayor finura de la distribución de poros en la pasta y la formación de la fase AFm preferentemente a la AFt. Consecuentemente, el ataque al hidróxido cálcico se ve sensiblemente reducido. Esta conclusión de estos autores vamos a tratar de ratificarla o rectificarla mediante la presente investigación.

Dichos autores continúan explicando además que la porosidad total aumenta en las pastas con CV durante las primeras etapas de hidratación, mientras que en pastas de cemento Portland, dicha porosidad disminuye debido al aumento de volumen producido con la formación de los hidratos. De acuerdo con este fenómeno y según tal autor es fácil suponer que el volumen de los hidratos de pastas con CV es menor, más denso y más compacto con la consecuente implicación en un aumento de resistencias. Parece ser que la distribución del tamaño de partícula y el contenido de óxido de calcio son los principales factores que influyen en las propiedades mecánicas de morteros fabricados con $\mathrm{CV}$, así como también la temperatura a medida que ésta aumenta las resistencias de las pastas de cemento con esta adición se han visto incrementadas.

Swamy y cols. (1983) afirma que un hormigón que contiene el 50\% de CV pertenecientes a la clase F, incluso en las condiciones peores de curado, van paulatinamente ganando resistencias mecánicas incluso transcurrido 1 año, mientras que el hormigón de cemento Portland puro en 
dichas condiciones de curado, pierde resistencias entre un 25 y 35\% comparado con el hormigón curado en condiciones normales. Si el hormigón es expuesto al aire seco, las pérdidas de resistencias y elasticidad se aprecian en mayor cuantía en hormigón de cemento Portland puro que el que contiene CV. Continúa afirmando que hormigones con un $30 \%$ de $\mathrm{CV}$ poseen una resistencia a 1 día y una elasticidad comparable a aquél sin adiciones de CV y que los hormigones con alto contenido de CV (70-80\%) poseen mejoras sensibles de resistencia a corto, medio y largo plazo.

Zhou y cols (2004) hace una interpretación de una manera particular e investiga las propiedades químicas idóneas de los cementos para conseguir mejores resistencias mecánicas con la adición de $\mathrm{CV}$ : El contenido de $\mathrm{K}_{2} \mathrm{O}$ y $\mathrm{C}_{3} \mathrm{~S}$ del cemento es directamente proporcional a las resistencias de las $\mathrm{CV}$ e inversamente proporcional al contenido de $\mathrm{C}_{2} \mathrm{~S}$ y $\mathrm{CaSO}_{4}$. Aunque el contenido de $\mathrm{K}_{2} \mathrm{O}$ es perjudicial en cementos Portland puros, este componente, sin embargo, mejora las resistencias de los mismos con adición de CV.

Mehta y col. (1982) indican que la adición de CH disminuye las resistencias de pastas de cemento con adición de $\mathrm{CV}$, mientras que la adición de yeso las disminuye a primeras edades pero las incrementa a largo plazo ya que todo el yeso se consume en los primeros 28 días, dando lugar a la formación de ettringita en los capilares y poros, creando una masa global más densa. Este incremento de resistencias a largo plazo por adición de yeso se ve mejorado con una pequeña adición de $\mathrm{CH}$ que aumenta la reactividad de las $\mathrm{CV}$ y mantiene el $\mathrm{pH}$ necesario en los poros.

Por último, es necesario indicar lo que precisa la norma española UNE 83-414: La característica de cada CV en particular, así como la del cemento con la que se usa y la proporción de ambos en el hormigón, afectan a las resistencias a una determinada edad y a la evolución de las mismas. Aunque se produce un retardo en las resistencias iniciales, la actividad puzolánica de las $\mathrm{CV}$ contribuye a aumentar las resistencias a edades posteriores, si se mantiene húmedo el hormigón, llegando a dar más resistencia generalmente que el hormigón sin CV. Esta aseveración tan general, difiere de las investigaciones previas afines de Talero (1986).

Chindaprasirt y cols. (2004) examinaron la influencia de la finura de las cenizas volantes en la demanda de agua y algunas de las propiedades del mortero endurecido. Además de las cenizas volantes originales, se obtuvieron otras cinco distintas en finura tamizando y usando un separador de aire, utilizando para ello dos tamices, números 200 y 325, se utilizaron para obtener dos lotes de ceniza volante fina graduada. La sustitución de ceniza volante fue del $40 \%$ en peso.

En las pruebas, se encontró que la resistencia a la compresión del mortero dependía de la finura de las cenizas volantes. La resistencia de aquel mortero que contiene la CV fina era mejor que la del mortero con la ceniza original a todas las edades, ya que la ceniza volante muy fina daba la mayor resistencia.

El uso de todas las CVs provocó una mejora significativa en la contracción por secado, aunque con las cenizas volantes gruesas este efecto diminuyó debido a la gran cantidad de agua de la mezcla.

Además, se obtuvo una mejora significativa de la resistencia a la expansión por sulfatos para todos los valores de finura, excepto para la ceniza volante gruesa, donde se observó mayor expansión. La resistencia al ataque con ácido sulfúrico también se mejoró con la incorporación de todas las cenizas volantes. En este caso, la ceniza volante gruesa dio el mejor rendimiento con la tasa más baja de pérdida de peso probablemente debido a la mejor la unión de las partículas de 
ceniza volante gruesa y la matriz de cemento y menos productos de hidratación. Se sugiere que las cenizas volantes finas sean más reactivas. y su uso dio como resultado una matriz de cemento más densa y mejores propiedades mecánicas del mortero.

Estudios más recientes (Sideris y cols., 2006) tratan de evaluar la repuesta de cementos mezcla altamente adcionados frente el ataque conjunto de dos ataques químicos agresivos sulfatos y carbonatación. En la prueba de resistencia a sulfato, todas las muestras se sumergieron en una solución de $\mathrm{Na}_{2} \mathrm{SO}_{4}$ al 5\% durante 24 meses. Se utilizaron dos cenizas volantes y dos puzolanas naturales para la producción de 13 cementos de mezcla. Los resultados muestran que la adición de mezclas puzolánicas en la mayoría de los casos tuvo un efecto positivo sobre la resistencia a los sulfatos. La profundidad de carbonatación en todos los morteros mezclados fue mayor que en el mortero de cemento Portland. Sin embargo, la tasa de carbonatación de los morteros mezclados se redujo a medida que avanzaba la hidratación.

Por su parte Donatello y cols. (2013) evaluaron la resistencia a los sulfatos de pastas y morteros de cemento con una elvada cantidad de ceniza volante en su composición $(80 \%$ aproximadamente) que fueron activados químicamente adicionándole $\mathrm{Na}_{2} \mathrm{SO}_{4}$. Los citados materiales base cemento fueron sometidos a un ataque químico agresivo sumergiéndolos durante 90 días en una disolución acuosa del $4,4 \%$ en peso de $\mathrm{Na}_{2} \mathrm{SO}_{4}$. Como consecuencia de ello, se observaron cambios en las resistencias a la compresión de los morteros y en las fases cristalinas generadas, tras su inmersión. Estos ensayos se repitieron con un cemento SR comercial. En general ambos conjuntos de morteros demostraron una resistencia adecuada a inmersión en una solución de $\mathrm{Na}_{2} \mathrm{SO}_{4}$ al 4,4\%, no explicando estos autores el por qué de la resistencia sulfática de estos cementos con altos niveles de ceniza volante.

Para tratar de dar luz a esta problemática Piasta (2017) diseñó un estudio para explicar el progreso y las causas del daño estructural de un concreto expuesto a $\mathrm{CO}_{2}$ atmosférico y agua de lluvia y yeso. Durante el proceso de carbonatación, el producto básico identificado en el hormigón la microestructura fue calcita o calcita "secundaria", que apareció en la superficie del hormigón, en las grietas o en forma de estalactitas. La formación de etringita y calcita se observó en las columnas de concreto expuestas a las interacciones de yeso, dióxido de carbono y agua de lluvia.

\subsubsection{Resistencias mecánicas}

En general, los cementos con cenizas volantes de alta sustitución reducen considerablemente la resistencia inicial de los materiales a base de cemento, y debido a esta desventaja, la cantidad agregada de cenizas volantes en el hormigón prefabricado curado al vapor es muy limitada.

Cengiz, (2005) llevó a cabo una investigación de laboratorio para evaluar las propiedades de resistencia de hormigones compactados con rodillo el cual contenia elevadas proporciones de cenizas volantes (50\% y 70\%), curadas tanto en cámara húmeda como en ambiente del laboratorio. Se preparó el reemplazo del cemento Portland normal con dos cenizas volantes tipo F, de alta y baja calidad, según el investigador. Las relaciones a/c oscilaron entre 0.28 y 0.43 .

Para ello se determinaron las resistencias mecánicas a la compresión y a la flexión. Se calculó la relación entre la resistencia a la flexión y la resistencia a la compresión. También se evaluó 
la influencia del contenido de pérdida al fuego (PF) de las cenizas volantes en la demanda de agua y la resistencia del hormigón.

El estudio mostró que la producción de hormigón de altas resistencias era posible con un alto contenido de cenizas volantes. Asímismo, se confirmó que cuanto mayor fue la PF de las cenizas volantes se aumentó la demanda de agua del hormigón fresco y se encontró que el hormigón altamente adcionado es más vulnerable en condiciones de curado en seco. Se concluyó que estos hormigones son materiales adecuados tanto para estructuras como para pavimentos.

McCarthy y col. (2005) realizaron un estudio para examinar el uso de altos niveles de cenizas volantes tipo F como componente del hormigón, en niveles de sustitución más allá del nivel de $30 \%$ comúnmente adoptado.

Los resultados obtenidos indicaron que se podían alcanzar niveles de CV hasta el $45 \%$ en masa combinado con cemento Portland para producir beneficios significativos en el diseño de los concretos. No obstante, la resistencia temprana, que puede ser una variable crítica, podría reducirse en comparación con un $\mathrm{CP}$.

En el estudio se contempló el uso de un cemento Portland de rápido endurecimiento y un clinker de baja energía combinado con CV en un $45 \%$, para poder contrarestar así el déficit de resistencias a edades tempranas. Se encontró que ambos eran efectivos para igualar el comportamiento de resistencia temprana del concreto del CP. Esas pruebas cubrieron las propiedades en estado fresco (pérdida de trabajabilidad, exudación y pérdida de agua, las propiedades en estado endurecido (desarrollo de resistencias, módulo de elasticidad, contracción por secado y fluencia) y las propiedades de durabilidad (adsorción, permeabilidad, carbonatación y difusión del cloruro) de estos hormigones.

Los resultados indicaron que, en casi todos los casos, se logró un rendimiento similar o mejorado con el hormigón con altas cantidades de ceniza volante, comparado con el de CP, y estos hallazgos ofrecían una ruta para extender el uso de CV.

Felekoglu, (2006) estudió la posibilidad fabricar hormigones con un alto contenido de cenizas volantes como una opción económica y duradera para fines estructurales y de hormigonado general. El objetivo del estudio fue investigar la posibilidad del uso de tres tipos de cenizas volantes turcas de diferentes fuentes como adición al hormigón. Para ello, se prepararon mezclas de hormigón sustituyendo 40, 50, 60 y 70\% de cemento por cenizas volantes. Las propiedades mecánicas y los costes de materiales de las mezclas se compararon con el hormigón convencional a la misma edad de 28 días.

Los resultados mostraron que, para aplicaciones estructurales, estos hormigones solo pueden utilizarse usando las cenizas volantes dentro de unos límites de propiedades químicas y físicas específicas.

Hannesson y cols. (2012) buscaron optimizar el aspecto de sustentabilidad de un hormigón autocompactante para aplicaciones estructurales maximizando el contenido de material cementante suplementario. Para ello se utilizaron cuatro materiales distintoss: dos cenizas volantes y dos escorias. Se realizaron veintiuna mezclas variando el porcentaje de 0 a $100 \%$ de cemento Portland reemplazado. 
El desarrollo de resistencia a la compresión en edades tempranas para aquellas mezclas que contenían materiales cementicios suplementarios fue normalmente menor que el de control. Con niveles de reemplazo más altos, el rendimiento varió significativamente según el tipo de adición.

Se utilizaron las ecuaciones de fuerza de Bolomey y Féret para evaluar la eficiencia de cada material. Se observó una relación directa entre la relación $\mathrm{CaO} /\left(\mathrm{SiO}_{2}+\mathrm{Al}_{2} \mathrm{O}_{3}\right)$ de cementante y el factor de eficiencia.

Shaikh y col. (2015) estudiaron la influencia de la adición de una ceniza volante ultrafina sobre el comportamiento mecánico resistente (resistencia a la compresión) de hormigones que contienen altos contenidos de cenizas volantes tipo F como reemplazo parcial de cemento. Determinaron las resistencias mecánicas a compresión a las edades de 3, 7, 28, 56 y 90 días.

Los resultados obtenidos mostraron que la adición del $8 \%$ en peso de la ceniza volante ultrafina mejoró significativamente la resistencia a la compresión, tanto a edades tempranas como a edades tardías de los hormigones que contenían altas proporciones de CV tipo F. Además, demostraron la efectividad de la ceniza ultrafina en la mejoría del empaquetamiento del sistema y en la aceleración de la actividad puzolánica para producir más geles CSH por el mayor consumo de $\mathrm{CH}$.

Estos mismos investigadores, (Shaikh y col., 2014) también estudiaron previamente la influencia en hormigones con la misma dosificación adicionando nanopartículas de $\mathrm{CaCO}_{3}$, obteniendo las mismas conclusiones.

Un estudio mucho más amplio realizó ese mismo año Supit y cols. (2014) en el que estudiaron el efecto de las cenizas volantes ultrafinas sobre el desarrollo de la resistencia a la compresión de morteros que contenían cenizas volantes tipo clase F en un alto porcentaje. Para ello dosificaron, en primer lugar, varios morteros compuestos de un cemento de mezcla binario en los que el cemento Portland (CEM I) fue reemplazado progresivamente por ceniza volante ultrafina en cantidades del $5 \%, 8 \%, 10 \%, 12 \%$ y $15 \%$ (en peso). Adicionalmente, se prepararon morteros de cemento con elevada cantidad de ceniza volante tipo $\mathrm{F}, 40 \%, 50 \%, 60 \%$ y $70 \%$ en peso como morteros de control. Una vez seleccionado aquel mortero con mayor resistencia a la compresión, correspondiente a una determinada cantidad de ceniza volante ultrafina, se evaló el efecto de la cantidad seleccionada de esta ceniza en los morteros de alta sustitución.

El estudio revelo que los morteros de cemento con un $8 \%$ de reemplazo de cemento por ceniza volante ultrafina exhibieron la mayor resistencia a la compresión a las edades de 7 y 28 días. También se pudo apreciar el mejor desempeño mecánico resistente de los morteros con elevadas proporciones de ceniza volante tipo F, particularmente a edades tempranas a causa de la elevada superficie específica de la ceniza ultrafina que promovió el proceso de hidratación y mejora la microestructura de los morteros de cemento para obtener una mayor resistencia y unas mejores propiedades mecánicas.

En esta investigación, también se estudió la microestructura y las fases presentes en los morteros después de 28 días mediante MEB y EDX y DRX. Los resultados indican la efectividad de esta ceniza ultrafina en el incremento de la densidad de empaquetamiento y en la aceleración de la actividad puzolánica para producir más geles de C-S-H al consumir hidróxido de calcio $(\mathrm{CH})$. 
Por su parte, Bondar y col. (2014) estudiaron la posibilidadde incrementar las resistencias mecánicas a edades tempranas de pastas de cementos con altos porcentajes de ceniza volante adcionando para ello polvo de horno de cemento y yeso para activar la CV. Para ello, se analizó la microestructura de las pastas preparadas.

Estos investigadores encontraron que el polvo de horno de cemento era mucho más efectivo que el yeso activando la ceniza, mejorando por ello apreciablemente las resistencias mecanizas de las pastas altamente adicionadas.

Para el caso particular de los hormigones autocompactantes, Celik y cols. (2014) estudiaron el efecto del reemplazo de cemento Portland, por ceniza volante o puzolana natural sobre las propiedades mecánico-resistentes y la durabilidad en hormigones con elevada sustitución. Para ello, se utilizaron una puzolana natural, un vidrio basáltico con elevado contenido de alúmina y sílice y una CV tipo F. Adicionalmente, también se utilizó como adición filler calizo para formular cementos ternarios. Para ello se realizaron pruebas de resistencias mecánicas a compresión, de migración del ión cloruro, y de permeabilidad. Los resultados fueron comparados con dos concretos de referencia, el primero con un $100 \%$ de cemento Portland, y el segundo con un $85 \%$ de CPO y $15 \%$ de filler calizo.

Los hormigones altamente adicionados con ceniza volante y puzolana natural mostraron resultados de resistencia y durabilidad comparables a los de los concretos de referencia, identificándose que ambos pueden usarse efectivamente para producir hormigones autocompactantes de bajo costo y respetuosos con el medio ambiente.

Con el fín de mejorar esta problemática Mei y cols. (2018) estudiaron la forma de mejorar las resistencias iniciales de cementos con elevado contenido de ceniza volante curado al vapor. Al sistema que contenía $40 \%$ ceniza volante se le adicionó nano- $\mathrm{SiO}_{2}$ y sulfato de sodio. El efecto de estos dos productos químicos sobre la hidratación, la estructura de los poros y la microestructura de la zona transición interfacial (ITZ) fueron investigados. Los resultados muestran que tanto nanosílice como el sulfato de sodio mejoran la compresión de los cementos de mezcla, y la razón a la que atrubullen este fenómeno es porque estas dos sustancias químicas pueden acelerar la hidratación del cemento y la reacción puzolánica de la ceniza volante. Por el contrario, debido a la alta actividad de reacción puzolánica y los efectos de llenado y nucleación, la nanosílice tiene un efecto mucho más fuerte en la estructura y el refinado del poro, mientras que el sulfato de sodio puede ejercer un efecto mucho mayor en la aceleración la hidratación de las cenizas volantes.

\subsubsection{Módulo de elasticidad}

Al igual que para la resistencia a compresión, el módulo de elasticidad es menor a primeras edades y mayor a edades altas en hormigones con $\mathrm{CV}$ y es inversamente proporcional al contenido de CV.

En el año 2010, Duran-Herrera y cols. (2011) presentaron un trabajo de investigación experimental orientado al desarrollo de herramientas prácticas de diseño de hormigones para aplicación industrial, e ilustraron los beneficios potenciales del efecto sinérgico de una ceniza volante tipo $\mathrm{F}$ y un aditivo superplastificante (tipo policarboxilato de alto rango) en la producción del hormigón convencional. Los diferentes hormigones considerados en este estudio fueron producidos con sustituciones en masa de cemento por CV entre el $15 \%$ y el $75 \%$, y una caída de 
consistencia objetivo de $200 \mathrm{~mm} \pm 20 \mathrm{~mm}$. El contenido total de agua se minimizó mediante el uso de una dosis óptima de aditivo superplastificante. Esta reducción de agua resultó ser del 18\%, 15\% y $11 \%$ respectivamente para las mezclas de referencia de $\mathrm{a} / \mathrm{c}=0.5, \mathrm{a} / \mathrm{c}=0.55, \mathrm{y} \mathrm{a} / \mathrm{c}=0.6$.

La liberación de calor y el flujo de calor se analizaron a través de calorimetría isotérmica y semi-adiabática, que ilustran que la liberación de calor por unidad de masa de cemento es independiente de $\mathrm{a} / \mathrm{c}$,

Estos investigadores destacaron el efecto beneficioso del aditivo en términos de reducción de cemento y retención de asentamientos. Además, establecieron correlaciones entre la sustitución de CV y la pérdida de asentamiento, los tiempos de fraguado, la resistencia a la compresión y el módulo de elasticidad estática. También se reportaron desarrollos de resistencia a la compresión hasta una edad de 56 días, así como las correlaciones entre el módulo de ruptura y la resistencia a la compresión o la tensión de desformación a la edad de 28 días.

Así, Kayali y col. (2013) examinó la practicidad y la idoneidad de la sustitución de cemento por cenizas volantes tipo $\mathrm{F}$ en alta proporción, tanto en mezclas binarias, como en mezclas ternarias (cenizas volantes/humo de sílice / cemento Portland). La investigación se centró en las condiciones realistas de la fabricación del hormigón en obra y los efectos en los aspectos físicos del material, así como las consecuencias en la corrosión de las armaduras.

Estos investigadores encontraron que las cenizas volantes de clase F podian reemplazar el $50 \%$ del cemento Portland y al mismo tiempo se pudo apreciar en la mejora de la resistencia a la corrosión iniciada por el ión cloruro. Sin embargo, dicha sustitución puede reducir significativamente los valores de las propiedades mecánicas.

La norma UNE 83414 indica que el módulo de elasticidad del hormigón con CV sigue un comportamiento similar al de la resistencia a la compresión, en comparación con el hormigón de referencia sin CV. El efecto de las CV en el módulo de elasticidad no es tan importante como sus efectos en las resistencias mecánicas, pues las características del cemento y de los áridos tienen más incidencia en el módulo de elasticidad que el uso de CV.

\subsubsection{Resistencia al deslizamiento.}

La magnitud de este parámetro depende de las condiciones de temperatura y humedad, resistencias, módulo de elasticidad, contenido de áridos, edad del hormigón. El efecto sobre el deslizamiento de las CV se extiende hasta el punto en el que éstas modifican las resistencias. Un hormigón con un volumen dado de cemento y CV cargado a los 28 días de edad o menos, normalmente da lugar a una mayor tensión de deslizamiento que su homólogo sin adición de CV, debido a las menores resistencias mecánicas conseguidas para dicha edad con el hormigón con CV. Nasser y col. $(1986 ;$ 1987) concretan que cuando se realizan ensayos comparativos de resistencia al deslizamiento entre un hormigón de cemento Portland y otro sustituyendo el 50\% del mismo por cenizas, los resultados apuntan hacia resultados mejores con el primero. Cuando el hormigón con o sin CV son selladas para prevenir la pérdida de agua en similares condiciones de hormigón en masa, la tensión de deslizamiento es igual a la edad de 1 año, sin embargo, si este mismo ensayo se realiza sin sellar el hormigón, la tensión de deslizamiento del hormigón que contienen CV es aproximadamente la mitad que la del hormigón sin adición. 
Ravindrarajah (1987) indica que, con las CV, dependiendo del cemento utilizado y las condiciones de curado, se podrán obtener una mejora de este parámetro o, por el contrario, tener un efecto perjudicial, por lo que no se puede llegar a una afirmación contundente.

Brooks (2002) indica que la resistencia al deslizamiento aumenta a medida que el nivel de reemplazamiento por CV aumenta, pero se hace inversamente proporcional a medida que el tiempo de carga aumenta, mientras que Bilodeau y col. (2000) afirman que la resistencia al deslizamiento es similar para hormigones con alto porcentaje de CV que de cemento Portland puro.

\subsubsection{Adherencia del hormigón al acero}

Este parámetro depende de la superficie de contacto, de la profundidad del reforzado y de la densidad del hormigón. Las CV, como se describió con anterioridad, aumentan el volumen de la pasta de cemento y reducen la segregación. Así pues, la interfase de contacto se mejora y, por lo tanto, la unión al parecer debe ser más fuerte, aunque el peligro de carbonatación aumente y la debilite más por otro lado.

La norma UNE 83414 indica que la adherencia entre el hormigón y el acero, depende de la superficie total de acero en contacto con el hormigón, del cemento, recubrimiento de la armadura y de la dosificación del hormigón y de su puesta en obra. Las CV aumentan el volumen de la pasta y reducen la exudación, por lo cual puede aumentar el contacto con la parte inferior de la armadura que es donde suele acumularse el agua exudada, resultando un incremento de la adherencia.

\subsubsection{Unión hormigón nuevo-viejo}

Es algo menor cuando se utiliza hormigones con CV. La norma UNE 83414 indica que la adherencia de un hormigón fresco durante el endurecimiento no se afecta grandemente al utilizar CV. Para conseguir una adecuada adherencia entre hormigón fresco y endurecido que tenga en su composición $\mathrm{CV}$, se utilizarán las mismas técnicas que con los hormigones sin CV.

\subsubsection{Resistencia al impacto}

Este parámetro está claramente influido por las resistencias mecánicas y por la granulometría más o menos compacta del hormigón. Por tanto, la influencia de las CV sobre la resistencia al impacto está en el orden de la influencia en las resistencias mecánicas.

La norma UNE 83414 indica que la resistencia al impacto de un hormigón está influenciada en gran medida por la resistencia a compresión del mortero y por la tenacidad del árido grueso. El uso de CV influye en la resistencia al impacto sólo en la medida en que mejore las resistencias finales del hormigón.

\subsubsection{Resistencia a la abrasión}

La resistencia a la compresión, el curado, el acabado y las propiedades de los áridos, son los factores que mayoritariamente influyen en la resistencia a la abrasión. Para similares resistencias, condiciones de curado y acabados, las resistencias a la abrasión son similares para un hormigón con o sin CV e incluso mejores. Esta afirmación es opuesta a la indicada por Bilodeau y 
cols. (1994) cuyos resultados experimentales dan lugar a más bajas resistencias para los hormigones con alto contenido en CV clase F, que para su homólogo de cemento Portland.

En este sentido, Zhang (1995) estudió el efecto de las cenizas volantes en la microestructura de pastas de cemento con un elevado contenido de ceniza volante y cómo esta composición afecta el patrón de las grietas y la relación tensión-deformación. Las pastas se prepararon incorporando un $58 \%$ de ceniza volante. El autor explica que las cenizas volantes parecen actuar como microagregados en las pastas y la propagación de las grietas generalmente se desvía alrededor de las partículas de cenizas volantes.

Además, comparó el desempeño de estas pastas con las correspodientes a un CP con resistencia similar, concluyendo que las curvas de tensión-deformación para las pastas altamente adicionadas eran menos lineales y comienzaban a desviarse en aproximadamente $60-70 \%$ de la resistencia máxima a 28 días.

Sobre la base de esta información, se propuso que la pasta altamente adicionada con ceniza volante podría considerarse microscópicamente como material compuesto, considerando las partículas de cenizas volantes como microagregados reactivos incrustados en una matriz de productos de hidratación y reacción. El efecto de los altos volúmenes de cenizas volantes en varias propiedades del hormigón tales como el módulo de elasticidad, contracción, fluencia, así como la permeabilidad también se vieron influenciados.

Asimismo, Papayianni y col. (2010) estudiaron la posibilidad de producir un hormigón de alta resistencia y alto rendimiento utilizando para ello grandes volúmenes de subproductos industriales. Éstos fueron cenizas volantes con alto contenido de calcio y escoria de horno de cuchara como material cementicio suplementario, y escoria de horno de arco eléctrico como árido. Las cenizas volantes se utilizaron constituyendo el $50 \%$ de la masa total de cementante y la escoria de horno de cuchara el 30\%. Los áridos de escoria se utilizaron en reemplazo de árido grueso o en reemplazo de áridos finos y gruesos.

Los resultados obtenidos demostraron que los hormigones dosificados consiguieron una alta resistencia (> $70 \mathrm{MPa}$ ), una buena resistencia a la abrasión y una buena tenacidad a la fractura.

La norma UNE 83414 indica que los factores de los que depende la resistencia a la abrasión son las resistencias a la compresión, el curado, alisado y las propiedades del árido. Para la misma resistencia a la compresión el hormigón adecuadamente alisado y curado presenta la misma resistencia a la abrasión con y sin CV.

\subsubsection{Influencia sobre la temperatura de hidratación}

Las reacciones químicas del cemento con el agua generan calor que se convierte en un factor muy importante en el desarrollo de las propiedades de resistencias y tensiones a primeras edades debido al cambio de volumen en el hormigón.

La mayor parte de este calor es producido en los primeros estados de la hidratación del $\mathrm{C}_{3} \mathrm{~S}$ y $\mathrm{C}_{3} \mathrm{~A}$ del cemento. El calor generado y el porcentaje de hidratación que se da dependen del tipo y cantidad de cemento utilizado, la masa de la estructura, el método de puesta en obra, la temperatura del hormigón, el tiempo de puesta en servicio y el tiempo de curado. 
Debido al efecto adverso en el contenido de aire ocluido de la cantidad de carbón que poseen las $\mathrm{CV}$, éstas son utilizadas principalmente en hormigones sin oclusión de aire y no expuestos a severos cambios climáticos. Sin embargo, se han observado que no existen efectos adversos, sino que a veces, es todo lo contrario en hormigones de alto contenido de $\mathrm{CV}$ o al utilizar $\mathrm{CV}$ con una pérdida por calcinación del 12\%, siempre que el hormigón tenga una madurez adecuada cuando sea expuesto a las primeras heladas, a pesar de que la norma ASTM C618 restrinja la pérdida por calcinación al $6 \%$. Esto queda contradicho por los resultados obtenidos por Nasser y col. $(1986 ; 1987)$ que dicen que la resistencia a los ciclos hielo-deshielo se ve empeorada por la adición de 35-50\% de CV, incluso curados bajo agua durante 80 días, y que la reducción de las CV a un $20 \%$ presenta una resistencia comparable a la que poseería un hormigón de cemento Portland. Dicha reducción de resistencia con altas proporciones de CV queda explicada por Nasser de manera que indica que existe una lenta migración de portlandita y ettringita desde el denso gel de CSH a las zonas de huecos de aire y aunque el hormigón con CV es menos susceptible a la migración de portlandita, sus huecos de aire contienen hidratos más fibrosos que hacen incrementarse la porosidad de la pasta.

Debido a que, a menudo, las resistencias a primeras edades son menores en el hormigón que contiene $\mathrm{CV}$, la resistencia a los ciclos hielo-deshielo se ve retrasada con respecto a un hormigón que no las contiene (Nasser y col., 1986; 1987) pero si aumenta la cantidad de cemento para conseguir igual resistencia a los 28 días de edad (por tanto, la dosificación del aireante debe ser también aumentada), esta resistencia se hace comparativa. Gebler y col. (1986) demuestran mediante sus trabajos que este parámetro se ve empeorado en hormigones con aire ocluido por adición de CV cuando se curan a bajas temperaturas.

Cuando un hormigón que contiene CV clase F es curado a bajas temperaturas, éste posee alguna menor resistencia a los ciclos hielo-deshielo que si contuviera CV de clase C.

Cengiz, (2002) estudió en el laboratorio la evolución del calor en hormigones altamente adicionados con cenizas volantes. La evolución del calor del hormigón se estudió midiendo el aumento de temperatura en el material en condiciones de curado adiabático.

Se encontró que la característica de la evolución del calor del hormigón de las cenizas volantes depende en gran medida del nivel de reemplazo de las cenizas volantes y la dosis de superplastificante usado para mantener la trabajabilidad. También se encontró que el uso de cenizas volantes como reemplazo del cemento dio lugar a una reducción en el valor máximo de la temperatura. El aumento del nivel de reemplazo de las cenizas volantes causó un menor aumento de la temperatura en el hormigón y el aditivo superplastificante causó un retraso en el tiempo del segundo máximo de la curva calorimétrica.

La norma UNE 83414 indica que la resistencia al deterioro del hormigón en los ciclos hielodeshielo, cuando contiene o no, CV, depende del adecuado sistema de huecos, de la estabilidad de los áridos, de la edad del hormigón y su grado de hidratación (madurez), de la resistencia mecánica de la pasta de cemento y de la humedad del hormigón. Hay que suministrar mezclas con la seguridad de que el hormigón tendrá una resistencia mecánica adecuada cuando se exponga por primera vez al ciclo hielo-deshielo.

En este sentido quedan preguntas con respecto a la influencia que tiene la ceniza volante sobre la hidratación del cemento. De la Varga y cols. (2018) examinaron aspectos físicos (Superficie 
nucleación, espaciado de partículas de cemento, etc) y aspectos químicos (reacciones puzolánicas e hidráulicas) de las cenizas volantes y cemento en mezclas que contienen altos volúmenes de cenizas volantes. Además de usar cenizas volantes, se utilizó también como adción un fíller siliceo. Fueron empleados tres porcentajes de sustitución $40 \%, 60 \%$ y 80\%. Los resultados indicaron que el mayor espacio de cemento y efectos de nucleación / desfloculación proporcionados por la adición de las cenizas son dominantes cuando se comparan con el efecto químico (es decir, reactividad a la ceniza volante) a edades tempranas (menos de $48 \mathrm{~h}$ ), para las mezclas con un nivel de reemplazo de volumen del $40 \%$. Este efecto es aún mayor en mezclas con mayores niveles de reemplazo de cenizas volantes. En edades tempranas, la adición de las cenizas volantes elegidas para este estudio causó retraso en el sistema, como se observa en el flujo de calor medido. El retraso es más grande a medida que aumenta el nivel de reemplazo de cenizas volantes. Después de 48 h, las mezclas que continian las cenizas volantes exhibieron una mayor liberación de calor acumulado que indicaría un mayor grado de hidratación / reacción.

\subsubsection{Resistencia a las sales de deshielo}

Los hormigones con altas proporciones de CV (56-58\% del peso del material cementante) poseen bajas resistencias a las sales de deshielo e incluso, se ha observado este dato negativo para hormigones con aire ocluido que contiene un $25 \%-50 \%$ de CV independientemente del método de curado empleado.

Este efecto es tanto menor cuanto mayor es la relación a/c. Sin embargo, Nagataki y cols. (1986) y Kayyali y col. (1988) afirman, apoyados en sus resultados experimentales, que la adición de las CV favorece la penetración de los iones cloruro y, por tanto, la carbonatación. El primero de ellos indica que dicho efecto es más destacado a primeras edades, aunque a largo plazo la penetración se iguala a la que poseería un mortero de cemento Portland.

Mas tarde, Bouzoubaa y cols. (2000) presentaron datos sobre el desempeño del hormigón utilizadon cementos de mezcla con elevado porcentaje de cenizas volantes y adicionando separadamente el cemento Portland y la ceniza. Entre los parámetros estudiados se incluyeron las resistencias a la compresión y a la penetración del ión cloruro.

Independientemente del tipo de ceniza volante utilizada, el hormigón dosificado con los cementos de mezcla con elevada proporción de ceniza volante desarrolló una resistencia a la compresión más alta a todas las edades que la del hormigón adicionado con cenizas. En cuanto la resistencia al ión clouro vieron una mejoría en esta resistencia con los cementos de mezcla también.

\subsubsection{Permeabilidad (porosidad) y protección contra la corrosión}

La permeabilidad del agua del hormigón depende de las interconexiones entre huecos de aire en el hormigón, contenido en material cementicio, contenido de agua, granulometría, consolidación y eficacia de curado. Dunstan (1986) indica que la permeabilidad de un hormigón que contiene altas proporciones de CV y bajas en cemento es similar a aquel hormigón que no contiene CV y un alto contenido de cemento. Medidas de la porosidad han demostrado que la distribución de los poros es muy distinta entre un hormigón con CV y sin ellas. Estos dos efectos, menor permeabilidad al agua y a los gases y porosidad dan lugar a hormigones de mayor 
durabilidad global. Sin embargo, Baum y cols. (1985) indica que a la misma edad y relación a/c, la pasta de cemento que contiene $\mathrm{CV}$ está caracterizada por una porosidad total y capilar mayor y a edades tempranas hasta 28 días, por un diámetro de los mismos mayor.

El hidróxido de calcio liberado en la hidratación del cemento es soluble en agua y puede salir fuera del hormigón endurecido, dejando espacios vacíos para la entrada de agua, por tanto, las propiedades puzolánicas de las $\mathrm{CV}$ reducen el riesgo de que se produzca este fenómeno de corrosión tanto o más cuanto menor es la relación a/c, y la permeabilidad también se ve reducida.

Unos años mas tarde Lam y cols. (2000) adviertieron en su trabajo que, aunque las cenizas volantes se han venido usando ampliamente en el hormigón como reemplazo del cemento, se habían realizado pocos trabajos para determinar el grado de hidratación de los sistemas de cenizas volantes/cemento con alto grado de sustitución. Por ello, en su investigación, estudiaron el grado de hidratación del cemento en pastas determinando el contenido de agua no evaporable y se determinó el grado de reacción de las cenizas volantes en las mismas pastas utilizando para ello un método de disolución selectiva basado en la relación entre el grado de hidratación del cemento y la relación efectiva de agua a cemento $(\mathrm{a} / \mathrm{c})$.

Los resultados obtenidos demostraron la teoría de que las pastas con alto contenido en cenizas volantes tuvieron un grado de hidratación menor. No obstante, ese grado de hidratación fue superior en las pastas con un contenido de ceniza volante de $45 \%$ a $55 \%$. Las pastas con un contenido de ceniza volante superior al $80 \%$ permanecieron sin reaccionar después de 90 días de curado.

Asímismo se pudo ver el fenómeno de que el grado de hidratación del cemento en pastas con alto contenido de cenizas volantes mejoró incrementando la relación a/c. Este efecto fue más significativo para las pastas con relaciones a/c más bajas en la que se perdió resistencia. Por lo tanto, concluyeron que, en la preparación de un hormigón con un alto contenido de cenizas volantes, a menor a/c podrían caer las resistencias mecánicas significativamente.

En este trabajo, Lam y cols. (2000) también incluyeron un modelo para describir la relación entre la relación a/c, el grado de hidratación del cemento y la relación gel/espacio. Se encontró que las proporciones de gel/espacio de las pastas con cenizas volantes eran equivalentes con la relación gel/espacio de las pastas de CP en términos de la relación con la resistencia a la compresión. Los datos de relación gel/espacio, los correlacionaron con resultados de porosimetría por intrusión de mercurio, pero la primera se correlacionó más y mejor con la resistencia a la compresión que la segunda.

Por su parte, Jiang y cols. (2000), presentaronun modelo matemático para predecir la profundidad de carbonatación del hormigón con alto contenido en cenizas volantes. Para ello, se realizó una prueba de carbonatación acelerada realizado sobre un hormigón $\mathrm{CP}$ y sobre uno altamente adicionado.

Las profundidades de la carbonatación pronosticadas a partir del modelo eran, en comparación con los resultados de la prueba equivalentes. Se muestra que la relación a/c y el contenido de cemento son los factores clave que afectan al proceso de carbonatación del hormigón. Adicionalmente, se demostró que el el período de curado puede mejorar el comportamiento de carbonatación del hormigón. Concluyen finalmente que, el comportamiento frente a la 
carbonatación de este tipo de hormigones, con proporción de mezcla adecuada puede cumplir con los requisitos del hormigón estructural.

Hill y col. (2002) también estudiaron la microestructura y los productos de hidratación formados en tres pastas de cemento con un alto porcentaje de reemplazo, es decir, cemento Portland mezclado con $75 \%$ y $90 \%$ de escoria granulada de alto horno y el $75 \%$ de ceniza de combustible pulverizada. Ambas pastas se compararon con un correspondiente a un CPO. Todas las pastas se curaron al aire en las mismas condiciones de temperatura y humedad, por un periodo de hasta seis meses en algunas de ellas. Los productos de hidratación se identificaron mediante difracción de rayos $\mathrm{X}(\mathrm{DRX})$ y su microestructura se analizó por MEB.

Aunque los productos de hidratación observados fueron en su mayoría lo esperados, debido a los altos niveles de reemplazo, el grado en que estas fases estaban presentes era inusual. En particular, el hidróxido de calcio inicialmente formado en los sistemas de cemento con escoria de alto horno se consumió totalmente en seis meses, lo que indica el importante comportamiento puzolánico de de la escoria en tan altos niveles de reemplazo.

Donatello y cols. (2013) también evaluaron la resistencia al ataque ácido de pastas y morteros de cemento con una elevada cantidad de ceniza volante en su composición ( $80 \%$ aproximadamente) que fueron activados químicamente adicionándole $\mathrm{Na}_{2} \mathrm{SO}_{4}$. Los citados materiales base cemento fueron sometidos a un ataque ácido agresivo sumergiéndolos durante 90 días en una disolución $0,1 \mathrm{M}$ de $\mathrm{HCl}$. Tras esa inmersión se observaron cambios en las resistencias a la compresión de los morteros y en las fases cristalinas generadas. Estos ensayos se repitieron con un cemento SR comercial.

Estos investigadores identificaron una mayor resistencia al ambiente ácido de las pastas preparadas al partir del cemento SR comercial que para el caso de las pastas que contenían el $80 \%$ de ceniza volante. Este fenómeno fue justificado por la mayor presencia $\mathrm{Ca}(\mathrm{OH})_{2}$ y fases que contenían ión $\mathrm{CO}_{3}^{2-}$, que actúan como agentes de tampones ácidos. También identificaron que después de los 90 días de inmersión, la ettringita y la portlandita todavía podría observarse en partes internas de las pastas del cemento Portland SR examinadas por DRX y MEB/EDX. Adicionalmente, en las pastas del cemento con altas proporciones de ceniza volante no hubo portlandita suficiente para poder revertir, junto con las principales fuentes de álcali presentes $\mathrm{NaOH} / \mathrm{Na}_{2} \mathrm{CO}_{3}$, altamente solubles, como para actuar eficazmente contra el ambiente altamente ácido. Para finalizar, estos investigadores mostraron que las pastas de ambos cementos mostraron signos característicos del ataque ácido en la estructura del gel CSH.

Ese mismo año también, Bae y cols. (2014) se centraron en el estudio de identificación y caracterización microestructural de los productos de hidratación formados en cementos de mezcla altamente adicionados con cenizas volantes mediante microdifracción de rayos $\mathrm{X}$ de escaneo monocromático ( $\mu$-SXRD) y MEB-EDX. Se estudiaron pastas de cemento con hasta un $80 \%$ de reemplazo de cenizas volantes.

Este análisis mostró que el C-S-H que se formó en el sistema cementante con un contenido en ceniza volante superior al 50\% poseia una estructura similar a la C-S-H (I) con una relación Ca/Si comparativamente más baja que la de un cemento Portland. Por otra parte, observaron la coexistencia de C-S-H (I) y strätlingita en sistemas que contienían $80 \%$ de ceniza volante, lo que 
confirmaba que la cantidad de fases de alúmina y silicato proporcionadas por las cenizas volantes es un factor importante para la formación de estos dos productos de hidratación.

Por su parte, Shaikh y col. (2015) estudiaron la influencia de la adición de una ceniza volante ultrafina en la durabilidad de hormigones que contienen altos contenidos de cenizas volantes tipo F como reemplazo parcial de cemento. Estas propiedades de durabilidad las midieron a las edades de 28 y 90 días. Para ello, se determinó la corrosión inducida por el ión cloruro, la permeabilidad al agua y volumen de huecos permeables al ion cloruro.

Los resultados obtenidos mostraron que la adición del $8 \%$ en peso de la ceniza volante ultrafina mejoraron las propiedades de durabilidad en la mayoría de los casos con respecto al hormigón que contenía un 32\% de CV tipo F, estos dos a su vez, mostraron mejores propiedades e durabilidad que aquel hormigón ordinario dosificado que contenía un 100\% de cemento. En este sentido, demostraron la efectividad de la ceniza ultrafina en la mejoría del empaquetamiento del sistema y en la aceleración de la actividad puzolánica para producir más geles CSH por el mayor consumo de $\mathrm{CH}$.

Estos mismos investigadores, (Shaikh y col., 2014) también estudiaron previamente la influencia en hormigones con la misma dosificación adicionando nanopartículas de $\mathrm{CaCO}_{3}$, obteniendo las mismas conclusiones.

Asímismo, en el mismo año, Van den Heede y col. (2014) evaluaron la vida útil frente a la carbonatación de concretos adicionados con altas cantidades de ceniza volante mediante varios métodos predictivos aparte del tradicional colorimétrico. Los perfiles de carbonatación que obtuvieron al exponer a hormigones con alto porcentaje de sustitución de ceniza volante a un ambiente al $10 \%$ de $\mathrm{CO}_{2}, 20{ }^{\circ} \mathrm{C}$ y $60 \%$ de $\mathrm{HR}$ fueron el $55 \%$ superior del perfil obtenido al $1 \%$ de $\mathrm{CO}_{2}$, a $20{ }^{\circ} \mathrm{C}$ y $60 \%$ de HR. Así, para el primer caso, concluyen que, en la predicción de la vida útil de estos hormigones, ésta podría superar fácilmente los 100 años.

Tambien, De la Varga y cols. (2014) investigaron la resistencia a la penetración del ión cloruro de morteros altamente adicionados con ceniza volante tipo $C$ con bajas relaciones de a/c que fueron sometidos a distintos tiempos de curado. En concreto, se obtuvieron resultados de la velocidad de migración y penetración de este anión, su correspondiente coeficiente de difusión, la resistividad eléctrica y la adsorción de agua de los morteros fabricados.

La investigación se centró en dos porcentajes de reemplazo de ceniza volante, 40\% y $60 \%$ en volumen, con y sin curado interno con áridos finos ligeros prehumedecidos. Asímismo, todas estas mezclas fueron comparadas con el con un CPO. Los resultados indicaron que las mezclas con alta sustitución de ceniza volante, con y sin curado interno, proporcionaron beneficios en términos de coeficientes de transporte reducidos en comparación con las mezclas de CPO.

\subsubsection{Retracción hidráulica. Retracción por secado ó "Drying shrinkage"}

Este parámetro depende de la fracción de volumen de la pasta de cemento, contenido y tipo de este y de los áridos (aggregate). En este caso, la adición de CV, aumenta el volumen de la pasta de cemento, por consiguiente, la retracción debe ser ligeramente superior si el contenido de agua permanece constante. Si existe una reducción de agua dicha retracción debe ser similar a la del hormigón sin adición de CV. Carraquillo (1987) y Abdun-Nur y cols. (1987) indican que la 
retracción depende del curado a edades tempranas, sobre todo, en lo que se refiere a hormigones que contengan $\mathrm{CV}$.

Gebler y col. (1986) indican que dicha retracción no viene influida por la adición de CV y Swamy y col. (1983) precisa que los hormigones con un contenido del 35 al 40\%, incluso del 15$30 \%$, de CV se caracterizan por sus más bajas retracciones. Nasser y col. $(1986 ; 1987)$ incluso precisa que este parámetro se ve mejorado en hormigones que contienen un $50 \%$ de $\mathrm{CV}$, e incluso entre un 25-75\%. Sivasundaram y col. (1992) indica que, en hormigones con altas proporciones de adición de CV volantes con bajo contenido de cal, dicha retracción es similar e incluso más baja que la del hormigón sin adición.

Termkhajornkit y cols. (2005) trataron de correlacionar la retracción autógena y el grado de hidratación de las cenizas volantes, para ello utilizó un método de disolución selectiva. Posteriormente, se examinó la relación entre el grado de hidratación de las cenizas volantes y la retracción autógena.

Los resultados mostraron que el grado de hidratación de las cenizas volantes aumentó a medida que aumentó su superficie Blaine y el grado de hidratación de las cenizas volantes aumentó con el tiempo. Asímismo, la retracción autógena se incrementó en función del aumento en el grado de hidratación de las cenizas volantes. Por otra parte, se encontró que la cantidad total de $\mathrm{Al}_{2} \mathrm{O}_{3}$ muestras de cemento y cenizas volantes afectó la contracción autógena a edades tempranas, pero la influencia a largo plazo fue muy pequeña.

En este sentido, y en cuanto a la reología y la trabajabilidad de estos sistemas, Bentz y col. (2010) realizaron mediciones reológicas, de Vicat convencionales y estudios de tiempos de fraguado para verificar que las cenizas volantes ASTM tipo C y tipo F realmente reducen los tiempos de fraguado en pastas altamenete adicionadas

Continuan explicando que las reducciones dependen de la clase de ceniza volante y sugieren que las mezclas de prueba son imprescindibles para aplicar estas tecnologías a cada combinación específica de ceniza volante/cemento/aditivo empleado en obra real. Concluyen que, para tales estudios de selección, la medición reológica del esfuerzo de cizalla puede proporcionar una indicación más rápida de la compatibilidad entre materiales que las mediciones de penetración con aguja Vicat convencionales en pastas.

La norma UNE 83414 indica que la retracción por secado del hormigón es una función de la fracción del volumen de pasta, del contenido de cemento y del tipo de árido. En los casos en que la adición de $\mathrm{CV}$ aumenta el volumen de pasta, la retracción por secado puede aumentar ligeramente, si el contenido de agua permanece constante. Si tiene lugar una reducción del contenido de agua, la retracción debe ser la misma que la del hormigón sin CV.

La norma UNE 83414 indica que la reacción entre la sílice vítrea de las CV y los compuestos alcalinos en especial sodio y potasio, liberados durante el proceso de hidratación del cemento, reducen su disponibilidad para las reacciones de expansión con los áridos que contienen la sílice reactiva. El uso de adecuadas cantidades de CV puede reducir la reacción con los áridos y disminuir o eliminar la expansión nociva del hormigón. 


\subsubsection{Resistencia química a ambientes marinos}

Malhotra y cols (1991) en sus investigaciones demostraron que un 25\% de CV sustituyendo al cemento, da lugar a hormigones con buenas resistencias a ambientes marinos, siempre que la relación a/c sea menor de 0.5 .

Donatello y cols. (2013) también evaluaron la resistencia al agua de mar de pastas y morteros de cemento con una elvada cantidad de ceniza volante en su composición $(80 \%$ aproximadamente) que fueron activados químicamente adicionándole Na2SO4. Los citados materiales base cemento fueron sometidos a un ataque químico agresivo sumergiéndolos durante 90 días en una disolución salina que cumplía con las prescripciones de la norma ASTM de prepración de aguas de mar de forma artificial. También se observaron cambios en las resistencias a la compresión de los morteros y en las fases cristalinas generadas, tras su inmersión, en este caso en agua de mar. Estos ensayos se repitieron con un cemento SR comercial.

Ambos conjuntos de morteros demostraron una resistencia adecuada a la inmersión en agua de mar tipo ASTM después de 90 días. No obstante, estos investigadores identificaron el mayor contenido de fase $A F t$ en las pastas preparadas al partir del cemento SR comerciald que permitió la conversión parcial de AFt a sal de Friedel por el ambiente rico en ión Cl- propio del agua de mar.

\subsubsection{Resistencia a la fatiga}

La resistencia a la fatiga de hormigones que contienen CV varía dependiendo de la clase de CV utilizadas y la proporción de estas que reemplaza al cemento. Pueden ser obtenidos hormigones con adición de CV con una resistencia a compresión similar o mayor que la obtenida para un hormigón patrón de cemento Portland puro cuando se reemplaza un $25 \%$ en peso de cemento por $\mathrm{CV}$ clase $\mathrm{F}$ y un $50 \%$ por $\mathrm{CV}$ clase $\mathrm{C}$.

Existen una clase especial de CV denominadas "cenizas sulfíticas" que son producidas por los fabricantes que, por motivos ecológicos de prevención de la contaminación atmosférica, han desulfurizado los gases de combustión. Como resultado de este proceso, existen importantes modificaciones en la composición de los residuos enriquecidos con sulfuros. Este es el caso de las CV sulfíticas con altas proporciones de cal.

Esta clase especial de CV ha sido también utilizada como material hidráulico reemplazando al cemento, cuyo estudio experimental da como resultado las siguientes conclusiones: Poseen una mayor finura que las CV volantes clásicas, por tanto, se incrementa la demanda de agua para una misma consistencia. Existe un importante empeoramiento de las resistencias que esconde los efectos de la reacción puzolánica.

No parece que la presencia de sulfitos tenga ningún efecto en la durabilidad del hormigón: los sulfitos parecen ser estables en ambientes básico, no oxidándose a sulfatos; el grado de carbonatación y corrosión no están influidos significativamente por la presencia de las CV sulfíticas.

El método más efectivo para evaluar el comportamiento de una determinada CV en el hormigón y establecer las proporciones de mezcla para una aplicación específica es realizar numerosas amasadas con numerosas proporciones de mezcla y ensayarlas, ya que no existen 
métodos de predicción de las proporciones más adecuadas y requisitos del material a cumplir. No obstante Talero (1986) ha propuesto un método a través de mortero selenitoso tipo ASTM C452, cuyo mejor resultado a 28 días, tanto en RM28 (las mayores posibles), daría la mezcla oportuna utilizable para el hormigón.

Para un hormigón económico, las CV de bajo contenido de cal se utilizan normalmente entre un 15 a un $25 \%$ del total de material cementante y las de alto contenido en cal, del 15 al 35\%. Se pueden utilizar mayores porcentajes para reducir las posibilidades de fisuraciones al hielo, para controlar la reacción árido-álcali y otras aplicaciones especiales (Nasser y col. 1986; 1987).

Existe un modelo matemático para definir la composición del hormigón con CV volantes propuesto por Dunstan (1986).

\subsubsection{Resistencia a las altas temperaturas}

Donatello y cols. (2014) evaluaron los cambios físicos y químicos que tuvieron lugar en pastas de cemento con elevados contenidos de ceniza volante, entono al 80\%, exponiéndolas a altas temperaturas, hasta $1000^{\circ} \mathrm{C}$. Las pruebas se repitieron utilizando también para ello un cemento con adciones comercial CEM II / A-M (MS).

Estos investigadores muestran como las pastas dosificadas a partir del cemento que contenía elevados porcentajes de ceniza volante tuvieron un muy buen comportamiento mecánico resistente después de la exposición al calor que aumentó, incluso, cuando se alcanzaron temperaturas entre 800 y $1000^{\circ} \mathrm{C}$. Este comporamiento, resultó distinto al mostrado por el cemento comercial el cual mostró una disminución continua en la resistencia residual después del calentamiento y posterior enfriamiento. El aumento de la resistencia residual de las pastas que contenia elevados porcentajes de CVcoincidió con un importante fenómeno de retracción, asociado con un proceso de sinterización y la formación de nuevas fases cristalinas, tales como anortita, gehlenita, wollastonita, diópsido y albita.

Por el contrario, el cemento MS formó fundamentalmente fases de silicato de calcio no hidráulicas al calentar a temperaturas superiores a $800^{\circ} \mathrm{C}$. Las diferencias en la formación de fases de ambos cementos fueron vinculados a diferentes composiciones elementales de partida. La pasta con alto contenido de ceniza volante era considerablemente más rica en $\mathrm{Si}, \mathrm{Al}$, Fe y álcalis, pero más pobre en Ca.

Además, concluyen y advierten que la composición elemental de las fases cementantes es un factor un factor importante a tener en cuenta al evaluar el comportamiento a alta temperatura de este tipo de cementos y hormigones que contengan contenidos significativamente altos de materiales cementicios suplementarios.

En este sentido, Rashad (2015b), investigó el comportamiento de hormigones de alto contenido en cenizas volantes mezclado con escoria granulada de alto horno bajo el efecto de elevadas temperaturas. Para ello, se reemplazó el cemento parcialmente con una ceniza volante de tipo F (CV) a un nivel del 70\% para producir sus correspondientes hormigones. Adicionalmente, este reemplazo se modificó sustituyendo parcialmente la ceniza CV por escoria en un $10 \%$ y $20 \%$ respectivamente. Todos estos hormigones se compararon con uno dosificado utilizando para ello cemento Portland. 
Después del curado, las muestras se expusieron a temperaturas elevadas que oscilaron entre $400{ }^{\circ} \mathrm{C}$ y $1000{ }^{\circ} \mathrm{C}$., y a continuación, se anotaron sus correspondientes pesos y sus resistencias a la compresión antes y después de haber estado expuesto a altas temperaturas. Asímismo, se identificaron las distintas fases presentes por DRX y por MEB.

Los resultados indicaron una mayor resistencia relativa de todos los tipos de hormigones altamente adcionados, destacando aquel que contenía $70 \%$ de CV. No obstante, la incorporación de escoria mostró un efecto negativo en los citados hormigones, reduciéndose la resistencia a la compresión residual.

Los mismos ensayos y análisis fueron repetidos por este mismo autor (Rashad, 2015a), sustituyendo en esta ocasión la CV por humo de sílice, en lugar de escoria, en los mismos porcentajes de reemplazo. En este caso, los hormigones que contenían humo de sílice exhibieron un buen desempeño después de someterlos a temepraturas superiores a $600^{\circ} \mathrm{C}$. Sin embargo, los sometidos a temperaturas por encima de los $800^{\circ} \mathrm{C}$ experimentaron una degradación muy severa.

Para terminar, Bouzoubaa y cols. (2001) realizaron una investigación muy extensa que evaluó un gran número de propiedades físicas, mecánico-resistentes y de durabilidad de hormigones dosificados con alta cantidad de ceniza volante. Además, para la obtención de resultados también se utilizó un cemento de mezcla, el cual contenia una ceniza volante que poseía una finura que no cumplia con la norma ASTM C 618.

Se evaluaron muchas propiedades del hormigón en estado fresco: el asentamiento, el contenido de aire, la pérdida de asentamiento, la estabilidad del contenido de aire, la exudación y los tiempos de fraguado. En estado endurecido fueron las siguientes propiedades: resistencia a la compresión, resistencia a la flexión, módulo de elasticidad de Young, contracción por secado, resistencia a la abrasión, penetración del ión cloruro, ciclos de congelación/descongelación y respuesta ante las sales de deshielo.

\subsection{Conclusión obtenida del estudio bibliográfico realizado de los cementos portland con elevados contenidos de adiciones puzolánicas.}

De todos estos datos bibliográficos, los de mayor aplicabilidad de acuerdo con los objetivos de esta investigación son los relativos a la Resistencia Sulfática, que como se ha podido observar, las investigaciones realizadas no han sido concluyentes para este nuevo tipo de cementos con adiciones puzolánicas recogidos en la vigente Instrucción RC-16 como Cementos Puzolánicos CEM IV/B ó Cementos con escorias de horno alto CEM III/A y CEM III/B. 



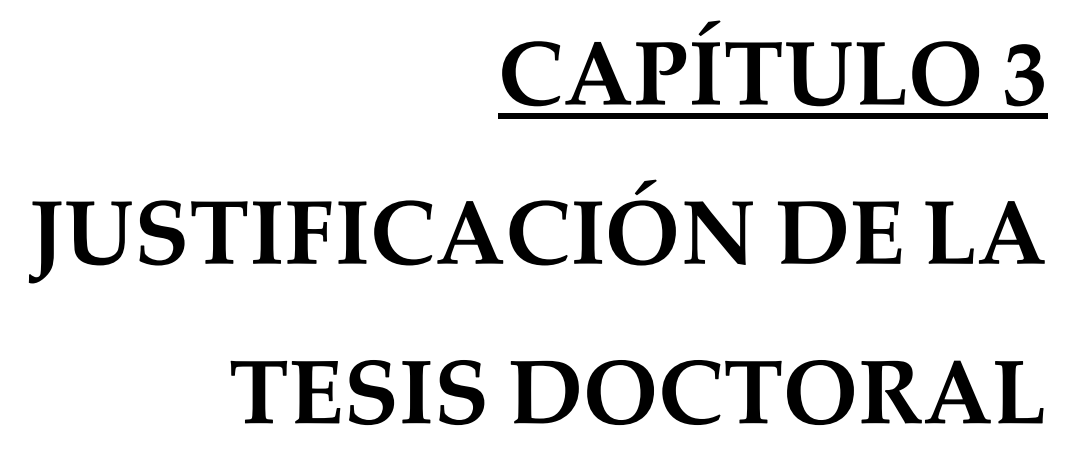



A falta de adecuadas especificaciones sobre RS de los cementos puzolánicos tipo CEM IV/B de la vigente Instrucción RC-16, o al menos a la falta de un método acelerado de ensayo para caracterizarlos y diferenciarlos en tal sentido, y partiendo de los resultados experimentales de Talero (1986) y más concretamente los obtenidos mediante el método acelerado de ensayo de LA, se puede decir con fundamento que impera el efecto químico directo de la sustitución física de cemento PY-4 ó PY-6 por puzolana.

Adicionalmente, por lo general, sea cual fuere el CPM acompañante correspondiente que se considere, a igualdad de cemento de mezcla 60/40 y edad del ensayo intermedia y/o final, las probetas L-A correspondientes mostraron, dentro de una misma familia los menores valores del $\triangle \varnothing$ y PAV, y en general un mejor comportamiento que el resto de sus hermanas 70/30 y 80/20 por este orden de mejor a peor, sea cual fuese la puzolana empleada, siendo tal comportamiento relativamente bastante aproximado entre todas ellas 60/40, y más aún cuando el CPM acompañante correspondiente ha sido un PY.

Y la causa de ello fue la menor presencia de cemento Portland P ó PY en dicho grupo 60/40 de todas las familias, que en los correspondientes grupos hermanos 70/30 y 80/20, y consecuentemente la menor presencia en el tiempo de portlandita, $\mathrm{Ca}(\mathrm{OH})_{2}$, que provendría de 
la hidratación de la fracción correspondiente P o PY, en todas ellas, la cual resulta ser imprescindible y necesaria para desarrollar la puzolana "Z" su actividad puzolánica, traducible principalmente y entre otras,

- En la formación de geles tobermoríticos CSH de origen su contenido de $\mathrm{SiO}_{2}{ }^{\mathrm{r}}, \mathrm{y}$

- En la formación de ett-rf de origen su contenido de $\mathrm{Al}_{2} \mathrm{O}_{3}{ }^{\mathrm{r}}$, a la cual le es también imprescindible y necesario que el valor del $\mathrm{pH}$ de la fase líquida que rodea a sus materias formadoras o reaccionantes, $\mathrm{CaSO}_{4}, \mathrm{Al}_{2} \mathrm{O}_{3}{ }^{\mathrm{r}}, \mathrm{Ca}(\mathrm{OH})_{2}$ y $\mathrm{H}_{2} \mathrm{O}$, en el instante mismo de su formación no sea $<10.80$ según Lea (1970) en ausencia de yeso y aluminatos de calcio hidratados diversos.

Y esa misma razón fue también la causa por la que en el caso de los parámetros RMC y RMF, determinados de las correspondientes probetas de $1 \times 1 \times 6 \mathrm{~cm}$ de mortero selenitoso ASTM C452 disminuyeron sus valores de Resistencias mecánicas.

Estos resultados obtenidos por Talero (1986) permitieron aseverar lo siguiente:

En contra de la opinión generalizada existente al respecto y de acuerdo con los resultados experimentales obtenidos, se puede decir que, por lo general, los Cementos Portland con Adiciones Puzolánicas únicamente de hasta un $20 \%$ en peso, 80/20, no mejoran el grado de RS de su CPM constitutivo sólo.

Sin embargo, el aumento de RS, que poseen un grado de RS superior al de su CPM constitutivo sólo, se originó por lo común en los correspondientes cementos de mezcla 60/40, o sea, con un $40 \%$ en peso de puzolana. Siendo además por ello calificados de moderada o elevada RS en todos los casos, mientras que los $80 / 20$ no lo fueron.

Tales generalizaciones anteriores se verificaron con mayor razón cuanto más alumínica que silícica era la puzolana constitutiva.

La dependencia del grado de RS o RM a edades iniciales de un Cemento de mezcla constituido por Portland y Puzolana, única y exclusivamente y con un contenido de esta última del $20 \%, 30 \%$ ó $40 \%$, en peso, de la puzolana que lo constituye, no hacen que el grado de RS ó RM a edades iniciales de sus cementos de mezcla respectivos, resulte ser siempre superior al correspondiente de su Cemento Portland P o PY, constitutivo solo, y viceversa, sino tan sólo las adecuadas para cada fin.

Por lo tanto y según todo lo anteriormente escrito, cabe la posibilidad de podernos hacer las siguientes preguntas con fundamento:

$1^{\text {a }} \quad$ ¿Es posible que una puzolana dada que ha demostrado no sólo no impedir el ataque de los iones sulfatos al cemento Portland que la acompaña sino además facilitarlo e incrementarlo incluso, pueda llegar a comportarse de forma totalmente contraria ante dicho ataque agresivo al serle añadida en mayores cantidades a este último, mayores al $40 \%$ haciendolo incluso sulfato-resistente en mayor o menor grado, al nuevo cemento de mezcla resultante cuando con anterioridad su "hermano mayor" claramente no lo era? 
$2^{\mathrm{a}} \quad$ ¿Es posible que la idea anterior se puede hacer extensiva cualitativamente y en idéntica medida, al resto de las puzolanas naturales y artificiales ensayadas, aunque lógicamente alcanzando dicha "idealidad" citada en la anterior pregunta con diferentes cantidades presentes de cada puzolana, según sea su carácter químico?

$3^{\text {a }} \quad$ En el supuesto posible de que la mayor presencia de puzolana en detrimento de cemento Portland y consecuentemente de portlandita $\mathrm{Ca}(\mathrm{OH}) 2$ proveniente de su hidratación, pudiera ser el motivo del aparente mejor comportamiento de dicha puzolana por alumínica que sea a partir de una cantidad presente de la misma en adelante en el cemento de mezcla ¿Cómo se comportaría en el ensayo correspondiente de RMC y RMF en mortero normalizado RC-75? ¿Llegaría a cumplir las especificaciones correspondientes establecidas al efecto y a 28 días del Pliego RC-75 y del nuevo Pliego RC-88 hoy Instrucción RC-16?

$4^{\mathrm{a}} \quad$ En el supuesto posible de que las preguntas anteriores formuladas, resultaren ser todas ellas afirmativas ¿Sería posible tomarlas todas ellas en sentido opuesto, es decir, disminuir la RS y aumentar las RM, sin más que añadirle razonadamente cal apagada $=\mathrm{Ca}(\mathrm{OH}) 2$ en polvo, al cemento puzolánico tipo CEM IV/B de la Instrucción RC-16 correspondiente, o cualquier otro material hidráulico incluso, que mediante dicha característica, origine hidróxido de calcio, $\mathrm{Ca}(\mathrm{OH}) 2$, semejante en alguna medida al que origina tras su hidratación el cemento Portland?

Estos cuestionamientos dan origen a esta investigación materia de Tesis Doctoral producto de los resultados obtenidos con adiciones de puzolanas inferiores al 40\% de Talero (1986). Esta investigación centra su estudio por tanto en el comportamiento Sulfático y Mecánico Resistente de Cementos Portland con elevados contenidos de Puzolana superiores al 40\%, su fundamento Químico y justificación de otras consecuencias posibles como la resistencia al ataque del CO2 del aire o Resistencia a la Carbonatación. 



\section{CAPÍTULO 4 OBJETIVOS}



A partir de las 4 preguntas planteadas con el fundamento debido al final del Capítulo anterior de esta Memoria y de todo lo expuesto en todos sus apartados, los objetivos de este trabajo de investigación objeto de Tesis Doctoral se pueden compendiar de la siguiente forma:

1.- Evaluar el desempeño de los cementos Puzolánicos de mezcla con niveles de sustitución superiores al $40 \%$ frente al ataque químico de Sulfatos.

Evaluar experimentalmente la resistencia sulfática de los cementos Puzolánicos de la vigente Instrucción para la Recepción de Cementos RC-16 y de la norma UNE-EN 197-1:2011 o cementos tipo CEM IV/A-SR y IV/B-SR, constituidos por cualquier cemento Portland ordinario (CPO) y cualquier puzolana natural ${ }^{*}$ y/o artificial ${ }^{1}$, esté contemplada o no incluso por dicha Instrucción, pero adicionada al mismo desde un nivel de reemplazo superior al $40 \%$, determinando por qué motivo son más resistentes aún al ataque de los sulfatos cuanto mayor es su nivel de reemplazo.

2.- Analizar el comportamiento sobre las resistencias Mecánicas a Compresión y Flexotracción de los cementos Puzolánicos de mezcla con niveles de sustitución superiores al $40 \%$.

${ }^{1}$ Dado el tema y los objetivos de esta investigación objeto de Tesis Doctoral, quedan excluidas las puzolanas que poseen un elevado contenido de sílice reactiva, SiO2r-(\%) > 80\%, tales como el humo de sílice, la nanosílice, las diatomeas y rocas opalinas y otras rocas semejantes: ágata, ópalo, jaspe, calcedonia, ónix, sílex, pedernal, etc. 
Analizar la afectación de las resistencias mecánicas a Compresión y Flexotracción de los cementos Puzolánicos adicionados con niveles de sustitución superiores al $40 \%$ referenciados en el anterior objetivo 1, explicando las razones fundamentales de su comportamiento.

\section{Examinar el comportamiento frente al ataque del CO2 del aire o carbonatación Negativa de} los Cementos Puzolánicos de mezcla con niveles de sustitución superiores al $40 \%$.

Examinar el comportamiento frente al ataque del $\mathrm{CO}_{2}$ del aire o Carbonatación Negativa, en condiciones favorables de humedad relativa y a temperatura ambiente, de los Cementos Puzolánicos adicionados con niveles de sustitución superiores al 40\% referenciados en el primer objetivo 1, determinando la razón de su comportamiento. 


\section{CAPÍTULO 5}

FUNDAMENTOS 

Antes de comenzar este Capítulo 5, Fundamentos, se ha de hacer constar que pese a ser el capítulo siguiente el correspondiente a la Selección y Caracterización de Materiales, una consecuencia lógica y directa de los capítulos Objetivos y Fundamentos a lo largo de la exposición de este último será obligado realizar algunas referencias concretas a aquellos y en especial al 6, causa por la que en cada ocasión que se necesite se habrá de acudir a la Tabla 6-1 del Capítulo 6, donde se encuentran agrupados ordenadamente los resultados del análisis químico cualitativo y cuantitativo de cada uno de ellos.

Es también muy importante para la comprensión y entendimiento de esta Investigación por parte del lector estudiar lo que he llamado Conceptos Fundamantales y los cuales se encuentran como el ANEXO I. Aquí podrán encontrar conceptos generales del cemento Portland, proceso de fabricación y composición, un capítulo muy importante como la Hidratación del cemento, formación de las fases mineralógicas del Clinker, Silicatos de Calcio, ( $\mathrm{C}_{3} \mathrm{~S}$ y $\mathrm{C}_{2} \mathrm{~S}$ ), Aluminatos Tricalcico, $\left(\mathrm{C}_{3} \mathrm{~A}\right)$, la fase ferrítica $\left(\mathrm{C}_{4} \mathrm{AF}\right)$ y su interacción. Conceptos de microestructura del cemento hidratado, la formación del Gel CSH, composición y estructura de la Portlandita, composición de las fases Aluminoferríticas, AFt y AFm, conceptos y propiedades 
de la fase líquida.

Un capítulo clave de entendimiento de las adiciones minerales al cemento Portland, la composición química de las adiciones Puzolánicas y su actividad Puzolánica, las diferentes clasificaciones de las adiciones Puzolánicas, las adiciones Puzolánicas más comunes y sus caracterizaciones.

También la comprensión de los procesos de hidratación en presencia de estas adiciones puzolánicas y finalmente el comportamiento del cemento Portland con adiciones minerales frente al ataque de diferentes medios agresivos. En este tema una profundización de la resistencia a los Sulfatos de los cementos con adiciones Puzolánicas y frente al ataque del $\mathrm{CO}_{2}$ del aire o carbonatación.

Puesto que esta investigación, objeto de Tesis Doctoral, es la continuación de la Tesis Doctoral titulada "Contribución al Estudio Analítico y Físico-Químico del Sistema: Cementos Portland-Puzolanas-Yeso", (Talero, 1986), para la consecución de los Objetivos citados en el Capítulo 4 de esta Memoria resulta necesario referirnos a las Conclusiones Generales que dicho autor obtuvo entonces y que constituyen el Anexo II de la Memoria de esta Tesis Doctoral.

\section{1.- Fundamentos Teóricos.}

\subsection{1.- Fundamentos Teóricos Principales.}

\section{Primer Fundamento Teórico}

Entrando aún más en el detalle comentado antes de la mayor aproximación al mejor comportamiento en RS de las probetas L-A 60/40 sobre las 70/30 y 80/20 "hermanas", por este orden y sea cual fuere la puzolana "Z" empleada y así ensayada y el CP (CPO o CPRS) con el que se mezcló, vistas en las Figuras II-1 a II-5., se consideró, de acuerdo con sus correspondientes resultados que se habían obtenido antes del ensayo de Frattini (Figuras II-6. a II-11.), que dicho mejor comportamiento se tenía y tiene que deber bastante más, con toda probabilidad y como decíamos:

* A que en tales probetas L-A 60/40 no se debe de haber alcanzado la cantidad necesaria y suficiente de portlandita en su fase líquida para superar permanentemente el valor del $\mathrm{pH}>$ 10,8 exigible y necesario de dicho origen, para la formación de toda la cantidad de ettringita expansiva y nociva que todo el contenido de $\mathrm{Al}_{2} \mathrm{O}_{3}{ }^{\mathrm{r}}(\%)$ de la fracción $40 \%$ de cada puzolana " $\mathrm{Z}$ " junto con todo el contenido de $\mathrm{C}_{3} \mathrm{~A}(\%)$ de la correspondiente fracción de cada $\mathrm{CP}$ con la que se mezcló, $60 \%$, son capaces de formar conjuntamente en un medio sulfático común -coprecipìtación-, que no, en cambio,

* A que en todas ellas se haya alcanzado más, mejor y en su totalidad la estequiometria que "gobierna" el "sistema" pasta selenitosa de cualquiera de las probetas L-A 60/40 fabricadas, lo que era y es imposible lógicamente:

112 
$\checkmark$ Porque la cantidad de $\mathrm{C}_{3} \mathrm{~A}$ reaccionante de la fracción 60\% del CPM (P ó PY) con la que se mezcló la puzolana es distinta en cada caso mientras que la de $\mathrm{Al}_{2} \mathrm{O}_{3}{ }^{\mathrm{r}-}$ de la fracción $40 \%$ de puzolana M (o de cualquier otra puzolana) es constante en todas sus probetas L$\mathrm{A}=60 / 40$. Lo que deberá de originar cantidades de ettringita-Total (ett-Total) y de $\Delta \varnothing(\%)$ muy distintos y, por consiguiente un Efecto Sinérgico Expansivo muy distinto también de una probeta L-A 60/40 a otra de dicha puzolana $\mathrm{M}$, y eso mismo fue lo que se produjo en la investigación de R. Talero (Martin-Luengo (1992); Rahhal y col. (2014); Talero (1992, 1996, 2002, 2003a, 2003b, 2005a, 2005b; 2005c, 2005d, 2005e 2007, 2008, 2009, 2010, 2011b); Talero y col. (1991, 1994); Talero y cols. $(1999,2016))$.

$\checkmark$ Porque la estequiometria así nos lo confirma, ya que en la probeta L-A P-1/M 60/40 se

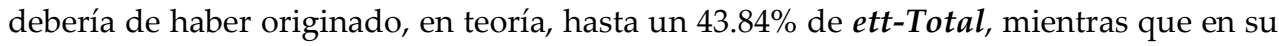
homónima PY6/ M 60/40, sólo un 7.83\%, siendo la diferencia entre ambas cantidades de ett-Totales originadas del $36.01 \%$, lo que no se corresponde, en absoluto, con la diferencia de $\Delta \varnothing_{730 \text { dias }}$ existente entre ambas probetas $\mathrm{L}-\mathrm{A}$, en este caso, del $10,75 \%$, siendo un poco mayor pero aún insuficiente en el caso de la probeta L-A PY4/ M 60/40, del $13.84 \%$, pero, en cualquier caso, siendo ambas cantidades muy distintas de la diferencia teórica de $\Delta \varnothing_{730 \text { dias }}(\%)$ que debería de haberse producido la cual debería de haber sido más próxima al valor de la diferencia de ambas cantidades de ett-Totales anteriores originadas, es decir, próxima al $36.01 \%$, y ese comportamiento no se produjo tampoco en las investigaciones de R. Talero (Martin-Luengo (1992); Rahhal y col. (2014); Talero (1992, 1996, 2002, 2003a, 2003b, 2005a, 2005b; 2005c, 2005d, 2005e 2007, 2008, 2009, 2010, 2011b); Talero y col. $(1991,1994) ;$ Talero y cols. $(1999,2016))$, sino el comportamiento contrario u opuesto al tener que primar, sobre todo, dicha diferencia de $\Delta \varnothing_{730 \text { dias }}(\%), \mathrm{y}$

$\checkmark$ Porque para mayor abundamiento, en el caso de las probetas L-A 60/40 del CPM acompañante correspondiente PY4 ó PY6, respectivamente, y puzolana M, deberían de haber tenido prácticamente igual o parecido $\Delta \varnothing(\%)$ a la edad de 730 días, dado que la ett-T en ambos casos deberá de ser igual prácticamente por ser la ett-rf constante y la ettlf prácticamente nula por ser prácticamente nulos los contenidos potenciales de $\mathrm{C}_{3} \mathrm{~A}(\%)$ de ambos cementos Portland matrices PY4 y PY6. Y ese comportamiento tampoco se ha producido sino todo lo contrario una vez más, pues el $\Delta \varnothing_{730 \text { días }}$ de la probeta L-A PY4/ M 60/40 ha sido del $12.4 \%$, y el $\Delta \varnothing_{730}$ días de la probeta L-A PY6/ M 60/40 ha sido de $25.56 \%$, es decir, un poco más del doble, ergo, bastante dispares, habiendo sido mayor el del PY6/ M 60/40, muy probablemente por tener su CP acompañante correspondiente PY6 un $79.43 \%$ de $\mathrm{C}_{3} \mathrm{~S}$, esto es un $21.24 \%$ de $\mathrm{C}_{3} \mathrm{~S}$ más que el PY4. Lo que le tuvo que posibilitar poder tener aquél de origen en su fase líquida, mayor disponibilidad de reserva portlandítica y, por consiguiente, que la $\left.[\mathrm{CaOH})_{2}\right]$ necesaria y suficiente en la fase líquida de su probeta sea siempre mayor durante el transcurso del ensayo (y su $\mathrm{pH}>10.8$ también) y durante mucho más tiempo para facilitar así una mayor formación de ett-rf de origen $40 \%$ de $\mathrm{M} \mathrm{y}$, consiguientemente, un mayor $\Delta \varnothing(\%)$ de su probeta L-A en este caso la PY6/ M 60/40, sobre la PY4/ M 60/40, como así se produjo una vez más en la 
referida investigación de R. Talero (Martin-Luengo (1992); Rahhal y col. (2014); Talero (1992, 1996, 2002, 2003a, 2003b, 2005a, 2005b; 2005c, 2005d, 2005e 2007, 2008, 2009, 2010, 2011b); Talero y col. (1991, 1994); Talero y cols. $(1999,2016))$. Y todo ello sin olvidar tampoco y, por otra parte, la ettringita de muy lenta formación, ett-vlf, o de origen $\mathrm{C}_{4} \mathrm{AF}$ y sus s.s. que también puede formarse mucho más tarde que pronto a diferencia de la de origen $\mathrm{C}_{3} \mathrm{~A}$.

De todo lo anterior cabe deducir finalmente, por tanto, que un mayor reemplazo de puzolana por CP por encima del $40 \%$ en peso: 50/50, 40/60, 30/70, etc., podría asegurar la no formación de toda o casi toda o al menos una gran parte de la cantidad total de ettringita previsible de cualquier origen y etiología que se podría formar, como se había formado antes en la referida investigación Talero (1986) cuando no superó nunca el 40\% de reemplazo, y consiguientemente, podría asegurar una menor e incluso nula expansividad resultante de las correspondientes probetas L-A 50/50, 40/60, 30/70, etc. . Pero ¿Con tales porcentajes de reemplazo tan elevados de puzolana, sea la que fuere, por $\mathrm{CP}$, se llegarían realmente a cumplir más pronto que tarde y según sea el carácter químico de la puzolana que constituya a dichos cementos de mezcla, las especificaciones reglamentadas existentes al efecto de resistencias mecánicas características a compresión (RMC) y Flexotracción (RMF) muy especialmente, en probetas de mortero normalizado $1: 3$ de $4 \times 4 \times 16 \mathrm{~cm}$, a las edades de 1, 3, 7, y 28 días e incluso a la edad de 90 días si fuera necesario para determinadas construcciones? Porque a tal efecto no se ha de olvidar que el mejor comportamiento en RS de la puzolana cuando su porcentaje de reemplazo por CP supere, en mayor o menor medida, el $40 \%$, se ha argumentado antes que seguramente es debido a la considerable y muy considerable incluso actividad puzolánica que genera y desarrolla la puzolana desde edades muy tempranas según de alumínico sea su carácter químico una vez más. Lo que habrá que confirmar mediante esta investigación ya que conllevará ineludiblemente, por una parte, una disminución considerable de portlandita de la fase líquida de su pasta e, irremediablemente también,una disminución proporcional del espesor, la dureza y la consistencia microestructural de la interfase y de la zona de transición a la interfase (ZTI) árido silíceo (de su referido mortero normalizado correspondiente en este caso), pasta de cemento (puzolánico Tipo CEM IV/B especialmente en este caso también), como R. Talero y cols. habían justificado antes mediante filler silíceo (Talero, (2012b, 2013); Delgado (2013)), y se puede deducir con facilidad de las conclusiones obtenidas por Delgado de las investigaciones que realizó y que fueran objeto de su Tesis Doctoral (Delgado, 2013), investigaciones ambas que justifican ahora la respuesta a la cuestión planteada o pregunta formulada que es la siguiente: Presumiblemente NO y, en particular, a 28 y/ó a 90 días como así lo atestiguan y preconizan además los correspondientes resultados experimentales obtenidos por R. Talero (Martin-Luengo (1992); Rahhal y col. (2014); Talero (1992, 1996, 2002, 2003a, 2003b, 2005a, 2005b; 2005c, 2005d, 2005e 2007, 2008, 2009, 2010, 2011b); Talero y col. (1991, 1994); Talero y cols. $(1999,2016))$, con probetas de mortero normalizado (1:2,75 de árido silíceo tipo $\alpha$-cuarzo) ASTM C452 de 1x1x6 cm de estos y de otros cementos de mezcla PA y PUZ que ensayó, donde, sobre todo y por lo general, a las edades intermedias y finales del ensayo, las probetas citadas de los cementos de mezcla 60/40 
fueron las que menores valores de RMC y RMF tuvieron en casi todos los casos. Y previsiblemente los deberán de tener menores valores aún que su correspondiente valor característico a 28 y/ó 90 días, si tal adición de puzolana cualquiera reemplaza al CP en cantidad superior y bastante superior incluso al 40\% según sea de alumínico, una vez más respectivamente, su carácter químico, como se va a demostrar en esta investigación.

Y otro tanto deberá de ocurrir con la carbonatación puesto que la experiencia en España ha demostrado que deja pronto de ser positiva para el caso de los CP puros al tornarse en negativa con tan sólo $20 \%$ de reemplazo por ceniza volante o por puzolana natural (Pliego de cementos RC-75), y seguramente tanto más negativa deberá de resultar aún cuanto mayor sea el porcentaje de reemplazo de CP por puzolana, lógicamente, lo que también se va a demostrar en esta investigación.

No obstante y a pesar de todo, dicho comportamiento peor en RMC, en RMF y en carbonatación negativa podrá revertirse segura y fácilmente sin más que añadirle Cal Apagada hidróxido de calcio, $\mathrm{Ca}(\mathrm{OH})_{2}$, en estado sólido $(=\mathrm{CH})$ - a los nuevos cementos de mezcla binarios anteriores: Cemento PY-n (ó P-nō)/Puzolana "Z" 50/50, 40/60, 30/70 y 20/80, ..., más nunca, en cambio, Cal Hidráulica, lógicamente, ya que solaparía o enmascararía la hidraulicidad derivada de la propia reacción puzolánica de los correspondientes contenidos de $\mathrm{SiO}_{2}{ }^{\mathrm{r}}-(\%)$ y de $\mathrm{Al}_{2} \mathrm{O}_{3}{ }^{\mathrm{r}}-(\%)$ muy especialmente y, sobre todo, de la Puzolana con dicha Cal Apagada que se le adicione. $\mathrm{Y}$ tanta más cantidad habría que añadirle de Cal Apagada, cuanto mayor hubiera sido su porcentaje de reemplazo, es decir, la cantidad presente de adición puzolánica o contenido de puzolana " $Z$ ", y menor, por consiguiente, la de cemento Portland PY-no ó P-no, para de este modo, poder proporcionarle:

- a los nuevos cementos de mezcla binarios mencionados antes, o mejor quizás de dos componentes cementantes distintos, la cantidad de basicidad portlandítica que tanto necesitaban pero que les faltaba la cual les será suplida en esta investigación mediante Cal Apagada, $\mathrm{Ca}(\mathrm{OH})_{2}, \mathrm{y}$

- a la cantidad de puzolana "Z" que los constituye en cada caso, el medio básico necesario y suficiente en el tiempo pero de origen Cal Apagada, como se acaba de decir, para que la misma pueda mostrar su auténtico y verdadero "carácter" químico ó "intencionalidad de comportamiento", ante un medio químico agresivo, o no, determinado (en este caso la agresividad de los sulfatos de acuerdo con esta investigación objeto de Tesis Doctoral), según Talero (1986), para convertirlas finalmente en mezclas ternarias o mejor quizás de tres componentes distintos: Cemento Portland PY-n ${ }^{\circ}($ ó P-nº + Puzolana "Z" + Cal Apagada.

Pero en tal caso, no se deberá olvidar tampoco, por otra parte, que si los dos componentes finales de la misma, es decir, Puzolana "Z" + Cal Apagada, se mezclaran entre sí previamente y por separado, se obtendría una mezcla más o menos hidráulica -tipificada al efecto y entre otras, por la norma ASTM C 593-06 para la caracterización mecánica de la(s) puzolana(s)-, cuyos contenidos en óxidos ácidos, $\mathrm{SiO}_{2}, \mathrm{Al}_{2} \mathrm{O}_{3}$ y $\mathrm{Fe}_{2} \mathrm{O}_{3}$, y básico, $\mathrm{CaO}$, fundamentalmente, podrían llegar a ser similares, en su rango posible de variabilidad, a los que ya de por si presentan las 
escorias siderúrgicas como tales (NF P 18-506 - 1992; ASTM Standard C989-94a; UNE-EN 151671:2008), las cuales y como es sabido, lo presentan comprendido entre los valores que se encuentran en la Tabla 5-1.

TABLA 5-1.-ENTORNOS DE VARIABILIDAD DE LOS CONTENIDOS DE ÓXIDOS ÁCIDOS Y BÁSICOS FUNDAMENTALES DE LAS ESCORIAS GRANULADAS DE ALTO HORNO

\begin{tabular}{cccc}
\hline $\begin{array}{c}\text { Óxidos Ácidos y Básicos } \\
\text { Fundamentales }\end{array}$ & Valor Máximo (\%) & Valor Mínimo (\%) \\
\hline \multirow{3}{*}{ Ácidos } & $\mathrm{SiO}_{2}$ & 40 & 27 \\
& $\mathrm{Al}_{2} \mathrm{O}_{3}$ & 24 & 5 \\
\multirow{2}{*}{ Básico } & $\mathrm{Fe}_{2} \mathrm{O}_{3}$ & 5 & 0 \\
& $\mathrm{CaO}$ & 52 & 28 \\
\hline
\end{tabular}

Y estos valores límite, máximos y mínimos, expuestos serían fácilmente alcanzables -y en especial los de $\mathrm{SiO}_{2}, \mathrm{Al}_{2} \mathrm{O}_{3}$ y $\mathrm{CaO}$ - sin más que añadirle de un 30\% a un $40 \%$ ó 45\%, según casos, en peso, de cal viva $\mathrm{CaO}$, o mejor de su equivalente en $\mathrm{Cal}$ Apagada, $\left[\mathrm{Ca}(\mathrm{OH})_{2}\right.$ sólido], a cualquiera de las puzolanas naturales, O, A, C y/o artificiales, CV19, CV10 y M, que se van a emplear justificadamente una vez más de nuevo en esta investigación objeto de Tesis Doctoral, como se verá en el Capítulo 6. Con lo que de este modo, los contenidos "teóricos" resultantes de óxidos: ácidos, $\mathrm{SiO}_{2}, \mathrm{Al}_{2} \mathrm{O}_{3}$ y $\mathrm{Fe}_{2} \mathrm{O}_{3}$ y básico, $\mathrm{CaO}$, fundamentalmente, de las mezclas binarias anteriores respectivas, Puzolana "Z" + Cal Apagada, en el supuesto de haberles añadido a todas y cada una de ellas un 30\% en masa, de cal viva, o mejor su equivalente en cal apagada, $\mathrm{Ca}(\mathrm{OH})_{2}$, $46.25 \%$ (en cuyo caso habría que poner de puzolana "Z" un 53.75\% en masa) pasarían a ser como sigue, véase la Tabla 5-2 (Puzolana "Z" / CH = 53.75\% / 46.25\% = 1.16).

Y como se puede ver, la composición química, cuali y cuantitativa (\%), de las posibles escorias siderúrgicas "teóricas" resultantes caen prácticamente dentro de los correspondientes entornos de variabilidad posibles de los de las escorias siderúrgicas expuestos en la Tabla 5-1. Y tales mezclas silico-alumínico-calcáreas expuestas en la Tabla 5-2. habrían de ser más semejantes aún a las propias escorias siderúrgicas, si las mismas hubieran sufrido un calentamiento hasta su fusión, equivalente al que sufren estas últimas en un Alto Horno de fabricación de arrabio seguido de su enfriamient brusco con agua o con aire. Con lo que al enfriarlas bruscamente podrían originar incluso además de la notabilísima fracción vítrea, alguna otra escasamente cristalina y perteneciente al vasto mundo de las "melilitas", cuyo componente alumínico concretamente: desde el $\mathrm{C}_{2} \mathrm{~A}$ al $\mathrm{C}_{12} \mathrm{~A}$ z en contadas ocasiones serían, junto al propio $\mathrm{CA}$ amorfo y $\mathrm{C}_{2} \mathrm{AS}$ que también las constituyen y en mayor cantidad incluso, las fuentes"alumínicas", en este caso, para la formación de ettringita expansiva según el diagrama ternario estable y meta-estable de Eitel (1957).

Y de todos los métodos aceleradores de ensayo que emplean cal apagada para la caracterización mecánica de puzolanas naturales y artificiales, el que figura en la norma ASTM C593-06 es el que utiliza una mayor relación (cantidad de Puzolana "Z" (=360 g) / cantidad de Cal Apagada $(=\mathrm{CH}=180 \mathrm{~g})=2$ para preparar un mortero 1:2.75, mientras que el método equivalente y propio del IETcc que ya preconizara D. Pablo García de Paredes (†), el valor de la citada relación 
es de $(3 / 1)=3$ y el tipo de mortero a preparar es 1:3.

TABla 5-2. COMPOSICiÓN QUímica, CUALI Y CUANTITATIVA (\%), DE POSIBLES ESCORIAS SIDERÚRgicAs "TEÓRICAS" RESUlTANTES AL AÑADIRLE 45.25\% EN MASA DE CAL APAGADA, $\mathrm{CA}(\mathrm{OH})_{2}(\approx 35 \%$ EN MASA DE CAL VIVA, $\mathrm{CaO})$ A LAS SEIS PUZOLANAS UTILIZADAS EN ESTA INVESTIGACIÓN

\begin{tabular}{cccccccc}
\hline \begin{tabular}{c} 
Óxidos Ácidos y Básicos \\
\multicolumn{2}{c}{ Fundamentales }
\end{tabular} & $\mathrm{O}$ & $\mathrm{CV} 19$ & $\mathrm{~A}$ & $\mathrm{C}$ & $\mathrm{CV} 10$ & $\mathrm{M}$ \\
\hline \multirow{2}{*}{ Ácidos } & $\mathrm{SiO}_{2}$ & 33,44 & 33,49 & 30,63 & 40,14 & 36,53 & 54,45 \\
& $\mathrm{Al}_{2} \mathrm{O}_{3}$ & 10,26 & 22,19 & 14,33 & 14,89 & 21,96 & 17,11 \\
\multirow{2}{*}{ Básico } & $\mathrm{Fe}_{2} \mathrm{O}_{3}$ & 10,24 & 11,87 & 8,92 & 2,31 & 3,13 & 0,88 \\
& $\mathrm{CaO}$ & 45,48 & 39,03 & 46,11 & 37,38 & 37,86 & 35,63 \\
\hline
\end{tabular}

Por consiguiente y de acuerdo con los cálculos teóricos realizados anteriormente y que han dado como fruto los valores que figuran en la Tabla 5-2, dicha relación para las seis puzolanas mencionadas sería $1,16=53.75 \% / 46.25 \%$. Por lo que si la hipótesis de trabajo de partida se lograra demostrar no con dicha relación de 1,16, ni tampoco con la de la norma ASTM C593-76a (=2) y ni mucho menos tampoco con la del propio $\operatorname{IETcc}(=3)$, sino con un valor de la relación Puzolana "Z" / Cal Apagada mucho mayor aún si fuera posible, por ejemplo, igual a 4, 5, 6, 7, etc., y aún a costa de tener que ir aparentemente en contra de lo dicho al respecto con anterioridad cuando decíamos que "a mayor cantidad de puzolana "Z" añadida, mayor cantidad de cal apagada a añadirle", quedaría más y mejor demostrada aún la veracidad de la citada hipótesis de trabajo de partida o "hipótesis motriz" de esta investigación. Y para ello se habrían de tener en cuenta una vez más de nuevo, las tipologías de puzolanas naturales y artificiales que R. Talero tuvo que seleccionar, con el fundamento debido (el diagrama ternario estable y meta-estable de Eitel (1957) acabado de mencionar) para poder realizar sus investigaciones de ataque de los sulfatos también a CP con puzolanas naturales y artificiales hasta un $40 \%$ de reemplazo y que fueron objeto de su 1a Tesis Doctoral (Talero, 1986) según las cuales aquellas puzolanas naturales y artificiales que posean carácter químico más "silícico" que "alumínico" -caso de la O, CV19 y A, habrían de necesitar quizás mayores cantidades de cal apagada aún dentro de la disminución gradual de la misma de una mezcla a la siguiente "hermana" con más puzolana "Z", para así poder demostrar su "intencionalidad de comportamiento" en un medio químico agresivo-selenitoso en el caso que nos ocupa-, o no, determinado; mientras que aquellas otras con el carácter químico predominante contrario, o sea, más"alumínico" que "silícico" -caso de la C, CV10 y M mayormente, necesitarían quizás menores cantidades de cal apagada aún para igual fin $\mathrm{y}$, por consiguiente, permitirían quizás poder preparar bastante mayor número de mezclas que contendrían cada vez más puzolana"alumínica" y menos cal apagada para revertir así su buen comportamiento aparente en RS pero no tan bueno, sino todo lo contrario, en RMC y RMF y en carbonatación negativa que dejarían de serlo al estar ya más cercano a la realidad.

Por consiguiente y de acuerdo con lo anterior, la relación Puzolana "Z" / Cal Apagada 
habría de aumentarse aún más en este último caso, y con la adición de puzolanas "alumínicosilícicas" y "alumínicas" más todavía, y todo lo contrario en el caso de las puzolanas "sílicoaluminicas" por cuyo motivo se consideró que, en cualquier caso, la citada relación debería estar comprendida entre 3 y 6,5 a lo sumo que, por redondeo se fijaría en 7 finalmente, véase la Tabla 5-3. De aquí que los cementos de mezcla binarios, o mejor quizás, de dos componentes cementantes: cemento Portland y puzolana "Z", y ternarios, o mejor quizás, de tres componentes cementantes: cemento Portland, puzolana "Z" y cal apagada, a ensayar, deberían de ser los siguientes, véase la Tabla 5-3.

\section{Segundo Fundamento Teórico}

En función de los Objetivos de esta investigación y de todo lo escrito hasta el momento sobre los Fundamentos para alcanzarlos, se estableció como Hipotesis de Trabajo la siguiente:

Considerar que en los cementos de mezcla constituidos por cemento Portland, P ó PY, y puzolana(s) únicamente, con un contenido de esta(s) última(s) comprendido entre el $40 \%$ y el $80 \%$ en peso de aquél Po PY, el auténtico comportamiento, actuación y efecto, sobre todo, de aumentar o disminuir su RS por una mayor y menor, respectivamente, presencia de la(s) misma(s) en dicha mezcla lo que irremediablemente deberá de conllevar: 


\section{TAbla 5-3.- Relación PuZOlana "Z" / CAL Apagada ó Relación AP "Z" / CH}

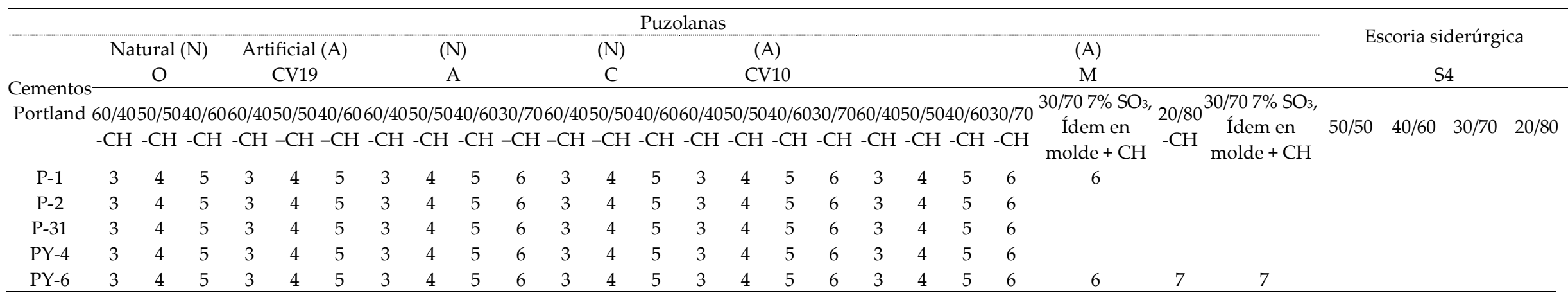


- por una parte, disminuir y aumentar, respectivamente también, el espesor, la dureza y la consistencia microestructural de la interfase y de la zona de transición a la interfase (ZTI) pasta-árido silíceo correspondiente de su mortero normalizado 1:3 que se utilizará en esta investigación para determinarles sus $\mathrm{RMC}_{\mathrm{x} \text { días }} \mathrm{y} \mathrm{RMF}_{\mathrm{x} \text { días, }}-\mathrm{y}$ las del hormigón y mortero fabricados con este $\mathrm{u}$ otro tipo de árido de naturaleza silicea también, $\mathrm{y}$

- por otra, aumentar en menor o mayor medida, respectivamente una vez más, su degradación por carbonatación negativa,

Por tanto, su comportamiento frente al ataque de los Sulfatos deberá de ser consecuencia directa del simple efecto Fïsico y Químico de su porcentajede reemplazo, en peso, por aquél, y de su especial y/o particular composición química reactiva y morfología y, en definitiva, del carácter químico alumínico más o menos acusado de la puzolana y de la cantidad y rapidez de la actividad puzolánica derivada de él según sea su estado físico amorfo o vítreo, respectivamente. Y dicho comportamiento se deberá de manifestar a través del nuevo conjunto de la pasta del mortero normalizado en este caso, de cemento puzolánico Tipo CEM IV/A, Tipo CEMIV/B y de cemento Compuesto Tipo V pero constituido por CP y puzolana " $\mathrm{Z}$ " solamente aunque no lo contemple la vigente Instrucción RC-16, los cuales se prepararán expresamente para esta investigación como "blended cements".

De este modo y al reemplazar, a igualdad de peso, parte del cemento Portland, P o PY, base o matriz, por puzolana hará que la puzolana actúe, en principio, de "diluyente" o "dispersante" físico de aquél y, de modo tal, que el nuevo cemento de mezcla normalizado originado PA o Tipos CEM II/A- y B-P, -Q, -V, -W y -T o PUZ o Tipos CEM IV/A y CEM IV/B, dado el trabajo de investigación que nos ocupa, así como también su posible mortero e incluso hormigón correspondientes, contendrán, por unidad de peso y volumen, menor porcentaje de fracción Portland y, por consiguiente:

- de $\mathrm{C}_{3} \mathrm{~A}$, por una parte, con las ventajas al caso de una menor cantidad de formación de ettringita por su causa ante el ataque de aguas selenitosas, ergo, un posible efecto expansivo y/o disruptivo menor de su conjunto, ante dicho ataque químico agresivo, y una probable RS mayor del cemento de mezcla resultante, y

- de $C_{3} S, C_{2} S$ y standard de cal, por otra parte, con las ventajas también al caso anterior pero corregidas y aumentadas, dado que y según se dijo en el Capítulo 1, para que se pueda llegar a formar y mantener la ettringita formada se hace necesario además de sus compuestos reaccionantes formadores, que el valor del $\mathrm{pH}$ del medio portlandítico que la rodea sea $>10.8$, el cual si bien puede llegar a alcanzarse de inmediato en la fase líquida acuosa que rodea un grano de clínker Portland tras su hidratación, bien pudiera quizás no mantenerse en el tiempo tras la acción puzolánica de la puzolana "Z" que lo acompañe mezclado con él, máxime si la misma es eminentemente "alumínica"en carácter químico (en mayor o menor medida lo que la faculta para poder ser utilizadas en esta investigación como se verá en el Capítulo 6) o eminentemente "silícica"(tipo humo de sílice que no diatomeas ni similares las cuales, no obstante, en cualquier caso y sean las que fueren no se considerarán ni utilizarán, por tanto, 
en esta investigación por contravenir su título y objetivo primordial, puesto que todas ellas protegen de por si químicamente al CPO frente al ataque de los sulfatos, por su muy elevado contenido de $\mathrm{SiO}_{2}{ }^{\mathrm{r}-}(\%)$ pero en cantidad de reemplazo de cada una acorde con el contenido de $\mathrm{C}_{3} \mathrm{~A}(\%)$ de dicho $\left.\mathrm{CPO}\right)$, y si su presencia está por encima del $40 \%$ en peso, como es el caso que nos ocupa y que investigamos. Aunque, por otra parte, todo ello generará también una serie de efectos colaterales no deseados, puesto que dicho posible descenso del valor del $\mathrm{pH}$ de la fase líquida de la pasta cementante del mortero y del hormigón correspondientes, no facilitará:

- el reforzamiento y consistencia de la unión pasta-árido silíceo ni la fraguabilidad y endurecimiento en el tiempo de dicha unión ni el de la propia pasta cementante de aquellos y con ella de todo el conjunto, mortero u hormigón del que forme parte, lo que se deberá traducir, por tanto, en un descenso notable y/o muy notable incluso en ocasiones, de sus valores de RM y en especial los de RMF mayormente, por la razón acabada de citar,

- ni tampoco que la carbonatación positiva que sufre la pasta del CP puro se mantenga en el tiempo porque no se mantiene al tornarse negativa más tarde que pronto según sea una vez más de acusado el carácter químico alumínico de la puzolana y su porcentaje de reemplazo, sino más bien todo lo contrario.

En definitiva y para resumir, este aumento de la RS y de la carbonatación negativa y disminución de las RM de un cemento Portland cuando se reemplaza por puzolana en cantidades mayores del $40 \%$, debe de ser consecuencia:

- En primer lugar, del efecto de dilución Física que debe de sufrir e imperar sobre la formación de ettringita y la unión pasta-árido silíceo, al actuar en principio e hipotéticamente la puzolana sólo como un INERTERs e INERTErm, es decir, a más puzolana añadida menos ett-lf formada de origen $\mathrm{C}_{3} \mathrm{~A}$ del $\mathrm{CP}$ y, además, menor espesor y dureza de la unión pasta-árido silíceo de ella derivada y producida en su mortero u hormigón y,

- En segundo lugar y, sobre todo, del efecto químico derivado de la actividad puzolánica que logra generar y desarrollar la considerable cantidad de puzolana con la que se mezcló. Lo que se deberá de traducir irremediablemente y más pronto que tarde, en un descenso considerable de la portlandita en la fase líquida de su pasta que es la que provoca, en definitiva, el referido aumento de RS y la referida disminución de RM además de promoverle su mayor degradación ulterior por carbonatación negativa.

Por lo que como consecuencia de esta previsible dualidad de acciones a un mismo tiempo de las puzolanas naturales y artificiales en porcentajes de reemplazo mayores del $40 \%$, beneficiosa por protectora, en cuanto a RS se refiere, y perjudicial, en cuanto a RM se refiere y entre ellas la RMF mayormente, y en cuanto a la mayor carbonatación negativa que produce, se la puede denominar Aumento de la RS (beneficiosa) y de la carbonatación negativa (perjudicial) y Disminución de la RM (perjudicial también) de un cemento Portland mediante su sustitución FÍSICO-QUÍMICA, a igualdad de peso, por puzolana en cantidades de reemplazo mayores del $40 \%$, la formación de ettringita de cualquier origen y etiología deberá de disminuir y el espesor y 
la dureza de la unión pasta-árido silíceo también mientras que, por el contrario, la carbonatación negativa deberá de aumentar. Lo que R. Talero denominó el efecto químico INVERSO de la sustitución física de cemento P ó PY matriz por puzolana alumínica más que silícica, en elevadas cantidades (> 40\% de reemplazo), o efecto químico INVERSO a secas, a pesar de que en esta otra situación sus partes más reactivas, la $\mathrm{Al}_{2} \mathrm{O}_{3}{ }^{\mathrm{r}-} \mathrm{y}$ la $\mathrm{SiO}_{2}{ }^{\mathrm{r}-}$, hayan intentado reaccionar químicamente como lo hacían antes, lo que resulta menos posible al no haber en la fase líquida cantidad de portlandita, $\mathrm{Ca}(\mathrm{OH})_{2}$, necesaria y suficiente para ello en ese momento, por lo que se comportan más bien como INERTERs e INERTErm. Y no sólo dicha fracción más reactiva de la puzolana cuanto más la menos o nada reactiva por ser cristalina. Por consiguiente y de acuerdo con lo anterior, a más puzolana con carácter químico alumínico más que silícico que se añada en porcentaje de reemplazo por $\mathrm{CP}>40 \%$ :

- Menor cantidad ettringita de cualquier origen y etiología se deberá de formar, ergo, su RS deberá de aumentar,

- Menor habrá de ser el espesor y la dureza de la unión pasta-árido silíceo de su mortero u hormigón que la contenga y que hayan sido fabricados con dicho tipo de áridos, ergo, menor habrá de ser su RMC y RMF, y

- Mayor deberá de ser aún la carbonatación negativa que provoque.

Por todo ello y teniendo en cuenta todo el fundamento teórico anterior, este trabajo se ha circunscrito fundamentalmente a la sustitución física del ion $\mathrm{Al}^{3+}$ del $\mathrm{C}_{3} \mathrm{~A}$ principalmente de un cemento Portland, por el ion $\mathrm{Si}^{4+}, \mathrm{Al}^{3+}, \mathrm{Fe}^{3+}$, etc., en forma de puzolanas "silícico-alumínicas", "alumínico-silícicsa" y "alumínicas", mayormente, en caráter químico, según Talero (1986) pero no, en cambio, en forma de puzolanas "silícicas"al contravenir, como se ha dicho antes, estas otras puzolanas naturales y artificiales el título y los Objetivos de esta investigación objeto de Tesis Doctoral. De aquí que en esta investigación y a diferencia de la que realizó dicho autor con motivo de su $1^{\underline{a}}$ Tesis Doctoral mencionada (Talero, 1986), no ha habido necesidad alguna de tener que utilizar también puzolanas "silícicas" naturales (tipo diatomeas, ópalos, etc.), ni artificiales tampoco (tipo humo de sílice, nanosílice, los inquemados de la paja y cáscara de arroz, del bagazo de la caña de azúcar y del bambú, etc.) para tratar de alcanzar los objetivos previstos, ya que dichos tipos de puzolanas por su muy especial y particular composición química reactiva, forma y tamaño medio de sus partículas y su textura íntima y, en definitiva, su composición químicofísica, poseen un elevado contenido de $\mathrm{SiO}_{2}{ }^{\mathrm{r}}(\%)$ o sílice amorfa, en estado vítreo casi toda ella, mejoran o aumentan ya de por sí y por lo general, la RS de los cementos Portland P y PY con los que se mezclen hasta un $40 \%$ en peso (aunque la cantidad óptima de cada tipo al que reemplacen ha de ser acorde con su contenido de $\left.\mathrm{C}_{3} \mathrm{~A}(\%)\right)$ :

- por acción FÍSICA: por dilución o dispersión del contenido de $\mathrm{C}_{3} \mathrm{~A}$ del cemento Portland con el que se mezclara, $y$

- por acción QUÍMICA propiamente dicha: por formación de geles tobermoríticos protectores del ataque sulfático, según Talero (1986). 
$\mathrm{Y}$ si en el presente trabajo lo que se pretende demostrar es que la $\mathrm{Al}_{2} \mathrm{O}_{3^{\mathrm{r}-}}$ de las puzolanas naturales y artificiales en cantidades de reemplazo $>40 \%$, es tanto menos nociva ante el ataque del yeso por el menor ESE que origina (Talero, 1986) con el C 3 A de la fracción Portland que la acompaña debido, sobre todo, a la falta de la cantidad de portlandita necesaria y suficiente en la fase líquida de su correspondiente probeta L-A, cuanto mayor es su presencia en el cemento, no ha lugar, por consiguiente, utilizar aquellas otras que por formar muchos geles tobermoríticos, por poseer mucha $\mathrm{SiO}_{2}{ }^{\mathrm{r}}$, impiden, por tal motivo "protector", de dicho ataque químico agresivo.

\section{Tercer Fundamento Teórico}

En función de lo dicho en el $4^{\circ}$ párrafo del Primer Fundamento Teórico se ha tratado de convertir cualquier cemento Portland de elevada, o no, resistencia al ataque de los iones sulfato, en otro nuevo cemento normalizado, puzolánico Tipo CEM IV/B según la vigente Instrucción de cementos RC-16 en este caso, mediante la adición seriada de las puzolanas naturales y artificiales seleccionadas anteriores en cantidades $\geq 40 \%$, en peso de cemento Portland P o PY puro:

- cuyo grado de resistencia sulfática (RS) a dicho ataque químico agresivo fuera mayor,

- cuyo grado de espesor y dureza de la unión pasta-árido silíce fuera tal que traducidos en valores de RMC y RMF especialmente, de sus correspondientes probetas de mortero normalizado (Talero, 1986) tipo UNE-EN 196-1:2005, la 1ª ó RMC habrá de alcanzar un valor mínimo permisible de $175 \mathrm{Kp} / \mathrm{cma}$ la edad de 28 días,para los cementos Puzolánicos de esta investigación, Tipo IV/A, IV/B y cementos Compuestos Tipo V con puzolana nada más, por la razón siguiente: al ser la principal Aplicación Técnica que resulte finalmente de esta investigación objeto de Tesis Doctoral, aplicable mayormente a las construcciones futuras de Estructuras de Edificación de hormigón armado pero de poco porte, no obstante, que se tengan que asentar además en terrenos selenitosos necesariamente, tales como urbanizaciones constituidas por promociones de chalets individuales, pareados o adosados $\mathrm{u}$ otras viviendas y construcciones semejantes de poco porte y altitud como talleres, polígonos industriales, agrícolas, ganaderas y mineros, así como sus respectivas naves, serrerías, granjas de animales, graneros, silos y cobertizos y otros edificios semejantes, con admitir, de acuerdo con la Instrucción para el Proyecto y la Ejecución de Obras de Hormigón en Masa y Armado EH-91 (dejó de estar en vigor en España en el año 1998), como Resistencia de Proyecto el valor mínimo admisible de $175 \mathrm{Kp} / \mathrm{cma}$ la edad de 28 días bastaría. Y a tal efecto hay que recordar que dicha Instrucción tipificaba entonces en su Artículo 26.2., las resistencias mecánicas de los hormigones del siguiente modo: H-125, H-150, H-175, H-200, H-250, H-300, H-350, H-400, H450, y H-500, en la que los números indican la resistencia mecánica característica especificada del hormigón a compresión a 28 días de edad, expresada en $\mathrm{Kp} / \mathrm{cm}^{2}$. Aclarando además dicha Instrucción en sus Comentarios que "Los tipos H-125 a H-250 se emplean, generalmente, en estructuras de Edificación y los restantes de la serie recomendada encuentran su principal aplicación en importantes obras de Ingeniería Civil y Prefabricación".

En cambio, la vigente instrucción de Hormigón Estructural tipifica a los hormigones en su Artículo 39.2. conforme a esta otra serie: 20, 25, 30, 35, 40, 45, 50, 55, 60, 70, 80, 90 y 100, en la 
que las cifras indican la resistencia mecánica característica especificada del hormigón a compresión a 28 días de edad, expresada en $\mathrm{N} / \mathrm{mm}^{2}$, aclarando además dicho Artículo que "La resistencia de $20 \mathrm{~N} / \mathrm{mm}^{2}$ se limita en su utilización a hormigones en masa". De lo que se deduce, por tanto, que el resto de hormigones de dicha serie se utilizarán armados.

Es decir, el tipo mínimo de hormigón armado de dicha serie que se ha de utilizar obligatoriamente en la actualidad para Edificación es el $25 \mathrm{~N} / \mathrm{mm}^{2}$, mientras que en el caso de la Instrucción EH-91 dicho valor era precisamente el tipo máximo ó $\mathrm{H}-250 \mathrm{Kp} / \mathrm{cm}^{2}$, por lo que al tratarse en este caso y como se ha dicho antes, de construcciones de Edificación de poco porte se adoptaría como valor límite mínimo para los objetivos de esta investigación, el valor medio entre H-125 y H-250 que no es otro que el H-175, es decir, un valor mínimo de 175 $\mathrm{Kp} / \mathrm{cm}^{2}$ de RMC a la edad de 28 días, aunque en este caso y para esta investigación, en probetas de mortero normalizado del Pliego RC-75.

Además y teniendo en cuenta una vez más y, por otra parte, el denodado esfuerzo que los fabicantes de cemento vienen haciendo, de un tiempo a esta parte, para minimizar lo más posible la causa principal de la fabricación del clínker Portland que contribuye al «Efecto Invernadero», como es la considerable aportación de $\mathrm{CO}_{2}$ que su fabricación conlleva $(0,72 \mathrm{Tm}$ de $\mathrm{CO}_{2} / \mathrm{Tm}$ de cemento) vista en el PREÁMBULO, hubo que optar por dicho valor mínimo de $175 \mathrm{Kp} / \mathrm{cm}^{2}$ de RMC a la edad de 28 días, y no, en cambio, por el máximo de $250 \mathrm{Kp} / \mathrm{cm}^{2}$ ya que este último límite de RMC admite con dificultad mayores cantidades de reemplazo del $40 \%$ de puzolana por CP para alcanzarlo, mientras que el primero si los admite. Contribuyendo en menor grado al Calentamiento Global derivado del «Efecto Invernadero».

- de $\mathrm{RMF} \geq 5$ a $6 \mathrm{~N} / \mathrm{mm}^{2}\left(\approx\right.$ de 51 a $\left.61 \mathrm{Kp} / \mathrm{cm}^{2}\right)$, según dicho Pliego RC-75.

\section{Cuarto Fundamento Teórico}

Para tratar de confirmar la veracidad de los tres fundamentos teóricos anteriores se le añadiría razonada y justificadamente Cal Apagada $\left(=\mathrm{Ca}(\mathrm{OH})_{2}\right.$ sólido $\left.=\mathrm{CH}\right)$, conforme a la propuesta realizada en el penúltimo párrafo del Primer Fundamento Tóorico, a cada uno de los cementos puzolánicos Tipo CEM IV/B (Instrucción RC-16) de laboratorio que se preparen con cada una de las 6 puzolanas naturales y artificiales anteriores (la M, C, CV10, A, O, y CV19) y cada uno de los 5 CP anteriores también (el P1, P2, P31, PY4 y PY6) para tratar de revertir así el sentido de las reacciones químicas de hidratación selenitosa (o no):

- Para la formación conjunta -co-precipitación- de ettringita de origen $\mathrm{Al}_{2} \mathrm{O}_{3}{ }^{\mathrm{r}}$ - de la puzolana y de origen $\mathrm{C}_{3} \mathrm{~A}$ del $\mathrm{CPO}$ con el que se mezcló cuya cantidad formada deberá de ser entonces mayor, lo que le deberá de provocar al nuevo cemento puzolánico Tipo CEM IV/B con cal apagada disminución de su RS,

- Para generar el aumento claro de dichas RMC y RMF a 28 y 90 días en probetas de mortero normalizado del nuevo cemento puzolánico Tipo CEM IV/B con cal apagada anterior, y 
- Para disminuir su carbonatación negativa, o al menos, que tarde más tiempo en generarse y desarrollarse sus consecuencias negativas para la pasta cementante y subsidiariamente para sus armaduras en el caso del hormigón armado.

La dosificación razonada y justificada de cal apagada que se añadiría finalmente al cemento puzolánico Tipo CEM IV/B de cada puzolana natural y artificial anterior, se puede ver en la Tabla 5-4.

Finalmente, los fundamentos teóricos anteriores e hipótesis de comportamientos de partida de esta investigación se van a concretar o confirmar respectivamente de una manera práctica con el fin de alcanzar los Objetivos previstos de la misma, utilizando para ello:

- el método normalizado que figura en el antiguo Pliego de Recepción de Cementos RC-75 (Talero, 1986), para determinarles a todos los cementos de mezcla anteriores con y sin Cal Apagada, los valores de RMC y de RMF a las edades correspondientes de 7, 28 y 90 días, en probetas de $4 \times 4 \times 16 \mathrm{~cm}$ de mortero normalizado 1:3, $\mathrm{y}$

- el método acelerado de ensayo L-A (Blondiau, 1961) y sus especificaciones correspondientes para determinarles grado de RS, y finalmente

- la mayor o menor carbonatación negativaque deberán de sufrir en probetas de mortero normalizado EN 196-1:2005 sometidas a un ataque de carbonatación acelerada en una atmósfera del $20 \%$ de $\mathrm{CO}_{2}$ en volumen.

\subsection{2.- Fundamentos Teóricos Secundarios.}

Para alcanzar el cuarto objetivo principal y, en función de todos ellos, se trató de Calificar y Clasificar a los cementos puzolánicos Tipo CEM IV/B (Instrucción RC-16) de laboratorio, mediante este parámetro de RS y este método acelerado de ensayo L-A (Blondiau, 1961), al igual que ya se realizara para los cementos Portland P y PY puro y fuera realizado también con fundamento de igual modo para los cementos PA (Pliego PCCH-64) y PUZ (Pliego RC-75), por Talero mediante los trabajos de investigación de su $1^{\underline{a}}$ Tesis Doctoral (Talero, 1986).

\section{2.- Fundamentos Prácticos.}

\subsection{1.- Fundamentos Prácticos: Selección de materiales hidráulicos. Razones caulitativas y cuantitativas.}

La selección de los materiales hidráulicos (por ser cementiceos) para la realización de esta nueva investigación, objeto de Tesis Doctoral también, se realizó siguiendo las mismas directrices, fundamentos e hipótesis de trabajo de las investigaciones anteriores llevadas a cabo:

1‥ Por Talero (1986), en primer lugar, relativas al comportamiento frente al ataque de los sulfatos (y más concretamente frente al ataque del yeso, al ser este el agresivo sulfático natural más 
abundante en España y en otros muchos países mediterráneos, en forma de terrenos y aguas selenitosas) de los cementos Portland con y sin puzolanas naturales y artificiales hasta un $40 \%$ de reemplazo.

2a. Por Mejía (1997), en segundo lugar, relativas al comportamiento de los mismos cementos Portland, de las mismas puzolanas naturales y artificiales (más alguna que otra puzolana artificial más) y de los mismos cementos de mezcla anteriores (cantidad de reemplazo no > $40 \%$ ), pero esta vez frente al ataque de los cloruros (del rocío marino especialmente, dado que España posee $\approx 8.000 \mathrm{Km}$ de costas, y de las sales de deshielo aunque en bastante menor medida en el caso de España también) a las armaduras del hormigón armado,

TABLA 5-4.- RELACiÓN PUZOLANA "Z" / CAL APAGADA Ó RELACIÓN AP "Z" / CH, ENTRE 3 Y 7 A LO SUMO

\begin{tabular}{|c|c|c|c|c|c|c|c|c|c|c|c|c|c|c|c|c|c|c|c|c|c|c|c|c|}
\hline & & & & & & & & & & & Puz & olan & & & & & & & & & & & & \\
\hline & Nat & Iral & (N) & & $\begin{array}{l}\text { tifici } \\
\text { (A) }\end{array}$ & & & (I & & & & $(\mathrm{N})$ & & & (A & & & & & & (A) & & & \\
\hline & & $\mathrm{O}$ & & & CV19 & & & A & & & & C & & & $\mathrm{CV}$ & & & & & & $\mathrm{M}$ & & & \\
\hline $\begin{array}{c}\text { Ceme } \\
\text { ntos } \\
\text { Portl } \\
\text { and }\end{array}$ & 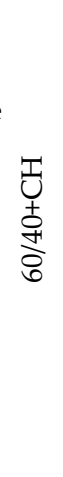 & & $\begin{array}{l}\mathbb{I} \\
u \\
+ \\
8 \\
o \\
\vdots\end{array}$ & 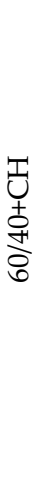 & 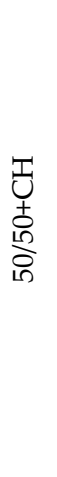 & 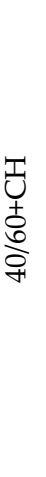 & 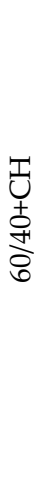 & 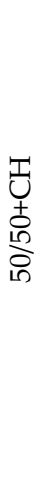 & 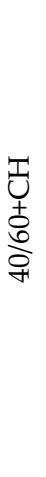 & 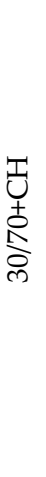 & $\begin{array}{l}\text { I } \\
\text { t } \\
+ \\
+1 \\
8 \\
8\end{array}$ & 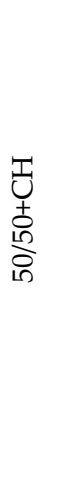 & 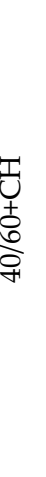 & $\begin{array}{l}\frac{T}{4} \\
+ \\
+ \\
8 \\
8\end{array}$ & 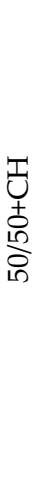 & 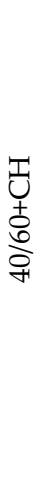 & 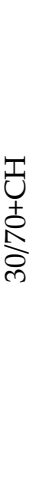 & 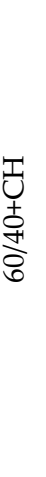 & 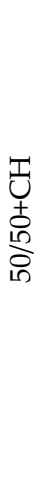 & 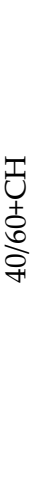 & 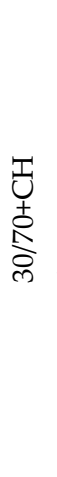 & 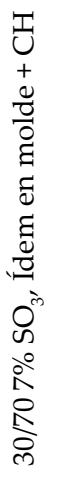 & 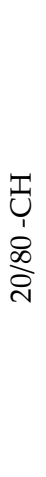 & 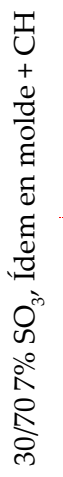 \\
\hline P-1 & 3 & 4 & 5 & 3 & 4 & 5 & 3 & 4 & 5 & 6 & 3 & 4 & 5 & 3 & 4 & 5 & 6 & 3 & 4 & 5 & 6 & 6 & & \\
\hline P-2 & 3 & 4 & 5 & 3 & 4 & 5 & 3 & 4 & 5 & 6 & 3 & 4 & 5 & 3 & 4 & 5 & 6 & 3 & 4 & 5 & 6 & & & \\
\hline P-31 & 3 & 4 & 5 & 3 & 4 & 5 & 3 & 4 & 5 & 6 & 3 & 4 & 5 & 3 & 4 & 5 & 6 & 3 & 4 & 5 & 6 & & & \\
\hline PY-4 & 3 & 4 & 5 & 3 & 4 & 5 & 3 & 4 & 5 & 6 & 3 & 4 & 5 & 3 & 4 & 5 & 6 & 3 & 4 & 5 & 6 & & & \\
\hline PY-6 & 3 & 4 & 5 & 3 & 4 & 5 & 3 & 4 & 5 & 6 & 3 & 4 & 5 & 3 & 4 & 5 & 6 & 3 & 4 & 5 & 6 & 6 & 7 & 7 \\
\hline
\end{tabular}

3a . Por Rahhal (2002), en tercer lugar, relativas al comportamiento de los mismos cementos Portland, de las mismas puzolanas naturales y artificiales (más alguna que otra puzolana artificial más y adiciones minerales cristalinas tipo filler silíceo, $\alpha-\mathrm{SiO}_{2}$, y calizo, $\mathrm{CaCO}_{3}$, para que hagan además de «referencia» relativa de las puzolánicas naturales y artificiales anteriores) y de los mismos cementos de mezcla anteriores (cantidad de reemplazo no > 40\%), 
pero esta vez enfrentados a agua destiladanada más para determinarles así la cantidad de de calor de hidratación que desprendían (velocidad de liberación de calor de hidratación y calor de hidratación acumulado). Puesto que cuando es excesivo, sus malas consecuencias y efectos colaterales no deseados para la durabilidad del hormigón, aunque indirectamente y mucho más tardíos, llegan a ser también considerables como en el caso del ataque de los sulfatos al cemento del hormigón y el de los cloruros a sus armaduras, y de ambos, sulfatos y cloruros juntos en el agua de mar, lo hacen directamente.

4‥ Por Pedrajas (2015), en cuarto lugar, relativas al comportamiento reológico de las pastas frescas de los cementos Portland anteriores con y sin las mismas puzolanas naturales y artificiales (más alguna que otra puzolana artificial más y adiciones minerales cristalinas tipo filler silíceo, $\alpha-\mathrm{SiO}_{2}$, y calizo, $\mathrm{CaCO}_{3}$, para que hagan además de «referencia» relativa igualmente de las puzolánicas naturales y artificiales anteriores) y en los mismos porcentajes de reemplazo no superiores nunca al $40 \%$. Puesto que cuando dicho comportamiento reológico de sus pastas frescas no es apropiado se producen segregaciones y/o exudaciones no deseadas de alguno(s) de sus componentes o de todos ellos en el supuesto de que se trate de su hormigón o mortero, lo que dificulta considerablemente su mezclado, amasado, transporte, vertido, colocación y puesta en obra y vibrado en el caso del hormigón convencional y, más aún, si es autocompacto. Y nuevamente,

5ª Por Talero (2017), en quinto lugar, relativas a la determinación del contenido de alúmina reactiva, $\mathrm{Al}_{2} \mathrm{O}_{3}{ }^{\mathrm{r}}-(\%)$, a las puzolanas naturales y artificiales anteriores una vez más (y también a alguna que otra puzolana artificial más, y a todas las demás que existan en el mundo y puedan existir en el futuro), mediante un nuevo método de análisis químico por vía húmeda convencional el cual es susceptible de poder ser elevado en su momento y cuando proceda a rango normativo.

Para todas y cada una de las cinco investigaciones anteriores, sus respectivos autores tuvieron que seleccionar y utilizar, por tanto, antes de todo y con el fundamento y justificación debidos (los mismos que R. Talero estableció por primera vez en su 1ำ Tesis Doctoral la cual es la primera de las cinco mencionadas), una serie de adiciones puzolánicas naturales y artificiales las cuales y por causa de lo anterior, han tenido que ser necesariamente una vez más para esta nueva investigación objeto también de esta nueva Tesis Doctoral, las mismas que las que seleccionó y utlizó por primera vez para su $1^{\mathfrak{a}}$ Tesis Doctoral. Pero en esta ocasión y dado el título y objetivos de la misma, se van a utilizar para determinar la razón o el por qué del buen comportamiento mostrado frente al ataque de los sulfatos (en forma de yeso una vez más) de todas ellas pero esta vez la cantidad de reemplazo del CP por la puzolana va a ser siempre $>40 \%$.

Por consiguiente y de acuerdo con lo anterior, los materiales hidráulicos (por ser cementíceos) seleccionados para la realización de esta nueva investigación, objeto de Tesis Doctoral también, han sido los siguientes:

- Cementos Portland industriales de elevada resistencia, o no, al ataque de los iones sulfato: tres P y dos PY (Pliego RC-75), cuya notación numerada correspondiente y análisis químico, 
figuran en la Tabla 6-1.

- Cementos Portland con sus diferentes mezclas: cuya notación figuran en el aparatado 5.1.

- Puzolanas españolas: Seis, de las cuales, tres son naturales -O, A y C-y otras tres artificiales de las cuales dos han sido cenizas volantes -CV19 y CV10- y la tercera un metacolín ( $\mathrm{M}=$ arcilla caolintica activada con $\approx 50 \%$ de $\alpha$-cuarzo ó $\alpha$-SiOz molido como impureza). Véase su notación y análisis químico en la Tabla 6-6.

\subsection{2.- Fundamentos prácticos: Razones cualitativas y cuantitativas de la misma.}

De los cementos Portland (CP) se eligieron los suficientes y necesarios para tratar de alcanzar los diferentes objetivos de este trabajo:

- El contenido de $\mathrm{C}_{3} \mathrm{~A}$ de los mismos quedara dentro del entorno de variabilidad del $15 \%$ al $0 \%$, en el cual suelen estar comprendidos prácticamente todos los cementos Portland, y que

- Cementos Portland de contenido de $\mathrm{C}_{3} \mathrm{~A}>5 \%$ (tres: el P1, P2 y P31) y cementos Potland con $\mathrm{C}_{3} \mathrm{~A}<5 \%$ (dos: el PY4 y el PY6)

De los Cementos Puzolánicos Tipo CEM IV/B (Instrucción RC-16), con todos y cada uno de los $5 \mathrm{CP}$ anteriores y cada una de las 6 puzolanas seleccionadas se prepararon los suficientes y necesarios Cementos Puzolánicos Tipo CEM IV/B y Tipo V con puzolana natural y artificial.

De las Puzolanas: De acuerdo con los objetivos del Capítulo 4 y los Fundamentos Prácticos $1^{\circ}$ y $2^{\circ}$, se han seleccionado dos sub-familias de puzolanas, a saber: una sub-familia de origen inorgánico o puzolanas naturales, y una sub-familia de origen industrial o puzolanas artificiales, de modo que dada su composición química general, se pudiera disponer en cierta medida, de ejemplos concretos de casos extremos, o al menos con connotaciones notables en tal sentido, es decir, se pudiera disponer de:

- una puzolana eminentemente alumínica en carácter químico, la M en este caso referida antes, véase las Tablas 6.8 y 6.9 y

- una puzolana eminentemente férrica o afín en carácter químico, la CV19 en este caso, véase la Tablas 6-8 y 6-9.

Según todo ello y entrando ya en materiales específicos y concretos, se han elegido:

1. Como puzolana alumínica o con un carácter químico más alumínico que silícico, el metacaolín cuarzoso M referido antes, véase la Tabla 6-6, y una ceniza volante, la CV10, de módulo de fundentes $\mathrm{Al}_{2} \mathrm{O}_{3}(\%) / \mathrm{Fe}_{2} \mathrm{O}_{3}(\%)$, elevado, véase la Tabla 6-6, aunque utilizando siempre como referencia cuando se necesite dicha alumínica $\mathrm{M}, \mathrm{y}$

2. Como puzolana férrica o bastante más férrica que alumínica, la ceniza volante, CV19, de módulo de fundentes $\mathrm{Al}_{2} \mathrm{O}_{3}(\%) / \mathrm{Fe}_{2} \mathrm{O}_{3}(\%)$, no elevado, véase la Tabla 6-6, relacionada únicamente por su origen $\left(\mathrm{Al}_{2} \mathrm{O}_{3}(\%)+\mathrm{Fe}_{2} \mathrm{O}_{3}(\%)\right.$ que sean similares) con la $\mathrm{CV} 10$ anterior con el fin de determinar, en lo posible, la influencia en su coportamiento de su considerable contenido de $\mathrm{Fe}_{2} \mathrm{O}_{3}(\%)$, véase la Tabla 6-6. 
No obstante, y al objeto de abarcar y completar lo más posible, al igual que ocurriera anteriormente con la gama de cementos Portland P y PY elegida, todo el campo de variabilidad físico-química existente en el campo de estos materiales puzolánicos y más concretamente entre los extremos silícico y alumínico en carácter químico, se eligieron además otras puzolanas naturales españolas que fueron las siguientes:

3. Sílico-alumínicas en carácter químico por ser más silícas que aluminícas, caso de las puzolanas naturales $\mathrm{O}$ y A, y alumínico-silícica por todo lo contrario, caso de la $\mathrm{C}$, las cuales han sido o son empleadas comúnmente por la industria cementera española.

\subsection{3.- Fundamentos Prácticos: Selección de otros materiales.}

Otros materiales seleccionados para la realización de esta nueva investigación han sido los siguientes:

- Piedra de Yeso natural molida hasta el grado de finura de molido indicado por la norma ASTM C452-68: para ser utilizada como agresivo sulfático por ser los más típicos y característicos por su abundancia, en España y en otros muchos países de la cuenca mediterránea.

- Cal Apagada [Ca(OH)2 R.A.]: para tratar de demostrar los Fundamentos Teóricos Principales.

\subsection{4.- Definición y Estudio, en su caso, de los diversos materiales seleccionados para la realización de esta investigación.}

5.2.4.1.- Características de los cementos Portland seleccionados, con y sin las Adiciones Puzolánicas que se han seleccionado para la realización de esta investigación.

Composición química: Los resultados obtenidos del análisis químico cuantitativo de cada uno de los cementos Portland seleccionados para la realización de esta investigación, se encuentran agrupados ordenadamente en la Tabla 6-1. De los mismos se han de hacer las aclaraciones adicionales siguientes, además de las ya realizadas en el margen inferior de aquella:

a) El análisis químico de los cementos Portland ordinarios o no resistentes al ataque del yeso, $\mathrm{P}$, los resistentes al ataque del yeso, PY, y los puzolánicos, PUZ, y de entre todos ellos y, sobre todo, los puzolánicos Tipo CEM IV/B, preparados en el Laboratorio para esta investigación y considerados "blended cements", se ha realizado de acuerdo con los métodos analíticos que se encuentran en la vigente Instrucción de cementos RC-16. Los resultados obtenidos figuran en la Tabla 6-1.

b) El Residuo Insoluble, R.I., de los cementos Portland se realizó mediante ataque ácidobásico de ácido clorhídrico diluido, $\mathrm{HCl}$ 1:5, y carbonato sódico diluido, $\mathrm{Na}_{2} \mathrm{CO}_{3}$ al 5\%. 
c) Los contenidos de sodio, $\mathrm{Na}+$, y potasio, $\mathrm{K}+$, se han determinado por fotometría de llama.

d) La Cal Libre se ha determinado por el método descrito en la vigente Instrucción de cementos RC-16.

e) Los resultados obtenidos, expresados como óxidos, excepto la Pérdida por Calcinación, (P.F.) y el Residuo Insoluble, (R.I.), se dan en tanto por cierto (\%) en peso; estos resultados están referidos a muestra seca a $105-110^{\circ} \mathrm{C}$, ver la Tabla 6.1.

f) El peso específico real de cada cemento se ha determinado, mediante el ensayo correspondiente descrito, en la referida Instrucción RC-16.

Otros Resultados: A partir de los valores de la composición química de los 5 cementos Portland se ha determinado, mediante cálculo con las fórmulas de Bogue, la Composición Potencial de cada uno de ellos, la cual se encuentra en la Tabla 6-1.

Asímismo y, por otra parte, se les han determinado además a los 5 CP sus Módulos de Silicatos, de Fundentes y de Standard de Cal e igualmente determinados Índices utilizados en la industria del cemento.

Otras determinaciones: El Índice de Puzolanicidad de los cementos de mezcla Tipo "blended cements" fabricados en el Laboratorio, se ha determinado mediante el ensayo de puzolanicidad, según Frattini, objeto de la UNE EN 196-5. Este ensayo es obligatorio para los cementos puzolánicos. Asimismo, este ensayo se le ha realizado también a todos los cementos Portland con adiciones activas preparados con cada uno de los cementos Portland seleccionados resistentes o no al ataque sulfático de dosificación $80 \%$ en peso y $20 \%$ en peso de adición puzolánica, no estando normalizado el mismo para tal tipo de cementos. Este ensayo normalizado y reglamentado es obligatorio para los cementos puzolánicos (Instrucción RC-16) únicamente pero no para los cementos Portland con puzolanas naturales y/o artificiales en porcentajes de reemplazo $\leq 20 \%$ (Instrucción RC-16) para los que sólo es "voluntario" u optativo. De aquí que se le haya realizado únicamente a todos los correspondientes puzolánicos "de Laboratorio" mencionados antes.

\subsubsection{2.- Características de las Adiciones Puzolánicas seleccionadas.}

- Composición Química

Los resultados obtenidos del análisis químico, realizado mediante la norma UNEEN 196-2 de cada una de las seis puzolanas seleccionadas para la realización de esta investigación, se encuentran agrupados ordenadamente en la Tabla 6-6. En cambio, sus correspondientes contenidos $\mathrm{de}_{\mathrm{SiO}_{2}-\mathrm{r}}(\%)$ y de $\mathrm{Al}_{2} \mathrm{O}_{3}{ }^{\mathrm{r}-}(\%)$ se determinaron mediante la norma UNE 80225:2012 y mediante el nuevo método de análisis químico por vía húmeda diseñado y puesto a punto por (Talero, 2017), respectivamente. Y de todos ellos se han de hacer las aclaraciones siguientes, además de las ya realizadas en los márgenes inferiores de dicha Tabla 6-6. 
- Determinación del Peso Específico Real:

El peso específico real de las puzolanas se ha determinado mediante las normas ASTM C311-11 Y ASTM C595M-95.

- Cálculo de Módulos:

A partir de los valores de la composición química de las puzolanas se han calculado aquellos Módulos o Índices, no normalizados, afines con los del cemento Portland que se incluyen en la Tabla 6-8 y 6-9, aunque, a decir verdad, ninguno de ellos posee utilidad práctica alguna. En cambio, el de la suma y el cociente de ambos contenidos mencionados de $\mathrm{SiO}_{2}{ }^{\mathrm{r}-}(\%)$ y de $\mathrm{Al}_{2} \mathrm{O}_{3^{\mathrm{r}}}$ (\%) de la puzolana natural o artificial si la tienen, puesto que con ambas relaciones se consigue, realmente, realizarle a cada puzolanaun «Control de Calidad» perfecto y continuado (máxime si la Puzolana es artificial tipo cenizas volantes, arcillas activadas, puzolanas naturales calcinadas y esquistos calcinados), es decir, a sus correspondientes lotes o partidas matrices también antes de podérselas incorporar, en caso de aceptaciónque o rechazo lógicamente, al clínker Portland en cantidad adecuada para cada fin constructivo y con su cantidad óptima de piedra de yeso natural que se le incorpore como regulador de fraguado, en el molino de una planta de Cemento y/o al propio cemento Portland directamente en dicha planta y/o en una planta de Hormigón Preparado. Y predecir incluso el comportamiento de su cemento de mezcla y/o el de su correspondiente hormigón, mortero y pasta en estado fresco, recién endurecido y endurecido del todo, con vistas al aseguramiento de su durabilidad prevista y deseada frente al ataque de un medio químico agresivo o no determinado como son los sulfatos, los cloruros, el agua de mar (sulfatos y cloruros juntos), la carbonatación negativa, la RAA, etc., o simplemente el agua potable nada más en su quíntuple vertiente derivada a un tiempo: Cantidad de Agua para la Pasta de Consistencia Normal, Tiempos de Fraguado (Principio y Fin), Resistencias Mecánicas a Compresión y Flexotracción a edades inciales especialmente, Calor de Hidratación originado y Comportamiento Reológico de sus pastas frescas con vista a su ordenada trabajabilidad.

En definitiva, con estas dos relaciones numéricas, la suma y el cociente de ambos parámetros químicos reactivos de cualquier puzolana natural y artificial silícea y aluminosa en naturaleza, no sólo se le podrá realizar permanentemente a la puzolana su perfecto «Control de Calidad» mencionado, sino que además $\mathrm{y}$, sobre todo, se le podrá predecir sin más su comportamiento:

1. En el resto de análisis químicos y ensayos físicos y mecánicos tipificados, normalizados, reglamentados y establecidos desde hace ya mucho tiempo, para su aceptación o rechazo nada más (según la vigente Instrucción dl Cementos RC-16 y de Hormigón Estructural EHE-08; ó en el caso de USA, según las normas ASTM C311, C595M y C618), al ser, en realidad este otro, un «Control de Calidad» imperfecto por incompleto; puesto que en siendo la cantidad de Pérdida al Fuego de la Puzolana natural o artificial $\leq 5 \%$, todos los parámetros químicos, focalizados en el ensayo de Frattini y en su contenido de $\mathrm{SiO}_{2}{ }^{\mathrm{r}}(\%)$, y físicos característicos mencionados antes, son fruto de ambas relacionesnuméricas mencionadas, la suma y al 
cociente de los contenidos de $\mathrm{SiO}_{2}{ }^{\mathrm{r}}-(\%)$ y $\mathrm{Al}_{2} \mathrm{O}_{3}{ }^{\mathrm{r}}-(\%)$ muy especialmente de la Puzolana, pero no al contrario, e igualmente

2. El de su cemento de mezcla y el de sus productos derivados: hormigones, morteros, pastas y prefabricados, frente al ataque de los medios químicos agresivos o no mencionados antes y, en definitiva, conseguir el aseguramiento de su durabilidad prevista.

En resumen desde el punto de vista de la Durabilidad Química que una Puzolana natural o artificial le puede llegar a conferir al cemento de mezcla de base Portland y/o a sus productos derivados, hormigones, morteros, pastas y prefabricados, del que forrme parte, el actual «Control de Calidad» reglamentado en España [la vigente Instrucción española de CementosRC-16 y la de Hormigón Estructural EHE-08] (ergo, en la UE igualmente) y normalizado en USA para las puzolanas naturales y artificiales [las normas ASTM C311, C595M y C618] (y entre estás últimas para las cenizas volantes especialmente) es imperfecto al estar basado en un conjunto de análisis químicos y ensayos físicos y mecánicos que, aunque normalizados, lo único que permiten es la aceptación o el rechazo nada más de la Puzolana en el supuesto de que los satisfagan o no todos ellos, respectivamente, para podérsela incorporar a dicho CP y/o a sus productos derivados mencionados. Lo que no deja de crearles incertidumbre e inseguridad a sus usuarios. En cambio, el «Control de Calidad» de la Puzolana en caso de aceptación, realizado mediante la constancia en el tiempo de ambas relaciones numéricas, la suma y el cociente, de ambos parámetros químicos reactivos de la misma (sus contenidos de $\mathrm{SiO}_{2}{ }^{\mathrm{r}}(\%)$ y de $\mathrm{Al}_{2} \mathrm{O}_{3}{ }^{\mathrm{r}}-(\%)$ muy especialmente, con sus desviaciones típicas de repetibilidad y reproduciblidad que les son propias) no sólo garantiza comportamientos a edades muy tempranas sino, además y sobre todo, a largo plazo, su durabilidad química prevista y deseada, por lo que no cabe incertidumbre alguna al poderle predecir, además, a sus usuarios el comportamiento más probable de su $\mathrm{CP}$ y/o de sus productos derivados mencionados frente al ataque de un medio químico agresivo o no determinado mencionado antes también.

Finalmente, y en el caso de las cenizas volantes calcáreas porque su contenido de " $\mathrm{CaO}$ reactivo" no es menor del 10\% y aún estando comprendido entre $10 \%$ y $15 \%$ e incluso más del $15 \%$, también le son de mucha utilidad ambas relaciones numéricas para su perfecto «Control de Calidad», sólo que habrá de tenerse en cuenta además este otro contenido para que según sea de elevado, obrar en consecuencia de acuerdo con el apartado 5.2.4.3. de la norma UNE-EN 1971:2011.

Y por último y en cuanto al contenido de $\mathrm{SO}_{3}(\%)$ de estas otras cenizas volantes que también suele ser elevado, se habrá de tener la misma precaución sólo que referida a su cemento de mezcla cuya cantidad de piedra de yeso natural incorporada inicialmente al clínker Portland (como regulador de fraguado) que lo consituye, habrá de verse reducida en cantidad suficiente para que su límite máximo permitido de $\mathrm{SO}_{3}(\%)$ no se supere de ningún modo ni bajo ningún concepto (Instrucción RC-16).

- Estudio por DRX: 
De cada una de las puzolanas seleccionadas para este trabajo, se ha hecho el estudio por DRX. Los difractogramas experimentales obtenidos de cada una de las puzolanas se encuentran en las Figuras 6-1 y 6-2, habiéndose identificado los picos de los compuestos cristalinos constitutivos de cada una de ellas que se señalan en las citadas figuras.

\subsubsection{3.- Características del Yeso.}

Composición Química: La composición química de la piedra de yeso natural utilizada como agresivo en esta investigación, se ha determinado mediante la técnica de trabajo descrita en la norma ASTM C471-13. Los resultados obtenidos figuran en la Tabla 7-2. Asimismo, los contenidos de $\mathrm{Na}^{+}$y K $\mathrm{K}^{+}$, se le han determinado por fotometría de llama.

Por otra parte, a partir de los valores de la composición química del yeso, se determinó por cálculo según especifica la citada norma su composición potencial, ver Tabla 7-2, presentando una riqueza en $\mathrm{CaSO}_{4} \bullet 2 \mathrm{H}_{2} \mathrm{O}$ del $95.58 \%$. 



\section{CAPÍTULO 6}

SELECCIÓN Y CARACTERIZACIÓN

DE MATERIALES 



\section{1.- Selección de Materiales.}

\subsection{1.- Selección de los cementos Portland.}

Los cementos Portland seleccionados para realizar la parte experimental de esta investigación han sido CINCO, de los que habitualmente se fabrican y comercializan en España. En primer lugar, tres cementos Portland ordinarios (CPO) tipo CEM I 42,5 R (UNE-EN 197-1) por lo que poseen resistencia mecánica inicial alta, a 2 días, siendo además el valor de su categoría mecánico-resistente a compresión de $42,5 \mathrm{MPa}$, pero, en cambio, no posee la característica adicional de «elevada resistencias a los sulfatos» o SRC (Instrucción RC-16) ni, tampoco al «agua de mar» por tanto. En cambio, los otros dos cementos Portland si poseían está última característica adicional de ser potencialmente «resistentes al ataque de los sulfatos» y al «agua de mar», adicionalmente por ser ambos cementos Portland tipo CEM I 42,5 R SR3 (UNE-EN 197-1). Sin embargo y lógicamente, éstos dos cementos Portland no poseían la propiedad de desarrollar elevadas resistencias mecánicas iniciales a la edad de 2 días muy a pesar de que su categoría mecánico-resistente fuera también 42,5 MPa.

Asimismo y de acuerdo con lo dicho en el apartado 5.2.1., todos los cementos Portland mencionados o sólo algunos de ellos se han venido empleando en la realización de las diferentes investigaciones realizadas y que han sido objeto de Tesis Doctorales también, en el grupo de investigación de R. Talero (Talero, (1986, 2017); Mejía, 1997; Martín-L., 1997; Rahhal, 2002; 
Delgado, 2013; Trusilewicz, 2014 y Pedrajas 2016), y además en estas investigaciones realizadas y que son objeto, igualmente de esta nueva Tesis Doctoral por lo que figuran en esta MEMORIA, motivo por el cual se dispone de una considerable experiencia y fiabilidad en su uso, así como bastante conocimiento de sus respectivos comportamientos frente al ataque por separado y en exclusiva, de sulfatos y cloruros. Y también sin ninguno de estos dos agentes químicos agresivos, es decir, habiéndolos hidratado sólo con agua destilada o potable, para determinarles el calor de hidratación que generan a edades iniciales y el comportamiento reológico de sus pastas frescas, con y sin adiciones minerales tipo puzolanas naturales y artificiales o tipo filler silíceo o calizo mayormente.

No obstante, lo anterior y de acuerdo con los objetivos de esta investigación, otros motivos adicionales que han justificado la selección de estos cinco cementos Portland (P1, P2, P31, PY4 y PY6) han sido los siguientes:

Con respecto al cemento Portland ordinario P1:

- Por una parte, por su muy elevado contenido potencial de $\mathrm{C}_{3} \mathrm{~A}(14,11 \%)$, que es la fase del cemento Portland que primero y más rápidamente se hidrata de todas, otorgándole por ello una parte muy significativa a sus resistencias mecánicas a edades iniciales. Aunque, por otro lado, es la fase más susceptible de sufrir el ataque por separado y en exclusiva del ion sulfato (con resultado negativo para el material cemento que lo constituye) y del ion cloruro (con resultado positivo para las armaduras de su correspondiente hormigón armado) y, por consiguiente, del «agua de mar» (con resultado muy dispar según que la estructura de hormigón armado o en masa se encuentre total o parcialmente sumergida), y

- Por otra, por su significativo contenido potencial de $C_{3} S(51,03 \%)$ que es la fase del cemento Portland que se hidrata, genera y desarrolla poco después que el $\mathrm{C}_{3} \mathrm{~A}$, la mayor parte de la resistencia mecánica ulterior y final. Asimismo, es necesario hacer constar también que fue el cemento Portland ordinario (CPO) más finamente molido de los tres utilizados en esta investigación, $\left(\mathrm{SEB}=319 \mathrm{~m}^{2} / \mathrm{Kg}\right)$.

Con respecto al cemento Portland ordinario P2:

- Por una parte, por poseer también un elevado contenido potencial de $C_{3} \mathrm{~A}(11,09 \%)$, si bien algo menor que el del cemento Portland P1 acabado de ver, aunque no por ello no deja de ser de muy baja o nula resistencia sulfática como el P1 y

- Por otra, por su no elevado contenido potencial de $C_{3} S$, (33,47\%) que es la fase del cemento Portland que desarrolla la mayor resistencia mecánica al hidratarse. Asimismo, es necesario hacer constar también que este cemento Portland ordinario no estaba tan finamente molido como el cemento Portland P1, SEB $\left(302 \mathrm{~m}^{2} / \mathrm{Kg}\right)$, su tipificación por RMC tuvo que ser menor necesariamente.

Con respecto al cemento Portland ordinario P31:

- Por una parte, por ser el cemento Portland ordinario con menor contenido potencial de $\mathrm{C}_{3} \mathrm{~A}(7,62 \%)$ de los tres seleccionados por, cuya razón, es y será de los tres el menos susceptible de sufrir el ataque del ión sulfato, hasta el punto, de poderlo catalogar de 
«moderada resistencia a los sulfatos» según R. Talero (Talero, 1986) y, por consiguiente, del «agua de mar», $y$

- Por otra, por su elevado contenido potencial de $C_{3} S(57,45 \%)$ hasta el punto de ser el mayor de los tres cementos Portland ordinarios seleccionados.

$>$ Con respecto al cemento Portland «resistente a lo sulfatos» PY4:

- Por una parte, por su también elevado contenido potencial de $\mathrm{C}_{3} \mathrm{~S}$ (51,43\%) como el del P1, lo que da por resultado elevadas concentraciones de portlandita propiamente dicha en la fase líquida desde el comienzo de su hidratación ya que, a diferencia del P1, su contenido de $\mathrm{Na}_{2} \mathrm{Oeq}$. era muy bajo, 0,018\%<0,6\% (Instrucción RC-16; Instrucción EHE-08 y ASTM C150:07), lo que lo facultaba y faculta para poderlo catalogar además de bajo contenido en alcalinos.

- Por otra parte, y como reseña más importante aún de él relacionada con su catalogación anterior, es que su contenido potencial de $\mathrm{C}_{3} \mathrm{~A}$ era nulo $(\approx 0,00 \%)$ siendo también su categoría mecánico-resistente como la del P1, es decir, 42,5 $\mathrm{MPa}$.

> Con respecto al cemento Portland «resistente a los sulfatos» igualmente PY6:

- Por una parte, por su muy elevado contenido potencial de $C_{3} S(79,43 \%)$, lo que da por resultado muy elevadas concentraciones de portlandita en la fase líquida desde los primeros estadios de su hidratación, aunque a edades posteriores también, puesto que, en cualquier caso, su contenido de $\mathrm{Na}_{2} \mathrm{Oeq}$. era, 0,56\% < 0,6\% (Instrucción RC-16; Instrucción EHE-08 y ASTM C150:07), lo que lo facultaba también para poderlo catalogar igualmente de bajo contenido en alcalinos.

- Por otra parte, y como reseña más importante aún de él relacionada también con su catalogación anterior, es que su contenido potencial de $\mathrm{C}_{3} \mathrm{~A}$ era también nulo $(\approx 0,00 \%)$, siendo igualmente, su categoría mecánico-resistente como la del P1y la del PY4, es decir, $42,5 \mathrm{MPa}$, mientras que su SEB era algo mayor $\left(329 \mathrm{~m}^{2} / \mathrm{Kg}\right)$.

\subsection{2.- Selección de las adiciones minerales puzolánicas.}

En función de los objetivos de esta investigación se seleccionaron seis adiciones minerales puzolánicas atendiendo a su naturaleza silícea y aluminosa, según la norma ASTM C618, y carácter químico más alumínico que silícico o, al contrario, según Talero $(1986,2007)$. El uso de la mayoría de ellas, como tales, está ampliamente implantado en la fabricación de cementos (Instrucción RC16), incluso algunas de ellas, como las cenizas volantes (CV10, CV19), se contempla su adición en planta de hormigón (UNE EN 13263-1; UNE EN 450-1).

De manera específica y desde el punto de vista estadístico, mediante las puzolanas naturales y artificiales seleccionadas de acuerdo con el diagrama ternario de Eitel (1957), se ha logrado abarcar, con toda intención, un amplio rango de variabilidad de estas adiciones minerales activas tipo puzolana que se pueden encontrar no sólo en España sino también en otros muchos países con origen y pasado volcánico, total o sólo parcial, más o menos acusado y que puedan ser adicionadas al cemento Portland. Por ello, se puede confirmar con el fundamento debido, que 
COMPORTAMIENTO SULFÁTICO Y MECÁNICO-RESISTENTE DE CEMENTOS PORTLAND CON ELEVADOS

con todas ellas quedaban representados todos los caracteres químicos-excepto el eminentemente silícico (por no ser necesario dado el objetivo primordial de esta investigación)-, que puede tener una puzolana (Talero, 1986; 2017).

Las puzolanas seleccionadas, fueron las siguientes:

- Tres puzolanas naturales, por ser las que tradicionalmente se han utilizado en España para fabricar cementos (Instrucción RC-16). Todas ellas de naturaleza silícea y aluminosa (ASTM C618) pero de carácter químico distinto:

- La primera, la puzolana natural de Olot, Gerona (O), caracterizada por su notable mayor contenido de $\mathrm{SiO}_{2}{ }^{\mathrm{r}}, 40,70(\%)$ respecto al de $\mathrm{Al}_{2} \mathrm{O}_{3^{-1}}, 5,37(\%)$, pero sin dejar por ello de lado tampoco su considerable contenido TOTAL de óxido de hierro (III), $\mathrm{Fe}_{2} \mathrm{O}_{3}, 11,89$ (\%) (lo que no dejaba de ser anómalo, no obstante), por lo que su carácter químico era y es silícicoférrico-alumínico (Talero, 1986; 2017),

- La segunda, la puzolana natural de Almagro, Ciudad Real (A), caracterizada igualmente por su considerable mayor contenido de $\mathrm{SiO}_{2}{ }^{\mathrm{r}-}, 37,69(\%)$ respecto al de $\mathrm{Al}_{2} \mathrm{O}_{3^{-}}{ }^{\mathrm{r}}, 7,70(\%)$, pero sin dejar por ello de lado tampoco su considerable también contenido TOTAL de óxido de hierro (III), $\mathrm{Fe}_{2} \mathrm{O}_{3}, 10,73$ (\%) (lo que no dejaba de ser tampoco anómalo, no obstante), pese a lo cual su carácter químico era y es silícico-alumínico (Talero, 1986; 2017), y, por último,

- La tercera, la puzolana natural de las Islas Canarias (C), caracterizada igualmente por su considerable mayor contenido de $\mathrm{SiO}_{2}{ }^{\mathrm{r}}, 38,50(\%)$ respecto al de $\mathrm{Al}_{2} \mathrm{O}_{3^{\mathrm{r}}}, 11,41(\%)$, pero dejando, esta vez sí, de lado su bajo contenido TOTAL de óxido de hierro (III), $\mathrm{Fe}_{2} \mathrm{O}_{3}$, 3,17(\%), por lo que su carácter químico era y es alumínico-silícico (Talero, 1986; 2017).

- Dos cenizas volantes españolas también, al igual que las puzolanas naturales de naturaleza silícea y aluminosa (ASTM C618) acabadas de ver, pero de carácter químico distinto. La razón de haber seleccionado estás dos cenizas volantes y no otras es que sus respectivos caracteres químicos eran y son extremos u opuestos como los de las puzolanas naturales $\mathrm{O}$ y $\mathrm{C}$.

- La primera, la ceniza volante CV10, caracterizada igualmente por su considerable mayor contenido de $\mathrm{SiO}_{2}{ }^{\mathrm{r}-}, 38,37(\%)$ respecto al de $\mathrm{Al}_{2} \mathrm{O}_{3^{\mathrm{r}}}, 13,60(\%)$, pero dejando esta vez también de lado su poco contenido TOTAL de óxido de hierro (III), $\mathrm{Fe}_{2} \mathrm{O}_{3}, 4,22(\%)$, carácter químico alumínico-silícico (Talero, 1986; 2017), porque el carácter químico alumínico de la puzolana supera al silícico aunque no puede ponerlo de manifiesto tan rápidamente como la puzolana natural C, acabada de ver, porque su estado físico es vítreo casi todo él, lo que conlleva tener que ser disuelto antes plenamente por la portlandita y/o la cal apagada, $\mathrm{Ca}(\mathrm{PH}) 2, \mathrm{y}$

- La segunda, la ceniza volante CV19, cuyo carácter químico era y es silícico-férrico-alumínico (Talero, 1986; 2017) por todo lo contrario: su considerable contenido TOTAL de óxido de hierro (III), $\mathrm{Fe}_{2} \mathrm{O}_{3}, 15,71$ (\%) (lo que no dejaba de ser igualmente anómalo, no obstante), muy a pesar de su también notable mayor contenido de $\mathrm{SiO}_{2}{ }^{\mathrm{r}}, 36.88$ (\%) respecto al de $\mathrm{Al}_{2} \mathrm{O}_{3^{\mathrm{r}}}$, $5,21(\%)$, al igual que la puzolana natural $\mathrm{O}$.

La utilización de las cenizas volantes para fabricar cementos, hormigones y morteros está amparada por la vigente Instrucción RC-16, por una parte, y por la vigente Instrucción EHE-08, respectivamente, por otra, la cual a su vez recoge y ampara la norma UNE EN 
450-1.

- Un metacaolín, de naturaleza silícea y aluminosa igualmente (ASTM C 618) pero carácter químico eminentemente alumínico (Talero, 1986; 2017) porque si su contenido de $\mathrm{SiO}_{2}{ }^{\mathrm{r}-}$ era considerable, $38,30 \%$, el de $\mathrm{Al}_{2} \mathrm{O}_{3}{ }^{r-}$ lo era mucho más aún, $14,86 \%$, es decir, el mayor de todas. Este metacaolín se obtuvo mediante la calcinación del caolín a $780{ }^{\circ} \mathrm{C}$ durante 3 días. Dicho metacaolín (M) se encontraba impurificado por cerca del 50\% de cuarzo.

Antes de comenzar a realizar la caracterización de todas las adiciones minerales puzolánicas seleccionadas, todas y cada una de ellas, fueron sometidas a un proceso de secado durante 120 horas en una estufa a $40^{\circ} \mathrm{C}$, hasta que la masa de la muestra tomada de cada una fuera constante. Transcurrido ese tiempo y una vez secas de ese modo, se procedió a su molienda, por separado -excepto para el caso de las cenizas volantes por no ser necesario, a causa del muy pequeño tamaño de sus partículas (ASTM C595M), hasta conseguir que su finura de molido por tamizado en húmedo cumpliera lo especificado al respecto por la norma ASTM C 595M: que la masa de puzolana molida retenida en el tamiz de $45 \mu \mathrm{m}$ de luz de malla, ha de ser inferior al $20 \%$. El procedimiento operativo se especifica con todo detalle en la norma ASTM C 311.

El molino empleado fue un molino de bolas, de $0,15 \mathrm{~m}^{3}$ de capacidad, cargado con pequeños cilindros $(\varnothing=1,5 \mathrm{~cm}$ y $\mathrm{h}=1,5 \mathrm{~cm})$ de acero, denominados filpers, en la proporción de $15 \mathrm{Kg}$ de la puzolana natural seca a moler y $19 \mathrm{Kg}$ de filpers. Finalmente, y al mismo tiempo que se efectuó cada molienda, se realizó el control del tiempo de molienda que se necesitó para que cada puzolana natural alcanzara la finura de molido pretendida mediante su tamizado en húmedo mencionado.

\section{2.- Caracterización de los cementos Portland.}

La caracterización químico-física de los cinco cementos Portland seleccionados comprendió los siguientes análisis químicos y determinaciones físicas y mecánicas:

- Análisis químico cuantitativo y determinación de su composición mineralógica potencial mediante los cálculos de Bogue.

- Análisis mineralógico cualitativo por difracción de rayos X (DRX) aunque sólo de los más significativos de los cinco: del P1 y del PY6.

- Determinación de la densidad real y de la superficie específica Blaine de todos ellos y de la distribución de tamaños de partícula sólo de los más significativos de los cinco: del P1 y del PY6.

- Determinación de la cantidad de agua para la pasta de consistencia normal, de los tiempos de fraguado y de la estabilidad de volumen de todos ellos.

- Determinación de la resistencia mecánica a flexotracción y a compresión en probetas de $4 \times 4$ $x 16 \mathrm{~cm}$, de mortero normalizado de todos ellos.

- Determinación del grado de saturación en $\mathrm{Ca}(\mathrm{OH})_{2}$ de la fase líquida en contacto con la pasta de cada cemento Portland, expresada como $[\mathrm{CaO}]$ y $\left[\mathrm{OH}^{-}\right]$aunque sólo de los más significativos de los cinco: del P1 y del PY6. 
COMPORTAMIENTO SULFÁTICO Y MECÁNICO-RESISTENTE DE CEMENTOS PORTLAND CON ELEVADOS CONTENIDOS DE PUZOLANAS (> 40\%): SU FUNDAMENTO QUÍMICO Y JUSTIFICACIÓN DE OTRAS CONSECUENCIAS POSIBLES

\subsection{1.- Análisis químico y composición mineralógica potencial.}

El análisis químico cuantitativo de los cinco cementos Portland seleccionados se realizó de acuerdo con la norma UNE-EN 196-2, y con los resultados que se obtuvieron se les determinó, a continuación, su composición potencial mediante las fórmulas de Bogue (UNE 80304). Los resultados de su análisis químico cuantitativo, expresados como óxidos, y los del cálculo de su composición mineralógica potencial se muestran en la Tabla 6-1.

TABLA 6-1.- COMPOSICIÓN QUÍMICA Y MINERALÓGICA POTENCIAL DE LOS CEMENTOS PORTLAND.

\begin{tabular}{|c|c|c|c|c|c|}
\hline \multicolumn{6}{|c|}{ Cementos Portland Matrices } \\
\hline Parámetros Químicos (\%) & P1 & P2 & P31 & PY4 & PY6 \\
\hline P.C. & 1,60 & 2,91 & 3,45 & 1,64 & 1,11 \\
\hline R.I. & 0,70 & 1,21 & 0,86 & 0,43 & 0,15 \\
\hline $\mathrm{SiO}_{2}$ & 19,18 & 19,36 & 18,13 & 22,10 & 21,70 \\
\hline $\mathrm{Al}_{2} \mathrm{O}_{3}$ & 6,44 & 6,03 & 5,30 & 1,98 & 1,52 \\
\hline $\mathrm{Fe}_{2} \mathrm{O}_{3}$ & 1,73 & 2,89 & 3,80 & 4,46 & 4,11 \\
\hline $\mathrm{CaO}$ & 63,93 & 59,49 & 61,68 & 65,59 & 67,97 \\
\hline $\mathrm{MgO}$ & 1,48 & 1,21 & 1,82 & 0,83 & 0,42 \\
\hline $\mathrm{Na}_{2} \mathrm{O}$ & 0,90 & 1,23 & 0,76 & 0,15 & 0,43 \\
\hline $\mathrm{K}_{2} \mathrm{O}$ & 0,52 & 0,69 & 0,31 & 0,05 & 0,20 \\
\hline $\mathrm{Na}_{2} \mathrm{O}_{\text {eq }}$ & 1,24 & 1,68 & 0,96 & 0,18 & 0,56 \\
\hline $\mathrm{SO}_{3}$ & 3,30 & 4,94 & 3,86 & 2,78 & 2,34 \\
\hline TOTAL & 100,01 & 99,96 & 99,97 & 100,01 & 99,95 \\
\hline $\mathrm{H}_{2} \mathrm{O}\left(105^{\circ} \mathrm{C}\right)$ & 0,24 & 0,93 & 0,33 & 0,22 & 0,22 \\
\hline CaO libre & 1,90 & 0,70 & 0,63 & 1,20 & 1,75 \\
\hline \multicolumn{6}{|c|}{ Cálculo Potencial de Bogue (\%) } \\
\hline $\mathrm{C}_{3} \mathrm{~S}$ & 51,03 & 33,47 & 58,70 & 58,19 & 79,43 \\
\hline $\mathrm{C}_{2} \mathrm{~S}$ & 16,48 & 30,26 & 7,70 & 19,46 & 2,29 \\
\hline $\mathrm{C}_{3} \mathrm{~A}$ & 14,11 & 11,09 & 7,62 & 0,00 & 0,00 \\
\hline $\mathrm{C}_{4} \mathrm{AF}$ & 5,33 & 8,79 & 11,56 & 11,75 & 10,19 \\
\hline
\end{tabular}

De estos resultados se han de destacar determinados aspectos dada su importancia de cara a la justificación de los cementos Portland seleccionados, con el fundamento debido, para esta investigación. Puesto que todos presentan diferencias significativas en cuanto a su composición química cuantitativa y mineralógica potencial que es preciso reseñar y que son las siguientes:

- En primer lugar, su muy diferente contenido de $C_{3} S$, destacando por encima de todos el del cemento Portland PY6 pudiéndose afirmar que este cemento Portland seleccionado era uno de los de mayor contenido de $\mathrm{C}_{3} \mathrm{~S}$ de los que se fabrican en la actualidad en todo el mundo: $79,43 \%$. Lo que haría que al hidratarse liberara elevadas cantidades de portlandita, $\mathrm{Ca}(\mathrm{OH})_{2}$, a la fase liquida de su pasta en estado fresco y endurecido. Y no sólo a edades iniciales sino también a edades posteriores avanzadas. Por el contrario, los demás no liberarían tanta portlandita al hidratarse en iguales condiciones porque su contenido de $\mathrm{C}_{3} \mathrm{~S}$ no era tan elevado, siendo el cemento Portland que poseía menor contenido en $\mathrm{C}_{3} \mathrm{~S}$ el P2, 33.47\%, muy a pesar de que el de $\mathrm{C}_{2} \mathrm{~S}$ sí lo fuera, 30,26\%. Esta era la primera diferencia significativa entre todos los cementos Portland seleccionados y para más detalle, véase la diferencia significativa siguiente. 
- En segundo lugar, el bastante elevado contenido de $C_{3} A$ del cemento Portland P1, 14,11\%, haría que este cemento Portland seleccionado fuera uno de los de mayor contenido posible de esta fase mineralógica, lo que haría también, por otra parte, que pudiera ser catalogado como un cemento Portland ordinario, al igual que los cementos Portland P2 y P31. A estos tres cementos Portland se les puede catalogar, por tanto, de «muy baja o nula resistencia al ataque de los sulfatos», siendo, no obstante, su hipotética resistencia potencial mayor conforme se disminuye su contenido de $\mathrm{C}_{3} \mathrm{~A}$ (\%). En cambio, y por su parte, los cementos Portland PY4 y PY6 poseían un contenido potencial de $\mathrm{C}_{3} \mathrm{~A}$ prácticamente nulo, mientras que la suma $\mathrm{C}_{3} \mathrm{~A}(\%)$ $+\mathrm{C}_{4} \mathrm{AF}(\%)$ verificó su condición de ser ambos «resistentes al ataque por los sulfatos (SRC») y, por ende, también «resistentes al ataque del agua de mar (MR)», según la vigente Instrucción de cementos RC-16 quedando clasificados como SR3 por dicha Instrucción y la norma UNEEN 197-1 a la que ampara. Y todo porque, a pesar de poseer un contenido muy reducido de $\mathrm{C}_{3} \mathrm{~A}(\%)$, dicho contenido no llega a ser nulo como para poderlos clasificar como SR0. Y con respecto a la norma ASTM C150, ambos cementos Portland seleccionados, PY4 y PY6, pudieron clasificarse como tipo V (de «elevada resistencia potencial al ataque de los sulfatos»).

- Por último, es necesario reseñar también el diferente contenido, dentro de lo pequeño como debe, de los elementos químicos alcalinos $\mathrm{Na}^{+}$y $\mathrm{K}^{+}$, expresados como óxidos, $\mathrm{Na}_{2} \mathrm{O}$ y $\mathrm{K}_{2} \mathrm{O}$, respectivamente, y/o como Na2Oeq., de todos los cementos Portland seleccionados. Así, mientras que los cementos Portland PY4 y PY6 poseían una reducida concentración de óxidos alcalinos $\mathrm{Na}_{2} \mathrm{O}(\%)$ y $\mathrm{K}_{2} \mathrm{O}(\%)$, pudiéndose catalogar por ello y según la norma ASTM C150, como «cementos de bajo contenido en álcalis», puesto que sus respectivos contenidos equivalentes de álcalis ó $\mathrm{Na}_{2} \mathrm{O}_{\text {eq. }}\left(\mathrm{Na}_{2} \mathrm{O}+0,658 \cdot \mathrm{K}_{2} \mathrm{O}\right)$ son inferiores a $0,60 \%$. En cambio, y por su parte, los cementos Portland P1, P2 y P31 no pudieron catalogarse igual, puesto que sus correspondientes contenidos equivalentes de álcalis, $\mathrm{Na}_{2} \mathrm{O}_{\text {eq. }}(\%)$, resultaron ser mayores que $0,60 \%$. Esta característica adicional de un cemento, denominada en inglés "low alkaly cement", está asociada a su vez, por lo general y de manera muy directa en el caso de los cementos Portland puros, a que posea o no la característica SRC, ya que la misma es debida a la temperatura mayor o menor, respectivamente, que se necesita alcanzar en el horno para fabricar su clínker Portland el cual poseerá a su vez un contenido muy bajo o muy elevado, respectivamente también, de fase alumínica tipo $\mathrm{C}_{3} \mathrm{~A}$ especialmente.

Finalmente, se confirmó que los cinco cementos Portland cumplían con todas las prescripciones químicas que se les exigen a todos los cementos comunes de acuerdo con la vigente Instrucción RC-16, en cuento a los parámetros P.C., R.I. y los contenidos de $\mathrm{SO}_{3}$ y cloruros.

\subsection{2.- Análisis mineralógico por DRX.}

La caracterización mineralógica de los componentes cristalinos sintéticos mayoritarios de dos de los cinco cementos Portland seleccionados, el P1 y el PY6, se realizó mediante difracción de rayos X (DRX). El difractómetro empleado fue un equipo automático Philips Modelo PW 1730, con monocromador de grafito, con ánodo de $\mathrm{Cu}$, siendo la longitud de onda $\mathrm{K} 1 \mathrm{del} \mathrm{Cu}=1,54056$, la $\mathrm{K} 2=1,54439$, con relación de $(\mathrm{K} 1 / \mathrm{K} 2)=0,50$, habiendo sido el tiempo de contaje de $0,80 \mathrm{~s}$ y el 
COMPORTAMIENTO SULFÁTICO Y MECÁNICO-RESISTENTE DE CEMENTOS PORTLAND CON ELEVADOS CONTENIDOS DE PUZOLANAS (> 40\%): SU FUNDAMENTO QUÍMICO Y JUSTIFICACIÓN DE OTRAS CONSECUENCIAS POSIBLES

paso de ángulo de $0.02^{\circ}$. El método de preparación de las muestras fue el de polvo compactado por presión. Los difractogramas así obtenidos son los que se muestra en las Figuras 6-1y 6-2.

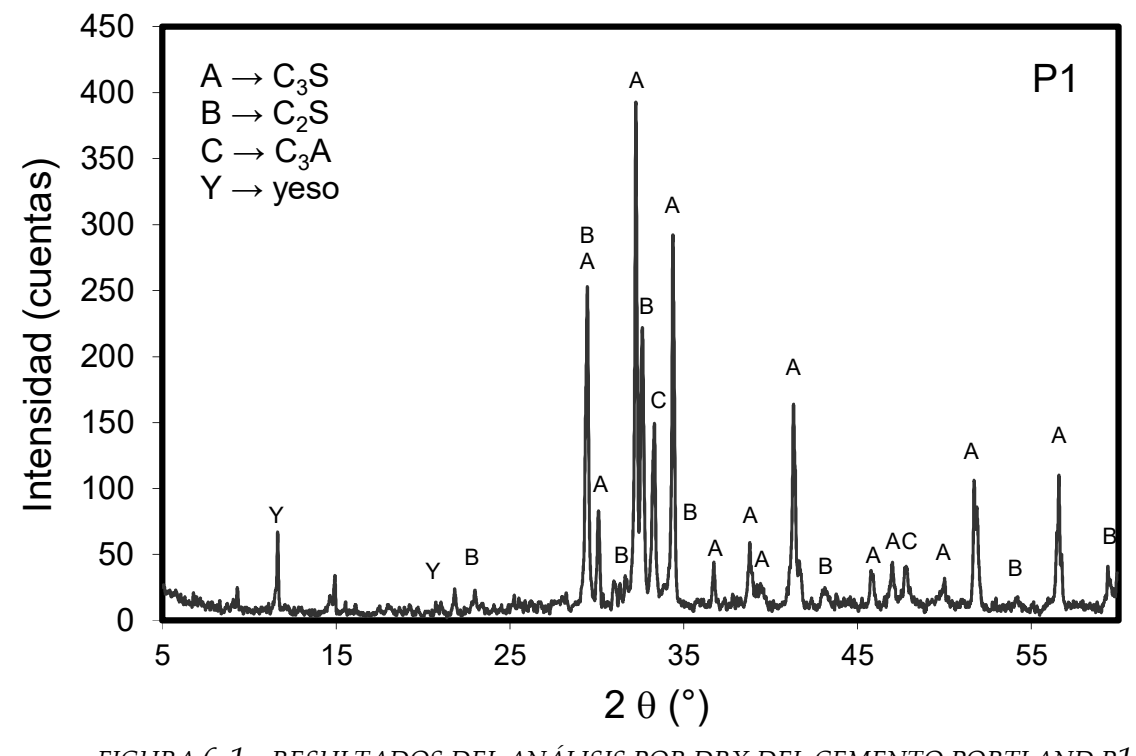

En el difractograma del cemento Portland P1 se identificó la presencia mayoritaria de $\mathrm{C}_{3} \mathrm{~S}$ y, en menor proporción, de $\mathrm{C}_{3} \mathrm{~A}$ y $\mathrm{C}_{2} \mathrm{~S}$, habiéndose identificado además $\mathrm{C}_{4} \mathrm{AF}$ en mucha menor cantidad. Asimismo, se pudieron identificar también los picos característicos de la cantidad de yeso que se le adicionó en fábrica como regulador de fraguado.

Por su parte, en el difractograma del cemento Portland PY6 se identificó la presencia muy mayoritaria de $\mathrm{C}_{3} \mathrm{~S}$, y, en menor proporción también, de $\mathrm{C}_{2} \mathrm{~S}$ y $\mathrm{C}_{4} \mathrm{AF}$, habiendo identificado además otros picos de difracción de poca intensidad que podrían corresponder igualmente a la cantidad de yeso que se le adicionó en fábrica como regulador de fraguado. Por el contrario, y tal como preconizaron los cálculos de Bogue, no se observó ninguno de los picos de difracción característicos de la fase $\mathrm{C}_{3} \mathrm{~A}$.

Finalmente, y en cuanto al resto de los cementos Portland seleccionados, el P2, el P31 y el PY4, no se consideró necesario realizarles igualmente su análisis por DRX, al haber mostrado, frente al ataque de los sulfatos, un comportamiento acorde con su correspondiente contenido potencial de $\mathrm{C}_{3} \mathrm{~A}$ (\%) determinado mediante los cálculos de Bogue habiendo estado comprendido siempre entre el del P1 y el del PY6 acabados de ver.

\subsection{3.- Determinación de la densidad real, superficie específica y distribución de tamaños de partícula.}

El método empleado para la determinación de la densidad real de los cinco cementos Portland seleccionados fue el del volumenómetro de Le Chatelier cuyo procedimiento operatorio se halla descrito en la norma EN 196-6. Una vez obtenido este parámetro físico, se les determinó además la finura de molido por el método Blaine de permeabilidad al aire (SEB), descrito en la 
norma EN 196-6, y expresada como superficie específica. Los resultados obtenidos se muestran en la Tabla 6-2.

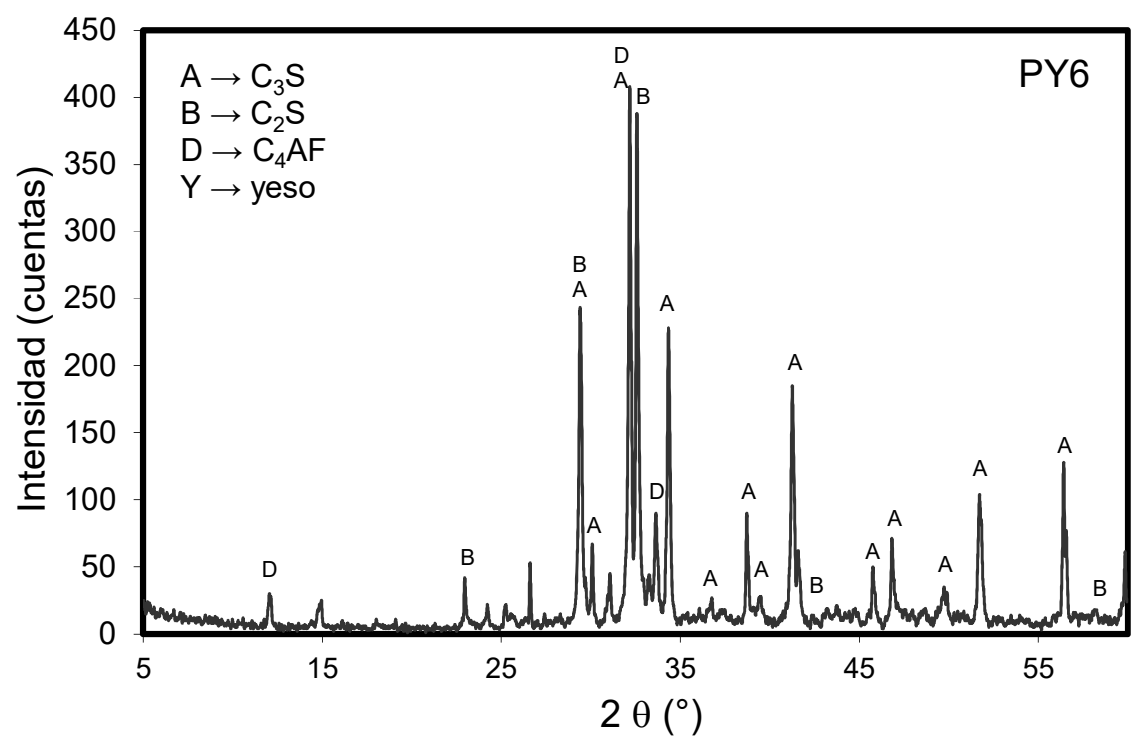

FIGURA 6-2.- RESULTADOS DEL ANÁLISIS POR DRX DEL CEMENTO PORTLAND PY6.

El cemento Portland PY6 resultó ser, como debía, el cemento con mayor densidad real en razón de su característica adicional $S R C$, por carecer de fase $C_{3} A$ prácticamente, ergo, las de $C_{3} S$ y $\mathrm{C}_{4} \mathrm{AF}$ tuvieron que ser como lo fueron, bastante elevadas. Además, $\mathrm{y}$, por otra parte, poseía una mayor SEB, en comparación con la de los tres cementos Portland ordinarios seleccionados a la par. Lo que habría de traducirse necesariamente desde edades iniciales, en una mayor concentración de portlandita en la fase líquida de su pasta fresca, recién endurecida y endurecida del todo.

TABLA 6-2.- DENSIDAD REAL Y SUPERFICIE ESPECÍFICA BLAINE (SEB) DE DOS DE LOS CINCO CEMENTOS PORTLAND.

\begin{tabular}{ccccccc}
\hline \multicolumn{8}{c}{ Cementos Portland Seleccionados } \\
\hline Parámetros Físicos (\%) & P1 & P2 & P31 & PY4 & PY6 \\
\hline Densidad real $\left(\mathrm{g} / \mathrm{cm}^{3}\right)$ & 3,08 & 3,06 & 3,06 & 3,16 & 3,21 \\
SEB $\left(\mathrm{m}^{2} / \mathrm{Kg}\right)$ & 319 & 301 & 325 & 323 & 329 \\
\hline
\end{tabular}

Adicionalmente se les determinó también la distribución de tamaños de partícula mediante granulometría láser a dos de los cinco cementos Portland seleccionados para esta investigación: al P1 y al PY6. La determinación se realizó con un granulómetro modelo Mastersizer 2000 de Malvern Instruments ${ }^{\circledR}$. El agente dispersante utilizado fue alcohol isopropílico. Los resultados de dicha determinación se muestran en las Figs. 6-3 y 6-4.

Y del análisis de los datos de ambas Figuras se obtuvo la distribución de tamaños de sus respectivas partículas. Todos los resultados obtenidos mostraron valores que se podían considerar normales para cualquier cemento Portland que actualmente se fabrica y comercializa. 
COMPORTAMIENTO SULFÁTICO Y MECÁNICO-RESISTENTE DE CEMENTOS PORTLAND CON ELEVADOS CONTENIDOS DE PUZOLANAS (> 40\%): SU FUNDAMENTO QUÍMICO Y JUSTIFICACIÓN DE OTRAS CONSECUENCIAS POSIBLES

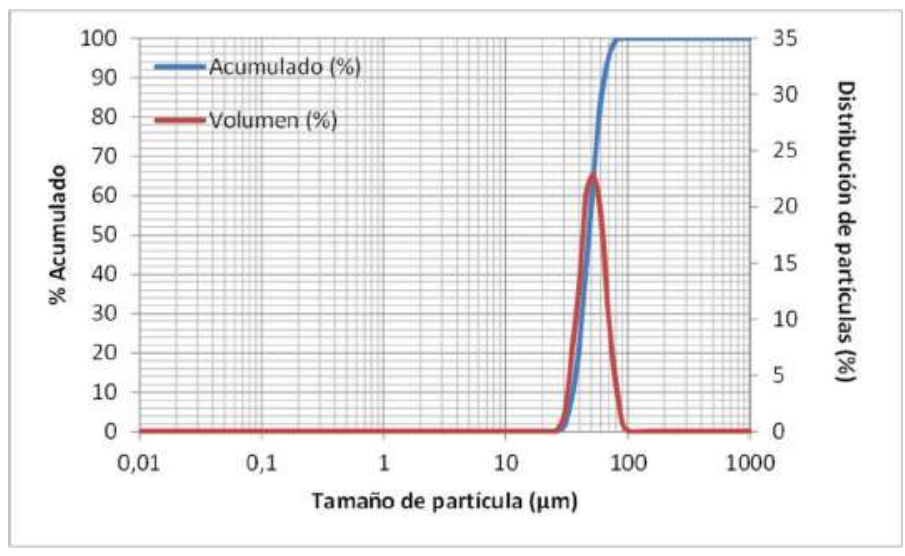

FIGURA 6-3.- DISTRIBUCIÓN DE TAMAÑOS DE PARTÍCULA DEL CEMENTO PORTLAND P1.

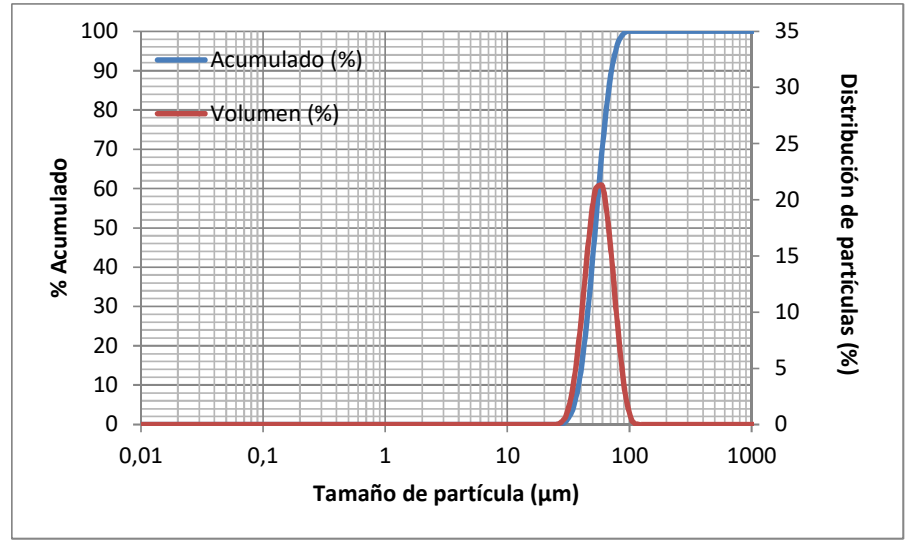

FIGURA 6-4.- DISTRIBUCIÓN DE TAMAÑOS DE PARTÍCULA DEL CEMENTO PORTLAND PY6.

\subsection{4.-Determinación de la cantidad de agua necesaria para la pasta de consistencia normal, tiempos de fraguado y estabilidad de volumen.}

La cantidad de agua para la pasta de consistencia normal, los tiempos de fraguado y la estabilidad de volumen se determinaron de acuerdo con el procedimiento operatorio descrito en la norma UNE-EN 196-3, tal y como prescribe la Instrucción RC-16. Los resultados obtenidos de estos parámetros se muestran en la Tabla 6-3.

$\mathrm{Y}$ en cuanto a los tiempos de fraguado y la estabilidad de volumen se refiere, todos los cementos Portland seleccionados cumplieron con sus correspondientes especificaciones establecidas por la vigente Instrucción de cementos RC-16 las cuales y,

- en cuanto a los primeros, son las de poseer un inicio de fraguado de su pasta fresca igual o superior a 1:00 h y un final de fraguado de la misma igual o inferior a 12:00 h, y

- en cuanto a la segunda debe de ser inferior, como lo fueron, a una expansión de $10 \mathrm{~mm}$.

Los valores obtenidos de cada uno de ellos se encuentran en la Tabla A1.1.3. 
TABLA 6-3.- RESULTADOS DE LA CANTIDAD DE AGUA PARA LA PASTA DE CONSISTENCIA NORMAL, TIEMPOS DE FRAGUADO Y ESTABILIDAD DE VOLUMEN.

\begin{tabular}{|c|c|c|c|c|c|c|}
\hline \multirow{3}{*}{$\begin{array}{l}\text { Cemento } \\
\text { Portland }\end{array}$} & \multirow{3}{*}{$\begin{array}{l}\text { Agua para la pasta de } \\
\text { consistencia normal }(\%)\end{array}$} & \multirow{2}{*}{\multicolumn{3}{|c|}{ Tiempos de fraguado (h:m) }} & \multicolumn{2}{|c|}{ Agujas Le Chatelier (mm) } \\
\hline & & & & & \multirow{2}{*}{$\begin{array}{c}\begin{array}{c}\text { Agua a } \\
100^{\circ} \mathrm{C}\end{array} \\
7 \mathrm{~d}\end{array}$} & \multirow{2}{*}{$\begin{array}{c}\begin{array}{c}\text { Agua a } 21 \pm \\
2^{\circ} \mathrm{C}\end{array} \\
7 \mathrm{~d}\end{array}$} \\
\hline & & Principio & Fin & Tiempo & & \\
\hline P1 & 0,31 & 2:00 & $2: 39$ & $0: 39$ & 1,20 & 0,40 \\
\hline P2 & 0,28 & $2: 10$ & 3:09 & $0: 59$ & 1,10 & 0,60 \\
\hline P31 & 0,30 & $1: 00$ & $1: 32$ & $0: 30$ & 0,70 & 0,40 \\
\hline PY4 & 0,27 & $2: 15$ & $2: 65$ & $0: 50$ & 0,40 & 0,10 \\
\hline PY6 & 0,28 & 2:05 & $3: 25$ & $0: 80$ & 1,00 & 0,30 \\
\hline
\end{tabular}

\subsection{5.- Determinación de las resistencias mecánicas a compresión en probetas de mortero normalizado.}

Para llevar a cabo la determinación, comprobación y verificación de la condición mecánicoresistente (42,5 R) de todos y cada uno de los cinco cementos Portland seleccionados (P1, P2, P31, PY4 y PY6), tal y como prescribe también dicha Instrucción RC-16, se le determinaron sus resistencias mecánicas a compresión (RMC) en probetas de 4x4x16 cm, de sus correspondientes morteros normalizados 1:3, a las edades de 2, 7y 28 días, de acuerdo con el procedimiento operatorio y aparatos que se describen en la norma UNE-EN 196-1.

Los cementos Portland P1, P31 y PY6 satisficieron sus correspondientes especificaciones mecánico-resistentes establecidas también por dicha Instrucción RC-16 para la clase 42,5 R, las cuales son las de poseer una resistencia mecánica a compresión a 2 días de edad, igual o mayor que $20,0 \mathrm{~N} \cdot \mathrm{mm}^{-2}$, y a 28 días de edad, igual o mayor que $42,5 \mathrm{~N} \cdot \mathrm{mm}^{-2}$ y menor o igual que 62,5 $\mathrm{N} \cdot \mathrm{mm}^{-2}$. De acuerdo, por tanto, con dichas especificaciones mecánico-resistentes, estos tres cementos Portland seleccionados tuvieron diferencias significativas a la edad de 2 días, las cuales están íntimamente relacionadas:

- por una parte, con su correspondiente composición mineralógica, ya que la fase $C_{3} A$ de cualquier cemento Portland es la que primero y más rápidamente se hidrata y desarrolla resistencias mecánicas a edades iniciales, seguida a corta distancia en tiempo por la fase $C_{3} S$, y

- por otra, con su SEB también pues no en vano y a pesar de lo anterior, tanto el CP P31 como el CP PY6 satisficieron igualmente ambas especificaciones a pesar de que sus respectivos contenidos potenciales de $\mathrm{C}_{3} \mathrm{~A}, 7,62 \%$ y $0 \%$, eran menores y bastante menores incluso, que el del P1, 14,11\%, no siendo para nada paradójico, sino todo lo contrario, que su SEB fuera precisamente, en cambio, la menor de los tres: $319 \mathrm{~m}^{2} / \mathrm{Kg}$ contra $325 \mathrm{~m}^{2} / \mathrm{Kg}$ y $329 \mathrm{~m}^{2} / \mathrm{Kg}$, respectivamente.

Finalmente, los cementos Portland P2 y PY4, tuvieron que catalogarse, de acuerdo con sus características mecánico-resistentes, de la clase $32,5 \mathrm{~N}$. 
COMPORTAMIENTO SULFÁTICO Y MECÁNICO-RESISTENTE DE CEMENTOS PORTLAND CON ELEVADOS CONTENIDOS DE PUZOLANAS ( $>40 \%$ ): SU FUNDAMENTO QUÍMICO Y JUSTIFICACIÓN DE OTRAS CONSECUENCIAS POSIBLES

TABLA 6-4.- RESISTENCIAS MECÁNICAS A COMPRESIÓN (SEGÚN NORMA UNE-EN 196-1), A 2, 7, 28 DÍAS DE EDAD, DE LOS CEMENTOS PORTLAND SELECCIONADOS.

\begin{tabular}{cccc}
\hline & \multicolumn{3}{c}{ RMC (MPa) } \\
Cemento & \multicolumn{3}{c}{ Portland } \\
\cline { 2 - 4 } & 2 días & 7 días & 28 días \\
\hline P1 & 37,83 & 47,34 & 50,44 \\
P2 & 16,3 & 25,4 & 33,2 \\
P31 & 38,2 & 49,1 & 59,7 \\
PY4 & 14,7 & 22,2 & 39,1 \\
PY6 & 21,13 & 27,27 & 51,31 \\
\hline
\end{tabular}

\subsection{6.- Determinación, mediante el ensayo de Frattini, de la [CaO] y [OH-]de la fase}

líquida en contacto con la pasta de cada cemento Portland seleccionado.

La determinación del grado de saturación en $\mathrm{Ca}(\mathrm{OH})_{2}$, expresada como [CaO] y [OH-], de la fase líquida en contacto con la pasta de cada cemento Portland seleccionado, se realizó mediante el ensayo de Frattini (1949). Este ensayo fue ideado y desarrollado primero y normalizado más tarde, para caracterizar las adiciones minerales que eran puzolánicas de las que no lo eran, con el fin de fabricar con las que lo fueran, cementos puzolánicos o cementos tipo CEM IV, sin más que incorporárselas a cada cemento Portland en cantidades adecuadas. En la actualidad este ensayo es objeto de la norma UNE-EN 196-5 la cual se encuentra amparada, a su vez, por la vigente Instrucción RC 16.

No obstante y a pesar de que este ensayo esté prescrito expresamente por dicha Instrucción RC-16 para controlar y verificar la calidad de los cementos puzolánicos o tipo CEM IV únicamente, en esta investigación se ha considerado imprescindible y necesario utilizarlo también para determinar las concentraciones iónicas de $\mathrm{Ca}^{2+}$, expresadas como [CaO], y de $\mathrm{OH}^{-}$, de la fase líquida de todas y cada una de las pastas frescas y endurecidas de dos de los cinco cementos Portland seleccionados, y las de sus correspondientes cementos de mezcla con cada una de las seis adiciones puzolánicas seleccionadas también, por separado.

TABLA 6-5.- ENSAYO DE FRATTINI: RESULTADOS DE LA [CaO] Y [OH-] DE LA FASE LÍQUIDA EN CONTACTO CON LA PASTA DE CADA CEMENTO PORTLAND SELECCIONADO.

\begin{tabular}{|c|c|c|c|c|c|c|c|c|}
\hline \multirow{4}{*}{$\begin{array}{l}\text { Cemento } \\
\text { Portland }\end{array}$} & \multicolumn{8}{|c|}{ Edad } \\
\hline & \multicolumn{2}{|c|}{1 día } & \multicolumn{2}{|c|}{2 días } & \multicolumn{2}{|c|}{7 días } & \multicolumn{2}{|c|}{28 días } \\
\hline & {$[\mathrm{CaO}]$} & [OH-] & {$[\mathrm{CaO}]$} & {$\left[\mathrm{OH}^{-}\right]$} & {$[\mathrm{CaO}]$} & {$\left[\mathrm{OH}^{-}\right]$} & {$[\mathrm{CaO}]$} & {$\left[\mathrm{OH}^{-}\right]$} \\
\hline & $\mathrm{mM} \cdot \mathrm{l}^{-1}$ & $\mathrm{mM} \cdot \mathrm{I}^{-}$ & $\mathrm{mM} \cdot \mathrm{l}^{-1}$ & $\mathrm{mM} \cdot \mathrm{l}^{-}$ & $\mathrm{mM} \cdot \mathrm{l}^{-1}$ & $\mathrm{mM} \cdot \mathrm{I}^{-}$ & $\mathrm{mM} \cdot \mathrm{l}^{-1}$ & $\mathrm{mM} \cdot \mathrm{l}^{-}$ \\
\hline P1 & 9,00 & 65,50 & 7,60 & 72,50 & 6,80 & 71,25 & 6,45 & 78,00 \\
\hline PY6 & 28,30 & 42,75 & 21,50 & 42,50 & 16,55 & 39,45 & 16,10 & 42,00 \\
\hline
\end{tabular}

Por consiguiente y de acuerdo con lo anterior, la utilidad de este ensayo radicó en esta investigación, en la caracterización de la fase líquida de las pastas frescas y endurecidas de los 
dos cementos Portland seleccionados, en relación a la especie iónica $\mathrm{Ca}^{2+}$ especialmente, por ser subsidiaria de sus procesos de hidratación y formación de productos de reacción, en estado puro y mezclados con las referidas adiciones puzolánicas. $Y$ en cuanto a la edad del ensayo, la vigente Instrucción RC-16 prescribe para los cementos puzolánicos o tipo CEM IV, las edades de 8 y 15 días, si bien y como se ha dicho antes, el ensayo se ha aplicado únicamente, por representatividad, a dos cementos Portland de los cinco seleccionados al ser los más extremos de todos en composición potencial, y las edades elegidas para realizar el ensayo fueron las de 1, 2, 7 y 28 días. Dada la importancia que tiene este ensayo en la justificación de la selección realizada de los cementos Portland, en la Tabla 6-5 se encuentran los resultados obtenidos de cada uno.

Los valores obtenidos de $[\mathrm{CaO}]$ y $\left[\mathrm{OH}^{-}\right]$de la fase líquida en contacto permanente con la pasta de cada cemento Portland se situaron, como era lo lógico, en la zona de sobresaturación del $\mathrm{Ca}(\mathrm{OH})_{2}$ en una disolución alcalina a $40^{\circ} \mathrm{C}$, por ser propio y característico de todos los cementos tipo CEM I no siendo por ello de aplicación obligatoria dicho ensayo a este tipo de cementos. Y al comparar los valores obtenidos de $[\mathrm{CaO}]$ y $\left[\mathrm{OH}^{-}\right]$se pudo observar cómo el cemento Portland PY6 fue el que liberó siempre y como debía, a igualdad de edad del ensayo mencionada, mayor cantidad de [CaO]. Sin embargo y con respecto a la alcalinidad expresada como [ $\left.\mathrm{OH}^{-}\right]$, se produjo, como debía también, el fenómeno contrario. Esto fue debido al elevado contenido equivalente de elementos alcalinos ó $\mathrm{Na}_{2} \mathrm{O}_{\text {eq, }}$ delos cementos Portland $\mathrm{P} 2$ y P1, respectivamente, con respecto al resto. Ya que sus respectivos contenidos equivalentes de alcalinos, eran, como se recordará, 1,68\% y $1,24 \%$, respectivamente. $\mathrm{Y}$ esta diferencia tan significativa entre las $[\mathrm{CaO}]$ y $\left[\mathrm{OH}^{-}\right]$de ambos cementos Portland ha de jugar necesariamente, como jugó de hecho, un papel determinante en el ensayo de puzolanicidad y en la generación de calor de hidratación (Rahhal, 2002) y en el comportamiento reológico de sus pastas frescas (ㄹedrajas, 2016) especialmente más aún.

\section{3.- Caracterización de las adiciones minerales puzolánicas seleccionadas.}

La caracterización químico-física de todas y cada una de las seis adiciones puzolánicas seleccionadas comprendió los siguientes análisis químicos, y determinaciones físicas y mecánicas:

- Análisis químico cuantitativo.

- Análisis mineralógico cualitativo por difracción de rayos X (DRX).

- Determinación de la densidad, de la superficie específica Blaine y de la distribución de tamaños de partícula.

- Determinación del contenido de sílice reactiva, $\mathrm{SiO}_{2}{ }^{\mathrm{r}-}$.

- Determinación del contenido de alúmina reactiva, $\mathrm{Al}_{2} \mathrm{O}_{3}{ }^{\mathrm{r}-}$.

- Determinación de su actividad puzolánica mediante el ensayo de Frattini.

- Determinación de su actividad puzolánica mediante el Indice de actividad resistente en probetas de $4 \mathrm{~cm} \times 4 \mathrm{~cm} \times 16 \mathrm{~cm}$ de mortero normalizado 1:3.

A continuación se describen los procedimientos operatorios de cada uno de los referidos análisis y determinaciones realizadas, se exponen sus resultados, así como el análisis, estudio, discusión e interpretación de todos y cada uno de ellos. 


\subsection{1.- Análisis químico cuantitativo.}

El análisis químico cuantitativo de todas y cada una de las SEIS adiciones puzolánicas seleccionadas, se realizó aplicando diferentes métodos y técnicas de análisis instrumental, en función del elemento u óxido a determinar, los cuales fueron los siguientes análisis:

- mediante la técnica de Espectrometría de Emisión Óptica (ICP-OES), con un equipo marca Varian modelo 725, y también,

- mediante Espectrometría de Emisión de Fluorescencia de rayos-X (FRX), con un equipo marca Bruker AXS modelo S8 tiger, por el método de polvo en pastilla prensada.

Y, por último, se realizaron además determinados análisis mediante los procedimientos operatorios de las normas UNE-EN 196-2, ASTM C 311 y UNE-EN 450-1.

TABLA 6-6.- RESULTADOS DEL ANÁLISIS QUÍMICO DE LAS SEIS PUZOLANAS SELECCIONADAS.

\begin{tabular}{lcccccccccccc}
\hline \multirow{2}{*}{ Puzolana } & \multicolumn{10}{c}{ Óxido (\%) } \\
\cline { 2 - 11 } & P.C. & R.I. & $\mathrm{SiO}_{2}$ & $\mathrm{Al}_{2} \mathrm{O}_{3}$ & $\mathrm{Fe}_{2} \mathrm{O}_{3}$ & $\mathrm{CaO}$ & $\mathbf{M g O}$ & $\mathrm{Na}_{2} \mathrm{O}$ & $\mathrm{K}_{2} \mathrm{O}$ & $\mathrm{SO}_{3}$ & $\mathrm{Cl}$ & TOTAL \\
\hline $\mathbf{O}$ & 0,40 & 1,10 & 45,12 & 13,84 & 13,82 & 10,48 & 9,54 & 3,18 & 2,40 & 0,46 & 0,01 & 100,35 \\
$\mathbf{A}$ & 3,92 & n.p. & 41,38 & 19,36 & 12,05 & 11,11 & 10,58 & 1,24 & 0,44 & n.p. & 0,10 & 100,18 \\
C & 6,92 & 0,43 & 54,18 & 20,10 & 3,12 & 2,38 & 2,04 & 5,64 & 5,17 & n.p. & 0,05 & 100,48 \\
CV10 & 6,92 & 0,18 & 49,29 & 29,63 & 4,22 & 2,86 & 1,81 & 0,50 & 3,60 & 0,94 & n.p. & 99,95 \\
CV19 & 0,83 & 0,12 & 45,47 & 30,09 & 16,12 & 4,03 & 1,12 & 0,20 & 2,80 & 1,92 & n.p. & 102,70 \\
M & 0,60 & 0,22 & 73,55 & 23,11 & 1,19 & 0,63 & 0,03 & 0,07 & 0,70 & n.p. & n.p. & 100,10 \\
Técnica & EN & EN & ICP- & ICP- & ICP- & ICP- & ICP- & ICP- & ICP- & EN & XRF & \\
\hline
\end{tabular}

n.p.- no presente o por debaio del límite de detección

De este modo, se obtuvieron los contenidos totales de los parámetros químicos genéricos más significativos de todas y cada una de ellas los cuales fueron los siguientes: $\mathrm{SiO}_{2}, \mathrm{Al}_{2} \mathrm{O}_{3}, \mathrm{Fe}_{2} \mathrm{O}_{3}$, $\mathrm{CaO}, \mathrm{MgO}, \mathrm{SO}_{3}, \mathrm{~K}_{2} \mathrm{O}, \mathrm{Na}_{2} \mathrm{O}$. Asimismo, se consideró conveniente determinarle también la Pérdida al Fuego o Pérdida por Calcinación (P.C.) y el residuo insoluble (R.I.). Los resultados de la composición química cuantitativa de las puzolanas seleccionadas se encuentran en la Tabla 66.

Y de acuerdo con los postulados y fundamentos particulares utilizados para su selección, vistos en el capítulo 3, se ha logrado abarcar como se puede ver en la Tabla 6-6, toda la gama de variabilidad de composición química posible de las mismas, acorde con los contenidos totales posibles de sus óxidos ácidos mayoritarios a saber: $\mathrm{SiO}_{2}, \mathrm{Al}_{2} \mathrm{O}_{3}$ y $\mathrm{Fe}_{2} \mathrm{O}_{3}$.

De los resultados obtenidos de sus análisis químicos, se ha de destacar que la puzolana natural C poseía un elevado contenido de alcalinos, $\mathrm{Na} 2 \mathrm{O}_{2}+\mathrm{K}_{2} \mathrm{O}(10,81 \%)$, equivalente a 9,04\% de $\mathrm{Na}_{2} \mathrm{O}_{\text {eq }}(\%)$, solubles en agua. A este respecto y dentro del grupo de las puzolanas naturales, resulta lógico que haya sido la puzolana $\mathrm{O}$ la que presentó un moderado contenido de $\mathrm{Na}_{2} \mathrm{Oeq}$ $(4,76 \%)$. En cambio, el correspondiente contenido de la puzolana natural de Almagro (Ciudad Real) es sensiblemente menor, 1,53\%. Por otra parte, el contenido de alcalinos del metacaolín, M, era nulo, dado que su caolín originario (de Guadalajara) no poseía elementos alcalinos 
lógicamente.

Por su parte, las dos cenizas volantes, CV10 y CV19, se diferenciaron en que sus respectivos contenidos de $\mathrm{Fe}_{2} \mathrm{O}_{3}$, eran muy dispares: 4,22\% la CV10 y 16,12\% la CV19. En este sentido, en relación también con este parámetro químico y dentro de las puzolanas naturales seleccionadas, la $\mathrm{O}$ fue la que presentó un mayor contenido de $\mathrm{Fe}_{2} \mathrm{O}_{3}, 13,82 \%$, seguida corta distancia por la $\mathrm{A}$, $12,05 \%$, mientras que la puzolana $C$ fue la que poseía, en cambio, el contenido menor de las tres y a bastante distancia, además, de ellas, 3,12\%.

\subsection{2.- Análisis mineralógico por DRX de las SEIS adiciones minerales puzolánicas seleccionadas.}

El análisis mineralógico por DRX fue realizado con el mismo difractómetro y en las mismas condiciones de medida que el análisis realizado a los dos cementos Portland ${ }^{1}$ seleccionados. Los difractogramas obtenidos son los que se muestran en las siguientes Figs.6-5 y 6-6.

En líneas generales y una vez realizada la identificación de los picos de difracción de rayosX, se pudo afirmar que en todas las adiciones minerales puzolánicas existe la presencia de una apreciable cantidad de fracción cristalina dispersa en una matriz amorfa y/o vítrea más o menos abundante, según la adición que se considere. Esta fase vítrea y/o amorfa es la de mayor interés desde el punto de vista de su actividad puzolánica, y, por consiguiente, de interés técnico más aún. Y no tanto quizás su cantidad, cuanto más su calidad reflejada en sus contenidos de $\mathrm{SiO}_{2}{ }^{\mathrm{r}-}$ (\%) y $\mathrm{Al}_{2} \mathrm{O}_{3}{ }^{\mathrm{r}}-(\%)$ muy especialmente. Y para más detalle, véanse los apartados 6.3.4. y 6.3.5. Asimismo, y en este sentido, en los difractogramas de las puzolanas CV10, CV19, O y A se observó una banda difusa que demuestra la condición primordialmente vítrea y/o amorfa de las mismas (Talero, 1990).

En las Figura 6-5 se muestran los difractogramas obtenidos de las tres primeras puzolanas. En las puzolanas naturales $\mathrm{O}, \mathrm{A}$ y $\mathrm{C}$, se identificaron los picos característicos comunes para las tres del cuarzo ó $\alpha-\mathrm{SiO}_{2}$, del diópsido $\left(\mathrm{CaMgSi}_{2} \mathrm{O}_{6}\right)$ y de la forsterita $\left(\mathrm{Mg}_{2} \mathrm{SiO}_{4}\right)$, aunque también se identificó silicato férrico tipo hedenbergita $\left(\mathrm{CaFeSi}_{2} \mathrm{O}_{6}\right)$ en el caso de la puzolana $\mathrm{A}$, mientras que en el caso de la puzolana $C$, se identificó además la presencia de phillipsita $\left((\mathrm{Ca}, \mathrm{K}, \mathrm{Na})_{6}\left(\mathrm{Si}_{10} \mathrm{Al}_{6}\right) \mathrm{O}_{32} \cdot 12 \mathrm{H}_{2} \mathrm{O}\right)$ y alguna otra zeolita.

En las Figura 6-6 se muestran los difractogramas obtenidos de las otras cuatro puzolanas seleccionadas para esta investigación. Y el en caso de las cenizas volantes CV10 y CV19, se identificaron los picos característicos del cuarzo, hematite $\left(\mathrm{Fe}_{2} \mathrm{O}_{3}\right)$ y mullita $\left(\mathrm{SiO}_{2}\right)$, aunque también se identificó maghemita $\left(\mathrm{Fe}_{2.67} \mathrm{O}_{4}\right)$ en la CV19. Por su parte, en el metacaolín, tan solo cuarzo le fue identificado.

${ }^{1}$ Véase nuevamente el apartado 6.2.2 de esta MEMORIA de Tesis Doctoral. 
COMPORTAMIENTO SULFÁTICO Y MECÁNICO-RESISTENTE DE CEMENTOS PORTLAND CON ELEVADOS CONTENIDOS DE PUZOLANAS (> 40\%): SU FUNDAMENTO QUÍMICO Y JUSTIFICACIÓN DE OTRAS CONSECUENCIAS POSIBLES
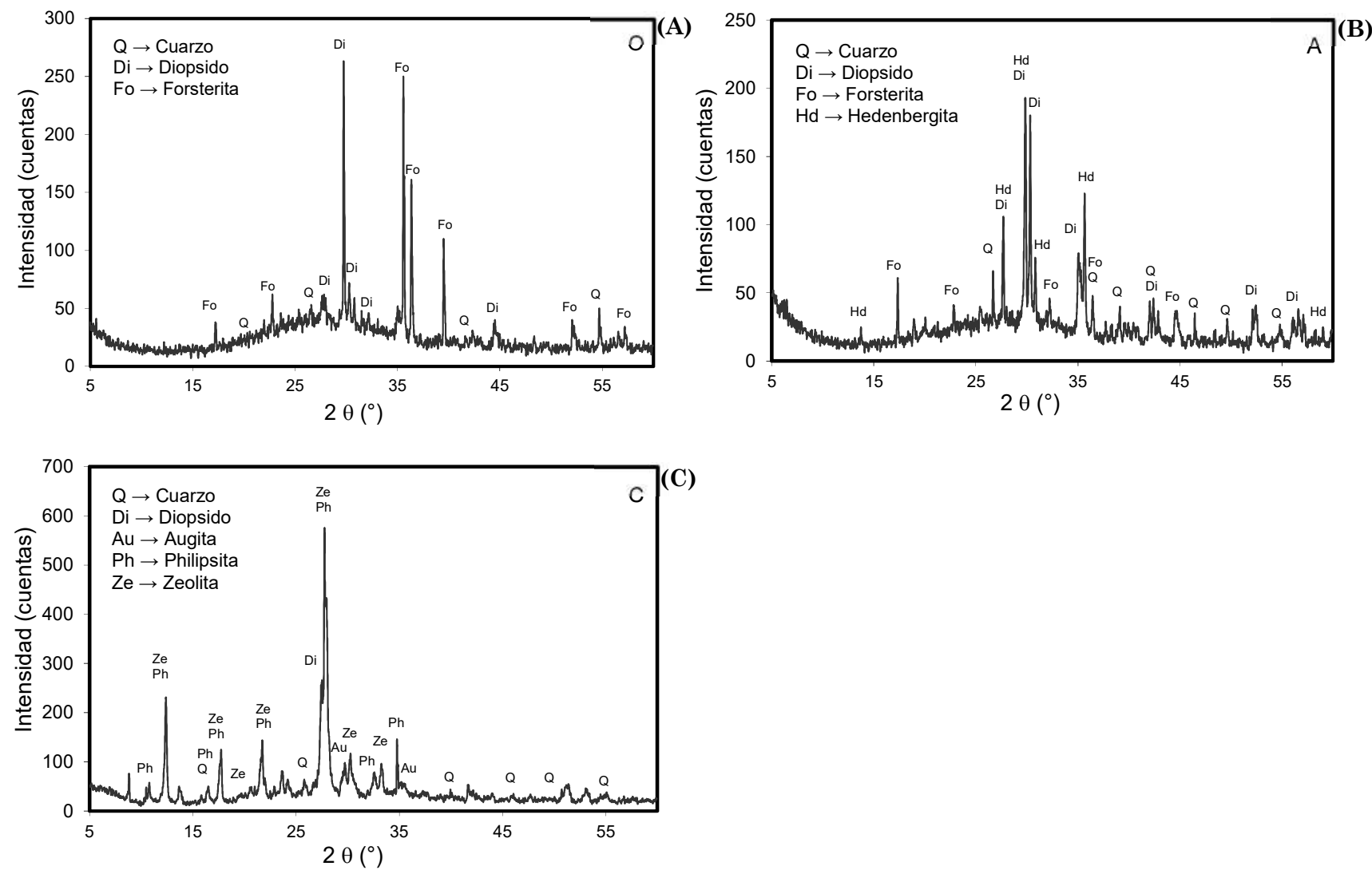

FIGURA 6-5.- RESULTADOS DEL ANÁLISIS POR DRX. (A) PUZOLANA O; (B) PUZOLANA A; (C) PUZOLANA C.

\subsection{3.- Determinación de la densidad real, superficie específica y distribución de tamaños de partícula.}

El método empleado para la determinación de la densidad real de cada una de las adiciones puzolánicas seleccionadas fue el mismo que para los cementos Portland, es decir: el volumenómetro de Le Chatelier (EN 196-6). Una vez obtenido este parámetro, nuevamente se determinó la finura de molido a la mayoría de ellas expresada como superficie específica por el método Blaine o SEB (EN 196-6). Los resultados obtenidos se muestran en la Tabla 6-7.

Y en cuanto a la densidad real, dichos resultados muestran que todos sus correspondientes valores se encuentran dentro del mismo orden de magnitud, destacando por elevado, no obstante, el valor obtenido de la puzolana natural $O$, debido con total seguridad, a la presencia de cantidades significativas de $\mathrm{Fe}_{2} \mathrm{O}_{3}$ en su constitución.

Complementariamente, se les determinó además la distribución de tamaños de partícula mediante granulometría láser. La determinación se realizó con el mismo equipo que para el caso de los dos de los cinco cementos Portland ${ }^{2}$ seleccionados. Los resultados de dicha determinación se muestran en las Figs. 6-7 y 6-8.

2Véase nuevamente el apartado 6.2.3 de esta MEMORIA de Tesis Doctoral. 

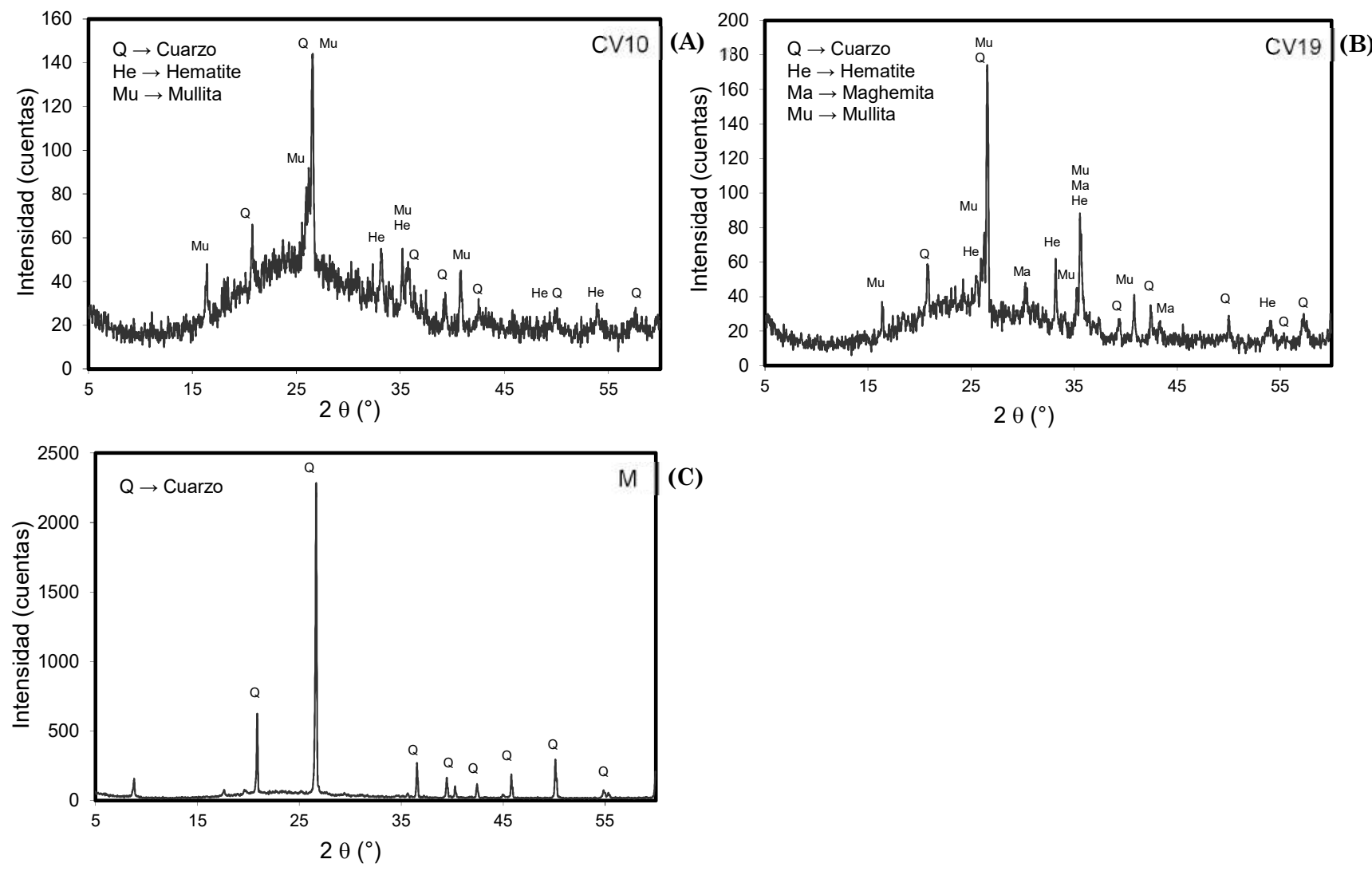

(C)

FIGURA 6-6.- RESULTADOS DEL ANÁLISIS POR DRX. (A) PUZOLANA CV10; (B) PUZOLANA CV19; (C) PUZOLANA M.

Y del análisis de los datos de ambas Figuras se obtuvo la distribución de tamaños de las partículas de las adiciones puzolánicas seleccionadas. Todos los resultados obtenidos mostraron valores que se podían considerar normales para cualquier puzolana molida a la finura del cemento (ASTM C 311). No obstante, y con base en dichos resultados, se demostró que ninguna de las puzolanas seleccionadas tenía una distribución de tamaño de partícula semejante, como por otra parte era lo lógico. Puesto que si bien sus partículas poseían un tamaño medio que se encontraba entre los mismos límites, no es menos cierto tampoco que, a igualdad de todo lo demás, eran diferentes en mayor o menor medida.

TABLA 6-7.- DENSIDAD REAL, SUPERFICIE ESPECÍFICA BLAINE (SEB) O SUPERFICIE ESPECÍFICA BET (SE-BET) DE LAS SEIS PUZOLANAS SELECCIONADAS.

\begin{tabular}{lccccccc}
\hline \multicolumn{1}{c}{ Puzolanas Seleccionadas } \\
\hline \multicolumn{1}{c}{ Parámetros Físicos (\%) } & O & A & C & CV10 & CV19 & M \\
\hline Densidad real $\left(\mathrm{g} / \mathrm{cm}^{3}\right)$ & 3,08 & 2,41 & 2,68 & 2,09 & 2,43 & 2,55 \\
SEB $\left(\mathrm{m}^{2} / \mathrm{Kg}\right)$ & 404 & 403 & 402 & 401 & 399 & \\
SE-BET $\left(\mathrm{m}^{2} / \mathrm{Kg}\right)$ & & & & & & 726 \\
\hline
\end{tabular}

Y del mismo modo se pudo apreciar también que, las muestras analizadas de todas y cada una de dichas adiciones puzolánicas estaban constituidas, en mayor o menor medida, por dos fracciones: la considerada fracción vítrea y/o amorfa, y otra parte o fracción formada por fenocristales, diferenciables entre ellas, como se demostró también por DRX, Figs. 6-5 y 6-6. 
Todo ello quedaría confirmado, además, por este análisis granulométrico que se le realizó a cada una de ellas, con la aparición de dos máximos, más o menos significativos, pero más visibles siempre en el caso de las tres puzolanas naturales $(\mathrm{O}, \mathrm{A}, \mathrm{C})$ y las dos cenizas volantes (CV10 y CV19). Lo que indicaba, por otra parte, que todo el material constitutivo de cada puzolana mencionada, no se ha comportado de un modo homogéneo frente a la molienda, independientemente de la muestra de la misma que se molió ni del tiempo de molienda diferente que necesitó cada una para molerla adecuadamente, por la considerable variabilidad en su composición mineralógica y estado físico.
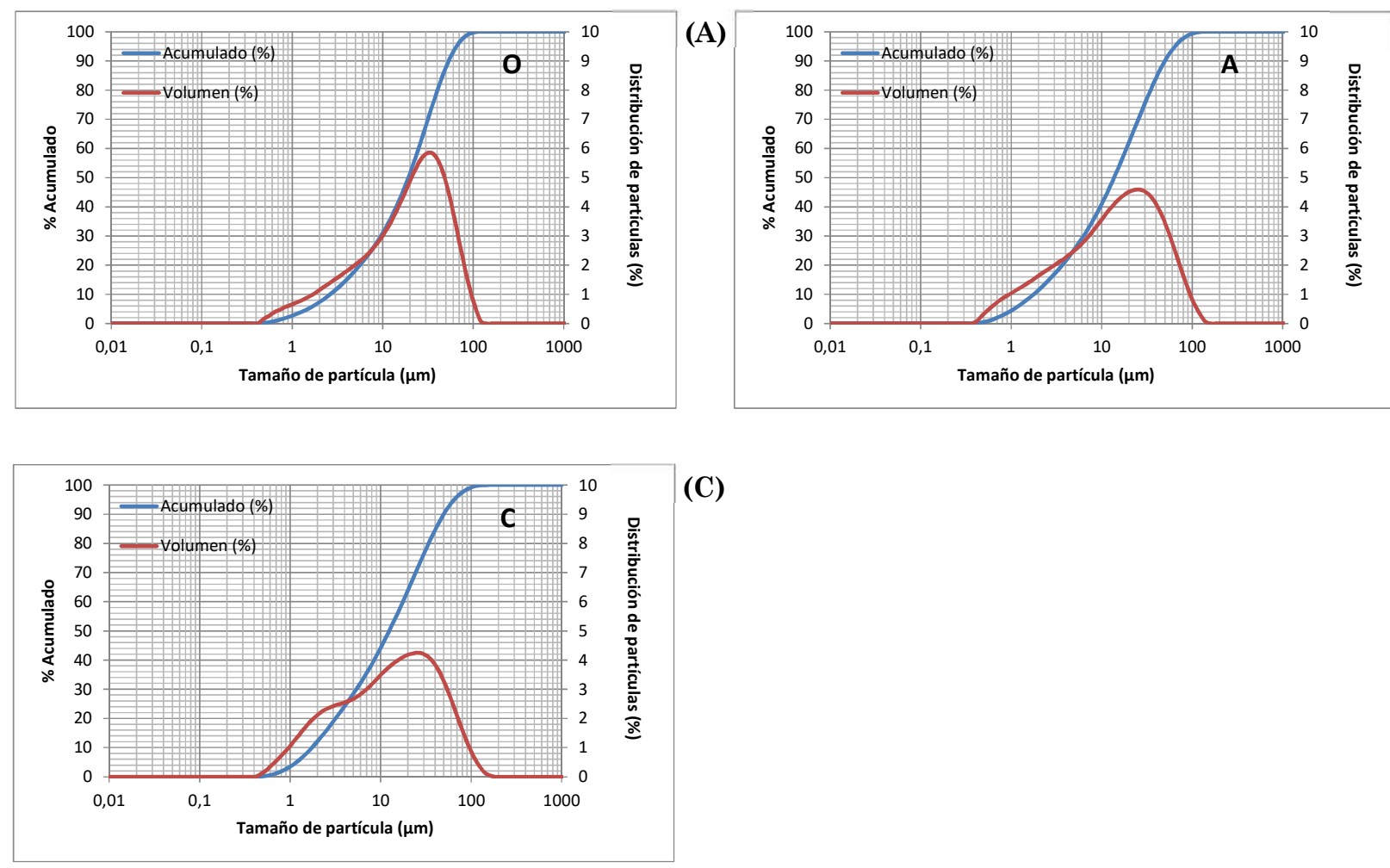

(C)

Figura 6-7.- Distribución de tAMAÑos de PARTícula. (A) PUZOLANA O; (B) PUZOLANA A; (C) PUZOLANA C;

Además, se pudo comprobar también que aquellas adiciones puzolánicas seleccionadas que debían de poseer un mayor contenido de fracción cristalina debían de ser, las puzolanas naturales (O, A, C) y las cenizas volantes (CV10 y CV19), al ser sus correspondientes distribuciones de tamaño de partícula menos uniformes que para el caso del metacaolín M. 

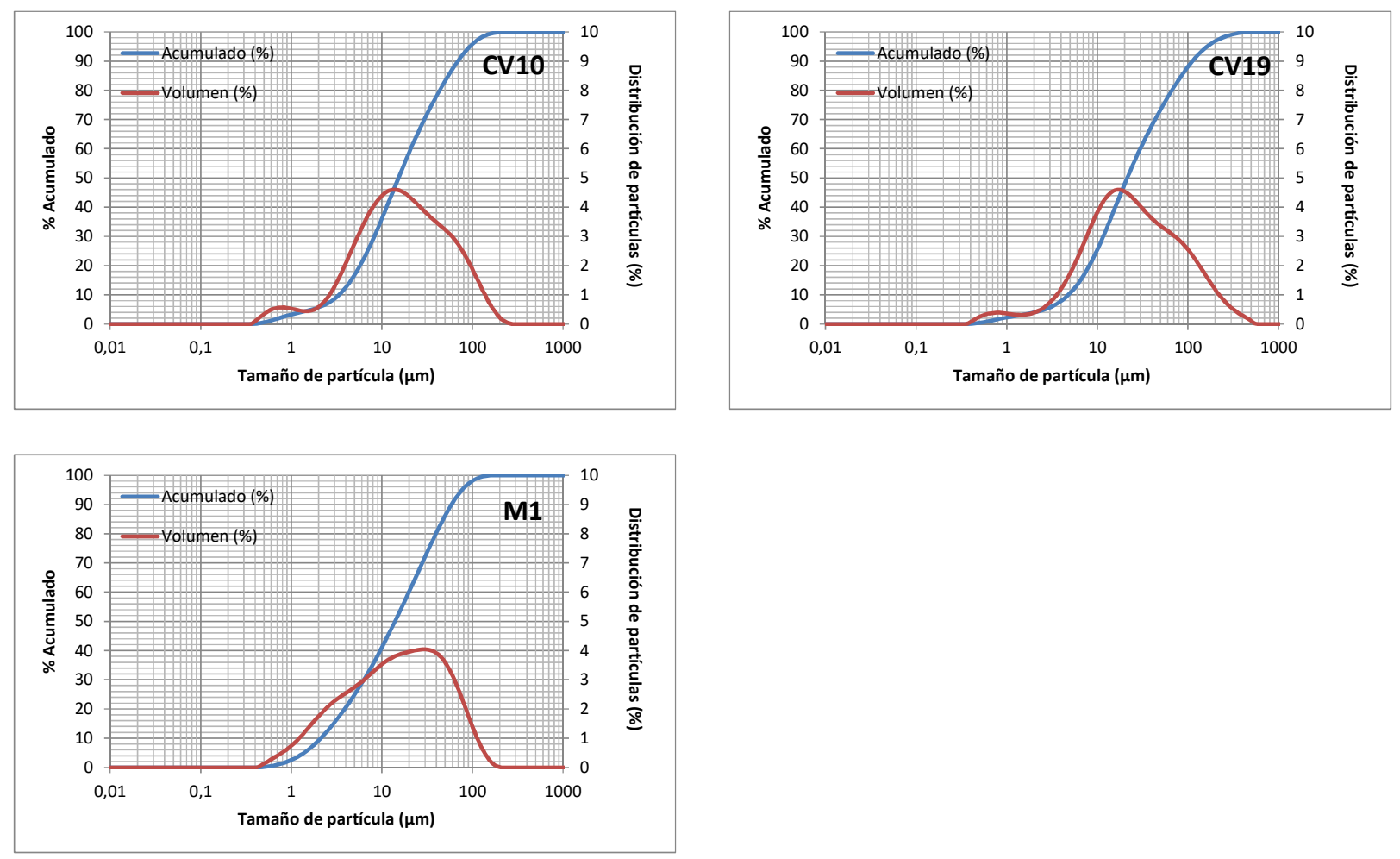

FIGURA 6-8.- DISTRIBUCIÓN DE TAMAÑOS DE PARTíCULA. (A) PUZOLANA CV10; (B) PUZOLANA CV19; (C) PUZOLANA M.

\subsection{4.- Determinación del contenido de sílice reactiva, $\mathrm{SiO}_{2^{r-}}$, de cada una de las puzolanas seleccionadas.}

De acuerdo con la vigente Instrucción RC-16, este parámetro químico, entre otros muchos, es preceptivo determinárselo en España a los materiales puzolánicos, naturales y artificiales, recogidos y amparados por dicha Instrucción, para poder ser adicionados en diferentes porcentajes a los cementos Portland en fábrica, para lo que dicho contenido no debe ser menor del 25\% en masa. Por consiguiente y de acuerdo con dicha especificación química, el referido parámetro químico le fue determinado a cada adición puzolánica seleccionada mediante la norma UNE 80225.

De los resultados obtenidos de la determinación de este factor hidráulico, "sílice reactiva", $\mathrm{SiO}_{2}{ }^{\mathrm{r}}$, mediante el método analítico objeto de la norma UNE 80225, véanse en la Tabla 6-8, se desprende que todas han superado la especificación química de que dicho contenido mínimo no debe ser menor que 25\% en masa de acuerdo con la Instrucción RC-16, por cuyo motivo y, en principio, se logró confirmar que todas pueden ser consideradas como puzolana y añadírsele, por ello, al cemento Portland en cantidades reglamentadas (EN 197-1) excepto el metacaolín $\mathrm{M}$ por no contemplarlo ninguna de las dos muy a pesar de ser una muy buena puzolana artificial. Y tras el análisis de los resultados, se pudo advertir que los valores del contenido de $\mathrm{SiO}_{2}{ }^{\mathrm{r}}$ - de las adiciones puzolánicas seleccionadas, han oscilado entre el 36,88\% de la puzolana CV19, y el 40,70\% de la O. 
COMPORTAMIENTO SULFÁTICO Y MECÁNICO-RESISTENTE DE CEMENTOS PORTLAND CON ELEVADOS CONTENIDOS DE PUZOLANAS ( $>40 \%$ ): SU FUNDAMENTO QUÍMICO Y JUSTIFICACIÓN DE OTRAS CONSECUENCIAS POSIBLES

TABLA 6-8.- CONTENIDO DE SÍLICE TOTAL Y SÍLICE REACTIVA DE CADA UNA DE LAS PUZOLANAS SELECCIONADAS.

\begin{tabular}{lccccccc}
\hline \multicolumn{8}{c}{ Puzolanas Seleccionadas } \\
\hline \multicolumn{1}{c}{ Parámetros químicos (\%) } & O & A & C & CV10 & CV19 & M \\
\hline $\mathrm{SiO}_{2}(\%)$ & 45,12 & 41,38 & 54,18 & 49,29 & 45,47 & 73,55 \\
$\mathrm{SiO}_{2}{ }^{-}(\%)$ & 40,70 & 37,69 & 38,50 & 38,37 & 36,88 & 38,30 \\
\hline
\end{tabular}

\subsection{5.- Determinación del contenido de alúmina reactiva, $\mathrm{Al}_{2} \mathrm{O}_{3^{r-}}$, de cada una de las puzolanas seleccionadas.}

La importancia de este otro parámetro químico o "factor hidráulico" también de la puzolana, reside en que, de acuerdo con los resultados de las investigaciones realizadas al efecto por R. Talero, la alúmina reactiva, $\mathrm{Al}_{2} \mathrm{O}_{3}{ }^{\mathrm{r}}$, de las puzolanas de cualquier origen y etiología, se involucra de forma muy directa, ya sea para bien, para mal o para peor, en todos los ataques químicos agresivos y/o de hidratación a edades iniciales especialmente del cemento Portland que las contiene. En cambio, la sílice reactiva, $\mathrm{SiO}_{2}{ }^{\mathrm{r}-}$, no, sino de forma indirecta nada más, lo que también puede llegar a tener sus ventajas e inconvenientes según el medio químico agresivo o no que se considere.

TABLA 6-9.- CONTENIDO DE ALÚMINA TOTAL Y ALÚMINA REACTIVA DE CADA UNA DE LAS PUZOLANAS SELECCIONADAS.

\begin{tabular}{lccccccc}
\hline \multicolumn{7}{c}{ Puzolanas Seleccionadas } \\
\hline \multicolumn{1}{c}{ Parámetros químicos (\%) } & O & A & C & CV10 & CV19 & M \\
\hline $\mathrm{Al}_{2} \mathrm{O}_{3}(\%)$ & 13,84 & 19,36 & 20,10 & 29,63 & 30,09 & 23,11 \\
$\mathrm{Al}_{2} \mathrm{O}_{3}{ }^{r-}(\%)$ & 5,37 & 7,70 & 11,41 & 13,60 & 5,21 & 14,86 \\
\hline
\end{tabular}

Para determinar su correspondiente contenido de alúmina reactiva, $\mathrm{Al}_{2} \mathrm{O}_{3}{ }^{\mathrm{r}-}$, se utilizó el nuevo método de análisis químico por vía húmeda (NMAQVH), ideado, diseñado y puesto a punto por Talero (2017), objeto también de su 2a Tesis Doctoral (Leída y Defendida el día 6 de julio de 2017 en la Facultad de Farmacia de la UCM). Con lo que desde esa fecha la imposibilidad que se tenía de determinar con la precisión y rapidez debidas, este otro "factor hidráulico" tan significativo de las puzolanas naturales y artificiales, mediante dicho NMAQVH de R. Talero, cesó, hasta el punto de poder llegar a ser elevado en su momento dicho método a rango normativo, dada su enorme sencillez operatoria, facilidad de manejo, repetitividad, fiabilidad, rapidez de respuesta (desde el punto de vista técnico: no más de 28 días a lo sumo), bajo coste económico y estar totalmente exento de peligro para la integridad de la persona que lo haya de poner en práctica.

Los resultados obtenidos de la determinación del factor hidráulico "alúmina reactiva", $\mathrm{Al}_{2} \mathrm{O}_{3}{ }^{r-}$, de todas y cada una de las puzolanas seleccionadas, mediante dicho NMAQVH de Talero (2017), se muestran en la Tabla 6-9. Dichos resultados se obtuvieron a la edad de 28 días, lo que, desde el punto de vista técnico, hace aceptable al método no sólo para investigación, sino, sobre todo, para control de calidad, máxime si además algunas puzolanas pueden proporcionar su contenido total de $\mathrm{Al}_{2} \mathrm{O}_{3}{ }^{\mathrm{r}-}(\%)$ mucho antes de 28 días incluso como es el caso de los metacaolines 
y alguna que otra puzolana natural española como la $C$ que lo comenzaron a cumplir a la edad de 1 día incluso. Y tras el análisis de los resultados, se pudo advertir también que los valores del contenido de $\mathrm{Al}_{2} \mathrm{O}_{3}{ }^{\mathrm{r}-}$ de las muestras de cada una de las adiciones puzolánicas seleccionadas, han oscilado entre el valor de $5,21 \% \pm 0,50 \%$, de la ceniza volante CV19, y el $14,86 \% \pm 0,50 \%$ de la $M$, pudiéndose destacar además que, este rango de variabilidad podría ser "equivalente" al de un clínker Portland cuya composición potencial de Bogue hubiera dado por resultado un contenido de $C_{3}$ A del $[5,21 \%$ al 14,86\%] $\pm 0,50 \%$, sólo que dicho contenido, o mejor aún sus hidratos de calcio, se originan en realidad esta vez, cuando el contenido de $\mathrm{Al}_{2} \mathrm{O}_{3}{ }^{\mathrm{r}-}$ de cada adición puzolánica anterior o cualquier otra, ya sea natural o artificial, reaccione químicamente en medio acuoso y a temperatura ambiente con la portlandita originada de la hidratación de la fracción de CP con la que se mezcló la puzolana y/o con cal apagada, ya sea ésta hidráulica o no. Por este motivo y para diferenciarlo del $\mathrm{C}_{3} \mathrm{~A}$ auténtico del clínker Portland, se la ha denominado " $\mathrm{C}_{3} \mathrm{~A}$ equivalente" $\mathrm{y}$, para abreviar, se ha simbolizado "C 3 Aeq.".

\subsection{6.- Determinación, mediante el ensayo de Frattini, de la actividad puzolánica de todas y cada una de las seis puzolanas seleccionadas.}

La actividad puzolánica de cada puzolana seleccionada le fue determinada, como es preceptivo y está reglamentado, mediante el ensayo de Frattini (1949). Y de acuerdo con la norma UNE EN 196-5, este ensayo permite evaluar por vía química, la actividad puzolánica que genera y desarrolla la puzolana de un cemento puzolánico, ya sea tipo CEM IV/A (de 11\% a 35\% de reemplazo) ó CEM IV/B (de 36\% a 55\% de reemplazo) (Instrucción RC-16), así como también, la actividad puzolánica de una puzolana dada, ya sea ésta natural o artificial, añadida a un cemento Portland tipo CEM I, en cantidades de reemplazo diferentes de las de ambos cementos puzolánicos; ya sean dichas cantidades de reemplazo mayores del $55 \%$ como si son menores < $11 \%$ ), mediante la comparación de la cantidad de hidróxido de calcio que, pasado un periodo de tiempo preceptivo también, 8 y/ó 15 días, contiene la disolución acuosa que, a $40^{\circ} \mathrm{C}$, está en contacto con la muestra inicial de $20 \mathrm{~g}$ del cemento en estudio, con la isoterma de solubilidad del hidróxido de calcio en una disolución alcalina a la misma temperatura. No obstante, y por los ensayos de carbonatación negativa acelerada a los que serán sometidos finalmente los cementos de mezcla de esta investigación con porcentajes de reemplazo de CP por puzolana $>40 \%$ en peso (con y sin cal apagada y/o yeso), este ensayo de puzolanicidad o de Frattini se les determinó además a edades $>28$ días (a 60,90,120,150,180...días) para poder relacionarlos así con los correspondientes de carbonatación negativa acelerada que se obtengan con vistas a su justificación científica y técnica a tenor de lo previsto en este sentido, en el párrafo final de la respuesta a la $3^{\underline{a}}$ cuestión o pregunta formulada y planteada en el Capítulo 3. Fundamentos de esta MEMORIA.

Además y de acuerdo con la Tabla A1.1.4 de la vigente Instrucción de cementos RC-16, titulada "Prescripciones químicas de los cementos comunes, incluidos los de bajo calor de hidratación", este ensayo de puzolanicidad o ensayo de Frattini, está prescrito únicamente para los referidos "Cementos puzolánicos" o Tipo CEM IV (contenido de clínker Portland: entre 89\% y $45 \%$; contenido de puzolana natural y/o artificial: entre $11 \%$ y 55\%), los cuales para ser considerados y catalogados como tales, lo han de cumplir a la edad de 8 ó de 15 días nada más. 
En cambio, el resto de los cementos de la Tabla A1.1.1, titulada "Cementos comunes", de dicha Instrucción RC-08, no lo han de cumplir a ninguna edad. Lo que no implica, no obstante, que en las investigaciones objeto de esta Tesis Doctoral dicho ensayo de Frattini no sea válido para evaluar también la reactividad puzolánica que un material puzolánico cualquiera, natural o artificial, puede llegar a desarrollar a cualquier otra edad con el cemento Portland al que se le incorpore en cualquier otra proporción, que sí lo es, para poderla relacionar así, con otros parámetros químicos y/o físicos y/o mecánicos del mismo en pos también de su justificación como se podrán justificar así los de carbonatación negativa mencionados. Por este motivo, se decidió evaluar, además, mediante dicho ensayo de Frattini, la puzolanicidad de todas las puzolanas seleccionadas, pero no a las edades preceptivas anteriores de 8 y 15 días, sino a las edades iniciales, pero no preceptivas de 2,7 y 28 días, en principio, y 60, 90, 120, 150, 180, etc. más tarde. Las dos últimas edades, por ser las edades preceptivas de dicho ensayo antes del año 1993, de acuerdo con el Pliego PCCH-64 y el Pliego RC-75, la primera, por su indudable interés científico y técnico, y todas las demás por su indudable relación directa con los previsibles resultados que se obtengan de la carbonatación negativa de sus correspondientes morteros normalizados.

Y para ello, se decidió evaluarle la puzolanicidad a las mezclas, por separado, de cada una de las seis puzolanas seleccionadas, con dos de los cementos Portland de referencia, el P1 y el PY6, de composición mineralógica potencial muy dispar, en las proporciones porcentuales de mezcla $80 \% / 20 \%$ y $60 \% / 40 \%$ en peso, en lo sucesivo, $80 / 20$ y $60 / 40$, respectivamente, cemento Portland/Puzolana seleccionada " $Z$ ". Lo que hizo que los cementos de mezcla así preparados pudieran ser asimilados o equiparados en función de su composición únicamente, a los cementos tipo CEM II/A y CEM IV/B, respectivamente, de la vigente Instrucción RC-16. Y del mismo modo a todos los demás con porcentaje de reemplazo $>40 \%$ en peso, de puzolana " $\mathrm{Z}$ " por $\mathrm{CP}$, con y sin cal apagada y/o yeso.

Los resultados obtenidos de este ensayo de Frattini de los referidos cementos de mezcla 80/20 y 60/40 se encuentran en las Tablas 6-10 y 6-11. Y de los mismos se han podido obtener las siguientes observaciones:

- De los cementos de mezcla del cemento Portland P1 preparados con cada puzolana seleccionada en proporción porcentual 80/20 y 60/40: Todas y cada una de las puzolanas seleccionadas han demostrado una actividad puzolánica cierta, por lo que se confirmó una vez más el acierto de su selección. Además, se ha logrado demostrar que, aumentando la cantidad de reemplazo de cemento Portland P1 por puzolana, se aumenta la actividad puzolánica correspondiente en todos los sentidos: cantidad (mayor) y tiempo necesario para cumplirla (menor), como se puede apreciar en la Tabla 6-10. Puesto que todas y cada una de las correspondientes mezclas cumplieron más pronto, a 2 días, o más tarde, a 28 días, el ensayo de Frattini, dado que el sistema "pasta de cemento parcialmente hidratada $<$ fase líquida", evolucionó más aún hacia la zona de sub-saturación con el transcurso del ensayo, debido a la actividad puzolánica desarrollada por sus correspondientes contenidos de puzolana.

Asimismo, se pudo identificar también perfectamente, que a pesar de haber cumplido la puzolana $\mathrm{O}$ el ensayo de Frattini, fue la puzolana que lo cumplió con mayor dificultad de todas, puesto que sus correspondientes cementos de mezclas lo cumplieron a 28 días nada más. 
Además, se pudo apreciar también en todos los casos, que, excepto para el caso de la puzolana $\mathrm{C}$ por su elevado contenido de elementos alcalinos, $\mathrm{Na}^{+} \mathrm{y} \mathrm{K} \mathrm{K}^{+}$(véase para más detalle, la Tabla 6-11), los valores de alcalinidad total, $\left[\mathrm{OH}^{-}\right]$, fueron, en general, algo menores que los del cemento P1, conforme se aumentó el porcentaje de reemplazo, fruto de la mayor presencia de puzolana en la mezcla. Lo que se debió, por una parte, al efecto de dilución física del CPP1 por la puzolana, y por otra y, sobre todo, a la actividad puzolánica que debieron de haber desarrollado sus contenidos de $\mathrm{SiO}_{2}{ }^{\mathrm{r}-}(\%)$ y $\mathrm{Al}_{2} \mathrm{O}_{3}{ }^{\mathrm{r}}-(\%)$ especialmente, todo lo cual se tradujo, en definitiva, en un descenso a la par y como debía, de la $[\mathrm{CaO}]$ y de $\left[\mathrm{OH}^{-}\right]$en la fase líquida del ensayo de Frattini con el transcurso de la hidratación de sus correspondientes cementos de mezcla.

TABLA 6-10.- ENSAYO DE FRATTINI DE LOS CEMENTOS DE MEZCLA DEL CP P1 CON CADA PUZOLANA SELECCIONADA: RESULTADOS A LAS EDADES DE 2, 7 Y 28 DÍAS.

\begin{tabular}{|c|c|c|c|c|c|c|}
\hline \multicolumn{7}{|c|}{ P1 } \\
\hline \multirow{4}{*}{$\begin{array}{l}\text { Cementos de } \\
\text { mezcla }\end{array}$} & \multicolumn{6}{|c|}{ Edad } \\
\hline & \multicolumn{2}{|c|}{2 días } & \multicolumn{2}{|c|}{7 días } & \multicolumn{2}{|c|}{28 días } \\
\hline & {$[\mathrm{CaO}]$} & {$\left[\mathrm{OH}^{-}\right]$} & {$[\mathrm{CaO}]$} & {$\left[\mathrm{OH}^{-}\right]$} & {$[\mathrm{CaO}]$} & {$\left[\mathrm{OH}^{-}\right]$} \\
\hline & $\mathrm{mM} \cdot 1^{-1}$ & $\mathrm{mM} \cdot \mathrm{l}^{-}$ & $\mathrm{mM} \cdot 1^{-1}$ & $\mathrm{mM} \cdot 1^{-}$ & $\mathrm{mM} \cdot 1^{-1}$ & $\mathrm{mM} \cdot l^{-1}$ \\
\hline P1/O 80/20 & 9,80 & 67,50 & 8,70 & 75,00 & 5,25 & 82,50 \\
\hline P1/O 60/40 & 11,10 & 61,00 & 9,00 & 69,00 & 3,80 & 80,00 \\
\hline P1/A 80/20 & 9,85 & 68,00 & 3,80 & 63,40 & 4,60 & 85,00 \\
\hline P1/A 60/40 & 10,35 & 59,50 & 3,65 & 71,55 & 3,55 & 82,00 \\
\hline P1/C 80/20 & 5,10 & 83,00 & 3,30 & 82,25 & 3,10 & 117,00 \\
\hline P1/C 60/40 & 2,30 & 83,50 & 2,05 & 99,90 & 0,75 & 116,00 \\
\hline P1/CV10 80/20 & 11,20 & 67,50 & 6,55 & 69,75 & 4,25 & 77,50 \\
\hline P1/CV10 60/40 & 9,50 & 60,50 & 3,80 & 60,00 & 2,10 & 71,00 \\
\hline P1/CV19 80/20 & 9,55 & 68,00 & 6,50 & 63,50 & 4,30 & 71,50 \\
\hline P1/CV1960/40 & 11,55 & 61,00 & 5,60 & 54,50 & 1,50 & 61,50 \\
\hline P1/M 80/20 & 6,35 & 55,00 & 6,25 & 63,00 & 5,50 & 71,50 \\
\hline P1/M 60/40 & 2,15 & 35,00 & 1,65 & 44,50 & 1,45 & 43,00 \\
\hline
\end{tabular}

En color azul, aquellos cementos de mezcla que cumplieron el ensayo de Frattini más pronto o más tarde

- De los cementos de mezcla con el cemento Portland PY6, preparados con cada puzolana seleccionada en proporción porcentual 80/20 y 60/40 (Tabla 6-11): Todas y cada una de las puzolanas seleccionadas han demostrado una actividad puzolánica cierta, por lo que se confirmó igualmente y una vez más el acierto de su selección. Y con este otro cemento Portland PY6 se volvió a presentar de nuevo, casi el mismo fenómeno que se presentó con los cementos de mezcla preparados con el cemento Portland P1. Puesto que la puzolana que cumplió esta vez el ensayo de Frattini a 28 días nada más, no sólo fue la puzolana O sino además la A, habiéndolo cumplido más y mejor conforme se aumentó también su porcentaje de reemplazo, sólo que a un rango o nivel de [CaO] mayor, puesto que el contenido de $\mathrm{C}_{3} \mathrm{~S}$ del cemento Portland matriz PY6 era bastante elevado y por ende mayor que el del P1, 79,43\%; habiéndose producido además la evolución del sistema "pasta de cemento parcialmente hidratada $<$ fase 
COMPORTAMIENTO SULFÁTICO Y MECÁNICO-RESISTENTE DE CEMENTOS PORTLAND CON ELEVADOS CONTENIDOS DE PUZOLANAS ( $>40 \%$ ): SU FUNDAMENTO QUÍMICO Y JUSTIFICACIÓN DE OTRAS CONSECUENCIAS POSIBLES

líquida" hacia la zona de sub-saturación, respecto a la de su cemento Portland de referencia PY6 puro. Y otro tanto le ocurrió también a los correspondientes valores de alcalinidad, $\left[\mathrm{OH}^{-}\right.$ ], sólo que amortiguados y disminuidos por el menor contenido de $\mathrm{Na}_{2} \mathrm{Oeq} .(\%)$ de dicho PY6 $0,56 \% \leq 0,60 \%$.

TABLA 6-11.- ENSAYO DE FRATTINI DE LOS CEMENTOS DE MEZCLA DEL CP PY6 CON CADA PUZOLANA SELECCIONADA: RESULTADOS A LAS EDADES DE 2, 7 Y 28 DÍAS.

\begin{tabular}{|c|c|c|c|c|c|c|}
\hline \multirow{5}{*}{$\begin{array}{l}\text { Cementos de } \\
\text { mezcla }\end{array}$} & \multicolumn{4}{|c|}{ PY6 } & & \\
\hline & \multirow{2}{*}{\multicolumn{2}{|c|}{2 días }} & \multicolumn{2}{|c|}{ Edad } & \multirow{2}{*}{\multicolumn{2}{|c|}{28 días }} \\
\hline & & & \multicolumn{2}{|c|}{7 días } & & \\
\hline & {$[\mathrm{CaO}]$} & {$\left[\mathrm{OH}^{-}\right]$} & {$[\mathrm{CaO}]$} & {$\left[\mathrm{OH}^{-}\right]$} & {$[\mathrm{CaO}]$} & {$\left[\mathrm{OH}^{-}\right]$} \\
\hline & $\mathrm{mM} \cdot \mathrm{l}^{-1}$ & $\mathrm{mM} \cdot \mathrm{l}^{-}$ & $\mathrm{mM} \cdot \mathrm{l}^{-1}$ & $\mathrm{mM} \cdot \mathrm{l}^{-}$ & $\mathrm{mM} \cdot \mathrm{l}^{-1}$ & $\mathrm{mM} \cdot \mathrm{l}^{-1}$ \\
\hline PY6/O80/20 & 21,00 & 45,00 & 16,45 & 47,50 & 11,00 & 50,50 \\
\hline PY6/O60/40 & 21,60 & 47,00 & 16,25 & 48,00 & 6,75 & 53,50 \\
\hline PY6/A 80/20 & 20,30 & 47,50 & 16,00 & 48,50 & 10,65 & 54,00 \\
\hline PY6/A 60/40 & 19,90 & 46,00 & 12,05 & 44,50 & 5,55 & 60,50 \\
\hline PY6/C80/20 & 11,15 & 56,00 & 7,60 & 64,75 & 5,25 & 83,00 \\
\hline PY6/C 60/40 & 5,00 & 61,50 & 1,55 & 86,95 & 0,60 & 100,00 \\
\hline PY6/CV10 80/20 & 21,75 & 45,50 & 10,25 & 41,50 & 8,75 & 43,50 \\
\hline PY6/CV10 60/40 & 21,35 & 45,50 & 8,45 & 35,00 & 5,50 & 47,50 \\
\hline PY6/CV19 80/20 & 20,65 & 44,00 & 13,95 & 40,50 & 10,00 & 40,50 \\
\hline PY6/CV19 60/40 & 21,05 & 45,00 & 11,20 & 35,50 & 4,25 & 35,50 \\
\hline PY6/M80/20 & 16,60 & 41,00 & 12,30 & 36,00 & 11,80 & 35,50 \\
\hline PY6/M60/40 & 11,15 & 28,00 & 5,30 & 19,80 & 5,05 & 21,50 \\
\hline
\end{tabular}

En color azul, aquellos cementos de mezcla que cumplieron el ensayo de Frattini

En definitiva, todas las puzolanas naturales y artificiales seleccionadas para la realización de esta investigación objeto de Tesis Doctoral, cumplieron el ensayo de puzolanicidad mediante el ensayo de Frattini (Frattini, 1949; UNE EN 196-5), por lo que se les puede atribuir con total fundamento que poseen actividad puzolánica cierta en mayor o menor grado. Lo que no obsta para que haya habido diferencias entre ellas en cuanto a la edad a la que lo cumplieron, debido no sólo a la muy diferente composición mineralógica potencial de los dos cementos Portland con los que se mezclaron, por separado, para este ensayo, sino además y sobre todo, debido a los correspondientes contenidos de los factores hidráulicos, $\mathrm{SiO}_{2}{ }^{\mathrm{r}}(\%)$ y $\mathrm{Al}_{2} \mathrm{O}_{3}{ }^{\mathrm{r}-}(\%)$ especialmente, de cada puzolana, los cuales fueron en realidad los que generaron y desarrollaran su actividad puzolánica más pronto o más tarde, de una forma u otra y en mayor o menor medida.

Por otra parte, y como se recordará, los cementos Portland de referencia, fueron ensayados también mediante el ensayo de Frattini, y sus resultados se han mostrado ya en el apartado 6.2.6. 


\subsection{7.- Determinación del Índice de actividad resistente en probetas de mortero normalizado.}

Una vez caracterizadas todas y cada una de las SEIS puzolanas seleccionadas, desde el punto de vista mineralógico, químico y físico, a cada una de ellas se las caracterizó también de forma mecánico-resistente relativa y absoluta en mortero normalizado (norma ASTM C 311), mediante sus correspondientes cementos de mezcla, 80/20, a los que se les determinó sus Índices de Actividad Resistente $-I A R_{x d}$ - a 28 días de edad, para lo que hubo que utilizar arena normalizada tipo ASTM C 778.

El Índice de Actividad Resistente (IAR) se define como la relación (en porcentaje) entre, la resistencia mecánica a compresión de probetas de mortero tipo ASTM C 109, fabricadas con cada una de las adiciones puzolánicas en estudio y un cemento Portland, en la proporción porcentual en masa 80/20, y la resistencia mecánica a compresión de las correspondientes probetas de mortero normalizado 1:2,75, fabricadas con un $100 \%$ del cemento Portland puro o de referencia, el cual para este ensayo se utilizó el cemento Portland P1. Su conservación se realizó sumergiéndolas en agua destilada hasta la edad de rotura en un relación 1/5 en volumen probetas/agua, para no provocar así la lixiviación de la portlandita generada fruto de la hidratación de la pasta de cemento.

Además y de acuerdo, con la citada norma ASTM C 311, el IAR a la edad de 28 días no debe ser inferior a $75 \%$. Y a tal efecto, es importante destacar además que, los valores de este parámetro mecánico relativo adicional, como es el "Índice de Actividad Resistente" (IAR), son de gran utilidad, al ser, en gran medida también, un fiel reflejo de la actividad puzolánica desarrollada por su fracción de puzolana respectiva. Hasta el punto, de que el veredicto emanado de sus resultados, de "aceptación" o "rechazo" para fabricar cementos y sus productos derivados, hormigones, morteros y pastas, es concordante con el emanado de sus correspondientes resultados del ensayo de Frattini.

Los resultados obtenidos de este parámetro mecánico relativo, IAR28dias, se muestran en la Tabla 6-12. Y de su análisis, estudio, discusión e interpretación se pudo confirmar, una vez más que, todas las puzolanas seleccionadas desarrollaron actividad puzolánica apreciable, verificada, como se ha dicho antes, con anterioridad mediante el ensayo de Frattini. Sin embargo, sus valores de $I A R_{28 d}$ fueron muy dispares a causa de su muy distintos contenidos de componentes reactivos $\left(\mathrm{SiO}_{2} \mathrm{r}-(\%)\right.$ y $\mathrm{Al}_{2} \mathrm{O}_{3}{ }^{\mathrm{r}}-(\%)$, no obstante, la reacción puzolánica que produjo cada una de ellas fue suficiente como para que sus prestaciones mecánico-resistentes pudieran ser calificadas, en general, de aceptables para poder, considerarlas, por tanto, como puzolanas.

Y una vez más, la razón de haber obtenido este diferente comportamiento de todas ellas con el cemento Portland de referencia P1, ha sido, como se ha dicho antes, los diferentes contenidos de $\mathrm{SiO}_{2}{ }^{\mathrm{r}-}$ y $\mathrm{Al}_{2} \mathrm{O}_{3}{ }^{\mathrm{r}-}$ especialmente, de cada puzolana seleccionada. La especificación del IAR28d de la norma ASTM C 618, lo superaron con facilidad, las puzolanas seleccionadas C, CV10 y M, es decir, aquellas que poseían un mayor contenido del factor hidráulico $\mathrm{Al}_{2} \mathrm{O}_{3}{ }^{\mathrm{r}-}(\%)$. 
COMPORTAMIENTO SULFÁTICO Y MECÁNICO-RESISTENTE DE CEMENTOS PORTLAND CON ELEVADOS CONTENIDOS DE PUZOLANAS (> 40\%): SU FUNDAMENTO QUÍMICO Y JUSTIFICACIÓN DE OTRAS CONSECUENCIAS POSIBLES

TABLA 6-12.- ÍNDICE DE ACTIVIDAD RESISTENTE, IAR, DE CADA UNA DE LAS ADICIONES PUZOLÁNICAS SELECCIONADAS MEZCLADAS CON EL CEMENTO PORTLAND P1 EN PROPORCIÓN 80/20 EN MASA. EDAD: 28 DÍAS.

Puzolanas Seleccionadas

\begin{tabular}{ccccccc}
\hline Parámetro mecánico-resistente & O & A & C & CV10 & CV19 & M \\
\hline IAR 28 dias $(\%)$ & 59,20 & 69,60 & 75,00 & 77,30 & 71,10 & 75,10 \\
\hline
\end{tabular}




\section{CAPÍTULO 7}

\section{METODOLOGÍA Y}

PROCEDIMIENTO EXPERIMENTAL 

A lo largo de este capítulo se van a describir las metodologías seguidas y los procedimientos experimentales utilizados para la dosificación ordenada y por separado de los materiales seleccionados, cementos Portland, 5 (3CPO y 2 CPRS), adiciones puzolánicas, 6 (3 puzolanas naturales, 2 cenizas volantes silíceas y 1 metacaolín), cal apagada y yeso para la preparación de pastas y morteros, así como se describirán también los análisis y ensayos realizados para la consecución de los objetivos propuestos.

De forma resumida se puede decir que la investigación se basó en la realización de los análisis y ensayos programados para alcanzar los objeticos propuestos con dichas pastas y morteros de cemento Portland con cada una de tales adiciones minerales puzolánicas, cal y yeso mezcladas con él por separado y en exclusiva, cuyas variables de diseño fueron las siguientes:

a) en primer lugar, los cementos Portland seleccionados fueron de muy diferente composición mineralógica, en cuanto a sus contenidos potenciales de $\mathrm{C}_{3} \mathrm{~S}(\%)$ y $\mathrm{C}_{3} \mathrm{~A}(\%)$ muy especialmente,

b) en segundo lugar, varias adiciones minerales: seis puzolánicas de muy distinto carácter químico. 
c) en tercer lugar, cal apagada -hidróxido de calcio, $\mathrm{Ca}(\mathrm{OH})_{2} \mathrm{y}$

d) por último, piedra de yeso natural, $\mathrm{CaSO}_{4} \cdot 2 \mathrm{H}_{2} \mathrm{O}$, molida.

El resto de las variables implicadas en la investigación, es decir: la relación agua-cemento, el grado de finura de molido o tamaño medio de las partículas de cada uno de los materiales seleccionados mencionados, los métodos de dosificación y mezclado de las pastas y los medios de curado y almacenamiento que se les aplicó fueron siempre los mismos. Por lo que sobre esta base, las diferencias de comportamiento que se obtuvieran entre las pastas y morteros de cada uno de ellos serían debidas a las cuatro variables anteriormente citadas, cuyo grado de compatibilidad tendrán influencia además sobre el comportamiento mecánico resistente y de respuesta frente al ataque de los sulfatos y del $\mathrm{CO}_{2}$ del aire o carbonatación negativa de sus morteros y pastas mencionados, respectivamente.

Así pues, el planteamiento y desarrollo general de la Parte Experimental de esta investigación, se ha realizado del siguiente modo:

Basándonos en los Objetivos, Fundamentos e Hipótesis de Trabajo de la misma así como también en las Conclusiones correspondientes de la parte operatoria previa de la Memoria de la Tesis Doctoral de Talero, (1986) y en especial en el cuestionamiento realizado por dicho autor en la última de las mismas, referente al posible Efecto expansivo Aditivo, Sinérgico, Antagónico o Inverso que se puede producir entre la ett-rf o de origen $\mathrm{Al}_{2} \mathrm{O}_{3}{ }^{\mathrm{r}-}$ de una puzolana y la ett-lf o de origen $\mathrm{C}_{3} \mathrm{~A}$ de un cemento Portland Ordinario (CPO), al encontrarse ambos materiales cementiceos juntos y en exclusiva en un medio selenitoso común pero en forma de cemento Puzolánico Tipo CEM IV/B y Mixto o Tipo V constituido también por CPO y puzolana únicamente Instrucción RC-16, cuya respuesta la dio lógicamente dicho autor demostrando experimentalmente que dicho Efecto expansivo era Sinérgico (de forma abreviada ESE). Dado el tema de investigación que nos ocupa, se trató de manifestar, exponer y precisar dicho tipo de ESE, según hubiera o no, cantidad de $\mathrm{Ca}(\mathrm{OH})_{2}$ necesaria y suficiente para ello, mediante la puesta en práctica y preparación de las mezclas hidráulicas correspondientes las cuales serían ensayadas en RS mediante el método acelerado de ensayo L-A (Blondiau, 1961) y en RM en carbonatación negativa en forma de probetas de 4x4x16 cm, de mortero normalizado tipo EN 196-1, lo que ha conformado, como decimos, la Parte Experimental de esta investigación. Así pues y, en consecuencia, se ha operado de la siguiente manera:

Seleccionados y elegidos con el fundamento debido, como se ha visto en el capítulo 3, cinco cementos Portland y seis puzolanas, en primer lugar, se procedió a determinar las RS tanto de los cementos Portland como de todos y cada uno de los cementos de mezcla preparados y dosificados en el laboratorio con o sin $\mathrm{CH}$ y/o yeso, mediante el método acelerado de ensayo Le Chatelier Anstett (Blondiau, 1961) (método de pasta selenitosa). Este método se utiliza para determinar la resistencia potencial de los cementos al ataque de los sulfatos, pero adaptado por Talero (1986; 1987; 2002), permite además la caracterización sulfática de las adiciones puzolánicas (Talero, 
1993a), pudiéndose deducir de sus resultados en un corto espacio de tiempo, en 28 días tan sólo, el carácter químico más o menos alumínico de la puzolana que así se ensaye y con él la durabilidad química que le puede llegar a conferir al cemento Portland al que reemplace y a sus productos derivados, hormigones, morteros, pastas y prefabricados, del que forme parte, frente al ataque de un medio químico agresivo o no determinado. Por todo ello, también se caracterizaron sulfáticamente todas las adiciones puzolánicas seleccionadas para esta investigación objeto de Tesis Doctoral.

Paralelamente, se procedió a la determinación de las correspondientes resistencias mecánicas en probetas de 4x4×16 cm de mortero normalizado tipo EN 196-1, de cada uno de los cementos de mezcla propuestos, determinándoseles, las propias a flexotracción, y a compresión a las edades de 7, 28 y 90 días según la norma EN 196-1, para lo cual hubo que utilizar también arena silícea normalizada CEN EN 196-1. Para la realización de estos ensayos, se prepararon mezclas de de cada uno de los 5 cementos Portland seleccionados con todas y cada una de las adiciones minerales puzolánicas seleccionadas también por separado y en proporciones idénticas a las correspondientes probetas cilíndricas de $\varnothing 80 \mathrm{~mm}$ x $30 \mathrm{~mm}$ que fueron sometidas al ensayo de ataque por los sulfatos de Le Chatelier Anstett. Así, la determinación de las resistencias mecánicas a flexotracción y a compresión a las edades de 7, 28 y 90 días, se realizó fabricando tres probetas de mortero normalizado 1:3 de dimensiones $4 \times 4 \times 16 \mathrm{~cm}$ con cada cemento adicionado preparado y edad de Mortero.

Por otra parte, se determinó la actividad puzolánica de cada una de las 6 adiciones minerales puzolánicas seleccionadas, y lo que es más importante, la evolución de la [CaO] y la $\left[\mathrm{OH}^{-}\right]$de la fase líquida de cada pasta de cemento a 7 y 28 días.

Por último, se procedió a la determinación de la velocidad de penetración de la carbonatación negativa en probetas idénticas a las que fueron ensayadas mecánicamente a flexotracción, y a compresión a las edades de 7, 28 y 90 días según la norma EN 196-1. El método de ensayo utilizado fue escogido para la determinación acelerada de la profundidad de carbonatación negativa en el hormigón endurecido y en morteros a partir de la exposición en una cámara con concentraciones del $20 \%$ de dióxido de carbono $\left(\mathrm{CO}_{2}\right)$.

Los métodos de estudio fueron planificados de modo que finalmente fuera posible discernir qué efecto provoca cada una de las variables de las que dependía esta investigación: composición mineralógica del cemento Portland, propiedades y carácter químico de las adiciones minerales puzolánicas, el porcentaje de reemplazo y por último, la adición o no de cal apagada. Sólo de este modo, los resultados experimentales que se obtuvieran posibilitarían validar la hipótesis de trabajo que se estableció de partida, así como también, establecer diversas conclusiones en lo referente al comportamiento mecánico-resistente y a la potencial resistencia o no al ataque de los sulfatos y de la carbonatación negativa de los cementos de mezcla de base Portland altamente adicionados con puzolanas para extrapolarlo, así al comportamiento de sus productos derivados, hormigones, morteros, pastas y prefabricados.

Y dado el número y la diversidad de pastas y morteros que se tuvieron que dosificar y preparar con los materiales seleccionados, 5 cemento Portland y 6 puzolanas, así como también 
COMPORTAMIENTO SULFÁTICO Y MECÁNICO-RESISTENTE DE CEMENTOS PORTLAND CON ELEVADOS CONTENIDOS DE PUZOLANAS ( $>40 \%$ ): SU FUNDAMENTO QUÍMICO Y JUSTIFICACIÓN DE OTRAS CONSECUENCIAS POSIBLES

de los métodos y procedimientos utilizados, se ha creído conveniente realizar la representación esquemática de la Fig. 7-1, de modo que desde un principio le quedará claro al lector de esta MEMORIA de Tesis Doctoral, todo lo que de aquí en adelante se expondrá, sin menoscabo de que cada una de las caracterizaciones se describa además detalladamente a lo largo de este capítulo.

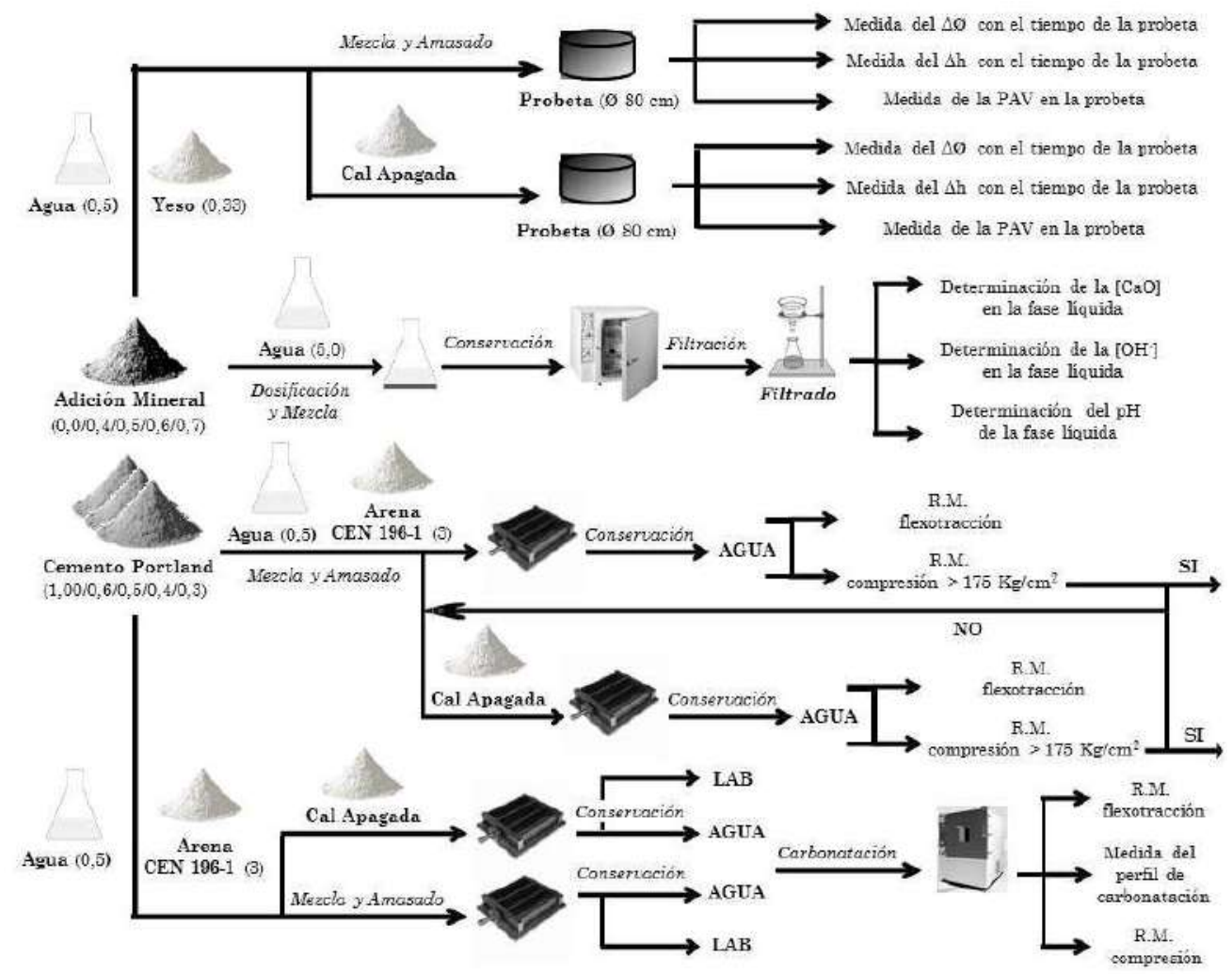

FIGURA 7-1.- REPRESENTACIÓN ESQUEMÁTICA CON EL RESUMEN DEL PLAN EXPERIMENTAL DE ENSAYOS Y ANÁLISIS REALIZADOS A LAS DIFERENTES PASTAS Y MORTEROS OBJETO DE INVESTIGACIÓN.

\section{1.- Dosificación de los materiales. Cementos de mezcla propuestos.}

Para la realización de los análisis y ensayos programados, se dosificaron y mezclaron distintos cementos de mezcla con cada uno de los cinco cementos Portland seleccionados y cada una de las 6 puzolanas, además, a varias de ellas se le adicionaron, por un lado, cal apagada, y por otro yeso. $\mathrm{Y}$ a tal efecto es preciso reseñar que las combinaciones de mezcla entre los cementos Portland y las puzolanas fueron 161 al combinar todas y cada una de ellas con todos y cada uno de los cementos Portland por separado y en exclusiva, en varios porcentajes de reemplazo que fueron los siguientes, a saber:

- $\quad \mathrm{P} 1$ 100/00 $\rightarrow$ 100\% CEM I 42,5R (CEM I).

- P1/M 60/40 $\rightarrow$ 60\% CEM I 42,5R + 40\% Metacaolín (No contemplado por RC-16). 
- P1/M 50/50 $\rightarrow 50 \%$ CEM I 42,5R + 50\% Metacaolín (No contemplado por RC-16).

- P1/M 50/50 + CH $\rightarrow 50 \%$ CEM I 42,5R + 50\% Metacaolín + CH (No contemplado).

- P1/M 40/60 $\rightarrow 40 \%$ CEM I 42,5R + 60\% Metacaolín (No contemplado por RC-16).

- $\mathrm{P} 1 / \mathrm{M} 40 / 60+\mathrm{CH} \rightarrow 40 \%$ CEM I 42,5R + 60\% Metacaolín + CH (No contemplado).

- $\mathrm{P} 1 / \mathrm{M} 30 / 70 \rightarrow 30 \%$ CEM I 42,5R + 70\% Metacaolín (No contemplado por RC-16).

- $\mathrm{P} 1 / \mathrm{M} 30 / 70+\mathrm{CH} \rightarrow 30 \%$ CEM I 42,5R + 70\% Metacaolín + CH (No contemplado).

- $\mathrm{P} 1 / \mathrm{CV} 1060 / 40 \rightarrow 60 \%$ CEM I 42,5R + 40\% Ceniza Volante (CEM IV/B).

- P1/CV10 50/50 $\rightarrow$ 50\% CEM I 42,5R + 50\% Ceniza Volante (CEM IV/B).

- $\mathrm{P} 1 / \mathrm{CV} 1050 / 50+\mathrm{CH} \rightarrow 50 \%$ CEM I 42,5R + 50\% Ceniza Volante $+\mathrm{CH}$ (No cont.)

- P1/CV10 40/60 $\rightarrow$ 40\% CEM I 42,5R + 60\% Ceniza Volante (ESP-VI).

- P1/CV10 40/60 + CH $\rightarrow 40 \%$ CEM I 42,5R + 60\% Ceniza Volante + CH (No cont.).

- $\mathrm{P} 1 / \mathrm{CV} 10$ 30/70 $\rightarrow$ 30\% CEM I 42,5R + 70\% Ceniza Volante (ESP-VI).

- $\mathrm{P} 1 / \mathrm{CV} 10$ 30/70 + CH $\rightarrow 30 \%$ CEM I 42,5R + 70\% Ceniza Volante + CH (No cont.).

- $\mathrm{P} 1 / \mathrm{C} 60 / 40 \rightarrow 60 \%$ CEM I 42,5R + 40\% Puzolana Natural (CEM IV/B).

- $\mathrm{P} 1 / \mathrm{C} 50 / 50 \rightarrow 50 \%$ CEM I 42,5R + 50\% Puzolana Natural (CEM IV/B).

- $\mathrm{P} 1 / \mathrm{C} 50 / 50+\mathrm{CH} \rightarrow 50 \%$ CEM I 42,5R + 50\% Puzolana Natural + CH (No cont.)

- $\mathrm{P} 1 / \mathrm{C} 40 / 60 \rightarrow 40 \%$ CEM I 42,5R + 60\% Puzolana Natural (ESP-VI).

- $\mathrm{P} 1 / \mathrm{C} 40 / 60+\mathrm{CH} \rightarrow 40 \%$ CEM I 42,5R + 60\% Puzolana Natural + CH (No cont.).

- $\mathrm{P} 1 / \mathrm{C} 30 / 70+\mathrm{CH} \rightarrow 30 \%$ CEM I 42,5R + 70\% Puzolana Natural + CH (No cont.).

- P1/A 60/40 $\rightarrow$ 60\% CEM I 42,5R + 40\% Puzolana Natural (CEM IV/B).

- P1/A 50/50 $\rightarrow 50 \%$ CEM I 42,5R + 50\% Puzolana Natural (CEM IV/B).

- P1/A 50/50 + CH $\rightarrow 50 \%$ CEM I 42,5R + 50\% Puzolana Natural + CH (No cont.)

- P1/A 40/60 $\rightarrow 40 \%$ CEM I 42,5R + 60\% Puzolana Natural (ESP-VI).

- $\mathrm{P} 1 / \mathrm{A} 40 / 60+\mathrm{CH} \rightarrow 40 \%$ CEM I 42,5R + 60\% Puzolana Natural + CH (No cont.).

- $\mathrm{P} 1 / \mathrm{A} 30 / 70+\mathrm{CH} \rightarrow 30 \%$ CEM I 42,5R + 70\% Puzolana Natural + CH (No cont.).

- $\mathrm{P} 1 / \mathrm{O} 60 / 40 \rightarrow 60 \%$ CEM I 42,5R + 40\% Puzolana Natural (CEM IV/B).

- $\mathrm{P} 1 / \mathrm{O} 50 / 50 \rightarrow 50 \%$ CEM I 42,5R + 50\% Puzolana Natural (CEM IV/B).

- $\mathrm{P} 1 / \mathrm{O} 50 / 50+\mathrm{CH} \rightarrow 50 \%$ CEM I 42,5R + 50\% Puzolana Natural + CH (No cont.)

- $\mathrm{P} 1 / \mathrm{O} 40 / 60 \rightarrow 60 \%$ CEM I 42,5R + 50\% Puzolana Natural (CEM IV/B).

- $\mathrm{P} 1 / \mathrm{O} 40 / 60+\mathrm{CH} \rightarrow 60 \%$ CEM I 42,5R + 50\% Puzolana Natural + CH (No cont.) 
- P1/CV19 60/40 $\rightarrow 60 \%$ CEM I 42,5R + 40\% Ceniza Volante (CEM IV/B).

- P1/CV19 50/50 $\rightarrow$ 50\% CEM I 42,5R + 50\% Ceniza Volante (CEM IV/B).

- $\quad \mathrm{P} 1 / \mathrm{CV} 1950 / 50+\mathrm{CH} \rightarrow 50 \%$ CEM I 42,5R + 50\% Ceniza Volante + CH (No cont.)

- $\quad \mathrm{P} 1 / C V 1940 / 60 \rightarrow 40 \%$ CEM I 42,5R + 60\% Ceniza Volante (ESP-VI).

- $\mathrm{P} 1 / \mathrm{CV} 19$ 40/60 + CH $\rightarrow 40 \%$ CEM I 42,5R + 60\% Ceniza Volante + CH (No cont.).

- $\quad$ P2 100/00 $\rightarrow 100 \%$ CEM I 42,5R (CEM I).

- P2/M 60/40 $\rightarrow 60 \%$ CEM I 42,5R + 40\% Metacaolín (No contemplado por RC-16).

- P2/M 50/50 $\rightarrow 50 \%$ CEM I 42,5R + 50\% Metacaolín (No contemplado por RC-16).

- $\mathrm{P} 2 / \mathrm{M} 50 / 50+\mathrm{CH} \rightarrow 50 \%$ CEM I 42,5R + 50\% Metacaolín + CH (No contemplado).

- P2/M 40/60 $\rightarrow 40 \%$ CEM I 42,5R + 60\% Metacaolín (No contemplado por RC-16).

- $\quad \mathrm{P} 2 / \mathrm{M} 40 / 60+\mathrm{CH} \rightarrow 40 \%$ CEM I 42,5R + 60\% Metacaolín + CH (No contemplado).

- P2/M 30/70 $\rightarrow$ 30\% CEM I 42,5R + 70\% Metacaolín (No contemplado por RC-16).

- $\mathrm{P} 2 / \mathrm{M} 30 / 70+\mathrm{CH} \rightarrow 30 \%$ CEM I 42,5R + 70\% Metacaolín + CH (No contemplado).

- P2/CV10 60/40 $\rightarrow$ 60\% CEM I 42,5R + 40\% Ceniza Volante (CEM IV/B).

- P2/CV10 50/50 $\rightarrow$ 50\% CEM I 42,5R + 50\% Ceniza Volante (CEM IV/B).

- $\mathrm{P} 2 / \mathrm{CV} 1050 / 50+\mathrm{CH} \rightarrow 50 \%$ CEM I 42,5R + 50\% Ceniza Volante $+\mathrm{CH}$ (No cont.)

- $\mathrm{P} 2 / \mathrm{CV} 10$ 40/60 $\rightarrow 40 \%$ CEM I 42,5R + 60\% Ceniza Volante (ESP-VI).

- $\mathrm{P} 2 / \mathrm{CV} 10$ 40/60 + CH $\rightarrow 40 \%$ CEM I 42,5R + 60\% Ceniza Volante + CH (No cont.).

- $\mathrm{P} 2 / \mathrm{CV} 10$ 30/70 $\rightarrow 30 \%$ CEM I 42,5R + 70\% Ceniza Volante (ESP-VI).

- $\mathrm{P} 2 / \mathrm{C} 60 / 40 \rightarrow 60 \%$ CEM I 42,5R + 40\% Puzolana Natural (CEM IV/B).

- P2/C 50/50 $\rightarrow 50 \%$ CEM I 42,5R + 50\% Puzolana Natural (CEM IV/B).

- $\mathrm{P} 2 / \mathrm{C} 50 / 50+\mathrm{CH} \rightarrow 50 \%$ CEM I 42,5R + 50\% Puzolana Natural + CH (No cont.)

- P2/A 60/40 $\rightarrow 60 \%$ CEM I 42,5R + 40\% Puzolana Natural (CEM IV/B).

- P2/A 50/50 $\rightarrow$ 50\% CEM I 42,5R + 50\% Puzolana Natural (CEM IV/B).

- P2/A 50/50 + CH $\rightarrow 50 \%$ CEM I 42,5R + 50\% Puzolana Natural + CH (No cont.)

- $\mathrm{P} 2 / \mathrm{O} 60 / 40 \rightarrow 60 \%$ CEM I 42,5R + 40\% Puzolana Natural (CEM IV/B).

- $\quad \mathrm{P} 2 / \mathrm{O} 50 / 50 \rightarrow 50 \%$ CEM I 42,5R + 50\% Puzolana Natural (CEM IV/B).

- $\mathrm{P} 2 / \mathrm{O} 50 / 50+\mathrm{CH} \rightarrow 50 \%$ CEM I 42,5R + 50\% Puzolana Natural + CH (No cont.)

- P2/CV19 60/40 $\rightarrow$ 60\% CEM I 42,5R + 40\% Ceniza Volante (CEM IV/B). 
- P2/CV19 50/50 $\rightarrow$ 50\% CEM I 42,5R + 50\% Ceniza Volante (CEM IV/B).

- $\quad \mathrm{P} 2 / \mathrm{CV} 1950 / 50+\mathrm{CH} \rightarrow 50 \%$ CEM I 42,5R + 50\% Ceniza Volante $+\mathrm{CH}$ (No cont.)

- P31 100/00 $\rightarrow$ 100\% CEM I 42,5R (CEM I).

- P31/M 60/40 $\rightarrow$ 60\% CEM I 42,5R + 40\% Metacaolín (No contemplado por RC-16).

- P31/M 50/50 $\rightarrow$ 50\% CEM I 42,5R + 50\% Metacaolín (No contemplado por RC-16).

- P31/M 40/60 $\rightarrow 40 \%$ CEM I 42,5R + 60\% Metacaolín (No contemplado por RC-16).

- P31/M 40/60 + CH $\rightarrow 40 \%$ CEM I 42,5R + 60\% Metacaolín + CH (No contemplado).

- P31/M 30/70 $\rightarrow$ 30\% CEM I 42,5R + 70\% Metacaolín (No contemplado por RC-16).

- P31/M 30/70 + CH $\rightarrow$ 30\% CEM I 42,5R + 70\% Metacaolín + CH (No contemplado).

- P31/CV10 60/40 $\rightarrow$ 60\% CEM I 42,5R + 40\% Ceniza Volante (CEM IV/B).

- P31/CV10 50/50 $\rightarrow$ 50\% CEM I 42,5R + 50\% Ceniza Volante (CEM IV/B).

- $\mathrm{P} 31 / \mathrm{CV} 10$ 40/60 $\rightarrow$ 40\% CEM I 42,5R + 60\% Ceniza Volante (ESP-VI).

- $\mathrm{P} 31 / \mathrm{CV} 10$ 40/60 + CH $\rightarrow 40 \%$ CEM I 42,5R + 60\% Ceniza Volante + CH (No cont.).

- $\quad \mathrm{P} 31 / \mathrm{CV} 10$ 30/70 $\rightarrow$ 30\% CEM I 42,5R + 70\% Ceniza Volante (ESP-VI).

- $\mathrm{P} 31 / \mathrm{CV} 10$ 30/70 + CH $\rightarrow 40 \%$ CEM I 42,5R + 60\% Ceniza Volante + CH (No cont.).

- P31/C 60/40 $\rightarrow$ 60\% CEM I 42,5R + 40\% Puzolana Natural (CEM IV/B).

- P31/C 50/50 $\rightarrow$ 50\% CEM I 42,5R + 50\% Puzolana Natural (CEM IV/B).

- P31/C 40/60 $\rightarrow 40 \%$ CEM I 42,5R + 60\% Ceniza Volante (ESP-VI).

- $\mathrm{P} 31 / \mathrm{C} 40 / 60+\mathrm{CH} \rightarrow 40 \%$ CEM I 42,5R + 60\% Puzolana Natural + CH (No cont.).

- P31/A 60/40 $\rightarrow 60 \%$ CEM I 42,5R + 40\% Puzolana Natural (CEM IV/B).

- P31/A 50/50 $\rightarrow 50 \%$ CEM I 42,5R + 50\% Puzolana Natural (CEM IV/B).

- P31/A 40/60 $\rightarrow$ 40\% CEM I 42,5R + 60\% Puzolana Natural (ESP-VI).

- P31/A 40/60 + CH $\rightarrow 40 \%$ CEM I 42,5R + 60\% Puzolana Natural + CH (No cont.).

- $\mathrm{P} 31 / \mathrm{O} 60 / 40 \rightarrow 60 \%$ CEM I 42,5R + 40\% Puzolana Natural (CEM IV/B).

- $\mathrm{P} 31 / \mathrm{O} 50 / 50 \rightarrow 50 \%$ CEM I 42,5R + 50\% Puzolana Natural (CEM IV/B).

- $\mathrm{P} 31 / \mathrm{O} 50 / 50+\mathrm{CH} \rightarrow 50 \%$ CEM I 42,5R + 50\% Puzolana Natural + CH (No cont.)

- $\mathrm{P} 31 / \mathrm{O} 40 / 60 \rightarrow 40 \%$ CEM I 42,5R + 60\% Puzolana Natural (ESP-VI).

- $\mathrm{P} 31 / \mathrm{O} 40 / 60+\mathrm{CH} \rightarrow 40 \%$ CEM I 42,5R + 60\% Puzolana Natural + CH (No cont.).

- P31/CV19 60/40 $\rightarrow$ 60\% CEM I 42,5R + 40\% Ceniza Volante (CEM IV/B).

- P31/CV19 50/50 $\rightarrow$ 50\% CEM I 42,5R + 50\% Ceniza Volante (CEM IV/B). 
- $\quad \mathrm{P} 31 / \mathrm{CV} 19$ 50/50 + CH $\rightarrow 50 \%$ CEM I 42,5R + 50\% Ceniza Volante + CH (No cont.)

- $\quad$ P31/CV19 40/60 $\rightarrow$ 50\% CEM I 42,5R + 50\% Ceniza Volante (CEM IV/B).

- P31/CV19 40/60 + CH $\rightarrow$ 50\% CEM I 42,5R + 50\% Ceniza Volante + CH (No cont.)

- $\quad$ PY4 100/00 $\rightarrow 100 \%$ CEM I 42,5N SR (CEM I).

- PY4/M 60/40 $\rightarrow$ 60\% CEM I 42,5N SR + 40\% Metacaolín (No contemplado).

- PY4/M 50/50 $\rightarrow$ 50\% CEM I 42,5N SR + 50\% Metacaolín (No contemplado).

- PY4/M 50/50 + CH $\rightarrow$ 50\% CEM I 42,5N SR + 50\% Metacaolín + CH (No cont.).

- PY4/M 40/60 $\rightarrow 40 \%$ CEM I 42,5N SR + 60\% Metacaolín (No contemplado).

- PY4/M 40/60 + CH $\rightarrow 40 \%$ CEM I 42,5N SR + 60\% Metacaolín + CH (No cont.).

- PY4/CV10 60/40 $\rightarrow$ 60\% CEM I 42,5N SR + 40\% Ceniza Volante (CEM IV/B).

- PY4/CV10 50/50 $\rightarrow$ 50\% CEM I 42,5N SR + 50\% Ceniza Volante (CEM IV/B).

- PY4/CV10 50/50 + CH $\rightarrow$ 50\% CEM I 42,5N SR + 50\% Ceniza Volante + CH (No c.).

- PY4/CV10 40/60 $\rightarrow$ 40\% CEM I 42,5N + 60\% Ceniza Volante (ESP-VI).

- PY4/CV10 40/60 + CH $\rightarrow$ 40\% CEM I 42,5N SR + 60\% Ceniza Volante + CH (No c.).

- PY4/C 60/40 $\rightarrow 60 \%$ CEM I 42,5N SR + 40\% Puzolana Natural (CEM IV/B).

- PY4/C 50/50 $\rightarrow 50 \%$ CEM I 42,5N SR + 50\% Puzolana Natural (CEM IV/B).

- PY4/C 50/50 + CH $\rightarrow 50 \%$ CEM I 42,5N SR + 50\% Puzolana Natural + CH (No c.).

- PY4/C 40/60 $\rightarrow$ 40\% CEM I 42,5N SR + 60\% Puzolana Natural (ESP-VI).

- PY4/C 40/60 + CH $\rightarrow 40 \%$ CEM I 42,5N SR + 60\% Puzolana Natural + CH (No c.).

- PY4/A 60/40 $\rightarrow$ 60\% CEM I 42,5N SR + 40\% Puzolana Natural (CEM IV/B).

- PY4/A 50/50 $\rightarrow$ 50\% CEM I 42,5N SR + 50\% Puzolana Natural (CEM IV/B).

- PY4/A 50/50 + CH $\rightarrow 50 \%$ CEM I 42,5N SR+ 50\% Puzolana Natural + CH (No c.).

- PY4/A 40/60 $\rightarrow 40 \%$ CEM I 42,5N SR+ 60\% Puzolana Natural (ESP-VI).

- PY4/A 40/60 + CH $\rightarrow 40 \%$ CEM I 42,5N SR+60\% Puzolana Natural + CH (No c.).

- PY4/O 60/40 $\rightarrow$ 60\% CEM I 42,5N SR + 40\% Puzolana Natural (CEM IV/B).

- PY4/O 50/50 $\rightarrow$ 50\% CEM I 42,5N SR + 50\% Puzolana Natural (CEM IV/B).

- PY4/O 50/50 + CH $\rightarrow 50 \%$ CEM I 42,5N SR+ 50\% Puzolana Natural + CH (No cont.)

- PY4/CV19 60/40 $\rightarrow$ 60\% CEM I 42,5N SR + 40\% Ceniza Volante (CEM IV/B).

- PY4/CV19 50/50 $\rightarrow$ 50\% CEM I 42,5N SR + 50\% Ceniza Volante (CEM IV/B). 
- PY4/CV19 50/50 + CH $\rightarrow 50 \%$ CEM I 42,5N SR + 50\% Ceniza Volante + CH (No c.)

- PY6 100/00 $\rightarrow 100 \%$ CEM I 42,5N SR (CEM I).

- PY6/M 60/40 $\rightarrow$ 60\% CEM I 42,5N SR + 40\% Metacaolín (No contemplado).

- PY6/M 50/50 $\rightarrow$ 50\% CEM I 42,5N SR + 50\% Metacaolín (No contemplado).

- PY6/M 50/50 + CH $\rightarrow 50 \%$ CEM I 42,5N SR + 50\% Metacaolín + CH (No cont.).

- PY6/M 40/60 $\rightarrow$ 40\% CEM I 42,5N SR + 60\% Metacaolín (No contemplado).

- PY6/M 40/60 + CH $\rightarrow$ 40\% CEM I 42,5N SR + 60\% Metacaolín + CH (No cont.).

- PY6/M 30/70 $\rightarrow$ 30\% CEM I 42,5N SR + 70\% Metacaolín (No contemplado).

- PY6/M 30/70 + CH $\rightarrow$ 30\% CEM I 42,5N SR + 70\% Metacaolín + CH (No cont.).

- PY6/CV10 60/40 $\rightarrow 60 \%$ CEM I 42,5N SR + 40\% Ceniza Volante (CEM IV/B).

- PY6/CV10 50/50 $\rightarrow$ 50\% CEM I 42,5N SR + 50\% Ceniza Volante (CEM IV/B).

- PY6/CV10 50/50 + CH $\rightarrow$ 50\% CEM I 42,5N SR + 50\% Ceniza Volante + CH (No c.).

- PY6/CV10 40/60 $\rightarrow$ 40\% CEM I 42,5N + 60\% Ceniza Volante (ESP-VI).

- PY6/CV10 30/70 $\rightarrow$ 30\% CEM I 42,5N SR + 70\% Ceniza Volante (ESP-VI).

- PY6/CV10 30/70 + CH $\rightarrow$ 30\% CEM I 42,5N SR + 70\% Ceniza Volante + CH (No c.).

- PY64/C 60/40 $\rightarrow 60 \%$ CEM I 42,5N SR + 40\% Puzolana Natural (CEM IV/B).

- PY6/C 50/50 $\rightarrow 50 \%$ CEM I 42,5N SR + 50\% Puzolana Natural (CEM IV/B).

- PY6/C 50/50 + CH $\rightarrow 50 \%$ CEM I 42,5N SR + 50\% Puzolana Natural + CH (No c.).

- PY6/C 40/60 $\rightarrow$ 40\% CEM I 42,5N SR + 60\% Puzolana Natural (ESP-VI).

- PY6/A 60/40 $\rightarrow$ 60\% CEM I 42,5N SR + 40\% Puzolana Natural (CEM IV/B).

- PY6/A 50/50 $\rightarrow$ 50\% CEM I 42,5N SR + 50\% Puzolana Natural (CEM IV/B).

- PY6/A 50/50 + CH $\rightarrow 50 \%$ CEM I 42,5N SR+ 50\% Puzolana Natural + CH (No c.).

- PY6/A 40/60 $\rightarrow 40 \%$ CEM I 42,5N SR+ 60\% Puzolana Natural (ESP-VI).

- PY6/O 60/40 $\rightarrow$ 60\% CEM I 42,5N SR + 40\% Puzolana Natural (CEM IV/B).

- PY6/O 50/50 $\rightarrow$ 50\% CEM I 42,5N SR + 50\% Puzolana Natural (CEM IV/B).

- PY6/O 50/50 + CH $\rightarrow$ 50\% CEM I 42,5N SR+ 50\% Puzolana Natural + CH (No cont.)

- PY6/O 40/60 $\rightarrow 40 \%$ CEM I 42,5N SR + 60\% Puzolana Natural (CEM IV/B).

- PY6/CV19 60/40 $\rightarrow$ 60\% CEM I 42,5N SR + 40\% Ceniza Volante (CEM IV/B).

- PY6/CV19 50/50 $\rightarrow$ 50\% CEM I 42,5N SR + 50\% Ceniza Volante (CEM IV/B).

- PY6/CV19 50/50 + CH $\rightarrow$ 50\% CEM I 42,5N SR + 50\% Ceniza Volante + CH (No c.) 
- PY6/CV19 40/60 $\rightarrow$ 40\% CEM I 42,5N SR + 60\% Ceniza Volante (ESP-VI).

Haber dosificado de esta manera los cementos Portland y las puzolanas, en las proporciones porcentuales de mezcla $60 \% / 40 \%, 50 \% / 50 \%, 40 \% / 60 \%$ y $30 \% / 70 \%$ en peso, cemento Portland/Puzolana, hizo que, en la mayoría de los casos, los cementos de mezcla así preparados pudieran ser asimilados o equiparados, en función de su composición, a los cementos tipo CEM IV/B y ESP VI, respectivamente, de acuerdo con la vigente Instrucción de Cementos RC-16. Para el caso particular del metacaolín, ninguno de los cementos de mezcla preparados con esta puzolana pudo ajustarse a ninguna designación recogida en dicha Instrucción en vigor de Cementos RC-16.

No obstante, y a pesar de lo anterior, para poder alcanzar los objetivos de esta investigación objeto de Tesis Doctoral, hubo necesidad de dosificar, preparar y ensayar también del mismo modo, otros cementos de mezcla adicionales, con el fin de tener un perfecto rango de variabilidad de mezclas, con y sin cal apagada en su composición, y para tener perfectamente definida toda la población de cementos y adiciones minerales, puzolánicas que se pueden encontrar en la actualidad.

Y en cuanto a la relación agua/cemento utilizada, que tan importante resulta ser para el estudio de las propiedades físicas, mecánico-resistentes y de durabilidad de los cementos de mezcla dosificados y para todos los cementos, en general, se utilizaron dos relaciones en función del parámetro o propiedad de la pasta o mortero a determinar o analizar:

a) Cuando la fase líquida de la pasta fresca fue el componente a analizar, la relación agua/cemento fue de 5, es decir, la misma relación que la utilizada en el ensayo de Frattini (1949). Dicha relación a/c se utilizó para los ensayos y análisis de determinación de las [CaO] y $\left[\mathrm{OH}^{-}\right]$de la fase líquida constitutiva de cada pasta y la determinación de su pH.

b) Cuando el comportamiento mecánico-resistente y la durabilidad fueron los vectores o parámetros sujetos a determinación, la relación agua/cemento utilizada fue, en cambio, de 0,5. Esta relación se utilizó para los casos del ensayo mecánico-resistente de acuerdo con la norma EN 196-1 y para los ensayos de durabilidad frente al ion sulfato (Le Chatelier-Anstett) y el $\mathrm{CO}_{2}$ del aire o carbonatación negativa.

Todos los análisis y ensayos programados se realizaron siguiendo la secuencia de procedimientos que se detalla a continuación:

1. Primeramente, se han analizado y estudiado, discutido e interpretado los resultados experimentales obtenidos tanto de RM, como de RS, de los 5 CP puros, 3 P-nº y 2 PY-no . Dicho análisis, estudio, discusión e interpretación se encuentran en el apartado 8.2.1.

2. A continuación, se realizó otro tanto con los resultados experimentales obtenidos de RS y RM de los correspondientes cementos de mezcla con o $\sin \mathrm{CH}$ y/o yeso, respectivamente, que fueron los siguientes: 
a. P-n o ${ }^{\circ}$ PY-n $/ " Z ", 60 \% / 40 \%$ (= 60/40) para determinarles sus valores de RMC7, 28 y 90d y RMF7, 28 y 90d, únicamente,

b. P-n ó PY-n ${ }^{\circ} / Z ", 50 \% / 50 \%$ (= 50/50), 40\%/60\% (= 40/60), 30\%/70\% (=30/70) y 20\%/80\% (= 20/80),

c. P-n ó PY-n $/ " Z ", 50 \% /(40 \%+10 \% C H)(=50 / 40+10 \mathrm{CH}), 40 \% /(50 \%+10 \% \mathrm{CH})(=40 / 50+$ $10 \mathrm{CH})$,

d. P-1 ó PY-6/S4, 50\%/50\% (= 50/50),

e. P-n ${ }^{\circ}$ y/o PY-n $/(" Z "+C H), 40 \% /(50 \%+10 \% \mathrm{CH})(=40 / 50+10 \mathrm{CH})$,

f. P-1 ó PY $-6 / S 440 \% / 60 \%=(40 / 60)$,

g. P-n ${ }^{\circ}$ y/o PY-n $/(" Z "+C H), 30 \% /(60 \%+10 \% \mathrm{CH})(=30 / 60+10 \mathrm{CH})$,

h. P-n ${ }^{\circ}$ y/o PY-n /("Z" + CH + Yeso), 30\%/(60\% + 10\% CH) + (7.0\% SO3),

i. $\mathrm{P}-\mathrm{n}^{\circ} \mathrm{y} / \mathrm{o} \mathrm{PY}-\mathrm{n}^{\circ} /(" \mathrm{Z} " \mathrm{CH}+\mathrm{Yeso}), 20 \% /(70 \%+10 \% \mathrm{CH})(=20 / 70+10 \mathrm{CH}), \mathrm{y}$

j. $\quad$ P-n ${ }^{\circ}$ y/o PY-n $/(" Z "+C H+Y e s o) ; 20 \% /(70 \%+10 \% \mathrm{CH})+(7.0 \%$ SO3 $)$

A los cuales se les hicieron los siguientes análisis:

- Su grado de RS respectivo mediante el método acelerado de ensayo L-A (Blondiau, 1961) y su evolución en función del contenido de puzolana "Z", de cal apagada, de yeso, según el caso,

- La creación, evolución y desarrollo en el tiempo de las características organolépticas de las probetas L-A anteriores, y

- Otro tanto de las resistencias mecánicas en mortero normalizado tipo EN 196-1.

\subsection{1.- Pastas de cemento. Dosificación de componentes.}

Todas y cada una de las pastas de cemento fueron dosificadas y preparadas utilizando para ello una balanza Controls D0630/6 A, cuya pesada máxima era 6000 g. Dicha balanza tenía una precisión de 0,1 g. La dosificación de las mezclas se realizó en todos los casos en frascos de policarbonato con tapón de rosca, para evitar cualquier pérdida de humedad, y generar así un medio estanco. Una vez obtenidas las muestras con la cantidad adecuada pesada de cada uno de los materiales, se sometieron todas ellas a un proceso de mezclado con el fin de conseguir una buena homogeneidad y uniformidad de reparto de los componentes sólidos de cada mezcla. En este caso, el proceso de mezclado se realizó en un molino mezclador marca WAB, modelo TÚRBULA (Figura 7-5), durante un tiempo de 25 minutos, durante el cual, los contenedores de cada muestra se exponen a un movimiento tridimensional que somete a los componentes sólidos de cada mezcla y a la propia mezcla, a un vaivén continuo y a cambios constantes de dirección consiguiendo, por tanto, la mezcla homogénea de los diferentes sólidos pulverulentos que la constituyen. Estos mezcladores presentan una extraordinaria eficacia de mezclado debido a que 
cumplen con los movimientos de rotación, traslación e inversión de la teoría geométrica de mezclado de Schatz. Además, se emplean en las más variadas industrias y son muy adecuados para investigación, en especial, cuando se precisan condiciones de alta homogeneidad y tiempos de mezcla cortos.

\section{2.- Ensayo de resistencia química a los sulfatos: Método de ensayo acelerado \\ (MAE) Le Chatelier-Anstett.}

Este MAE, fue aplicable en sus orígenes únicamente a los cementos Portland y se basa en la determinación del hinchamiento que experimentan probetas cilíndricas, llamadas comúnmente "tortas", de $80 \mathrm{~mm}$ de diámetro y $30 \mathrm{~mm}$ de altura, preparadas comprimiendo a 20 $\mathrm{Kg} / \mathrm{cm}^{2}$ durante 1 minuto, una mezcla de dos partes en peso, del cemento a ensayar parcialmente hidratado (del $10 \%$ al $14 \%$ ) y una parte en peso, de yeso $\left(\mathrm{CaSO}_{4} \bullet 2 \mathrm{H}_{2} \mathrm{O}\right)$ del $95 \%$ de riqueza.

No obstante, y a pesar de las restricciones limitativas de aplicabilidad iniciales expresamente impuestas por este MAE Le Chatelier-Anstett para los cementos Portland en exclusiva, lo cierto es que posteriormente, se ha venido aplicando a múltiples y variados cementos de mezcla o cementos mixtos, con base en la notable severidad del mismo, habiéndose demostrado también mediante las investigaciones realizadas por R. Talero que, también puede ser aplicado a cementos Portland con adiciones puzolánicas y siderúrgicas.

\subsection{1.- Procedimiento Operativo.}

Para la realización de este ensayo se ha seguido la técnica operativa descrita por Blondiau (1961), la cual únicamente se circunscribe a pastas de cemento en lugar de morteros como así lo contemplan las distintas normas norteamericanas y consiste en preparar en una primera fase, una pasta del cemento a ensayar parcialmente hidratada.

En primer lugar, se pesaron en la balanza habitual que se utilizó ${ }^{1}, 100 \mathrm{~g}$ de cada uno de los cementos de mezcla con una precisión de $\pm 0,1$ gr. Dicha masa de cada cemento de mezcla varió dependiendo del porcentaje de reemplazo de cada uno, por lo que se deben recordar las proporciones con las que se ha trabajado en esta investigación objeto de Tesis Doctoral: (60/40), (50/50), (40/60) y (30/70). Véase la Tabla 7-1, en donde se especifica la masa concreta de cada cemento Portland y cada puzolana en función del porcentaje de reemplazo de su cemento mezcla.

Seguidamente, los $100 \mathrm{~g}$ de cada cemento de mezcla se molieron hasta pasar íntegramente por el tamiz de 4900 mallas/ $\mathrm{cm}^{2}$, para a continuación adicionarles $50 \%$ en peso de $\mathrm{H}_{2} \mathrm{O}$ destilada, pesada con la misma balanza y siguiendo el mismo procedimiento que para el caso de los cementos $^{2}$, y, a continuación, se amasa manualmente la pasta de cemento fresca resultante, conservándose la pasta así preparada, durante 24 horas, en la cámara húmeda bajo unas

\footnotetext{
1 Véase el apartado 7.1.1 de esta MEMORIA de Tesis Doctoral.

2 Véase el apartado 7.1.1 de esta MEMORIA de Tesis Doctoral.
} 
condiciones ambientales se encuentran en torno a $23^{\circ} \mathrm{C}$ de temperatura y un $95 \%$ de humedad relativa.

TABLA 7-1.- DOSIFICACIÓN DE COMPONENTES PARA LA PREPARACIÓN DE LOS CEMENTOS DE MEZCLA EN FUNCIÓN DEL PORCENTAJE DE REEMPLAZO PARA LA DETERMINACIÓN DE SU EXPANSIÓN EN PROBETAS DE PASTA TIPO LE CHATELIER-ANSTETT.

\begin{tabular}{cccc}
\hline \multicolumn{4}{c}{ Cementos de Mezcla } \\
\hline Proporción de la mezcla (\%) & $\begin{array}{l}\text { Masa Total } \\
(\mathrm{g})\end{array}$ & $\begin{array}{l}\text { Cemento } \\
\text { Portland }(\mathrm{g})\end{array}$ & $\begin{array}{l}\text { Adición } \\
\text { Mineral (g) }\end{array}$ \\
\hline $\mathbf{1 0 0 / 0 0}$ & 100 & 100 & 0 \\
$\mathbf{7 0 / 3 0}$ & 100 & 70 & 30 \\
$\mathbf{6 0 / 4 0}$ & 100 & 60 & 40 \\
$\mathbf{5 0 / 5 0}$ & 100 & 50 & 50 \\
$\mathbf{4 0 / 6 0}$ & 100 & 40 & 60 \\
$\mathbf{3 0 / 7 0}$ & 100 & 30 & 70 \\
\hline
\end{tabular}

Una vez fraguada la pasta preparada, se desmenuza, mediante raspado y troceado, en forma de "miga de pan" para conservarse, a continuación, bajo agua destilada durante el tiempo suficiente para que la diferencia entre el peso específico del cemento que se ensaya anhidro y de dicho cemento así hidratado, sea mayor del 20\%, alcanzándose esta condición en un plazo de tiempo no superior a los 14 días.

Una vez hidratada convenientemente las pastas desmenuzadas de los cementos a ensayar, se secaron en una estufa de convección sin sobrepasar en ningún caso la temperatura límite de $40^{\circ} \mathrm{C}$ (temperaturas superiores a $40^{\circ} \mathrm{C}$ extraen agua de cristalización de las fases AFt y AFm), hasta que la masa de cada muestra permaneciera constante. En la estufa se habían introducido además un frasco de PVC con lentejas de $\mathrm{NaOH}$ para prevenir la carbonatación de las pastas, siguiendo un principio de actuación similar al seguido por Kjellsen (1990) ${ }^{3}$. Este proceso de secado a $40^{\circ} \mathrm{C}$ en una atmósfera exenta de $\mathrm{CO}_{2}$ se mantuvo hasta peso constante.

A continuación, las pastas parcialmente hidratadas se mezclaron en proporción en peso 2:1 con piedra de yeso natural molida $\left(\mathrm{CaSO}_{4} \bullet 2 \mathrm{H}_{2} \mathrm{O}\right)$ del $95 \%$ de riqueza que actuará como agente agresivo. Las características físicas y químicas del yeso utilizado en este ensayo se muestran en la Tabla 7-2. Dicha mezcla selenitosa se pulverizó hasta que sus partículas tuvieran un tamaño tal que puedan pasar por el tamiz de 0,2 $\mathrm{mm}$ de luz de malla. Finalmente, a cada mezclaconglomerante se le añadió un $6 \%$ en peso de agua destilada y tras colocarla en el molde, se preparó la probeta cilíndrica respectiva aplicando una presión de $20 \mathrm{~kg} / \mathrm{cm}^{2}$ durante un minuto en una prensa adecuada.

Cada torta se conservó adecuadamente sobre un chasis apropiado cubierto de papel de filtro permanentemente humedecido con agua destilada en su totalidad por capilaridad en una atmósfera saturada de humedad (Figura 7-2). Una vez preparada la torta se le determinó con un calibrador su diámetro y altura iniciales $\varnothing_{0}$ y ho, respectivamente, así como también la

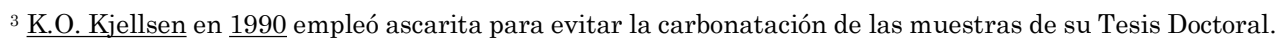
La ascarita es un asbesto recubierto de hidróxido de sodio muy utilizado para absorber el anhídrido carbónico. 
COMPORTAMIENTO SULFÁTICO Y MECÁNICO-RESISTENTE DE CEMENTOS PORTLAND CON ELEVADOS CONTENIDOS DE PUZOLANAS (> 40\%): SU FUNDAMENTO QUÍMICO Y JUSTIFICACIÓN DE OTRAS CONSECUENCIAS POSIBLES

penetración de la Aguja de Vicat, PAV. Tales determinaciones se volvieron a efectuar a las edades de $1,7,14,21,28,60,90,120,150,180,270,365,545$ y 730 días.

TABLA 7-2.- PARÁMETROS QUÍMICOS Y COMPOSICIÓN MINERALÓGICA DE LA PIEDRA DE YESO NATURAL MOLIDA UTILIZADA PARA ESTE ENSAYO DE DURABILIDAD.

\begin{tabular}{cccc}
\hline \multicolumn{3}{c}{ Yeso } \\
Parámetros Químicos (\%) & \multicolumn{2}{c}{ Composición Mineralógica (\%) } \\
\hline $\mathrm{H}_{2} \mathrm{O}\left(40^{\circ} \mathrm{C}\right.$ a $\left.217^{\circ} \mathrm{C}\right)$ & 20,13 & $\mathrm{CaSO}_{4} 2 \mathrm{H}_{2} \mathrm{O}$ & 95,58 \\
$\mathrm{CO}_{2}\left(217^{\circ} \mathrm{C}\right.$ a $\left.1000^{\circ} \mathrm{C}\right)$ & 0,75 & $\mathrm{CaSO}_{4} 1 / 2 \mathrm{H}_{2} \mathrm{O}$ y/o $\mathrm{CaSO}_{4}$ & 2,47 \\
$\mathrm{SO}_{3}$ & 45,87 & $\mathrm{CaCO}_{3}$ & 0,75 \\
$\mathrm{CaO}$ & 32,54 & $\mathrm{MgCO}$ & 0,81 \\
$\mathbf{M g O}$ & 0,36 & $\mathrm{TOTAL}$ & 99,61 \\
$\mathrm{Na} \mathbf{O}$ & 0,02 & & \\
$\mathbf{K}{ }_{2} \mathrm{O}$ & 0,01 & $\mathrm{H}_{2} \mathrm{O}$ a $40^{\circ} \mathrm{C}$ & 0,41 \\
TOTAL & 99.98 & & \\
\hline
\end{tabular}

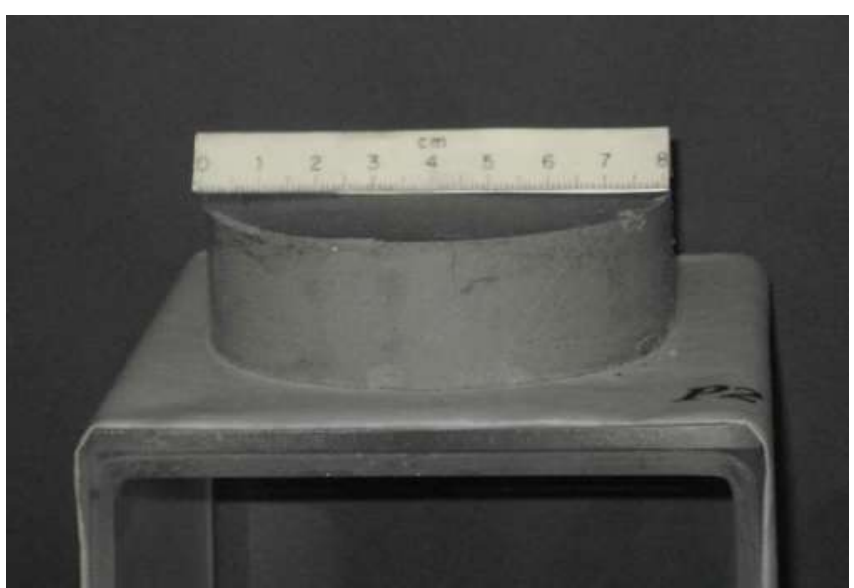

FIGURA 7-2.- TORTA CARACTERÍSTICA DEL ENSAYO LE CHATELIER-ANSTETT.

\subsection{2.- Parámetros característicos del ensayo de Le Chatelier Anstett.}

\subsubsection{1.- Incremento Porcentual de Diámetro $\Delta \emptyset x d(\%)$.}

El "Incremento Porcentual de Diámetro" $\Delta \varnothing x d(\%)$ de la probeta L-A o hinchamiento sufrido por la misma, y en su caso, a una edad dada, y que se determina mediante la siguiente fórmula:

$$
\Delta \emptyset_{x d}(\%)=\frac{\emptyset_{x d}-\emptyset_{0}}{\emptyset_{0}} \cdot 100
$$

Tanto los diámetros, Øo y Øxd, como la altura, h, de cada probeta L-A se midieron con un calibrador o "pie de rey" en mm y a las edades del ensayo de $0,1,7,14,21,28,60,90,120,150$, 
180, 270, 365, 545 y 730 días.

\subsubsection{2.- Velocidad de Incremento Diametral Vсø $(\Delta \emptyset(\%) / d i ́ a)$.}

La "Velocidad de Incremento Diametral", $V_{c}=(\Delta \varnothing(\%) /$ día $)$ que está íntimamente ligada con la velocidad de formación de ettringita o velocidad de la reacción de formación de la misma o velocidad de "degradación" o "envejecimiento de la probeta L-A" y que se determina mediante la siguiente fórmula:

$$
V_{C \emptyset}=\frac{\Delta \emptyset_{y d}-\emptyset_{x d}}{y-x}
$$

siendo la edad "y días" mayor a la edad "x días".

\subsubsection{3.- Incremento porcentual de diámetro por unidad de masa de puzolana " $\mathrm{Z}$ ", $\Delta \emptyset x d(\%) / " Z "$.}

El "Incremento porcentual de diámetro por unidad de masa de puzolana Z", $\Delta \varnothing(\%) / " Z "$, que nos podrá reflejar en su caso, de forma clara y sobre todo cuando el cemento Portland matriz acompañante de la puzolana " $Z$ " tiene un contenido de $\mathrm{C}_{3} \mathrm{~A}$ lo menor posible, como es el caso de los cementos Portland con la característica adicional de ser "resistente a los sulfatos", PY4 y PY6, utilizados en este trabajo, que

- en el caso de este tipo de cementos de mezcla con tan elevados contenidos de puzolana, y

- a diferencia de lo obtenido por R. Talero en sus trabajos (Talero, 1986) en los que utilizó los correspondientes cementos de mezcla con menor contenido de puzolana que los utilizados en esta investigación objeto de Tesis Doctoral, el grado de hinchamiento de la probeta L-A en todos los casos no va a ser quizás tanta función directa de la característica puzolánica de la adición utilizada en el ensayo, cuanto más del contenido necesario y suficiente de $\mathrm{Ca}(\mathrm{OH})_{2}$,

- bien como portlandita del CP P-nº ó PY-nº acompañante respectivo,

- bien como cal apagada $=\mathrm{Ca}(\mathrm{OH})_{2}$ R.A., en la probeta L-A para que dicha puzolana desarrolle su propia actividad puzolánica y con ella nos muestre su auténtico y verdadero "carácter" "silícico", "silícico-alumínico", "silícico-férrico-alumínico", "alumínico-silícico" o "alumínico", según Talero (1986)- con las consecuencias tecnológicas al caso.

\subsubsection{4.- Penetración de la Aguja de Vicat", P.A.V. (mm).}

La "Penetración de la Aguja de Vicat", P.A.V. (mm), se midió a las mismas edades del ensayo que el $\Delta \varnothing(\%)$, pero con una Aguja de Vicat tal y como especifica expresamente el extinto Pliego RC-75.

Para la realización de este ensayo se utiliza el aparato de Vicat manual, con una aguja representada en la Figura 7-3. La aguja debe ser de acero y tener la forma de un cilindro recto con una longitud efectiva de, al menos, $45 \mathrm{~mm}$ y un diámetro de $(1,13 \pm 0,05) \mathrm{mm}$. La masa total de las partes móviles debe ser $(300 \pm 1) \mathrm{g}$. Su movimiento debe ser exactamente vertical y sin rozamiento apreciable, y sus ejes deben coincidir con el de la aguja. Este equipo que se describe figura en la norma UNE EN 196-3. 

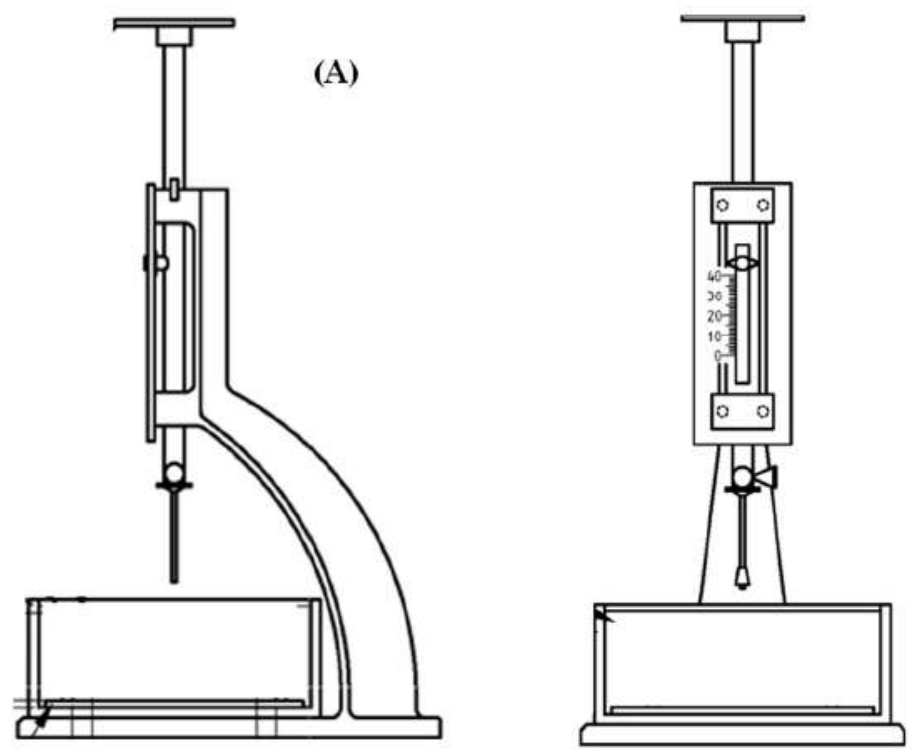

(B)

FIGURA 7-3.- APARATO DE VICAT TÍPICO (EXTRAIDO DE UNE EN 196-3).

Preliminarmente y al inicio del ensayo, se ajusta el aparato de Vicat provisto de la aguja (véase la Figura 7-4), montada antes del ensayo, bajando la aguja hasta que esté en contacto con la placa base que vaya a utilizarse dentro del contenedor y ajustando la puesta a cero en la escala. Se levanta la aguja hasta la posición de espera.

Se coloca la aguja con el dispositivo anular de sujeción de diámetro aproximado de $5 \mathrm{~mm}$ para facilitar la observación exacta de penetraciones pequeñas.

A las edades fijadas, la probeta Le Chatelier- Anstett y la placa base se llevaron al aparato de Vicat y se situaron debajo de la aguja. Se bajó la aguja despacio hasta que entre en contacto con la pasta. Se esperó en esta posición entre 1 y 2 segundos, con el fin de evitar una velocidad inicial o aceleración forzada de las partes móviles. Se sueltan rápidamente las partes móviles y la aguja penetra verticalmente en la pasta. Se leyó la escala cuando la penetración terminó, o $30 \mathrm{~s}$ después de la liberación de la aguja, lo que ocurrió primero.

Seguidamente, se anotó la lectura de la escala, que indica la distancia entre el extremo de la aguja y la placa base.

\subsubsection{5.- Evolución de las Características Orgánicas, ECO, de la probeta L-A}

La evolución de las Características Orgánicas, ECO, de la probeta L-A se ha determinado tomando una fotografía de las probetas L-A a las edades del ensayo que se consideraron más adecuadas según los objetivos de este trabajo, que fueron las siguientes: $0,1,7,14,21,28,60,90$, 120, 150, 180, 270, 365, 545 y 730 días. 


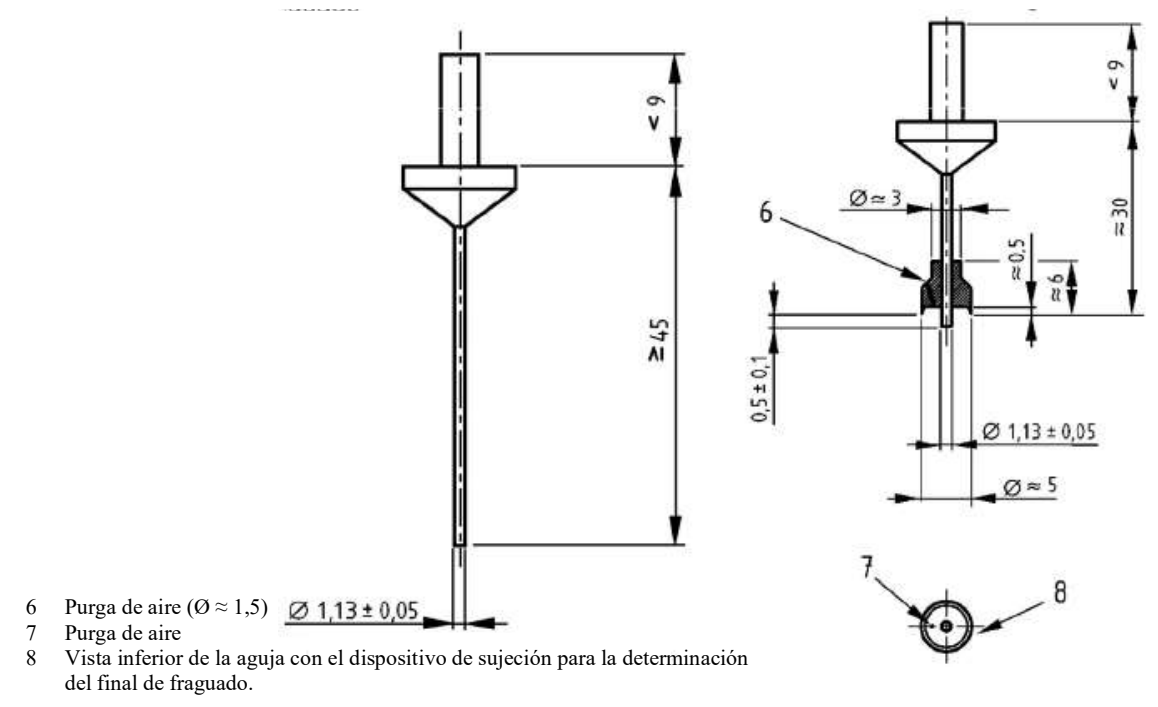

FIGURA 7-4.- AGUJA PARA LA DETERMINACIÓN DEL PRINCIPIO Y FINAL DE FRAGUADO (EXTRAIDO DE UNE EN 196-3).

\subsection{3.- Caracterización microestructural de las pastas Le Chatelier-Anstett}

La caracterización microestructural de todas las pastas frescas de cemento preparadas y estudiadas se realizó mediante su análisis mineralógico por DRX de los productos de hidratación formados en cada pasta hidratada de su probeta L-A a la edad correspondiente más adecuada del MAE Le Chatelier-Anstett

7.2.3.1.- Determinación cualitativa y semicuantitativa mediante DRX de los compuestos de hidratación formados en las pastas frescas de cemento.

Para poder realizar un buen análisis por Difracción de rayos $X$ deben de tenerse en consideración varias etapas en la toma de datos las cuales son las siguientes: la preparación de la muestra, la caracterización del material a analizar, las características generales del difractómetro y las condiciones de medida. Asimismo, y en el caso de las muestras multifásicas es conveniente, sobre todo, que el tamaño de las partículas de cada fase sea homogéneo.

Del mismo modo y en la medida de lo posible, la muestra en polvo para la realización de las medidas mediante la técnica analítica de Difracción de Rayos X, debe de estar constituida por cristales orientados al azar para evitar la orientación preferente de los mismos. Es mejor eliminar este posible efecto antes de realizar las medidas para evitar aplicar correcciones posteriormente, puesto que, debido a él, los picos de baja intensidad puede que no lleguen a observarse. La orientación preferente tiene lugar cuando, debido a la forma de sus cristales, la muestra presenta una tendencia mayor a orientarse en una dirección específica más que en otras, produciendo una sistemática distorsión de las intensidades de las reflexiones.

\subsubsection{2.- Descripción del equipo y condiciones analíticas de la determinación realizada.}

En esta investigación objeto de Tesis Doctoral, el análisis por difracción de Rayos X que se 
presenta es únicamente cualitativo y semicuantitativo.

El análisis por DRX de cada una de las muestras dispuesta en forma de pastilla una vez secas convenientemente, se realizó mediante un equipo automático Philips Modelo PW 1730, con ánodo de $\mathrm{Cu}$, siendo la longitud de onda $\mathrm{K} 1$ del $\mathrm{Cu}=1,54056$, la $\mathrm{K} 2=1,54439$, con relación de $(\mathrm{K} 1 / \mathrm{K} 2)=0,50$, que consta de dos goniómetros y del sistema óptico constituido por un sistema de rendijas Soller seguido de una rendija de divergencia de $2 \mathrm{~mm}$, situada delante de la muestra, después de la cual, se sitúa una rendija de recepción de $0.2 \mathrm{~mm}$. Y tras ésta, hay colocadas una rendija de antidivergencia de $2 \mathrm{~mm}$, el sistema de rendijas Soller secundario y una rendija de recepción de $0.2 \mathrm{~mm}$. Finalmente y a continuación de este último, se sitúa un monocromador curvo de grafito (eliminación de la radiación K๑ del cobre), con una rendija del detector de 0.2 $\mathrm{mm}$. Las condiciones de trabajo para el goniómetro fueron: el voltaje $40 \mathrm{kV}$ y la intensidad de corriente $20 \mathrm{~mA}$. Además, el tiempo de contaje fue de $0,80 \mathrm{~s}$ y el paso de ángulo de $0.02^{\circ}$.

El software utilizado para la manipulación de los datos de cada difractograma fue EVA 12, en su versión de 2006 de licencia DiffracPlus Basic Evaluation Package. Este programa pertenece a un paquete de programas DIFFRAC plus BASIC de la casa BRUKER, y en él se recogen numerosas aplicaciones.

\subsubsection{3.- Preparación de las pastas Le Chatelier Anstett para su análisis por DRX.}

El análisis por difracción de rayos $\mathrm{X}, \mathrm{DRX}$, se le ha realizado a las pastas hidratadas de cada probeta L-A, para así tratar de identificar la diferencia en la formación de productos de hidratación selenitosa de los distintos cementos de mezcla a causa de la presencia de puzolanas naturales y artificiales con distinto carácter químico. La edad a la cual se realizó el análisis por DRX de las pastas frescas, se correspondió con las distintas edades de ensayo.

El procedimiento seguido para la toma de muestras de cada probeta Le Chatelier a una edad determinada, se llevó a cabo extrayendo cierta cantidad de pasta por medio de una espátula.

Seguidamente, las muestras de pasta fresca se secaron en un desecador sin sobrepasar en ningún caso la temperatura límite de $40^{\circ} \mathrm{C}$ (temperaturas superiores a $40{ }^{\circ} \mathrm{C}$ extraen agua de cristalización de las fases AFt y AFm), hasta que la masa de cada muestra permaneciera constante. En el desecador se había introducido nuevamente un frasco de PVC con lentejas de $\mathrm{NaOH}$ para prevenir la carbonatación de las pastas, siguiendo un principio de actuación similar al seguido por Kjellsen (1990). Seguidamente se envasó cada muestra herméticamente y sin aire (para evitar la carbonatación) hasta el momento de realizarle su análisis por DRX.

A continuación, se procedió a su molienda y tamizado en seco hasta conseguir que su finura de molido fuera la óptima para su análisis por DRX, es decir, que la totalidad de la masa de la muestra pasara por el tamiz de $45 \mu \mathrm{m}$ de luz de malla. Y para ello se utilizó el procedimiento especificado en la norma UNE 83484 EX.

Finalmente, se prepararon pastillas en polvo por presión a partir de cada una de las muestras secas y molidas para ser analizadas. 


\section{3.- Determinación del comportamiento mecánico-resistente de los cementos de mezcla en mortero normalizado tipo EN 196-1.}

La determinación del comportamiento mecánico-resistente de todos y cada uno de los cementos de mezcla que se tuvieron que dosificar y preparar, se limitó al método de ensayo especificado en la norma UNE EN 196-1.

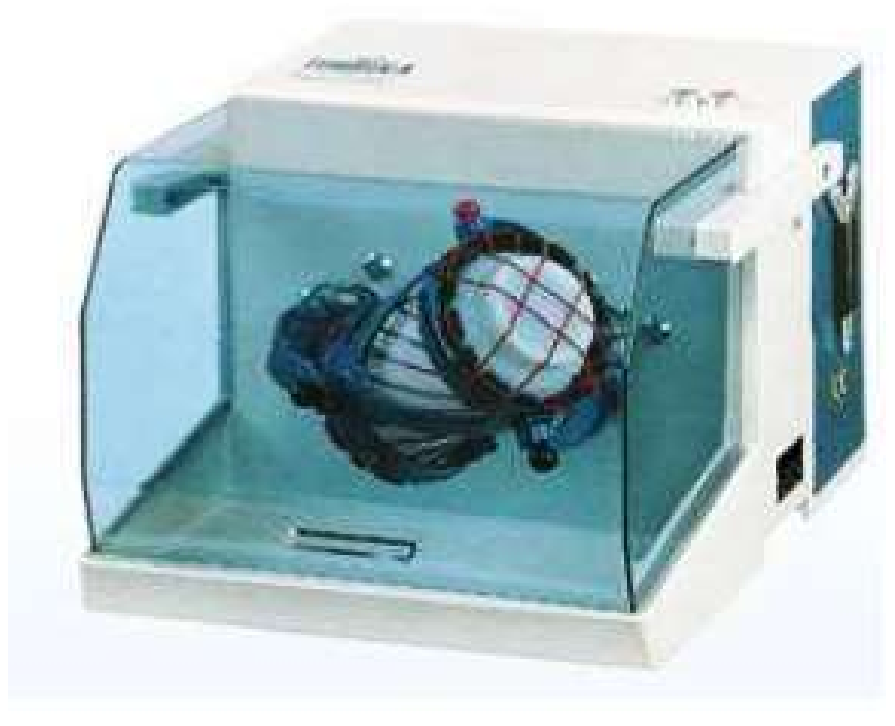

FIGURA 7-5.- IMAGEN DEL MEZCLADOR TUBULAR WAB.

Bajo esta Norma se realizó el procedimiento operativo llevado a cabo para determinar:

- La resistencia mecánica a flexotracción de cada mortero sobre tres de sus probetas de dimensiones $4 \times 4 \times 16 \mathrm{~cm}$, de acuerdo con la norma anteriormente especificada UNE-EN 1961. El valor final de la resistencia mecánica a flexotracción sería el promedio de los tres resultados obtenidos.

- La resistencia mecánica a compresión de cada mortero sobre cada una de las dos mitades resultantes de cada una de las probetas de dimensiones $4 \times 4 \times 16 \mathrm{~cm}$, de acuerdo con dicha norma UNE-EN 196-1. El valor final de la resistencia mecánica a compresión sería el promedio de los seis resultados obtenidos.

La prensa que se utilizó para determinarle a las probetas de mortero dichos parámetros mecánicos fue una prensa Ibertest 200/10, la cual cumplía con las especificaciones de la norma UNE-EN 196-1. Y las edades de ensayo a las que se les determinaron los valores de ambos tipos de resistencia mecánica fueron 7,28 y 90 días.

Las probetas se fabrican con un mortero plástico constituido por una parte en masa de cemento, tres partes en masa de arena normalizada CEN, y media parte de agua (relación agua/cemento de 0,50). Se pueden utilizar arenas normalizadas CEN de diferentes orígenes y países, con la condición de que, al ser utilizadas, los resultados de las resistencias mecánicas no 
difieran de forma significativa de los obtenidos utilizando la arena de referencia CEN.

En el procedimiento de referencia, el mortero se prepara por amasado mecánico y se compacta en un molde utilizando una compactadora. Pueden emplearse otros equipos y procedimientos de compactación alternativos, con la condición de que, al ser utilizados, los resultados de las resistencias mecánicas no difieran de forma significativa de los obtenidos utilizando la compactadora y el procedimiento de referencia.

Las probetas se conservan en el molde en una atmósfera húmeda durante 24 h, y, después del desenmoldado, las probetas se sumergen en agua hasta el momento de los ensayos de resistencia.

\section{4.- Ensayo de puzolanicidad o ensayo de Frattini. Determinación de la [CaO] y [OH-] de la fase líquida en contacto con cada pasta.}

La posible actividad puzolánica de una adición mineral, se determina habitualmente en la UE mediante el ensayo de Frattini (1949)4, entre otros ensayos. El ensayo de Frattini permite, como se ha dicho antes y de acuerdo con la norma UNE EN 196-5, evaluar por vía química, la actividad puzolánica de una adición mineral para determinar si es puzolana o no, así como también y si es puzolana, confirmarle además que el cemento de base Portland del que forme parte es puzolánico, ya sea tipo CEM IV/A ó CEM IV/B (Instrucción RC-16) (así como también, la actividad puzolánica de una puzolana dada, ya sea ésta natural o artificial, añadida a un cemento Portland tipo CEM I, en cantidades de reemplazo. Y en ambos casos, mediante la comparación de la cantidad de hidróxido de calcio que, pasado un período de tiempo preceptivo también, 8 y/ó 15 días, contiene la disolución acuosa que, a $40^{\circ} \mathrm{C}$, está en contacto con la muestra inicial de $20 \mathrm{~g}$ del cemento en estudio, con la isoterma de solubilidad del hidróxido de calcio en una disolución alcalina a la misma temperatura.

En este sentido y de acuerdo con la Tabla A1.1.4 de la vigente Instrucción RC-16, titulada "Prescripciones químicas de los cementos comunes, incluidos los de bajo calor de hidratación", este ensayo de puzolanicidad o ensayo de Frattini está prescrito únicamente para los "Cementos puzolánicos" o Tipo CEM IV (contenido de clínker Portland: entre 89\% y 45\%; contenido de puzolana natural y/o artificial: entre $11 \%$ y 55\%), los cuales para ser considerados y catalogados como tales, lo han de cumplir a la edad de 8 ó 15 días. En cambio, el resto de los cementos de la Tabla A1.1.1, titulada "Cementos comunes", de dicha Instrucción RC-16, no lo han de cumplir a ninguna edad. Lo que no implica, no obstante, que en la investigación objeto de esta Tesis Doctoral, dicho ensayo de Frattini no sea válido para evaluar la reactividad puzolánica que un material puzolánico cualquiera, natural o artificial, puede llegar a desarrollar a cualquier edad con el cemento Portland al que se le incorpore en cualquier otra proporción, que sí lo es, para

${ }^{4}$ Véanse los apartados 6.2.6 y 6.3.6 de esta MEMORIA de Tesis Doctoral. 
poderla relacionar así, con otros parámetros químicos y/o físicos y/o mecánicos del mismo en pos de su justificación.

Por este motivo, se decidió determinar, además, mediante dicho ensayo de Frattini, la puzolanicidad de todas las adiciones minerales puzolánicas seleccionadas para esta investigación. Pero no sólo, la actividad puzolánica de cada una de ellas, sino también, y sobre todo la $[\mathrm{CaO}]$ y $\left[\mathrm{OH}^{-}\right]$presentes en la fase líquida de cada pasta. Por lo que la selección de las edades del ensayo, en este caso, no pudieron ser lógicamente, las tradicionalmente utilizadas para el mismo, es decir: la de 8 y 15 días, sino que las edades escogidas fueron otras: 7 y 28 días, edades ambas vigentes en el Pliego RC-75. En definitiva, edades estas cuyos resultados en el ensayo de puzolanicidad se pueden correlacionar bastante más y mejor con los resultados obtenidos en los preceptivos ensayos mecánico-resistentes con probetas de mortero normalizado de estos mismos cementos de mezcla preparados. De aquí que tengan un mayor interés científico y técnico.

Por todo ello, se decidió determinar la [CaO $]$ y [OH-] presentes en la fase líquida de la pasta de cada una de las adiciones minerales seleccionadas y mezcladas, por separado, con uno de los cementos Portland de referencia, P1, de composición cristalina conocida, en las proporciones porcentuales de mezcla 70/30, 60/40, 50/50, 40/60 y 30/70.

\subsection{1.- Fundamento.}

El cemento Portland, desde el primer momento que entra en contacto con el agua, genera un medio en el que los procesos de transformación del material inicial debido a la acción del agua (hidrólisis) se suceden de modo vertiginoso, y de fijación del agua sin transformación del material de reacción (hidratación) entran en juego de manera considerable. Todas las reacciones químicas que se producen durante la hidratación del cemento Portland son reacciones estequiométricas y exotérmicas con la característica fundamental de que todos sus componentes liberan portlandita (CH) (r5.1), como se recordó en el apartado 1.3.4.

$$
\mathrm{C}_{3} \mathrm{~S}, \mathrm{C}_{2} \mathrm{~S}+\mathrm{H} \rightarrow \text { gel } \mathrm{CSH}+\mathrm{CH}
$$

La $[\mathrm{CaO}]$ en el medio, y concretamente en la fase líquida de la pasta, va a tener una influencia clara en su comportamiento mecánico-resistente y durabilidad. Si en dicho medio, que es la pasta de cemento, existen además adiciones minerales tipo puzolana que, como es sabido, posee la propiedad de reaccionar químicamente con la portlandita presente, $\mathrm{CH}$, para realizar su actividad puzolánica, las propiedades físicas y químicas de dicha pasta serán con seguridad distintas de las de la pasta del cemento Portland puro u original y, por consiguiente, su comportamiento mecánico-resistente y durabilidad se podrán ver afectados incluso de consideración en ocasiones por su no adecuación. Ni en calidad ni en cantidad. Las reacciones químicas de la fracción reactiva más significativa de las puzolanas naturales y artificiales con el $\mathrm{Ca}(\mathrm{O})_{2}$ en medio acuoso y a temperatura ambiente, son las siguientes: 


$$
\begin{gathered}
\mathrm{SiO}_{2}{ }^{\mathrm{r}-}+\mathrm{CaO}+\mathrm{H}_{2} \mathrm{O}=\mathrm{C}-\mathrm{S}-\mathrm{H}+\mathrm{Q} \\
\mathrm{Al}_{2} \mathrm{O}_{3}{ }^{\mathrm{r}-}+\mathrm{CaO}+\mathrm{H}_{2} \mathrm{O}=\mathrm{C}_{3} \mathrm{AH}_{6}, \mathrm{C}_{4} \mathrm{AH}_{13}, \mathrm{C}_{4} \mathrm{AH}_{19}+\mathrm{Q}
\end{gathered}
$$

Por todo ello, la $[\mathrm{CaO}]$ y $\left[\mathrm{OH}^{-}\right]$presentes en la fase líquida de cada pasta, fueron determinadas por vía química, mediante la norma UNE-EN 196.5 o ensayo de Frattini (1949). Este ensayo se considera positivo cuando la concentración de hidróxido de calcio en la fase líquida de la muestra se ubica por debajo de la isoterma de solubilidad. De un modo gráfico se establece la situación de la fase líquida con respecto a la línea de saturación de $\mathrm{CaO}$ en dicha disolución alcalina, mediante la representación de los valores experimentales obtenidos de $[\mathrm{CaO}]$ frente a $\left[\mathrm{OH}^{-}\right]$-lo que también se denomina "alcalinidad total", suma de las alcalinidades provenientes de los contenidos de $\mathrm{OH}^{-}, \mathrm{HCO}_{3}^{-}$y $\mathrm{CO}_{3}{ }^{2-}$ - de dicha fase líquida. Véase la Fig. 7-6.

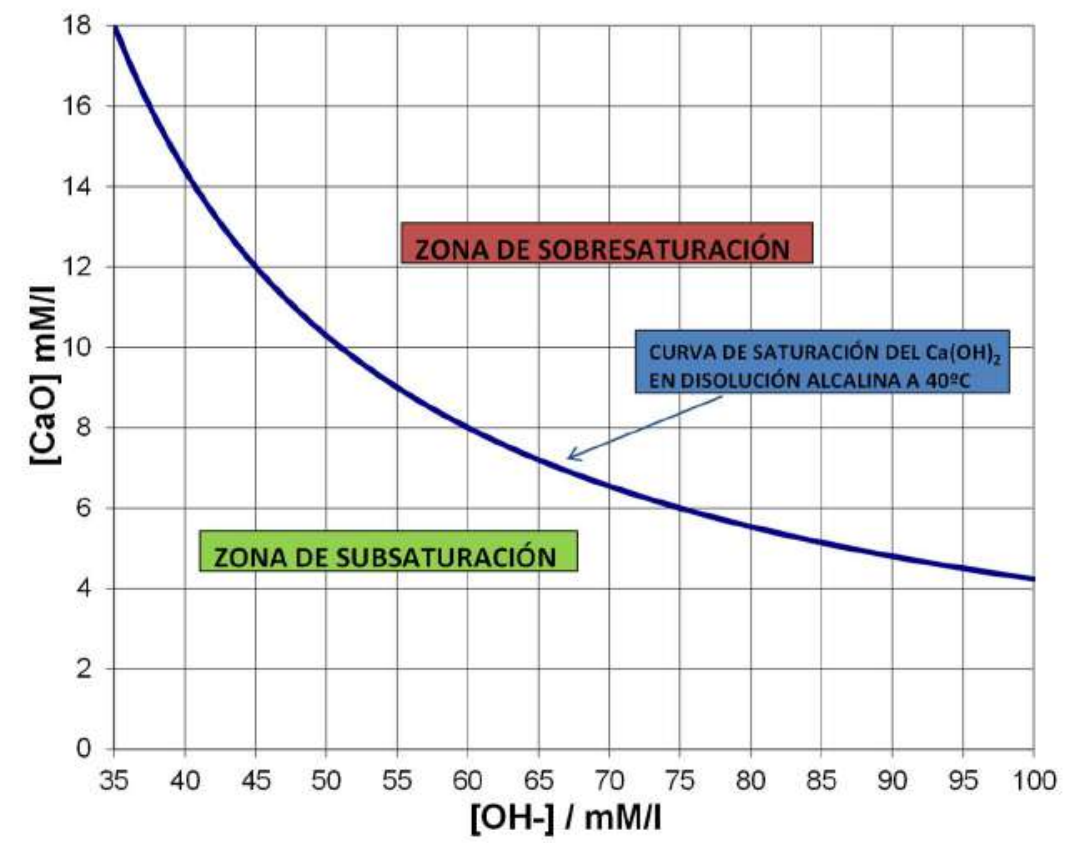

FIGURA 7-6.- GRÁFICA DEL ENSAYO DE FRATTINI.

\subsection{2.- Determinación de la basicidad de la fase líquida en contacto con cada pasta fresca}

\section{de los cementos de mezcla anteriores: el pH.}

Por otra parte, el pH, abreviatura de Potencial Hidrógeno, es otro parámetro químico muy importante, para determinar de este otro modo, el grado mayor o menor alcalinidad de la fase líquida en contacto con cada pasta de cemento. Por lo que su determinación será de gran utilidad también.

La escala del $\mathrm{pH}$ va desde 0 hasta 14 . Los valores menores que 7 indican el rango de acidez y los mayores que 7 el de alcalinidad o basicidad. El valor 7 se considera neutro. 
Matemáticamente el $\mathrm{pH}$ es el logaritmo negativo de la concentración molar de los iones hidrogeno o protones $\left(\mathrm{H}^{+}\right)$o iones hidronio $\left(\mathrm{H}_{3} \mathrm{O}^{+}\right)$(véase la ecuación (5.7).

$$
p H=-\log \left[H^{+}\right]
$$

Antes de proceder a la determinación del pH de la fase líquida en contacto con cada pasta de cemento, cada muestra se sometió al mismo pre-tratamiento realizado para el caso del ensayo de Frattini adaptado con el fin de obtener una muestra de ensayo homogénea ${ }^{5}$. Se tomaron, aproximadamente, $100 \mathrm{~g}$ de cada muestra de laboratorio por medio de un divisor de muestras (cuarteador) o por cuarteo. Se tamizó esta porción en un tamiz de $125 \mu \mathrm{m}$ hasta que el residuo permaneció constante. Seguidamente, se molió el material retenido hasta que pasó por completo por el tamiz de $125 \mu \mathrm{m}$ y se transfirió la muestra a un frasco limpio y seco con cierre hermético y se mezcló en el molino mezclador ${ }^{6}$ durante un tiempo de 25 minutos. Estas operaciones se efectuaron lo más rápido posible con el fin de asegurar que la muestra estuviera expuesta al aire durante un tiempo mínimo.

Este análisis a diferencia del ensayo de Frattini, se llevó a cabo a una temperatura constante común para todas las determinaciones, que fue $25^{\circ} \mathrm{C}$.

A continuación, y para cada una de las muestras se vertieron en un recipiente de polietileno $100 \mathrm{ml}$ de agua destilada medidos con pipeta y se cerró herméticamente el recipiente, pasándose, seguidamente, a un baño termostático que contenía agua potable a una temperatura de $25^{\circ} \mathrm{C}$, cuya forma de mantener su isotermicidad era a través de una resistencia eléctrica conectada a un controlador de temperatura. Una vez alcanzado el equilibrio térmico (aproximadamente $1 \mathrm{~h}$ ), se sacó el recipiente del baño y se pesaron $(20,00 \pm 0,01) \mathrm{g}$ del cemento de mezcla (véase la Tabla 7 3) a ensayar en cada caso y se pasaron al recipiente de polietileno, utilizando para ello un embudo de vástago ancho.

TABLA 7-3.- DOSIFICACIÓN DE COMPONENTES PARA LA PREPARACIÓN DE LOS CEMENTOS DE MEZCLA EN FUNCIÓN DEL PORCENTAJE DE REEMPLAZO PARA LA DETERMINACIÓN DEL PH DE LA FASE LÍQUIDA DE SU PASTA FRESCA.

\begin{tabular}{cccc}
\hline \multicolumn{4}{c}{ Cementos de Mezcla } \\
\hline Proporción de la mezcla (\%) & $\begin{array}{l}\text { Masa Total } \\
(\mathbf{g})\end{array}$ & $\begin{array}{l}\text { Cemento } \\
\text { Portland (g) }\end{array}$ & $\begin{array}{l}\text { Adición } \\
\text { Mineral (g) }\end{array}$ \\
\hline $\mathbf{1 0 0 / 0 0}$ & 20 & 20 & 0 \\
$\mathbf{7 0 / 3 0}$ & 20 & 14 & 6 \\
$\mathbf{6 0 / 4 0}$ & 20 & 12 & 8 \\
$\mathbf{5 0 / 5 0}$ & 20 & 10 & 10 \\
$\mathbf{4 0 / 6 0}$ & 20 & 8 & 12 \\
$\mathbf{3 0 / 7 0}$ & 20 & 6 & 14 \\
\hline
\end{tabular}

Inmediatamente después, se cerró el recipiente herméticamente y se agitó vigorosamente la mezcla durante unos $20 \mathrm{~s}$ para evitar la formación de grumos de cemento. Para ello, se aplicó

\footnotetext{
5 Véanse el apartado 7.1.1 de esta MEMORIA de Tesis Doctoral.
}

${ }^{6}$ Véanse el apartado 7.1.1 de esta MEMORIA de Tesis Doctoral. 
al recipiente un movimiento giratorio horizontal para evitar que una parte de la muestra o del líquido se proyectara hacia la parte superior y quedara separada del resto de la disolución.

Finalmente, se dejó reposar el recipiente en el baño termostático hasta la hora de su análisis químico. Todas las operaciones que se realizaron fuera del baño termostático se hicieron con la mayor rapidez posible (duración máxima $1 \mathrm{~min}$ ) para evitar que se produjera un descenso apreciable de la temperatura del contenido del recipiente.

Las edades de análisis propuestas en esta ocasión fueron idénticas que para los análisis químicos anteriores, de aquí que, las edades propuestas fueran también: 7 y 28 días. En el momento oportuno y preciso, se sacó cada recipiente del baño termostático y se procedió al análisis químico de su fase líquida.

El sistema para la determinación electroquímica del pH está formado por un electrodo de medida y uno de referencia. El electrodo de referencia debe presentar un valor constante del potencial independientemente del valor del pH de la solución a estudiar y de las condiciones de medida. El electrodo de medida por su parte, debe responder únicamente a la actividad de los iones $\mathrm{H}^{+}$de la disolución. El sistema se complementa con la electrónica asociada a los electrodos de medida y de referencia, que permite leer la lectura en unidades de $\mathrm{pH}$ o en milivoltios, (véase la Figura 7-7).

La relación que liga la diferencia de potencial y el $\mathrm{pH}$ de la disolución a determinar viene dada por la ecuación de Nernst (5.2):

$$
E_{i}=N \times\left(p H_{i}-p H_{p}\right)
$$

Dónde:

$E_{\mathrm{i}}$ Diferencia de potencial entre el electrodo de referencia y el electrodo de medida; que será igual a la diferencia de potencial existente entre la parte interior y exterior de la membrana de vidrio del electrodo de medida, si la referencia externa (electrodo de referencia) es la misma que la referencia interna del electrodo de medida.

N Factor del Nernst (ecuación 5.3).

$$
N=\operatorname{Ln} 10 \frac{R \times T}{F}
$$

siendo $\mathrm{R}=8.3143\left[\mathrm{~J} \cdot \mathrm{K}^{-1} \mathrm{~mol}^{-1}\right]$ la constante de los gases perfectos, $\mathrm{T}$ la temperatura en grados Kelvin y $\mathrm{F}=96487\left[\mathrm{Cmol}^{-1}\right]$ la cte. de Faraday.

pHi $\mathrm{pH}$ conocido de la solución interna del electrodo de medida. Normalmente $\mathrm{pHi}=7$.

$\mathrm{pH}_{\mathrm{p}} \mathrm{pH}$ de la disolución que se quiere determinar. 


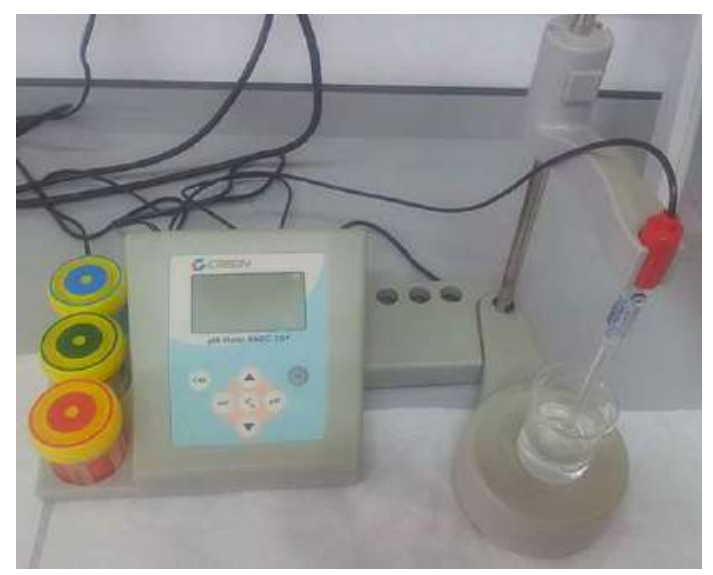

FIGURA 7-7.- PHMETRO UTILIZADO EN ESTA INVESTIGACIÓN.

\section{5.- Determinación de la velocidad de penetración de la carbonatación en probetas de mortero normalizado. Interrelación con el comportamiento mecánico-resistente.}

Este método de ensayo se basa en la determinación de la profundidad de carbonatación en probetas de mortero endurecido suponiendo el avance difusivo del $\mathrm{CO}_{2}$ por fronteras móviles hasta producir un frente de carbonatación que se identifica mediante la aplicación del ensayo colorimétrico de la fenolftaleína.

Hay que tener en cuenta que los resultados así obtenidos se corresponden con un proceso de carbonatación acelerada y no podría utilizarse en modelos de carbonatación natural a no ser que se disponga de la correlación de las condiciones del ensayo con las de carbonatación natural. Su empleo inmediato sería solo a efectos comparativos en las condiciones del ensayo.

La interrelación de las condiciones de carbonatación determinación del comportamiento de todos los cementos de mezcla que se tuvieron que dosificar y preparar, se realizó a través del método de ensayo especificado en la norma UNE EN 196-1, determinando, por ello:

- La resistencia mecánica a flexotracción de cada mortero sobre dos probetas de dimensiones 4 x 4 x $16 \mathrm{~cm}$, de acuerdo con la norma anteriormente especificada UNE EN 196-1. El valor final de la resistencia mecánica a flexotracción sería el promedio de los dos resultados obtenido, y

- La resistencia mecánica a compresión de cada mortero sobre cada una de las dos mitades resultantes de cada una de las probetas de dimensiones $4 \times 4 \times 16 \mathrm{~cm}$, de acuerdo con la norma anteriormente especificada UNE EN 196-1. El valor final de la resistencia mecánica a compresión sería el promedio de los cuatro resultados obtenidos. 


\subsection{1.- Preparación de las probetas de mortero.}

Para fabricar las probetas de mortero que iban a ser ensayadas mecánicamente tras su exposición en ambiente concentrado de $\mathrm{CO}_{2}$, se utilizó arena normalizada CEN EN 196-1" la cual cumplía con todos los requisitos que le son preceptivos ${ }^{7}$. La arena normalizada CEN estaba envasada en bolsas con un contenido de $(1,350 \pm 5)$ g; cumpliendo con la distribución granulométrica especificada en la Tabla 7-4.

En cuanto a los cementos a ensayar ${ }^{8}$ se expusieron al aire ambiental el menor tiempo posible y se conservaron en recipientes completamente llenos y herméticos de polipropileno. Cada muestra fue homogeneizada convenientemente ${ }^{9}$. Asimismo, para todos los ensayos se utilizó agua destilada.

Las probetas se fabrican con un mortero plástico constituido por una parte en masa de cemento y tres partes en masa de arena normalizada CEN. La citada masa pesada de cada cemento de mezcla varió dependiendo del porcentaje de reemplazo de cada uno, por lo que se debe recordar las dos proporciones con los que se ha trabajado en esta investigación, (50/50), y (40/60). Véase la Tabla 7-4, en donde se especifica la masa concreta de cada cemento Portland seleccionado y de cada puzolana seleccionada en función del porcentaje de reemplazo de su cemento mezcla.

TABLA 7-4.- DOSIFICACIÓN DE COMPONENTES PARA LA PREPARACIÓN DE LOS CEMENTOS DE MEZCLA EN FUNCIÓN DEL PORCENTAJE DE REEMPLAZO PARA SU ENSAYO ACELERADO DE DURABILIDAD FRENTE A LA CARBONATACIÓN.

\begin{tabular}{cccc}
\hline \multicolumn{4}{c}{ Cementos de Mezcla } \\
\hline Proporción de la mezcla (\%) & Masa Total & Cemento & Adición \\
& $(\mathrm{g})$ & Portland (g) & Mineral (g) \\
\hline $\mathbf{5 0 / 5 0}$ & 450 & 225 & 225 \\
$\mathbf{6 0 / 4 0}$ & 450 & 270 & 180 \\
\hline
\end{tabular}

TABLA 7-5.- RELACIÓN A/C DE CADA UNO DE LOS MORTEROS PREPARADOS.

\begin{tabular}{ccccc}
\hline \multirow{2}{*}{ Adición } & \multicolumn{4}{c}{ Cemento de Mezcla } \\
\cline { 2 - 5 } & $50 / 50$ & $50 / 50+\mathrm{CH}$ & $40 / 60$ & $40 / 60+\mathrm{CH}$ \\
\hline O & 0,50 & 0,50 & - & - \\
M & - & - & 0,50 & 0,50 \\
\hline
\end{tabular}

Seguidamente, a cada cemento de mezcla se le adicionó una cantidad conocida de agua destilada, con el fin de cumplir la relación agua/cemento común propuesta para cada mortero

\footnotetext{
7 Véase el apartado 7.2.1 de esta MEMORIA de Tesis Doctoral.

8 Véase el apartado 7.1 de esta MEMORIA de Tesis Doctoral.

${ }_{9}^{9}$ Véase el apartado 7.1.1 de esta MEMORIA de Tesis Doctoral.
} 
preparado a partir de cada cemento de mezcla que iba a ser evaluada su respuesta frente al ataque del $\mathrm{CO}_{2}$ y que fue 0,5 , pesada con la misma balanza y siguiendo el mismo procedimiento que para el caso de los cementos ${ }^{10}$. Es importante puntualizar, que la relación a/c propuesta no se pudo mantener para el caso de los cementos de mezcla que contenían la puzolana $\mathrm{M}$, ya que con esa cantidad de agua adicionada a sus pastas era bastante difícil poder amasarlas de una forma óptima, por lo que se tuvo que incrementar necesariamente esta relación para que estas pastas pudieran ser trabajables y para lograr un buen amasado, asegurando así que cada mezcla contuviera la cantidad de agua necesaria para que las reacciones de hidratación se produjeran. El agua destilada necesaria que se adicionaría a cada cemento de mezcla, previamente se introdujo en un baño termostático ${ }^{11}$ hasta que alcanzase el equilibrio térmico, para ser mezclada con cada cemento de mezcla. En la Tabla 7-5 se especifica la relación a/c de cada uno de los morteros preparados y ensayados.

En el amasado de cada mortero y posterior preparación de sus correspondientes probetas, prismáticas normalizadas de $40 \mathrm{~mm}$ x $40 \mathrm{~mm}$ de sección transversal y $160 \mathrm{~mm}$ de longitud, se siguió el procedimiento especificado en la norma EN 196-1212. El mortero se prepara por amasado mecánico y se compacta en un molde utilizando una compactadora.

\subsection{2.- Conservación y curado de las probetas de mortero.}

El acondicionamiento de las probetas de mortero comienza colocando sobre cada molde utilizado una lámina de vidrio para cubrir la superficie superior del mismo, trasladándose éste a continuación a la cámara húmeda para su conservación hasta el momento de su desenmoldado. A las 24 horas de haber fabricado las probetas se procedió a su desenmoldado con ayuda de un martillo de goma.

Seguidamente se marcó cada una de las probetas y del número total de las probetas de mortero fabricadas con cada uno de los cementos de mezcla, se dividió en dos lotes, cada uno de ellos expuesto a distinto ambiente de conservación y curado:

1. Al aire de laboratorio cuyas condiciones fueron de $20,0 \pm 2,0^{\circ} \mathrm{C}$ y una humedad relativa igual o superior al $50 \%$, durante 28 días.

2. Bajo agua destilada en un recipiente hermético a $20,0 \pm 2,0^{\circ} \mathrm{C}$ durante 28 días. Se colocaron las probetas sobre emparrillados y se mantuvieron separadas unas de otras, de forma que el agua tuviera libre acceso a las seis caras de las probetas. En ningún momento durante la conservación se superó la relación $1 / 5$ en volumen probetas/agua, para no provocar así la lixiviación de la portlandita generada fruto de la hidratación de la pasta de cemento. El curado bajo agua destilada

\footnotetext{
${ }^{10}$ Véase el apartado 7.1.1 de esta MEMORIA de Tesis Doctoral.

11 Véase el apartado 7.3.4 de esta MEMORIA de Tesis Doctoral.

12 Véase el apartado 7.2 .2 de esta MEMORIA de Tesis Doctoral.
} 
Una vez concluido este proceso de curado de las probetas de mortero, éstas se secaron en una estufa de convección sin sobrepasar en ningún caso la temperatura límite de $40^{\circ} \mathrm{C}$ (temperaturas superiores a $40^{\circ} \mathrm{C}$ extraen agua de cristalización de las fases AFt y AFm), hasta que la masa de cada muestra permaneciera constante. En la estufa se habían introducido además un frasco de PVC con lentejas de $\mathrm{NaOH}$ para prevenir la carbonatación de las pastas, siguiendo un principio de actuación similar al seguido por Kjellsen (1990). Este proceso de secado a $40^{\circ} \mathrm{C}$ en una atmósfera exenta de $\mathrm{CO}_{2}$ se mantuvo hasta peso constante.

\subsection{3.- Equipo y ambiente del proceso de carbonatación}

Una vez curadas las probetas y concluido el pre-acondicionamiento de las mismas a $40^{\circ} \mathrm{C}$, se colocaron dentro de la cámara de ensayo o cámara de carbonatación, de tal forma que al menos el $90 \%$ de la superficie de apoyo estuviera expuesta a la acción del aire con dióxido de carbono. Las probetas, en el interior de la cámara estuvieron separadas entre sí en una distancia de al menos $2 \mathrm{~cm}$.

El ensayo simula de manera artificial un ambiente con un $20 \%$ de $\mathrm{CO}_{2}$ y se caracteriza por realizarse en las siguientes condiciones ambientales: temperatura $(\mathrm{T})$ de $(25 \pm 2){ }^{\circ} \mathrm{C}$; humedad relativa (HR) del $(65 \pm 5) \%$ y concentración de $\mathrm{CO} 2$ de $20 \% \pm 0,5 \%$.

La Cámara de ensayo (véase la Figura 7-8) debe ser capaz de mantener la concentración general $\mathrm{CO}_{2}$, la temperatura y la humedad en los valores indicados. Para ello, y para la realización del ensayo se optó por utilizar una incubadora de $\mathrm{CO}_{2}$ el cual sirvió para crear unas condiciones de precisión y exactitud que posibilitan unos resultados reproducibles. El equipo utilizado fue una incubadora de $\mathrm{CO}_{2}$ Panasonic MCO-18AC-PE IncuSafe $\mathrm{CO}_{2}$ incubator con control de temperatura y de $\mathrm{CO}_{2}$. Las condiciones de la cámara son mantenidas con precisión por el controlador del microprocesador P.I.D.

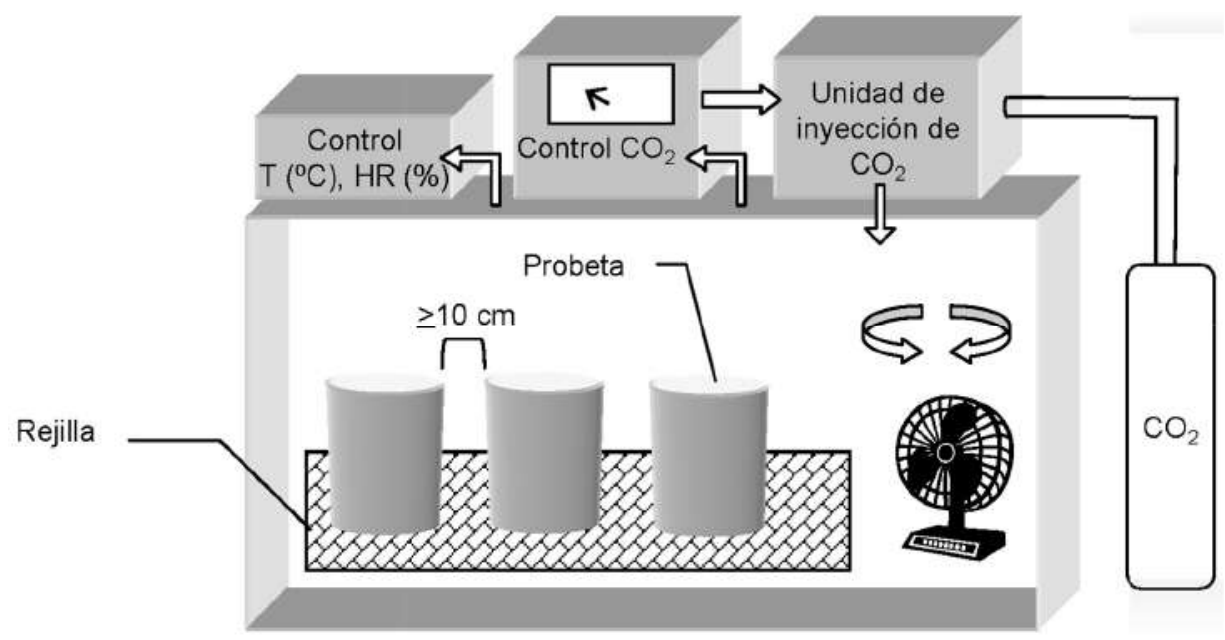

FIGURA 7-8.- ESQUEMA GENERAL DE LA CÁMARA DE ENSAYO (EXTRAÍDO DE UNE 83993-2). 
Mediante la colocación de una disolución saturada de $\mathrm{NaNO}_{3}$ en la bandeja inferior de la incubadora se consiguió la HR en el interior de la cámara del (65 \pm 5$) \%$, de acuerdo con la norma norteamericana ASTM E 104. Con estas condiciones de HR se provoca un efecto carbonatador del $\mathrm{CO}_{2}$ máximo. Las citadas condiciones de $\mathrm{HR}$ fueron controladas in situ y en continuo mediante un higrómetro digital.

La profundidad de carbonatación en las probetas de mortero se midió, de acuerdo con la norma UNE 112011, después de 14, 28, 60, 90 y 120 días de ensayo en la cámara.

\subsection{4.- Determinación de la RMF de las probetas carbonatadas.}

Para la determinación de la RMF en los morteros preparados y sometidos al ensayo de carbonatación acelerada, de acuerdo con la norma EN 196-1, se utilizó el método de carga de los tres puntos. La prensa que se utilizó para determinarle a las probetas de mortero dichos parámetros mecánicos, fue la habitual ${ }^{13}$.

El procedimiento del ensayo comienza colocando la probeta en la prensa, con una cara lateral sobre los rodillos soporte y con su eje longitudinal normal a los soportes. Se aplica la carga verticalmente mediante los rodillos de carga sobre la cara lateral opuesta del prisma y se incrementa uniformemente, a una velocidad de $(50 \pm 10) \mathrm{N} / \mathrm{s}$ hasta rotura.

A continuación, se mantienen las mitades de la probeta cubiertas con un paño húmedo hasta el ensayo de compresión y se calcula la resistencia a flexotracción, Rf, en $\mathrm{MPa},{ }^{14}$ :

\subsection{5.- Determinación de la profundidad de carbonatación en los morteros endurecidos.}

En este apartado tiene por objeto describir un método de ensayo para determinar la profundidad de carbonatación en los morteros preparados y sometidos al ensayo de carbonatación acelerada, de acuerdo con la norma UNE 112011. Con este ensayo puede obtenerse información del estado de carbonatación de dichas probetas de mortero, para así relacionarlo con el cemento de mezcla utilizado.

La medida de la profundidad de la capa carbonatada en los hormigones, o cualquier material de base cemento se basa en la determinación de la reducción de la alcalinidad que supone la carbonatación, la cual puede ponerse de manifiesto mediante un indicador de $\mathrm{pH}$, que la hace visible por cambios de coloración.

Se utiliza como indicador una disolución de fenolftaleína al 1\% disuelta en alcohol etílico al 70\%. Así, se prepararon $100 \mathrm{~cm}^{3}$ de indicador, disolviendo $1 \mathrm{~g}$ de fenolftaleína en $70 \mathrm{~cm}^{3} \mathrm{de}$ alcohol etílico del $96 \%$ de pureza y se añaden después $30 \mathrm{~cm}^{3}$ de agua destilada. La fenolftaleína toma color rojo-púrpura para valores de $\mathrm{pH}$ superiores a 9,5 (hormigón no carbonatado) y se vuelve incolora en valores inferiores a 8 (hormigón carbonatado). Para valores entre 8 y 9,5 toma

${ }^{13}$ Véase el apartado 7.2 .3 de esta MEMORIA de Tesis Doctoral.

${ }^{14}$ Véase el apartado 7.2 .3 de esta MEMORIA de Tesis Doctoral. 
tonalidades entre rosa y rojo-púrpura.

En todos los casos la medición se efectuó sobre la superficie fracturada de cada probeta después de haber sido sometida al ensayo mecánico de flexotracción, limpia de partículas sueltas debe efectuar sobre una superficie. Asimismo, se realizó siempre la medición inmediatamente después de la fractura de la probeta, ya que la superficie fracturada se carbonata con rapidez. La aplicación del indicador se realizó mediante goteo directamente sobre la fractura y con la superficie de aplicación del indicador hacia arriba.

Las medidas se deben tomar con una precisión de 0,5 $\mathrm{mm}$. En las determinaciones debe tenerse en cuenta lo siguiente:

a) Si la carbonatación presenta un frente homogéneo, como el indicado en la Figura 7-9, la profundidad de carbonatación se expresa como dk.

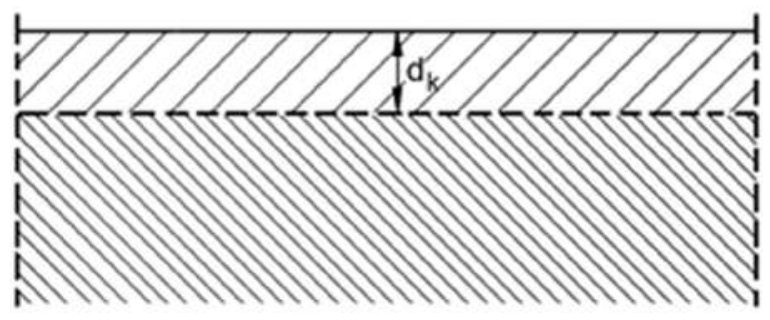

FIGURA 7-9.- REPRESENTACIÓN GRÁFICA DE UN FRENTE HOMOGÉNEO DE CARBONATACIÓN (EXTRAÍDO DE UNE 112011).

b) Cuando el frente de carbonatación aparezca de forma irregular, como el señalado en la Figura 7-10, la medida se expresa como la penetración media, dk, la penetración máxima, dk máx., y la penetración mínima, dk mín. De igual modo se procede cuando la carbonatación presente penetraciones singulares como la que se indica en la Figura 7-11.

c) Debe indicarse si el color que adquiere la superficie con el indicador no es rojo-púrpura sino rosado (que corresponde a un $\mathrm{pH}$ entre 8 y 9,5) y, en ese caso, su profundidad y frecuencia.

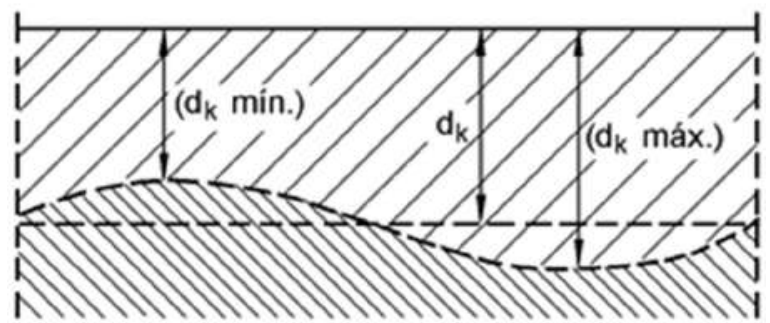

FIGURA 7-10.- REPRESENTACIÓN GRÁFICA DE UN FRENTE IRREGULAR DE CARBONATACIÓN (EXTRAÍDO DE UNE 112011). 


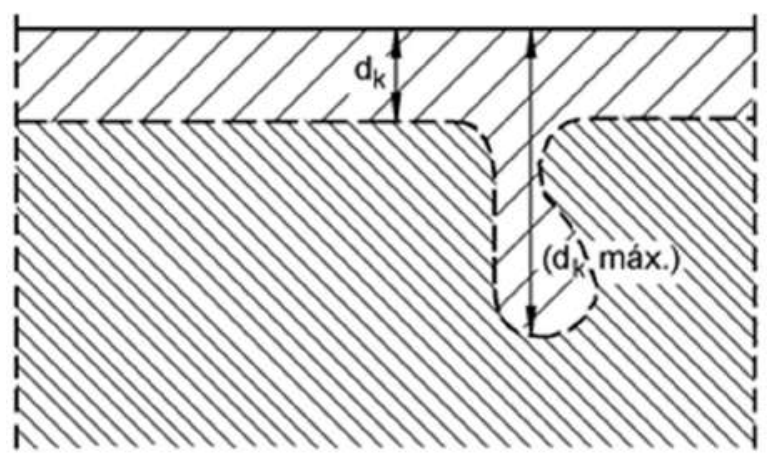

FIGURA 7-11.- REPRESENTACIÓN GRÁFICA DE UN FRENTE SINGULAR DE CARBONATACIÓN (EXTRAÍDO DE UNE 112011).

d) Deben considerarse carbonatadas aéreas de transición que hayan perdido su color después de $24 \mathrm{~h}$ de la aplicación estando protegidas del contacto con el aire.

Se tomó el perfil del avance del $\mathrm{CO}_{2}$ en las probetas de mortero tal y como se indica en la Figura /-12. Las medidas de profundidad del agresivo se deberían hacer, preferentemente, en las superficies más expuestas al aire, que corresponden a las caras superior (a) y laterales (b y c) de la probeta. Las mediciones de los valores de la profundidad deberían hacerse con un cierto espaciamiento.

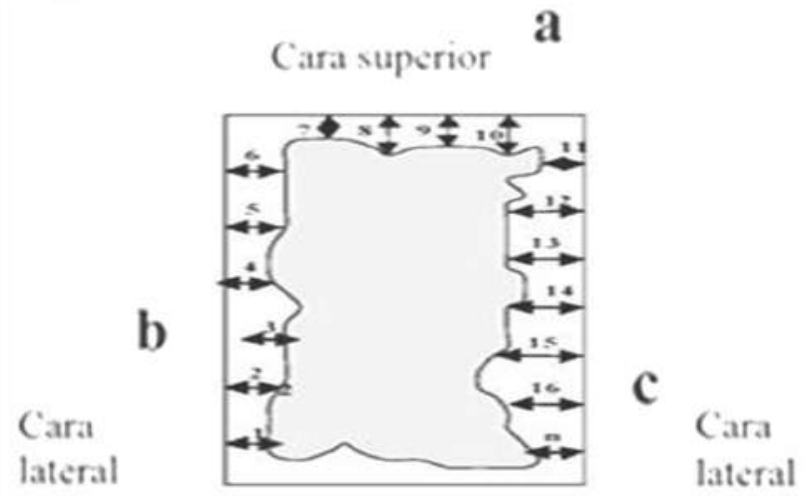

FIGURA 7-12- MEDIDAS DE PROFUNDIDAD DE CARBONATACIÓN (EXTRAÍDO DE UNE 83993-2).

\subsection{6.- Determinación de la R.M.C. de las probetas carbonatadas.}

Para la determinación de la RMC en los morteros preparados y sometidos al ensayo de carbonatación acelerada, de acuerdo con la norma EN 196-1, se utilizó la misma prensa que en el ensayo de flexotracción ${ }^{15}$. De esta forma se ensayaron los semiprismas en los ensayos previos de

${ }^{15}$ Véase el apartado 7.2 .3 de esta MEMORIA de Tesis Doctoral. 
COMPORTAMIENTO SULFÁTICO Y MECÁNICO-RESISTENTE DE CEMENTOS PORTLAND CON ELEVADOS CONTENIDOS DE PUZOLANAS ( $>40 \%$ ): SU FUNDAMENTO QUÍMICO Y JUSTIFICACIÓN DE OTRAS CONSECUENCIAS POSIBLES

flexotracción y de determinación de la profundidad de carbonatación.

Finalmente, se calcula la resistencia a flexotracción, Rf, en $\mathrm{MPa}^{16}$ :

${ }^{16}$ Véase el apartado 7.2.4 de esta MEMORIA de Tesis Doctoral. 


\section{CAPÍTULO 8}

\section{RESULTADOS OBTENIDOS: SU ANÁLISIS, ESTUDIO, DISCUSIÓN E INTERPRETACIÓN}



A lo largo de este Capítulo se van a describir los resultados obtenidos de todos y cada uno de los análisis y ensayos descritos en el Capítulo 7 de esta Memoria de Tesis Doctoral que se han realizado. Y de su estudio, discusión e interpretación se obtendrán una serie de CONCLUSIONES que satisfarán los objetivos propuestos de las cuales se obtendrá, además, una serie de CONSECUENCIAS Y RECOMENDACIONES TÉCNICAS que complementen más y mejor las ya existentes y reglamentadas de este tipo de cementos Portland con cantidades de reemplazo por puzolanas $>40 \%$, en lo concerniente a su durabilidad en su sentido más amplio y no sólo frente al ataque de los sulfatos [RC-16 y Norma UNE-EN 197-1:2011].

De forma resumidase puede decir por tanto que, el análisis, estudio, discusión e interpretación de todos los resultados obtenidos de la realización de los análisis y ensayos programados con pastas y morteros normalizados de dichos cemento Portland con y sin cantidades de reemplazo por puzolanas $>40 \%$, siguió la estructura que se detalla a continuación:

1. En primer lugar, se analizaron los resultados obtenidos de la determinación de la actividad puzolánica de cada una de las puzolanas seleccionadas y de la evolución, con el porcentaje de reemplazo por $\mathrm{CP}$, de la $[\mathrm{CaO}]$ y de la $\left[\mathrm{OH}^{-}\right]$enla fase líquida en contacto con su 
correspondiente pasta de cemento, a las edades de 7 y 28 días. Asimismo, se analizaron también los resultados obtenidos de la determinación del pH de dicha fase líquida en las mismas condiciones que en el ensayo de puzolanicidad.

2. En segundo lugar, se analizaron los resultados obtenidos de todos y cada uno de los CP y de sus cementos de mezcla mencionados (preparados y dosificados ${ }^{1}$ antes) y ensayados mediante el MAE de Le Chatelier Anstett (L-A), para obtener así el comportamiento de sus probetas de pasta parcialmente hidratada o probetas L-A, frente al ataque de los sulfatos, habiéndosele determinado, para ello, a cada una y a diferentes edades previamente programadas para todas, los siguientes parámetros físicos: Incremento porcentual de Diámetro $(\Delta \varnothing x \mathrm{xd}(\%))$, Velocidad de IncrementoDiametral $V_{c \varnothing}(\Delta \varnothing(\%) /$ día), Incremento Porcentual de Diámetro por unidad de masa de puzolana "Z", $\Delta \varnothing x d(\%) / " Z$ " y Penetración de la Aguja de Vicat", PAV. (mm).

3. En tercer lugar, se analizaron los resultados obtenidosdel comportamiento mecánicoresistente de los cementos de mezcla mencionados ${ }^{2}$ en probetas de $4 \times 4 \times 16 \mathrm{~cm}$ de mortero normalizado tipo EN 196-1, habiéndoseles determinado, para ello, sus RMC y RMF.Y en

4. Cuarto y último lugar, se analizaron los resultados obtenidos de la determinación de la profundidad de carbonatación en probetas de dicho mortero normalizado "hermanas" y endurecidas hasta la edad de 28 días, consecuencia directa del efecto difusivo del $\mathrm{CO}_{2}(20 \%)$ a través del airea temperatura $\left(\mathrm{T}^{\mathrm{a}}\right)$ de $(25 \pm 2){ }^{\circ} \mathrm{Cy} \mathrm{HR}$ del $(65 \pm 5) \%$, de su red de macroporos, poros, microporos y capilares.

\section{1.- Ensayo de resistencia química a los sulfatos: Método de ensayo acelerado}

\section{(MAE) Le Chatelier-Anstett.}

La determinación la resistencia potencial al ataque del ión sulfato de todos los cementos Portland puros o de referencia seleccionados y de sus mezclas, por separado, con todas y cada una de las puzolanas selccionadas también (véanse en el apartado 7.1. del Capítulo 7), con y sin $\mathrm{CH}$, de mezcla en esta Tesis Doctoral se ajustó a los métodos de ensayo para determinar, en primer lugar, el incremento porcentual de Diámetro ( $\Delta \varnothing \mathrm{xd}(\%))$, en segundo lugar, la velocidad de Incremento Diametral VCØ $(\Delta \varnothing(\%) /$ día), en tercer lugar, el incremento Porcentual de Diámetro por unidad de masa de puzolana "Z", $\Delta \varnothing x d(\%) /$ "Z" y por último, la penetración de la Aguja de Vicat", PAV. (mm). Por ello en este apartado, se han analizado, estudiado, comparado, discutido e interpretado los resultados experimentales obtenidos en los procedimientos de determinación de todos y cada uno de estos parámetros de cada una de las probetas Le ChatelierAnstett fabricadas.

\footnotetext{
${ }^{1}$ Véase el apartado 7.1de esta MEMORIA de Tesis Doctoral.

${ }^{2}$ Véase el apartado 7.1de esta MEMORIA de Tesis Doctoral.
} 


\subsection{1.-De los cementos Portland de referencia.}

Esta parte de la investigación ya fue realizada por causa de otros objetivos afines de Talero, (2016) surgidos como consecuencia de sus trabajos de Tesis Doctoral. Por consiguiente, no ha lugar aquí su repetición. No obstante, quién desee conocerlos con mayor detalle podrá encontrarlos en su MEMORIA correspondiente que se encuentra en la Biblioteca del Instituto "Eduardo Torroja" de Ciencias de la Construcción.

Aquí únicamente se expondrán los resultados circunscritos a los cinco cementos Portland utilizados en esta investigación objeto de Tesis Doctoral. En ellos se puede ver la presencia en este medio tan permanentemente básico y selenitoso en el tiempo de ettringita de lenta formación o de origen $\mathrm{C}_{3} \mathrm{~A}$, de muy lenta formación o de origen $\mathrm{C}_{4} \mathrm{AF}$ del $\mathrm{CP}$ y/o taumasita, todas ellas a causa y origen del deterioro por expansión de las 5 probetas L-A correspondientes.

\subsection{2.-De los cementos de mezcla preparados y dosificados que figuran en el apartado}

\section{1. del Capítulo 7.}

Antes de todo se debe recordar que que esta Discusión y su correspondiente Interpretación, se van a referir en un principio a las probetas L-A (Blondiau, 1961) de los cementos CEM IV y CEM V de acuerdo con la Instrucción RC-16, y los derivados con cal apagada, $\mathrm{CH}$, y/o yeso, preparados en el laboratorio con: las puzolanas naturales $\mathrm{O}$, A y $\mathrm{C}$, las puzolanas artificiales CV10, CV19 y M,y los CP: P-1, P-2, P-31, PY-4 y PY-6, respectivamente.

Así pues y en vista de que en este caso los valores de los parámetros citados obtenidos de las probetas L-A preparadas con cada una de las adiciones activas anteriores, han tenido oscilaciones múltiples y diversas a lo largo de los dos años de duración del ensayo, se ha creído conveniente y oportuno analizarlos y estudiarlos de una manera agrupada al objeto de su más cómoda interpretación. A tal fin y para el caso de las probetas L-A, se han hecho dos agrupaciones con los mismos, la de los parámetros $\Delta \varnothing$, VCø e $\Delta \varnothing / g$ "Z" por un lado y la del parámetro P.A.V., por otro.

En todas las probetas L-A de los cementos puzolánicos preparados al efecto con cada una de dichas adiciones activas, la creación, evolución y/o desarrollo de los valores del $\Delta \emptyset$, VCø e $\Delta ø / g$ "Z" correspondientes, ha sido:

- $\quad \Delta ø$ y $\Delta ø / g$ " $Z$ ": de aumento por lo general grande, mediano o pequeño hinchamiento con resquebrajamiento inclusive, más o menos acusado de la probeta L-A en ocasiones, que, en su caso, llegó a dar, más pronto o más tarde, con su destrucción total o parcial, pero que una vez alcanzado en su caso el máximo valor del $\Delta \emptyset$, la probeta L-A dejó de crecer colapsándose incluso, y tendiendo a fraguar muy lentamente, como se verá más adelante por los valores de P.A.V. correspondientes; todo ello según la adición activa y/o el cemento Portland matriz que la acompañaba cada caso.

- VCø: de disminución rápida e incluso muy apreciable en ocasiones hasta la práctica nulidad de la misma, según los casos, pero con el hecho notable y destacable en todos 
ellos, de que sea cual fuere la probeta L-A del cemento de mezcla de que se trate, sus mayores valores de $\mathrm{VC} \varnothing$, alcanzados por la misma se consiguieron durante los primeros 28 días, y más aún se podría precisar, que en ocasiones dentro de sus primeras 24 horas o 7 días a lo sumo, el cual estuvo seguido, por lo general, en tales ocasiones, de una disminución también muy notable que fue más brusca que la que la de su cemento Portland matriz acompañante P-noo o PY-no solo.

- Parámetro P.A.V.: la creación, evolución y desarrollo de los valores de este parámetro a lo largo de todo el ensayo resultó ser diferente de uno a otro cemento, según fue su contenido de aluminato tricálcico y/o de cal apagada $=\mathrm{CH}$, y/o (cantidad) de adición activa "Z" (TT) y/o el "carácter" (Talero y cols., 2017) de la misma.

Así, si tomamos como patrón el proceso evolutivo de los valores de este parámetro correspondientes a las probetas L-A de los cementos Portland matrices puros con mayor contenido de $\mathrm{C}_{3} \mathrm{~A}$ y por tanto más susceptibles al ataque del yeso o lo que es lo mismo mínima o nula estabilidad de volumen ante dicho ataque agresivo, el resto de cementos mixtos de laboratorio con o sin cal apagada, $\mathrm{CH}$, han tenido un proceso evolutivo de máxima o mínima (o mejor quizás nula) estabilidad de volumen o bien situaciones intermedias entre ambas de inicio la una o la otra, a lo largo de todo el ensayo.

No obstante, de todos los cementos puzolánicos así ensayados cabe destacar por su interés aquellos en los que el proceso evolutivo es asimilable a una curva de Gauss invertida, como por ejemplo son los casos de los cementos mixtos 30/70 -1/(M+CH) y P31/(M+CH), entre otros.

Pues bien, ello es una vez más señal inequívoca de las diferentes velocidades de formación de la ett-rf o de origen puzolana, de la ett-lf o de origen $C_{3} A$ de los cementos Portland matrices P1 y P-31 respectivos y que ya demostrara Talero, (2016) mediante sus trabajos de Tesis Doctoral, así como también de la correspondiente ACCIÓN SINÉRGICA EXPANSIVA (Talero, 2010; 2011a; 2011b) habida en cada caso, la cual dejaría libre tanto más $C_{3} A$ residual para formar ett-lf con posterioridad (edades finales del ensayo) cuanto mayor haya sido el contenido del mismo y/o la finura del molido de su cemento Portland matriz, causa y origen en dicho orden, de la rama ascendente y su pendiente de los valores del P.A.V. a las edades finales del ensayo, que ha sido lo ocurrido en esta investigación.

Y el que no haya ocurrido otro tanto con el $\mathrm{P} 2 /(\mathrm{M}+\mathrm{CH})$ 30/70 como en teoría debería haber ocurrido al estar comprendido el contenido de $\mathrm{C}_{3} \mathrm{~A}$ de su cemento Portland matriz-11.09\%-entre el del P-1 -14.11\%- y el del P-31 -7.69\%-, viene a reafirmar la anterior hipótesis justificativa, aunque aparentemente y en principio pareciere lo contrario. Pues no se ha de olvidar de ellas que el parámetro finura de molido, interviene bastante en su justificación. Y como podemos ver en la Tabla 6-2, la superficie específica del cemento Portland P2 es de $3015 \mathrm{~cm}^{2} / \mathrm{g}$ mientras que la del P1 es de $3192 \mathrm{~cm}^{2} / \mathrm{g}$ y el tiempo de fraguado otro tanto, véase la Tabla 6-3,- lo cual hace que el cemento de mezcla de aquél, o sea el $\mathrm{P} 2 /(\mathrm{M}+\mathrm{CH}) 30 / 70$, se pueda encontrar más próximo a la definición del "Optimo de Regulador de Fraguado", por tener su "Optimo de Finura de Molido" de un cemento Portland con adiciones puzolánicas, dada por R. Talero mediante sus trabajos de Tesis Doctoral (Talero, 1986), que los cementos mixtos homónimos P1/(M+CH) 30/70 y 202 
P31/(M+CH) 30/70, con las consecuencias tecnológicas al caso, como son que el "ritmo del fraguado" de la probeta L-A correspondiente se asemeje bastante más a la de la pasta de cualquier cemento con adiciones, o no, en aquél caso, el $\mathrm{P} 2 /(\mathrm{M}+\mathrm{CH}) 30 / 70$, que en estos dos últimos P1/(M+CH) 30/70 y P31/(M+CH) 30/70, que no se deberán parecer en nada, como así ha ocurrido en esta investigación.

Y otro tanto de la citada similitud mostrada por el fraguado de la probeta L-A P2/(M+CH) 30/70, que deberá ocurrir si el cemento Portland matriz contiene poco o nada de $\mathrm{C}_{3} \mathrm{~A}$ y sea cual fuese su superficie específica, como así ha ocurrido también en esta investigación, véanse al efecto los valores de P.A.V. de la probeta L-A del CEMENTO DE MEZCLA PY6/(M+CH) 30/70 que así nos lo confirman al ser la creación, evolución y desarrollo de los valores de los mismos semejantes a los de la probeta L-A del cemento $\mathrm{P} 2 /(\mathrm{M}+\mathrm{CH})$ 30/70 y no en cambio a los de las probetas L-A de los cementos $\mathrm{P} 1 /(\mathrm{M}+\mathrm{CH})$ 30/70 y $\mathrm{P} 31 /(\mathrm{M}+\mathrm{CH})$ 30/70 por las razones apuntadas.

\subsubsection{1-A igualdad de puzolana seleccionada " $Z$ " y cantidad de su reemplazo por CP.}

\subsubsection{1-Familias $P-n^{\circ}$ y $P Y-n{ }^{\circ} Z^{\prime \prime} 50 / 50$.}

Se determianaron todos y cada uno de los parámetros anterior mente descritos: $\Delta \varnothing, \mathrm{VC}$, $\Delta \varnothing / g$ "Z" у P.A.V.

Por lo general se cumple que en las clasificaciones que se obtienen a las edades fundamentales del ensayo de los cementos Portland matrices con un contenido de $\mathrm{C}_{3} \mathrm{~A}$ extremo o sea el P1 y el PY6, ambos han desarrollado posiciones contrarias sea cual fuere la puzolana "Z" que los acompañé. La excepción mostrada por la puzolana $C$ se deba a su aparente "capacidad de cambio" (Talero y col., 2009b). Del mismo modo el CPO P2 ha mostrado por lo general un diferente comportamiento al P1 a pesar de ser el contenido de $\mathrm{C}_{3} \mathrm{~A}$ de aquel, 11.09\%, inmediatamente inferior al del P1, $14.11 \%$, y no así en cambio los contenidos de $\mathrm{C}_{3} \mathrm{~S}$ y $\mathrm{C}_{2} \mathrm{~S}$ de ambos $\mathrm{CPO}$ que han resultado ser bastante dispares, lo que podría justificar quizás este distinto comportamiento de ambos en estas clasificaciones de los cementos mixtos P-n ${ }^{\circ}$ y PY- $n^{\circ} / " Z "$ 50/50. Para mayor detalle, véase la Tabla 6-1.

\subsubsection{2-Familias $P-n^{\circ}$ y $P Y-n^{\circ} /^{\prime \prime} Z^{\prime \prime} 40 / 60$.}

Por lo general se ha cumplido que las clasificaciones que se han obtenido de los CPO correspondientes en función de los diferentes parámetros determinados han sido distintas según el carácter de la puzolana "Z" que los acompañó en cada caso.

\subsubsection{3-Familias $P-n^{\circ}$ y $P Y-n{ }^{\circ} Z^{\prime \prime} 30 / 70$.}

Por lo genera, se ha cumplido con todos los parámetros determinados lo mismo que lo expresado en el apartado 8.1.2.1.3 correspondiente a las Familias P-nº y PY-no/"Z" 40/60. 
COMPORTAMIENTO SULFÁTICO Y MECÁNICO-RESISTENTE DE CEMENTOS PORTLAND CON ELEVADOS CONTENIDOS DE PUZOLANAS (> 40\%): SU FUNDAMENTO QUÍMICO Y JUSTIFICACIÓN DE OTRAS CONSECUENCIAS POSIBLES

TABLA 8-1.- CLASIFICACIÓN DE LOS DISTINTOS CEMENTOS PORTLAND DE REFERENCIA A IGUALDAD DE PUZOLANA EN EL ENSAYO L-A. CEMENTO DE MEZCLA P-N ${ }^{\circ}$ Y PY-N/"Z" 50/50

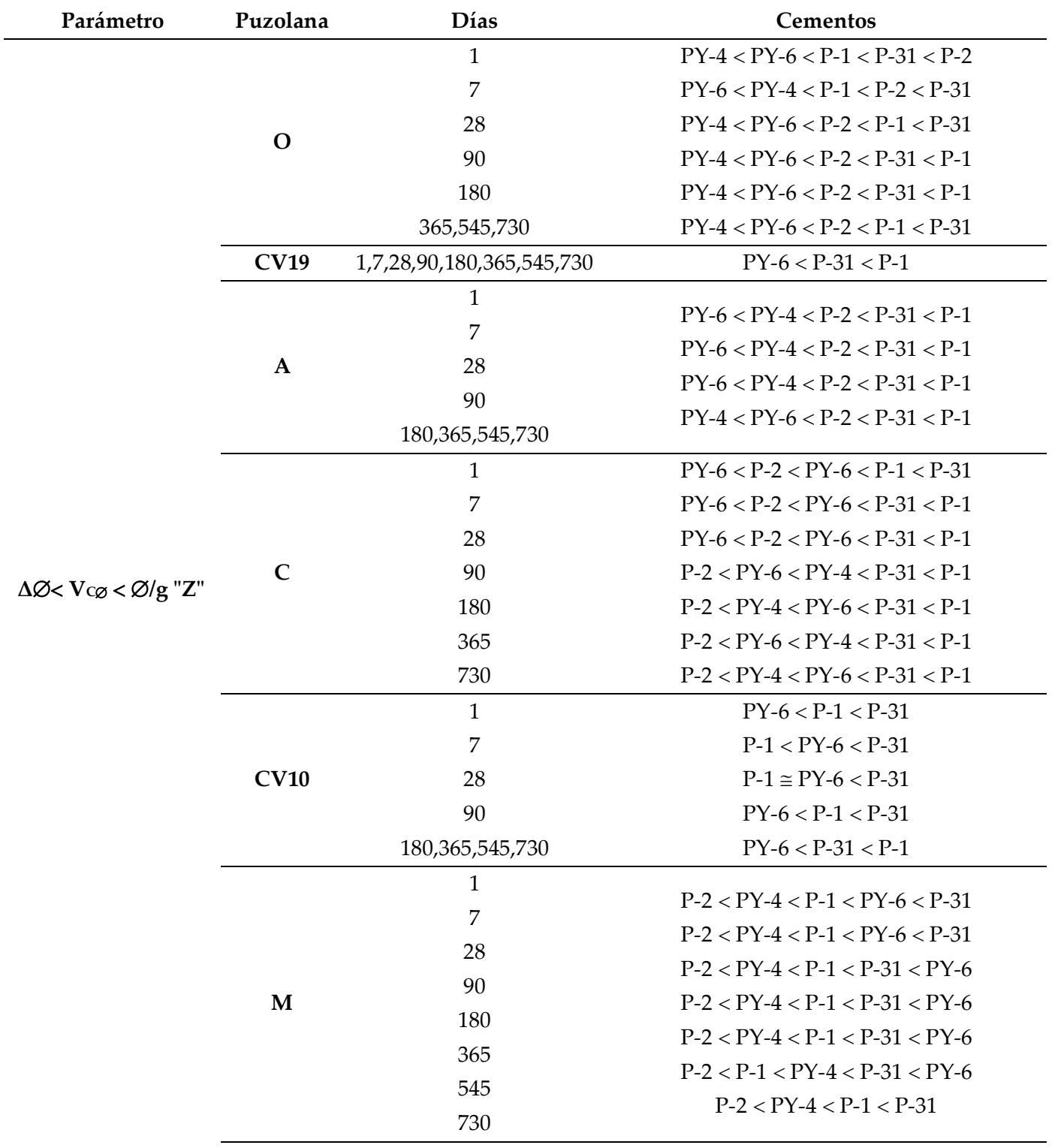

\subsubsection{4-Familias $P-n^{\circ}$ y $P Y-n^{\circ} / " Z " 50 / 50+C H(" Z " / C H=4)$.}

Vale aquí prácticamente la misma discusión expuesta para los cementos de mezcla correspondientes sin $\mathrm{CH}$, véase para más detalle el apartado 8.1.2.1.1

\subsubsection{5-Familias $P-n^{\circ}$ y PY- ${ }^{\circ} /{ }^{\prime \prime} Z^{\prime \prime} 40 / 60+C H(" Z " / C H=5)$.}

Vale aquí prácticamente la misma discusión expuesta para los cementos de mezcla correspondientes $\sin \mathrm{CH}$, pero sobretodo los correspondientes a 50/50 con $\mathrm{CH}$. Véase para más 
detalle el apartado 8.1.2.1.1

TABLA 8-2.- CLASIFICACIÓN DE LOS DISTINTOS CEMENTOS PORTLAND DE REFERENCIA A IGUALDAD DE PUZOLANA EN EL ENSAYO L-A. CEMENTO DE MEZCLA P-N Y PY-N/"Z" 40/60 + CH

\begin{tabular}{|c|c|c|c|}
\hline Parámetros & Puzolana & Días & Cementos \\
\hline \multirow{3}{*}{$\Delta \varnothing<\mathrm{V}_{\mathrm{C} \varnothing}<\Delta \varnothing / \mathrm{g}$ "Z" } & \multirow{6}{*}{ M } & 1 & PY-6 $<$ PY-4 $<$ P-1 $<$ P-2 \\
\hline & & 7,28 & PY- $6<$ P-1 $<$ P- $2<$ PY- 4 \\
\hline & & $90,180,365,545,730$ & $\mathrm{P}-1<\mathrm{P}-2<\mathrm{PY}-6<\mathrm{PY}-4$ \\
\hline \multirow{3}{*}{ < P.A.V. < (mm) } & & 1 & P-1 $<$ PY-4 $<$ PY-6 $<$ P-2 \\
\hline & & 7,28 & $\mathrm{P}-1<\mathrm{P}-2<\mathrm{PY}-4<\mathrm{PY}-6=\mathrm{PT}$ \\
\hline & & $90,180,365,545,730$ & P-1 $<$ P- $2<$ PY $-6<$ PY- 4 \\
\hline
\end{tabular}

\subsubsection{6-Familias $P-n^{\circ}$ y $P Y-n^{\circ} / " Z " 30 / 70+C H(" Z " / C H=6)$.}

Vale aquí prácticamente la misma discusión expuesta para los cementos de mezcla correspondientes sin $\mathrm{CH}$. pero sobretodo los correspondientes a 50/50 con $\mathrm{CH}$. Véase para más detalle el apartado 8.1.2.1.3

TABLA 8-3.- CLASIFICACIÓN DE LOS DISTINTOS CEMENTOS PORTLAND DE REFERENCIA A IGUALDAD DE PUZOLANA EN EL ENSAYO L-A. CEMENTO DE MEZCLA P-N Y PY-N /"Z" 30/70 + CH

\begin{tabular}{|c|c|c|c|}
\hline Parámetros & Puzolana & Días & Cementos \\
\hline \multirow{2}{*}{$\Delta \varnothing<\mathrm{V}_{C \varnothing}<\Delta \varnothing / \mathrm{g}$ "Z" } & \multirow{5}{*}{ M } & 1 & $\mathrm{P}-2<\mathrm{P}-31<\mathrm{PY}-6<\mathrm{P}-1$ \\
\hline & & $7,28,90,180,365,545,730$ & $\mathrm{P}-2<\mathrm{P}-31<\mathrm{P}-1<\mathrm{PY}-6$ \\
\hline \multirow{3}{*}{$<$ P.A.V. $<(\mathrm{mm})$} & & 1 & P-2 $<$ PY-6 $<$ P-31 $<$ P-1 \\
\hline & & 7 & $\mathrm{P}-2<\mathrm{P}-31<\mathrm{PY}-6=\mathrm{P}-1$ \\
\hline & & $28,90,180,365,545,730$ & $0 \approx \mathrm{P}-2<\mathrm{PY}-6<\mathrm{P}-31<\mathrm{P}-1$ \\
\hline
\end{tabular}

\subsubsection{7-Familias $P-n^{\circ}$ y $P Y-n{ }^{\circ} Z^{\prime \prime} 30 / 70+7 \% S_{3}$.}

A destacar en esta ocasión la notable estabilidad de las probetas L-A correspondientes a ambos cementos mixtos con exceso de yeso $\left(=7.0 \% \mathrm{SO}_{3}\right)$.

TABLA 8-4.- CLASIFICACIÓN DE LOS DISTINTOS CEMENTOS PORTLAND DE REFERENCIA A IGUALDAD DE PUZOLANA EN EL ENSAYO L-A. CEMENTO DE MEZCLA P-N ${ }^{\circ}$ Y PY-N"Z" 30/70 + 7\% SO

\begin{tabular}{|c|c|c|c|}
\hline Parámetros & Puzolana & Días & Cementos \\
\hline$\Delta \varnothing<\mathrm{V}_{\mathrm{C} \varnothing}<\Delta \varnothing / \mathrm{g}$ & \multirow{3}{*}{ M } & 1 & $0=\mathrm{P}-1=\mathrm{PY}-6$ \\
\hline "Z" & & $7,28,90,180,365,545,730$ & $0=\mathrm{P}-1<\mathrm{PY}-6 \approx 0$ \\
\hline$<$ P.A.V. $<(\mathrm{mm})$ & & $1,7,28,90,180,365,545,730$ & $0=\mathrm{P}-1=\mathrm{PY}-6$ \\
\hline
\end{tabular}

\subsubsection{8-Familias $P-n^{\circ}$ y PY-n ${ }^{\prime \prime} \mathrm{Z}^{\prime \prime} 30 / 70+\mathrm{CH}(" \mathrm{Z} " / \mathrm{CH}=6)+7 \% \mathrm{SO}_{3}$.}

Vale aquí prácticamente lo mismo que para lo dicho para la discusión anterior. Véase el apartado anterior 8.1.2.1.7. 
COMPORTAMIENTO SULFÁTICO Y MECÁNICO-RESISTENTE DE CEMENTOS PORTLAND CON ELEVADOS CONTENIDOS DE PUZOLANAS ( $>40 \%$ ): SU FUNDAMENTO QUÍMICO Y JUSTIFICACIÓN DE OTRAS CONSECUENCIAS POSIBLES

TABLA 8-5.- CLASIFICACIÓN DE LOS DISTINTOS CEMENTOS PORTLAND DE REFERENCIA A IGUALDAD DE PUZOLANA EN EL ENSAYO L-A. CEMENTO DE MEZCLA P-N ${ }^{\circ}$ Y PY-N"Z" 30/70 + CH + 7\% SO3.

\begin{tabular}{cccc}
\hline Parámetros & Puzolana & Días & Cementos \\
\hline \multirow{2}{*}{$\Delta \varnothing<\mathrm{V}_{\varnothing}<<\varnothing / \mathrm{g}$ "Z" } & & 1,7 & $0=\mathrm{PY}-6<\mathrm{P}-1=0.13$ \\
& \multirow{3}{*}{$\mathrm{M}$} & 28,90 & $0.25=\mathrm{PY}-6=\mathrm{P}-1=0.25$ \\
& & $180,365,545,730$ & $0.13=\mathrm{PY}-6<\mathrm{P}-1=0.25$ \\
\hline <P.A.V. $<(\mathrm{mm})$ & & $1,7,28,90,180,365,545,730$ & $0=\mathrm{P}-1=\mathrm{PY}-6$ \\
\hline
\end{tabular}

\subsubsection{2- Interpretaciones de los comportamientos encontrados en el apartado 8.1.2.1.}

\subsubsection{1-Familias $P-n^{\circ}$ y $P Y-n^{\circ} / " Z "$ "50/50.}

Parámetros $\Delta \emptyset$, VCø e $\Delta \emptyset / g$ "Z":

Ello resulta ser una vez más una demostración palpable de que las puzolanas O, CV19 y A, en estas proporciones 50/50, tienen un carácter más "silícico" que "alumínico". El comportamiento, en particular, de la puzolana $\mathrm{C}$, resulta chocante puesto que R. Talero cuando la utilizó en sus ensayos en proporciones 80/20, 70/30 y 60/40 mostró que tenía el comportamiento contrario, es decir, un carácter más "alumínico" que "silícico" (Talero y col., 2007b).

Por consiguiente, dicho comportamiento contrario al mostrado en las investigaciones previas de Talero y col. (2007b) en la proporción 50/50 utilizada en esta investigación, al haber resultado ser más próximo al de INERTES, nos demuestra que la causa es la falta de la cantidad de portlandita de origen cemento Portland necesaria y suficiente en la fase líquida de la probeta L-A correspondiente para que dicha puzolana C pueda mostrar su auténtico y verdadero carácter "alumínico" que en las citadas proporciones ensayadas por R. Talero si lo tuvo (Talero, 1986). Por ello el CPO P1 acaba por alcanzar las posiciones más a la derecha en el caso de tales puzolanas y más hacia el centro e incluso a la izquierda más extrema en el caso de la CV10 y M que al haber podido demostrar ser, no obstante, más "alumínicas" que "silícicas" que la $\mathrm{C}$, han originado con el CPO P1, un ESE de distinto signo.

Y si el CPO tuviera menor cantidad de $\mathrm{C}_{3} \mathrm{~S}$ en beneficio del $\mathrm{C}_{2} \mathrm{~S}$ e incluso algo menos de $\mathrm{C}_{3} \mathrm{~A}$ con la desventaja al caso de menor cantidad de portlandita en la fase líquida de su probeta L-A, su comportamiento podría haber llegado a ser el contrario al de P1, como así ha ocurrido en nuestra investigación con el P2 y el resto de las puzolanas ensayadas; pero específicamente con la $\mathrm{C}$ y $\mathrm{M}$ por ser más alumínicas que el resto, aún lo rebajarían dicho nivel de portlandita más aún por su acción puzolánica y no tanto en cambio la $\mathrm{O}, \mathrm{CV} 10$ y A con las que le ocurriría lo contrario al CPO P2, es decir, que trataría de parecerse en comportamiento al P1, como así también ha ocurrido en nuestra investigación, véase la Tabla 8-1.

Y como prueba adicional de la veracidad de lo que decimos está el comportamiento contrario mostrado en estos parámetros $\Delta \varnothing, \mathrm{VC}$ e $\Delta \varnothing / \mathrm{g}$ "Z" por dicho CPO P2 en el cemento de mezcla con $\mathrm{CH} \mathrm{P-2/(C+CH)} \mathrm{50/50,} \mathrm{el} \mathrm{cual} \mathrm{abandona} \mathrm{la} \mathrm{posición} \mathrm{más} \mathrm{extrema} \mathrm{de} \mathrm{todas} \mathrm{las}$ clasificaciones obtenidas para situarse más en el centro y a la derecha de estas según las diferentes 
edades del ensayo. Y otro tanto le deberá ocurrir por la misma razón al P1/(C+CH) 50/50, como así también ha ocurrido en esta investigación, véase la Tabla 8-1.

$\mathrm{Y}$ otra situación contraria y equivalente les ocurre a las puzolanas $\mathrm{O}$ y $\mathrm{CV} 10$ con los $\mathrm{CPO}$ P1 y P2 y CH. Puede observarse como con las mismas y a pesar de encontrarse en menor presencia en tales cementos de mezcla con $\mathrm{CH}$, se alcanzaron sólo mayores de $\Delta \varnothing$, VCø e $\Delta \varnothing / g$ "Z" y P.A.V., sino también diferentes posicionamientos de sus $\mathrm{CP}$ respectivos P1 y P2. De tal manera que el primero se comportó más y mejor como tal CPO de escasa o nula RS con la puzolana O y ESE negativo con la CV10, mientras que el P-2 ha podido producir dicho ESE positivo con la A e incluso la $\mathrm{C}$ y negativa y más parecida a la del P1 con la $\mathrm{O}$, por el motivo contrario en composición mineralógica que dicho P1, véase la Tabla 6-1.

Finalmente, otra prueba más en favor de la razón aducida respecto al comportamiento de INERTES de las puzolanas O, CV19 y A mayormente, es que las clasificaciones que se han obtenido a las edades finales del ensayo de los 3 ó 5 CP que las acompañan, coinciden prácticamente con la que se obtuvo en función de su contenido de $\mathrm{C}_{3} \mathrm{~A}$ de menor a mayor valor.

En el caso de la CV19 el posicionamiento del CPO P-1 podría ser debido además al ESE deletéreo entre su ett-rf y los geles de $\mathrm{Fe}(\mathrm{OH})_{3}$ que su elevado contenido de $\mathrm{Fe}_{2} \mathrm{O}_{3}$ podría originar según Martín-Luengo (1997).

Por último, el posicionamiento adquirido en todas las clasificaciones obtenidas de los parámetros $\triangle \varnothing$, VCø e $\Delta \varnothing / g$ "Z" por el CPO P-2 en el caso de la puzolana C -el de la izquierda más extrema- confirma que dicha puzolana es más "alumínica" que "silícica". Según ello dicho posicionamiento del CPO P-2 debería ser ratificado por una puzolana "alumínica" como así ha ocurrido con la $\mathrm{M}$ en nuestra investigación. Y el que ambas posiciones no se hayan mantenido en el caso del parámetro P.A.V. demuestra que el ESE originada con el CPO P-2 ha sido negativa quizás debido a su "capacidad de cambio" mientras que la originada con la puzolana $\mathrm{M}$ ha sido positiva por todo lo contrario y su mayor carácter "alumínico" que la C.

Parámetro P.A.V.:

Los resultados experimentales de este parámetro vienen a reafirmar la veracidad de las razones aducidas con sus parámetros correspondientes anteriores. De aquí que lo que allí era aumento del $\Delta \varnothing$ y parámetros derivados correspondientes aquí resulta ser aumento del P.A.V. y viceversa.

\subsubsection{2-Familias $P-n^{\circ}$ y $P Y-n^{\circ} / " Z^{\prime \prime} 40 / 60$.}

La primera razón explicativa de lo ocurrido dada en la Discusión correspondiente resulta lógica, aunque incomprensible en principio dado el precario número de cementos de mezcla con puzolana A ensayados en esta ocasión dados los objetivos fundamentales de esta investigación.

No obstante, y como dicho número no fue precario en el caso de la puzolana $\mathrm{M}$, que no hay que olvidar, que según las investigaciones preliminares de Talero (1986) es eminentemente "alumínica", ésta será básicamente la que permita poder dar una explicación razonable de lo 
ocurrido en base a las diferentes clasificaciones obtenidas con su parámetro P.A.V. a las edades fundamentales del ensayo.

Así y según dicho parámetro los CPO P-1 y P-2 han tenido un comportamiento semejante y lógicamente el contrario, en mayor o menor medida, el resto.

Y el comportamiento del P-1 de haber ocupado en principio la demarcación más extrema derecha para ir moviéndose hacia la izquierda con el transcurso del ensayo y acabar a las edades finales del mismo en la demarcación más extrema izquierda de la clasificación, nos demuestra que entre dicho CPO P-1 y la puzolana M ha habido un ESE más deletéreo que en el caso del P-2 -lo más probable por contener éste menor cantidad de $\mathrm{C}_{3} \mathrm{~A}, 11.09 \%$ por $14.11 \%$ del P-1- el cual y por este motivo el semejante recorrido "derecha-izquierda" lo desarrolla y finaliza en tan sólo 7 días. Ello demuestra que en esta ocasión el ESE entre el CPO P-2 y la puzolana M ha sido menos deletérea que con el P-1.

Y el comportamiento clasificatorio del resto de los CP ensayados con esta puzolana $\mathrm{M}$ deberá ser justificado en base al motivo contrario pues bastantes menores son sus contenidos de $\mathrm{C}_{3} \mathrm{~A}$, véase la Tabla 6-1.

\subsubsection{3-Familias $P-n^{\circ}$ y $P Y-n^{\circ} / " Z " 30 / 70$.}

Vale aquí el mismo razonamiento dado para interpretar el comportamiento de las Familias P-no y PY-no/"Z" 40/60, pero corregido y aumentado. Y decimos esto porque en este caso 30/70, tanto la acción negativa o deletérea entre el CPO P-1 y la puzolana M como la positiva y no deletérea entre el CPO P-1 y la puzolana M como la positiva y no deletérea entre el P-2 y dicha puzolana $\mathrm{M}$ han resultado ser netamente mayores y por consiguiente más claras. Y la veracidad de esta razón se ve corroborada por semejante comportamiento clasificatorio obtenido de tales CPO P-1 y P-2 cuando al cemento de mezcla correspondiente se le añadió $\mathrm{CH}$, véase la Tabla 8-3.

\subsubsection{4-Familias $P-n^{\circ}$ y $P Y-n^{\circ} / " Z " 50 / 50+C H(" Z " / C H=4)$.}

Vale aquí prácticamente a misma interpretación dada para sus cementos de mezcla correspondientes sin $\mathrm{CH}$. Véase el apartado 8.1.2.2.1.

\subsubsection{5-Familias $P-n^{\circ}$ y $P Y-n^{\circ} / " Z^{\prime \prime} 40 / 60+C H(" Z " / C H=5)$.}

Vale aquí prácticamente la misma interpretación dada para sus cementos correspondientes $\sin \mathrm{CH}$ y la correspondiente a los cementos de mezcla 50/50 con $\mathrm{CH}$ pero corregida y mejorada. Pues en este caso el ESE originado por la puzolana M los CPO P-1 y P-2 y la CH resulta ser bastante más semejante entre ambos. Por lo que al no haber influido tanto la pequeña diferencia entre sus contenidos de $\mathrm{C}_{3} \mathrm{~A}$-aunque si justifica lo suficiente que el P-2 haya ido a la zaga del P1- ni la mayor diferencia entre sus contenidos de $\mathrm{C}_{3} S$ y $\mathrm{C}_{2} \mathrm{~S}$, dicho comportamiento tan semejante ha de ser debido necesariamente a la cantidad igual de $\mathrm{CH}$ que los acompañó, dado que cuando la misma no estuvo presente no lo fue y si en cambio el contrario. 


\subsubsection{6-Familias $P-n^{\circ}$ y $P Y-n^{\circ} / " \mathrm{Z} " 30 / 70+C H$ ("Z"/CH=6).}

Dado que las clasificaciones obtenidas de esta Familia han sido prácticamente semejantes a las de su correspondiente Familia de cementos de mezcla sin cal apagada cabe deducir con fundamento que en esta mezcla y para este tipo de puzolana tan alumínica (Talero y col., 2007b), la cantidad de $\mathrm{CH}$ añadida a su cemento de mezcla no ha resultado ser la suficiente y necesaria para poder provocar al menos la semejanza de comportamientos obtenida en semejante caso y proporción 40/60, véase la Tabla 8-2 y la interpretación anterior del apartado 8.1.2.2.5.

\subsubsection{7-Familias Familias $P-n^{\circ}$ y $P Y-n^{\circ} / " Z^{\prime \prime} 30 / 70+7 \% \mathrm{SO}_{3}$.}

La causa de la notable estabilidad mostrada por ambas probetas L-A estriba en que la ettringita que se ha de formar en ambos casos se debe de haber formado en casi su totalidad durante los 14 días que el material hidráulico correspondiente hubo de estar bajo agua antes de secarlo a $40^{\circ} \mathrm{C}$ y prepararlo con $1 / 3$ parte de yeso para hacer con el mismo su probeta L-A correspondiente, muestra de la presencia de ettringita que ha de provenir necesariamente del CPO P-1 y/o la puzolana alumínica M.

\subsubsection{3-Análisis, Estudio, Discusión e Interpretación mediante las figuras obtenidas con los valores de los parámetros determinados en RS.}

\subsubsection{1-Figuras obtenidas con valores del parámetro $\Delta \emptyset$}

\subsection{1- Discusión e Interpretación General.}

$\mathrm{Al}$ observar las curvas correspondientes representativas de los valores obtenidos del parámetro $\Delta \varnothing$ durante el tiempo de duración del ensayo (Figuras 8-1, 8-2, 8-3, 8-4 y 8-5), se pudo comprobar lo siguiente:

a) En el caso de las curvas correspondientes a las puzolanas $\mathrm{O}$ y A: Cuando el contenido de $\mathrm{C}_{3} \mathrm{~A}$ de su $\mathrm{CP}$ acompañante fue menor del 7.0\% $\mathrm{SO}_{3}$, ambas curvas, junto con la de la CV19 (que se analizará y estudiará más adelante), fueron las que menor área o superficie abarcaron de todas con sus respectivos ejes de ordenadas, por menos pendiente de su curva representativa y enmarcadora, correspondiente.

Y hasta tal punto habían sido menores en pendiente y área, que, en una cierta medida, se aproximaban bastante a las correspondientes de sus respectivos CP solos PY-4 y PY-6, los cuales y en su razón de su prácticamente nulo contenido de $\mathrm{C}_{3} \mathrm{~A}$, habían sido, lógicamente, los que menores valores de ambos parámetros, habían originado.

No obstante, y a pesar de lo cual, llamó mucho la atención, por un lado, que este mismo comportamiento fuera mostrado también cuando el $\mathrm{CP}$ acompañante de ambas $\mathrm{AP}, \mathrm{O}$ y A, fue el P-2, cuyo contenido de $\mathrm{C}_{3} \mathrm{~A}$ originario, era, por contra, elevado, $11.09 \%$, y por otro, que el citado 
comportamiento no fuera ratificado además, cuando los $\mathrm{CP}$ acompañantes de ambas puzolanas, O y A, fueron el P-1 (14.11\% $\left.\mathrm{C}_{3} \mathrm{~A}\right)$ y el P-31 $\left(7.62 \% \mathrm{C}_{3} \mathrm{~A}\right)$, respectivamente, ya que en estos otros casos, sus curvas correspondientes tuvieron mayores pendientes y por tanto abarcaron más superficie.

b) En el caso de la ceniza CV19: Sin menoscabo de todo lo escrito en el sub-apartado anterior (a), acerca de las puzolanas O y A, en este otro caso de la CV19, se pudo observar además que los valores de la pendiente y área abarcada por sus tres correspondientes curvas representativas 50/50 guardaron claramente en cambio una relación directa con el contenido de $\mathrm{C}_{3} \mathrm{~A}$ de su CP que la acompañó en cada ocasión.

c) En el caso de la puzolana C: En este otro caso, no ocurrió lo que con las puzolanas O, A y CV19, vistas antes, sino que por el contrario, todas las curvas fueron, en gran medida, cualitativa y cuantitativamente semejantes en su evolución y valores de la pendiente y área abarcada, hubiera estado o no, el $\mathrm{C}_{3} \mathrm{~A}$ presente, lo que quizás se podía traducir en un cierto sentido como que todas habían finalizado antes o después, siendo "paralelas" entre si y, a la vez, al eje de abscisas. No obstante, la clasificación entre todas ellas en función de su área abarcada fue la siguiente:

$$
>\text { CM 50/50 > P-1/C }>\text { P-31/C }>\text { PY-4/C }>\text { P-2/C } \approx \text { PY-6/C. }
$$

d) En el caso de la ceniza CV10: Ocurrió que las curvas correspondientes a sus cementos de mezcla 50/50 sin $\mathrm{CH}$, preparados con $\mathrm{CP}$ de contenido de $\mathrm{C}_{3} \mathrm{~A}<8.0 \%$, el P-31 y el PY-6, en este caso, tuvieron una creación, evolución y desarrollo totalmente contrario a la de su citado CP respectivo. Así, si las de estos dos últimos solos fueron lentamente de menos a más, en el valor de su pendiente y área abarcada, durante el transcurso del ensayo y en mayor medida cuanto mayor fue el contenido de $\mathrm{C}_{3} \mathrm{~A}$ de su citado $\mathrm{CP}$, y viceversa, a la de sus correspondientes cementos de mezcla preparados con esta CV10, les ocurrió prácticamente lo contrario, es decir, un aumento rápido durante las edades iniciales del ensayo para a continuación frenar bruscamente su crecimiento para acabar situándose paralelas al eje de abscisas y delimitar aproximadamente y por esta causa, una superficie o área más bien rectangular en mayor o menor medida, pero en cualquier caso y a igualdad de todo lo demás, más rectangular aún que las correspondientes curvas de la puzolana $\mathrm{C}$.

Y el hecho adicional ocurrido de que en el caso del cemento de mezcla P-1/CV10 50/50, ocurriera lo contrario hasta la edad de 150-180 días, hasta el punto de que la creación, evolución y desarrollo de ambas curvas, la del cemento de mezcla P-1/CV10 50/50 y la de su CP P-1 sólo, fueran bastante semejantes entre si aunque con ligera supremacía de la primera sobre la segunda, desde dicha edad hasta la finalización de dicho ensayo, vino a confirmar por un lado su "parentesco" cierto con la puzolana C, analizada y estudiada antes, y por otro, la adopción del formato superficial rectangular denunciado antes también.

e) En el caso de la puzolana M: ocurrió, por un lado, todo lo contrario a lo ocurrido en los tres primeros casos anteriores, es decir, aumento muy rápido de su pendiente, en todos los cementos de mezcla durante las primeras edades del ensayo, para a continuación aumentar poco 
o nada incluso, hasta el punto de llegar a situarle más paralelas aún al eje de abscisas que en los casos referidos antes de las puzolanas C y CV10, y por otro, dichas curvas de $\Delta \varnothing$ de los cementos de mezcla de la puzolana M, mejor quizás "rectas" en esta ocasión, al haber sido las más paralelas de todas al eje de abscisas, abarcaron una superficie más claramente "rectangular" cuya área resultó ser bastante más directamente proporcional al contenido de $\mathrm{C}_{3} \mathrm{~S}$ de su $\mathrm{CP}$ que al contenido de $\mathrm{C}_{3} \mathrm{~A}$ del mismo.

f) Análisis y Estudio Comparativo:

1. Curvas de las puzolanas C, CV10 y M. Sea cual fuere el contenido de $\mathrm{C}_{3} \mathrm{~A}$ del $\mathrm{CP}$ que acompañó a estas, en proporción 50/50, todas sus curvas representativas tuvieron unas pendientes durante el transcurso del ensayo, de un orden de magnitud, en cierta medida, semejante, pero sobre todo, configuraron con el eje de abscisas unas áreas o superficies que también en cierta medida eran semejantes entre si, cuali y cuantitativamente, pero sobre todo fue el comportamiento principal observado, adscribibles en mayor o menor medida, a un rectángulo.

No obstante, y a pesar de lo anterior, la mayor semejanza del área o superficie abarcada con el "rectángulo", fue mostrada por la puzolana $\mathrm{M}$, mientras que la menos semejanza fue mostrada por las C y CV10, y menos aún por la CV10, la cual y hasta la edad del ensayo,

- de 180 días (cuando su CP fue el P-1), y

- de 280 días (cuando su CP fue el P-31 o el PY-6),

resultó ser más bien semejante a un "triangulo rectángulo", uno de cuyos vértices, "el izquierdo" precisamente, se encontraba situado prácticamente en todos los casos, en la edad inicial del ensayo de 1 día.

2. Curvas de las puzolanas O, A y CV19. Sin embargo, las curvas desarrolladas por estas otras adiciones originaron todo lo contrario a las de las tres anteriores, tanto en la cantidad de superficie abarcada como en la pendiente de la misma, pero sobre todo, en la figura geométrica delimitada, que en estos otros casos, se hizo más bien asimilable en cambio a un "triángulo rectángulo" o simplemente a un "ángulo" de mayor o menor graduación, hubiera estado o no, presente, el $\mathrm{C}_{3} \mathrm{~A}$, respectivamente, con la salvedad de que cuando fue el CP P-2 el que formó parte del cemento de mezcla, el valor de tal ángulo o superficie abarcada, se hizo más bien semejante al de los correspondientes cementos de mezcla del PY-4 y del PY-6.

\subsection{2-Discusión e Interpretación de las Familias $P-n^{\circ}$ y $P Y-n^{\circ} /^{\prime \prime} Z^{\prime \prime} 50 / 50$.}

a) Caso de las curvas correspondientes a las puzolanas, $\mathrm{O}$ y $\mathrm{A}$. El hecho de que las curvas correspondientes a los cementos de mezcla PY-4 y PY-6/O y A 50/50, vinieran a ser semejantes en su pendiente y área abarcada, a las de sus CP PY-4 ó PY-6 solos, venía a confirmar una vez más que en estas proporciones de mezcla 50/50 PY-no/"Z", tales puzolanas mostraban un carácter más "silícico" que "alumínico", es decir, ser claramente "silico-aluminosas". 
COMPORTAMIENTO SULFÁTICO Y MECÁNICO-RESISTENTE DE CEMENTOS PORTLAND CON ELEVADOS CONTENIDOS DE PUZOLANAS ( $>40 \%$ ): SU FUNDAMENTO QUÍMICO Y JUSTIFICACIÓN DE OTRAS CONSECUENCIAS POSIBLES
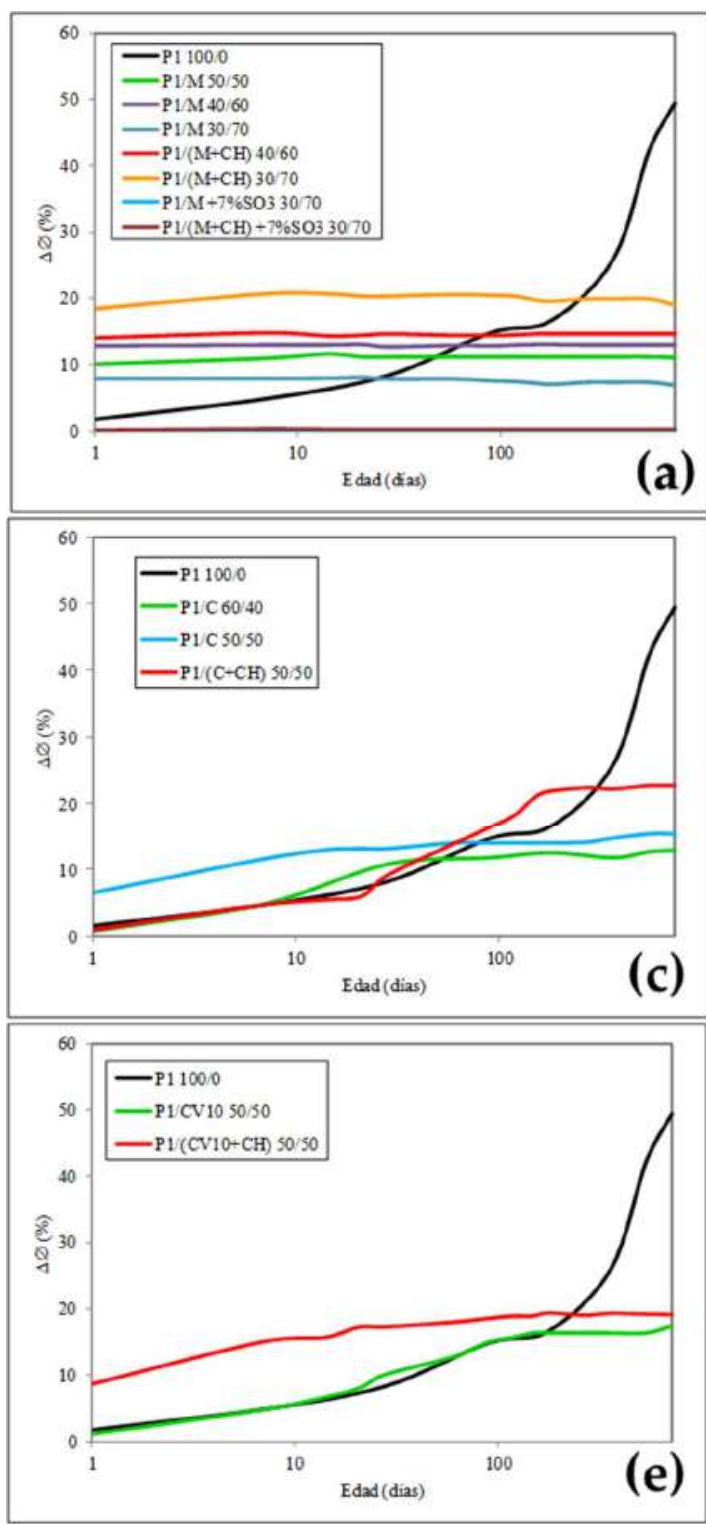

FIGURA 8-1.- RESULTADOS OBTENIDOS DE $\triangle \varnothing$ EN EL ENSAYO LE CHATELIER ANSTETT PARA TODOS LOS CEMENTOS DE MEZCLA PREPARADOS CON CP P1 Y TODAS LAS PUZOLANAS UTILIZADAS EN ESTA INVESTIGACIÓN.
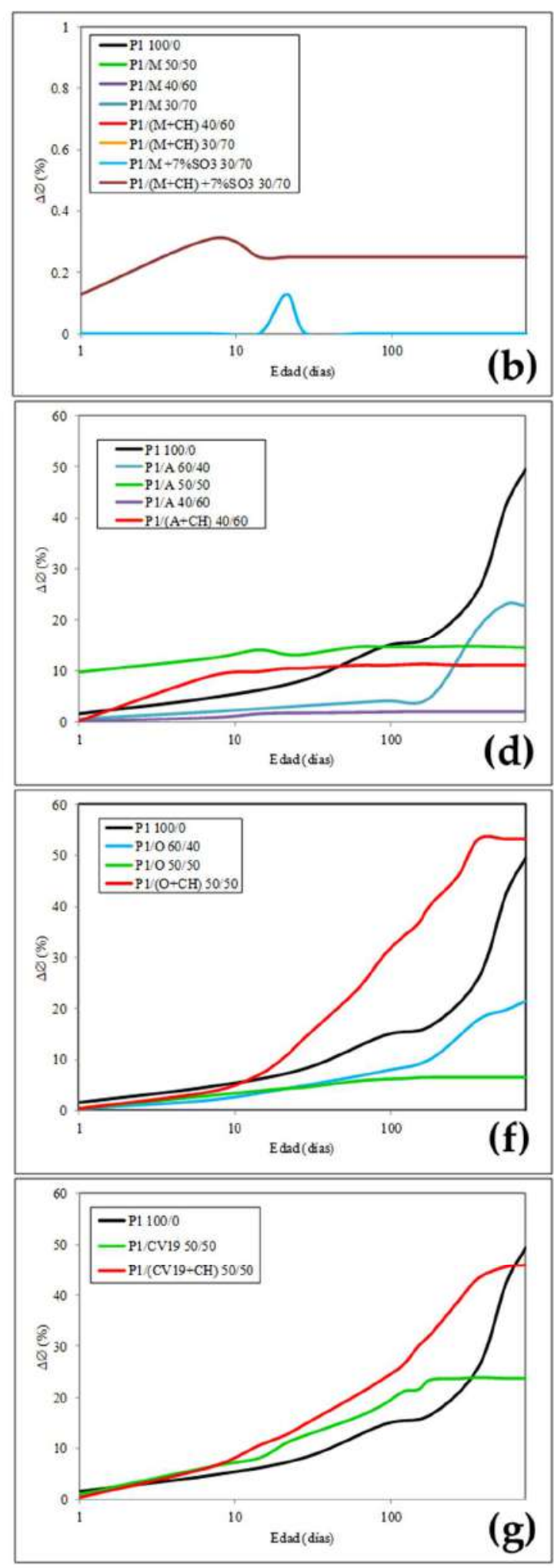

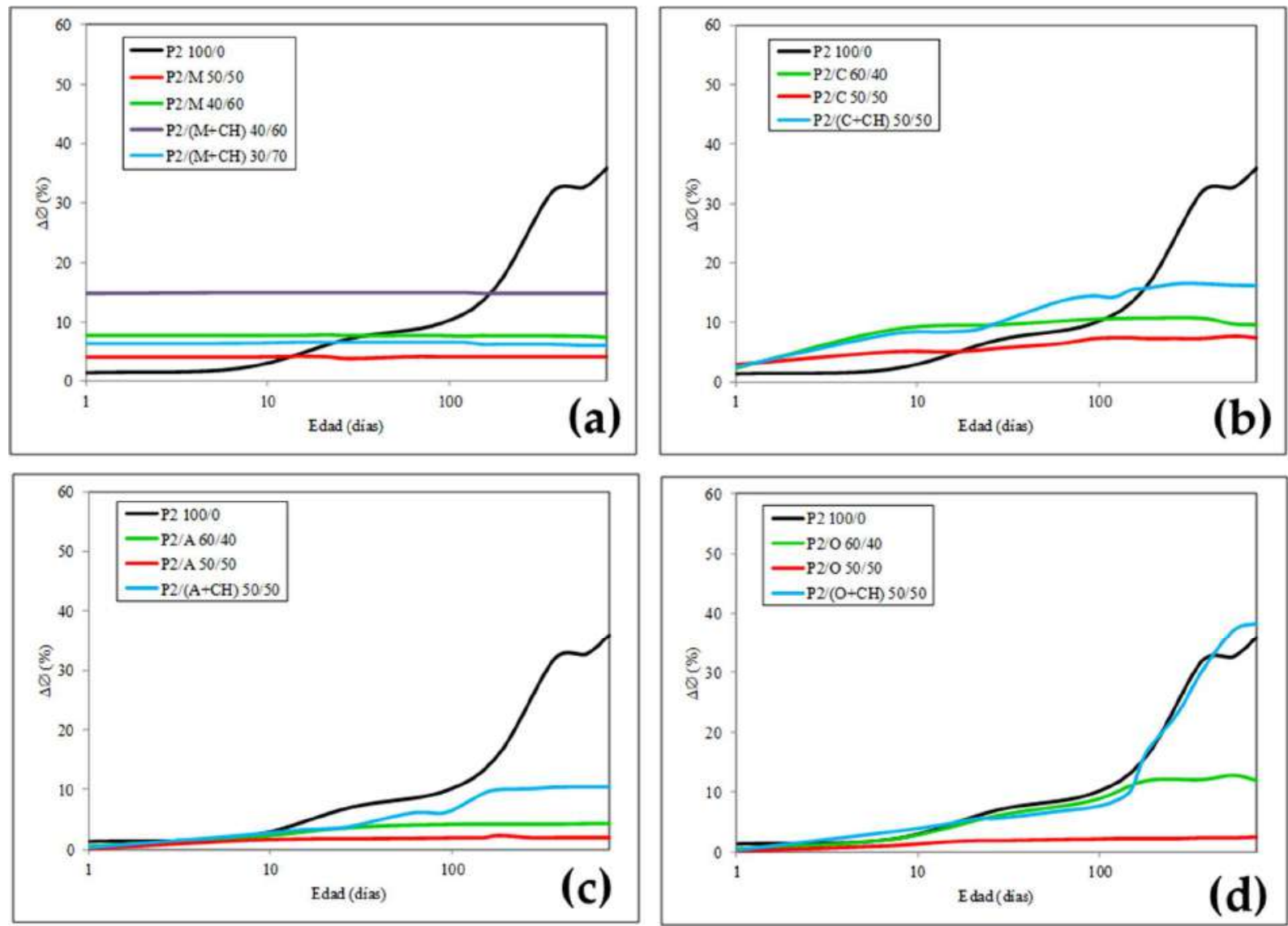

FIGURA 8-2.- RESULTADOS OBTENIDOS DE $\triangle \varnothing$ EN EL ENSAYO LE CHATELIER ANSTETT PARA TODOS LOS CEMENTOS DE MEZCLA PREPARADOS CON CP P2 Y TODAS LAS PUZOLANAS UTILIZADAS EN ESTA INVESTIGACIÓN.

En cambio, el hecho de que, por una parte, las curvas correspondientes a sus cementos de mezcla P-2/O y A 50/50, fueran también prácticamente semejantes a las anteriores, mientras que, por otra parte, las de sus otros cementos de mezcla P-1 y P-31/O y A 50/50, no lo fueran, sino que por contra fueran bastante diferentes debido a sus mayores magnitudes de tales parámetros, pendiente y superficie abarcada, vino a demostrar que para la creación, evolución y desarrollo de las curvas de los CEMENTO DE MEZCLA P-1 y P-31/O y A 50/50 -de mayor valor en su pendiente y área abarcada-, no había sido tan importante la presencia de $\mathrm{C}_{3} \mathrm{~A}$ de su $\mathrm{CP}$, cuanto más si lo había sido, la presencia de la cantidad necesaria de portlandita en este caso, derivada de su hidratación correspondiente durante todo el periodo de tiempo del ataque selenitoso. Por ello el valor de la pendiente y área abarcada, resultó ser, en las curvas de estos cementos de mezcla P-1, P-2 y P-31/O y A 50/50, bastante más proporcional a sus contenidos respectivos originarios de $\mathrm{C}_{3} \mathrm{~S}, 51.05 \%$, 33.47\% y $58.70 \%$, respectivamente, que de C3A, $14.11 \%, 11.09 \%$ y $7.63 \%$, respectivamente, lo que no quería decir tampoco que no lo fueran nada en absoluto respecto a este último contenido. 
COMPORTAMIENTO SULFÁTICO Y MECÁNICO-RESISTENTE DE CEMENTOS PORTLAND CON ELEVADOS CONTENIDOS DE PUZOLANAS (> 40\%): SU FUNDAMENTO QUÍMICO Y JUSTIFICACIÓN DE OTRAS CONSECUENCIAS POSIBLES
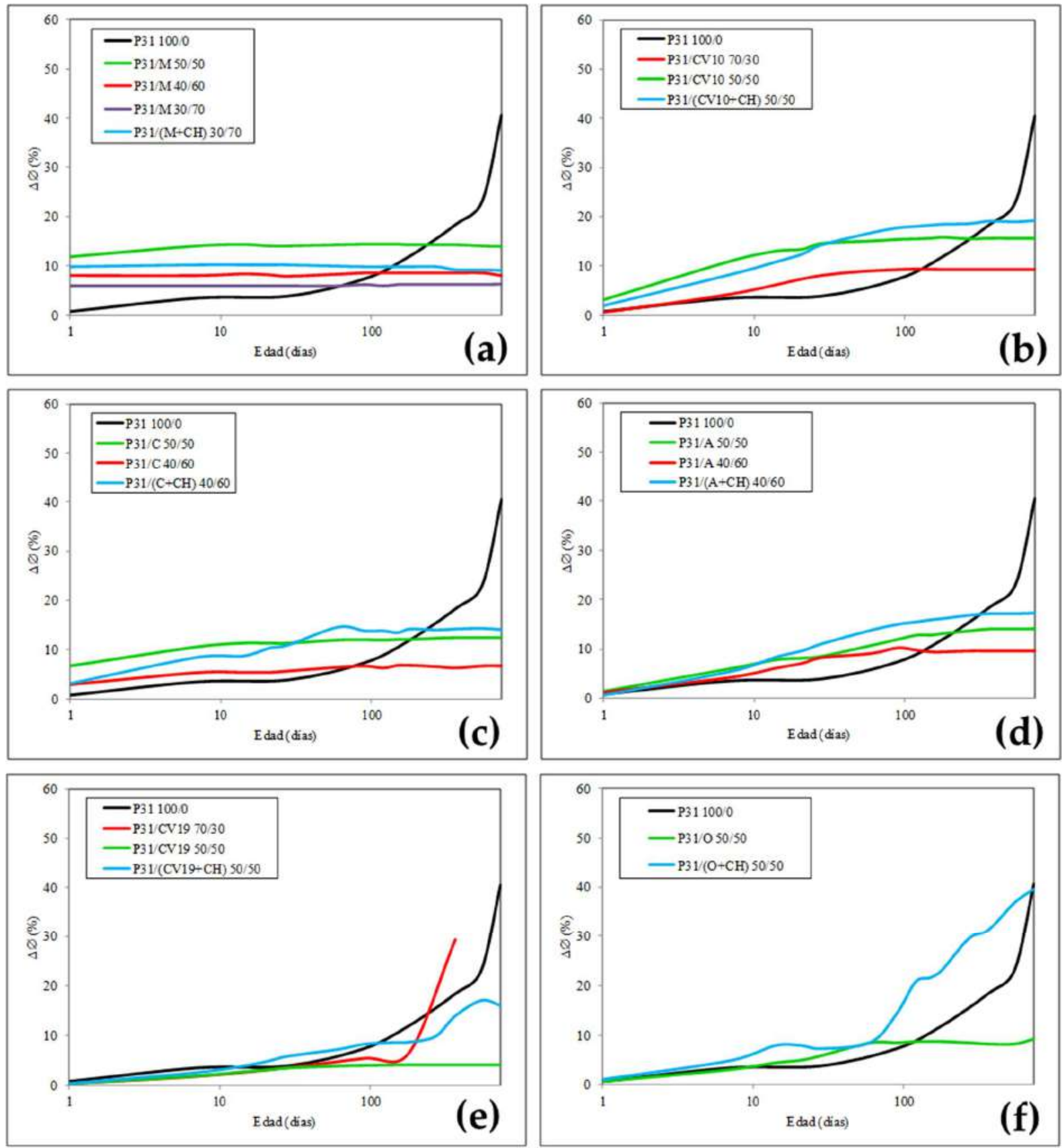

FIGURA 8-3.- RESULTADOS OBTENIDOS DE $\triangle \varnothing$ EN EL ENSAYO LE CHATELIER ANSTETT PARA TODOS LOS CEMENTOS DE MEZCLA PREPARADOS CON CP P31 Y TODAS LAS PUZOLANAS UTILIZADAS EN ESTA INVESTIGACIÓN 

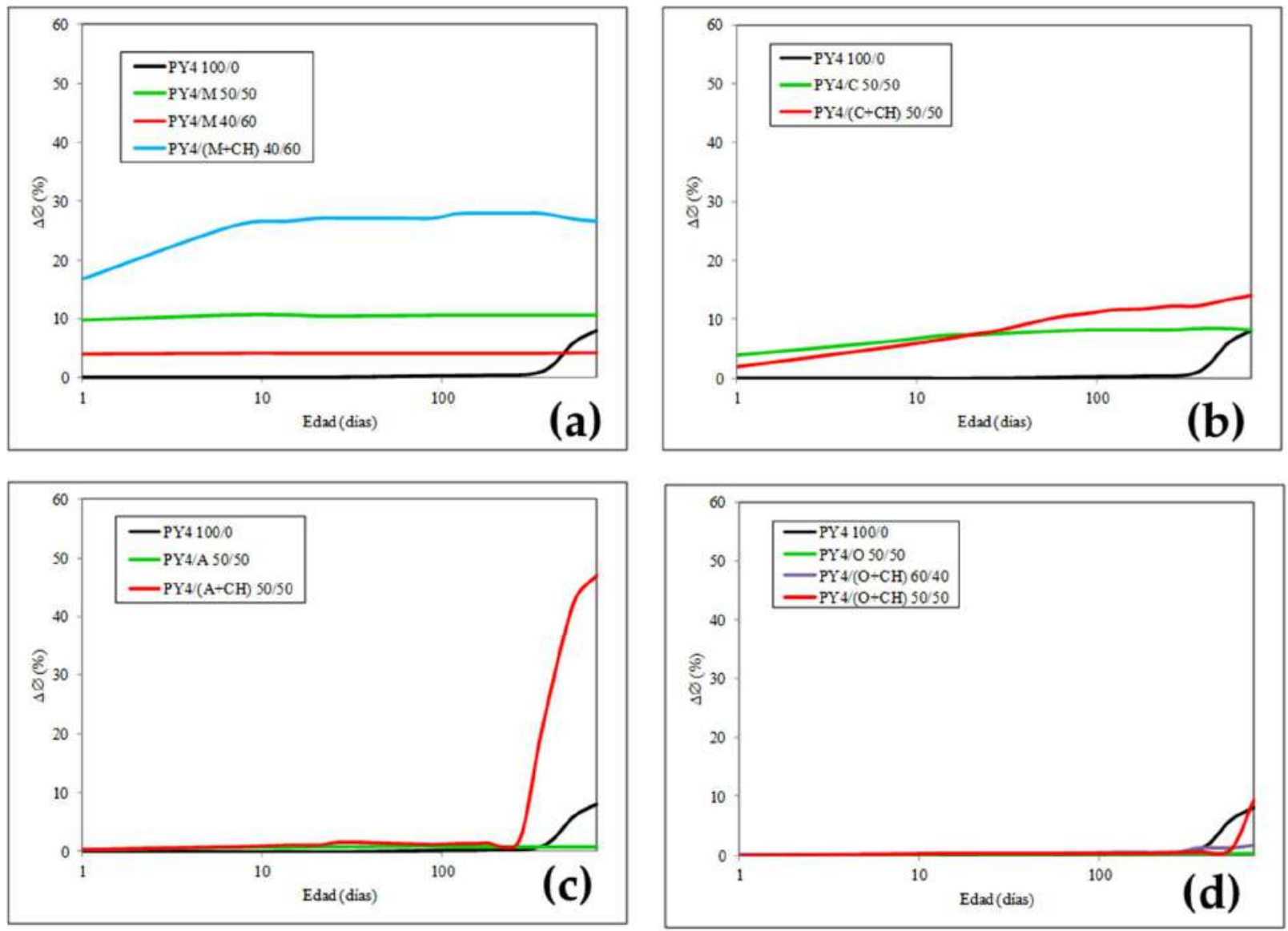

FIGURA 8-4.- RESULTADOS OBTENIDOS DE $\triangle \varnothing$ EN EL ENSAYO LE CHATELIER ANSTETT PARA TODOS LOS CEMENTOS DE MEZCLA PREPARADOS CON CP PY4 Y TODAS LAS PUZOLANAS UTILIZADAS EN ESTA INVESTIGACIÓN

De esta manera venía a verificarse una vez más, una de las hipótesis de trabajo iniciales que promovió esta investigación, ó HTI, la cual quedaría plenamente ratificada y confirmada en su certeza, al poder observar que todas las curvas correspondientes a sus respectivos cementos de mezcla con $\mathrm{CH}$, originaron unas nuevas curvas con mayor pendiente y área abarcada, las cuales, y en el caso concreto de la puzolana $\mathrm{O}$, fueron por lo común, mayores aún, cuando el $\mathrm{C}_{3} \mathrm{~A}$ estuvo presente a cuando no lo estuvo. Véanse al efecto las Figs. 8-1 (f), 8-2 (d), 8-3 (f), 8-4 (d) y 85 (h).

Además, vinieron a demostrar también que, aún siendo las dos puzolanas, O y A, "silícicoalumínicas", la fracción alumínica de la A debía ser mayor que la de la $\mathrm{O}$, como así fue ${ }^{3}$, puesto que, por una parte y cuando la CH estuvo presente junto a los CP PY-4 y PY-6 la puzolana A pudo originar unas curvas de pendientes y áreas abarcadas, muy notables (y en cuya consecución los contenidos respectivos de $\mathrm{C}_{4} \mathrm{AF}$ de ambos $\mathrm{CP}, 11.75 \%$ y $10.19 \%$, respectivamente, también

\footnotetext{
${ }^{3}$ Véase el apartado 6.3.5 de esta MEMORIA de Tesis Doctoral.
} 
debieron influir), mientras que la puzolana $\mathrm{O}$, no; de paso quedó aquí demostrado además que a pesar de todo, la fracción alumínica de la puzolana A debía de ser más difícilmente lixiviable en estos medios básicos y selenitosos y en definitiva algo menos reactiva, que la de las puzolanas $C$ y CV10, pero sobre todo, que la de la puzolana M.

Por otra parte, que dicha puzolana A pudo originar con sus cementos de mezcla de los $\mathrm{CP}$ P-1 y P-31, principalmente, un mayor ESExd+ que la puzolana $\mathrm{O}$, es decir, cuando los contenidos de $\mathrm{C}_{3} \mathrm{~A}$ y $\mathrm{C}_{3} \mathrm{~S}$ de su $\mathrm{CP}$ acompanante fueron adecuados (14.11\% y 7.62\%, en el caso del $\mathrm{C}_{3} \mathrm{~A}, \mathrm{y}$ $51.05 \%$ y $58.70 \%$, en el caso del $\mathrm{C}_{3} \mathrm{~S}$, respectivamente); de aquí que y como el contenido de $\mathrm{C}_{3} \mathrm{~S}$ del CP P-2 no fue adecuado, $33.47 \%$, a pesar de que el de $\mathrm{C}_{3} \mathrm{~A}$ si lo fuera, $11.09 \%$, el cemento de mezcla P-2/A 50/50 no hubo originar prácticamente ESE + a ninguna edad del ensayo (escasamente se produjo alguna ESE7d + a la edad de 7 días únicamente pero para ello hubo que emplear los valores del $\Delta \varnothing_{7 \mathrm{~d}}$ del cemento de mezcla PY-4/O 50/50 que no en cambio si los valores utilizados hubieran sido los del cemento de mezcla PY-6/O 50/50; véanse más adelante los cálculos correspondientes realizados.
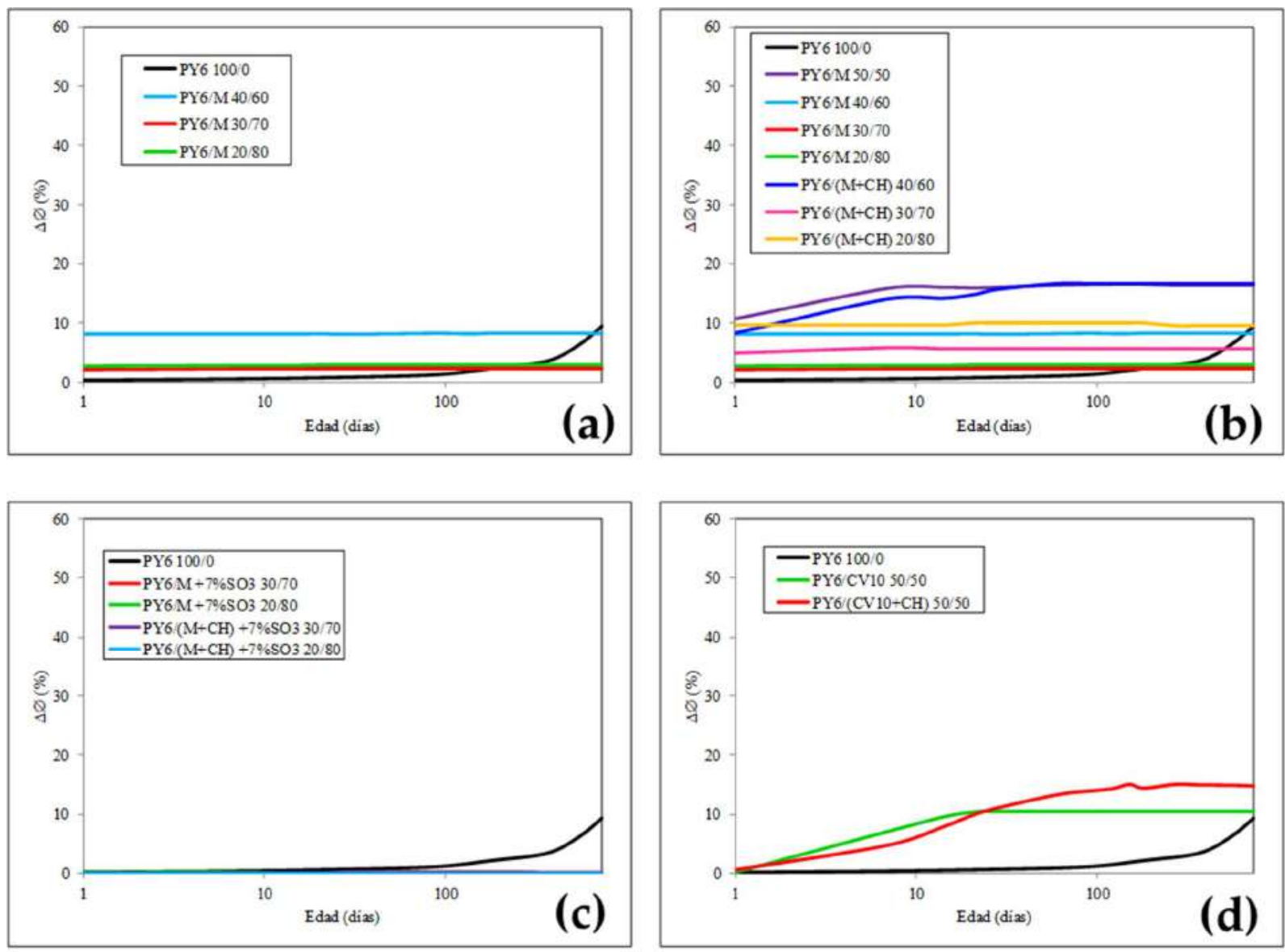

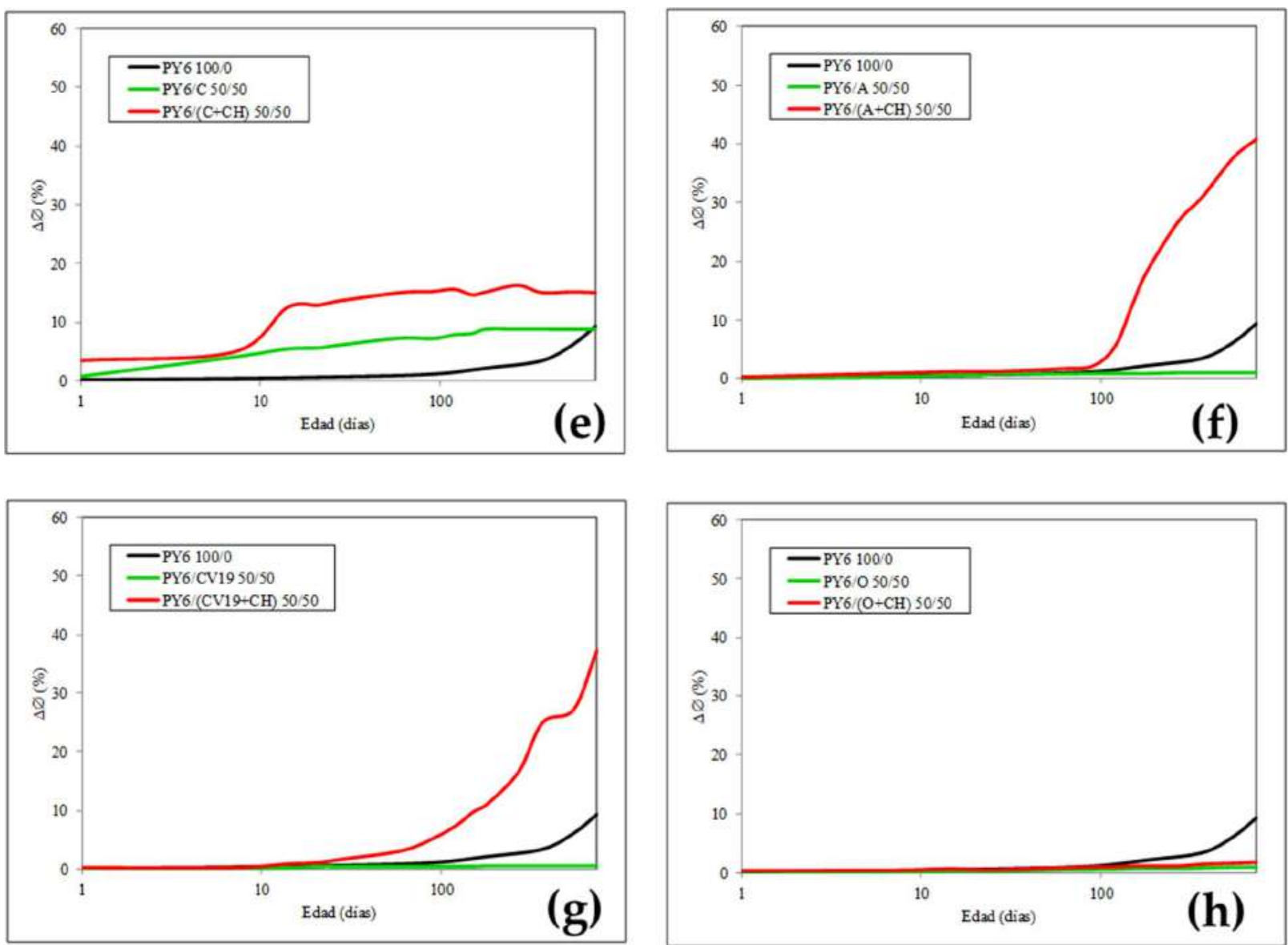

FIGURA 8-5.- RESULTADOS OBTENIDOS DE $\triangle \varnothing$ EN EL ENSAYO LE CHATELIER ANSTETT PARA TODOS LOS CEMENTOS DE MEZCLA PREPARADOS CON CP PY6 Y TODAS LAS PUZOLANAS UTILIZADAS EN ESTA INVESTIGACIÓN

Con todo ello se lograba en definitiva verificar una vez más en esta investigación una de las hipótesis de trabajo ó HTI que la promovieron, a saber: que ante un ataque muy severo del yeso, el buen o mal comportamiento que pueda llegar a mostrar una determinada puzolana "Z" que es añadida a un CP dado en cantidades superiores al $40 \%$ en masa, no sólo va a depender, y a lo que se podido verificar depende de hecho, del carácter de aquella, sino también y sobre todo, de la cantidad de portlandita -o lo que es lo mismo de $\mathrm{C}_{3} \mathrm{~S}$ principalmente, del $\mathrm{CP}$ que la acompañe, sin menoscabo del $\mathrm{C}_{3} \mathrm{~A}$ - que la misma necesita @la cual ha de estar presente en el medio@ para poder ponerlo de manifiesto con todas sus consecuencias tecnológicas negativas en este caso, según el tema de investigación que nos ocupa.

Y en su defecto, TODAS las puzolanas podrían llegar a mostrar un buen comportamiento en RS y todo lo contrario, como se podrá comprobar, en RM. Véase el apartado 8.2.

NOTA ACLARATORIA: Como se recordará y según Talero (2010, 2011b), el ESE a una edad dada, asignada por una determinada puzolana "Z" en una cantidad presente (\%), consiste 
en la relación existente entre el valor del $\Delta \varnothing$ a dicha edad ó $\Delta \varnothing x d$ del cemento de mezcla P-1/"Z" $50 / 50$ (en este caso) y el valor que resulta de sumar el $50 \%$ del $\triangle \varnothing x d$ de la probeta L-A del cemento de mezcla PY-4 y/o u o/y PY-6/"Z" 50/50, aunque en estos cálculos se ha considerado de estos dos últimos valores, únicamente aquel que resultó ser más desfavorable para poder confirmar la veracidad de la razón aducida, es decir, ó el del cemento de mezcla PY-4/"Z" 50/50 ó el del cemento de mezcla CEMENTO DE MEZCLA PY-6/"Z" 50/50.

Si dicha relación es >, el ESE es positivo (+), y en caso contrario, o sea, <, el ESE es negativo $(-)$

A continuación, se exponen algunos ejemplos prácticos a propósito de esta investigación:

TABLA 8-6.- EJEMPLO PRACTICO DEL ESE PRODUCIDO EN EL CEMENTO DE MEZCLA P-1/O 50/50.

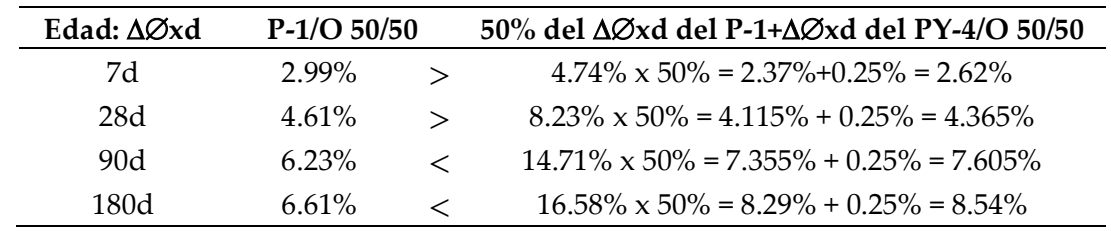

TABLA 8-7.- EJEMPLO PRACTICO DEL ESE PRODUCIDO EN EL CEMENTO DE MEZCLA P-1/A 50/50.

\begin{tabular}{|c|c|c|c|}
\hline Edad: $\Delta \varnothing x d$ & P-1/A 50/ 50 & \multicolumn{2}{|r|}{$50 \%$ del $\Delta \varnothing x d$ del P-1+ $\Delta \varnothing x d$ del PY-4 ó PY-6/O 50/50 } \\
\hline $7 \mathrm{~d}$ & $12.47 \%$ & $>$ & $2.37 \%+0.62 \%(\mathrm{PY}-4 / \mathrm{O})=2.99 \%$ \\
\hline $28 \mathrm{~d}$ & $13.22 \%$ & $>$ & $4.115 \%+0.81 \%(P Y-6 / O)=4.925 \%$ \\
\hline $90 \mathrm{~d}$ & $14.71 \%$ & $>$ & $7.355 \%+0.87 \%(\mathrm{PY}-6 / \mathrm{O})=8.225 \%$ \\
\hline $180 \mathrm{~d}$ & $14.71 \%$ & $>$ & $8.29 \%+0.87 \%(P Y-6 / O)=9.16 \%$ \\
\hline \multicolumn{4}{|l|}{$270 \mathrm{~d}$} \\
\hline $365 d$ & $14.84 \%$ & $>$ & $(25.94 \% \times 50 \%)=12.97 \%+1.00 \%(P Y-6 / O)=13.97 \%$ \\
\hline $730 \mathrm{~d}$ & & & \\
\hline
\end{tabular}

TABLA 8-8.- EJEMPLO PRACTICO DEL ESE PRODUCIDO EN EL CEMENTO DE MEZCLA P31/O 50/50.

\begin{tabular}{|c|c|c|}
\hline Edad: $\Delta \varnothing \mathrm{xd}$ & P-31/O 50/50 & $50 \%$ del $\Delta \varnothing x d$ del P-31+ $\varnothing$ xd del PY-4 ó PY-6/O 50/50 \\
\hline $7 d$ & $2.99 \%$ & $50 \% \times 3.49 \%=1.745 \%+0.25 \%(\mathrm{PY}-4 / \mathrm{O})=1.995 \%$ \\
\hline $28 \mathrm{~d}$ & $5.80 \%$ & $50 \% \times 3.87 \%=1.935 \%+0.25 \%(\mathrm{PY}-4 / \mathrm{O})=2.185 \%$ \\
\hline $90 d$ & $8.48 \%$ & $50 \% \times 7.36 \%=3.68 \%+0.56 \%(\mathrm{PY}-6 / \mathrm{O})=4.24 \%$ \\
\hline $180 \mathrm{~d}$ & $8.73 \%$ & $50 \% \times 11.97 \%=5.985 \%+0.75 \%(\mathrm{PY}-6 / \mathrm{O})=6.735 \%$ \\
\hline $\begin{array}{l}270 d \\
365 d \\
730 d\end{array}$ & $8.48 \%$ & 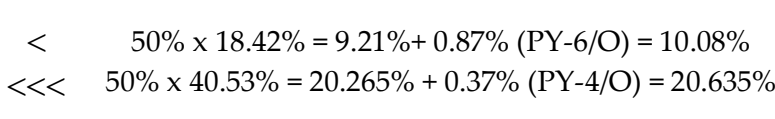 \\
\hline
\end{tabular}

TABLA 8-9.- EJEMPLO PRACTICO DEL ESE PRODUCIDO EN EL CEMENTO DE MEZCLA P31/A 50/50.

\begin{tabular}{|c|c|c|c|}
\hline Edad: $\Delta \varnothing x d$ & P-31/A 50/50 & & $50 \%$ del $\Delta \varnothing x d$ del P-31+ $\Delta \varnothing x d$ \\
\hline $7 d$ & $5.99 \%$ & $>$ & $1.745 \%+0.25 \%(\mathrm{PY}-4 / \mathrm{O})=1.995 \%$ \\
\hline $28 \mathrm{~d}$ & $8.48 \%$ & $>$ & $1.935 \%+0.25(\mathrm{PY}-4 / \mathrm{O})=2.185 \%$ \\
\hline $90 \mathrm{~d}$ & $11.97 \%$ & $>$ & $3.68 \%+0.56 \%(\mathrm{PY}-6 / \mathrm{O})=4.24 \%$ \\
\hline $180 \mathrm{~d}$ & $13.16 \%$ & $>$ & $5.985 \%+0.75 \%(\mathrm{PY}-6 / \mathrm{O})=6.735$ \\
\hline $365 d$ & $14.09 \%$ & $>$ & $9.21 \%+0.87 \%(\mathrm{PY}-6 / \mathrm{O})=10.08 \%$ \\
\hline $730 \mathrm{~d}$ & $14.15 \%$ & $<$ & $20.265 \%+0.37 \%(\mathrm{PY}-4 / \mathrm{O})=20.635 \%$ \\
\hline
\end{tabular}


TABLA 8-10.- EJEMPLO PRACTICO DEL ESE PRODUCIDO EN EL CEMENTO DE MEZCLA P-2/O 50/50.

\begin{tabular}{|c|c|c|c|}
\hline Edad: $\Delta \varnothing x d$ & \multicolumn{2}{|c|}{$\mathrm{P}-2 / \mathrm{O} 50 / 50$} & $50 \%$ del $\Delta \varnothing x d$ del P-2 $+\Delta \varnothing x d$ PY-4/O 50/50 \\
\hline $7 d$ & 1.00 & $<$ & $2.12 \% \times 50 \%=1.06 \%+0.25 \%=1.31 \%$ \\
\hline $28 \mathrm{~d}$ & 1.87 & $<$ & $7.11 \% \times 50 \%=3.555 \%+0.37 \%=3.925 \%$ \\
\hline $90 \mathrm{~d}$ & 2.12 & $<$ & $9.73 \% \times 50 \%=4.865 \%+0.37 \%=5.235 \%$ \\
\hline $180 \mathrm{~d}$ & 2.24 & $<$ & $15.96 \% \times 50 \%=7.98 \%+0.25 \%=8.23 \%$ \\
\hline $730 \mathrm{~d}$ & 2.50 & $<<<$ & $35.91 \% \times 50 \%=17.955 \%+0.37 \%=18.325 \%$ \\
\hline
\end{tabular}

TABLA 8-11.- EJEMPLO PRACTICO DEL ESE PRODUCIDO EN EL CEMENTO DE MEZCLA P-2/O 50/50.

\begin{tabular}{|c|c|c|c|}
\hline Edad: $\Delta \varnothing x d$ & \multicolumn{2}{|c|}{ P-2/A 50/50 } & $50 \%$ del $\Delta \varnothing x d$ del P-2+ $\triangle \varnothing x d$ PY-4/O 50/50 \\
\hline $7 \mathrm{~d}$ & $1.43 \%$ & $>$ & $1.06 \%+0.25 \%(\mathrm{PY}-4 / \mathrm{O})=1.31 \%$ \\
\hline $7 \mathrm{~d}$ & $1.43 \%$ & $=$ & $1.06 \%+0.37 \%(\mathrm{PY}-6 / \mathrm{O})=1.43 \%$ \\
\hline $28 \mathrm{~d}$ & $1.75 \%$ & $<$ & $3.555 \%+0.37 \%(\mathrm{PY}-4 / \mathrm{O})=3.925 \%$ \\
\hline $90 \mathrm{~d}$ & $1.87 \%$ & $<$ & $4.865 \%+0.37 \%(\mathrm{PY}-4 / \mathrm{O})=5.235 \%$ \\
\hline $180 \mathrm{~d}$ & $2.24 \%$ & $<$ & $7.98 \%+0.25 \%(\mathrm{PY}-4 / \mathrm{O})=8.23 \%$ \\
\hline $730 \mathrm{~d}$ & $1.93 \%$ & $<<<$ & $17.955 \%+0.37 \%(\mathrm{PY}-4 / \mathrm{O})=18.325 \%$ \\
\hline
\end{tabular}

En cuanto mayor contenido de $\mathrm{C}_{3} \mathrm{~A}$ hubiera tenido y aportado su $\mathrm{CP}$ acompañante, en este caso el P-1; no obstante, y una vez más, quedó aquí demostrado que en estas mezclas 50/50 importaba mucho también, el mayor contenido de $\mathrm{C}_{3} \mathrm{~S}$ junto a la de $\mathrm{C}_{3} \mathrm{~A}, \mathrm{y}$ consiguientemente quedó confirmada una vez más la veracidad de una de las hipótesis iniciales de trabajo que promovió esta investigación.

Y para verificar aún más dicho ESExd + aducida y originada en su caso, señal inequívoca de que el carácter de esta puzolana C tenía que ser más "alumínico" que "silícico", no hubo más que ver la pendiente y el área abarcados por las curvas correspondientes a sus citados cementos de mezcla pero con cal apagada $(+\mathrm{CH})$, los cuales aumentaron en general en valor absoluto teniendo incluso a rectangularizarse más sus áreas correspondientes y además tanto más pronto cuanto menor fue la presencia de $\mathrm{C}_{3} \mathrm{~A}$, y viceversa, tal como era lógico, y siendo además ello señal inequívoca de que había sido por causa del mayor carácter "alumínico" que "silícico" de esta puzolana C.

b) Caso de las curvas correspondientes a la ceniza CV10. Vale aquí la misma interpretación dada para la puzolana C sólo que corregida y ligeramente mejorada o aumentada, lo que en términos tecnológicos venía a significar que esta ceniza CV10 debería de ser calificada o caracterizada como algo más "alumino-silícica", aun que la puzolana $C$, por el motivo de que en presencia o ausencia de $\mathrm{C}_{3} \mathrm{~A}$ y/o $\mathrm{CH}$, las pendientes y áreas abarcadas correspondientes habían resultado ser ligeramente menores a las edades iniciales del ensayo vendría a significar que si bien la cantidad de $\mathrm{Al}_{2} \mathrm{O}_{3}{ }^{\mathrm{r}-}$ de la $\mathrm{CV} 10$ debía de ser ligeramente mayor que la de la puzolana $\mathrm{C}$, la de esta última, no obstante, debía de encontrarse en mejores condiciones termoquímicas y de reactividad en suma, para poder formar la ett-rf que la de la CV10, quizás únicamente porque la $\mathrm{Al}_{2} \mathrm{O}_{3}{ }^{r-}$ de esta última se encontraba como vidrio que primeramente había de ser disuelto para posteriormente poder lixiviarle el hidróxido de calcio su $\mathrm{Al}_{2} \mathrm{O}_{3}{ }^{\mathrm{r}-}$; mientras que la $\mathrm{Al}_{2} \mathrm{O}_{3}{ }^{\mathrm{r}-}$ de la puzolana $C$ quizás se encontraba como la de la puzolana $\mathrm{M}$, es decir, amorfa, y por tanto más y mejor dispuesta en definitiva para poder formar ett-rf. 
De aquí que en general y a igualdad de todo lo demás, el inicio del área abarcada en cada caso por la curva de cada cemento de mezcla fuera más semejante entre las de las puzolanas C y M que entre las de las CV10 y M.

c) Caso de las curvas correspondientes a la puzolana M. Todo ello fue debido a que, en todos los casos, la ASExd + correspondiente originada fue proporcional a la cantidad de $\mathrm{C}_{3} \mathrm{~A}$ que la acompañó mayormente, lo que venía a indicar que la $\mathrm{Al}_{2} \mathrm{O}_{3}{ }^{\mathrm{r}-}$ de esta puzolana $\mathrm{M}$ se debía de encontrar en mayor cantidad y mejores condiciones termoquímicas y de reactividad en suma que las del resto de las puzolanas ensayadas y comparadas con ella; pero, sobre todo, que debía de estar en estado amorfo que no vítreo. Trusilewicz y cols. (2012) demostraron, que se encuentra tetra o penta-coordinada con el oxigeno, lo que justifica sobradamente su mejor y más inmediata disponibilidad termoquímica para poder formar ett-rf y ASExd + en su caso.

Por tanto, a la vista de las figuras originadas por el resto de las puzolanas ensayadas, analizadas y comparadas de esta manera con la puzolana $\mathrm{M}$, cabía pensar que: bien su cantidad de $\mathrm{Al}_{2} \mathrm{O}_{3}{ }^{\mathrm{r}-}$ había de ser aún menor, o bien, se encontraba mayormente como vidrio, aunque ello quizás más bien en el caso de las puzolanas artificiales CV19 y CV10 que en el caso de las puzolanas naturales $\mathrm{O}, \mathrm{A}$ y $\mathrm{C}$; y en especial en esta última, como se ha podido ver con anterioridad, o bien, a ambas causas anteriores en mayor o menor grado, pero a un mismo tiempo.

Estos muy diferentes comportamientos mostrados por las puzolanas $\mathrm{C}, \mathrm{CV} 10 \mathrm{y} \mathrm{M}$, por una parte, y O, A y CV19, por otra, vinieron a confirmar una vez más el muy diferente carácter de las puzolanas C, CV10 y M ("aluminico-silícicas", las dos primeras, y "alumínica", la última) por un lado y de las puzolanas O, A y CV19, por otro ("silícico-alumínicas", las dos primeras, y "silícicoférrico-alumínica", la última), con las correspondientes consecuencias tecnológicas ya conocidas de cada carácter en estos medios tan selenitosos o de sales de deshielo o sin agresividad alguna.

Por otra parte, y en cuanto al mayor o menor grado de rectangularidad mostrado por las superficies abarcados por las curvas de las puzolanas C, CV10 y M, se pudo decir también lo siguiente:

Las diferentes superficies abarcadas, dentro de su muy relativa semejanza, por las curvas de las puzolanas C y CV10 por una parte, y la M por otra, vinieron a confirmar una vez más, el diferente carácter de las puzolanas C y CV10 ("aluminico-silícicas") por un lado y de la M ("alumínica") por otro, con las correspondientes consecuencias tecnológicas ya conocidas de cada carácter en estos medios tan selenitosos o de sales de deshielo o su agresividad alguna.

Por otra parte y ateniéndose finalmente y sobre todo a las diferentes figuras de las superficies enmarcadas por las curvas de la puzolana $C$ y las enmarcadas por las curvas de la puzolana CV10, se pudo deducir también que cuantitativamente esta última puzolana debía ser algo más " aluminico-silícicas" que la primera, pero en cambio la primera, ó puzolana C, debía poseer su $\mathrm{Al}_{2} \mathrm{O}_{3}{ }^{\mathrm{r}-}$ en mejores condiciones termoquímicas y de reactividad química en suma, que la última, ó ceniza CV10; no obstante cabía también la posibilidad que la menor reactividad de la $\mathrm{Al}_{2} \mathrm{O}_{3}{ }^{\mathrm{r}-}$ de la ceniza CV10 fuera debida a que ésta puzolana era mayormente vítrea por cuyo motivo habría necesitado quizás inicialmente, mayor cantidad de tiempo que la puzolana C -las 
edades adscritas a cada cemento de mezcla en esta Discusión- para que la disolución portlandítica y con $\mathrm{CH}$, correspondiente, atacara dicho vidrio, lo disolviera y le lixiviara finalmente su cantidad total de $\mathrm{Al}_{2} \mathrm{O}_{3}{ }^{\mathrm{r}-}$ para formar ettringita. Esta otra razón se veía además reforzada en su certeza por el hecho de que sus cementos de mezcla con $\mathrm{CH}$ tuvieron que ser curados bajo agua durante 14 días y posteriormente secados adecuadamente antes de realizarle su probeta L-A respectiva, puesto que cuando se operó del mismo modo con la ceniza CV19, también mayormente vítrea pero de carácter opuesto al de la CV10, ocurrió lo mismo; lo que venía a demostrar que dicho periodo de tiempo de 14 días de curado bajo agua no había sido el suficiente ni necesario para quelas cantidades totales de vidrio de ambas cenizas, CV10 y CV19, debieron de necesitar más

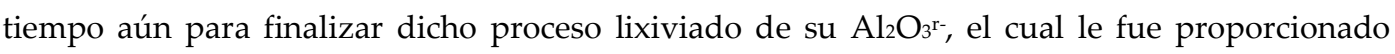
estando formado ya para entonces parte de su probeta L-A respectiva, con las consecuencias al caso del retraso reaccionante inicial y la falta de rectangularidad inicial detectada también, de sus superficies correspondientes.

No obstante y en cualquier caso lo que sí quedó claro del análisis y estudio comparativo así realizado, fue la cantidad de $\mathrm{Al}_{2} \mathrm{O}_{3}{ }^{\mathrm{r}-}$ de la puzolana $\mathrm{C}$, debía de ser algo menor quizás pero sobre todo más reactiva, que la de la ceniza CV10, o sea, que la puzolana C debía poseer su $\mathrm{Al}_{2} \mathrm{O}_{3}{ }^{\mathrm{r}-}$ en un estado físico-químico y de reactividad en suma con el yeso en estos medios portlandíticos, más adecuado y por ende más semejante al de la puzolana $\mathrm{M}$-que a su vez era la que más reactivo y en mayor cantidad lo contenía de las seis puzolanas ensayadas y comparadas con ella en esta investigación-, que la ceniza CV10. Y como prueba adicional de la certeza de esta deducción, estuvo el hecho de la mayor rectangularidad en general, de las superficies abarcadas por las curvas de la puzolana $\mathrm{C}$ que las abarcadas por las curvas de la ceniza CV10, cuando el CH no estuvo presente.

Finalmente, y en cuanto a la mayor o menor graduación del ángulo abarcado por las curvas de las puzolanas $\mathrm{O}, \mathrm{Ay}$ CV19, según hubiera estado presente o no, el $\mathrm{C}_{3} \mathrm{~A}$, excepto en el caso de que el cemento de mezcla fue el P-2, se pudo verificar, por un lado, la diferencia de carácter de estas tres puzolanas respecto de las otras tres, o C, CV10 y M, y por otro, la razón dada en el apartado (a) de esta interpretación para tratar de explicar, la mayor semejanza habida entre las curvas y áreas abarcadas correspondientes, en el caso de que el cemento de mezcla constitutivo fue el P-2, el PY-4 ó el PY-6, que no en el caso del P-1y el P-31, donde no hubo tal semejanza, sino todo lo contrario.

d) Caso de las curvas correspondientes a la puzolana C. El comportamiento de las curvas de esta puzolana $\mathrm{C}$ que fue contrario de la $\mathrm{O}, \mathrm{A}$ y CV19, por lo que vino a confirmar una vez más que el carácter de esta puzolana $C$ había de ser contrario necesariamente al de aquellas tres, es decir, más "alumínico" que "silícico" y/o "férrico", o lo que era lo mismo, su carácter había de ser "alumínico-silícico".

Dicho carácter "alumínico-silícico" de la C, le había permitido por tanto a esta haber podido originar en su caso una mayor ESExd + -el cual se ha calculado al efecto como prueba y se encuentra en la página siguiente junto a los de las CV10 y M-.

A continuación, se exponen algunos nuevos ejemplos prácticos a propósito de esta 
COMPORTAMIENTO SULFÁTICO Y MECÁNICO-RESISTENTE DE CEMENTOS PORTLAND CON ELEVADOS CONTENIDOS DE PUZOLANAS ( $40 \%$ ): SU FUNDAMENTO QUÍMICO Y JUSTIFICACIÓN DE OTRAS CONSECUENCIAS POSIBLES

investigación:

TABLA 8-12.- EJEMPLO PRACTICO DEL ESE PRODUCIDO EN EL CEMENTO DE MEZCLA P-1/C 50/50.

\begin{tabular}{|c|c|c|c|}
\hline Edad: $\Delta \varnothing_{\mathrm{xd}}$ & \multicolumn{2}{|c|}{ P-1/C 50/50 } & $50 \%$ del $\Delta \varnothing_{x d}$ del P-1+ $\Delta \varnothing_{x d}$ del PY-4 ó PY-6/C 50/50 \\
\hline $7 \mathrm{~d}$ & $11.60 \%$ & $>$ & $2.37 \%+6.17 \%$ ó $4.05 \%=8.54 \%$ \\
\hline $28 \mathrm{~d}$ & $13.09 \%$ & $>$ & $4.115 \%+7.48 \%$ ó $6.11 \%=11.595 \%$ \\
\hline $90 \mathrm{~d}$ & $13.97 \%$ & $<$ & $7.355 \%+8.11 \%$ ó $7.14 \%=14.495 \%$ \\
\hline $730 d$ & $15.34 \%$ & $<$ & $12.97 \%+8.10 \%$ ó $8.73 \%=21.07 \%$ \\
\hline
\end{tabular}

TABLA 8-13.- EJEMPLO PRACTICO DEL ESE PRODUCIDO EN EL CEMENTO DE MEZCLA P-1/(C+CH) 50/50.

\begin{tabular}{|c|c|c|c|}
\hline Edad: $\Delta \varnothing_{\mathrm{xd}}$ & $\mathrm{P}-1 /(\mathrm{C}+\mathrm{CH})$ & $50 / 50$ & $50 \%$ del $\Delta \varnothing_{x d}$ del P-1+ $\Delta \varnothing_{x d}$ del PY-4 ó PY-6/(C+CH) 50/50 \\
\hline $7 \mathrm{~d}$ & $4.74 \%$ & $<$ & $2.37 \%+5.30 \%$ ó $4.93 \%=9.67 \%$ \\
\hline $28 \mathrm{~d}$ & $9.10 \%$ & $<$ & $4.115 \%+8.04 \%$ ó $13.72 \%=12.155 \%$ \\
\hline $90 \mathrm{~d}$ & $16.33 \%$ & $<$ & $7.355 \%$ + $10.97 \%$ ó $15.27 \%=18.325 \%$ \\
\hline $730 \mathrm{~d}$ & $22.63 \%$ & $<$ & $12.97 \%+13.97 \%$ ó $15.09 \%=26.94 \%$ \\
\hline
\end{tabular}

TABLA 8-14.- EJEMPLO PRACTICO DEL ESE PRODUCIDO EN EL CEMENTO DE MEZCLA P-1/CV10 50/50.

\begin{tabular}{|c|c|c|c|}
\hline Edad: $\Delta \varnothing_{\mathrm{xd}}$ & \multicolumn{2}{|c|}{ P-1/CV10 50/50 } & $50 \%$ del $\Delta \varnothing_{x d}$ del P-1+ $\Delta \varnothing_{x d}$ del PY-6/CV10 50/50 \\
\hline $7 \mathrm{~d}$ & $4.80 \%$ & $<$ & $2.37 \%+7.05 \%=9.42 \%$ \\
\hline $28 \mathrm{~d}$ & $10.10 \%$ & $<$ & $4.115 \%+10.35 \%=14.465 \%$ \\
\hline $90 \mathrm{~d}$ & $15.71 \%$ & $<$ & $7.355 \%+10.35 \%=17.705 \%$ \\
\hline $730 \mathrm{~d}$ & $17.46 \%$ & $<$ & $12.97 \%+10.35 \%=23.32 \%$ \\
\hline
\end{tabular}

TABLA 8-15.- EJEMPLO PRACTICO DEL ESE PRODUCIDO EN EL CEMENTO DE MEZCLA P-1/(CV10+CH) $50 / 50$.

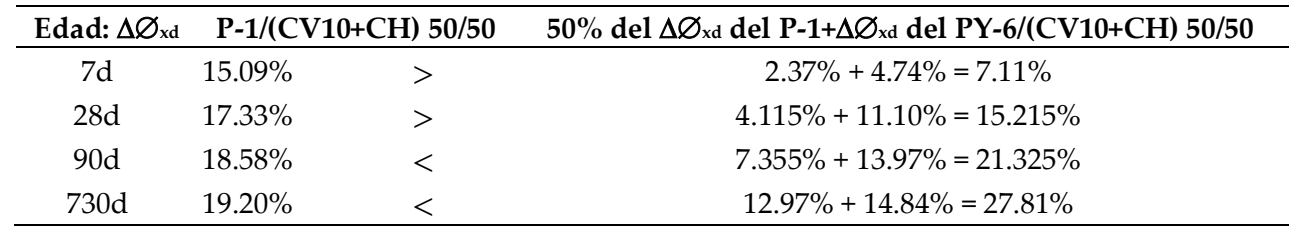

TABLA 8-16.- EJEMPLO PRACTICO DEL ESE PRODUCIDO EN EL CEMENTO DE MEZCLA P-1/M 50/50.

\begin{tabular}{|c|c|c|c|}
\hline Edad: $\Delta \varnothing_{\mathrm{xd}}$ & \multicolumn{2}{|c|}{ P-1/M 50/50 } & $50 \%$ del $\Delta \varnothing_{x d}$ del P-1+ $\Delta \varnothing_{x d}$ del PY-4 ó PY-6/M 50/50 \\
\hline $7 d$ & $10.85 \%$ & $<$ & $2.37 \%+10.66 \%$ ó $15.77 \%=13.03 \%$ \\
\hline $28 \mathrm{~d}$ & $18.21 \%$ & $<$ & $4.115 \%+10.47 \%$ ó $15.96 \%=20.075 \%$ \\
\hline $90 \mathrm{~d}$ & $19.39 \%$ & $<$ & $7.355 \%+10.60 \%$ ó $16.46 \%=23.815 \%$ \\
\hline $730 \mathrm{~d}$ & $18.58 \%$ & $<$ & $12.97 \%+10.60 \%$ ó $16.40 \%=29.37 \%$ \\
\hline
\end{tabular}

d) Caso de las curvas correspondientes a la ceniza CV19. Este comportamiento mostrado en estas condiciones, 50/50 $\sin \mathrm{CH}$, por la ceniza CV19 vendría a confirmar una vez más que la misma debía de poseer también un carácter "silícico-alumínico", como las dos anteriores $\mathrm{O}$ y A, pero sin descartar el "férrico" ("férrico") (en razón de su muy notable contenido de $\mathrm{Fe}_{2} \mathrm{O}_{3}$ $(16.12 \%)$ y en forma de maghemita mayormente ( $\gamma$-Fe2O3), en este caso); puesto que si bien los valores de sus pendientes y áreas abarcadas por sus tres curvas, en este caso 50/50, a saber, la P1, P-31 y PY-6/CV19, habían guardado una clara relación directa con el contenido de C3A de su $\mathrm{CP}$ respectivo, la misma quedaría rota no obstante, cuando la cal apagada $(+\mathrm{CH})$ estuvo presente, ya que en tales nuevas circunstancias 50/50 con $\mathrm{CH}$ y a tenor de la mayor semejanza obtenida 
entre sus curvas P-1 y PY-6/(CV19+CH) 50/50, principalmente, hubo de adscribirse el comportamiento de la misma en cambio, al posible ESExd+ que se debió de originar en esta otra ocasión, en el caso del CM P-1/(CV19+CH) 50/50, entre su ett-lf y la expansividad de los geles de $\mathrm{Fe}(\mathrm{OH})$, según demostró Martín-Luengo, (1996), mientras que, en el caso del CM P-31 y PY6/(CV19+CH) 50/50, entre la ett-lf del P-31 y la ett-vlf del P-31 y del PY-6 y la expansividad de esos mismos geles de $\mathrm{Fe}(\mathrm{OH})$. Véanse los cálculos correspondientes que ratifican tales ESExd+.

A continuación, se exponen algunos nuevos ejemplos prácticos a propósito de esta investigación:

TABLA 8-17.- EJEMPLO PRACTICO DEL ESE PRODUCIDO EN EL CEMENTO DE MEZCLA P-1/CV19 50/50.

\begin{tabular}{|c|c|c|c|}
\hline Edad: $\Delta \varnothing_{x d}$ & \multicolumn{2}{|c|}{ P-1/CV19 50/50 } & $50 \%$ del $\Delta \varnothing_{x d}$ del P-1+ $\Delta \varnothing_{x d}$ del PY-6/CV19 50/50 \\
\hline $7 \mathrm{~d}$ & $6.42 \%$ & $>$ & $2.37 \%+0.13 \%=2.50 \%$ \\
\hline $28 \mathrm{~d}$ & $12.47 \%$ & $>>$ & $4.115 \%+0.44 \%=4.555 \%$ \\
\hline $90 d$ & $18.58 \%$ & $>>$ & $7.355 \%+0.50 \%=7.855 \%$ \\
\hline $180 \mathrm{~d}$ & $23.38 \%$ & $>>>$ & $8.29 \%+0.50 \%=8.50 \%$ \\
\hline $545 \mathrm{~d}$ & $23.63 \%$ & $>$ & $42.14 \% \times 50 \%=21.07 \%+0.50 \%=21.57 \%$ \\
\hline $730 \mathrm{~d}$ & $23.63 \%$ & $<$ & $49.37 \% \times 50 \%=24.685 \%+0.50 \%=25.185 \%$ \\
\hline
\end{tabular}

TABLA 8-18.- EJEMPLO PRACTICO DEL ESE PRODUCIDO EN EL CEMENTO DE MEZCLA P-31/CV19 50/50.

\begin{tabular}{|c|c|c|c|}
\hline Edad: $\Delta \varnothing_{\mathrm{xd}}$ & \multicolumn{2}{|c|}{ P-31/CV19 50/50 } & $50 \%$ del $\Delta \varnothing_{x d}$ del P-31+ $\Delta \varnothing_{x d}$ del PY-6/CV19 50/50 \\
\hline $7 \mathrm{~d}$ & $1.75 \%$ & $<$ & $1.74 \%+0.13 \%=1.87 \%$ \\
\hline $28 \mathrm{~d}$ & $3.37 \%$ & $>$ & $1.935 \%+0.44 \%=2.375 \%$ \\
\hline $90 d$ & $3.87 \%$ & $<$ & $3.68 \%+0.50 \%=4.18 \%$ \\
\hline $730 \mathrm{~d}$ & $3.99 \%$ & $<<<$ & $20.265 \%+0.50 \%=20.765 \%$ \\
\hline
\end{tabular}

TABLA 8-19.- EJEMPLO PRACTICO DEL ESE PRODUCIDO EN EL CEMENTO DE MEZCLA P-31/CV19 50/50.

\begin{tabular}{cccc}
\hline Edad: $\Delta \varnothing_{\text {xd }}$ & \multicolumn{2}{c}{ P-1/(CV19+CH) $\mathbf{5 0 / 5 0}$} & $\mathbf{5 0} \%$ del $\Delta \varnothing_{\text {xd }}$ del P-1+ $\varnothing \varnothing_{\text {xd }}$ del PY-6/(CV19+CH) 50/50 \\
\hline $7 \mathrm{~d}$ & $6.36 \%$ & $>$ & $2.37 \%+0.25 \%=2.62 \%$ \\
$28 \mathrm{~d}$ & $14.71 \%$ & $>$ & $4.115 \%+1.68 \%=5.795 \%$ \\
$90 \mathrm{~d}$ & $23.69 \%$ & $>>$ & $7.355 \%+5.24 \%=12.595 \%$ \\
$180 \mathrm{~d}$ & $32.36 \%$ & $>$ & $8.29 \%+11.1 \%=19.39 \%$ \\
$365 \mathrm{~d}$ & $43.39 \%$ & $>$ & $25.94 \%+50 \%=12.97 \%+24.94 \%=37.91 \%$ \\
$730 \mathrm{~d}$ & $45.95 \%$ & $<$ & $24.685 \%+37.16 \%=61.845 \%$ \\
\hline
\end{tabular}

TABLA 8-20.- EJEMPLO PRACTICO DEL ESE PRODUCIDO EN EL CEMENTO DE MEZCLA P-31/CV19 50/50.

\begin{tabular}{|c|c|c|c|}
\hline Edad: $\Delta \varnothing_{\mathrm{xd}}$ & $\mathrm{P}-31 /(\mathrm{CV} 19+\mathrm{CH})$ & $50 / 50$ & $50 \%$ del $\Delta \varnothing_{x d}$ del P-31+ $\Delta \varnothing_{x d}$ del PY-6/(CV19+CH) $50 / 50$ \\
\hline $7 \mathrm{~d}$ & $2.49 \%$ & $>$ & $1.74 \%+0.25 \%=1.99 \%$ \\
\hline $28 \mathrm{~d}$ & $5.74 \%$ & $>$ & $1.935 \%+1.68 \%=3.61 \%$ \\
\hline $90 \mathrm{~d}$ & $8.17 \%$ & $<$ & $3.68 \%+5.24 \%=8.92 \%$ \\
\hline $540 d$ & $16.96 \%$ & $<$ & $23.17 \% \times 50 \%=11.585 \%+11.1 \%=22.68 \%$ \\
\hline
\end{tabular}

Aunque no obstante y en principio, parecía que, a tenor de este parámetro $\Delta \varnothing$, su correspondiente fracción "alumínica" (acompañante de la "silícica" y "férrica", en esta ocasión), debía de estar comprendida en calidad y cantidad, entre la de la puzolana $O$ y la de la puzolana $\mathrm{A}$, aunque, al parecer, más próxima a la de la $\mathrm{A}$ que a la de la $\mathrm{O}$, puesto que, cuando el $\mathrm{C}_{3} \mathrm{~A}$ estuvo 
presente, caso de la curva del CM P-1/(CV19+CH) 50/50, la semejanza con la curva correspondiente a la puzolana $\mathrm{O}$, fue mayor, véase dicha mayor semejanza entre ambas curvas, $\mathrm{P}-1 /(\mathrm{CV} 19+\mathrm{CH})$ 50/50 y $\mathrm{P}-1 /(\mathrm{O}+\mathrm{CH})$ 50/50, en la Figura 8-1(g). Mientras que, cuando el $\mathrm{C}_{3} \mathrm{~A}$ no estuvo presente, caso de la curva, del CM PY-6/(CV19+CH) 50/50, la mayor semejanza alcanzada fue con la curva del CM PY-6/(CV19+CH) 50/50, la mayor semejanza alcanzada fue con la curva del CM PY-6/(A+CH) 50/50.

Por el contrario, los contenidos de $\mathrm{Fe}_{2} \mathrm{O}_{3}$ de las puzolanas $\mathrm{O}$ y CV19 $(13.82 \%$ y $16.12 \%$, respectivamente), no debían ser, en cambio, equivalentes en actividad, o mejor quizás, en su facilidad de ser lixiviados por el hidróxido de calcio de cualquier origen, dado que las curvas respectivas PY-6/(O+CH) 50/50 y PY-6/(CV19+CH) 50/50, no fueron semejantes, sino todo lo contrario, lo cual era lo lógico, puesto que si bien, el elemento $\mathrm{Fe}^{3+}$ podía y puede ser lixiviado con facilidad de la maghemita de la ceniza CV19, mediante estas disoluciones tan básicas de $\mathrm{Ca}(\mathrm{OH})_{2}$, el de la puzolana $\mathrm{O}$, por contra, no, por encontrarse en forma de enstatita y forsterita ferroán, principalmente.

Y para verificar más aún esta razón dada, se tuvo el hecho del muy diferente comportamiento mostrado por esta puzolana CV19 con $\mathrm{CH}$, al mostrado, en semejantes circunstancias, por la puzolana O. Así mientras que las curvas que originó esta puzolana $\mathrm{CV} 19+\mathrm{CH}$ con cada CPM, y sus áreas abarcadas respectivas, fueron bastante semejantes entre si, las tres, hubiera estado o no, presente el $\mathrm{C}_{3} \mathrm{~A}$, las correspondientes a la puzolana $\mathrm{O}$ no lo fueron nada en absoluto, cuando el $C_{3} A$ estuvo prácticamente ausente. Véanse las Figs. 8-1(g), 8-3(e) y 8$5(\mathrm{~g})$.

Estos resultados experimentales obtenidos con ambas puzolanas cuando el $\mathrm{CH}$ estuvo presente nos han permitido poder adscribirles definitivamente el siguiente "carácter" a cada una de ellas mediante el parámetro $\Delta \varnothing$ : a la ceniza CV19, el carácter "férrico-silícico-alumínico" y a la puzolana $\mathrm{O}$, el carácter "silicico-alumínico".

No obstante, y a pesar de lo cual, ambos caracteres habrían de serles ratificados mediante el resto de los parámetros determinados, pero en especial la VC $\varnothing$ y la P.A.V., para su adscripción definitiva.

\subsection{3-Discusión e Interpretación de las Familias $P-n^{\circ}$ y PY-n ${ }^{\circ} " Z " Z^{\prime \prime} 50 / 50+C H$.}

En el caso de las curvas correspondientes a las AP O y CV19 (+CH) 50/50: cuando el CP común que las acompañó fue el P-1, sus curvas representativas correspondientes resultaron ser bastante semejantes entre si, en su creación, evolución y desarrollo durante el transcurso del ensayo, y consiguientemente sus pendientes y áreas abarcadas. Sin embargo, cuando el CP que las acompañó fue el P-31 o el PY-6, no ocurrió lo mismo, sino todo lo contrario al caso anterior, es decir, las áreas abarcadas, aun habiendo podido hacerse también asimilables a un triángulo rectángulo o en definitiva, a un ángulo, según se considere, el grado de semejanza, resultó ser en el mejor de los casos, algo menor, caso de las curvas P-31/(O+CH) 50/50 y PY-6/(CV19+CH) 50/50, 
e incluso, bastante menor, caso de las curvas P-31/(CV19+CH) 50/50 y PY-6/(O+CH) 50/50, y además y sobre todo, ocurrió también, todo lo contrario entre ellas mismas, ya que mientras, en el caso del CP P-31, la superficie abarcada por la puzolana $\mathrm{O}(+\mathrm{CH})$ resultó ser mayor que la abarcada por la curva de la ceniza CV19 $(+\mathrm{CH})$, en el caso del segundo, ó PY-6, resultó lo contrario, o sea, la de la ceniza CV19 $(+\mathrm{CH})$ fue mayor que la de la $\mathrm{O}(+\mathrm{CH})$.

Primeramente, véase la Interpretación correspondiente a esta Discusión en la Interpretación del caso (b) del apartado 8.1.3.1.1.2, y a continuación, la propia interpretación de esta Discusión

1a. A tenor de la creación, evolución y desarrollo de sus curvas correspondientes de $\Delta \varnothing$ durante el transcurso del ensayo, la reactividad postrera con el yeso en la probeta L-A, de la cantidad mayor o menor pero presumiblemente residuales, de $\mathrm{C}_{3} \mathrm{~A}$ y/o también de $\mathrm{C}_{4} \mathrm{AF}$, que las acompañó en cada caso de esta otra situación con $\mathrm{CH}$, debió al parecer, quedar resaltada o exaltada casi siempre [en cuatro casos -las probetas L-A P-1/((O y CV19))+CH 50/50, P-31/(O+CH) 50/50 y PY-6/(CV19+CH) 50/50- de un total de seis, o sea, más las probetas L-A P-31/(CV19+CH) 50/50 y PY-6/(O+CH) 50/50], en relación con la de su CP solo. De aquí que llamara mucho la atención el hecho de que en el caso de estas dos puzolanas, la citada exaltación de la reactividad del $\mathrm{C}_{3} \mathrm{~A}$ y/o $\mathrm{C}_{4} \mathrm{AF}$ que las acompañaba finalmente en cada caso, hubiera sido común, equivalente y notable, pero únicamente cuando tales contenidos de $\mathrm{C}_{3} \mathrm{~A}$ y/o $\mathrm{C}_{4} \mathrm{AF}$, provinieron del $\mathrm{CP} \mathrm{P}-1$, que no en cambio cuando provinieron del CP P-31 o del CP PY-6, con los que dicho notable grado de potenciación o exaltación, no fue común sino dispar, habiendo sido ya descrito además desde otro punto de vista en la Discusión anterior correspondiente al apartado 8.1.2.2.1.

Primeramente, véase la interpretación correspondiente a esta Discusión, en la interpretación del caso (b) de la Discusión anterior correspondiente al apartado 8.1.3.1.1.2 y a continuación la propia interpretación correspondiente a esta Discusión, que se encuentra más adelante.

2a . En el caso de las curvas correspondientes a la puzolana A $(+\mathrm{CH})$ 50/50. Al no haber podido disponer en esta ocasión, nada más que de la curva correspondiente al cemento de mezcla PY-6/(A+CH) 50/50, no se pudo crear discusión ni interpretación alguna a igualdad de puzolana A precisamente. Únicamente se pudo crear alguna discusión e interpretación cuando se comparó con la puzolana $\mathrm{O}$ por un lado y con dicha puzolana O y la ceniza CV19, por otro.

En el primer caso, véase la interpretación correspondiente a esta Discusión, en la interpretación de la Discusión anterior correspondiente al apartado 8.1.3.1.1.2 y a continuación la propia interpretación correspondiente a esta Discusión, que se encuentra más adelante.

3a . En el caso de las curvas correspondientes a la puzolana C $(+\mathrm{CH})$ 50/50. En la Interpretación de la Discusión del apartado 8.1.3.1.1.2, correspondiente a esta misma puzolana, pero sin $\mathrm{CH}$, básicamente se dijo que el carácter "alumínico-silícico" que se le había podido adscribir en aquellas condiciones del ensayo, venía a justificar la creación de una cierta ASExd + inicial por todos los cementos de meazcla allí ensayados, que era la causa y el origen del paralelismo total o parcial alcanzado, más pronto que tarde, por sus curvas correspondientes 
representativas.

Pues bien, esta razón, se vería reafirmada más aún en su certeza cuando el $\mathrm{CH}$ estuvo presente en este ensayo, ya que en todos los casos, y como era lo lógico, la ASExd + originada fue mayor (bien durante todo el ensayo, o bien, a partir de una edad determinada del mismo, la cual fue tanto más tardía cuanto más $\mathrm{C}_{3} \mathrm{~A}$ estuvo presente, y viceversa) y además y en cierta medida, más semejante entre si -evolución de las curvas y áreas abarcadas-, cuanto más adecuado a esta puzolana $\mathrm{C}(+\mathrm{CH})$ fue el contenido de $\mathrm{C}_{3} \mathrm{~A}$ del $\mathrm{CP}$ que la acompañó, y viceversa.

Por ello, al haber podido ser caracterizada esta puzolana C como "aluminico-silícica" en estas condiciones del ensayo y no en cambio como "alumínico", al igual que la puzolana $\mathrm{M}$, únicamente pudo originar un ESE + con menores o nulas presencias de $\mathrm{C}_{3} \mathrm{~A}$. $\mathrm{Y}$ en caso contrario y por tal motivo precisamente, no debía haber podido originar un ESE + con el CP P-1, a diferencia también de dicha puzolana $\mathrm{M}$, que es lo que ha ocurrido en esta fase de la investigación.

Por esta razón y con dicho CP P-1, habría sobrado $\mathrm{C}_{3} \mathrm{~A}$ suficiente para, después de haber podido promover su actividad puzolánica en dicho medio y la sinergia correspondiente en sus probetas L-A, entre la ett-rf y la ett-lf, haber podido originar unas curvas bastante más paralelas al eje de abscisas que las demás.

Y para verificar esta hipótesis, no hubo más que ver que entre todas y a pesar de todo, la del cemento de mezcla con $\mathrm{CH} \mathrm{P}-2 /(\mathrm{C}+\mathrm{CH}) 50 / 50$ era la más parecida de todas porque su $\mathrm{CP}$ era y es el que poseía el contenido de $\mathrm{C}_{3} \mathrm{~A}, 11.09 \%$, más próximo al del CP P-1, 14.11\%. Véanse al efecto la Figs. 8-1(c), 8-2(b), 8-3(c), 8-4(b) y 8-5(e).

$4^{\mathrm{a}} \quad$ En el caso de las curvas correspondientes a la puzolana AP CV10 $(+\mathrm{CH})$ 50/50: vale aquí toda la interpretación dada para explicar el comportamiento de la puzolana $\mathrm{C}$ con $\mathrm{CH}$ sólo que, corregida y mejorada, pues la búsqueda por parte de su curva correspondiente del paralelismo con el eje de las abscisas comenzó y se alcanzó más pronto aún que en el caso de la puzolana $\mathrm{C}$, y además estando en la situación más difícil de todas: con el CP P-1. Véanse las Figs. 8-1(e), 8-3(e) y 8-5(d).

$5^{\mathrm{a}} \quad$ En el caso de las curvas correspondientes de la puzolana $\mathrm{M}(+\mathrm{CH})$ 50/50: valen aquí todas las explicaciones y interpretaciones dadas con anterioridad tanto, para verificar la hipótesis inicial, como para ratificar su carácter eminentemente "alumínico", lo que le permitió que todas las razones esgrimidas para tratar de justificar el comportamiento en este MAE L-A con o sin $\mathrm{CH}$, de las puzolanas $\mathrm{C}$ y CV10, le fueran también adscribibles en esta ocasión y con mayor razón aún por su mayor carácter "alumínico" que el de aquellas y por consiguiente mayor ESE + a igual edad y mayor rectangularidad y mayor superficie abarcada por su curva correspondiente, a igualdad de medio, o sea, ya estuviera presente el $\mathrm{CH}$, o no.

6a. En el caso de las curvas correspondientes a la puzolanas $\mathrm{C}$ y CV10 $(+\mathrm{CH}) 50 / 50$ : las áreas correspondientes enmarcadas por sus curvas respectivas fueron algo más semejantes cuando el CP acompañante común fue el PY-6, que no cuando lo fue el P-1. A tenor de la creación, evolución y desarrollo de tres curvas correspondientes de $\Delta \varnothing$ durante el transcurso del ensayo, la reactividad portrera con el yeso en la probeta L-A, de la cantidad mayor o menor pero 
presumiblemente residual, de $\mathrm{C}_{3} \mathrm{~A}$ y/o también de $\mathrm{C}_{4} \mathrm{AF}$ que las acompañó, debieron al parecer quedar anuladas siempre ( $\mathrm{y}$ en particular la de $\mathrm{C}_{3} \mathrm{~A}$ ), en relación con la de su correspondiente $\mathrm{CP}$ P-1 ó P-31, solos, que no en cambio en relación con la del CP PY-6 (en particular la de $\mathrm{C}_{4} \mathrm{AF}$, en este caso), cuyo caso resulto potenciada o exaltada. Véase su interpretación en el apartado correspondiente venidero.

Una vez comentados los resultados obtenidos, se puede realizar la siguiente interpretación de éstos:

a) Mediante estos dos comportamientos mostrados en estas proporciones de mezcla con $\mathrm{CH}$, 50/50, por la puzolanas O y CV19 aparte de quedar verificada una vez más la hipótesis principal de trabajo que promovió esta investigación ó hipótesis inicial, quedó demostrado además que si bien ambas puzolanas podían ser caracterizadas como "silícico-alúminicas" o mejor quizás como "silícico-férrico-alumínica", la O debía poseer su fracción "alumínica" más reactiva y/o en mayor cuantía que la CV19, mientras que esta otra debía tener más reactiva la fracción "férrica".

Ello habría permitido por tanto que cuando el $\mathrm{C}_{3} \mathrm{~A}$ hubiera estado presente en cantidad adecuada, caso del CP P-31, el área abarcada por la puzolana $\mathrm{O}(+\mathrm{CH})$ hubiera sido mayor, por mayor ESE + (de origen, ett-rf y ett-lf y/o ett-vlf, en este caso), que la abarcada por la puzolana CV19 $(+\mathrm{CH})$, la cual y por contra, habría podido originar en cambio su ESE + (de origen ett-lf y geles de $\mathrm{Fe}(\mathrm{OH})_{3}$ en este otro caso) cuando la cantidad adecuada fue de hidróxido de calcio, en esta otra ocasión proporcionando por el propio $\mathrm{CH}$ añadido y por el $0 \%$ de $79.43 \%$ de $\mathrm{C}_{3} \mathrm{~S}$ del CP PY-6.

b) Mediante estos dos comportamientos mostrados en estas proporciones de mezcla con $\mathrm{CH}$, 50/50, por la puzolana C y CV10, aparte de quedar verificada una vez más la HTI, quedó también puesto de manifiesto que la puzolana CV10 debía ser más vítrea que la C aunque ésta debía poseer en cambio su $\mathrm{Al}_{2} \mathrm{O}_{3}{ }^{\mathrm{r}-}$ en mejores condiciones termo-químicas y reactivas en suma que aquella (ien estado amorfo como la de la AP M?), sin menospreciar que también pudiera poseer $\mathrm{Al}_{2} \mathrm{O}_{3}{ }^{r-}$ en estado vítreo, incluso a pesar de que su contenido pudiera ser algo menor.

Ello quizás habría permitido por tanto, que, ante la ausencia de cte, las $\mathrm{Al}_{2} \mathrm{O}_{3}{ }^{\mathrm{r}-}$ amorfas habrían dispuesto de menores condiciones básicas para poder desarrollar su actividad puzolánica (sin el yeso -primeros 14 días- y con el yeso después) y consiguientemente habrían necesitado mayor cantidad de tiempo para poder desarrollarla pero para entonces ya en su propia probeta L-A P-no y PY-no /C 50/50, mientras que las $\mathrm{Al}_{2} \mathrm{O}_{3}{ }^{\mathrm{r}-}$ vítreas, habrían necesitado más tiempo aún; en consecuencia ya la edad de 1 día de cada probeta L-A, los valores del $\Delta \varnothing 1 \mathrm{~d}$ de las probetas L-A de la puzolana $C$ debían de haber sido mayores que los de la probeta L-A correspondiente de la ceniza CV10. En cambio, ante la presencia de cte, debería haber ocurrido lo contrario, coadyuvado además porque en estas otras circunstancias, la mayor "capacidad de cambio" de la puzolana C sobre la ceniza CV10, se hubiera desarrollado más y mejor, lo que unido a la mayor presencia de $\mathrm{C}_{3} \mathrm{~A}$ (caso del cemento de mezcla $\mathrm{P}-1 /(\mathrm{C}+\mathrm{CH}) 50 / 50$ habría hecho que su probeta L-A proporcionara 
mayores valores de P.A.V. y/o fraguara más lentamente que la de la probeta L-A correspondiente de la ceniza CV10, como así ha ocurrido en esta fase de la investigación, en el caso del CP PY-6 y en el caso del CP acompañante P-1, respectivamente.

TABLA 8-21.- COMPARATIVA ENTRE $\Delta \varnothing_{1 \mathrm{D}}$ (\%) P-№ Y PY-6/"Z" 50/50 DE LAS PUZOLANAS C Y CV10.

\begin{tabular}{|c|c|c|c|c|c|c|}
\hline & \multicolumn{6}{|c|}{$\Delta \varnothing_{1 d}(\%)$ P-no y PY-6/"Z" 50/50 } \\
\hline & \multicolumn{2}{|c|}{ P-1 } & \multicolumn{2}{|c|}{ P-31 } & \multicolumn{2}{|c|}{ PY-6 } \\
\hline & $\mathrm{C}$ & CV10 & $\mathrm{C}$ & CV10 & $\mathrm{C}$ & CV10 \\
\hline$-\mathrm{CH}$ & 6.55 & 1.12 & 6.61 & 3.12 & 0.87 & 0.25 \\
\hline$+\mathrm{CH}$ & 1.00 & 8.73 & * & 1.87 & 3.55 & 0.50 \\
\hline
\end{tabular}

*Esta probeta L-A no se preparó en razón de los planteamientos operativos de esta investigación.

\subsection{4-Discusión e Interpretación de las Familias de CM P-no y PY-no $/\left({ }^{\prime \prime} Z^{\prime \prime}+C H\right)$ 40/60.}

En estas familias de cementos de mezcla con ó sin $\mathrm{CH}$, se pudieron destacar los siguientes hechos:

1ํ. Confirmación de la Hipótesis inicial a través de las curvas correspondientes a los P-1/M (con ó sin CH) 40/60 y P-2/M (con ó sin CH) 40/60:

Los contenidos de $\mathrm{C}_{3} \mathrm{~A}$ de ambos $\mathrm{CP}$ eran elevados y del mismo orden de magnitud, $14.11 \%$, el P-1, y, 11.09\%, el P-2. Por el contrario, sus contenidos respectivos de $\mathrm{C}_{3} \mathrm{~S}$, eran dispares, $51.05 \%$ y $33.47 \%$, es decir, de muy diferente orden de magnitud. Por este motivo, la menor área abarcada por las curvas del P-2/M, con ó sin $\mathrm{CH}, 40 / 60$, hubo de adscribirse necesariamente a estos muy diferentes contenidos de $\mathrm{C}_{3} \mathrm{~S}$, que no de $\mathrm{C}_{3} \mathrm{~A}$.

Además, y como verificación adscribible a dicha deducción estuvo el hecho de que el área abarcada por el cemento de mezcla P-2/M 40/60, con o sin $\mathrm{CH}$, fue semejante a la de los correspondientes cementos de mezcla del PY-4 y PY-6 con 0.00\% $\mathrm{C}_{3} \mathrm{~A}$. Por ello el $\mathrm{C}_{3} \mathrm{~A}$ del P-2 en estas circunstancias no pudo formar ett-lf suficiente.

2o. Las áreas abarcadas por las curvas de los cementos de mezcla de la puzolana A, con ó $\sin \mathrm{CH}$, fueron ligera y extrañamente superiores y más triangulares, cuando dicha puzolana A estuvo acompañada por el CP P-1.

La causa debió ser que, a igualdad de edad del ensayo, los valores de P.A.V. de las probetas L-A correspondientes al CP P-1 $\left(14.11 \% \mathrm{C}_{3} \mathrm{~A}\right)$, fueron mayores que los de las probetas L-A correspondientes al CP P-31 $\left(7.62 \% \mathrm{C}_{3} \mathrm{~A}\right)$, véase las Figs. 8-16 y 8-18, con las consecuencias tecnológicas correspondientes al caso, aquí denunciadas.

3o. La diferente magnitud mostrada por las áreas de las curvas PY-4/M 40/60 y PY6/M 40/60, por un lado, y PY-4/(M+CH) 40/60 y PY-6/(M+CH) 40/60, por otro.

Ambas diferencias fueron achacables a una misma causa: La presencia de cantidad suficiente de portlandita en el caso de la probeta L-A PY-4/M 40/60 y no en cambio en la probeta L-A PY-6/M 40/60, para que la puzolana M hubiese podido formar toda la ett-rf, que era capaz. Por ello, como el CP PY-6 poseía un contenido de $\mathrm{C}_{3} \mathrm{~S}$ (= 79.43\%) superior al del PY-4 (= 58.19\%), mayor cantidad de ett-rf, le permitió formar a dicha puzolana $\mathrm{M}$, y consiguientemente, mayor 228 
área pudo abarcar su correspondiente curva de $\Delta \varnothing$.

Y para verificar esta razón aducida, se tuvo al hecho de que el área fue mayor si bien con la ausencia de la puzolana $M$ en el cemento de mezcla. Véanse a propósito las Figs. 8-4(a) y 8-5(a y b). Por consiguiente y según ello, la probeta L-A PY-4/M40/60 debió de originar a la edad de 1 día al menos, menores valores de P.A.V. que la PY-4/M 40/60, como así ha ocurrido en esta fase de la investigación. Véase a propósito la Fig. 8-19.

Sin embargo, al haber ocurrido lo contrario en tales cementos de mezcla 40/60 con $\mathrm{CH}$ vino a indicar que el cemento de mezcla PY-6/(M+CH) 40/60 se debía encontrar más próximo a la cantidad óptima de hidróxido de calcio de cualquier origen, para poder ser caracterizado como "cemento expansivo", puesto que, a pesar de ello, los valores de RM fueron mayores, que los del CM PY-4/(M+CH) 40/60.

\subsection{5- Discusión e Interpretación de las Familias de CM P-n y $\mathrm{PY}-n^{\circ} /(\mathrm{M}+\mathrm{CH})+7.0 \% \mathrm{SO}_{3}$} $30 / 70$.

Estas familias estaban constituidas por los cementos de mezcla P-1, P-2, P-31 y PY-6/M 30/70, con y sin $\mathrm{CH}$, y P-1 y PY-6/M 30/70+7.0\% $\mathrm{SO}_{3}$, con y $\sin \mathrm{CH}$, y se pudieron destacar los siguientes hechos:

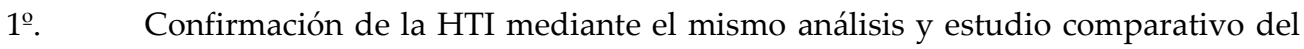
caso anterior 40/60.

$2^{\circ}$. Que las áreas abarcadas por las curvas de ๑® de todos los cementos de mezcla Pno y PY-6/M 30/70, con o sin CH, eran perfectos o casi perfectos, rectángulos, lo que venía a indicar que en estos medios selenitosos, la $\mathrm{Al}_{2} \mathrm{O}_{3}{ }^{r-}$ de la puzolana $\mathrm{M}$ debía de ser la que se encontraba en mejores condiciones termo-químicas y reactivas en suma, de las seis puzolanas comparadas con ella, para poder originar rápidamente ett-rf y provocar la correspondiente ESE +, en su caso, que en esta ocasión debía corresponder mayormente en ambas situaciones, con y $\sin \mathrm{CH}$, a los cementos de mezcla P-1/M 30/70 y P-1/(M+CH) 30/70, puesto que su CP P-1 pudo aportar más $\mathrm{C}_{3} \mathrm{~A}$ que los demás $\left(30 \% \times 14.11 \%=4.23 \% \mathrm{C}_{3} \mathrm{~A}\right)$, como así ha ocurrido en esta fase de la investigación. Véanse a propósito las Figs. 8-1(a y b) y 8-5 (b y c).

3․ Que la práctica nulidad del área abarcada por la recta, más que curva, en estos casos, de los valores de $\Delta \varnothing$ de los cementos de mezcla P-1 y PY-6/M 30/70, con y $\sin 7.0 \% \mathrm{SO}_{3}$, y con y $\sin \mathrm{CH}$, fue debido a que la ett-rf que la $\mathrm{Al}_{2} \mathrm{O}_{3}{ }^{\mathrm{r}-}$ de la puzolana $\mathrm{M}$ debía formar, ya la originó durante sus 14 días de conservación bajo agua de tales cementos de mezcla. En ellas se pudo y puede observar la presencia de ettringita mientras que cuando no estuvo presente dicha cantidad del $7.0 \% \mathrm{SO}_{3}$, no se formó.

Por ello, cuando con tales materiales cementantes se fabricó su probeta L-A correspondiente, la misma no expandió, fraguando además en todos los casos, con rapidez, extraordinaria incluso antes de 1 día, caso de las probetas P-1/M 30/70 con o $\sin 7.0 \% \mathrm{SO}_{3}$, con o $\sin \mathrm{CH}$, notable, entre 1 y 14 días, caso de las probetas $\mathrm{PY}-6 / \mathrm{M} 30 / 70$, con o $\sin 7.0 \% \mathrm{SO}_{3}$, con o $\sin$ 
CH. Véase a propósito la Fig. 8-20.

4‥ Véanse a continuación en el apartado venidero 8.1.2.5., las diferencias de comportamiento mostradas por estos cementos de mezcla en el parámetro P.A.V., y la razón aportada para tratar de justificarlas.

\subsection{6- Discusión e Interpretación de las Familias de CM PY-6/(M+CH) +7.0\%SO3 20/80.}

Vale aquí todo lo dicho anteriormente para los correspondientes cementos de mezcla P-1 y PY-6/M, principalmente.

\subsubsection{2-Figuras obtenidas con los valores del parámetro $V C_{\varnothing}$}

\subsection{1- Discusión e Interpretación de las Familias de CM P-nº y PY-no/"Z" 50/50.}

Al observar las curvas correspondientes obtenidas con los valores del parámetro VCø durante el tiempo de duración del ensayo, se pudo comprobar lo siguiente:

(a) En el caso de las curvas correspondientes a las puzolanas O y A. Figuras 8-6(e, g), 8-7(c,d), 8-8(d,f), 8-9(c,d) y 8-10 (f,h): En general y de acuerdo con los valores proporcionados por tales puzolanas en este parámetro, el comportamiento de estas fue semejante a igualdad de cemento de mezcla, habiendo sido no obstante en el caso del CP común P-31, cuando sus curvas correspondientes abarcaron más área y valor absoluto de su pendiente. Por otra parte, y si el contenido de $\mathrm{C}_{3} \mathrm{~A}$ de su $\mathrm{CP}$ fue $>8.0 \%$, su curva correspondiente se pudo hacer bastante asimilable a una curva de Gauss completa mientras que si dicho contenido de $\mathrm{C}_{3} \mathrm{~A}$ fue $<8.0 \%$, se pudo hacer más bien asimilable, a su rama descendente.

Y la causa común de ambos comportamientos hubo de ser achacables a que en el caso del CP P-31 en tales proporciones de mezcla, se pudo disponer de la cantidad adecuada de $\mathrm{C}_{3} \mathrm{~A}$ y $\mathrm{C}_{3} \mathrm{~S}$, para que ambas puzolanas pudieran mostrar más claramente la actividad puzolánica en estos medios tan selenitosos, de su respectiva fracción "alumínica" de su ya conocido carácter común "silícico-alumínico". Además, quedó demostrado de esta otra manera que la fracción "alumínica" de la puzolana debía ser mayor que la de la O.

No obstante, y, en cualquier caso, ambas fracciones "alumínicas" de su carácter químico común "silícico-alumínico", no son elevadas, puesto que cuando el $\mathrm{C}_{3} \mathrm{~A}$ estuvo presente, es decir, fue $<8.0 \%$, no lograron provocar un ESE + notable, hasta el punto de que ambas fueron dominadas o gobernadas por el CP P-1 (14.11\% C3 A) ó el P-2 (11.09\% C3 A). 

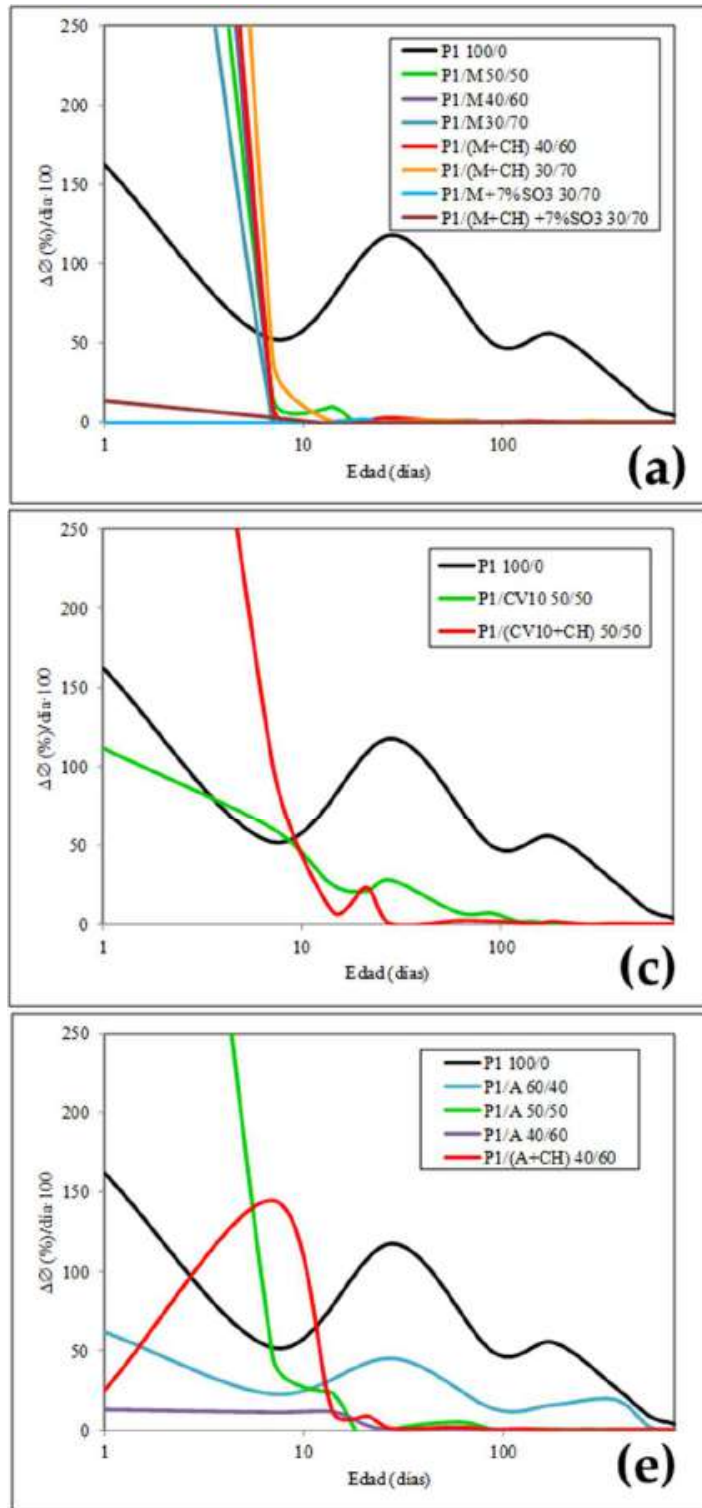

FIGURA 8-6.- RESULTADOS OBTENIDOS DE VCø EN EL ENSAYO LE CHATELIER ANSTETT PARA TODOS LOS CEMENTOS DE MEZCLA PREPARADOS CON CP P1 Y TODAS LAS PUZOLANAS UTILIZADAS EN ESTA INVESTIGACIÓN.
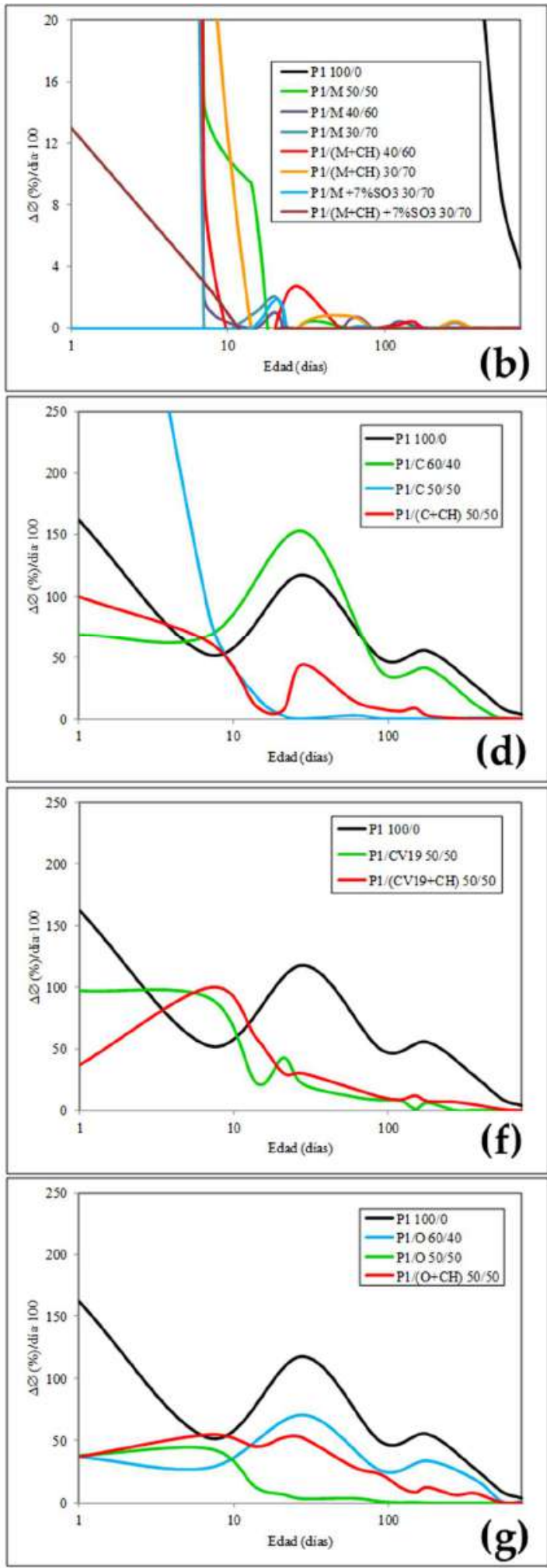
En definitiva, el hecho común de que cuando tuvo mayor presencia el $\mathrm{C}_{3} \mathrm{~A}$, la curva correspondiente se hizo más asimilable a una curva de Gauss, hubo de achacarse necesariamente, a la presencia adicional de dicho $\mathrm{C}_{3} \mathrm{~A}$ ante el ataque del yeso, con las consecuencias pertinentes descritas al caso, quedando de nuevo patente a la vez, que la máxima altura alcanzada por la misma resultó ser bastante más proporcional al contenido de $\mathrm{C}_{3} \mathrm{~S}$ que de $\mathrm{C}_{3} \mathrm{~A}$, dado que cuando la cte estuvo presente, los valores de ambas alturas se aproximaron bastante, por no decir que casi llegaron a coincidir. Véanse y compárense entre si, las respectivas curvas de trazo, por un lado, pero, sobre todo, las curvas continuas, por otro, de las Figuras 8-6(e, g), 8-7(c,d), 8-8(d,f), 8$9(\mathrm{c}, \mathrm{d})$ y $8-10(\mathrm{f}, \mathrm{h})$.
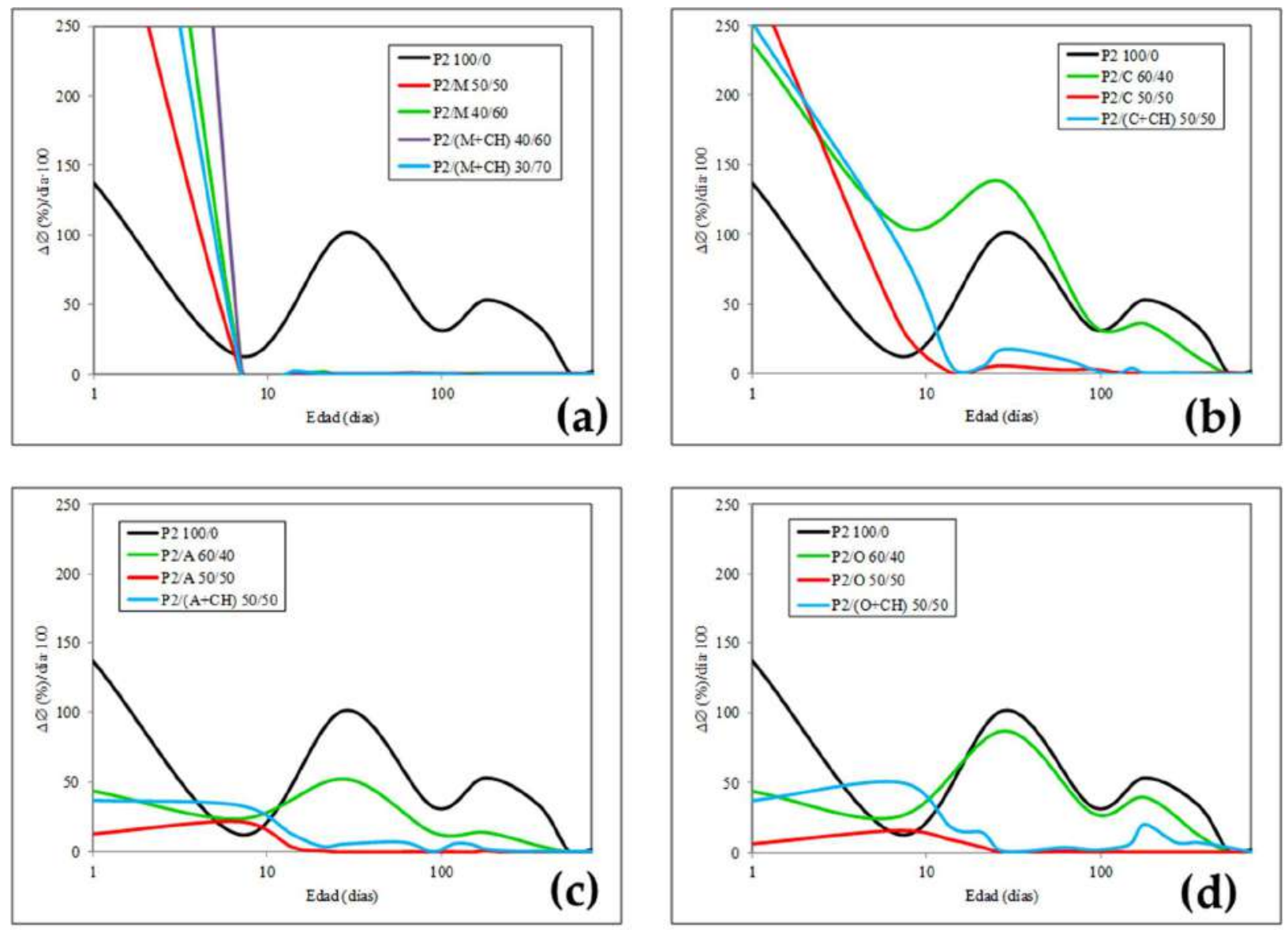

FIGURA 8-7.- RESULTADOS OBTENIDOS DE VCø EN EL ENSAYO LE CHATELIER ANSTETT PARA TODOS LOS CEMENTOS DE MEZCLA PREPARADOS CON CP P2 Y TODAS LAS PUZOLANAS UTILIZADAS EN ESTA INVESTIGACIÓN

(b) En el caso de las curvas correspondientes a la puzolana CV19. Figuras 8-6(f), 88(e) y 8-10(g): Lo más destacable de todo, fueron estos dos comportamientos:

- Que la mayor área abarcada por sus curvas representativas se produjo cuando el $\mathrm{C}_{3} \mathrm{~A}$ estuvo muy presente, caso del cemento de mezcla P-1/CV19 50/50. En este caso, su curva correspondiente se pudo hacer algo más asimilable a una curva de Gauss completa que 
cuando el $\mathrm{C}_{3} \mathrm{~A}$ estuvo prácticamente ausente ó cemento de mezcla PY-6/O 50/50, en cuyo caso, se pudo hacer claramente asimilable a la rama descendente de dicha curva de Gauss, si bien con bastante discreción, al igual que la puzolana $\mathrm{O}$.

- En el caso comparativo de los cementos de mezcla PY-6/O y PY-6/CV19 50/50, el área y valor absoluto de la pendiente negativa de las curvas del primero, con y $\sin \mathrm{CH}$, fueron algo mayores a los del último.

Ambos comportamientos no ratificaron la deducción obtenida tras semejante análisis y estudio comparativo realizado, mediante el parámetro absoluto $\Delta \varnothing$, véase el apartado subapartado anterior 8.1.3.1.1.1 y en especial, el subapartado (b) que hacía referencia a que la $\mathrm{Al}_{2} \mathrm{O}_{3}{ }^{\mathrm{r}-}$ de la puzolana CV19 debía de ser más parecida en calidad y cantidad, a la puzolana A que a la de la puzolana $\mathrm{O}$.

Pues bien, como decimos, ambos comportamientos aquí descritos de las puzolanas CV19 y O mediante el parámetro relativo $\mathrm{VC} \varnothing$, no ratifican la deducción anterior, sino más bien, la rectifican. Ya que a edades iniciales y cuando el $C_{3} \mathrm{~A}$ estuvo más o menos ausente, los valores de VCø de las probetas L-A P-31 y PY-6/(O+CH) 50/50, fueron algo mayores que los de las probetas L-A P-31 y PY-6/(CV19+CH) 50/50. Mientras que cuando dicho $\mathrm{C}_{3} \mathrm{~A}$ estuvo muy presente, no, sino todo lo contrario.

(c) En el caso de las curvas correspondientes a las puzolanas C, CV10 y M. Figs. 86(a,b,c,d), 8-7(a,b), 8-8(a,b,c), 8-9(a,b) y 8-10 (a,b,c,d,e). De entrada, se pudo vez que tan sólo las curvas de la probeta L-A PY-6/CV10 50/50, con y sin CH, fueron de las tres puzolanas, las más asimilables a una curva de Gauss completa. En resto fueron bastante más asimilables a su rama descendente. Independientemente de que una vez más hubiera quedado aquí verificada la HMI, el hecho de, por un lado, tanto las áreas abarcadas por sus curvas correspondientes de trazos o continuas, como, por otro, que los valores absolutos de sus pendientes negativas respectivas, hubiesen sido mayores a igualdad de CP acompañante, que las que habían proporcionado las $\mathrm{AP}$ anteriores O, CV19 y A, vino a demostrar una vez más que su contenido de fracción "alumínica" tenía que ser mayor que el de "silícica" y en cualquier caso mayor que el de las puzolanas $\mathrm{O}$, CV19 y A.

Además, y en este caso, la puzolana M lo tenía que tener el mayor de todas por la gran proximidad a la práctica verticalidad que mostraron sus correspondientes curvas de trazos en todos los casos $\sin \mathrm{CH}$ y además la mayor verticalidad de las seis puzolanas.

(d) En el caso de las curvas correspondientes a las puzolanas O, CV19, A, por un lado, y C, CV10 y M, por otro: En general las tres primeras puzolanas mostraron unas curvas que fueron bastante más asimilables a una curva de Gauss completa cuanto más presente estuvo el $\mathrm{C}_{3} \mathrm{~A}$. En cambio, las tres segundas generalmente no ya que más bien pudieron hacerse asimilables a la rama descendente de dicha curva de Gauss. Además, que dicha rama descendente se aproximo tanto más a una línea vertical cuanto más "alumínica" que "silícica" fue la puzolana que la originó. 
COMPORTAMIENTO SULFÁTICO Y MECÁNICO-RESISTENTE DE CEMENTOS PORTLAND CON ELEVADOS CONTENIDOS DE PUZOLANAS ( $>40 \%$ ): SU FUNDAMENTO QUÍMICO Y JUSTIFICACIÓN DE OTRAS CONSECUENCIAS POSIBLES
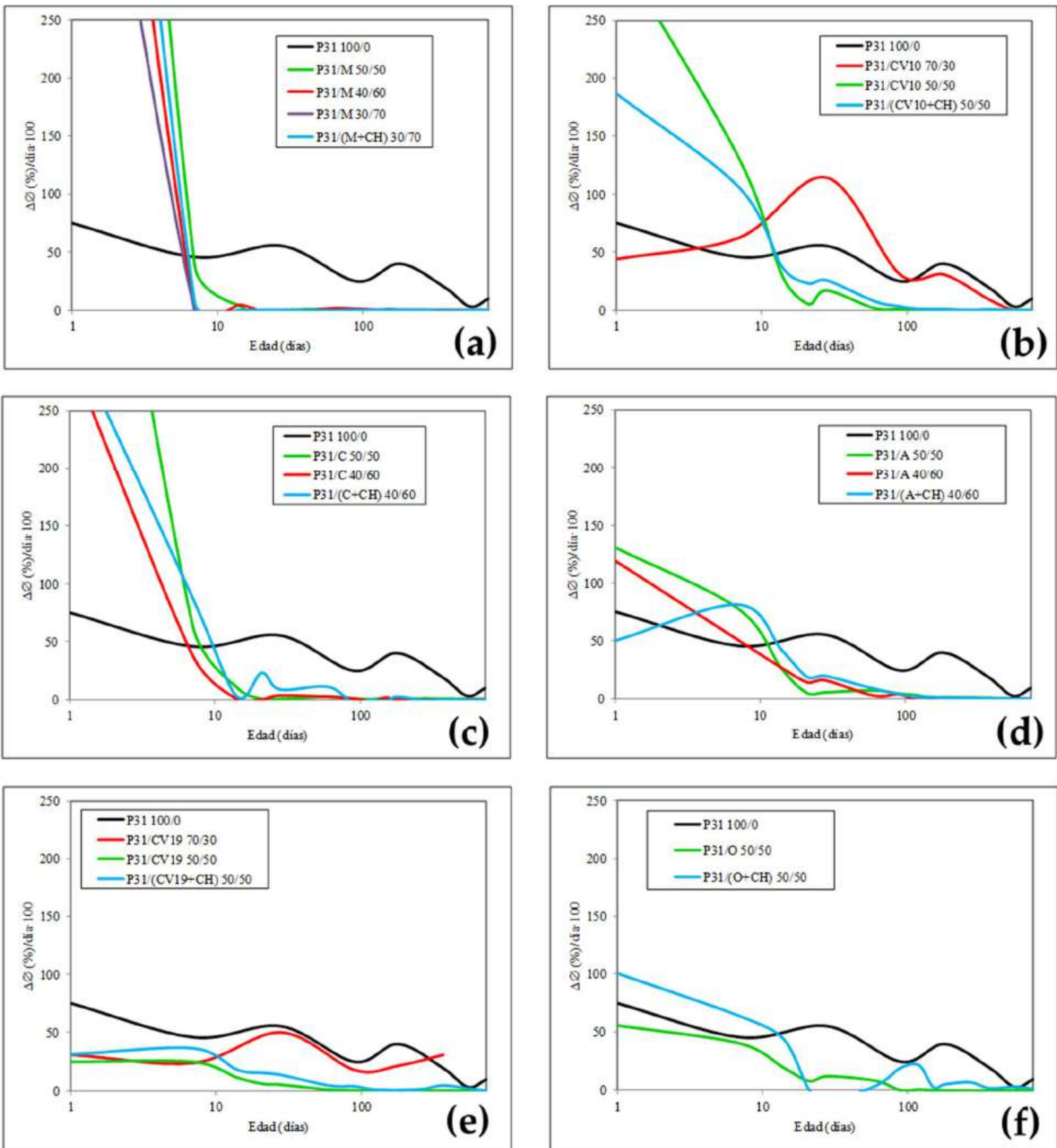

FIGURA 8-8.- RESULTADOS OBTENIDOS DE VCø EN EL ENSAYO LE CHATELIER ANSTETT PARA TODOS LOS CEMENTOS DE MEZCLA PREPARADOS CON CP P31 Y TODAS LAS PUZOLANAS UTILIZADAS EN ESTA INVESTIGACIÓN 

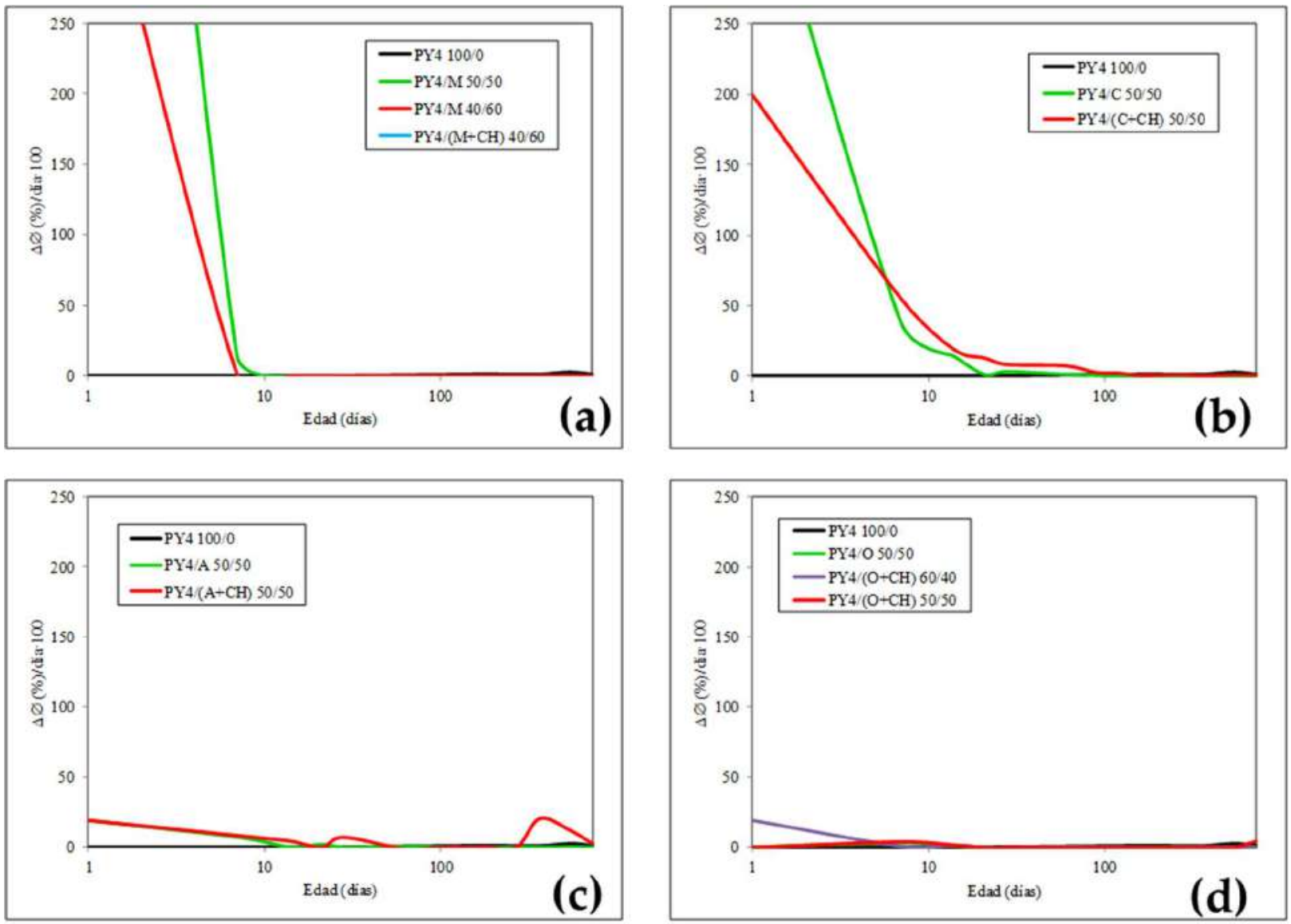

FIGURA 8-9.- RESULTADOS OBTENIDOS DE VCø EN EL ENSAYO LE CHATELIER ANSTETT PARA TODOS LOS CEMENTOS DE MEZCLA PREPARADOS CON CP PY4 Y TODAS LAS PUZOLANAS UTILIZADAS EN ESTA INVESTIGACIÓN
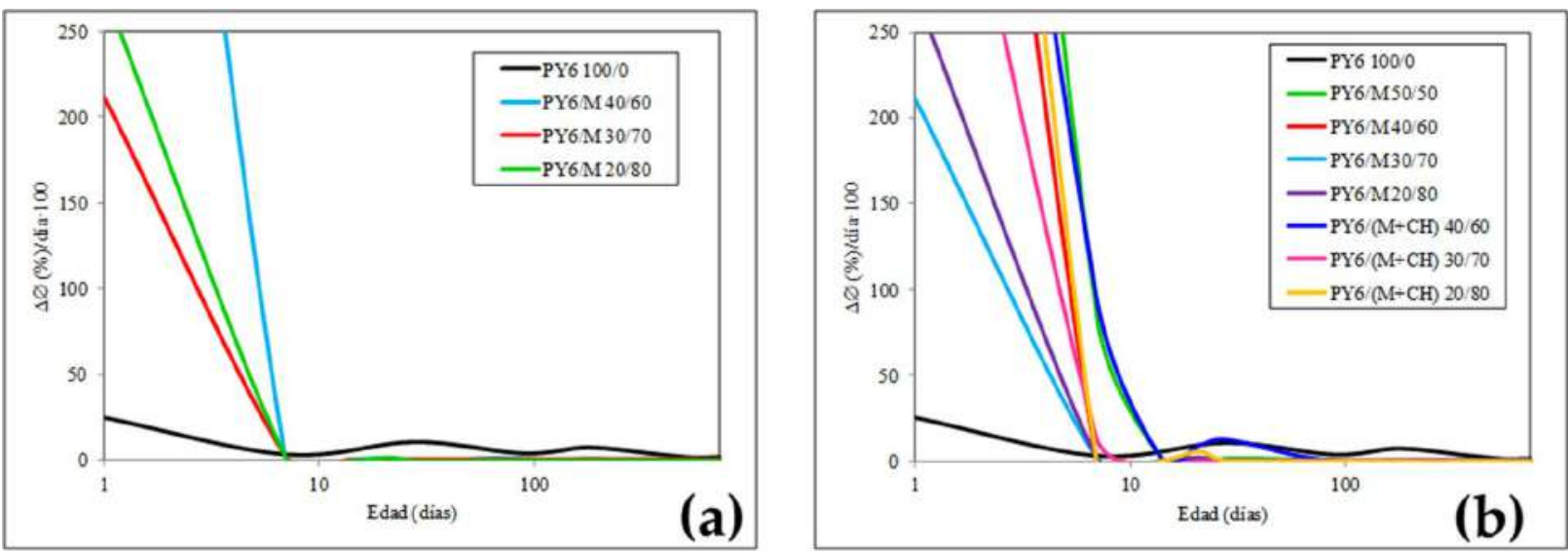
COMPORTAMIENTO SULFÁTICO Y MECÁNICO-RESISTENTE DE CEMENTOS PORTLAND CON ELEVADOS CONTENIDOS DE PUZOLANAS ( $>40 \%$ ): SU FUNDAMENTO QUÍMICO Y JUSTIFICACIÓN DE OTRAS CONSECUENCIAS POSIBLES
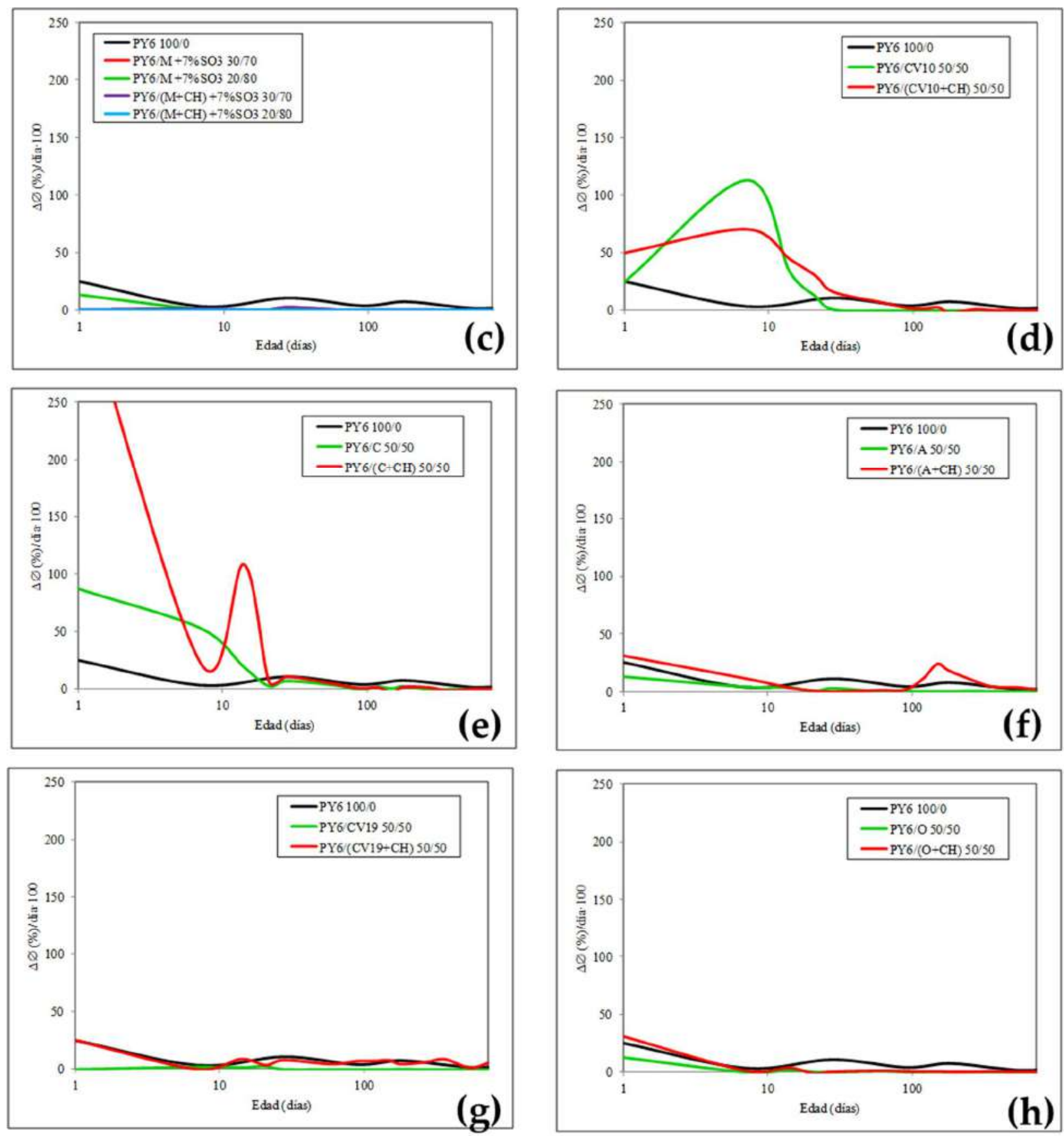

FIGURA 8-10.- RESULTADOS OBTENIDOS DE VCø EN EL ENSAYO LE CHATELIER ANSTETT PARA TODOS LOS CEMENTOS DE MEZCLA PREPARADOS CON CP PY6 Y TODAS LAS PUZOLANAS UTILIZADAS EN ESTA INVESTIGACIÓN

Todo ello fue la demostración palpable de diferente carácter de las puzolanas O, CV19 y A, por un lado, y de las puzolanas C, CV10 y M, por otro. De modo y manera que si las tres 
primeras habían podido ser caracterizadas como "silícico-alumínica", las tres segundas tenían que poseer necesariamente el carácter opuesto, o sea, "alumínico-silícica", debiendo además ser la puzolana M la más "alumínica" de estas tres hasta el punto de haber podido adjudicarle el carácter "alumínica" en exclusiva.

\subsection{2-Discusión e Interpretación de las Familias $P-n^{\circ}$ y $P Y-n^{\circ} / " Z^{\prime \prime} 50 / 50+C H$.}

Vale aquí íntegramente todo lo dicho en relación con este parámetro $\mathrm{V}_{\varnothing \varnothing}$, de los correspondientes $\mathrm{CM}$ 50/50 sin $\mathrm{CH}$, en el apartado 8.1.3.1.2.1.

No obstante, en el análisis comparativo realizado a ambas familias de $\mathrm{CM}$ con y $\sin \mathrm{CH}$, se pudo observar también que, por lo común, el valor absoluto de la pendiente de cada curva y su área abarcada era mayor cuando el $\mathrm{CH}$ estuvo presente a cuando no lo estuvo, si bien, se produjeron situaciones contrarias en ocasiones, debidas, quizás, al estado de dureza inicial o fraguado, de cada probeta L-A, con y $\sin \mathrm{CH}$,

- bien, por causa de la ettringita de diferente origen, según los casos, o

- bien, por causa del propio $\mathrm{CH}$ presente, o

- bien, por ambas causas anteriores citadas, en mayor o menor grado.

Así se produjeron en ocasiones significados cruces entre ambas curvas -la continua y la discontinua o de trazos- de un mismo $\mathrm{CM}$ con y $\sin \mathrm{CH}$, respectivamente, a unas edades del ensayo que coincidían más o menos exactamente con los cruces creados mediante los valores del parámetro P.A.V. Entre ellas se encontraban las familias de CM 50/50, PY-6/CV10, PY-4/C, P-31/O y CV10 y P-1/CV19.

\subsection{3-Discusión e Interpretación de las Familias de CM P-no y PY-no/("Z" $+C H)$ 40/60.}

En realidad, las probetas L-A que se van a comparar en esta ocasión son: la P-1, P-2, P-31, PY-4 y PY-6/M 40/60, la P-31/A 40/60 y la P-31/C 40/60.

En lugar de realizar su AEDI de forma individualizada y separada, se va a realizar de forma comparada. No obstante, se empezará por la probeta L-A de la puzolana M para decir que, tanto si la probeta L-A estuvo acompañada por cte, como si no lo estuvo, se produjo en todas ellas, una mayor aproximación a la verticalidad que la que alcanzaron en el caso de las correspondientes probetas L-A "hermanas mayores" 50/50, acabadas de ver e interpretar. Y siempre más próximas a la verticalidad, cuando el cte estuvo presente, o cuando estuvo ausente.

Este comportamiento fue, por una parte, la demostración palpable de que esta puzolana $\mathrm{M}$ debía y tenía mayor fracción "alumínica" de las cinco comparadas con ella, la cual sería por tanto la causa y el origen del ESE + que pudo originar cuando el $C_{3} \mathrm{~A}$ estuvo presente, y por otra, la verificación una vez más de la HTI.

De aquí el carácter de "alumínico" que se le había adjudicado a la misma con fundamento, mediante el parámetro $\Delta \varnothing$. Véase la discusión e interpretación del apartado 8.1.3.1.1.1. 
COMPORTAMIENTO SULFÁTICO Y MECÁNICO-RESISTENTE DE CEMENTOS PORTLAND CON ELEVADOS CONTENIDOS DE PUZOLANAS (> 40\%): SU FUNDAMENTO QUÍMICO Y JUSTIFICACIÓN DE OTRAS CONSECUENCIAS POSIBLES
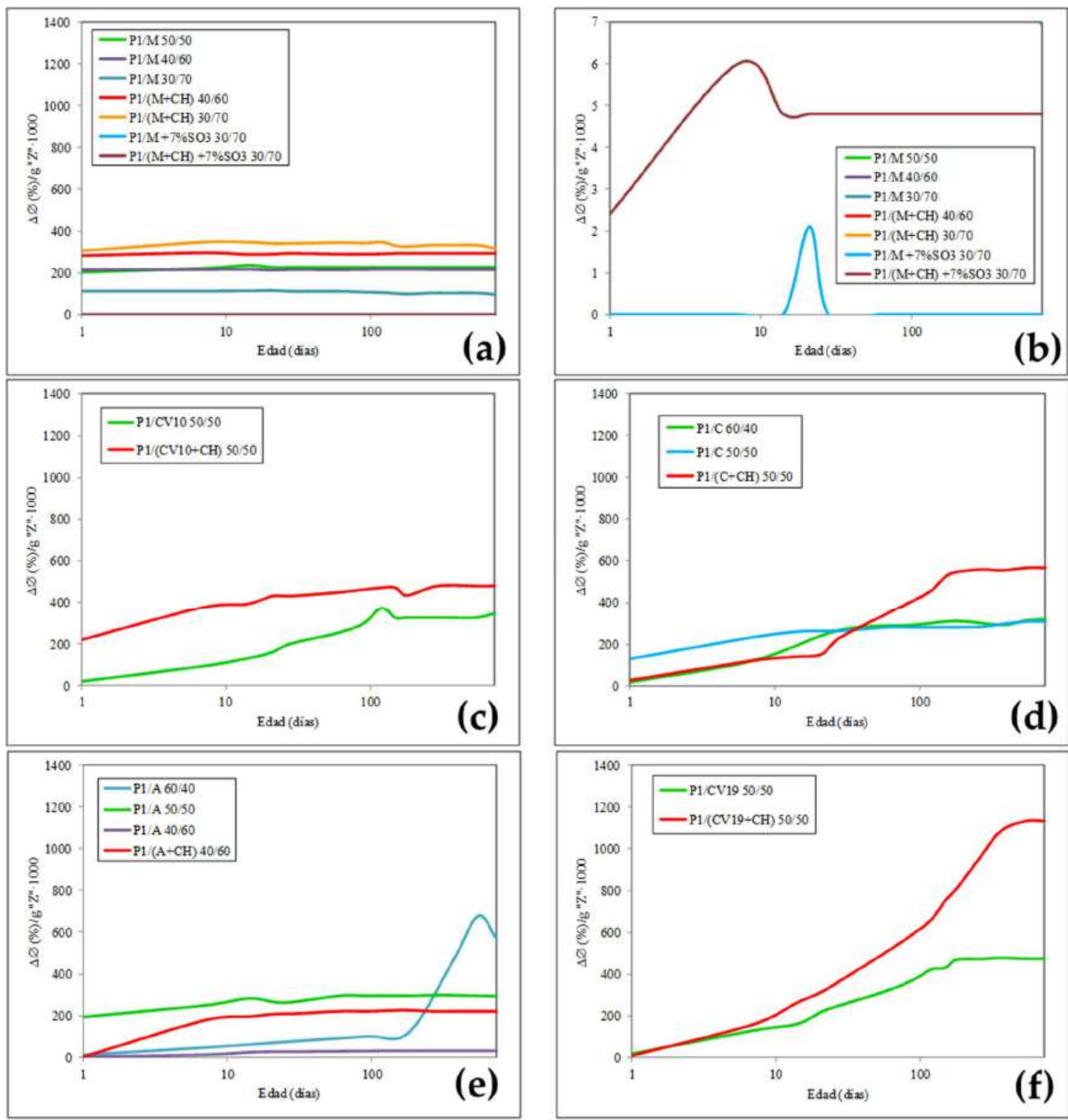

FIGURA 8-11.- RESULTADOS OBTENIDOS DE $\triangle \varnothing / g$ "Z" EN EL ENSAYO LE CHATELIER ANSTETT PARA TODOS LOS CEMENTOS DE MEZCLA PREPARADOS CON CP P1 Y TODAS LAS PUZOLANAS UTILIZADAS EN ESTA INVESTIGACIÓN.

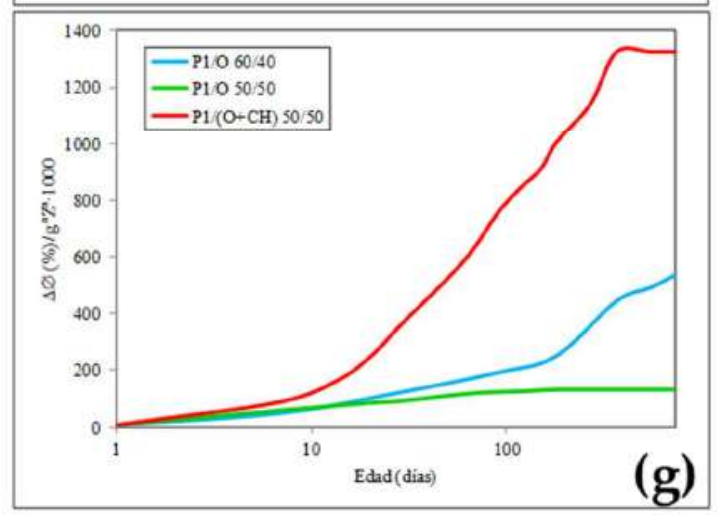



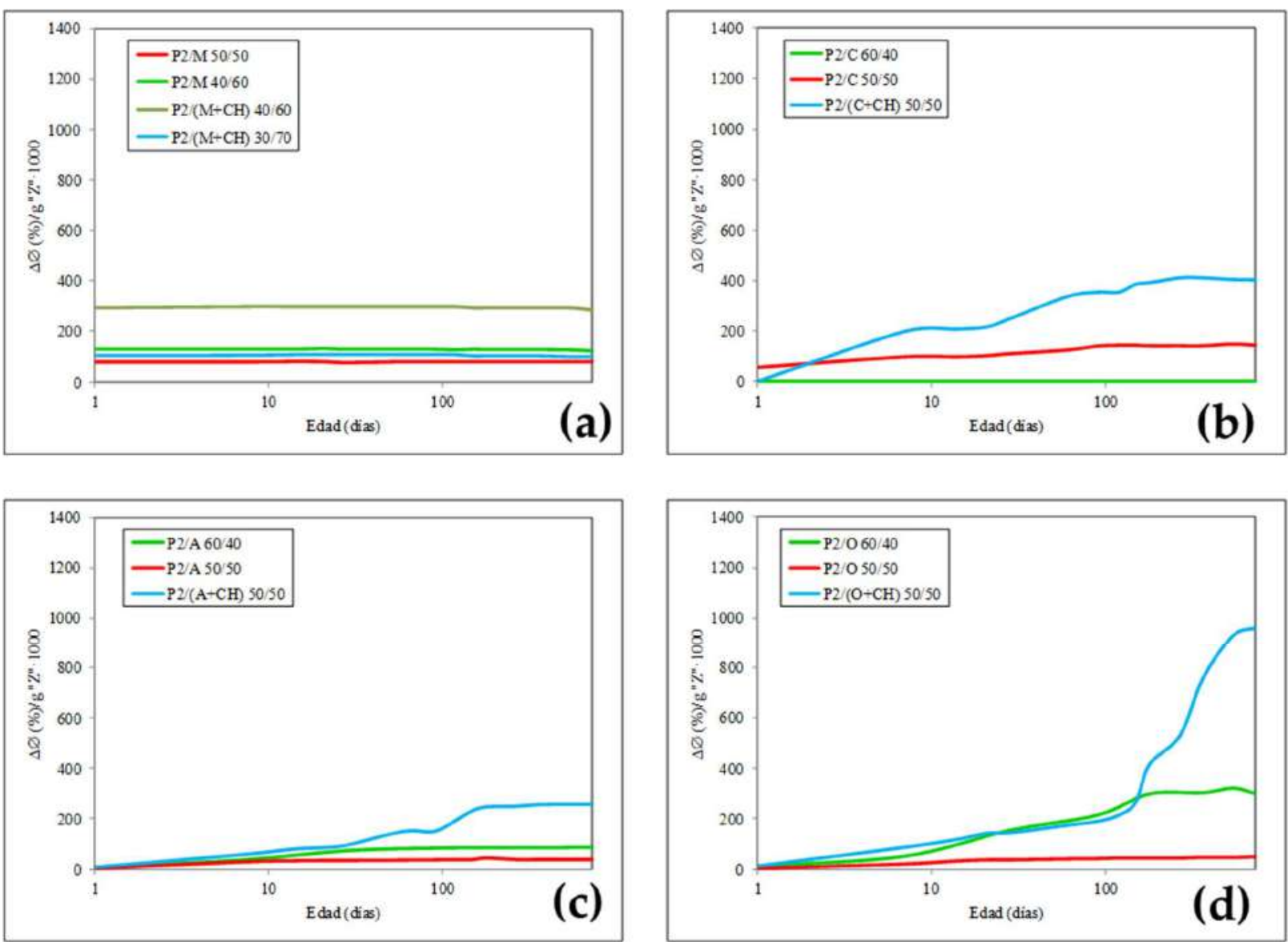

FIGURA 8-12.- RESULTADOS OBTENIDOS DE $\triangle \varnothing / \mathrm{g}$ "Z" EN EL ENSAYO LE CHATELIER ANSTETT PARA TODOS LOS CEMENTOS DE MEZCLA PREPARADOS CON CP P2 Y TODAS LAS PUZOLANAS UTILIZADAS EN ESTA INVESTIGACIÓN

Según lo anterior, como de las dos puzolanas que quedaban por analizar y estudiar, la $\mathrm{C}$ y A en esta ocasión, habían mostrado unas curvas discontinuas ( $\sin \mathrm{CH}$ ) o continuas (con $\mathrm{CH}$ ), diferentes entre si, pero de modo y manera que las de la puzolana $\mathrm{C}$ se asemejaban bastante más a las de la $\mathrm{M}$ que las de la A (que más bien quizás no se asemejaban en nada en especial cuando el $\mathrm{CH}$ estuvo presente, o en todo caso, se asemejaban bastante menos), correspondía a la primera o puzolana $\mathrm{C}$, poseer una fracción "alumínica" mayor y a la puzolana A la menor. Y ambas bastante menores a su vez a la de la puzolana $\mathrm{M}$.

De aquí que mientras a la puzolana $\mathrm{C}$ se le había podido adjudicar el carácter "alumínicosilícico" mediante el parámetro $\Delta \varnothing$, a la puzolana A se le había podido adjudicar el carácter contrario, o sea, "silícico-alumínico". Véase la discusión e interpretación anterior 8.1.3.1.1.1. 
COMPORTAMIENTO SULFÁTICO Y MECÁNICO-RESISTENTE DE CEMENTOS PORTLAND CON ELEVADOS CONTENIDOS DE PUZOLANAS (> 40\%): SU FUNDAMENTO QUÍMICO Y JUSTIFICACIÓN DE OTRAS CONSECUENCIAS POSIBLES
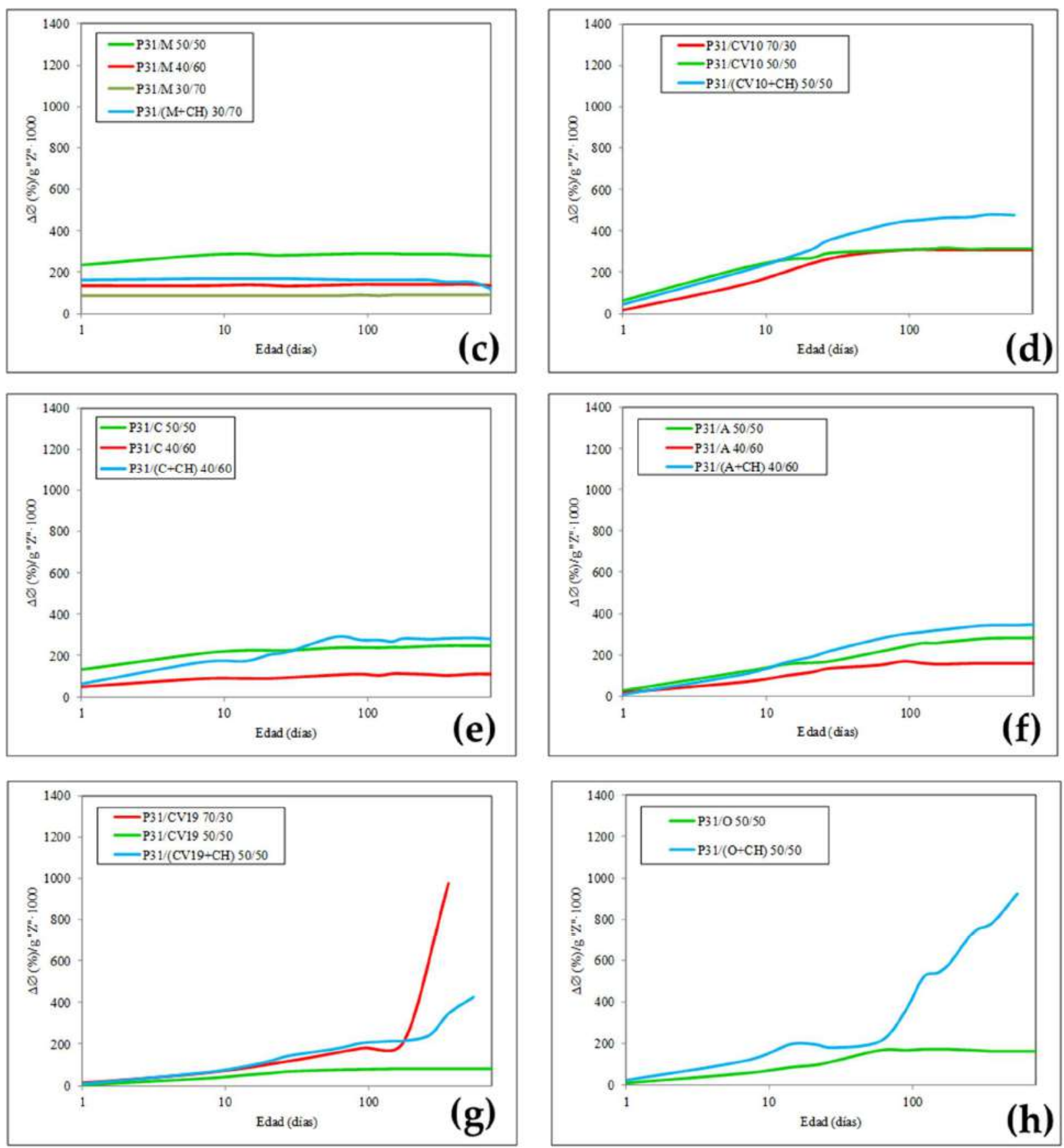

FIGURA 8-13.- RESULTADOS OBTENIDOS DE $\triangle \varnothing / g$ "Z" EN EL ENSAYO LE CHATELIER ANSTETT PARA TODOS LOS CEMENTOS DE MEZCLA PREPARADOS CON CP P31 Y TODAS LAS PUZOLANAS UTILIZADAS EN ESTA INVESTIGACIÓN 

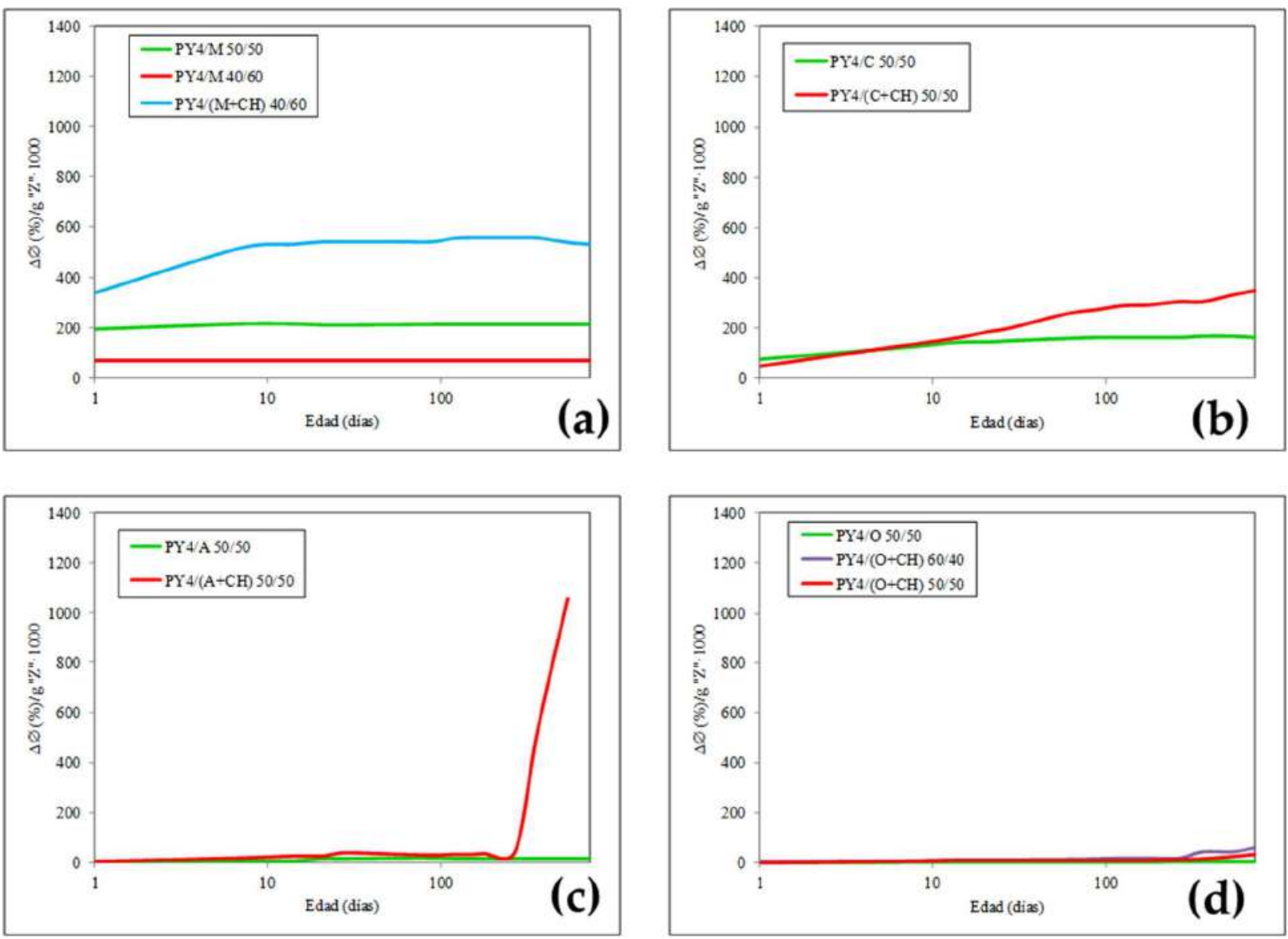

FIGURA 8-14.- RESULTADOS OBTENIDOS DE $\triangle \varnothing / \mathrm{g}$ "Z" EN EL ENSAYO LE CHATELIER ANSTETT PARA TODOS LOS CEMENTOS DE MEZCLA PREPARADOS CON CP PY4 Y TODAS LAS PUZOLANAS UTILIZADAS EN ESTA INVESTIGACIÓN

8.1.2.3.2.4-Discusión e Interpretación de las Familias de CM P-n ${ }^{o}$ y $\mathrm{PY}-n^{\circ} /(\mathrm{M}+\mathrm{CH})+7.0 \% \mathrm{SO}_{3}$ $30 / 70$

Vale aquí íntegramente todo lo dicho en relación con este parámetro VCø, de los correspondientes CM "hermanos mayores" 40/60, en el sub-apartado anterior 8.1.3.1.2.3.

\subsection{5-Discusión e Interpretación de las Familias de CM PY-6/(M+CH)+7.0\% $\mathrm{SO}_{3} 20 / 80$}

Vale aquí íntegramente todo lo dicho en relación con este parámetro VCø, de los correspondientes $\mathrm{CM}$, en el sub-apartado anterior 8.1.3.1.2.4. 
COMPORTAMIENTO SULFÁTICO Y MECÁNICO-RESISTENTE DE CEMENTOS PORTLAND CON ELEVADOS CONTENIDOS DE PUZOLANAS (> 40\%): SU FUNDAMENTO QUÍMICO Y JUSTIFICACIÓN DE OTRAS CONSECUENCIAS POSIBLES
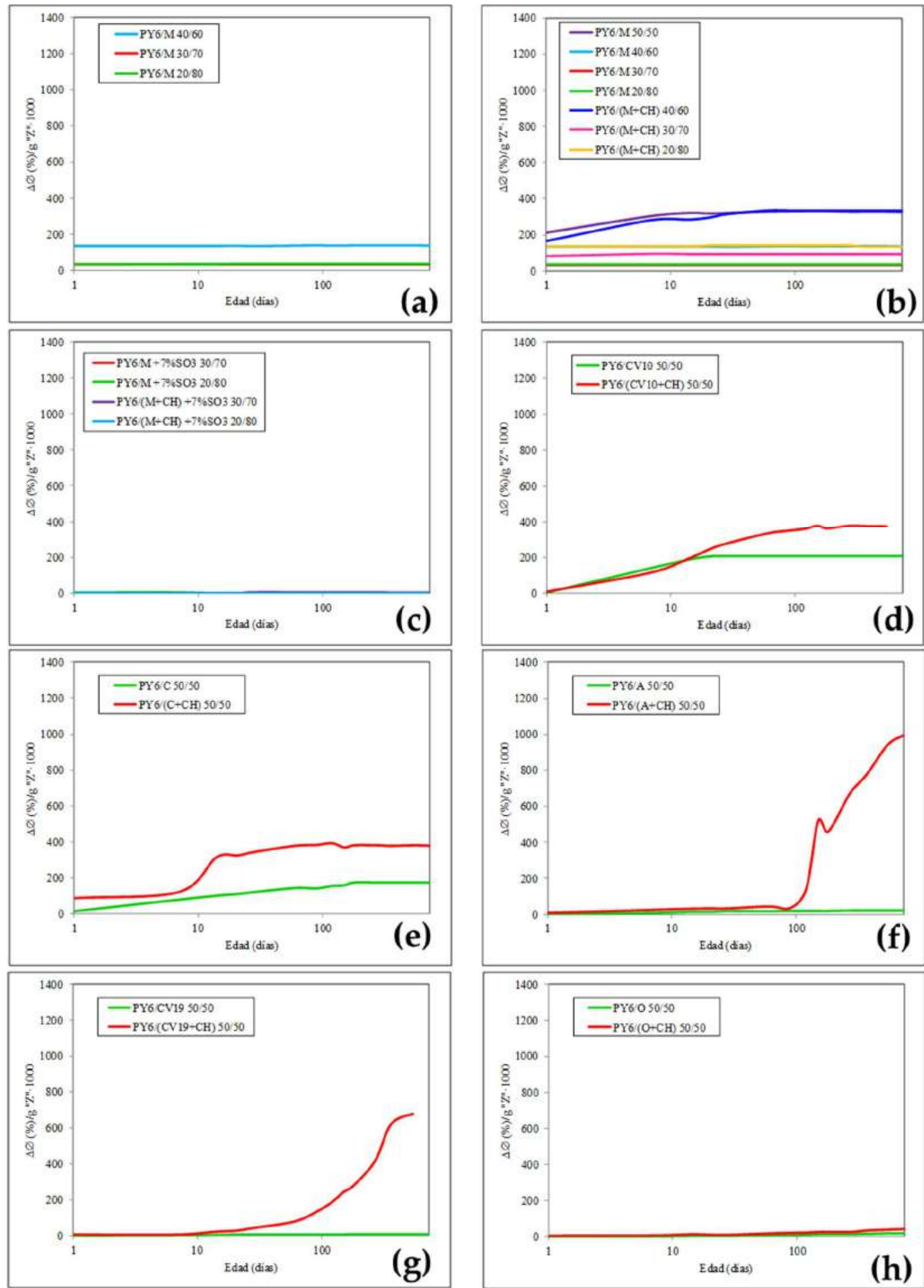

FIGURA 8-15.- RESULTADOS OBTENIDOS DE $\triangle \varnothing / g$ "Z" EN EL ENSAYO LE CHATELIER ANSTETT PARA TODOS LOS CEMENTOS DE MEZCLA PREPARADOS CON CP PY6 Y TODAS LAS PUZOLANAS UTILIZADAS EN ESTA INVESTIGACIÓN 
8.1.2.4-A igualdad de cemento Portland y cantidad de adición adición puzolánica. Parámetros $\Delta \emptyset, V C \varnothing, \Delta \emptyset / g$ "Z" y P.A.V.

\subsubsection{1-Sin cal apagada ni yeso}

8.1.2.4.1.1-Discusión e Interpretación de las Familias $P-n^{o}$ y $P Y-n^{o} /{ }^{\prime \prime} Z^{\prime \prime} 50 / 50$

TABLA 8-22.- CLASIFICACIÓN DE LAS DICTINTAS PUZOLANAS A IGUALDAD DE CEMENTO PORTLAND DE REFERENCIA EN EL ENSAYO L-A DE LOS CEMENTOS P1/"Z" 50/50.

\begin{tabular}{|c|c|c|c|}
\hline Parámetros & $\begin{array}{c}\text { Cementos } \\
\text { mixtos }\end{array}$ & Edad (días) & Clasificaciones obtenidas de las AP ensayadas \\
\hline$\Delta \varnothing<\mathrm{Vc} \varnothing<\Delta \varnothing / \mathrm{g} " \mathrm{Z} "$ & & $\begin{array}{c}1 \\
7 \\
28 \\
90,180 \\
365 \\
545,730\end{array}$ & $\begin{array}{l}\mathrm{O}<\mathrm{CV} 19<\mathrm{CV} 10^{*}<\mathrm{C}<\mathrm{A}<\mathrm{M} \\
\mathrm{O}<\mathrm{CV} 10<\mathrm{CV} 19<\mathrm{M}<\mathrm{C}<\mathrm{A} \\
\mathrm{O}<\mathrm{CV} 10<\mathrm{M}<\mathrm{CV} 19<\mathrm{C}<\mathrm{A} \\
\mathrm{O}<\mathrm{M}<\mathrm{C}<\mathrm{A}<\mathrm{CV} 10^{*}<\mathrm{CV} 19 \\
\mathrm{O}<\mathrm{M}<\mathrm{A}<\mathrm{C}<\mathrm{CV} 10<\mathrm{CV} 19\end{array}$ \\
\hline$<$ P.A.V. $<$ & P-1*/"Z" 50/50 & $\begin{array}{c}1 \\
7 \\
28 \\
90 \\
180 \\
365 \\
545 \\
730\end{array}$ & $\begin{array}{c}0=\mathrm{O}<\mathrm{CV} 19^{*}<\mathrm{CV} 10<\mathrm{C}<\mathrm{A}<\mathrm{M} \\
\mathrm{O}<\mathrm{M}^{*}<\mathrm{C}<\mathrm{A}<\mathrm{CV} 10<\mathrm{CV} 19 \\
\mathrm{O}<\mathrm{M}<\mathrm{C}^{*}<\mathrm{CV} 10<\mathrm{A}<\mathrm{CV} 19 \\
\mathrm{O}<\mathrm{M}<\mathrm{C}<\mathrm{A}<\mathrm{CV} 10<\mathrm{CV} 19^{*} \\
\mathrm{O}<\mathrm{M}<\mathrm{C}<\mathrm{CV} 10<\mathrm{A}<\mathrm{CV} 19^{*} \\
0=\mathrm{O}<\mathrm{M}<\mathrm{C}<\mathrm{CV} 10<\mathrm{A}<\mathrm{CV} 19^{*} \\
0=\mathrm{O}<\mathrm{M}<\mathrm{CV} 10<\mathrm{S} 4<\mathrm{C}<\mathrm{CV} 19<\mathrm{A}^{*} \\
0=\mathrm{O}<\mathrm{M}<\mathrm{CV} 10<\mathrm{C}<\mathrm{CV} 19<\mathrm{A}^{*}\end{array}$ \\
\hline
\end{tabular}

TABLA 8-23.- CLASIFICACIÓN DE LAS DICTINTAS PUZOLANAS A IGUALDAD DE CEMENTO PORTLAND DE REFERENCIA EN EL ENSAYO L-A DE LOS CEMENTOS P2/"Z" 50/50.

\begin{tabular}{|c|c|c|c|}
\hline Parámetros & $\begin{array}{c}\text { Cementos } \\
\text { mixtos }\end{array}$ & Edad (días) & Clasificaciones obtenidas de las AP ensayadas \\
\hline \multirow{7}{*}{$\Delta \varnothing<\mathrm{Vc} \varnothing<\Delta \varnothing / \mathrm{g} " \mathrm{Z} "$} & \multirow{15}{*}{$\mathrm{P}-2^{*} / " \mathrm{Z} " 50 / 50$} & 1 & \\
\hline & & 7 & $\mathrm{O}<\mathrm{A}^{*}<\mathrm{C}<\mathrm{M}$ \\
\hline & & 28 & $\mathrm{O}<\mathrm{A}^{*}<\mathrm{M}<\mathrm{C}$ \\
\hline & & 90 & $\mathrm{~A}<\mathrm{O}^{*}<\mathrm{M}<\mathrm{C}$ \\
\hline & & 180 & $\mathrm{~A}<\mathrm{O}<\mathrm{M}<\mathrm{C}^{*}$ \\
\hline & & 365545 & $\mathrm{~A}=\mathrm{O}<\mathrm{M}<\mathrm{C}^{*}$ \\
\hline & & $\begin{array}{c}365,545 \\
730\end{array}$ & $\mathrm{~A}<\mathrm{O}<\mathrm{M}<\mathrm{C}^{*}$ \\
\hline \multirow{8}{*}{$<$ P.A.V. $<$} & & 1 & \\
\hline & & 7 & * \\
\hline & & 28 & * \\
\hline & & 90 & * \\
\hline & & 180 & * \\
\hline & & 365 & $0=\mathrm{O}=\mathrm{A}=\mathrm{M}<\mathrm{C}^{*}$ \\
\hline & & 545 & $0=U=A=M<C$ \\
\hline & & 730 & \\
\hline
\end{tabular}

Sea cual fuere el CP que se considere, por lo general se ha verificado que los valores obtenidos de tales parámetros determinados en su probeta L-A y los correspondientes a la probeta L-A de cada CM preparado con el mismo y la puzolana "Z" = O, CV19, A, C, CV10 y M, 
respectivamente, aumentaron del siguiente modo a las edades fundamentales del ensayo según era el "carácter" de dicha puzolana "Z", véanse las Tablas 8-22, 8-23, 8-24 y 8-25.

No obstante y en casi todos los casos, excepto en el del CM PY-6/M 50/50, todas las probetas L-A de los cementos mixtos P-no/"Z" 50/50 han mostrado por lo general unos valores de $\triangle \varnothing$, VCØ, y $\Delta \varnothing / g$ "Z" que han resultado ser mayores o muchísimo mayores incluso, que los correspondientes a las probetas L-A de los cementos mixtos homónimos PY-no/"Z" 50/50.

TABLA 8-24.- CLASIFICACIÓN DE LAS DICTINTAS PUZOLANAS A IGUALDAD DE CEMENTO PORTLAND DE REFERENCIA EN EL ENSAYO L-A DE LOS CEMENTOS P31/"Z" 50/50.

\begin{tabular}{|c|c|c|c|}
\hline Parámetros & $\begin{array}{c}\text { Cementos } \\
\text { mixtos }\end{array}$ & Edad (días) & Clasificaciones obtenidas de las AP ensayadas \\
\hline \multirow{7}{*}{$\Delta \varnothing<\mathrm{Vc} \varnothing<\Delta \varnothing / \mathrm{g} " \mathrm{Z} "$} & & 1 & CV19 $<\mathrm{O}^{*}<\mathrm{A}<\mathrm{CV} 10<\mathrm{C}<\mathrm{M}$ \\
\hline & & 7 & $\mathrm{CV} 19<\mathrm{O}^{*}<\mathrm{A}<\mathrm{C}<\mathrm{CV} 10<\mathrm{M}$ \\
\hline & & 28 & $\mathrm{CV}_{19} *<\mathrm{O}<\mathrm{A}<\mathrm{C}<\mathrm{CV} 10<\mathrm{M}$ \\
\hline & & 180 & $\mathrm{CV}_{19} * \mathrm{O}<\mathrm{A}<\mathrm{C}<\mathrm{M}<\mathrm{CV} 10$ \\
\hline & & 365 & $\mathrm{CV} 19<\mathrm{O}<{ }^{*} \mathrm{C}<\mathrm{A}<\mathrm{M}<\mathrm{CV} 10$ \\
\hline & & 545 & CV19 $<$ O $<$ C $<$ A $<$ M $<$ CV10* \\
\hline & & 730 & $\mathrm{CV} 19<\mathrm{O}<\mathrm{C}<\mathrm{A}=\mathrm{M}<\mathrm{CV} 10^{*}$ \\
\hline \multirow{8}{*}{$<$ P.A.V. $<$} & $\mathrm{P}-31^{*} / " \mathrm{Z} " 50 / 50$ & 1 & $0=\mathrm{O}=\mathrm{A}^{*}<\mathrm{CV} 19<\mathrm{CV} 10<\mathrm{M}$ \\
\hline & & 7 & $0=\mathrm{CV} 19=\mathrm{A}<\mathrm{O}^{*}<\mathrm{M}<\mathrm{CV} 10$ \\
\hline & & 28 & $0=\mathrm{CV} 19<\mathrm{O}<\mathrm{A}<\mathrm{C}<\mathrm{M}<\mathrm{CV} 10^{*}$ \\
\hline & & 90 & $0=\mathrm{O}=\mathrm{CV} 19=\mathrm{C}<\mathrm{A}<\mathrm{M}<\mathrm{CV} 10^{*}$ \\
\hline & & 180 & $0=\mathrm{O}=\mathrm{CV} 19<\mathrm{A}<\mathrm{C}<\mathrm{M}<\mathrm{CV} 10^{*}$ \\
\hline & & 365 & $0=\mathrm{O}<\mathrm{CV} 19<\mathrm{A}<\mathrm{C}<\mathrm{M}<\mathrm{CV} 10^{*}$ \\
\hline & & 545 & $0=\mathrm{O}=\mathrm{CV} 19<\mathrm{A}<\mathrm{M}<\mathrm{CV} 10<\mathrm{C}^{*}$ \\
\hline & & 730 & $0=\mathrm{O}=\mathrm{CV} 19=\mathrm{A}<\mathrm{M}<\mathrm{C}<\mathrm{CV} 10^{*}$ \\
\hline
\end{tabular}

TABLA 8-25.- CLASIFICACIÓN DE LAS DICTINTAS PUZOLANAS A IGUALDAD DE CEMENTO PORTLAND DE REFERENCIA EN EL ENSAYO L-A DE LOS CEMENTOS PY4/"Z" 50/50.

\begin{tabular}{|c|c|c|c|}
\hline Parámetro & $\begin{array}{c}\text { Cementos } \\
\text { mixtos }\end{array}$ & Edad (días) & Clasificaciones obtenidas de las AP ensayadas \\
\hline \multirow{5}{*}{$\Delta \varnothing<\mathrm{Vc} \varnothing<\Delta \varnothing / \mathrm{g} " \mathrm{Z} "$} & \multirow{12}{*}{ PY-4*/"Z" 50/50 } & 1,7 & \multirow{2}{*}{$0=\mathrm{O}^{*}<\mathrm{A}<\mathrm{C}<\mathrm{M}$} \\
\hline & & 28,90 & \\
\hline & & 180 & * \\
\hline & & 365,545 & $\mathrm{O}<\mathrm{A}<\mathrm{C}<\mathrm{M}$ \\
\hline & & 730 & \\
\hline \multirow{7}{*}{$<$ P.A.V. $<$} & & 1 & $0=\mathrm{O}^{*}=\mathrm{A}<\mathrm{M}<\mathrm{C}$ \\
\hline & & 7 & $0=\mathrm{O}^{*}=\mathrm{A}<\mathrm{M}<<<\mathrm{C}$ \\
\hline & & 28 & $0=\mathrm{O}^{*}=\mathrm{A}=\mathrm{M}<\mathrm{C}$ \\
\hline & & 90 & $0=\mathrm{O}^{*}=\mathrm{A}=\mathrm{M}<\mathrm{C}$ \\
\hline & & 180,365 & $0=\mathrm{O}^{*}=\mathrm{A}=\mathrm{M}=\mathrm{C}$ \\
\hline & & 545 & * \\
\hline & & 730 & $0=\mathrm{O}=\mathrm{A}=\mathrm{M}<\mathrm{C}^{*}$ \\
\hline
\end{tabular}

La causa por la que la CV19 en la Figura 8-22 acabó totalmente por situarse a la derecha de la clasificación, mientras en la Figura 8-24 le ocurrió lo contrario, fue debido al ESE entre los $\mathrm{Fe}(\mathrm{OH})_{3}$ y la ett-lf que con el P-1 se debió de formar en gran cantidad porque poseía un mayor contenido de $\mathrm{C}_{3} \mathrm{~A}, 14.11 \%$, en cambio con el $\mathrm{P}-31$ no, porque su contenido de $\mathrm{C}_{3} \mathrm{~A}$ era menor, $7.63 \%$. 


\subsection{2-Discusión e Interpretación de las Familias $P-n^{o}$ y $P Y-n^{o} /{ }^{\prime \prime} Z^{\prime \prime} 40 / 60$.}

Sea cual fuere el CP que se considerase, por lo general se ha verificado que el $\triangle \varnothing, \mathrm{VC} \varnothing$, $\triangle \varnothing / g$ "Z" y P.A.V. de su probeta L-A y los correspondientes a las probetas L-A de cada CM preparado con el mismo y la puzolana "Z" = A, C y M, respectivamente, aumentaron del siguiente modo a las edades fundamentales del ensayo según era el "carácter" de dicha puzolana "Z", véanse las Tablas 8-26, 8-27 y 8-28.

TABLA 8-26.- CLASIFICACIÓN DE LAS DICTINTAS PUZOLANAS A IGUALDAD DE CEMENTO PORTLAND DE REFERENCIA EN EL ENSAYO L-A DE LOS CEMENTOS PY6/"Z" 50/50.

\begin{tabular}{|c|c|c|c|}
\hline Parámetro & $\begin{array}{c}\text { Cementos } \\
\text { mixtos }\end{array}$ & Edad (días) & Clasificaciones obtenidas de las AP ensayadas \\
\hline \multirow{8}{*}{$\begin{array}{c}\Delta \varnothing<\mathrm{Vc} \varnothing<\Delta \varnothing / \mathrm{g} \\
\text { "Z" }\end{array}$} & \multirow{13}{*}{ PY-6*/"Z" 50/50 } & 1 & $0=\mathrm{CV} 19<\mathrm{O}=\mathrm{A}<\mathrm{CV} 10^{*}<\mathrm{C}<\mathrm{M}$ \\
\hline & & 7 & ${ }^{*} \mathrm{CV} 19=\mathrm{O}<\mathrm{A}<\mathrm{C}<\mathrm{CV} 10<\mathrm{M}$ \\
\hline & & 28 & ${ }^{*} \mathrm{O}<\mathrm{CV} 19<\mathrm{A}<\mathrm{C}<\mathrm{CV} 10<\mathrm{M}$ \\
\hline & & 90 & ${ }^{*} \mathrm{CV} 19<\mathrm{O}<\mathrm{A}<\mathrm{C}<\mathrm{CV} 10<\mathrm{M}$ \\
\hline & & 180 & ${ }^{*} \mathrm{CV} 19<\mathrm{O}<\mathrm{A}<\mathrm{C}<\mathrm{CV} 10<\mathrm{M}$ \\
\hline & & 365 & $\mathrm{CV} 19<\mathrm{O}<\mathrm{A}<\mathrm{C}^{*}<\mathrm{CV} 10<\mathrm{M}^{*}$ \\
\hline & & 545 & $\mathrm{CV} 19<\mathrm{O}=\mathrm{A}<\mathrm{C}<\mathrm{CV} 10<\mathrm{M}^{*}$ \\
\hline & & 730 & $\mathrm{CV} 19<\mathrm{O}=\mathrm{A}<\mathrm{C}<\mathrm{CV} 10<\mathrm{M}^{*}$ \\
\hline \multirow{5}{*}{$<$ P.A.V. $<$} & & 1 & $0=\mathrm{O}^{*}=\mathrm{CV} 19=\mathrm{A}=\mathrm{CV} 10<\mathrm{C}<\mathrm{M}$ \\
\hline & & 7 & $0=\mathrm{O}^{*}=\mathrm{CV} 19=\mathrm{A}<\mathrm{C}<\mathrm{CV} 10<\mathrm{M}$ \\
\hline & & $\begin{array}{c}28 \\
90180\end{array}$ & $0=\mathrm{O}^{*}=\mathrm{CV} 19=\mathrm{A}<\mathrm{CV} 10<\mathrm{C}<\mathrm{M}$ \\
\hline & & 90,180 & $0=\mathrm{O}^{*}=\mathrm{CV} 19=\mathrm{A}=\mathrm{CV} 10<\mathrm{C}<\mathrm{M}$ \\
\hline & & $\begin{array}{c}365,545 \\
730\end{array}$ & $0=\mathrm{CV} 19==\mathrm{A}=\mathrm{CV} 10<\mathrm{C}<\mathrm{M}^{*}$ \\
\hline
\end{tabular}

TABLA 8-27.- CLASIFICACIÓN DE LAS DICTINTAS PUZOLANAS A IGUALDAD DE CEMENTO PORTLAND DE REFERENCIA EN EL ENSAYO L-A DE LOS CEMENTOS P1/"Z" 40/60.

\begin{tabular}{|c|c|c|c|}
\hline Parámetro & $\begin{array}{l}\text { Cementos } \\
\text { mixtos }\end{array}$ & Edad (días) & Clasificaciones obtenidas de las AP ensayadas \\
\hline \multirow{4}{*}{$\Delta \varnothing<\mathrm{Vc} \varnothing<\Delta \varnothing / \mathrm{g} \mathrm{"Z"}$} & \multirow{10}{*}{$P-1 * / " Z " 40 / 60$} & 1,7 & \multirow{2}{*}{$\mathrm{A}<\mathrm{M}$} \\
\hline & & 28,90 & \\
\hline & & 180,365 & \multirow{2}{*}{$\mathrm{A}<\mathrm{M}$} \\
\hline & & 545,730 & \\
\hline \multirow{6}{*}{$<$ P.A.V. $<$} & & 1 & \\
\hline & & 7 & $0=\mathrm{A}<\mathrm{M}$ \\
\hline & & 28 & $0=\mathrm{A}$ \\
\hline & & 90,180 & $0=\mathrm{A}^{*}<\mathrm{M}=\mathrm{PT}$ \\
\hline & & 365,545 & $0=\mathrm{A}=\mathrm{M}$ \\
\hline & & 730 & \\
\hline
\end{tabular}


COMPORTAMIENTO SULFÁTICO Y MECÁNICO-RESISTENTE DE CEMENTOS PORTLAND CON ELEVADOS CONTENIDOS DE PUZOLANAS ( $>40 \%$ ): SU FUNDAMENTO QUÍMICO Y JUSTIFICACIÓN DE OTRAS CONSECUENCIAS POSIBLES

TABLA 8-28.- CLASIFICACIÓN DE LAS DICTINTAS PUZOLANAS A IGUALDAD DE CEMENTO PORTLAND DE REFERENCIA EN EL ENSAYO L-A DE LOS CEMENTOS P31/"Z" 40/60.

\begin{tabular}{|c|c|c|c|}
\hline Parámetro & $\begin{array}{c}\text { Cementos } \\
\text { mixtos }\end{array}$ & Edad (días) & Clasificaciones obtenidas de las AA ensayadas \\
\hline \multirow{6}{*}{$\Delta \varnothing<\mathrm{V} c \varnothing<\Delta \varnothing / \mathrm{g} " \mathrm{Z} "$} & \multirow{12}{*}{ P-31*/"Z" 40/60 } & 1 & \\
\hline & & 7 & ${ }^{*} \mathrm{~A}<\mathrm{C}<\mathrm{M}$ \\
\hline & & 28 & ${ }^{*} \mathrm{~A}<\mathrm{C}<\mathrm{M}$ \\
\hline & & 90 & ${ }^{*} \mathrm{C}<\mathrm{M}<\mathrm{A}$ \\
\hline & & 365,545 & $\mathrm{C}^{*}<\mathrm{M}<\mathrm{A}$ \\
\hline & & 730 & $\mathrm{C}<\mathrm{M}<\mathrm{A}^{*}$ \\
\hline \multirow{6}{*}{$<$ P.A.V. $<$} & & 1 & \\
\hline & & 7 & $\begin{array}{l}0={ }^{*} \mathrm{~A}<\mathrm{M}<\mathrm{C} \\
0=\mathrm{A}\end{array}$ \\
\hline & & 28 & $\begin{array}{c}U=A<M^{*}<C \\
M<A^{*}<C\end{array}$ \\
\hline & & 90 & $\begin{array}{l}0=A<M<C \\
M=A^{n}<C\end{array}$ \\
\hline & & 180,365 & $0=\mathrm{A}<\mathrm{M}<\mathrm{C}$ \\
\hline & & 545,730 & $0=A=M=C$ \\
\hline
\end{tabular}

\subsection{3-Discusión e Interpretación de las Familias $P-n^{o}$ y $P Y-n^{o} / " Z " 30 / 70$.}

Sea cual fuere el CP que se considerase, por lo general se ha verificado que el $\Delta \varnothing, \mathrm{VC} \varnothing$, $\triangle \varnothing / g$ "Z" y P.A.V de su probeta L-A y los correspondientes a la de su CM preparado con el mismo y la puzolana "Z" = M, aumentaron del siguiente modo, véase Tabla 8-29.

TABLA 8-29.- CLASIFICACIÓN DE LOS DISTINTOS CEMENTOS A IGUALDAD DE PUZOLANA M DE REFERENCIA EN EL ENSAYO L-A DE LOS CEMENTOS P-№ Y PY-№/"M".

\begin{tabular}{|c|c|c|c|}
\hline Parámetros & Cementos mixtos & Edad (días) & Clasificaciones obtenidas de los CPM \\
\hline \multirow{8}{*}{$\begin{array}{c}\Delta \varnothing<\mathrm{Vc} \varnothing<\Delta \varnothing / \mathrm{g} \\
\text { "Z" }\end{array}$} & \multirow{14}{*}{ P-n $/ \mathrm{M} 30 / 70$} & 1 & $\mathrm{P}-31<\mathrm{P}-2<\mathrm{P}-2 / \mathrm{M}<\mathrm{P}-1<\mathrm{P}-31 / \mathrm{M}<\mathrm{P}-1 / \mathrm{M}$ \\
\hline & & 7 & $\mathrm{P}-2 / \mathrm{M}<\mathrm{P}-2<\mathrm{P}-31<\mathrm{P}-1<\mathrm{P}-31 / \mathrm{M}<\mathrm{P}-1 / \mathrm{M}$ \\
\hline & & 28 & $\mathrm{P}-1 / \mathrm{M}<\mathrm{P}-1<\mathrm{P}-2 / \mathrm{M}<<<\mathrm{P}-2 ; \mathrm{P}-31<<\mathrm{P}-31 / \mathrm{M}$ \\
\hline & & 90 & $\mathrm{P}-2 / \mathrm{M}<\mathrm{P}-31 / \mathrm{M}<\mathrm{P}-31<\mathrm{P}-1 / \mathrm{M}<\mathrm{P}-2<\mathrm{P}-1$ \\
\hline & & 180 & $\mathrm{P}-2 / \mathrm{M}<\mathrm{P}-31 / \mathrm{M}<\mathrm{P}-1<\mathrm{P}-31<\mathrm{P}-2<\mathrm{P}-1$ \\
\hline & & 365,545 & $\mathrm{P}-2 / \mathrm{M}<\mathrm{P}-31 / \mathrm{M}<\mathrm{P}-1 / \mathrm{M}<\mathrm{P}-31<\mathrm{P}-1<\mathrm{P}-2$ \\
\hline & & 730 & $\mathrm{P}-2 / \mathrm{M}<\mathrm{P}-31 / \mathrm{M}<\mathrm{P}-1 / \mathrm{M}<\mathrm{P}-31<\mathrm{P}-2<\mathrm{P}-1$ \\
\hline & & 1 & $\mathrm{P}-31<\mathrm{P}-2<\mathrm{P}-1<\mathrm{P}-2 / \mathrm{M}<\mathrm{P}-31 / \mathrm{M}<\mathrm{P}-1 / \mathrm{M}$ \\
\hline \multirow{5}{*}{ < P.A.V. < (mm) } & & 7 & $\mathrm{P}-31 / \mathrm{M}=\mathrm{P}-2 / \mathrm{M}<\mathrm{P}-31<\mathrm{P}-1 / \mathrm{M}<\mathrm{P}-2<\mathrm{P}-1$ \\
\hline & & 28 & $\mathrm{P}-31 / \mathrm{M}=\mathrm{P}-2 / \mathrm{M}<\mathrm{P}-1 / \mathrm{M}<\mathrm{P}-31<\mathrm{P}-2<\mathrm{P}-1$ \\
\hline & & 90 & $\mathrm{P}-2 / \mathrm{M}<\mathrm{P}-31 / \mathrm{M}<\mathrm{P}-31<\mathrm{P}-1 / \mathrm{M}<\mathrm{P}-2<\mathrm{P}-1$ \\
\hline & & 180 & $\mathrm{P}-2 / \mathrm{M}<\mathrm{P}-31 / \mathrm{M}<\mathrm{P}-1 / \mathrm{M}<\mathrm{P}-31<\mathrm{P}-2<\mathrm{P}-1$ \\
\hline & & 365,545 & $\mathrm{P}-1 / \mathrm{M}<\mathrm{P}-31 / \mathrm{M}<\mathrm{P}-1 / \mathrm{M}<\mathrm{P}-31<\mathrm{P}-1<\mathrm{P}-2$ \\
\hline \multirow{6}{*}{$\begin{array}{c}\Delta \varnothing<\mathrm{Vc} \varnothing<\Delta \varnothing / \mathrm{g} \\
\text { "Z" }\end{array}$} & & 730 & $\mathrm{P}-2 / \mathrm{M}<\mathrm{P}-31 / \mathrm{M}<\mathrm{P}-1 / \mathrm{M}<\mathrm{P}-31<\mathrm{P}-2<\mathrm{P}-1$ \\
\hline & \multirow{9}{*}{ PY-6/M 30/70 } & 1,7 & PY-6 < PY-6/M \\
\hline & & 28,90 & $\begin{array}{l}\text { PY-6 }=P Y-6 / M \\
1 Y-6<1 / M-0 / M\end{array}$ \\
\hline & & 180 & 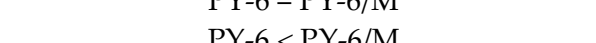 \\
\hline & & 365 & $\begin{array}{l}\text { PY- } 6<P Y-6 / M 1 \\
\text { PY-6/M } 1 \text { PY-6 }\end{array}$ \\
\hline & & 545,730 & PY-6/M $<$ PY-6 \\
\hline \multirow{4}{*}{ < P.A.V. < (mm) } & & 1,7 & \\
\hline & & 28,90 & PY-6 = PY $-6 / \mathrm{M}$ \\
\hline & & 180,365 & PY-6/M $<<<$ PY-6 \\
\hline & & 545,730 & \\
\hline
\end{tabular}




\subsection{4-Discusión e Interpretación de las Familia PY-6/M 20/80.}

Por lo general se ha verificado que el $\triangle \varnothing, \mathrm{VC}, \triangle \varnothing / \mathrm{g}$ "Z" y P.A.V de la probeta L-A del CP PY-6 y los correspondientes a la de su CM preparado con el mismo y la puzolana "Z" = M, aumentaron del siguiente modo a las edades fundamentales del ensayo, véase la Tabla 8-30.

TABLA 8-30.- CLASIFICACIÓN DE LOS DisTiNTOS CEMENTOS A IGUALDAD DE PUZOLANA M DE REFERENCIA EN EL ENSAYO L-A DE LOS CEMENTOS PY6/"M".

\begin{tabular}{cccc}
\hline Parámetros & Cemento mixto & Edad (días) & Clasificaciones obtenidas de los CPM \\
\hline$\Delta \varnothing$ & & 1,7 & \\
Vc $\varnothing$ & & 28,90 & PY-6 $<$ PY-6/M \\
$<\Delta \varnothing /$ g "Z" $<$ & PY-6/M 20/80 & 180 & \\
P.A.V. & & 365,545 & PY-6/M $<$ PY-6 \\
\hline
\end{tabular}

\subsubsection{2-Con cal apagada ni yeso}

\subsection{1-Discusión e Interpretación de las Familias $P-n^{o}$ y $P Y-n^{o} /\left(" Z^{\prime \prime}+C H\right) \quad 50 / 50$ $\left({ }^{\prime \prime} \mathrm{Z}^{\prime \prime} / \mathrm{CH}\right)=4$}

Sea cual fuese el CP que se considere, por lo general se ha verificado que el $\Delta \varnothing, \mathrm{VC},, \Delta \varnothing / \mathrm{g}$ "Z" y P.A.V. de su probeta L-A y los correspondientes a las de cada CM preparado con el mismo, cal apagada $=$ CH, y la puzolana "Z" = O, CV19, A, C, CV10 y M, respectivamente, (habiendo sido la relación "Z"/CH =4), aumentaron del siguiente modo a las edades fundamentales del ensayo según era el "carácter" de dicha puzolana "Z".Véanse las Tablas 8-31, 8-32, 8-33, 8-34, 8-35.

TABLA 8-31.- CLASIFICACIÓN DE LAS DISTINTAS PUZOLANAS A IGUALDAD DE CEMENTO PORTLAND DE REFERENCIA EN EL ENSAYO L-A DE LOS CEMENTOS P1/("Z"+CH) 50/50

\begin{tabular}{|c|c|c|c|}
\hline Parámetro & $\begin{array}{c}\text { Cementos } \\
\text { mixtos }+\mathrm{CH}\end{array}$ & Edad (días) & Clasificaciones obtenidas de las AP ensayadas \\
\hline$\Delta \varnothing<\mathrm{Vc} \varnothing<\Delta \varnothing / \mathrm{g} " \mathrm{Z} "$ & 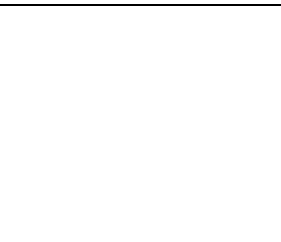 & $\begin{array}{c}1 \\
7 \\
28 \\
90 \\
180,365 \\
545,730\end{array}$ & $\begin{array}{l}\mathrm{A}<\mathrm{O}=\mathrm{CV} 19<\mathrm{C}^{*}<\mathrm{CV} 10 \\
\mathrm{O}<{ }^{*} \mathrm{C}<\mathrm{CV} 19<\mathrm{A}<\mathrm{CV} 10 \\
\mathrm{C}<\mathrm{A}<\mathrm{O}<\mathrm{CV} 19<\mathrm{CV} 10 \\
\mathrm{~A}^{*}<\mathrm{C}<\mathrm{CV} 10<\mathrm{CV} 19<\mathrm{O} \\
\mathrm{A}<\mathrm{CV} 10<\mathrm{C}^{*}<\mathrm{CV} 19<\mathrm{O}\end{array}$ \\
\hline$<$ P.A.V. $<$ & $\mathrm{P}-1^{*} /(" \mathrm{Z} "+\mathrm{CH}) 50 / 50$ & $\begin{array}{c}1 \\
7 \\
28 \\
90 \\
180 \\
365 \\
545 \\
730\end{array}$ & $\begin{array}{c}0=\mathrm{O}=\mathrm{CV} 19<\mathrm{A}^{*}<\mathrm{C}<\mathrm{CV} 10 \\
\mathrm{~A}^{*}<<\mathrm{CV} 19<<\mathrm{C}=\mathrm{CV} 10=\mathrm{PT} \\
\mathrm{A}^{*}<<\mathrm{O}<\mathrm{CV} 10<\mathrm{CV} 19=\mathrm{C}=\mathrm{PT} \\
\mathrm{A}<<\mathrm{O}<<\mathrm{CV} 10<\mathrm{CV} 19=\mathrm{C}=\mathrm{PT} \\
\mathrm{A}<<\mathrm{CV} 10<\mathrm{C}<\mathrm{O}<\mathrm{CV} 19^{*}=\mathrm{PT} \\
\mathrm{A}<\mathrm{CV} 10<\mathrm{CV} 19<\mathrm{O}^{*}=\mathrm{PT} \\
\mathrm{A}<\mathrm{CV} 10<\mathrm{CV} 19<\mathrm{O}^{*}=\mathrm{PT} \\
\mathrm{A}<\mathrm{CV} 10<\mathrm{CV} 19<\mathrm{C}<\mathrm{O}^{*}=\mathrm{PT}\end{array}$ \\
\hline
\end{tabular}


COMPORTAMIENTO SULFÁTICO Y MECÁNICO-RESISTENTE DE CEMENTOS PORTLAND CON ELEVADOS CONTENIDOS DE PUZOLANAS ( $>40 \%$ ): SU FUNDAMENTO QUÍMICO Y JUSTIFICACIÓN DE OTRAS CONSECUENCIAS POSIBLES

TABLA 8-32.- CLASIFICACIÓN DE LAS DISTINTAS PUZOLANAS A IGUALDAD DE CEMENTO PORTLAND DE REFERENCIA EN EL ENSAYO L-A DE LOS CEMENTOS P2/("Z"+CH) 50/50

\begin{tabular}{|c|c|c|c|}
\hline Parámetro & $\begin{array}{c}\text { Cementos } \\
\text { mixtos }+\mathrm{CH}\end{array}$ & Edad (días) & Clasificaciones obtenidas de las AA ensayadas \\
\hline \multirow{4}{*}{$\Delta \varnothing<\mathrm{Vc} \varnothing<\Delta \varnothing / \mathrm{g} " \mathrm{Z} "$} & \multirow{11}{*}{$\mathrm{P}-2^{*} /(" \mathrm{Z}+\mathrm{CH}) 50 / 50$} & 1 & $0=\mathrm{A}<\mathrm{C}^{*}$ \\
\hline & & $7,28,90$ & ${ }^{*} \mathrm{~A}<\mathrm{O}^{*}<\mathrm{C}$ \\
\hline & & 180,365 & $\mathrm{~A}<\mathrm{C}^{*}>\mathrm{O}$ \\
\hline & & 545,730 & $\mathrm{~A}<\mathrm{C}^{*}>\mathrm{O}$ \\
\hline \multirow{7}{*}{$<$ P.A.V. $<$} & & 1 & $0=\mathrm{A}<\mathrm{O}^{*}<\mathrm{C}$ \\
\hline & & 7 & $0=\mathrm{A} \approx \mathrm{O}^{*}<\mathrm{C}=\mathrm{PT}$ \\
\hline & & 28,90 & $0=\mathrm{O}=\mathrm{A}<\mathrm{C}^{*}=\mathrm{PT}$ \\
\hline & & 180 & $\mathrm{~A}<\mathrm{O}<\mathrm{C}^{*}$ \\
\hline & & 365 & $\mathrm{~A}<\mathrm{C}<\mathrm{O}^{*}$ \\
\hline & & 545 & $\mathrm{~A}<\mathrm{C}<\mathrm{O}=\mathrm{PT}$ \\
\hline & & 730 & $\mathrm{~A}<\mathrm{C}<\mathrm{O}$ \\
\hline
\end{tabular}

TABLA 8-33.- CLASIFICACIÓN DE LAS DISTINTAS PUZOLANAS A IGUALDAD DE CEMENTO PORTLAND DE REFERENCIA EN EL ENSAYO L-A DE LOS CEMENTOS P31/("Z"+CH) 50/50

\begin{tabular}{|c|c|c|c|}
\hline Parámetro & $\begin{array}{l}\text { Cementos } \\
\text { mixtos }+\mathrm{CH}\end{array}$ & Edad (días) & $\begin{array}{c}\text { Clasificaciones obtenidas de las AP } \\
\text { ensayadas }\end{array}$ \\
\hline \multirow{5}{*}{$\Delta \varnothing<\mathrm{Vc} \varnothing<\Delta \varnothing / \mathrm{g}$ "Z" } & & 1,7 & \\
\hline & & 28,90 & $+\mathrm{CV} 19^{*}>\mathrm{CV} 10$ \\
\hline & & 180,365 & $\mathrm{CV} 19^{*}<\mathrm{C}^{*}<\mathrm{O}^{*}$ \\
\hline & & 545,730 & \\
\hline & $\mathrm{P}-31^{*} /(" \mathrm{Z} "+\mathrm{CH}) 50 / 50$ & 1 & \\
\hline \multirow{3}{*}{$<$ P.A.V. $<$} & & 7,28 & $0=\mathrm{O}<\mathrm{CV} 19<\mathrm{C}$ \\
\hline & & 90,180 & ${ }^{*} \mathrm{CV} 19^{*}<\mathrm{O}<\mathrm{C}$ \\
\hline & & $\begin{array}{c}365,545 \\
730\end{array}$ & $\mathrm{CV} 19<\mathrm{C}^{*}>\mathrm{O}$ \\
\hline
\end{tabular}

TABLA 8-34.- CLASIFICACIÓN DE LAS DISTINTAS PUZOLANAS A IGUALDAD DE CEMENTO PORTLAND DE REFERENCIA EN EL ENSAYO L-A DE LOS CEMENTOS PY4/("Z"+CH) 50/50 y PY6/("Z"+CH) 50/50

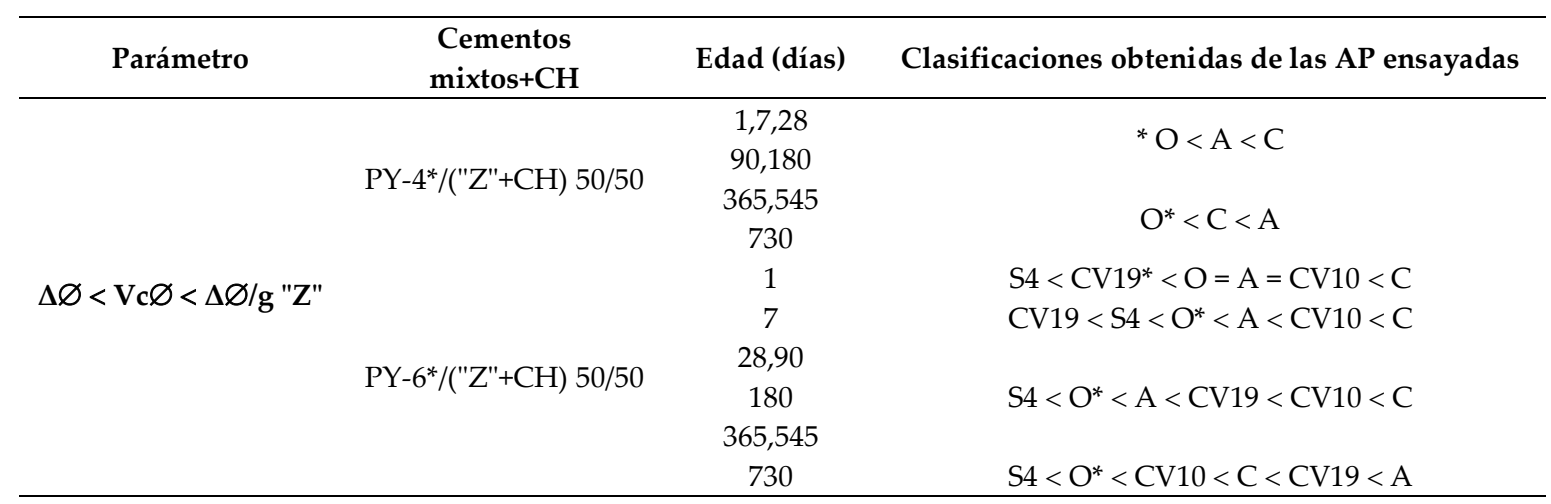


TABLA 8-35.- CLASIFICACIÓN DE LAS DISTINTAS PUZOLANAS A IGUALDAD DE CEMENTO PORTLAND DE REFERENCIA EN EL ENSAYO L-A DE LOS CEMENTOS PY4/("Z"+CH) 50/50 Y PY6/("Z"+CH) 50/50

\begin{tabular}{lccc}
\hline Parámetro & Cementos mixtos+CH & Edad (días) & Clasificaciones obtenidas de las AP ensayadas \\
\hline & $1,7,28$ & $0={ }^{*} \mathrm{O}=\mathrm{A}<\mathrm{C}$ \\
& 90,180 & $0=\mathrm{O}<\mathrm{C}^{*}<\mathrm{A}$ \\
& & $\mathrm{C}<\mathrm{O}^{*}<\mathrm{A}=\mathrm{PT}$ \\
& 365 & $\mathrm{C}^{*}<\mathrm{A}<\mathrm{O}=\mathrm{PT}$ \\
& 545 & $0=\mathrm{O}=\mathrm{CV} 19=\mathrm{A}<\mathrm{CV} 10<\mathrm{C}$ \\
& 730 & $0=\mathrm{O}=\mathrm{CV} 19=\mathrm{A}<\mathrm{C}<\mathrm{CV} 10$ \\
& 1 & $0=\mathrm{CV} 10=\mathrm{O}<\mathrm{CV} 19<\mathrm{C}<\mathrm{A}$ \\
& $7,28,90$ & $0=\mathrm{CV} 10=\mathrm{O}<\mathrm{C}<\mathrm{CV} 19<\mathrm{A}=\mathrm{PT}$ \\
& 180 & $0=\mathrm{CV} 10=\mathrm{O}<\mathrm{C}<\mathrm{CV} 19<\mathrm{A}$ \\
& 365 & $0=\mathrm{CV} 10=\mathrm{O}<\mathrm{C}<\mathrm{CV} 19<\mathrm{A}=\mathrm{PT}$ \\
\end{tabular}

\subsection{2-Discusión e Interpretación de las Familias $P-n^{o} /\left({ }^{\prime \prime} Z^{\prime \prime}+C H\right) 40 / 60,\left({ }^{\prime \prime} / C H=5\right)$}

Sea cual fuere el CP que se considere, por lo general se ha verificado que el $\Delta \varnothing, \mathrm{VC} \varnothing, \Delta \varnothing / \mathrm{g}$ "Z" y P.A.V de su probeta L-A y las correspondientes a las de cada CM preparado con el mismo, cal apagada, $\mathrm{CH}$, y la puzolana "Z" = A, C y M, respectivamente, (habiendo sido la relación "Z"/CH = 5) aumentaron del siguiente modo a las edades fundamentales de ensayo, véase la Tabla 8-36.

TABLA 8-36.- CLASIFICACIÓN DE LAS DISTINTAS PUZOLANAS A IGUALDAD DE CEMENTO PORTLAND DE REFERENCIA EN EL ENSAYO L-A DE LOS CEMENTOS P-1 Y P-31*/("Z"+CH) 40/60

\begin{tabular}{|c|c|c|c|}
\hline Parámetro & Cementos mixtos+CH & Edad (días) & Clasificaciones obtenidas de las AP ensayadas \\
\hline \multirow{5}{*}{$\Delta \varnothing<\mathrm{Vc} \varnothing<\Delta \varnothing / \mathrm{g} " \mathrm{Z} "$} & \multirow{10}{*}{ P-1 y $\mathrm{P}-31^{*} /(" \mathrm{Z}+\mathrm{CH}) 40 / 60$} & 1,7 & $A^{*}<C<M$ \\
\hline & & 28 & $\begin{array}{c}A^{*}<C<M \\
* M<C^{*}<A^{*}\end{array}$ \\
\hline & & 90,180 & ${ }^{\top} \mathrm{M} 1<\mathrm{C}^{\top}<\mathrm{A}^{\top}$ \\
\hline & & 365,545 & ${ }^{*} \mathrm{M}^{*}<\mathrm{C}^{*}<\mathrm{A}$ \\
\hline & & 730 & $\mathrm{~N} N<\mathrm{C}<\mathrm{A}$ \\
\hline \multirow{5}{*}{$<$ P.A.V. $<$} & & 1 & $0={ }^{*} \mathrm{~A}<\mathrm{M}<\mathrm{C}$ \\
\hline & & 7 & $0=\mathrm{A}<\mathrm{M}^{*}<\mathrm{C}=\mathrm{PT}$ \\
\hline & & 28,90 & $\mathrm{M}<\mathrm{A}^{*}<=\mathrm{PT}$ \\
\hline & & 180,365 & \\
\hline & & 545,730 & $\mathrm{~A}<\mathrm{M}<\mathrm{C}^{*}=\mathrm{PT}$ \\
\hline
\end{tabular}


COMPORTAMIENTO SULFÁTICO Y MECÁNICO-RESISTENTE DE CEMENTOS PORTLAND CON ELEVADOS CONTENIDOS DE PUZOLANAS ( $>40 \%$ ): SU FUNDAMENTO QUÍMICO Y JUSTIFICACIÓN DE OTRAS CONSECUENCIAS POSIBLES

8.1.2.4.2.3-Discusión e Interpretación de las Familias P- $n^{o}$ y PY- $n^{o} /\left({ }^{\prime \prime} Z^{\prime \prime}+C H\right)$ 30/70, $\left({ }^{\prime \prime} \mathrm{Z} " \mathrm{CH}=6\right)$

TABLA 8-37.- CLASIFICACIÓN DE LAS DISTINTAS PUZOLANAS A IGUALDAD DE CEMENTO PORTLAND DE REFERENCIA EN EL ENSAYO L-A DE LOS CEMENTOS P-NNo Y PY-№/("Z"+CH) 30/70

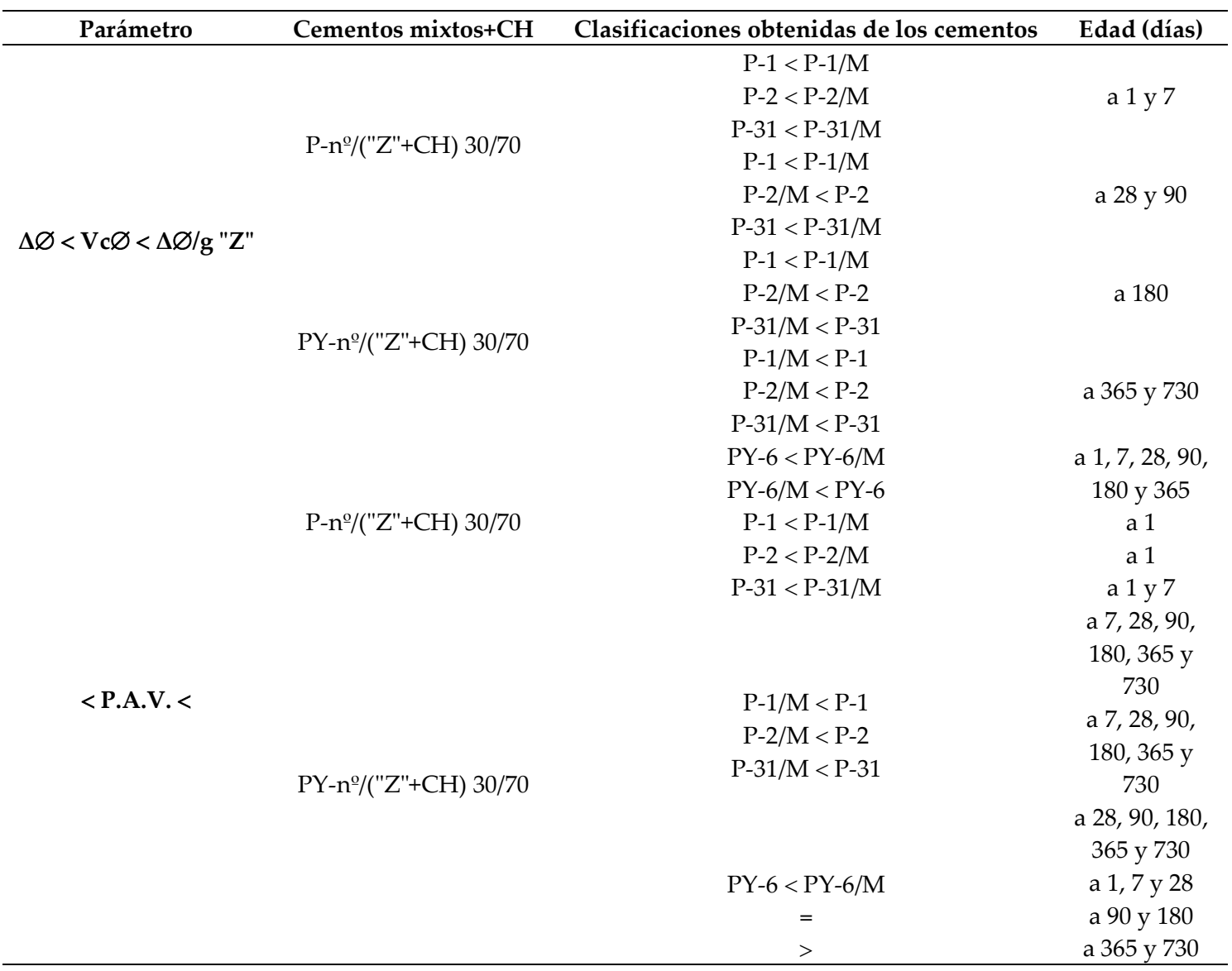

Sea cual fuere el CP que se considere, por lo general se ha verificado que el $\Delta \varnothing, \mathrm{VC} \varnothing, \Delta \varnothing / \mathrm{g}$ "Z" y P.A.V. de su probeta L-A y las correspondientes a la de su CM preparado con el mismo, la puzolana "Z" = M y cal apagada = CH (habiendo sido la relación ("Z"/CH =6), aumentaron del siguiente modo a las edades fundamentales del ensayo, véase la Tabla 8-37.

\subsection{4-Discusión e Interpretación de las Familias PY-6/(M+CH) 20/80, ("Z"/CH = 7)}

Por lo general se ha verificado que el $\Delta \varnothing, \mathrm{VC} \varnothing, \Delta \varnothing / \mathrm{g}$ "Z" y P.A.V de su probeta L-A del CP PY-6 y las correspondientes a la de su CM preparado con el mismo y la puzolana "Z" = M, aumentaron del siguiente modo a las edades fundamentales del ensayo, véase la Tabla 8-38.

TABLA 8-38.- CLASIFICACIÓN DE LAS DISTINTAS PUZOLANAS A IGUALDAD DE CEMENTO PORTLAND DE REFERENCIA EN EL ENSAYO L-A DE LOS CEMENTOS PY-6/(M+CH) 20/80 


\begin{tabular}{|c|c|c|c|}
\hline Parámetro & $\begin{array}{c}\text { Cementos } \\
\text { mixtos+CH }\end{array}$ & Clasificaciones obtenidas de los cementos & Edad (días) \\
\hline \multirow{2}{*}{$\begin{array}{c}\Delta \varnothing \mathrm{Vc} \varnothing<<\Delta \varnothing / \mathrm{g} \mathrm{"Z"} \\
\text { P.A.V. }\end{array}$} & & PY-6 < PY-6/(M+CH) & a $1,7,28,90,180$ y 365 \\
\hline & & PY-6/(M+CH) < PY-6 & a 730 \\
\hline
\end{tabular}

\subsubsection{3-Sin cal apagada y con yeso}

\subsection{1-Discusión e Interpretación de las Familias (P-1 y PY-6/M 30/70) +7.0\%SO3).}

Sea cual fuere el CP que se considere, por lo general se ha verificado que el $\triangle \varnothing, \mathrm{VC} \varnothing, \Delta \varnothing / \mathrm{g}$ "Z" y P.A.V. de su probeta L-A y las correspondientes a la de su CM preparado con la puzolana $\mathrm{M}$ y yeso $=7.0 \%$ de $\mathrm{SO}_{3}=15.05 \%$ de yeso, $\mathrm{CaSO}_{4} \cdot 2 \mathrm{H}_{2} \mathrm{O}$, aumentaron del siguiente modo a las edades fundamentales del ensayo, véase la Tabla 8-39.

TABLA 8-39.- CLASIFICACIÓN DE LAS DISTINTAS PUZOLANAS A IGUALDAD DE CEMENTO PORTLAND DE REFERENCIA EN EL ENSAYO L-A DE LOS CEMENTOS P-1 Y PY-6/M 30/70) +7.0\%SO3

\begin{tabular}{|c|c|c|}
\hline Parámetro & Clasificaciones obtenidas de los cementos & Edad (días) \\
\hline \multirow{2}{*}{$\Delta \varnothing<\mathrm{Vc} \varnothing<\Delta \varnothing / \mathrm{g} " \mathrm{Z} "$} & $0=\left[(\mathrm{P}-1 / \mathrm{M} 30 / 70)+7.0 \% \mathrm{SO}_{3}\right]<\mathrm{P}-1$ & a $1,7,28,90,180,365$ y 730 \\
\hline & $0=\left[(\mathrm{PY}-6 / \mathrm{M} 30 / 70)+7.0 \% \mathrm{SO}_{3}\right]<\mathrm{PY}-6$ & $\begin{array}{c}=\text { a } 1 \\
<\text { a } 7,28,90,180,365 \text { y } 730\end{array}$ \\
\hline \multirow[b]{2}{*}{$<$ P.A.V. $<$} & $0=\left[(\mathrm{P}-1 / \mathrm{M} 30 / 70)+7.0 \% \mathrm{SO}_{3}\right]<\mathrm{P}-1$ & a $1,7,28,90,180,365$ y 730 \\
\hline & $\begin{array}{c}0=\left[(\mathrm{PY}-6 / \mathrm{M} 30 / 70)+7.0 \% \mathrm{SO}_{3}\right]=\mathrm{PY}-6 \\
{\left[(\mathrm{PY}-6 / \mathrm{M} 30 / 70)+7.0 \% \mathrm{SO}_{3}\right]<\mathrm{PY}-6}\end{array}$ & $\begin{array}{l}\text { a } 1,7,28,90 \text { y } 180 \\
\quad \text { a } 365 \text { y } 730\end{array}$ \\
\hline
\end{tabular}

\subsection{2-Discusión e Interpretación de las Familias (PY-6/M 20/80) +7.0\% $\left.\mathrm{SO}_{3}\right)$.}

Por lo general se ha verificado que el $\Delta \varnothing, \mathrm{VC} \varnothing, \Delta \varnothing / \mathrm{g}$ "Z" y P.A.V. de su probeta L-A del CP PY-6 y las correspondientes a la de su CM preparado con el mismo, la puzolana "Z" = M y yeso $=7.0 \%$ de $\mathrm{SO}_{3}=15.05 \%$ de yeso, $\mathrm{CaSO}_{4} \cdot 2 \mathrm{H}_{2} \mathrm{O}$, aumentaron del siguiente modo a las edades fundamentales del ensayo, véase la Tabla 8-40.

TABLA 8-40.- CLASIFICACIÓN DE LAS DISTINTAS PUZOLANAS A IGUALDAD DE CEMENTO PORTLAND DE REFERENCIA EN EL ENSAYO L-A DE LOS CEMENTOS (PY-6/M 20/80) +7.0\%SO3.

\begin{tabular}{ccc}
\hline Parámetro & Clasificaciones obtenidas de los cementos & Edad (días) \\
\hline$\Delta \varnothing<$ Vc $\varnothing<\Delta \varnothing /$ g "Z" & {$\left[(\right.$ PY-6/M 20/80 $\left.)+7.0 \% \mathrm{SO}_{3}\right] \leq \mathrm{PY}-6=0$} & $<$ a 1 \\
& & $<$ a $7,28,90,180,365$ y 730 \\
$<$ <P.A.V. $>>$ & $0=$ PY-6 $>\left[(\mathrm{PY}-6 / \mathrm{M} 20 / 80)+7.0 \% \mathrm{SO}_{3}\right]$ & $<$ a $1,7,28,90$ y 180 \\
& & $>$ a 365 y 730 \\
\hline
\end{tabular}

\subsubsection{4- Con cal apagada y yeso, 365 y 730 días del ensayo}

8.1.2.4.4.1-Discusión e Interpretación de las Familias (P-1 y PY-6/(M+CH) 30/70) +7.0\% SO 3 . 
Por lo general se ha verificado que el $\Delta \varnothing, \mathrm{VC} \varnothing, \Delta \varnothing / \mathrm{g}$ "Z" y P.A.V. de las probetas L-A de los CP, P-1 y PY-6, y los de la correspondiente al CM preparado con la puzolana $\mathrm{M}$, cal apagada y yeso $=7.0 \%$ de $\mathrm{SO}_{3}=15.05 \%$ de yeso, $\mathrm{CaSO}_{4} \cdot 2 \mathrm{H}_{2} \mathrm{O}$, aumentaron del siguiente modo a las edades fundamentales del ensayo, véase la Tabla 8-41.

En todas las probetas L-A los valores del $\triangle \varnothing, \mathrm{VC} \varnothing, \Delta \varnothing / \mathrm{g} " Z$ " y P.A.V. de las mezclas 30/70 y 20/80, con CH sólo, han superado a los de las demás porque en las demás ya se formó su ett-rf o ett-T durante sus 14 días de hidratación bajo agua. Por este motivo y con posterioridad, sus probetas L-A fueron estables mientras que la del $(\mathrm{M}+\mathrm{CH})$ no, por el motivo totalmente contrario.

TABLA 8-41.- CLASIFICACIÓN DE LAS DISTINTAS PUZOLANAS A IGUALDAD DE CEMENTO PORTLAND DE REFERENCIA EN EL ENSAYO L-A DE LOS CEMENTOS P-1 Y PY-6/(M+CH) 30/70) +7.0\% SO3.

\begin{tabular}{ccc}
\hline Parámetro & Clasificaciones obtenidas de los cementos & Edad (días) \\
\hline$\Delta \varnothing<\mathrm{V} c \varnothing<\Delta \varnothing / \mathrm{g}$ "Z" & {$\left[(\mathrm{P}-1 /(\mathrm{M}+\mathrm{CH})]+7.0 \% \mathrm{SO}_{3}\right]<\mathrm{P}-1$} & a $1,7,28,90,180,365$ y 730 \\
& {$\left[(\mathrm{PY}-6 /(\mathrm{M}+\mathrm{CH})]+7.0 \% \mathrm{SO}_{3}\right]<\mathrm{PY}-6$} & $<$ a 1 \\
& & $<$ a $7,28,90,180,365$ y 730 \\
& & a $1,7,28,90,180,365$ y 730 \\
<.A.V. $<$ & $0=\left[\left(\mathrm{P}-1 /(\mathrm{M}+\mathrm{CH})+7.0 \% \mathrm{SO}_{3}\right]<\mathrm{P}-1\right.$ & $=$ a $1,7,28,90$ y 180 \\
& $0=\left[\left(\mathrm{PY}-6 /(\mathrm{M}+\mathrm{CH})+7.0 \% \mathrm{SO}_{3}\right]<\mathrm{PY}-6\right.$ & $<$ a 365 y 730 \\
\hline
\end{tabular}

\subsection{2-Discusión e Interpretación de las Familias PY-6/(M+CH) 20/80)+7.0\% $\mathrm{SO}_{3}$.}

Por lo general se ha verificado que el $\Delta \varnothing, \mathrm{VC} \varnothing, \Delta \varnothing / \mathrm{g} " \mathrm{Z}$ y P.A.V. de la probeta L-A del CP PY-6 y los de la correspondiente al CM preparado con la puzolana $\mathrm{M}$, cal apagada y yeso = $7.0 \% \mathrm{SO}_{3}=15.05 \%$ de yeso, $\mathrm{CaSO}_{4} \cdot 2 \mathrm{H}_{2} \mathrm{O}$, aumentaron del siguiente modo a las edades fundamentales del ensayo, véase la Tabla 8-42.

TABLA 8-42.- CLASIFICACIÓN DE LAS DISTINTAS PUZOLANAS A IGUALDAD DE CEMENTO PORTLAND DE REFERENCIA EN EL ENSAYO L-A DE LOS CEMENTOS PY-6/(M+CH) 20/80) +7.0\% SO3.

\begin{tabular}{ccc}
\hline Parámetro & Clasificaciones obtenidas de los cementos & Edad (días) \\
\hline$\Delta \varnothing<\mathrm{Vc} \varnothing<\Delta \varnothing / \mathrm{g} " \mathrm{Z} "$ & $0=\left[[\mathrm{PY}-6 /(\mathrm{M}+\mathrm{CH}) 20 / 80]+7.0 \% \mathrm{SO}_{3}\right]<\mathrm{PY}-6$ & $<$ a 1 \\
& & $\begin{array}{c}\text { a } 7,28,90,180,365 \\
\text { y } 730\end{array}$ \\
<P.A.V. $<$ & $0=\left[[\mathrm{PY}-6 /(\mathrm{M}+\mathrm{CH}) 20 / 80]+7.0 \% \mathrm{SO}_{3}\right]<\mathrm{PY}-6$ & $\begin{array}{c}\text { a } 1,7,28,90 \mathrm{y} 180 \\
<\text { a } 365 \mathrm{y} 730\end{array}$ \\
\hline
\end{tabular}

\subsubsection{5- Interpretaciones de los comportamientos encontrados en el apartado 8.1.2.4.}

\subsubsection{1-Familias $P-n^{\circ}$ y $P Y-n{ }^{\circ} / Z^{\prime \prime} 50 / 50$.}

\section{Parámetros $\Delta \varnothing$}

Resultó muy interesante haber podido comprobar cómo a igualdad de CP P-1, P-31, PY-4 y PY-6 principalmente, la clasificación de las ensayadas en función del valor $\Delta \varnothing \mathrm{xd}$ de su probeta L-A, a diferentes edades del ensayo, pero no especial las iniciales, coincidió con la que se 
obtuviera de las mismas en función de su contenido de $\mathrm{Al}_{2} \mathrm{O}_{3}{ }^{\mathrm{r}-4}$

Y la coincidencia de tales clasificaciones obtenidas tenía que ser debida necesariamente a que al tener la ett-rf, o de origen puzolana, una mayor velocidad de formación que la de origen $\mathrm{C}_{3} \mathrm{~A}$ del cemento Portland (Talero, 2008), aquella se debió de haber formado principalmente, en exclusiva incluso y a las edades iniciales del ensayo, cuanto menor fuera el contenido de $\mathrm{C}_{3} \mathrm{~A}$ del cemento Portland que la acompañaba, o aún siendo de mediano o elevado contenido, caso de los CP P-31 y P-2, por este orden, aquí utilizados, resulten muy "diluido" por la notable y muy notable incluso, adición de puzolana ( $\geq 40 \%$ en peso) a los mismos.

De esta manera a mayor cantidad de ett-rf que debió de originar la puzolana "Z" ensayada, mayores $\Delta \varnothing$ debiera haber provocado a edades semejantes en su probeta L-A correspondiente; con lo cual y mediante el valor resultante del citado parámetro en tales condiciones y edades iniciales del ensayo especialmente comparadas y no en cambio a las edades finales ${ }^{5}$, más y mejor se podrán haber clasificado tales puzolanas, como así ha sido el caso. Véanse al efecto las Tablas 8-22, 8-23, 8-24 y 8-25, las clasificaciones obtenidas de las puzolanas ensayadas con los CP PY-6, PY-4, P-31 y P-2, principalmente.

Resultó también muy interesante haber podido comprobar que excepto con el CP P-1 y a las edades intermedias, de 180 días, y a finales del ensayo de 365, 545 y 730 días, la puzolana M había ocupado principalmente los lugares más a la derecha de las clasificaciones obtenidas, sea cual fuere el CP que le acompañaba y el parámetro que se considerase. Este mismo comportamiento clasificatorio fue adscribible también en cierta medida a las puzolanas C y CV10.

En cambio, las puzolanas O, CV19 y A, mostraron un comportamiento clasificatorio contrario, es decir, los lugares más a la izquierda de las clasificaciones obtenidas.

Ello resultó ser una prueba demostrativa más de que en el caso de las puzolanas M, CV10 y C imperó, en mayor o menor grado, su carácter "alumínico" sobre el "silícico" mientras que en las resultantes puzolanas $\mathrm{O}, \mathrm{CV} 19$ y A, imperó lo contrario, es decir, el carácter "silícico" sobre el "alumínico".

Y el hecho del entrecruzamiento clasificatorio producido entre las puzolanas M y CV19 cuando el CP que las acompañaba fue el P-1, demostró que con la M debió producirse un ESE + entre ambos tipos de ettringita -la ett-lf o de origen $\mathrm{C}_{3} \mathrm{~A}$ del P-1 y la ett-rf o de origen $\mathrm{Al}_{2} \mathrm{O}_{3}{ }^{\mathrm{r}-}$ de la puzolana M- y con la CV19 también pero esta vez más tardío y sólo entre la ett-lf y el gel de $\mathrm{Fe}(\mathrm{OH})_{3}$ derivado del elevado contenido de Fe de dicha puzolana (Martín Luengo, 1996).

Y como prueba demostrativa de la veracidad de este razonamiento, estuvo el hecho de que

${ }^{4}$ Véase la Tabla 6-9 de esta MEMORIA de Tesis Doctoral.

${ }^{5}$ Porque para entonces ya se habrá podido formar en su caso toda la ett-rf origen C3A del cemento Portland que la acompañe pudiendo perder interés tecnológico tales clasificaciones obtenidas a las edades iniciales, ya que la expansividad de la ett-rf es un hecho y el $\mathrm{Qu}$ que origine para entonces en su probeta L-A también. Y todo ello si para entonces hay cantidad necesaria y suficiente de portlandita y/o cal apagada pues en caso contrario las interesantes clasificaciones obtenidas a las edades iniciales del ensayo se mantendrían hasta las finales y aún posteriormente. 
en el caso del CM PY-6/CV19 50/50, la puzolana CV19 ocupó en las distintas clasificaciones obtenidas lugares de la izquierda y cuando la cal apagada estuvo presente, caso del PY$6 /(\mathrm{CV} 19+\mathrm{CH})$ 50/50, se fue trasladado hacia las posiciones de la derecha con transcurso del ensayo, tal y como ocurriera en el caso del CM P-1/CV19 50/50. En el caso del PY-6/(CV19+CH) 50/50, el ESE + se debió de haber producido en cambio entre la ett-vlf o de origen $\mathrm{C}_{4} \mathrm{AF}$ del PY-6 y el gel de $\mathrm{Fe}(\mathrm{OH}) 3$ de la puzolana CV19.

\section{Parámetro P.A.V.}

Valen aquí íntegramente los mismos razonamientos expuestos para justificar lo ocurrido antes, con los correspondientes $\Delta \varnothing$ de este mismo apartado, ya que a cada $\Delta \varnothing$ originado, equivalía a decir que se había producido a la par, a una misma edad del ensayo al menos, un

valor P.A.V. determinado tanto mayor cuanto mayor había sido su $\Delta \varnothing$ originado al mismo tiempo por consecuencia de la ett-rf de origen puzolana "Z" y el ESE + adecuada correspondiente.

\subsubsection{2-Familias $P-n^{\circ}$ y $P Y-n^{\circ} / " Z^{\prime \prime} 40 / 60$.}

Parámetros $\triangle \varnothing$ y P.A.V.

Valen aquí íntegramente los mismos razonamientos respectivos expuestos para justificar lo ocurrido a propósito de ambos parámetros a las correspondientes probetas L-A "hermanas mayores" 50/50. Véase al efecto la interpretación del apartado 8.1.2.5.2, pero corregidos y mejorados, pues en este caso la coincidencia de clasificaciones se produjo hasta con los CM del CP P-1 y a edades iniciales mayormente, como era y es lo lógico. Véase las Tablas 8-27, 8-28.

\subsubsection{3- Familias $P-n^{o}$ y PY-6/M 30/70.}

Parámetros $\triangle \varnothing$ y P.A.V.

Valen aquí íntegramente los mismos razonamientos respectivos expuestos para justificar lo ocurrido a propósito de ambos parámetros, a las correspondientes probetas L-A "hermanas mayores" 50/50. Véase al efecto la interpretación del apartado 8.1.2.5.2. Tablas 8-29, 8-30.

\subsubsection{4-Familias PY-6/M 20/80}

Parámetros $\Delta \varnothing$ y P.A.V.

Valen aquí íntegramente los mismos razonamientos respectivos expuestos para justificar lo ocurrido a propósito de ambos parámetros, a las correspondientes probetas L-A "hermanas mayores" 50/50. Véase al efecto la interpretación del apartado 8.1.2.5.2. Tabla 8-31. 

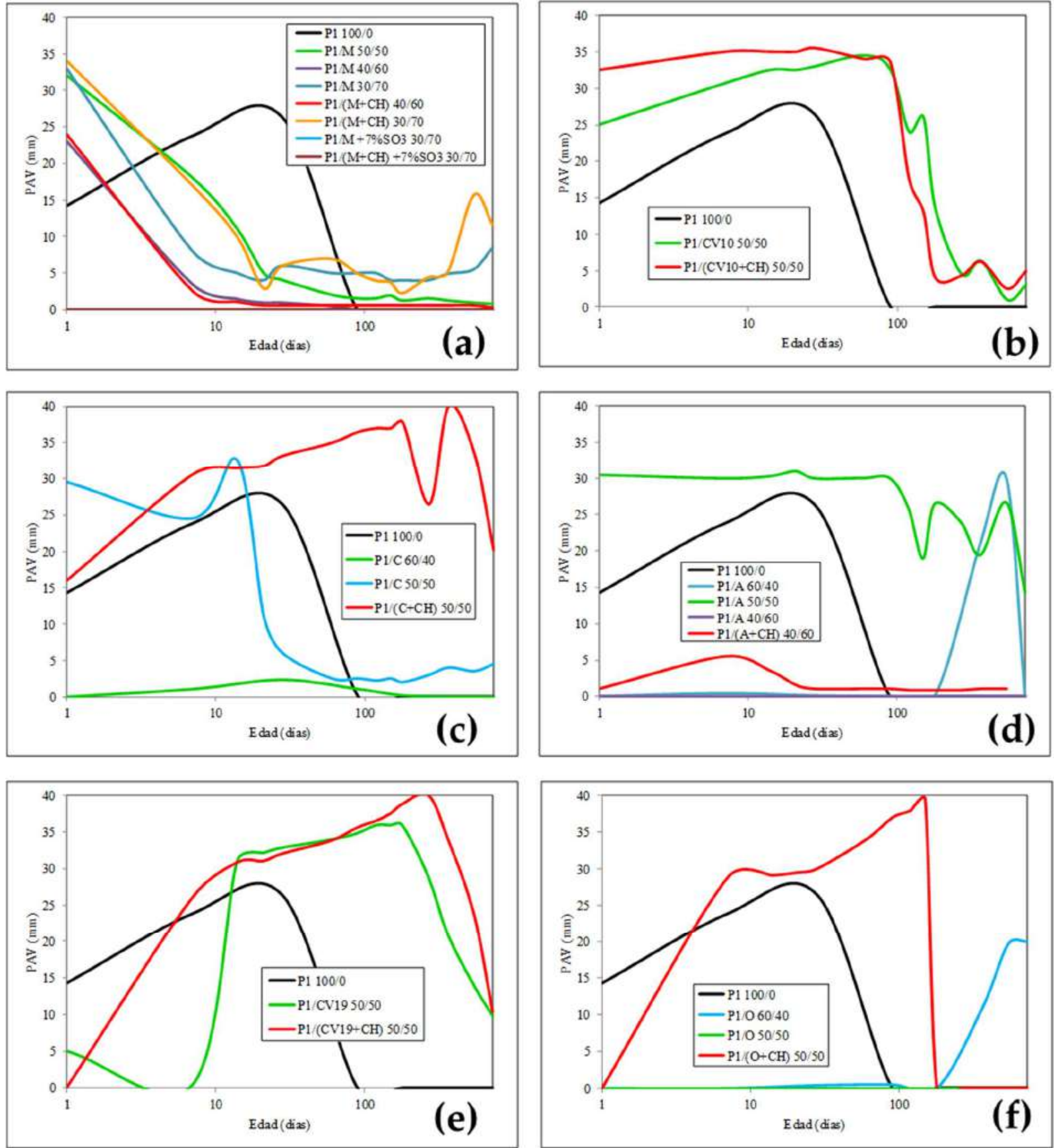

FIGURA 8-16.- RESULTADOS OBTENIDOS DE P.A.V. EN EL ENSAYO LE CHATELIER ANSTETT PARA TODOS LOS CEMENTOS DE MEZCLA PREPARADOS CON CP P1 Y TODAS LAS PUZOLANAS UTILIZADAS EN ESTA INVESTIGACIÓN 

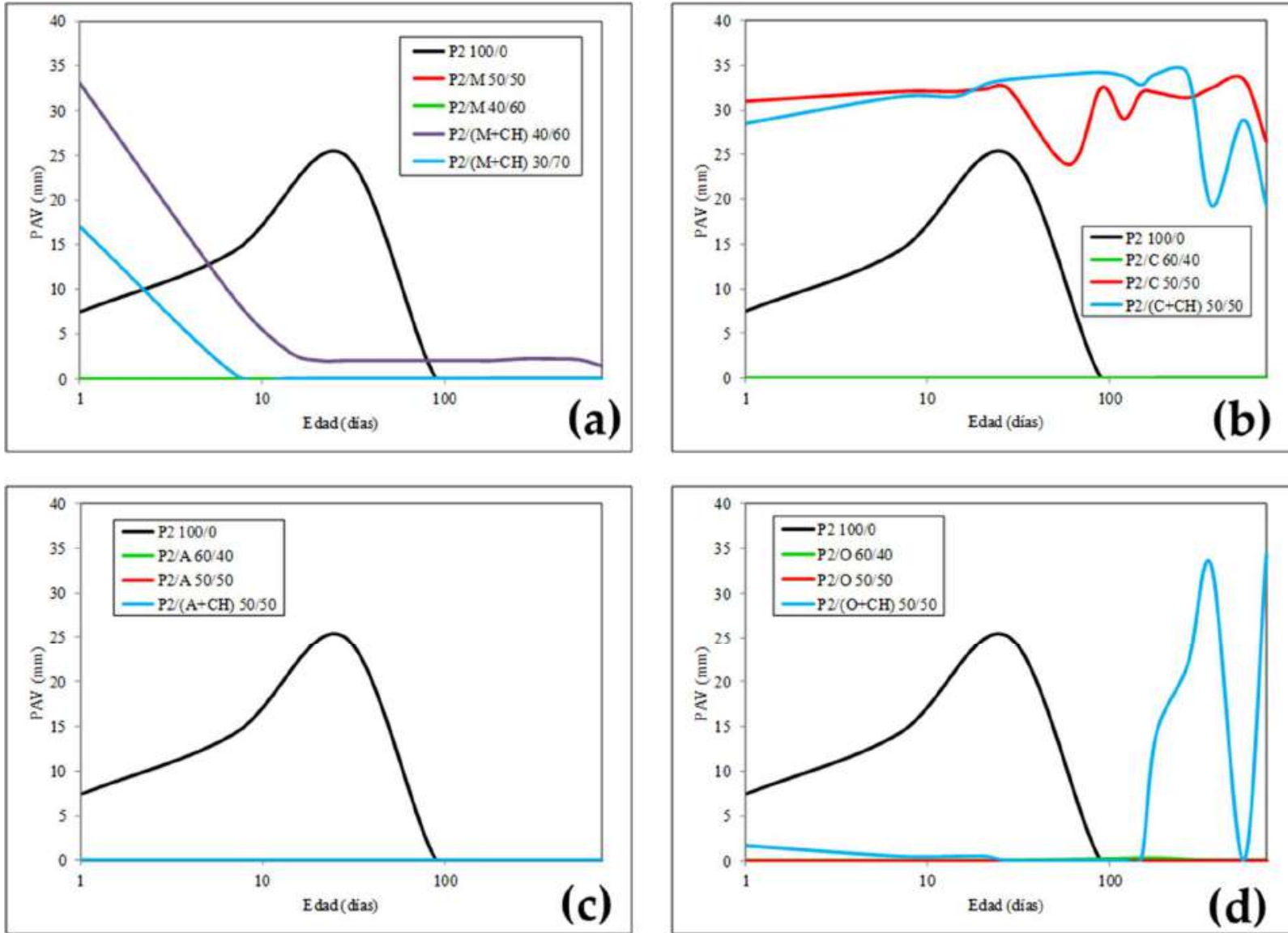

FIGURA 8-17.- RESULTADOS OBTENIDOS DE P.A.V. EN EL ENSAYO LE CHATELIER ANSTETT PARA TODOS LOS CEMENTOS DE MEZCLA PREPARADOS CON CP P2 Y TODAS LAS PUZOLANAS UTILIZADAS EN ESTA INVESTIGACIÓN

\subsubsection{5-Familias $P-n^{o}$ y $P Y-n^{o} /\left(" Z^{\prime \prime}+C H\right) 50 / 50$}

Parámetros $\triangle \varnothing$ y P.A.V.

Una vez más quedó aquí justificada la razón explicativa dada a propósito de los ocurrido con este parámetro a las probetas L-A "hermanas" sin cal apagada. Véase al efecto la interpretación del apartado 8.1.2.5.2, y retomémosla donde dice... "cuanto menor sea el contenido de $\mathrm{C}_{3} \mathrm{~A}$ del CP que la acompañe o aún siendo de mediano o elevado contenido, caso de los CP P31 y P-2, por este orden, aquí utilizados, resulten muy "diluidos" por la notable o muy notable incluso adición de puzolana ( $\geq 40 \%$ en peso) a los mismos, o cuando los mismos aún teniendo dicho contenido de $\mathrm{C}_{3} \mathrm{~A}$ elevado caso del P-1 aquí utilizado, estuvieran presentes por defecto y se les añadiera en cambio cal apagada suficiente para que la puzolana " $Z$ " añadida hubiera podido mostrar a la edad de 1 día al menos, su verdadero "carácter", es decir, originar a tal edad todo o parte de la ett-rf que era capaz de formar antes de que empezara a formar su ett-lf, el $\mathrm{C}_{3} \mathrm{~A}$ de la 
fracción Portland que la acompañaba, y por este motivo, clasificarse en función de su $\Delta \varnothing$ originado a tal edad, coincidiendo dicha clasificación con la expuesta en la Tablas 8-32 y 8-33, como así ha sido el caso.

Y ello debía de haber ocurrido con mayor razón y del mismo modo a la edad de 1 día al menos, cuando el CP hubiera sido de menor contenido de $\mathrm{C}_{3} \mathrm{~A}$, caso del P-2 y el P-31, utilizados en este trabajo, aunque en este último caso y por la razón aducida, la coincidencia de clasificaciones se podría haber prolongado quizás, durante más edades de ensayo, 7, 28 y 60, ... días, como así también ha sido el caso, véanse la Tablas 8-32 y 8-33.

Y todo ello, con mayor razón aún y edades del ensayo sin llegar a las finales, cuando el CP hubiera poseído un contenido de $\mathrm{C}_{3} \mathrm{~A}$ bajo o nulo, como así también ha sido el caso, véase la Tablas 8-32 y 8-33, pues la no coincidencia total de ambas clasificaciones en el caso de los CM con cal apagada del CP PY-6, resultó ser intrascendente por haber sido los valores absolutos correspondientes muy semejantes.

\subsubsection{6-Familia P-no y PY-n ${ }^{o}\left({ }^{\prime \prime} Z^{\prime \prime}+C H\right) 40 / 60$}

Parámetros $\triangle \varnothing$ y P.A.V.

El orden adoptado por las únicas probetas L-A comparables en este caso a las diferentes edades del ensayo tanto mediante el parámetro $\Delta \varnothing$ como mediante el parámetro P.A.V. correspondiente tuvo justificación, en el carácter "alumínico" de la puzolana $\mathrm{M}$, en el carácter "silícico-alumínico" de la puzolana A, y en el carácter "alumínico-silícico" de la puzolana C, según los cuales la puzolana habría originado mayor ESE + con el CP P-1 -facilitado por la cal apagada presente- que la puzolana A, y consiguiente, mayor tendencia a fraguar con prontitud y tener valores de P.A.V. menores que la puzolana A, como así ha ocurrido en este caso, véanse la Tablas 8-34 y 8-35. De aquí que al haber sido puzolana $C$ "alumínico-silícica" y haber estado presente en menor cantidad de $\mathrm{C}_{3} \mathrm{~A}$ (el P-31 tiene $7.62 \%$ de $\mathrm{C}_{3} \mathrm{~A}$ contra el $14.11 \%$ de $\mathrm{C}_{3} \mathrm{~A}$ que tiene el P-1), la puzolana $C$ no pudo originar tan notable ESE + a las edades iniciales como la $\mathrm{M}$, a pesar de lo cual el $\Delta \varnothing$ de sus probetas L-A a tales edades debería de haber sido también mayores que los de la puzolana A que era "silícico-alumínico" y el P.A.V. quizás también, precisamente por esa menor ASE citada, como así ha sido también el caso, véase la Tabla 8-34.

Por el contrario, y a edades posteriores, mientras que la relación entre la puzolana $\mathrm{M}$ y la A debía de haberse conservado en ambos parámetros, la de la $\mathrm{C}$ y la $\mathrm{A}$, no. Pues al no ser tan "alumínicas" como la $\mathrm{M}$, en dicho orden, la A debió demandar a las edades iniciales, menor cantidad de $\mathrm{C}_{3} \mathrm{~A}$ para su ESE y en consecuencia, provocan que a las edades ulteriores fuera dicho $\mathrm{C}_{3} \mathrm{~A}$ residual el que origine los mayores valores del $\Delta \varnothing$ y originándose al P.A.V. todo lo contrario, ya que la probeta L-A de la puazolana $C$ origina en este caso menor $\Delta \varnothing$ por haber estado menos fraguado por ser más alumínica que la A. Por lo tanto y en definitiva, el que las probetas de las $\mathrm{A}$ y $C$, hubieran relaciones diferentes mediante sus parámetros $\Delta \varnothing$ y P.A.V., había de ser achacable necesariamente al menor carácter alumínico de la A sobre la $\mathrm{C}$ y no a ser éste el suficiente $\mathrm{y}$ necesario para portarse como la probeta L-A M en su anterior comparación con la A. 

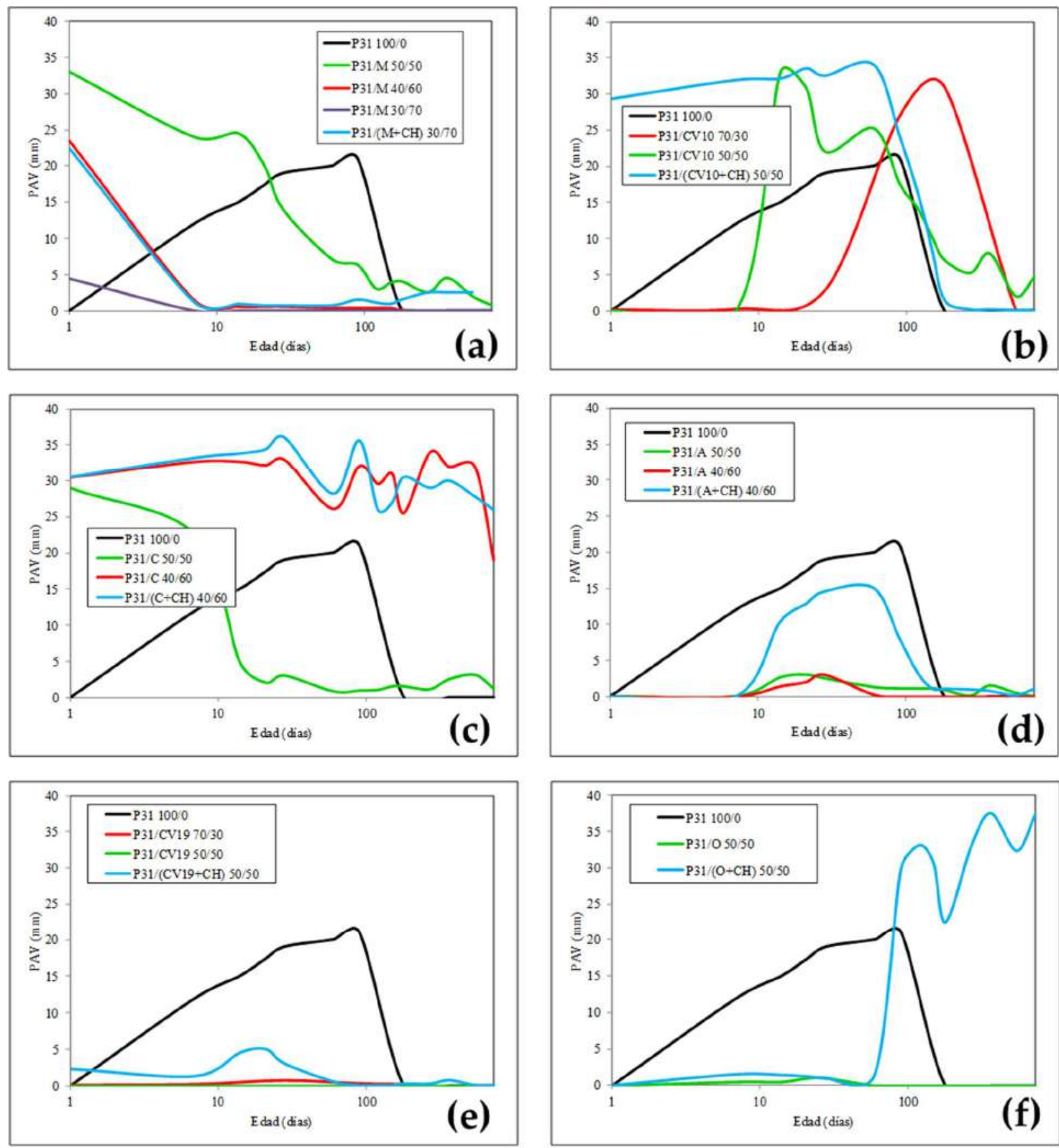

FIGURA 8-18.- RESULTADOS OBTENIDOS DE P.A.V. EN EL ENSAYO LE CHATELIER ANSTETT PARA TODOS LOS CEMENTOS DE MEZCLA PREPARADOS CON CP P31 Y TODAS LAS PUZOLANAS UTILIZADAS EN ESTA INVESTIGACIÓN 

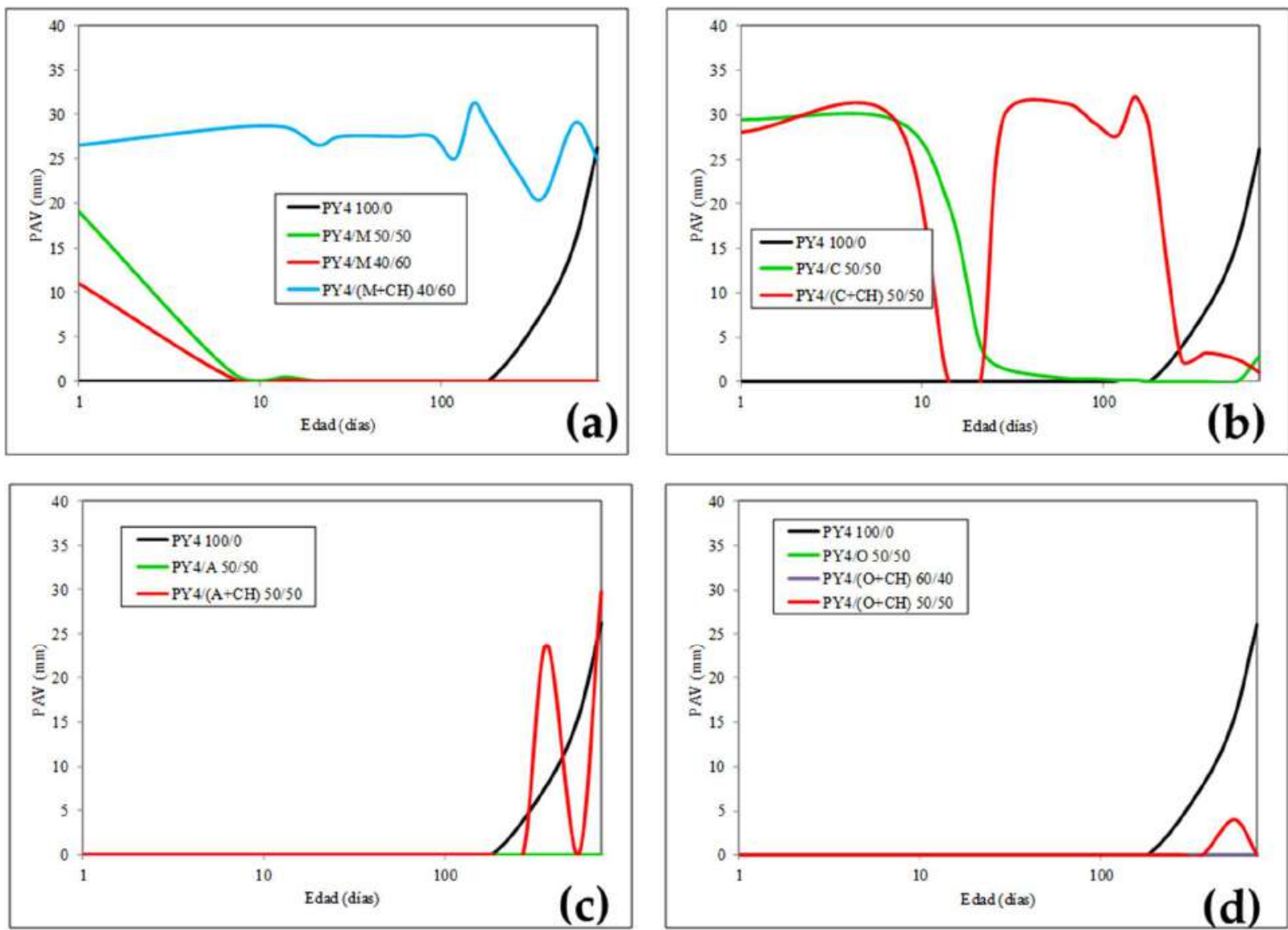

FIGURA 8-19.- RESULTADOS OBTENIDOS DE P.A.V. EN EL ENSAYO LE CHATELIER ANSTETT PARA TODOS LOS CEMENTOS DE MEZCLA PREPARADOS CON CP PY4 Y TODAS LAS PUZOLANAS UTILIZADAS EN ESTA INVESTIGACIÓN

\subsubsection{7-Familias $P-n^{o}$ y $P Y-n^{o} /\left(" Z^{\prime \prime}+C H\right) 30 / 70$}

Parámetros $\triangle \varnothing$ y P.A.V.

Lo ocurrido con ambos parámetros vino a confirmar una vez más que la ett-rf o de origen $\mathrm{Al}_{2} \mathrm{O}_{3^{r}}$ de la puzolana, en este caso la $\mathrm{M}$, había de tener y tiene de hecho una notable mayor velocidad de formación que la ett-lf o de origen $\mathrm{C}_{3} \mathrm{~A}$ del cemento Portland. Por este motivo en todos los casos de CP P-nº o PY-nº y el de su CM con cal apagada correspondiente, a las edades iniciales del ensayo especialmente, tanto el valor del $\Delta \varnothing$ como el de P.A.V., resultaron ser mayores que los del $\mathrm{CP}$, y tanto mayores cuanto mayor fuese el contenido de $\mathrm{C}_{3} \mathrm{~A}$ del citado $\mathrm{CP}$ para de este modo poder originar mayor ESE + y consiguientemente mayor $\Delta \varnothing$ y P.A.V.; no teniéndose que guardar relación de mayoría alguna entre las diferentes familias y según sea el contenido de $\mathrm{C}_{3} \mathrm{~A}$ de su $\mathrm{CP}$ porque principalmente la finura de molido de la fracción $\mathrm{CP}$, influye 
que su ESE sea mayor que la de otro CM semejante cuyo cemento Portland tuviera menor de $\mathrm{C}_{3} \mathrm{~A}$.
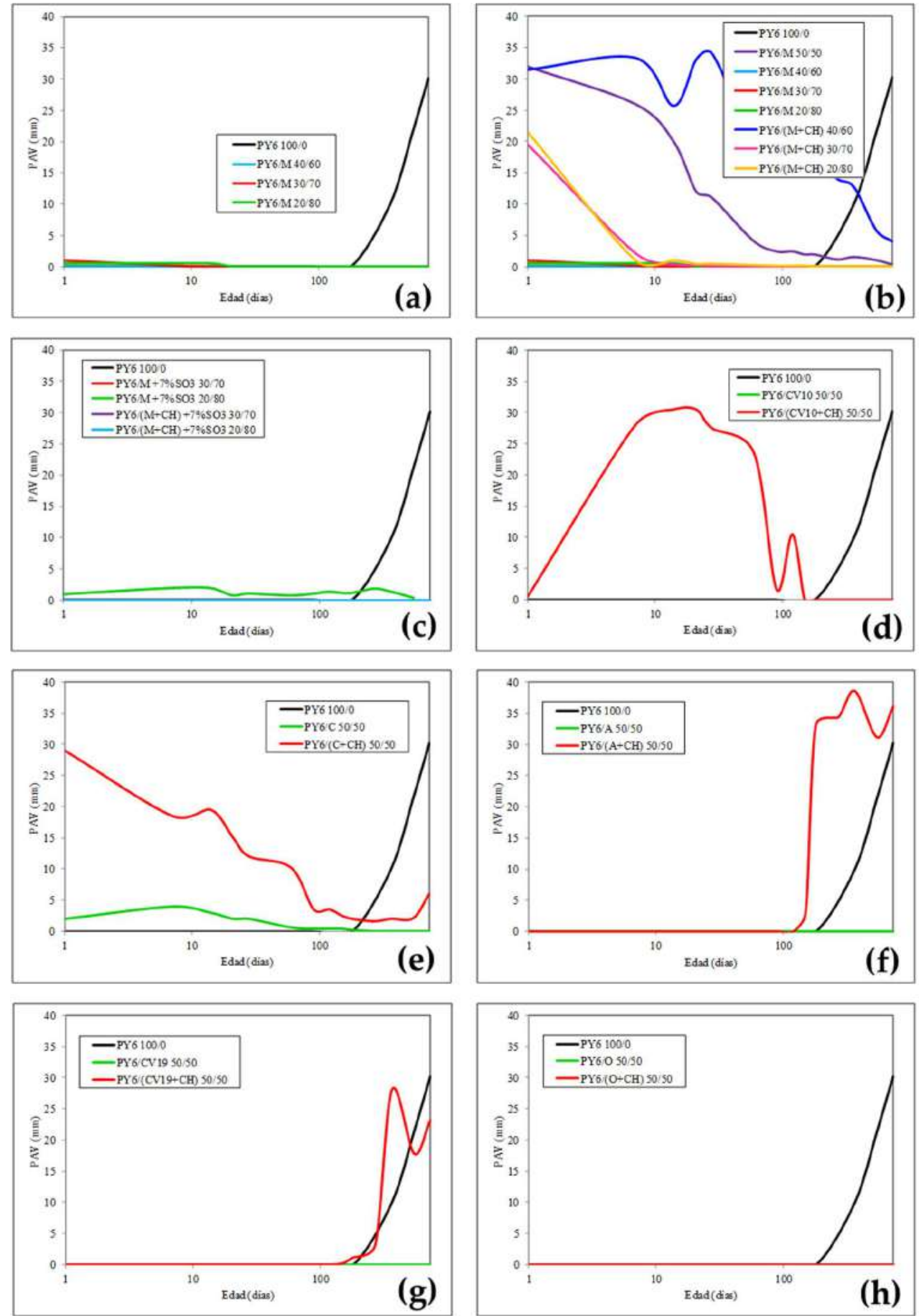

FIGURA 8-20.- RESULTADOS OBTENIDOS DE P.A.V. EN EL ENSAYO LE CHATELIER ANSTETT PARA TODOS LOS CEMENTOS DE MEZCLA PREPARADOS CON CP PY6 Y TODAS LAS PUZOLANAS UTILIZADAS EN ESTA INVESTIGACIÓN 


\subsubsection{8-Familia PY-6/(M+CH) 20/80}

Parámetros $\triangle \varnothing$ у P.A.V.

Valen aquí íntegramente idénticos razonamientos expuestos para interpretar la Discusión anterior del apartado 8.1.2.5.7.

\subsubsection{9-Familia [(P-1 y PY-6/M 30/70) +7.0\%SO 3$]$}

Parámetros $\triangle \varnothing$ y P.A.V.

Valen aquí íntegramente idénticos razonamientos expuestos para interpretar la Discusión anterior del apartado 8.1.2.5.7. Véase la Tabla 8-38.

\subsection{0-Familia $\left[(P Y-6 / M 20 / 80)+7.0 \% \mathrm{SO}_{3}\right]$}

Parámetros $\triangle \varnothing$ y P.A.V.

En lo que respecta al $\Delta \varnothing$, vale aquí la misma razón justificativa dada para su CM "hermano mayor 30/70", con anterioridad en la interpretación de la Discusión anterior del apartado 8.1.2.5.9 Véase la Tabla 8-39.

Por el contrario, y en lo que respecta a P.A.V. la razón de lo ocurrido, durante las primeras edades del ensayo estriba en el notable contenido de piedra de yeso natural de la probeta L-A que en cualquier caso retrasara su fraguado. Durante las edades finales del ensayo, a la expansión de la propia probeta L-A de su cemento Portland matriz PY-6 por formación de ettringita de muy lenta formación o de origen $\mathrm{C}_{4} \mathrm{AF}$ mayormente en esta ocasión, y durante las edades intermedias del ensayo, el cambio o trasiego de ambas situaciones anteriores.

\subsection{1-Familia [P-1 y PY-6/(M+CH) 30/70] +7.0\% SO $]$}

Parámetros $\triangle \varnothing$ у P.A.V.

Valen aquí íntegramente y con mayor razón aún por estar presente la cal apagada, las razones justificativas dadas a propósito de ambos parámetros en la interpretación 8.1.2.5.2.

\subsubsection{6-A igualdad de CM y derivados con cal apagada y/o yeso: Análisis y Estudio Comparativo, Discusión e Interpretación en RS, EXTERNO e INTERNO.}

\subsubsection{1-Análisis y Estudio Comparativo en RS, EXTERNO:}

Es el que ha sido realizado entre familias de CM -con y sin cal apagada y/o yeso- con CP diferente, habiéndose presentado los casos que se muestran a continuación. 
COMPORTAMIENTO SULFÁTICO Y MECÁNICO-RESISTENTE DE CEMENTOS PORTLAND CON ELEVADOS CONTENIDOS DE PUZOLANAS ( $>40 \%$ ): SU FUNDAMENTO QUÍMICO Y JUSTIFICACIÓN DE OTRAS CONSECUENCIAS POSIBLES

\subsection{1-Sin cal apagada $=\mathrm{CH}$, ni yeso}

8.1.2.6.1.1.1-Caso de que el CP constitutivo era de elevado $(\geq 8 \%$, el $P-1=14.11 \%$ C $A$ y el P-2 $\left.=11.09 \% C_{3} A\right)$ o moderado $\left(=8 \%\right.$, el P-31 = 7.62\% $\left.C_{3} A\right)$ contenido de aluminato tricálcico, $\left.C_{3} A\right)$.

\subsection{1.1-Familias $P-n^{o} /{ }^{\prime \prime} Z^{\prime \prime} 50 / 50$.}

Parámetros $\triangle \varnothing$, VC $\varnothing$ e $\triangle \varnothing / " Z "$ (g): Todas las probetas L-A de los CM preparados con el CP P-1 y cada una de las puzolanas ensayadas O, CV19, A, C, CV10 y M, han mostrado por lo general y de principio a fin del ensayo, unos valores de $\Delta \varnothing, \mathrm{VC} \varnothing$ e $\Delta \varnothing / " Z "$ (g), superiores a los correspondientes de las probetas L-A de los CM preparados con las mismas y los CP P-2 y P-31, respectivamente. No obstante, han existido algunas diferencias apreciables entre:

- Las probetas L-A de los CM P-1/O 50/50 y P-31/O 50/50, por un lado,

- Las probetas L-A de los CM P-1/M 50/50 y P-31/M 50/50, por otro, y

- Las probetas L-A de la familia del CP P-2 y las correspondientes del P-31, por otro.

Todas ellas se justificarán debidamente en la interpretación ulterior correspondiente.

A pesar de lo cual y a las edades finales del ensayo, los valores del $\Delta \varnothing$ de las probetas L-A de los CP solos, o sea, del P-1, P-2, P-31 y con la del PY-4 y PY-6 se verá también, han resultado ser netamente mayores que las de sus familias derivadas respectivas, habiendo ocurrido todo lo contrario a las edades iniciales de ensayo y mayormente en los P-nº.

\section{Parámetro P.A.V.:}

1. Caso de que el Pf1d y el Ff $>730$ días hayan sido cero ó valor de P.A.V. $=0$ mm ó $\approx 0 \mathrm{~mm}$ y Tf $=0$ días y horas: Los CM P-1, P-2 y P-31/O 50/50, P-2/A 50/50 y P-2/M 50/50.

2. Caso de que el $\mathrm{Ff}$ ha sido $>2$ años, habiendo sido además $\mathrm{Pf}_{1 \mathrm{~d}}=\mathrm{P} . \mathrm{A} . \mathrm{V} .=$ elevado ó máximo: Los CM P-1/CV19, A y CV10 50/50 y P-2/C 50/50.

3. Caso de Tf variable cualitativa y cuantitativamente:

- De 6 días y Pfid = P.A.V.= 2.5 mm: El CM P-31/CV19 50/50,

- De 2 años y Pf1-7d = P.A.V. = 0 mm y Pf14d = P.A.V.= 2.6 mm: El CM P-31/A 50/50, $\mathrm{y}$

- $\quad$ De 2 años y Pf 1 = P.A.V. = elevado: Los CM P-1/C, CV10 y M 50/50 y P-31/C, CV10 y $\mathrm{M} 50 / 50$.

En definitiva que la creación, evolución y desarrollo de los valores del P.A.V. tomaron la forma, o bien de una línea recta o sinuosamente recta y horizontal por valores nulos o casi nulos de P.A.V., caso de los CM P-1, P-2 y P-31/O 50/50, P-2/A 50/50 y P-2/M 50/50, o bien de una línea recta o sinuosamente recta, descendente y pendiente negativa diversa, o pequeña, caso de los $\mathrm{CM}$ P-31/CV19 y A 50/50, o grande, caso de los CM P-1 y P-31/M 50/50, o bien de una curva de Gauss 
cuyo máximo valor ha estado centrado o desplazado a la izquierda o a la derecha del punto central milimétrico del eje de abscisas (PCMEA) comprendido entre 1 y 730 días de edad del ensayo, caso de los CM P-1/CV19, A y CV10 50/50, P-2/C 50/50 y P-31/CV10 50/50, o bien de una curva de Gauss invertida con semejantes desplazamientos de su mínimo valor (que en el caso anterior era el máximo) caso de los CM P-1/C y P-31/C 50/50.

Por último y para cada CP empleado, las clasificaciones que se han obtenido, de las puzolanas ensayadas en forma de CM P-no/"Z" 50/50, a las edades fundamentales del ensayo de $1,7,28,90,180,360,545$ y 730 días, y en función del valor del parámetro $\Delta \varnothing x d$ correspondiente, han sido las siguientes. Véanse las Tablas 8-24, 8-25 y 8-26

\subsection{1.1.2- Familias $P-n^{o} / " Z " 40 / 60$.}

Parámetros $\Delta \varnothing$, VCØ e $\Delta \varnothing / " Z "$ (g): Vale aquí íntegramente todo lo dicho en el apartado 8.1.2.6.1.1.1.1, sólo que en esta ocasión única y exclusivamente aplicado a las puzolanas $\mathrm{A}, \mathrm{C}$ y $\mathrm{M}$ y con las discrepancias P-1/A 40/60 y P-31/A 40/60 por un lado y las probetas L-A de los CM P2/M 40/60 y P-31/M 40/60 por otro.

Parámetro P.A.V.:

1. Caso de que el Pf y Ff $>70$ días hayan sido cero o valor de P.A.V. $=0 \mathrm{~mm}$ ó $\approx 0$ $\mathrm{mm}$ y Tf $=0$ días y horas: El CM P-1/A 40/60.

2. Caso de que el $\mathrm{Ff}$ haya sido $>2$ años, habiendo sido además el $\mathrm{Pf}_{1 \mathrm{~d}}=\mathrm{P}$.A.V. $=$ máximo $\mathrm{y} \approx$ constante durante el transcurso del ensayo: El cemento mixto P-31/C 40/60.

3. Caso de situaciones intermedias a las dos anteriores ó $\mathrm{Tf}(\mathrm{Pf}=\mathrm{P} . \mathrm{A} . \mathrm{V} .=0 \mathrm{~mm}$ ó $\approx$ $0 \mathrm{~mm}$, hasta la edad de 14 días a lo sumo y Ff $=$ P.A.V. $=0 \mathrm{~mm}$ ó $\approx 0 \mathrm{~mm}$, con posterioridad, pero $<2$ años) variable, a saber:

- de 6 días y Pf1d = P.A.V. = 16 mm: El CM P-2/M 40/60,

- de 60 días y Pf1d = P.A.V. = 23 mm: El CM P-1/M 40/60,

- de 90 días y Pf14d = P.A.V. = $1.4 \mathrm{~mm}$ y antes (a 1 y a 14 días) $=0 \mathrm{~mm}$ : El CM P-31/A 40/60, y

- de 270 días y Pf1d = 23.5 mm: El CM P-31/M 40/60.

En definitiva, que en esta ocasión la creación, evolución y desarrollo de los valores de P.A.V. tomaron la forma, o bien de una línea recta y horizontal por valor nulo de P.A.V., caso del CM P-1/A 40/60, o bien de una línea recta y notablemente descendente y pendiente diversa, caso de los CM P-1, P-2 y P-31/M 40/60, o bien de una suave curva de Gauss de valores pequeños de P.A.V. y valor máximo desplazado a la izquierda, caso del CM P-31/A 40/60, o bien de una curva de Gauss pero de notables valores absolutos de P.A.V. desde el inicio del ensayo que empezaron a disminuir a las edades finales del mismo caso del CM P-31/C 40/60. 


\subsection{1.1.3- Familias $P-n^{o} / " Z " 30 / 70$.}

Parámetros $\triangle \varnothing$, VC $\varnothing$ e $\Delta \varnothing / " Z "$ (g): Vale aquí íntegramente todo lo dicho en el apartado anterior 8.1.2.6.1.1.1.1, solo que en este caso, circunscrito única y exclusivamente a la puzolana $\mathrm{M}$ con la única discrepancia apreciable habida en este caso entre las tortas de los cementos mixtos P-2/M 30/70 y P-31/M 30/70.

Parámetro P.A.V.:

1. Caso de que el Pf1d y el Ff $>365$ días hayan sido cero o valor de P.A.V. $=0$ mm ó $\approx 0 \mathrm{~mm}$ y el Tf $=0$ días y horas: El CM P-2/M 30/70.

2. Caso de que el Tf haya sido variable cuali y cuantitativamente a saber:

- $\quad$ de 6 días y Pf1d = P.A.V. = 4.5 mm: El CM P-31/M 30/70, y

- $\quad$ de 2 años y Pf1d = P.A.V. = 33 mm y P.A.V.7d-730d = 5.26 mm: El CM P-1/M 30/70.

En definitiva, que en esta ocasión la creación, evolución y desarrollo de los valores de P.A.V. tomaron la forma, o bien de una línea recta, horizontal y valor nulo, caso del cemento P2/M 30/70, o bien de una línea recta, descendiente y pendiente diversa, caso del CM P-31/M 30/70 y $\mathrm{P}-1 / \mathrm{M} 30 / 70$ por este orden.

\subsection{2- Caso de que el CP constitutivo era de nulo contenido de aluminato tricálcico, C3A, el PY-4 y el PY-6.}

\subsection{2.1-Familias $P Y-n^{o} /{ }^{\prime \prime} Z^{\prime \prime} 50 / 50$.}

Parámetros $\triangle \varnothing$, VCØ e $\Delta \varnothing / " Z "$ (g): Todas las probetas L-A de los CM preparados con el CP PY-6 y cada una de las puzolanas ensayadas O, CV19, A, C, CV10 y M, acabaron por mostrar por lo general más pronto o más tarde, unos valores de $\Delta \varnothing$ ligeramente superiores a los correspondientes de las probetas L-A de los CM preparados con las mismas y con el CP PY-4.

Parámetro P.A.V.:

1. Caso de que el Pf1d y Ff $>730$ días hayan sido cero ó valor de P.A.V. $=0$ mm ó $\approx$ 0 mm y el Tf $=0$ días y horas. Los CM PY-4/O y A 50/50 y PY-6/O, CV19 y A 50/50,

2. Caso de que el Tf haya sido variable cuali y cuantitativamente, a saber:

- de 21 días y Pf = P.A.V. = 19 mm: El CM PY-4/M 50/50,

- de 90 días y Pf = P.A.V. = 0 mm, Pf7d = P.A.V. = 5.5 mm: El CM PY-6/CV10 50/50,

- $\quad$ de 180 días y Pf1d = P.A.V. = 29.5 mm: El CM PY-4/C 50/50,

- $\quad$ de 270 días y Pf1d = P.A.V. = 2 mm y Pf7d = P.A.V. = 4 mm: El CM PY-6/C, y

- $\quad$ de $>2$ años y Pf1d = P.A.V. = 32 mm: El CM PY-6/M 50/50.

En definitiva, que, en esta ocasión, la creación, evolución y desarrollo de los valores de P.A.V. tomaron la forma, o bien de una línea recta y horizontal por valor nulo de P.A.V., caso de los CM PY-4/O y A 50/50 y PY-6/O, CV19 y A 50/50, o bien de una línea recta descendente y 
pendiente diversa, caso del resto de los CM así ensayados.

\subsection{2.2- Familias PY-no/"Z" 40/60.}

Parámetros $\Delta \varnothing$, VC $\varnothing$ e $\Delta \varnothing / " Z "$ (g): Vale aquí íntegramente todo lo dicho en el apartado 8.1.2.6.1.1.2.1, sólo que en esta ocasión única y exclusivamente para las puzolanas $\mathrm{A}$ y $\mathrm{M}$, y con las discrepancias notables habidas en este caso entre las probetas L-A de los CM P-1/A 40/60 y P31/A 40/60 por un lado y las probetas L-A de los CM P-2/M 40/60 y P-31/M 40/60 por otro.

Parámetro P.A.V.:

1. Caso de que el Tf haya sido cualitativamente común y cuantitativamente variable: de 7 días y Pf1d = P.A.V. = 23 mm: El CM PY-4/M 40/60.

En definitiva, que en esta ocasión, la creación, evolución y desarrollo de los valores de P.A.V. en todos los casos tomaron en general la forma de una línea recta y suave o notablemente descendente pero de pendiente diversa.

\subsection{2.3- Familia PY-no /"Z" 30/70.}

Parámetros $\Delta \varnothing$, VCØ e $\Delta \varnothing / " Z "$ (g): Dado que en este caso la familia en discusión queda circunscrita a un solo CM, el PY-6/M 30/70, no hay lugar por tanto realizar estudio comparativo alguno con su probeta L-A correspondiente.

Parámetro P.A.V.:

Vale aquí íntegramente todo lo dicho al respecto en el apartado anterior sólo que el Tf en este caso queda también circunscrito a 7 días y Pf1d = P.A.V. $=1 \mathrm{~mm}$.

\subsection{2.4- Familia PY-no ${ }^{\prime \prime} Z^{\prime \prime} 20 / 80$.}

Parámetros $\triangle \varnothing$, VCØ e $\Delta \varnothing / " Z "$ (g): Vale aquí íntegramente todo lo dicho en el apartado anterior 8.1.2.6.1.1.2.3.

Parámetro P.A.V.:

En este caso este parámetro proporcionó un Tf de 21 días para un Pf1d = P.A.V. = $0.5 \mathrm{~mm}$, y en definitiva la creación, evolución y desarrollo de los valores de P.A.V. tomaron la forma de una línea recta muy suavemente descendente, por los valores iniciales muy pequeños que con prontitud pasarían a la nulidad más absoluta.

\subsection{2-Con cal apagada $=\mathrm{CH}$, ni yeso}

8.1.2.6.1.2.1-Caso de que el CP constitutivo era de elevado o moderado contenido de aluminato tricálcico, $\left.C_{3} A\right)$. 


\subsection{1.1-Familias $P$ - $n$ - /"Z"}

Parámetros $\Delta \varnothing, \mathrm{VC} \varnothing$ e $\Delta \varnothing / " Z "$ (g): Vale aquí íntegramente todo lo expuesto en el apartado anterior 8.1.2.6.1.1.1.1 pero corregido y mejorado, ya que las apreciables discrepancias allí denunciadas, aquí dejan de serlo casi todas ellas por las razones justificativas que se expondrán en su correspondiente interpretación ulterior.

Parámetro P.A.V.:

1. Caso de que el Pf $f_{1 \mathrm{~d}}$ y el Ff $>730$ días hayan sido cero o valores de P.A.V. $=0 \mathrm{~mm}$ ó $\approx 0 \mathrm{~mm}:$ El CM con $\mathrm{CH}, \mathrm{P}-2 /(\mathrm{A}+\mathrm{CH})$.

2. Caso de que el Pf1d = P.A.V. $=0 \mathrm{~mm}$ y el $\mathrm{Ff}_{>730 \mathrm{~d}}=$ P.A.V. = elevado ó máximo: Los CM con $\mathrm{CH}, \mathrm{P}-1$ y $\mathrm{P}-31 /(\mathrm{O}+\mathrm{CH})$ 50/50.

3. Caso de que el Pf1d = P.A.V. $=0 \mathrm{~mm}$, desarrolle sinusoidad simple de P.A.V. máximo entre 14 y 270 días y $\mathrm{Ff}_{>730 \mathrm{~d}}=$ P.A.V.730d $=10.3 \mathrm{~mm}$ : El CM con CH, P-1/(CV19+CH) 50/50, y otro tanto se podría decir del CM con $\mathrm{CH}, \mathrm{P}-31 /(\mathrm{CV} 19+\mathrm{CH})$ 50/50, sólo que los valores de P.A.V. han sido de bastante menor valor absoluto a todas las edades del ensayo habiendo producido incluso el Ff a edad de 545 días.

4. $\quad$ Caso de que el Pf1d = P.A.V. $=1.7 \mathrm{~mm}$ y desarrollo sinusoidal simple de signo contrario al anterior, luego Ff28-120d = P.A.V. = $0 \mathrm{~mm}$ y P.A.V.150-730d creciente habiendo sido a 730 días = $34.4 \mathrm{~mm}: \mathrm{El} \mathrm{CM}$ con $\mathrm{CH}, \mathrm{P}-2 /(\mathrm{O}+\mathrm{CH}) 50 / 50$.

5. $\quad$ Caso de que el Pf1d = P.A.V. = elevado y Ff

- $\quad>2$ años (a los 545 días, caso del CM con CH, P-31/(CV10+CH) 50/50,

- $\quad$ <2 años, caso de los CM con CH, P-1/(CV10+CH) 50/50 y P-31/(CV10+CH) 50/50, y

- $\quad$ sinusoidal doble (ascendente-descendente-ascendente-descendente), caso del CM con $\mathrm{CH}, \mathrm{P}-1 /(\mathrm{C}+\mathrm{CH})$ 50/50.

En definitiva, que la creación, evolución y desarrollo de los valores de P.A.V. en este caso tomaron la forma en esta ocasión, o bien de una línea recta o sinuosamente recta por valores nulos o casi nulos de P.A.V., caso del $\mathrm{CM}$ con $\mathrm{CH}$, P-2/(A+CH) 50/50, o bien de una línea recta y ascendente, o mejor quizás la rama ascendente de una curva de Gauss, caso del $\mathrm{CM}$ con $\mathrm{CH}$, $\mathrm{P}$ $1 /(\mathrm{O}+\mathrm{CH}) 50 / 50$ y $\mathrm{P}-31 /(\mathrm{O}+\mathrm{CH}) 50 / 50$, o bien la rama descendente de la curva de Gauss, caso de los $\mathrm{CM}$ con $\mathrm{CH}$ P-1/(A+CH) 50/50 y P-2/(C+CH) 50/50, o bien de una curva de Gauss cuyo máximo valor puede estar centrado o desplazado a la derecha en punto central milimétrico del eje de abscisas comprendido entre 1 y 730 días de edad del ensayo, caso de los cementos mixtos con $\mathrm{CH}$, P-1/(C+CH) 50/50 y P-31/(CV19+CH) 50/50, y P-1/(CV19+CH) 50/50 y P-31/(CV10+CH) 50/50, respectivamente, o bien de una curva de Gauss invertida con semejantes desplazamientos de su mínimo valor que en el caso anterior, caso de los $\mathrm{CM}$ con $\mathrm{CH}, \mathrm{P}-1 /(\mathrm{CV} 10+\mathrm{CH}) 50 / 50$ y $\mathrm{P}-2 /(\mathrm{O}+\mathrm{CH})$ $50 / 50$.

\subsection{1.2- Familias $P-n \%\left({ }^{\circ} \mathrm{Z}^{\prime \prime}+\mathrm{CH}\right) 40 / 60 ;[(" \mathrm{Z} " / \mathrm{CH})=5]$.}


Parámetros $\Delta \varnothing$, VCØ e $\Delta \varnothing / " Z "$ (g): Vale aquí íntegramente todo lo expuesto en el apartado correspondiente anterior 8.1.2.6.1.2.1.1, con la única discrepancia apreciable habida en este caso entre las probetas L-A de los CM con CH, P-1/(A+CH) 40/60 y P-31/(A+CH) 40/60.

Parámetro P.A.V.:

1. Caso de que el Pf1d y el Ff $>730$ días hayan sido cero o valor de P.A.V. $=0$ mm ó $\approx 0$ mm: Los CM con CH P-1, P-2/(A y M+CH) 40/60.

2. Caso de que el valor de P.A.V. $=0.2 \mathrm{~mm}$ a 545 días: $\mathrm{El} \mathrm{CM}$ con $\mathrm{CH}$ P-31/(A+CH) $40 / 60, y$

3. Caso de que el Pf1d = P.A.V. = elevado con valor máximo a 14 días y el Ff sea $>2$ años: El CM con CH P-31/(C+CH) 40/60.

En definitiva, que la creación, evolución y desarrollo de los valores de P.A.V. en este caso tomaron la forma: o bien de una línea recta, descendente y pendiente diversa, caso de los CM con $\mathrm{CH}, \mathrm{P}-1$ y P-2/(M+CH) 40/60, o bien de una curva de Gauss de valores absolutos diferentes y valores máximos desplazados a la izquierda caso de los $\mathrm{CM}$ con $\mathrm{CH}, \mathrm{P}-1$ y $\mathrm{P}-31 /(\mathrm{M}+\mathrm{CH})$ 40/60, o bien de una curva sinusoidal de valores absolutos elevados y finalmente descendentes caso de los $\mathrm{CM}$ con $\mathrm{CH} \mathrm{P}-31 /(\mathrm{C}+\mathrm{CH}) 40 / 60$.

\subsection{1.3- Familia $P-n^{o} /\left({ }^{\prime \prime} Z^{\prime \prime}+C H\right) 30 / 70 ;\left[\left(" Z Z^{\prime \prime} / C H\right)=6\right]$.}

Parámetros $\Delta \varnothing$, VCØ e $\Delta \varnothing / " Z "$ (g): Vale aquí íntegramente la primera parte de todo lo expuesto en el apartado correspondiente anterior 8.1.2.6.1.2.1.2, ya que no existe discrepancia alguna y si en cambio concordancia con la idea general expuesta también al principio del apartado correspondiente anterior 8.1.2.6.1.2.1.1.

Parámetro P.A.V.:

1. Caso de que el Pf1d = P.A.V. $=17 \mathrm{~mm}$ y Ff $=$ P.A.V. $=0 \mathrm{~mm}$ : El CM con CH, P2/(M+CH) 30/70,

2. $\quad$ Caso cualitativamente semejante al $\mathrm{n}-4$ del apartado anterior a 8.1.2.6.1.2.1.1, $\mathrm{y}$ por tanto diferentes valores de P.A.V. en cada fase, a saber, $\mathrm{Pf}_{1 \mathrm{~d}}=$ P.A.V. $=34 \mathrm{~mm}$, P.A.V. mismo a $180 \mathrm{~d}=2.3 \mathrm{~mm}$ y P.A.V. a 730 días $=16.8$ y Ff > 2 años: El CM con CH, P-1/(M+CH) 30/70,

3. Caso cualitativamente semejante al anterior, aunque sinusoidal doble con Pf1d = P.A.V. máximo $=22.5 \mathrm{~mm}, 1^{\circ}$ P.A.V. mayor a 90 días $=1.5 \mathrm{~mm}, 2^{2}$ P.A.V. mínimo a 150 días $=0.9$ mm, P.A.V. a 730 días $=4.5$ mm y Ff > 2 años: $\mathrm{El} \mathrm{CM}$ con $\mathrm{CH}, \mathrm{P}-31 /(\mathrm{M}+\mathrm{CH})$ 30/70.

En definitiva, que la creación, evolución y desarrollo de los valores de P.A.V. en este caso tomaron la forma, o bien de una línea recta y descendente, caso del $\mathrm{CM}$ con $\mathrm{CH}, \mathrm{P}-2 /(\mathrm{M}+\mathrm{CH})$ 30/70, o bien de una curva de Gauss invertida y valor mínimo centrado y diferentes valores absolutos caso de los CM con CH, P-1 y P-31/(M+CH) 30/70. 
COMPORTAMIENTO SULFÁTICO Y MECÁNICO-RESISTENTE DE CEMENTOS PORTLAND CON ELEVADOS CONTENIDOS DE PUZOLANAS ( $>40 \%$ ): SU FUNDAMENTO QUÍMICO Y JUSTIFICACIÓN DE OTRAS CONSECUENCIAS POSIBLES

\subsection{2-Caso de que el CP constitutivo era de nulo contenido de C3A, el PY-4 y el PY-6.}

\subsection{2.1-Familias PY-no/"Z" 50/50, [("Z"/CH) = 4].}

Parámetros $\Delta \varnothing$, VCØ e $\Delta \varnothing / " Z "$ (g): Vale aquí íntegramente todo lo expuesto en el apartado anterior 8.1.2.6.1.2.1.

Parámetro P.A.V.:

1. Caso de que el Pf1d y el Ff $>730$ días hayan sido cero o valor de P.A.V. $=0$ mm ó $\approx 0 \mathrm{~mm}$ y Tf $=0$ días y horas: $\mathrm{El} \mathrm{CM}$ con $\mathrm{CH}, \mathrm{PY}-6 /(\mathrm{O}+\mathrm{CH})$ 50/50,

2. Caso de que la P.A.V. desde 1 a 120 días $=0 \mathrm{~mm}$, el $P f_{150 \mathrm{~d}}=0.2$ y $3 \mathrm{~mm}$, respectivamente y $\mathrm{Pf}_{365 \mathrm{~d}}=23.1 \mathrm{~mm}$, y en notable aumento con el transcurso del ensayo, y el $\mathrm{Ff}$ >730 días: $\mathrm{Los} \mathrm{CM}$ con $\mathrm{CH}, \mathrm{PY}-6 /(\mathrm{CV} 19$ y A+CH) 50/50 y P-1/(A+CH) 50/50.

3. $\quad$ Caso de que el Pf1d $=$ P.A.V. $=15$ y $0.5 \mathrm{~mm}$, respectivamente, con $\mathrm{Ff}_{150 \mathrm{~d}}=0 \mathrm{~mm}$, caso de los $\mathrm{CM}$ con $\mathrm{CH}$, PY-4 y PY-6/(C+CH) 50/50, o con desarrollo sinusoidal múltiple y descendente con el transcurso del ensayo, caso del CM con CH, PY-6/(CV10+CH) 50/50.

En definitiva, que la creación, evolución y desarrollo de los valores de P.A.V. en este caso tomaron la forma de una línea recta y descendente con notable pendiente que alcanza su nulidad con notable prontitud.

\subsection{3-Sin cal apagada $=C H, y$ con yeso}

Antes de continuar con la presente discusión, se ha de hacer constar que a continuación se realizarán los análisis y estudios comparativos a igualdad de masa de los constituyentes del CM correspondiente, dado que los que han tenido que ser preparados por motivos subsidiarios de los resultados experimentales confirmativos de las hipótesis de trabajo de partida, lo han sido unitarios y en exclusiva.

De aquí la imposibilidad de poder constituir "familias" de $n^{o}$ de individuos o CM de laboratorio de "progenitor" común, es decir, de CP P-nº ó PY-no, común, y si en cambio y únicamente "familias de masa común".

Así pues y según ello, las discusiones a realizar a continuación serán las siguientes:

\subsection{1-Caso de que el CP constitutivo era de elevado o nulo contenido de aluminato} tricálcico, $\left.C_{3} A\right)$.

\subsection{1.1-Familias [(P-1 ó PY-6/M 30/70)+7.0\% SO $)$ ]}

Esta familia está constituida por dos cementos mixtos únicamente diferenciados tan sólo en el CP que los constituye. Ya que en un caso fue el P-1 $\left(14.11 \% \mathrm{C}_{3} \mathrm{~A}\right)$ y en el otro el PY-6 $(0.00 \%$ $\left.\mathrm{C}_{3} \mathrm{~A}\right)$. 
Parámetros $\Delta \varnothing$, VCØ e $\Delta \varnothing / " Z "$ (g): La creación, evolución y desarrollo de los valores de estos parámetros de sus probetas L-A respectivas a lo largo de todo el ensayo han resultado ser contrarios a lo que en teoría y por estequiometria cabía esperar.

Parámetro P.A.V.

En esta ocasión el Pf1d y Ff >730d han sido cero o valores de P.A.V. $=0$ mm y Tf $=0$ días y horas. En definitiva, que la creación, evolución y desarrollo de los valores de P.A.V. en ambos casos ha sido el de una línea recta por nulidad de tales valores.

\subsection{1.2-Familias $\left.\left[(\mathrm{PY}-6 / \mathrm{M} 20 / 80)+7.0 \% \mathrm{SO}_{3}\right)\right]$}

Dado que en esta ocasión la "familia" en discusión queda circunscrita a un solo CM, el [(PY-

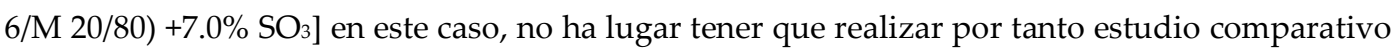
alguno, aunque si quizás pueda realizarse en alguna medida cierta y como así ha sido el caso, con las tortas de sus correspondientes "hermanos mayores" anteriores [(P-1/M 30/70) $\left.+7.0 \% \mathrm{SO}_{3}\right]$ y $\left[\left(\mathrm{PY}-6 / \mathrm{M} \mathrm{30/70)}+7.0 \% \mathrm{SO}_{3}\right]\right.$, respectivamente.

Así pues y según ello el estudio comparativo que referimos queda como sigue:

Parámetros $\Delta \varnothing$, VCØ e $\Delta \varnothing / " Z "$ (g): La creación, evolución y desarrollo de los valores de estos parámetros de sus probetas L-A respectivas a lo largo de todo el ensayo han resultado ser como cabía esperar prácticamente iguales y nulos o casi nulos en todos los casos. Y la ligera discrepancia mostrada por la probeta L-A del CM PY-6/M 30/70, no debe de preocupar en exceso.

Parámetro P.A.V.:

1. Caso de que el Pf1d y Ff $>730 \mathrm{~d}$ han sido cero o valor P.A.V. $=0 \mathrm{~mm}$ y $\mathrm{Tf}=0$ días y horas: Los CM con yeso [(P-1 y PY-6/M 30/70) +7.0\% SO3 3 , y

2. $\quad$ Caso de que el Pf1d = 1, evolución y desarrollo sinusoidal múltiple y de valores pequeños a lo largo del ensayo, valor del P.A.V.730d $=0.2 \mathrm{~mm}$ y Ff $730 \mathrm{~d}$ : El CM con yeso [(PY-6/M $\left.20 / 80)+7.0 \% \mathrm{SO}_{3}\right]$.

En definitiva, que la creación, evolución y desarrollo de los valores de P.A.V. en este caso último, ha resultado ser una línea suavemente sinuosa de valores pequeños.

8.1.2.6.1.4-Con cal apagada $=\mathrm{CH}, \mathrm{y}$ con yeso

8.1.2.6.1.4.1-Caso de que el CP constitutivo era de elevado o nulo contenido de aluminato tricálcico, $\left.C_{3} A\right)$.

\subsection{1.1-Familias [(P-1 ó PY-6/(M+CH) 30/70) +7.0\% SO3)]}

Parámetros $\Delta \varnothing, \mathrm{VC} \varnothing$ e $\Delta \varnothing / " \mathrm{Z} "$ (g): Vale aquí todo lo dicho al respecto en el apartado anterior 8.1.2.6.1.3.1.2., sólo que la creación, evolución y desarrollo de los valores del $\Delta \varnothing$ de sus 
probetas L-A respectivas han resultado ser en esta ocasión concordantes a lo que en teoría por estequiometría cabía esperar.

Parámetro P.A.V.:

En esta ocasión el Pf1d, Ff $>730 \mathrm{~d}$ ha sido cero o valor de P.A.V. $=0 \mathrm{~mm}$ y Tf $=0$ días y horas. En definitiva, que la creación, evolución y desarrollo de los valores de P.A.V. en este caso ha resultado ser una línea recta por nulidad de tales valores.

\subsection{1.2-Familias $\left.\left[(P Y-6 /(M+C H) 20 / 80)+7.0 \% S O_{3}\right)\right]$}

Parámetros $\Delta \varnothing, \mathrm{VC} \varnothing$ e $\Delta \varnothing / " Z "$ (g): Vale aquí íntegramente todo lo dicho al respecto en el correspondiente apartado anterior 8.1.2.6.1.4.1.1.

Parámetro P.A.V.:

Vale aquí íntegramente todo lo dicho al respecto en el correspondiente apartado anterior 8.1.2.6.1.4.1.1. En definitiva, que la creación, evolución y desarrollo de los valores de P.A.V. en este caso ha resultado ser una línea recta por nulidad de tales valores.

\subsubsection{2-Análisis y Estudio Comparativo en RS, INTERNO:}

Es el que ha sido realizado entre los tres o los dos cementos mixtos y derivados con cal apagada que componen por lo común una familia dada de CP P-nº ó PY-nº común.

\subsection{1-A igualdad de familia de cementos mixtos y derivados con cal apagada de CP P-noó}

PY-no común. Parámetros $\triangle \emptyset, V C \varnothing, \Delta \emptyset / g$ "Z" y P.A.V.

(1) Sea cual fuere la familia de cementos mixtos que se considere, se ha producido por lo general más pronto o más tarde según el caso y como era lo lógico, -según nuestras hipótesis de partida y planteamientos de actuación para realizar esta investigación-, una mayoría notable e incluso muy notable en ocasiones, de los valores de los parámetros $\Delta \varnothing$, VCØ, $\triangle \varnothing / g$ "Z" y P.A.V. de los cementos mixtos derivados con $\mathrm{CH}$ sobre los correspondientes $\sin \mathrm{CH}$, véase la Tabla 8-43.

TABla 8-43.- VALORES DE lOS PARÁmetros $\Delta \varnothing$, VC $\varnothing, \Delta \varnothing / G$ "Z" Y P.A.V. DE LOS CEMENTOS MIXTOS DERIVADOS CON CH SOBRE LOS CORRESPONDIENTES SIN CH.

\begin{tabular}{rll}
\hline$<\Delta \varnothing<\mathrm{Vc} \varnothing<\Delta \varnothing /$ g "Z" $<$ P.A.V. $<$ & P-nº y PY-no/"Z" & $100 / 00>60 / 40>50 / 50>40 / 60>30 / 70$ \\
& P-nº y PY-no $/(" Z "+C H)$ & $60 / 40>50 / 50>40 / 60>30 / 70$ \\
\hline
\end{tabular}

(2) En todas las familias de cementos mixtos y derivados con $\mathrm{CH}$ se ha verificado por lo general que los valores de los cuatro parámetros determinados $\Delta \varnothing, \mathrm{VC} \varnothing, \Delta \varnothing / \mathrm{g} " \mathrm{Z} " \mathrm{y}$ P.A.V., ha disminuido con la adición de puzolana "Z", véase la relación expuesta en la discusión anterior. Esta generalidad dejó de cumplirse en las familias P-1/M 50/50, 40/60 y $30 / 70$ por un lado y $\mathrm{P}-2 /(\mathrm{M}+\mathrm{CH}) 30 / 70$ y $20 / 80$ por otro. 


\subsubsection{7-Análisis, Estudio, Discusión e Interpretación de los parámetros $\Delta \emptyset$, y P.A.V.}

Antes de comenzar estas interpretaciones se desea aclarar que todas ellas se van a llevar a cabo mediante los parámetros $\Delta \varnothing$ y P.A.V., principalmente dado que sus derivados correspondientes VCØ y $\triangle \varnothing / g$ "Z", han confirmado las hipótesis de trabajo previas sustentados sobre los mismos, aunque no obstante y con posterioridad tendrán tratamiento propio.

\subsubsection{1- De la Discusión 8.1.2.5.1.1.1.1.: Familias de CM P-no/"Z" 50/50.}

Parámetro $\triangle \varnothing$ :

El hecho denunciado al final del apartado que aquí se interpreta, referente al parámetro $\Delta \varnothing$, y que se refiere a que a las edades finales del ensayo mayormente los valores del $\Delta \varnothing$ de las probetas L-A de los CP solos, o sea, del P-1, P-2, P-31, PY-4 y PY-6, han resultado ser netamente mayores que los de sus familias de cementos mixtos derivadas respectivas, habiendo ocurrido todo lo contrario a las edades iniciales del ensayo y mayormente en los $\mathrm{P}-\mathrm{n}^{\mathrm{o}}$, ha sido debido al ESE (Talero, 2010; 2011a; 2011b) habido en cada caso entre la ett-rf originada de la puzolana "Z" de turno y la ett-lf originada del $\mathrm{C}_{3} \mathrm{~A}$ del CP P-nº mayormente, que la acompaña.

Por otra parte, los hechos denunciados:

a) Por un lado, que los valores de $\Delta \varnothing$ y P.A.V. hayan resultado ser mayores cuantitativamente y durante más tiempo en el caso de las probetas L-A de los cementos mixtos $\mathrm{P}-31 / \mathrm{O}$ 50/50 y P-31/M 50/50 que en el caso de las probetas L-A de los cementos mixtos P-1/O 50/50 y P-1/M 50/50, hubo de obedecer necesariamente a las mismas razones. $\mathrm{Y}$ estas razones no pudieron ser otras que el mayor contenido de $\mathrm{C}_{3} \mathrm{~S}$ del CP P-31 (58.70\%) sobre el P-1 (51.08\%), que debió haber proporcionado una mayor basicidad de origen portlandita en el tiempo, de la fase líquida correspondiente, lo que a su vez se debió haberse traducido,

1. en un mayor ESE entre la ett-lf y el gel del $\mathrm{Fe}(\mathrm{OH})_{3}$ proveniente de la puzolana $\mathrm{O}$ -la cual no debemos de olvidar que en su composición química tiene un contenido de $\mathrm{Fe}_{2} \mathrm{O}_{3}$ del 13.82\%-, según Martín Luengo (1997), y

2. en un menor ESE entre la ett-rf y la ett-lf según Talero (1986), en el caso de la probeta L-A del CM P-1/M 50/50 que en la del P-31/M 50/50.

Esta razón aducida del mayor contenido de $\mathrm{C}_{3} \mathrm{~S}$ del CP P-31 sobre el P-1, se vio reforzada además por los siguientes hechos:

i. $\quad$ Por el comportamiento de los valores de tales parámetros $\Delta \varnothing$ y P.A.V., de la probeta L-A del CM P-2/O 50/50 que aún resultaron ser menores todavía que los de las probetas L-A del P-1/O 50/50 y P-31/O 50/50, respectivamente, dado que el valor de dicho contenido de C3S del P-2 era y es menor aún y para más señas el menor de todos ellos, 33.47\%, incluidos el PY-4 y el PY-6.

ii. Por el comportamiento totalmente contrario de las probetas L-A correspondientes con cal apagada, es decir, la $\mathrm{P}-1 /(\mathrm{O}+\mathrm{CH}) 50 / 50$ y la $\mathrm{P}-31 /(\mathrm{O}+\mathrm{CH}) 50 / 50$ y sus probetas L-A 
equivalentes en objetivos para justificar este caso P-nº y PY-no/(M+CH) $>50 / 50$, que ya si atendrían a lo que en teoría cabía esperar de ellas en un principio pudiéndose llegar incluso a incluir en el mismo, el comportamiento de la probeta L-A P-2/(O+CH) $50 / 50$ que tan sólo llegó a superar en por muy poco a los 545 días $\Delta \varnothing$ y algo más en P.A.V. y a las edades finales del ensayo como era lo lógico, a la probeta L-A P$31 /(\mathrm{O}+\mathrm{CH})$ mientras que en resto de las edades del ensayo le fue a la zaga probablemente por la causa aducida de tener el CP P-2 el menor contenido de $\mathrm{C}_{3} \mathrm{~S}$ de los tres, $\mathrm{y}$

iii. Por el comportamiento más generalizado del resto de los cementos mixtos correspondientes preparados con las adiciones puzolánicas CV19, A, C y CV10, mayormente, en los que al empezar a dejar de ser más "silícicas" para empezar a ser más "alumínicas", especialmente las dos últimas que son claramente "alumino-silícicas", habría podido originarse en tales casos mayor ESE y consiguientemente mayor $\Delta \varnothing$ cuanto mayor contenido de $\mathrm{C}_{3} \mathrm{~A}$ poseyera el $\mathrm{CP}$ que la hubiese acompañado unido al suficiente de $\mathrm{C}_{3} \mathrm{~S}$ (en este caso $51.5 \%$, el P-1) para proporcionar el medio básico portlandítico necesario y suficiente para ello.

De aquí que si en tales casos de las puzolanas CV19, A, C y CV10, el CP no hubiera poseído cantidad suficiente de $\mathrm{C}_{3} \mathrm{~A}$ (7.62\% el P-31) y/o de $\mathrm{C}_{3} \mathrm{~S}$ (33.47\% el P-2), se habría producido menor ESE y consiguientemente menor $\triangle \varnothing$, VCØ y $\triangle \varnothing / \mathrm{g}$ "Z", como así ha sido el caso con dichas puzolanas y tales CP P-31 y P-2 respectivamente, así como también con la puzolana "C" en los CM P-1/C 50/50 y PY-6/C 50/50, lógicamente.

b) Por otro, que los valores de $\triangle \varnothing, \mathrm{VC} \varnothing$ y $\Delta \varnothing / \mathrm{g}$ "Z" de la probeta L-A P-31/M 50/50 hubieran resultado ser mayores que los de la probeta L-A P-1/M 50/50 cuando por estequiometria debería de haber ocurrido todo lo contrario, vino a demostrar que a pesar del exceso de yeso en ambos cementos mixtos -el 33.33\%-, el último, o sea el P-1/M 50/50, debió estar más cerca de su cantidad "Óptima de Regulador de Fraguado" según Talero, (1986) que el P-31/M. De aquí que aquel tendiera a finalizar su fraguado más pronto que éste o lo que es equivalente en este caso, que la disminución de los valores de P.A.V. de su probeta L-A fuera más acusada a las edades iniciales del ensayo, como así ha ocurrido en nuestra investigación, véanse tales valores del P.A.V. en la tabla P.A.V. P-nº/"Z" 50/50, sin olvidar tampoco la razón antes aludida de la menor cantidad de C3S del CP P-1 que el P-31, con sus posibles influencias adicionales al caso a saber, menor cantidad en el tiempo de portlandita en la fase liquida y menores fuerzas de signo contrario expansoras $<>$ fraguadoras o endurecedoras, $\mathrm{y}$

c) Por otro, los notables valores de $\triangle \varnothing$, VC $\varnothing$ e $\Delta \varnothing / " Z "$ (g) alcanzados por la puzolana CV19 en su probeta L-A P-1/CV19 50/50 y no así en cambio en su probeta L-A P31/CV19 50/50, pusieron de manifiesto que la formación del total de ettringita que en mayor cantidad y por estequiometria, se debió formar, en la primera, debió favorecer una más y mayor formación de los geles de hidróxido férrico, $\mathrm{Fe}(\mathrm{OH})_{3}$, que el notable contenido de $\mathrm{Fe}^{3+}$ en dicha puzolana debió de formar en el medio básico portlandítico (como demostró Martín Luengo, (1997)) por cuya expansividad adicional se debió ver aquella más coadyuvada que ésta. 


\section{Parámetro P.A.V.:}

1. La rectilineidad y horizontalidad por nulidad más o menos acusada de los valores de P.A.V. en la probeta L-A P-1/O 50/50, unido a la no nulidad de los valores correspondientes de $\Delta \varnothing$ de su probeta L-A, significaría que la pasta cementante selenitosa había fraguado y endurecido con prontitud, bien por el ESE adecuado para ello, o bien por falta de cantidad de portlandita (hidróxido de calcio sintético) de la hidratación de la fracción P-1 que la acompañaba y, que sería necesaria y suficiente para que la cantidad de puzolana "Z" presente -la "O" en este caso- hubiera podido mostrar su auténtico y verdadero "carácter", habiendo tenido a actuar por tanto más como INERTERS que como tal puzolana.

Y la conformidad de la veracidad de esta última hipótesis se obtuvo con la probeta L-A de dicha puzolana $\mathrm{O}$ y cal apagada, $\mathrm{CH}$, la cual por lo general perdió la nulidad de tales valores de P.A.V. y por consiguiente la horizontalidad de los mismos, transformándose en una curva de Gauss con su valor máximo en las edades finales de ensayo al igual que la de los CP puros P-1 y P-31 (no en vano el 50\% de $14.11 \% \mathrm{C}_{3} \mathrm{~A}$ del P-1 $=7.05 \% \mathrm{C}_{3} \mathrm{~A}$ ), lo que indicaba en definitiva que la puzolana O había actuado en este caso más como INERTES que como puzolana "silícicoalumínica".

2. La rectilineidad y disminución más o menos acusada y rápida de los valores de P.A.V., unido, o no, a la consecución rápida de los máximos valores de $\Delta \varnothing$ de su probeta L-A para permanecer prácticamente descendentes durante casi todo el ensayo, indicarían claramente, que la puzolana "Z" había de ser necesariamente "alumínica" o "alumínico-silícica", y que entre la $\mathrm{Al}_{2} \mathrm{O}_{3}{ }^{\mathrm{r}-}$ de la citada puzolana "Z" y el $\mathrm{C}_{3} \mathrm{~A}$ del CP P-no que la acompañaba, se tuvo que producir un ESE tanto mayor cuanto más "alumínica" que "silícica" fue la citada puzolana "Z", como así ha sido el caso, véanse las probetas L-A de los cementos mixtos P-31/C 50/50 y P-31/M 50/50.

3. La curva de Gauss con el valor máximo de P.A.V. de la probeta L-A centrado, pero más o menos desplazado a la derecha o a la izquierda, tenía y tiene diferentes significados según sea el caso:

Así, si dicho valor máximo de P.A.V. se encuentra desplazado a la izquierda, la puzolana "Z" deberá ser en tales proporciones 50/50 más "alumínica" que "silícica" y por consiguiente habrá podido provocar un ESE tanto mayor cuanto mayor sea el contenido de $\mathrm{C}_{3} \mathrm{~A}$ del $\mathrm{CP}$ que la acompañe como así ha sido el caso, véanse al efecto las probetas $\mathrm{L}-\mathrm{A}$ de los cementos mixtos P1/A y P-31/CV10 50/50, cabiendo además la posibilidad adicional de que la cantidad de $\mathrm{C}_{3} \mathrm{~A}$ del $\mathrm{CP}$ que le acompañe, sea excedentaria en yeso para provocar dicho ESE, en cuyo caso el valor máximo de la curva de Gauss, se debería ver por el contrario desplazado a la derecha lo que vendría a indicar que la puzolana "Z" en cuestión habría y ha de ser no obstante, más "silícica" que "alumínica" o aún siendo lo contrario, no serlo lo suficiente en tales proporciones 50/50, caso de la probeta L-A del CM P-1/C 50/50, y del CM con cal apagada P-2/(O+CH) 50/50, e incluso, no ser máximo sino mínimo y provocar una curva de Gauss invertida, en cuyo caso la puzolana "Z" en cuestión habría y ha de ser, como se dijo al principio, más "alumínica" que "silícica" o aún siendo lo contrario, serlo lo suficiente en tales proporciones $50 / 50$, sobre todo con $\mathrm{CH}$, caso de la probeta L-A del CM P-1/C 50/50, y del CM con CH P-2/(O+CH) 50/50,para que al final de la acción 
puzolánica correspondiente en dicho medio tan selenitoso el $\mathrm{C}_{3} \mathrm{~A}$ residual origine expansiones ulteriores y valores de P.A.V. correspondientes que asemejarían en mayor o menor grado a los del CP P-2 sólo en este caso como así ha ocurrido en esta investigación. E incluso que no sea excedentaria, sino estequiométrica para dicho fin, en cuyo caso el valor máximo de P.A.V. se produciría a las edades iniciales, 1 día mayormente, para a continuación disminuir progresivamente hasta la finalización del ensayo y la curva de Gauss dejaría de serlo para transformarse en una línea más o menos recta pero progresivamente descendente, caso de las probetas L-A de los cementos mixtos P-31/C y M 50/50; y en el caso de que a las edades finales de ensayo ascendiese mucho o poco, nos encontraríamos en el último caso anterior, bien por ett-rf, caso de las probetas L-A de cementos mixtos con y sin cal apagada P-1/M 30/70 y P-1/(M+CH) 30/70, bien por ett-lf, caso de la probeta L-A del CM P-1/C 50/50.

\subsubsection{2-De la Discusión 8.1.2.5.1.1.1.2.: Familias de CM P-no/"Z" 40/60.}

\section{Parámetro $\triangle \varnothing$ :}

La discrepancia habida en esta ocasión entre los valores de $\Delta \varnothing$ de las probetas L-A de los cementos mixtos P-1/A 40/60 y P-31/A 40/60 por un lado y las probetas L-A de los cementos mixtos P-2/M 40/60 y P-31/M 40/60 por otro, ha de tener la misma interpretación que la dada antes para las probetas L-A de los cementos mixtos P-1/O 50/50y P-31/O 50/50, véase la Interpretación de la Discusión 8.1.2.6.1., no habiéndose corroborado al parecer en principio y por escaso margen en este otro caso, por el comportamiento de las probetas L-A correspondientes con cal apagada, porque a pesar de contener la misma cal apagada, no deberemos olvidar que venía realizando los ensayos en el sentido de "diluir" en cal apagada el sistema CP + puzolana "Z", lo que en algunos casos como el que se interpreta, pudo quizás no ser aún cantidad suficiente y necesaria de cal apagada, para que tales probetas L-A hubieran podido mostrar el previo comportamiento totalmente contrario, es decir, que el $\Delta \varnothing x d$ del P-1/(A+CH) 40/60 fuera > P-31/(A+CH) 40/60, como hubiera sido lo deseado.

No obstante, cuando se examina con detenimiento en esta última comparación aludida, véase las Figs. 8-1, 8-2, 8-3, 8-4 y 8-5, se pudo observar que al menos durante las tres primeras edades del ensayo de 7,14 y 21 días, si se produjo esa tan deseada relación $\triangle \varnothing x d$ del P-1/(A+CH) $40 / 60>\Delta \varnothing x d$ del P-31/(A+CH) 40/60. Y en tal medida y forma que pudo ver adscrita al ESE producida entre la cantidad de $\mathrm{C}_{3} \mathrm{~A}$ aportada por la fracción del CP P-1, 7.05\% a dicha probeta L$\mathrm{A}, \mathrm{y}$ la de $\mathrm{Al}_{2} \mathrm{O}_{3}{ }^{\mathrm{r}-}$ aportada igualmente por la fracción de puzolana $\mathrm{A}$, a la misma, con sus al parecer implicaciones tecnológicas beneficiosas en este caso de haber podido obligar la $\mathrm{Al}_{2} \mathrm{O}_{3^{r}}$ de esta última fracción A y además esto de su $\mathrm{SiO}_{2}{ }^{r^{-}}$y $\mathrm{Fe}_{2} \mathrm{O}_{3}{ }^{\mathrm{r}-}$ y mediante la formación de su ett-rf, a que el 7.05\% de $\mathrm{C}_{3} \mathrm{~A}$ aportado por la fracción del CP P-1 que la acompañaba, formara también inmediatamente, tras de aquella y de forma más o menos solapada con ella toda la ett-lf-aunque en estas circunstancias adecuadas en forma de ett-rf también según Talero, (1986)- que por estequiometria era capaz también de formar. De aquí que al no haberse podido formar con posterioridad y hasta la finalización del ensayo más ettringita de cualquier origen y etiología, la probeta L-A correspondiente P-1/(A+CH) 40/60 no aumentó su $\Delta \varnothing$ y su P.A.V. fue nulo, véanse 
las Figs. 8-1, 8-2, 8-3, 8-4 y 8-5.

Y si en tales probetas L-A 40/60, los granos de clínker Portland con sus moléculas de $\mathrm{C}_{3} \mathrm{~A}$ hubieran estado más alejadas de las de $\mathrm{Al}_{2} \mathrm{O}_{3}{ }^{\mathrm{r}-}$ de la PUZOLANA A por menor presencia, 3.81\% en el caso de la probeta L-A P-31/(A+CH) 40/60, el correspondiente ESE, se debería haber producido en este caso con mayor dificultad, es decir, más lentamente y en menor cantidad en cualquier caso, por mayor distancia entre una molécula de $\mathrm{C}_{3} \mathrm{~A}$ y otra de $\mathrm{Al}_{2} \mathrm{O}_{3}{ }^{\mathrm{r}}$. De esta manera

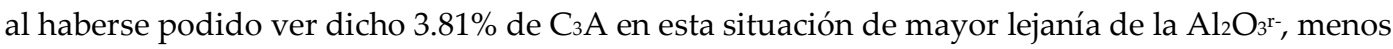
sustraído, impulsado o arrastrado a formar ettringita a continuación o a la par que la originada, ett-rf, por la $\mathrm{Al}_{2} \mathrm{O}_{3}{ }^{\mathrm{r}-}$ de la puzolana A debido a la acción puzolánica de ésta en este medio con $\mathrm{CH}$ tan selenitoso, habría podido quedar más libre para poder formar toda la que debía formar más lentamente y en definitiva a edades más tardías o finales del ensayo y en definitiva a la velocidad semejante a la del correspondiente CP sólo. Con lo cual y para tales edades intermedias y mejor tardías del ensayo, los valores, de $\Delta \varnothing$ de la probeta L-A P-31/(A+CH) 40/60 deberían haber sido mayores que los de la probeta L-A P-1/(A+CH) 40/60, y los de P.A.V. también y en forma quizás de curva de Gauss durante algunas edades intermedias o finales del ensayo, como así ha ocurrido en esta investigación, véanse las Figs. 8-1, 8-2, 8-3, 8-4 y 8-5.

Y esta hipótesis explicativa se ve fortalecida además por el hecho de que si bien el $\Delta \varnothing x d$ del P-1/(A+CH) 40/60 ha resultado ser < P-31/(A+CH) 40/60, en la mayor parte de la edad del ensayo, no deberemos olvidar que la diferencia de $\Delta \varnothing_{\max }$ alcanzadas por tales probetas L-A con y sin cal apagada, se vió disminuida con la presencia de dicha cal apagada. Así, sin cal apagada dicho valor de $\Delta \varnothing_{\max }$ a 3 años, resultó ser de $8.15 \%=10.61 \%-2.64 \%$, mientras que con cal apagada resultó ser $5.11 \%=17.33 \%-12.22 \%$, es decir, prácticamente 3 unidades menor.

Y este hecho se vería corroborado más y mejor aún lógicamente, por aquellas otras puzolanas con mayor y mejor disponibilidad de su $\mathrm{Al}_{2} \mathrm{O}_{3}{ }^{\mathrm{r}-}$ caso de la $\mathrm{C}$ y $\mathrm{M}$ y por aquellos $\mathrm{CP}$ claramente belíticos caso del P-2, como los valores de $\Delta \varnothing$ y P.A.V. del P-2/M 40/60 resultaron ser $<\mathrm{P}-2 /(\mathrm{M}+\mathrm{CH})$ 40/60, y los valores de $\Delta \varnothing$ y P.A.V. del PY-6/(M+CH) resultaron ser también $<$ PY$6 /(\mathrm{M}+\mathrm{CH})$ 40/60, viéndose corroborado este último caso además, porque la intensidad de pico de la ett-rf ó de origen PY-6/M 40/60, fue = $13<$ que la de origen PY-6/(M+CH) 40/60 = 53, véanse las Figs. 8-1, 8-2, 8-3, 8-4 y 8-5.

Parámetro P.A.V.

1. La rectilineidad y horizontalidad por nulidad más o menos acusada de los valores de P.A.V., tenía idénticas razones explicativas que las proporcionadas para el caso de las correspondientes probetas L-A de los cementos mixtos 50/50.

2. La rectilineidad y disminución más o menos acusada y rápida de los valores de P.A.V., tenía idénticas razones explicativas que las proporcionadas para el caso de las correspondientes probetas L-A de los cementos mixtos 50/50.

3. La suave curva de Gauss pero de valores absolutos de P.A.V., elevados y al final descendentes, tenía idénticas razones explicativas que las proporcionadas para el caso de las correspondientes probetas L-A de los cementos mixtos 50/50. 
Por último y para el caso de la probeta L-A P-31/C 40/60 sin interpretación se hará al final de este apartado.

\subsubsection{3-De la Discusión 8.1.2.6.1.1.1.3.: Familias de CM P-no/"Z" 30/70.}

Parámetro $\triangle \varnothing$ :

En esta ocasión al quedar circunscrita la puzolana "Z" a la M resultó todo mucho más fácil de interpretar.

Así la causa por la que la probeta L-A del CM P-1/M 30/70 ha proporcionado menores valores de $\Delta \varnothing$ a lo largo de todo el ensayo que la probeta L-A P-31/M 30/70, ha de ser achacable necesariamente a su menor disponibilidad de portlandita a lo largo de todo el ensayo como consecuencia del notable menor contenido de C3S de su CP P-2 (33.47\% C3S) en comparación al del P-31 (58.70\% $\left.\mathrm{C}_{3} \mathrm{~S}\right)$.

Y este parámetro es tan fundamental para que la cantidad presente de la puzolana "Z" de turno -la $\mathrm{M}$ en esta ocasión- pueda proporcionar toda la cantidad de ett-rf que ella es capaz de formar junto con la de origen $\mathrm{C}_{3} \mathrm{~A}$ ó ett-lf del cemento Portland que le acompañe, que la probeta L-A del CM P-1/M 30/70 aun habiendo proporcionado mayores valores de $\Delta \varnothing$ que todas las demás y sobre todo y por la razón apuntada que la P-31/M 30/70, no lo ha sido tanto apenas $\approx$ $1.0 \%$ de diferencia, y no la mitad de una a otra, cómo en el principio y por simple estequiometria, cabía haber espesar, ya que el CP P-1 tiene un $14.11 \%$ de $\mathrm{C}_{3} \mathrm{~A}$ para poder formar ett-lf mientras que el P-31 sólo tiene $7.62 \% \mathrm{C}_{3} \mathrm{~A}$, o sea prácticamente la mitad, para igual fin. Por tanto, el no haberse podido producir tal diferencia porcentual de $\Delta \varnothing$ de sus probetas L-A y si en cambio y tan sólo el 1\%, ha de ser achacado también y necesariamente a idéntica razón anterior es decir a que el contenido de $\mathrm{C}_{3} \mathrm{~S}$ del P-31, 58.70\%, es también mayor que el del P-1, 51.05\%.

Y esta razón se ve reforzada además cuando al ponerle cal apagada a las probetas L-A en estudio, las diferencias de $\Delta \varnothing$ entre las probetas L-A P-1/(M+CH) 30/70 y P-31/(M+CH) 30/70 se incrementaron lógicamente, a favor de la primera, mientras que, las notables diferencias de $\Delta \varnothing$ entre las probetas L-A P-2/(M+CH) 30/70 y P-31/(M+CH) 30/70, se aminoraron, como era lógico.

Y el motivo por el que en todos los casos la creación, evolución y desarrollo de los valores de $\Delta$ h P.A.V. tomó la forma de una suave curva de Gauss, se hubo de deber al hecho de que tras haberse provocado en todos ellos su ESE respectivo, el material expandido y no cohesionado, simplemente por gravedad, se colapsó; de aquí que a las alturas de tales probetas L-A les ocurriera otro tanto, corregido y aumentado.

Parámetro P.A.V.

1. La rectilineidad y horizontalidad por nulidad, tiene las mismas razones explicativas que las proporcionadas para el caso de las correspondientes probetas L-A de los cementos mixtos 50/50, las cuales se podrían resumir en que la "dureza ficticia" de la probeta LA no le viene por estar fraguada sino más bien por el simple hecho de su prensado inicial a la hora de prepararla. Y una prueba de ello es que el valor de $\Delta \varnothing$ fue muy bajo a lo largo de todo 
ensayo.

2. La rectilineidad y disminución acusada y rápida de los valores de P.A.V. tiene idénticas razones explicativas que las proporcionadas para el caso de las correspondientes probetas L-A de los cementos mixtos 50/50, unidas a la falta de la portlandita, $\mathrm{Ca}(\mathrm{OH})_{2}$, necesarios para poder mostrar esta puzolana $\mathrm{M}$ en este parámetro otra creación, evolución y desarrollo de este. De aquí que este hecho variacional se pudiera manifestar cuando la cal apagada estuvo presente, en cuyo caso y lógicamente,

- La probeta L-A P-2/(M+CH) 30/70 ha mostrado semejante comportamiento a cuando se encontraba sin cal apagada, aunque mucho más cuantificado o de mayores valores absolutos, y

- Las probetas L-A P-1/(M+CH) 30/70 y P-31/(M+CH) 30/70 ya han podido mostrar con claridad dos fases claramente diferenciadas en su curva de Gauss invertida respectiva: la primera rama descendente correspondiente a la expansividad de la ett-rf o de origen puzolana $\mathrm{M}$, y la segunda o rama ascendente correspondiente a la ett-lf o de origen $C_{3} \mathrm{~A}$ de la fracción Portland P-n ${ }^{o}$ que la acompaña, la mayor cantidad de $\mathrm{C}_{3} \mathrm{~A}, \mathrm{C}_{3} \mathrm{~S}$ y SEB aportada por la fracción $\mathrm{P}-1,30 \%$ de $14.11 \%, 51.05 \%$ y $3192 \mathrm{~cm}^{2} / \mathrm{g}$, respectivamente, no son las más adecuadas para hacer que el $70 \%$ de la puzolana $\mathrm{M}$ presente origine un ESE tal que todo el $\mathrm{C}_{3} \mathrm{~A}$ pase a ettringita en las primeras edades del ensayo, que si ha debido ocurrir en el caso de la probeta L-A P-2/(M+CH) 30/70 por todo lo contrario y por ende con un CP P-2 más adecuado para dicho fin estable. Por tal motivo en aquella probeta L-A P-1/(M+CH) 30/70 el valor de P.A.V. aumentó de nuevo a las edades finales del ensayo y en está P-2/(M+CH) 30/70, no. Y otro tanto de inadecuación ha debido ocurrir en el caso de la probeta L-A P31/(M+CH) 30/70 por la misma razón apuntada para el caso de la probeta L-A P-31/(A+CH) 40/60 al final del tercer párrafo de la interpretación de la discusión 8.1.2.6.2, Parámetro $\Delta \varnothing$.

Y como confirmación adicional de esta razón dada, estaría el hecho de que cuando el CP que acompañara a dicha puzolana $M$ fuera de nulo contenido de $C_{3} A$, caso del PY-4 y PY-6 utilizados también en este trabajo, sus probetas L-A correspondientes no deberían mostrar rama ascendente en la curva de Gauss invertida de los valores correspondientes de P.A.V. de las probetas L-A de cementos mixtos semejantes PY-6/(M+CH) 30/70, es decir la creación, evolución y desarrollo de tales valores de P.A.V. de dicho CM con cal apagada debería de haber sido una línea recta y descendente con mayor o menor inclinación según su rapidez en alcanzar el valor cero, como así ha sido el caso.

\subsubsection{4-De la Discusión 8.1.2.6.1.1.2.1-Familias $P Y-n^{o}{ }^{\prime \prime} Z^{\prime \prime}$ 50/50.}

\section{Parámetro $\triangle \varnothing$ :}

La causa por la que los valores de $\Delta \varnothing$ de las probetas L-A PY-6/"Z" 50/50 fueron mayores que los de sus homónimas del PY-4 a lo largo de todo el ensayo, ha de estribar necesariamente en el mayor contenido de C3S del CP PY-6, 79.43\%, sobre el PY-4, 58.19\%, lo que se hubo de traducir por tanto en una mayor disponibilidad de Portlandita liberada de la hidratación de tales 
contenidos de $\mathrm{C}_{3} \mathrm{~S}$ durante todo el ensayo en las probetas L-A de los cementos mixtos preparados con el PY-6 a los preparados con el PY-4. De esta manera, la puzolana "Z" de turno, pudo mostrar más y mejor su auténtico y verdadero "carácter" o "intencionalidad de comportamiento" y en consecuencia proporcionar mayores valores de $\Delta \varnothing$ en su mezcla con el PY-6 que con el PY-4, como así ha sido el caso, véase a 8-25 y 8-26. Esta razón explicativa se vio además reforzada por el comportamiento semejante, pero de mayor valor absoluto y desde los inicios del ensayo mayormente, de las correspondientes probetas L-A con cal apagada, véanse las Tabla 8-34.

Todo ello en su conjunto no es sino una manera más de reafirmar la veracidad de la hipótesis de trabajo inicial o de partida de la presente investigación.

Parámetro P.A.V.

1. La rectilineidad y horizontalidad por nulidad más o menos acusada de sus valores de P.A.V. unida a la notable pequeñez de los correspondientes valores de $\Delta \varnothing$ de sus probetas L-A, tendría en la presente ocasión como única razón explicativa la carencia de la Portlandita necesaria y suficiente para que la correspondiente puzolana "Z" de turno, O, CV19 y A, pudiera mostrar su auténtico y verdadero carácter. De aquí que las mismas no poseen, un contenido notable de $\mathrm{Al}_{2} \mathrm{O}_{3}{ }^{\mathrm{r}-6}$, actuarón más como un INERTE INTEGRAL, es decir, INERTERS e INERTERM a un mismo tiempo, que, como tales puzolanas, con las ventajas en RS e inconvenientes en $\mathrm{RM}$ al caso.

Y como confirmación de tal razón explicativa, están los hechos siguientes:

a) Que las probetas L-A de los correspondientes cementos "hermanos" 50/50 preparados con las puzolanas más "alumínicas": la -C, CV10 y M-, han mostrado diferente proceso evolutivo tanto en P.A.V. como en $\Delta \varnothing$.

c) Que las probetas L-A de los correspondientes cementos mixtos con cal apagada han mostrado diferente también su proceso evolutivo.

2. La rectilineidad y disminución más o menos acusada y rápida de los valores de P.A.V., unido al comportamiento semejante en los correspondientes valores de $\Delta \varnothing$ de dichas probetas L-A, indicaban claramente que la puzolana "Z" de turno en esta ocasión tenía que ser "alumínica" o "alumínico-silícica" y que el cemento Portland que la acompañaba en este caso, aportó poco o nada de $\mathrm{C}_{3} \mathrm{~A}$, como así ha sido el caso con el PY-4 y PY-6, y en consecuencia todo el sistema probeta L-A se encontraría "gobernado" desde el origen por la ett-rf de la $\mathrm{Al}_{2} \mathrm{O}_{3}{ }^{\mathrm{r}-}$ de tales puzolanas C, CV10 ó M, la cual se debería haber formado en su mayor parte e incluso en su totalidad, en las edades iniciales de la probeta L-A cuanto más "alumínica" fuera la puzolana "Z" y portlandita existiera en el medio y viceversa, como así también ha sido el caso, véanse los valores de P.A.V. de las probetas de los cementos mixtos PY-4 y PY-6/C 40/60 y PY-4 y PY-6/M 40/60 y algunos de ellos con cal apagada PY-4 y PY-6/(C+CH) 40/60.

\footnotetext{
${ }^{6}$ Véase la Tabla 6-9 de esta MEMORIA de Tesis Doctoral.
} 


\subsubsection{5-De la Discusión 8.1.2.6.1.1.2.2-Familias PY-no ${ }^{\prime \prime} Z^{\prime \prime} 40 / 60$.}

Parámetro $\triangle \varnothing$ :

Vale aquí íntegramente la razón explicativa y justificativa expuesta para semejante parámetro en el caso de la Familia de cementos mixtos PY-no/"Z" 50/50, véase el apartado anterior 8.1.2.7.4.

Parámetro P.A.V.

1. La rectilineidad por nulidad de los valores de P.A.V., unida a la apreciable pequeñez de sus correspondientes valores de $\Delta \varnothing$, tiene en esta ocasión la misma razón explicativa aducida para el mismo caso y parámetro interpretado de la discusión 8.1.2.7.4.

2. La rectilineidad y disminución más o menos acusada y rápida de los valores de P.A.V. reafirman claramente y una vez más idénticas razones aducidas para el mismo caso y parámetro de los correspondientes cementos mixtos 50/50, véase el parámetro P.A.V. de la interpretación de la discusión 8.1.2.7.4.

Obsérvese en este caso como la diferencia de valores absolutos de P.A.V. a la edad de 1 día ha de ser adscribible necesariamente al diferente contenido de $\mathrm{C}_{3} \mathrm{~S}$ de ambos CP PY-6 -79.43\%-y PY-4 -58.19\%- respectivamente, viéndose además dicha razón reafirmada por el comportamiento del citado parámetro en el caso de estar presente la cal apagada en ambos casos PY-6 y PY$4 /(\mathrm{M}+\mathrm{CH}) 40 / 60$.

\subsubsection{6-De la Discusión 8.1.2.6.1.1.2.3-Familias PY6/M 30/70.}

\section{Parámetro $\triangle \varnothing$ :}

Vale aquí íntegramente la razón explicativa y justificativa expuesta para semejante parámetro en el caso de la Familia de cementos mixtos PY-no/"Z" 50/50 y PY-no/"Z" 40/60, véanse las interpretaciones de las discusiones 8.1.2.7.4 y 8.1.2.7.5.

Parámetro P.A.V.

Valen aquí íntegramente idénticas razones explicativas y justificativas expuestas para semejante parámetro en el caso de la Familia de cementos mixtos PY-no/"Z" 40/60.

\subsubsection{7-De la Discusión 8.1.2.6.1.1.2.4-Familias PY6/M 20/80.}

Parámetro $\triangle \varnothing$ :

Vale aquí íntegramente idéntica razón explicativa y justificativa expuesta para semejante parámetro en el caso de la Familia de cementos mixtos PY-6/M 30/70, véase la interpretación de la Discusión 8.1.2.7.6.

Parámetro P.A.V.

Valen aquí íntegramente idénticas razones explicativas y justificativas expuestas para 
COMPORTAMIENTO SULFÁTICO Y MECÁNICO-RESISTENTE DE CEMENTOS PORTLAND CON ELEVADOS CONTENIDOS DE PUZOLANAS (> 40\%): SU FUNDAMENTO QUÍMICO Y JUSTIFICACIÓN DE OTRAS CONSECUENCIAS POSIBLES

semejante parámetro en el caso de la Familia de cementos mixtos PY-no/"Z" 40/60 y 30/70.

\subsubsection{8-De la Discusión8.1.2.6.1.2.1.1-Familia $P-n^{o} /\left({ }^{\prime \prime} Z^{\prime \prime}+C H\right) 50 / 50$, con relación $\left[\left(^{\prime \prime} Z^{\prime \prime} / C H\right)=\right.$}

4].

\section{Parámetro $\triangle \varnothing$ :}

Vale aquí íntegramente idénticas razones explicativas y justificativas expuestas para semejante parámetro en la discusión 8.1.2.7.1, para cuya interpretación fue necesario apoyarse además en estos resultados experimentales obtenidos estando presente la cal apagada en la probeta L-A correspondiente.

Parámetro P.A.V.

Valen aquí íntegramente idénticas razones explicativas y justificativas expuestas para semejante parámetro en la discusión 8.1.2.7.1, para cuya interpretación fue necesario apoyarse en estos resultados experimentales obtenidos estando presente la cal apagada en la probeta L-A, significaría que el material pasta selenitosa de cemento parcialmente hidratado no fraguó ni endureció por no permitírselo la formación permanente y continuada de ett-lf mayormente -o de origen $\mathrm{C}_{3} \mathrm{~A}$ de la fracción Portland que acompañaba a la puzolana "Z"- al igual que ocurrió con la probeta L-A de su CP solo. Y ello significó y significa por tanto lo siguiente:

- Que la puzolana "Z" debe ser en este caso "sílico-aluminosa" y por tanto deberá comportarse y actuar en tales condiciones con un marcado carácter de INERTERS más que como tal puzolana, y

- Que la cantidad de $\mathrm{C}_{3} \mathrm{~A}$ del CP que la acompañaba se encuentra bastante dispersa en la probeta L-A por "dilución física" y por tanto el mecanismo de formación de la ettringita de cualquier origen y etología ha de ser más adscribible al modelo "topoquímico" con disolución previa, que al de "through-solution".

\subsubsection{9-De la Discusión8.1.2.6.1.2.1.2-Familia $P-n^{o} /\left({ }^{\prime \prime} Z^{\prime \prime}+C H\right) 40 / 60$, con relación $\left[\left({ }^{\prime \prime} Z^{\prime \prime} / C H\right)=\right.$}

5].

Parámetro $\triangle \varnothing$ :

La discrepancia habida en este caso entre el comportamiento de las probetas L-A de los cementos mixtos con cal apagada $\mathrm{P}-1 /(\mathrm{A}+\mathrm{CH})$ 40/60 y $\mathrm{P}-31 /(\mathrm{A}+\mathrm{CH})$ 40/60 ha de ser adscribible necesariamente y una vez más, al mayor contenido de $\mathrm{C}_{3} \mathrm{~S}$ del CP P-31, 58.70\%, sobre el P-1, $57.05 \%$, y por consiguiente a la mayor disponibilidad de portlandita durante todo el ensayo derivada de la hidratación de su mayor disponibilidad de $\mathrm{C}_{3} \mathrm{~S}$. Con lo que de esta manera la puzolana A en cuestión habría mostrado más y mejor su verdadero "carácter" o "intencionalidad de comportamiento" y en consecuencia, habría podido originar mayor ESE con las consecuencias al caso, a saber, mayores valores de $\Delta \varnothing$ y P.A.V. de la probeta L-A P-31/(A+CH) 40/60 sobre la probeta L-A P-1/(A+CH) 40/60, durante todo el ensayo, como así ha sido el caso véase al efecto la 
Tabla 8-36.

Parámetro P.A.V.

1. La rectilineidad con disminución más -caso del P-1/(M+CH) 40/60- o menos -caso del P-2/(M+CH) 40/60- acusada y apreciablemente diferentes valores absolutos de P.A.V. y ascenso ulterior de la primera a las edades finales del ensayo, ha de ser adscribible necesariamente en este caso a la mayor y más completo ESE producido en la segunda probeta LA que en la primera, bien por la mayor disponibilidad de $\mathrm{C}_{3} \mathrm{~A}$ para dicho fin, del CP P-1 14.11\%, sobre el P-2, 11.09\%, bien por el mayor contenido de $\mathrm{C}_{3} \mathrm{~S}$ para dicho fin, del CP P-1, 51.05\%, sobre el P-2, 33.47\%, o bien por la mayor finura de molido o superficie específica del CP P-1, $3192 \mathrm{~cm}^{2} / \mathrm{g}$ sobre el P-2, $3015 \mathrm{~cm}^{2} / \mathrm{g}$, aunque en esta ocasión esta razón pudiera quizás llegar a tener menor importancia dado que en el método L-A, todos los cementos primeramente se muelen hasta pasar íntegramente por el tamiz de 4900 mallas $/ \mathrm{cm}^{2}$, con lo que de esta manera se anula bastante en su comportamiento en el citado ensayo, la influencia de sus caracteres físicos sobre los puramente químicos, o bien alguna(s) de las tres causas anteriores o todas ellas a un tiempo y en mayor o menor grado.

2. En este caso y a la vista de los resultados experimentales de P.A.V. proporcionados por las probetas L-A de ambos cementos mixtos con $\mathrm{CH}, \mathrm{P}-1 /(\mathrm{A}+\mathrm{CH})$ 40/60 y $\mathrm{P}$ $31 /(\mathrm{A}+\mathrm{CH})$ 40/60, se ha de convenir que las curvas representativas de los mismos son cualitativamente semejantes y cuantitativamente distintas en su creación, evolución y desarrollo a lo largo del ensayo, pero a favor del último. La razón de dicha diferencia ha de ser necesariamente y una vez más la que justificó semejanza en el parámetro $\Delta \varnothing$, es decir, la apreciable diferencia que existe entre los valores del contenido de $\mathrm{C}_{3} \mathrm{~S}$ de ambos $\mathrm{CP}$, con las consecuencias diferenciadoras al caso en este otro parámetro P.A.V.

3. En este caso y a pesar de la cal apagada presente no se debió de alcanzar el nivel necesario de hidróxido de calcio en la fase líquida para que dicha puzolana $\mathrm{C}$ se comportase como "alumino-silícica" que es y en consecuencia mostrase un ESE y evolución de los valores de P.A.V., semejante al caso 50/50 sin cal apagada.

De aquí que en su defecto, todo el conjunto se asemejó más en este comportamiento al de su CP P-31, con las lógicas y naturales tendencias alternativas de querer fraguar, derivadas de la alúmina reactiva de la puzolana $\mathrm{C}$ que constituía al $\mathrm{CM}$, las cuales se deberán manifestar tanto más pronto cuanto menos hidróxido de calcio posea la fase líquida de la probeta L-A, como así ha debido ocurrir con la probeta L-A correspondiente del CM sin cal apagada P-31/C 40/60

\subsection{0-De la Discusión8.1.2.6.1.2.1.3- Familias $P-n^{o} /\left({ }^{\prime \prime} Z^{\prime \prime}+C H\right) 30 / 70$.}

\section{Parámetro $\triangle \varnothing$ :}

Valen aquí íntegramente todas las razones explicativas y justificativas aducidas en este mismo caso sin cal apagada y para este mismo parámetro, en la correspondencia interpretación de la Discusión anterior 8.1.2.7.3., dado que los resultados experimentales aquí obtenidos son los que mayormente fundamentan tales razones explicativas y justificativas allí aducidas. 
Parámetro P.A.V.

1. La rectilineidad y disminución rápida hasta su nulidad de los valores de P.A.V. en el caso de la probeta L-A del CM con cal apagada P-2/(M+CH) 30/70, justifican una vez más que el ESE ha sido la adecuada o más óptima en este caso, para que toda la ett-Total (= ett-rf ó de origen $\mathrm{Al}_{2} \mathrm{O}_{3}{ }^{\mathrm{r}-}$ de la puzolana $\mathrm{M}$ más la ett-lf ó de origen $\mathrm{C}_{3} \mathrm{~A}$ del CP P-2) se forme con más prontitud y consecuentemente anule con prontitud los valores de P.A.V. a las edades iniciales del ensayo fundamento.

2. Las curvas de Gauss invertidas y de valores mínimos respectivos más o menos centrados obtenidas mediante este parámetro P.A.V., vienen a demostrar en ambos casos, P-1 y $\mathrm{P}-31 /(\mathrm{M}+\mathrm{CH}) 30 / 70$, que primeramente se deberá formar y en mayor medida, ett-rf de origen $\mathrm{Al}_{2} \mathrm{O}_{3^{r}}{ }^{r}$ de la puzolana $\mathrm{M}$ que de algún modo originará el correspondiente ESE y disminución más o menos rápida de los valores de P.A.V., la cual al no haber sido la adecuada o más óptima para este otro caso, podrá dejar libre del total de $\mathrm{C}_{3} \mathrm{~A}$ del $\mathrm{CP}$, que posteriormente y a lo largo plazo, llegaría a provocar aumento en los valores de P.A.V., pero tanto menor cuanto menor hubiese sido de origen dicho contenido de $\mathrm{C}_{3} \mathrm{~A}$ del citado $\mathrm{CP}$ y viceversa, como así ha sido el caso, véanse tales valores descendentes y ascendentes de P.A.V. de ambas probetas L-A en las Figuras 8-1, 82, 8-3, 8-4 y 8-5. De aquí que y según ello, los valores de la rama ascendente de P.A.V. en la probeta L-A P-31/(M+CH) 30/70, hayan sido de notable menor valor absoluto que los correspondientes de la probeta L-A P-1/(M+CH) 30/70, ya que el cemento Portland sólo contenía un $7.62 \%$ de $\mathrm{C}_{3} \mathrm{~A}$ mientras que el P-1 contenía $14.11 \% \mathrm{C}_{3} \mathrm{~A}$.

\subsection{1-De la Discusión 8.1.2.6.1.2.2.1-Familias PY-no $\left({ }^{\prime \prime} \mathrm{Z}^{\prime \prime}+\mathrm{CH}\right)$ 50/50, [("Z"/CH) = 4].}

\section{Parámetro $\Delta \varnothing$ :}

Vale aquí íntegramente la misma razón explicativa y justificativa aducida en semejante caso sin cal apagada y para semejante parámetro, máxime si los resultados experimentales obtenidos en esta ocasión reafirman la veracidad de la citada razón explicativa y justificativa, allí aducida.

Parámetro P.A.V.

1. La rectilineidad y horizontalidad por valor nulo de P.A.V., tiene idénticas razones explicativas y justificativas que las proporcionadas para semejantes caso P-2/A 50/50, P1 40/60, P-2/M 30/70 y 20/80 y semejante parámetro en las correspondientes interpretaciones de las discusiones anteriores.

2. La rectilineidad y ulterior ascensión a las edades intermedias y/o finales del ensayo de los valores de P.A.V. en el caso de las probetas L-A de los cementos mixtos con cal apagada, PY-6/(CV10+CH) 50/50, PY-4 y PY-6/(A y CV19+CH) 40/60, vienen a indicar que la ettringita que los origina ha de ser debida mayormente al C4AF del CP respectivo PY-4 y PY-6.

3. La forma clara de curva de Gauss con su máximo valor desplazado a la izquierda, tiene idéntica razón explicativa y justificativa que la proporcionada para semejantes casos P-1/A 
50/50, P-31/CV10 y (CV10+CH) 50/50 y semejante parámetro, en las correspondientes interpretaciones anteriores 8.1.2.7.1., 8.1.2.7.2. y 8.1.2.7.3. respectivamente, siendo quizás la causa de los mayores valores absolutos alcanzados en el caso de la probeta L-A PY-4/(C+CH) 50/50, la posible mayor "capacidad de cambio" de esta puzolana.

\subsection{2-De la Discusión 8.1.2.6.1.2.2.2-Familias PY- $n^{o} /\left({ }^{\prime \prime} \mathrm{Z}^{\prime \prime}+C H\right) 40 / 60,\left[\left({ }^{\prime \prime} \mathrm{Z}^{\prime \prime} / \mathrm{CH}\right)=5\right]$.}

Parámetro $\triangle \varnothing$ :

En esta ocasión ha ocurrido todo lo contrario a cuando el cemento no tenía cal apagada, es decir, el $\Delta \varnothing$ del PY-4/(M+CH) 40/60 es > al $\Delta \varnothing$ del PY6/(M+CH) 40/60, lo que en principio podía resultar ser paradójico cuando en realidad no lo es, ya que la explicación posible en este caso del comportamiento de la probeta L-A PY-4/(M+CH) 40/60, se basa en que cuando se forma la ett-rf, o de origen $\mathrm{Al}_{2} \mathrm{O}_{3}{ }^{r-}$ de la puzolana $\mathrm{M}$, en dicha probeta $\mathrm{L}-\mathrm{A}$, el entorno que le rodea en el instante mismo de su formación, ha de estar más endurecido que en el caso de la probeta L-A "hermana" PY-6/(M+CH) 40/60; con lo cual los efectos derivados del dualismo de esfuerzos expansiónfraguado, provocado en la primera probeta L-A o PY-4/(M+CH) 40/60, ha de dar por resultado final, mayor expansión y todo lo contrario en la probeta L-A "hermana" o PY-6/(M+CH) 40/60 que habrá estado más plástica por más tiempo, perdiendo de esta forma nocividad la expansividad de la ett-rf y consiguientemente originándose menores expansiones diametrales. Véanse al efecto como los valores de P.A.V. a la edad de 1 día de ambas probetas L-A así nos lo confirman. Y precisamente el que la P.A.V. de la probeta L-A PY-6/(M+CH) 40/60 haya sido mayor, 31.5, que el de la PY-4/(M+CH) 40/60, 26.5, justifica sobradamente su mayor formación del total de ett-rf que debería formar.

\section{Parámetro P.A.V.}

El hecho de que los máximos valores de la suave curva de Gauss originada en ambos casos estén situados en esta ocasión en lados diferentes -el de la probeta L-A PY-4/(M+CH) 40/60 a la derecha y el de la PY-6/(M+CH) 40/60 a la izquierda- fortalece una vez más las razones explicativas y justificativas de lo ocurrido, dadas en el apartado anterior.

\subsection{3-De la Discusión 8.1.2.5.1.2.2.3- Familia PY-6/(M+CH) 30/70, [("Z"'/CH) = 6].}

Parámetro $\triangle \varnothing$ :

La explicación de lo ocurrido con este parámetro en este caso, la podemos encontrar en la Discusión anterior 8.1.2.5.1.2.2.2., corregida y disminuida y decimos disminuida por haber resultado ser de menor valor absoluto.

Parámetro P.A.V.

La explicación de lo ocurrido con este otro parámetro en este caso, la podemos encontrar en el caso "hermano" sin cal apagada PY-6/M 30/70, pero corregida y aumentada por aquello de que los valores de P.A.V. han resultado ser mayores a todas las edades, en este caso. 
Y la razón de ello es una vez más la presencia de la cal apagada, la cual y en definitiva, es la que permite que aunque la probeta L-A posea menor cantidad de puzolana M que su probeta "hermana" PY-6/M 30/70, provoque mayor $\Delta \varnothing$ y de P.A.V., con lo que de nuevo y mediante ambas probetas L-A, PY-6/M 40/60 y PY-6/(M+CH) 40/60, se demuestra la veracidad de la hipótesis de partida del presente trabajo de investigación.

\subsection{4-De la Discusión 8.1.2.6.1.2.2.4- Familia PY-6/(M+CH) 20/80;("Z"/CH) = 7.}

\section{Parámetro $\triangle \varnothing$ :}

La explicación de lo ocurrido con este parámetro en este caso, la podemos encontrar en la Discusión anterior 8.1.2.7.13, corregida y aumentada, y decimos aumentada por haber resultado ser de mayor valor absoluto.

Y ello ha sido debido a que en este caso los valores correspondientes de P.A.V. han sido de menor valor absoluto que los de la probeta L-A correspondiente PY-6/(M+CH) 30/70 y por consiguiente más propiciadores de que la expansividad connatural de la ett-rf se torne en aumento del diámetro de la probeta L-A, y viceversa.

\subsection{5-De la Discusión 8.1.2.4.3.1-Familias [(P-1 ó PY-6/M 30/70) + 7.0\%SO 3 .}

\section{Parámetro $\triangle \varnothing$ :}

Una vez más la creación, evolución y desarrollo de los valores de este parámetro en ambas probetas L-A pueden resultarnos paradójicos cuando en realidad no lo son, puesto que toda o la mayor parte de la ettringita que deben de formar ambos materiales se deberá formar mientras que se curan bajo agua destilada 14 días, según prescribe expresamente el método acelerado de ensayo de Le Chatelier-Anstett. Y se podrá formar tanto más la citada totalidad de ettringita, cuanto mayor sea la cantidad de ettringita total a formar de la misma. Ya que, al deber de primar según Talero, (1986), el mecanismo topoquímico sobre el de "through-solution" en la formación de la ettringita, la expansividad de esta facilitará la consiguiente formación de la restante situada más en el interior del material cemento P-1/M 30/70 con yeso que se está "curando" bajo agua y viceversa. De esta manera y con posterioridad, la probeta L-A resultante deberá ser tanto más estables cuanto mayor sea el contenido de $\mathrm{C}_{3} \mathrm{~A}$ de su CP, en este caso el P-1, y viceversa, como así ha sido el caso, ya que en la probeta L-A no hay lugar formarse más ettringita de ningún tipo, pues toda ella o la mayor parte, se ha debido formar durante el curado bajo agua destilada, según decíamos antes.

El resto del yeso aportado, se transformarán en más ettringita reaccionando con $3.598 \mathrm{~g}$ de $\mathrm{C}_{3} \mathrm{~A}$. Dado que el cemento P-1/M 30/70 tiene 3.6711g de $\mathrm{C}_{3} \mathrm{~A}$, deberán de quedar finalmente 3.6711 - $3.598=0.0731 \mathrm{~g}$ de $\mathrm{C}_{3} \mathrm{~A}$ sin pasar a ettringita por haberse consumido totalmente para entonces los $13.275 \mathrm{~g}$ de yeso puestos inicialmente. Por este motivo la ettringita total formada, deberá originar finalmente algo de Mf1,2 ó 3, como así ha sido el caso. (Véase el ANEJO 2).

$\mathrm{Y}$ volviendo de nuevo al caso del material hidratado y seco a $40^{\circ} \mathrm{C}$ del CM P-1/M 30/70 con 
7.0\% de $\mathrm{SO}_{3}$, la cantidad de Mf3 originado por la razón química anteriormente aducida, deberá transformarse finalmente ettringita en su probeta L-A correspondiente pero siempre y cuando haya cantidad de Portlandita necesaria y suficiente para ello. Ya que si no la hubiera dicha transformación no llegaría a producirse, con lo que la probeta L-A correspondiente mostraría estabilidad de volumen y valor nulo de P.A.V. de principio a fin del ensayo.

Por otra parte, y volviendo al hilo del razonamiento explicativo del hecho que se está debatiendo, la estabilidad de volumen y P.A.V. de la probeta L-A P-1/M 30/70, se pueden aducir en su apoyo dos hechos ocurridos: El 1‥ Que en el caso de la probeta L-A "hermana" con cal apagada, es decir, la probeta L-A P-1/(M+CH) 30/70, dicha estabilidad de volumen y P.A.V. de principio a fin del ensayo no se ha producido y si en cambio el hecho contrario, es decir, la creación mayor o menor (más bien esto último) de $\Delta \varnothing$ mayormente, ya que la P.A.V. no deberá de verse afectada, es decir, ser nula porque la ettringita de cualquier origen que origine tal $\Delta \varnothing$ deberá ser con o sin ESE, y en cualquier caso, formarse totalmente en las primeras edades de la probeta L-A, con lo que no deberá afectar, como decíamos, al parámetro P.A.V.; y el $2^{2}$. Que en el caso del CM homónimo PY-6/M 30/70, si se ha producido en cambio algo de $\Delta \varnothing$ solamente porque el CP PY-6 posee $79.43 \%$ de $\mathrm{C}_{3} \mathrm{~S}$ mientras que el P-1 posee $51.05 \%$ de $\mathrm{C}_{3} \mathrm{~S}$.

Y ello podría quizás proporcionar a aquel o sea al PY-6/M 30/70 la Portlandita necesaria para que el resto de $\mathrm{Al}_{2} \mathrm{O}_{3}{ }^{\text {r- }}$ de la puzolana $\mathrm{M}$ que lo acompaña no transformada en ett-rf durante el curado de 14 días bajo agua, como se ha aducido al principio, pase a ett-rf en la probeta L-A correspondiente y origine el ligero $\Delta \varnothing$ que la probeta L-A homónima P-1/M 30/70 no ha podido originar por el motivo contrario.

Consecuentemente y según todo lo anteriormente expuesto, los valores correspondientes de P.A.V. habrán de ser en ambos casos y a lo sumo, muy pequeños, alcanzando su nulidad con prontitud e incluso nulos de principio a fin del ensayo y aún con posterioridad al mismo, esté o no presente la cal apagada, como así ha sido el caso y se da fe de ello.

\subsection{6-De la Discusión 8.1.2.6.1.3.1.2- Familia [(PY-6/M 20/80)+7.0\%SO3].}

Parámetro $\triangle \varnothing$ :

La razón por la que los valores de este parámetro adoptan la forma de una muy suave curva de Gauss con el máximo valor desplazado a la izquierda, ha sido dada en apartados anteriores. Y por otra parte el que hayan resultado ser tales valores bastante menores a los correspondientes de la probeta L-A "hermana superior" 30/70, confirma la falta de Portlandita por menor presencia de CP PY-6, y que en tal caso, la piedra de yeso natural molida puesta como agresivo, dificultará el fraguado, poco o mucho, de esta probeta L-A 20/80, pero el suficiente, para que los valores de P.A.V. correspondientes no hayan sido mulos durante todo el ensayo o la mayor parte de las edades del mismo. 


\subsection{7-De la Discusión - Familias [P-1 ó PY-6/(M+CH) 30/70+7.0\%SO}

\section{Parámetro $\triangle \varnothing$ :}

Aún siendo semejantes la evolución y desarrollo de los valores de $\Delta \varnothing$ de ambas probetas L-A, la causa por la que los de la probeta L-A del CP P-1 han resultado ser, mayores a las edades iniciales de 1, 7 y 14 días principalmente, ligeramente mayores a las edades de 21, 28, 60, 90, 120, 150 y 180 días, y de nuevo mayores a las edades restantes del ensayo hasta 2 años, que los correspondientes a los de la probeta L-A de CP P-1 sobre la del PY-6, por poseer aquel cemento P-1 mayor contenido de $\mathrm{C}_{3} \mathrm{~A}, 14.11 \%$, que el PY-6, $0.00 \%$ de $\mathrm{C}_{3} \mathrm{~A}, \approx 1.00 \%$ en la realidad, y por consiguiente mayor ESE resultante y mayor $\triangle \varnothing$ originado, como así ha sido el caso.

Y todo ello sin olvidar la interpretación dada de lo ocurrido, a las probetas L-A "hermanas" sin cal apagada con y sin yeso.

Parámetro P.A.V.

Como consecuencia de la razón expuesta en el apartado correspondiente anterior (A) de los valores de $\Delta \varnothing$ alcanzados por ambas probetas L-A, lógicamente los valores de P.A.V. habían de ser a lo sumo muy pequeños al principio del ensayo, para anularse con prontitud e incluso ser nulos de principio a fin del ensayo, como así ha sido el caso.

Como el $80 \%$ de $\mathrm{M}$ aporta $1.664 \mathrm{~g}$ de $\mathrm{Al}_{2} \mathrm{O}_{3}{ }^{\mathrm{r}-}$ (véase ANEJO 2) y sólo se necesitarán $0.199 \mathrm{~g}$ de $\mathrm{Al}_{2} \mathrm{O}_{3}{ }^{\mathrm{r}-}$ para pasar los $1.006434 \mathrm{~g}$ de yeso -que portan $100 \mathrm{~g}$ de CM PY-6/M 20/80- a ett-rf $(\approx$ $2.41 \mathrm{~g} \%$ ) resulta que sobrarían $1.664-0.199=1.465 \mathrm{~g}$ de $\mathrm{Al}_{2} \mathrm{O}_{3}{ }^{{ }^{r}-}$ y $0.2 \mathrm{~g}$ de $\mathrm{C}_{3} \mathrm{~A}$ del PY-6 sin pasar a ettringita. Con lo que la muy poca ett-rf formada $(2.418 \mathrm{~g} \%)$ puede reconvertirse en $\mathrm{Mf}(\approx 1.24 \mathrm{~g} \%)$, pero al tener que ser ambas cantidades muy pequeñas.

Por estos motivos, la probeta L-A correspondiente PY-6/M 20/80 deberá mostrar hinchamiento inicial rápido hasta 7 ó 14 días de edad para a continuación mantenerse constante durante el resto del ensayo y otro tanto su P.A.V. pero manteniéndose éste de valor nulo, durante el transcurso de este. Y siendo todo ello tanto más acusado con la cal apagada que en ausencia de esta, como así ha sido el caso.

Por el contrario, cuando al CM citado PY-6/M 20/80 se le puso un 7.0\% de $\mathrm{SO}_{3}$ equivalente a $15.0535 \%$ de yeso, los cálculos estequiométricos nos demuestran la posibilidad real de formarse ettringita a partir de su hidratación bajo agua desionizada durante 14 días antes, de secarlo a $40^{\circ} \mathrm{C}$ y realizarle su torta.

Así siendo el \% SO3 del CP PY-6 = 2.34\%, el CM PY-6/M 20/80 tendrá 2.34 x 20\%=0.468\% $\mathrm{SO}_{3}$. 


\section{2.-Determinación del comportamiento mecánico-resistente en probetas de} $4 \times 4 \times 16 \mathrm{~cm}$ de mortero normalizado tipo EN 196-1, de los cementos Portland de referencia y desus correspondientes cementos de mezcla con cada uan de las puzolanas seleccionadas

La determinación del comportamiento mecánico-resistente de todos los cementos Portalnd puros o de referencia seleccionados y de sus mezclas, por separado, con todas y cada una de las puzolanas seleccionadas también (véanse en el apartado 7.1. del Capítulo 7), con y sin $\mathrm{CH}$, se ajustó a los métodos de ensayo para determinar, en primer lugar, la RMF, y en segundo lugar, la RMC de sus correspondientes morteros normalizados tipo EN 196-1, por lo que en este apartado se han analizado, estudiado, comparado, discutido e interpretado los resultados experimentales obtenidos de RMC, RMF y de la relación RMF/RMCde cada par de valores anterior de cada una de las probetas.

\subsection{1.-De los cementos Portland de referencia.}

Se analizaron los resultados obtenidos de RMC y RMF de cada uno de los 5 cementos Portland puros o de referencia seleccionados: del P1, P2, P31, PY4 y PY6. Dichos resultados se muestran en la Tabla 8-44. Y sea cual fuere el cemento Portland seleccionado y ensayado que se considere, la evolución y desarrollo de los valores de RMC, RMF y RMF/RMC a lo largo de las tres edades del ensayodeterminadas $-7,28$ y 90 días-, ha sido de aumento generalizado, aunque a diferente velocidad de acuerdo con los contenidos potenciales de $\mathrm{C}_{3} \mathrm{~A}(\%)$ y $\mathrm{C}_{3} \mathrm{~S}(\%)$ de cada uno de ellos. O dicho de otro modo y para mayor claridad la evolución y desarrollo de los valores de RMC, RMF y RMF/RMC ha sido de crecimiento continuado en todos los casos, diferenciándose únicamente uno de otro en su velocidad de prosecución. De aquí que las clasificaciones que se han obtenido de los cinco cementos Portland seleccionados en función de cada uno dedichos parámetros a las diferentes edades de ensayomencionadas, hayan sido las siguientesy, como se puede ver, para nada coincidentes, véase la Tabla 8-45.

Y de acuerdo con los valores de RMC y RMF obtenidos en probetas de 4x4x416 cm de mortero normalizado tipo RC-75 de cada uno de los cinco cementos Portland ensayados, a las edades características del ensayo de 7, 28 y 90 días, el Tipo, la Clase y la Categoría a la que podrían ser asimiladosen principioy sin más a los cementos de la vigente Instrucción RC-16, serían los siguientes:

- el cemento Portland P-1 = al CEM I 42,5R,

- el cemento Portland P-2 = al CEM I 32,5 N,

- el cemento Portland P-31 = al CEM I 32,5 N,

- el cemento Portland PY-4 = al CEM I 32,5 N/SR0, y

- el cemento Portland PY-6 = al CEM I 42,5 N/SR0. 
COMPORTAMIENTO SULFÁTICO Y MECÁNICO-RESISTENTE DE CEMENTOS PORTLAND CON ELEVADOS CONTENIDOS DE PUZOLANAS ( $>40 \%$ ): SU FUNDAMENTO QUÍMICO Y JUSTIFICACIÓN DE OTRAS CONSECUENCIAS POSIBLES

TABLA 8-44.- VALORES DE RMC Y RMF EN PROBETAS DE 4X4X16 CM DE MORTERO NORMALIZADO TIPO RC-75, DE LOS CEMENTOS PORTLAND DE REFERENCIA: RELACIÓN CON SU COMPOSICIÓN POTENCIAL Y FINURA DE MOLIDO.

\begin{tabular}{|c|c|c|c|c|c|c|}
\hline \multirow[t]{2}{*}{ Resistencias Mecánicas } & \multirow[t]{2}{*}{ Edad (días) } & \multicolumn{5}{|c|}{$\begin{array}{c}\text { Valores de las RMC y RMF características en mortero normalizado } \\
\text { tipo EN 196-1 de los Cementos Portland Matrices (MPa) }\end{array}$} \\
\hline & & P1 & P2 & P31 & PY4 & PY6 \\
\hline \multirow{3}{*}{ Compresión RMC } & 7 & 36,9 & 24,6 & 26,6 & 27,5 & 29,9 \\
\hline & 28 & 42,9 & 27,7 & 35,3 & 35,8 & 42,6 \\
\hline & 90 & 46,6 & 39,8 & 40,6 & 42,6 & 58,3 \\
\hline \multirow{3}{*}{ Flexotracción RMF } & 7 & 7,1 & 5,5 & 6,4 & 5,6 & 5,7 \\
\hline & 28 & 7,3 & 6,6 & 7,0 & 7,1 & 7,4 \\
\hline & 90 & 7,9 & 7,1 & 7,6 & 8,8 & 9,0 \\
\hline \multicolumn{2}{|c|}{$\begin{array}{l}\text { Composición Potencial de Bogue y SEB de } \\
\text { los Cementos Portland Matrices }\end{array}$} & P1 & $\mathbf{P 2}$ & P31 & PY4 & PY6 \\
\hline $\mathrm{C}_{3} \mathrm{~S}(\%)$ & & 51,05 & 33,47 & 58,70 & 58,22 & 79,43 \\
\hline $\mathrm{C}_{2} \mathrm{~S}(\%)$ & & 16,48 & 30,26 & 7,70 & 19,46 & 2,29 \\
\hline $\mathrm{C}_{3} \mathrm{~A}(\%)$ & & 14,11 & 11,09 & 7,62 & 0,00 & 0,00 \\
\hline $\mathrm{C}_{4} \mathrm{AF}(\%)$ & & 5,33 & 8,79 & 11,56 & 11,75 & 10,19 \\
\hline $\operatorname{SEB}\left(\mathrm{cm}^{2} / \mathrm{g}\right)$ & & 3192 & 3015 & 3248 & 3233 & 3287 \\
\hline
\end{tabular}

Ahora y antes de proceder al análisis, estudio, discusión e interpretación de los resultados experimentales obtenidos de RMC y RMF de cada uno de ellos, conviene aclarar las razones por las que tres materiales diferentes: el cemento Portland, la arena silícea normalizada, tipo RC-75 y el agua, al mezclarse y amasarse conjuntamente y por igual en la forma, durante un tiempo dado y en cantidades determinadas pero fijas y constantes en todos los casos, a saber: cemento Portland $450 \mathrm{~g}$, arena silícea $=1.350 \mathrm{~g}$ y agua (de amasado) $=225 \mathrm{~g}$, dan como resultado final un nuevo material, el mortero normalizado de cemento, cuyas características morfológicas de sus probetas tipo EN 196-1 de 4x4×16 cm y dureza, así como también aumento de esta última conforme más se cura e hidrata bajo agua, permiten finalmente determinar y obtener valores también característicos cuando es sometido a esfuerzos de flexotración y compresión que les son propios y que nos permite caracterizarlo y diferenciarlo de otros morteros y, consiguientemente, al cemento Portland que los constituye en cada casotambién y sobre todo. Y las razones son las siguientes:

1. Como consecuencia de la hidratación de los componentes mineralógicos sintéticos del cemento Portland, a saber: el $\mathrm{C}_{3} \mathrm{~S}$, el $\mathrm{C}_{2} \mathrm{~S}$, el $\mathrm{C}_{3} \mathrm{~A}$ y el $\mathrm{C}_{4} \mathrm{AF}$, se originan unas reacciones químicas que en principio podíamos resumir del siguiente modo:

- Como resultado de tales reacciones químicas, el agua de amasado (225 g) de los morteros normalizados (tipo RC-75) preparados, así como también la de curado bajo agua, de sus probetas y a sus edades iniciales mayormente,

- Se satura casi desde el principio del ensayo en portlandita, $\mathrm{Ca}(\mathrm{OH})$, es decir, si el cemento que los constituye es Portland puro, y

- No se satura en portlandita desde el inicio del ensayo, si el cemento que los constituye es 288 
Portland con adiciones activas tipo puzolanas naturales o artificiales en cantidades de reemplazo $>20 \%$, dada la consustancial actividad puzolánica (fijación del $\mathrm{Ca}(\mathrm{OH})_{2}$ anterior) que tanto las caracteriza (y si son tipo escorias siderúrgicas también sólo que en cantidades de reemplazo > 50\% ó 60\% según la tipología de la escoria, NF P 18-506.

2. Como consecuencia de la saturación final en $\mathrm{Ca}(\mathrm{OH})_{2}$, tanto del agua de amasado como del agua de conservación de las probetas de mortero normalizado del cemento Portland puro, la misma reacciona con los granos gruesos y finos de la arena silícea, haciendo que la zona de transición a la interfase árido silíceo<>pasta de cemento Portland (Delgado, 2014) aumente su espesor con el transcurso del ensayo y, consiguientemente, aumente el esfuerzo de tracción pura que se haya de realizar para romperlo y conseguir despegar de este modo la pasta de dicho árido silíceo. Y la cuantificación de dicho esfuerzo de tracción se podría llevar a cabo sometiendo a las probetas de mortero al propio esfuerzo de tracción pura o, en su defecto, sometiéndolas al ensayo de flexotracción como así se ha realizado en esta investigación.

TAbla 8-45.- Clasificación mecánico-resistente de los Cementos PORTLAND.ANÁLISIS Y ESTUDIO COMPARATIVO CON SU COMPOSICIÓN POTENCIAL Y FINURA DE MOLIDO.

\begin{tabular}{|c|c|c|}
\hline Parámetros & Edad (días) & Cementos Portland \\
\hline \multirow{4}{*}{$<\mathrm{RMF}<$} & 3 & P-2 $<$ PY-4 $<$ PY-6 $<$ P-31 $<$ P-1 \\
\hline & 7 & $\mathrm{P}-2<\mathrm{PY}-4<\mathrm{PY}-6<\mathrm{P}-31<\mathrm{P}-\mathbf{1}$ \\
\hline & 28 & P-2 $<$ PY- $4<$ P-1 $<$ P- $31<$ PY-6 \\
\hline & $90^{*}$ & P-2 $<$ P-1 $<$ PY-4 $<$ P-31 $<$ PY-6 \\
\hline \multirow{4}{*}{$<\mathrm{RMC}<$} & 3 & P-2 $<$ PY-4 $<$ PY-6 $<$ P-31 $<$ P-1 \\
\hline & 7 & P-2 $<$ PY-4 $<$ PY-6 $<$ P-31 $<$ P-1 \\
\hline & 28 & P-2 $<$ PY-4 $<$ PY-6 $<$ P-31 $<$ P-1 \\
\hline & $90^{*}$ & P-2 $<$ P-1 $<$ PY-4 $<$ P-31 $<$ PY-6 \\
\hline \multirow{4}{*}{$<\mathrm{RMF} / \mathrm{RMC}<$} & $3^{* *}$ & P-1 $<$ P-2 $<$ P-31 $<$ PY-4 $<$ PY-6 \\
\hline & 7 & P1 $<$ P-2 $<$ P-31 $<$ PY $-4<$ PY-6 \\
\hline & 28 & P-1 $<$ P-31 $<$ PY-4 $<$ P-2 $<$ PY-6 \\
\hline & $90^{*}$ & P1 $<$ P-2 $<$ P-31 $<$ PY-4 $<$ PY-6 \\
\hline \multirow{2}{*}{$<\mathrm{C}_{3} \mathrm{~S}(\%)<$} & \multirow{2}{*}{ * } & P-2 $<$ P-1 $<$ PY-4 $<$ P-31 $<$ PY-6 \\
\hline & & $33.47<51.05<58.19<58.70<79.43$ \\
\hline \multirow{2}{*}{$<\mathrm{C}_{2} \mathrm{~S}(\%)<$} & \multirow{4}{*}{$* *$} & PY-6 $<$ P-31 < P-1 < PY-4 < P-2 \\
\hline & & $2.29<7.70<16.48<19.46<30.26$ \\
\hline \multirow{2}{*}{$>\mathrm{C}_{3} \mathrm{~A}(\%)>$} & & P1 $>$ P2 $>$ P31 $>$ PY4= PY6 \\
\hline & & $0.00=0.00<7.62<11.01<14.11$ \\
\hline \multirow{2}{*}{$<\mathrm{SEB}<\left(\mathrm{cm}^{2} / \mathrm{g}\right)$} & \multirow{2}{*}{ * } & P-2 $<$ P-1 $<$ PY-4 $<$ P-31 $<$ PY-6 \\
\hline & & $3015<3192<3233<3248<3287$ \\
\hline
\end{tabular}

3. Como consecuencia de los resultados experimentales obtenidos por Talero,(1986) y los correspondientes obtenidos en este trabajo, se demuestra que la ettringita de cualquier origen - del $\mathrm{C}_{3} \mathrm{~A}$ del cemento Portland, de la $\mathrm{Al}_{2} \mathrm{O}_{3}{ }^{r}$-de una adición puzolánica, etc.- y etiología, ha de ser más colmatante por expansora que enlazante del árido y la pasta, hecho éste 
mecánicamente lógico, aunque se encuentre, en mayor o menor grado, formando parte también de la zona de transición que se forma entre el árido silíceo y dicha pasta de cemento Portland más o menos hidratada conforme transcurre su conservación en agua.

4. Como consecuencia, una vez más, de los resultados experimentales obtenidos por Talero (1986) y Martín Luengo (1996), las características fisicoquímicas y morfológicas de las propias tobermoritas, les permiten poderlas clasificar en dos grupos claramente diferenciados, a saber,

- las tobermoritas con relación $\mathrm{C} / \mathrm{S}$ entre 1 y 2, tales como la afwillita, $\mathrm{S}_{2} \mathrm{C}_{3} \mathrm{H}_{3}$, y la hildebrandita, $\mathrm{SC}_{2} \mathrm{H}_{2}$, las cuales al parecer provienen mayormente de la hidratación del $\mathrm{C}_{3} \mathrm{~S}$ y $\mathrm{C}_{2} \mathrm{~S}$ del clínker Portland y consiguientemente se suelen encontrar másabundantemente en la propia pasta de cemento, $y$

- las tobermoritas con relación $\mathrm{C} / \mathrm{S}<1$, las cuales al parecer provienen mayormente,o de la adición activa, máxime si la misma es puzolánica y con carácter químico silícico (Talero, 1986), tales como humo de sílice, diatomitas, ópalos y similares, ypuzolánica también pero con carácter químico sílico-alumínico (Talero, 1986), tales como algunas cenizas volantes y puzolanas naturales mayormente, y/ode la reacciónquímica árido silíceo $<$ pasta de cemento Portland, o mejor quizás árido silíceo $\diamond$ portlandita, $\left(\mathrm{Ca}(\mathrm{OH})_{2}\right)$, de la fase líquida de la pasta de cemento Portlandmás o menos hidratada y en contacto con dicho árido silíeo, máxime si dicho árido es reactivo (ópalos y similares).

Por todo lo expuesto en relación con este tema dela zona de transicióna la interfase árido silíceo $>$ pasta de cemento (Delgado, 2014), los resultados experimentales obtenidos de la determinación de las RMC y RMF características a las edades de 7, 28 y 90 días, en probetas de $4 \times 4 \times 16 \mathrm{~cm}$ de mortero normalizado tipo RC-75, de cada uno de los cinco cementos Portland de referencia seleccionados y así ensayados se podrían interpretar con fundamento y según todo lo acabado de exponer, del siguiente modo:

4.1. El cemento Portland P1 al tener mayor cantidad de $\mathrm{C}_{3} \mathrm{~A}(14.11 \%)$ que el PY6 $\left(0.00 \% \mathrm{C}_{3} \mathrm{~A}\right)$, podrá formar lógicamente con su regulador de fraguado (piedra de yeso natural molida, $\mathrm{CaSO} 4 \cdot 2 \mathrm{H} 2 \mathrm{O}$ ) y a las edades iniciales del ensayo especialmente, mayor cantidad de ett-lf (Talero, 1986) que el PY4 ó el PY6. Esta ettringita, cuando es estequiométricamente deficitaria en regulador de fraguado, como así ocurre en el caso que nos ocupa -pues 14.11\% $\mathrm{C}_{3} \mathrm{~A}$ necesitaría un $12,54 \% \mathrm{SO}_{3}\left(=26.97 \%\right.$ de yeso, $\mathrm{CaSO}_{4} \bullet 2 \mathrm{H}_{2} \mathrm{O}$, y esta otra cantidad ya no actuaría como tal sino como agresivo)-porque sólo contiene $3,50 \%$ de $\mathrm{SO}_{3}\left(=7,53 \%\right.$ de yeso, $\mathrm{CaSO}_{4} \bullet 2 \mathrm{H}_{2} \mathrm{O}$, véase la Tabla 5-1), se convertiría durante el transcurso del ensayo hasta los 90 días en monosulfato- de calcio hidratado ó "Fase AFm".Y mientras que el Volumen Molar de la Fase AFm, es de 319,10 cm³ , el de la ett-lf o Fase AFt es de $715,09 \mathrm{~cm}^{3}$, o sea, 2,24 veces mayor y, por consiguiente y muy a pesar de su innata expansividad, con mayor poder de colmatación,estando el mortero ene stado fresco, y mayor poder por tanto de proporcionar mayores valores de RMC7d e incluso de RMF7da edades iniciales y todo lo contrario a edades más tardías, como así ha ocurrido en esta investigación. Véase en la Tabla 8-44 como:

$\mathrm{RMC}_{7 \mathrm{~d}} \mathrm{P} 1=369 \mathrm{Kp} / \mathrm{cm}^{2}>299 \mathrm{Kp} / \mathrm{cm}^{2}=\mathrm{RMC}_{7 \mathrm{~d}} \mathrm{PY} 6, \mathrm{y}$ 


$$
\begin{aligned}
& \mathrm{RMF}_{7 \mathrm{~d}} \mathrm{P} 1=71 \mathrm{Kp} / \mathrm{cm}^{2}>57 \mathrm{Kp} / \mathrm{cm}^{2}=\mathrm{RMF}_{7 \mathrm{~d}} \mathrm{PY} 6, \\
& \text { RMC }_{90 \mathrm{~d}} \mathrm{P} 1=466 \mathrm{Kp} / \mathrm{cm}^{2}<583 \mathrm{Kp} / \mathrm{cm}^{2}=\mathrm{RMC}_{90 \mathrm{~d}} \mathrm{PY} 6, \\
& \mathrm{RMF}_{90 \mathrm{~d}} \mathrm{P} 1=79 \mathrm{Kp} / \mathrm{cm}^{2}<90 \mathrm{Kp} / \mathrm{cm}^{2}=\mathrm{RMF}_{90 \mathrm{~d}} \mathrm{PY} 6,
\end{aligned}
$$

actuando además el grado de finura de molido de ambos cementos Portland comparados, a favor de esta hipótesis.

4.2. Y la contrariedad mostrada en este sentido por el cemento Portland P2únicamente ha de ser adscribidle a su notable menor contenido de $\mathrm{C}_{3} \mathrm{~S}, 33,47 \%$, y todo lo contrario de $\mathrm{C}_{2} \mathrm{~S}, 30,26 \%$, y su notable también menor grado de finura de molido que el resto, $3015 \mathrm{~cm}^{2} / \mathrm{g}$, (Tabla 8-44) lo cual determina como era esperado y así se confirma, que tanto la velocidad de su hidratación como la del espesor, fuerza y consistencia dela zona de transición a la interfase ITZ entre el árido silíceo y la pasta del cemento Portland P2 hidratado, tengan que ser necesariamente menores que las del P1 con las consecuencias tecnológicas pertinentes al caso para el tema que nos ocupa:valores de RMC y RMF características a 7, 28 y 90 días en probetas de 4×4×16 cm de mortero normalizado Tipo RC-75 menores y bastantees menores incluso que las del P1, véanse las Tablas 8-44 y 8-45, y por igual motivo último, sobre todo, que las de todos los demás

\subsubsection{Parámetro RMF.}

Mediante este parámetro se han de destacar los siguientes comportamientos clasificatorios observados de los cinco CP matrices seleccionados y así ensayados (véase la Tabla 8-45): Durante el transcurso del ensayo desde la edad de 3 hasta la de 90 días, se produjo unintercambio en las posiciones clasificatorias de los CP P1 y PY6 que puede catalogarse de contrario u opuesto por haber comenzado la del P1 (14,11\% C $3 \mathrm{~A}, 51,05 \% \mathrm{C}_{3} \mathrm{~S}, 16,46 \% \mathrm{C}_{2} \mathrm{~S}$ y SEB $\left.3192 \mathrm{~cm}^{2} / \mathrm{g}\right)$ en la última posición de la $1^{\underline{a}}$ clasificación (la de la edad de 3 días) para finalizar en la $2^{a}$ posición dela última clasificación (la de la edad de 90 días), mientras que la del PY6 (0\% C 3 A, 79,43\% C3S, 2,29\% $\mathrm{C}_{2} \mathrm{~S}$ y SEB $3287 \mathrm{~cm}^{2} / \mathrm{g}$ ) comenzó en la 3a posición y finalizó en la última la cual la había alcanzado además 62 días antes, es decir, a la edad de 28 días. $\mathrm{Y}$ a tal efeceto se ha de reseñar además que las SEB de ambos CP eran del mismo o muy perecido orden de magitud, es decir, eran comparables por, cuya razón, el CP P2 no pudo comportarse del mismo modo que el P1 a pesar de que su contenido potencial de $\mathrm{C}_{3} \mathrm{~A}$ era elevado también, 11,09\%, pero su SEB era bastante menor: $3015 \mathrm{~cm}^{2} / \mathrm{g}$, razón por la cual se ubicó siempre en la $1^{a}$ posisicoón de todas las clasificaciones obtenidas. En cambio el PY4, cuyo contenido potencial de $\mathrm{C}_{3} \mathrm{~A}$ era $0 \%$ como el del PY6 y su SEB comparable también, $3235 \mathrm{~cm}^{2} / \mathrm{g}$, si mostró un comportamiento clasificatorio semejante al del PY6 sólo que corregido y disminuido porque su contenido potencial de $\mathrm{C}_{3} \mathrm{~S}$ era bastanet menor que el del PY6, 58,19\%, mientras que el de $\mathrm{C}_{2} \mathrm{~S}$ era bastante mayor, lógicamente, 19,46\%,razón por la cual comenzaría su ubicación clasificatoria en la $2^{a}$ posición para finalizarlaen la $3^{a}$ posición de la última clasificación. Por lo que de acuerdo con todo lo anterior, el CP P.31, cuyo contenido potencial de $\mathrm{C}_{3} \mathrm{~A}$ era intermedio al de todos los demás $\mathrm{CP}, 7,62 \%$, y su SEB, 3248 $\mathrm{cm}^{2} / \mathrm{g}$, comparable igualmente con la del P1, PY4 y PY6, no se debería de haber clasificado en posición extrema alguna sino intermedia $y$, a ser posible, la misma en todas las clasificaciones 
obtenidas como así ha ocurrido en esta investigación: se ha clasificado siempre en la penúltima posición en todas ellas, véase de nuevo la Tabla 8-45.

\subsubsection{Parámetro RMC.}

En el caso de este parámetro, RMC, se puede decir lo mismo que en el correspondiente parámetro RMF sólo que corregido y aumentadoal heberse producido esta vez el intercambio de

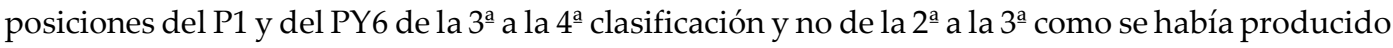
antes con la RMF.

\subsubsection{Parámetro RMF/RMC.}

En relación con este otro parámetro que no es "absoluto", como lo son la RMF y la RMC, sino "relativo", se ha de precisar, antes de todo, que no es un parámetro mecánico (físico) más sino tan sólo un número abstracto obtenido por división de dos parámetros mecánicos absolutos: RMF y RMC con idénticas unidades de medida: $\mathrm{Kp} / \mathrm{cm}^{2}$, razón por la que carece de unidad de medida aunque su valor da, no obstante, una idea aproximada de la fortaleza potencial de la unión pasta< árido silíceo nada más la cual es, en todo caso, proporcional a la $[\mathrm{CaO}]$ y $\left[\mathrm{OH}^{-}\right]$de la fase líquida de dicha pasta. Y tanto más dejará de ser proporcional cuanto mayor sea el porcentaje de reemplazo de puzolana por $\mathrm{CP}$, lógicamente.

La explicación de todo lo ocurrido ha de buscarse necesariamente y como no podía ser de otra manera, en la coincidencia total de las clasificaciones obtenidas de los cementos Portland así ensayados:

- en función de sus valores de RMF y RMC a la edad de 90 días del ensayo especialmente, y

- en función de sus respectivos contenidos potenciales de $\mathrm{C}_{3} \mathrm{~S}(\%)$ y/o de $\mathrm{C}_{3} \mathrm{~A}(\%)$ (al resto de las edades y cuanto más iniciales mejor) y/o SEB según convenga (veánse de nuevo las Tablas $8-44$ y $8-45)$.

Porque el mayor volumen molar de los hidratos derivados de la hidratación del $\mathrm{C}_{3} \mathrm{~A}$ sobre los correspondientes del $\mathrm{C}_{3} \mathrm{~S}(\%)$ y $\mathrm{C}_{2} \mathrm{~S}(\%)$, unida a la ya conocida mayor velocidad de hidratación del $C_{3} A$ sobre el $C_{3} S$ y más aún sobre el $C_{2} S$, explicaría el por qué el cemento Portland P1 se ha ubicado siempre:

- en la última posición de las primeras clasificaciones obtenidas en función de tales parámetros absolutos RMF y RMC, y

- en la $1^{a}$ posición siempre también, en las 4 clasificaciones obtenidas en función del parámetro relativo $\mathrm{RMF} / \mathrm{RMC}$.

De esta manera y a tales edades del ensayo, las probetas de mortero del P1 estarían mucho más «colmatadas» que «fortalecidas» en su unión química pasta<>árido silíceo, mientras que a las del cemento Portland PY6 les habría ocurrido todo lo contrario; viéndose justificado además este comportamiento por el notable mayor contenido potencial de $\mathrm{C}_{3} \mathrm{~S}$ del PY6 (79.43\%) sobre el 
P1 (51.05\%), lo que habría originado siempre mayor cantidad de portlandita de principio a fin del ensayo reforzándose con ello dicha unión pasta<>árido silíceo de su mortero y, por consiguiente, reforzando más los valores de RMF sobre los de RMC y el cociente entre ambos, del cemento Portland PY6 sobre el P1 como así ha ocurrido también en esta investigación.

Ello haría por tanto y en potencia, que los mayores valores de RMF y RMC y menores del cociente RMF/RMC del P1 sobre los demás cementos Portland a las edades de 3 y 7 días, fueran fruto de un mortero más «colmatado» que «fortalecido» en la unión química de su pasta y el árido silíceo, mientras que lo ocurrido al PY6 sería todo lo contrario.

Sin embargo, la razón por la que el cemento Portland P2 ha ocupado siempre, a todas las edades del ensayo, la $1^{a}$ posición de todas las clasificaciones obtenidas mediante los parámetros absolutos $\mathrm{RMF}$ y $\mathrm{RMC}$, ysu rápida evolución, en cambio, en las clasificaciones obtenidas mediante el parámetro relativo $\mathrm{RMF} / \mathrm{RMC}$, de su $2^{\underline{a}}$ posicióna las edades de 3 y 7 días, a la $4^{\underline{a}}$ posición a 28 días para volver a la $2^{\underline{a}}$ posición de nuevo en la clasificacióna la edad última de 90 días habiendo mostrado así y, en definitiva, que su comportamiento no era nada semejante al del P1 a pesar de que su contenido potencial de $\mathrm{C}_{3} \mathrm{~A}$ era bastante elevado también, 11,09\%, ha de buscarse necesariamente bastante más en su considerable menor SEB que en su considerable también mayor contenido potencial de $\mathrm{C}_{2} \mathrm{~S}$, 30,26\%(véansede nuevo una vez más las Tablas 8-44 y 8-45), y,que el resto de los cementos Portland así ensayados y comparados. Lo que habría dado por resultado esta vez a una menor liberación de portlandita que el resto y, por consiguiente, a una menor fortaleza de la unión química de su pasta con el árido silíceo con la consecuencia pertinente para el tema que nos ocupa de haber proporcionado unos menores valores de RMFy de RMC igualmente, véase la Tabla 8-45. De aquí que, y aunque en principio pareciera extraño, el cemento Portland P1 debería superar al P2 en las clasificaciones obtenidas mediante los parámetros absolutos RMF y RMC más no en cambio, en la obtenida mediante el parámetro relativo RMF/RMC, como así ha ocurrido de nuevoen esta investigación.

Por otra parte, la razón por la que el cemento Portland P31 ha ocupadosiempre también la $4^{\underline{a}}$ posición en las clasificaciones obtenidas mediante los parámetros absolutos RMF y RMC, yla $3^{\underline{a}}$ y $2^{\underline{a}}$ posiciones, por este orden, en las clasificaciones obtenidas mediante el parámetro relativo $\mathrm{RMF} / \mathrm{RMC}$, ha de buscarse necesariamente en sus contenidos potenciales intermedios de $\mathrm{C}_{3} \mathrm{~S}(\%)$ y $\mathrm{C}_{3} \mathrm{~A}(\%)$ entre el P1 y el PY6 pero, sobre todo, de SEB $\left(3248 \mathrm{~cm}^{2} / \mathrm{g}\right)$ que, al estar bastante más próxima a la del PY6 (3287 cm²/g) que a la del P1(3192 cm²/g), deberá de haberle condicionado bastante más para que en dichas clasificaciones obtenidas mediante los parámetros absolutos RMF y RMC, su posición no haya cambiado a ninguna edad y se encuentre, por tanto, más próxima a la del $1^{\circ}$, el P1, o a la del $2^{\circ}$, el PY6, según sea dicha edad.

Finalmente, la razón por la que el cemento Portland PY4 ha ocupado unas posiciones en las clasificaciones obtenidas mediante los parámetros absolutos RMF y RMC, muy próximas pero anteriores siempre a las del PY6, habiendo evolucionado además su posicionamiento inicial de la misma manera que lo ha hecho el PY-6,justifica sobradamente no sólo las razones anteriores aducidas para el posicionamiento y evolución del cemento Portland PY-6 en cada una de las clasificaciones citadas, sino también el posicionamiento y evolución del propio cemento Portland 
PY4 en las mismas, dado que a pesar de que su contenido potencial de $\mathrm{C}_{3} \mathrm{~A}$ es también nulo, su contenido potencial de $\mathrm{C}_{3} \mathrm{~S}$ es, en cambio, $58.19 \%$ y, por consiguiente, menor que el del PY6, $79.46 \%$.

\subsection{2.-De los cementos de mezcla preparados y dosificados que figuran en el apartado}

\section{1. del Capítulo 7.}

En primer lugar, se han analizado, estudiado, comparado, discutido e interpretado los resultados obtenidos de la determinación del comportamiento mecánico-resistente de las probetas de $4 \times 4 \times 16 \mathrm{~cm}$ de los morteros normalizados tipo EN 196-1 con una misma puzolana seleccionada mezclada, por separado, con cada uno de los $5 \mathrm{CP}$ seleccionados igualmente.

Por otra parte, y como aclaración adicional se ha de decir también que, en adelante, los parámetros RFMF, RMC y RMF/RMC se dejarán de calificar de absolutos y relativo, respectivamente, cada vez que sea necesario referirse a todos ellos o a sólo a alguno(s), denominándoseles, por tanto y sin más, RFMF, RMC y RMF/RMC.

\subsubsection{1-A igualdad de puzolana seleccionada " $Z$ " y cantidad de su reemplazo por CP.}

\subsection{Familia $P-n^{o}$ y $P Y-n^{o} /{ }^{\prime \prime} Z^{\prime \prime} 60 / 40$}

Todas las clasificaciones que surgen de los resultados obtenidos de los ensayos de RMC y RMF se muestran en las Figuras 8-21, 8-22, 8-23, 8-24 y 8-25. En este caso, los cementos puzolánicos P-nº y PY-nº/"Z" 60/40 así ensayados, comparados y clasificados han tenido, por lo general, un comportamiento y evolución a lo largo dela tres edades del ensayo, semejante, en gran medida, al de sus respectivoscementos Portland matrices solos, y en especial en el caso delos del P1 y PY6, pero desde la edad de 28 a 90 días nada más porque a la edad de 7 días fue diferente de una puzolana a otra y tanto más diferente cuanto mayor fue el carácter químico alumínico de la puzolana, ergo, cuanto mayor fue su contenido de $\mathrm{Al}_{2} \mathrm{O}_{3}{ }^{\mathrm{r}}-(\%)$.

De aquí que las razones allí aducidas ${ }^{7}$ son aplicables al comportamiento y evolución de los valores de RMC y RMF de sus correspondientes cementos Portland puros P1 y PY6 en sus clasificaciones respectivas, viéndose tales razones confirmadas en su certeza cuanto más "alumínica" haya sido la puzolana "Z" por la que se reemplazó el CP, ya que con la misma y por mayor colmatación de sus probetas de mortero con aluminatos de calcio hidratadosde origen el contenido de $\mathrm{Al}_{2} \mathrm{O}_{3}$ r- $(\%)$ de la puzolana " $\mathrm{Z}$ " y mantenimiento de los mismos, las clasificaciones que se obtuvieren en RMC de aquellos, del P1 y del PY6, deberían haber sido netamente superiores en todas o en algunas de las edades más avanzadas del ensayo(a 28 y/ó a 90 días) a cuando se ensayaron solos y más aún lógicamente, en el caso del PY6 que en el caso del P1, como así ha ocurrido una vez más en esta investigación, véanse las Figs. 8-21 y 8-25 y, de esta última,

\footnotetext{
${ }^{7}$ Véase el apartado 6.1.1 de esta MEMORIA de Tesis Doctoral.
} 
los valores de RMF especialmente. Además, obsérvese en la Tabla 8-46 como el cemento Portland PY6 matriz pasa en RMF de la posición $3^{\underline{a}}$ en las clasificaciones a 3 y 7 días a la posición final en las dos últimas clasificaciones del ensayo, mientras que en RMF y con la puzolana M pasa de la

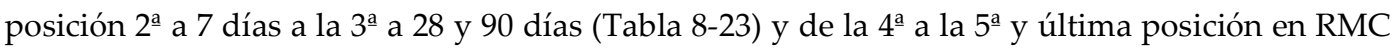
(Tabla 8-47), es decir, "ha ganado" en ambos casos una posición y no, en cambio, dos posiciones cuando se clasificó sin dicha puzolana, es decir, sólo. Por otra parte, ambas situaciones no son totalmente coincidentes al ser el parámetro RMF más sensible que el RMC en vista de que los aluminatos de calcio hidratados de cualquier origen y etiología colmatan poros más que refuerzan la unión pasta<>árido silíceo. Ello justifica, por tanto, en este caso de la puzolana M, las posiciones adoptadas por los cementos Portland PY4, PY6 y P1 a los que reemplazó, en las clasificaciones obtenidas mediante el parámetro RMF/RMC y que se encuentran en la Tabla 8-48.

TABLA 8-46.- ESTUDIO COMPARATIVO DE LOS CEMENTOS PORTLAND A CADA UNA DE LAS 3 EDADES DEL ENSAYO, EN FUNCIÓN DE LA RMF DE SUS MEZCLAS 60/40 CON CADA PUZOLANA SELECCIONADA.

\begin{tabular}{|c|c|c|}
\hline \multicolumn{3}{|r|}{ Parámetro RMF } \\
\hline \multirow{2}{*}{ Puzolana "Z" } & \multirow{2}{*}{ Edad (días) } & Familias P-no y PY-no/"Z" 60/40 \\
\hline & & Clasificaciones de los P-no y PY-no a diferentes edades \\
\hline \multirow{3}{*}{$\mathrm{O}$} & 7 & PY-4 = P-2 $<$ PY $-6<$ P-31 $<$ P-1 \\
\hline & 28 & PY- $4<$ P-2 $<$ PY $-6<$ P-31 $<$ P-1 \\
\hline & 90 & $\mathrm{P}-2<\mathrm{P}-1<\mathrm{P}-31<\mathrm{PY}-6<\mathrm{PY}-4$ \\
\hline \multirow{3}{*}{ CV19 } & 7 & PY $-4<$ P-2 $<$ PY $-6<$ P-31 $<$ P-1 \\
\hline & 28 & $\mathrm{P}-2<\mathrm{PY}-4<\mathrm{P}-1<\mathrm{PY}-6<\mathrm{P}-31$ \\
\hline & 90 & $\mathrm{P}-2<\mathrm{P}-1<\mathrm{P}-31<\mathrm{PY}-4<\mathrm{PY}-6$ \\
\hline \multirow{3}{*}{ A } & 7 & PY $-4<$ P-2 $<$ PY $-6<$ P-1 $<$ P-31 \\
\hline & 28 & $\mathrm{P}-2<\mathrm{PY}-4<\mathrm{PY}-6<\mathrm{P}-1<\mathrm{P}-31$ \\
\hline & 90 & $\mathrm{P}-2<\mathrm{P}-1<\mathrm{P}-31<\mathrm{PY}-4<\mathrm{PY}-6$ \\
\hline \multirow{3}{*}{$\mathrm{C}$} & 7 & P-1 $<$ PY $-6<$ P-2 $<$ P-31 $<$ PY -4 \\
\hline & 28 & $\mathrm{P}-1<\mathrm{P}-2<\mathrm{PY}-4<\mathrm{PY}-6<\mathrm{P}-31$ \\
\hline & 90 & $\mathrm{P}-1<\mathrm{P}-2<\mathrm{PY}-4<\mathrm{P}-31<\mathrm{PY}-6$ \\
\hline \multirow{3}{*}{ CV10 } & 7 & PY $-4<$ P-2 $<$ PY $-6<$ P-31 $<$ P-1 \\
\hline & 28 & PY-4 $<$ P-2 $<$ P-1 $<$ PY-6 $<$ P-31 \\
\hline & 90 & $\mathrm{P}-2<\mathrm{P}-1<\mathrm{PY}-4<\mathrm{P}-31<\mathrm{PY}-6$ \\
\hline \multirow{3}{*}{$\mathrm{M}$} & 7 & PY $-4<$ PY $-6<$ P- $2<$ P-31 $<$ P-1 \\
\hline & 28 & PY-4 $<$ P-2 $<$ PY $-6<$ P-31 $<$ P-1 \\
\hline & 90 & PY-4 $<$ P-2 $<$ PY $-6<$ P-1 $<$ P-31 \\
\hline
\end{tabular}


COMPORTAMIENTO SULFÁTICO Y MECÁNICO-RESISTENTE DE CEMENTOS PORTLAND CON ELEVADOS CONTENIDOS DE PUZOLANAS (> 40\%): SU FUNDAMENTO QUÍMICO Y JUSTIFICACIÓN DE OTRAS CONSECUENCIAS POSIBLES

TABLA 8-47.- ESTUdiO COMPARATIVO DE LOS CEMENTOS PORTLAND A CADA UNA DE LAS 3 EDADES DEL ENSAYO, EN FUNCIÓN DE LA RMC DE SUS MEZCLAS 60/40 CON CADA PUZOLANA SELECCIONADA.

\begin{tabular}{|c|c|c|}
\hline \multicolumn{3}{|r|}{ Parámetro RMC } \\
\hline \multirow{2}{*}{ Puzolana "Z" } & \multirow{2}{*}{$\begin{array}{l}\text { Edad } \\
\text { (días) }\end{array}$} & Familias P-no y PY-no/"Z" 60/40 \\
\hline & & Clasificaciones de los P-n ${ }^{0}$ y PY-n ${ }^{0}$ a diferentes edades \\
\hline \multirow{3}{*}{$\mathrm{O}$} & 7 & $\mathrm{P}-2<\mathrm{PY}-4<\mathrm{P}-31<\mathrm{P}-1<\mathrm{PY}-6$ \\
\hline & 28 & PY- $4<$ P- $2<$ P-31 $<$ PY $-6<$ P-1 \\
\hline & 90 & $\mathrm{P}-2<\mathrm{P}-31<\mathrm{P}-1<\mathrm{PY}-4<\mathrm{PY}-6$ \\
\hline \multirow{3}{*}{ CV19 } & 7 & P-2 $<$ P-31 $<$ PY-4 $<$ P-1 $<$ PY-6 \\
\hline & 28 & P-2 $<$ PY $-4<$ P-1 $<$ P-31 $<$ PY-6 \\
\hline & 90 & $\mathrm{P}-2<\mathrm{P}-1<\mathrm{P}-31<\mathrm{PY}-4<\mathrm{PY}-6$ \\
\hline \multirow{3}{*}{ A } & 7 & PY-6 $<$ P-2 $<$ PY $-4<$ P-1 $<$ P-31 \\
\hline & 28 & P-2 $<$ PY-6 $<$ PY $-4<$ P-1 $<$ P-31 \\
\hline & 90 & $\mathrm{P}-2<\mathrm{P}-1<\mathrm{P}-31<\mathrm{PY}-4<\mathrm{PY}-6$ \\
\hline \multirow{3}{*}{$\mathrm{C}$} & 7 & PY-6 $<$ P-2 $<$ P-31 $<$ P-1 $<$ PY-4 \\
\hline & 28 & P-2 $<$ P-1 $<$ PY- $4<$ PY- $6<$ P-31 \\
\hline & 90 & P-2 $<$ P-1 $<$ PY- $4<$ P-31 $<$ PY-6 \\
\hline \multirow{3}{*}{ CV10 } & 7 & PY $-4<$ P-2 $<$ PY $-6<$ P-31 $<$ P-1 \\
\hline & 28 & P-2 $<$ PY $-4<$ P-31 $<$ P-1 $<$ PY-6 \\
\hline & 90 & $\mathrm{P}-2<\mathrm{P}-31<\mathrm{P}-1<\mathrm{PY}-4<\mathrm{PY}-6$ \\
\hline \multirow{3}{*}{ M } & 7 & PY $-4<$ P-2 $<$ P-31 $<$ PY $-6<$ P-1 \\
\hline & 28 & P-2 $<$ PY $-4<$ P- $31<$ PY $-6<$ P- 1 \\
\hline & 90 & P-2 $<$ P-31 $<$ P-1 $<$ PY-4 $<$ PY-6 \\
\hline
\end{tabular}

TABLA 8-48.- ESTUDIO COMPARATIVO DE LA RELACIÓN RMF/RMC DE LOS CEMENTOS DE MEZCLA 60/40 EN FUNCIÓN DEL CEMENTO PORTLAND DE REFERENCIA UTILIZADO, CON IDÉNTICA PUZOLANA SELECCIONADA.

\begin{tabular}{|c|c|c|}
\hline \multicolumn{3}{|r|}{ Parámetro RMF/RMC } \\
\hline \multirow{2}{*}{ Puzolana "Z" } & \multirow{2}{*}{$\begin{array}{l}\text { Edad } \\
\text { (días) }\end{array}$} & Familias P-no y PY-no/"Z" 60/40 \\
\hline & & Clasificaciones de los P-no y PY-no a diferentes edades \\
\hline \multirow{3}{*}{$\mathrm{O}$} & 7 & PY-6 $<$ PY-4 $<$ P-2 $<$ P-31 $<$ P-1 \\
\hline & 28 & $\mathrm{P}-1<\mathrm{PY}-6<\mathrm{P}-31<\mathrm{P}-2=\mathrm{PY}-4$ \\
\hline & 90 & $\mathrm{P}-1<\mathrm{PY}-6<\mathrm{PY}-4<\mathrm{P}-2<\mathrm{P}-31$ \\
\hline \multirow{3}{*}{ CV19 } & 7 & PY $-4<$ PY $-6<$ P-2 $<$ P-1 $<$ P-31 \\
\hline & 28 & $\mathrm{PY}-6<\mathrm{P}-1<\mathrm{P}-31<\mathrm{P}-2=\mathrm{PY}-4$ \\
\hline & 90 & PY- $4<$ P-31 $<$ P-1 $<$ PY- $6<$ P-2 \\
\hline \multirow{3}{*}{ A } & 7 & PY $-4<$ P-31 $<$ P-1 $<$ P-2 $<$ PY -6 \\
\hline & 28 & $\mathrm{P}-31<\mathrm{PY}-4<\mathrm{P}-1<\mathrm{PY}-6<\mathrm{P}-2$ \\
\hline & 90 & $\mathrm{P}-31<\mathrm{PY}-4<\mathrm{P}-1<\mathrm{PY}-6<\mathrm{P}-2$ \\
\hline \multirow{3}{*}{$\mathrm{C}$} & 7 & $\mathrm{P}-1<\mathrm{PY}-4<\mathrm{P}-31<\mathrm{P}-2<\mathrm{PY}-6$ \\
\hline & 28 & $\mathrm{P}-1<\mathrm{P}-31<\mathrm{PY}-4<\mathrm{PY}-6<\mathrm{P}-2$ \\
\hline & 90 & $\mathrm{P}-1<\mathrm{P}-31<\mathrm{PY}-6<\mathrm{PY}-4<\mathrm{P}-2$ \\
\hline \multirow{3}{*}{ CV10 } & 7 & PY $-4<$ P- $2<$ PY $-6<$ P-31 $<$ P-1 \\
\hline & 28 & PY-4 $<$ P-1 = PY $-6<$ P-2 $<$ P-31 \\
\hline & 90 & $\mathrm{PY}-4<\mathrm{P}-1<\mathrm{PY}-6<\mathrm{P}-31<\mathrm{P}-2$ \\
\hline \multirow{3}{*}{ M } & 7 & PY $-4<$ PY $-6<$ P $-1<$ P-2 $<$ P-31 \\
\hline & 28 & PY-4 $<$ PY $-6<$ P-1 $<$ P-31 $<$ P-2 \\
\hline & 90 & PY-4 $<$ PY-6 $<$ P-1 $<$ P-31 $<$ P-2 \\
\hline
\end{tabular}


TABLA 8-49.- ESTUdiO COMPARATIVO DE LA RMC DE LOS CEMENTOS DE MEZCLA 60/40 EN FUNCIÓN DEL CEMENTO PORTLAND DE REFERENCIA UTILIZADO CON APORTE DE CAL APAGADA, CON IDÉNTICA PUZOLANA SELECCIONADA.

\begin{tabular}{|c|c|c|}
\hline \multicolumn{3}{|c|}{ Parámetro RMC } \\
\hline \multirow{2}{*}{ Puzolana "Z" } & \multirow{2}{*}{ Edad (días) } & Familias P-no y PY-no/("Z"+CH) 50/50 y $(" Z " / C H)=4$ \\
\hline & & Clasificaciones de los P-no y PY-no a diferentes edades \\
\hline \multirow{3}{*}{$\mathrm{O}+\mathrm{CH}$} & 7 & PY- $4<$ P-1 $<$ PY $-6<$ P-31 $<$ P-2 \\
\hline & 28 & PY-4 $<$ PY $-6<$ P-2 $<$ P-31 $<$ P-1 \\
\hline & 90 & $\mathrm{PY}-4<\mathrm{P}-2<\mathrm{P}-1<\mathrm{PY}-6<\mathrm{P}-31$ \\
\hline \multirow{3}{*}{$\mathrm{CV} 19+\mathrm{CH}$} & 7 & PY-6 $<$ P-1 \\
\hline & 28 & PY-6 $<$ P-1 \\
\hline & 90 & $\mathrm{P}-1<\mathrm{PY}-6$ \\
\hline \multirow{3}{*}{$\mathrm{A}+\mathrm{CH}$} & 7 & PY-6 $<$ PY $-4<$ P-2 \\
\hline & 28 & PY-4 $<$ PY-6 $<$ P-2 \\
\hline & 90 & PY- $4<$ P-2 $<$ PY -6 \\
\hline \multirow{3}{*}{$\mathrm{C}+\mathrm{CH}$} & 7 & PY-6 $<$ PY $-4<$ P-1 $<$ P-2 \\
\hline & 28 & P-1 $<$ PY-4 $<$ PY $-6<$ P-2 \\
\hline & 90 & $\mathrm{P}-1<\mathrm{P}-2<\mathrm{PY}-4<\mathrm{PY}-6$ \\
\hline
\end{tabular}

Y respecto de las posiciones inmediatamente posteriores, a 7 y 28 día, y anterior a 28 días, ocupadas por el cemento Portland PY4 respecto del P2, en las clasificaciones obtenidas a igualdad de puzolana $\mathrm{O}$, la explicaciones ha de buscarse necesariamente en sus muy dispares contenidos de $\mathrm{C}_{3} \mathrm{~S}$ y/o $\mathrm{C}_{2} \mathrm{~S}$ por un lado (PY4 = 58,19\% $\mathrm{C}_{3} \mathrm{~S}=33,47 \% \mathrm{C}_{3} \mathrm{~S}=\mathrm{P} 2 ; \mathrm{PY} 4=19,46 \% \mathrm{C}_{2} \mathrm{~S}=30,26 \% \mathrm{C}_{2} \mathrm{~S}=$ $\mathrm{P} 2$ ) y de $\mathrm{C}_{3} \mathrm{~A}$ por otro (PY4 =0,00\% $\mathrm{C}_{3} \mathrm{~A}=11,09 \% \mathrm{C}_{3} \mathrm{~A}=\mathrm{P} 2$ ) los cuales aportarían a cada edad citada, las cantidades de portlandita y de aluminatos de calcio hidratados necesarios respectivamente para "reforzar" la unión pasta-árido silíceo más que para "colmatar" poros, o viceversa, debiéndose de ver ello ratificado por el hecho de que si añadiéramos cal apagada, $\mathrm{Ca}(\mathrm{OH})_{2}$, el cemento Portland P2 debería superar al PY4, al menos a las edades iniciales de ensayo de 7 y 28 días, como ha sido el caso, véanse a propósito las Tablas 8-49 y 8-50.

Finalmente cabe destacar aquí el posicionamiento inicial adquirido por el cemento Portland P1 a todas las edades del ensayo en la clasificación de RMF de la puzolana C, lo que indica al parecer que en estas proporciones de mezcla la notable presencia de alcalinos de la puzolana C ("capacidad de cambio") (alero, 1986) y de C3A del citado P1, no debe de facilitar al parecer la unión pasta-árido silíceo y consiguientemente originan unos valores menores de RMF; viéndose además esta razón reforzada por el semejante comportamiento proporcionado por el cemento P2/C 60/40 que ha ido a la zaga a su hermano del P1 en la citada clasificación como, lo cual y según lo dicho, era lo lógico, pues el cemento Portland P2 tiene un $11.09 \%$ C 3 A y el P1, $14.11 \% \mathrm{C}_{3} \mathrm{~A}$.

Y aún todo ello se ve complementado además por el comportamiento y evolución del cemento PY6/C 60/40, al cual el haber resultado ser dispar al de los citados P1 y P2 conforme transcurrió el ensayo y ser el contenido de $\mathrm{C}_{3} \mathrm{~A}$ del PY6 $=0.00 \%$ y del $\mathrm{C}_{3} \mathrm{~S}=78.43 \%$, se justificaría por éstos últimos también dispares contenidos expuestos de $\mathrm{C}_{3} \mathrm{~A}$ y $\mathrm{C}_{3} \mathrm{~S}$ a los del P1 y P2. 
COMPORTAMIENTO SULFÁTICO Y MECÁNICO-RESISTENTE DE CEMENTOS PORTLAND CON ELEVADOS CONTENIDOS DE PUZOLANAS (> 40\%): SU FUNDAMENTO QUÍMICO Y JUSTIFICACIÓN DE OTRAS CONSECUENCIAS POSIBLES

TABLA 8-50.- ESTUDiO COMPARATIVO DE LA RELACIÓN RMF/RMC DE LOS CEMENTOS DE MEZCLA 60/40 EN FUNCIÓN DEL CEMENTO PORTLAND DE REFERENCIA UTILIZADO CON APORTE DE CAL APAGADA, CON IDÉNTICA PUZOLANA SELECCIONADA.

\begin{tabular}{|c|c|c|}
\hline \multicolumn{3}{|r|}{ Parámetro RMF/RMC } \\
\hline \multirow{2}{*}{ Puzolana "Z" } & \multirow{2}{*}{ Edad (días) } & Familias P-no y PY-no /("Z"+CH) 50/50 y ("Z"/CH) = 4 \\
\hline & & Clasificaciones de los P-no y PY-no a diferentes edades \\
\hline \multirow{3}{*}{$\mathrm{O}+\mathrm{CH}$} & 7 & P-2 $<$ PY-6 $<$ P-1 $<$ P-31 $<$ PY-4 \\
\hline & 28 & $\mathrm{P}-1<\mathrm{P}-2<\mathrm{PY}-6<\mathrm{P}-31<\mathrm{PY}-4$ \\
\hline & 90 & PY $-6<$ P-1 $<$ P- $31<$ P- $2<$ PY -4 \\
\hline \multirow{3}{*}{$\mathrm{CV} 19+\mathrm{CH}$} & 7 & $\mathrm{P}-1<\mathrm{PY}-6$ \\
\hline & 28 & P-1 $<$ PY-6 \\
\hline & 90 & PY-6 $<$ P-1 \\
\hline \multirow{3}{*}{$\mathrm{A}+\mathrm{CH}$} & 7 & $\mathrm{P}-1<\mathrm{P}-2<\mathrm{PY}-4<\mathrm{PY}-6$ \\
\hline & 28 & $\mathrm{P}-1<\mathrm{P}-2<\mathrm{PY}-4<\mathrm{PY}-6$ \\
\hline & 90 & $\mathrm{P}-1<\mathrm{P}-2<\mathrm{PY}-6<\mathrm{PY}-4$ \\
\hline \multirow{3}{*}{$\mathrm{C}+\mathrm{CH}$} & 7 & $\mathrm{P}-1<\mathrm{P}-2<\mathrm{PY}-6<\mathrm{PY}-4$ \\
\hline & 28 & $\mathrm{P}-2<\mathrm{PY}-6<\mathrm{P}-1<\mathrm{PY}-6$ \\
\hline & 90 & $\mathrm{PY}-6<\mathrm{P}-1<\mathrm{P}-2<\mathrm{PY}-4$ \\
\hline \multirow{3}{*}{$\mathrm{CV} 10+\mathrm{CH}$} & 7 & PY-4 $<$ PY-6 $<$ P-1 \\
\hline & 28 & P-1 $<$ PY-6 < PY-4 \\
\hline & 90 & PY-6 $<$ PY-4 $<$ P-1 \\
\hline
\end{tabular}

\subsection{Familia $P-n^{o}$ y $P Y-n^{o} / " Z^{\prime \prime} 50 / 50$}

TABLA 8-51.- ESTUDIO COMPARATIVO DE LA RMC DE LOS CEMENTOS DE MEZCLA 50/50 EN FUNCIÓN DEL CEMENTO PORTLAND DE REFERENCIA UTILIZADO, CON IDÉNTICA PUZOLANA SELECCIONADA.

\begin{tabular}{|c|c|c|}
\hline \multicolumn{3}{|r|}{ Parámetro RMC } \\
\hline \multirow{2}{*}{ Puzolana "Z" } & \multirow{2}{*}{ Edad (días) } & Familias P-no y PY-no/"Z" 50/50 \\
\hline & & Clasificaciones de los P-no y PY-no a diferentes edades \\
\hline \multirow{3}{*}{$\mathrm{O}$} & 7 & PY-4 $<$ P-1 $<$ P-2 $<$ PY-6 $<$ P-31 \\
\hline & 28 & PY- $4<$ P-2 $<$ PY- $6<$ P-1 $<$ P-31 \\
\hline & 90 & $\mathrm{P}-2<\mathrm{PY}-4<\mathrm{P}-1<\mathrm{PY}-6<\mathrm{P}-31$ \\
\hline \multirow{3}{*}{ CV19 } & 7 & PY $-6<$ P-31 $<$ P-1 \\
\hline & 28 & $\mathrm{P}-31<\mathrm{P}-1<\mathrm{PY}-6$ \\
\hline & 90 & $\mathrm{PY}-6<\mathrm{P}-31<\mathrm{P}-1$ \\
\hline \multirow{3}{*}{ A } & 7 & PY-6 $<$ P-2 $<$ PY $-4<$ P-31 $<$ P-1 \\
\hline & 28 & $\mathrm{P}-2<\mathrm{PY}-4<\mathrm{PY}-6<\mathrm{P}-1<\mathrm{P}-31$ \\
\hline & 90 & $\mathrm{P}-2<\mathrm{PY}-4<\mathrm{P}-1<\mathrm{PY}-6<\mathrm{P}-31$ \\
\hline \multirow{3}{*}{$\mathrm{C}$} & 7 & $\mathrm{PY}-6<\mathrm{P}-1<\mathrm{P}-2<\mathrm{P}-31<\mathrm{PY}-4$ \\
\hline & 28 & $\mathrm{P}-1<\mathrm{PY}-6<\mathrm{PY}-4<\mathrm{P}-2<\mathrm{P}-31$ \\
\hline & 90 & $\mathrm{P}-1<\mathrm{P}-2<\mathrm{P}-31<\mathrm{PY}-6<\mathrm{PY}-4$ \\
\hline \multirow{3}{*}{ CV10 } & 7 & PY-6 $<$ P-1 $<$ P-31 \\
\hline & 28 & P-1 $<$ PY-6 $<$ P-31 \\
\hline & 90 & $\mathrm{P}-1<\mathrm{P}-31<\mathrm{PY}-6$ \\
\hline \multirow{3}{*}{ M } & 7 & PY $-4<$ P-2 $<$ P-31 $<$ PY $-6<$ P-1 \\
\hline & 28 & $\mathrm{P}-2<\mathrm{PY}-4<\mathrm{P}-1<\mathrm{PY}-6<\mathrm{P}-31$ \\
\hline & 90 & P-2 $<$ P-1 $<$ PY-4 $<$ PY-6 $<$ P-31 \\
\hline
\end{tabular}


Todas las clasificaciones que surgen de los resultados obtenidos en los ensayos de RMC y RMF se muestran en las Tablas 8-51, 8-52 y 8-53. Teniendo en cuenta los razonamientos expuestos en la interpretación de la Familia P-no y PY-no/"Z" 60/40, lógicamente el parámetro RMF se verá más sensibilizado y disminuido cuanto menor sea el contenido de $\mathrm{C}_{3} \mathrm{~A}$ y/o $\mathrm{C}_{3} \mathrm{~S}$ y/o SE del cemento Portland que acompañe a la puzolana "Z".

TABLA 8-52.- ESTUdiO COMPARATIVO DE LA RMF DE LOS CEMENTOS DE MEZCLA 50/50 EN FUNCIÓN DEL CEMENTO PORTLAND DE REFERENCIA UTILIZADO, CON IDÉNTICA PUZOLANA SELECCIONADA.

\begin{tabular}{|c|c|c|}
\hline \multicolumn{3}{|r|}{ Parámetro RMF } \\
\hline \multirow{2}{*}{ Puzolana "Z" } & \multirow{2}{*}{$\begin{array}{l}\text { Edad } \\
\text { (días) }\end{array}$} & Familias P-n ${ }^{0}$ y PY-no/"Z" 50/50 \\
\hline & & Clasificaciones de los P-n ${ }^{0}$ y PY-no a diferentes edades \\
\hline \multirow{3}{*}{$\mathrm{O}$} & 7 & PY-6 $<$ P-2 $<$ PY $-4<$ P-31 $<$ P-1 \\
\hline & 28 & PY-4 $<$ P-31 $<$ P-1 $<$ PY-6 $<$ P-2 \\
\hline & 90 & $\mathrm{PY}-6<\mathrm{P}-1<\mathrm{P}-31<\mathrm{PY}-4<\mathrm{P}-2$ \\
\hline \multirow{3}{*}{ CV19 } & 7 & PY-6 $<$ P-1 $<$ P-31 \\
\hline & 28 & PY-6 < P-1 < P-31 \\
\hline & 90 & PY $-6<$ P-1 $<$ P-31 \\
\hline \multirow{3}{*}{ A } & 7 & P-1 $<$ PY $-4<$ P-2 $<$ P-31 $<$ PY-6 \\
\hline & 28 & P-1 $<$ P-31 $<$ PY-4 $<$ PY-6 $<$ P-2 \\
\hline & 90 & $\mathrm{P}-1<\mathrm{P}-31<\mathrm{PY}-4<\mathrm{PY}-6<\mathrm{P}-2$ \\
\hline & 7 & P-1 $<$ PY $-4<$ P-2 $<$ P-31 $<$ PY-6 \\
\hline \multirow[t]{2}{*}{$\mathrm{C}$} & 28 & $\mathrm{P}-2<\mathrm{PY}-4=\mathrm{P}-31<\mathrm{PY}-6<\mathrm{P}-1$ \\
\hline & 90 & $\mathrm{P}-1<\mathrm{PY}-6<\mathrm{P}-2<\mathrm{PY}-4<\mathrm{P}-31$ \\
\hline \multirow{3}{*}{ CV10 } & 7 & $\mathrm{P}-31=\mathrm{PY}-6<\mathrm{P}-1$ \\
\hline & 28 & P-31 $<$ P-1 $<$ PY -6 \\
\hline & 90 & PY-6 $<$ P-1 $<$ P-31 \\
\hline \multirow{3}{*}{ M } & 7 & PY-6 < PY-4 $<$ P-31 <P-2 < P-1 \\
\hline & 28 & PY-4 $<$ P-31 $<<$ PY $-6<$ P-2 $<$ P-1 \\
\hline & 90 & PY-6 $<$ P-31 $<$ PY- $4<$ P- $2<$ P-31 \\
\hline
\end{tabular}

De aquí que por causa de todos o sólo alguno(s) de tales contenidos citados, los cementos Portland PY4 y P2 ocuparían en la mayoría de los casos, las primeras posiciones en las clasificaciones correspondientes obtenidas, mientras que el P1, el P31 e incluso el PY6, ocuparían las últimas posiciones de tales clasificaciones, como así ha sido el caso, véase la Tabla 8-51. No cabe incluir en esta razón aducida, las clasificaciones correspondientes obtenidas mediante la puzolana C, ya que la misma debido aún a su potencial "capacidad de cambio", (Talero, 1986), proporciona otras clasificaciones de tales cementos Portland y en especial del P1, P2 y PY6, con lo que las razones expuestas al final de la interpretación para la Familia P-no y PY-nº/"Z" 60/40, son igualmente válidas para este caso.

Por otra parte, y respecto al parámetro RMC, obsérvese como en este tipo de mezcla 50/50, las puzolanas ensayadas cuanto más alumínicas son, han resultado ser más sensibles a la presencia de portlandita en el tiempo. Por tanto, cuanto más $\mathrm{C}_{3} \mathrm{~A}$ posea el cemento Portland que las acompañe, su clasificación deberá ir "perdiendo posiciones" con el transcurso del ensayo y viceversa, como así ha sido el caso, obsérvese la Tabla 8-52. 
COMPORTAMIENTO SULFÁTICO Y MECÁNICO-RESISTENTE DE CEMENTOS PORTLAND CON ELEVADOS CONTENIDOS DE PUZOLANAS (> 40\%): SU FUNDAMENTO QUÍMICO Y JUSTIFICACIÓN DE OTRAS CONSECUENCIAS POSIBLES

TABLA 8-53.- ESTUdiO COMPARATIVO DE LA RELACIÓN RMF/RMC DE LOS CEMENTOS DE MEZCLA 50/50 EN FUNCIÓN DEL CEMENTO PORTLAND DE REFERENCIA UTILIZADO, CON IDÉNTICA PUZOLANA SELECCIONADA.

\begin{tabular}{|c|c|c|}
\hline \multicolumn{3}{|r|}{ Parámetro RMF/RMC } \\
\hline \multirow{2}{*}{ Puzolana "Z" } & \multirow{2}{*}{ Edad (días) } & Familias P-nº y PY-nº/"Z" 50/50 \\
\hline & & Clasificaciones de los P-no y PY-no a diferentes edades \\
\hline \multirow{3}{*}{$\mathrm{O}$} & 7 & PY-6 $<$ P-2 $<$ PY- $4<$ P-31 $<$ P-1 \\
\hline & 28 & PY- $4<$ P-31 $<$ P-1 $<$ PY-6 $<$ P-2 \\
\hline & 90 & $\mathrm{PY}-6<\mathrm{P}-1<\mathrm{P}-31<\mathrm{PY}-4<\mathrm{P}-2$ \\
\hline \multirow{3}{*}{ CV19 } & 7 & PY-6 $<$ P-1 $<$ P-31 \\
\hline & 28 & PY-6 $<$ P-1 $<$ P-31 \\
\hline & 90 & PY-6 $<$ P-1 $<$ P-31 \\
\hline \multirow{3}{*}{ A } & 7 & P-1 $<$ PY $-4<$ P-2 $<$ P-31 $<$ PY -6 \\
\hline & 28 & $\mathrm{P}-1<\mathrm{P}-31<\mathrm{PY}-4<\mathrm{PY}-6<\mathrm{P}-2$ \\
\hline & 90 & $\mathrm{P}-1<\mathrm{P}-31<\mathrm{PY}-4<\mathrm{PY}-6<\mathrm{P}-2$ \\
\hline \multirow{3}{*}{$\mathrm{C}$} & 7 & $\mathrm{P}-1<\mathrm{PY}-4<\mathrm{P}-2<\mathrm{P}-31<\mathrm{PY}-6$ \\
\hline & 28 & $\mathrm{P}-2<\mathrm{PY}-4=\mathrm{P}-31<\mathrm{PY}-6<\mathrm{P}-1$ \\
\hline & 90 & $\mathrm{P}-1<\mathrm{PY}-6<\mathrm{P}-2<\mathrm{PY}-4<\mathrm{P}-31$ \\
\hline \multirow{3}{*}{ CV10 } & 7 & $\mathrm{P}-31=\mathrm{PY}-6<\mathrm{P}-1$ \\
\hline & 28 & $\mathrm{P}-31<\mathrm{P}-1<\mathrm{PY}-6$ \\
\hline & 90 & PY- $6<$ P-1 $<$ P-31 \\
\hline \multirow{3}{*}{ M } & 7 & PY $-6<$ PY $-4<$ P-31 $<$ P-2 $<$ P-1 \\
\hline & 28 & PY $-4<$ P-31 $<<$ PY $-6<$ P-2 $<$ P-1 \\
\hline & 90 & PY-6 $<$ P-31 $<$ PY-4 $<$ P-2 $<$ P-31 \\
\hline
\end{tabular}

\subsection{Familia $P-n^{o}$ y $P Y-n^{o} /{ }^{\prime \prime} Z^{\prime \prime} 40 / 60$}

Todas las clasificaciones que surgen de los resultados obtenidos en los ensayos de RMC y RMF se muestran en las Tablas 8-54, 8-55 y 8-56.

TABLA 8-54.- ESTUdiO COMPARATIVO DE LA RMF DE LOS CEMENTOS DE MEZCLA 40/60 EN FUNCIÓN DEL CEMENTO PORTLAND DE REFERENCIA UTILIZADO, CON IDÉNTICA PUZOLANA SELECCIONADA, A Y M.

\begin{tabular}{|c|c|c|}
\hline & \multirow{3}{*}{ Edad (días) } & Parámetro RMF \\
\hline \multirow{2}{*}{ Puzolana "Z" } & & Familias P-no y PY-no/"Z" 40/60 \\
\hline & & Clasificaciones de los P-n⿳0 y PY-n ${ }^{\circ}$ a diferentes edades \\
\hline \multirow{3}{*}{ A } & 7 & $\mathrm{P}-1<\mathrm{P}-31$ \\
\hline & 28 & $\mathrm{P}-31<\mathrm{P}-1$ \\
\hline & 90 & $\mathrm{P}-1<\mathrm{P}-31$ \\
\hline \multirow{3}{*}{ M } & 7 & PY $4<$ PY $-6<$ P-1 $<$ P-31 $<$ P-2 \\
\hline & 28 & PY $-4<$ P-1 $<$ P-31 $<$ PY- $6<$ P-2 \\
\hline & 90 & $\mathrm{P}-1<\mathrm{P}-31<\mathrm{PY}-4<\mathrm{PY}-6<\mathrm{P}-2$ \\
\hline
\end{tabular}


TABLA 8-55.- ESTUDIO COMPARATIVO DE LA RMC DE LOS CEMENTOS DE MEZCLA 40/60 EN FUNCIÓN DEL CEMENTO PORTLAND DE REFERENCIA UTILIZADO, CON IDÉNTICA PUZOLANA SELECCIONADA, A Y M.

\begin{tabular}{|c|c|c|}
\hline \multicolumn{3}{|r|}{ Parámetro RMC } \\
\hline \multirow[b]{2}{*}{ Puzolana "Z" } & \multirow{2}{*}{$\begin{array}{l}\text { Edad } \\
\text { (días) }\end{array}$} & Familias P-no y PY-no/"Z" 40/60 \\
\hline & & $\begin{array}{c}\begin{array}{c}\text { Clasificaciones de los P-no y PY-no a diferentes } \\
\text { edades }\end{array} \\
\end{array}$ \\
\hline \multirow{3}{*}{ A } & 7 & $\mathrm{P}-1<\mathrm{P}-31$ \\
\hline & 28 & $\mathrm{P}-31<\mathrm{P}-1$ \\
\hline & 90 & $\mathrm{P}-1<\mathrm{P}-31$ \\
\hline \multirow{3}{*}{ M } & 7 & PY $-4<$ P-31 $<$ P-1 $<$ P-2 $<$ PY -6 \\
\hline & 28 & PY-4 $<$ P-1 $<$ P-2 $<$ P-31 $<$ PY-6 \\
\hline & 90 & PY- $4<$ P-1 $<$ P-31 $<$ PY-6 $<$ P-2 \\
\hline
\end{tabular}

Para el caso de estos cementos de mezcla, valen aquí los razonamientos expuestos en las interpretaciones de la Familia P-nº y PY-no/"Z" 60/40 y la Familia P-nº y PY-nº/"Z" 50/50.

TABLA 8-56.- ESTUDiO COMPARATIVO DE LA RELACIÓN RMF/RMC LOS CEMENTOS DE MEZCLA 40/60 EN FUNCIÓN DEL CEMENTO PORTLAND DE REFERENCIA UTILIZADO, CON IDÉNTICA PUZOLANA SELECCIONADA, A Y M.

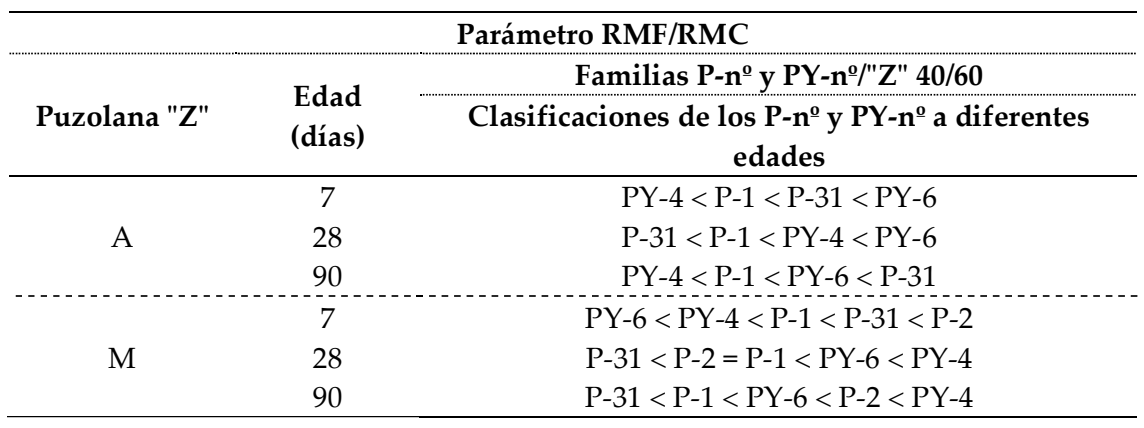

\subsection{Familia $P-n^{o}$ y $P Y-n^{o} /{ }^{\prime \prime} Z^{\prime \prime} 30 / 70$}

Todas las clasificaciones que surgen de los resultados obtenidos en los ensayos de RMC y RMF se muestran en las Tablas 8-57, 8-58 y 8-59.

Para el caso de estos cementos de mezcla, valen aquí los razonamientos expuestos en las interpretaciones de la Familia P-nº y PY-nº/"Z" 60/40, la Familia P-noo y PY-no/"Z" 50/50 y la Familia P-nº y PY-nº/"Z" 40/60. 
TABLA 8-57.- ESTUdiO COMPARATIVO DE LA RMF DE LOS CEMENTOS DE MEZCLA 30/70 EN FUNCIÓN DEL CEMENTO PORTLAND DE REFERENCIA UTILIZADO, CON LA PUZOLANA SELECCIONADA M.

\begin{tabular}{|c|c|c|}
\hline \multicolumn{3}{|r|}{ Parámetro RMF } \\
\hline \multirow{2}{*}{ Puzolana "Z" } & \multirow{2}{*}{ Edad (días) } & Familias P-no y PY-no/"Z" 30/70 \\
\hline & & Clasificaciones de los P-n ${ }^{\circ}$ y PY-no a diferentes edades \\
\hline \multirow{3}{*}{ M } & 7 & PY-6 $<$ P-31 $<$ P-2 $<$ P-1 \\
\hline & 28 & $\mathrm{P}-31<\mathrm{P}-2<\mathrm{PY}-6<\mathrm{P}-1$ \\
\hline & 90 & $\mathrm{P}-31<\mathrm{P}-2<\mathrm{PY}-6<\mathrm{P}-1$ \\
\hline
\end{tabular}

TABLA 8-58.- ESTUdiO COMPARATIVO DE LA RMF DE LOS CEMENTOS DE MEZCLA 30/70 EN FUNCIÓN DEL CEMENTO PORTLAND DE REFERENCIA UTILIZADO, CON LA PUZOLANA SELECCIONADA M.

\begin{tabular}{ccc}
\hline & \multicolumn{2}{c}{ Parámetro RMC } \\
\cline { 1 - 2 } Puzolana "Z" & Edad (días) & Familias P-n ${ }^{\mathbf{0}}$ y PY-no/"Z" 30/70 \\
\cline { 2 - 3 } & 7 & Clasificaciones de los P-n n $^{\mathbf{0}}$ y PY-no a diferentes edades \\
\hline \multirow{3}{*}{$\mathrm{M}$} & 28 & $\mathrm{P}-2<\mathrm{P}-1<\mathrm{P}-31<\mathrm{PY}-6$ \\
& 90 & $\mathrm{P}-1<\mathrm{P}-2<\mathrm{P}-31<\mathrm{PY}-6$ \\
$\mathrm{P}-31<\mathrm{P}-1<\mathrm{P}-2<\mathrm{PY}-6$ \\
\hline
\end{tabular}

TABLA 8-59.- ESTUDIO COMPARATIVO DE LA RMF DE LOS CEMENTOS DE MEZCLA 30/70 EN FUNCIÓN DEL CEMENTO PORTLAND DE REFERENCIA UTILIZADO, CON LA PUZOLANA SELECCIONADA M.

\begin{tabular}{|c|c|c|}
\hline \multicolumn{3}{|r|}{ Parámetro RMF/RMC } \\
\hline \multirow{2}{*}{ Puzolana "Z" } & \multirow{2}{*}{ Edad (días) } & Familias P-no y PY-no/"Z" 30/70 \\
\hline & & Clasificaciones de los P-n ${ }^{\circ}$ y PY-no a diferentes edades \\
\hline \multirow{3}{*}{ M } & 7 & PY-6 $<$ P-1 $<$ P-31 $<$ P-2 \\
\hline & 28 & PY-6 $<$ P-31 $<$ P-2 $<$ P-1 \\
\hline & 90 & $\mathrm{P}-31<\mathrm{PY}-6<\mathrm{P}-2<\mathrm{P}-1$ \\
\hline
\end{tabular}

\subsection{Familias P-2 y PY-4/(C+CH) 60/40}

Todas las clasificaciones que surgen de los resultados obtenidos en los ensayos de RMC y RMF se muestran en las Tablas 8-60, 8-61 y 8-62.

Para el caso de estos cementos de mezcla, valen aquí los razonamientos expuestos en las interpretaciones de la Familia P-no y PY-no/"Z" 60/40, la Familia P-no y PY-no/"Z" 50/50, la Familia P-no y PY-no/"Z" 40/60 y la Familia P-nº y PY-nº/"Z" 30/70. 
TABLA 8-60.- ESTUdio COMPARATIVO DE LA RMF DE LOS CEMENTOS DE MEZCLA P2/C 60/40 +CH, PY4/C 60/40+CH EN FUNCIÓN DEL CEMENTO PORTLAND DE REFERENCIA UTILIZADO, P2 Y PY 4 .

\begin{tabular}{|c|c|c|}
\hline & & Parámetro RMF \\
\hline \multirow{2}{*}{ Puzolana "Z" } & \multirow{2}{*}{ Edad (días) } & Familias P-no y PY-no/("Z"+CH) 60/40 y $(" \mathrm{Z} " / \mathrm{CH})=3$ \\
\hline & & Clasificaciones de los P-no y PY-no a diferentes edades \\
\hline \multirow{3}{*}{$\mathrm{C}+\mathrm{CH}$} & 7 & PY-4<P-2 \\
\hline & 28 & PY-4 $<$ P-2 \\
\hline & 90 & $\mathrm{P}-2<\mathrm{PY}-4$ \\
\hline
\end{tabular}

TABla 8-61.- ESTUdio COMPARATIVO DE LA RMC DE LOS CEMENTOS DE MEZCLA P2/C 60/40 +CH, PY4/C 60/40+CH EN FUNCIÓN DEL CEMENTO PORTLAND DE REFERENCIA UTILIZADO, P2 Y PY 4 .

\begin{tabular}{ccc}
\hline & \multicolumn{2}{c}{ Parámetro RMF } \\
\cline { 1 - 2 } Puzolana "Z" & Edad (días) & Familias P-no y PY-no/("Z"+CH) $60 / 40$ y ("Z"/CH) = 3 \\
\cline { 2 - 3 } & 7 & Clasificaciones de los P-no y PY-no a diferentes edades \\
\hline \multirow{3}{*}{$\mathrm{C}+\mathrm{CH}$} & 28 & $\mathrm{PY}-4<\mathrm{P}-2$ \\
& 90 & $\mathrm{PY}-4<\mathrm{P}-2$ \\
$\mathrm{P}-2<\mathrm{PY}-4$ \\
\hline
\end{tabular}

TABLA 8-62.- ESTUDIO COMPARATIVO DE LA RMF/RMC DE LOS CEMENTOS DE MEZCLA P2/C 60/40+CH, PY4/C 60/40+CH EN FUNCIÓN DEL CEMENTO PORTLAND DE REFERENCIA UTILIZADO, P2 Y PY 4 .

\begin{tabular}{|c|c|c|}
\hline & & Parámetro RMF/RMC \\
\hline \multirow{2}{*}{ Puzolana "Z" } & \multirow{2}{*}{ Edad (días) } & Familias P-no y PY-no/("Z"+CH) $60 / 40$ y $(" \mathrm{Z} " / C H)=3$ \\
\hline & & Clasificaciones de los P-no y PY-no a diferentes edades \\
\hline \multirow{3}{*}{$\mathrm{C}+\mathrm{CH}$} & 7 & P-2 $<$ PY-4 \\
\hline & 28 & $\mathrm{P}-2<\mathrm{PY}-4$ \\
\hline & 90 & $\mathrm{P}-2<\mathrm{PY}-4$ \\
\hline
\end{tabular}

\subsection{Familias $P-n^{o}$ y $P Y-n^{o} /\left({ }^{\prime \prime} Z^{\prime \prime}+C H\right) ~ 50 / 50$}

Todas las clasificaciones que surgen de los resultados obtenidos en los ensayos de RMC y RMF se muestran en las Tablas 8-63, 8-64 y 8-65.

Al ser el parámetro RMF dependiente mayormente de la fuerza de la unión pasta-árido silíceo, y ésta a su vez dependiente de la cantidad de portlandita (o lo que es lo mismo de la cantidad de $\mathrm{C}_{3} \mathrm{~S}$ mayormente que posee el cemento Portland que acompañe a la puzolana "Z") y/o de cal apagada, $\mathrm{Ca}(\mathrm{OH})_{2}$, presentes, lógicamente las clasificaciones obtenidas en este caso, por lo general, deberán superar en posiciones a las correspondientes sin cal apagada, como así ha sido el caso, véanse y compárense las Tablas 8-51 y 8-53, y podrían coincidir mayormente con las correspondientes clasificaciones obtenidas en el caso de la Familia P-no y PY-nº/"Z" 60/40 como así también ha sido el caso, véase y compárense la Tabla 8-45 con la Tabla 8-63, donde las 
clasificaciones del PY4 y P2 continúan siendo inmediatas y la del P-1 con la puzolana C, la de menor valor absoluto en razón de la "capacidad de cambio" de la puzolana C.

TABla 8-63.- estudio COMPARATIVO DE LA RMF DE los CEMENTOS DE MEZCla en FUNCIÓN DEL CEMENTO PORTLAND DE REFERENCIA UTILIZADO CON APORTE DE CAL APAGADA, CON IDÉNTICA PUZOLANA SELECCIONADA.

\begin{tabular}{|c|c|c|}
\hline \multicolumn{3}{|r|}{ Parámetro RMF } \\
\hline \multirow{2}{*}{ Puzolana "Z" } & \multirow{2}{*}{ Edad (días) } & Familias P-no y PY-no/("Z"+CH) 50/50 y ("Z"/CH) = 4 \\
\hline & & Clasificaciones de los P-n ${ }^{\circ}$ y PY-no a diferentes edades \\
\hline \multirow{3}{*}{$\mathrm{O}+\mathrm{CH}$} & 7 & P-1 $<$ PY-4 $<$ P-2 = PY-6 $<$ P-31 \\
\hline & 28 & PY-4 $<$ P-2 $<$ PY-6 $<$ P-1 $<$ P-31 \\
\hline & 90 & $\mathrm{P}-1<\mathrm{P}-2<\mathrm{PY}-4<\mathrm{PY}-6<\mathrm{P}-31$ \\
\hline \multirow{3}{*}{$\mathrm{CV} 19+\mathrm{CH}$} & 7 & PY-6 $<$ P-1 \\
\hline & 28 & PY-6 $<$ P-1 \\
\hline & 90 & PY-6 $<$ P-1 \\
\hline \multirow{3}{*}{$\mathrm{A}+\mathrm{CH}$} & 7 & PY $-4<$ PY $-6<$ P-2 \\
\hline & 28 & PY $-4<$ P-2 $<$ PY-6 \\
\hline & 90 & $\mathrm{P}-2<\mathrm{PY}-4<\mathrm{PY}-6$ \\
\hline \multirow{3}{*}{$\mathrm{C}+\mathrm{CH}$} & 7 & $\mathrm{P}-1<\mathrm{PY}-6<\mathrm{P}-2<\mathrm{PY}-4$ \\
\hline & 28 & P-1 $<$ PY $-6<$ PY $-4<$ P-2 \\
\hline & 90 & $\mathrm{P}-1<\mathrm{P}-2<\mathrm{PY}-6<\mathrm{PY}-4$ \\
\hline \multirow{3}{*}{$\mathrm{CV} 10+\mathrm{CH}$} & 7 & PY-4 $<$ PY-6 $<$ P-1 \\
\hline & 28 & PY-4 $<$ P-1 $<$ PY-6 \\
\hline & 90 & P-1 $<$ PY $-4<$ PY- 6 \\
\hline
\end{tabular}

TABla 8-64.- ESTUdio COMPARATIVO DE LA RMC DE LOS CEMENTOS DE MEZCla EN FUNCIÓN DEL CEMENTO PORTLAND DE REFERENCIA UTILIZADO CON APORTE DE CAL APAGADA, CON IDÉNTICA PUZOLANA SELECCIONADA.

\begin{tabular}{|c|c|c|}
\hline \multirow[b]{3}{*}{ Puzolana "Z" } & \multirow[b]{3}{*}{ Edad (días) } & Parámetro RMC \\
\hline & & Familias P-n ${ }^{\circ}$ y PY-no/("Z"+CH) 50/50 y $(" \mathrm{Z} " / C H)=4$ \\
\hline & & $\begin{array}{l}\text { Clasificaciones de los P-no }{ }^{\circ} \text { PY-no a diferentes } \\
\text { edades }\end{array}$ \\
\hline \multirow{3}{*}{$\mathrm{O}+\mathrm{CH}$} & 7 & PY-4 $<$ P-1 $<$ PY-6 $<$ P-31 $<$ P-2 \\
\hline & 28 & PY- $4<$ PY $-6<$ P-2 $<$ P-31 $<$ P-1 \\
\hline & 90 & $\mathrm{PY}-4<\mathrm{P}-2<\mathrm{P}-1<\mathrm{PY}-6<\mathrm{P}-31$ \\
\hline \multirow{3}{*}{$\mathrm{CV} 19+\mathrm{CH}$} & 7 & PY-6 $<$ P-1 \\
\hline & 28 & PY-6 < P-1 \\
\hline & 90 & $\mathrm{P}-1<\mathrm{PY}-6$ \\
\hline \multirow{3}{*}{$\mathrm{A}+\mathrm{CH}$} & 7 & PY-6 $<$ PY $-4<$ P-2 \\
\hline & 28 & PY-4 $<$ PY-6 $<$ P-2 \\
\hline & 90 & PY-4 $<$ P-2 $<$ PY-6 \\
\hline \multirow{3}{*}{$\mathrm{C}+\mathrm{CH}$} & 7 & PY-6 $<$ PY $-4<$ P-1 $<$ P-2 \\
\hline & 28 & $\mathrm{P}-1<\mathrm{PY}-4<\mathrm{PY}-6<\mathrm{P}-2$ \\
\hline & 90 & P-1 $<$ P- $2<$ PY $-4<$ PY-6 \\
\hline
\end{tabular}

El resto de los parámetros RMC y RMF/RMC no merecen interpretación ni comentario alguno por ser menos "sensible" que el RMF a la mayor o menor presencia del $\mathrm{Ca}(\mathrm{OH})$. 
TABLA 8-65.- ESTUDiO COMPARATIVO DE LA RELACIÓN RMF/RMC DE LOS CEMENTOS DE MEZCLA EN FUNCIÓN DEL CEMENTO PORTLAND DE REFERENCIA UTILIZADO CON APORTE DE CAL APAGADA, CON IDÉNTICA PUZOLANA SELECCIONADA.

\begin{tabular}{|c|c|c|}
\hline \multicolumn{3}{|r|}{ Parámetro RMF/RMC } \\
\hline \multirow{2}{*}{ Puzolana "Z" } & \multirow{2}{*}{ Edad (días) } & Familias P-no y PY-no/("Z"+CH) 50/50 y $(" Z " / C H)=4$ \\
\hline & & Clasificaciones de los P-no y PY-no a diferentes edades \\
\hline \multirow{3}{*}{$\mathrm{O}+\mathrm{CH}$} & 7 & P-2 $<$ PY-6 $<$ P-1 $<$ P-31 $<$ PY-4 \\
\hline & 28 & $\mathrm{P}-1<\mathrm{P}-2<\mathrm{PY}-6<\mathrm{P}-31<\mathrm{PY}-4$ \\
\hline & 90 & PY-6 $<$ P-1 $<$ P-31 $<$ P- $2<$ PY- 4 \\
\hline \multirow{3}{*}{$\mathrm{CV} 19+\mathrm{CH}$} & 7 & P-1 $<$ PY-6 \\
\hline & 28 & P-1 $<$ PY-6 \\
\hline & 90 & PY-6 $<$ P-1 \\
\hline \multirow{3}{*}{$\mathrm{A}+\mathrm{CH}$} & 7 & $\mathrm{P}-1<\mathrm{P}-2<\mathrm{PY}-4<\mathrm{PY}-6$ \\
\hline & 28 & $\mathrm{P}-1<\mathrm{P}-2<\mathrm{PY}-4<\mathrm{PY}-6$ \\
\hline & 90 & $\mathrm{P}-1<\mathrm{P}-2<\mathrm{PY}-6<\mathrm{PY}-4$ \\
\hline \multirow{3}{*}{$\mathrm{C}+\mathrm{CH}$} & 7 & $\mathrm{P}-1<\mathrm{P}-2<\mathrm{PY}-6<\mathrm{PY}-4$ \\
\hline & 28 & P-2 $<$ PY- $6<$ P-1 $<$ PY- 6 \\
\hline & 90 & PY-6 $<$ P-1 $<$ P- $2<$ PY -4 \\
\hline \multirow{3}{*}{$\mathrm{CV} 10+\mathrm{CH}$} & 7 & PY $-4<$ PY $-6<$ P-1 \\
\hline & 28 & $\mathrm{P}-1<\mathrm{PY}-6<\mathrm{PY}-4$ \\
\hline & 90 & PY-6 $<$ PY $-4<$ P-1 \\
\hline
\end{tabular}

\subsection{Familia $P-n^{\circ} /\left({ }^{\prime \prime} Z^{\prime \prime}+C H\right) 40 / 60$}

Todas las clasificaciones que surgen de los resultados obtenidos en los ensayos de RMC y RMF se muestran en las Tablas 8-66, 8-67 y 8-68.

Para el caso de estos cementos de mezcla, valen aquí los razonamientos expuestos en las interpretaciones de las Familias P-no y PY-n⿳/口"Z"+CH) 50/50.

TABLA 8-66.- ESTUdio COMPARATIVO DE LA RMF DE LOS CEMENTOS DE MEZCLA EN FUNCIÓN DEL CEMENTO PORTLAND DE REFERENCIA UTILIZADO, P1 Y P31, CON APORTE DE CAL APAGADA, CON LA PUZOLANA SELECCIONADA A.

\begin{tabular}{|c|c|c|}
\hline \multicolumn{3}{|r|}{ Parámetro RMF } \\
\hline \multirow{2}{*}{ Puzolana "Z" } & \multirow{2}{*}{ Edad (días) } & Familias P-no y PY-nº/("Z"+CH) $40 / 60$ y ("Z"/CH) = 5 \\
\hline & & Clasificaciones de los P-n ${ }^{0}$ y PY-n ${ }^{0}$ a diferentes edades \\
\hline \multirow{3}{*}{$\mathrm{A}+\mathrm{CH}$} & 7 & $\mathrm{P}-1<\mathrm{P}-31$ \\
\hline & 28 & $\mathrm{P}-1<\mathrm{P}-31$ \\
\hline & 90 & $\mathrm{P}-1<\mathrm{P}-31$ \\
\hline
\end{tabular}


COMPORTAMIENTO SULFÁTICO Y MECÁNICO-RESISTENTE DE CEMENTOS PORTLAND CON ELEVADOS CONTENIDOS DE PUZOLANAS (> 40\%): SU FUNDAMENTO QUÍMICO Y JUSTIFICACIÓN DE OTRAS CONSECUENCIAS POSIBLES

TABLA 8-67.- ESTUdio COMPARATIVO DE LA RMC DE LOS CEMENTOS DE MEZCLA EN FUNCIÓN DEL CEMENTO PORTLAND DE REFERENCIA UTILIZADO, P1 Y P31, CON APORTE DE CAL APAGADA, CON LA PUZOLANA SELECCIONADA A.

\begin{tabular}{|c|c|c|}
\hline \multicolumn{3}{|r|}{ Parámetro RMC } \\
\hline \multirow{2}{*}{ Puzolana "Z" } & \multirow{2}{*}{ Edad (días) } & Familias P-no y PY-no/("Z"+CH) 40/60 y $(" \mathrm{Z} " / \mathrm{CH})=5$ \\
\hline & & Clasificaciones de los P-no y PY-no a diferentes edades \\
\hline \multirow{3}{*}{$\mathrm{A}+\mathrm{CH}$} & 7 & $\mathrm{P}-1<\mathrm{P}-31$ \\
\hline & 28 & $\mathrm{P}-1=\mathrm{P}-31$ \\
\hline & 90 & $\mathrm{P}-1<\mathrm{P}-31$ \\
\hline
\end{tabular}

TABLA 8-68.- ESTUDIO COMPARATIVO DE LA RELACIÓN RMF/RMC DE LOS CEMENTOS DE MEZCLA EN FUNCIÓN DEL CEMENTO PORTLAND DE REFERENCIA UTILIZADO, P1 Y P31, CON APORTE DE CAL APAGADA, CON LA PUZOLANA SELECCIONADA A.

\begin{tabular}{|c|c|c|}
\hline & & Parámetro RMF/RMC \\
\hline \multirow{2}{*}{ Puzolana "Z" } & \multirow{2}{*}{ Edad (días) } & Familias P-no y PY-no/("Z"+CH) 40/60 y ("Z"/CH) = 5 \\
\hline & & Clasificaciones de los P-no y PY-no a diferentes edades \\
\hline \multirow{3}{*}{$\mathrm{A}+\mathrm{CH}$} & 7 & $\mathrm{P}-1<\mathrm{P}-31$ \\
\hline & 28 & $\mathrm{P}-1<\mathrm{P}-31$ \\
\hline & 90 & $\mathrm{P}-1<\mathrm{P}-31$ \\
\hline
\end{tabular}

\subsection{Familia $P-n^{o}$ y $P Y-n^{o} /(M+C H) 30 / 70$}

Todas las clasificaciones que surgen de los resultados obtenidos en los ensayos de RMC y RMF se muestran en las Tablas 8-69, 8-70 y 8-71.

Para el caso de estos cementos de mezcla, valen aquí las razones explicativas expuestas en la interpretación de las Familias P-nº y PY-no/"Z" 50/50, que como se recordará era la dedicada a la interpretación de los cambios posicionales adoptados por los cementos Portland P1 y PY6 mayormente, en las diferentes clasificaciones obtenidas de los mismos y el resto ensayados en función de los parámetros RMF, RMC y RMF/RMC, respectivamente, véase la Tabla 8-45.

TABLA 8-69.- ESTUDiO COMPARATIVO DE LA RMF DE LOS CEMENTOS DE MEZCLA EN FUNCIÓN DEL CEMENTO PORTLAND DE REFERENCIA UTILIZADO CON APORTE DE CAL APAGADA, CON LA PUZOLANA SELECCIONADA M.

\begin{tabular}{|c|c|c|}
\hline \multicolumn{3}{|r|}{ Parámetro RMF } \\
\hline \multirow{2}{*}{ Puzolana "Z" } & \multirow{2}{*}{ Edad (días) } & Familias P-no y PY-no/(M+CH) 30/70 (M/CH) $=6$ \\
\hline & & Clasificaciones de los P-no y PY-no a diferentes edades \\
\hline \multirow{3}{*}{$\mathrm{M}+\mathrm{CH}$} & 7 & PY-6 $<$ P-1 $<$ P-2 $<$ P-31 \\
\hline & 28 & $\mathrm{P}-1<\mathrm{P}-2<\mathrm{P}-31<\mathrm{PY}-6$ \\
\hline & 90 & $\mathrm{P}-1<\mathrm{P}-2<\mathrm{P}-31<\mathrm{PY}-6$ \\
\hline
\end{tabular}


TABlA 8-70.- ESTUdio COMPARATIVO DE LA RMF DE LOS CEMENTOS DE MEZCLA EN FUNCIÓN DEL CEMENTO PORTLAND DE REFERENCIA UTILIZADO CON APORTE DE CAL APAGADA, CON LA PUZOLANA SELECCIONADA M.

\begin{tabular}{|c|c|c|}
\hline \multicolumn{3}{|r|}{ Parámetro RMC } \\
\hline \multirow{2}{*}{ Puzolana "Z" } & \multirow{2}{*}{ Edad (días) } & Familias P-n ${ }^{0}$ y PY-no $/(M+C H) 30 / 70$ y $(M / C H)=6$ \\
\hline & & Clasificaciones de los P-no y PY-no a diferentes edades \\
\hline \multirow{3}{*}{$\mathrm{M}+\mathrm{CH}$} & 7 & $\mathrm{P}-1<\mathrm{P}-31<\mathrm{P}-2<\mathrm{PY}-6$ \\
\hline & 28 & $\mathrm{P}-1<\mathrm{P}-2<\mathrm{P}-31<\mathrm{PY}-6$ \\
\hline & 90 & $\mathrm{P}-1<\mathrm{P}-2<\mathrm{P}-31<\mathrm{PY}-6$ \\
\hline
\end{tabular}

TABLA 8-71.- ESTUDIO COMPARATIVO DE LA RELACIÓN RMF/RMC DE LOS CEMENTOS DE MEZCLA EN FUNCIÓN DEL CEMENTO PORTLAND DE REFERENCIA UTILIZADO CON APORTE DE CAL APAGADA, CON LA PUZOLANA SELECCIONADA M.

\begin{tabular}{|c|c|c|}
\hline & & Parámetro RMF/RMC \\
\hline \multirow{2}{*}{ Puzolana "Z" } & \multirow{2}{*}{ Edad (días) } & Familias P-n ${ }^{0}$ y PY-no $/(M+C H) 30 / 70$ y $(M / C H)=6$ \\
\hline & & Clasificaciones de los P-n ${ }^{0}$ y PY-no a diferentes edades \\
\hline \multirow{3}{*}{$\mathrm{M}+\mathrm{CH}$} & 7 & PY-6 $<$ P-1 $<$ P-2 $<$ P-31 \\
\hline & 28 & $\mathrm{P}-31<\mathrm{P}-2<\mathrm{PY}-6<\mathrm{P}-1$ \\
\hline & 90 & $\mathrm{P}-31<\mathrm{P}-2<\mathrm{PY}-6<\mathrm{P}-1$ \\
\hline
\end{tabular}

\subsection{Familias P1 y PY6/M 30/70 +7.0\% $\mathrm{SO}_{3}$}

Todas las clasificaciones que surgen de los resultados obtenidos en los ensayos de RMC y RMF se muestran en las Tablas 8-72, 8-73 y 8-74.

Para el caso de estos cementos de mezcla, valen aquí las razones explicativas expuestas en la interpretación de las Familias $\mathrm{P}-\mathrm{n}^{-} \mathrm{o}$ y $\mathrm{PY}-\mathrm{n}^{\circ} /(\mathrm{M}+\mathrm{CH})$ 30/70, sólo que en esta ocasión la colmatación de poros no se debe de originar mediante aluminatos de calcio hidratados sino mediante ettringita de lenta y/o rápida formación según sea el P1 o el PY6, respectivamente, el cemento Portland que acompañe a la puzolana M.

TABLA 8-72.- ESTUdio COMPARATIVO DE LA RMF DE LOS CEMENTOS DE MEZCLA EN FUNCIÓN DEL CEMENTO PORTLAND DE REFERENCIA UTILIZADO, P1 Y PY6 CON APORTE DE $7 \%$ DE SO3, CON LA PUZOLANA SELECCIONADA M.

\begin{tabular}{|c|c|c|c|}
\hline \multicolumn{4}{|c|}{ Parámetro RMF } \\
\hline \multirow{2}{*}{ Puzolana "Z" } & \multirow{2}{*}{ Edad (días) } & \multicolumn{2}{|c|}{ Familias P-1 y PY-6/M 30/70+7.0\% $\mathrm{SO}_{3}$} \\
\hline & & \multicolumn{2}{|c|}{ Clasificaciones de los P-n ${ }^{0}$ y PY-n ${ }^{0}$ a diferentes edades } \\
\hline \multirow{5}{*}{$\mathrm{M}$} & & & (b) $=$ bajo \\
\hline & 7 & (a) $=\mathrm{RC}-7 \mathrm{~s}$ & $\mathrm{H}_{2} \mathrm{O}$ \\
\hline & 28 & PY-6 $<$ P-1 & PY-6 $<$ P-1 \\
\hline & 90 & P-1 $<<$ PY-6 & P-1 $<<$ PY -6 \\
\hline & & P-1 $<<$ PY -6 & P-1 $<<$ PY -6 \\
\hline
\end{tabular}


COMPORTAMIENTO SULFÁTICO Y MECÁNICO-RESISTENTE DE CEMENTOS PORTLAND CON ELEVADOS CONTENIDOS DE PUZOLANAS (> 40\%): SU FUNDAMENTO QUÍMICO Y JUSTIFICACIÓN DE OTRAS CONSECUENCIAS POSIBLES

TABLA 8-73.- ESTUdiO COMPARATIVO DE LA RMC DE LOS CEMENTOS DE MEZCLA EN FUNCIÓN DEL CEMENTO PORTLAND DE REFERENCIA UTILIZADO, P1 Y PY 6 CON APORTE DE $7 \%$ DE SO3, CON LA PUZOLANA SELECCIONADA M.

\begin{tabular}{|c|c|c|c|}
\hline \multicolumn{4}{|c|}{ Parámetro RMC } \\
\hline \multirow{2}{*}{ Puzolana "Z" } & \multirow{2}{*}{ Edad (días) } & \multicolumn{2}{|c|}{ Familias P-1 y PY-6/M 30/70 +7.0\% $\mathrm{SO}_{3}$} \\
\hline & & \multicolumn{2}{|c|}{ Clasificaciones de los P-no y PY-no a diferentes edades } \\
\hline \multirow{4}{*}{ M } & 7 & (a) $=$ RC-75 & $\begin{array}{c}(b)=\text { bajo } \\
\mathrm{H}_{2} \mathrm{O}\end{array}$ \\
\hline & 28 & PY-6 < P-1 & PY-6 < P-1 \\
\hline & 90 & $\mathrm{P}-1<<\mathrm{PY}-6$ & $\mathrm{P}-1<<\mathrm{PY}-6$ \\
\hline & & $\mathrm{P}-1<<\mathrm{PY}-6$ & PY-6 $<<$ P-1 \\
\hline
\end{tabular}

TABLA 8-74.- ESTUDIO COMPARATIVO DE LA RELACIÓN RMF/RMC DE LOS CEMENTOS DE MEZCLA EN FUNCIÓN DEL CEMENTO PORTLAND DE REFERENCIA UTILIZADO, P1 Y PY6 CON APORTE DE 7\% DE SO3, CON LA PUZOLANA SELECCIONADA M.

\begin{tabular}{|c|c|c|c|}
\hline \multicolumn{4}{|c|}{ Parámetro RMF/RMC } \\
\hline \multirow{2}{*}{ Puzolana "Z" } & \multirow{2}{*}{ Edad (días) } & \multicolumn{2}{|c|}{ Familias P-1 y PY-6/M 30/70 +7.0\% $\mathrm{SO}_{3}$} \\
\hline & & \multicolumn{2}{|c|}{ Clasificaciones de los P-no y PY-no a diferentes edades } \\
\hline \multirow{4}{*}{ M } & \multirow{2}{*}{7} & $(a)=R C-75$ & $(b)=$ bajo $\mathrm{H}_{2} \mathrm{O}$ \\
\hline & & PY-6 < P-1 & P-1 $<<$ PY -6 \\
\hline & \multirow{2}{*}{$\begin{array}{l}28 \\
90\end{array}$} & P-1 $<<$ PY -6 & PY-6 < P-1 \\
\hline & & P-1 $<<$ PY -6 & P-1 $<<$ PY -6 \\
\hline
\end{tabular}

\subsection{Familias P-1 y PY-6/(M+CH) 30/70 +7.0\% $\mathrm{SO}_{3}$}

Todas las clasificaciones que surgen de los resultados obtenidos en los ensayos de RMC y RMF se muestran en las Tablas 8-75, 8-76 y 8-77.

Para el caso de estos cementos de mezcla, valen aquí los razonamientos expuestos en las interpretaciones de las Familias P1 y PY6/M 30/70 +7.0\% SO , no obstante, este comportamiento se vio favorecido por el aporte extra de hidróxido de calcio.

TABLA 8-75.- ESTUdiO COMPARATIVO DE LA RMF DE LOS CEMENTOS DE MEZCLA EN FUNCIÓN DEL CEMENTO PORTLAND DE REFERENCIA UTILIZADO, P1 Y PY6 CON APORTE DE $7 \% \mathrm{DE} \mathrm{SO}_{3}$ Y HIDRÓXIDO DE CALCIO, CON LA PUZOLANA SELECCIONADA M.

\begin{tabular}{|c|c|c|}
\hline \multicolumn{3}{|r|}{ Parámetro RMF } \\
\hline \multirow{2}{*}{ Puzolana "Z" } & \multirow{2}{*}{ Edad (días) } & Familias [P-1 y PY-6/(M+CH) 30/70 +7.0\% $\mathrm{SO}_{3}$ \\
\hline & & Clasificaciones de los P-1 y PY-6 a diferentes edades \\
\hline \multirow{3}{*}{ M } & 7 & PY-6 $<$ P-1 \\
\hline & 28 & P-1 $<<$ PY -6 \\
\hline & 90 & P-1 $<<$ PY -6 \\
\hline
\end{tabular}


TABLA 8-76.- ESTUdio COMPARATIVO DE LA RMC DE LOS CEMENTOS DE MEZCLA EN FUNCIÓN DEL CEMENTO PORTLAND DE REFERENCIA UTILIZADO, P1 Y PY6 CON APORTE DE $7 \%$ DE $\mathrm{SO}_{3}$ Y HIDRÓXIDO DE CALCIO, CON LA PUZOLANA SELECCIONADA M.

\begin{tabular}{ccc}
\hline & \multicolumn{3}{c}{ Parámetro RMC } \\
\hline \multirow{2}{*}{ Puzolana "Z" } & Edad (días) & Familias [P-1 y PY-6/(M+CH) $30 / 70+7.0 \% \mathrm{SO}_{3}$ \\
\cline { 3 - 3 } & 7 & Clasificaciones de los P-1 y PY-6 a diferentes edades \\
\hline \multirow{3}{*}{ M } & 28 & P-1 $<$ PY-6 \\
& 90 & P- $1<$ PY-6 \\
& $P-1<$ PY-6 \\
\hline
\end{tabular}

TABLA 8-77.- ESTUDIO COMPARATIVO DE LA RELACIÓN RMF/RMC DE LOS CEMENTOS DE MEZCLA EN FUNCIÓN DEL CEMENTO PORTLAND DE REFERENCIA UTILIZADO, P1 Y PY6 CON APORTE DE 7\% DE SO3 Y HIDRÓXIDO DE CALCIO, CON LA PUZOLANA SELECCIONADA M.

\begin{tabular}{|c|c|c|}
\hline \multicolumn{3}{|r|}{ Parámetro RMF/RMC } \\
\hline \multirow{2}{*}{ Puzolana "Z" } & \multirow{2}{*}{ Edad (días) } & Familias [P-1 y PY-6/(M+CH) 30/70 +7.0\% $\mathrm{SO}_{3}$ \\
\hline & & Clasificaciones de los P-1 y PY-6 a diferentes edades \\
\hline \multirow{3}{*}{ M } & 7 & PY-6 $<$ P-1 \\
\hline & 28 & PY-6 $<$ P-1 \\
\hline & 90 & P-1 $<<$ PY -6 \\
\hline
\end{tabular}

TABLA 8-78.- ESTUdiO COMPARATIVO DE LA RMF DE LOS CEMENTOS DE MEZCLA 60/40 EN FUNCIÓN DE LA PUZOLANA SELECCIONADA UTILIZADA, CON UN MISMO CEMENTO PORTLAND DE REFERENCIA.

\begin{tabular}{|c|c|c|}
\hline \multicolumn{3}{|r|}{ Parámetro RMF } \\
\hline \multirow{2}{*}{ Puzolana "Z" } & \multirow{2}{*}{ Edad (días) } & Familias P-nº y PY-no/"Z" 60/40 \\
\hline & & Clasificaciones de las AP a diferentes edades \\
\hline \multirow{3}{*}{$*=\mathrm{P}-1$} & 7 & $\mathrm{C}<\mathrm{CV} 19<\mathrm{A}<\mathrm{O}<\mathrm{CV} 10^{*}<\mathrm{M}$ \\
\hline & 28 & $\mathrm{C}<\mathrm{CV} 19<\mathrm{A}<\mathrm{O}<\mathrm{CV} 10^{*}<\mathrm{M}$ \\
\hline & 90 & $\mathrm{C}<\mathrm{A}<\mathrm{CV} 19<\mathrm{O}<\mathrm{CV} 10^{*}<\mathrm{M}$ \\
\hline \multirow{3}{*}{$*=\mathrm{P}-2$} & 7 & $\mathrm{CV} 19<\mathrm{O}<\mathrm{A}<\mathrm{C}^{*}<\mathrm{CV} 10<\mathrm{M}$ \\
\hline & 28 & $\mathrm{CV} 19<\mathrm{O}<\mathrm{C}<\mathrm{A}<\mathrm{CV} 19^{*}<\mathrm{M}$ \\
\hline & 90 & $\mathrm{O}<\mathrm{CV} 19<\mathrm{C}<\mathrm{A}^{*}<\mathrm{CV} 10<\mathrm{M}$ \\
\hline \multirow{3}{*}{$*=\mathrm{P}-31$} & 7 & $\mathrm{C}<\mathrm{CV} 19<\mathrm{O}<\mathrm{A}<\mathrm{CV} 19^{*}<\mathrm{M}$ \\
\hline & 28 & $\mathrm{O}<\mathrm{C}<\mathrm{CV} 19<\mathrm{A}^{*}<\mathrm{CV} 10<\mathrm{M}$ \\
\hline & 90 & $\mathrm{C}<\mathrm{A}<\mathrm{CV} 19<\mathrm{O}^{*}<\mathrm{CV} 10<\mathrm{M}$ \\
\hline \multirow{3}{*}{$*=$ PY -4} & 7 & $\mathrm{CV} 19<\mathrm{A}<\mathrm{O}<\mathrm{CV} 10<\mathrm{C}<\mathrm{M}$ \\
\hline & 28 & $\mathrm{O}<\mathrm{CV} 19<\mathrm{A}=\mathrm{C}<\mathrm{CV} 10<\mathrm{M}$ \\
\hline & 90 & $\mathrm{M}<\mathrm{C}<\mathrm{CV} 10<\mathrm{A}<\mathrm{CV} 19<\mathrm{O}$ \\
\hline \multirow{3}{*}{$*=P Y-6$} & 7 & $\mathrm{~A}<\mathrm{CV} 19<\mathrm{C}<\mathrm{O}<\mathrm{CV} 10<\mathrm{M}$ \\
\hline & 28 & $\mathrm{O}<\mathrm{A}<\mathrm{C}<\mathrm{CV} 19<\mathrm{CV} 10<\mathrm{M}$ \\
\hline & 90 & $\mathrm{M}<\mathrm{CV} 10<\mathrm{C}<\mathrm{O}<\mathrm{CV} 19<\mathrm{A}$ \\
\hline
\end{tabular}


COMPORTAMIENTO SULFÁTICO Y MECÁNICO-RESISTENTE DE CEMENTOS PORTLAND CON ELEVADOS CONTENIDOS DE PUZOLANAS (> 40\%): SU FUNDAMENTO QUÍMICO Y JUSTIFICACIÓN DE OTRAS CONSECUENCIAS POSIBLES

TABLA 8-79.- ESTUDiO COMPARATIVO DE LA RMC DE LOS CEMENTOS DE MEZCLA 60/40 EN FUNCIÓN DE LA PUZOLANA SELECCIONADA UTILIZADA, CON UN MiSMO CEMENTO PORTLAND DE REFERENCIA.

\begin{tabular}{|c|c|c|}
\hline \multicolumn{3}{|r|}{ Parámetro RMC } \\
\hline \multirow{2}{*}{ Puzolana "Z" } & \multirow{2}{*}{ Edad (días) } & Familias P-no y PY-no/"Z" 60/40 \\
\hline & & Clasificaciones de las AP a diferentes edades \\
\hline \multirow{3}{*}{$*=\mathrm{P}-1$} & 7 & $\mathrm{CV} 19<\mathrm{O}<\mathrm{C}<\mathrm{A}<\mathrm{CV} 10<\mathrm{M}^{*}$ \\
\hline & 28 & $\mathrm{C}<\mathrm{CV} 19<\mathrm{O}<\mathrm{CV} 10<\mathrm{A}^{*}<\mathrm{M}$ \\
\hline & 90 & $\mathrm{C}<\mathrm{O}<\mathrm{CV} 19<\mathrm{A}<\mathrm{CV} 10^{*}<\mathrm{M}$ \\
\hline \multirow{3}{*}{$*=\mathrm{P}-2$} & 7 & $\mathrm{CV} 19<\mathrm{O}<\mathrm{C}<\mathrm{A}^{*}<\mathrm{CV} 10<\mathrm{M}$ \\
\hline & 28 & $\mathrm{CV} 19<\mathrm{O}<\mathrm{C}<\mathrm{A}<\mathrm{CV} 10^{*}<\mathrm{M}$ \\
\hline & 90 & $\mathrm{O}<\mathrm{C}<\mathrm{CV} 10<\mathrm{A}<\mathrm{CV} 10<\mathrm{M}^{*}$ \\
\hline \multirow{3}{*}{$*=\mathrm{P}-31$} & 7 & $\mathrm{CV} 19<\mathrm{O}<\mathrm{C}<\mathrm{CV} 10<\mathrm{A}<\mathrm{M}^{*}$ \\
\hline & 28 & $\mathrm{O}<\mathrm{CV} 19<\mathrm{C}<\mathrm{CV} 10^{*}<\mathrm{M}<\mathrm{A}$ \\
\hline & 90 & $\mathrm{O}<\mathrm{C}<\mathrm{CV} 19<\mathrm{CV} 10<\mathrm{A}<\mathrm{M}^{*}$ \\
\hline \multirow{3}{*}{$*=P Y-4$} & 7 & $\mathrm{CV} 19<\mathrm{O}<\mathrm{C}<\mathrm{A}<\mathrm{CV} 10^{*}<\mathrm{M}$ \\
\hline & 28 & $\mathrm{O}<\mathrm{CV} 19<\mathrm{C}<\mathrm{A}<\mathrm{CV} 10^{*}<\mathrm{M}$ \\
\hline & 90 & $\mathrm{C}<\mathrm{A}<\mathrm{CV} 19<\mathrm{O}<\mathrm{CV} 10^{*}<\mathrm{M}$ \\
\hline \multirow{3}{*}{$*=P Y-6$} & 7 & $\mathrm{C}<\mathrm{A}<\mathrm{CV} 19<\mathrm{O}<\mathrm{CV} 10^{*}<\mathrm{M}$ \\
\hline & 28 & $\mathrm{C}<\mathrm{O}<\mathrm{A}<\mathrm{CV} 19<\mathrm{CV} 10^{*}<\mathrm{M}$ \\
\hline & 90 & $\mathrm{C}<\mathrm{O}<\mathrm{CV} 19<\mathrm{A}<\mathrm{CV} 10<\mathrm{M}^{*}$ \\
\hline
\end{tabular}

\subsubsection{2-A igualdad de cemento Portland de referencia y cantidad de este.}

\subsection{Familia $P-n^{o}$ y $P Y-n^{o} /{ }^{\prime \prime} Z^{\prime \prime} 60 / 40$}

Todas las clasificaciones que surgen de los resultados obtenidos en los ensayos de RMC y RMF se muestran en las Tablas 8-78, 8-79 y 8-80. Asímismo, en las Figuras 8-21, 8-22, 8-23, 8-24 y $8-25$, se representa la evolución de tanto de las RMF y RMC de cada uno de los cementos de mezcla en mortero normalizado EN 196-1.

Del análisis y estudio de los resultados obtenidos se identificaron los siguientes comportamientos:

1․ Los posicionamientos finales adoptados por las adiciones puzolánicas más alumínicas de todas (Talero, 1986) las ensayadas, en este caso la CV10 y la M, en la mayor parte de las clasificaciones obtenidas mediante los parámetros RMFy RMC y no en cambio en las obtenidas de su parámetro derivado RMF/RMC.

2o. Los posicionamientos iniciales o intermedios que adopta la puzolana C según sea el cemento Portland que la acompañe.

3o. La coincidencia total o casi total de clasificaciones obtenidas de las puzolanas ensayadas mediante los parámetros RMF y RMC, cementos Portland PY4 y PY6 y edades del ensayo de 28 y 90 días mayormente, y la que se obtendría invertida en función del contenido de $\mathrm{Al}_{2} \mathrm{O}_{3}{ }^{\mathrm{r}-}$ de las mismas (Talero, 1986). 
TABLA 8-80.- ESTUDIO COMPARATIVO DE LA RELACIÓN RMF/RMC DE LOS CEMENTOS DE MEZCLA 60/40 EN FUNCIÓN DE DE LA PUZOLANA SELECCIONADA UTILIZADA, CON UN MISMO CEMENTO PORTLAND DE REFERENCIA.

\begin{tabular}{|c|c|c|}
\hline \multicolumn{3}{|c|}{ Parámetro RMF/RMC } \\
\hline \multirow{2}{*}{ Puzolana "Z" } & \multirow{2}{*}{ Edad (días) } & Familias P-no y PY-no/"Z" 60/40 \\
\hline & & Clasificaciones de las AP a diferentes edades \\
\hline \multirow{3}{*}{$*=\mathrm{P}-1$} & 7 & $\mathrm{C}<\mathrm{A}^{*}<\mathrm{M}<\mathrm{CV} 10<\mathrm{O}<\mathrm{CV} 19$ \\
\hline & 28 & ${ }^{*} \mathrm{~A}<\mathrm{M}<\mathrm{CV} 10<\mathrm{C}<\mathrm{O}<\mathrm{CV} 19$ \\
\hline & 90 & ${ }^{*} \mathrm{CV} 10<\mathrm{C}<\mathrm{A}=\mathrm{M}<\mathrm{CV} 19<\mathrm{O}$ \\
\hline \multirow{3}{*}{$*=\mathrm{P}-2$} & 7 & $\mathrm{~A}<\mathrm{CV} 10^{*}<\mathrm{CV} 19<\mathrm{O}<\mathrm{C}<\mathrm{M}$ \\
\hline & 28 & ${ }^{*} \mathrm{CV} 10<\mathrm{A}<\mathrm{O}=\mathrm{M}<\mathrm{CV} 10<\mathrm{C}$ \\
\hline & 90 & ${ }^{*} \mathrm{~A}<\mathrm{CV} 10<\mathrm{CV} 19<\mathrm{M}<\mathrm{O}<\mathrm{C}$ \\
\hline \multirow{3}{*}{$*=\mathrm{P}-31$} & 7 & ${ }^{*} \mathrm{~A}<\mathrm{C}<\mathrm{CV} 10<\mathrm{O}<\mathrm{CV} 19<\mathrm{M}$ \\
\hline & 28 & $\mathrm{~A}^{*}<\mathrm{C}<\mathrm{M}<\mathrm{O}=\mathrm{CV} 10<\mathrm{CV} 19$ \\
\hline & 90 & ${ }^{*} \mathrm{~A}<\mathrm{CV} 19<\mathrm{CV} 10<\mathrm{M}<\mathrm{C}<\mathrm{O}$ \\
\hline \multirow{3}{*}{$*=P Y-4$} & 7 & ${ }^{*} \mathrm{M}<\mathrm{C}<\mathrm{A}<\mathrm{CV} 10<\mathrm{C}<\mathrm{CV} 19$ \\
\hline & 28 & $\mathrm{M}<\mathrm{CV} 10<\mathrm{A}^{*}<\mathrm{C}<\mathrm{O}<\mathrm{CV} 19$ \\
\hline & 90 & $\mathrm{M}^{*}<\mathrm{CV} 10<\mathrm{A}<\mathrm{CV} 19<\mathrm{O}<\mathrm{C}$ \\
\hline \multirow{3}{*}{$*=P Y-6$} & 7 & $\mathrm{M}<\mathrm{A}<\mathrm{CV} 10<\mathrm{O}<\mathrm{CV} 19^{*}<\mathrm{C}$ \\
\hline & 28 & $\mathrm{M}<\mathrm{CV} 10<\mathrm{CV} 19<\mathrm{A}<\mathrm{O}<\mathrm{C}^{*}$ \\
\hline & 90 & $\mathrm{M}<\mathrm{CV} 10<\mathrm{A}<\mathrm{CV} 19<\mathrm{O}<\mathrm{C}^{*}$ \\
\hline
\end{tabular}

Y las razones de tales hechos podrían ser las siguientes:
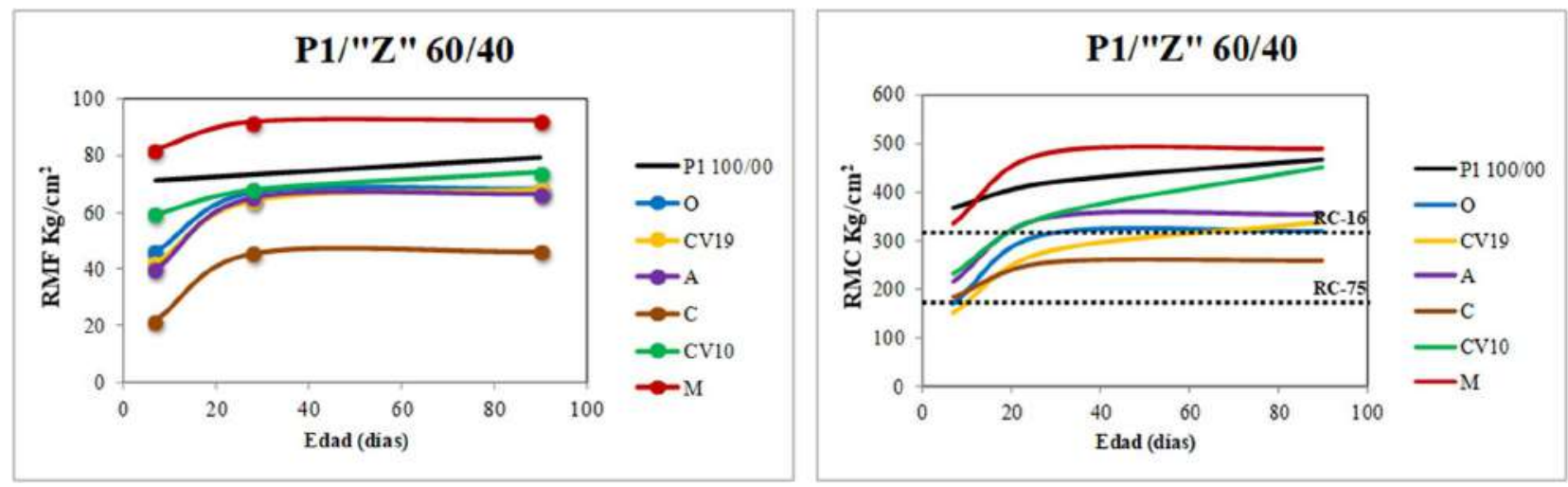

FIGURA 8-21.-REPRESENTACIÓN GRÁFICA DE LAS RMF Y RMC DE LOS CEMENTOS DE MEZCLA CONSTITUIDOS POR EL CEMENTO PORTLAND P1 Y CADA UNA DE LAS ADICIONES PUZOLÁNICAS SELECCIONADAS EN PROPORCIÓN 60/40. EDADES: 7, 28 Y 90 DÍAS. 

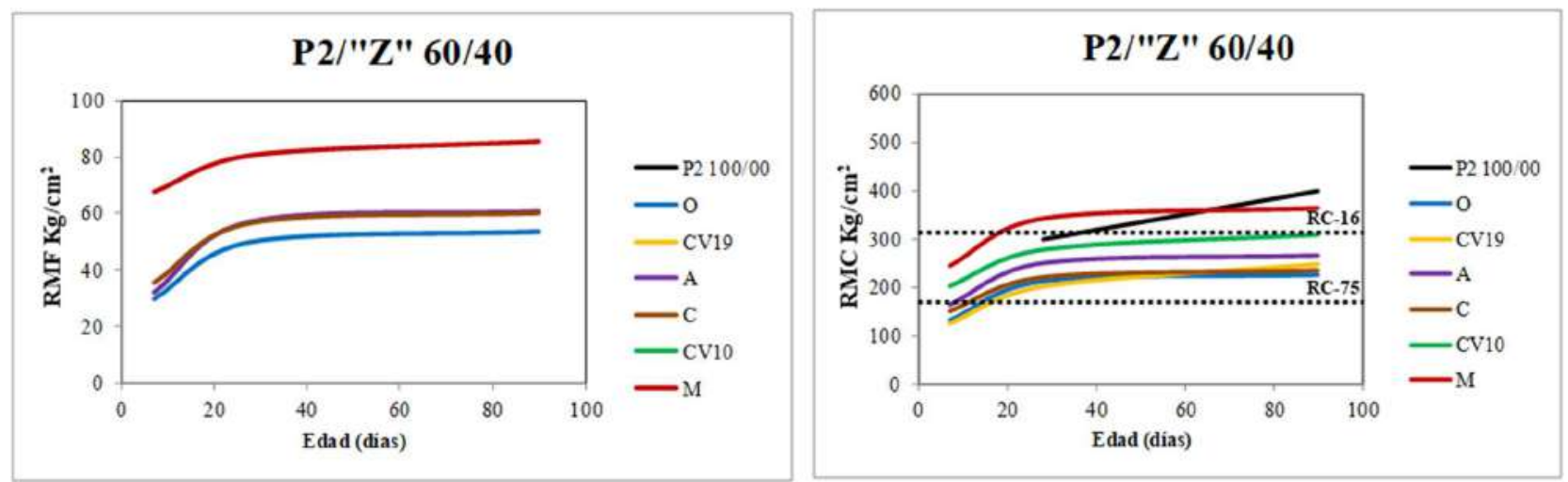

FIGURA 8-22.-REPRESENTACIÓN GRÁFICA DE LAS RMF Y RMC DE LOS CEMENTOS DE MEZCLA CONSTITUIDOS POR EL CEMENTO PORTLAND P2 Y CADA UNA DE LAS ADICIONES PUZOLÁNICAS SELECCIONADAS EN PROPORCIÓN 60/40. EDADES: 7, 28 Y 90 DÍAS.

4º . El mayor carácter químico "alumínico" de las puzolanas CV10 y M ha de dar lugar en todos los casos a mayores contenidos de aluminatos de calcio hidratados que al tener mayor volumen molecular que los correspondientes hidratos cálcicos de silicio, han de colmatar más las probetas de mortero y consiguientemente proporcionar los mismos mayores valores de RMF y RMC, como así ha sido el caso. Y el hecho de que tal mayoría en los posicionamientos de tales puzolanas no se haya mantenido en el caso de las correspondientes clasificaciones obtenidas mediante el parámetro derivado RMF/RMC, ratifica la razón dada de que los aluminatos de calcio hidratados son también más colmatadores que reforzadores de la unión pasta-árido silíceo. Y esta razón se ve apoyada por el hecho de que en el caso de que el CP acompañante de tales puzolanas portara y aportara a la mezcla $\mathrm{C}_{3} \mathrm{~A}$, caso del P1 y P31 aquí utilizados, mayor cantidad de aluminatos de calcio hidratados se deberán formar que en el caso del PY4 y el PY6 cuyos contenidos de $\mathrm{C}_{3} \mathrm{~A}$ son nulos. Por lo tanto, al deber estar más colmatadas aún las probetas de los primeros, P1, P2 y P31, que las correspondientes de los segundos PY4 y PY6, mayores valores de RMF deberán proporcionar y no tan elevados de RMC como así ha sido el caso. Y el hecho de que los cementos de matriz P2 no se hayan ajustado totalmente a esta razón dada ha de ser achacable necesariamente al bajo contenido de $\mathrm{C}_{3} \mathrm{~S}=33.47 \%$ y SEB $=3015 \mathrm{~cm}^{2} / \mathrm{g}$, de este cemento Portland, lo que daría lugar a igualdad de edad, menor aportación de portlandita en la fase líquida y consiguientemente a una menor formación de aluminatos de calcio hidratados de cualquier origen y etiologia, véanse los Frattini en los que a igualdad de puzolana los menores contenidos de $\mathrm{CaO}_{7 \mathrm{~d}}$ de los cementos de mezcla del P2 sobre los correspondientes del P1, unidos a los menores valores de RMF y RMC de sus morteros, ha de justificarse necesariamente por el menor contenido de $C_{3} S$ y SEB del P2 sobre el P1, lo que habrá de provocar:

a) una menor velocidad de hidratación de los granos de clínker,

b) una menor velocidad de liberación de portlandita, y 
c) una menor velocidad de reacción puzolánica.
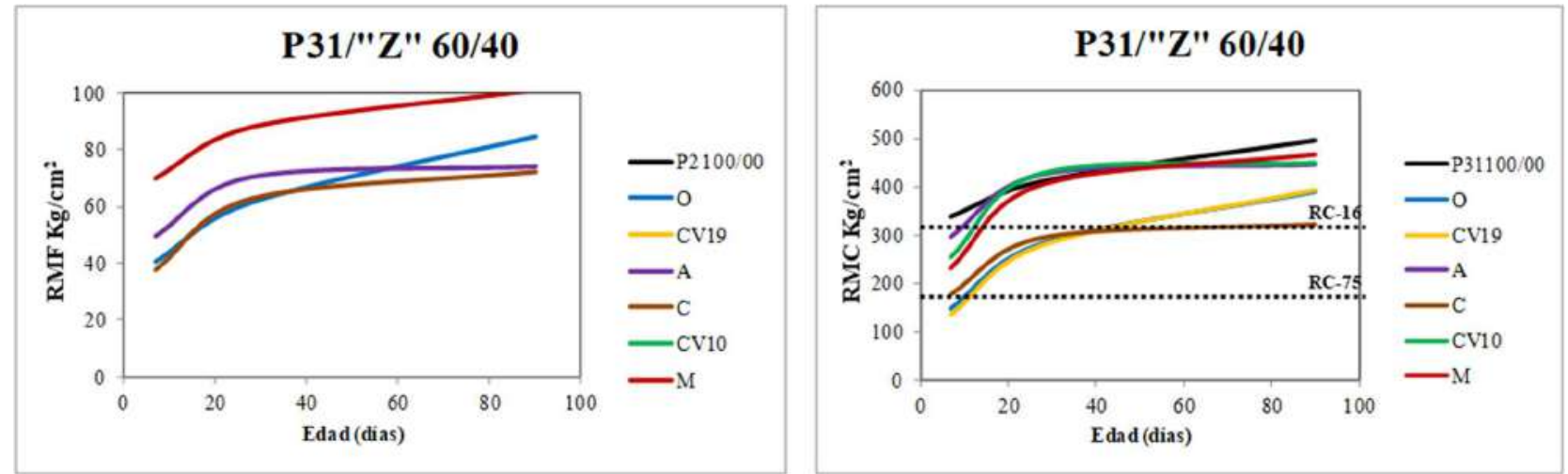

FIGURA 8-23.-REPRESENTACIÓN GRÁFICA DE LAS RMF Y RMC DE LOS CEMENTOS DE MEZCLA CONSTITUIDOS POR EL CEMENTO PORTLAND P31 Y CADA UNA DE LAS ADICIONES PUZOLÁNICAS SELECCIONADAS EN PROPORCIÓN 60/40. EDADES: 7, 28 Y 90 DÍAS.
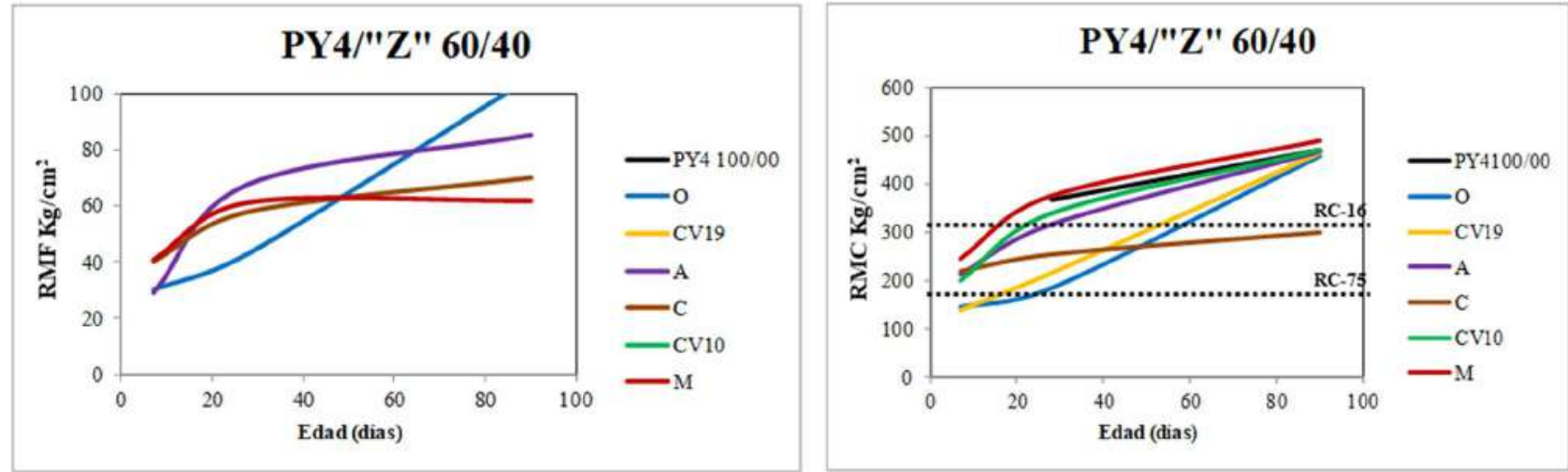

FIGURA 8-24.-REPRESENTACIÓN GRÁFICA DE LAS RMF Y RMC DE LOS CEMENTOS DE MEZCLA CONSTITUIDOS POR EL CEMENTO PORTLAND PY4 Y CADA UNA DE LAS ADICIONES PUZOLÁNICAS SELECCIONADAS EN PROPORCIÓN 60/40. EDADES: 7, 28 Y 90 DÍAS.

De aquí que a una edad inicial dada, antes de la de 7 días, el P1 haya podido proporcionar portlandita en cantidades suficientes para que se verifiquen reacciones puzolánicas mientras que el P2 no y por lo que parece recién a 7 días la acaba de proporcionar; con lo que las reacciones puzolánicas aún no se habrían iniciado a dicha edad y se verificarían en cambio con posterioridad a 7 días, por ejemplo a 28 días, como así ha sido el caso, pues a esta edad los cementos del P2 si cumplen ya el ensayo de Frattini cuando a 7 días no lo cumplieron. Con lo que de esta manera el cociente de ambos parámetros deberá aumentar y el posicionamiento de la puzolana $\mathrm{M}$ en la clasificación citada, Tabla 8-86, no estar en la posición más a la izquierda, sino en posiciones intermedias, como así también ha sido el caso.

$5^{\text {o. }}$ La "capacidad de cambio" ( $\underline{\text { Talero, } 1986}$ ) de la puzolana C dado su mayor contenido de alcalinos que el resto.

6 ㅇ. Las razones anteriormente expuestas justifican este hecho. 

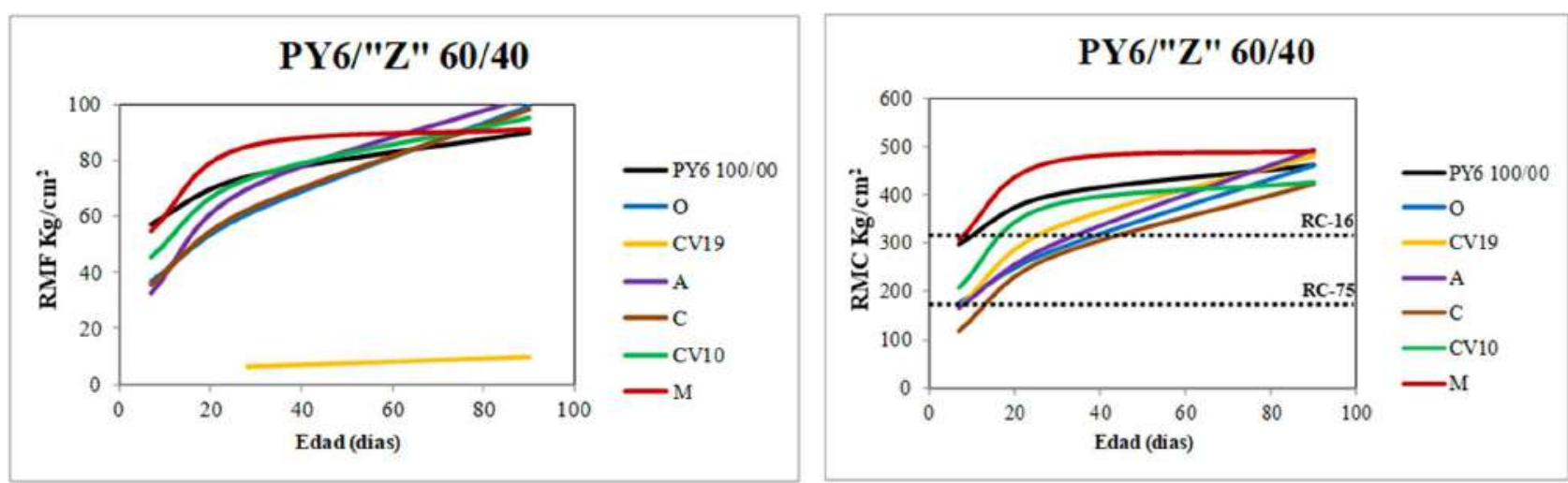

FIGURA 8-25.-REPRESENTACIÓN GRÁFICA DE LAS RMF Y RMC DE LOS CEMENTOS DE MEZCLA CONSTITUIDOS POR EL CEMENTO PORTLAND PY6 Y CADA UNA DE LAS ADICIONES PUZOLÁNICAS SELECCIONADAS EN PROPORCIÓN 60/40. EDADES: 7, 28 Y 90 DÍAS.

TABLA 8-81.- ESTUdiO COMPARATIVO DE LA RMF DE LOS CEMENTOS DE MEZCLA 50/50 EN FUNCIÓN DE LA ADiCión MINERAL UTILIZADA, CON UN Mismo CEMENTO PORTLAND DE REFERENCIA.

\begin{tabular}{|c|c|c|}
\hline \multicolumn{3}{|r|}{ Parámetro RMF } \\
\hline \multirow{2}{*}{ Puzolana "Z" } & \multirow{2}{*}{ Edad (días) } & Familias P-no y PY-no/"Z" 50/50 \\
\hline & & Clasificaciones de las AP a diferentes edades \\
\hline \multirow{3}{*}{$*=\mathrm{P}-1$} & 7 & $\mathrm{C}<\mathrm{A}<\mathrm{O}<\mathrm{CV} 19<\mathrm{CV} 10<\mathrm{S} 4<\mathrm{M}$ \\
\hline & 28 & $\mathrm{C}<\mathrm{O}<\mathrm{CV} 19<\mathrm{CV} 10<\mathrm{A}<\mathrm{S} 4<\mathrm{M}$ \\
\hline & 90 & $\mathrm{C}<\mathrm{A}<\mathrm{O}<\mathrm{CV} 19<\mathrm{CV} 10<\mathrm{M}<\mathrm{S} 4$ \\
\hline \multirow{3}{*}{$*=\mathrm{P}-2$} & 7 & $\mathrm{O}<\mathrm{C}<\mathrm{A}<\mathrm{M}$ \\
\hline & 28 & $\mathrm{O}<\mathrm{C}<\mathrm{A}<\mathrm{M}$ \\
\hline & 90 & $\mathrm{O}<\mathrm{C}<\mathrm{A}<\mathrm{M}$ \\
\hline \multirow{3}{*}{$*=\mathrm{P}-31$} & 7 & $\mathrm{C}<\mathrm{O}<\mathrm{CV} 19<\mathrm{CV} 10<\mathrm{A}<\mathrm{M}$ \\
\hline & 28 & $\mathrm{O}<\mathrm{CV} 19<\mathrm{CV} 10<\mathrm{C}<\mathrm{A}<\mathrm{M}$ \\
\hline & 90 & $\mathrm{C}<\mathrm{O}<\mathrm{CV} 19<\mathrm{A}<\mathrm{CV} 10<\mathrm{M}$ \\
\hline \multirow{3}{*}{$*=P Y-4$} & 7 & $\mathrm{~A}<\mathrm{O}<\mathrm{M}<\mathrm{C}$ \\
\hline & 28 & $\mathrm{O}<\mathrm{M}<\mathrm{A}<\mathrm{C}$ \\
\hline & 90 & $\mathrm{O}<\mathrm{M}<\mathrm{A}<\mathrm{C}$ \\
\hline \multirow{3}{*}{$*=$ PY -6} & 7 & $\mathrm{~A}<\mathrm{C}<\mathrm{CV} 19<\mathrm{O}<\mathrm{CV} 10<\mathrm{M}<\mathrm{S} 4$ \\
\hline & 28 & $\mathrm{C}<\mathrm{O}<\mathrm{A}<\mathrm{CV} 19<\mathrm{CV} 10<\mathrm{M}<\mathrm{S} 4$ \\
\hline & 90 & $\mathrm{CV} 19<\mathrm{C}<\mathrm{O}<\mathrm{A}=\mathrm{CV} 10<\mathrm{M}<\mathrm{S} 4$ \\
\hline
\end{tabular}

\subsection{Familia $P-n^{o}$ y $P Y-n^{o} /{ }^{\prime \prime} Z^{\prime \prime} 50 / 50$}

Todas las clasificaciones que surgen de los resultados obtenidos en los ensayos de RMC y RMF se muestran en las Tablas 8-81, 8-82 y 8-83. Asímismo, en las Figuras 8-26, 8-27, 8-28, 8-29 y 8-30, se representa la evolución de tanto de las RMF y RMC de cada uno de los cementos de mezcla en mortero normalizado EN 196-1. 
TABLA 8-82.- ESTUDIO COMPARATIVO DE LA RMC DE LOS CEMENTOS DE MEZCLA 50/50 EN FUNCIÓN DE LA ADiCiÓN MINERAL UTILIZADA, CON UN Mismo CEMENTO PORTLAND DE REFERENCIA.

\begin{tabular}{|c|c|c|}
\hline \multicolumn{3}{|r|}{ Parámetro RMC } \\
\hline \multirow{2}{*}{ Puzolana "Z" } & \multirow{2}{*}{ Edad (días) } & Familias P-no y PY-no/"Z" 50/50 \\
\hline & & Clasificaciones de las AP a diferentes edades \\
\hline \multirow{3}{*}{$*=\mathrm{P}-1$} & 7 & $\mathrm{O}<\mathrm{C}<\mathrm{CV} 19<\mathrm{A}<\mathrm{CV} 10<\mathrm{S} 4<\mathrm{M}$ \\
\hline & 28 & $\mathrm{C}<\mathrm{O}<\mathrm{CV} 19<\mathrm{CV} 10<\mathrm{A}<\mathrm{M}<\mathrm{S} 4$ \\
\hline & 90 & $\mathrm{C}<\mathrm{O}<\mathrm{A}<\mathrm{CV} 10<\mathrm{CV} 19<\mathrm{M}<\mathrm{S} 4$ \\
\hline \multirow{3}{*}{$*=\mathrm{P}-2$} & 7 & $\mathrm{O}<\mathrm{C}<\mathrm{A}<\mathrm{M}$ \\
\hline & 28 & $\mathrm{O}<\mathrm{A}<\mathrm{C}<\mathrm{M}$ \\
\hline & 90 & $\mathrm{O}<\mathrm{A}<\mathrm{C}<\mathrm{M}$ \\
\hline \multirow{3}{*}{$*=\mathrm{P}-31$} & 7 & $\mathrm{O}<\mathrm{CV} 19<\mathrm{C}<\mathrm{CV} 10<\mathrm{A}<\mathrm{M}$ \\
\hline & 28 & CV19 $<$ O $<$ CV10 $<$ C $<$ A $<$ M \\
\hline & 90 & $\mathrm{C}<\mathrm{O}<\mathrm{CV} 19<\mathrm{CV} 10<\mathrm{A}<\mathrm{M}$ \\
\hline \multirow{3}{*}{$*=P Y-4$} & 7 & $\mathrm{CV} 10<\mathrm{O}<\mathrm{A}<\mathrm{CV} 10<\mathrm{C}<\mathrm{M}$ \\
\hline & 28 & $\mathrm{O}<\mathrm{CV} 19<\mathrm{C}<\mathrm{A}<\mathrm{CV} 10<\mathrm{M}$ \\
\hline & 90 & $\mathrm{O}<\mathrm{CV} 19<\mathrm{A}<\mathrm{CV} 10<\mathrm{C}<\mathrm{M}$ \\
\hline \multirow{3}{*}{$*=$ PY -6} & 7 & $\mathrm{C}<\mathrm{CV} 19<\mathrm{A}<\mathrm{O}<\mathrm{CV} 10<\mathrm{M}<\mathrm{S} 4$ \\
\hline & 28 & $\mathrm{C}<\mathrm{O}<\mathrm{A}<\mathrm{CV} 10<\mathrm{CV} 19<\mathrm{M}<\mathrm{S} 4$ \\
\hline & 90 & $\mathrm{C}<\mathrm{O}<\mathrm{A}<\mathrm{CV} 19<\mathrm{CV} 10<\mathrm{M}<\mathrm{S} 4$ \\
\hline
\end{tabular}
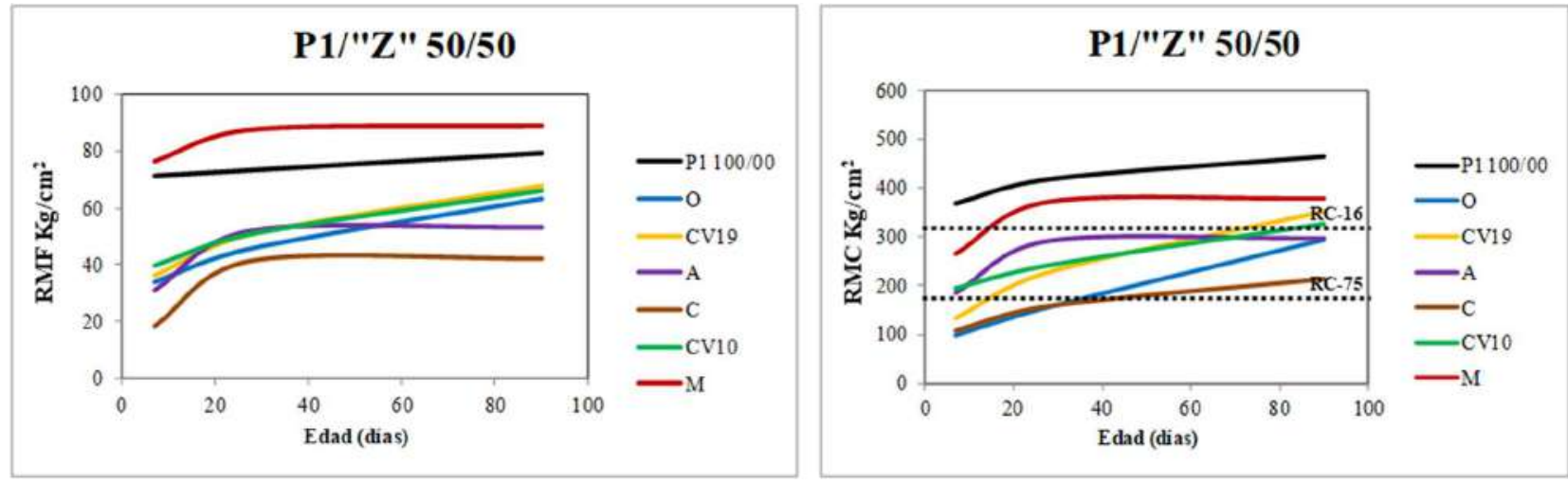

FIGURA 8-26.-REPRESENTACIÓN GRÁFICA DE LAS RMF Y RMC DE LOS CEMENTOS DE MEZCLA CONSTITUIDOS POR EL CEMENTO PORTLAND P1 Y CADA UNA DE LAS ADICIONES PUZOLÁNICAS SELECCIONADAS EN PROPORCIÓN 50/50. EDADES: 7, 28 Y 90 DÍAS.

En las clasificaciones expuestas en las Tablas 8-81, 8-82 y 8-83, destacan los mismos comportamientos identificados y explicados para el caso de la Familia correspondiente 60/40. No obstante, éstos fueron mucho más evidentes en este caso por el número de coincidencias de clasificaciones obtenidas y por la presencia de la escoria S4, cuyo posicionamiento más extremo derecha en las clasificaciones obtenidas es lógico, dado su notable mayor contenido de $\mathrm{CaO}$, que las puzolanas, véase la Tabla 8-81. 
COMPORTAMIENTO SULFÁTICO Y MECÁNICO-RESISTENTE DE CEMENTOS PORTLAND CON ELEVADOS CONTENIDOS DE PUZOLANAS (> 40\%): SU FUNDAMENTO QUÍMICO Y JUSTIFICACIÓN DE OTRAS CONSECUENCIAS POSIBLES
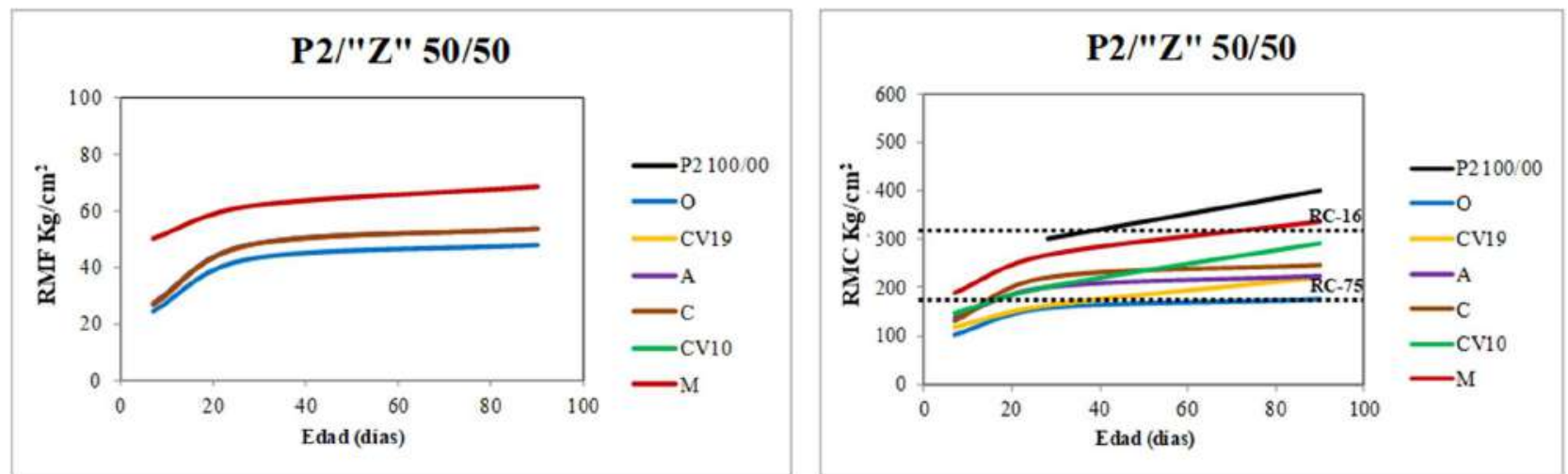

FIGURA 8-27.-REPRESENTACIÓN GRÁFICA DE LAS RMF Y RMC DE LOS CEMENTOS DE MEZCLA CONSTITUIDOS POR EL CEMENTO PORTLAND P2 Y CADA UNA DE LAS ADICIONES PUZOLÁNICAS SELECCIONADAS EN PROPORCIÓN 50/50. EDADES: 7, 28 Y 90 DÍAS.
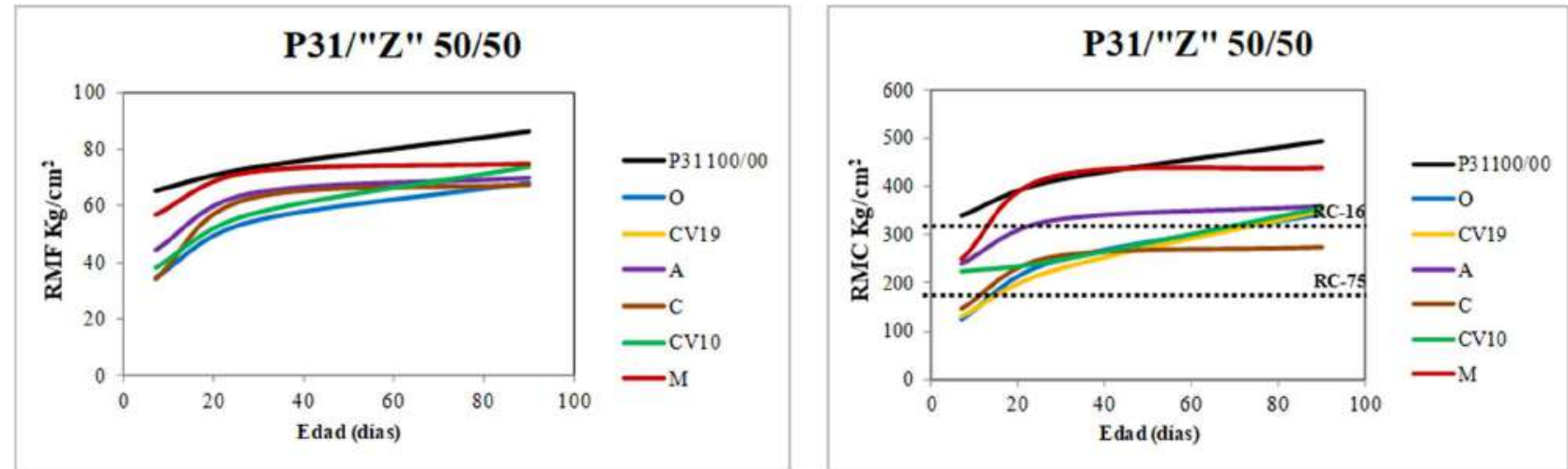

FIGURA 8-28.-REPRESENTACIÓN GRÁFICA DE LAS RMF Y RMC DE LOS CEMENTOS DE MEZCLA CONSTITUIDOS POR EL CEMENTO PORTLAND P31 Y CADA UNA DE LAS ADICIONES PUZOLÁNICAS SELECCIONADAS EN PROPORCIÓN 50/50. EDADES: 7, 28 Y 90 DÍAS.
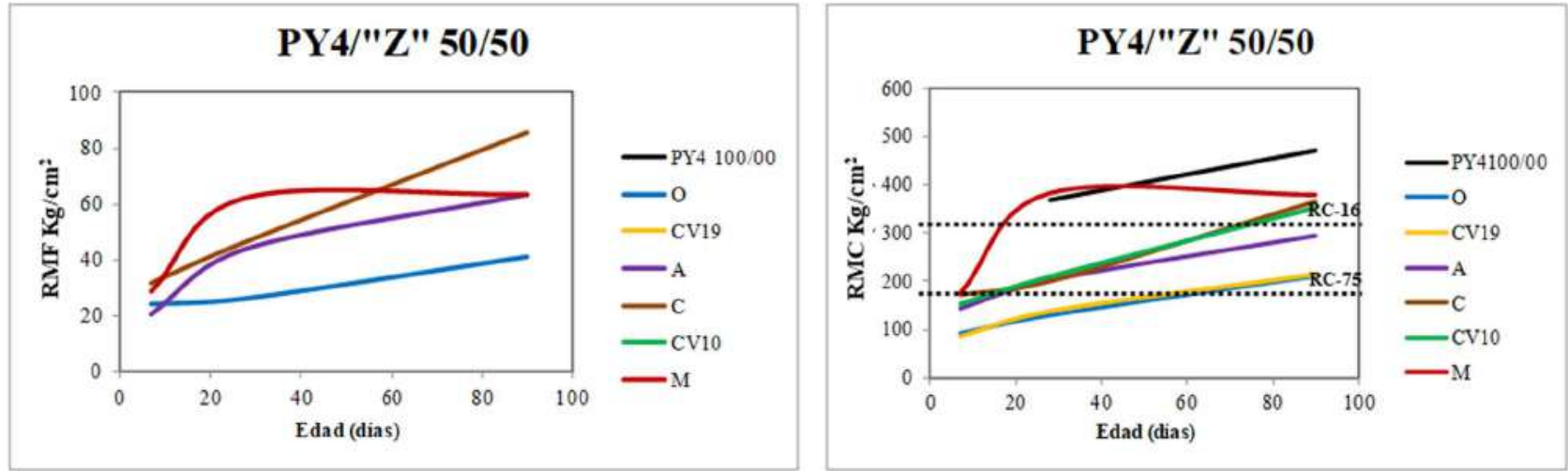

FIGURA 8-29.-REPRESENTACIÓN GRÁFICA DE LAS RMF Y RMC DE LOS CEMENTOS DE MEZCLA CONSTITUIDOS POR EL CEMENTO PORTLAND PY4 Y CADA UNA DE LAS ADICIONES PUZOLÁNICAS SELECCIONADAS EN PROPORCIÓN 50/50. EDADES: 7, 28 Y 90 DÍAS. 

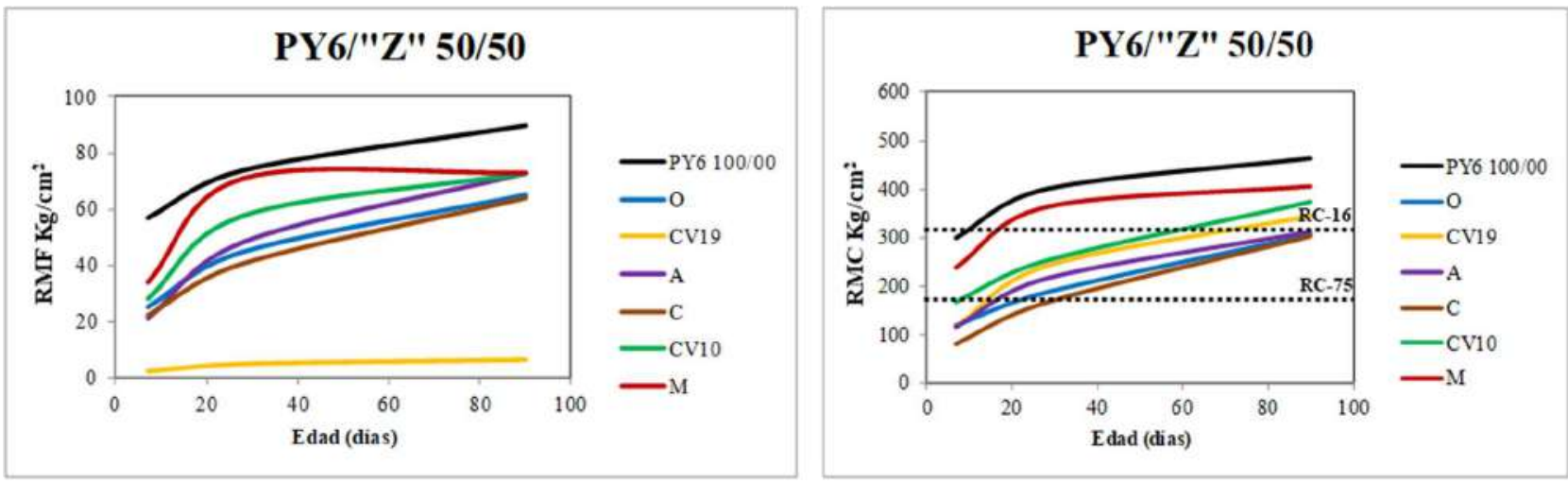

FIGURA 8-30.-REPRESENTACIÓN GRÁFICA DE LAS RMF Y RMC DE LOS CEMENTOS DE MEZCLA CONSTITUIDOS POR EL CEMENTO PORTLAND PY6 Y CADA UNA DE LAS ADICIONES PUZOLÁNICAS SELECCIONADAS EN PROPORCIÓN 50/50. EDADES: 7, 28 Y 90 DÍAS.

\subsection{Familia $P-n^{o}$ y $P Y-n^{o} /{ }^{\prime \prime} Z^{\prime \prime} 40 / 60$}

Todas las clasificaciones que surgen de los resultados obtenidos en los ensayos de RMC y RMF se muestran en las Tablas 8-83, 8-84 y 8-85. Asímismo, en las Figuras 8-31, 8-32, 8-33, 8-34 y 8-35, se representa la evolución de tanto de las RMF y RMC de cada uno de los cementos de mezcla en mortero normalizado EN 196-1. En las clasificaciones expuestas en los Tablas 8-83, 884 y 8-85 destacan los siguientes hechos:

TABLA 8-83.- ESTUDiO COMPARATIVO DE LA RELACIÓN RMF/RMC DE LOS CEMENTOS DE MEZCLA 50/50 EN FUNCIÓN DE LA ADICIÓN MINERAL UTILIZADA, CON UN MISMO CEMENTO PORTLAND DE REFERENCIA.

\begin{tabular}{|c|c|c|}
\hline \multicolumn{3}{|c|}{ Parámetro RMF/RMC } \\
\hline \multirow{2}{*}{ Puzolana "Z" } & \multirow{2}{*}{ Edad (días) } & Familias P-n ${ }^{o}$ y PY-no/"Z" 50/50 \\
\hline & & Clasificaciones de las AP a diferentes edades \\
\hline \multirow{3}{*}{$*=\mathrm{P}-1$} & 7 & $\mathrm{~A}<\mathrm{C}<\mathrm{S} 4<\mathrm{CV} 10<\mathrm{CV} 19<\mathrm{M}<\mathrm{O}$ \\
\hline & 28 & $\mathrm{~A}<\mathrm{CV} 10<\mathrm{S} 4<\mathrm{CV} 19<\mathrm{O}<\mathrm{M}<\mathrm{C}$ \\
\hline & 90 & $\mathrm{~A}<\mathrm{CV} 19<\mathrm{C}<\mathrm{CV} 10<\mathrm{O}<\mathrm{S} 4<\mathrm{M}$ \\
\hline \multirow{3}{*}{$*=\mathrm{P}-2$} & 7 & $\mathrm{~A}<\mathrm{C}<\mathrm{O}<\mathrm{M}$ \\
\hline & 28 & $\mathrm{C}<\mathrm{M}<\mathrm{A}<\mathrm{O}$ \\
\hline & 90 & $\mathrm{M}<\mathrm{C}<\mathrm{A}<\mathrm{O}$ \\
\hline \multirow{3}{*}{$*=\mathrm{P}-31$} & 7 & CV10 $<$ A $<$ M $<$ C $<$ O $<$ CV19 \\
\hline & 28 & CV10 $<$ M $<$ A $<$ O $<$ CV19 $<$ C \\
\hline & 90 & $\mathrm{M}<\mathrm{A}<\mathrm{CV} 19<\mathrm{O}<\mathrm{CV} 10<\mathrm{C}$ \\
\hline \multirow{3}{*}{$*=P Y-4$} & 7 & $\mathrm{~A}<\mathrm{M}<\mathrm{C}<\mathrm{CV} 19<\mathrm{C}<\mathrm{CV} 10$ \\
\hline & 28 & $\mathrm{M}<\mathrm{O}<\mathrm{A}<\mathrm{CV} 19<\mathrm{C}<\mathrm{CV} 10$ \\
\hline & 90 & $\mathrm{M}<\mathrm{O}<\mathrm{CV} 10<\mathrm{CV} 19<\mathrm{A}<\mathrm{C}$ \\
\hline \multirow{3}{*}{$*=P Y-6$} & 7 & $\mathrm{M}<\mathrm{CV} 10<\mathrm{S} 4<\mathrm{A}<\mathrm{O}<\mathrm{CV} 10<\mathrm{C}$ \\
\hline & 28 & $\mathrm{M}<\mathrm{CV} 19<\mathrm{S} 4<\mathrm{A}<\mathrm{CV} 10<\mathrm{O}<\mathrm{A}$ \\
\hline & 90 & $\mathrm{M}<\mathrm{CV} 19<\mathrm{CV} 10<\mathrm{C}<\mathrm{O}<\mathrm{S} 4<\mathrm{A}$ \\
\hline
\end{tabular}

1‥ El posicionamiento extremo izquierdo adoptado por la puzolana $\mathrm{M}$ en la mayor parte de las clasificaciones obtenidas.

$2^{\circ}$. El posicionamiento semejante mantenido por la puzolana $C$ en la mayor parte de las 
clasificaciones obtenidas al igual que ha ocurrido en las correspondientes de las Familias "hermanas superiores" 40/60 y 50/50, es decir, el extremo izquierdo.

Y mientras que el $2^{\circ}$ hecho tiene la misma razón que la dada al efecto en el caso de las Familias "hermanas superiores" 60/40 y 50/50, el $1^{\circ}$ hecho no, pues en este caso la mayor actividad puzolánica de la puzolana alumínica M que el resto unida a su mayor presencia, haría que el nivel de portlandita resultante en la fase líquida, fuera el suficiente y necesario para fortalecer lo suficiente la unión pasta-árido silíceo la cual se traduciría en menores valores de RMF obtenidos cuanto más alumínica sea la puzolana, y viceversa, como así ha sido el caso. Y como confirmación de esta razón aducida, están los hechos siguientes:

TABLA 8-84.- ESTUdio COMPARATIVO DE LA RMF DE LOS CEMENTOS DE MEZCLA 40/60 EN FUNCIÓN DE LA ADICIÓN MINERAL UTILIZADA (M, A, C Y S4), CON UN MISMO CEMENTO PORTLAND DE REFERENCIA (P1 Y P31).

\begin{tabular}{ccc}
\hline & \multicolumn{2}{c}{ Parámetro RMF } \\
\cline { 3 - 3 } Puzolana "Z" & $\begin{array}{c}\text { Edad } \\
\text { (días) }\end{array}$ & $\begin{array}{c}\text { Familias P-n }{ }^{\mathbf{0}} \text { y PY-no/"Z" } \\
\text { Clasificaciones de las AP a diferentes } \\
\text { edades }\end{array}$ \\
\hline & 7 & $\mathrm{~A}<\mathrm{M}<\mathrm{S} 4$ \\
P-1 & 28 & $\mathrm{M}<\mathrm{A}<<\mathrm{S} 4$ \\
& 90 & $\mathrm{M}<\mathrm{A}<<\mathrm{S} 4$ \\
& 7 & $\mathrm{C}<\mathrm{A}<\mathrm{M}$ \\
P-31 & 28 & $\mathrm{C}<\mathrm{A}<\mathrm{M}$ \\
& 90 & $\mathrm{C}<\mathrm{A}<\mathrm{M}$ \\
\hline
\end{tabular}

a) Que tales clasificaciones se ven confirmadas y razonadas por los menores valores correspondientes obtenidos de RMF y RMC del cemento P-nº y PY-nooM 30/70, véanse las Tablas 8-84, 8-85 y 8-86.

TABla 8-85.- ESTUdio COMPARATIVO DE LA RMC DE LOS CEMENTOS DE MEZCLA 40/60 EN FUNCIÓN DE LA ADICIÓN MINERAL UTILIZADA (M, A, C Y S4), CON UN MISMO CEMENTO PORTLAND DE REFERENCIA (P1 Y P31).

\begin{tabular}{|c|c|c|}
\hline \multicolumn{3}{|c|}{ Parámetro RMC } \\
\hline \multirow{2}{*}{ Puzolana "Z" } & \multirow{2}{*}{ Edad (días) } & Familias P-nº y PY-no /"Z" 40/60 \\
\hline & & Clasificaciones de las AP a diferentes edades \\
\hline \multirow{3}{*}{ P-1 } & 7 & $\mathrm{M}<\mathrm{A}<\mathrm{S} 4$ \\
\hline & 28 & $\mathrm{M}<\mathrm{A}<\mathrm{S} 4$ \\
\hline & 90 & $\mathrm{M}<\mathrm{A}<\mathrm{S} 4$ \\
\hline \multirow{3}{*}{ P-31 } & 7 & $\mathrm{C}<\mathrm{M}<\mathrm{A}$ \\
\hline & 28 & $\mathrm{C}<\mathrm{A}<\mathrm{M}$ \\
\hline & 90 & $\mathrm{C}<\mathrm{A}<\mathrm{M}$ \\
\hline
\end{tabular}


TABLA 8-86.- ESTUDiO COMPARATIVO DE LA RELACIÓN RMF/RMC DE LOS CEMENTOS DE MEZCLA 40/60 EN FUNCIÓN DE LA ADICIÓN MINERAL UTILIZADA (M, A, C Y S4), CON UN MISMO CEMENTO PORTLAND DE REFERENCIA (P1 Y P31).

\begin{tabular}{ccc}
\hline & \multicolumn{2}{c}{ Parámetro RMF/RMC } \\
Puzolana "Z" & Edad (días) & Familias P-n $\mathbf{0}$. PY-no/"Z" 40/60 \\
& 7 & Clasificaciones de las AP a diferentes edades \\
\hline \multirow{2}{*}{ P-1 } & 28 & $\mathrm{~A}<\mathrm{M}<\mathrm{S} 4$ \\
& 90 & $\mathrm{M}<\mathrm{A}<\mathrm{S} 4$ \\
& & $\mathrm{M}<\mathrm{A}<\mathrm{S} 4$ \\
P-31 & 28 & $\mathrm{~A}<\mathrm{C}<\mathrm{M}$ \\
& 90 & $\mathrm{M}<\mathrm{A}<\mathrm{C}$ \\
& $\mathrm{M}<\mathrm{A}<\mathrm{C}$ \\
\hline
\end{tabular}
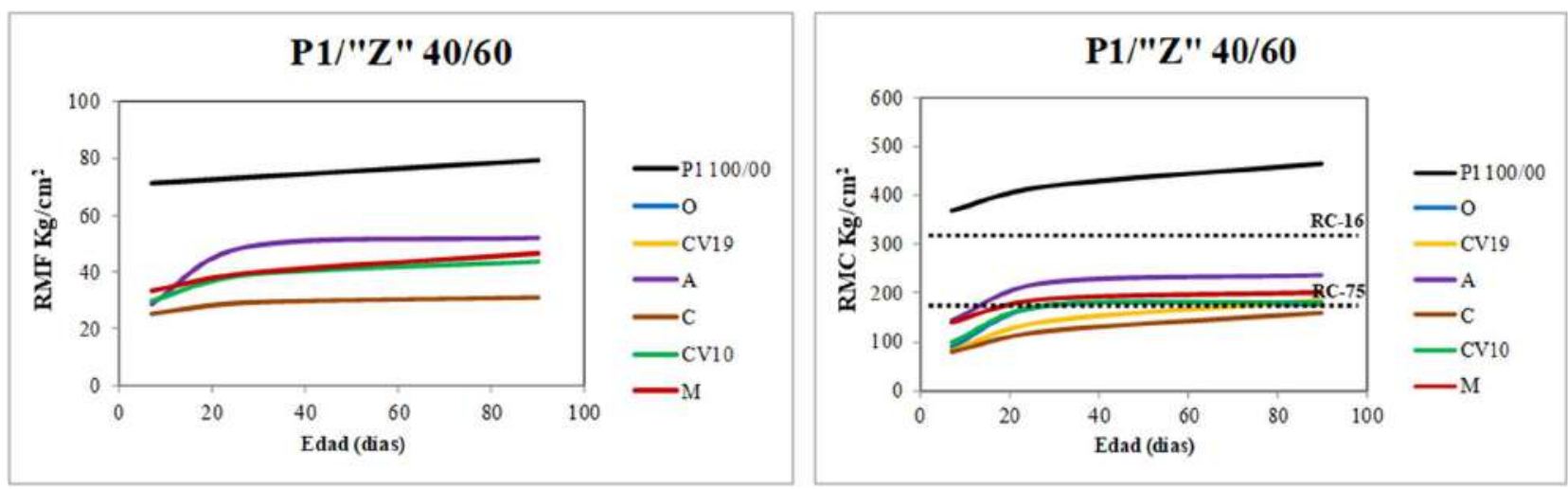

FIGURA 8-31.-REPRESENTACIÓN GRÁFICA DE LAS RMF Y RMC DE LOS CEMENTOS DE MEZCLA CONSTITUIDOS POR EL CEMENTO PORTLAND P1 Y CADA UNA DE LAS ADICIONES PUZOLÁNICAS SELECCIONADAS EN PROPORCIÓN 50/50. EDADES: 7, 28 Y 90 DÍAS.
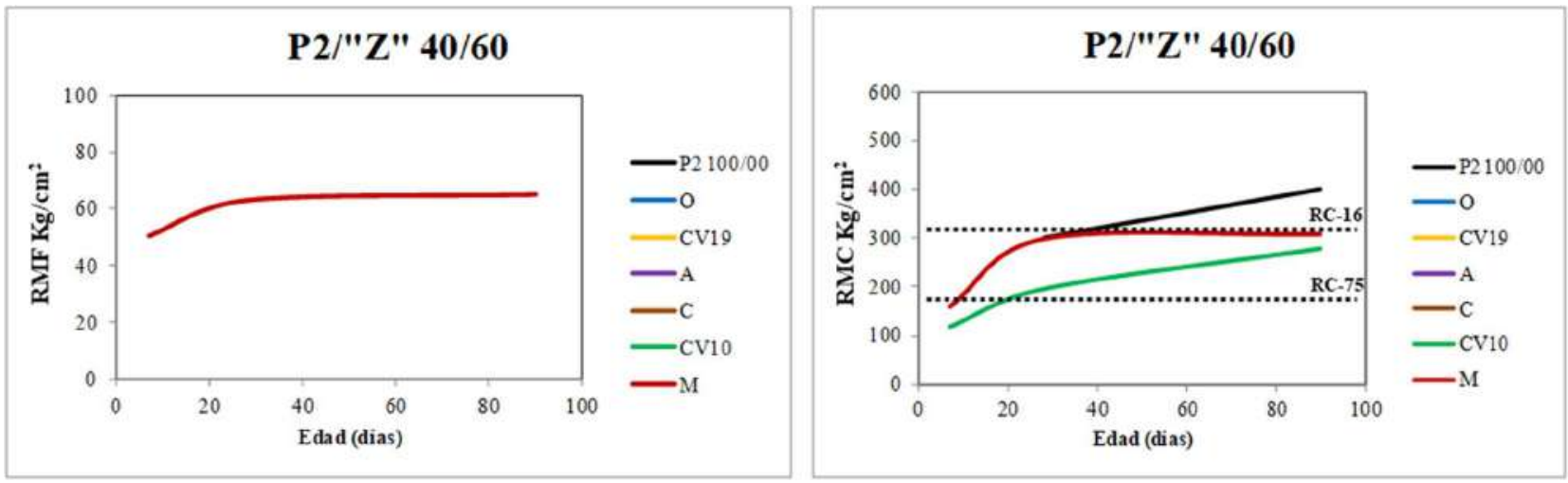

FIGURA 8-32.-REPRESENTACIÓN GRÁFICA DE LAS RMF Y RMC DE LOS CEMENTOS DE MEZCLA CONSTITUIDOS POR EL CEMENTO PORTLAND P2 Y CADA UNA DE LAS ADICIONES PUZOLÁNICAS SELECCIONADAS EN PROPORCIÓN 50/50. EDADES: 7, 28 Y 90 DÍAS. 

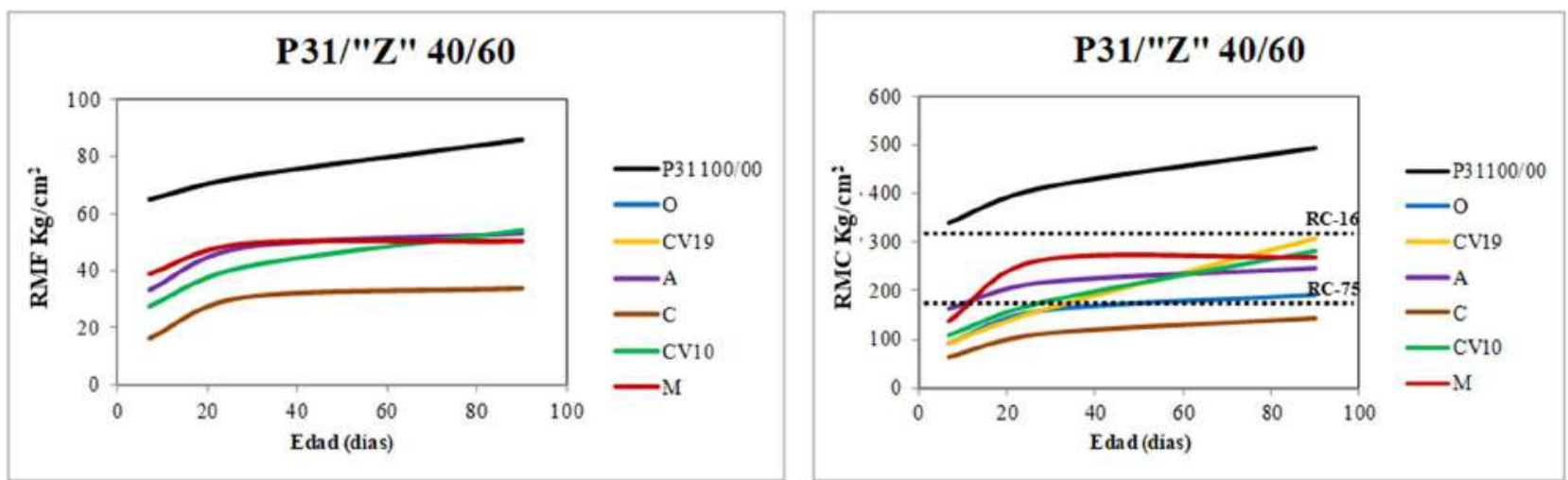

FIGURA 8-33.-REPRESENTACIÓN GRÁFICA DE LAS RMF Y RMC DE LOS CEMENTOS DE MEZCLA CONSTITUIDOS POR EL CEMENTO PORTLAND P31 Y CADA UNA DE LAS ADICIONES PUZOLÁNICAS SELECCIONADAS EN PROPORCIÓN 50/50. EDADES: 7, 28 Y 90 DÍAS.

b) Idem, por los mayores valores del cemento P-nº y PY-nº/(M+CH) 30/70.

c) Que tales clasificaciones de las puzolanas M y A sobre todo, cambian de lugar cuando se les añadió a sus CM cal apagada.

d) Que la escoria S4 ocupa por el contrario el posicionamiento totalmente opuesto, es decir, el extremo derecho, dado su propio contenido de cal $(42.55 \% \mathrm{CaO}$ contra $0.63 \mathrm{de} \mathrm{CaO}$ de la puzolana $\mathrm{M}$ ) que liberaría como $\mathrm{Ca}(\mathrm{OH})_{2}$ tras su activación por la fracción de cemento Portland acompañante respectiva.
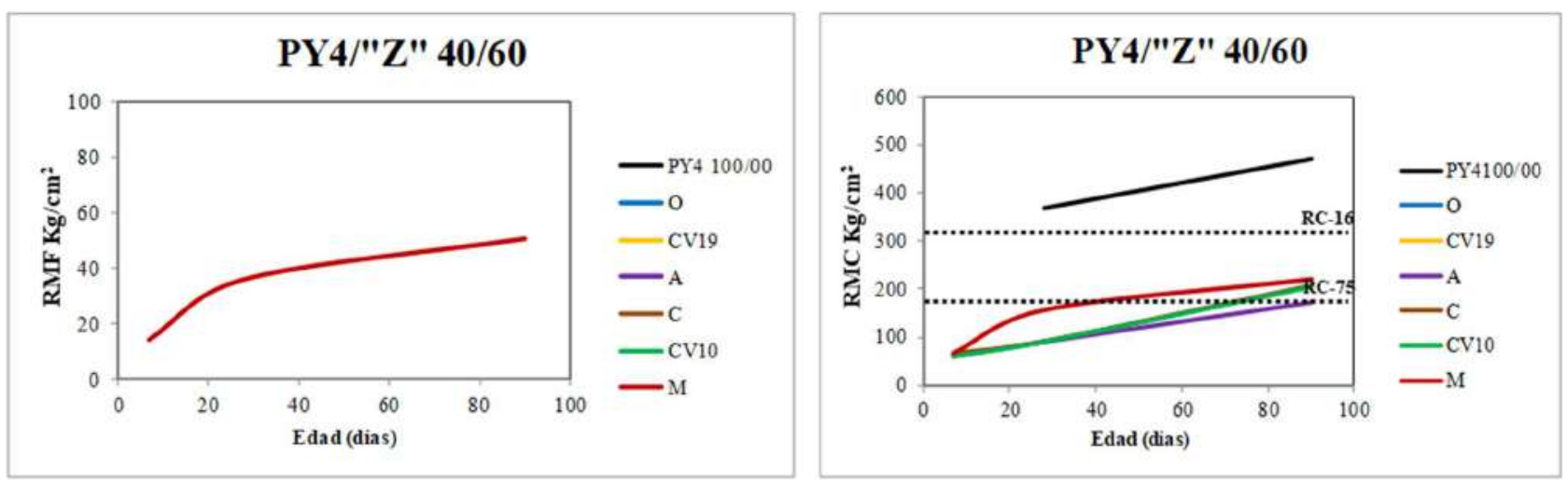

FIGURA 8-34.-REPRESENTACIÓN GRÁFICA DE LAS RMF Y RMC DE LOS CEMENTOS DE MEZCLA CONSTITUIDOS POR EL CEMENTO PORTLAND PY4 Y CADA UNA DE LAS ADICIONES PUZOLÁNICAS SELECCIONADAS EN PROPORCIÓN 50/50. EDADES: 7, 28 Y 90 DÍAS. 

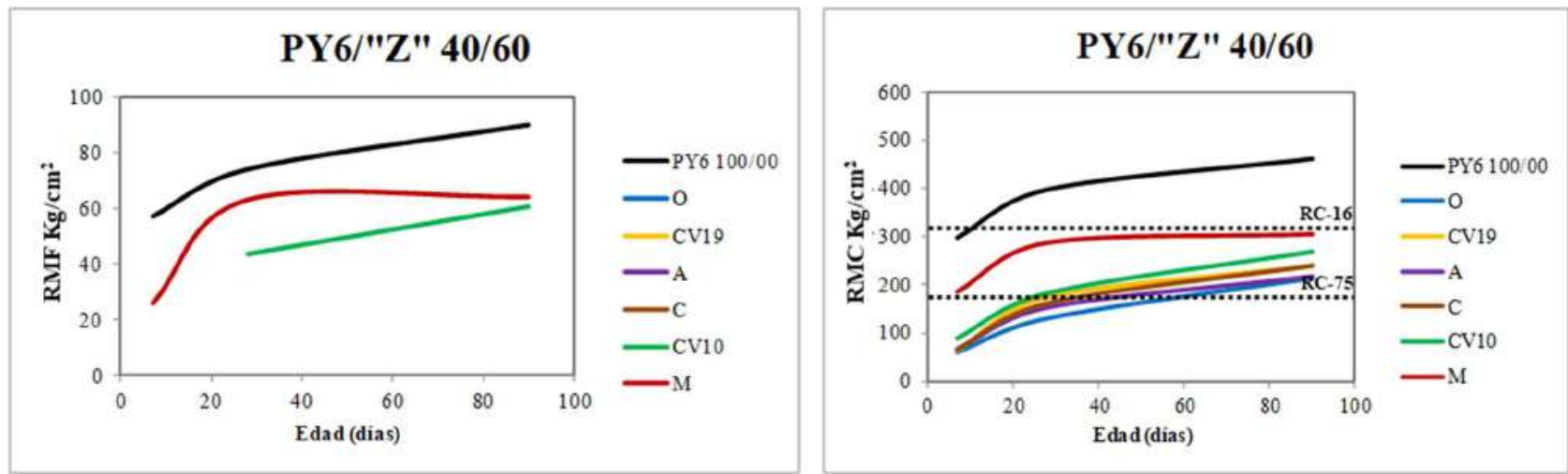

FIGURA 8-35.-REPRESENTACIÓN GRÁFICA DE LAS RMF Y RMC DE LOS CEMENTOS DE MEZCLA CONSTITUIDOS POR EL CEMENTO PORTLAND PY6 Y CADA UNA DE LAS ADICIONES PUZOLÁNICAS SELECCIONADAS EN PROPORCIÓN 50/50. EDADES: 7, 28 Y 90 DÍAS.

\subsection{Familias $P-n^{o}$ y $P Y-n^{o} /\left(" Z^{\prime \prime}+C H\right) 50 / 50$}

Todas las clasificaciones que surgen de los resultados obtenidos en los ensayos de RMC y RMF se muestran en las Tablas 8-87, 8-88 y 8-89. Asímismo, en las Figuras 8-36, 8-37, 8-38, 8-39 y $8-40$, se representa la evolución de tanto de las RMF y RMC de cada uno de los cementos de mezcla en mortero normalizado EN 196-1.

De las tres clasificacionesdestacan sobre todos los siguientes hechos:

$1^{\circ}$. En la Tabla 8-93, las posiciones extremas derechas ocupadas por las adiciones activas S4 $<\mathrm{M}$, caso del P-1 y $\mathrm{M}<\mathrm{S} 4$, caso del PY6.

TABla 8-87.- ESTUdio COMPARATIVO DE LA RMF DE lOS CEMENTOS DE MEZCla EN FUNCIÓN DE LA ADICIÓN MINERAL UTILIZADA, CON UN MISMO CEMENTO PORTLAND DE REFERENCIA, UTILIZADO CON APORTE DE CAL APAGADA.

\begin{tabular}{|c|c|c|}
\hline \multicolumn{3}{|r|}{ Parámetro RMF } \\
\hline \multirow{2}{*}{ Puzolana "Z" } & \multirow{2}{*}{ Edad (días) } & Familias P-no y PY-no/("Z"+CH) y S4 50/50 \\
\hline & & Clasificaciones de las AP a diferentes edades \\
\hline \multirow{3}{*}{ P-1 } & 7 & $\mathrm{O}<\mathrm{C}<\mathrm{CV} 19<\mathrm{CV} 10<\mathrm{S} 4<\mathrm{M}$ \\
\hline & 28 & $\mathrm{O}<\mathrm{C}<\mathrm{CV} 19<\mathrm{CV} 10<\mathrm{S} 4<\mathrm{M}$ \\
\hline & 90 & $\mathrm{O}<\mathrm{C}<\mathrm{CV} 19<\mathrm{CV} 10<\mathrm{S} 4<\mathrm{M}$ \\
\hline \multirow{3}{*}{$\mathrm{P}-2$} & 7 & $\mathrm{O}<\mathrm{A}<\mathrm{C}$ \\
\hline & 28 & $\mathrm{O}<\mathrm{A}<\mathrm{C}$ \\
\hline & 90 & $\mathrm{O}<\mathrm{A}<\mathrm{C}$ \\
\hline \multirow{3}{*}{ P-31 } & 7 & $\mathrm{O}<\mathrm{CV} 10$ \\
\hline & 28 & $\mathrm{O}<\mathrm{CV} 10$ \\
\hline & 90 & $\mathrm{O}<\mathrm{CV} 10$ \\
\hline \multirow{3}{*}{ PY-4 } & 7 & $\mathrm{O}<\mathrm{A}<\mathrm{C}$ \\
\hline & 28 & $\mathrm{O}<\mathrm{A}<\mathrm{C}$ \\
\hline & 90 & $\mathrm{O}<\mathrm{A}<\mathrm{C}$ \\
\hline \multirow{3}{*}{ PY-6 } & 7 & $\mathrm{O}<\mathrm{CV} 19<\mathrm{A}<\mathrm{C}<\mathrm{CV} 10<\mathrm{M}<\mathrm{S} 4$ \\
\hline & 28 & $\mathrm{O}<\mathrm{CV} 19<\mathrm{C}<\mathrm{A}<\mathrm{CV} 10<\mathrm{M}<\mathrm{S} 4$ \\
\hline & 90 & $\mathrm{O}<\mathrm{CV} 19<\mathrm{C}<\mathrm{A}<\mathrm{CV} 10<\mathrm{M}<\mathrm{S} 4$ \\
\hline
\end{tabular}


COMPORTAMIENTO SULFÁTICO Y MECÁNICO-RESISTENTE DE CEMENTOS PORTLAND CON ELEVADOS CONTENIDOS DE PUZOLANAS (> 40\%): SU FUNDAMENTO QUÍMICO Y JUSTIFICACIÓN DE OTRAS CONSECUENCIAS POSIBLES

TABLA 8-88.- ESTUDIO COMPARATIVO DE LA RMC DE LOS CEMENTOS DE MEZCLA EN FUNCIÓN DE LA ADICIÓN MINERAL UTILIZADA, CON UN MISMO CEMENTO PORTLAND DE REFERENCIA, UTILIZADO CON APORTE DE CAL APAGADA.

\begin{tabular}{|c|c|c|}
\hline \multicolumn{3}{|r|}{ Parámetro RMC } \\
\hline \multirow{2}{*}{ Puzolana "Z" } & \multirow{2}{*}{ Edad (días) } & Familias P-no y PY-no/("Z"+CH) y S4 50/50 \\
\hline & & Clasificaciones de las AP a diferentes edades \\
\hline \multirow{3}{*}{$\mathrm{P}-1$} & 7 & $\mathrm{O}<\mathrm{CV} 19<\mathrm{C}<\mathrm{CV} 10<\mathrm{A}<\mathrm{S} 4<\mathrm{M}$ \\
\hline & 28 & $\mathrm{C}<\mathrm{O}<\mathrm{CV} 19<\mathrm{CV} 10<\mathrm{A}<\mathrm{S} 4<\mathrm{M}$ \\
\hline & 90 & $\mathrm{O}<\mathrm{CV} 19<\mathrm{C}<\mathrm{A}<\mathrm{CV} 10<\mathrm{S} 4<\mathrm{M}$ \\
\hline \multirow{3}{*}{ P-2 } & 7 & $\mathrm{O}<\mathrm{A}<\mathrm{C}$ \\
\hline & 28 & $\mathrm{O}<\mathrm{A}<\mathrm{C}$ \\
\hline & 90 & $\mathrm{O}<\mathrm{A}<\mathrm{C}$ \\
\hline \multirow{3}{*}{ P-31 } & 7 & $\mathrm{O}<\mathrm{CV} 10$ \\
\hline & 28 & $\mathrm{O}<\mathrm{CV} 10$ \\
\hline & 90 & $\mathrm{O}<\mathrm{CV} 10$ \\
\hline \multirow{3}{*}{ PY-4 } & 7 & $\mathrm{O}<\mathrm{C}<\mathrm{A}$ \\
\hline & 28 & $\mathrm{O}<\mathrm{A}<\mathrm{C}$ \\
\hline & 90 & $\mathrm{O}<\mathrm{A}<\mathrm{C}$ \\
\hline \multirow{3}{*}{ PY-6 } & 7 & $\mathrm{C}<\mathrm{CV} 19<\mathrm{O}<\mathrm{A}<\mathrm{CV} 10<\mathrm{M}<\mathrm{S} 4$ \\
\hline & 28 & $\mathrm{O}<\mathrm{CV} 19<\mathrm{C}<\mathrm{A}<\mathrm{CV} 10<\mathrm{S} 4<\mathrm{M}$ \\
\hline & 90 & $\mathrm{O}<\mathrm{CV} 19<\mathrm{A}<\mathrm{CV} 10<\mathrm{C}<\mathrm{S} 4<\mathrm{M}$ \\
\hline
\end{tabular}

2․ En RMC, las posiciones también extremas derechas, ocupadas por tales adiciones activas $\mathrm{S} 4<\mathrm{M}$, caso del P1, y $\mathrm{M}<\mathrm{S} 4$ (una edad) y $44<\mathrm{M}$ (dos edades), caso del PY6.

3․ $\quad$ En RMF/RMC, los cambios de posición habidos durante el transcurso del ensayo de la escoria 44 desde la zona izquierda de la clasificación a los 7 días a la derecha de la misma a los 90 días.

TABLA 8-89.- ESTUDIO COMPARATIVO DE LA RELACIÓN RMF/RMC DE LOS CEMENTOS DE MEZCLA EN FUNCIÓN DE LA ADICIÓN MINERAL UTILIZADA, CON UN MisMO CEMENTO PORTLAND DE REFERENCIA, UTILIZADO CON APORTE DE CAL APAGADA.

\begin{tabular}{|c|c|c|}
\hline \multicolumn{3}{|c|}{ Parámetro RMF/RMC } \\
\hline \multirow{2}{*}{ Puzolana "Z" } & \multirow{2}{*}{ Edad (días) } & Familias P-no y PY-no/("Z"+CH) y S4 50/50 \\
\hline & & Clasificaciones de las AP a diferentes edades \\
\hline \multirow{3}{*}{ P-1 } & 7 & $\mathrm{C}<\mathrm{S} 4<\mathrm{CV} 19<\mathrm{O}<\mathrm{CV} 10<\mathrm{M}$ \\
\hline & 28 & $\mathrm{O}<\mathrm{CV} 10<\mathrm{S} 4<\mathrm{CV} 19<\mathrm{M}<\mathrm{C}$ \\
\hline & 90 & $\mathrm{O}<\mathrm{C}<\mathrm{CV} 10<\mathrm{CV} 19<\mathrm{S} 4<\mathrm{M}$ \\
\hline \multirow{3}{*}{ P-2 } & 7 & $\mathrm{~A}<\mathrm{O}<\mathrm{C}$ \\
\hline & 28 & $\mathrm{~A}<\mathrm{C}<\mathrm{O}$ \\
\hline & 90 & $\mathrm{~A}<\mathrm{C}<\mathrm{O}$ \\
\hline \multirow{3}{*}{ P-31 } & 7 & $\mathrm{CV} 10<\mathrm{O}$ \\
\hline & 28 & $\mathrm{CV} 10<\mathrm{O}$ \\
\hline & 90 & $\mathrm{CV} 10<\mathrm{O}$ \\
\hline \multirow{3}{*}{ PY-4 } & 7 & $\mathrm{~A}<\mathrm{O}<\mathrm{C}$ \\
\hline & 28 & $\mathrm{~A}<\mathrm{O}<\mathrm{C}$ \\
\hline & 90 & $\mathrm{~A}<\mathrm{O}<\mathrm{C}$ \\
\hline \multirow{3}{*}{ PY-6 } & 7 & $\mathrm{M}<\mathrm{S} 4<\mathrm{A}<\mathrm{CV} 10<\mathrm{O}<\mathrm{CV} 19<\mathrm{C}$ \\
\hline & 28 & $\mathrm{M}<\mathrm{CV} 10<\mathrm{O}<\mathrm{S} 4<\mathrm{A}<\mathrm{CV} 19<\mathrm{C}$ \\
\hline & 90 & $\mathrm{O}<\mathrm{CV} 19<\mathrm{C}<\mathrm{M}<\mathrm{A}<\mathrm{CV} 10<\mathrm{S} 4$ \\
\hline
\end{tabular}


Y la explicación de tales hechos ha de residir en lo siguiente:

a) Que los valores de RMF con el P1 y la puzolana M, deben de ser de un material, mortero más colmatado, que con la escoria $\mathrm{S} 4$, dados los notables contenidos de $\mathrm{C}_{3} \mathrm{~A}=14.11 \%$ y $\mathrm{Al}_{2} \mathrm{O}_{3}{ }^{\mathrm{r}-} \approx 2.08 \%$ que aquellos componentes poseen y la ASE correspondiente originada entre ambos. Y ello se ve ratificado además por el hecho de que cuando el cemento Portland acompañante de la puzolana $\mathrm{M}$ ha sido el PY6 con $0.00 \% \mathrm{C}_{3} \mathrm{~A}(\approx 1.00 \%$ en la realidad $<14.11 \%$ de $\mathrm{C}_{3} \mathrm{~A}$ del $\mathrm{P} 1$ ) y $79.43 \%$ de $\mathrm{C}_{3} \mathrm{~S}$, no se colmatará tanto y se liberará más y mejor la escoria S4 con lo que finalmente se deberá reforzar la unión pasta-árido silíceo y proporcionar mayores valores de RMF, como así ha sido el caso.
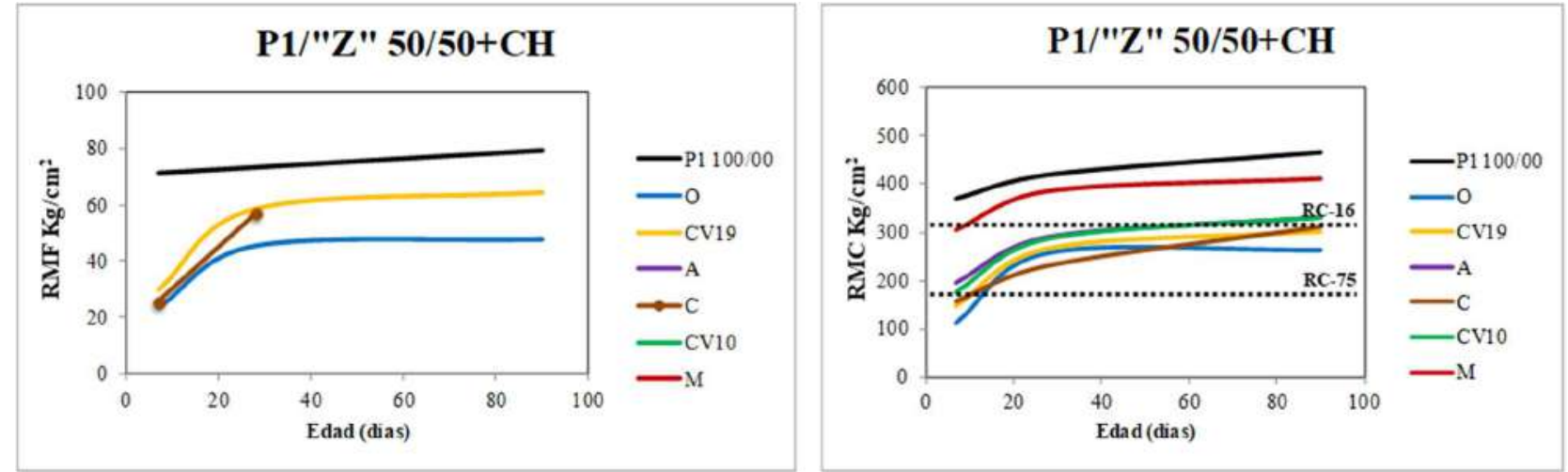

FIGURA 8-36.-REPRESENTACIÓN GRÁFICA DE LAS RMF Y RMC DE LOS CEMENTOS DE MEZCLA CONSTITUIDOS POR EL CEMENTO PORTLAND P1 Y CADA UNA DE LAS ADICIONES PUZOLÁNICAS SELECCIONADAS EN PROPORCIÓN 50/50 CON APORTE EXTRA DE CH. EDADES: 7, 28 Y 90 DÍAS.

b) Lo acaecido en RMC ratifica lo acaecido en el caso anterior y en especial cuando el cemento Portland P1 estuvo presente.
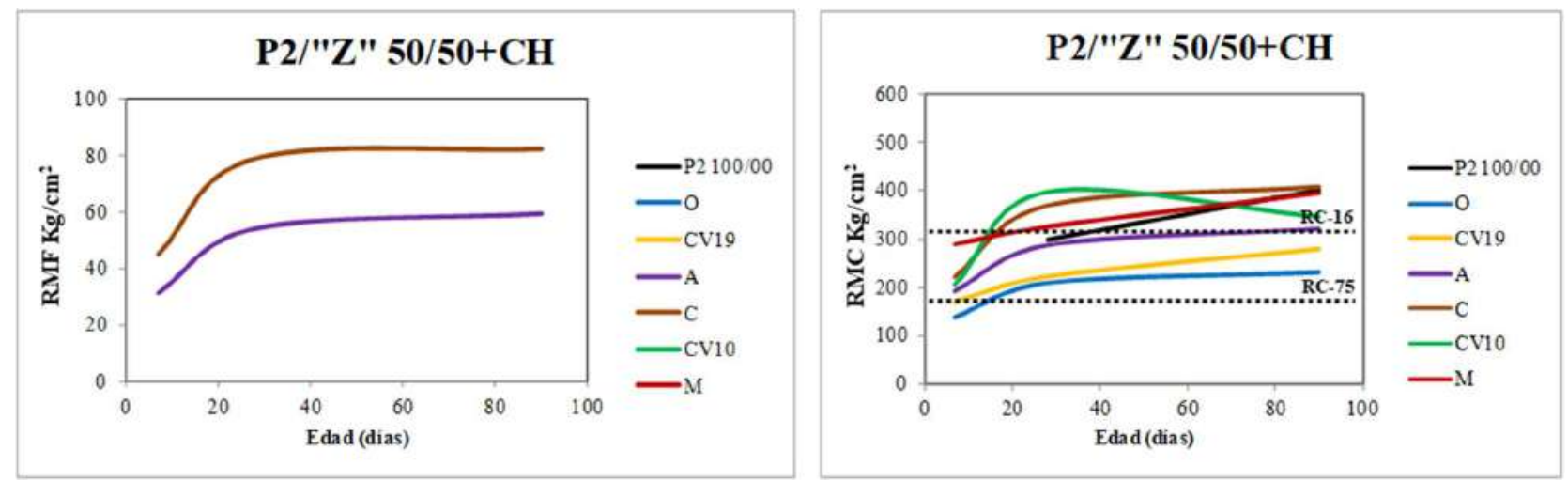

FIGURA 8-37.-REPRESENTACIÓN GRÁFICA DE LAS RMF Y RMC DE LOS CEMENTOS DE MEZCLA CONSTITUIDOS POR EL CEMENTO PORTLAND P2 Y CADA UNA DE LAS ADICIONES PUZOLÁNICAS SELECCIONADAS EN PROPORCIÓN 50/50 CON APORTE EXTRA DE CH. EDADES: 7, 28 Y 90 DÍAS.

c) Lo ocurrido con este parámetro $\mathrm{RMF} / \mathrm{RMC}$ ratifica las hipótesis anteriores pues los dos parámetros determinados, RMF y RMC, el que más se debe aumentar con el transcurso del ensayo, es el RMF, por ser más dependiente de la liberación de portlandita por la hidratación de la fracción Portland correspondiente y al contrario el RMC, por ser más 
COMPORTAMIENTO SULFÁTICO Y MECÁNICO-RESISTENTE DE CEMENTOS PORTLAND CON ELEVADOS CONTENIDOS DE PUZOLANAS (> 40\%): SU FUNDAMENTO QUÍMICO Y JUSTIFICACIÓN DE OTRAS CONSECUENCIAS POSIBLES

dependiente del rellenado de poros. De aquí que en el caso del P1, la puzolana M deberá caer siempre detrás de la escoria S4, mientras que en el caso del PY6 no, como así ha sido el caso.
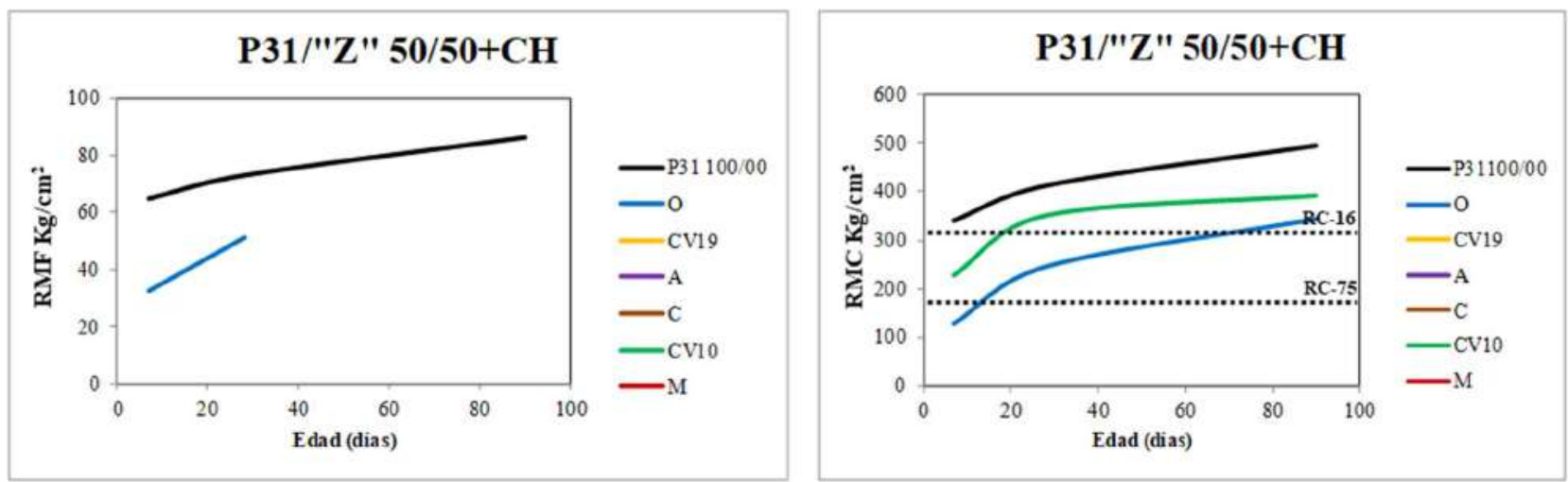

FIGURA 8-38.-REPRESENTACIÓN GRÁFICA DE LAS RMF Y RMC DE LOS CEMENTOS DE MEZCLA CONSTITUIDOS POR EL CEMENTO PORTLAND P31 Y CADA UNA DE LAS ADICIONES PUZOLÁNICAS SELECCIONADAS EN PROPORCIÓN 50/50 CON APORTE EXTRA DE CH. EDADES: 7, 28 Y 90 DÍAS.
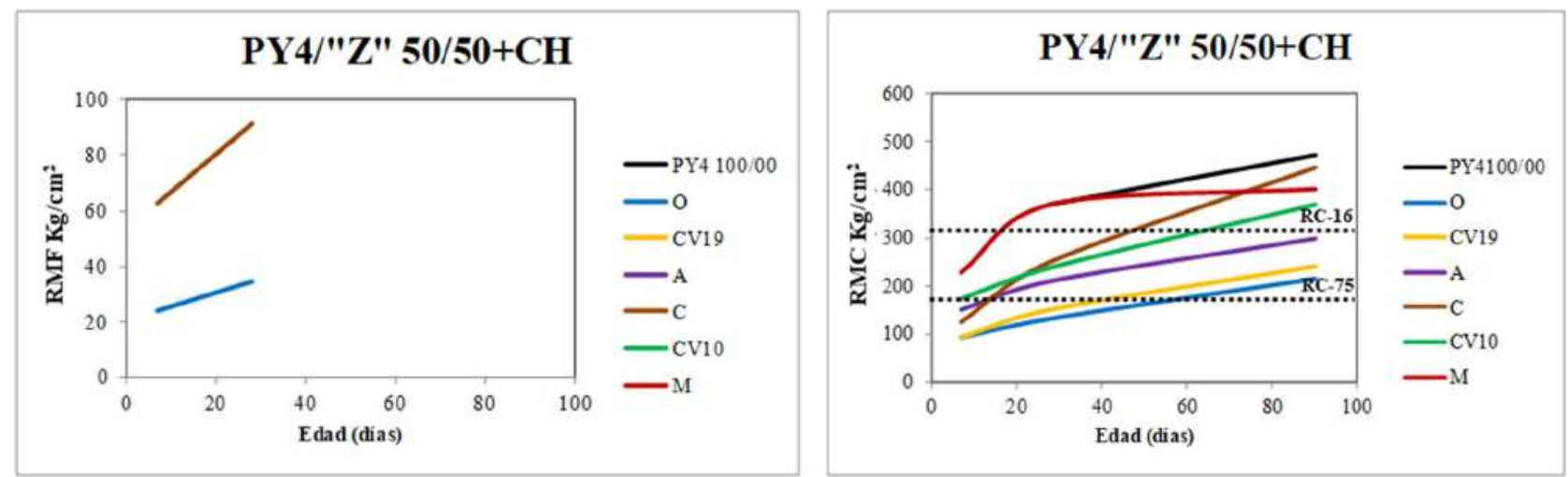

FIGURA 8-39.-REPRESENTACIÓN GRÁFICA DE LAS RMF Y RMC DE LOS CEMENTOS DE MEZCLA CONSTITUIDOS POR EL CEMENTO PORTLAND PY4 Y CADA UNA DE LAS ADICIONES PUZOLÁNICAS SELECCIONADAS EN PROPORCIÓN 50/50 CON APORTE EXTRA DE CH. EDADES: 7, 28 Y 90 DÍAS.
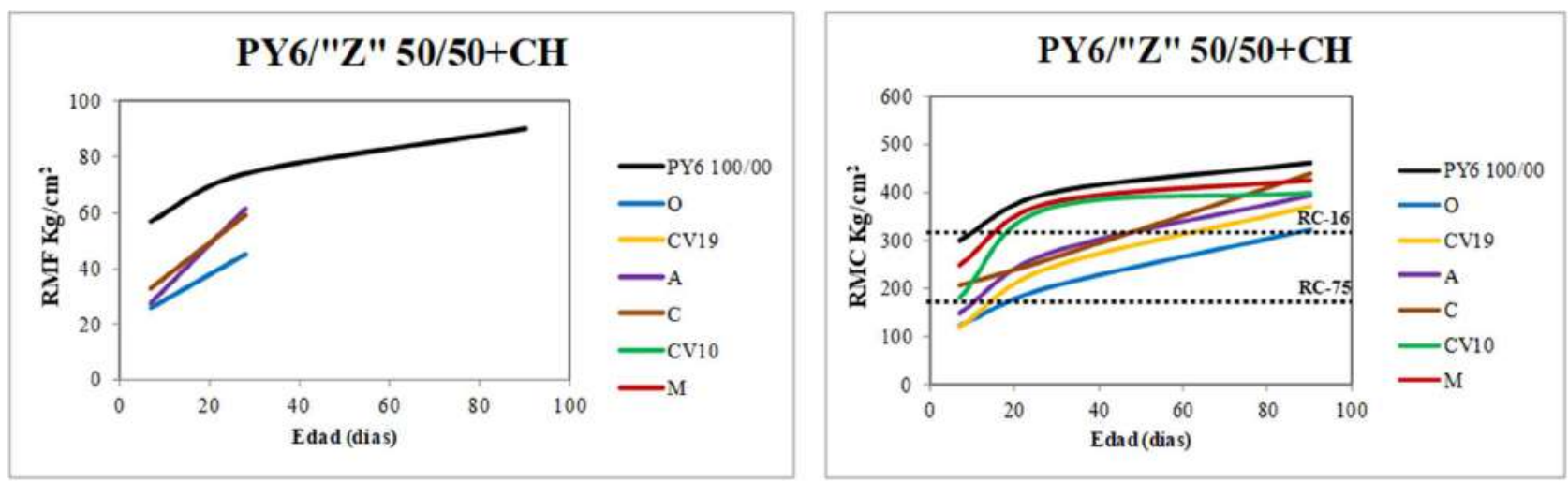

FIGURA 8-40.-REPRESENTACIÓN GRÁFICA DE LAS RMF Y RMC DE LOS CEMENTOS DE MEZCLA CONSTITUIDOS POR EL CEMENTO PORTLAND PYG Y CADA UNA DE LAS ADICIONES PUZOLÁNICAS 
SELECCIONADAS EN PROPORCIÓN 50/50 CON APORTE EXTRA DE CH. EDADES: 7, 28 Y 90 DÍAS.

\subsection{Familia $P-n^{o} /\left({ }^{\prime \prime} Z^{\prime \prime}+C H\right) 40 / 60$}

Todas las clasificaciones que surgen de los resultados obtenidos en los ensayos de RMC y RMF se muestran en las Tablas 8-90, 8-91 y 8-92. Asímismo, en las Figuras 8-41, 8-42, 8-43, 8-44 y $8-45$, se representa la evolución de tanto de las RMF y RMC de cada uno de los cementos de mezcla en mortero normalizado EN 196-1.

Las clasificaciones obtenidas en este caso por las adiciones activas C, M y S4, se pueden explica:

a) para el caso de la puzolana C, por la razón correspondiente aducida para el caso de las familias "hermanas superiores" 60/40 y 50/50, y

b) para el caso de la puzolana $\mathrm{M}$ y la escoria S4, por las razones correspondientes aducidas para el caso de la Familia P-no y PY-no/("Z"+CH) 50/50.

TABLA 8-90.- ESTUdio COMPARATIVO DE LA RMF DE LOS CEMENTOS DE MEZCLA EN FUNCIÓN EN FUNCIÓN DE LA ADICIÓN MINERAL UTILIZADA, CON UN MISMO CEMENTO PORTLAND DE REFERENCIA UTILIZADO, CON APORTE DE CAL APAGADA.

\begin{tabular}{|c|c|c|}
\hline \multicolumn{3}{|r|}{ Parámetro RMF } \\
\hline \multirow{2}{*}{ Puzolana "Z" } & \multirow{2}{*}{ Edad (días) } & Familias P-no y PY-no/("Z"+CH) y S4 40/60 \\
\hline & & Clasificaciones de las AP a diferentes edades \\
\hline \multirow{3}{*}{$\mathrm{P}-1$} & \multirow{3}{*}{$\begin{array}{l}28 \\
90\end{array}$} & $\mathrm{~A}<\mathrm{S} 4<\mathrm{M}$ \\
\hline & & $\mathrm{M}<\mathrm{A}<\mathrm{S} 4$ \\
\hline & & $\mathrm{A}<\mathrm{S} 4<\mathrm{M}$ \\
\hline \multirow{3}{*}{ P-31 } & 7 & $\mathrm{C}<\mathrm{A}<\mathrm{M}$ \\
\hline & 28 & $\mathrm{C}<\mathrm{A}<\mathrm{M}$ \\
\hline & 90 & $\mathrm{C}<\mathrm{A}<\mathrm{M}$ \\
\hline \multirow{3}{*}{ PY-6 } & 7 & $\mathrm{M}<\mathrm{S} 4$ \\
\hline & 28 & $\mathrm{M}<\mathrm{S} 4$ \\
\hline & 90 & $\mathrm{M}<\mathrm{S} 4$ \\
\hline
\end{tabular}

TABLA 8-91.- ESTUdiO COMPARATIVO DE LA RMC DE LOS CEMENTOS DE MEZCLA EN FUNCIÓN EN FUNCIÓN DE LA ADICIÓN MINERAL UTILIZADA, CON UN MISMO CEMENTO PORTLAND DE REFERENCIA UTILIZADO, CON APORTE DE CAL APAGADA.

\begin{tabular}{|c|c|c|}
\hline \multicolumn{3}{|r|}{ Parámetro RMC } \\
\hline \multirow{2}{*}{ Puzolana "Z" } & \multirow{2}{*}{ Edad (días) } & Familias P-no y PY-no/("Z"+CH) y S4 40/60 \\
\hline & & Clasificaciones de las AP a diferentes edades \\
\hline \multirow{3}{*}{ P-1 } & 7 & $\mathrm{~A}<\mathrm{S} 4<\mathrm{M}$ \\
\hline & 28 & $\mathrm{~A}<\mathrm{M}<\mathrm{S} 4$ \\
\hline & 90 & $\mathrm{~A}<\mathrm{M}<\mathrm{S} 4$ \\
\hline \multirow{3}{*}{ P-31 } & 7 & $\mathrm{C}<\mathrm{A}<\mathrm{M}$ \\
\hline & 28 & $\mathrm{C}<\mathrm{A}<\mathrm{M}$ \\
\hline & 90 & $\mathrm{C}<\mathrm{A}<\mathrm{M}$ \\
\hline \multirow{3}{*}{ PY-6 } & 7 & $\mathrm{~S} 4<\mathrm{M}$ \\
\hline & 28 & $\mathrm{~S} 4<\mathrm{M}$ \\
\hline & 90 & $\mathrm{M}<\mathrm{S} 4$ \\
\hline
\end{tabular}


COMPORTAMIENTO SULFÁTICO Y MECÁNICO-RESISTENTE DE CEMENTOS PORTLAND CON ELEVADOS CONTENIDOS DE PUZOLANAS (> 40\%): SU FUNDAMENTO QUÍMICO Y JUSTIFICACIÓN DE OTRAS CONSECUENCIAS POSIBLES

TABLA 8-92.- ESTUDiO COMPARATIVO DE LA RELACIÓN RMF/RMC DE LOS CEMENTOS DE MEZCLA EN FUNCIÓN EN FUNCIÓN DE LA ADICIÓN MINERAL UTILIZADA, CON UN MISMO CEMENTO PORTLAND DE REFERENCIA UTILIZADO, CON APORTE DE CAL APAGADA.

\begin{tabular}{|c|c|c|}
\hline \multicolumn{3}{|c|}{ Parámetro RMF/RMC } \\
\hline \multirow{2}{*}{ Puzolana "Z" } & \multirow{2}{*}{ Edad (días) } & Familias P-no y PY-no/("Z"+CH) y S4 40/60 \\
\hline & & Clasificaciones de las AP a diferentes edades \\
\hline \multirow{3}{*}{ P-1 } & 7 & $\mathrm{~A}<\mathrm{M}<\mathrm{S} 4$ \\
\hline & 28 & $\mathrm{M}<\mathrm{A}<\mathrm{S} 4$ \\
\hline & 90 & $\mathrm{M}<\mathrm{A}<\mathrm{S} 4$ \\
\hline \multirow{3}{*}{ P-31 } & 7 & $\mathrm{M}<\mathrm{A}<\mathrm{C}$ \\
\hline & 28 & $\mathrm{M}<\mathrm{A}<\mathrm{C}$ \\
\hline & 90 & $\mathrm{M}<\mathrm{A}<\mathrm{C}$ \\
\hline \multirow{3}{*}{ PY-6 } & 7 & $\mathrm{M}<\mathrm{S} 4$ \\
\hline & 28 & $\mathrm{~S} 4<\mathrm{M}$ \\
\hline & 90 & $\mathrm{~S} 4<\mathrm{M}$ \\
\hline
\end{tabular}

Comparación de los cementos mixtos con su cal apagada que a continuación se exponen mediante los parámetros RMF/"Z"(g) y RMC/"Z"(g).
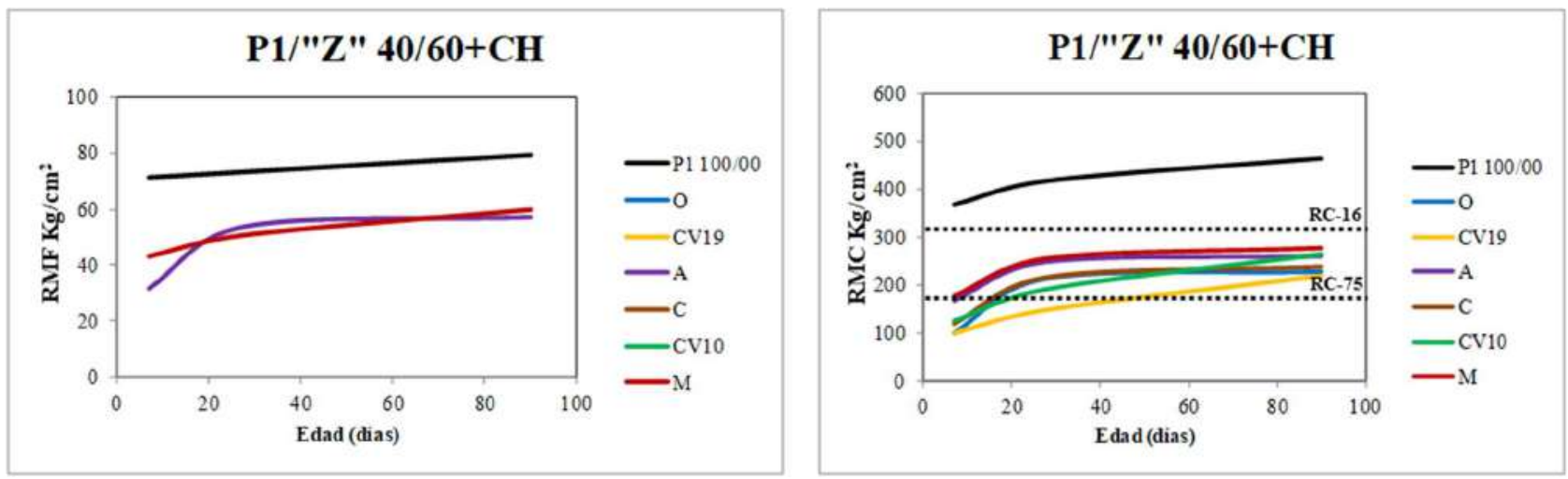

FIGURA 8-41.-REPRESENTACIÓN GRÁFICA DE LAS RMF Y RMC DE LOS CEMENTOS DE MEZCLA CONSTITUIDOS POR EL CEMENTO PORTLAND P1 Y CADA UNA DE LAS ADICIONES PUZOLÁNICAS SELECCIONADAS EN PROPORCIÓN 40/60 CON APORTE EXTRA DE CH. EDADES: 7, 28 Y 90 DÍAS. 

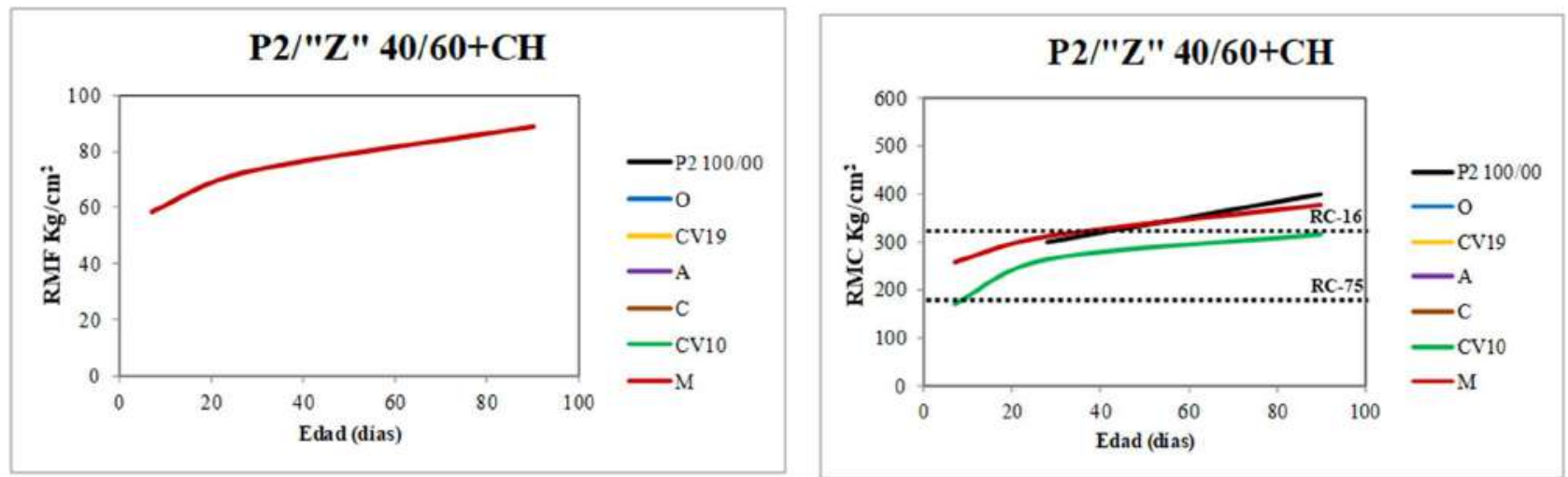

FIGURA 8-42.-REPRESENTACIÓN GRÁFICA DE LAS RMF Y RMC DE LOS CEMENTOS DE MEZCLA CONSTITUIDOS POR EL CEMENTO PORTLAND P2 Y CADA UNA DE LAS ADICIONES PUZOLÁNICAS SELECCIONADAS EN PROPORCIÓN 40/60 CON APORTE EXTRA DE CH. EDADES: 7, 28 Y 90 DÍAS.
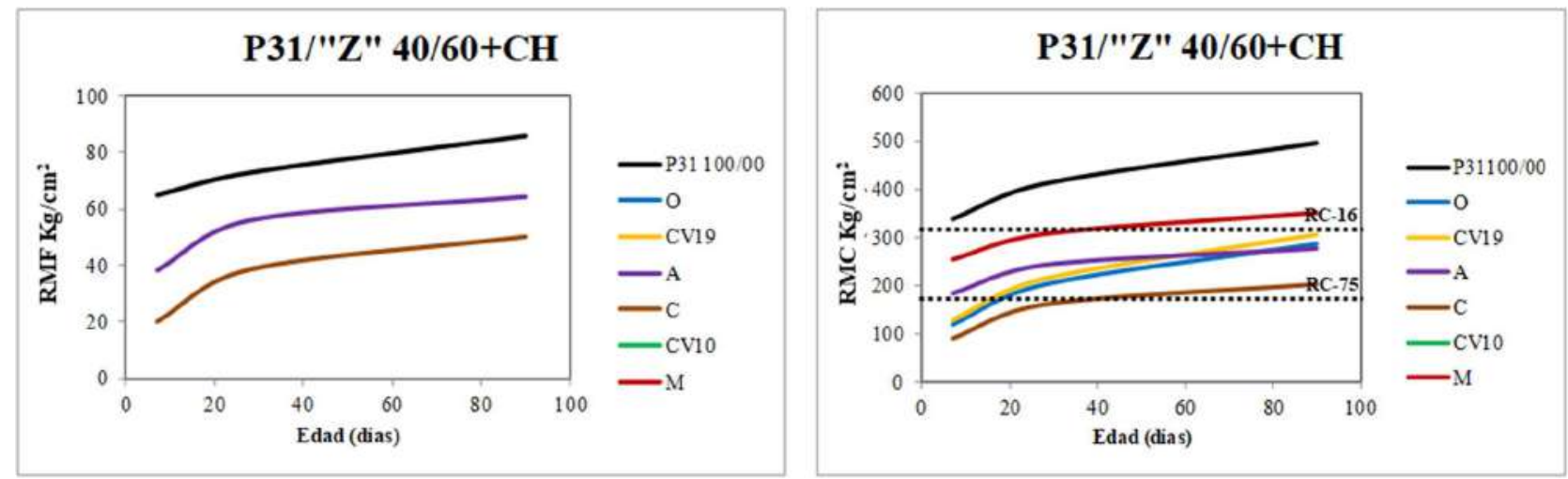

FIGURA 8-43.-REPRESENTACIÓN GRÁFICA DE LAS RMF Y RMC DE LOS CEMENTOS DE MEZCLA CONSTITUIDOS POR EL CEMENTO PORTLAND P31 Y CADA UNA DE LAS ADICIONES PUZOLÁNICAS SELECCIONADAS EN PROPORCIÓN 40/60 CON APORTE EXTRA DE CH. EDADES: 7, 28 Y 90 DÍAS.
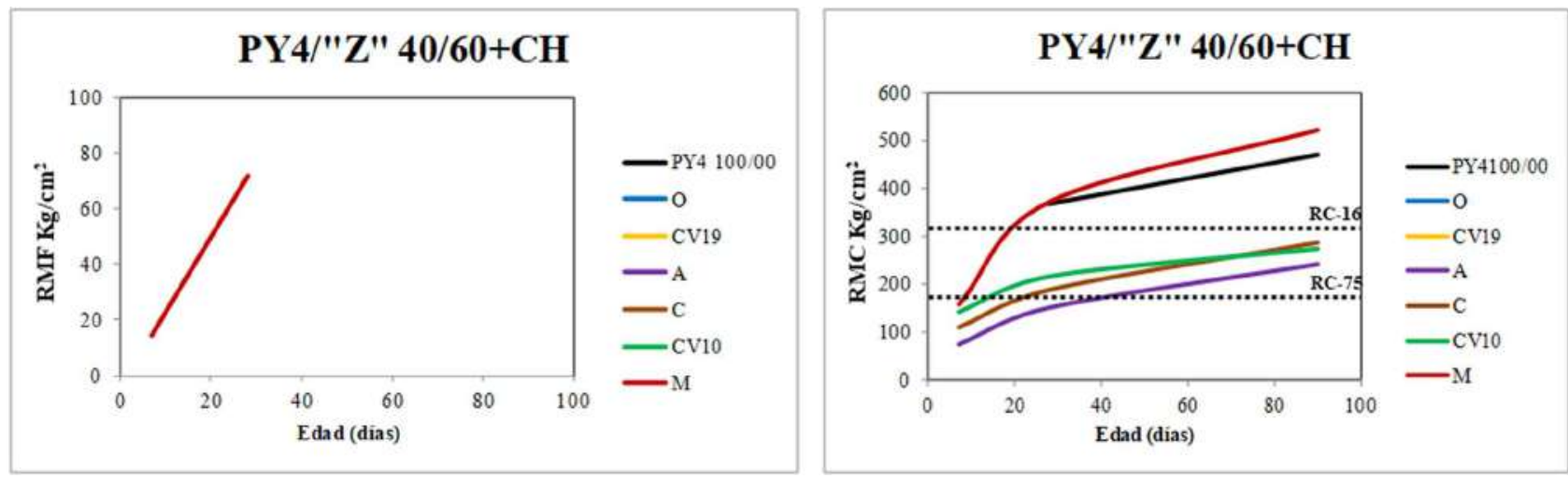

FIGURA 8-44.-REPRESENTACIÓN GRÁFICA DE LAS RMF Y RMC DE LOS CEMENTOS DE MEZCLA CONSTITUIDOS POR EL CEMENTO PORTLAND PY4 Y CADA UNA DE LAS ADICIONES PUZOLÁNICAS SELECCIONADAS EN PROPORCIÓN 50/50 CON APORTE EXTRA DE CH. EDADES: 7, 28 Y 90 DÍAS. 

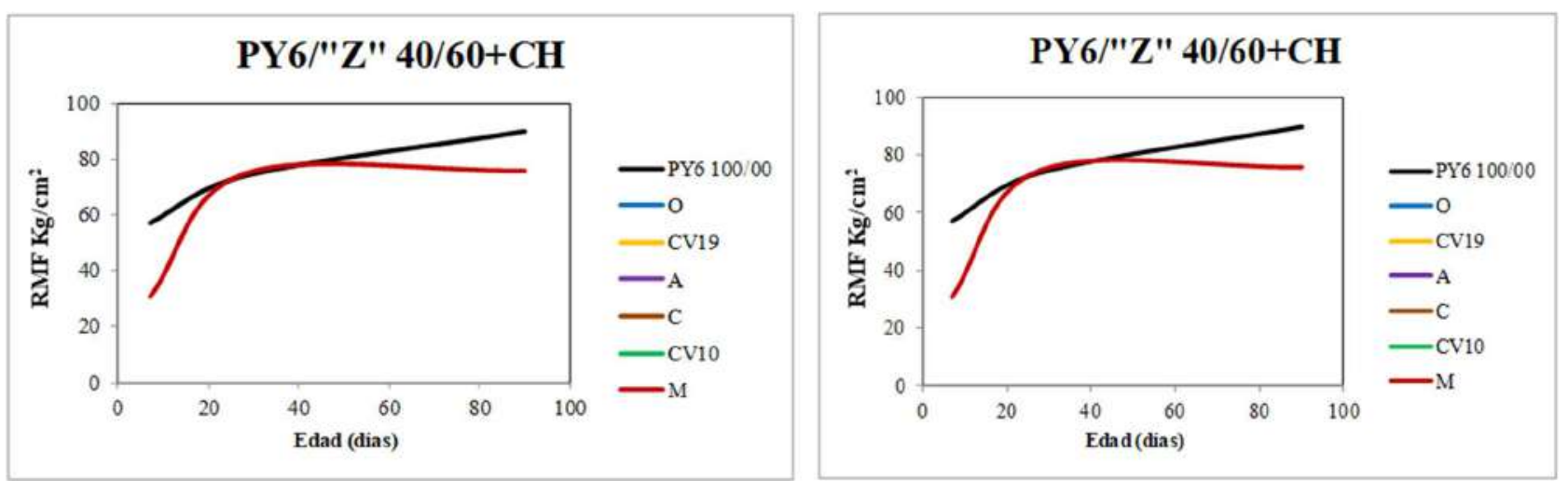

FIGURA 8-45.-REPRESENTACIÓN GRÁFICA DE LAS RMF Y RMC DE LOS CEMENTOS DE MEZCLA CONSTITUIDOS POR EL CEMENTO PORTLAND PYG Y CADA UNA DE LAS ADICIONES PUZOLÁNICAS SELECCIONADAS EN PROPORCIÓN 50/50 CON APORTE EXTRA DE CH. EDADES: 7, 28 Y 90 DÍAS.

\subsection{Familia $P-n^{o}$ y $P Y-n^{o} /{ }^{\prime \prime} Z^{\prime \prime} 30 / 70$}

En las Figuras 8-46, 8-47, 8-48 y 8-49, se representa la evolución de tanto de las RMF y RMC de cada uno de los cementos de mezcla en mortero normalizado EN 196-1.
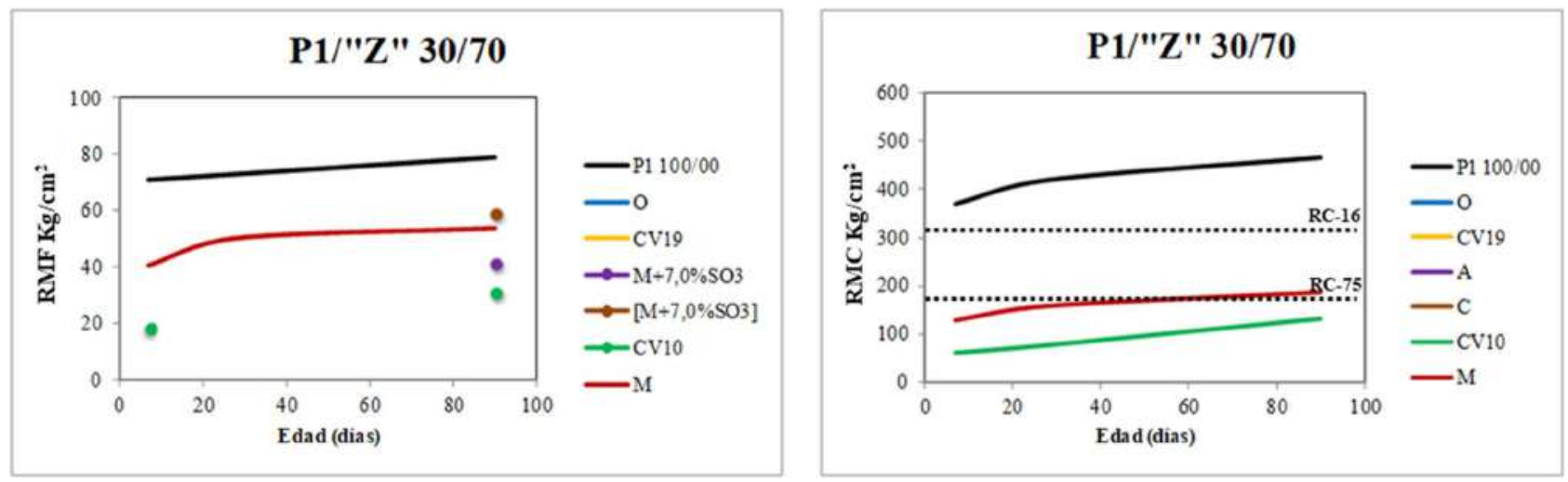

FIGURA 8-46.-REPRESENTACIÓN GRÁFICA DE LAS RMF Y RMC DE LOS CEMENTOS DE MEZCLA CONSTITUIDOS POR EL CEMENTO PORTLAND P1 Y CADA UNA DE LAS ADICIONES PUZOLÁNICAS SELECCIONADAS EN PROPORCIÓN 30/70. EDADES: 7, 28 Y 90 DÍAS. 

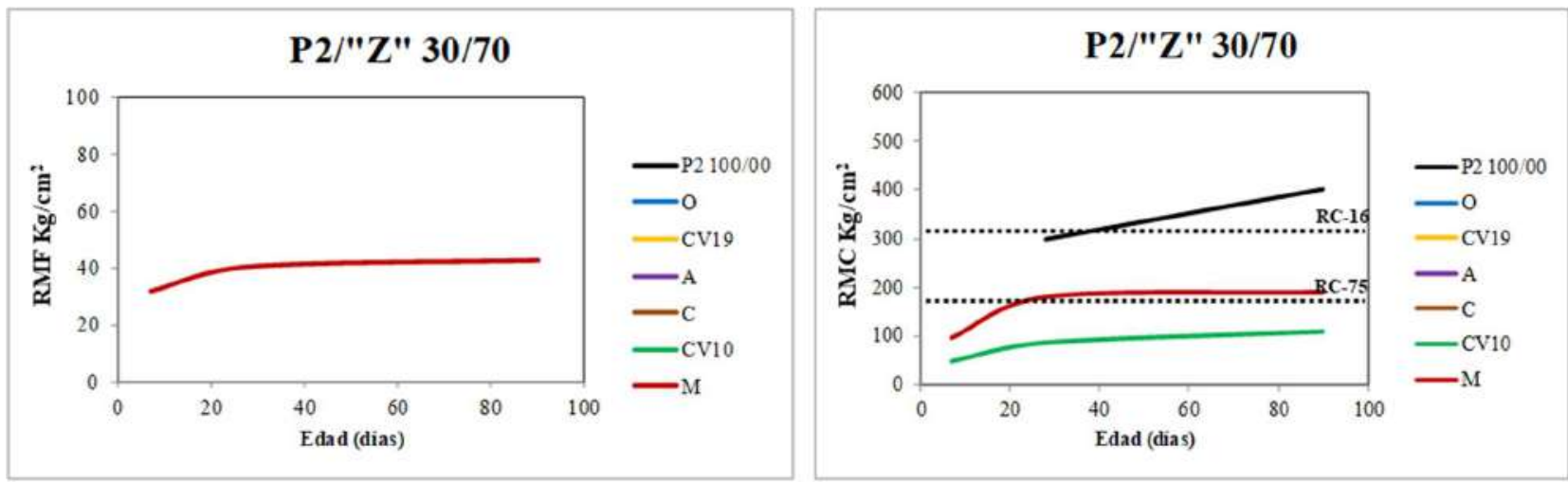

FIGURA 8-47.-REPRESENTACIÓN GRÁFICA DE LAS RMF Y RMC DE LOS CEMENTOS DE MEZCLA CONSTITUIDOS POR EL CEMENTO PORTLAND P2 Y CADA UNA DE LAS ADICIONES PUZOLÁNICAS SELECCIONADAS EN PROPORCIÓN 30/70. EDADES: 7, 28 Y 90 DÍAS.
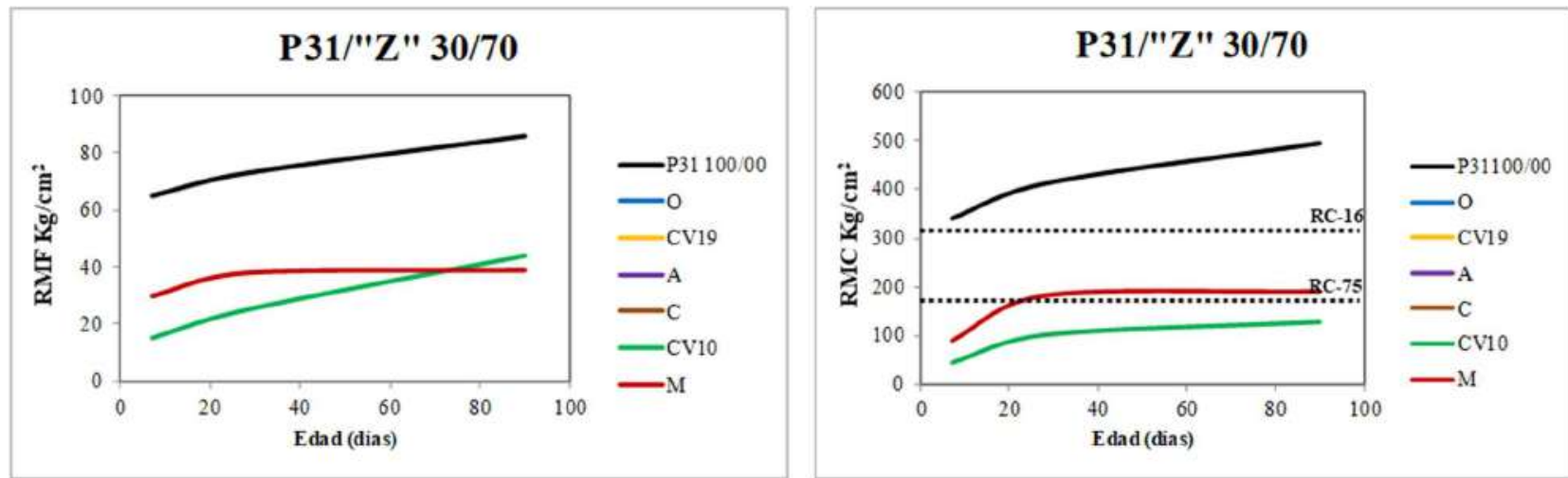

FIGURA 8-48.- REPRESENTACIÓN GRÁFICA DE LAS RMF Y RMC DE LOS CEMENTOS DE MEZCLA CONSTITUIDOS POR EL CEMENTO PORTLAND P31 Y CADA UNA DE LAS ADICIONES PUZOLÁNICAS SELECCIONADAS EN PROPORCIÓN 30/70. EDADES: 7, 28 Y 90 DÍAS.
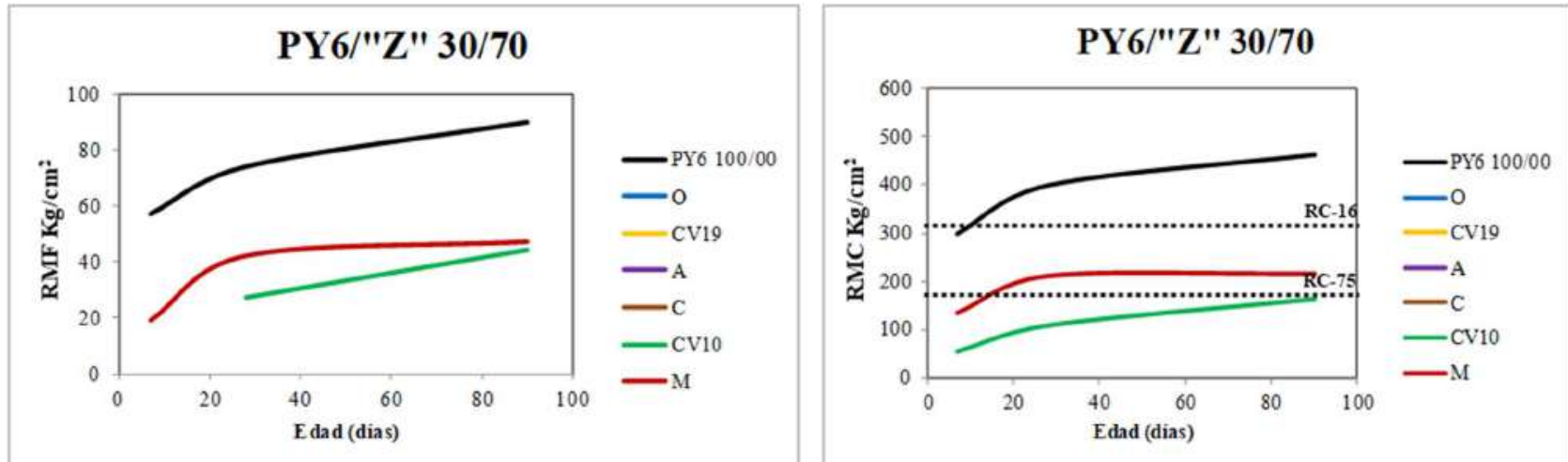

FIGURA 8-49.- REPRESENTACIÓN GRÁFICA DE LAS RMF Y RMC DE LOS CEMENTOS DE MEZCLA CONSTITUIDOS POR EL CEMENTO PORTLAND PY6 Y CADA UNA DE LAS ADICIONES PUZOLÁNICAS SELECCIONADAS EN PROPORCIÓN 30/70. EDADES: 7, 28 Y 90 DÍAS. 


\section{3.-Ensayo de puzolanicidad o ensayo de Frattini. Determinación de la [CaO] y}

\section{[OH-] de la fase líquida en contacto con cada pasta de cemento.}

En este apartado, se mostrarán todos los resultados obtenidos en la evaluación de la actividad puzolánica de todas las adiciones minerales puzolánicas seleccionadas en esta Tesis Doctoral mediante el ensayo de Frattini. Pero no solo, la actividad puzolánica de las citadas adiciones, sino también, y sobre todo la $[\mathrm{CaO}]$ y $\left[\mathrm{OH}^{-}\right]$presente en la disolución de poro de todos los cementos CEM IV/A y CEM IV/B preparados y dosificados en esta investigación. En esta ocasión, las edades escogidas fueron 7 y 28 días.

Por todo ello, se decidió evaluar la [CaO] y [OH-] presente en la disolución de poro, por separado, de cada una de las adiciones minerales mencionadas, con dos de los cementos Portland de referencia, concretamente P1 y PY6, aquellos que tenían su composición mineralógica más dispar, en las proporciones porcentuales de mezcla 70/30, 60/40, 50/50, y 40/60 cemento Portland/adición puzolánica.

\subsection{1.-De los cementos Portland de referencia}

Los resultados obtenidos, mediante el ensayo de Frattini, de la determinación de la evolución de la [CaO] y [OH-] en la disolución de poro en contacto con la pasta de los cementos Portland de referencia con mayor disparidad en su composición mineralógica, P1 y PY6, a las edades de 7 y 28 días se muestran en la Tabla 8-93 y en la Figura 8-50.

Los resultados obtenidos en el ensayo de Frattini, (Figura 8-50), confirmaron que ambos cementos se trataban de cementos Portland puros, puesto que no cumplieron el ensayo de Frattini a ninguna de las edades propuestas (ni lo cumplirán a ninguna edad, como es lógico), ya que todos los puntos del análisis se situaron por encima de la isoterma de solubilidad del $\mathrm{Ca}(\mathrm{OH})_{2}$ en la disolución alcalina. No obstante, del ensayo se pudo obtener la siguiente información acerca de las pastas frescas:

TABLA 8-93.- RESULTADOS DEL GRADO DE SATURACIÓN DE CAO DE LA FASE LÍQUIDA En CONTACTO CON los Cementos de Referencia P1 Y PY6

\begin{tabular}{ccccc}
\hline \multirow{2}{*}{$\begin{array}{c}\text { Cementos } \\
\text { de } \\
\text { referencia }\end{array}$} & \multicolumn{2}{c}{7 días } & \multicolumn{2}{c}{28 días } \\
\cline { 2 - 5 } & {$[\mathrm{CaO}]$} & {$[\mathrm{OH} \cdot]$} & {$[\mathrm{CaO}]$} & {$[\mathrm{OH}-]$} \\
& $\mathrm{mM} \cdot \mathrm{l}^{-1}$ & $\mathrm{mM} \cdot \mathrm{l}^{-1}$ & $\mathrm{mM} \cdot \mathrm{l}^{-1}$ & $\mathrm{mM} \cdot \mathrm{l}^{-1}$ \\
\hline P1 & 6,80 & 71,25 & 6,45 & 78,00 \\
PY6 & 16,55 & 39,45 & 16,10 & 42,00 \\
\hline
\end{tabular}

En negrita, aquellas mezclas que cumplieron el ensayo de 


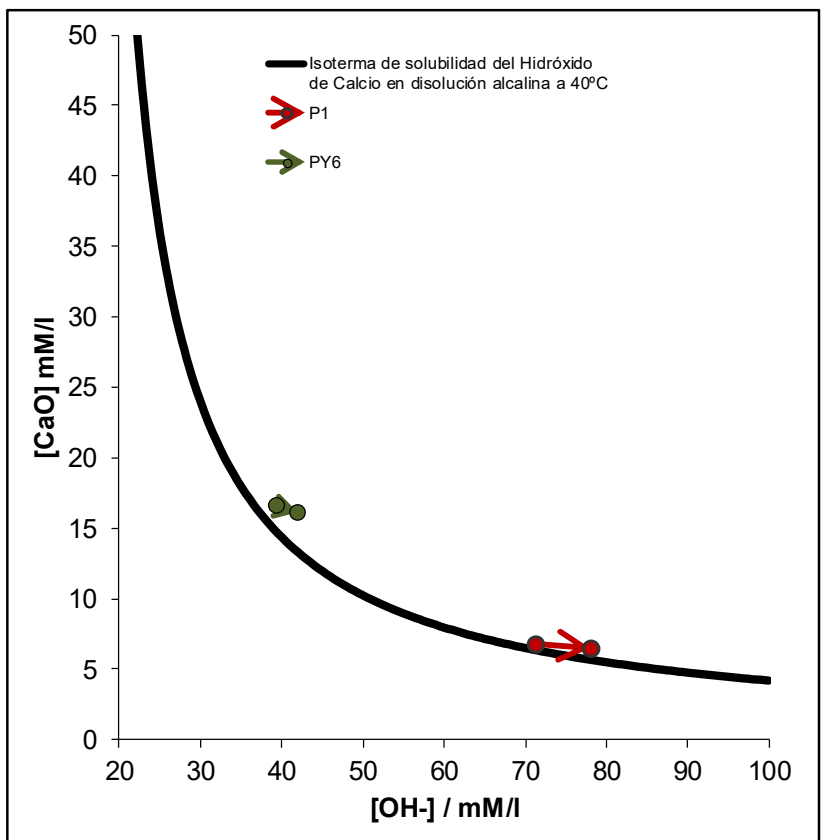

FIGURA 8-50.- REPRESENTACIÓN GRÁFICA DEL GRADO DE SATURACIÓN DEL CAO DE LA FASE LÍQUIDA EN CONTACTO CON LOS CEMENTOS DE REFERENCIA P1 Y PY6

i. Con independencia de la edad de ensayo considerado y a igualdad de todo lo demás, los valores $[\mathrm{CaO}]$ correspondientes a las pastas frescas del cemento Portland PY6 fueron significativamente más altos que para las pastas del cemento Portland P1, mientras que sus valores de $\left[\mathrm{OH}^{-}\right]$fueron más bajos que para el cemento Portland P1. La razón fundamental que explica este fenómeno es la muy diferente composición mineralógica de ambos cementos Portland ${ }^{8}$, resumida en su muy diferente contenido de la fase $\mathrm{C}_{3} \mathrm{~A}$ y de $\mathrm{Na}_{2} \mathrm{O}_{\text {eq }}{ }^{9}$. En consecuencia, la precipitación de portlandita en forma de cristales hexagonales fue mayor en el cemento Portland PY6 durante su hidratación. Por el contrario, se generó una mayor cantidad de $\mathrm{KOH}$ y $\mathrm{NaOH}$ en el caso de las pastas correspondientes al cemento Portland P1, y al ser mucho más solubles y presentar una mayor capacidad de intercambio (Talero, 2005a), permanecieron y aumentaron su concentración en la disolución de poro, conforme avanzó la hidratación de este cemento, especialmente $\mathrm{NaOH}$. Esto se tradujo en un aumento de la alcalinidad y por consiguiente de los valores de $\mathrm{pH}$ la fase líquida (Tabla 8-93).

ii. La [CaO] en la fase líquida durante el transcurso del ensayo, con el aumento de los valores de [OH-] fue parecida para ambos cementos Portland. Este comportamiento vendría a indicar los fenómenos simultáneos que se producen en la pasta fresca de cemento durante a primeras edades de hidratación del cemento Portland y precipitación de portlandita, es decir: la mezcla inicial con agua e hidratación del cemento hasta que la fase del líquida alcanzó el nivel de sobresaturación se reflejaría en los segmentos más o menos paralelos al eje X, y la precipitación

\footnotetext{
${ }^{8}$ Véase el apartado 6.2.1de esta MEMORIA de Tesis Doctoral.

${ }^{9}$ Según la norma ASTM C150, la concentración equivalente de álcalis, $\mathrm{Na}_{2} \mathrm{O}_{e q}$ se expresa: $\mathrm{Na} 2 \mathrm{O}+0,658 \cdot \mathrm{K}_{2} \mathrm{O}$.
} 
concomitante de cristales de portlandita de cada pasta aparecería como los segmentos de pendiente descendente más o menos pronunciada de las dos curvas. Este procedimiento, se iría repitiendo sucesivamente hasta que la fase líquida volviera a estar sobre saturada en portlandita lo que conllevaría una posterior precipitación de más portlandita. Este proceso continuará en ambos cementos Portland hasta que todo el contenido de $C_{3} S$ y $C_{2} S$ se agotara.

En este sentido, en las pastas de cemento nunca se producirá la precipitación de cristales de $\mathrm{NaOH}$ ni de $\mathrm{KOH}$ durante su hidratación, por ello, durante el ensayo, los valores de $\mathrm{pH}$ respectivos de la fase líquida de cada pasta lógicamente irán aumentando. Cuanto mayor sea el valor $\mathrm{Na}_{2} \mathrm{O}(\%)$ y $\mathrm{K}_{2} \mathrm{O}(\%)$ del cemento Portland, mayor será el incremento del valor del pH durante el ensayo. Por todo ello, la fase líquida de la pasta del cemento Portland P1 será mucho básica que la del cemento Portland PY6.

\subsection{2.-De los cementos de mezcla del cemento Portland P1 con cada una de las adiciones}

\section{puzolánicas}

A continuación, se analizaron los resultados obtenidos en el ensayo de Frattini de los cementos de mezcla preparados a partir del cemento Portland P1 y todas las puzolanas, en porcentajesde sustitución en masa del $60 \%, 50 \%, 40 \%$ y, en algunos casos del $30 \%$, a las edadesde 7 y 28 días. Los resultados obtenidos para todas las pastas se muestran en la Tabla 8-94.

Antes de proceder analizar los resultados obtenidos en el ensayo de puzolanicidad de las pastas preparadas, es necesario volver a recordar, que para este ensayo, los resultados obtenidos, a igualdad del cemento Portland utilizado será fiel reflejo, del carácter químico de la puzolana en cuestión, de la actividad puzolánica que sea capaz de desarrollar, y de sus características físicas y distribución de tamaño de sus partículas.

Por ello, del análisis y estudio de los resultados obtenidos en el análisis del grado de saturación de $\mathrm{CaO}$ en la fase líquida en contacto con las pastas frescas de los cementos de mezcla preparados con el cemento Portland P1 y todas las puzolanas utilizadas en esta Tesis Doctoral se puede decir lo siguiente:

a) Respecto a las puzolanas naturales $O, A$ y $C$ :

Los resultados obtenidos en la determinación del grado de saturación de $\mathrm{CaO}$ de la fase líquida en contacto con los cementos de mezcla preparados con el cemento Portland, P1 y las puzolanas naturales, utilizadas en esta Tesis Doctoral se muestran en las Figura 8-51, 8-52, 8-53. De su análisis y estudio de los resultados obtenidos se puede decir lo siguiente:

Por una parte, es muy significativo, que cuando el cemento Portland P1 se mezcló con cada una de las puzolanas, por separado, (Figuras 8-51, 8-52 y 8-53), la [CaO] de su correspondiente fase líquida (ensayadas conforme el ensayo de Frattini a $25^{\circ} \mathrm{C}$ ) disminuyó con respecto a la [CaO] de la fase líquida de la pasta de cemento P1, fenómeno éste que se vio favorecido con el aumento del porcentaje de reemplazo, poniéndose así de manifiesto dos efectos muy importantes para el comportamiento de las pastas de los cementos de mezcla: 
TABLA 8-94.- RESUlTADOS DEL GRADO DE SATURACIÓN DE CAO DE LA FASE LÍQUIDA EN CONTACTO CON LOS CEMENTOS DE MEZCLA PREPARADOS CON EL CEMENTO PORTLAND P1 Y TODAS LAS ADICIONES MINERALES PUZOLÁNICAS

\begin{tabular}{|c|c|c|c|c|}
\hline \multirow{4}{*}{$\begin{array}{l}\text { Cementos de } \\
\text { mezcla }\end{array}$} & \multicolumn{4}{|c|}{ Edad } \\
\hline & \multicolumn{2}{|c|}{7 días } & \multicolumn{2}{|c|}{28 días } \\
\hline & {$[\mathrm{CaO}]$} & {$\left[\mathrm{OH}^{-}\right]$} & {$[\mathrm{CaO}]$} & {$\left[\mathrm{OH}^{-}\right]$} \\
\hline & $\mathrm{mM} \cdot 1^{-1}$ & $\mathrm{mM} \cdot 1^{-1}$ & $\mathrm{mM} \cdot \mathrm{l}^{-1}$ & $\mathrm{mM} \cdot \mathrm{l}^{-1}$ \\
\hline P1 & 39,50 & 40,00 & 34,65 & 42,50 \\
\hline $\mathrm{P} 1 / \mathrm{M} 70 / 30$ & 10,65 & 46,25 & 11,50 & 45,50 \\
\hline P1/M60/40 & 8,65 & 46,25 & 9,15 & 47,75 \\
\hline $\mathrm{P} 1 / \mathrm{M} 50 / 50$ & 6,80 & 45,00 & 6,50 & 46,00 \\
\hline $\mathrm{P} 1 / \mathrm{M} 40 / 60$ & 5,88 & 50,00 & 5,30 & 49,25 \\
\hline $\mathrm{P} 1 / \mathrm{CV} 1070 / 30$ & 9,60 & 52,00 & 5,70 & 66,25 \\
\hline P1/CV1060/40 & 8,40 & 56,00 & 5,40 & 72,75 \\
\hline $\mathrm{P} 1 / \mathrm{CV} 1050 / 50$ & 6,85 & 59,00 & 4,70 & 74,00 \\
\hline P1/CV1040/60 & 6,00 & 63,50 & 4,40 & 73,50 \\
\hline $\mathrm{P} 1 / \mathrm{C} 60 / 40$ & 3,55 & 102,75 & 3,30 & 116,00 \\
\hline $\mathrm{P} 1 / \mathrm{C} 50 / 50$ & 3,43 & 102,50 & 2,90 & 116,00 \\
\hline $\mathrm{P} 1 / \mathrm{C} 40 / 60$ & 3,70 & 108,00 & 2,95 & 116,00 \\
\hline P1/A70/30 & 8,78 & 49,50 & 6,50 & 67,50 \\
\hline P1/A60/40 & 8,20 & 57,50 & 5,90 & 72,50 \\
\hline P1/A50/50 & 7,60 & 56,00 & 4,80 & 77,50 \\
\hline P1/A40/60 & 6,35 & 61,00 & 4,70 & 77,75 \\
\hline P1/CV1960/40 & 7,28 & 57,00 & 5,85 & 65,25 \\
\hline P1/CV1950/50 & 9,25 & 52,50 & 7,38 & 57,00 \\
\hline P1/CV1940/60 & 9,25 & 52,50 & 7,38 & 57,00 \\
\hline $\mathrm{P} 1 / \mathrm{O} 60 / 40$ & 9,10 & 66,25 & 4,78 & 80,00 \\
\hline $\mathrm{P} 1 / \mathrm{O} 50 / 50$ & 8,75 & 56,25 & 5,20 & 77,00 \\
\hline $\mathrm{P} 1 / \mathrm{O} 40 / 60$ & 8,45 & 60,00 & 5,40 & 70,00 \\
\hline
\end{tabular}

En negrita, aquellas mezclas que cumplieron el ensayo de Frattini

1. En primer lugar, un efecto de dilución física del P1. Dicho efecto se verá favorecido con el incremento del porcentaje de reemplazo de adición por cemento, puesto en el sistema habrá menos partículas de este último para hidratarse.

2. Y, en segundo lugar, un efecto de dilución química muy significativo, que conlleva una reducción más o menos significativa de la $\left[\mathrm{OH}^{-}\right]$y del contenido de la portlandita disponible en el medio, a causa fundamentalmente de la actividad puzolánica que debió de haber desarrollado su contenido de $\mathrm{SiO}_{2} \mathrm{O}^{\mathrm{r}}(\%)$, el cual posee la capacidad dual de reaccionar a la par:con los iones $\mathrm{Ca}^{2+}$ de la portlandita, para formar geles C-S-H, más tarde convertidos en 
tobermoritas, ycon los iones $\mathrm{OH}^{-}$de la portlandita, para originar inicialmente grupos silanol, $\mathrm{Si-OH}$, más tarde transformados en ácido silícico, que al reaccionar con más portlandita origina más geles C-S-H.

Esta premisa se cumplió para todas las puzolanas naturales, excepto para el caso de la puzolana canaria $C$, a causa de su elevado contenido de elementos alcalinos que posee ésta última, y especialmente potasio, $\mathrm{K}^{+}$, dado que la misma posee además un elevado contenido de cloruros (véase en la Tabla 6-6) por la ya referida ubicación geográfica de su cantera originaria, ypor otra, a la "capacidad de cambio catiónico" (Talero (1986); Talero (1991); Talero $(1992,2005)) q u e$ dicha muestra de puzolana natural ha generado también a la par con el transcurso del ensayo.

Con lo que todo ello se tradujo finalmente, en una mayor basicidad de la fase líquida tras su hidratación conforme se incrementó el porcentaje de reemplazo de la misma en la mezcla. Lo que deja de ser una indudable ventaja a la hora de proteger las armaduras de su corrosión electroquímica por ataque de cloruros (del rocío marino especialmente en este caso) y/o por carbonatación.

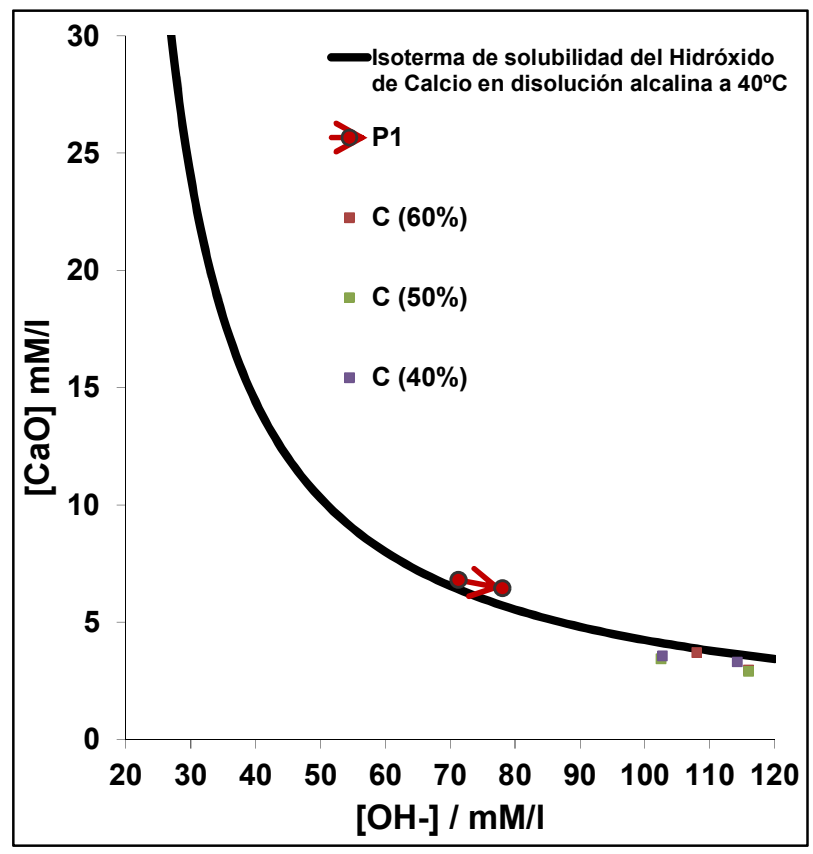

FIGURA 8-51.- REPRESENTACIÓN GRÁFICA DEL GRADO DE SATURACIÓN DE CAO DE LA FASE LÍQUIDA EN CONTACTO CON LOS CEMENTOS DE MEZCLA DEL CEMENTO PORTLAND P1 CON LA PUZOLANA C.

Además, respecto a estos cementos de mezcla, preparados con cada puzolana natural española, en proporción porcentual 70/30, 60/40, 50/50 y 40/60 (Figs. 8-51, 8-52 y 8-53). Una vez más se ha logrado demostrar que, aumentando la cantidad de reemplazo de cemento Portland P1 por puzolana natural, se aumenta la actividad puzolánica correspondiente en todos los 
sentidos: cantidad (mayor) y tiempo necesario para cumplirla (menor), como se puede apreciar en las Figs. 8-51, 8-52 y 8-53. Puesto que todas y cada una de las correspondientes mezclas P1/"Z" cumplieron el ensayo de Frattini, ya que el sistema "pasta de cemento parcialmente hidratada $>$ fase líquida", evolucionó más aún hacia la zona de subsaturación con el transcurso del ensayo, debido a la actividad puzolánica desarrollada por sus respectivos contenidos de puzolana. En cambio, el del cemento Portland matriz P1 no, lógicamente, por todo lo contrario. De aquí que su sistema "pasta de cemento parcialmente hidratada $<$ fase líquida" se ubicara, por el contrario, y como debía, dentro de la zona de sobresaturación. Y de principio a fin del ensayo, y aún posteriormente si se hubiera determinado, lo que no se consideró necesario.

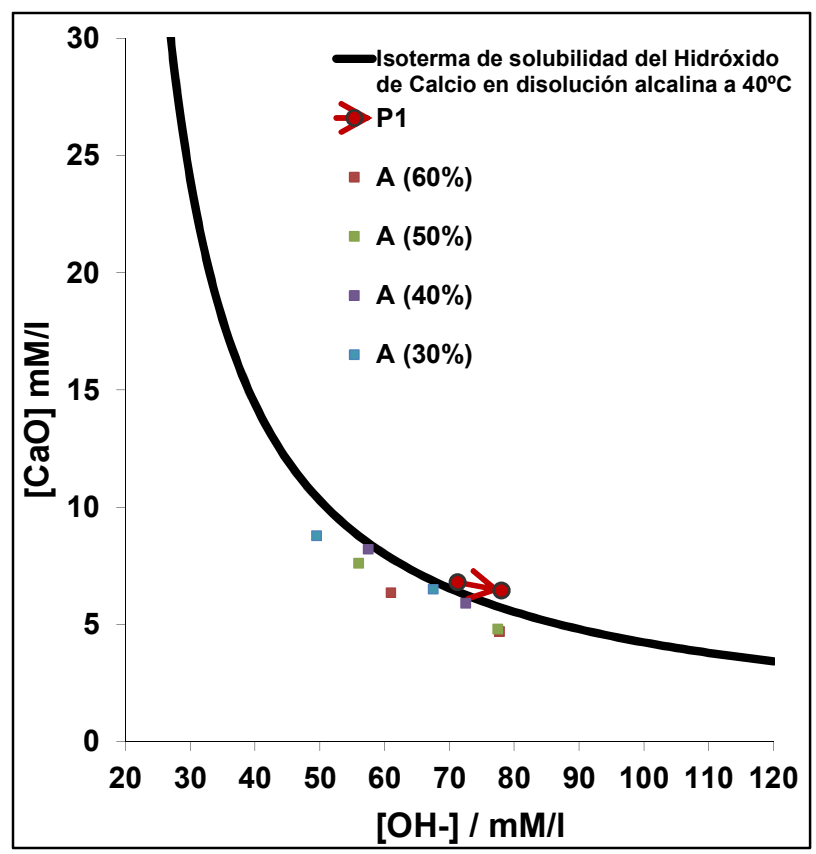

FIGURA 8-52.- REPRESENTACIÓN GRÁFICA DEL GRADO DE SATURACIÓN DEL CAO DE LA FASE LÍQUIDA EN CONTACTO CON LOS CEMENTOS DE MEZCLA DEL CEMENTO PORTLAND P1 CON LA PUZOLANA A.

Asimismo, se pudo identificar también perfectamente, que a pesar de cumplir el ensayo de Frattini, la puzolana $\mathrm{O}$, fue la puzolana que con más dificultad lo hizo, puesto que para el caso concreto de sus mezclas correspondiente P1/O 60/40 y P1/O 50/50 lo cumplió a 28 días tan solo. De ello, se dedujo, por tanto, que la cantidad adicionada no fue la suficiente como para que esta puzolana natural O hubiera podido haber desarrollado actividad puzolánica suficiente, con tan sólo 40\% Y 50\% de reemplazo, para cumplir el ensayo de Frattini a edad de 7 días. Lo que se pudo subsanar, no obstante, sin más que aumentar la cantidad de esta presente en el cemento de mezcla (60\% de reemplazo), el cual, entonces, lo pudo cumplir, incluso a la edad de 7 días (véase la Fig.

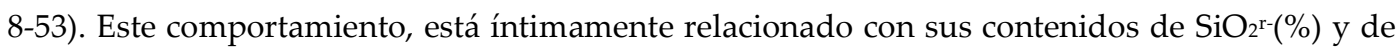
$\mathrm{Al}_{2} \mathrm{O}_{3}{ }^{\mathrm{r}}(\%)$, que son, en realidad, las fases que desarrollan la actividad puzolánica de esta adición mineral natural o de cualquier otra, aunque, como se explicó en los apartados 6.3.4. y 6.3.5., sus 
respectivos contenidos de $\mathrm{SiO}_{2}{ }^{\mathrm{r}-}$ y $\mathrm{Al}_{2} \mathrm{O}_{3}{ }^{\mathrm{r}-}$ fueron $40,70 \%$ y 5,37\% (véanse las Tablas 6-8 y 6-9). Por lo que su probada actividad puzolánica debe de estar justificada por los correspondientes contenidos de estos factores hidráulicos.

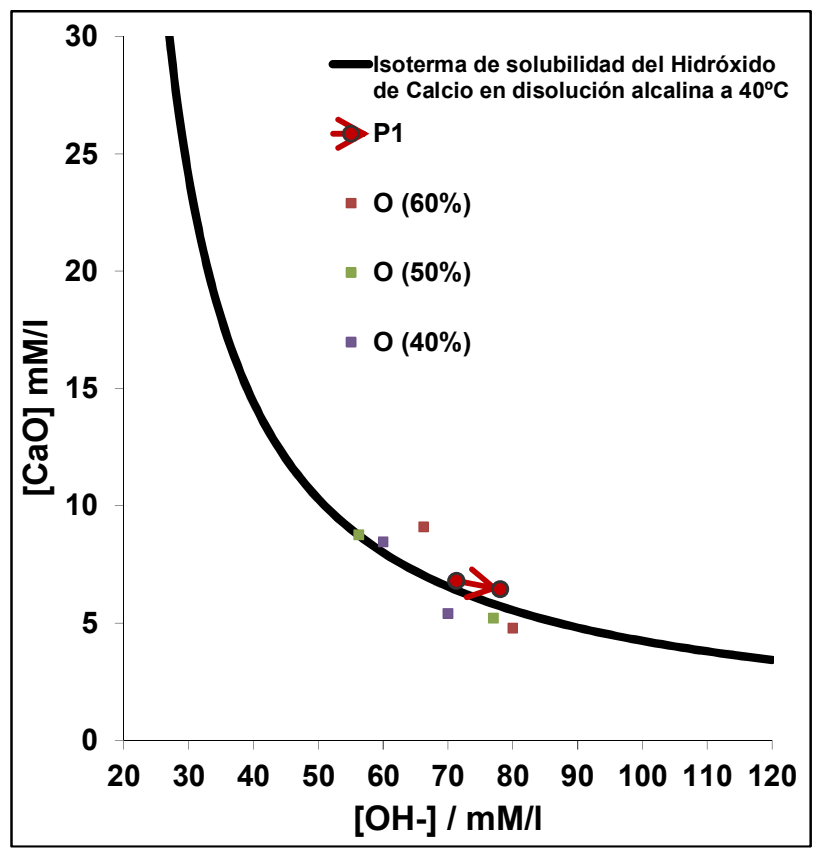

FIGURA 8-53.- REPRESENTACIÓN GRÁFICA DEL GRADO DE SATURACIÓN DEL CAO DE LA FASE LÍQUIDA EN CONTACTO CON LOS CEMENTOS DE MEZCLA DEL CEMENTO PORTLAND P1 CON LA PUZOLANA O.

En resumen y como conclusión, se podría decir que conforme se incrementa el porcentaje de adición puzolánica en las pastas de cemento en consumo de $\mathrm{Ca}(\mathrm{OH})_{2}$ es más siginificativo, y lógicamente, directamente relacionado con el contenido de $\mathrm{SiO}_{2} \mathrm{r}-(\%)$ y de $\mathrm{Al}_{2} \mathrm{O}_{3}{ }^{\mathrm{r}}(\%)$ de cada una de las puzolanas. Por ello, queda demostrado que en un cemento es altamente adicionado conforme se incrementa el contenido de puzolana existirá menos portlandita disponible para desarrollar la acción puzolánica, hasta el momento en el que el nivel de sustitución sea tal como para que la fase líquida de la pasta de cemento llegue a un nivel de subsaturación tran extremo que no exista portlandita suficiente en el medio como para la formación de geles CSH y aluminatos de calcio hidratados de origen puzolana. Como consecuencia, a este fenómeno se producirá un déficit significativo en el desarrollo de resistencias mecánicas de los cementos de mezcla altamente adicionados, como se ha podido demostrar en el apartado 8.2 de la Memoria de esta Tesis Doctoral. Este comportamiento indeseable de los cementos de mezcla propuestos se producirá en un porcentaje de sustitución distinto, en función contenido de $\mathrm{SiO}_{2} \mathrm{r}^{\mathrm{r}}(\%)$ y de $\mathrm{Al}_{2} \mathrm{O}_{3}{ }^{\mathrm{r}}$ (\%) de la puzolana utilizada, y con mayor o menor rapidez en función también del estado físico en el que se encuentren sus respectivos factores hidráulicos.

b) Respecto a las cenizas volantes CV10 y CV19: 
Los resultados obtenidos en la determinación del grado de saturación de $\mathrm{CaO}$ de la fase líquida en contacto con los cementos de mezcla preparados con el cemento Portland, P1 y las cenizas volantes, utilizadas en esta Tesis Doctoral se muestran en las Figuras 8-54 y 8-55. De su análisis y estudio de los resultados obtenidos se puede decir lo siguiente:

Por una parte, se repitió el comportamiento general mostrado con cada una de las adiciones puzolánicas, es decir, que cuando el cemento Portland P1 se mezcló con cada una de las dos cenizas volantes, por separado, (Figuras 8-54 y 8-55), la [CaO] de su correspondiente fase líquida volvió a disminuir con respecto a la $[\mathrm{CaO}]$ de la fase líquida de la pasta de cemento P1, fenómeno que, nuevamente, se vio favorecido con el aumento del porcentaje de reemplazo, poniéndose así de manifiesto también los dos efectos para el comportamiento de las pastas de los cementos de mezcla:

1. En primer lugar, el efecto de dilución física del P1, favorecido con el incremento del porcentaje de reemplazo de adición por cemento, puesto en el sistema habrá menos partículas de este último para hidratarse.

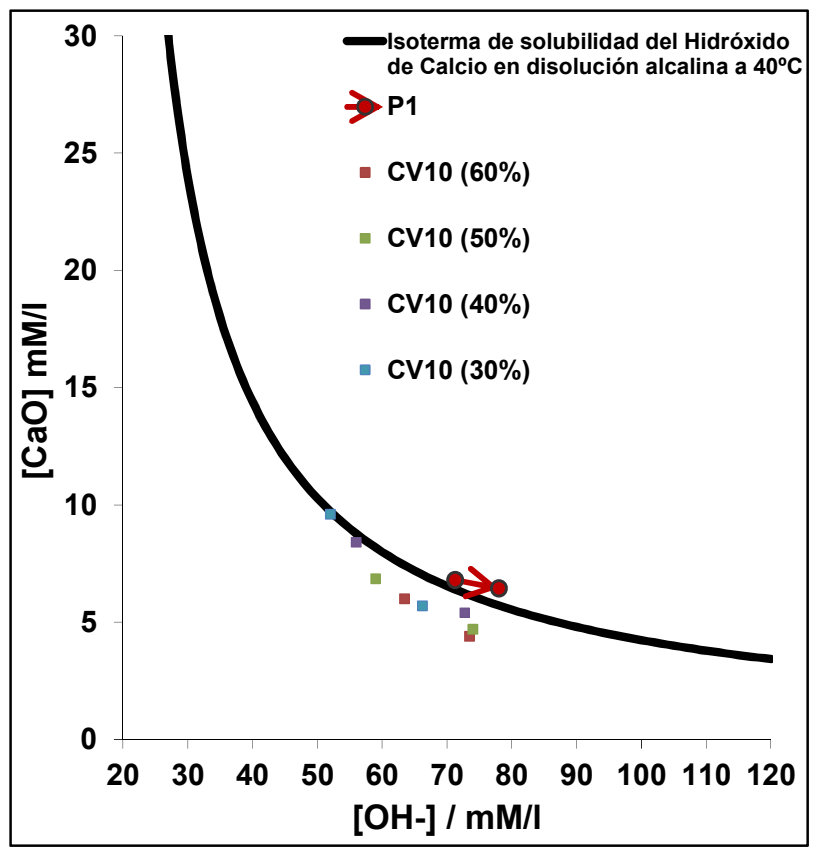

FIGURA 8-54.- REPRESENTACIÓN GRÁFICA DEL GRADO DE SATURACIÓN DEL CAO DE LA FASE LÍQUIDA EN CONTACTO CON LOS CEMENTOS DE MEZCLA DEL CEMENTO PORTLAND P1 CON LA CENIZA VOLANTE CV10.

2. Y, en segundo lugar, el efecto de dilución química, que conlleva una reducción más o menos significativa de la $\left[\mathrm{OH}^{-}\right]$y del contenido de la portlandita disponible en el medio, a causa fundamentalmente de la actividad puzolánica desarrollada por la $\mathrm{SiO}_{2} \mathrm{Or}-(\%)$ de las dos cenizas, la cual posee, como se ha citado con anterioridad, la capacidad dual de reaccionar a la par:con los iones $\mathrm{Ca}^{2+}$ de la portlandita, para formar geles C-S-H, más tarde convertidos en tobermoritas, ycon los iones $\mathrm{OH}^{-}$de la portlandita, para originar inicialmente grupos silanol, Si-OH, más tarde transformados en ácido silícico, que al reaccionar con más 
portlandita origina más geles C-S-H.

Con respecto a estos cementos de mezcla, preparados con cada ceniza volante, en proporción porcentual 70/30, 60/40, 50/50 y 40/60 (Figs. 8-54 y 8-55). Una vez más se ha logrado demostrar que, aumentando la cantidad de reemplazo de cemento Portland P1 por ceniza volante, se aumenta la actividad puzolánica correspondiente en todos los sentidos: cantidad (mayor) y tiempo necesario para cumplirla (menor), como se puede apreciar en las Figs. 8-54 y 855. Puesto que todas y cada una de las correspondientes mezclas P1/"Z" cumplieron el ensayo de Frattini, ya que el sistema "pasta de cemento parcialmente hidratada $\diamond$ fase líquida", evolucionó más aún hacia la zona de subsaturación con el transcurso del ensayo, debido a la actividad puzolánica desarrollada por sus respectivos contenidos de ceniza volante. En cambio, el del cemento Portland matriz P1 no, lógicamente, por todo lo contrario. De aquí que su sistema "pasta de cemento parcialmente hidratada <> fase líquida" se ubicara, por el contrario, y como debía, dentro de la zona de sobresaturación.

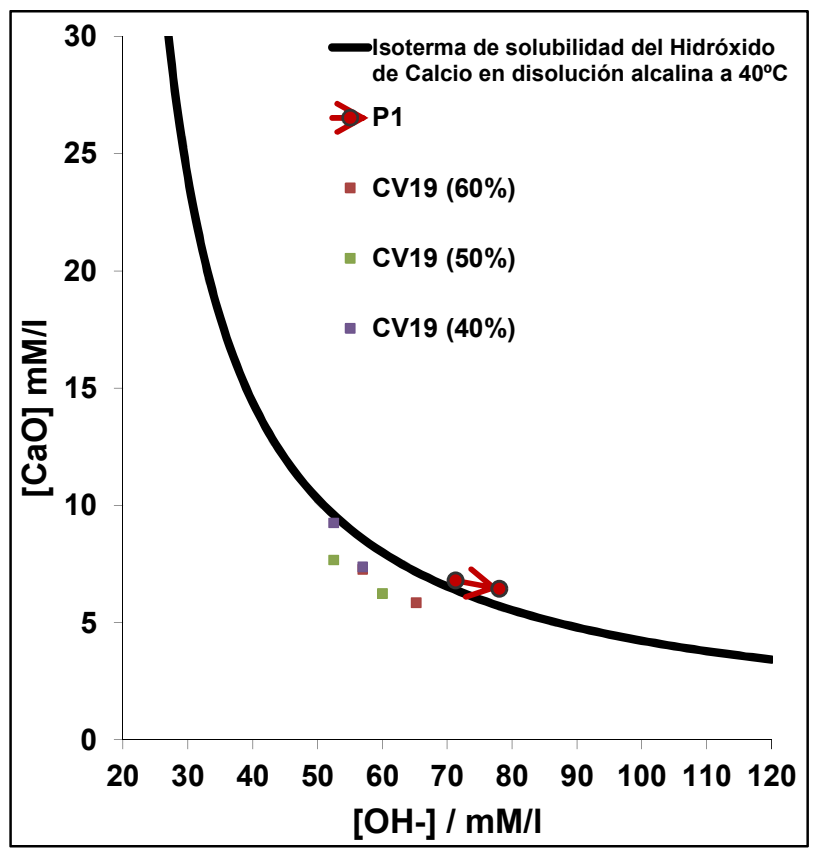

FIGURA 8-55.- REPRESENTACIÓN GRÁFICA DEL GRADO DE SATURACIÓN DEL CAO DE LA FASE LÍQUIDA EN CONTACTO CON LOS CEMENTOS DE MEZCLA DEL CEMENTO PORTLAND P1 CON LA CENIZA VOLANTE CV19.

Asimismo, se pudo identificar también perfectamente, que, a pesar del carácter químico opuesto de las dos cenizas, alumínico-silícico para el caso de la CV10 y silícico-férrico-alumínicopara la ceniza CV19, las dos cumplieron el ensayo de Frattini de manera similar, en tiempo y forma, ya que la evolución de la $[\mathrm{CaO}]$ y de $\left[\mathrm{OH}^{-}\right]$a 7 y 28 días fue equivalente. Este fenómeno común para las dos cenizas tiene su explicación en la velocidad con la que desarrollan su actividad puzolánica las cenizas, que era mucho más lenta, ya que el estado físico del contenido dede $\mathrm{SiO}_{2}{ }^{\mathrm{r}}$ - 
(\%) y de $\mathrm{Al}_{2} \mathrm{O}_{3}{ }^{\mathrm{r}}(\%)$ de cada una de las dos cenizas volantes, es eminentemente vítreo, por ello no es extraño que cumplimiento del ensayo de Frattini, por las dos cenizas se produzca de una forma más lenta. No obstante, la cantidad adicionada de ceniza en todos los casos fue la suficiente como para cumplir el ensayo de Frattini a edad de 7 días.

En resumen y como conclusión, se podría decir que conforme se incrementa el porcentaje de ceniza volante en las pastas de cemento en consumo de $\mathrm{Ca}(\mathrm{OH})_{2}$ es más siginificativo, y lógicamente, directamente relacionado con el contenido de $\mathrm{SiO}_{2}{ }^{\mathrm{r}}-(\%)$ y de $\mathrm{Al}_{2} \mathrm{O}_{3}{ }^{\mathrm{r}}-(\%)$ de cada una de las cenizas. Por ello, queda demostrado nuevamente que en un cemento altamente adicionado conforme se incrementa el contenido de ceniza en la matriz cementante existirá menos portlandita disponible para desarrollar la acción puzolánica, hasta el momento en el que el nivel de sustitución sea tal como para que la fase líquida de la pasta de cemento llegue a un nivel de subsaturación tran extremo que no exista portlandita suficiente en el medio para la formación de nuevos geles $\mathrm{CSH}$ y aluminatos de calcio hidratados de origen ceniza volante. Como consecuencia, a este fenómeno se producirá un déficit significativo en el desarrollo de resistencias mecánicas de los cementos de mezcla altamente adicionados, como se ha podido demostrar en el apartado 8.2 de la Memoria de esta Tesis Doctoral. Este comportamiento indeseable de los cementos de mezcla propuestos se producirá en un porcentaje de sustitución distinto, en función contenido de $\mathrm{SiO}_{2}{ }^{\mathrm{r}}-(\%)$ y de $\mathrm{Al}_{2} \mathrm{O}_{3}{ }^{\mathrm{r}}$ - $\%$ ) de la ceniza volante utilizada, y con mayor o menor rapidez en función también del estado físico en el que se encuentren sus respectivos factores hidráulicos.

d) Respecto almetacaolín $M$ :

Los resultados obtenidos en la determinación del grado de saturación de $\mathrm{CaO}$ de la fase líquida en contacto con los cementos de mezcla preparados con el cemento Portland, P1 y el metacaolín utilizado en esta Tesis Doctoral se muestra en la Figura 8-56. Del análisis y estudio de los resultados obtenidos se puede decir lo siguiente:

Por una parte, se repitió el comportamiento general mostrado con cada una de las adiciones puzolánicas, es decir, que cuando el cemento Portland P1 se mezcló con el metacaolín (Figura 8-56), la [CaO] de su correspondiente fase líquida volvió a disminuir con respecto a la [CaO] de la fase líquida de la pasta de cemento P1, pero esta vez corregido y aumentado a causa de la elevada, rápida y temprana actividad puzolánica del metacaolín en cuestión. Fenómeno que, nuevamente, se vio favorecido con el aumento del porcentaje de reemplazo, poniéndose así de manifiesto también los dos efectos para el comportamiento de las pastas de los cementos de mezcla:

1. En primer lugar, el efecto de dilución física del P1, favorecido con el incremento del porcentaje de reemplazo de adición por cemento, puesto en el sistema habrá menos partículas de este último para hidratarse.

2. Y, en segundo lugar, el efecto de dilución química, que conlleva una reducción muy significativa de la [OH-] y del contenido de la portlandita disponible en el medio (Fig. 8-56), a causa fundamentalmente de la actividad puzolánica desarrollada por elevado contenido de $\mathrm{SiO}_{2} \mathrm{Or}-(\%)$ del metacolín, el cual posee, como se ha citado con anterioridad, la capacidad 
dual de reaccionar a la par: con los iones $\mathrm{Ca}^{2+}$ de la portlandita y con los iones $\mathrm{OH}^{-}$de la portlandita.

Con respecto a estos cementos de mezcla, preparados con el metacaolín, en proporción porcentual 70/30, 60/40, 50/50 y 40/60 (Figs. 8-56). Una vez más se ha logrado demostrar, y esta vez con más razón todavía, que, aumentando la cantidad de reemplazo de cemento Portland P1 por metacaolín, se aumenta la actividad puzolánica correspondiente en todos los sentidos: cantidad (mayor) y tiempo necesario para cumplirla (menor), como se puede apreciar en las Fig. 8-56. Puesto que todas y cada una de las correspondientes mezclas P1/"Z" cumplieron el ensayo de Frattini sin lugar a dudas, ya que el sistema "pasta de cemento parcialmente hidratada $\diamond$ fase líquida", evolucionó más aún hacia la zona de subsaturación con el transcurso del ensayo, debido a la elevada, rápida y temprana actividad puzolánica del metacaolín. En cambio, el del cemento Portland matriz P1 no, lógicamente, por todo lo contrario. De aquí que su sistema "pasta de cemento parcialmente hidratada $<>$ fase líquida" se ubicara, por el contrario, y como debía, dentro de la zona de sobresaturación.

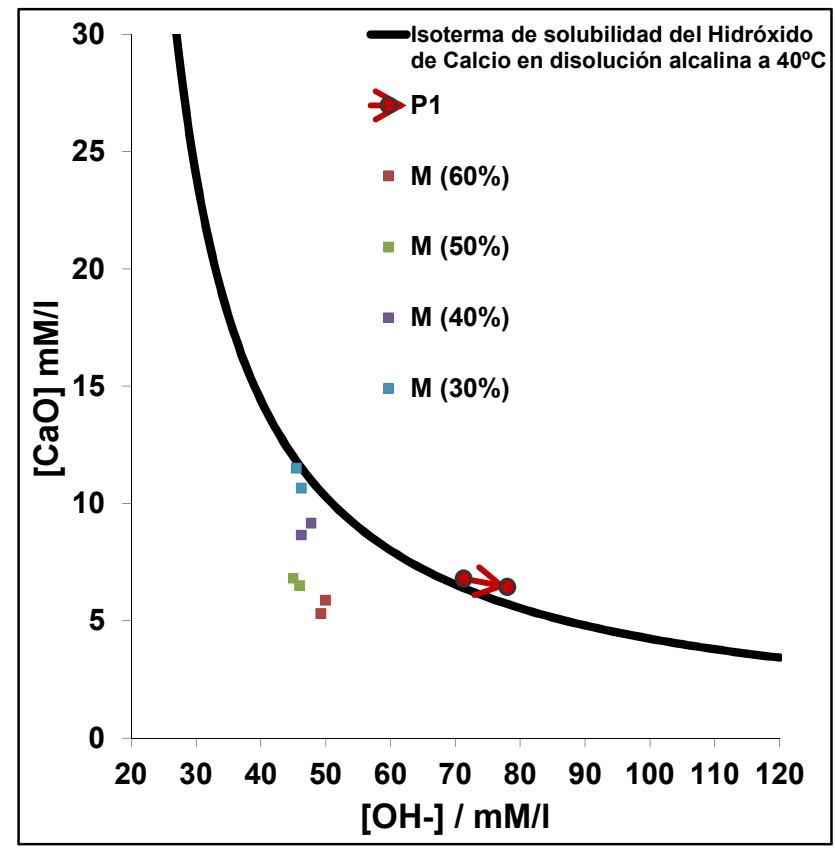

FIGURA 8-56.- REPRESENTACIÓN GRÁFICA DEL GRADO DE SATURACIÓN DEL CAO DE LA FASE LÍQUIDA EN CONTACTO CON LOS CEMENTOS DE MEZCLA DEL CEMENTO PORTLAND P1 CON EL METACAOLÍN M.

Asimismo, se pudo confirmar la elevada, rápida y temprana actividad puzolánica desarrollada por esta adición, por el fenómeno de descenso pronunciado en la [CaO] para todos los cementos de mezcla, ya que el estado físico del contenido de su alúmina reactiva era completamente amorfo, por lo que tuvo una influencia clara desde el comienzo de la hidratación del cemento Portland P1 (Pedrajas, 2016). La evolución de la [CaO] y de [OH-] a 7 y 28 días fue 
muy significativa en este sentido. Este fenómeno tiene su explicación en la velocidad con la que desarrolla su actividad puzolánica elmetacaolín, que era mucho más rápida, ya que el estado físico del contenido dede $\mathrm{SiO}_{2}{ }^{\mathrm{r}-}(\%)$ y de $\mathrm{Al}_{2} \mathrm{O}_{3}{ }^{\mathrm{r}}(\%)$ del metacaolín, es eminentemente amorfo, por ello no es extraño que cumplimiento del ensayo de Frattini, por el metacaolín se produzca de una forma más rápida y elevada.

En resumen y como conclusión, se podría decir que conforme se incrementa el porcentaje de metacaolín en las pastas de cemento en consumo de $\mathrm{Ca}(\mathrm{OH})_{2}$ desciende significativamente. Comportamiento éste, directamente relacionado con el contenido de $\mathrm{SiO}_{2}{ }^{\mathrm{r}}-(\%)$ y de $\mathrm{Al}_{2} \mathrm{O}_{3}{ }^{\mathrm{r}}$ - $\left.\%\right)$ del metacaolín. Por ello, queda demostrado nuevamente que en un cemento altamente adicionado conforme se incrementa el contenido de metacaolín en la matriz cementante existirá menos portlandita disponible para desarrollar la acción puzolánica, hasta el momento en el que el nivel de sustitución sea tal como para que la fase líquida de la pasta de cemento llegue a un nivel de subsaturación tran extremo que no exista portlandita suficiente en el medio para la formación de nuevos geles $\mathrm{CSH}$ y aluminatos de calcio hidratados de origen puzolana. Como consecuencia, a este fenómeno se producirá un déficit significativo en el desarrollo de resistencias mecánicas de los cementos de mezcla altamente adicionados, como se ha podido demostrar en el apartado 8.2 de la Memoria de esta Tesis Doctoral. Este comportamiento indeseable de los cementos de mezcla propuestos se producirá en un porcentaje de sustitución distinto, en función contenido de $\mathrm{SiO}_{2}{ }^{\mathrm{r}-}$ (\%) y de $\mathrm{Al}_{2} \mathrm{O}_{3} \mathrm{r}-(\%)$ de cada puzolana utilizada, y con mayor o menor rapidez en función también del estado físico en el que se encuentren sus respectivos factores hidráulicos.

\section{4.-Determinación de la velocidad de penetración de la carbonatación en probetas de mortero normalizado. Interrelación con el comportamiento mecánico-resistente.}

Se obtuvieron los resultados del ensayo de determinación de la profundidad de carbonatación en probetas de mortero tipo EN 196-1, identifcando por ello el frente de carbonatación de cada una de las probetas aplicando el ensayo colorimétrico de la fenolftaleína.

Hay que tener en cuenta que los resultados así obtenidos se corresponden con un proceso de carbonatación acelerada y no podría utilizarse en modelos de carbonatación natural a no ser que se disponga de la correlación de las condiciones del ensayo con las de carbonatación natural. Su empleo inmediato sería solo a efectos comparativos en las condiciones del ensayo.

La interrelación de las condiciones de carbonatación con el comportamiento mecánicoresistente de los cementos de mezcla escogidos, P1/M 40/60 y P1/O 50/50, se realizó a través del método de ensayo especificado en la norma UNE EN 196-1, determinando, por ello: su resistencia mecánica a flexotracción, y su resistencia mecánica a compresión. Las razonespor las cuales fueron seleccionados estos cementos de mezcla, y no otros, para el ensayo de carbonatación acelerada son las siguientes:

1. En primer lugar, se seleccionaron las puzolanas $\mathrm{M} \mathrm{y} \mathrm{O}$ por ser aquellas con un carácter 
químico totalmente opuesto a causa de su muy distintos contenidos ${ }^{10}$ de $\mathrm{Al}_{2} \mathrm{O}_{3}{ }^{\mathrm{r}-}$ y $\mathrm{SiO}_{2}{ }^{\mathrm{r}-}$ . Un carácter químico eminentemente aluminico para la primera de ellas, y silícicoférrico-alumínico para el caso de la última.

2. En segundo lugar, se escogieron los cementos de mezcla P1/M 40/60 y P1/0 50/50 por ser aquellos que, contando con las puzolanas $\mathrm{M}$ y $\mathrm{O}$ en su composición ya no cumplieron con los requerimientos mecánico-resistentes que se le exigían, es decir: una R.M.C. mínima de $175 \mathrm{Kg} / \mathrm{cm}^{2}$. Requerimiento éste, que superaron cuando se sustituyó en cantidad adecuada parte de la puzolana en cuestión por $\mathrm{CH}$.

\subsection{1.-De los cementos de mezcla P1/M 40/60 y P1/M 40/60+CH}

\subsubsection{1.- Resultados obtenidos en la medida del perfil de carbonatación.}

En primer lugar, se analizaron los resultados obtenidos en la medida del perfil de carbonatación de las probetas de mortero EN 196-1 de los cementos de mezcla correspondientes a la puzolana M P1/M 40/60 y P1/M 40/60+CH, curadas en dos ambientes distintos durante 28 días (laboratorio y $\mathrm{H}_{2} \mathrm{O}$ ) antes de ser sometidos al proceso de carbonatación acelerada de $20 \%$ de $\mathrm{CO}_{2}$. Los resultados obtenidos para todas las pastas se muestran en la Tabla 8-95 y en la Figs. 8$57,8-58,8-59$ y $8-60$.

TABLA 8-95.- RESUlTADOS DE LA MEDIDA DEL PERFIL DE CARBONATACIÓN DE LOS CEMENTOS DE MEZCLA PREPARADOS CON EL CEMENTO PORTLAND P1 Y LA PUZOLANA M EN PROPORCIÓN 40/60.

\begin{tabular}{|c|c|c|c|c|c|c|c|c|c|c|c|c|}
\hline \multicolumn{13}{|c|}{ PUZOLANA M } \\
\hline \multirow[b]{2}{*}{$\begin{array}{l}\text { Edad } \\
\text { (días) }\end{array}$} & \multicolumn{3}{|c|}{ P1/M 40/60 (28d Lab) } & \multicolumn{3}{|c|}{$\mathrm{P} 1 / \mathrm{M} 40 / 60\left(28 \mathrm{~d} \mathrm{H}_{2} \mathrm{O}\right)$} & \multicolumn{3}{|c|}{$\mathrm{P} 1 / \mathrm{M} 40 / 60+\mathrm{CH}(28 \mathrm{~d} \mathrm{Lab})$} & \multicolumn{3}{|c|}{$\mathrm{P} 1 / \mathrm{M} 40 / 60+\mathrm{CH}\left(28 \mathrm{~d} \mathrm{H}_{2} \mathrm{O}\right)$} \\
\hline & $\begin{array}{c}\text { Superior } \\
(\mathrm{mm})\end{array}$ & $\begin{array}{c}\text { Izquierdo } \\
(\mathrm{mm})\end{array}$ & $\begin{array}{c}\text { Derecho } \\
(\mathrm{mm})\end{array}$ & $\begin{array}{c}\text { Superior } \\
(\mathrm{mm})\end{array}$ & $\begin{array}{c}\text { Izquierdo } \\
(\mathrm{mm})\end{array}$ & $\begin{array}{c}\text { Derecho } \\
(\mathrm{mm})\end{array}$ & $\begin{array}{c}\text { Superior } \\
(\mathrm{mm})\end{array}$ & $\begin{array}{c}\text { Izquierdo } \\
(\mathrm{mm})\end{array}$ & $\begin{array}{c}\text { Derecho } \\
(\mathrm{mm})\end{array}$ & $\begin{array}{c}\text { Superior } \\
(\mathrm{mm})\end{array}$ & $\begin{array}{c}\text { Izquierdo } \\
(\mathrm{mm})\end{array}$ & $\begin{array}{c}\text { Derecho } \\
(\mathrm{mm})\end{array}$ \\
\hline 14 & \multicolumn{3}{|c|}{ CARBONATADO } & 1,2 & 1,7 & 1,8 & 1,3 & 1,4 & 1,3 & 0,9 & 1,1 & 1,2 \\
\hline 28 & \multicolumn{3}{|c|}{ CARBONATADO } & \multicolumn{3}{|c|}{ CARBONATADO } & \multicolumn{3}{|c|}{ CARBONATADO } & \multicolumn{3}{|c|}{ CARBONATADO } \\
\hline 180 & \multicolumn{3}{|c|}{ CARBONATADO } & \multicolumn{3}{|c|}{ CARBONATADO } & \multicolumn{3}{|c|}{ CARBONATADO } & \multicolumn{3}{|c|}{ CARBONATADO } \\
\hline
\end{tabular}

Antes de proceder analizar los resultados obtenidos en la determinación del perfil de carbonatación de cada una de las probetas de mortero, es necesario recordar que los resultados obtenidos en este ensayo, a igualdad del cemento Portland utilizado será fiel reflejo, del carácter químico de la puzolana en cuestión, de la actividad puzolánica que sea capaz de desarrollar, y de sus características físicas y distribución de tamaño de sus partículas.

Analizando los resultados obtenidos, se confirman los resultados obtenidos mediante el

\footnotetext{
${ }^{10}$ Véase el apartado 6.3.4. y 6.3.5. de esta MEMORIA de Tesis Doctoral.
} 
ensayo de Frattini ${ }^{11}$. La fase líquida de la pasta cementante de todos los cementos de mezcla doficados se encuentraban en un estado de subsaturación en portlandita. Por ello, no se produjo por secado, después de la etapa de curado, precipitación alguna de portlandita, y sí, en cambio, su reacción química con el $\mathrm{CO}_{2}$ del aire disuelto para formar bicarbonato, $\mathrm{HCO}_{3}$, y carbonato, $\mathrm{CO}_{3}{ }^{2-}$, al ser el $\mathrm{pH}$ de su disolución muy inferior al de la disolución sobresaturada de portlandita (aprox. de 12,3 a 12,5). Como consecuencia de este fenómeno, el fenómenod e carbonatación negativa fue progresando a través de la red de poros hacia el interior de las probetas con la edad del ensayo.

Este comportamiento confirma que a media que se incrementa el porcentaje de sustitución de clínker Portland por adiciones puzolánicas, el sistema cementante es cada vez más susceptible al ataque químico por carbonatación. Ya que, tras haberse desarrollado las reacciones puzolánicas con la portlandita por parte del metacolín M, la cantidad de $\mathrm{Ca}(\mathrm{OH})_{2}$ remanente en la disolución de poro de los morteros ensayados descendió considerablemente.

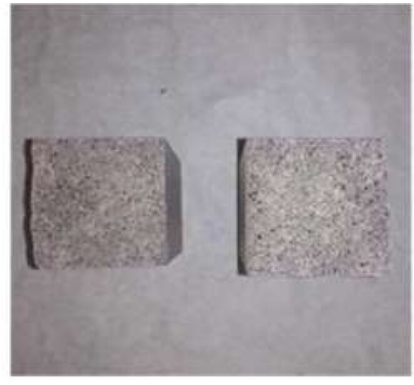

14 días

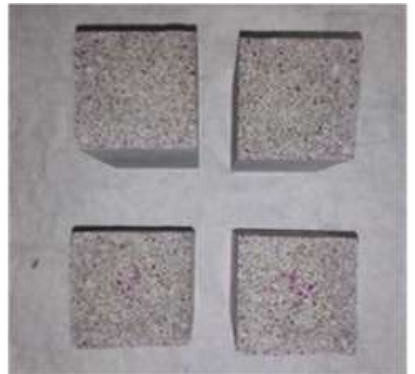

28 días

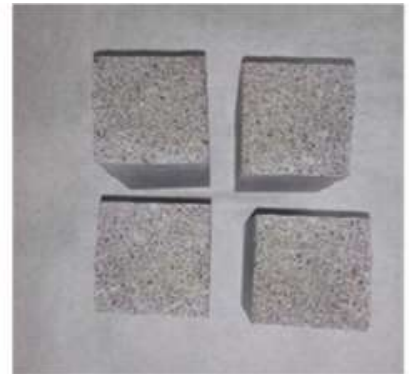

60 días

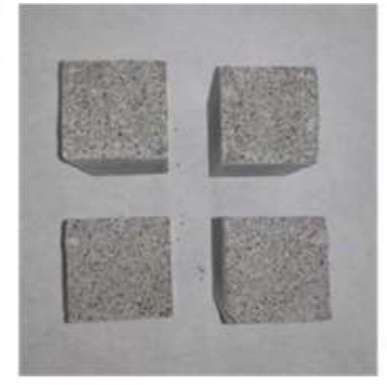

120 días

FIGURA 8-57.- EVOLUCIÓN DEL PERFIL DE CARBONATACIÓN EN LAS PROBETAS CORRESPONDIENTES AL CEMENTO DE MEZCLA P1/M 40/60 CURADAS DURANTE 28 DÍAS EN AMBIENTE DEL LABORATORIO.

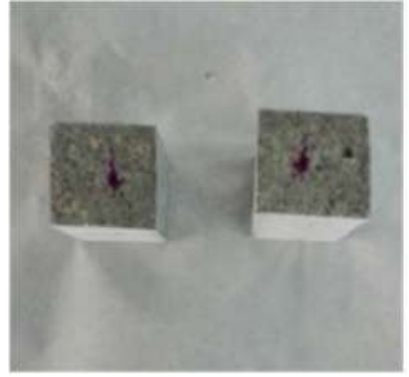

14 días

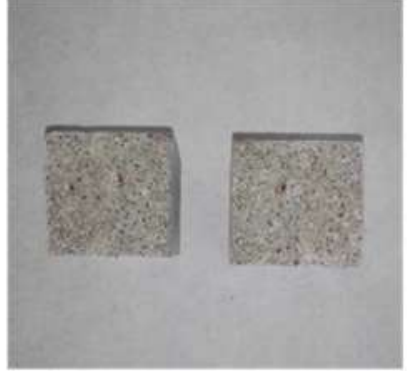

28 días

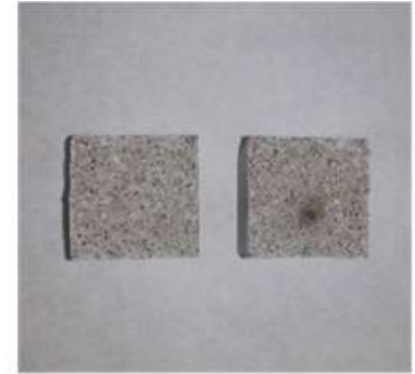

60 días

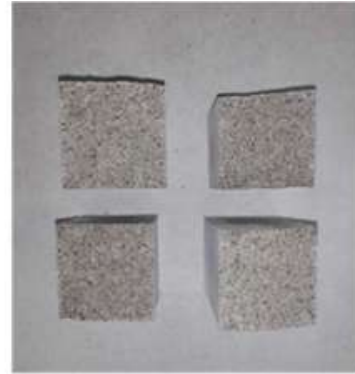

120 días

Figura 8-58.- EVOLUCIÓN DEL PERFIL DE CARBONATACIÓN EN LAS PROBETAS CORRESPONDIENTES AL CEMENTO DE MEZCLA P1/M 40/60 CURADAS DURANTE 28 DÍAS BAJO AGUA.

Asímismo, las probetas que fueron curadas bajo agua durante 28 días (Figura 8-658y Figura

\footnotetext{
${ }^{11}$ Véase el apartado 8.3. de esta MEMORIA de Tesis Doctoral.
} 
8-60) presentaron una mayor resistencia a la penetración del $\mathrm{CO}_{2}$ a través de su estructura porosa. El esmerado proceso de curado hídrico bajo agua de las probetas de mortero tras su desenmoldado, provocó un incremento en la velocidad y en el grado de hidratación de los morteros que contenían esta cantidad tan elevada de puzolana M. De aquí la importancia del curado hídrico suficiente para dificultar el fenómeno indeseable de la carbonatación.

En este sentido, también llama la atención que aquellas probetas que contenían un aporte adicional de $\mathrm{CH}$ (Figura 8-59 y Figura 8-60) presentaron una mayor resistencia a la penetración del $\mathrm{CO}_{2}$, en comparación con las probetas que no contenían esta cantidad adicional de cal apagada.Puesto que estos cementos de mezcla, de su correspondiente "familia",fueron aquellosque mayor cantidad de portlandita pudo generar y poner a disposición de la fase líquida de cada probeta de mortero con el transcurso del ensayo. O dicho de otro modo, tanto más cantidad de portlandita pudieron generar y poner a disposición de la fase líquida de dicho cemento Puzolánico 40/60 cuanto más progresó el ataque por carbonatación. Y no tanto porque la pudiera generar al ser un cemento altamente adicionado, sino por el aporte adicional de cal apagada.

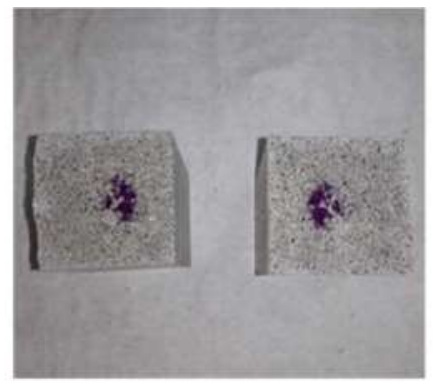

14 días

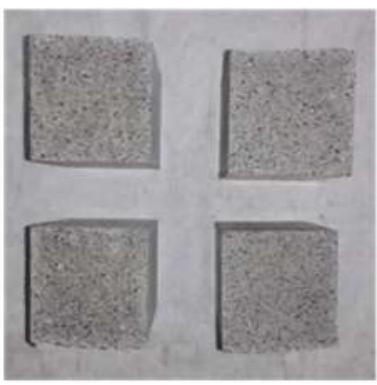

28 días

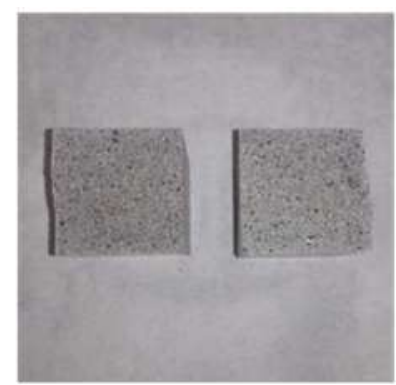

60 días

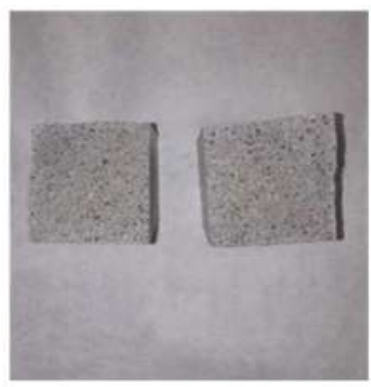

120 días

FIGURA 8-59.- EVOLUCIÓN DEL PERFIL DE CARBONATACIÓN EN LAS PROBETAS CORRESPONDIENTES AL CEMENTO DE MEZCLA P1/M 40/60+CH CURADAS DURANTE 28 DÍAS EN AMBIENTE DE LABORATORIO.

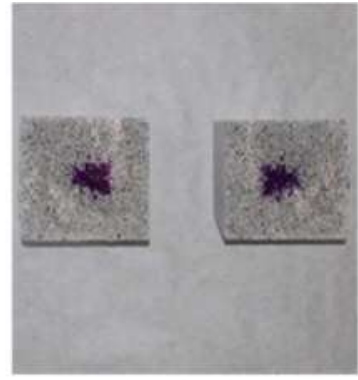

14 días

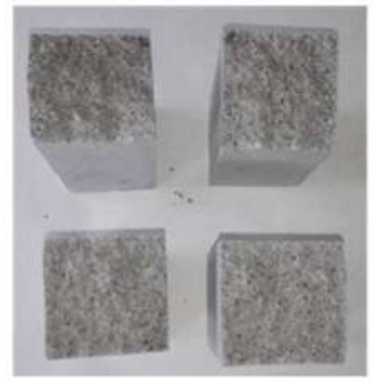

28 días

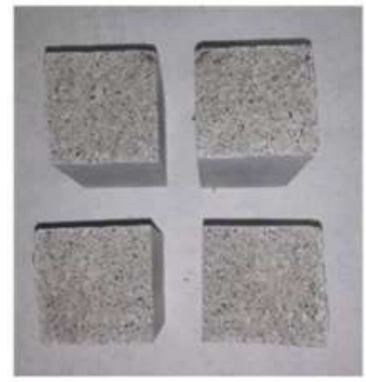

60 días

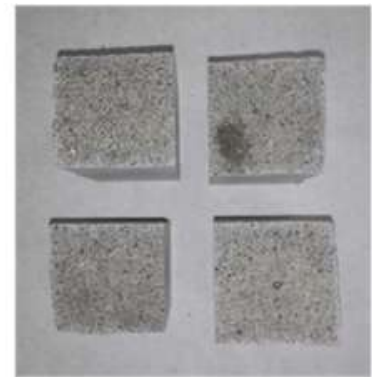

120 días

FIGURA 8-60.- EVOLUCIÓN DEL PERFIL DE CARBONATACIÓN EN LAS PROBETAS CORRESPONDIENTES AL CEMENTO DE MEZCLA P1/M 40/60+CH CURADAS DURANTE 28 DÍAS BAJO AGUA. 


\subsubsection{2.- Resultados obtenidos en la determinación de las RMF y RMC.}

De la determinación de las resistencias mecánicas a flexotracción, RMF, y a compresión, RMC, cuyos valores se recogen en la Tabla 8-96 y en la Figs. 8-61 y 8-62, se ha de decir, que ambos parámetros mecánicos absolutos son los más importantes por significativos para la caracterización mecánico-resistente de los cementos comunes. Y del análisis y estudio, discusión e interpretación de los valores obtenidos tras someter a estas probetas al proceso de carbonatación acelerada, se podrá correlacionar con los resultados de la medida del perfil de penetración de $\mathrm{CO}_{2}$.

Es aproximación interesante que se emplea habitualmente para predecir la carbonatación, se relaciona la profundidad de la carbonatación con la resistencia mecánica a compresión, dado que esta última propiedad es la que se determina con más frecuencia. De hecho, la resistencia a compresión y la porosidad del hormigón resultante dependen de la composición y de la conservación del hormigón. Es ampliamente conocido que la carbonatación del hormigón disminuye cuando su resistencia mecánica a compresión aumenta.

TABLA 8-96.- RESULTADOS DE RMFY RMC DE LOS CEMENTOS DE MEZCLA P1/M 40/60 SOMETIDOS AL ENSAYO DE CARBONATACIÓN ACELERADA. EDADES: 14, 28, 60, 120 Y 180 DÍAS.

\begin{tabular}{|c|c|c|c|c|c|c|c|c|}
\hline \multicolumn{9}{|c|}{ PUZOLANA M } \\
\hline \multirow{2}{*}{$\begin{array}{l}\text { Edad } \\
\text { (días) }\end{array}$} & \multicolumn{2}{|c|}{$\mathrm{P} 1 / \mathrm{M} 40 / 60$ (28d Lab) } & \multicolumn{2}{|c|}{$\mathrm{P} 1 / \mathrm{M} 40 / 60\left(28 \mathrm{~d} \mathrm{H}_{2} \mathrm{O}\right)$} & \multicolumn{2}{|c|}{$\mathrm{P} 1 / \mathrm{M} 40 / 60+\mathrm{CH}(28 \mathrm{~d} \mathrm{Lab})$} & \multicolumn{2}{|c|}{$\mathrm{P} 1 / \mathrm{M} 40 / 60+\mathrm{CH}\left(28 \mathrm{~d} \mathrm{H}_{2} \mathrm{O}\right)$} \\
\hline & $\begin{array}{l}\text { R.M.F. } \\
(\mathrm{MPa})\end{array}$ & $\begin{array}{c}\text { R.M.C. } \\
\text { (MPa) }\end{array}$ & $\begin{array}{l}\text { R.M.F. } \\
(\mathrm{MPa})\end{array}$ & $\begin{array}{c}\text { R.M.C. } \\
\text { (MPa) }\end{array}$ & $\begin{array}{l}\text { R.M.F. } \\
(\mathrm{MPa})\end{array}$ & $\begin{array}{c}\text { R.M.C. } \\
(\mathrm{MPa})\end{array}$ & $\begin{array}{l}\text { R.M.F. } \\
(\mathrm{MPa})\end{array}$ & $\begin{array}{l}\text { R.M.C. } \\
\text { (MPa) }\end{array}$ \\
\hline 14 & 5,40 & 20,13 & 5,18 & 33,83 & 5,74 & 24,75 & 4,89 & 36,70 \\
\hline 28 & 4,93 & 22,71 & 5,16 & 34,37 & 5,24 & 26,18 & 5,32 & 38,50 \\
\hline 60 & 4,86 & 20,34 & 5,10 & 32,90 & 4,86 & 26,96 & 5,29 & 39,12 \\
\hline 120 & 4,12 & 18,60 & 4,55 & 31,63 & 4,50 & 25,11 & 4,78 & 35,87 \\
\hline 180 & 3,40 & 15,90 & 4,04 & 29,70 & 3,98 & 21,17 & 4,29 & 33,64 \\
\hline
\end{tabular}

Así en primer lugar, todos los cementos de mezcla ensayados descendieron en su valor de RMC y RMF conforme avanzó el ensayo. No obstante, la evolución de esa pérdida fue distinta en función del ambiente de curado de las probetas y de la adción o no de cal apagada. Véanse la Tabla 8-96 y las Figs. 8-61 y 8-62:

- Las probetas curadas bajo agua durante 28 días superaron el valor del correspondiente mortero normalizado que fue curado en ambiente de laboratorio. Como se ha citado con anterioridad, este curado bajo agua provocó un incremento en la velocidad y en el grado de hidratación de los morteros que contenían esta cantidad tan elevada de puzolana M, provocando por ello una mayor resitencia de penetración del $\mathrm{CO} 2$ hacia el interior de las probetas, disminuyendo por ello la velocidad de incremento del perfil de carbonatación.

- Las probetas que contenían el aporte adicional de cal apagada tuvieron en descenso más tardío de sus correspondientes RMF y RMC respecto a aquellas probetas a las que no les adicionaron el hidróxido de calcio. La razón de este comportamiento lo podemos encontrar en la mayor cantidad de portlandita que pudieron poner a disposición de la fase líquida de dichos 
cementos de mezcla ante el proceso de carbonatación acelerada.

Debido a la carbonatación, se acaba desembocando finalmente en una pérdida gradual y notable de cohesión, adherencia y resistencias mecánicas de las probetas de mortero sometidos a este ensayo, con pérdida incluso de material o su simple desmoronamiento manual.

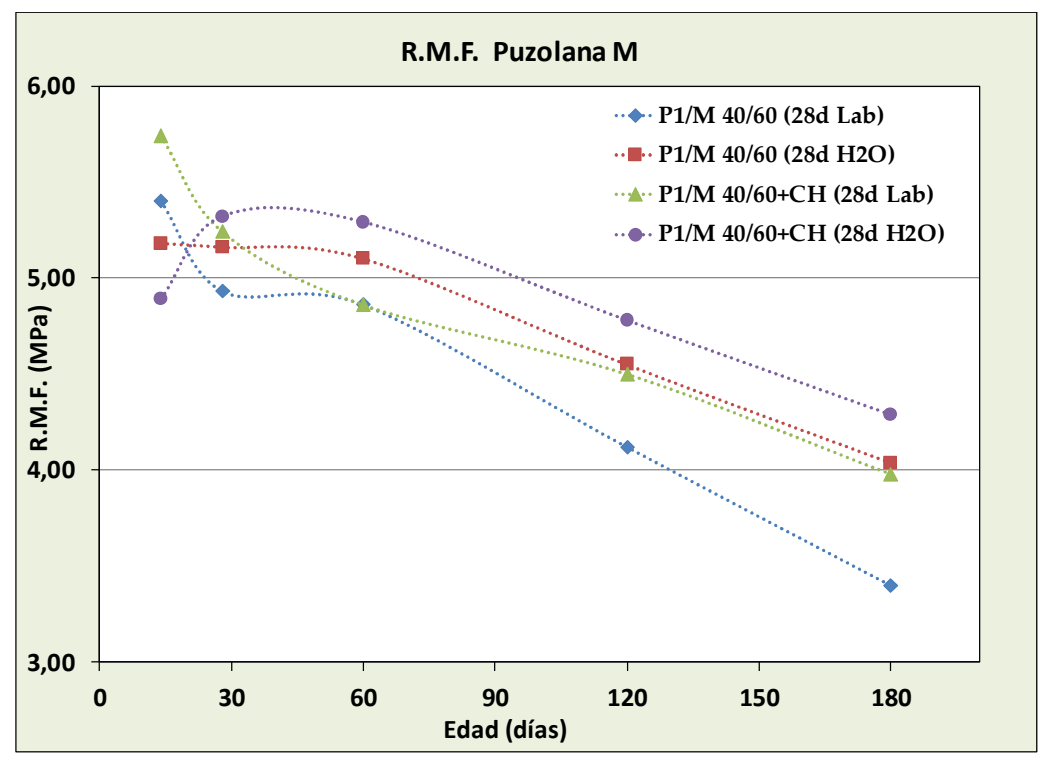

FIGURA 8-61.- RESULTADOS DE RMF DE LOS CEMENTOS DE LOS CEMENTOS DE MEZCLA P1/M 40/60 SOMETIDOS AL ENSAYO DE CARBONATACIÓN ACELERADA. EDADES: 14, 28, 60,120 Y 180 DÍAS.

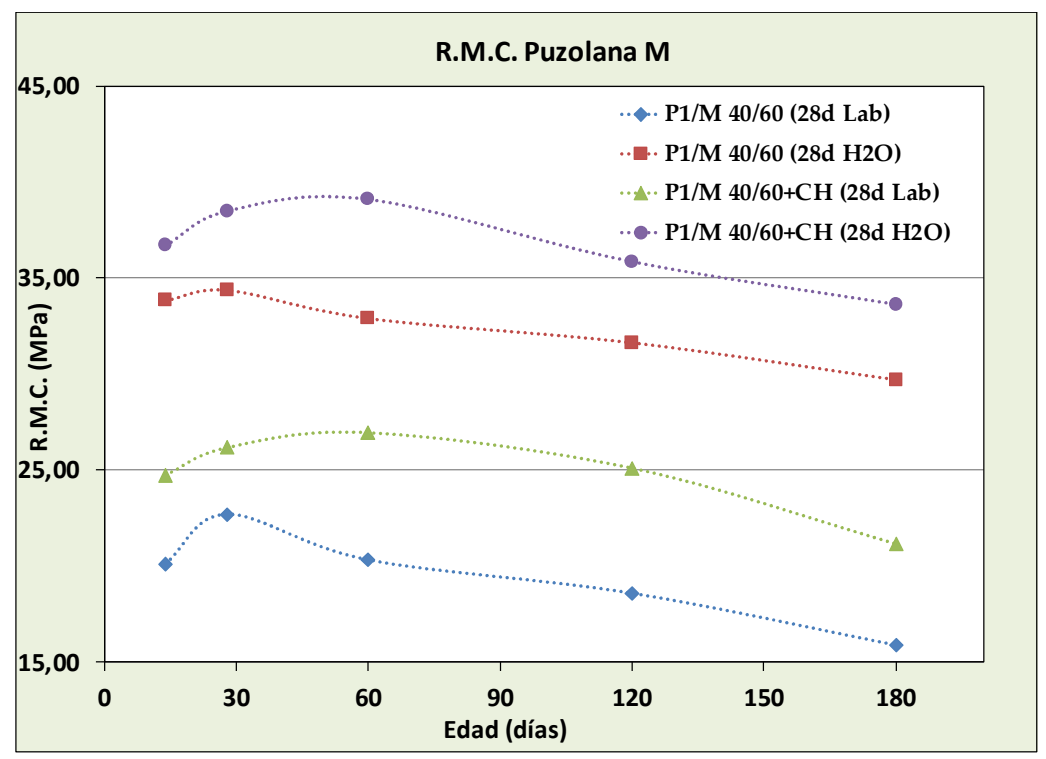

FIGURA 8-62.- RESULTADOS DE RMC DE LOS CEMENTOS DE LOS CEMENTOS DE MEZCLA P1/M 40/60 SOMETIDOS AL ENSAYO DE CARBONATACIÓN ACELERADA. EDADES: 14, 28, 60,120 Y 180 DÍAS. 
Todos estos comportamientos mostrados por las probetas de mortero del cemento de mezcla P1/M 40/60 sometidos al ensayo de carbonatación acelerada vienen a significar la pérdida continua de resistencias mecánicas de las mismas con la edad de ensayo, a causa del elevado porcentaje de sustitución de clínker por metacaolín M, 60\% nada menos. Este descenso de las propiedades mecánico resistentes de los morteros está directamente relacionado con la cantidad de portlandita disponible en la fase líquida de estos cementos. Asímismo, la característica puzolánica del metacolín M fue muy considerable, ya que la mayor cantidad de esta adición mineral en los cementos de mezcla provocó un descenso muy pronunciado en el nivel de portlandita disponible en la fase líquida, como así lo mostró el ensayo de Frattini ${ }^{12}$, a por acusa de su alta, rápida y temprana actividad puzolánica, hasta el punto de poder llegar a consumir la mayor parte de la reserva portlandítica dispobile en la fase líquida de los morteros ensayados.

\subsection{2.-De los cementos de mezcla P1/O 50/50 y P1/O 50/50+CH}

\subsubsection{1.- Resultados obtenidos en la medida del perfil de carbonatación}

En primer lugar, se analizaron los resultados obtenidos en la medida del perfil de carbonatación de las probetas de mortero EN 196-1 de los cementos de mezcla correspondientes a la puzolana $\mathrm{O}, \mathrm{P} 1 / \mathrm{O} 50 / 50$ y $\mathrm{P} 1 / \mathrm{O} 50 / 50+\mathrm{CH}$, curadas en dos ambientes distintos durante 28 días (laboratorio y $\mathrm{H}_{2} \mathrm{O}$ ) antes de ser sometidos al proceso de carbonatación acelerada de $20 \%$ de $\mathrm{CO}_{2}$. Los resultados obtenidos para todas las pastas se muestran en la Tabla 8-97 y en las Figs. 8-63, 8$64,8-65$ y $8-66$.

TABLA 8-97.- RESUltADOS DE LA MEDIDA DEL PERFIL DE CARBONATACIÓN DE LOS CEMENTOS DE MEZCLA PREPARADOS CON EL CEMENTO PORTLAND P1 Y LA PUZOLANA O EN PROPORCIÓN 50/50.

\begin{tabular}{|c|c|c|c|c|c|c|c|c|c|c|c|c|}
\hline \multicolumn{13}{|c|}{ PUZOLANA O } \\
\hline $\begin{array}{l}\text { Edad } \\
\text { (días) }\end{array}$ & $\begin{array}{l}\text { Superior } \\
(\mathrm{mm})\end{array}$ & $\begin{array}{l}\text { Izquierdo } \\
(\mathrm{mm})\end{array}$ & $\begin{array}{c}\text { Derecho } \\
(\mathrm{mm})\end{array}$ & $\begin{array}{l}\text { Superior } \\
(\mathrm{mm})\end{array}$ & $\begin{array}{l}\text { Izquierdo } \\
(\mathrm{mm})\end{array}$ & $\begin{array}{c}\text { Derecho } \\
(\mathrm{mm})\end{array}$ & $\begin{array}{l}\text { Superior } \\
(\mathrm{mm})\end{array}$ & $\begin{array}{l}\text { Izquierdo } \\
(\mathrm{mm})\end{array}$ & $\begin{array}{c}\text { Derecho } \\
(\mathrm{mm})\end{array}$ & $\begin{array}{c}\text { Superior } \\
(\mathrm{mm})\end{array}$ & $\begin{array}{l}\text { Izquierdo } \\
(\mathrm{mm})\end{array}$ & $\begin{array}{c}\text { Derecho } \\
(\mathrm{mm})\end{array}$ \\
\hline 14 & 0,9 & 1,1 & 1,2 & 0,4 & 0,7 & 0,8 & 0,4 & 0,9 & 0,9 & 0,8 & 0,8 & 0,8 \\
\hline 28 & \multicolumn{3}{|c|}{ CARBONATADO } & \multicolumn{3}{|c|}{ CARBONATADO } & \multicolumn{3}{|c|}{ CARBONATADO } & 1,0 & 1,2 & 1,4 \\
\hline 120 & \multicolumn{3}{|c|}{ CARBONATADO } & \multicolumn{3}{|c|}{ CARBONATADO } & \multicolumn{3}{|c|}{ CARBONATADO } & \multicolumn{3}{|c|}{ CARBONATADO } \\
\hline 180 & \multicolumn{3}{|c|}{ CARBONATADO } & \multicolumn{3}{|c|}{ CARBONATADO } & \multicolumn{3}{|c|}{ CARBONATADO } & \multicolumn{3}{|c|}{ CARBONATADO } \\
\hline
\end{tabular}

Antes de proceder analizar los resultados obtenidos en la determinación del perfil de carbonatación de cada una de las probetas de mortero, es necesario recordar que los resultados obtenidos en este ensayo, a igualdad del cemento Portland utilizado fue reflejo, del carácter químico de la puzolana en cuestión, en esta ocasión la puzolana $\mathrm{O}$, y de la actividad puzolánica que sea capaz de desarrollar, además de sus características físicas y distribución de tamaño de

\footnotetext{
${ }^{12}$ Véase el apartado 8.3. de esta MEMORIA de Tesis Doctoral.
} 
sus partículas. Además, es necesario señalar que los cementos de mezcla preparados en esta ocasión contenían un $10 \%$ más de clínker a causa de de que con el porcentaje de sustitución elegido para el caso del metacaolín M, no se consiguieron las resistencias mecánicas exigidas para estos cementos de $175 \mathrm{~kg} / \mathrm{cm}^{2}$. Por ello, el comportamiento de sus probetas frente al ensayo de carbonatación será distinto, y con casi total seguridad mejor, por su mayor contenido de clínker capaz de poner una mayor cantidad de portlandita en la fase líquida.

Analizando los resultados obtenidos, se confirma el comportamiento mostrado mediante el ensayo de Frattini ${ }^{13}$. La fase líquida de la pasta cementante de todos los cementos de mezcla doficados se encuentraban en un estado de subsaturación en portlandita en el momento de someterlos al ensayo de carbonatación acelerada. Por ello, no se produjo por secado, después de la etapa de curado, precipitación alguna de portlandita, y sí, en cambio, su reacción química con el $\mathrm{CO}_{2}$ del aire disuelto para formar bicarbonato, $\mathrm{HCO}_{3}^{-}$, y carbonato, $\mathrm{CO}_{3}^{2-}$, al ser el $\mathrm{pH}$ de su disolución muy inferior al de la disolución sobresaturada de portlandita (aprox. de 12,3 a 12,5). Como consecuencia de este fenómeno, la carbonatación negativa fue progresando a través de la red de poros hacia el interior de las probetas con la edad del ensayo, aunque de una forma distinta al tener una mayor cantidad de clínker en sus correspondientes cementos de mezcla.

Este comportamiento confirma que a media que se incrementa el porcentaje de sustitución de clínker Portland por adiciones puzolánicas, el sistema cementante es cada vez más susceptible al ataque químico por carbonatación. Ya que, tras haberse desarrollado las reacciones puzolánicas con la portlandita por parte de la puzolana $\mathrm{O}$, la cantidad de $\mathrm{Ca}(\mathrm{OH})_{2}$ remanente en la disolución de poro de los morteros ensayados descendió considerablemente.

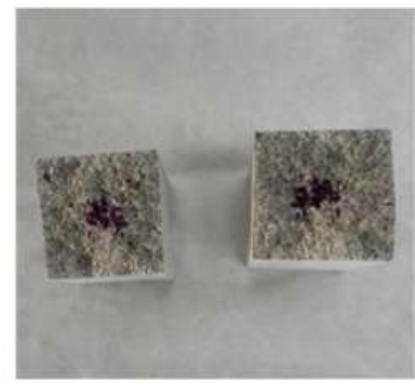

14 días

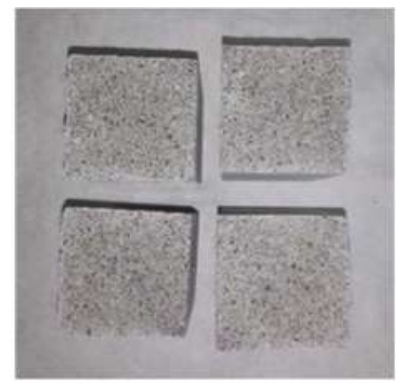

28 días

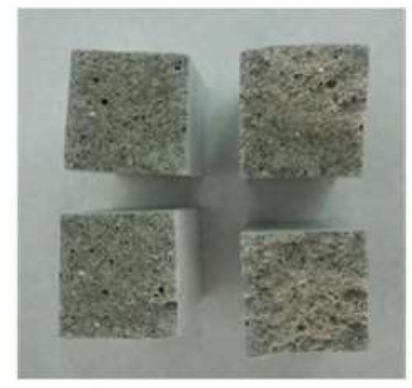

60 días

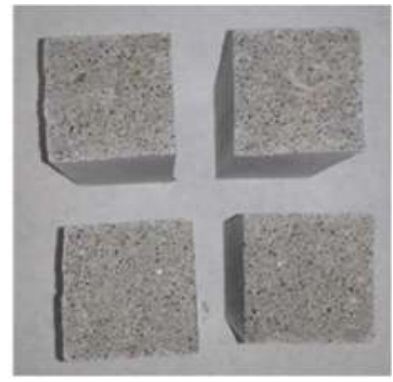

120 días

FIGURA 8-63.- EVOLUCIÓN DEL PERFIL DE CARBONATACIÓN EN LAS PROBETAS CORRESPONDIENTES AL CEMENTO DE MEZCLA P1/O50/50 CURADAS DURANTE 28 DÍAS EN AMBIENTE DEL LABORATORIO.

Asímismo, las probetas que fueron curadas bajo agua durante 28 días (Figura 8-64 y Figura 8-66) presentaron una mayor resistencia a la penetración del $\mathrm{CO}_{2}$ a través de su estructura porosa. El esmerado proceso de curado hídrico bajo agua de las probetas de mortero tras su desenmoldado, provocó un incremento en la velocidad y en el grado de hidratación de los morteros que contenían esta cantidad tan elevada de puzolana O. De aquí la importancia del

${ }^{13}$ Véase el apartado 8.3. de esta MEMORIA de Tesis Doctoral. 
curado hídrico suficiente para dificultar el fenómeno indeseable de la carbonatación.

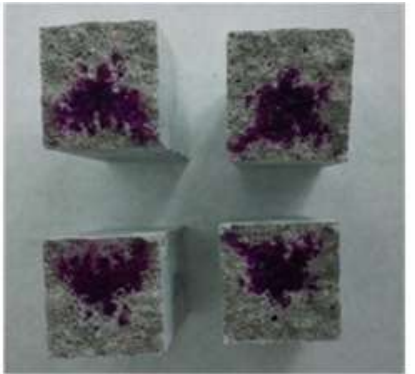

14 días

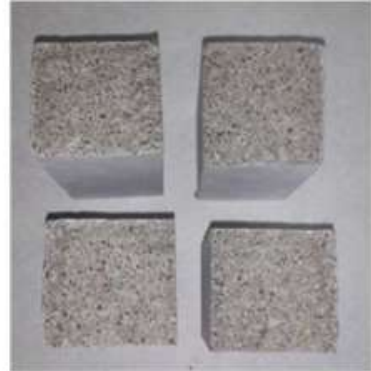

28 días

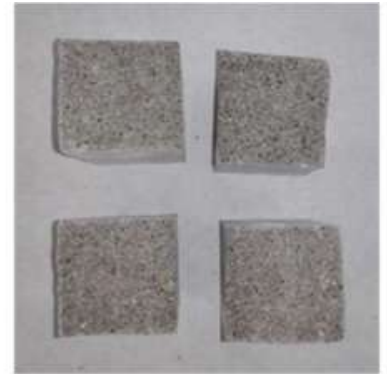

60 días

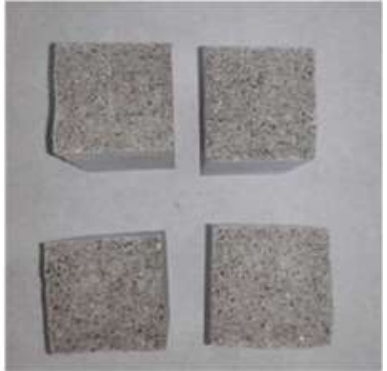

120 días

FIGURA 8-64.- EVOLUCIÓN DEL PERFIL DE CARBONATACIÓN EN LAS PROBETAS CORRESPONDIENTES AL CEMENTO DE MEZCLA P1/O50/50 CURADAS DURANTE 28 DÍAS BAJO AGUA.

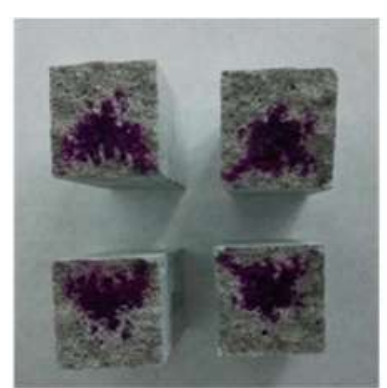

14 días

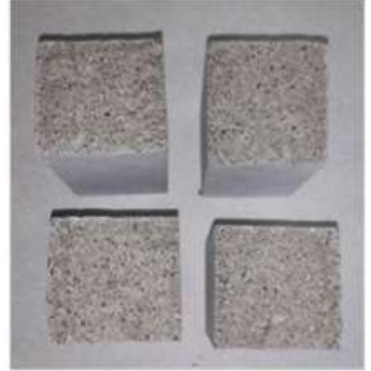

28 días

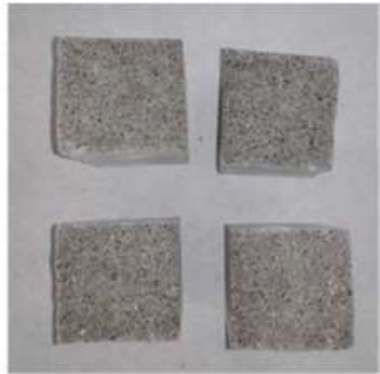

60 días

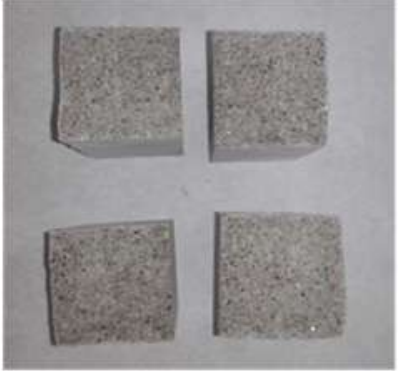

120 días

FIGURA 8-65.- EVOLUCIÓN DEL PERFIL DE CARBONATACIÓN EN LAS PROBETAS CORRESPONDIENTES AL CEMENTO DE MEZCLA P1/O50/50+CH CURADAS DURANTE 28 DÍAS EN AMBIENTE DE LABORATORIO.

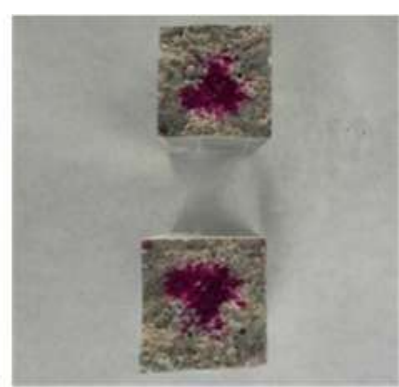

14 días

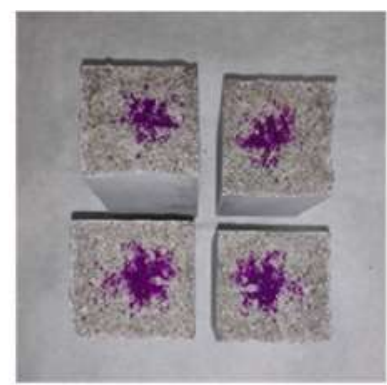

28 días

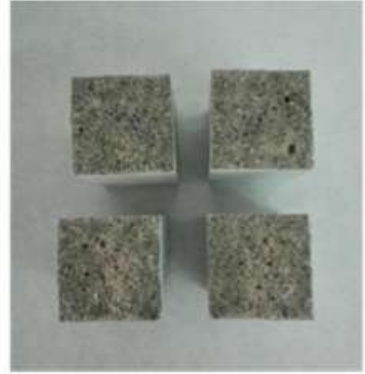

60 días

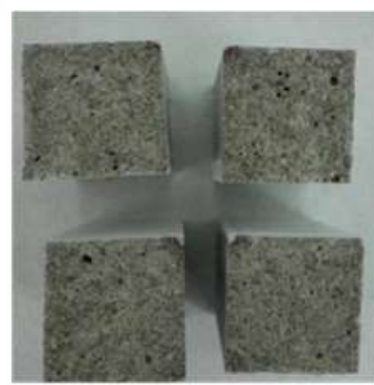

120 días

FIGURA 8-66.- EVOLUCIÓN DEL PERFIL DE CARBONATACIÓN EN LAS PROBETAS CORRESPONDIENTES AL CEMENTO DE MEZCLA P1/O50/50+CH CURADAS DURANTE 28 DÍAS BAJO AGUA.

En este sentido, también llama la atención que aquellas probetas que contenían un aporte 
adicional de $\mathrm{CH}$ (Figura 8-65 y Figura 8-66) presentaron una mayor resistencia a la penetración del $\mathrm{CO}_{2}$, en comparación con las probetas que no contenían esta cantidad adicional de cal apagada.Puesto que estos cementos de mezcla, de su correspondiente "familia", fueron aquellos que mayor cantidad de portlandita pudo generar y poner a disposición de la fase líquida de cada probeta de mortero con el transcurso del ensayo. O dicho de otro modo, tanto más cantidad de portlandita pudieron generar y poner a disposición de la fase líquida de dicho cemento Puzolánico 50/50 cuanto más progresó el ataque por carbonatación. Y no tanto porque la pudiera generar al ser un cemento altamente adicionado, sino por el aporte adicional de cal apagada.

\subsubsection{2.- Resultados obtenidos en la determinación de las RMF y RMC.}

De la determinación de las resistencias mecánicas a flexotracción, RMF, y a compresión, RMC, cuyos valores se recogen en la Tabla 8-98 y en la Figs. 8-67 y 8-68, se ha de decir, que ambos parámetros mecánicos absolutos son los más importantes por significativos para la caracterización mecánico-resistente de los cementos comunes. Y del análisis y estudio, discusión e interpretación de los valores obtenidos tras someter a estas probetas al proceso de carbonatación acelerada, se podrá correlacionar con los resultados de la medida del perfil de penetración de $\mathrm{CO}_{2}$.

Es aproximación interesante que se emplea habitualmente para predecir la carbonatación, se relaciona la profundidad de la carbonatación con la resistencia mecánica a compresión, dado que esta última propiedad es la que se determina con más frecuencia. De hecho, la resistencia a compresión y la porosidad del hormigón resultante dependen de la composición y de la conservación del hormigón. Es ampliamente conocido que la carbonatación del hormigón disminuye cuando su resistencia mecánica a compresión aumenta.

TABLA 8-98.- RESULTADOS DE RMF Y RMC DE LOS CEMENTOS DE MEZCLA P1/M 40/60 SOMETIDOS AL ENSAYO DE CARBONATACIÓN ACELERADA. EDADES: 14, 28, 60, 120 Y 180 DÍAS.

\begin{tabular}{|c|c|c|c|c|c|c|c|c|}
\hline \multicolumn{9}{|c|}{ PUZOLANA O } \\
\hline \multirow{2}{*}{$\begin{array}{l}\text { Edad } \\
\text { (días) }\end{array}$} & \multicolumn{2}{|c|}{$\mathrm{P} 1 / \mathrm{O} 50 / 50$ (28d Lab) } & \multicolumn{2}{|c|}{$\mathrm{P} 1 / \mathrm{O} 50 / 50\left(28 \mathrm{~d} \mathrm{H}_{2} \mathrm{O}\right)$} & \multicolumn{2}{|c|}{$\mathrm{P} 1 / \mathrm{O} 50 / 50+\mathrm{CH}$ (28d Lab) } & \multicolumn{2}{|c|}{$\mathrm{P} 1 / \mathrm{O} 50 / 50+\mathrm{CH}\left(28 \mathrm{~d} \mathrm{H}_{2} \mathrm{O}\right)$} \\
\hline & $\begin{array}{l}\text { R.M.F. } \\
(\mathrm{MPa})\end{array}$ & $\begin{array}{l}\text { R.M.C. } \\
(\mathrm{MPa})\end{array}$ & $\begin{array}{l}\text { R.M.F. } \\
\text { (MPa) }\end{array}$ & $\begin{array}{r}\text { R.M.C. } \\
(\mathrm{MPa})\end{array}$ & $\begin{array}{l}\text { R.M.F. } \\
(\mathrm{MPa})\end{array}$ & $\begin{array}{c}\text { R.M.C. } \\
(\mathrm{MPa})\end{array}$ & $\begin{array}{l}\text { R.M.F. } \\
\text { (MPa) }\end{array}$ & $\begin{array}{l}\text { R.M.C. } \\
\text { (MPa) }\end{array}$ \\
\hline 14 & 6,80 & 34,10 & 7,49 & 42,07 & 7,29 & 37,00 & 9,42 & 47,70 \\
\hline 28 & 6,48 & 36,07 & 8,13 & 41,87 & 7,36 & 38,72 & 8,39 & 49,37 \\
\hline 60 & 6,11 & 33,83 & 7,98 & 40,54 & 6,80 & 39,02 & 8,57 & 50,10 \\
\hline 120 & 5,22 & 32,13 & 7,20 & 39,62 & 6,00 & 38,39 & 7,77 & 46,20 \\
\hline 180 & 4,31 & 30,80 & 6,33 & 37,96 & 5,36 & 36,10 & 6,90 & 44,20 \\
\hline
\end{tabular}

Así en primer lugar, todos los cementos de mezcla ensayados descendieron en su valor de RMC y RMF conforme avanzó el ensayo. No obstante, la evolución de esa pérdida fue distinta en función del ambiente de curado de las probetas y de la adción o no de cal apagada. Véanse la Tabla 8-98 y las Figs. 8-67 y 8-68:

- Las probetas curadas bajo agua durante 28 días superaron el valor del correspondiente 350 
mortero normalizado que fue curado en ambiente de laboratorio. Como se ha citado con anterioridad, este curado bajo agua provocó un incremento en la velocidad y en el grado de hidratación de los morteros que contenían esta cantidad tan elevada de puzolana $\mathrm{O}$, provocando por ello una mayor resitencia de penetración del $\mathrm{CO}_{2}$ hacia el interior de las probetas, disminuyendo por ello la velocidad de incremento del perfil de carbonatación.

- Las probetas que contenían el aporte adicional de cal apagada tuvieron en descenso más tardío de sus correspondientes RMF y RMC respecto a aquellas probetas a las que no les adicionaron el hidróxido de calcio. La razón de este comportamiento lo podemos encontrar en la mayor cantidad de portlandita que pudieron poner a disposición de la fase líquida de dichos cementos de mezcla ante el proceso de carbonatación acelerada.

Debido a la carbonatación, se acaba desembocando finalmente en una pérdida gradual y notable de cohesión, adherencia y resistencias mecánicas de las probetas de mortero sometidos a este ensayo, con pérdida incluso de material o su simple desmoronamiento manual.

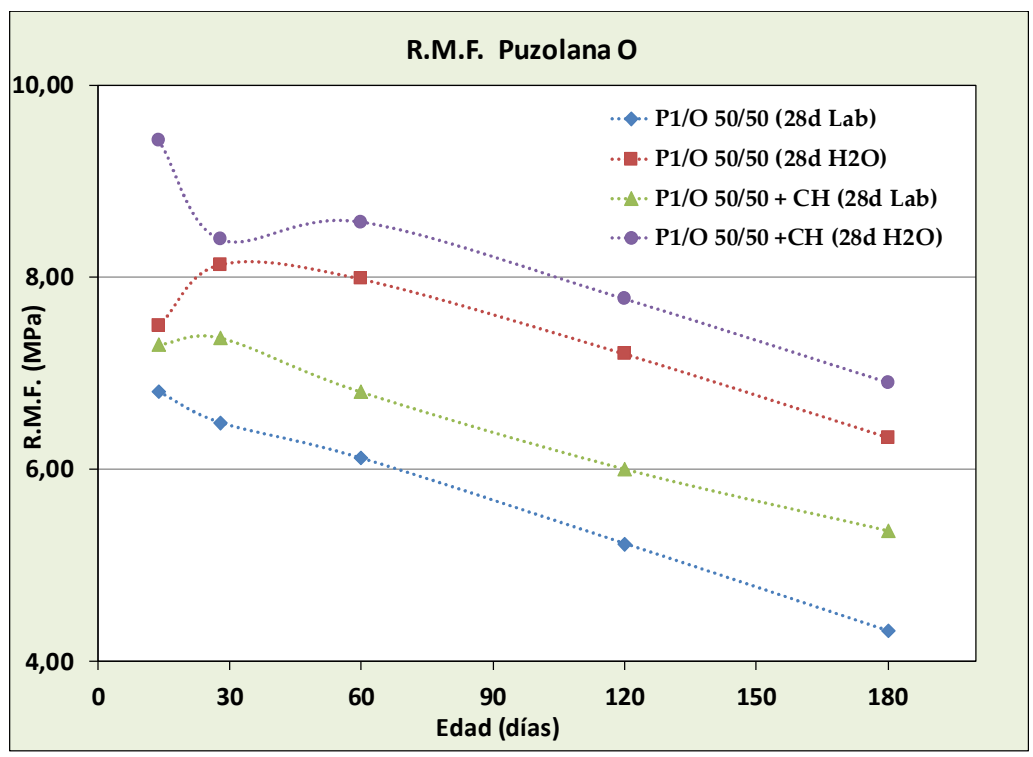

FIGURA 8-67.- RESULTADOS DE RMF DE LOS CEMENTOS DE LOS CEMENTOS DE MEZCLA P1/O50/50 SOMETIDOS AL ENSAYO DE CARBONATACIÓN ACELERADA. EDADES: 14, 28, 60,120 Y 180 DÍAS.

Todos estos comportamientos mostrados por las probetas de mortero del cemento de mezcla P1/O 50/50 sometidos al ensayo de carbonatación acelerada vienen a significar la pérdida continua de resistencias mecánicas de las mismas con la edad de ensayo, a causa del elevado porcentaje de sustitución de clínker por metacaolín O, 50\% nada menos. Este descenso de las propiedades mecánico resistentes de los morteros está directamente relacionado con la cantidad de portlandita disponible en la fase líquida de estos cementos. Asímismo, la característica puzolánica delapuzolana $\mathrm{O}$ fue muy considerable, ya que la mayor cantidad de esta adición mineral en los cementos de mezcla provocó un descenso muy pronunciado en el nivel de 
portlandita disponible en la fase líquida, como así lo mostró el ensayo de Frattini ${ }^{14}$, a por acusa de su alta, rápida y temprana actividad puzolánica, hasta el punto de poder llegar a consumir la mayor parte de la reserva portlandítica dispobile en la fase líquida de los morteros ensayados.

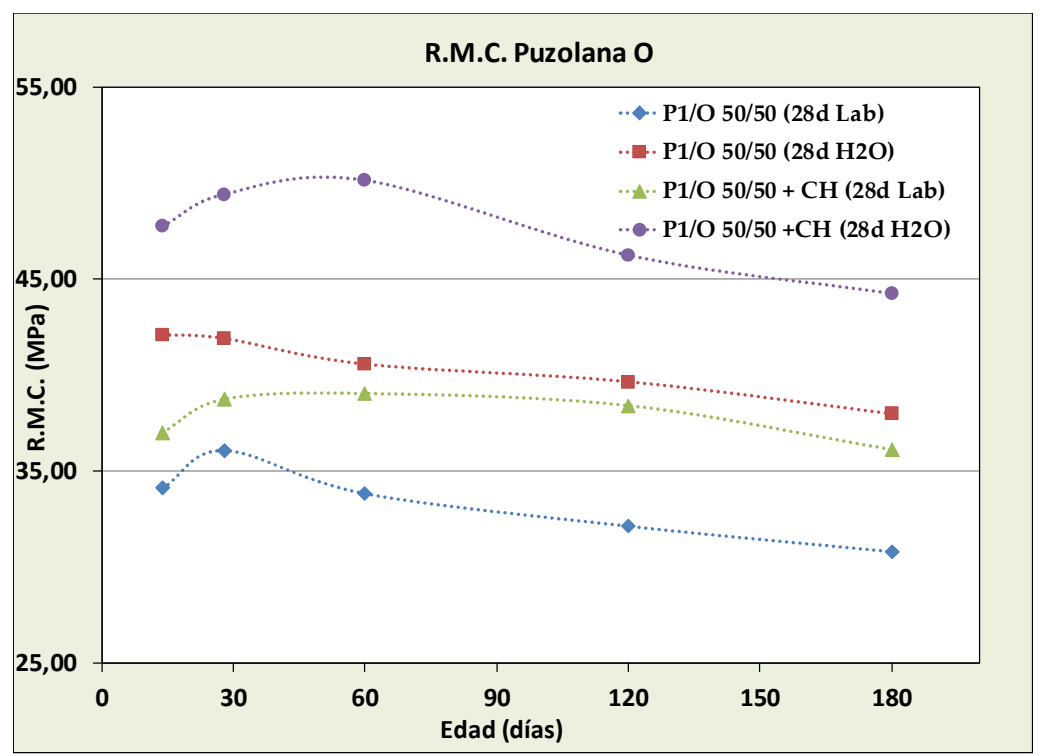

FIGURA 8-68.- RESULTADOS DE RMC DE LOS CEMENTOS DE LOS CEMENTOS DE MEZCLA P1/O50/50 SOMETIDOS AL ENSAYO DE CARBONATACIÓN ACELERADA. EDADES: 14, 28, 60,120 Y 180 DÍAS.

\footnotetext{
${ }^{14}$ Véase el apartado 8.3. de esta MEMORIA de Tesis Doctoral.
} 


\section{CONCLUSIONES}





\section{1.- Conclusiones Generales.}

Del análisis, estudio, discusión e interpretación de los resultados experimentales obtenidos en esta Investigación del Comportamiento Sulfático y Mecánico Resistente de Cementos Portland con elevados contenidos de Puzolanas superiores al 40\%, su Fundamento Químico y justificación de otras consecuencias posibles se ha podido obtener la siguiente conclusión general:

Los resultados obtenidos confirman la tesis descrita en los Objetivos de esta Investigación del aumento de la RS y de la carbonatación negativa y disminución de las RM de un cemento Portland cuando se reemplaza por puzolana en cantidades mayores del $40 \%$, este resultado es consecuencia del efecto químico derivado de la actividad puzolánica que logra generar y desarrollar la considerable cantidad de puzolana con la que se mezcló ocasionando adicionalmente un descenso considerable de la portlandita en la fase líquida de su pasta que es la que provoca en definitiva, el aumento de RS y la disminución de RM además de promoverle su mayor degradación ulterior por carbonatación negativa.

\section{2.- Conclusiones Específicas.}

Del análisis, estudio, discusión e interpretación de los resultados experimentales obtenidos en esta Investigación del Comportamiento Sulfático y Mecánico Resistente de Cementos Portland con elevados contenidos de Puzolanas superiores al 40\%, su Fundamento Químico y justificación de otras consecuencias posibles se han podido obtener las siguientes conclusiones específicas: 


\subsection{1.- Del comportamiento Sulfático de los cementos de mezcla.}

A medida que el contenido de CP (ya fuese CPO o CPRS) era menor, menor cantidad de portlandita pudo generar y poner a disposición de la fase líquida de cada probeta L-A. Es decir, a mayor cantidad de Puzolana tanto menos cantidad de portlandita pudo generar dicho cemento Puzolánico, resistiendo en mejor forma el ataque sulfático.

Conforme la hidratación selenitosa progresó, las probetas L-A con mayor nivel de sustitución de $\mathrm{CP}$ fueron la que menos aumentaron de volumen durante el transcurso de las demás edades del ensayo incluida la de su finalización, y aun posteriormente. La razón no es otra que la estimulación de la hidratación selenitosa que sufre por vía indirecta (Rahhal, 2009) el contenido de $\mathrm{C}_{3} \mathrm{~A}$, por la muy elevada, temprana y rápida actividad puzolánica, que logra generar y desarrollar el considerable contenido de $\mathrm{Al}_{2} \mathrm{O}_{3}{ }^{\mathrm{r}-}(\%)$ de la puzolanas utilizadas, metacaolín $\mathrm{M}$ $(14,86 \%)$, ceniza volante CV10 $(13,60 \%)$ y las puzolanas naturales A $(7,70 \%)$ y C $(11,41 \%)$ muy especialmente, desde el instante mismo de ponerse en contacto cada uno de los materiales sólidos implicados con el agua.

La razón de este comportamiento se debe a la menor concentración proporcional de portlandita ó [CaO] desde el principio al final del ensayo y tanto menor cuanto más progresa dicho ensayo y mayor fue el porcentaje de reemplazo de $\mathrm{CP}$ por puzolana, esta menor cantidad de Portlandita impidió la formación de toda la cantidad de ett-rf que cada puzolana "Z" podría ser capaz de formar por sí misma, de origen de su propio contenido total de $\mathrm{Al}_{2} \mathrm{O}_{3}{ }^{r}-(\%)$, e inducida, es decir, de origen del contenido de $\mathrm{C}_{3} \mathrm{~A}(\%)$ que la fracción del $\mathrm{CPO}$ con la que se mezcló aportó a la mezcla, al que logra estimular al hidratarse sulfáticamente, pero, en cualquier caso, la estimulación por esta última vía la realiza la puzolana "Z" en medida proporcional a la cantidad de actividad puzolánica generada y desarrollada antes por la fracción de su correspondiente contenido de $\mathrm{Al}_{2} \mathrm{O}_{3}{ }^{\mathrm{r}-}(\%)$.

Estos resultados de la presente TD, difieren del mal comportamiento mostrado por los cementos de mezcla en la Tesis Doctoral de Talero (1986), cuando su reemplazo no superó el 40\%.

\subsection{2.- Del comportamiento Mecánico resistente de los cementos de mezcla.}

Con tales porcentajes de reemplazo tan elevados de puzolana por $\mathrm{CP}$, en la mayoría de los casos no se llegó realmente a cumplir las especificaciones reglamentadas existentes al efecto de resistencias mecánicas características a compresión (RMC) y Flexotracción (RMF), afectadas en mayor o menor grado por el carácter químico de la puzolana que las constituía.

Se confirmó mediante esta investigación una disminución muy considerable de portlandita de la fase líquida de su pasta, en las probetas L-A analizadas no se alcanzó la cantidad necesaria y suficiente de portlandita en su fase líquida para superar permanentemente el valor del $\mathrm{pH}>10,8$ exigible como medio básico para garantizar la estabilidad en sus desempeños. Por otra parte se infirió una disminución proporcional del espesor, la dureza y la consistencia de la zona de transición a la interfase (ZTI) árido silíceo, pasta de cemento, donde por lo general, a las edades 
intermedias y finales del ensayo, las probetas con mayor nivel de sustitución de CP fueron las que menores valores de RMC y RMF tuvieron en casi todos los casos y más aún según sea su carácter químico alumínico como ha sido demostrado en esta investigación.

En insuficiencia de portlandita en la fase líquida de las probetas L-A y debido a que dicha actividad puzolánica ha sido considerable, se formó mucha menor cantidad de ett-rf que la que, en realidad, debería y podría formar en condiciones más favorables, es decir con mucha menor cantidad de reemplazo de puzolana "Z" por CP. De aquí que el comportamiento en RS de cada cemento de mezcla anterior ha demostrado ser mejor con el aumento mencionado del porcentaje de reemplazo de puzolana "Z" por CP mientras que en resistencias mecánicas a Compresión (RMC) y Flexotracción (RMF) disminuyeron.

\subsection{3.- Del Comportamiento frente al ataque por Carbonatación de los cementos de mezcla.}

Los resultados arrojados en esta TD en cuanto a carbonatación han demostrado que tanto más negativa resultó ser aún cuanto mayor fue el porcentaje de reemplazo de CP por puzolana.

La razón de este comportamiento se puede observar de los resultados obtenidos en el ensayo de Frattini (Figs. 8-56. a 8-61) de cada uno de los cementos de mezcla disponiendo de menor concentración proporcional aún de portlandita desde el principio al final del ensayo y tanto menor cuanto más progresaba dicho ensayo y mayor fue el porcentaje de reemplazo de $\mathrm{CP}$ por puzolana.

\subsection{4- Confirmación de la reversión de las reacciones químicas de hidratación selenitosa al adicionar cal apagada a cada uno de los cementos puzolánicos preparados: su efecto sobre las RMC y RMF así como la carbonatación negativa.}

No obstante dicho comportamiento peor en RMC, en RMF y en carbonatación negativa se pudo revertirse sin más que añadirle $\mathrm{Cal}$ Apagada (hidróxido de calcio), $\mathrm{Ca}(\mathrm{OH})_{2}$, en estado sólido a los nuevos cementos de mezcla binarios anteriores.

La adición de Cal apagada a los nuevos cementos de mezcla binarios les aportó la cantidad de basicidad portlandítica que necesitaban.

Ya con esta cantidad de Cal Apagada aportando el medio básico y suficiente, como se acaba de decir, la Puzolana pudo mostrar su verdadero carácter químico o comportamiento ante un medio químico agresivo, en este caso la agresividad de los sulfatos de acuerdo con esta investigación objeto de Tesis Doctoral, para convertirlas finalmente en mezclas ternarias; Cemento Portland + Puzolana "Z" + Cal Apagada.

Lo anterior para tratar de revertir así el sentido de las reacciones químicas de hidratación selenitosa con los siguientes resultados:

- La formación conjunta de ettringita de origen $\mathrm{Al}_{2} \mathrm{O}_{3}{ }^{\mathrm{r}}$ de la puzolana y de origen $\mathrm{C}_{3} \mathrm{~A}$ del $\mathrm{CPO}$ con el que se mezcló cuya cantidad formada fue entonces mayor, le provocó al nuevo cemento puzolánico Tipo CEM IV/B con cal apagada disminución de su RS. 
COMPORTAMIENTO SULFÁTICO Y MECÁNICO-RESISTENTE DE CEMENTOS PORTLAND CON ELEVADOS CONTENIDOS DE PUZOLANAS ( $>40 \%$ ): SU FUNDAMENTO QUÍMICO Y JUSTIFICACIÓN DE OTRAS CONSECUENCIAS POSIBLES

- Generó el aumento claro de dichas RMC y RMF a 28 y 90 días en probetas de mortero normalizado del nuevo cemento puzolánico Tipo CEM IV/B.

- Disminuyó su carbonatación negativa, o al menos tardó más tiempo en generarse y desarrollarse sus consecuencias negativas para la pasta cementante y subsidiariamente para sus armaduras en el caso del hormigón armado. 


\section{FUTURAS LINEAS DE INVESTIGACIÓN}





\section{1.- Primer punto de análisis: Adoptar incrementos mayores de adición puzolánica como solución a la sostenibilidad y reglamentar su mínima RMC.}

Se ha tratado de convertir cualquier cemento Portland de elevada, o no, resistencia al ataque de los iones sulfato, en otro nuevo cemento normalizado, puzolánico Tipo CEM IV/B según la vigente Instrucción de cementos RC-16 en este caso, mediante la adición seriada de las puzolanas naturales y artificiales seleccionadas anteriores en cantidades superiores al $40 \%$, en peso de cemento Portland P o PY puro.

Siendo el grado de resistencia sulfática (RS) a dicho ataque químico agresivo mayor, pero por otra parte los valores de RMC y RMF han disminuido considerablemente, en sus correspondientes probetas de mortero normalizado, tipo UNE-EN 196-1:2005, sería importante fijar una RMC que habría de alcanzar un valor mínimo permisible, por ejemplo de $175 \mathrm{Kp} / \mathrm{cm} 2$ a la edad de 28 días, para los cementos Puzolánicos de esta investigación, Tipo IV/A, IV/B y cementos Compuestos Tipo V con puzolana nada más, pues permitiría una Aplicación Técnica resultante finalmente de esta investigación objeto de Tesis Doctoral, aplicable mayormente a las construcciones no estructurales de hormigón armado o Cementos de uso General no estructural de menor desempeño en resistencias mecánica. Adicionalmente, sería un cemento capaz de resistir ataque a los sulfatos, pudiéndose asentar además en terrenos selenitosos. Podría ser motivo de estudio la definición de alcance de estos cementos con altas adiciones de puzolana, y definir una resistencia mínima de cumplimiento para obras de uso general no estructural que bien podría ser el valor de $175 \mathrm{Kg} / \mathrm{cm} 2$ o $17.5 \mathrm{Mpa}$., a la edad de 28 días, ya que un cemento con alto nivel de adición puzolánico difícilmente podrá alcanzar una RMC de los actuales códigos, y 
de esta manera se estaría contribuyendo a la reducción o mitigación del Calentamiento Global derivado del «Efecto Invernadero».

Además y teniendo en cuenta el decidido esfuerzo que la Industria del Cemento viene haciendo para reducir tanto como le sea posible las emisiones de $\mathrm{CO} 2$ al ambiente, generado en el proceso de producción del Clinker y que contribuyen a disminuir el «Efecto Invernadero», vista en el Capítulo 1 de esta Tesis Doctoral, adoptar un valor mínimo de RMC para edificaciones de menor desempeño en RMC permitiría incrementar los niveles de sustitución de puzolanas en reemplazo del Clinker Portland, como ya ha sido demostrado en esta Tesis Doctoral, contribuyendo de una manera Sostenible.

\section{2.- Segundo punto de análisis: Promover la activación térmica de Arcillas calcinables para la producción de Puzolanas naturales calcinadas.}

Los resultados de la presente Tesis Doctoral ofrecen el entendimiento para el uso de Puzolanas teniendo en cuenta las Prestaciones y sus afectaciones, así como su Durabilidad de los cementos adicionados en mayor o menor cantidad de Puzolanas dependiendo de su carácter químico.

La activación Térmica de Arcillas Calcinables de acuerdo con sus caracterizaciones completas por análisis de DRX y Termografía, teniendo en cuenta adicionalmente su contenido de Caolín Equivalente puede ser promovido al poder la Industria Cementera producir a partir de estas Arcillas, Puzolanas de excelente calidad en términos de sus Factores Hidráulicos, controlando la calidad de las mismas.

La producción de puzolanas naturales calcinadas ofrece un beneficio ambiental importante que debe ser demostrado por cuanto no se da el proceso de descarbonatación propio de la caliza en el Horno Cementero, reduciendo el 60\% de las emisiones de CO2 al ambiente por este concepto y disminuyendo también una porción importante de las emisiones de $\mathrm{CO} 2$ correspondientes al uso de combustibles, pues la temperatura requerida de calcinación de las Arcillas suele estar alrededor de los $800 \mathrm{C}$, que es mucho menor que la temperatura requerida para la producción del Clinker Portland siendo aproximadamente de 1,400 C. Esto con seguridad sería una línea de investigación aplicada bien importante para la Industria cementera.

El mercado de materiales cementíceos como la escoria y la ceniza volante no sustituye más del 10\% de la producción de cemento en el mundo. Adicionalmente las exigencias del cambio climático a los Países están obligando a asumir posiciones de reducciones importantes sobre las emisiones de gases efecto invernadero. Ya algunos países como Alemania y los países Nórdicos han tomado la decisión de no generar energía con base en carbón para la década 2020, en consecuencia la generación de cenizas volantes ira en disminución paulatinamente.

La existencia de Arcillas en el globo terráqueo es alta a niveles similares de la Caliza, por tanto, es una opción definitiva la producción de puzolanas naturales calcinadas o Arcillas calcinadas y a futuro será la mejor forma de reducir el consumo de Clinker en la producción de cemento. 
En la actualidad se está promoviendo el empleo de puzolanas a partir de la arcilla calcinada por la confederación Suiza y universidades como la Universidad Central de las Villas en Cuba, la Ecole Politechnique Federale de Lausanne (EPFL) en Suiza y el IPT de Sao Paulo han logrado avances importantes en el tema. De igual manera en el norte de Brasil se viene produciendo Puzolana a partir de Arcillas Calcinables en diferentes compañías cementeras, en Colombia se está iniciando su producción y en India también se tiene una producción de este tipo de Puzolana. 



\section{REFERENCIAS}





\section{- ARTÍCULOS EN REVISTAS, CONTRIBUCIONES A CONGRESOS $Y$ PÍTULOS DE LIBRO-}

\section{- A -}

Abdun-Nur E.A., Aitcin P.C., Bell L.W., Best F.J., Brenno G.L., Butler B.W., Call B.M., Carrasquillo R.L., Cook J.E., Deno D.W., Ehmke B.A., Werner II O.R., Fox, T.A., Hall R.H., Holland T.C., (1987) "Use of Fly Ash in Concrete". Volume 84 (5), p.p. 381-409

Acker P., (2004) “Swelling, shrinkage and creep: a mechanical approach to cement hydration".- Inorganic Materials and Structures, 37 (268), pp. 237243.

Afridi M.U.K., Ohama Y., Demura K., Iqbal M.Z., (2001) "A note on the comparison of crack resistance of $\mathrm{Ca}(\mathrm{OH})_{2}$ crystals of unmodified and polymer-modified mortars in carbonated atmosphere".- Cement and Concrete Research, 31 (11), pp. 1643-1645.

Andersen M.D., Jakobsen H.J., Skibsted J., (2003) "Incorporation of aluminium in the calcium silicate hydrate (C-S-H) of hydrated Portland cements: A high-field ${ }^{27} \mathrm{Al}$ and ${ }^{29} \mathrm{Si}$ MAS NMR investigation".Inorganic Chemistry, 42 (7), pp. 2280-2287.

Andersson K., Allard B., Bengtsson M, Magnusson B., (1989) "Chemical composition of cement pore solutions".- Cement and Concrete Research, 19 (3), pp. 327-332.

\section{- B -}

Bae S., Meral C., Oh J., Moond J., Kunz M., Monteiro P., (2014) “Characterization of morphology and hydration products of high-volume fly ash paste by monochromatic scanning $\mathrm{x}$-ray micro-diffraction $(\mu-S X R D) "$. Cement and Concrete Research 59, pp. 155-164.

Bailey J.E., Hampson C.J., (1982) “The chemistry of the aqueous phase of Portland cement".- Cement and Concrete Research, 12 (2), pp. 227-236.

Bates P.H., Klein A.A., (1917) “Properties of the calcium silicates and calcium aluminate occurring in normal Portland cement".- Bureau of Standards Technology, paper núm. 78.
Baum H., Soroka I., Bentur A., (1985) “Properties and structure of oil shale ash pastes I: Composition and physical features. Cement and Concrete Research, 15 (2), pp. 303-314.

Baykov A.A., Tuma A.S., (1936). Rev: Chem. Abstr., 31, pp. 8863-8867.

Beaudoin J.J., (1983) “Comparison of mechanical properties of compacted calcium hydroxide and Portland cement paste systems".- Cement and Concrete Research, 13 (3), pp. 319-324.

Beaudoin J.J., Gu P., Myers R.E., (1998) “The fracture of C-S-H and C-S-H mixtures".- Cement and Concrete Research, 28 (3), pp. 341-347.

Bensted, J. (1977) “Some problems of ettringite and of thaumasite in the gypsum plaster/cement contact area. Proceedings of the International RILEM Symposium On Calcium Sulphates and Derived Materials, Saint Rémy-Lčs-Chevreuse, pp. 479-487.

Bentz D.P, Ferraris C.F., (2010) “Rheology and setting of high volume fly ash mixtures". Cement \& Concrete Composites 32, pp. 265-270.

Bensted, J., (1988) "Thaumasite - a deterioration product of hardened cement structures", Il Cemento, 85, 1, pp. 3-10.

Bentur A., Ish-Shalom, M., (1975) “Properties of type $\mathrm{K}$ expansive cement of pure components IV. hydration of mixtures of C3S with pure expansive component". Cement and Concrete Research, 5 (6), pp. 597-606.

Berger R.L., (1972) “Calcium hydroxide: its role in the fracture of tricalcium silicate pastes".- Science, 175 (4022), pp. 626-629.

Berger R.L., McGregor J.D., (1973) “Effect of temperature and water-solid ratio on growth of $\mathrm{Ca}(\mathrm{OH})_{2}$ crystals formed during hydration of $\mathrm{Ca}_{3} \mathrm{SiO}_{5}$ ".- Journal of the American Ceramic Society, 56 (2), pp. 73-79.

Bernal J.D., Megaw H.D., (1935) “The function of hydrogen in intermolecular forces".-- Proceedings of the Royal Society of London Series A-Mathematical and Physical Sciences, 151 (A384), pp. 384-420.

Bernal J.D., Jeffery J.W., Taylor H.F.W., (1952) "Crystallographic research on the hydration of Portland cement. A first report on investigations in progress".- Magazine of Concrete Research, 4 (11), pp. 49-54.

Bezjak A., Jelenic, I., (1966) “Crystal structure investigation of calcium aluminium sulphate hydrate - Ettringite". Croat. Chem. Acta. 38, pp. 239-242. 
Bhatty J.I., Dollimore D., Gamlen G.A., Mangabhai R.J., Olmez H., (1986) "Estimation of calcium hydroxide in OPC, OPC/PFA and OPC/PFA polymer modified systems".- Thermochimica Acta, 106, pp. 115-123.

Bilodeau A., Malhotra V.M., (2000) “High-volume fly ash system: concrete solution for sustainable development".- ACI Struct. J. 97 (1), pp. 41-48.

Bilodeau A., Sivasundaram V., Painter K.E., Malhotra V.M., (1994) “Durability of concrete incorporating high volumes of fly ash from sources in the U.S". ACI Materials Journal, 91 (1), pp. 3-12.

Birchall J.D., Howard A.J., (1980) "Some general considerations of a membrane/osmosis model for Portland cement hydration".- Cement and Concrete Research, 10 (2), pp. 145-155.

Birchall J.D., Thomas N.L., (1984) “The mechanism of retardation of setting of OPC by sugars".- Proceedings of the British Ceramic Society, 35, pp. 305315.

Blaine R.L., (1960) "Proton magnetic resonance in hydrated Portland cements" en Fourth International Symposium on the Chemistry of Cement, pp. 297-305, Washington DC, Estados Unidos.

Blondiau L. (1961) "Considerations diverses relatives a ' l'e'ssai de resistance chimique au sulfate de calcium suivant le processus Le Chatelier Anstett. Rev. Mater. Constr. Trav. Publics III (546), pp. 189 200.

Bolomey J., (1936) "Influencia de la adición de polvo de piedra al cemento en la calidad del hormigón", HORMIGÓN y ACERO, Vol. III, 23, pp. 8590.

Bonavetti V.L, Rahhal V.F., Irassar E.F., (2001) "Studies on the carboaluminate formation in limestone filler-blended cements".- Cement and Concrete Research, 31 (6), pp. 853-859.

Bondar D., Coakley E., (2014) “Use of gypsum and CKD to enhance early age strength of High Volume Fly Ash (HVFA) pastes". Construction and Building Materials 71, pp. 93-108

Bouzoubaa`N., Zhang M.H., Malhotra V.M., (2000) "Laboratory-produced high-volume fly ash blended cements: compressive strength and resistance to the chloride-ion penetration of concrete". Cement and Concrete Research 30 (7), pp. 1037-1046.

Bouzoubaa`N., Zhang M.H., Malhotra V.M., (2001) "Mechanical properties and durability of concrete made with high-volume fly ash blended cements using a coarse fly ash". Cement and Concrete Research 31 (10), pp. 1393-1402.

Bradbury H.W., (1982). Silicates Industriales, XLVII, (12), pp. 283-288, (1982).

Brandenberguer E., Vuagnat M., (1946) “Studie zur frage der erhärtung der kalksandsteine".Hunziker Mitteilungen, 3 (5), p. 1.

Brindley G.W., Nakahira M., (1959) "The CaoliniteMullite Reaction Series: I. A Survey of Outstanding Problems", J Am Ceram Soc, 42 (7), pp. 311-314.

Brooks J.J., (2002) "Prediction of setting time of fly ash concrete". ACI Materials Journal, 99 (6), pp. 591-597.

Brough A.R., Dobson C.M., Richardson I.G., Groves G.W., (1994) "In situ solid state NMR studies of $\mathrm{Ca}_{3} \mathrm{SiO}_{5}$ : Hydration at room temperature and at elevated temperatures using ${ }^{29} \mathrm{Si}$ enrichment".Journal of Materials Science, 29 (15), pp. 3926-3940.

Brouwers H.J.H., Van Eijk R.J., (2003) “Alkali concentrations of pore solution in hydrating OPC".Cement and Concrete Research, 33 (2), pp. 191-196.

Brown P.W., (1987) "Early hydration of tetracalcium aluminoferrite in gypsum and lime-gypsum solutions".- Journal of the American Ceramic Society, 70 (7), pp. 493-496.

Busing W.R., Levy H.A., (1957) “Neutron diffraction study of calcium hydroxide".- Journal of Chemical Physics, 26 (3), pp. 563-568.

Buttler F.G., Dent Glasser L.S., Taylor H.F.W., (1959) "Studies on $4 \mathrm{CaO} \cdot \mathrm{Al}_{2} \mathrm{O}_{3} \cdot 13 \mathrm{H}_{2} \mathrm{O}$ and the related natural mineral hydrocalumite".- Journal of the American Ceramic Society, 42, pp. 121-126.

\section{- C -}

Calleja, J, (1988) "Adiciones activas, tradicionales y no tradicionales, en cementos y hormigones", Colloquia 88, Vol. I, pp. 101-120.

Calleja J.; Aguanell M., (1980) “Consideraciones sobre el ensayo de ANSTTET y el comportamiento de los cementos frente a los sulfatos". Mater. Construcc., $\mathrm{n}^{\mathrm{o}} 179$, pp. $39-48$.

Candlot F., (1890) "Rôle de chlorure de calcium et $\mathrm{du}$ sulfate du chaux sur la prise et le durcissement des mortiers".- Bulletin de la Société d'Encouragement pour l'Industrie Nationale, 89, pp. 682-685.

Carrasquillo R.L., Snow P.G., (1987) “Effect of Fly 
Ash on Alkali-Aggregate Reactiom in Concrete. ACI Materials Journal, 84 (4), pp. 299-305.

Carrasquillo R.L., Snow P.G., (1987) “Effect of Fly Ash on Alkali-Aggregate Reactiom in Concrete. ACI Materials Journal, 84 (4), pp. 299-305.

Celik K., Meral C., Mancio M., Mehta P.K., Monteiro P., (2014) “A comparative study of self-consolidating concretes incorporating high-volume natural pozzolan or high-volume fly ash". Construction and Building Materials 67, pp. 14-19.

Cengiz D.A., (2002) "Heat evolution of high-volume fly ash concrete". Cement and Concrete Research 32, pp. 751-756.

Cengiz D.A., (2005) “Strength properties of highvolume fly ash roller compacted and workable concrete, and influence of curing condition". Cement and Concrete Research 35, pp. 1112 - 1121.

Chapelle J. (1958) “Sulpho-calcic attack of slags and pozzolans". Revue des Matériaux de Construction et de Travaux Publics. Edition C: Chaux, ciment, plâtre, agglomérés, 511, pp. 87-100, 512: 136-151, 513: 159-170, 514-515: 193-201, 516: 231-242.

Chatterji, S. (1974) "A discussion of the paper "contribution to the hydration of expansive cement on the basis of metakaolinite" by M. Matousek and Z. Šauman". Cement and Concrete Research, 4 (4), p. 685.

Chatterji, S. (1976) "A discussion of the paper "Scanning electron micrographic studies of ettringite formation" by P. K. Mehta". Cement and Concrete Research, 6 (5), pp. 711-712.

Chatterji S., Jeffery J.W., (1963a) “Studies of Early Stages of Paste Hydration of Different Types of Portland Cements". Journal of the American Ceramic Society, 46 (6), pp. 268-273.

Chatterji S., Jeffery J.W., (1963b) “A new hypothesis of sulphate expansion". Magazine of Concrete Research, 15 (44), pp. 83-86.

Chen J.J., Thomas J.J., Taylor H.F.W., Jennings H.M., (2004) "Solubility and structure of calcium silicate hydrate".- Cement and Concrete Research, 34 (9), pp. 1499-1519.

Chen J.J., Thomas J.J., Jennings H.M., (2006) “Decalcification shrinkage of cement paste".- Cement and Concrete Research, 36 (1), pp. 801-809.

Chen M., Shi Z., (1997) “Rate of ettringite formation from calcium aluminoferritte hydration", 10th International Congress on Chemistry of Cement, Vol. II, p. 8, Göteborg, Noruega.
Chindaprasirt P., Homwuttiwong S., Sirivivatnanon V., (2004). "Influence of fly ash fineness on strength, drying shrinkage and sulfate resistance of blended cement mortar". Cement and Concrete Research 34, pp. 1087-1092

Christensen A.N., Jensen T.R., Hanson J.C., (2004) "Formation of ettringite, $\mathrm{Ca}_{6} \mathrm{Al}_{2}\left(\mathrm{SO}_{4}\right)_{3}(\mathrm{OH})_{12} \cdot 26 \mathrm{H}_{2} \mathrm{O}, \mathrm{AFt}$, and monosulfate, $\mathrm{Ca}_{4} \mathrm{Al}_{2} \mathrm{O}_{6}\left(\mathrm{SO}_{4}\right) \cdot 14 \mathrm{H}_{2} \mathrm{O}, \mathrm{AFm}-14$, in hydrothermal hydration of Portland cement and of calcium aluminium oxide-calcium sulphate dehydrate mixtures studied by in situ synchrotron X-ray powder diffraction".- Journal of Solid State Chemistry, 177 (6), pp. 1944-1951.

Chudek J.A., Hunter G., Jones M.R., Scrimgeour S.N., Hewlett P.C., Kudryavtsev A.B., (2000) “Aluminium-27 solid state NMR spectroscopic studies of chloride binding in Portland cement and blends".- Journal of Materials Science, 35 (17), pp. 4275-4288.

Claringbull G.F., Hey M.H., (1952) “A re-examination of tobermorite".- American Mineralogist, 37 (11-1), pp. 1064-1064.

Cohen M.D., Richards C.W., (1982) “Effects of the particle sizes of expansive clinker on strength-expansion characteristics of type $\mathrm{K}$ expansive cements". Cem. Concr. Res., 12, pp. 717-725.

Cohen M.D., Mather B., (1991) "Sulfate Attack on Concrete - Research Needs".- ACI Materials .Journal, 88 (1), pp. 62-69.

Collepardi M., Masidda L., (1971) “Hydration of tricalcium silicate".- Journal of the American Ceramic Society, 54 (9), pp. 419-422.

Conejaud M.L., (1980) “Mechanism of seawater attack on cement mortar".-- International Conference on the Performance of Concrete in Marine Environment, Canadá, ACI SP-65, pp.39-61.

Collepardi M., Baldini G., Pauri M., Corradi M., (1978). "Tricalcium aluminate hydration in the presence of lime, gypsum or sodium sulphate". Cem. Concr. Res., 8 (5), pp. 571-580.

Cong X., Kirkpatrick R.J., (1996) "29Si MAS NMR study of the structure of calcium silicate hydrate".Advanced Cement Based Materials, 3 (3-4), pp. 144156.

Courtois , A.; Dusausoy , Y.; Lafaille , A.; Protas , J. (1968) "Etude Préliminaire de la Structure Crystalline de L'ettringite". C. R. Acad. 266, pp. 1911- 1913. 
Cultrone G., Sebastian E., Huertas M.O., (2005) "Forced and natural carbonation of lime-based mortars with and without additives: Mineralogical and textural changes".- Cem.Conr.Res., 35, pp. 2278-2289.

\section{- D -}

D'Ans J., Eick H., (1954). Zement-Kalk-Gips, 7, pp. 449-459.

Dana E.S., (1932). Text Book of mineralogy. System of mineralogy, $7^{\mathrm{a}}$ e d., T -II, pp. 589-770.

Davis R.E., Kelly, J.W., Troxell J.E., Davis H.E., (1935) "Properties of mortars and concretes containing portland-pozzolan cements". Proceedings Journal of American Concrete Institute, 32, pp. 80114.

De la Varga I., Castro J, Bentz D.P., Zunino F., Weiss J., (2018). “Evaluating the hydration of high volume fly ash mixtures using chemically inert fillers". Construction and Building Materials $161 \mathrm{pp}$. 221-228.

De la Varga I., Spragg R.P., Di Bella C., Castro J, Bentz D.P., Weiss J., (2014). “Fluid transport in high volume fly ash mixtures with and without internal curing". Cement \& Concrete Composites 45, pp. $102-110$

de Luxán Baquero M. (1967) “Conglomerantes puzolánicos. Propiedades y aplicaciones". Informes de la Construcción, 196, (20), pp. 61-75.

Diamond S., Lachowski E.E., (1983) “Investigation of the composition and morphology of individual particles of portland cement paste. 2. Calcium sulfoaluminates". Cem. Concr. Res., 13, pp. 335-340.

Dolado J.S., Manzano H., Porro A., Ayuela A., Hamaekers J., Griebel M., (2007) “On the formation of cementitious C-S-H nanoparticles: a computational bottom-up approach" en Proceedings of the $12^{\text {th }}$ International Congress on Chemistry of Cement, W5-03.1, Montréal, Canadá.

Donatello S., Palomo A., Fernández-Jiménez A., (2013). Durability of very high volume fly ash cement pastes and mortars in aggressive solutions. Cement \& Concrete Composites 38 , pp.12-20.

Donatello S., Kuenzel C., Palomo A., Fernández-Jiménez A., (2014). High temperature resistance of a very high volume fly ash cement paste. Cement \& Concrete Composites 45 , pp.234-242.

Dunstan M.R.H., (1986) "Fly Ash as the 'Fourth
Ingredient' in Concrete Mixtures", ACI Special Publication, Vol. 91, pp. 171-200.

Durán-Herrera A., Juárez C.A., Valdez P., Bentz D.P., (2011) "Evaluation of sustainable high-volume fly ash concretes". Cement \& Concrete Composites 33, pp.39-45.

\section{- E -}

Eitel W., (1957) "Recent Investigations of the System: Lime-Alumina-Calcium Sulfate-Water and its importance in Building Research Problems". .- Journal of Am. Concr. Inst., 28 (7), pp. 679-698.

Emanuelson A., Henderson E., Hansen S., (1996) "Hydration of ferrite $\mathrm{Ca}_{2} \mathrm{AlFeO}_{5}$ in the presence of sulphates and bases".- Cement and Concrete Research, 26(11), pp. 1689-1694.

\section{- F -}

Feldman R.F., Sereda P.J., (1970) “A new model for hydrated cement and its practical implications".Engineering Journal, 53 (8-9), pp. 53-59.

Feldman R.F., Ramachandran V.S., (1982) “Microstructure of calcium hydroxide depleted Portland cement paste. 1 . Density and helium flow measurements".- Cement and Concrete Research, 12 (2), pp. 179-189.

Felekoglu B., (2006) "Utilisation of Turkish fly ashes in cost effective HVFA concrete production". Fuel, 85, pp.1944-1949.

Flint E.P., Wells L.S., (1934) "Study of the system $\mathrm{CaO}-\mathrm{SiO}_{2}-\mathrm{H}_{2} \mathrm{O}$ at $30{ }^{\circ} \mathrm{C}$ and of the reaction of water on anhydrous calcium silicates".- Journal of Research of the National Bureau of Standards, 12 (6), p. 751-783.

Flint E.P., McMurdie H.F., Wells L.S., (1941) “Hydrothermal and X-ray studies of the garnet-hydrogarnet series and the relationship of the series to hydration products of Portland cement".- Journal of Research of the National Bureau of Standards, 26 (1), pp. 13-33.

Flint E.P., Wells L.S., (1944) “Analogy of hydrated calcium silicoaluminates and hexacalcium aluminate to hydrated calcium sulfoaluminates".- Journal of Research of the National Bureau of Standards, 33 (6), pp. 471-478.

Frattini N., (1949) "Solubilità dell'idrato di calcio in presenza di idrato di potassio e idrato di sodio".- 
Annali di Chimica Applicata, 39, pp. 616-620.

Francois M., Renaudin G., Evrard O., (1998) “A cementitious compound with composition $3 \mathrm{CaO} \cdot \mathrm{Al}_{2} \mathrm{O}_{3} \cdot \mathrm{CaCO}_{3} \cdot 11 \mathrm{H}_{2} \mathrm{O}^{\prime \prime}$.- Acta Crystallographica. Section C, Crystal Structure Communications, C54, pp. 1214-1217.

\section{- G -}

Garcia de Paredes P., (1978) “Durabilidad del hormigón I. Resistencia química de los cementos. Método de ensayo de la durabilidad frente a los sulfatosy cloruros". Mat. Constr., 170, pp. 67-89

Glasser F.P., Kindness A., Stronach S.A., (1999) "Stability and solubility relationships in AFm phases - Part I. Chloride, sulphate and hydroxide".Cement and Concrete Research, 29 (6), pp. 861-866.

Glasser F.P., Marchand J., Samson E., (2007) “Durability of concrete - degradation phenomena involving detrimental chemical reactions".- $12^{\text {th }}$ Intern. Congress on Chemistry of Cement, Proceedings, THPL-1, Montréal (Canadá).

Glasser F.P., Marchand J., Samson E., (2008) “Durability of concrete - Degradation phenomena involving detrimental chemical reactions".- Cement and Concrete Research, 38 (2), pp. 226-246

Gebler S.H., Klieger P., (1986) “Effect of Fly Ash on Physical Properties of Concrete". Publication SP American Concrete Institute, 1, pp. 1-50

Gmira A., Zabat M., Pellenq R.J.M., Van Damme H., (2004) "Microscopic physical basis of the poromechanical behavior of cement-based materials".Materials and Structures, 37 (265), pp. 3-14.

Goma F., (1983) “Evaluation Method of Cement Content and Additives to Fresh Concrete. Importance of $\mathrm{SO}_{3} /$ Cement Ratio.

Grzymek J., Roszczynialski W., Gustaw K., (1980) "Hydration of cements with pozzolanic additions", 7th International Congress on the Chemistry of Cement, Paris, Vol. IV, pp. 66-71.

Groves G.W., (1981) “Microcrystalline calcium hydroxide in Portland cement pastes of low water/cement ratio".- Cement and Concrete Research, 11 (2) , pp. 713-718.

Groves G.W., (1987) “TEM studies of cement hydration".- Materials Research Society Proccedings, 85, pp. 3-12.

Grutzeck M.W., (1999) “A new model for the formation of calcium silicate hydrate (CSH)".-
Materials Research Innovations, 3 (3), pp. 160-170.

\section{- H -}

Haecker C.J., Garboczi E.J., Bullard J.W., Bohn R.B., Sun Z., Shah S.P., Voigt T., (2005) "Modeling the linear elastic properties of Portland cement paste".Cement and Concrete Research, 35 (10), pp. 19481960.

Hannesson G., Kuder K., Shogren R., Lehman D., (2012) "The influence of high volume of fly ash and slag on the compressive strength of self-consolidating concrete". Construction and Building Materials 30, pp. 161-168

Hansen W. C., (1962) "Solid-liquid reactions in Portland cement paste". Materials Res. Standards 2, pp. 490-93.

Henager C.H., Wilson, C.K., Arrand, Colin O.D., Ball, Claire, Ball Jr., Hiram P., Batson, Gordon B., Corey, John F., (...), Hoff, George C. (1984) “Guide for specifying, mixing, placing and finishing. Journal of the American Concrete Institute, 81 (2), pp. 140-148.

Hill J., Sharp J.H., (2002) “The mineralogy and microstructure of three composite cements with high replacement levels". Cement \& Concrete Composites 24, pp. 191-199.

Holuj F., Drozdowski M., Czajkowski M., (1985) "Brillouin spectrum of $\mathrm{Ca}(\mathrm{OH}){ }_{2}$ ".- Solid State Communications, 56 (12), pp. 1019-1021.

\section{- I -}

Idorn G.M., Thaulow N., (1983) "Examination of 136 Years Old Portland Cement Concrete".- Cement and Concrete Research, 13 (5), pp. 739-743.

Irassar, E.F., (1990) "Sulfate Resistance of Blended Cement: Prediction and Relation with Flexural Strength", Cem Concr Res, 20 (2), pp. 209-218.

Irassar E.F., Di Maio A., Batic O.R., (1991) "Durability of Concrete Containing Mineral Admixtures in Sulfate Soil", Durability of Concrete, ACI Supplementary Papers, p. 21.

Irassar E.F., Di Maio A., Batic O.R., (1996) "Sulfate Attack on Concrete with Mineral Admixtures", Cem Concr Res, 26 (1), pp. 113-123.

Irassar E. F., Rahhal V., Pedrajas C., Talero R., (2014) "Rheology of Portland cement pastes with calcined clays addition". TechConnet World 2014; 
ISBN/ISSN: 9781482258325, Proceedings: Nanotech, Microtech, Biotech. Washingotn D.C.

\section{- J -}

Jaspers M. J. M., (1968) “Contribution à l'étude experimentale de la mesure par l'essai Le ChatelierAnstett (L-A) de la résistance des ciments aux sulfates et chlorures". Rev. Mater. Constr. Trav. Publics, no 633-634, pp. 244-256.

Jaspers M. J. M., (1970) “Contribution à l'étude experimentale de la mesure de la résistance aux sulfates des ciments selon la métode ASTM C 452-68". Rev. Mater. Constr. Trav. Publics, no 656, pp. 135143.

Jennings H.M., Dalgleish B.J., Pratt P.L., (1981) "Morphological development of hydrating tricalcium silicate as examined by electron microscopy techniques".- Journal of the American Ceramic Society, 64 (10), pp. 567-572.

Jennings H.M., (2000) "A model for the microstructure of calcium silicate hydrate in cement paste".Cement and Concrete Research, 30 (1), pp. 101-116.

Jennings H.M., (2004) “Colloid model of CSH and implications to the problem of creep and shrinkage".- Materials and Structures, 37 (265), pp. 59-70.

Jiang L, Lin B., Cai Y., (2000) “A model for predicting carbonation of highvolume fly ash concrete, Cem. Concr. Res. 30 pp. 699-702.

Jones F.E., (1938). II international symposium on the Chemistry of Cements, pp. 231-245.

Jones M.R., Macphee D.E., Chudek J.A., Hunter G., Lannegrand R., Talero R., Scrimgeour S.N., (2003) "Studies using ${ }^{27} \mathrm{Al}$ MAS NMR of AFm and AFt phases and the formation of Friedel's salt".- Cement and Concrete Research, 33 (2), pp. 177-182.

\section{- K -}

Kalousek G.L., Benton E.J., (1970) “Mechanish of seawater attack on cement pastes". J Amer Concrete Inst, 67 (2), pp. 187-192.

Kalousek G.L., Porter L.C., Benton E.J., (1972) "Concrete for Long-Time Service in Sulphate Environment". Cement and concrete Research, 2 (1), pp79-89.

Kantro D.L., Brunauer S., Weise C.H., (1962) “Development of surface in hydration of calcium silicates. II. Extension of investigations to earlier and later stages of hydration".- Journal of Physical Chemistry, 66 (10), pp. 1804-1809.

Kayali O., Sharfuddin Ahmed M., (2013) “Assessment of high volume replacement fly ash concrete - Concept of performance index". Construction and Building Materials 39, pp. 71-76.

Kayyali O.A., Haque M.N., (1988) “Effect of carbonation on the chloride concentration in pore solution of mortars with and without fly ash. Cement and Concrete Research, 18 (4), pp. 636-648.

Kobayashi K., Suzuki K., Uno Y., (1994) "Carbonation of concrete structures and decomposition of CSH".- Cem.Concr.Res., 24 (1), pp. 55-61.

Koch A., Steinegger H., (1960) "Ein schnellprufverfahren fur zemente auf ihr verhalten bei sulfatangriff", Zement-Kalk-Gips, 7, pp. 317324.

Kühl H. (1961). Zement Chemic; Tomo III, $3^{\underline{a}}$ ed., pp.118-130.

Kurczyk H.G., Schwiete H.E., (1960) “Concerning the hydration products of $\mathrm{C}_{3} S$ and $\mathrm{C}_{2} \mathrm{~S}^{\text {" }}$ en $4^{\text {th }}$ International Symposium on the Chemistry of Cement, pp. 349-358, Washington, DC, Estados Unidos.

Kurdowsky K, Thiel J., (1981) "On the role of free calcium oxide in expansive cements". Cem Concr Res, 11 (1), pp. 29-40.

Kuzel H.J., (1968) "Ersatz $\mathrm{Al}^{3+}$ durch $\mathrm{Cr}^{3+}$ und $\mathrm{Fe}^{3+}$ in $3 \mathrm{CaO} \cdot \mathrm{Al}_{2} \mathrm{O}_{3} \cdot \mathrm{CaCl}_{2} \cdot \mathrm{nH}_{2} \mathrm{O}$ und $3 \mathrm{CaO} \cdot \mathrm{Al}_{2} \mathrm{O}_{3} \cdot \mathrm{CaSO}_{4} \cdot \mathrm{nH}_{2} \mathrm{O}^{\prime \prime}$.- Zement-Kalk-Gips, 21 (12), pp. 493-499.

Kuzel H.J., (1996) “Initial hydration reactions and mechanism of delayed ettringite formation in Portland cements".- Cement and Concrete Composites, 18 (3), pp. 195-203.

\section{- L -}

Lachaud R. (1979) “Thaumasite and Ettringite in Building Materials". Ann Inst Tech Batim Trav Publics, (370), pp. 1-7.

Laffaille A., Protas J., (1970) “Nouvelles données sur la structure de la thaumasite". Comptes Rendus Hebdomadaires des Sciences de l'Académie des Sciences, Série D, 270, pp. 2151-2154.

Lafuma H., (1929) “Theory of expansion of cements".- Revue des Matériaux Construction et Trav. Publ., 243, pp. 441-444. 
Lam L., Wong Y.L., Poon C.S., (2000) “Degree of hydration and gel/space ratio of high-volume fly ash/cement systems". Cement and Concrete Research 30, pp. 747-756.

Lannegrand R., Ramos G., Talero R., (2001) “Estado del conocimiento sobre la sal de Friedel".Materiales de Construcción, 51 (262), pp. 63-71.

Laugesen J.L., (2003) “Density functional calculation of elastic properties of portlandite and foshagite", en $1^{\text {st }}$ International Symposium Nanotechnology in Construction, Paisley, Reino Unido.

Laugesen J.L., (2005) "Density functional calculations of elastic properties of portlandite, $\mathrm{Ca}(\mathrm{OH}) 2^{\prime \prime}$.Cement and Concrete Research, 35 (2), pp. 199-202.

Le Chatelier H., (1882) “Recherches expérimentales sur la constitution des ciments et la théorie de leur prise".- Comptes Rendus de l'Académie des Sciences, 94, pp. 867-869.

Le Chatelier H., (1919) “Crystalloids against colloids in the theory of cements".- Transactions of the Faraday Society,14 (1-2), pp. 8-11.

Lerch W., Ashton F.W., Bogue H., (1929). Journal Research of National Bureau Standards, JR-NBS, 2, (4), 715.

Liang T., Nanru Y., (1994) "Hydration products of calcium aluminoferrite in the presence of gypsum".- Cement and Concrete Research, 24 (1), pp. 150-158.

Lossier H., (1952) Zement-Kalk-Gips 5, 226.

López Ruiz A., (1955a) "Posibilidades de empleo de las arcillas en la fabricación de aglomerantes económicos". Publicación no ${ }^{\circ}$ 84, Laboratorio Central de Ensayos de Materiales de Construcción (LCEMC o actual CEDEX).

López Ruiz A., (1955b) "Determinación experimental rápida de las condiciones óptimas de activación de arcillas para su transformación en puzolanas artificiales". Publicación nº 85, LCEMC (= CEDEX).

Lukas W. (1976) "Substitution of Si in the lattice of ettringite". Cem. Conc. Res., 6 (2), pp. 225-234.

\section{- M -}

McCarthy M.J., Dhir R.K., (2005) “Development of high volume fly ash cements for use in concrete construction". Fuel 84, pp. 1423-1432.

Malhotra V.M., Carette G.G., Bilodeau, A.,
Sivasundaram V., (1991) "Some Aspects of Durability of High Volume ASTM Class F Fly Ash Concrete", International Conference on Durability of Concrete, Montreal, Canada, SP-126, American Concrete Institute, Detroit, pp. 65-82 .

Malquori G, Spadano S., (1936) "Azione combinata del gesso e della calce sui materiali pozzolanici". La Ricerca Scientifica, Vol. 7, pp. 185-191.

Manzano H., Dolado J.S., Guerrero A., Ayuela A., (2007) "Mechanical properties of crystalline calcium-silicate-hydrates: comparison with cementitious C-S-H gels".-- Physica Status Solidi (a), 204 (6), pp. 1775-1780.

Martínez-Val J. M., (2005) “Alternativas tecnológicas al Protocolo de Kyoto". Cemento y Hormigón, 881, pp. 48-62.

Mather B. (1984) "A discussion of the paper "theories of expansion in sulfoaluminate-type expansive cements: Schools of thought," by M.D. Cohen". Cement and Concrete Research, 14 (4), pp. 603-609

Mather K. (1978) “Cement Standards, Evolution and Trends" P.K. Mehta Editor, ASTM STP 663, pp. 74-86.

Matschei T., Lothenbach B., Glasser F.P., (2007a) "The AFm phase in Portland cement".- Cement and Concrete Research, 37 (2), pp. 118-130.

McMurdie H.F., Flint E.P., (1943) “X-ray patterns of hydrated calcium silicates".- Journal of Research of the National Bureau of Standards, 31 (4), pp. 225228.

Mei J., Tan H., Li H., Maa B., Liu X., Jiang W., Zhang T., Li X., (2018) "Effect of sodium sulfate and nano$\mathrm{SiO} 2$ on hydration and microstructure of cementitious materials containing high volume fly ash under steam curing. Construction and Building Materials 163 pp. 812-825.

Megaw H.D., Kelsey C.H., (1956) “Crystal structure of tobermorite".- Nature, 177 (4504), pp. 390-391.

Mehta P.K., (1969) "Morphology of calcium sulphoaluminate hydrate". J. Am. Ceram. Soc., 52, pp. 521-522.

Mehta P.K., (1973a) "Mechanism of expansion associated with ettringite formation". Cem. Concr. Res., 3, pp. 1-6.

Mehta P.K., (1973b) “Effect of Lime on Hydration of Pastes Containing Gypsum and Calcium Aluminates or Calcium Sulfoaluminate". Journal of the American Ceramic Society, 56 (6), pp. 315-319. 
Mehta P.K., (1976a) "Scanning electron micrographic studies of ettringite formation". Cem. Concr. Res., 6, pp. 169-182.

Mehta, P.K. (1976b) "Reply to S. Chatterji's discussion of the paper "scanning electron micrographic studies of ettringite formation". Cement and Concrete Research, 6 (5), pp. 713-714.

Mehta P.K., (1983) “Mechanism of sulfate attack on Portland cement concrete-another look." Cem. Concr. Res., 13, pp. 401-406.

Mehta, P.K., (1986) "Effect of fly ash composition in sulfate resistance of cement", ACI Journal, V, 83, p.p 994-1000.

Mehta P.K., (1999) "Concrete technology for sustainable development", Concr. Int., 21 (11), pp. 4752.

Mehta, P.K., Gjørv, O.E. (1982) “Properties of portland cement concrete containing fly ash and condensed silica-fume". Cement and Concrete Research, 12 (5), pp. 587-595.

Mehta P.K., Hu F., (1978) “Further Evidence for Expansion of Ettringite by Water Adsorption". Journal of the American Ceramic Society, 61 (3-4), pp. 179-181.

Mehta P.K., Klein A., (1965) “Formation of Ettringite by Hydration of a System Containing an Anhydrous Calcium Sulfoaluminate". Journal of the American Ceramic Society, 48 (8), pp. 435-436.

Mehta P.K., Wang S., (1982) “Expansion of ettringite by water adsorption". Cement and Concrete Research, 12 (1), pp. 121-122.

Mejía R., Talero R., (1995) "Absorción de agua y penetración de cloruros, en morteros de cemento adicionados". Ponencia, ACTAS 5o Congreso Iberoamericano de Corrosión y Protección, Simposium II: Comunicaciones Orales y Posters, Tenerife, España.

Mejía R., Talero R., (1997) "Agresividad de los cloruros en función del tipo de cemento". Ponencia, ACTAS, IV Congresos Nacional de Corrosión y Protección, Paipa, Colombia.

Mejía, R., Delvasto, S., Talero, R., (2000) "A new pozzolan high performance cementitious materials", Mater Construcc, Vol. 50, n²60, pp. 5-13.

Mejía, R., Delvasto, S., Talero, R., (2003) "Chloride diffusion measured by a modified permeability test in normal and blended cements", Adv Cem Res, Vol. 15, no3, p. 113-118.
Michaelis W., (1892) “Der Zementbacillus".Tonindustrie Zeitung, 16, pp. 105-106.

Michaelis W., (1908) "Über Kalkmörter".Tonindustrie Zeitung, 32, pp. 738-742.

Midgley H.G., Pettifer K. (1971) "The micro structure of hydrated super sulphated cement". Cem. Concr. Res., 1, pp. 101-104.

Mikhail, R.Sh., Abo-El-Enein, S.A., Hanafi, S., Good, R.J., (1981) "Ettringite formation in compressed expansive cement pastes". Cement and Concrete Research, 11 (5-6), pp. 665-673.

Miller D.G., (1928). Proc. ASTM, 31ํAnnual Meeting, V. 28, Part. III, TP, p. 448-489.

Miller D.G., (1946). Proc. 49ำ Annual Meeting ASTM, V.46, 278-288.

Mills R.H., (1981) "Preferential precipitation of calcium hydroxide on alkali-resistant glass-fibres".Cement and Concrete Research, 11 (5-6), pp. 689697.

Monosi S., Collepardi M., (1986) "Effect of silica fume on the hydration products of C3A-Gypsum", Proceedings, 8th International Congress on the Chemistry of Cement (ICCC), Rio de Janeiro, Brasil, Vol. III, pp. 120-129.

Moore A.E., Taylor H.F.W. (1968) “Crystal structure of ettringite".- Nature 218 (5146), pp. 10481049.

Mori T., Tanaka K., (1973) “Average stress in matrix and average elastic energy of materials with misfitting inclusions".- Acta Metallurgica, 21 (5), pp. 571-574.

Moya S., Sanz J., Serratosa J.M., Madani A., Aza S., (1988) "Aluminum-27 and Silicon-29 Magic Angle Spinning Nuclear Magnetic Resonance Study of the Kaolinite-Mullite Transformation", J Am Ceram Soc, 71 (10), pp. C-418-C-421.

Murat R., (1983a) "Hydration reaction and hardening of calcined clays and related minerals. Part I: Preliminary investigation on metacaolinite", Cem Concr Res,13 (2), pp. 259-266.

Murat R., (1983b) "Hydration reaction and hardening of calcined clays and related minerals. Part II: Influence of mineralogical properties of the raw-caolinite of the reactivity of metacaolinite", Cem Concr Res,13 (4), pp. 511-518.

Murat R., Comel C., (1983) "Hydration reaction and hardening of calcined clays and related minerals. Part III: Influence of calcination process of caolinite 
on mechanical strengths of hardened metacaolinite", Cem Concr Res,13 (5), pp. 631-637.

\section{$-\mathbf{N}$ -}

Nagataki S., Ohga H., Kim E.K., (1986) “Effect of curing conditions on the Carbonation of Concrete with Fly Ash and the Corrosion of Reforcement in long-term tests. Publication SP - American Concrete Institute, 1, pp. 521-540

Nasser K.W., Al-Manaseer, A.A. (1986) "Shrinkage and Creep of Concrete containing 50 percent lignite Fly Ash at different Stress-Strength ratios. Publication SP - American Concrete Institute, 1, pp. 433448 .

Nasser K.W., Al-Manaseer A.A., (1987) ““Shrinkage and Creep of Concrete containing 50 percent lignite Fly Ash at High Temperatures". Cement, Concrete and Aggregates 9(2), pp. 95-100

Negro A., Bachiorrini A., (1982) “Expansion associated with ettringite formation at different temperatures". Cement and Concrete Research, 12 (6), pp. 677-684.

Negro A., Bachiorrini A., (1983) “A reply to a discussion by S. Chatterji of the paper "expansion associated with ettringite formation at different temperatures". Cement and Concrete Research 13(4), pp. 589-590.

Neville A.M., (2004) “The confused world of sulfate attack on concrete".- Cement and Concrete Research, 34 (8), pp. 1275-1296.

Newberry S.B., Smith M.M., (1903) “Constitution of hydraulic cements".- Journal of the Society of Chemical Industry, 22, pp. 94-95.

Nishikawa T., Suzuki K., Ito S., (1992) "Descomposition of synthesized ettringite by carbonation".- Cem.Concr.Res., 22 (1), pp. 6-14.

Nonat A., (2004) "The structure and stoichiometry of C-S-H".- Cement and Concrete Research, 34 (9) pp. 1521-1528.

\section{$-\mathrm{O}$ -}

Ormsley W.C., Bolz L.H., (1966) "Microtexture and Composition of Reaction Products in the System Kaolin-Lime-Water", J Am Ceram Soc, Vol. 49 (7), pp. 364-366.

Otxoa A., (2004) “Valorización material en el proceso de fabricación de cemento. La experiencia de Sociedad Finaciera y Minera, S.A". Cemento y Hormigón, 864, pp. 55-62.

$$
-\mathbf{P}-
$$

Papayianni I., Anastasiou E, (2010) “Production of high-strength concrete using high volume of industrial by-products". Constr Build Mater 24 pp. 1412 1417.

Petch H.E., Megaw H.D., (1954) “Crystal structure of brucite $\mathrm{Mg}(\mathrm{OH})_{2}$ and portlandite $\mathrm{Ca}(\mathrm{OH})_{2}$ in relation to infrared absorption".- Journal of the Optical Society of America, 44 (9), pp. 744-745.

Piasta W., (2017) "Analysis of carbonate and sulphate attack on concrete structures". Engineering Failure Analysis 79 pp.606-614

Pierce, J.S., (1982) “Use of Fly Ash in combating sulfate attack in Concrete". United States Department of Energy, Morgantown Energy Technology Center (Report) DOE/METC 2, pp. 208-231.

Polivka M, Brown E.H., (1961) "Influence of Various Factors on Sulphate Resistance of Concrete Containing Pozzolan". Proceedings, ASTM, Vol. 58, pp. 1077-1100. Discusión con Swayze.

Powers T.C., Brownyard L.C., (1947) "Studies of the physical properties of hardened Portland cement paste". - Journal of the American Concrete Intitute, 43 (9), pp. 933-992.

Powers T.C., (1958) "Structure and physical properties of hardened Portland cement paste".-- Journal of the American Ceramic Society, 41 (1), pp. 1-6.

Puertas F., Blanco-Varela M.T., (2004) “Use of alternative fuels in cement manufacture. Effect on clinker and cement characteristics and properties". Materiales de Construcción. 54, pp. 51-64.

\section{- R -}

Rahhal, V. Talero, R. (2003a) "Effect of three natural pozzolans in Portland cement hydration".- Mater Construcc, Vol. 53, no269, pp. 29-40.

Rahhal V., Talero R., (2003b) "Influencia de cenizas volantes sobre la hidratación de cementos Portland", HORMIGÓN, 4 (40), pp. 9-17.

Rahhal V., Talero R., (2003c) "Estudio de la influencia de las adiciones silícicas y alumínicas sobre el cemento Portland", Ponencia, ACTAS, XIV Reunión Técnica de la Asociación Argentina de Tecnología 
del Hormigón, Tomo I, p. 115-122, Argentina.

Rahhal, V., Talero, R., (2004) “Influence of two different fly ashes on the hydration of Portland cements".- Journal of Thermal Analysis and Calorimetry, 78 (1), pp. 191-205.

Rahhal V., Talero R., (2005) “Early hydration of portland cement with crystalline mineral additions".- Cement and Concrete Research, 35 (7), pp. $1285-1291$.

Rahhal V., Talero R., (2014) “Very early detection of ettringite from pozzolan origin". Constr Build Mater, 53, pp 674-679.

Rahhal V., Bonavetti V., Delgado A., Talero R., (2007a) "Esquema de la hidratación de cementos Portland con adiciones minerales cristalinas".- Actas electrónicas del IX Congreso Latinoamericano de Patología de la Construcción - XI Congreso de Control de la Calidad en la Construcción, publicación A5, Quito, Ecuador.

Rahhal V., Cabrera O., Talero R., Delgado A., (2007b) "Calorimetry of Portland cement with silica fume and gypsum additions".- Journal of Thermal Analysis and Calorimetry, 87 (2), pp. 331-337.

Rahhal V., Talero R., (2008) “Calorimetry of Portland cement with metakaolins, quartz and gypsum additions".- Journal of Thermal Analysis and Calorimetry, 91 (3), pp. 825-834.

Rahhal V., Bonavetti V., Delgado A., Pedrajas C., Talero R., (2009) "Scheme of the Portland cement hydration with crystalline mineral admixtures and other aspects".-- Silicates Industriels, 74 (11-12), pp. 347-352.

Rahhal V., Bonavetti V., Trusilewicz L, Pedrajas C., Talero R., (2012) "Role of the filler on Portland cement hydration at early ages".- Construction and Building Materials, 27 (1), pp. 82-90.

Rahhal V., Pedrajas C., Irassar F., Talero R., (2014) “Efecto de puzolanas naturales sobre la reología de pastas de cemento Portland, CONCRETO Y CEMENTO, 5(2). pp. 1-11.

Ramachandran V. S., Sereda P. J., Feldman R. F., (1964) "Mechanism of Hydration of Calcium Oxide". Nature volume 201, pp. 288-289.

Ramachandran V.S., (1979) "Differential thermal method of estimating calcium hydroxide in calcium silicate and cement pastes".- Cement and Concrete Research, 9 (6), pp. 677-684.

Rankin G.A., (1919) “The setting and hardening of
Portland cement".- Transactions of the Faraday Society,14 (1-2), pp. 23-28.

Rashad A.M., (2015a) “An exploratory study on high-volume fly ash concrete incorporating silica fume subjected to thermal loads". Journal of Cleaner Production 87, pp. 735-744.

Rashad A.M., (2015b) “An investigation of highvolume fly ash concrete blended with slag subjected to elevated temperatures". Journal of Cleaner Production 93, pp. 47-55.

Ravindrarajah R., (1987) “Utilization of waste concrete for new construction". Conservation and Recycling, 10 (2-3), pp. 69-74.

Renaudin G., Francois M., Evrard O., (1999) “Order and disorder in the lamellar hydrated tetracalcium monocarboaluminate compound".- Cement and Concrete Research, 29, pp. 63-69.

Richardson I.G., Groves G.W., (1992) “Models for the composition and structure of calcium silicate hydrate (C-S-H) gel in hardened tricalcium silicate pastes".- Cement and Concrete Research, 22 (6), pp. 1001-1010.

Richardson I.G., Groves G.W., (1993a) “Microstructure and microanalysis of hardened ordinary Portland cement pastes".- Journal of Materials Science, 28 (1), pp. 265-277.

Richardson I.G., Groves G.W., (1993b) “The incorporation of minor and trace elements into calcium silicate hydrate (C-S-H) gel in hardened cement pastes".- Cement and Concrete Research, 23 (1), pp. $131-138$.

Richardson I.G., Groves G.W., (1993c) a reply to Discussions by H.F.W. Taylor of the Papers "models for the composition and structure of calcium silicate hydrate (C-S-H) gel in hardened tricalcium silicate pastes" and "The incorporation of minor and trace elements into calcium silicate hydrate (CS-H) gel in hardened cement pastes".- Cement and Concrete Research, 23 (4), pp. 999-1000.

Richardson I.G., (1999) "The nature of C-S-H in hardened cements".- Cement and Concrete Research, 29 (8), pp. 1131-1147.

Richardson I.G., (2000) "The nature of hydration products in hardened cement pastes".- Cement and Concrete Composites, 22 (2), pp. 97-113.

Richardson I.G., (2004) “Tobermorite/jennite- and tobermorita/calcium hydroxide-based models for the structure of C-S-H: applicability to hardened pastes of tricalcium silicate, $\beta$-dicalcium silicate, 
Portland cement, and blends of Portland cement with blast-furnace slag, metakaolin, or silica fume".- Cement and Concrete Research, 34 (9), pp. 1733-1777.

Richartz W., (1969) “Uber die Gefuge-und Festigkeitsentwicklung des Zementsteins".- Betontechnische Berichte, pp. 67-83, Betonverlag $\mathrm{GmbH}$, Düsseldorf, Alemania.

Rigo da Silva C.A., Reis R.J.P., Lameiras F.S., Vasconcelos W.L., (2002) “Carbonation-related microstructural changes in long-term durability concrete".- Mater.Res., 5, pp. 287-293.

Río A, Celani A, Angeletti L., (1961) "La composizione dei cementi pozzolanici e la loro resistenza alle acque solfatiche". L'Industria Italiana del Cemento, ANNO XXXI (4), pp. 184-193.

Rose J., Bénard A., El Mrabet S., Masion A., Moulin I., Briois V., Olivi L, Bottero J.Y., (2006) “Evolution of iron speciation during hydration of $\mathrm{C}_{4} \mathrm{AF}^{\prime \prime}$.Waste Management, 26 (7), pp. 720-724.

\section{$-S$ -}

Samanta C., Chatterjee M.K. (1982) "Sulfate resistance of portland-pozzolanic cements in relation to strength. Cement and Concrete Research, 12 (6), pp. 726-734.

Santarelli L. (1941) “Cementi ferrici a basso modulo calcare". L' Ingegnere genllaio, pp. 1.

Schwiete H.E., Ludwig U., Albeck j., (1969) “Combining of Calcium Chloride and Calcium Sulphate in hydration of aluminate-ferritic clínker constituents". Zement-Kalk-Gips, 22 (5), pp. 225-234.

Seligman P., Greening N. R., (1964) “Early Hydration Reactions of Portland Cement by X-Ray Diffraction". Highw. Res. Rec., 62. PCA Res Dept Bull., No. 185. pp. 80-105.

Shaikh F.U.A., Supit S.W.M., (2014) “Mechanical and durability properties of high volume fly ash (HVFA) concrete containing calcium carbonate $\left(\mathrm{CaCO}_{3}\right)$ nanoparticles". Construction and Building Materials 70, pp. 309-321.

Shaikh F.U.A., Supit S.W.M., (2015) “Compressive strength and durability properties of high volume fly ash (HVFA) concretes containing ultrafine fly ash (UFFA)". Construction and Building Materials 82, pp. 192-205.

Supit S.W.M., Shaikh F.U.A., Sarker P.K., (2014) "Effect of ultrafine fly ash on mechanical properties of high volume". Construction and Building Materials 51, pp. 278-286.

Sideris K.K., Savva A.E., Papayianni J., (2006) “Sulfate resistance and carbonation of plain and blended cements". Cement \& Concrete Composites 28 pp. 47-56.

Sivasundaram V., Malhotra V.M., (1992) “Properties of concrete incorporating low quantity of cement and high volumes of ground granulated slag".- ACI Mater. J. 89 (6) pp. 554-563.

Skoblinskaya, N.N., Krasilnikov, K.G. (1975) "Changes in crystal structure of ettringite on dehydration. 1". Cement and Concrete Research, 5 (4), pp. 381-393.

Slegers P.A., Rouxhet P.G., (1976) "Carbonation of the hydration products of tricalcium silicate".Cem.Concr.Res., 6, pp. 381-388.

Smith R.H., Bayliss P., Gamble, B.R., Mills R.H., (1972) "Crystallographic investigation of CSH(1)".Cement and Concrete Research, 2 (5), pp. 559-566.

Sorensen E.V., (1982). Silicates Industriales, XLVII (109, p.223-228.

Stutzman P, (2001) “Contributions of NIST/NBS researchers to the crystallography of construction materials".- Journal of Research of the National Institute of Standards and Technology, 106 (6), pp. 1051-1061.

Suzuki K., Nishikawa T., Ito S., (1985) “Formation and carbonation of CSH in water".Cem.Concr.Res., 15, pp. 213-224.

Swamy R.N., Ali Sami A.R., Theodorakopoulos D.D., (1983) "Early Strength fly ash concrete for structural applications". Journal of the American Concrete Institute, 80 (5), pp. 414-423.

\section{- T -}

Taber S. (1916) “The growth of crystals under external pressure”. Am J Sci, 4 (41), pp.532-556

Talero, R., (1987) "Cementos puzolánicos de mayor resistencia al ataque de aguas selenitosas que los cementos Portland de elevada resistencia a las mismas. y vice versa", Mater Constr, 37 (207), pp. 3750 .

Talero, R., (1990) "Qualitative analysis of natural pozzolans, fly ashes and blast furnace slag by XRD", Journal of Materials in Civil Engineering, 2 (2), pp. 106-115. 
Talero R., (1991) “Patología del Hormigón: Su destrucción galopante por ataque del yeso: $2^{\underline{a}}$ Terapia preventiva-Óptimo de $\mathrm{SO}_{3}$. Su determinación".- Ciclo de Conferencias sobre: Aplicaciones, Patologías y Terapias de Estructuras, Hormigón y otros Materiales de Construcción, pp. 333-346, Zaragoza, España.

Talero R., (1992) "Ettringite from Portland cement origin and ettringite form pozzolan origin: analogies, differences and semiquantitative relations with their respective origins, Interrogations". Proceedings, 9th Intern, Congress on the Chemistry of Cement, New Dehli, India, Vol. IV, Theme III, p. 343-349.

Talero R., (1993a) "Sulphatic characterization of pozzolanic additions: accelerated methods of the test to determine it (Le Chatelier-Ansttet and ASTM C452-68 tests)" en Proceedings of the $10^{\text {th }}$ International Coal Ash Symposium, , Vol.2, Section 8: Concrete III, Orlando-Florida, Estados Unidos.

Talero R., (1996) “Comparative XRD analysis ettringite originating from pozzolan and from Portland cement".-Cement and Concrete Research, 26 (8), pp.1277-1283.

Talero R., (2002) “Kinetochemical and morphological differentiation of ettringites by the Le Chatelier-Ansttet test".- Cem.Concr.Res., 32, pp. 707-717.

Talero R., (2003a) “Kinetochemical and morphological differentiation of ettringites by metakaolin, portland cements and the Le Chatelier-Ansttet test. Parameter: Vicat Needle Penetration".- Silic.Ind., 68 (11-12), pp. 137-146.

Talero R., (2003b) “Performance of the metakaolin and portland cements forming ettringite: Kinetic and morphological differences".- 11th Intern. Congress on the Chemistry of Cement, Vol.2, pp.853867, Durban (Rep. Sudáfrica).

Talero R., (2005a) “Performance of metakaolin and portland cements in ettringite formation as determined by ASTM C452-68: Kinetic and morphological differences". Cem.Concr.Res., 35 (7), pp. 12691284

Talero R., (2005b) "Synergic Expansive Effect of ettringite from pozzolan and from OPC, co-precipitating in a common plaster-bearing solution". IV International $\mathrm{ACI} / \mathrm{CANMET}$ Conference on Quality of Concrete Structures and Recent Advances in Concrete Materials and Testing, Supplemetary Cementing Materials, Ref. n⿳⺈⿴囗十, 33, Olinda, Pernanbuco, Goaânia, Goiás, Brasil, pp. 892-913.
Talero R., (2005c) "Efecto Sinérgico Expansivo entre la Ettringita de origen Puzolana y de origen Cemento Portland". VIII Congreso Latinoamericano de Patología de la Construcción y X Congreso de Control de Calidad en la Construcción, CONPAT 2005. ACTAS, Vol. I: Control de Calidad, Capítulo III, Materiales, Ponencia ES31, p. III,123-III,130, Asunción, Paraguay.

Talero R., (2005d) "Synergic Expansive Effect of ettringite from pozzolan and from OPC, co-precipitating in a common plaster-bearing solution". IV International ACI/CANMET Conference on Quality of Concrete Structures and Recent Advances in Concrete Materials and Testing, Supplemetary Ce-

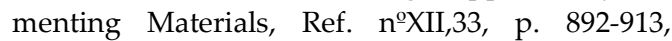
Olinda, Pernanbuco, Goaânia, Goiás, Brasil.

Talero R. (2005e) "Efecto Sinérgico Expansivo entre la Ettringita de origen Puzolana y de origen Cemento Portland". VIII Congreso Latinoamericano de Patología de la Construcción y X Congreso de Control de Calidad en la Construcción, CONPAT 2005. ACTAS, Vol. I: Control de Calidad, Capítulo III, Materiales, Ponencia ES31, p. III,123-III,130, Asunción, Paraguay.

Talero R., (2007) "Performance of metacaolin and Portland cement in ettringite formation as determined by Le Chatelier-Ansttet test: Kinetic and morphological differences and new specification". Silicates Industriels, 72 (11-12), pp. 191-204.

Talero R., (2008) "Diferenciación cinética y morfológica de Ettringitas mediante Metakaolín, cementos Portland y el ensayo ASTM C 452-68. Parte I: diferenciación cinética".- Materiales de Construcción, 58 (292), pp.45-66.

Talero R., (2009) "Diferenciación cinética y morfológica de ettringitas mediante metakaolín, cementos Portland y el ensayo ASTM C 452-68. Parte II: diferenciación morfológica mediante análisis por SEM y DRX".- Materiales de Construcción, 59 (293), pp. 35-51.

Talero R., (2010) “Expansive Synergic Effect of ettringite from pozzolan (metakaolin) and from OPC, co-precipitating in a common plaster-bearing solution: Part I: By cement pastes and mortars".Construction and Building Materials, 24, (9), pp. 1779-1789.

Talero R., (2011a) “Expansive synergic effect of ettringite from pozzolan (metakaolin) and from OPC, co-precipitating in a common plaster-bearing solution. Part II: Fundamentals, explanation and justification".- Construction and Building 
Materials, 25 (3), pp. 1139-1158.

Talero R., (2011b) "Co-precipitación de ettringita de rápida y lenta formación, Consecuencia: Efecto Sinérgico Expansivo, Su demostración mediante morteros y hormigones". Mater Constr, 61 (303). pp. 327-352.

Talero R., (2012a) “Synergic effect of Friedel's salt from pozzolan and from OPC co-precipitating in a chloride solution".- Construction and Building Materials, 33, pp. 164-180.

Talero R., (2012b) "Gypsum attack: performance of silicic pozzolans and Portland cements as determined by ASTM C452-68". Adv Cem Res, 24 (1). pp. 1-15.

Talero R., (2013) "Performance of silicic pozzolans and Portland cements in their behavior in front of gypsum attack as determined by ASTM C 452-68".Materiales de Construccion, 63 (310), pp. 159-193.

Talero R., Palacios J, (1991). "Ettringita de origen Portland y de origen puzolana: Analogías, diferencias e interrogaciones tecnológicas". 45th RILEM Intern, Seminar on Direct Transfer of Research Results to Industry, ACTAS, Buenos Aires, Argentina, p. 102-110.

Talero R., Martín-Luengo M.P., (1992) "Behaviour of grinded brick used as mineral admixture to Portland cements against gypsum attack", II Jornada sobre Aplicaciones Arquitectónicas de los Materiales Compuestos y Aditivados, ACTAS, pp.83-102, ETS Arquitectura de Madrid, Universidad Politecnica de Madrid.

Talero, R., Martín-Luengo, M.P., (1993a) "Comportamiento de los cementos con humo de sílice contra el ataque del yeso", Ponencia, ACTAS, III Jornada sobre Aplicaciones Arquitectónicas de los Materiales Compuestos y Aditivados, ETS de Arquitectura de Madrid, Universidad Politécnica de Madrid.

Talero, R., Martín-Luengo, M.P., (1993b) "Comportamiento de cimentos con microsilica contra ataque do yeso", Ponencia, ACTAS, Congresso Nacional do Química do Cemento, Río de Janeiro, Brasil.

Talero R., Bollati M.R., (1994) "Behavior of metacaolin used as addition to concrete against gypsum attack". Supplementary Papers, 3rd CANMET/ACI International Conference on Durability of Concrete, Nice, Francia.

Talero R., Delgado A., (2007a) “El humo de sílice o la razón primordial de los hormigones de altas resistencias y/o altas prestaciones" en XVII Curso de Estudios Mayores de la Construcción del IETcc-
CSIC - Seminario 12 Reciclado de materiales en el sector de la construcción, pp. 107-119, Madrid.

Talero R., Rahhal V., (2007b) "Influence of aluminic pozzolans, quartz and gypsum additions on Portland cement hydration". 12th Intern. Congress on the Chemistry of Cement, Proceedings, Montreal.

Talero R., Delgado A., (2009a) “Los cementos, sus adiciones y la durabilidad del hormigón", en Geomateriales, Materiales de construcción y desarrollo sostenible, Edita Sanfeliú, T, Jordán, M.M. y Excmo. Ayuntamiento de Castellón de La Plana, pp. 295348, Castellón de La Plana, España.

Talero R., Rahhal V., (2009b) “Calorimetric comparison of Portland cements containing silica fume and metacaolin, Is silica fume, like metakaolin, ¿characterized by pozzolanic activity that is more specific than generic?". J Therm Anal Cal, 96 (2). pp. 383-393.

Talero R., Trusilewicz L., (2012) "Morphological Differentiation and Crystal Growth Form of Friedel's Salt Originated from Pozzolan and Portland Cement". Ind Eng Chem Res, 51, pp. 12517-12529.

Talero R., Bollati M.R., Hernández-O F., (1999) "Manufacturing non-traditional mortars and concretes by OPC, metakaolin and gypsum (15.05\%)".Materiales de.Construcción, 49 (256), pp. 29-41.

Talero R., Pedrajas C., Delgado A., Rahhal V., (2009b) "Re-use of incinerated agro-industial waste as pozzolanic addition. Comparison with Spanish silica fume".- Materiales de Construcción, 59 (296), pp. 53-89.

Talero R., Trusilewicz L., Delgado A., Pedrajas C., Lannegrand R., Rahhal V., Mejía R., Delvasto S., Ramírez F.A., (2011) “Comparative and semi-quantitative XRD análisis of Friedel's salt originating from pozzolan and Portland cement".- Construction and Building Materials, 25 (5), pp. 2370-2380.

Talero R., Arámburo C., Sánchez M.I., Río O., González M., Blázquez A., Frías M., Pedrajas C., (2017) "OPC and SRPC containing calcined paper sludge waste, Performance in front of sulfate attack: Ettringite and/or thaumasite formation".- Journal of Materials in Civil Engeneering, 29 (2), pp. 939949.

Taplin J.H., (1959) "A method for following the hydration reaction in Portland cement paste".- Australian Journal of Applied Science, 10 (3), pp. 329345. 
Tavasci, B., (1946) "Struttura Della pozzoloana di Segni", Il Cemento, 43 (4), pp. 25.

Tavasci, B., (1948) "Struttura della malta di calce e pozzolana di Bacoli", Il Cemento, 45 (3), pp. 114120.

Tavasci, B., (1954) "Struttura delle malte e cementi pozzolanici", Ann Chim, 44, pp. 621.

Taylor H.F.W., (1950) “Hydrated calcium silicates. Part 1. Compound formation at ordinary temperatures".- Journal of the Chemical Society, DEC, pp. 3682-3690.

Taylor M.A., Broms B.B., (1964) “Shear bond strength between coarse aggregate and cement paste or mortar".- Journal of the American Concrete Institute, 61 (8), pp. 939-956.

Taylor H.F.W., Howison J.W., (1965) “Relationship between calcium silicates and clay minerals".- Clay Minerals Bulletin, 3, pp. 98-111.

Taylor H. F. W., (1973) “Crystal Structures of Some Double Hydroxide Minerals". Mineralogical Magazine, 39, pp. 377-389.

Taylor H.F.W., (1986) “Proposed structure for calcium silicate hydrate gel".-- Journal of the American Ceramic Society, 69 (6), pp. 464-467.

Tennis P.D., Jennings H.M., (2000) “A model for two types of calcium silicate hydrate in the microstructure of Portland cement pastes".- Cement and Concrete Research, 30 (6) pp. 855-863.

Teoreanu, I., Dumitrescu, C., (1982) “Mechanisms of controlled expansion cements hardening". Cement and Concrete Research, 12 (2), pp. 141-155.

Termkhajornkit P., Nawaa T., Nakaib M., Saitoc T., (2005) "Effect of fly ash on autogenous shrinkage". Cement and Concrete Research 35, pp. 473-482.

Thiery M., Villain G., Dangla P., Platret G., (1992): "Investigation of the carbonation front shape on cementitious materials: Effcts of the chemical kinetics".-- Cem.Concr.Res., 37, pp. 1047-1058.

Thorwaldson T., (1952). Proc. Third Int'l. Symp. Chem. of Cements. Cement and Concrete Association, p. 463.

Tomes L.A., Hunt C.M., Blaine R.L., (1957) “Some factors affecting the surface area of Portland cement as determined by water vapour and nitrogen adsorption".-Journal of Research of the National Bureau of Standards, 59 (6), pp. 357-364.

Trusilewicz L., Fernández-Martínez F., Rahhal V.,
Talero R., (2012) "TEM and SAED Characterization of Metacaolin. Pozzolanic Activity", J Amer Ceram Soc, 95 (9), p. 2989-2996.

Turriziani R., Schippa G., (1956) "La presa e l'indurimento delle malte di pozzolana, calce e solfato di calcio", Ric. Scientifica, 26, p. 3387.

Turriziani R, Rio A. (1957) "Resistenza chimica dei cementi pozzolanici". L'Industria Italiana del Cemento, ANNO XXVII, nº 6, pp.145-151.

Tuthill L.H. (1956) "Resistance to chemical attack". ASTM Sp Publ. 169, pp. 188-200.

\section{$-\mathrm{U}-$}

Uchikawa H., Uchida, S., (1974) "The analysis of ettringite in hardened cement paste". Cement and Concrete Research, 4 (5), pp. 821-834.

Uchikawa H., Sawaki D., Hanehara S., (1995). “Influence of kind and added timing organic admixture on the composition, structure and property of fresh cement paste". Cement and Concrete Research 25, (2) pp. 353-364.

Ulm F.J., Delafargue A., Constantinides G., (2005) "Experimental microporomechanics" en Applied micromechanics of porous materials - CISM Courses and Lectures No. 480, International Centre for Mechanical Sciences. Ed. L. Dormieux/F.J. Ulm. Springer Wien New York, pp. 207-288.

\section{- V -}

Van den Heede P., De Belie N.,(2014) " A service life based global warming potential for high-volume fly ash concrete exposed to carbonation". Construction and Building Materials 55, pp. 183-193.

\section{- W -}

Way S.J., Cole, W.F., (1982) "Calcium hydroxide attack on rocks", Cem Concr Res, 12 (5), pp. 611-617.

Wells L.S., Clarke W.F., McMurdie H.F., (1943) "Study of the system $\mathrm{CaO}-\mathrm{Al}_{2} \mathrm{O}_{3}-\mathrm{H}_{2} \mathrm{O}$ at temperatures of $21^{\circ} \mathrm{C}$ and $90^{\circ} \mathrm{C}^{\prime \prime}$.- Journal of Research of the National Bureau of Standards, 30 (5), pp. 367409.

Williamson R.B., (1972) "Solidification in Portland cement".- Progress in Materials Science, 15 (3), pp. 189-286. 
Wittmann F.H., (1974) "Bestimmung physikalischer Eigenschaften des Zementsteins".Deutscher Ausschuss fuer Stahlbeton, Heft 232:163, , W.Ernst \& Sohn, Berlín, Alemania.

Wittmann F.H., (1988) “Creep and shrinkage mechanism in concrete", en Creep \& Shrinkage of Concrete, Ed. Z.P. Bazant/F.H. Wittman, JohnWiley and Sons Inc., Nueva York, Estados Unidos.

Wolochow D., (1952): Proc, 55ํㅜ Annual Meeting ASTM, V.52, 250-66.

\section{- X -}

Xiantuo C., Ruizhen Z., (1994) “Kinetic study of ettringite carbonation reaction".- Cem.Concr.Res., 24 (7), pp. 1383-1389.

\section{- Z -}

Zhang M.H., (1995) “Microstructure, crack propagation, and mechanical properties of cement pastes containing high volumes of fly ashes, Cem Concr Res 25, pp. 1165-1178.

Zhou Q., Glasser F.P., (2000) "Kinetics and mechanism of the carbonation of ettringite".Adv.Cem.Res., 12 (3), pp. 131-136.

Zhou Q., Lachowski E.E., Glasser F.P., (2004) "Metaettringite, a decomposition product of ettringite".- Cement and Concrete Research, 34 (4), pp. 703-710.

Zimbelmann R., (1985) "A contribution to the problem of cement-aggregate bond".- Cement and Concrete Research, 15 (5), pp. 801-808.

Zohdi T.I., Monteiro P.J.M., Lamour V., (2002) “Extraction of elastic moduli from granular compacts".- International Journal of Fracture, 115 (3), pp. 49-54.

\section{- TESIS DOCTORALES -}

Barba Solana C., (1968) “Contribución al estudio de los materiales puzolánicos". Tesis Doctoral, Ftad. de CC. Químicas - UCM .

Delgado A., (2014) “Contribución al análisis y estudio de la Zona Interfacial Árido-Pasta de Cemento Portland".- Tesis Doctoral, Universidad de Castilla la Mancha, Facultad CC. Químicas, 29 mayo. Director: Rafael Talero, España.

Kalousek G.L., (1941). Ph.D. Thesis, University of
Maryland.

Martín-Luengo M.P., (1997) “Contribución al análisis y estudio del comportamiento en resistencias sulfática y mecánicas, de algunos componentes cristalinos y amorfos de las cenizas volantes".- Tesis Doctoral, Facultad de Ciencias Químicas, Universidad Autónoma de Madrid, España.

Mejía R., (1997) “Contribución al estudio analítico y físico-químico del sistema: cementos Portlandpuzolanas-escoria siderúrgica-cloruros-agua".- Tesis Doctoral, Universidad Complutense de Madrid, Facultad CC. Químicas, 29 mayo. Director: Rafael Talero, España.

Pedrajas C, (2016) “Contribución al análisis y estudio del comportamiento reológico de pastas frescas de cementos Portland con adiciones minerales activas, tipo puzolana, y no activas, tipo filler". Tesis Doctoral, Universidad de castilla la Mancha, Facultad de CC. Químicas, 8 febrero. Directores: Rafael Talero y Viviana Rahhal, España.

Rahhal V., (2002) “Caracterización de las adiciones puzolánicas por calorimetría de conducción".- Tesis Doctoral, E.T.S. de Ingenieros de Caminos, Canales y Puertos, Universidad Politécnica de Madrid, España.

Rodger S.A., (1984) "The chemistry of admixture interaction during cement hydration".- Tesis Doctoral, Universidad de Oxford, Reino Unido.

Soria F., (1966) “Contribución al estudio de los cementos resistentes a los sulfatos". Tesis Doctoral, Universidad Complutense de Madrid, España.

Talero R., (1986) “Contribución al estudio analítico y físico-químico del sistema: cementos puzolánicos-yeso-agua $\left(\text { a } 20 \pm 2{ }^{\circ} \mathrm{C}\right)^{\prime \prime}$.- Tesis Doctoral, Facultad de Ciencias Químicas, Universidad Complutense de Madrid, España.

Talero R., (2017) “Nuevo método químico por vía húmeda, para determinar el contenido de alúmina reactiva de puzolanas naturales y artificiales". Tesis Doctoral en fase de redacción y montaje para su próxima Defensa Pública en la Facultad de Farmacia de la Universidad Complutense de Madrid España.

\section{- BIBLIOGRAFÍA -}

Bajkov A.A., (1948) “Gesammelte arbeiten”, vol. V, Moscú, Rusia.

Biczok I. (1972) “Corrosión y protección del hormigón". Ed. URHO 
Billington D.P., (1983) "The tower and the bridge", Princeton University Press, Princeton, Nueva Jersey, Estados Unidos.

Bogue R.H., (1959) “The Chemistry of Portland Cement", $2^{\text {nd }}$ Edition, Reinhold Publishing Corporation, Nueva York, Estados Unidos.

Bussagli M., (2001) "Comprender la arquitectura", Ed. Susaeta, Madrid, España.

Calavera, J., (1996) "Patología de Estructuras de Hormigón Armado y Pretensado. Tomo I", INTEMAC.

Calleja J. (1966) “Apología de los conglomerantes puzolánicos". Cemento-Hormigón, núm. 386.

Calleja J. (1968) "Tratamientos térmicos del hormigón". Monografías del Instituto Eduardo Torroja de la Construcción y del Cemento; 269.

Calleja, J., (1969) "Las Puzolanas", Monografías del Instituto "Eduardo Torroja", Vol. 281, pp. 1-95.

Davies, N., (1997) “Europe. A History”. Ed. Pilmico, Londres, Reino Unido.

Demeude H., Roy P., (2001) “Israel”. Ed. Taschen GMBH, Colonia, Alemania.

Fernández C., (1972) “Acueductos romanos en España". Publicaciones del Instituto de Ciencias de la Construcción Eduardo Torroja - Consejo Superior de Investigaciones Científicas, Madrid, España.

Font Quer, P., (1953) "Diccionario de Botánica", Labor. S.A., (ed.), Madrid, España.

Francis A.J., (1977) "The Cement Industry 17961914: A History", David \& Charles Publishers, Devon, Reino Unido.

Fundación CEMA (2011) “Reciclado y valoración de Residuos en la Industria cementera en EspañaInformación Técnica". Fundación laboral del Cemento y el Medio Ambiente. Estudio realizado por el Institut cerdá.

Fundación CEMA (2012) “Recuperación energética de residuos en la Industria cementera-Información Técnica" Fundación laboral del Cemento y el Medio Ambiente.

Grimshaw R.W., (1971) "The Chemistry and Physics of Clays and Allied Ceramic Materials", 4th Edition Revised, Ernes Benn Limited, London.

Lara F., (2000) "Historia de la Humanidad 3: Mesopotamia", Arlanza, Madrid, España.

Lea F.M., Desch C.H., (1956) “The Chemistry of
Cement and Concrete", Edward Arnold Ltd., Londres, Reino Unido.

Lea F.M., (1970) "The Chemistry of Cement and Concrete", Edward Arnold Ltd., Londres, Reino Unido.

López Ruiz A., (1955a) "Posibilidades de empleo de las arcillas en la fabricación de aglomerantes económicos", Laboratorio Central de Ensayos de Materiales de Construcción, Publicación no 84, c/ Alfonso XII, 11, Madrid.

López Ruiz A., (1955b) "Determinación experimental rápida de las condiciones óptimas de activación de arcillas para su transformación en puzolanas artificiales", Laboratorio Central de Ensayos de Materiales de Construcción, Publicación no 85, c/ Alfonso XII, 11, Madrid.

Mehta P.K., (1991) "Concrete in the marine environment", Modern Concrete Technology Series, Elsevier Applied Science Publishers LTD. Londres, Reino Unido.

Mindess S., Young J.F., (1981) “Concrete" $1^{\text {st }}$ Prentice Hall Inc., Englewood Cliffs, NJ, Estados Unidos.

Plum, N.M., Poulsen, E., Idorm, G.M., (1958) "Preliminary survey of alkali reaction in concrete", Ingeniorum Int. (ed.), Danemark, 2, pp. 26-32.

Ramachandran, V.S., (1995), "Concrete Admixtures Handbook. Properties. Science and Technology", Institute for Research in Construction, National Research Council Canada, Ottawa, Ontario, Canada, NOYES Publications, Park Ridge, New Jersey, EEUU.

Ranc R., Cariou B., (1989) “Quality and durability of concretes made with fillerized cements, the French experience".- BRE Seminar on limestonefilled cements, Londres.

International Standard Organization (1949) "Symposium on Use of Pozzolanic Materials in Mortars and Concretes: First Pacific Area". National Meeting, San Francisco, California, October 10-14, 1949

Soria F. (1967) “Panorama de los cementos puzolánicos en el futuro". Cia. Española de Puzolanas. Premio Luxan.

Soriano I., (1988) "Reacciones de interacción entre el árido y el cemento".- Seminario S-1. Durabilidad del Hormigón y de los Materiales Pétreos, Mecanismos de degradación, CEMCO 88, IETcc-CSIC, Madrid. 
Stierlin H., (2001) “Los mayas, palacios y pirámides de la selva virgen", Taschen $\mathrm{GmbH}$, Colonia, Alemania.

Talero., (1991) “Patologías y Terapias del Hormigón II: La "Capacidad de cambio catiónico" de las adiciones puzolánicas ¿Patología o Terapia para su Hormigón en Masa o Armado correspondiente?".Monografía n. 406, sept. 1991; Instituto de C.C. "Eduardo Torroja"-CSIC, C/.Serrano Galvache nº 4, 28033-MADRID.

Talero R., Delgado A., (2013†) “La durabilidad integral del hormigón".- Documento privado en última fase de redacción para publicar previsiblemente como Monografía de la serie Materiales del IETcc-CSIC, $\approx 300$ pp.

Taylor H.F.W., (1990) "Cement Chemistry", Academic Press Inc. San Diego, CA, Estados Unidos.

Taylor H.F.W., (1997) “Cement Chemistry", $2^{\text {nd }}$ Edition, Thomas Thelford Publishing, Londres, Reino Unido.

Tosco, U., (1973) "Atlas de Botánica", Partes 1aㅡ y 2aㅡ, Instituto Geografico de Agostini, Editorial TEIDE, S.A., España.

Turriziani, R., (1961) "Aspects of the Chemistry of Pozzolans", Taylor, H.F.W., (ed.), "The Chemistry of Cements", Academic Press, London y New York.

Van Arkel A.E., (1956) "Molecules and Crystals in Inorganic Chemistry 2nd edition". Interscience Publishers, Inc., 250 Fifth Ave., New York.

Wildung D., (2001) “Egipto, de la prehistoria a los romanos", Taschen $\mathrm{GmbH}$, Colonia, Alemania.

\section{- DOCUMENTOS TÉCNICOS -}

ACI 226 1R-87, “Groung Granulated Blast-Furnace Slag as a Cementitious Constituent in Concrete". American Concrete Institute, 2001, Detroit, MI, Estados Unidos.

ASTM Standard C109/C109M, 2007e1, "Standard Test Method for Compressive Strength of Hydraulic Cement Mortars (Using 2-in. or [50-mm] Cube Specimens)", ASTM International, West Conshohocken, PA.

ASTM Standard C150, 2007, "Standard Specification for Portland Cement", ASTM International, West Conshohocken, PA.

ASTM C311, 2011, "Standard Test Methods for Sampling and Testing Fly Ash or Natural Pozzolans for Use in Portland-Cement Concrete", ASTM
International, West Conshohocken, PA, 2011.

ASTM C474-13, 2013 "Standard Test Methods for Joint Treatment Materials for Gypsum Board Construction". ASTM International, West Conshohocken, PA, 2011.

ASTM Standard C563, 1995 “Standard Test Method for Optimum SO3 in Hydraulic Cement Using 24-h Compressive Strength", ASTM International, West Conshohocken, PA, 1995.

ASTM Standard C563, 2003 "Standard Test Method for Optimum SO3 in Hydraulic Cement Using 24-h Compressive Strength", ASTM International, West Conshohocken, PA, 2003.

ASTM Standard C593, 2006 "Standard Specification for Fly Ash and Other Pozzolans for Use With Lime for Soil Stabilization". ASTM International, West Conshohocken, PA.

ASTM C 595M, 1995 "Standard Specification for Blended Hydraulic Cements". ASTM International, West Conshohocken, PA, 1995.

ASTM C618, 2012, "Standard Specification for Coal Fly Ash and Raw or Calcined Natural Pozzolan for Use in Concrete", ASTM International, West Conshohocken, PA, 2012

ASTM Standard C778, 2006, "Standard Specification for Standard Sand", ASTM International, West Conshohocken, PA, 2006.

ASTM Standard C989, 1994 "Standard Specification for Granulated Blast-Furnace Slag for Use in Concrete and Mortars". ASTM International, West Conshohocken, PA.

ASTM C1012 / C1012M-18a (2018) “Standard Test Method for Length Change of Hydraulic-Cement Mortars Exposed to a Sulfate Solution". ASTM International, West Conshohocken, PA.

ASTM E104-02, 2012 “Standard Practice for Maintaining Constant Relative Humidity by Means of Aqueous Solutions". ASTM International, West Conshohocken, PA.

BS 8500-1:2015 “Concrete - Complementary British Standard to BS EN 206 Part 1: Method of specifying and guidance for the specifie".

DIN 1043/44, Deutsches Institut für Normung e.V.

Instrucción para la Recepción de Cementos (RC-08) (R.D. 956/2008 - BOE de 19 de junio 2008, núm. 148, pp. 27794-27841).

Instrucción del Hormigón Estructural (EHE-08) (R.D. 1247/2008 - BOE de 18 de julio 2008, núm. 203, 
pp. 35176-35178), entrada en vigor el 01 de diciembre de 2008

Naciones Unidas. (1997) "Protocolo de Kyoto". Convención Marco de las Naciones Unidas sobre el Cambio Climático (UNFCCC).

NF P 18-506 - 1992: “Additions pour béton hydraulique. Laitier vitrifié moulu de haut-forneau".

Pliego General de Condiciones para la Recepción de Conglomerantes Hidráulicos, PCCH-64 (O.M; 9 de abril de 1964; B.O.E. núm. 109, 9 de mayo de1964 y B.O.E. núm.222, 15 de septiembre de 1964).

Pliego de Prescripciones Técnicas generales para la recepción de Cementos RC-75 (D.P. 1964/1975 de 23 de mayo; B.O.E. núm. 206, 28 de agosto de 1975).

Protocolo de Kyoto, 1997. Convención marco de las naciones unidas sobre cambio climático (UNFCCC), Naciones Unidas.

Basica de Residuos Tóxicos y Peligrosos. (R.D. 952/1997 - BOE de 20 de junio de 1997, por e/ que se modifiea e/ Reg/amento para /a ejeeuciôn de /a Ley 20/1986, de 14 de maya, , aprobado mediante Rea/ Deereto 833/1988, de 20 de ju/io.

UNE-EN 196-1:2005 "Métodos de ensayo de cementos. Parte 1: Determinación de resistencias mecánicas".- AENOR.

UNE-EN 196-2:2006 "Métodos de ensayo de cementos. Parte 2: Análisis químico de cementos". AENOR.

UNE-EN 196-3:2005 "Métodos de ensayo de cementos. Parte 3: Determinación del tiempo de fraguado y de la estabilidad de volumen".- AENOR.

UNE-EN 196-5:2006 “Métodos de ensayo de cementos. Parte 5: Ensayo de puzolanicidad para cementos puzolánicos".- AENOR.

UNE-EN 196-6:2010 "Métodos de ensayo de cementos. Parte 6: Determinación de la finura". AENOR.

UNE-EN 197-1:2011 “Cemento. Parte 1: Composición, especificaciones y criterios de conformidad de los cementos comunes".- AENOR.

UNE-EN 206:2013+A1:2018 “Hormigón. Especificaciones, prestaciones, producción y conformidad.:2008 "Hormigón. Parte 1: Especificaciones, prestaciones, producción y conformidad".AENOR.

UNE-EN 450-1:2006+A1 "Cenizas volantes para hormigón. Parte 1: Definiciones. especificaciones y criterios de conformidad".- AENOR.

UNE-EN 451-2:2005 "Métodos de ensayo de cenizas volantes. Parte 2: Determinación de la finura por tamizado en húmedo".- AENOR.

UNE-EN 13263-1:2006 "Humo de sílice para hormigón. Parte 1: Definiciones, requisitos y criterios de conformidad". - AENOR.

UNE-EN 15167-1:2008 “Escorias granuladas molidas de horno alto para su uso en hormigones, morteros y pastas".- AENOR

UNE 112011, 2011 “Corrosión en armaduras. Determinación de la profundidad de carbonatación en hormigones endurecidos y puestos en servicio. AENOR

UNE 80225:2012: “Determinación del dióxido de silicio $\left(\mathrm{SiO}_{2}\right)$ reactivo en los cementos, en las puzolanas y en las cenizas volantes".- AENOR.

UNE 80304:2006 “Cementos. Cálculo de la composición potencial del clínker pórtland". - AENOR.

UNE 83414:1990 EX “Adiciones al hormigón. Ceniza volante. Recomendaciones generales para la adición de cenizas volantes a los hormigones fabricados con cemento tipo l". - AENOR.

UNE 83484:1996 EX “Adiciones al hormigón. Escorias granuladas molidas de horno alto. Determinación de la finura". - AENOR. 
ANEXO I 



\section{I.1.- Cemento Portland.}

\section{I.1.1.- Generalidades.}

En términos generales, los cementos pueden clasificarse en dos grupos bien diferenciados. Por una parte están los cementos Portland puros, y por otra, los cementos Portland con adiciones minerales (también llamados «cementos de mezcla»), según sean obtenidos por la molturación conjunta de mezclas binarias de clínker Portland y de regulador de fraguado o de mezclas ternarias de clínker Portland, regulador de fraguado y una o varias adiciones minerales molidas (de manera conjunta, o por separado, y mezcladas posteriormente con el cemento Portland, o por ambos procedimientos, más o menos conjuntados). La Instrucción para la Recepción de Cemento de 2016 (en adelante, Instrucción RC-16) incluye ambos grupos en los cementos comunes. La composición de todos los cementos comunes es la que se muestra en la Tabla I-1.

Los cementos Portland puros se designan, de acuerdo con esta Instrucción RC-08, como CEM I seguido de la clase de resistencia mecánica $(32,5$ - 42,5 - 52,5) y de la letra R si es de «alta resistencia inicial» o de la letra $\mathrm{N}$ si es de «resistencia inicial normal». 
COMPORTAMIENTO SULFÁTICO Y MECÁNICO-RESISTENTE DE CEMENTOS PORTLAND CON ELEVADOS CONTENIDOS DE PUZOLANAS (> 40\%): SU FUNDAMENTO QUÍMICO Y JUSTIFICACIÓN DE OTRAS CONSECUENCIAS POSIBLES

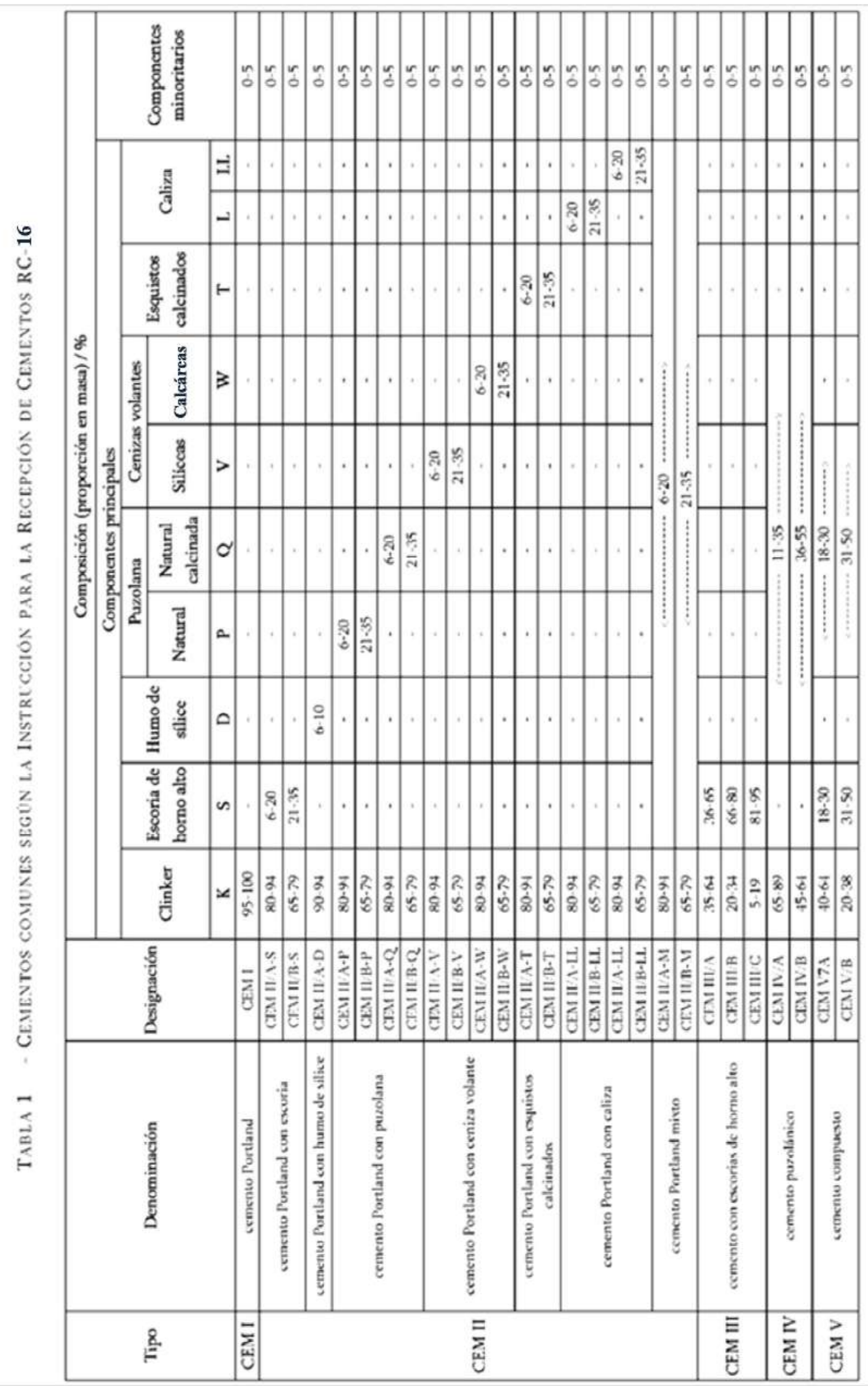

TABLA I-1.-INSTRUCCIÓN PARA LA RECEPCIÓN DE CEMENTO RC-16. 
Por otra parte, el resto de los cementos comunes abarca a los cementos Portland con adiciones minerales (en lo sucesivo, adiciones sin más), que en función de su tipo y proporción se designan como CEM II, CEM III, CEM IV o CEM V. El CEM II se designa seguido de una barra (/) y de la letra que indica el subtipo (A o B) separada por un guión (-) de la letra que identifica la adición al cemento Portland. Las adiciones posibles son escoria de horno alto (S), humo de sílice (D), puzolana natural $(\mathrm{P})$, puzolana natural calcinada $(\mathrm{Q})$, ceniza volante silícea $(\mathrm{V})$, ceniza volante calcárea (W), esquistos calcinados (T) y filler calizo (L y LL). A este tipo pertenecen los cementos Portland mixtos, los cuales poseen más de una de algunas de las referidas adiciones. Para designar estos cementos deberá aparecer en el puesto de la letra de la adición una M seguida de un paréntesis en el que se especifique con la letra correspondiente las adiciones que contiene. A continuación, se indica la clase de resistencia mecánica (32,5 - 42,5 - 52,5), y la letra R, si se trata de un cemento de «alta resistencia inicial»o la letra $\mathrm{N}$, en el caso de ser de «resistencia inicial normal».

Los otros cementos Portland con adiciones quedan designados como CEM III, CEM IV y CEM V, si se trata respectivamente de «cemento con escorias de horno alto», «cemento puzolánico» o «cemento compuesto». Se designan con el tipo seguido de una barra (/) y de la letra que indica el subtipo (A, B o C). En el caso de cementos puzolánicos tipo IV o cemento compuesto tipo V, se indicará, además, entre paréntesis, las letras de las adiciones que incluyen en su composición. A continuación, se reflejará la clase de resistencia mecánica $(32,5-42,5-52,5)$, y, seguidamente, la letra $\mathrm{R}$ si, se trata de un cemento de «alta resistencia inicial», o la letra $\mathrm{N}$, en el caso de ser de «resistencia inicial normal».

Pero con independencia del tipo de cemento común, una de las tres propiedades técnicas más importantes que caracterizan un cemento es su resistencia mecánica. La resistencia mecánica se determina mediante el procedimiento descrito en la norma UNE-EN 196-1. La resistencia mecánica es una característica propia del cemento que determina, junto a otros parámetros, el empleo que se le vaya a dar al cemento. La resistencia mecánica del cemento varía en función de la composición mineralógica del clínker, del tipo de adición, de la proporción de ambos y de sus finuras de partícula. Las otras propiedades físico-químicas se ven afectadas por la variación de estos factores, entre las que se pueden citar por su mayor importancia sus tiempos de fraguado, su estabilidad de volumen y la liberación de calor durante su hidratación. Por este motivo, existen límites en el principio y final del fraguado para cada clase de resistencia mecánica, en la estabilidad de volumen para todos los cementos comunes y en la liberación de calor de hidratación para los cementos comunes de bajo calor de hidratación. De modo que sin tener en cuenta estos últimos, las prescripciones que existen para determinar la clase de resistencia mecánica de los cementos comunes son las que figuran en la Tabla I-2.

El principal uso final del cemento en los destinos de la Tabla I-1 se hace mayoritariamente en forma de hormigón. Las especificaciones y usos del hormigón se recogen en un reglamento específico siempre que este material vaya a desempeñar una función estructural, pudiendo tratarse de hormigón en masa, armado o pretensado. La reglamentación vigente en España es la Instrucción del Hormigón Estructural EHE de 2008 (en adelante, Instrucción EHE-08), la cual a su vez indica los cementos de la Instrucción RC-16 que pueden ser utilizados para la fabricación de cada tipo de hormigón. Esta información es la que se muestra en la Tabla I-3.

Tradicionalmente y de todos los cementos comunes, el cemento Portland fue durante mucho tiempo prácticamente el único cemento, o al menos el cemento mayoritario, que se 
COMPORTAMIENTO SULFÁTICO Y MECÁNICO-RESISTENTE DE CEMENTOS PORTLAND CON ELEVADOS CONTENIDOS DE PUZOLANAS (> 40\%): SU FUNDAMENTO QUÍMICO Y JUSTIFICACIÓN DE OTRAS CONSECUENCIAS POSIBLES

empleaba en la fabricación de hormigón para la construcción. Pero desde el año 1975, la incorporación de adiciones minerales naturales y artificiales ha provocado que el uso del cemento Portland se haya reducido hasta las cifras actuales. Y todo debido a que la sustitución de diversas fracciones de éste por adiciones minerales es símbolo de sostenibilidad con el medioambiente y ahorro energético en su fabricación. Y todo ello, muy a pesar de que las propiedades, características en estado fresco y durabilidad química del cemento resultante no sean las mismas en idénticas condiciones de servicio (Pedrajas, 2016; Talero y Delgado, 2013+), comportándose en muchos ambientes no sólo igual sino incluso peor. Por lo que progresivamente el cemento Portland se está destinando para usos cada vez más específicos en las que las exigencias de proyecto son máximas. La tendencia acabada de comentar sigue en aumento, y más aún cuantas más restricciones se imponen o menores cuotas de emisión de $\mathrm{CO}_{2}$ se otorgan a las empresas fabricantes de cemento. No obstante, y a pesar de todo ello, el cemento Portland continúa siendo el más importante de todos los cementos que se fabrican en la actualidad, y como ya se ha dicho, es la base y fundamento de la fabricación de gran parte del resto de cementos comunes.

TABLA I-2.- PRESCRIPCIONES MECÁNICAS Y FÍSICAS DE LOS CEMENTOS COMUNES (FUENTE: INSTRUCCIÓN PARA LA RECEPCIÓN DE CEMENTO RC-16).

\begin{tabular}{|c|c|c|c|c|c|c|}
\hline \multirow{3}{*}{$\begin{array}{l}\text { Clase de } \\
\text { resistencia }\end{array}$} & \multicolumn{3}{|c|}{ Resistencia a compresión } & EN 196-1 & \multicolumn{2}{|c|}{$\begin{array}{c}\text { Tiempo de fraguado } \\
\text { EN 196-3 }\end{array}$} \\
\hline & \multicolumn{2}{|c|}{$\begin{array}{l}\text { Resistencia inicial } \\
\mathrm{MPa}\end{array}$} & \multicolumn{2}{|c|}{$\begin{array}{l}\text { Resistencia nominal } \\
\mathrm{MPa}\end{array}$} & \multirow{2}{*}{$\begin{array}{l}\text { Inicio } \\
\text { min }\end{array}$} & \multirow{2}{*}{$\begin{array}{c}\text { Final } \\
\mathbf{h}\end{array}$} \\
\hline & 2 días & 7 días & & & & \\
\hline $32,5 \mathrm{~N}$ & - & $\geq 16,0$ & \multirow[b]{2}{*}{$\geq 32,5$} & \multirow[b]{2}{*}{$\leq 52,5$} & \multirow[b]{2}{*}{$\geq 75$} & \multirow{4}{*}{$\leq 12$} \\
\hline $32,5 \mathrm{R}$ & $\geq 10,0$ & - & & & & \\
\hline $\begin{array}{l}42,5 \mathrm{~N} \\
42,5 \mathrm{R}\end{array}$ & $\begin{array}{l}\geq 10,0 \\
\geq 20,0\end{array}$ & - & $\geq 42,5$ & $\leq 62,5$ & $\geq 60$ & \\
\hline $\begin{array}{l}52,5 \mathrm{~N} \\
52,5 \mathrm{R}\end{array}$ & $\begin{array}{l}\geq 20,0 \\
\geq 30,0\end{array}$ & - & $\geq 52,5$ & - & $\geq 45$ & \\
\hline
\end{tabular}

TABLA I-3.- TIPOS DE CEMENTO UTILIZABLES POR TIPO DE HORMIGÓN (FUENTE: INSTRUCCIÓN DEL HORMIGÓN ESTRUCTURAL EHE-08).

\begin{tabular}{cc}
\hline Tipo de hormigón & Tipo de cemento \\
\hline Hormigón en masa & Cementos comunes excepto los tipos CEM II/A-Q, CEM II/B-Q, CEM II/A-W, \\
& CEM II/B-W, CEM II/A-T, CEM II/B-T y CEM III/C. Cementos para usos \\
especiales ESP VI-1 \\
Hormigón armado & Cementos comunes excepto los tipos CEM II/A-Q, CEM II/B-Q, CEM II/A-W, \\
Hormigón pretensado & CEM II/B-W, CEM II/A-T, CEM II/B-T, CEM III/C y CEM V/B. \\
\hline
\end{tabular}




\section{I.1.2.- Fabricación y composición del cemento Portland.}

Los cementos son materiales artificiales finamente molidos, de naturaleza inorgánica y mineral. Cuando se amasan con agua son capaces de proporcionar una pasta en estado plástico que fragua y endurece tanto expuesta al aire como sumergida en agua, siendo muy poco soluble en ésta, dando compuestos estables que continúan endureciéndose progresivamente con el tiempo. Todas estas propiedades y características físico-químicas de los cementos se compendian en el término «conglomerantes hidráulicos» que es la expresión técnica con la que también se les denomina. De todos ellos y como se viene diciendo, el más importante es el cemento Portland.

El cemento Portland está constituido en más de un $95 \%$ por clínker ${ }^{1}$ Portland y una pequeña cantidad de piedra de yeso natural que actúa como regulador de fraguado. Ambos, molidos hasta valores de superficie específica Blaine (SEB) de $3.500 \mathrm{~cm}^{2} / \mathrm{g}$, considerada como finura normal, o hasta $5.000 \mathrm{~cm}^{2} / \mathrm{g}$, como elevada finura. Su reacción con el agua conduce a la hidratación de las fases hidráulicas del clínker Portland, y con ella, al fraguado y endurecimiento de este, es decir, le proporcionan el ya consabido carácter hidráulico que lo caracteriza y que justifica su resistencia mecánica, estabilidad volumen y durabilidad.

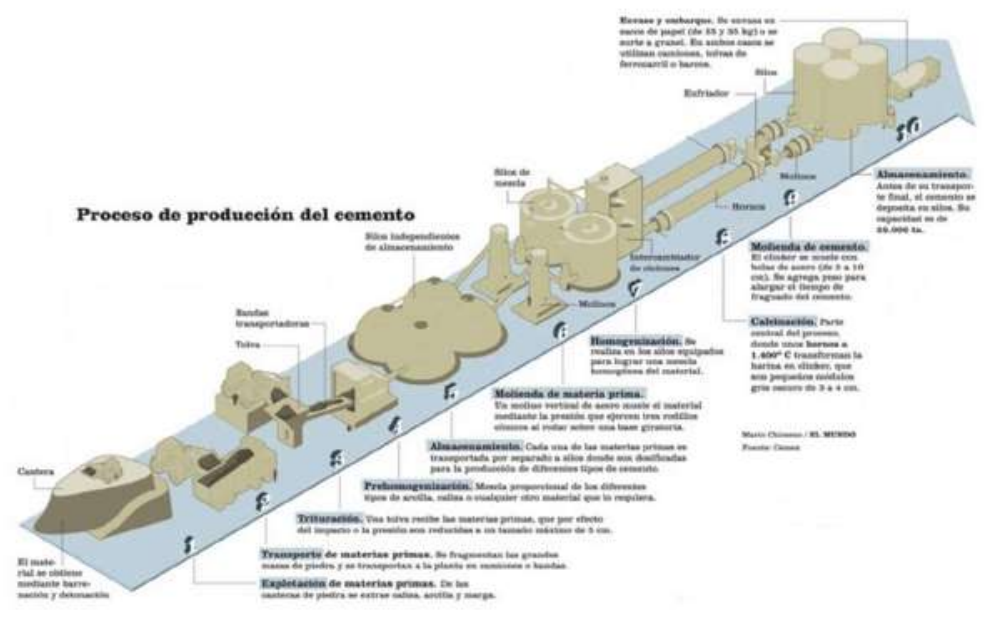

FIGURA I-1.- ESQUEMA DEL PROCESO DE PRODUCCIÓN DEL CEMENTO PORTLAND.

Las materias primas para la fabricación del clínker Portland son relativamente comunes por su abundancia. En general, se trata de una mezcla de materiales de composición química específica que calcinadas a elevada temperatura $\left(1400-1500{ }^{\circ} \mathrm{C}\right)$ en hornos tubulares rotatorios, y tras un enfriamiento súbito, producen la cristalización de ciertas fases que le habrán de conferir las propiedades hidráulicas referidas. A la mezcla de materiales adecuadamente dosificados se le denomina «crudo» del clínker Portland. El crudo suele estar constituido por caliza y arcilla, además de fundentes o mineralizadores (bauxita, hematita, magnetita, limonita, pirita, etc.) y otros materiales que actúan como correctores de módulo (por ejemplo, arena silícea). Los fundentes y correctores de módulo, que suponen una apreciable menor aportación, no introducen elementos extraños a los de la composición de las principales materias primas, siendo, entre sus funciones,

${ }^{1}$ Del holandés «klinken» cuyo significado es resonar (Bussagli, 2001). 
COMPORTAMIENTO SULFÁTICO Y MECÁNICO-RESISTENTE DE CEMENTOS PORTLAND CON ELEVADOS

obtener la composición deseada del clínker, reducir la temperatura necesaria en el horno para llevar a cabo el proceso de clinkerización y/o minimizar el consumo energético del horno. Véase en la Figura I-1 el esquema de fabricación del cemento Portland, así como determinados datos del consumo de este.

En realidad, tras el enfriamiento súbito de la masa reactiva que sale del horno, las fases del clínker de cemento Portland no cristalizan totalmente, lo cual es deseable para una mejor molienda de este y una mejor distribución de sus fases hidráulicas. Estas fases poseen un elevado desorden estructural, lo que se traduce en elevada energía interna, provocando que cuando se ponen en contacto con el agua manifiesten tan rápidamente sus propiedades hidráulicas, con el correspondiente desprendimiento de calor de hidratación.

De este modo, el clínker Portland que se origina está formado fundamentalmente por los componentes cristalinos que se muestran en la Tabla I-4.

TABLA I-4.- COMPOSICIÓN MINERALÓGICA HABITUAL DEL CLÍNKER PORTLAND.

\begin{tabular}{cccc}
\hline Nombre & Fórmula & Notación & Contenido (\%) \\
Silicato tricálcico, alita & $3 \mathrm{CaO} \cdot \mathrm{SiO}_{2}$ & $\mathrm{C}_{3} \mathrm{~S}$ & $45-70$ \\
Silicato bicálcico, velita & $2 \mathrm{CaO} \cdot \mathrm{SiO}_{2}$ & $\mathrm{C}_{2} \mathrm{~S}$ & $15-35$ \\
Aluminato tricálcico, celita & $3 \mathrm{CaO} \cdot \mathrm{Al}_{2} \mathrm{O}_{3}$ & $\mathrm{C}_{3} \mathrm{~A}$ & $0-15$ \\
Aluminato-ferrito-tetracálcico, brownmillerita & $4 \mathrm{CaO} \cdot \mathrm{Al}_{2} \mathrm{O}_{3} \cdot \mathrm{Fe}_{2} \mathrm{O}_{3}$ & $\mathrm{C}_{4} \mathrm{AF}$ & $3-15$ \\
Cal libre & $\mathrm{CaO}$ & - & $0-2$ \\
\hline
\end{tabular}

Los componentes del clínker Portland no son especies puras y en realidad no se corresponden exactamente con las fórmulas citadas, ya que existen elementos minoritarios que los transforman en disoluciones sólidas de adición y/o sustitución que en ocasiones llegan a ser tan importantes o más que aquellos (Taylor, 1990). Además, todos los componentes mineralógicos poseen polimorfismo cristalino, lo que les confiere diferentes propiedades químico-físicas que son muy importantes desde el punto de vista de su molienda y posterior comportamiento mecánicoresistente e hidráulico, en definitiva.

Los componentes del clínker Portland no son especies puras y en realidad no se corresponden exactamente con las fórmulas citadas, ya que existen elementos minoritarios que los transforman en disoluciones sólidas de adición y/o sustitución que en ocasiones llegan a ser tan importantes o más que aquellos (Taylor, 1990). Además, todos los componentes mineralógicos poseen polimorfismo cristalino, lo que les confiere diferentes propiedades químico-físicas que son muy importantes desde el punto de vista de su molienda y posterior comportamiento mecánicoresistente e hidráulico en definitiva.

Por su parte, el silicato tricálcico o alita, $\mathrm{C}_{3} \mathrm{~S}$, posee hasta siete formas polimórficas diferentes. La estabilidad de cada una de ellas depende de la temperatura y de los elementos estabilizadores. Tres de sus formas polimórficas son triclínicas, tres monoclínicas y tan sólo una romboédrica.

Esta fase puede contener hasta un $4 \%$ de cationes como estabilizadores de red, de entre los cuales los más importantes son $\mathrm{Na}^{+}, \mathrm{K}^{+}, \mathrm{Fe}^{3+}, \mathrm{Al}^{3+} \mathrm{y} \mathrm{Mg}^{2+}$. La proporción y existencia de cada uno de 
los polimorfos cristalinos de la alita en el clínker Portland, depende, además de la temperatura y de la velocidad de enfriamiento a la salida del horno.

El silicato bicálcico, o belita, $\mathrm{C}_{2} \mathrm{~S}$, posee también polimorfismo. En total, son cinco sus formas polimórficas. Al igual que en el caso de la alita, las formas de la belita de alta temperatura se encuentran estabilizadas por cationes sustituyentes.

En el clínker Portland principalmente se encuentra la forma $\beta$ si bien la estabilización de las formas $\alpha$ mediante diferentes métodos fundamenta la fabricación de los cementos belíticos, ya que estas formas poseen mejores propiedades hidráulicas que la forma $\beta$. La presencia de la forma $\gamma$ no es deseable por ser perjudicial, por sus escasas propiedades hidráulicas y su pobre estabilidad de volumen.

El aluminato tricálcico, o celita, $\mathrm{C}_{3} \mathrm{~A}$, presenta polimorfismo en función de la cantidad de iones alcalinos estabilizadores que se encuentren (hasta un 5,7\%). De este modo se obtienen sus cuatro formas polimórficas, de menor a mayor contenido de alcalinos, las cuales son las siguientes, a saber: cúbica I, cúbica II, ortorrómbica y monoclínica.

Finalmente, un caso interesante es el del ferrito-aluminato tetracálcico, o brownmillerita, $\mathrm{C}_{4} \mathrm{AF}$, el cual se considera como una disolución sólida comprendida entre los componentes $\mathrm{C}_{2} \mathrm{~A}$ y $\mathrm{C}_{2} \mathrm{~F}$ (ferrito bicálcico), expresándose su fórmula química como $\mathrm{Ca}_{2}\left(\mathrm{Al}_{x} \mathrm{Fe}_{1-x}\right)_{2} \mathrm{O}_{5}$. La relación $\mathrm{Al} / \mathrm{Fe}$ depende de la composición de las materias primas, de la temperatura de clinkerización y de la temperatura y velocidad de enfriamiento. De este modo, puede afirmarse, por tanto, que existen dos pseudo-isomorfos ortorrómbicos de esta fase para $\mathrm{x}=0 \mathrm{y} \mathrm{x}=1$.

Por último, en la Fig. I-2 se muestra una imagen de una muestra de clínker donde se aprecian los diferentes compuestos mineralógicos del clínker de cemento Portland descritos anteriormente.

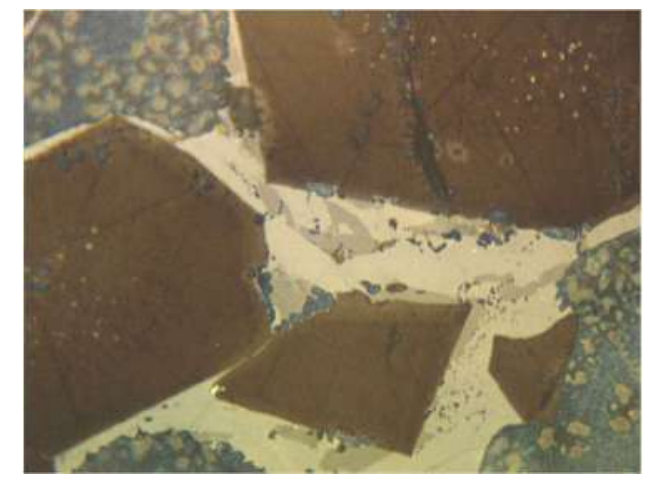

FIGURA I-2.- IMAGEN MICROSCÓPICA DE LUZ REFLEJADA DE UN CLÍNKER (NIST \#2688). OBTENIDA CON UNA ANCHURA DE CAMPO DE $10 \mu m$ (STUTZMAN, 2001) C3S (MARRÓN), C2S (AZUL), C3A (GRIS), C4AF (BLANCO).

\section{I.1.3.- Hidratación del cemento Portland.}

Cuando el cemento Portland se mezcla con agua se producen una serie de reacciones químicas exotérmicas cuyos productos de reacción conforman progresivamente una red sólida que se densifica con el tiempo a medida que transcurre la hidratación. Lo que aumenta progresivamente su dureza y resistencia mecánica. De este modo, se pasa del estado plástico al estado endurecido. 
Este proceso es muy rápido en el caso del clínker Portland, razón por la cual se le incorpora el «regulador de fraguado» mencionado anteriormente (normalmente, piedra de yeso natural, $\mathrm{CaSO}_{4} \cdot 2 \mathrm{H}_{2} \mathrm{O}\left(\mathrm{C} \overline{\mathrm{S}} \mathrm{H}_{2}\right)$, en cantidad óptima (Talero, 1986; Talero, 1991; ASTM C563) o al menos adecuada. Su función es ralentizar, retrasar o retardar la muy rápida hidratación inicial del $C_{3} \mathrm{~A}$ (motivo por el cual en un principio se le denominó también «retardador de fraguado», término este otro, con el que aún se le conoce en la actualidad).

En este contexto, se diferencian entonces claramente dos etapas en el proceso de hidratación; la primera, el fraguado, que representa la pérdida inicial de la plasticidad de la pasta y, la segunda etapa el endurecimiento, que se traduce en su consolidación ulterior hasta adquirir características pétreas. En un principio, los fenómenos responsables del fraguado y endurecimiento se justificaron sobre la base de dos teorías:

- La primera, conocida como «teoría cristalina» (Le Chatelier, 1882, 1919), supone que el proceso de fraguado y endurecimiento se produce por la disolución en agua de los materiales de partida, con formación de una disolución sobresaturada con relación a las nuevas formaciones hidratadas que, como consecuencia, cristalizan, se entrelazan, y con el tiempo crecen generando una estructura monolítica.

- La segunda, conocida como «teoría coloidal» (Michaelis, 1908), supone que la consolidación tiene lugar por una reacción topoquímica, con succión de agua de la superficie al interior de las partículas de cemento y la formación de nuevas formaciones hidratadas geliformes que se transforman paulatinamente en una estructura monolítica.

En la actualidad, se ha aceptado que el proceso responde a un mecanismo que conjuga los aspectos racionales de ambas teorías. Fue Bajkov (1948) quien desarrolló la «teoría coloidequímica», según la cual todo el proceso de fraguado y endurecimiento puede dividirse en tres períodos:

1. Período de preparación, en el que se produce la disolución de las sustancias anhidras para formar una disolución saturada.

2. Etapa de formación coloidal, en el que se producen reacciones topoquímicas entre las partículas y la disolución saturada, originándose formas cristalizadas de dimensiones coloidales.

3. Período de formación de la red cristalina y cristalización, previa disolución de las pequeñas partículas coloidales, y precipitación de las materias disueltas en forma de partículas mayores.

La validación, aplicación, modificación y mejora de la «teoría coloidequímica» ha sido objeto de posteriores investigaciones, siendo las más destacadas las realizadas por Powers (1958) y Bogue (1959), las cuales junto a muchas otras repercutieron en una mejor comprensión del fenómeno de hidratación del cemento Portland.

Por otra parte, el mecanismo real que explica las propiedades hidráulicas del cemento Portland es muy complejo, estando afectado por numerosos factores: la composición química y mineralógica del cemento, su finura de molido, la temperatura de endurecimiento, la relación aguacemento, etc. Antes de proseguir, se ha de informar también que la Química del Cemento no hace una distinción clara entre los fenómenos de «hidrólisis» e «hidratación», a pesar de que sus fundamentos sean muy diferentes. Ambos fenómenos se producen cuando el cemento entra en contacto con el agua. Es decir, los fenómenos responsables del fraguado y endurecimiento del 
cemento comprenden procesos de descomposición del material debido a la acción del agua (hidrólisis), y de fijación del agua sin descomposición del material de reacción (hidratación). De aquí en adelante, se describirán estos procesos denominándolos hidratación sin más, a menos que se especifique lo contrario cuando su distinción sea relevante.

En definitiva, cuando el cemento Portland se mezcla con agua, se constituyen disoluciones sobresaturadas e inestables temporalmente; luego se produce la precipitación gradual de los solutos en exceso que tienden a alcanzar el equilibrio con los productos de la hidratación que se originan. La velocidad de hidratación y el grado de saturación temporal de la fase líquida se determina por el estado físico de los componentes del cemento Portland, así como por su naturaleza química y mineralógica. Debido a que los compuestos anhidros originales no pueden existir en disolución acuosa, el resultado final de la acción del agua es el de la hidratación completa de los mismos, la cual, y por lo común, no se llega a verificar totalmente nunca, es decir, a cualquier edad siempre será posible encontrar fases del cemento Portland aún anhidras, siendo precisamente esta propiedad la que le confiere al hormigón de cemento Portland su ya contrastada durabilidad, al fundamentarse precisamente y en definitiva, en dicho reservorio de cal. Los compuestos hidratados, por otra parte, pueden existir permanentemente en contacto con ciertas disoluciones, aunque en muchos casos forman disoluciones incongruentes, en las que el compuesto se descompone parcialmente.

Todas las reacciones químicas que se producen durante la hidratación del cemento Portland pueden ser descritas mediante reacciones estequiométricas, con velocidades y liberación de calor de reacción características. A este respecto, en la Tabla I-5 se resumen las características de la hidratación de los componentes del cemento Portland.

TABLA I-5.- CARACTERÍSTICAS DE LA HIDRATACIÓN DE LOS COMPONENTES DEL CEMENTO PORTLAND (TAYLOR, 1990).

\begin{tabular}{ccc}
\hline Componente mineralógico & Velocidad de reacción & Calor de hidratación $/ \mathbf{~ J}^{*} \mathbf{k g}^{-1}$ \\
\hline $\mathrm{C}_{3} \mathrm{~S}$ & Moderada & 0,502 \\
$\mathrm{C}_{2} \mathrm{~S}$ & Lenta & 0,260 \\
$\mathrm{C}_{3} \mathrm{~A}$ & Inmediata & 0,867 \\
$\mathrm{C}_{3} \mathrm{~A}+\mathrm{C} \overline{\mathrm{S}} \mathrm{H}_{2}$ & Inmediata & 1,452 \\
$\mathrm{C}_{4} \mathrm{AF}$ & Moderada & 0,419 \\
$\mathrm{CaO}$ & Inmediata & 4,879 \\
\hline
\end{tabular}

La velocidad de hidratación de los componentes del cemento Portland por separado, durante los primeros días sigue el orden siguiente: $\mathrm{C}_{3} \mathrm{~A}>\mathrm{C}_{3} \mathrm{~S}>\mathrm{C}_{4} \mathrm{AF}>\mathrm{C}_{2} \mathrm{~S}$. La mayor velocidad de hidratación corresponde al $\mathrm{C}_{3} \mathrm{~A}$, seguida de la del $\mathrm{C}_{3} \mathrm{~S}$, mientras que el $\mathrm{C}_{2} \mathrm{~S}$ se hidrata mucho más lentamente. Como ya se ha comentado, la presencia de yeso retarda la hidratación del $\mathrm{C}_{3} \mathrm{~A}$. Con respecto a la hidratación del $\mathrm{C}_{4} \mathrm{AF}$ en presencia de yeso se cree que la reacción es más lenta incluso que la del $\mathrm{C}_{2} \mathrm{~S}$, mientras que la hidratación del $\mathrm{C}_{4} \mathrm{AF}$ en ausencia de $\mathrm{C} \overline{\mathrm{S}} \mathrm{H}_{2}$ es por el contrario más rápida. 
Cuando los componentes del cemento Portland se encuentran mezclados íntimamente en diferentes proporciones, su velocidad está comprendida entre la de cada uno de los referidos compuestos por separado. Sin embargo, es posible que dos muestras distintas del mismo cemento Portland, no tengan velocidades de hidratación iguales, debido a diferencias en el grado de finura de molido, en la velocidad de calcinación o en el enfriamiento del clínker, o bien, a factores adicionales, tales como la presencia de elementos alcalinos e impurezas y otros compuestos minoritarios del cemento Portland.

Lógicamente, la contribución de cada uno de los componentes mineralógicos mencionados en el desarrollo de la resistencia mecánica es muy diferente también, debido a que los productos de reacción que originan al hidratarse son también diferentes. De este modo, en la Fig. I-3 se halla representada la contribución al desarrollo de la resistencia mecánica del cemento Portland de cada uno de sus componentes.

Por una parte, el $\mathrm{C}_{3} \mathrm{~A}$ y el $\mathrm{C}_{3} \mathrm{~S}$ proporciona resistencia mecánica a corta edad, pero en especial el $\mathrm{C}_{3} \mathrm{~A}$, y el $\mathrm{C}_{3} \mathrm{~S}$ y el $\mathrm{C}_{2} \mathrm{~S}$ contribuyen a la resistencia mecánica final. Así, es posible cambiar también el desarrollo de la resistencia mecánica de un cemento Portland variando su composición mineralógica. Por ejemplo, para lograr elevadas resistencias mecánicas a cortas edades se aumentan, por lo común, las cantidades de $\mathrm{C}_{3} \mathrm{~S}$ y $\mathrm{C}_{3} \mathrm{~A}$, pero consecuentemente, el calor de hidratación liberado es mayor; en cambio, si se quiere un cemento de baja resistencia mecánica inicial, se incrementará el porcentaje de $\mathrm{C}_{2} \mathrm{~S}$ lo que subsidiariamente provoca una menor liberación de calor de hidratación. No obstante, y a pesar de lo anterior, las cantidades de calor de hidratación desprendido también pueden ser controladas, y de hecho lo son, mayormente, ajustando la finura de molido del clínker y el regulador de fraguado a partir del cual se obtiene un determinado cemento Portland. Puesto que las reacciones de hidratación del cemento son todas exotérmicas, la mezcla permanece caliente debido al calor de hidratación generado internamente durante el endurecimiento. Así, la evolución de la velocidad de liberación del calor de hidratación dependerá tanto de la velocidad de generación como de la de disipación.

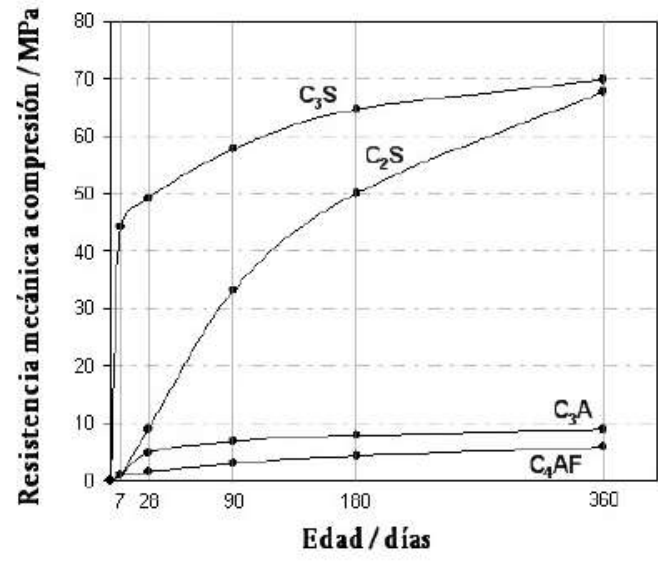

FIGURA I-3.- DESARROLLO DE LA RESISTENCIA MECÁNICA DE LOS COMPUESTOS PUROS DEL CLÍNKER PORTLAND (ADAPTADO DE BOGUE, 1959).

Todo lo relacionado con el historial térmico del cemento, mortero u hormigón es de suma importancia, ya que una excesiva liberación de calor podría originar fenómenos indeseables como la pérdida de agua de amasado y retracción hidráulica, térmica y por secado, entre otras. Lo que se 
traduce en pérdida de resistencia mecánica, aumento de la porosidad, y aparición de fisuras y microfisuras, lo que repercute finalmente en la durabilidad final del material. Las reacciones de hidratación del cemento Portland han sido ampliamente estudiadas mediante técnicas calorimétricas (Rahhal, 2002), ya que es posible, además de cuantificar el calor de hidratación y obtener la velocidad de reacción, predecir, desde el punto de vista técnico, cuál va a ser el comportamiento de la mezcla cementante durante las primeras horas de hidratación en relación a la liberación de calor de hidratación.

A continuación, se describirán los procesos de hidratación de cada uno los compuestos mineralógicos puros más significativos del cemento Portland, así como las propiedades y microestructura de sus principales productos de reacción. Adicionalmente, se expondrán también las características fundamentales de la fase líquida del cemento Portland.

\section{I.1.3.1.- Hidratación de los silicatos de calcio, $C_{3} S$ y $C_{2} S$.}

Las reacciones químicas de hidratación de los dos silicatos de calcio fundamentales del cemento Portland, el $\mathrm{C}_{3} \mathrm{~S}$ y el $\mathrm{C}_{2} \mathrm{~S}$, son similares, y difieren únicamente en la cantidad de hidróxido de calcio, $\mathrm{Ca}(\mathrm{OH})_{2}$, que se produce, el cual, por su origen, recibe el nombre de «portlandita» $(\mathrm{CH})$. El principal producto sólido de las reacciones de hidratación es una red de silicatos de calcio hidratados sin fórmula definida $(\mathrm{CaO}) \times \cdot(\mathrm{SiO} 2) y \cdot(\mathrm{H} 2 \mathrm{O}) \mathrm{z}$, que se denomina gel $\mathrm{CSH}$ o CSH simplemente. Estas reacciones pueden representarse según la reacción química (r1).

$$
\mathrm{C}_{3} \mathrm{~S}, \mathrm{C}_{2} \mathrm{~S}+\mathrm{H} \rightarrow \text { gel } \mathrm{CSH}+\mathrm{CH}
$$

Teniendo en cuenta la estequiometría del proceso, la reacción química anterior se puede escribir según estas otras dos:

$$
\begin{aligned}
& 2 \mathrm{C}_{3} \mathrm{~S}+6 \mathrm{H} \rightarrow \mathrm{C}_{3} \mathrm{~S}_{2} \mathrm{H}_{3}+3 \mathrm{CH} \\
& 2 \mathrm{C}_{2} \mathrm{~S}+4 \mathrm{H} \rightarrow \mathrm{C}_{3} \mathrm{~S}_{2} \mathrm{H}_{3}+\mathrm{CH}
\end{aligned}
$$

Los silicatos de calcio hidratados formados son, a primeras edades, amorfos o pobremente cristalinos. En un principio, debido a que su fórmula química promedio aproximada es C3S2H3, recibió el nombre de «tobermorita» por coincidencia con la fórmula química de la tobermorita (Claringbull y col. 1952; Taylor y Broms, 1964). Esta designación ha ido cayendo en desuso a favor de la referida designación de gel CSH, ya que este compuesto posee, a diferencia de la tobermorita, una estructura tipo gel (Smith y cols. 1972).

Las reacciones químicas de hidratación de los silicatos de calcio no se detienen cuando la fase líquida alcanza la saturación en hidróxido de calcio, sino que continúan alcanzando incluso la sobresaturación en hidróxido de calcio, lo que provoca que precipite finalmente como cristales de portlandita. Este fenómeno se produce sucesivamente hasta el punto que la disolución intersticial del hormigón de cemento Portland es capaz de mantener el nivel de sobresaturación durante un largo período de tiempo. El gel CSH formado permanece estable en contacto con la disolución saturada de $\mathrm{CH}$, pero si hay deficiencia de esta última, nuevas fracciones de silicatos de calcio se 
hidratan liberando de nuevo portlandita hasta elevar el valor de la concentración lo suficiente como para alcanzar de nuevo las condiciones de sobresaturación. El equilibrio se alcanza solamente cuando está presente también en el sólido un gel CSH menos básico y la concentración de hidróxido de calcio en la disolución ha alcanzado el valor requerido para hacer estable el silicato más básico remanente (Mindess y Young. 1981).

Como se pudo observar en la Tabla 1-4, el $\mathrm{C}_{3} \mathrm{~S}$ es el componente mayoritario del cemento Portland, y, por tanto, el silicato de calcio de mayor interés. Se han identificado las siguientes cinco etapas diferentes durante su hidratación (Rahhal, 2002):

- Etapa 1: Se produce la hidrólisis inicial y la disolución de los iones, generándose un elevado desprendimiento inicial de calor que cesa tras aproximadamente $15 \mathrm{~min}$. Esta etapa posee un control químico rápido.

- Etapa 2: Período «estacionario» o «latente». Esta etapa se caracteriza por la relativa inactividad química debida a un control de nucleación lento. En esta etapa continúa la disolución de los iones. El inicio de fraguado se produce entre la segunda y la cuarta hora, tiempo durante el cual el $\mathrm{C}_{3} \mathrm{~S}$ comienza a reaccionar nuevamente con cierta intensidad con el agua de amasado, lo que caracteriza el final de este período.

- Etapa 3: Período de «aceleración». El control de la reacción vuelve a ser químico, el C 35 alcanza la máxima velocidad de hidratación al final de este período. En esta etapa se produce la formación inicial de productos de reacción, que son los responsables de que se produzca el final de fraguado, lo que se produce entre la cuarta y la octava hora, a partir de la cual comienza el endurecimiento.

- Etapa 4: Período de «desaceleración». El endurecimiento continúa progresivamente, mientras que la velocidad de hidratación disminuye. A medida que se forman mayor cantidad de productos de hidratación el control químico ralentiza el proceso, a la vez, que cobra mayor importancia el control por difusión.

- Etapa 5: Período de «estabilización». Se produce entre las doce y las veinticuatro horas. Prácticamente sólo existe el control por difusión, produciendo una lenta formación de productos de hidratación en comparación con las etapas 3 y 4.

En relación al mecanismo químico que rige este proceso, se puede decir que cuando las partículas de $\mathrm{C}_{3} \mathrm{~S}$ entran en contacto con el agua se liberan rápidamente iones $\mathrm{Ca}^{2+}$ y $\mathrm{OH}^{-}$de sus superficies. El pH asciende por encima de 12 en pocos minutos, volviéndose la disolución muy alcalina. La hidrólisis y disolución de iones disminuye, aunque continúa durante el periodo «latente». Cuando las concentraciones de calcio e ión hidroxilo alcanzan un valor crítico, el $\mathrm{CH}$ y el gel CSH comienzan a formarse a partir de la disolución sobresaturada, continuando la reacción de hidratación del $\mathrm{C}_{3} \mathrm{~S}$. El periodo «latente» se debe a la necesidad de llegar a una determinada concentración iónica en disolución para que se produzca la nucleación de los cristales. Mientras que los cristales de portlandita precipitan a partir de la disolución, el gel CSH se desarrolla sobre la superficie de los granos de $\mathrm{C}_{3} \mathrm{~S}$, y a medida que la hidratación continúa, se forman progresivamente capas de los productos de hidratación cuya densidad aumenta con el tiempo. Los productos de hidratación constituyen, por tanto, una resistencia adicional al proceso de difusión, lo que conduce a que se produzca un cambio de régimen en el control del proceso. Así, del «control 
químico» se pasa al «control por difusión», por lo que el movimiento a través de las capas del gel CSH determina la velocidad de reacción.

De los dos productos de reacción que se forman, el CH y el gel CSH, este último es el de más importancia para el fraguado y el posterior endurecimiento de la pasta. El gel CSH que se forma inicialmente en las superficies de las partículas de silicato de calcio, posee una estructura de fibras, las cuales continúan creciendo, produciéndose el entrecruzamiento progresivo con fibras de gel CSH de partículas adyacentes. Esta es la principal causa de la pérdida inicial de la plasticidad de la pasta y de su endurecimiento (Collepardi y col. 1971).

La referida resistencia a la difusión aumenta tanto que la hidratación completa no es posible a menos que las partículas de $\mathrm{C}_{3} \mathrm{~S}$ fueran de un tamaño lo suficientemente pequeño, o que la mezcla se volviera a moler sucesivamente para exponer nuevas superficies al agua. En caso contrario, que es el caso real, se obtiene un producto que muestra núcleos de $\mathrm{C}_{3} \mathrm{~S}$ aún anhidros, rodeados por una capa de CSH muy impermeable.

El mecanismo de hidratación de las partículas de $\mathrm{C}_{2} \mathrm{~S}$ es similar a las de $\mathrm{C}_{3} \mathrm{~S}$, si bien y como ya se ha indicado, de una forma más lenta, lo cual es lo lógico, dado su menor contenido de $\mathrm{CaO}$. La cantidad de calor liberado en la hidratación del $\mathrm{C}_{2} \mathrm{~S}$ es muy inferior a la del $\mathrm{C}_{3} \mathrm{~S}$ lógicamente también, incluso tan pequeña que hace que experimentalmente su curva calorimétrica no sea medible. Debido a ello, este compuesto mineralógico es el de mayor interés en la fabricación de cementos de «bajo calor de hidratación» y de los denominados «cementos belíticos», si bien, la fabricación de estos cementos Portland es muy difícil por métodos convencionales. Además, por otra parte, estos cementos belíticos poseen una baja resistencia mecánica.

Para poder comparar y tener una idea aproximada, si quiera relativa, de la velocidad de hidratación de ambos silicatos de calcio, cítese que Taylor (1990) demostró que en el caso del $C_{3} S$ se ha desarrollado alrededor del $80 \%$ de la hidratación a las 100 horas, mientras que, a la misma edad, el $\mathrm{C}_{2} \mathrm{~S}$ sólo alcanza el $10 \%$.

\section{I.1.3.2.- Hidratación del aluminato tricálcico, $C_{3} A$.}

El aluminato tricálcico, $\mathrm{C}_{3} \mathrm{~A}$, reacciona muy rápidamente con el agua. Siendo, lógicamente, su velocidad de reacción es mucho menor en una disolución saturada en cal. Como ya se ha mencionado antes, al clínker Portland se le incorpora piedra de yeso natural finamente molida, $\mathrm{C} \overline{\mathrm{S}}$ $\mathrm{H}_{2}\left(\mathrm{CaSO}_{4} \cdot 2 \mathrm{H}_{2} \mathrm{O}\right)$, al objeto de retardar el endurecimiento excesivamente rápido que produce la hidratación del $C_{3} A$. Es por ello, que abordar la reacción de hidratación del $C_{3} A$ puro en ausencia de iones sulfato carece de importancia, ya que, además, el $C_{3} A$ en presencia de estos iones no produce ninguno de los productos que se originarían en ausencia del mismo.

Los productos de hidratación que se forman cuando el $\mathrm{C}_{3} \mathrm{~A}$ se hidrata en presencia de iones sulfato dependen de la razón molar $\mathrm{SO}_{3} / \mathrm{Al}_{2} \mathrm{O}_{3}$. Así y en función de las razones molares que se muestran en la Tabla I-6, se formarán conjuntamente o por separado las siguientes fases: trisulfoaluminato de calcio hidratado, denominado ettringita o Fase AFt, y monosulfoaluminato de calcio hidratado o Fase AFm.

La ettringita formada a partir de la hidratación del $\mathrm{C}_{3} \mathrm{~A}$ en presencia de iones sulfato, provenientes del regulador de fraguado, recibe el nombre de ettringita «primaria», para 
COMPORTAMIENTO SULFÁTICO Y MECÁNICO-RESISTENTE DE CEMENTOS PORTLAND CON ELEVADOS CONTENIDOS DE PUZOLANAS (> 40\%): SU FUNDAMENTO QUÍMICO Y JUSTIFICACIÓN DE OTRAS CONSECUENCIAS POSIBLES

diferenciarla de la ettringita «secundaria» que puede llegar a formarse una vez endurecida la pasta de cemento Portland bajo condiciones poco favorables, las del ataque químico de los sulfatos (Cohen y Mather. 1991; Neville, 2004; Glasser y cols. 2008; Talero y Delgado, 2009, 2013†). A tal efecto se ha de aclarar aquí que, cuando aparezca el término ettringita en cualquiera de sus designaciones (trisulfoaluminato de calcio hidratado o Fase AFt) siempre hará referencia a la ettringita primaria, siempre y cuando no se indique lo contrario.

TABLA I-6.- PRODUCTOS DE HIDRATACIÓN DEL C3A EN FUNCIÓN DE LA RAZÓN SO3/AL2O3.

\begin{tabular}{cc}
\hline Razón molar $\mathrm{SO}_{3} / \mathrm{Al}_{2} \mathrm{O}_{3}$ & Productos de hidratación estables \\
3,0 & Fase AFt \\
$3,0-1,0$ & Fase AFt - Fase AFm \\
1,0 & Fase AFm \\
$<1,0$ & Disolución sólida de Fase AFm \\
0 & Hidrogranate \\
\hline
\end{tabular}

La ettringita es un producto de hidratación estable, pero únicamente mientras haya iones sulfatos disponibles en la disolución, lo que explica la razón molar $\mathrm{SO}_{3} / \mathrm{Al}_{2} \mathrm{O}_{3}$ necesaria para su estabilidad recogida en la Tabla I-6. La reacción química que describe su formación es la siguiente:

$$
\mathrm{C}_{3} \mathrm{~A}+3 \mathrm{C} \overline{\mathrm{S}} \mathrm{H}_{2}+26 \mathrm{H} \rightarrow \mathrm{C}_{6} \mathrm{AS}_{3} \mathrm{H}_{32}
$$

Si el sulfato reacciona totalmente antes de que el $C_{3} \mathrm{~A}$ complete su hidratación, la ettringita se transforma en monosulfoaluminato de calcio hidratado de menor contenido en sulfato, según esta otra reacción química:

$$
\mathrm{C}_{3} \mathrm{~A}+\mathrm{C}_{6} \mathrm{AS}_{3} \mathrm{H}_{32}+4 \mathrm{H} \rightarrow 3 \mathrm{C}_{4} \mathrm{~A} \overline{\mathrm{S}} \mathrm{H}_{12}
$$

En determinadas situaciones, cuando el $\mathrm{C}_{3} \mathrm{~A}$ reacciona más rápidamente con los iones sulfato sin que haya tiempo suficiente a una nueva redisolución de los iones sulfato en el agua de amasado, se forma antes la Fase AFm que la Fase AFt. Ambas reacciones químicas de hidratación del $\mathrm{C}_{3} \mathrm{~A}$ son exotérmicas.

Al igual que sucede con la formación de gel CSH sobre las partículas de $\mathrm{C}_{3} \mathrm{~S}$, la formación de ettringita sobre la superficie del $C_{3} A$ retarda su hidratación, ya que su acumulación en su derredor supone una barrera que se opone a la difusión. Esta barrera se rompe durante la conversión a monosulfoaluminato de modo que el $\mathrm{C}_{3} \mathrm{~A}$ remanente vuelve a reaccionar rápidamente otra vez y la cantidad de calor de hidratación generada entonces es mucho mayor incluso que para el $\mathrm{C}_{3} \mathrm{~S}$.

La hidratación del $\mathrm{C}_{3} \mathrm{~A}$ posee ciertas similitudes con la del $\mathrm{C}_{3} \mathrm{~S}$. En una primera etapa de hidrólisis y disolución iónica se desprende una gran cantidad de calor que desciende progresivamente durante los primeros 10 a $15 \mathrm{~min}$. La disolución rápida de los iones sulfato del regulador de fraguado forma rápidamente ettringita. Este proceso no lleva asociado un elevado desprendimiento de calor, sino su posterior transformación a Fase AFm. El tiempo que tarda en 
producirse esta transformación depende de la cantidad de iones sulfato disponible. De este modo, a mayor cantidad de yeso en el sistema, la ettringita permanecerá más tiempo estabilizada como tal, y al contrario, la conversión a monosulfoaluminato se produce para la mayoría de los cementos entre las 12 y 36 horas después de haberse formado inicialmente la ettringita.

Cuando el monosulfoaluminato entra en contacto con una nueva fuente de iones sulfato, se forma nuevamente ettringita, correspondiendo también a esta transformación un aumento de volumen. El proceso sucede según la reacción química siguiente:

$$
\mathrm{C}_{4} \mathrm{AS}_{12}+2 \mathrm{CS}_{2}+16 \mathrm{H} \rightarrow \mathrm{C}_{6} \mathrm{AS}_{3} \mathrm{H}_{32}
$$

Cuando la hidratación del $\mathrm{C}_{3} \mathrm{~A}$ se produce en ausencia de yeso, puede producirse un fraguado relámpago debido a la rápida formación de aluminatos de calcio hidratados, que puede representarse por la reacción química siguiente:

$$
2 \mathrm{C}_{3} \mathrm{~A}+21 \mathrm{H} \rightarrow \mathrm{C}_{4} \mathrm{AH}_{13}+\mathrm{C}_{2} \mathrm{AH}_{8}
$$

Estos hidratos no son estables y con el transcurso del tiempo y en ausencia de yeso, se convierten a hidrogranates según esta otra reacción química:

$$
\mathrm{C}_{4} \mathrm{AH}_{13}+\mathrm{C}_{2} \mathrm{AH}_{8} \rightarrow 2 \mathrm{C}_{3} \mathrm{AH}_{6}+9 \mathrm{H}
$$

Es posible que aún con la presencia de yeso, si el aluminato tricálcico es muy reactivo, aparezcan aluminatos de calcio hidratados. Cuando la cantidad de yeso es pequeña y queda $\mathrm{C}_{3} \mathrm{~A}$ sin reaccionar, se forma una disolución sólida de $\mathrm{C}_{4} \mathrm{~A} \overline{\mathrm{S}} \mathrm{H}_{12}$ y $\mathrm{C}_{4} \mathrm{AH}_{13}$, ambos de estructura cristalina semejante, mediante la reacción química siguiente:

$$
\mathrm{C}_{4} \mathrm{~A} \overline{\mathrm{S}} \mathrm{H}_{12}+\mathrm{C}_{3} \mathrm{~A}+\mathrm{CH}+12 \mathrm{H} \rightarrow 2 \mathrm{C}_{3} \mathrm{~A}(\mathrm{CS}, \mathrm{CH}) \mathrm{H}_{12}
$$

\section{I.1.3.3.- Hidratación de la fase ferrítica, $C_{4} A F$.}

La hidratación del $\mathrm{C}_{4} \mathrm{AF}$ se produce de una forma similar a la del $\mathrm{C}_{3} \mathrm{~A}$ con o sin yeso. No obstante, las reacciones químicas son mucho más lentas y menos exotérmicas. Cuando se hidrata en su estado puro, este compuesto mineralógico no produce un fraguado relámpago tal y como sucede con el $\mathrm{C}_{3} \mathrm{~A}$. Los iones sulfato también retardan la hidratación del $\mathrm{C}_{4} \mathrm{AF}$, pero, en general, no con tanta intensidad como sucede con el $C_{3}$ A. Emanuelson y cols. (1996), en un estudio sobre la hidratación de la fase ferrítica, expusieron brevemente el conocimiento existente sobre el tema, enumerando los puntos en los que los diferentes investigadores estaban, o no, de acuerdo. De este modo, existía un claro acuerdo en que tanto el $\mathrm{C}_{3} \mathrm{~A}$ como el $\mathrm{C}_{4} \mathrm{AF}$ generan productos de reacción similares, en que el $\mathrm{C}_{3} \mathrm{~A}$ reacciona mucho más rápido que el $\mathrm{C}_{4} \mathrm{AF}$, en que la hidratación del $\mathrm{C}_{3} \mathrm{~A}$ es la más exotérmica, y en que la hidratación de ambos compuestos es retardada por la presencia en el agua de sulfato de calcio e hidróxido de calcio, siendo este retardo mayor cuando ambos se encuentran conjuntamente, debiéndose este retardo a la formación de una capa «protectora» de productos de reacción sobre los granos en hidratación. Sin embargo, existen diferentes opiniones 
COMPORTAMIENTO SULFÁTICO Y MECÁNICO-RESISTENTE DE CEMENTOS PORTLAND CON ELEVADOS

sobre la naturaleza de esa capa «protectora», el mecanismo por el que esta capa eventualmente se destruye y la distribución del hierro en los productos de hidratación.

En realidad, el $\mathrm{C}_{4} \mathrm{AF}$ se trata de una de las posibles composiciones del sistema $\mathrm{Ca}_{2}\left(\mathrm{Al}_{x} \mathrm{Fe}_{1}\right.$ х) ${ }_{2} \mathrm{O}_{5}$, si bien y a pesar de ser la composición más representativa, no es la única. De este modo, se trata de una disolución sólida de composición variable cuya velocidad de hidratación dependerá de la composición global de esta sistema, en la cual se pueden encontrar otros elementos, tales como el $\mathrm{Si}^{4+}$, el $\mathrm{Ti}^{4+} \mathrm{o}$ el $\mathrm{Mg}^{2+}$, principalmente (Taylor, 1990). Por otra parte, se cumple la regla general que cuanto mayor es el contenido de hierro menor es su velocidad de hidratación. En la hidratación de esta fase, el hierro como óxido de hierro (III), juega un papel tan importante como el aluminio como óxido de aluminio (III). Como se observa, en las reacciones químicas (r10) y r11) existiría un defecto de cal para que se formen los correspondientes compuestos sulfatados de aluminio y/o hierro, a menos que, también se formen los hidróxidos de aluminio y/o hierro.

$$
\begin{aligned}
& \mathrm{C}_{4} \mathrm{AF}+3 \mathrm{CS} \mathrm{SH}_{2}+21 \mathrm{H} \rightarrow \mathrm{C}_{6}(\mathrm{~A}, \mathrm{~F}) \overline{\mathrm{S}}_{3} \mathrm{H}_{32}+(\mathrm{A}, \mathrm{F}) \mathrm{H}_{3} \\
& \mathrm{C}_{4} \mathrm{AF}+\mathrm{C}_{6}(\mathrm{~A}, \mathrm{~F}) \overline{\mathrm{S}}_{3} \mathrm{H}_{32}+7 \mathrm{H} \rightarrow 3 \mathrm{C}_{4}(\mathrm{~A}, \mathrm{~F}) \overline{\mathrm{S}}_{3} \mathrm{H}_{12}+(\mathrm{A}, \mathrm{F}) \mathrm{H}_{3}
\end{aligned}
$$

La expresión (A, F) de ambas fórmulas químicas indica que los óxidos de hierro y aluminio son intercambiables, aunque su relación Al/Fe no sea la misma (Talero, 1986). Por su parte, Chen y col. (1997) obtuvieron los tiempos de formación de la Fase AFt a partir del $\mathrm{C}_{4} \mathrm{AF}$ y del $\mathrm{C}_{6} \mathrm{AF}_{2}$, al ser mezclados con yeso en proporciones variables de 1:1, 1:2, 1:3 y 1:4, todos con relación agua/sólido de 0,5. Los tiempos para la formación total de la Fase AFt para el $\mathrm{C}_{4} \mathrm{AF}$ resultó ser de 30 días y para el $\mathrm{C}_{6} \mathrm{AF}_{2}$ fue de 60 días. Estos valores confirman el hecho de que la hidratación del $\mathrm{C}_{4} \mathrm{AF}$ es mucho más lenta que la del $\mathrm{C}_{3} \mathrm{~A}$, así como su menor velocidad cuanto mayor es su contenido de hierro (III).

\section{I.1.3.4.- Interacción de los componentes del cemento Portland durante la hidratación.}

La hidratación, por separado, de los componentes del cemento Portland, como se ha visto hasta aquí, es válida para algunos propósitos, por ejemplo, establecer la correspondencia entre los compuestos mineralógicos y los productos de reacción que se originan. Aun así, los mecanismos de reacción de estos compuestos cuando se hallan conjuntamente son diferentes, ya que se producen reacciones competitivas y la diferente evolución de las especies iónicas en la disolución puede inhibir o acelerar la hidratación de algunas fases frente a otras, así como también, pueden favorecer la formación de unos productos de hidratación sobre otros.

El cemento Portland normal tiene una curva típica de evolución del calor que es combinación de la del $\mathrm{C}_{3} \mathrm{~S}$ y $\mathrm{C}_{3} \mathrm{~A}$ cuando se encuentran por separado. De este modo es posible identificar diferentes etapas tal y como se observa en la representación de la Fig. I-4. 

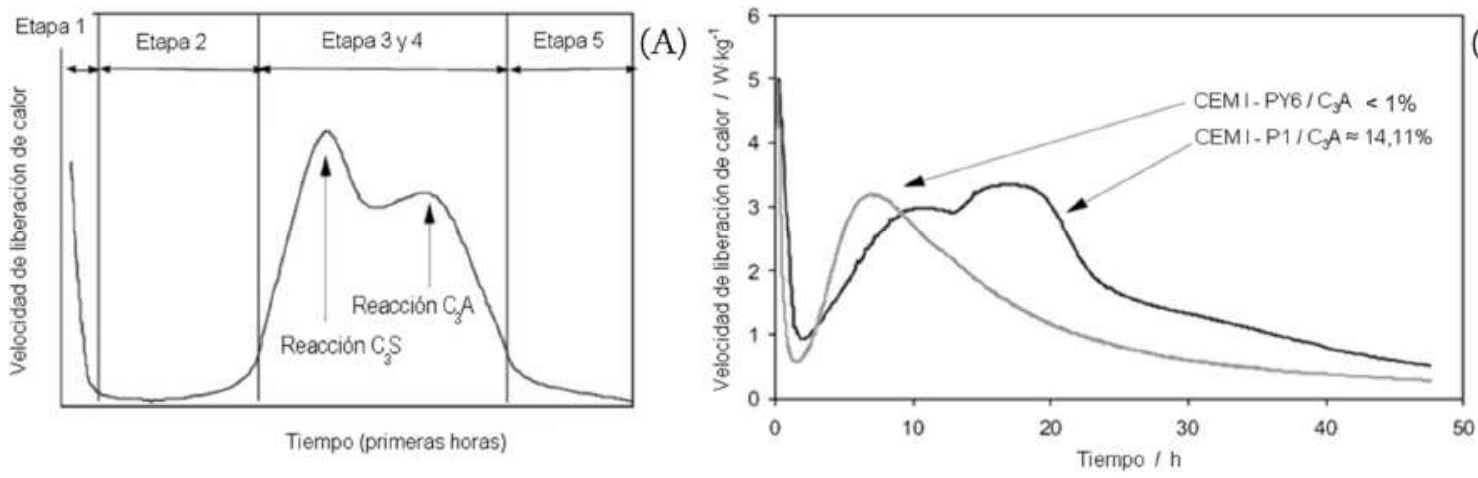

FIGURA I-4.- VELOCIDAD DE LIBERACIÓN DE CALOR; (A) ETAPAS; (B) PARA LOS CEM I, P1 Y PY6 (A PARTIR DE $\underline{\text { RAHHAL, 2002). }}$

En un principio el $\mathrm{C}_{3} \mathrm{~A}$ y $\mathrm{C}_{4} \mathrm{AF}$ compiten por los iones sulfato, pero por ser el aluminato tricálcico más reactivo, reacciona más rápido y tiende a reaccionar con más iones sulfato que el $\mathrm{C}_{4} \mathrm{AF}$. Sin embargo, este efecto incrementa la reactividad del $\mathrm{C}_{4} \mathrm{AF}$, el cual también reacciona con iones sulfato, y, en consecuencia, se forma más Fase AFm y AFt de las esperadas atendiendo únicamente al contenido $\mathrm{C}_{3} \mathrm{~A}$. De un modo estimado, la cantidad de sulfoaluminato de calcio hidratado formado en una pasta de cemento Portland, puede ser menor a la mitad de la calculada teóricamente a partir de los compuestos puros del cemento Portland. El yeso incrementa la velocidad de hidratación de los silicatos de calcio, que también compiten por los iones sulfato durante la hidratación; aparentemente, el gel CSH incorpora en su estructura, cantidades significativas de sulfatos y además de hierro y de aluminio, entre otros elementos minoritarios. Un contenido elevado de regulador de fraguado, mucho más del necesario, según la norma ASTM C563-95, contribuye a la formación de grandes cantidades de ettringita, la cual se puede originar incluso después de haber endurecido la pasta, produciéndose la expansión y fisuración de la microestructura debido al incremento de volumen aparejado a su formación (ettringita secundaria); esta y no otra es la razón de su efecto deletéreo para el hormigón. Por el contrario, cuando el contenido de regulador de fraguado es bajo, la disolución sólida de Fase AFm se formará antes de finalizar la Etapa 2 de la hidratación del $\mathrm{C}_{3} \mathrm{~S}$, reduciendo la cantidad de portlandita e impidiendo la nucleación de los productos de hidratación del $\mathrm{C}_{3} \mathrm{~S}$. Ello se traduce en un retardo de la Etapa 3 donde ha de producirse el final de fraguado. De estos dos efectos igualmente negativos, se establece la necesidad de asegurar la existencia de un contenido óptimo de regulador de fraguado para cada clínker Portland con adiciones minerales activas (obtenido mediante el método ASTM C452-68 adaptado por Talero (1986) para este otro fin dosificador), pero, sobre todo, sin tales adiciones minerales (obtenido mediante dicha norma ASTM C563-95).

Como complemento a la contribución a la resistencia mecánica de los componentes mineralógicos del cemento Portland que se mostró en la Fig. I-3, en la Fig. I-5, se muestra la evolución de los principales productos de hidratación durante los primeros 90 días.

Como se puede observar, el producto mayoritario de hidratación del cemento Portland es el gel CSH que llega a constituir del 50\% al 60\% del volumen de sólidos de la pasta de cemento. A este compuesto sigue en volumen de sólido la portlandita con un $20 \%$ al $25 \%$. El resto hasta completar el 100\%, está constituido por los sulfoaluminatos y los ferritoaluminatos hidratados, cuya proporción relativa depende, como ya se ha explicado, de las cantidades de $\mathrm{C}_{3} \mathrm{~A}, \mathrm{C}_{4} \mathrm{AF}$ y de 
regulador de fraguado. A estos últimos productos de hidratación hay que añadir las partículas de cemento que permanecen anhidras. En esta representación esquemática se ha representado además la evolución de la porosidad, la cual disminuye a medida que se generan más productos de hidratación, como es lógico.

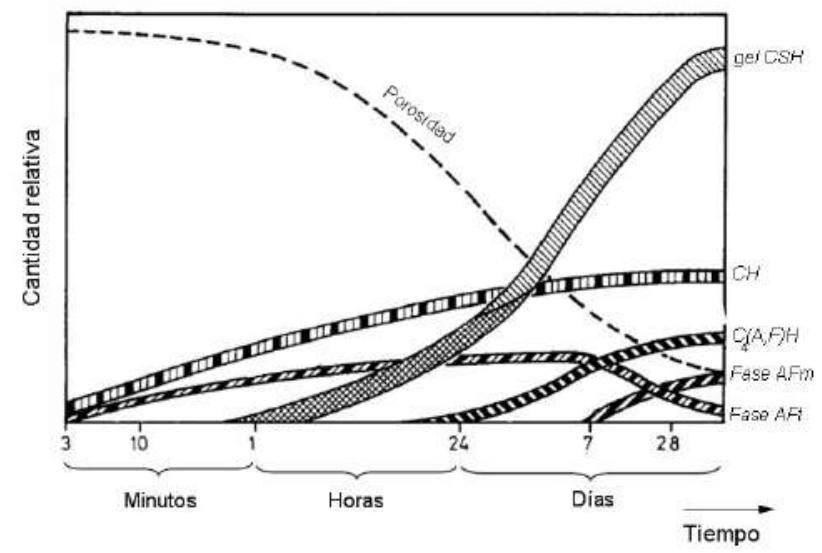

FIGURA I-5.- EVOLUCIÓN DE LOS PRODUCTOS DE HIDRATACIÓN DE UN CEMENTO PORTLAND (RICHARTZ, 1969, ADAPTADO DE ZIMBELMANN, 1985).

La cantidad de productos de hidratación evoluciona durante toda la vida de servicio del material fabricado a partir del cemento Portland, produciéndose cambios progresivos en la microestructura de alguno de ellos, e inclusive, generándose otros nuevos. Lo que es debido a la diferente estabilidad de cada una de las fases en función del ambiente de exposición en el que se encuentre el material en cuestión. Así, por ejemplo, se pueden producir cambios microestructurales debido a fenómenos de carbonatación, de ataque por los iones sulfato, de ataque por iones cloruro, de lixiviación, de ataque por aguas ácidas o de ataque por agua de mar, entre otros muchos.

Finalmente, a todo lo anterior se debe de añadir también que, debido a los fenómenos que se producen durante la hidratación inicial del cemento Portland, que conducen al rápido incremento de la resistencia a la difusión, en el cemento Portland siempre quedan cantidades apreciables remanentes de partículas anhidras, las cuales, con el tiempo, continúan hidratándose produciendo nuevos productos de hidratación, lo que en los casos más beneficiosos conduce a una mayor densificación de la microestructura de la pasta.

\section{I.1.4.- Microestructura del cemento Portland hidratado.}

Todos los fenómenos descritos anteriormente hacen que la pasta de cemento Portland endurecida posea una gran resistencia mecánica a compresión y una menor resistencia a tracción, y de igual modo el hormigón y los morteros que con él se fabriquen. Esto se debe a las propiedades de cada uno de los productos de hidratación, a su proporción y a las múltiples interacciones existentes entre ellos. Asimismo, es un parámetro fundamental, también, la porosidad y la distribución de tamaños de poro existentes en el material. Estos factores no sólo determinan las propiedades físico-mecánicas del material, sino también su durabilidad en el ambiente de exposición al que vaya a estar sometido durante su servicio.

En los apartados subsiguientes se describirán la microestructura y propiedades de los 
productos de hidratación más importantes del cemento Portland: gel CSH, CH, y las Fases AFm y AFt. Asimismo, se abordará también la naturaleza y composición química de la fase líquida.

\section{I.1.4.1.- Gel CSH.}

\section{I.1.4.1.1 Descubriendo la composición y estructura de los silicatos de calcio hidratados.}

Como ya se ha indicado, este producto de hidratación es el que mayor volumen de sólidos ocupa en la pasta de cemento Portland, y como tal, es el primer responsable de su resistencia mecánica. Es por ello que el estudio de la microestructura y propiedades de esta fase haya sido el objetivo de numerosas investigaciones, incluso desde el primer cuarto del siglo XX (Bates y col. 1917). A pesar de ello, la estructura de esta fase no es aún del todo conocida, ya que la microestructura de estos silicatos de calcio hidratados es muy variable, poseyendo estructuras diversas que van desde el ámbito amorfo al pobremente cristalino.

El parámetro característico del gel CSH es su relación molar $\mathrm{Ca} / \mathrm{Si}$, lo que determina su mayor o menor basicidad y estabilidad. En un principio, Le Chatelier (1882) defendió que las propiedades del cemento Portland se debían a un silicato de calcio hidratado de fórmula $\mathrm{CaO} \cdot \mathrm{SiO}_{2} \cdot 2,5 \mathrm{H}_{2} \mathrm{O}$. Posteriormente, Newberry y col. (1903) corrigieron esta hipótesis mediante la siguiente fórmula química 1,5-2CaO·SiO $2(a q)$, y Rankin (1919) definió esta fase como sílice hidratada. Se realizaron numerosas investigaciones hasta que Bogue (1959) volviera a indicar que la composición más probable de esta fase era $1,5 \mathrm{CaO} \cdot \mathrm{SiO}_{2}(\mathrm{aq})$.

Durante este tiempo, se realizaron numerosas investigaciones encaminadas a establecer las condiciones de formación de los silicatos de calcio hidratados, así como su estabilidad. A este respecto, Kühl y col. (1934) demostraron que cuando la proporción de CaO de los silicatos de calcio hidratados era superior a 50\%, tenía lugar un considerable aumento de su solubilidad, hasta el punto de que cuando la relación $\mathrm{Ca} / \mathrm{Si}$ era de 1,5 se disuelve en agua tanto $\mathrm{CaO}$ a temperatura ordinaria que es posible alcanzar la saturación. Por otra parte, Flint y col. (1934) realizaron una investigación del sistema $\mathrm{Ca}(\mathrm{OH})_{2}-\mathrm{SiO}_{2}-\mathrm{H}_{2} \mathrm{O}$ a distintas temperaturas, concluyendo que cuando la cantidad relativa de Ca frente a Si era inferior a 40\%, no se formaba silicato de calcio hidratado alguno, ni incluso a elevadas temperaturas. Por consiguiente, la formación de silicatos de calcio hidratados se produciría a partir de aquél que contuviera, al menos, una proporción de $40 \%$ de $\mathrm{CaO}$ y $60 \%$ de $\mathrm{SiO}_{2}$, es decir, una relación $\mathrm{Ca} / \mathrm{Si}$ de 0,67 .

Por otra parte, gracias a los estudios de Powers y Brownyard (1947), se pudo establecer las propiedades de coloide y gel de los silicatos de calcio hidratados. Estos investigadores aportaron además información sobre la porosidad del gel CSH, fijándola en aproximadamente el 28\%.

No obstante, la estructura geliforme de los silicatos de calcio hidratados que se forman hace muy difícil su identificación y su posterior cuantificación por difracción de rayos-X (en adelante, DRX) de cada uno de los silicatos de calcio hidratados existentes (McMurdie y col. 1943, Brandenberguer y col. 1946, Bernal y cols. 1952). Ya que, en realidad, se produce una mezcla de ellos, siendo sus difractogramas de DRX muy semejantes. Por su parte, Taylor (1950) consideró que los silicatos de calcio hidratados que se originaban en la hidratación del cemento Portland estaban relacionados con los que se podían formar en suspensiones diluidas. Así llegó a identificar dos tipos, el tipo I y el tipo II, en función de que tuvieran una baja o elevada relación $\mathrm{Ca} / \mathrm{Si}$, 
respectivamente. Así el gel CSH tipo I poseía una estructura por capas, alongadas en una dirección determinada, lo cual se traducía en una estructura fibrilar. Este tipo particular de silicato de calcio hidratado poseía una composición química promedio similar a la de la tobermorita² (Claringbull y col. 1952; Taylor y Broms, 1964).

Paralelamente, otra serie de investigaciones tuvieron como objeto determinar la cantidad de agua que existía en los silicatos de calcio hidratados. Así y por vez primera, R.L Blaine (1960) identificó mediante RMN, dos tipos de moléculas de agua en esta fase. Este investigador definió a cada uno de estos tipos como agua adsorbida y como agua combinada, lo que además venía a confirmar los resultados obtenidos en un trabajo anterior en el que había participado (Tomes y col. 1957). Así mientras el primer tipo de agua se hallaba adsorbida a la estructura únicamente por fuerzas de Van der Waals, el segundo tipo formaba parte de esta.

De todo lo anterior, el hecho más decisivo en el desarrollo del conocimiento sobre el gel CSH es el de la aproximación de su estructura a la de la tobermorita. Esto posibilitó estudiar con mayor fundamento la evolución de la microestructura de estos silicatos, y, por ende, de la hidratación de la pasta de cemento. La estructura de la tobermorita se convirtió en la base a partir de la cual se proponían modificaciones oportunas y mecanismos de reacción y transformación para poder explicar las diferencias existentes, tanto en propiedades como en composición química, entre este mineral cristalino y el gel CSH originado a partir de la hidratación del cemento Portland. Ya que, desde los inicios hasta ahora, los investigadores han aportado valores muy diferentes de la relación $\mathrm{Ca} / \mathrm{Si}$, siendo el intervalo de valores de esta relación para el gel $\mathrm{CSH}$ de 0,7 a 2,3 (Richardson, 1999), lo cual difiere en la mayor parte de los casos y como es obvio de 0,83 . En cuanto al gel CSH de origen cemento Portland, la relación varía entre 1,2 a 2,3 con un promedio de 1,75 (Richardson y col. 1993a; Richardson, 1999; Nonat, 2004).

\section{I.1.4.1.2 Estructura del gel CSH y sus principales modelos microestructurales}

Se han desarrollado numerosos modelos que describen la estructura del gel CSH como una estructura laminada, donde las cadenas de silicatos se sitúan en láminas paralelas, dejando espacios en los que se adsorben fuertemente moléculas de agua; dichos espacios interlaminares son inferiores al tamaño de diez moléculas de agua, por lo que se estableció que dicha agua debía pertenecer a la propia estructura del gel y no a agua libre sin combinar químicamente (Feldman y col. 1970; Wittmann, 1974, 1988). La longitud de las cadenas de silicato constitutivas del gel CSH se establece en función del número de átomos de silicio unidos directamente mediante un átomo de oxígeno, habiéndose obtenido por Grutzeck (1999) que las longitudes posibles son las que responden a la serie 3n-1, para n igual a 1, 2 ó 3, es decir, sólo se pueden formar dímeros, pentámeros, octámeros, etc. Desde el punto de vista del mecanismo de formación del gel CSH, esta serie implica que dos dímeros, como unidades constitutivas, se unen mediante un tetraedro de sílice, es decir un monómero, para formar el pentámero, y así sucesivamente.

La estructura de la tobermorita posee cadenas lineales silicatos en las que el tetraedro de silicato se coordina directamente con $\mathrm{Ca}^{2+}$ cada tres tetraedros. La repetición secuencial de esta estructura es la que constituye progresivamente la cadena de silicatos. Por otra parte, dos de los

${ }^{2}$ La tobermorita es un silicato de calcio hidratado cristalino poco abundante que se encuentra en algunas partes de Irlanda del Norte, cuya estructura fue descrita en 1956 por Megaw y col. Su fórmula química aproximada es $\mathrm{Ca}_{4}\left(\mathrm{Si}_{6} \mathrm{O}_{18} \mathrm{H}_{2}\right) \cdot \mathrm{Ca} \cdot 4 \mathrm{H}_{2} \mathrm{O}$, lo que implica una relación $\mathrm{Ca} / \mathrm{Si}$ de 0,83 . 
tres tetraedros de silicato comparten vértices O-O con la parte central de la lámina de Ca-O. Estos tetraedros son contiguos y a ellos se refiere habitualmente como tetraedros «apareados» (del inglés «paired»). El tercer tetraedro, que comparte un átomo de oxígeno del vértice piramidal del poliedro de $\mathrm{Ca}$, conecta dos grupos de tetraedros apareados y por eso recibe el nombre de tetraedro «puente» (del inglés «bridging»), que es el que durante la formación del silicato de calcio hidratado une dos dímeros, constituyéndose así un pentámero.

Por su parte, Taylor y col. (1965) fueron quienes explicaron el mecanismo por el cual es posible que aumente la relación $\mathrm{Ca} / \mathrm{Si}$ del gel CSH con respecto a la tobermorita. Su explicación se fundamentó en la sustitución de los tetraedros puente de sílice por iones interlaminares de $\mathrm{Ca}^{2+}$. Desde entonces varios modelos han sido propuestos para explicar el aumento de la relación $\mathrm{Ca} / \mathrm{Si}$ desde 0,83 a 1,7-1,8 que son las relaciones habituales que se observan experimentalmente en pastas de cemento Portland o de $\mathrm{C}_{3} \mathrm{~S}$. Los referidos modelos microestructurales pueden dividirse en dos grupos:

- Los basados en el sistema $\mathrm{T} / \mathrm{CH}$, tobermorita-disolución sólida de hidróxido de calcio, el cual implica estructuras similares a la tobermorita en las que se hallan interestratificadas láminas de $\mathrm{Ca}(\mathrm{OH})_{2}$.

- Los basados en el sistema tobermorita-jennita ${ }^{3}, \mathrm{~T} / \mathrm{J}$, el cual implica estructuras similares a la tobermorita y a la jennita intercaladas.

Algunos ejemplos del sistema T/CH son los aportados por Kurczyk y col. (1960), Kantro y cols. (1962), y Birchall y col. (1984), mientras que del sistema T/J es el de Taylor (1986).

A pesar de que se hayan propuesto varios modelos microestructurales para tratar de explicar las características reales del gel CSH, aún no se dispone de un conocimiento completo acerca de la heterogeneidad de esta fase, del mecanismo de formación, de la morfología y el ordenamiento estructural del gel, y de los cambios que sufre el mismo con el tiempo. Se sabe que la naturaleza del gel CSH está afectada por diferentes factores como la composición mineralógica del cemento Portland, su relación agua-cemento, su temperatura de curado, su grado de hidratación y/o la presencia de adiciones minerales, entre otras. Actualmente, se está cada vez más cerca de descifrar las incógnitas que aún rodean a la naturaleza del gel CSH, si bien se debe comentar que la incorporación de adiciones minerales al cemento Portland supone un mayor grado de complejidad en el sistema, lo que conlleva inevitablemente a la formación de diferentes fases y por diferentes mecanismos, lo que afecta muy notablemente al gel CSH, y es causa principal de que el campo potencial de su estudio de esta fase se haya traspasado límites inimaginables hace tan sólo una década. Adicionalmente, nuevas técnicas analíticas instrumentales avanzadas aportan resultados que ponen de manifiesto cada vez más factores que afectan a la estructura y ordenamiento de esta fase, dependientes a su vez del sistema cementante.

De este modo, las principales incógnitas sobre este gel CSH son las relacionadas con la variabilidad de la relación $\mathrm{Ca} / \mathrm{Si}$, la heterogeneidad en su composición a pequeña escala, las modificaciones que introducen la presencia de iones sustituyentes y las transformaciones a lo largo del tiempo en función del ambiente de exposición a que esté sometido. Con respecto a su

\footnotetext{
${ }^{3}$ La jennita es también un silicato de calcio hidratado cristalino, cuya fórmula constitutiva es en este caso $\mathrm{Ca}_{9} \mathrm{Si}_{6} \mathrm{O}_{18}(\mathrm{OH})_{6} \cdot 8 \mathrm{H}_{2} \mathrm{O}$. Su relación $\mathrm{Ca} / \mathrm{Si}$ es, por tanto, igual a 1,5 .
} 
COMPORTAMIENTO SULFÁTICO Y MECÁNICO-RESISTENTE DE CEMENTOS PORTLAND CON ELEVADOS CONTENIDOS DE PUZOLANAS (> 40\%): SU FUNDAMENTO QUÍMICO Y JUSTIFICACIÓN DE OTRAS CONSECUENCIAS POSIBLES

composición, se sabe que la relación $\mathrm{Ca} / \mathrm{Si}$ global a nivel micrométrico de un gel CSH es prácticamente constante e independiente de la zona que se analiza, mientras que, por debajo de los $100 \mathrm{~nm}$, el análisis de diferentes partes ofrece valores muy dispares de su relación Ca/Si, la cual está comprendida entre 2,1 y 1,2 (Richardson y col. 1993a; Richardson, 2000).

Dependiendo de la característica o propiedad considerada, el gel CSH puede ser clasificado de diferente manera. Así, de acuerdo al lugar donde se origine, el gel CSH puede ser de dos tipos «interno» o «externo» (del inglés «inner» o «outer», respectivamente). Así, el gel CSH que se forma en el volumen original de la partícula de cemento Portland se denomina «interno» (en adelante, gel $\left.\mathrm{CSH}^{\mathrm{I}}\right)$, mientras que el formado en el espacio ocupado inicialmente por fase líquida se denomina «externo» (en adelante, gel CSH${ }^{\mathrm{E}}$ ) (Taplin, 1959), no obstante, para los objetivos de esta Tesis Doctoral no es relevante su diferenciación, por lo que se hablará de gel CSH sin más. El diferente volumen de que disponen para desarrollarse hace que el ordenamiento del gel CSH a mayor escala sea diferente, y, a priori, posean propiedades diferentes. En un primer lugar, el desarrollo del gel $\mathrm{CSH}^{\mathrm{E}}$ sería el principal responsable del fraguado y endurecimiento del cemento Portland y no el gel $\mathrm{CSH}^{\mathrm{I}}$.

Por otra parte, y en cuanto a su respectiva morfología y ordenamiento estructural, se ha de comentar también que ha sido demostrado que si el gel $\mathrm{CSH}^{\mathrm{I}}$ se forma a partir de grandes partículas de C3S, presenta una estructura compacta y una morfología homogénea (Williamson, 1972; Groves, 1987). Mientras que, si el gel CSH ${ }^{I}$ se forma a partir de partículas demasiado pequeñas, en el interior de éstas el gel originado poseerá una baja densidad y un pobre empaquetamiento (véase la siguiente Fig. I-6), lo que contribuye enormemente al aumento de la porosidad del material.

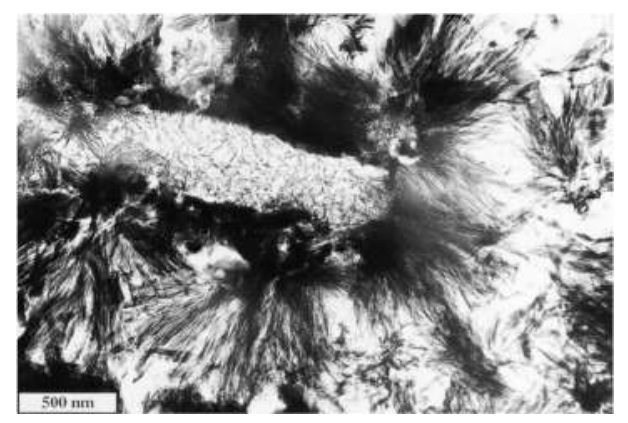

FIGURA I-6.- MICROGRAFÍA TEM EN LA QUE SE MUESTRAN GEL CSHI DE BAJA DENSIDAD RODEADO DE UNA CORONA DE GEL CSHE FIBRILAR RELATIVAMENTE DENSO EN UNA PASTA DE CEMENTO PORTLAND A EDAD AVANZADA (RICHARDSON, 1999).

Teniendo en cuenta lo acabado de comentar sobre la disponibilidad de volumen, está claro que este fenómeno ocurrirá cuando, además de una partícula de tamaño muy pequeño, las propias partículas se hallen tan distantes entre sí que todo el $\mathrm{CaO}_{\text {y }} \mathrm{SiO}_{2}$ de la partícula inicialmente anhidra formen gel CSHE, lo cual, por otra parte, se produce con más facilidad cuanto mayor sea la relación agua-cemento.

Por su parte, el gel $\mathrm{CSH}^{\mathrm{E}}$ posee una morfología fibrilar direccional (Williamson, 1972; Groves, 1987; Jennings, 1981). Si ambos tipos de gel, el gel CSH ${ }^{\mathrm{I}}$ y el gel CSHE, se originan a partir de una partícula lo suficientemente grande en condiciones favorables, es posible identificar 
claramente la zona que delimita a ambos tipos, tal y como se observa en la Fig. I-7(A), junto a su respectiva morfología en las Figs. I-7(B) y (C).

Por otra parte, y haciendo una aportación al tema, Groves (1987) estimó, a partir de micrografías de TEM, que la porosidad del gel $\mathrm{CSH}^{\mathrm{I}}$ era inferior a los $10 \mathrm{~nm}$ de diámetro. Además de las imágenes de la Fig. I-7, Richardson (2004) obtuvo otras imágenes de la estructura del gel mediante TEM. En éstas observó que el gel $\mathrm{CSH}^{\mathrm{I}}$ estaba constituido por pequeñas partículas globulares de entre 6 y $8 \mathrm{~nm}$ de diámetro homogéneamente distribuidas, corroborando de paso que la porosidad que quedaba entre los glóbulos era efectivamente inferior a los $10 \mathrm{~nm}$.

Asimismo, Richardson (2004) abordó el estudio del gel CSH${ }^{\mathrm{E}}$, encontrando que la morfología de las fibras dependía del espacio disponible a la hora de su formación. Así, cuando el espacio disponible era suficientemente grande (por ejemplo, en poros grandes) la relación longitudanchura era elevada, mientras que ocurría todo lo contrario si el crecimiento se producía en un espacio más confinado. El espacio entre las fibras de este gel conforma una red porosa tridimensional, que constituye parte de la porosidad capilar. Al igual que el gel CSH', este gel está constituido también por partículas globulares, pero de tamaño mucho más variable, de tres a varias decenas de nanómetros.
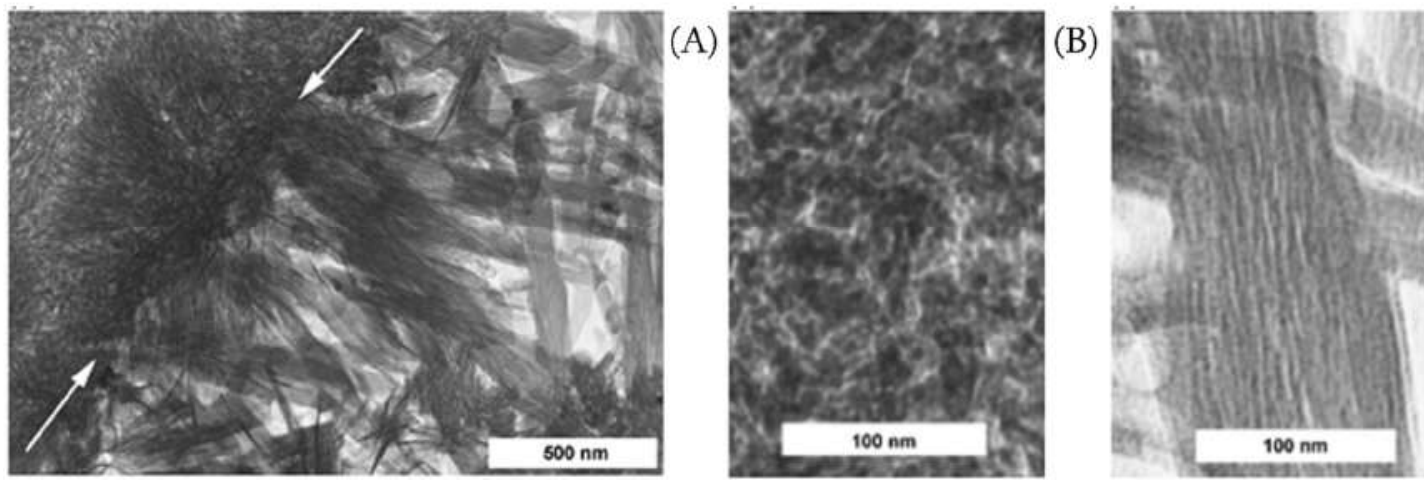

FIGURA I-7.- MICROGRAFÍAS TEM EN LAS QUE SE MUESTRA: (A) GEL CSH (ESQUINA SUPERIOR IZQUIERDA) Y GEL CSHE, EN UNA PASTA DE C3S ENDURECIDA DURANTE 8 AÑOS $\left(T=20^{\circ} \mathrm{C}\right.$, RELACIÓN AGUA/SÓLIDO =0,4); LAS FLECHAS BLANCAS INDICAN EL LÍMITE ENTRE AMBOS TIPOS DE GEL CSH; (B) IMAGEN AMPLIADA DE UNA REGIÓN EN EL GEL CSH'; (C) IMAGEN AMPLIADA DE UNA REGIÓN EN EL GEL CSHE (RICHARDSON, 2004).

Ahora cabe preguntarse con fundamento: ¿qué modelo, $\mathrm{T} / \mathrm{CH}$ o T/J, es el que se debe aplicar a las partículas globulares? Los resultados que se han expuesto no permiten dar respuesta a esta pregunta, ni siquiera los que se han realizado por otros investigadores y otras técnicas analíticas. Así y mediante análisis por DRX de pastas de cemento Portland se obtienen únicamente dos picos débiles y anchos para el gel CSH centrados entre 3,2-2,7 ̊̊ y 1,86-1,79 ̊̊ (Taylor, 1997), no habiendo ningún signo evidente de espaciados interplanares, $y$, por consiguiente, no pudiéndose discernir entre la tobermorita y la jennita. Asimismo, otros ensayos complementarios como el de Difracción de Electrones de una Selección de Área (del inglés Selected Area Electron Diffraction, cuyo acrónimo es SAED) han confirmado los resultados obtenidos por DRX, y los han 
ampliado, ya que el análisis de una pasta endurecida de cemento Portland mostró la inclusión de $\mathrm{CH}$ en el gel $\mathrm{CSH}^{4}$.

Otro de los aspectos microestructurales relacionados con el gel CSH es la sustitución de $\mathrm{Si}^{4+}$ de los tetraedros por $\mathrm{Al}^{3+}$, lo cual ocurre únicamente en los tetraedros puente (Richardson y cols. 1993b; Andersen y cols. 2003), lo que modifica sus propiedades, produciendo como un primer efecto una descompensación de carga. Este hecho es más frecuente en los cementos de mezcla con adiciones puzolánicas (Richardson, 2004), sobre todo, cuando su carácter químico es alumínico o alumínico-silícico (clasificación según Talero, 1993a, 1996; Talero y cols. 1999) y con escorias

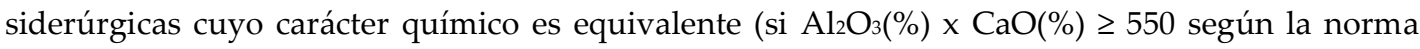
francesa NF P 18-506).

Al igual que la relación $\mathrm{Ca} / \mathrm{Si}$ del gel $\mathrm{CSH}$ es un parámetro fundamental, la longitud promedio de las cadenas de silicato ${ }^{5}$ es otro. Los valores aportados de este otro parámetro, a partir de diversas investigaciones, han venido a reforzar la teoría de crecimiento de $3 n-1$, a la vez que permite caracterizar el grado de polimerización del gel CSH de la pasta de cemento Portland. Se sabe que con el tiempo se produce un incremento del valor de este parámetro en pastas de cemento Portland, por ejemplo, Rodger (1984) obtuvo un crecimiento de 2 a 3,1 de este parámetro durante 12 meses. El incremento de este parámetro en una misma pasta de cemento (cemento Portland o cemento de mezcla) implica un aumento de la resistencia mecánica del material. Sin embargo, esto no es aplicable cuando se trata de diferentes sistemas, es decir, en diferentes cementos Portland o cementos de mezcla, ya que se producen muchos otros fenómenos que imposibilitan realizar tal aseveración.

Como se habrá podido observar, hasta ahora existen diferentes modelos microestructurales para describir la estructura más básica del gel CSH, a la vez que existen diferentes morfologías y ordenamientos estructurales para el mismo, además de efectos como la sustitución iónica o la variación del crecimiento de las cadenas de silicato, pero en realidad ¿qué modelo microestructural es capaz de explicar las diferentes morfologías y ordenamientos del gel CSH, a la vez que da explicación fundamentada de la relación $\mathrm{Ca} / \mathrm{Si}$ del mismo? La respuesta no es nada trivial, ya que de ello dependen, en gran medida, la microestructura del material de base cemento y su durabilidad química. Y para encontrar una respuesta, se ha de recurrir a los diferentes modelos microestructurales existentes en la bibliografía, destacando por encima del resto el modelo de Richardson y col. (1992, 1993c), debido a que, por una parte, da cuenta de todos los fenómenos anteriores y, por otra, incluye y explica otros modelos microestructurales de especial relevancia, tales como los formulados por Taylor (1986), Cong y col. (1996), Nonat y col. (1998) o Chen y cols. (2004), entre muchos otros. La demostración de esto último puede encontrarse en Richardson

\footnotetext{
${ }^{4}$ La imposibilidad de diferenciarlos con estas técnicas analíticas se debe a que espaciados en la región entre 3 y $1,8 \AA$ A se corresponden con la repetición de las distancias en la lámina de Ca-O de la estructura de la tobermorita y de la jennita.

${ }^{5}$ De acuerdo con Richardson (1999), la longitud promedio de cadenas de silicato $\left(\mu_{\mathrm{LC}}\right)$ puede obtenerse a partir de la expresión: $\mu_{\mathrm{LC}}=2\left(\mathrm{Q}^{1}+\mathrm{Q}^{2}\right) / \mathrm{Q}^{1}$; obteniendo los $\mathrm{Q}^{\mathrm{n}}(0 \leq \mathrm{n} \leq 4)$ mediante ${ }^{29}$ Si RMN. Q representa un tetraedro de silicato y $\mathrm{n}$ el número de átomos de oxígeno comunes a otros tetraedros de silicato. De este modo, $\mathrm{Q}^{0}$ representa unidades aisladas de tetraedros de silicato, $\mathrm{Q}^{1}$ representa los tetraedros finales de una cadena de silicato y $\mathrm{Q}^{2}$ representa los tetraedros que forman parte del centro de la cadena.
} 
(2004), en la que este autor califica los anteriores modelos como un caso particular de un modelo más general.

\section{I.1.4.1.3 Propiedades del gel CSH en función de su estructura.}

A continuación, no se va a describir el referido modelo en Richardson (2004), sino sus implicaciones prácticas sobre el modelo, la morfología y el ordenamiento estructural del gel CSH «interno» y «externo». Así y de acuerdo con este modelo general, ambos puntos de vista estructurales, la tobermorita (T) y la jennita (J), pueden ser válidos para la descripción del gel CSH en pastas de cemento Portland. Por su parte, el modelo T/J puede explicar que a edades cortas se obtenga una distribución bimodal de la relación $\mathrm{Ca} / \mathrm{Si}$. La tendencia con el tiempo a que se obtenga una distribución unimodal de esta relación puede explicarse en base a la polimerización que ocurre en unidades largas de estructura tipo J. Esto a su vez puede constituir una explicación de por qué permanecen grandes cantidades de dímero incluso después de varias décadas de reacción. Aunque es necesario que coexistan con ciertas cadenas largas de tipo $\mathrm{T}$ para acomodar el $\mathrm{Al}^{3+}$ tetraédrico. Con el progreso del tiempo, la polimerización se dificulta debido al acceso restringido de los dímeros a los tetraedros puente en el interior de las partículas del gel CSH. Los datos de composición y estructura del gel CSH en pastas de cemento Portland a larga edad no pueden ser descritos por un sistema únicamente de tipo J, a menos que exista una elevada protonación de las cadenas, lo cual es poco probable. En el extremo opuesto, se encontraría el gel CSH originado en presencia de sílice reactiva, el cual estaría basado en la estructura $\mathrm{T}$.

De acuerdo a este modelo general, puede establecerse una relación entre la morfología y la estructura del gel CSH. El gel CSH de mezclas de cemento Portland con ciertas adiciones minerales, es decir, las pastas hidratadas de algunos cementos de mezcla poseen una morfología de hojas o similar a láminas, la cual ha sido asociada con la estructura de tipo T. Pues bien, ya que en el cemento Portland se producen unidades J y capas de $\mathrm{CH}$, y ya que en este tipo de cemento la morfología del gel CSHE, como ya se describió, es fibrilar, el cambio morfológico puede asociarse de un modo razonado al aumento de la relación $\mathrm{Ca} / \mathrm{Si}$. Pero el cambio morfológico no puede asociarse en exclusiva a este aumento ya que en otros sistemas se forma gel CSH de morfología laminar basado en el modelo $\mathrm{T} / \mathrm{CH}$ con una elevada relación $\mathrm{Ca} / \mathrm{Si}$. Es por ello que el cambio morfológico debe estar asociado más a la presencia de unidades tipo J que a la de una disolución sólida de $\mathrm{CH}$. No obstante y a pesar de esto último, existe otra posibilidad para que se produzcan estas diferencias morfológicas, y es que debido a diferentes composiciones químicas, la formación del gel CSH puede producirse a muy diferentes velocidades de transferencia de los complejos desde la disolución hasta las partículas de gel CSH que están desarrollándose, lo que se traduce finalmente en diferentes disposiciones espaciales. De este modo, en sistemas de cemento Portland, el crecimiento se produce en una dimensión produciéndose fibras, mientras que en otros sistemas se producirá en dos dimensiones obteniéndose la morfología de hojas o láminas. Ambas estructuras estarán inter-estratificadas con estructuras de tipo $\mathrm{CH}$ formando láminas o fibras arrugadas.

La aplicación del modelo general al gel CSH de los granos pequeños de $\mathrm{C}_{3} \mathrm{~S}$ totalmente hidratados del cemento Portland (que como ya se refirió posee una elevada relación Ca/Si y una elevada porosidad), posibilita afirmar que el gel CSH está formado esencialmente por estructura tipo $\mathrm{T}$ (con grandes cantidades de dímero). Y ya que el gel CSH con una estructura tipo $\mathrm{T}$ tiene propiedades diferentes a un gel CSH con estructura tipo J, es muy probable que el gel CSH originado en partículas pequeñas tenga diferentes propiedades a cualquier otro tipo de gel CSH 
formado en la pasta. Finalmente, cabe destacar también que el pequeño tamaño de las partículas de gel CSH en las pastas hidratadas de cemento Portland, en comparación con la de cementos de mezcla, produce un efecto de borde muy significativo, que, de paso, podría ser la explicación de que se encuentren grandes cantidades de unidades de silicatos monoméricos hidratados aún a elevados grados de hidratación (por ejemplo, según Brough y cols. 1994 a $20^{\circ} \mathrm{C}$ un 2\%).

Finalmente, y una vez expuestos las principales consecuencias del modelo general de Richardson y col. (1992, 1993c), se abordarán las propiedades mecánicas del gel CSH. Para ello se habrá de exponer los principios de la «teoría coloidal» aplicada a esta fase, para explicar además el ordenamiento estructural de los silicatos de calcio hidratados. Recuérdese a este respecto la estructura globular de cada tipo de gel que evidenció Richardson (2004), así como la diferente dimensión y diferente homogeneidad del tamaño de los glóbulos que asoció a cada uno, para así poder reafirmar que el ordenamiento estructural del gel CSH es el de una estructura amorfa coloidal que se organiza en glóbulos. Estos glóbulos serían las unidades constitutivas (de aproximadamente $2 \mathrm{~nm}$ ) que por diferentes modos de empaquetamiento conducirían a todas las diferentes estructuras y tipologías de gel CSH descritas hasta ahora. Dentro de estas unidades se encontrarían las cadenas de silicatos de calcio hidratados, y ocupando una fracción volumétrica del 18\%, cierta porosidad de orden nanométrico (Tennis y col. 2000; Jennings, 2000, 2004).

Desde un punto de vista micromecánico, el diferente empaquetamiento de los glóbulos conduce finalmente a dos tipos de del CSH con porosidades y propiedades micromecánicas muy diferentes en función de la densidad de este. Por una parte, se tiene un gel CSH de alta densidad con un $24 \%$ de porosidad, y un gel CSH de baja densidad con un $37 \%$ de porosidad. Estas dos formas de empaquetamiento se encuentran representadas gráficamente en la Figura I-8.

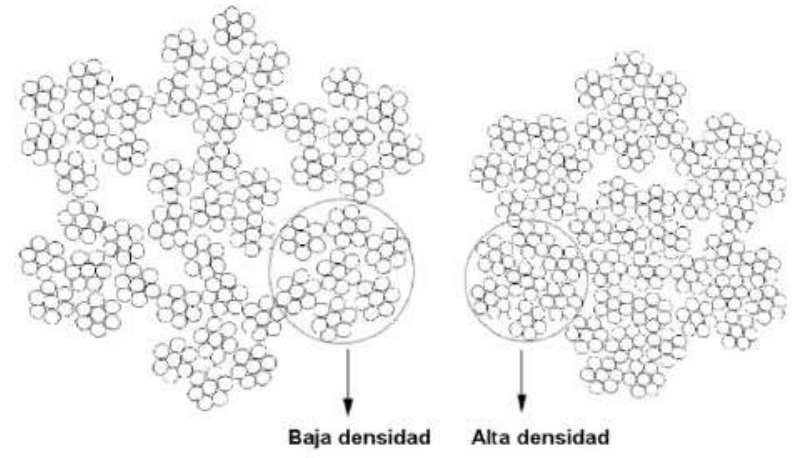

FIGURA I-8.- REPRESENTACIÓN DEL GEL CSH DE BAJA DENSIDAD (IZQUIERDA) Y GEL CSH DE ALTA DENSIDAD (DERECHA) SEGÚN EL MODELO DESCRITO EN JENNINGS (2000).

Lo importante de ambos tipos de empaquetamiento es que sus propiedades mecánicoelásticas varían. De este modo, los módulos elásticos se sitúan entre 26-39 GPa para el gel CSH de alta densidad, y entre 13-26 GPa para el de baja (Ulm y cols. 2005). En ambos casos y al contrario de lo que sucedía en los glóbulos, el agua que rellena los poros de ambos tipos de gel no es agua estructural, sino que pertenece a la fase líquida, y contiene entre otras las unidades monoméricas y diméricas de silicato no enlazadas. Las diferencias entre las propiedades de un gel y otro son tales, que es posible diferenciar unas pastas de cemento de otras en función de la proporción de ambos tipos de gel, lo cual es consecuencia como ya se ha dicho, de las diferentes condiciones en las que transcurran los procesos de hidratación, a parte de la composición química del sistema cementante. 
A pesar de que el diferente modo de empaquetamiento del gel CSH parece haber sido aceptada como la explicación de cada una de las diferentes propiedades mecánicas, existe otra explicación posible (aunque defendida minoritariamente). Esta explicación se fundamenta sobre la base de la coexistencia de dos zonas con diferente relación Ca/Si (Acker, 2004), y no con densidad de empaquetamiento diferente como se viene diciendo.

TABLA I-7.- PROPIEDADES MECÁNICAS CALCULADAS PARA SILICATOS DE CALCIO HIDRATADOS CRISTALINOS Y ALGUNOS DATOS EXPERIMENTALES OBTENIDOS PARA EL GEL CSH (ADAPTADA DE MANZANO Y COLS. 2007).

\begin{tabular}{|c|c|c|c|c|c|c|}
\hline Especie & $\mathrm{Ca} / \mathrm{Si}$ & $\mathrm{H}_{2} \mathrm{O} / \mathrm{Ca}$ & K / GPa & G / GPa & E / GPa & $\mathbf{N}$ \\
\hline $\begin{array}{c}\text { Nekoita } \\
\mathrm{Ca}_{3} \mathrm{Si}_{6} \mathrm{O}_{15} \cdot 7 \mathrm{H}_{2} \mathrm{O}\end{array}$ & 0,5 & 2,33 & 57 & 28 & 72 & 0,29 \\
\hline $\begin{array}{l}\text { Tobermorita } 9 \AA \\
\mathrm{Ca}_{5} \mathrm{Si}_{6} \mathrm{O}_{16}(\mathrm{OH})_{2}\end{array}$ & 0,8 & 0,00 & 68 & 67 & 152 & 0,13 \\
\hline $\begin{array}{c}\text { Tobermorita } 11 \AA \\
\mathrm{Ca}_{4} \mathrm{Si}_{6} \mathrm{O}_{15}(\mathrm{OH})_{2} \cdot 5 \mathrm{H}_{2} \mathrm{O}\end{array}$ & 0,66 & 1,25 & 74 & 29 & 77 & 0,32 \\
\hline $\begin{array}{c}\text { Tobermorita } 14 \AA \\
\mathrm{Ca}_{5} \mathrm{Si}_{6} \mathrm{O}_{16}(\mathrm{OH})_{2} \cdot 7 \mathrm{H}_{2} \mathrm{O}\end{array}$ & 0,8 & 1,40 & 46 & 39 & 91 & 0,17 \\
\hline $\begin{array}{c}\text { Foshagita } \\
\mathrm{Ca}_{8} \mathrm{Si}_{6} \mathrm{O}_{16}(\mathrm{OH})_{2}\end{array}$ & 1,3 & 0,00 & 74 & 40 & 102 & 0,27 \\
\hline $\begin{array}{c}\text { Jennita } \\
\mathrm{Ca}_{9} \mathrm{Si}_{6} \mathrm{O}_{18}(\mathrm{OH})_{6} \cdot 8 \mathrm{H}_{2} \mathrm{O}\end{array}$ & 1,5 & 0,89 & 43 & 26 & 66 & 0,24 \\
\hline $\begin{array}{l}\text { Hillebrandita } \\
\mathrm{Ca}_{6} \mathrm{Si}_{3} \mathrm{O}_{10}(\mathrm{OH})_{4}\end{array}$ & 2,0 & 0,00 & 64 & 33 & 86 & 0,28 \\
\hline $\begin{array}{c}\text { Valores experimentales } \\
\text { del gel CSH }\end{array}$ & & & $\begin{array}{c}15 \\
\text { Ulm y cols. } \\
2004\end{array}$ & $\begin{array}{c}9,7 \\
\text { Ulm y cols. } \\
2004\end{array}$ & $\begin{array}{c}20-30 \\
\text { Ulm y cols. } \\
2005\end{array}$ & $\begin{array}{c}\begin{array}{c}0,25 \\
\text { Le Belego }\end{array} \\
\underline{2001}\end{array}$ \\
\hline
\end{tabular}

Con la diferente estructura y empaquetamiento del gel CSH, se estima que su resistencia mecánica es debida a enlaces de tipo covalente e iónico, en aproximadamente un $65 \%$, y a fuerzas de unión de Van der Waals, en un 35\%. Por lo general, el enlace entre el gel CSH y otros productos de hidratación es bueno. El gel CSH posee una elevada área superficial (100-700 m². $\left.\mathrm{g}^{-1}\right)$. Y en cuanto a otras propiedades mecánicas del gel CSH, cabe destacar el estudio realizado por Beaudoin y cols. (1998) sobre el comportamiento de fractura de gel CSH sintético y una mezcla de gel CSH sintético y $\mathrm{CH}$. Estos investigadores prepararon diversas muestras mediante compactación, obteniéndose para cada una diferente porosidad y diferente composición química, de modo que la relación $\mathrm{Ca} / \mathrm{Si}$ resultó estar comprendida entre 0,68 y 1,49. Estos autores evaluaron la dependencia del factor crítico de intensidad de tensiones $\left(\mathrm{K}_{\mathrm{c}}\right)$ con la porosidad, la relación $\mathrm{Ca} / \mathrm{Si}$ y la relación polímero/dímero del gel CSH. De la interpretación de los resultados concluyeron que debía existir una mezcla óptima de cadenas largas y cortas de silicatos para que se obtenga la máxima resistencia a fractura del gel $\mathrm{CSH}$, ya que la muestra con mayor resistencia a la fractura fue la que menor valor de la relación 
polímero/dímero tenía. Asimismo, y como era lógico, la fractura de las muestras de gel CSH y gel $\mathrm{CSH} / \mathrm{CH}$ dependía de la porosidad para un gran intervalo de relación $\mathrm{Ca} / \mathrm{Si}$ y $\mathrm{H}_{2} \mathrm{O} / \mathrm{Si}$. Una conclusión muy importante que obtuvieron también fue la independencia entre la fractura de las muestras ensayadas y su relación $\mathrm{Ca} / \mathrm{Si}$, aunque se obtuvieron la mayor resistencia a la fractura cuando dicha relación fue igual a 0,99 y no para 0,68. A pesar de esto último, no se pueden extrapolar directamente estos resultados al gel CSH que se produce durante la hidratación del cemento Portland, ya que sería demasiado simplista, pues como se viene indicando durante todo este apartado, la microestructura del gel CSH está afectada por numerosos factores que lo dotan de empaquetamientos y ordenamientos estructurales muy diferentes.

En la actualidad, se está ampliando el estado del conocimiento sobre la naturaleza y las propiedades del gel CSH a través del estudio de las discrepancias existentes entre las propiedades mecánico-elásticas del gel CSH que se obtienen experimentalmente y las calculadas teóricamente para los silicatos de calcio hidratados cristalinos (Gmira y cols. 2004; Laugesen, 2003), ya que las propiedades teóricas suponen una sobreestimación de las propiedades experimentales en al menos cuatro veces.

Por otra parte, se está intentando establecer, además, una relación entre las propiedades mecánico-elásticas experimentales y la estructura de cada uno de los silicatos de calcio cristalinos, para finalmente comprobar si existe una relación directa estructura-propiedades. Asimismo, y en relación con esto último, cabe destacar también el trabajo de Manzano y cols. (2007), los cuales llevaron a cabo el cálculo teórico avanzado mediante simulación dinámica por campos de fuerza de las propiedades mecánico-elásticas de los silicatos de calcio hidratados cristalinos que poseen una relación $\mathrm{Ca} / \mathrm{Si}$ comprendida dentro de los valores habituales en el gel CSH. A continuación, se hará referencia a E como módulo de elasticidad longitudinal (módulo de Young), a G como módulo de elasticidad transversal (módulo cortante), a $\mathrm{K}$ como módulo de compresibilidad y $v$ como coeficiente de Poisson. En la Tabla I-7 se muestran estas propiedades calculadas para cada una de las especies simuladas.

Obsérvense en la Tabla I-7 las referidas discrepancias existentes entre las propiedades teóricas de los silicatos de calcio hidratados cristalinos y las obtenidas experimentalmente para el gel CSH. Asimismo, se ha de prestar especial atención, por todo lo ya comentado a lo largo de este apartado, entre los valores de la tobermorita $14 \AA$, de la jennita y los valores obtenidos experimentalmente. Salvo para el coeficiente de Poisson, se obtienen grandes diferencias entre estos valores. Estas diferencias han tratado de ser explicadas (Manzano y cols. 2007) en base al factor de empaquetamiento, dependiente de la porosidad del gel, mediante el esquema Mori-Tanaka (Mori y col. 1973), tras lo cual, y a pesar de haber obtenido menores valores de las constantes elásticas, las propiedades teóricas siguen suponiendo una sobreestimación de las propiedades obtenidas experimentalmente. Este hecho ha conducido a la necesidad de introducir en las simulaciones una variable adicional, la de la longitud de las cadenas de silicato (Dolado y cols. 2007; Manzano y cols. 2007). Como ya se comentó, el grado de polimerización del gel CSH es una característica fundamental del mismo, siendo las especies más abundantes los dímeros y pentámeros (es decir, cuando se cumple la regla para $\mathrm{n}=1$ y 2), aún a pesar de que existan cadenas de mayor longitud. Por este motivo, las simulaciones referidas anteriormente introdujeron como defecto en las estructuras cristalinas de la tobermorita $14 \AA$ ( $\mathrm{T}$ ) y la jennita (J), la longitud finita de las mismas, igual a 2 y 5 (especies T 2, T 5, J 2 y J 5). Las nuevas propiedades elásticas calculadas para estas 
especies están de acuerdo con los valores experimentales que se obtienen, habiendo podido afirmar estos investigadores que la discrepancia podía haberse debido fundamentalmente a la diferente longitud de las cadenas de silicato. Véanse los resultados de estos cálculos en la Tabla I-8.

Finalmente, se ha de mencionar también, en relación a la obtención de propiedades para su posterior comparación con las obtenidas experimentalmente, que las posibilidades ofrecidas por la simulación y el cálculo numérico aportan valiosa información con respecto al gel CSH. Y todo ello, debido a que existe una limitación técnica que imposibilita obtener y evaluar las diferencias existentes en esta fase, ya que las características particulares responsables de unas determinadas propiedades se producen a nivel atómico y nanométrico. Un ejemplo de las ventajas que aportan estos cálculos puede encontrarse en el trabajo realizado por Dolado y cols. (2007), en los que se ha simulado el efecto sobre las propiedades mecánicas que se produce por la sustitución en los tetraedros puente de los átomos de $\mathrm{Si}^{4+}$ por los de $\mathrm{Al}^{3+}$ en pentámeros y cristales de tobermorita y jennita.

Los resultados que aparecen también en la Tabla I-8, permiten por simple comparación observar cómo la sustitución iónica produce efectos contrarios en los cristales (de longitud infinita) en comparación con las unidades pentaméricas. Así, mientras que en los cristales supone la desestabilización de la red cristalina, en las unidades pentaméricas supone un aumento de la cohesión de las cadenas.

TABLA I-8.- PROPIEDADES MECÁNICAS CALCULADAS PARA CADENAS FINITAS DE 2 Y 5 ÁTOMOS DE SILICIO PARA ESTRUCTURAS BASADAS EN TOBERMORITA (T) Y EN JENNITA (J). LOS VALORES SIN DEFECTOS SE INDICAN COMO T $\infty$ Y J $\infty$. EN PARÉNTESIS APARECEN LOS VALORES DESPUÉS DE LA APLICACIÓN DEL ESQUEMA MORI-TANAKA.

\begin{tabular}{|c|c|c|c|c|}
\hline Especie & K / GPa & G / GPa & E / GPa & Referencia \\
\hline Т 2 & $29(14)$ & $14(8)$ & $36(19)$ & $\begin{array}{l}\text { Manzano y cols. (2007) } \\
\text { Dolado y cols. (2007) }\end{array}$ \\
\hline T 5 & $21(10)$ & $10(5)$ & $25(14)$ & $\begin{array}{l}\text { Manzano y cols. (2007) } \\
\text { Dolado y cols. (2007) }\end{array}$ \\
\hline $\mathrm{T} \infty$ & $46(25)$ & $39(21)$ & $91(49)$ & $\begin{array}{l}\text { Manzano y cols. (2007) } \\
\text { Dolado y cols. (2007) }\end{array}$ \\
\hline $\mathrm{J} 2$ & $29(13)$ & $11(6)$ & $29(16)$ & $\begin{array}{l}\text { Manzano y cols. (2007) } \\
\text { Dolado y cols. (2007) }\end{array}$ \\
\hline J 5 & $29(15)$ & $19(10)$ & $47(25)$ & $\begin{array}{l}\text { Manzano y cols. (2007) } \\
\text { Dolado y cols. (2007) }\end{array}$ \\
\hline$J \infty$ & $43(22)$ & $26(22)$ & $64(35)$ & $\begin{array}{l}\text { Manzano y cols. (2007) } \\
\text { Dolado y cols. (2007) }\end{array}$ \\
\hline $\mathrm{T}^{(\mathrm{Al})} 5$ & 27 & 13 & 35 & Dolado y cols. (2007) \\
\hline $\mathrm{T}^{(\mathrm{Al})} \infty$ & 38 & 25 & 61 & Dolado y cols. (2007) \\
\hline $\mathrm{J}^{(\mathrm{Al})} 5$ & 36 & 18 & 48 & Dolado y cols. (2007) \\
\hline$J_{(A l)}^{\infty}$ & 38 & 24 & 60 & Dolado y cols. (2007) \\
\hline
\end{tabular}


COMPORTAMIENTO SULFÁTICO Y MECÁNICO-RESISTENTE DE CEMENTOS PORTLAND CON ELEVADOS

\section{I.1.4.2.- Portlandita (CH).}

\section{I.1.4.2.1 Composición y estructura de la portlandita.}

El estudio de esta fase ha suscitado mucho interés desde hace tiempo. La portlandita, $\mathrm{Ca}(\mathrm{OH})_{2}$, es el segundo producto de reacción más abundante de la hidratación del cemento Portland y ocupa aproximadamente un 20-25\% de la fracción volumétrica de los productos de hidratación (Bhatty y cols. 1986). Es una fase muy importante no sólo desde el punto de vista cristalino, sino sobre todo de la durabilidad del material (Talero y Delgado, 2009, 2013+). Y además en todos los sentidos y vías, ya sea por vía directa o indirecta. Por vía directa, al provenir de su disolución primigenia sobresaturada y precipitar por ello en forma de cristales hexagonales en las superficies externas de la pieza o de la estructura de hormigón armado de cemento Portland, una vez retirado sin más de su encofrado y quedar expuestas al aire, cuyo $\mathrm{CO}_{2}$ a continuación termina por carbonatarlas, pero esta vez de forma positiva. Y es que los cristales de portlandita forman, debido a este fenómeno, cristales de carbonato de calcio, $\mathrm{CaCO}_{3}$, que recubren dichas superficies como si de una «piel protectora se tratara». Y por vía indirecta también, al ser el primer responsable de que se mantenga la elevada basicidad de la matriz de cemento Portland, que proporciona, por una parte, estabilidad y resistencia mecánica a la pasta de cemento Portland y, por consiguiente, al resto de componentes granulares que la constituyen, $\mathrm{y}$, por otra, en su caso, protege el acero de las armaduras, y es importante hasta tal punto, que cuando su nivel disminuye demasiado las armaduras de acero al carbono se corroen. La disminución de la concentración de $\mathrm{CH}$ puede ocurrir debido a fenómenos de lixiviación por aguas puras, de disolución por aguas ácidas, por carbonatación negativa, etc. En este último caso, la portlandita, en iguales circunstancias medioambientales, no es capaz de precipitar al aire sin más, al provenir, en este otro caso, de su transformación en bicarbonato de calcio, $\mathrm{Ca}\left(\mathrm{HCO}_{3}\right)_{2}$, por su interacción previa con dicho $\mathrm{CO}_{2}$ del aire cuando aún se encontraba en subsaturación en la fase líquida de la red de poros del material (fenómeno que acontece en cementos de mezcla con adiciones activas) y/o al reaccionar químicamente también con éste, ni de resistir las tensiones y la retracción que se produce tras dicha interacción con el $\mathrm{CO}_{2}$ (Afridi y cols. 2001). Además, la portlandita influye, en gran medida, en propiedades del material como son la resistencia mecánica, la elasticidad, la retracción, la fisuración o la fluencia.
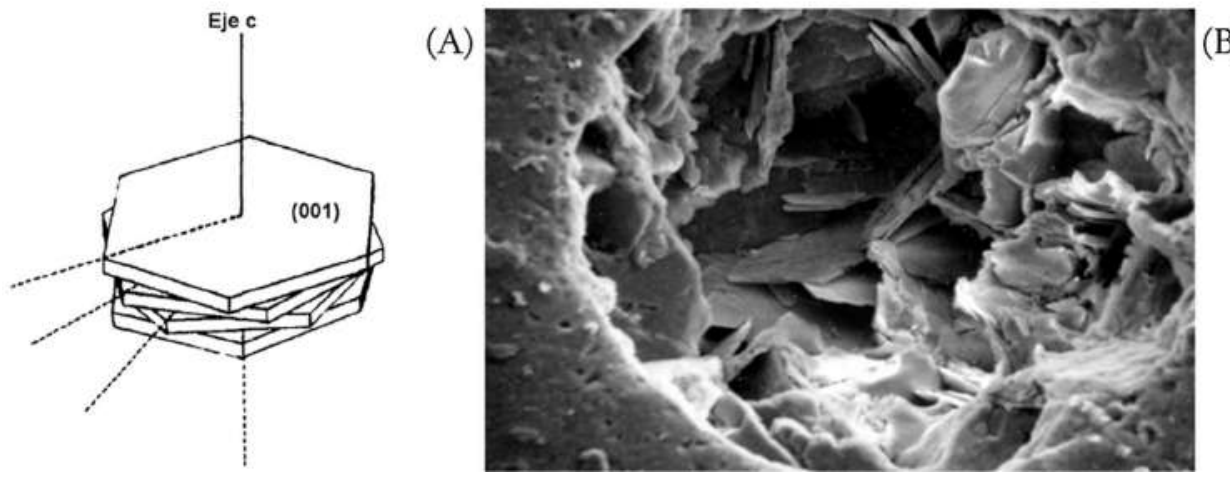

(B)

FIGURA I-9.- AGRUPACIÓN DE CRISTALES DE PORTLANDITA.(A) ASOCIACIÓN DE CRISTALES DE PORTLANDITA (ADAPTADA DE GROVES, 1981); (B) PORTLANDITA EN UN PORO DE LA MATRIZ DE CEMENTO PORTLAND (PORTLAND CEMENT ASSOCIATION). 
A diferencia del gel CSH, el CH es de estequiometría y sistema cristalino definidos, aunque no todo el $\mathrm{Ca}(\mathrm{OH})_{2}$ de la pasta de cemento Portland sea cristalino. Por ejemplo, Ramachandran (1979) identificó $\mathrm{Ca}(\mathrm{OH})_{2}$ amorfo, mientras que poco más tarde Mills (1981) y Feldman y col. (1982) identificaron $\mathrm{Ca}(\mathrm{OH})_{2}$ poroso. No obstante, poroso o no, casi todo el $\mathrm{CH}$ se encuentra en su forma cristalina, conteniendo, no obstante, grandes cantidades de defectos. Su morfología cristalina es hexagonal, siendo la forma más común con la que aparece en la matriz de cemento Portland la de agrupaciones cristalinas laminares. Obsérvese en la Fig. I-9 cristales de portlandita originados en un poro de la matriz de dicho cemento con elevada densidad de defectos y la representación esquemática de una agrupación de cristales de portlandita.

La estructura cristalina de la portlandita fue establecida mediante espectroscopía de rayosX por Bernal y col. (1935), por Petch y col. (1954), y, más tarde, mediante difracción de neutrones por Busing y col. (1957). Su estructura cristalina es trigonal del grupo espacial $\mathrm{P} \overline{3} \mathrm{~m} 1$, siendo, por

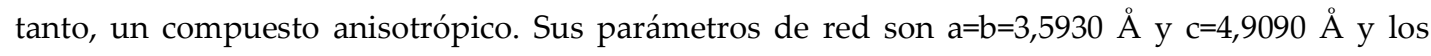
ángulos $\alpha=\beta=90^{\circ}$ y $\gamma=120^{\circ}$. La celda unidad trigonal contiene cinco átomos y aparece en la Fig. I10.

Los átomos de $\mathrm{Ca}^{2+}$ se encuentran coordinados octaédricamente con los átomos de oxígeno, y cada $\mathrm{O}^{2-}$ lo está tetraédricamente con el calcio y un hidrógeno. La estructura está dispuesta en láminas a lo largo del plano (001), constituyendo los octaedros sus unidades constitutivas. El oxígeno e hidrógeno conforman los grupos hidroxilo cuya dirección es perpendicular al plano (001). La interacción entre las láminas de portlandita se debe a fuerzas dispersivas débiles, ya que la distancia mínima entre un hidrógeno y un oxígeno es $2,757 \AA$, mientras que la distancia entre un par de átomos de oxígeno es de 3,33 Å, lo cual imposibilita la existencia de enlaces por puentes de hidrógeno o de otro tipo de enlace fuerte entre láminas.

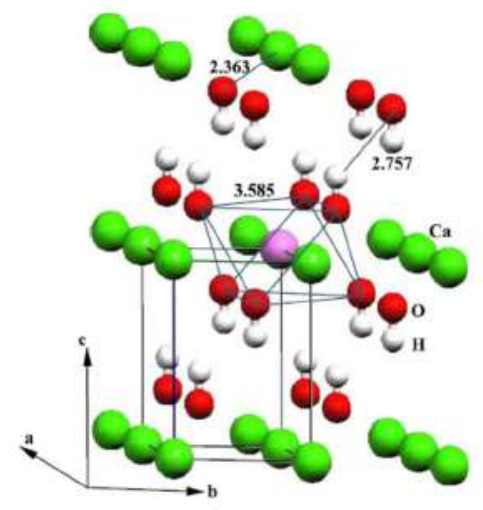

FIGURA I-10.- CELDA UNIDAD DE LA PORTLANDITA (LAUGESEN, 2005).

La portlandita procede en su mayoría de la hidratación del $\mathrm{C}_{3} \mathrm{~S}$ y del $\mathrm{C}_{2} \mathrm{~S}$. Así, cuando la alita se hidrata, al menos el $40 \%$ del volumen de productos de hidratación es $\mathrm{CH}$. Cuando se añade agua al cemento Portland sobre un portamuestras de vidrio es posible observar, mediante microscopía óptica, el crecimiento de cristales hexagonales de CH. Berger y col. (1973) realizaron mediante esta técnica el estudio del crecimiento de cristales de $\mathrm{CH}$ a partir de la hidratación de $\mathrm{C}_{3} \mathrm{~S}$ con diferentes relaciones agua-cemento. Estos investigadores observaron que los cristales que crecían eran relativamente grandes, alcanzando en ocasiones dimensiones de $100 \mu \mathrm{m}$. Por otra 
COMPORTAMIENTO SULFÁTICO Y MECÁNICO-RESISTENTE DE CEMENTOS PORTLAND CON ELEVADOS

parte, Berger (1972) había establecido que los cristales que se forman durante la hidratación del cemento Portland eran de menor tamaño.

Un método de estudio por el cual se ha podido obtener gran información sobre el $\mathrm{CH}$ es el de examen de superficies de fractura (con o sin replicación) de materiales de base cemento mediante microscopía electrónica de barrido (SEM). Gracias a esta otra técnica analítica se ha podido determinar que el tamaño de los cristales depende en gran medida de la relación agua-cemento. De este modo en pastas de cemento Portland con una elevada relación, los cristales pueden llegar a ser de $100 \mu \mathrm{m}$ e incluso mayores, siendo los mayores cristales los que aparecen asociados a grandes poros que presumiblemente estuvieron rellenos de fase líquidas (Lea, 1970). Asimismo y mediante esta técnica analítica Williamson (1972) pudo identificar también $\mathrm{CH}$ «pobremente cristalino» atribuido a una morfología dendrítica. A pesar de la utilidad de esta técnica analítica, la tendencia de reducir al máximo posible la relación agua-cemento de los morteros y hormigones hace que no sea posible identificar tan fácilmente cristales de $\mathrm{CH}$, ya que el tamaño de estos es muy reducido. No obstante, la elevada resistencia mecánica de estos materiales permite preparar muestras de calidad para el uso de otras técnicas analíticas más sensibles, como es el caso de la microscopía electrónica de transmisión (TEM), en la que es posible además realizar difracción de electrones. Gracias, a esta otra técnica analítica fue posible identificar cristales de $\mathrm{CH}$ de mucho menor tamaño, que en ocasiones se encontraban embebidos en el gel CSH (Groves y col. 1981). Estos descubrimientos posibilitarían después elaborar las teorías del sistema T/CH para explicar la existencia de gel CSH con elevada relación $\mathrm{Ca} / \mathrm{Si}$, tal y como se explicó en el apartado anterior dedicado a esta otra fase. Por otra parte, existen también otros factores que afectan al tamaño de los cristales de $\mathrm{CH}$, como son principalmente la temperatura y el tiempo de hidratación (Beaudoin, 1983).

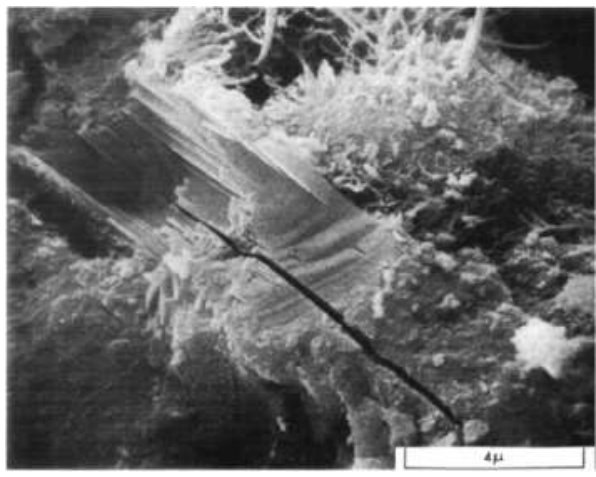

FIGURA I-11.- MICROGRAFÍA ELECTRÓNICA DE LA SUPERFICIE DE FRACTURA DE UNA PASTA DE CEMENTO PORTLAND DONDE SE MUESTRA UNA FISURA PARALELA AL PLANO BASAL DE UN CRISTAL DE PORTLANDITA (WILLIAMSON, 1972).

Todo esto posibilita afirmar, por tanto, que existen dos posibles formas diferentes de encontrar el $\mathrm{CH}$ en la pasta de cemento Portland: por un lado, en forma de cristales de escala micrométrica, y, por otro, como láminas intercaladas con las unidades de silicato de calcio hidratado componiendo el gel CSH. Es muy importante realizar esta distinción, pues como se va a explicar, de la forma en la que se encuentre el $\mathrm{CH}$ puede afectar a las propiedades físico-mecánicas de la pasta de cemento Portland hidratada. Así, por ejemplo, la existencia de agrupaciones de grandes cristales de $\mathrm{CH}$ suponen un debilitamiento de la matriz de cemento Portland, ya que poseen un plano de fractura interlaminar muy bien definido (Williamson, 1972; Ramachandran, 
1979), lo que se debe a la débil unión entre las láminas explicada anteriormente como ya se explicó antes. Un ejemplo de ello se encuentra en la Fig. I-11.

De este modo, el plano de fractura de la portlandita es uno de los defectos de mayor importancia en los materiales de base cemento Portland (Williamson, 1972). Las particulares características del $\mathrm{CH}$ hacen que su resistencia a la fractura sea inferior a la del gel CSH (Beaudoin y cols. 1998).

Por el contrario, cuanto menor es el tamaño de los cristales de $\mathrm{CH}$ el efecto deletéreo de los mismos se reduce debido al acortamiento de sus planos de ruptura. Según Groves y col. (1981), la existencia de $\mathrm{CH}$ embebido en el gel CSH podría llegar a suponer un refuerzo del mismo.

\section{I.1.4.2.2. Propiedades mecánico-elásticas de la portlandita.}

La determinación de las propiedades de esta fase no es sencilla, pues entre otras cosas no es posible disponer de cristales sin defectos lo suficientemente grandes para acometer los ensayos necesarios.

La portlandita es un compuesto anisotrópico, al depender, por tanto, sus propiedades de la dirección del cristal para la que se calcule. Por este motivo y desde el punto de vista mecánico, la presencia de $\mathrm{CH}$ en la matriz de cemento Portland puede llegar a reforzar o debilitarla en función de la orientación de sus agregados cristalinos. Es lógico pensar, por tanto, que la orientación de los agregados cristalinos de portlandita será aleatoria en una situación real, debiendo hablar más de propiedades compuestas que de cada una de las propiedades particulares para cada dirección. A pesar de esto, es necesario disponer de las propiedades anisotrópicas para la obtención de estas propiedades compuestas, para lo cual es indispensable en, primer lugar, definir la matriz de coeficientes de rigidez. A este respecto, fueron Holuj y cols. (1985) quienes determinaron los experimentalmente, mediante espectroscopía Brillouin, y más tarde Laugesen (2005), mediante cálculos basados en la teoría de la densidad funcional. Excepto para uno de los coeficientes, en los que la diferencia entre valores es de cuatro veces, en ambos trabajos se obtuvieron valores muy próximos, con variaciones inferiores al $25 \%$.

Por otra parte, Laugesen (2005) calculó también los valores de los módulos de Young en función del ángulo de deformación con respecto dicho eje c de la portlandita, obteniendo que el módulo era mayor en las direcciones perpendiculares al eje c, mostrando además una gran dependencia direccional con valores comprendidos entre 22,56 y 99,39 GPa.

\section{I.1.4.3.- Fase AFm y Fase AFt.}

\section{I.1.4.3.1. Composición y estructura de las fases aluminoferríticas.}

Como ya se comentó, la Fase AFm y la Fase AFt son los principales productos de la hidratación del $\mathrm{C}_{3} \mathrm{~A}$ y del $\mathrm{C}_{4} \mathrm{AF}$ del cemento Portland. Los primeros estudios sobre la formación y estructura de ambas fases dentro de los sistemas $\mathrm{CaO}-\mathrm{Al}_{2} \mathrm{O}_{3}-\mathrm{H}_{2} \mathrm{O}$ y $\mathrm{CaO}-\mathrm{CaSO}_{4}-\mathrm{Al}_{2} \mathrm{O}_{3}-\mathrm{H}_{2} \mathrm{O}$, se debe a Flint y cols. $(1934 ; 1941 ; 1944)$ y Wells y cols. $(1943)$. Ambos productos de reacción se forman durante los primeros estadios de la hidratación, encontrándose la pasta de cemento Portland en su estado plástico. En realidad, se puede afirmar que ambas fases constituyen un balance Fase AFm/AFt durante el proceso de hidratación del cemento Portland. La situación más deseable para 
este balance es que la Fase AFt se origine y se transforme parcialmente en Fase AFm durante el estado plástico de la pasta de cemento Portland, pues el origen de dicha Fase AFt conlleva un elevado aumento de volumen. Tanto si se trata por reacción de las fases anhidras del clínker Portland, como si se produce a partir de la Fase AFm. En las pastas de cemento Portland, el sistema $\mathrm{C}_{3} \mathrm{~A}-\mathrm{Fase} \mathrm{AFm}-\mathrm{Fase} \mathrm{AFt}$ condiciona, para mal o para bien, la durabilidad del material frente al ataque, por separado de los iones sulfato (Talero, 1986), y de los iones cloruro (Mejía, 1997; Jones y cols. 2003; Talero y cols. 2011) y en el ataque conjunto de ambas especies iónicas en el caso del agua de mar (Mehta, 1991; Lannegrand, 2001), así como en el fenómeno deletéreo autógeno, que sufren algunos hormigones como consecuencia de su curado por encima de los 50-60 ${ }^{\circ} \mathrm{C}$, que les causa la formación retardada de ettringita (Candlot, 1890; Michaelis, 1892; Lafuma, 1929) conocido como DEF (del inglés «delayed ettringite formation»).

Por una parte, la denominación Fase AFm engloba una serie de fases de aluminato de calcio hidratados relacionadas estructuralmente con la hidrocalumita. Su fórmula química representativa es $\left[\mathrm{Ca}_{2}(\mathrm{Al}, \mathrm{Fe})(\mathrm{OH})_{6}\right] \cdot \mathrm{X} \cdot \mathrm{xH}_{2} \mathrm{O}$, donde $\mathrm{X}$ puede ser cualquiera de los iones intercambiables con una carga negativa (por ejemplo, cloruro) o con la mitad de dos cargas negativas (p.ej. sulfato, carbonato, aluminosilicato). El paréntesis ( $\mathrm{Al}, \mathrm{Fe})$, en este otro caso, indica que algunos átomos de aluminio pueden estar sustituidos por Fe(III). La estructura básica de la Fase AFm fue determinada por Buttler y cols. (1959), habiendo sido refinada cristalinamente con posterioridad para sus diferentes subtipos por Francois y cols. (1998) y Renaudin y cols. (1999). Su estructura consiste en hojas de $\mathrm{M}(\mathrm{OH})_{6}$ de iones octaédricos, similares a los descritos para la portlandita pero con un tercio de los iones $\mathrm{M}^{2+}$ sustituidos por un ión trivalente, principalmente $\mathrm{Al}^{3+} \mathrm{y}$ en menor cantidad $\mathrm{Fe}^{3+}$. $\mathrm{La}$ carga positiva en exceso produce que el espaciado interlaminar sea mucho mayor que en la portlandita, debiendo existir aniones intercalados para compensar ese exceso de carga. La baja densidad reticular de los aniones permite que también existan moléculas adicionales de agua. El contenido de estos aniones en la Fase AFm depende tanto de la composición del cemento como de las condiciones de servicio del material. Así, en el caso de que se trate de un cemento Portland, los aniones serán hidroxilo, sulfato y, mientras que si el cemento es de mezcla el anión característico es alguna de las especies de los aluminosilicatos. El contenido de esta fase en la pasta hidratada de cemento Portland es minoritario con respecto al gel CSH o la portlandita, sin embargo, en algunos cementos de mezcla, caso de los cementos siderúrgicos o con escorias de horno alto, su contenido puede llegar hasta un $20 \%$.

Por otra parte, una vez en servicio, la Fase AFm puede sufrir cambios, así por ejemplo, los iones cloruro pueden desplazar a los otros aniones, o bien en un exceso de sulfatos puede llegar a producir Fase AFt. En general, la Fase AFm es muy sensible a las condiciones ambientales, siendo estos procesos de intercambio iónico relativamente rápidos, por lo que requieren únicamente días o semanas a $20^{\circ} \mathrm{C}$ (Glasser y cols. 1999). En Fig. I-12 de la página siguiente se halla representado el diagrama de composición de la Fase AFm para cada tipo de anión X.

Y en relación a la estabilidad de esta fase, se puede decir que muchos de los subtipos de la Fig. I-12 son metaestables en las condiciones habituales en las que se encuentran los materiales de base cemento pudiendo descomponerse o reaccionar, mientras que otros tienen un intervalo definido de estabilidad (Matschei y cols. 2007a). Y en cuanto al caso del cemento Portland, la Fase AFm consiste en realidad en una disolución sólida entre la hidroxi-AFm y el monosulfoaluminato, siendo respectivamente $\mathrm{X}=\mathrm{OH}^{-}$y SO $4^{2-}$. 


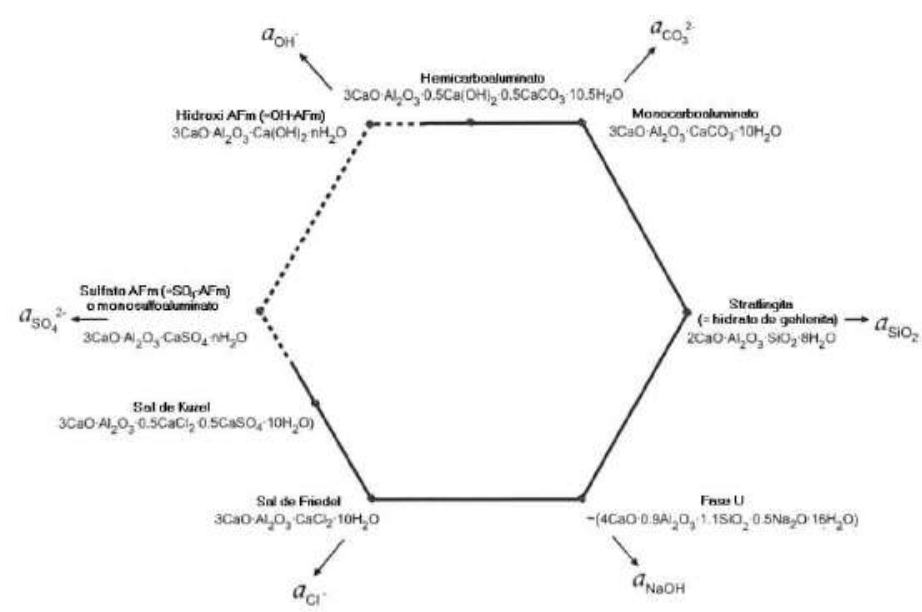

FIGURA I-12.- DIAGRAMA DE COMPOSICIÓN-ACTIVIDAD DE LA FASE AFM A $25^{\circ} \mathrm{C}$. LAS FASES CONSIDERADAS INESTABLES TERMODINÁMICAMENTE A $25{ }^{\circ} \mathrm{C}$ ESTÁN INDICADAS MEDIANTE LÍNEA DISCONTINUA. LOS PUNTOS INDICAN LA FORMACIÓN DE UNA SÓLO TIPO. NO SE MUESTRAN LAS DISOLUCIONES SÓLIDAS ENTRE LOS DIFERENTES TIPOS (ADAPTADO DE GLASSER Y COLS. 1999).

La existencia de esta disolución sólida ha sido objeto de grandes discrepancias entre investigadores, debido a que es muy difícil establecer los intervalos de miscibilidad de cada una de las especies, ya que en general, todos los tipos de la Fase AFm son de baja cristalinidad y las variaciones de la posición e intensidad de los picos de DRX que se producen en función de la composición no permiten identificar y distinguir los tipos coexistentes. Asimismo, otra dificultad adicional para su estudio es su rápida carbonatación y la rápida pérdida del agua que la constituye.

En la Fig. I-13 se puede observar la similitud entre dos de los tipos de la Fase AFm, en particular para $\mathrm{X}=\mathrm{SO}_{4}^{2-}$ y $\mathrm{Cl}^{-}$.
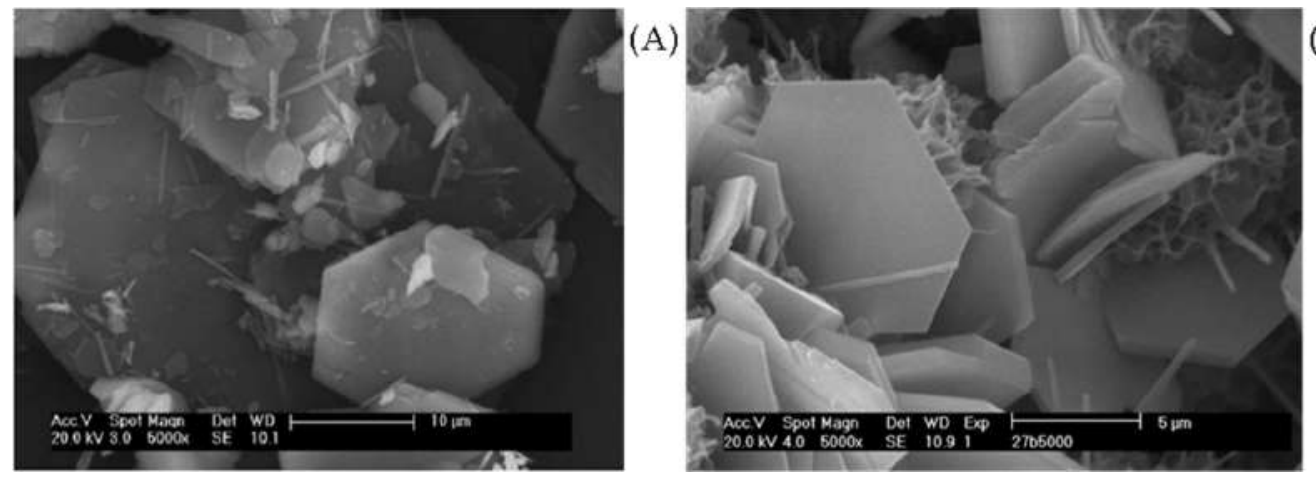

\section{(B)}

FIGURA I-13.- FASE AFM: (A) MONOSULFOALUMINATO (X=SO42-) (A PARTIR DE MATSCHEI Y COLS. 2007a); (B) SAL DE FRIEDEL $\left(\mathrm{X}=\mathrm{Cl}^{-}\right)$(FUENTE PROPIA).

Recientemente, ha sido demostrado mediante cálculos termodinámicos que el monocarboaluminato $\left(X=\mathrm{CO}^{2-}\right)$ es totalmente miscible con los dos tipos anteriores, pudiéndose afirmar que la disolución sólida que se forma en la pasta de cemento Portland hidratada está constituida por las tres (Matschei y cols. 2007a). Esto se debe a que en el cemento Portland pueden existir cantidades suficientes de carbonato de diversas procedencias (acompañando al regulador de fraguado, formando una disolución sólida con los sulfatos alcalinos en el proceso de clinkerización, por meteorización del cemento Portland antes de su uso o como carga mineral, entre 
otras), e incluso pueden provenir de los finos de los áridos calizos, efecto éste que no se considera en la mayoría de las ocasiones (Bonavetti y cols. 2001).

En cuanto a la estabilidad relativa de las diferentes fases es sabido que cuando existen en el cemento Portland cantidades suficientes de carbonato, el desplazamiento que sufre el anión sulfato durante la hidratación por el carbonato en la Fase AFm conduce a la formación de mayor cantidad de Fase AFt. Así pues, obsérvese en la Fig. I-14 la importancia del contenido del carbonato en la estabilidad y en el resultado final del balance Fase AFm/AFt.

Como se viene comentando, algunos de los tipos de Fase AFm sufren cambios durante la vida de servicio del hormigón. Así por ejemplo, se tiene la formación tardía de ettringita a partir de Fase AFm y aniones sulfato, $\mathrm{SO}_{4}{ }^{2-}$, o si en el medio se halla alguna fuente de anión cloruro, $\mathrm{Cl}$, se forma la sal de Friedel (Chudek y cols. 2000; Lannegrand y cols. 2001), la cual nuevamente en presencia de aniones sulfato suficientes produce ettringita (Jones y cols. 2003), mientras que en presencia de carbonatos (de calcio, por ejemplo, calcita) forma carboaluminatos de calcio hidratados. Algunas de las transformaciones de los aluminatos de calcio hidratados causan incremento de volumen con la aparición de microfisuras en el material cementante y la subsiguiente reducción de su resistencia mecánica y estabilidad de volumen, e incluso aumento de su vulnerabilidad al ingreso de otros agresivos químicos.
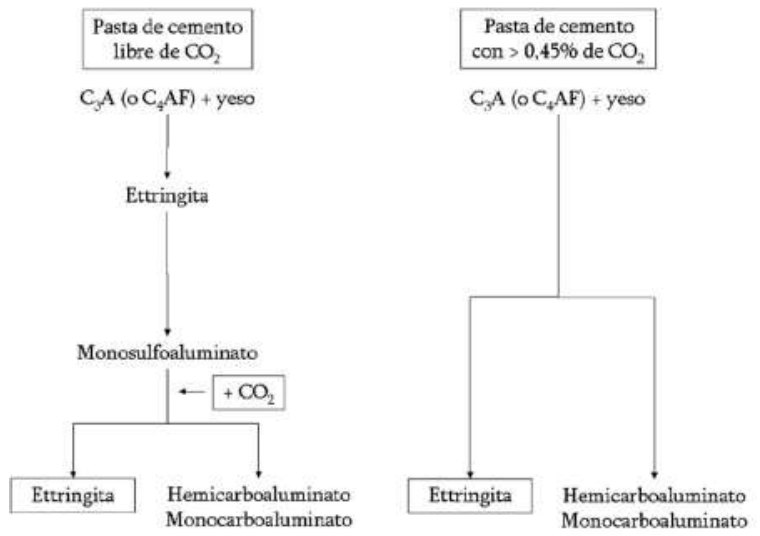

FIGURA I-14.- INFLUENCIA DEL CO2 EN LAS REACCIONES DE HIDRATACIÓN DEL C3A EN LOS CEMENTOS PORTLAND (ADAPTADO Y AMPLIADO A PARTIR DE KUZEL, 1996).

Por su parte, la Fase AFt se forma casi de inmediato cuando el $\mathrm{C}_{3} \mathrm{~A}$ del cemento Portland entra en contacto con el agua de amasado. Si esto ocurre en presencia de una concentración suficiente de ión sulfato (principalmente, del regulador de fraguado), se forma la ettringita, que es el tipo más importante de esta fase. Si esta cantidad no fuera suficiente, la ettringita formada se convierte a monosulfoaluminato (es decir, a la Fase AFm cuyo $\mathrm{X}=\mathrm{SO}_{4}{ }^{2}$ ). E incluso si la cantidad de regulador de fraguado fuera insuficiente puede no llegar a formarse ettringita, sino monosulfoaluminato directamente. Cabe destacar la investigación realizada, a este respecto, por Christensen y cols. (2004) en la que siguieron la evolución de las especies involucradas en estas transformaciones mediante difracción de rayos- $\mathrm{X}$ mediante sincrotrón. Encontraron que, en todos los casos, el monosulfoaluminato que se formaba poseía $14 \mathrm{H}_{2} \mathrm{O}$ en su composición, e identificaron el $\mathrm{C}_{4} \mathrm{AH}_{19}$ como intermedio en la transformación de la Fase AFt a Fase AFm. Así, la evolución de 
las cantidades relativas de cada una de las especies que determinaron durante las diez primeras horas es la que se muestra en la Fig. I-15.

En cuanto a la importancia de la ettringita sobre las propiedades de la pasta de cemento Portland, la misma es la responsable, junto al gel CSH, de la resistencia mecánica del material a corta edad. Aun así, no forma una masa de productos de hidratación tan densa como para ser comparable a la del gel CSH, sino que se debe al entrecruzamiento de sus cristales. En la Fig. I-16 se muestra la morfología de sus cristales, y debido a la elevada relación de aspecto altura/anchura y su contenido de agua estructural supone un gran incremento de volumen con respecto a los componentes químicos a partir de los que se forma.

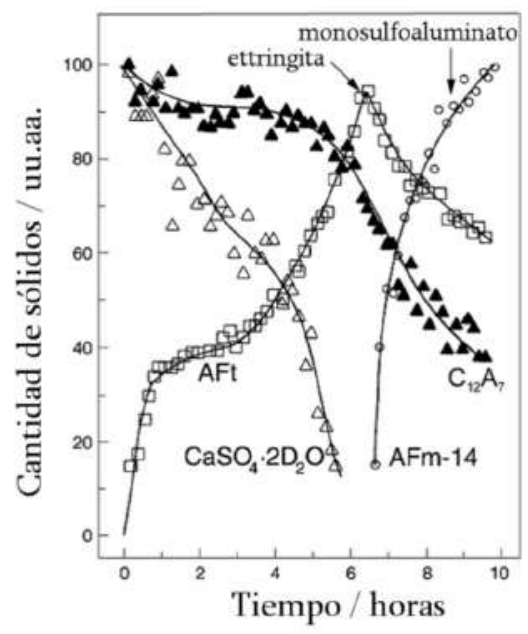

FIGURA I-15.- CANTIDAD NORMALIZADA DE SÓLIDOS CALCULADA A PARTIR DE LA INTEGRAL DE LAS REFLEXIONES DE BRAGG PARA EL C12A7, CASO4.2D2O, ETTRINGITA Y MONOSULFATO A $27^{\circ} \mathrm{C}$ (ADAPTADO DE CHRISTENSEN Y COLS. 2004).

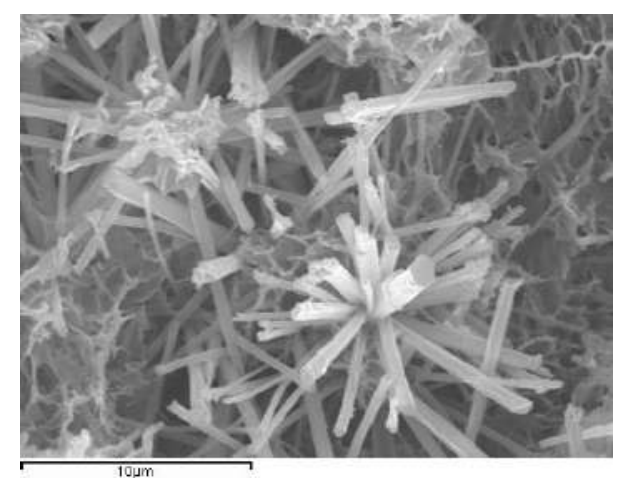

FIGURA I-16.- FASE AFT: ETTRINGITA $\left(\mathrm{X}=S \mathrm{SO}^{2}-\right.$ ) (FUENTE PROPIA).

Cuando ha correspondido en este apartado se ha indicado que tanto el $\mathrm{C}_{3} \mathrm{~A}$ como el $\mathrm{C}_{4} \mathrm{AF}$ originan los mismos productos de hidratación, en los cuales el $\mathrm{Fe}^{3+}$ puede llegar a sustituir el $\mathrm{Al}^{3+}$ en cada uno de ellos. Sin embargo, en las figuras y en el texto se ha considerado únicamente de «aluminatos» y no de «ferritos», o a ambos. Esto se debe a que aún no ha sido comprendida completamente la extensión de este fenómeno. Por este motivo, ha preferido tratarse este tema como apostilla. Pues bien, a este respecto la relación $\mathrm{Fe} /(\mathrm{Al}+\mathrm{Fe})$ de cada fase, o si en realidad se 
trata de disolución sólida es causa de discrepancia. A este respecto, Brown (1987) obtuvo que esta relación podía tener valores comprendidos entre 0 y 1, mientras que Kuzel (1968) había apuntado a la existencia de una disolución sólida entre estos dos extremos: $\mathrm{C}_{4} \mathrm{ASH}_{12}$ y $\mathrm{C}_{4} \mathrm{FSH}_{12}$. Ninguno de estos investigadores pudo aportar resultados de la incorporación de Fe en la Fase AFm. Así, de entre los trabajos de investigación disponibles que pretendieron este objetivo, cabe destacar el realizado por Liang y col. (1994) sobre la hidratación del $\mathrm{C}_{4} \mathrm{AF}$, por el que concluían que durante la hidratación de éste en presencia de yeso, se produce $\mathrm{Fe}(\mathrm{OH})_{3}$, así como Fase AFt, Fase AFm, $\mathrm{C}_{2}(\mathrm{~A}, \mathrm{~F}) \mathrm{H}_{8}$ o $\mathrm{C}_{4}(\mathrm{~A}, \mathrm{~F}) \mathrm{H}_{13}$ y $\mathrm{Al}(\mathrm{OH}) 3$, siendo su aportación más relevante la evidencia de que el $\mathrm{Fe}^{3+}$ sí que se incorpora también en la Fase $\mathrm{AFm}$, con una relación $\mathrm{Fe} /(\mathrm{Fe}+\mathrm{Al})$ que aumenta cuando lo hace la misma en el $\mathrm{C}_{4} \mathrm{AF}$ (recuérdese que realmente se trata de una disolución sólida entre $\mathrm{C}_{2} \mathrm{~F}$ y $\mathrm{C}_{2} \mathrm{~A}$ ). No obstante, recientemente Rose y cols. (2006) han identificado la formación de $\mathrm{FeOOH}$ amorfo embebidos en estas fases, no habiendo encontrado evidencias de que el $\mathrm{Fe}^{3+}$ se introduzca en la estructura de la Fase AFm. No obstante, y sea como fuere, no existen claras evidencias de un muy diferente comportamiento, propiedades y estabilidad de estas fases en función de su contenido de hierro.

\section{I.1.4.3.2. Propiedades mecánico-elásticas de las fases aluminoferríticas.}

En cuanto a las propiedades mecánico-elásticas de las fases aluminoferríticas, lo cierto es que no existen muchos estudios e investigaciones, al contrario de lo que sucede con las fases anteriores, que hayan tenido por objetivo determinarlas y así establecer cuál es su contribución a las propiedades de la pasta de cemento Portland. La escasez de investigaciones específicas para aportar mayor número de datos sobre las propiedades de estas fases radica en la previsible escasa contribución a las propiedades globales del material en base al poco volumen que ocupan del total de la pasta de cemento. No obstante y a pesar de que sus propiedades mecánicas no son de mucho interés, es indudable su importancia durante la hidratación del cemento Portland, tal y como ha sido comentado.

En el caso particular de la Fase AFm no conocemos ninguno, no obstante Haecker y cols. (2005) postularon que sus propiedades deberían ser próximas al producto de la hidratación del cemento Portland cuya estructura cristalográfica fuera la más parecida, por tanto las de la portlandita. Y con respecto a la Fase AFt, Zohdi y cols. (2002) determinaron sus propiedades a partir de las propiedades mecánico-elásticas de pellets compactados de partículas granulares de esta fase, en los que su porosidad era conocida. Los resultados de tales determinaciones mostraron que du módulo de Young era de 47,2 GPa, mientras que el módulo cortante de 19,9 GPa. No obstante, en una publicación posterior Haecker y cols. (2005) asumieron que esta fase poseía las mismas propiedades que las del gel CSH.

\section{I.1.4.4.- Concepto y propiedades de la fase líquida}

La fase líquida es la disolución acuosa que ocupa en cualquier momento la red de poros del material de base cemento. Así, por ejemplo, a primeras edades la fase líquida es aquélla a partir de la cual se produce la nucleación y precipitación de los productos de hidratación del cemento Portland, bien en su propio seno, o bien en su interfase de contacto con los propios granos de 
cemento Portland y con los productos neoformados, y que está constituida primeramente por el agua de amasado, a la que hay que sumar después el agua de curado hídrico.

La fase líquida inicial con el paso de los días, semanas, meses e incluso años, va consumiéndose por la generación de nuevos productos de hidratación, pero puede llegar a evaporarse, o bien puede permanecer en el interior del material, ya que si la pieza de material es muy gruesa, éste puede no llegar a alcanzar nunca un equilibrio higrométrico con el medio ambiente al que esté expuesto, o si lo hace será a muy largo plazo, caso por ejemplo de las presas de fábrica de hormigón. A este hecho, ha de sumarse también que, en función del ambiente de exposición en el que se encuentre el material, éste puede llegar a ser objeto de determinados fenómenos en los que ciertas disoluciones van a penetrar en la red de poros, modificando la composición química fase líquida existente, constituyendo la nueva fase líquida. En estos casos, la fase líquida va a determinar la durabilidad del material de base cemento.

Así pues, y a modo de ejemplo, un determinado hormigón puede sufrir lixiviación por aguas puras, estar expuesto a ciclos de humedad-secado por lluvias intermitentes, por cambios higrotérmicos, o por variación del nivel freático, puede sufrir ciclos de hielo-deshielo en los que el aumento de volumen de la fase líquida genera presiones disruptivas en el material, o puede ser objeto de diferentes ataques químicos agresivos como el de las aguas sulfáticas, las aguas con cloruros, o del agua de mar (ataque conjunto de los iones sulfato y cloruro). De todos estos fenómenos, el estudio de la fase líquida en el caso del ataque por los iones sulfato y por los iones cloruro es el que más interés científico-técnico ha acaparado por su gravedad por el rápido deterioro de la matriz de cemento y de las armaduras de acero por corrosión por picadura que producen, respectivamente. Ello es debido a que la composición química de la fase líquida es primordial en los procesos de migración y movilidad iónica de especies traza a través del material. En todos estos otros casos, la fase líquida difiere notablemente de la fase líquida inicial, ya que, entre otros, posee elevadas concentraciones de especies iónicas que son ajenas a los propios materiales componentes del material de base cemento.

Debido a la naturaleza del cemento Portland, puede considerarse que en condiciones de saturación completa del material, o sin que se haya alcanzado el referido equilibrio higrométrico con el ambiente, la fase líquida del mismo, en un determinado momento, poseerá elevadas concentraciones iónicas, siendo éstas muy similares a las de la fase líquida inicial después de haber transcurrido pocos días. Por lo que los cambios microestructurales van a seguir produciéndose gracias a la movilidad iónica a través de la misma, en las interfases con las partículas aún anhidras (Birchall y col. 1980), y lo que es más, en las interfases con aquellos productos de hidratación metaestables, o por precipitación de nuevos productos de hidratación a partir de la misma. Estos procesos provocan que la microestructura del hormigón cambie continuamente con el tiempo, consumiéndose la fase líquida por la producción de nuevos productos de hidratación, lo que lleva aparejado la reducción progresiva de la porosidad y el aumento de la resistencia mecánica del material, aunque acompañados también por su retracción correspondiente que, por lo común, no afecta significativamente a su durabilidad prevista.

La fase líquida es diferente para cada cemento, diferenciándose la fase líquida de la pasta del cemento Portland puro de la fase líquida de dicha pasta pero con adiciones minerales activas o de la de un cemento de mezcla. Puesto que en que la del primero, siempre va a alcanzar elevadas concentraciones de $\mathrm{Ca}(\mathrm{OH})_{2}$, en tal magnitud que la misma se está en condiciones de 
sobresaturación casi permanentes. Mientras que de la fase líquida de los cementos de mezcla no se puede decir lo mismo, sino todo lo contrario, antes o después llegan a la subsaturación, pues el fundamento de la incorporación de las adiciones minerales activas es que alguno de sus componentes vítreos y/o amorfos reaccionen químicamente con el $\mathrm{Ca}(\mathrm{OH})_{2}$ liberado por la fracción de cemento Portland, formando nuevas cantidades de productos de hidratación similares a los de éste, pero debido a las reacciones puzolánicas, de las puzolanas naturales y/o artificiales, y/o a la de las escorias siderúrgicas en elevadas cantidades especialmente.

Por su parte, en la pasta del cemento Portland, el nivel de sobresaturación de la fase líquida, con respecto a varias de sus fases sólidas, es uno de los factores responsables del mecanismo de su fraguado y endurecimiento (Birchall y col. 1980; Bailey y col. 1982), dependiendo ambos procesos, a su vez, de la composición mineralógica y la finura del cemento Portland. Esto es igual que afirmar que cada cemento Portland posee una fase líquida particular. A su vez, pueden existir diferencias locales en los valores de concentración de las especies en función de la proximidad de granos de una u otra mineralogía, aunque, contrariamente a como se representa habitualmente, los granos de cemento Portland contienen varios compuestos mineralógicos (debido a los procesos de división aleatorios que produce la molienda del clínker Portland), y, por ello, este efecto, en realidad, no habrá de ser muy notable y menos aún determinante. Sin embargo, una variación mucho más notable en los valores de las concentraciones de las diferentes especies en la fase líquida, es el que se tiene desde partes de la disolución alejadas de las partículas de cemento Portland hasta la interfase con los mismos, ya que existe un mayor grado de sobresaturación en la cercanía a las partículas que en sus partes alejadas, lo que se debe, además, a la estanqueidad del fluido que constituye la fase líquida (Birchall y col. 1980).

Desde un punto de vista teórico, para definir una disolución deberán conocerse por tanto las especies iónicas presentes en la misma y cuál es la actividad de cada una de ellas. De los estudios disponibles hasta la fecha, pueden citarse, a continuación, las especies mayoritarias que pueden estar presentes en la fase líquida. Entre las especies catiónicas se encuentran: $\mathrm{H}^{+}, \mathrm{Ca}^{2+}, \mathrm{CaOH}^{+}$, los elementos alcalinos $\mathrm{Na}^{+}$y K${ }^{+}$, e incluso el triplete iónico $\mathrm{Ca}_{2} \mathrm{SO}_{4}{ }^{2+}$. Entre las especies aniónicas se encuentran: $\mathrm{OH}^{-}, \mathrm{SO}_{4}{ }^{2-}, \mathrm{Al}(\mathrm{OH})_{4}{ }^{-},\left[\mathrm{Al}(\mathrm{OH})_{4}\left(\mathrm{H}_{2} \mathrm{O}\right)_{2}\right]^{-}$y si la concentración de aluminato es muy elevada y el $\mathrm{pH}>13$ se tendrá $\mathrm{AlO}_{2}^{-}$. Además, de estas especies existen los pares iónicos: $\mathrm{NaOH}^{\circ}$, $\mathrm{KOH}^{\circ}$ y $\mathrm{CaSO}_{4}^{\circ}$ (los cuales no habrán de confundirse con sus respectivas formas sólidas). Asimismo, en la fase líquida se encuentran grandes concentraciones de silicatos y aluminatos en una gran variedad de formas iónicas, con carga variable, diferente grado de polimerización y diferente grado de hidratación. Y también son especies características de la fase líquida el $\mathrm{H}_{4} \mathrm{SiO}_{4}$ y sus derivadas $\mathrm{H}_{3} \mathrm{SiO}_{4}{ }^{-}, \mathrm{H}_{2} \mathrm{SiO}_{4}{ }^{2-}$.

La diferente actividad y proporción relativa de estas especies iónicas dotan a una fase líquida de unas propiedades químicas particulares, las cuales van a diferenciarla de otras, y van a determinar la velocidad de reacción y la de generación de productos de hidratación. En relación a las propiedades de la fase líquida más importantes, enumerar que éstas son:

- la fuerza iónica, Ic, que afecta a las reacciones de intercambio de iones con las fases sólidas,

- el potencial redox, Eh, que determina el estado de oxidación de los elementos multivalentes, $\mathrm{y}$

- el exponente de hidrógeno, $\mathrm{pH}$, que determina el grado de hidrólisis de los iones hidrolizables. 
A modo de ejemplo, en la Tabla I-9 se muestran los resultados obtenidos por Andersson y cols. (1989) de la concentración de especies iónicas y de los parámetros característicos de la fase líquida de tres cementos Portland ${ }^{6}$.

TABLA I-9- PROPIEDADES DE LAS DISOLUCIONES DE PORO DE CEMENTOS PORTLAND (A PARTIR DE ANDERSSON Y COLS. 1989).

\begin{tabular}{|c|c|c|c|}
\hline \multirow{2}{*}{ Datos } & \multicolumn{3}{|c|}{ Cemento Portland } \\
\hline & SPP (tipo*: CPO) & CPA (tipo*: CPO) & SRP (tipo*: CPRS) \\
\hline Volumen ${ }^{\mathrm{a}}$ & 8 & 4 & 9 \\
\hline Edad $^{b}$ & 10 & 4 & 9 \\
\hline Relación agua-cemento & 0,5 & 0,36 & 0,5 \\
\hline \multicolumn{4}{|l|}{ Elementos, concentración / mg.1- } \\
\hline $\mathrm{Na}^{+}$ & 1500 & 1800 & 600 \\
\hline $\mathrm{K}^{+}$ & 6300 & 5700 & 600 \\
\hline $\mathrm{Ca}^{2+}$ & 90 & 20 & 470 \\
\hline $\mathrm{Mg}^{2+}$ & 0.2 & 0,1 & 0,2 \\
\hline $\mathrm{Al}^{3+}$ & 5 & 30 & 5 \\
\hline $\mathrm{Si}^{4+}$ & 6 & 6 & 6 \\
\hline $\mathrm{Fe}^{3+}$ & 0,5 & 0,5 & 0,5 \\
\hline \multicolumn{4}{|l|}{ Propiedad característica } \\
\hline $\mathrm{I}_{c^{c}}$ & 0,23 & 0,22 & 0,04 \\
\hline $\mathrm{Eh}^{\mathrm{d}}$ & 139 & 196 & 84 \\
\hline $\mathrm{pH}$ & 13,4 & 13,2 & 13,1 \\
\hline
\end{tabular}

* CPO: Cemento Portland Ordinario / CPRS: Cemento Portland Resistente al ataque por Sulfatos

a Volumen de fase líquida obtenida a partir de $0,2 \mathrm{~kg}$ de sólido, en $\mathrm{ml}$

b Edad de la pasta de cemento antes de la obtención de la fase líquida, en meses

c Calculada de acuerdo a Ic $=0,5 \sum \mathrm{Ci}_{\mathrm{i}} \cdot \mathrm{Zi}^{2}$

d Expresado en $\mathrm{mV}$

Nótese que los cementos Portland denominados como SPP y CPA, se trataban, en realidad, de cementos Portland ordinarios (en adelante, CPO), es decir, sin ninguna clase de resistencia química adicional, mientras que el SRP era un cemento Portland resistente al ataque de los sulfatos (en adelante, CPRS)7. No obstante, Andersson y cols. (1989) no aportaron explicación alguna sobre las diferencias obtenidas en función del diferente tipo de cemento Portland empleado. Los valores obtenidos se deben, con toda seguridad, a la composición mineralógica particular de cada tipo de cemento Portland, CPO o CPRS. Por este motivo, la fase líquida del CPRS-SRP resultó ser muy diferente con respecto a las de los CPOs, SPP y CPA.

En general, y como se puede observar en la Tabla I-9, con independencia del tipo de

\footnotetext{
${ }^{6}$ En Andersson y cols. (1989) aparecen datos similares para otros tipos de cementos, los cuales no han sido considerados de interés en relación al tema de esta Tesis Doctoral siendo, por tanto, obviados.

${ }^{7}$ La principal diferencia entre un CPO y un CPRS es que éste último ha de cumplir que su contenido de $\mathrm{C}_{3} \mathrm{~A}$ $\leq 5 \%$ y que la suma $\mathrm{C}_{3} \mathrm{~A}+\mathrm{C}_{4} \mathrm{AF} \leq 22 \%$, mientras que los primeros, no (para más información consúltese la Instrucción RC-08).
} 
cemento Portland, las disoluciones de poro resultaban ser eminentemente básicas, con un $\mathrm{pH}$ comprendido entre 13,2 y 13,4. No obstante, existían grandes diferencias del tipo de cemento Portland en los valores de sus potenciales redox (positivos y, por tanto, indicadores de condiciones oxidantes) y de la fuerza iónica. Ambas propiedades resultaron ser muy inferiores en el caso del CPSR-SRP. Y atendiendo ahora a las diferencias particulares entre los distintos tipos de cemento Portland, se puede afirmar que el CPRS-SRP era el cemento que menor concentración de elementos alcalinos aporta a la fase líquida y, por el contrario, mucha mayor concentración de $\mathrm{Ca}^{2+}$, como es lo lógico. Este hecho es común para los CPRS, en la mayoría de los casos, ya que son el tipo de cemento Portland con una mayor proporción de $\mathrm{CaO}$ en su fórmula química por unidad de masa, lo cual acompañado de la necesidad de reducir su contenido de $\mathrm{Al}_{2} \mathrm{O}_{3}$ en favor del de $\mathrm{Fe}_{2} \mathrm{O}_{3}$, de los materiales empleados como fundentes, obliga a que las temperaturas de clinkerización en su proceso fabril, sean más elevadas que en el caso de los CPO, lo que logra reducir el contenido de elementos alcalinos por su volatilización ${ }^{8}$, a la vez que incrementa su precio por la necesidad de un mayor consumo de energía para fabricar su clínker.

La concentración de elementos alcalinos en la fase líquida se trata de uno de sus parámetros característicos más importantes (Brouwers y col. 2003). De este modo, se puede mencionar que si ésta concentración es muy elevada, se pueden llegar a producir en presencia de ciertos áridos, la nada deseada reacción álcali-árido.

Finalmente, las concentraciones de la fase líquida y, por tanto, la formación de productos de hidratación, como es lógico están muy influenciados por la temperatura. La temperatura determina la solubilidad y los niveles de saturación en la fase líquida con respecto a cada una de las fases sólidas, alterando sus actividades iónicas, su $p H$, su potencial redox y su fuerza iónica (Thomas y cols. 2003; Lothenbach y cols. 2007). Aún así, para los cementos Portland se mantienen las generalidades y diferencias, comentadas anteriormente para la fase líquida, en los intervalos de temperaturas en los que se preparan y ponen en obra estos materiales hidráulicos de forma usual.

\section{I.2.- Adiciones minerales que se le incorporan al cemento Portland.}

\section{I.2.1.- Generalidades.}

En el mundo de los materiales de construcción de base cemento Portland (CP), se entiende por adiciones minerales, los materiales inorgánicos amorfos y/o vítreos y cristalinos, naturales o artificiales, de diferente origen, que incorporados al CP en cantidades apropiadas son capaces de generar los mismos productos de hidratación que el propio cemento Portland, si bien, únicamente los amorfos y/o vítreos nada más. La mejor cualidad de estos materiales es el ahorro energético que reporta su utilización en la fabricación de cemento Portland, al poder reemplazarlo, en parte, hasta un límite máximo permitido para cada tipo, lo que también conlleva apreciables beneficios medioambientales (reducción de la emisión de $\mathrm{CO}_{2}$ a la atmósfera, puesto que, como es bien sabido, la fabricación de $1 \mathrm{Tm}$ de cemento Portland origina aproximadamente $1 \mathrm{Tm}$ de $\mathrm{CO}_{2}$ (Mehta, 1999;

${ }^{8}$ Recuérdese, a tal efecto, que la temperatura de clinkerización está comprendida entre los $1.400{ }^{\circ} \mathrm{C}$ y los $1.500{ }^{\circ} \mathrm{C}$, y que los respectivos puntos de ebullición del sodio y del potasio son de $1.429{ }^{\circ} \mathrm{C} \mathrm{y} 1.305^{\circ} \mathrm{C}$, respectivamente, con entalpías de vaporización de 96,96 y $79,87 \mathrm{~kJ} \cdot \mathrm{mol}^{-1}$. 
Uzal y cols., 2007) y económicos: directos e indirectos. En otras palabras, las razones que se adujeron en su día para adicionarle al $\mathrm{CP}$ adiciones minerales puzolánicas, siderúrgicas e incluso fíller silíceo o calizo especialmente, fueron de índole económica (al parecer, abaratamiento de los costes de producción del cemento) y ecológica, principalmente.

Entre dichos materiales inorgánicos aptos para ser adicionadas al $\mathrm{CP}$, se pueden destacar principalmente los siguientes:

Adiciones minerales activas: puzolanas naturales y artificiales y escorias siderúrgicas, las cuales están constituidas por cierta fracción cristalina, la menor, por lo general, dispersa en una matriz amorfa y/o vítrea, la mayor, por lo general también, y esta última, a su vez y en el caso de las puzolanas, está constituida por componentes reactivos, llamados factores hidráulicos (sílice reactiva, alúmina reactiva, etc.) (Calleja, 1969) entre los cuales cabe destacar por su abundancia, de mayor a menor, la sílice reactiva, $\mathrm{SiO}_{2}{ }^{\mathrm{r}}$, la alúmina reactiva, $\mathrm{Al}_{2} \mathrm{O}_{3}{ }^{\mathrm{r}}, \mathrm{y}$ el óxido de hierro (III) reactivo, $\mathrm{Fe}_{2} \mathrm{O}_{3^{\mathrm{r}}}$, (asimismo y entre las cenizas volantes especialmente, existen algunas, las de la combustión de lignitos, que también contienen óxido de calcio reactivo, y sulfatos, etc.), los cuales, por su marcado carácter químico ácido, poseen la capacidad de reaccionar químicamente, a temperatura ambiente y en medio acuoso, con la cal apagada y/o con la portlandita liberada por el CP tras su hidratación, para formar silicatos y aluminatos de calcio hidratados semejantes a los del propio cemento Portland, contribuyendo, por ello, a las resistencias mecánicas finales del material endurecido que las contiene. Este comportamiento tan peculiar de estas adiciones minerales es el que se ha dado en llamar actividad puzolánica. Entre este tipo de adiciones minerales activas se tienen las puzolanas naturales (rocas sedimentarias fósiles de naturaleza silícea como diatomeas, rocas volcánicas vítreas, etc.) y artificiales (cenizas volantes de las centrales térmicas, el humo de sílice, la nanosílice, las arcillas activadas térmicamente como metacaolines, los esquistos calcinados, los residuos inquemados de la incineración adecuada de la paja y de la cáscara de arroz o del bagazo de la caña de azúcar, etc.).

Todas las escorias siderúrgicas son, en cambio, productos artificiales provenientes de la industria de la siderurgia integral, las cuales mediante su enfriamiento brusco desde temperaturas elevadas, con agua (el método más común utilizado) o con aire (el menos común), se vitrifican, necesitando a continuación, una vez molidas a la finura del cemento Portland, un activador alcalino (disolución acuosa de pH básico o muy básico: cal apagada, portlandita, sosa, potasa, etc.) para poder formar así también los compuestos hidráulicos estables e insolubles en agua como los del propio cemento Portland.

Adiciones minerales cristalinas o mal llamadas "inertes" (Rahhal y cols., 2012): son unos materiales inorgánicos igualmente de origen natural o artificial, que a diferencia de las adiciones minerales activas, se comportan con el cemento Portland durante su hidratación inicial y ulterior, de manera totalmente distinta, lo que justifica que no se las pueda considerar totalmente "inertes", bajo ningún concepto, pero sin que por ello se les pueda adscribir tampoco nunca propiedad hidráulica alguna. Su nombre común es filler y son de origen silíceo o calizo especialmente. Su incorporación requiere cierto proceso de preparación física (homogeneización, secado, molienda, etc.) y en ningún caso debería afectar negativamente la demanda del agua de amasado. Y ni mucho menos tampoco a las resistencias mecánicas y químicas del hormigón resultante ni a su durabilidad prevista, lo 
COMPORTAMIENTO SULFÁTICO Y MECÁNICO-RESISTENTE DE CEMENTOS PORTLAND CON ELEVADOS

que puede resultar sumamente difícil, por no decir imposible, según sea la naturaleza del filler y/o la cantidad que se incorpore (Rahhal y cols., 2012).

En España y desde el año 1975, casi todas las construcciones de edificación y obra civil, se han realizado y se continuarán realizando con hormigones que, por lo común, contienen cantidades diversas de adiciones puzolánicas naturales y artificiales (su estado físico es vítreo y/o amorfo en su mayor parte, es decir, no cristalino) por ser este tipo de adiciones minerales activas las que más abundan, aunque no, repartidas por igual. En determinadas regiones de España abundan bastante más las cenizas volantes, mientras que en otras las que abundan son las puzolanas naturales. En cambio, la adición de escorias siderúrgicas molidas (su estado físico es vítreo) al CP ha estado circunscrita finalmente a las fábricas de cemento de la cornisa cantábrica, en general, y, posteriormente, a la asturiana y sus provincias colindantes, en particular, aunque últimamente se ha sumado a ellas alguna otra ubicada en el sureste de España. Antes de esa fecha, los hormigones utilizados para construir, eran en su mayoría, de cemento Portland puro.

En todos los países de la UE está permitido también incorporarle en fábrica al CP, adiciones minerales cristalinas muy molidas, tipo filler, aún a pesar de que ya Bolomey, (1936) se hubiera posicionado radicalmente en contra, con el fundamento debido, de esta práctica tan habitual hoy. Hasta el punto de haber llegado a escribir el siguiente corolario de la investigación que realizó entonces al efecto (Bolomey, 1936), de añadirle "polvo de piedra" (que era como se le denominaba entonces al fíller actual) al CP para ver su influencia en las resistencias mecánicas y en otros parámetros físicos: "Por estas razones la adición de polvo de piedra al cemento debe proscribirse absolutamente".

\section{I.2.2.- Composición química de las adiciones puzolánicas.}

Un importante parámetro, para diferenciar una puzolana de los demás materiales que pudieran estar también incluidos en la definición dada antes de adiciones minerales activas, es la composición química de sus componentes, así como también, las proporciones en las que se encuentren. De aquí que las normas vigentes (UNE EN 197-1; ASTM C 311; ASTM C 618; UNE EN 450-1) que las contemplan las siguientes especificaciones de obligado cumplimiento para todas ellas:

- $\quad$ que el contenido de la suma de $\mathrm{SiO}_{2}(\%), \mathrm{Al}_{2} \mathrm{O}_{3}(\%)$ y $\mathrm{Fe}_{2} \mathrm{O}_{3}(\%)$ sea $\geq 70 \%$ (ASTM C 618),

- $\quad$ que el contenido de sílice reactiva $\left(\mathrm{SiO}_{2}{ }^{\mathrm{r}}\right)$ (UNE 80225$)$ no sea inferior al $25 \%$ (Calavera, 1996), es decir, que sea $\geq 25 \%$.

En consecuencia, las adiciones puzolánicas, en principio, se pueden clasificar también por su composición química tomando de referencia su contenido en óxidos ácidos. Lo que no es de mucha utilidad en cuanto a su capacidad de reaccionar químicamente a temperatura ambiente y en medio acuoso, con la cal apagada ni con la portlandita y, en definitiva, para poder discernir su utilidad o no para la construcción.

Por todo ello, de acuerdo con Calleja (1969), más descriptiva en este aspecto resulta su composición mineralógica, mientras que para Talero (1986), lo que las caracteriza es su adecuación o no para un fin determinado para la construcción: fabricar hormigones, morteros y pastas de 
cemento que resistan a unos medios agresivos determinados y/o que proporcionen elevadas resistencias mecánicas a edades iniciales o no, o proporcionar ambas características a un mismo tiempo. Lo que ineludiblemente está relacionado con sus contenidos de $\mathrm{SiO}_{2}{ }^{\mathrm{r}}, \mathrm{Al}_{2} \mathrm{O}_{3}{ }^{\mathrm{r}-}$ y $\mathrm{Fe}_{2} \mathrm{O}_{3}{ }^{\mathrm{r}}$.

A continuación, en la Tabla I-10 se muestran valores entre los que varían las composiciones químicas de las adiciones puzolánicas que se le incorporan a los cementos Portland.

TABLA I-1O.- COMPOSICIÓN QUÍMICA DE LAS ADICIONES PUZOLÁNICAS (EN PARÉNTESIS: VALORES MEDIOS).

\begin{tabular}{cccccccccc}
\hline Constituyentes & $\mathrm{SiO}_{2}$ & $\mathrm{Al}_{2} \mathrm{O}_{3}$ & $\mathrm{Fe}_{2} \mathrm{O}_{3}$ & $\mathbf{C a O}$ & $\mathbf{M g O}$ & $\mathrm{Na}_{2} \mathrm{O}$ & $\mathrm{K}_{2} \mathrm{O}$ & $\mathrm{SO}_{3}$ & $\mathbf{P F}$ \\
\hline Porcentajes & $28-100$ & $0-45$ & $0-20$ & $0-34$ & $0-11$ & $0-7$ & $0-8$ & $0-14$ & $0-15$ \\
Puzolanas de origen & $42-73$ & $10-20$ & $1-14$ & $0-12$ & $0-11$ & $1-5$ & $1-5$ & $0-0.05$ & $0-15$ \\
mineral & $(57,0)$ & $(15,0)$ & $(5,0)$ & $(5,0)$ & $(2,0)$ & $(3,0)$ & $(3,0)$ & $(0,025)$ & $(7,0)$ \\
Puzolanas de origen & $65-85$ & $5-15$ & $1-10$ & $0-5$ & $1-2$ & $0-0.5$ & $0-1$ & $0-1$ & $1-10$ \\
orgánico & $(75,0)$ & $(10,0)$ & $(5,0)$ & $(2,0)$ & $(2,0)$ & $(0,5)$ & $(0,5)$ & $(0,5)$ & $(5,0)$ \\
Puzolanas en & $42-85$ & $5-20$ & $1-14$ & $0-12$ & $0-11$ & $0-5$ & $0-5$ & $0-1$ & $0-15$ \\
general & $(65,0)$ & $(12,5)$ & $(5,0)$ & $(3,5)$ & $(1,5)$ & $(2,0)$ & $(2,0)$ & $(0,5)$ & $(6,0)$ \\
\hline
\end{tabular}

Toda adición puzolánica de cualquier origen, posee una parte, generalmente la mayor, amorfa, y otra, generalmente la menor, cristalina. Además, la parte amorfa es la que más la caracteriza y posee un estado físico que puede ser un compendio de vítreo, amorfo, gel, pseudogel, numolítico, pseudo-cristalino, etc.

Consecuentemente, dicha parte amorfa puede llegar a originar con el tiempo minerales más o menos argilizados, tales como, augita, $(\mathrm{Ca}, \mathrm{Mg}, \mathrm{Fe})_{2}(\mathrm{Si}, \mathrm{Al})_{2} \mathrm{O}_{6}$, herschelita o chabazita- $\mathrm{Na}$, $\mathrm{NaAISi}_{2} \mathrm{O}_{6} \cdot \mathrm{H}_{2} \mathrm{O}$, feldespatos, etc., productos todos ellos que suelen provenir de una mayor o menor meteorización de sus vidrios volcánicos originales. La parte cristalina suele ser, en cambio, lo que más diferencia a las adiciones puzolánicas (Calavera, 1996) y está representada, por lo general, por sílico-aluminatos cristalinos, naturales o no, bastante estables e inatacables por ácidos fuertes, y quizás menos, por bases fuertes. Por lo común, las mencionadas estructuras ordenadas se obtienen por síntesis mediante calentamientos, fusiones y/o recristalizaciones de diverso grado y cantidad, que dan por resultado mullita o porcelanita, $\mathrm{Al}_{4+2} \times \mathrm{Si}_{2-2 x} \mathrm{O}_{10-x}(\mathrm{x} \approx 0.4)$, sillimanita, $\mathrm{Al}_{2} \mathrm{SiO}_{5}$, cuarzo, $\mathrm{SiO}_{2}$, tridimita, $\mathrm{SiO}_{2}$, cristobalita, $\mathrm{SiO}_{2}$, andalucita, $\mathrm{Al}_{2} \mathrm{SiO}_{5}$, disteno, $\mathrm{Al}_{2} \mathrm{SiO}_{5}$, o cianita, $\mathrm{Al}_{2} \mathrm{SiO}_{5}$, hematita, $\mathrm{Fe}_{2} \mathrm{O}_{3}$, magnetita, $\mathrm{Fe}_{3} \mathrm{O}_{4}$, maghemita, $\mathrm{Fe}_{2.67} \mathrm{O}_{4}$, etc., aunque por ser su cantidad escasa, son las que menos influencian o caracterizan la adición. En cambio, la parte amorfa y/o vítrea (o parte reactiva) es la que más.

\section{I.2.3.- Actividad puzolánica.}

\section{I.2.3.1.- Reacciones químicas entre la adición puzolánica y el $\mathrm{Ca}(\mathrm{OH})_{2}$}

Teniendo en cuenta que los constituyentes minerales de las adiciones puzolánicas pueden ser múltiples y variados, además de encontrarse en diferentes cantidades, a continuación, se presentan las reacciones químicas ( $r 12, r 13, r 14, r 15)$ que pueden producirse entre el hidróxido de calcio y los tres principales factores hidráulicos (Uzal y cols., 2007) de las adiciones puzolánicas mencionadas antes, que son la sílice reactiva, $\mathrm{SiO}_{2}{ }^{\mathrm{r}-}$, la alúmina reactiva, $\mathrm{Al}_{2} \mathrm{O}_{3}{ }^{\mathrm{r}-}$, y el óxido de hierro reactivo, $\mathrm{Fe}_{2} \mathrm{O}_{3}{ }^{\mathrm{r}}$, sin despreciar los álcalis, que aunque no son factores hidráulicos, propiamente 
dichos, pueden llegar a estar también presentes con apreciable influencia sobre las resistencias mecánicas y la durabilidad del material resultante (Talero y col., 1991; Rahhal, 2002).

$$
\begin{aligned}
& \mathrm{SiO}_{2}{ }^{\mathrm{r}-}+\mathrm{CaO}+\mathrm{H}_{2} \mathrm{O}=\mathrm{C}-\mathrm{S}-\mathrm{H}+\mathrm{Q} \\
& \mathrm{Al}_{2} \mathrm{O}_{3}{ }^{\mathrm{r}-}+\mathrm{CaO}+\mathrm{H}_{2} \mathrm{O}=\mathrm{C}_{3} \mathrm{AH}_{6}, \mathrm{C}_{4} \mathrm{AH}_{13}, \mathrm{C}_{4} \mathrm{AH}_{19}+\mathrm{Q} \\
& \mathrm{C}_{4} \mathrm{AH}_{13}+\mathrm{H}_{2} \mathrm{O}+\text { yeso }=\mathrm{AFm}+\mathrm{Q} \\
& \mathrm{AFm}+\mathrm{H}_{2} \mathrm{O}+\text { yeso }=\mathrm{AFt}+\mathrm{Q}
\end{aligned}
$$

Y los productos de reacción resultantes de las reacciones químicas mencionadas dependerán de la naturaleza de la adición mineral de que se trate (su composición mineral y constitución química), por lo que se formarán los compuestos químicos hidratados hidráulicamente estables o inestables. Finalmente, la naturaleza, el carácter químico y/o el tamaño medio de partícula de la adición mineral determinarán, en cambio, su comportamiento frente al ataque de un medio agresivo o no, determinado, del hormigón, mortero o pasta de cemento del que forme parte.

\section{I.2.3.2.- Razones de la actividad puzolánica}

De acuerdo con lo que opinó Calleja, (1969), las causas de la actividad puzolánica de un determinado material podrían ser las siguientes:

"La actividad puzolánica responde a un principio general que reviste aspectos particulares en casos concretos." El autor basó dicho principio en que la sílice reactiva, $\mathrm{SiO}_{2}{ }^{\mathrm{r}-}$, y la alúmina reactiva, $\mathrm{Al}_{2} \mathrm{O}_{3}{ }^{\mathrm{r}-}$ , como componentes ácidos de los materiales puzolánicos, reaccionan químicamente en medio acuoso y a temperatura ambiente, con la portlandita y/o la cal apagada, dando uniones muy débiles (adsorción por fuerzas de Van der Waals). Los casos particulares en los que se da la necesaria labilidad de estas uniones están constituidos por las estructuras zeolíticas, los vidrios volcánicos o no, y los materiales activados térmica y/o químicamente.

Calleja, (1969) destacó también que las acciones de la sílice y la alúmina reactivas debían considerarse conjuntamente, ya que la presencia de esta última especialmente, favorecía en gran medida la acción puzolánica, de modo directo o indirectamente si la presencia de un mayor contenido de álcalis estaba implicada también. Dado que los álcalis se fijan parcialmente, los nuevos productos resultantes de la reacción puzolánica tienen carácter de pseudogeles. En cambio, el óxido de hierro reactivo, $\mathrm{Fe}_{2} \mathrm{O}_{3}{ }^{\mathrm{r}}$, se supone que actúa como la $\mathrm{Al}_{2} \mathrm{O}_{3^{\mathrm{r}}}$, pero de una forma más atenuada y lenta.

Mientras tanto, las estructuras zeolíticas son atacadas por la portlandita más rápidamente que las puzolanas vítreas y la fijan en mayor medida que la correspondiente a un intercambio catiónico con álcalis, indicando una ruptura de la estructura reticular y de los enlaces químicos, lo que da lugar a una participación de su sílice y de su alúmina.

La actividad de las puzolanas de origen mineral se atribuye tanto a sus constituyentes amorfos como a algunos, muy pocos, cristalinos, y en particular, a los de naturaleza zeolítica. De 
modo que a mayores densidades corresponde menos agua zeolítica (pérdida al fuego, PF), sílice soluble y álcalis y mayor residuo insoluble (Tabla I-11).

Según esto, y dado que los constituyentes mineralógicos en estado vítreo son más densos que en estado cristalino, parece ser que las fracciones ligeras (cristalinas) son más alcalinas y zeolíticas que las densas (vítreas) y, en consecuencia, más activas. Estas ideas han llevado a establecer la hipótesis de que minerales cristalizados como la leucita - $\left(\mathrm{Si}_{2} \mathrm{AlO}_{6}\right) \mathrm{K}$, o bien $4 \mathrm{SiO}_{2} \cdot \mathrm{Al}_{2} \mathrm{O}_{3} \cdot \mathrm{K}_{2} \mathrm{O}$ y la analzima, $\left(\mathrm{Si}_{2} \mathrm{AlO}_{6}\right) \mathrm{Na} \cdot \mathrm{H}_{2} \mathrm{O}$, o bien $4 \mathrm{SiO}_{2} \cdot \mathrm{Al}_{2} \mathrm{O}_{3} \cdot \mathrm{Na}_{2} \mathrm{O} \cdot 2 \mathrm{H}_{2} \mathrm{O}$, zeolita hidrotermal-, que se encuentran en las tobas, cambian las bases alcalinas, primero por agua y después por cal, realizando así la acción puzolánica. En este aspecto se consideran minerales leucíticos con menor $\mathrm{K}_{2} \mathrm{O}$ y más $\mathrm{H}_{2} \mathrm{O}$ que la leucita.

Otro punto de vista análogo fue el que atribuía la puzolanicidad de las tobas a los llamados oligoelementos de las mismas, como el cloro y el azufre, según lo cual la actividad residiría principalmente en minerales sodalíticos, como por ejemplo la sodalita, $\left(\left(\mathrm{SiAlO}_{4}\right) \mathrm{Cl}_{2}\right)_{6} \mathrm{Na}$. Aunque fue difícil admitir que ello fuera así, dada la pequeña proporción de estos minerales en las tobas.

TABLA I-11.- COMPOSICIÓN QUÍMICA APROXIMADA DE LAS PUZOLANAS, EN FUNCIÓN DE SU PESO ESPECÍFICO.

\begin{tabular}{cccc}
\hline Parámetros Químicos (\%) & \multicolumn{2}{c}{ Peso específico (g/ml) } \\
\hline PF $\left(\mathrm{H}_{2} \mathrm{O}\right)$ & 2,30 & - & 2,65 \\
Sílice soluble & 13 & $>$ & 2,65 \\
Álcalis & 40 & $>$ & 10 \\
R.I. & 8 & $>$ & 0 \\
\hline
\end{tabular}

No obstante, la tesis contraria más contrastada científicamente fue la que atribuyó la actividad puzolánica a los constituyentes vítreos, basándose en su mayor energía potencial y reactividad, y por analogía, con lo que se observaba en el comportamiento de las escorias básicas granuladas de horno alto utilizadas en la fabricación de cementos siderúrgicos.

La actividad basada en las fracciones vítreas de las puzolanas se atribuyó al vidrio volcánico o al vidrio zeolítico o parcialmente zeolítizado, con lo que en este último caso cobraba prioridad de nuevo el carácter zeolítico como causa de la actividad puzolánica (Turriziani, 1961). Los vidrios volcánicos son vidrios parcialmente alterados, o alterados a fondo, que se encuentran en la mayoría de las puzolanas naturales: puzolanas italianas (laciales romanas de Segni, de naturaleza leucítica, o flegreanas napolitanas de Bacoli y de la Campania, de naturaleza alcalitraquítica), puzolanas españolas (insulares naturales y peninsulares), tierras griegas de Santorín, etc.

Tavasci $(1946 ; 1948)$ observó con el microscopio las puzolanas italianas, encontrando materiales vítreos de textura microporosa, con proporciones variables de cristales, alterados o no, y en distinto grado. El vidrio de las puzolanas leucíticas de Segni, más básicas y alteradas, contenía leucita y piroxenos (augita) y vidrio muy alterado, de naturaleza zeolítica, conteniendo chabacita y phillipsita, y su composición se aproximaba a la de la labradorita (Tavasci, 1954), en tanto que el vidrio con burbujas de las puzolanas, alcalitraquíticas de Bacoli contenía sanidino, plagioclasas, piroxenos (augita) y magnetita y su composición se aproximaba a la de la oligoclasa, o fue intermedia entre la de la ortoclasa $\left(\mathrm{KAlSi}_{3} \mathrm{O}_{8}\right)$ y la de la anortita $\left(\mathrm{CaAl}_{2} \mathrm{Si}_{2} \mathrm{O}_{8}\right)$. 
Según los estudios de Turriziani, 1961, la formación del vidrio volcánico activo tiene lugar por el enfriamiento brusco del magma fundido lanzado en las erupciones y pulverizado por el escape de los gases. Esta eliminación de gases confiere al material una textura de gran superficie interna (de "aerogel"), de tal manera que cuando la erupción no es explosiva no se forma tanto vidrio ni éste es tan activo, debido a su enfriamiento lento. Esto explica que las erupciones del Monte Etna, a diferencia de las del Vesubio, no hayan producido materiales puzolánicos, los cuales abundan, por tanto, en Nápoles y brillan por su ausencia en Sicilia, y sirvió de apoyo a la tesis que asignaba la actividad puzolánica a las estructuras vítreas. En efecto, los materiales arrojados por el Etna en Catania nunca fueron puzolanas verdaderas, sino cenizas volcánicas incoherentes, leucotefríticas, cristalinas y poco alteradas por falta de erupción explosiva, igual que las cenizas vesubianas proyectadas después de las explosiones.

Otro apoyo de la misma tesis fue el hecho de que las cenizas y lavas de magmas álcalitraquíticos, leucíticos, leucotefríticos y haüynofíricos, cuando son fundidos y templados bruscamente, adquieren propiedades puzolánicas de las que antes carecían. En el caso del trass alemán, la actividad depende de la fase vítrea, que, si bien es más abundante en el bávaro, en cambio es más activa en el renano.

Un hecho práctico derivado de la aceptación de esta hipótesis fue que una extracción de las puzolanas con ácido clorhídrico al 20 \% y con hidróxido sódico al 10 \% disuelve el vidrio y deja un residuo insoluble cristalino con algo de vidrio. Esta extracción puede dar idea de la actividad de los materiales de un mismo yacimiento.

Otra idea complementaria suponía que la actividad dependía de los gases liberados en el proceso eruptivo, los cuales creaban la estructura de "aerogel". Ello indicaba que fueron las condiciones físicas de este "aerogel", formado por pulverizaciones del magma fundido, por acción del aire, del vapor de agua y de otros gases, las que condicionan la actividad puzolánica, particularmente, el estado de gran división del gel de sílice desecado que contenía el componente vítreo. La masa vítrea a la que en la correspondiente hipótesis se atribuyó la acción puzolánica sería, según esto, un gel de sílice-alúmina-óxido férrico, de propiedades dependientes de la naturaleza física, más que de la composición química del material puzolánico (Uzal y cols., 2007).

Otra hipótesis de las causas de la actividad puzolánica propuesta por Calleja, (1969), fue la que la relacionaba con su composición química, es decir, con sus constituyentes minerales. Así, por ejemplo, la norma alemana DIN 1043/44 exige que los materiales puzolánicos tengan un $7 \%$ de agua de hidratación (agua enlazada física o químicamente) como mínimo, basándose en una relación establecida entre la acción puzolánica y el mencionado contenido de agua de hidratación. No obstante, fue una hipótesis bastante restringente, ya que muchas puzolanas con menos agua demostraban una acción puzolánica a veces mejor que las que sí cumplían con el requisito de dicha norma. Y todo era debido a que algunas de ellas sometidas al proceso de calcinación, sí perdían agua, al mismo tiempo que aumentaban su reactividad por romper los enlaces químicos correspondientes a los componentes reactivos tales como la sílice y la alúmina reactiva, especialmente si sufren un enfriamiento brusco del proceso. Finalmente, dicha hipótesis respaldó todos aquellos materiales que originalmente contenían vidrio que puede perder su actividad puzolánica al tratarse térmicamente, en cualquier caso también, dependiendo de las condiciones programadas de dichos tratamientos térmicos (temperatura y tiempo del proceso de enfriamiento). 
Otro estudio, de carácter químico, relacionaba la reactividad de las puzolanas con la presencia de cationes alcalinos y alcalino-térreos, que influyen en el grado de condensación de los poliedros $\mathrm{Si}-\mathrm{O}$ y Al-O dando como resultado unas estructuras más abiertas a las redes espaciales de los constituyentes mineralógicos de estos materiales. Otra hipótesis del mismo rango relacionaba la actividad puzolánica con el contenido en componentes solubles (sílice y alúmina reactiva, principalmente), definiendo la palabra "soluble" como lo atacable por ácido (clorhídrico), por un lado, o lo atacable por hidróxido de calcio (solubilidad en medio alcalino), por otro. Adicionalmente, dicha hipótesis reconocía la parte activa de la puzolana como correspondiente a la parte "soluble", mientras que está demostrado que la parte "insoluble", aunque con menor grado, también presenta cierta actividad que además no se ve afectada por el tratamiento en medio ácido. Finalmente, las alteraciones neumatolíticas, ocasionadas por gases y aguas subterráneas, y en particular por vapor sobrecalentado y aguas carbónicas, que son la causa de la actividad puzolánica, producen la eliminación de la parte soluble de un material puzolánico. No obstante, si dicha eliminación se refiere a los componentes básicos, los materiales pasan a formas más activas.

En el caso de las tobas puzolánicas compactas (trasses renanos, bávaros, italianos, rumanos, rusos y canarios), que proceden de los mismos materiales pero transformados después por alteraciones matamórficas, fue más operante la hipótesis que basaba su actividad en el vidrio zeolítico o parcialmente zeolitizado. En efecto, los citados materiales, que, como las tobas amarillas napolitanas, son rocas tobáceas compactas y blandas junto con un material pumicítico incoherente, separados por capas poco coherentes, constan de una matriz zeolítica isotrópica con fragmentos de cristales de los minerales de las puzolanas vítreas de las respectivas zonas (pumita, sanidino, hornblenda, augita, biotita, etc.). La matriz zeolítica o zeolitizada suele estar muy alterada y constar de herschelita y/o chabacita y/o phillipsita (las tobas españolas naturales, por ejemplo, constan exclusivamente de phillipsita, con sanidino y pumicita en una matriz isotrópica). También suelen tener buena actividad las tobas liparíticas y riolíticas profundamente zeolitizadas que contienen analcita o analzima, las propias pumitas y lavas vítreas.

Esta hipótesis se reforzó con otra acerca de la formación de tobas compactas y semicompactas, que atribuyó la formación a procesos de zeolitización de la fase vítrea de los materiales piroclásticos incoherentes originales arrojados en las erupciones volcánicas, merced a un proceso de autometamorfismo por acción hidrotérmica o neumatolítica, llevada a cabo por aguas carbónicas y vapor recalentado, como ya se ha indicado. Esto ha podido ser comprobado y reproducido en experiencias de zeolitización artificial en el laboratorio, tratando puzolanas flegreanas y vidrios riolíticos, álcali-traquíticos, leucíticos y basálticos y otros materiales pirocláticos, con potasa cáustica al $1 \%$ a temperaturas de $235-280^{\circ} \mathrm{C}$ y a presiones de 36 y 60 atmósferas, con lo cual se obtienen materiales muy próximos a las tobas de la región flegreana. La serie de transformaciones que tiene lugar consiste en la toma de agua, en el aumento de la relación $\mathrm{Fe}_{2} \mathrm{O}_{3} / \mathrm{FeO}$, con la adquisición consiguiente de un tono de color pajizo, y en la transformación del vidrio en herschelita, analcita y ortoclasa, dependiendo de la naturaleza del material de partida y de las condiciones experimentales, variables entre los límites indicados. La actividad de estos productos no cambia por efecto de los tratamientos térmicos, salvo que en los materiales de origen estén presentes minerales de arcilla.

Dicha hipótesis se ve confirmada por el hecho de que los materiales de las partes bajas de las canteras puzolánicas y los más modernos y de formación más reciente suelen ser menos 
reactivos, estos últimos, por poseer mayor cantidad de cristales, y ambos, por haber experimentado una alteración menos profunda. La alteración (hidratación de materiales eruptivos que han sufrido una deshidratación previa por calcinación sin llegar a fusión) es un fenómeno secundario, y como causa única de la actividad puzolánica es difícil de aceptar en general, puesto que a veces una alteración excesiva o la simple alteración suele ser perjudicial a estos efectos. Por lo que debe contar, por tanto, la propia naturaleza original del material eruptivo alterado.

Estas hipótesis tan poco consistentes demostraban que la solución del problema estaba todavía lejos de ser alcanzada y que, como se indicaba antes, era preciso adoptar una transitoria y ecléctica, admitiendo constituyentes materiales (cristalinos y vítreos) y que todos los componentes químicos poseen una actividad mayor o menor. Por consiguiente, es lógico pensar que aquellas puzolanas más ricas en cualquiera de dichos constituyentes o componentes deban su actividad principalmente a ellos, pero sin que los restantes dejen de contribuir en su medida, como tampoco los estados físicos de división de dichos constituyentes, en cuanto a su superficie interna, y los estados de alteración química, en cuanto a la presencia de cationes de cambio, etc. Lo que quiere decir que cada puzolana o tipo de ellas representa un caso particular, no siendo posible, al menos por el momento, establecer una teoría general y unitaria acerca de la actividad puzolánica.

Pero, en realidad, la verdadera luz a la solución de todas estas discrepancias acerca de los constituyentes vítreos y cristalinos de las puzolanas, la daría Talero, (1986) al clasificarlas, acuerdo con su carácter químico, dado que dicha clasificación que propuso y que se verá más adelante, se basó propiamente en sus componentes químicos reactivos más significativos por mayoritarios y efectivos frente al ataque de los sulfatos: la sílice reactiva, $\mathrm{SiO}_{2^{\mathrm{r}}}$, y la alúmina reactiva, $\mathrm{Al}_{2} \mathrm{O}_{3}{ }^{\mathrm{r}}$, especialmente.

Algo análogo sucede con las puzolanas de origen orgánico, si bien en el caso de éstas el problema es más sencillo, pues, a pesar de que desde el "moler" con $65 \%$ de sílice soluble y $6 \%$ de agua de hidratación, hasta el trípoli y el keiselgur japonés, con cerca de $95 \%$ de sílice y $8 \%$ de agua, pasando por las "gaice" y las diatomitas, existen diferencias de composición, éstas no son tan grandes, dado, además, el pequeño contenido restante de sesquióxidos, etc., como para no atribuir razonablemente la actividad puzolánica a la sílice hidratada vítrea (conjunto de $\mathrm{SiO}_{2}+\mathrm{nH}_{2} \mathrm{O}$, que en estos materiales supone el $70 \%$ sino quizás el $100 \%$ ), que las constituye mayoritariamente en forma de ópalo o geiserita, véase la Tabla I-12.

Dado que otros materiales de análogo origen y composición química son inactivos frente a la cal, la actividad de las puzolanas de origen orgánico no es sólo cuestión de contenido en sílice hidratada, sino también del estado físico y grado de división de la misma. Lo prueba, por una parte, el hecho de que las puzolanas activas poseen una estructura natural porosa con una gran superficie específica interna y, por otra, la circunstancia de que ciertos ópalos y basaltos no activos cobran actividad cuando se molturan a elevada finura y se someten a una lixiviación con ácido clorhídrico concentrado.

La sílice hidratada vítrea y amorfa es reactiva, siendo el componente eficaz de las puzolanas de origen orgánico, procede en su mayor parte de los esqueletos de infusorios radiolarios y de algas diatomeas, aparte de los citados ópalos y geiseritas. Pero no todas las puzolanas de esta procedencia, con elevado contenido en sílice reactiva, tienen la misma actividad. En algunas de ellas se incrementa también sometiéndolas a calcinación, como sucede con el "moler" danés, con la "gaice" 
francesa del valle del Mosa, con el Trípoli y la tierra de la isla Santorín (Grecia), y con las "tierras blancas" italianas del norte del Lacio, muy ligeras y porosas, cuyo análisis microscópico demuestra presencia de cuarzo, mica y feldespatos más o menos alterados, en una matriz amorfa de gel de sílice.

Como materiales puzolánicos, los materiales citados suelen comportarse tanto mejor cuanto mayor es su contenido de sílice amorfa y menor la proporción de impurezas cristalinas de otros constituyentes. Es curioso señalar aquí, como inciso, que los conglomerados hidráulicos a base de clínker de CP y de estas puzolanas resisten particularmente, y mejor que otros, los ataques por aguas agresivas naturales, por la gran cantidad de gel de tobermorita que forman, con una relación cal/sílice baja.

TABLA I-12.- MINERALOGÍA Y PETROGRAFÍA DE LAS PUZOLANAS NATURALES: ÓXIDOS E HIDRÓXIDOS.

\begin{tabular}{|c|c|c|c|}
\hline $\begin{array}{c}\text { Especie } \\
\text { Mineral }\end{array}$ & Composición & Variedades & Presentación y Forma \\
\hline \multirow[t]{2}{*}{ Cuarzo } & \multirow[t]{2}{*}{ Anhídrido silícico $\left(\mathrm{SiO}_{2}\right)$} & $\begin{array}{c}\text { Cristal de roca } \\
\text { Cuarzo } \\
\text { ahumado } \\
\text { Cuarzo lechoso } \\
\text { Falso topacio } \\
\text { Falso jacinto } \\
\text { Amatista }\end{array}$ & $\begin{array}{c}\text { Cristales } \\
\text { (sistema hexagonal) }\end{array}$ \\
\hline & & $\begin{array}{l}\text { Calcedonia } \\
\text { Ágata u ónice } \\
\text { Sílex } \\
\text { Pedernal } \\
\text { Jaspe }\end{array}$ & Masas \\
\hline Ópalo & Sílice hidratada $\left(\mathrm{SiO}_{2} / \mathrm{nH}_{2} \mathrm{O}\right)$ & $\begin{array}{c}\text { Hialita } \\
\text { Ópalo noble } \\
\text { Jilópalo } \\
\text { Geiresita } \\
\text { Trípoli }\end{array}$ & Amorfo \\
\hline Corindón & $\begin{array}{l}\text { Sesquióxido de aluminio } \\
\qquad\left(\mathrm{Al}_{2} \mathrm{O}_{3}\right)\end{array}$ & $\begin{array}{c}\text { Zafiro y } \\
\text { Leucozafiro } \\
\text { Rubí oriental } \\
\text { Amatista } \\
\text { oriental } \\
\text { Esmeralda } \\
\text { oriental } \\
\text { Topacio oriental } \\
\text { Carbunclo }\end{array}$ & $\begin{array}{c}\text { Cristales } \\
\text { (sistema hexagonal) }\end{array}$ \\
\hline Oligisto & Óxido férrico $\left(\mathrm{Fe}_{2} \mathrm{O}_{3}\right)$ & $\begin{array}{l}\text { Hematites roja } \\
\text { Ocre rojo }\end{array}$ & Cristales (trigonal) \\
\hline Limonita & $\begin{array}{l}\text { Óxido férrico hidratado } \\
\qquad\left(\mathrm{Fe}_{2} \mathrm{O}_{3} \mathrm{nH}_{2} \mathrm{O}\right)\end{array}$ & $\begin{array}{l}\text { Hematites parda } \\
\text { Ocre amarillo }\end{array}$ & Amorfo \\
\hline
\end{tabular}

\section{I.2.4.- Clasificación de las adiciones puzolánicas.}


COMPORTAMIENTO SULFÁTICO Y MECÁNICO-RESISTENTE DE CEMENTOS PORTLAND CON ELEVADOS

Las puzolanas fueron usadas en morteros de cal ya por los romanos en muchas clases de estructuras, incluyendo las obras de carácter marítimo. El buen estado en que se encuentran hoy muchas de estas construcciones, pone de manifiesto el buen comportamiento y la durabilidad que comportan dichos materiales en tales medios (Taylor, 1997).

En la actualidad, las puzolanas se utilizan incorporadas directamente a los hormigones, morteros y pastas de cemento o a los propios cementos Portland directamente. Así, dependiendo de la cantidad que se les aporte, el cemento de mezcla será de una clase u otra (UNE EN 197-1; Instrucción RC-16) y valdrá para unos fines constructivos u otros (Instrucción EHE-08).

Por consiguiente y de acuerdo con lo anterior, no ha de extrañar que, desde aquella época romana hasta hoy, se hayan producido varias clasificaciones de las adiciones puzolánicas, dependiendo del aspecto o punto de vista que se considere. Así se han clasificado y clasifican aún:

- por su origen (naturales y artificiales),

- por su composición mineralógica,

- por el comportamiento en medio acuoso de su parte activa frente a la cal de cualquier origen,

- ídem, frente a ataques ácidos diversos de $\mathrm{HCl}$, de $\mathrm{HF}$, de $\mathrm{HNO}_{3}, \mathrm{H}_{3} \mathrm{PO}_{4}$, etc., y últimamente y como se ha dicho antes,

- $\quad$ por su carácter químico.

La última clasificación por su "carácter químico" fue introducida por Talero, (1986), y se traduce en base a su comportamiento frente al ataque, por separado, de sulfatos y cloruros, cuyo fundamento químico se verá en los apartados siguientes.

\section{I.2.4.1.- Clasificación de las adiciones puzolánicas por su composición mineralógica.}

Bajo esta clasificación de las puzolanas, se diferencian materiales de naturaleza silícea o silícea y aluminosa o combinación de ambas (Calleja, 1969; Instrucción RC-16), que por sí mismos no poseen propiedades hidráulicas (capacidad de endurecimiento al haberse mezclado con agua), pero que en medio acuoso y a temperatura ambiente se combinan químicamente con el hidróxido de calcio y con la portlandita para formar compuestos hidratados insolubles que poseen propiedades cementantes, los cuales son semejantes además a los que proporciona el propio $\mathrm{CP}$ al hidratarse. Esta definición de las puzolanas recoge diferentes adiciones minerales naturales, así como también productos artificiales o semi-artificiales (Taylor 1997; UNE EN 450-1).

\section{I.2.4.2.- Clasificación de las adiciones puzolánicas por su origen.}

Otra clasificación de las adiciones puzolánicas puede ser por su origen, según el cual se clasifican en naturales, artificiales y semi-artificiales. 
Las adiciones puzolánicas naturales pueden ser de origen inorgánico y orgánico. Las puzolanas naturales de origen inorgánico están constituidas en general, por ciertas rocas incoherentes y compactas de origen volcánico o rocas sedimentarias (ASTM C 618; Instrucción RC16)], constituidas principalmente por aluminosilicatos que forman vidrios con textura porosa y desordenada. Las adiciones puzolánicas de origen orgánico están constituidas en cambio por esqueletos de seres vivos, "frústulos" (Font Quer, 1953; Tosco, 1973), y comprenden principalmente a las diatomitas de origen marino y lacustre, con elevados contenidos de sílice vítrea.

Las adiciones puzolánicas artificiales son principalmente subproductos de otras industrias, y, por lo común, son las cenizas volantes (ASTM C 618; UNE EN 450-1; Instrucción RC-16), obtenidas de la combustión de carbones minerales diversos (antracitas, hullas, lignitos) en centrales termoeléctricas, y los humos de sílice (UNE EN 13263-1; UNE 83460-2), obtenidos en el horno de arco eléctrico de las industrias de aleaciones de ferrosilicio y silicio metal, al condensarse los vapores de óxido de silicio, dando lugar a la sílice vítrea que también es amorfa. Otras adiciones minerales artificiales de semejante composición química semejante a la de las diatomeas y al humo de sílice, son las cenizas de la incineración adecuada de la paja y la cáscara de arroz y del bagazo de la caña de azúcar. También son puzolanas artificiales los restos bauxiticos y caoliníticos procedentes de la metalurgia extractiva de aluminio a partir de bauxita y caolines diversos adecuadamente calcinados, los restos de las industrias cerámicas y de refractarios y similares.

Las adiciones puzolánicas semi-artificiales son principalmente las arcillas naturales sometidas a tratamiento térmico adecuado (Talero, 1986; Murat, 1983a; 1983b; Murat y col. 1983), los esquistos calcinados, los lodos residuales incinerados de las fábricas de papel, los múltiples y variados subproductos de la industria cerámica (Martín Luengo, 1997; Talero y col., 1992), gaice, moler, etc., y otros materiales afines.

\section{I.2.4.3.- Clasificación de las adiciones puzolánicas por el comportamiento de su parte activa o reactiva.}

Calleja, (1969; 1988), adoptó un criterio de caracterización de las adiciones puzolánicas por el comportamiento de su parte vítrea y/o amorfa o activa (componentes ácidos) que poseen frente a la portlandita, estando constituida a su vez dicha parte vítrea y/o amorfa por $\mathrm{SiO}_{2}{ }^{\mathrm{r}}, \mathrm{Al}_{2} \mathrm{O}_{3^{\mathrm{r}-}}$ y $\mathrm{Fe}_{2} \mathrm{O}_{3^{\mathrm{r}}}$ (de mayor a menor contenido) a los que denominó "factores hidráulicos".

Sin embargo, la norma ASTM C 618 define las puzolanas naturales y artificiales como "materiales silíceos y aluminosos, que por sí mismos no poseen valor cementíceo alguno, pero que finamente divididos y en presencia de humedad, reaccionarán con hidróxido de calcio a temperaturas ordinarias para formar compuestos que poseen propiedades cementíceas", clasificándolas por su origen en tres clases:

- Clase N, que son las puzolanas naturales (entre las cuales se encuentran la tierra de diatomeas, las rocas opalinas, los tuffs y cenizas volcánicas o pumicitas y materiales que necesitan calcinación adecuada para inducirles propiedades puzolánicas satisfactorias, tales como las arcillas activadas y los esquistos calcinados),

- Clase F, que son los inquemados o cenizas volantes obtenidas de la incineración de antracitas y carbones bituminosos, las cuales por lo común poseen unos contenidos de $\mathrm{CaO}$ pequeños, 
COMPORTAMIENTO SULFÁTICO Y MECÁNICO-RESISTENTE DE CEMENTOS PORTLAND CON ELEVADOS CONTENIDOS DE PUZOLANAS (> 40\%): SU FUNDAMENTO QUÍMICO Y JUSTIFICACIÓN DE OTRAS CONSECUENCIAS POSIBLES

- Clase $C$, que son los inquemados o cenizas volantes de la incineración de lignitos y carbones sub-bituminosos, las cuales en cambio poseen unos contenidos de $\mathrm{CaO}>10 \%$. Algunas de estas últimas pueden tener incluso ciertas propiedades cementíceas y, por ende, son hidráulicas.

Asimismo y por su parte, la norma UNE-EN 197-1 las contempla y engloba en principio a todas en su apartado 5.2.3., titulado "Materiales puzolánicos $(P, Q)$ " y, en segundo lugar, especifica por separado en otros tantos sub-apartados, y de acuerdo con su origen, natural o artificial, las que en realidad ampara únicamente, las cuales son las siguientes: puzolana natural (de origen volcánico o rocas sedimentarias con composición química y mineralógica adecuadas), ceniza volante silícea, ceniza volante calcárea, esquisto calcinado y humo de sílice, mientras que las define de forma genérica de este modo: "Los materiales puzolánicos son sustancias naturales de composición silícea o silícoaluminosa o una combinación de ambas. [..] Los materiales puzolánicos no endurecen por sí mismos cuando se amasan con agua, pero finamente molidos y en presencia de agua, reaccionan, a temperatura ambiente, con el hidróxido de calcio disuelto $\left(\mathrm{Ca}\left(\mathrm{OH}_{2}\right)\right)$ para formar compuestos de silicato de calcio y aluminato de calcio capaces de desarrollar resistencia. Estos compuestos son similares a los que se forman durante el endurecimiento de los materiales hidráulicos. Las puzolanas están compuestas esencialmente por dióxido de silicio reactivo $\left(\mathrm{SiO}_{2}\right)$ y óxido de aluminio $\left(\mathrm{Al}_{2} \mathrm{O}_{3}\right)$. El resto contiene óxido de hierro $\left(\mathrm{Fe}_{2} \mathrm{O}_{3}\right)$ y otros óxidos. La influencia de la proporción del óxido de calcio reactivo es despreciable para el endurecimiento. El contenido de dióxido de silicio reactivo no debe ser menor del 25 \% en masa", y de forma específica de este otro modo:

- Puzolana natural (P): "Las puzolanas naturales son normalmente materiales de origen volcánico o rocas con composición química y mineralógica adecuadas",

- Puzolana natural calcinada (Q): "Las puzolanas naturales calcinadas son de origen volcánico, arcillas, pizarras o rocas sedimentarias activadas por tratamiento térmico",

- Cenizas volantes (V, W): "Las cenizas volantes se obtienen por precipitación electrostática o mecánica de partículas pulverulentas arrastradas por los flujos gaseosos de hornos alimentados con carbón pulverizado. Y para su definición, véase más adelante todo lo escrito al respecto en la norma UNE-EN 450-1",

- Ceniza volante silícea (V): "La ceniza volante silícea es un polvo fino, de partículas esféricas en su mayoría, que tiene propiedades puzolánicas. Consta esencialmente de dióxido de silicio reactivo $\left(\mathrm{SiO}_{2}\right)$ y de óxido de aluminio $\left(\mathrm{Al}_{2} \mathrm{O}_{3}\right)$. El resto contiene óxido de hierro $\left(\mathrm{Fe}_{2} \mathrm{O}_{3}\right)$ y otros compuestos. La proporción de óxido de calcio reactivo $(\mathrm{CaO})$ debe ser menor del 10,0 \% en masa, y el contenido de óxido de calcio libre, determinado según el método descrito en la Norma UNE EN 451-2, no debe exceder del 1,0\% en masa. También es aceptable la ceniza volante con un contenido de óxido de calcio libre superior al 1,0\% en masa pero inferior al 2,5\% en masa, con la condición de que el requisito de expansión (estabilidad de volumen) no sobrepase los $10 \mathrm{~mm}$ cuando se ensaye de acuerdo con la Norma EN 196-3, utilizando una mezcla de un $30 \%$ en masa de ceniza volante silícea y un $70 \%$ en masa de un cemento CEM I conforme con la Norma UNE EN 197-1. El contenido de dióxido de silicio reactivo no debe ser inferior al $25 \%$ en masa."

- Ceniza volante calcárea (W): "La ceniza volante calcárea es un polvo fino que tiene propiedades hidráulicas y/o puzolánicas. Consta esencialmente de óxido de calcio reactivo (CaO), dióxido de silicio reactivo $\left(\mathrm{SiO}_{2}\right)$ y óxido de aluminio $\left(\mathrm{Al}_{2} \mathrm{O}_{3}\right)$. El resto contiene óxido de hierro $\left(\mathrm{Fe}_{2} \mathrm{O}_{3}\right)$ y otros 
compuestos. La proporción de óxido de calcio reactivo no debe ser menor del 10,0 \% en masa. La ceniza volante calcárea que contenga entre el 10,0 \% y el 15,0 \% en masa de óxido de calcio reactivo debe tener un contenido no inferior al $25,0 \%$ en masa de dióxido de silicio reactivo."

Por otra parte, la norma UNE-EN 450-1 define las cenizas volantes de siguiente manera: "Es un polvo fino de partículas principalmente de forma esférica y cristalina, procedentes de la combustión de carbón pulverizado, las cuales poseen propiedades puzolánicas y que principalmente están compuestas de $\mathrm{SiO}_{2}$ y $\mathrm{Al}_{2} \mathrm{O}_{3}$. El contenido de sílice reactiva, definida y determinada según la norma UNE EN-197-1, supone al menos $25 \%$ de su masa".

Asimismo, la norma UNE-EN 13263-1, titulada "Humo de sílice para hormigón. Parte 1: Definiciones, requisitos y criterios de conformidad", define el humo de sílice del siguiente modo: "Partículas muy finas de dióxido de silicio amorfo recogidas como subproducto del proceso de fundición utilizado para la producción de silicio metal y aleaciones de ferrosilicio".

Finalmente, la Instrucción RC-16 les proporciona a las puzolanas prácticamente la misma denominación como en el caso de la norma UNE EN 197-1.

\section{I.2.4.4.- Clasificación de las adiciones puzolánicas por su carácter químico.}

En la investigación que realizó Rahhal, (2002), se reafirmó, una vez más, la complejidad de clasificar y catalogar las puzolanas en función de sus contenidos totales de óxidos y, en definitiva, en función de su composición química, al considerarla insuficiente para la caracterización de su actividad, pero indicando, no obstante, que la composición química de su parte vítrea y/o amorfa era la más apropiada para dicho fin clasificador y/o catalogador, $\mathrm{y}$, por tanto, para su empleo y adecuada dosificación en hormigones, morteros y pastas de cemento. Esta indicación no era más que el reflejo fiel de criterio que primero adoptó Calleja, $(1969 ; 1988)$ para caracterizar las puzolanas naturales nada más, en función del comportamiento de su parte activa (sus óxidos ácidos más abundantes: $\mathrm{SiO}_{2}, \mathrm{Al}_{2} \mathrm{O}_{3}$ y $\mathrm{Fe}_{2} \mathrm{O}_{3}$ ) frente a la cal, a los que denominó "factores hidráulicos", puesto que la reacción puzolánica consiste en la fijación química del hidróxido de calcio por tales componentes ácidos.

Sin embargo, dicha clasificación no logró ser satisfactoria cuando de lo que se trataba era de predecir además, la durabilidad química que las adiciones puzolánicas podrían llegarle a inferir al CP al que reemplacen parcialmente, ya fuera éste CPO o CPRS. Lo que justificó que, años más tarde, Talero, (1986) propusiera otra clasificación y catalogación muy diferente, con base en los resultados y conclusiones de sus investigaciones, la cual y como se ha mencionado antes, estaba basada en su carácter químico, fruto de sus contenidos de $\mathrm{SiO}_{2}{ }^{\mathrm{r}-}$ y $\mathrm{Al}_{2} \mathrm{O}_{3}{ }^{\mathrm{r}-}$ especialmente, y, por consiguiente, del resultado de su respectivo comportamiento frente al ataque de los sulfatos, podía llegar a ser incluso totalmente contrario u opuesto entre sí. Puesto que o lo impedían o al menos lo dificultaban (caso de las diatomeas, el humo de sílice, la nanosílice y similares), o, por el contrario, lo facilitaban en grado sumo (caso del metacaolín, las arcillas activadas, los esquistos calcinados, los inquemados de los lodos de papeleras, y similares), respectivamente.

De hecho que con su presencia podía llegar a producirse el fenómeno que Talero, (1986) denominó "ataque rápido del yeso" al hormigón, en razón de su extremada rapidez e intensidad en generarse, desarrollarse y producirse. Además, dicha clasificación o catalogación era aplicable a 
todos los tipos de puzolanas de cualquier origen, natural y artificial. De aquí que, en buena lógica, dicho autor propusiera clasificarlas o catalogarlas, independientemente de por su origen, en las siguientes familias o gamas: puzolanas con carácter químico alumínico o silícico, y mezclas aleatorias entre ambos caracteres químicos extremos, en las cuales imperará siempre el carácter químico alumínico sobre el silícico o al contrario, es decir, su carácter químico será alumínico-silícico o silícicoalumínico, y sin que por ello se pueda deducir sin más del primero de ellos, el alumínico-silícico, que el contenido de $\mathrm{Al}_{2} \mathrm{O}_{3}{ }^{\mathrm{r}-}$ de la puzolana tiene que ser necesaria y obligatoriamente mayor que el de $\mathrm{SiO}_{2}{ }^{\mathrm{r}}$, asi como también pueda haber alguna familia más cuyo carácter químico puede ser silícicoférrico-alumínico, en razón de su apreciable contenido de $\mathrm{Fe}_{2} \mathrm{O}_{3}$, como es el caso de la propia puzolana natural de Olot (Gerona) o de Almagro (Ciudad Real).

Por último y si, a pesar de lo anterior, existiera aún alguna duda sobre el acierto que dicha clasificación o catalogación de las puzolanas de cualquier origen, natural y artificial, supuso para el avance en el conocimiento del comportamiento de las adiciones puzolánicas pero sobre todo, de la durabilidad química que pueden llegarle a conferir, en cantidad adecuada, a cada $\mathrm{CP}$, las investigaciones ulteriores que le dirigió también sobre ataque de los sulfatos a Martín-Luengo, (1997) a Mejía, (1997) sobre el comportamiento de las mismas puzolanas naturales y artificiales, pero esta vez, frente al ataque de los cloruros, seguidamente a Rahhal (2002) y Pedrajas (2016) sobre el comportamiento de esas mismas puzolanas en el calor de hidratación desprendido a edades iniciales y el comportamiento reológico de las mismas a las mismas edades pero, sobre todo, esta investigación, realizada también al efecto con las mismas puzolanas naturales y artificiales, vendrían a ratificarla de nuevo.

Por consiguiente, y de acuerdo con dicha acertada propuesta clasificatoria de Talero, todas las puzolanas naturales y artificiales de bajo contenido en $\mathrm{CaO}$, consideradas como un conjunto heterogéneo pero indivisible o conjunto "disjunto", pueden clasificarse, independientemente de por su origen, por su composición química reactiva, cuali- y cuantitativa y estructural, pero sobre todo, según su comportamiento frente al ataque del yeso (sulfatos), por un lado, y de las sales de deshielo (cloruros), por otro, de sus cementos de mezcla de los que formen parte. Lo que permitió clasificarlas a todas en los siguientes grupos o familias o gamas, a saber:

- Una gama de naturaleza silícea (Calleja, 1969), y de carácter químico silícico (Talero, 1986): tales como el residuo inquemado de la incineración adecuada de la cáscara y la paja del arroz y del bagazo de la caña de azúcar, de origen artificial, y diatomeas, ópalo, gilópalo, sílex, calcedonia, pedernal, etc., de origen natural.

$\mathrm{Su}$ contenido en sílice reactiva, $\mathrm{SiO}_{2}{ }^{\mathrm{r}}$, es elevado, lo que aumenta las resistencias sulfáticas del CPO con el que se mezclen, en cantidad y curado hídrico adecuados, pero disminuye sus resistencias mecánicas y su resistencia a la corrosión electroquímica de las armaduras de su hormigón armado, excepto el humo de sílice, el cual, por contra, las eleva todas, en primer lugar, físicamente, merced a su muy pequeño tamaño medio de partícula y, en segundo lugar, químicamente, merced a la muy elevada, temprana y rápida actividad puzolánica que desarrolla reaccionando a la par con los iones $\mathrm{Ca}^{2+} \mathrm{y}$ los $\mathrm{OH}^{-}$de la portlandita, o mejor quizás y para ser más exactos, físico-químicamente, pero teniendo siempre el aspecto físico prioridad. Lo que le permite generar, por tanto, una pasta cementante muy densa, merced a las notables cantidades de geles C-S-H, que origina con mucha rapidez, más tarde transformados en tobermoritas, y grupos silanol, $\mathrm{Si}-\mathrm{OH}$, que tras convertirse a continuación 
en ácido silícico, reaccionan también con más portlandita para originar más geles C-S-H aún. En esta Tesis Doctoral, esta familia de puzolanas no ha quedado representada por el propio objetivo de la misma. Los resultados que puedan obtenerse con estas dos puzolanas no serían de interés, o mejor dicho trivales, de acuerdo con el carácter químico de éstas (Talero, 1986).

- Una gama de naturaleza silícea y aluminosa (Calleja, 1969), y de carácter químico alumínico (Talero, 1986), porque su contenido de alúmina reactiva, $\mathrm{Al}_{2} \mathrm{O}_{3}{ }^{\mathrm{r}-}$, es elevado y muy decisivo en cuanto a su perjudicial influencia en la resistencia sulfática del CP con el que se mezclen, a pesar incluso, de que éste sea de elevada resistencia sulfática. Por el contrario, en ausencia de sulfatos esta gama de puzolanas eleva considerablemente las resistencias mecánicas, especialmente a edades muy tempranas, y, además, impiden o al menos dificultan el ataque de los cloruros a las armaduras del hormigón armado: primero, químicamente (por formación de sal de Friedel, que, a diferencia de la ettringita y la Fase AFm, no es expansiva), y después, físicamente, o mejor quizás y para ser más exactos también, químico-físicamente, pero teniendo siempre el aspecto químico prioridad. En esta Tesis Doctoral esta familia de puzolanas ha estado representada por el metacaolín M.

- Otra gama de naturaleza silícea y aluminosa también (Calleja, 1969), de carácter químico silícico-alumínico (Talero, 1986), donde el carácter químico silícico de la puzolana supera al alumínico. En esta Tesis Doctoral, esta familia de puzolanas ha estado representada por la puzolana natural de Almagro (Ciudad Real), A.

- Una gama de naturaleza silícea y aluminosa también (Calleja, 1969), de carácter químico alumínico-silícico (Talero, 1986), porque el carácter químico alumínico de la puzolana supera al silícico. En esta Tesis Doctoral, esta familia de puzolanas ha estado representada por la puzolana natural de las Islas Canarias, C, así como también, la ceniza volante CV10.

- Una gama de naturaleza silícea y aluminosa también (Calleja, 1969), de carácter químico silícico-férrico-alumínico (Talero, 1986), caracterizada por su mayor contenido de $\mathrm{SiO}_{2}{ }^{\mathrm{r}}$ respecto al de $\mathrm{Al}_{2} \mathrm{O}_{3}{ }^{r-}$, pero sin dejar por ello de lado esta vez el contenido de óxido de hierro (III) reactivo, $\mathrm{Fe}_{2} \mathrm{O}_{3}{ }^{\mathrm{r}}$. En esta Tesis Doctoral, esta familia de puzolanas ha estado representada por la puzolana natural de Olot (Gerona), O, y la ceniza volante CV19.

\section{I.2.5.- El origen de la nomenclatura aplicada para los componentes reactivos/activos de las puzolanas $\left(\mathrm{SiO}_{2}{ }^{r-}, \mathrm{Al}_{2} \mathrm{O}_{3^{r-}}\right.$ y $\left.\mathrm{Fe}_{2} \mathrm{O}_{3}{ }^{r-}\right)$.}

Talero, (1986) mediante la lectura oficial de su Tesis Doctoral titulada: "Contribución al Estudio Analítico y Físico-Químico del Sistema: Cementos Puzolánicos-Yeso-Agua", se pudieron clasificar las puzolanas, como se acaba de ver, por vez primera, por su actividad puzolánica relacionada con la composición química de sus partes reactivas/activas, constitutivas de su fracción vítrea y/o amorfa, la cual es la que conforma de manera mayoritaria estos materiales cementíceos, a diferencia de la cristalina que es la minoritaria y menos o nada reactiva, en igualdad de condiciones, excepto las zeolitas.

Aunque la definición y precisión del estado físico, ni la cualificación energética ni físicoquímica de dichas partes reactivas $\left(\mathrm{SiO}_{2}{ }^{\mathrm{r}-}\right.$ y $\mathrm{SiO}_{2} \mathrm{a}^{\mathrm{a}}, \mathrm{Al}_{2} \mathrm{O}_{3}{ }^{\mathrm{r}-} \mathrm{y} \mathrm{Al}_{2} \mathrm{O}_{3^{\mathrm{a}}}, \mathrm{Fe}_{2} \mathrm{O}_{3^{\mathrm{r}-}}$ y $\left.\mathrm{Fe}_{2} \mathrm{O}_{3^{\mathrm{a}}}\right)$ no fue entonces, en realidad, el objetivo de dicha Tesis Doctoral, sino determinar el comportamiento de la $\mathrm{SiO}_{2}{ }^{\mathrm{r}-\mathrm{y}}$ la 
$\mathrm{Al}_{2} \mathrm{O}_{3}{ }^{\mathrm{r}-}$ especialmente, de las puzolanas naturales y artificiales frente al ataque de los sulfatos, para poder obtener así de él la nueva denominación y terminología necesaria que, en lo sucesivo, debería adscribírsele a todas y cada una de ellas (aunque no se atuviera a las reglas de la formulación química de la IUPAC), y no la que se le venía adscribiendo hasta entonces y aún ahora, que es por su origen, natural o artificial nada más, para de dicha caracterización sulfática, poder deducir también en 28 días, el más que probable comportamiento de su cemento de mezcla con $\mathrm{CP}$, frente al ataque de un medio agresivo o no determinado, que era, en suma, lo más importante, desde el punto de vista técnico, es decir, su prestación técnica y de durabilidad. Puesto que, no sólo hasta esa fecha, sino también hasta hoy mismo, las especificaciones químicas, físicas y mecánicas existentes y que obligatoriamente han de cumplir, únicamente permiten dilucidar su aceptación o rechazo nada más, para poder ser añadidas a los $\mathrm{CP}$, en fábrica, y/o a los hormigones y morteros, en planta.

Más tarde, Moya y cols. (1988) realizaron una investigación, mediante la cual demostraron con la técnica de RMN-MAS $\left({ }^{27} \mathrm{Al}\right.$ y $\left.{ }^{29} \mathrm{Si}\right)$, la presencia de $\mathrm{Al}$ tetra- y penta-coordinado en la caolinita deshidroxilada a diferentes regímenes de temperatura, hasta la formación de mullita. Consecuentemente, lo que Talero denominó como alúmina reactiva, y representó como $\mathrm{Al}_{2} \mathrm{O}_{3}{ }^{\mathrm{r}}$, se correspondía, a partir de entonces, con la alúmina tetra- o penta-coordinada, o alúmina amorfa del metacaolín, la cual es diferente físicamente de la de las demás puzolanas tales como las cenizas volantes y otros vidrios volcánicos también con propiedades puzolánicas, en los que dichos tipos de alúminas aparecen mayoritariamente en estado vítreo, o vítreo y amorfo a la par, lo que se traduce en que poseen una cierta dureza o resistencia mecánica a pesar de su fragilidad al impacto. En cambio, el estado físico-químico de la alúmina reactiva del metacaolín es mayoritariamente amorfo, es decir, no posee resistencia mecánica alguna, en razón de ser por su origen, el caolín, un material suelto, particulado y pulverulento.

Por último y a propósito de este tema, cabe mencionar aquí también, que ambas investigaciones citadas han sido complementadas recientemente por Trusilewicz, y cols. (2012), con el estudio de otro caolín semejante, que previamente había sido transformado también térmicamente en metacaolín, lo que permitió conferirle un $96 \%$ de ruptura a la estructura cristalina de su roca caolínica original, proporcionándole de este modo, la muy notable actividad puzolánica que posee y lo caracteriza, y que su roca madre, el caolín, no puede poseer nunca bajo ningún concepto en razón de su acusada cristanilidad. Y los resultados de TEM y SAED, obtenidos por Trusilewicz y cols. (2012) han permitido a sus autores poder demostrar también que el Al tetra- y/o penta-coordinado del metacaolín, le conforma, en realidad, una estructura metaestable y similar, en cierto modo, a la fase cristalina de la $\chi$-alúmina. Por otro lado, dichos autores han concluido además, que el particular carácter químico de una adición puzolánica dependerá no solamente de la historia físico-química y geológica (en el caso de las puzolanas naturales nada más) del material de partida, sino también, de la distribución de los átomos y de la correlación de su respectiva coordinación, puesto que la relación cuantitativa de $\mathrm{SiO}_{2}{ }^{\mathrm{r}} / \mathrm{Al}_{2} \mathrm{O}_{3^{\mathrm{r}}}$ es también sustancial para conferirle dicho carácter químico.

\section{I.2.6.- Adiciones puzolánicas más comunes que se utilizan habitualmente como sustitución parcial del cemento Portland.}




\section{I.2.6.1.- Metacaolines.}

El metacaolín se obtiene por calentamiento adecuado del caolín o caolinita.

- Generalidades geológicas del caolín

El caolín pertenece al grupo de minerales que componen las arcillas o rocas arcillosas, las cuales se denominan también "pelíticas" y, en general "lutitas" siendo rocas detríticas y estando formadas por partículas de tamaño menor de $0.05 \mathrm{~mm}$. Los denominados como "minerales de la arcilla", la caolinita, la illita y la montmorillonita, poseen una estructura cristalina diferente aunque formada por estratos sucesivos de tetraedros de sílice y octaedros de alúmina, formando estos últimos aproximadamente un tercio de su composición. En general, estos minerales son capaces de absorber cantidades variables de agua, volviéndose entonces plásticos, lo que constituye una de sus propiedades físicas más notables, tornándose, en cambio, compactos por desecación.

En general, se puede decir que las rocas arcillosas son el primer resultado de la alteración superficial de otras rocas pre-existentes, generalmente rocas ricas en feldespatos que contenían minerales alumínicos en cantidades considerables. Dependiendo del lugar donde se depositen, ya sea el de su propio origen o diferente, dan lugar a los depósitos de arcillas "residuales" o "sedimentarias", respectivamente, siendo este último caso una precipitación de partículas coloidales en suspensión acuosa, la cual se puede acelerar considerablemente por la presencia en la misma de sales disueltas.

\section{- Propiedades físico-químicas del metacaolín}

La composición química de estas rocas es muy compleja, predominando en ellas el $\mathrm{Si}^{4+}$, bien formando parte de los minerales de la arcilla, bien como cuarzo detrítico, o de diversos silicatos detríticos. Asimismo, el catión $\mathrm{Al}^{3+}$, forma también parte principal de los minerales de la arcilla así como de los feldespatos detríticos originarios.

La relación S/A es un índice característico de los minerales de la arcilla y depende del "grado de descomposición" de los feldespatos originales, lo que, a su vez, es un índice del "grado de madurez" de la lutita.

Dependiendo del tratamiento térmico programado para una arcilla, se obtiene una determinada "metamorfosis" cristalográfica que puede dar lugar a nuevos compuestos, de diferente cristanilidad, conservando, en cierto modo, su estructura cristalográfica original, caso del caolín (Trusilewicz y cols. 2012) o no, para otras arcillas de este grupo.

El caolín, $2 \mathrm{SiO}_{2} \cdot \mathrm{Al}_{2} \mathrm{O}_{3} \cdot 2 \mathrm{H}_{2} \mathrm{O}, \mathrm{S}_{2} \mathrm{AH}_{2}$, sometido a un calentamiento adecuado se puede trasformar en metacaolín o metacaolínita o metanakrita o anhídrido caolínico, $2 \mathrm{SiO}_{2} \cdot \mathrm{Al}_{2} \mathrm{O}_{3}, \mathrm{~S}_{2} \mathrm{~A}$, el cual es un producto metaestable e intermedio artificial resultante de la deshidroxilación (pérdida de grupos $\mathrm{OH}^{-}$de la red cristalina del caolín) térmica adecuada (Grimshaw, 1971) (calentamiento en el rango de temperaturas 600 a $800^{\circ} \mathrm{C}$ ) de esta arcilla (Trusilewicz y cols. 2012). La mencionada etapa de deshidroxilación, siendo parte de la descomposición térmica del caolín en condiciones programadas, empieza por lo general a $550^{\circ} \mathrm{C}$, manteniéndose incluso a $900^{\circ} \mathrm{C}$, que es cuando la estructura cristalina sufre un colapso y, al subir aún más la temperatura, empieza a formarse la así llamada pseudo-mullita. Obtenido de esta manera el metacaolín, dependiendo de las condiciones de deshidroxilación aplicadas, y al ser un material puzolánico, puede mostrar cambios de su solubilidad, por ejemplo en ácidos (HF, HCl), (López Ruiz, 1955a). 
En síntesis, la descomposición térmica del caolín empieza a $120^{\circ} \mathrm{C}$ con la pérdida de humedad (el agua higroscópica, coloidal y de hidratación, y la físicamente adsorbida, o absorbida en poros del material). Después y a medida que sube la temperatura del proceso, los grupos hidróxilo integrantes de la red cristalina del caolín empiezan a separarse de la misma (etapa de deshidroxilación), debido al aumento de la energía de vibración que se les confiere, alcanzando el valor o grado de agitación térmica suficiente para poderse unir con un protón cercano y formar una molécula de agua para finalmente separarse de la estructura cristalina, lo que puede representarse por la siguiente reacción química (r16):

$$
-\mathrm{OH}^{-}+-\mathrm{OH}^{-} \leftrightarrow \mathrm{H}_{2} \mathrm{O}+\mathrm{O}_{2}{ }^{-}
$$

En el caso de que el grupo $\mathrm{OH}^{-}$pudiera unirse con el protón $\mathrm{H}^{+}$más lejano, podrían producirse más deformaciones en la estructura cristalina del material resultante (metacaolín), lo que iría en beneficio de su meta-estabilidad. Finalmente y como Trusilewicz y cols. (2012) confirmaron, el metacaolín resultante adopta una estructura de tipo transicional, cercana a la estructura metaestable de la $\chi$-alúmina, la cual, no obstante, continua conservando la "memoria cristalina" del caolín originario. Lo que las investigaciones anteriores de Brindley y col. (1959) ya habían indicado que la estructura del metacaolín mantiene las posiciones reticulares respectivas de sus cationes $\mathrm{Al}^{3+} \mathrm{y} \mathrm{Si}^{4+}$ aunque coordinadas con el oxigeno de manera distinta. En cambio más tarde, (Grimshaw, 1971) se tomó parte por una disposición específica del oxígeno donde éste está unido de manera aleatoria con los cationes $\mathrm{Al}^{3+}$ y $\mathrm{Si}^{4+}$, considerando la migración del protón $\mathrm{H}^{+}$en busca de los grupos hidróxilo $\mathrm{OH}^{-}$como esencial para la forma estructural final. Y de manera complementaria, se postuló una elevada concentración de defectos reticulares aparejados con la coordinación tetraédrica del aluminio, por lo que no se puede adscribir una estructura fija, determinada y definida a dicha fase.

No obstante, en lo que sí han estado de acuerdo todos los autores ha sido en que la fase metaestable del metacaolín conserva la orientación cristalográfica original de su caolinita matriz en un grado considerable, es decir, posee, como se acaba de decir, "memoria cristalina", que en terminología mineralógica recibe el nombre de "transformación topológica" o "reacción topoquímica", en cuya estructura los $\mathrm{Al}$ y $\mathrm{Si}$ ocupan posiciones reticulares de tal modo que aquella es marginalmente diferente que la que debiera ser para la $\gamma-\mathrm{Al}_{2} \mathrm{O}_{3}$, lo que había sido propuesto ya antes por Brindley y col. (1959), véase la Tabla I-13.

TABLA I-13.- TRANSFORMACIONES TÉRMICAS DE CAOLÍN.

\begin{tabular}{ccc}
\hline Caolín & Metacaolín & Espinela $980^{\circ} \mathrm{C}$ \\
\hline $6 \mathrm{O}^{2-}$ & $6 \mathrm{O}^{2-}$ & $6 \mathrm{O}^{2-}$ \\
$4 \mathrm{Si}^{4+}$ & $4 \mathrm{Si}^{4+}$ & $3 \mathrm{Si}^{4+}$ \\
$2(\mathrm{OH})^{1-}+4 \mathrm{O}^{2-} \rightarrow 6 \mathrm{O}^{2-}$ & $\rightarrow$ & $6 \mathrm{O}^{2-}+2 \mathrm{Cristobalita}^{2-}$ \\
$4 \mathrm{Al}^{3+}$ & $4 \mathrm{Al}^{3+}$ & $4 \mathrm{Al}^{3+}$ \\
$6(\mathrm{OH})^{1-}$ & $2 \mathrm{O}^{2-}$ & - \\
\hline
\end{tabular}

Dichos autores afirmaron que la espinela se desarrolla a los $980^{\circ} \mathrm{C}$, pero que su efecto cristalino puede apreciarse incluso antes, en el caso de que la velocidad de calentamiento fuera lenta. En caso contrario, se formaría directamente la pseudo-mullita, debido a la migración catiónica, conservándose por ello la orientación de las capas. 
No obstante, Jaffee (Grimshaw, 1971) aceptó la idea de que el metacaolín posee enlaces fijos $\mathrm{Si}-\mathrm{O}-\mathrm{Al}$ aunque mucho más débiles que los del caolín original, de aquí que el ion aluminio pueda lixiviarse (ataques ácido-básicos diversos) completamente de esta fase.

En definitiva, la pérdida del agua del caolín en la etapa de deshidroxilación (entre $600-800^{\circ} \mathrm{C}$, principalmente) produce una fuerte dislocación o segregación de los átomos en sus moléculas, sin que éstas pierdan su "fisonomía" de la estructura original, provocando así una "modificación amorfa" de la arcilla o "metafase" del caolín (similar a la metaestable de la $\chi$-alúmina (Trusilewicz y cols. 2012) que se denomina "metacaolín". La prórroga del calentamiento a temperaturas mayores de $800^{\circ} \mathrm{C}$ provoca que la energía térmica rompa los ya debilitados enlaces $\mathrm{Si}-\mathrm{O}-\mathrm{Al}$, pudiendo dar lugar a la formación de $\gamma$-alúmina en cantidades variables dependiendo del tiempo y velocidad del calentamiento programado. Según investigaciones de Jaffee (Grimshaw, 1971), la máxima activación del proceso de trasformación se consigue en muestras sometidas a ciclos rápidos de calentamiento, gracias a un nuevo reordenamiento de los enlaces en cuestión con nuevos ángulos, dando a estas temperaturas $\left(>920^{\circ} \mathrm{C}\right)$ un metacaolín muy inestable y posibilitando de este modo la formación de la pseudo-mullita.

Finalmente y de acuerdo con todo lo anterior, la estructura del metacaolín se puede considerar, por tanto y sin más, como una combinación o unión débil entre la sílice y la alúmina.

- Aspectos científico-técnicos del metacaolín: su actividad puzolánica y mecanismo de endurecimiento subsiguiente.

La fase del proceso del tratamiento térmico anteriormente descrito que justifica la actividad puzolánica del metacaolín es la etapa de deshidroxilación, en la que se suele eliminar toda el agua de "cristalización", estable a $105{ }^{\circ} \mathrm{C}$, en el rango de temperaturas entre 500 y $800{ }^{\circ} \mathrm{C}$. No obstante, dependiendo de la temperatura programada y también de la duración del ciclo de calentamiento, se obtendrán metacaolines de diferentes grados de actividad puzolánica. Se ha demostrado (Trusilewicz y cols. 2012)] que la "capacidad de fijación" de la cal (químicamente) por el metacaolín en un medio húmedo varía en función de la temperatura máxima empleada pero comprendida en el rango $500-800^{\circ} \mathrm{C}$. Por otro lado, la "capacidad de absorción" (físicamente) máxima es la que se produce a la temperatura de $500^{\circ} \mathrm{C}$. En cambio, por encima de $900{ }^{\circ} \mathrm{C}$ se origina un nuevo material distinto del metacaolín, ya que tiene escasa actividad puzolánica, por lo que al mezclarlo con cal apagada y agua no muestra ni desarrolla propiedad hidráulica alguna y la puzolánica es significativamente más pequeña. Este nuevo material formado es la pre-mullita o la mullita incluso (López Ruiz, 1955a; 1955b), la cual se suele utilizar como material refractario para los hornos, entre otros usos, pero no para construcción propiamente como se utiliza el metacaolín en particular, y, en general, las arcillas activadas térmicamente.

Por otra parte, la actividad puzolánica que muestra el metacaolín frente a la cal apagada puede dar lugar a múltiples compuestos, entre los que se encuentran, aluminatos y silicatos de calcio hidratados. De aquí que Turriziani y col. (1956), tras unos estudios llevados a cabo, utilizando las técnicas analíticas de DRX y TG, confirmaron, con mezclas de metacaolín y cal apagada, la presencia del silicato tipo I (1-1.5 $\mathrm{CaO} \cdot \mathrm{SiO}_{2} \cdot \mathrm{H}_{2} \mathrm{O}$ ) y del compuesto de Strätling (sílico-aluminato de calcio hidratado, $\left.2 \mathrm{CaO} \cdot \mathrm{Al}_{2} \mathrm{O}_{3} \cdot \mathrm{SiO}_{2} \cdot \mathrm{H}_{2} \mathrm{O}\right)$. Además, se demostró también que en determinadas condiciones de temperatura $\left(42{ }^{\circ} \mathrm{C}\right)$ se puede formar, y con preferencia, el aluminato tricálcico hexahidratado, $\mathrm{C}_{3} \mathrm{AH}_{6}$, adoptando éste la forma cúbica y pudiéndose transformar bajo ciertas condiciones (el contenido en calcio en el medio superando el 55 \% así como la existencia de la 
COMPORTAMIENTO SULFÁTICO Y MECÁNICO-RESISTENTE DE CEMENTOS PORTLAND CON ELEVADOS

cantidad suficiente de yeso) en ettringita, $\mathrm{Ca}_{6} \mathrm{Al}_{2}\left(\mathrm{SO}_{4}\right)_{3}(\mathrm{OH})_{12} \cdot 26 \mathrm{H}_{2} \mathrm{O}$. Por otra parte, Ormsley y col. (1966) gracias a un estudio del sistema "caolín-cal-agua", determinaron únicamente la presencia de C-S-H (I) y/o C-S-H (II), coincidentes con los que pueden provenir de la hidratación del CP, y siendo los causantes, según los autores, del aumento de las resistencias mecánicas de los mismos.

Calleja, (1969; 1988) anotó que las hipótesis de los distintos investigadores oscilan entre admitir la formación de un aluminato de calcio hidratado, la de un silicato de calcio hidratado o la de un sílico-aluminato de calcio hidratado, con o sin carácter zeolítico. No obstante y según dicho autor, los compuestos correspondientes al equilibrio de la reacción química del metacaolín con disolución saturada de $\mathrm{Ca}(\mathrm{OH})_{2}$, son el disilicato tricálcico hidratado $2 \mathrm{SiO}_{2} \cdot 3 \mathrm{CaO}$ aq y el sílicoaluminato bicálcico hidratado $\mathrm{SiO}_{2} \cdot \mathrm{Al}_{2} \mathrm{O}_{3} \cdot 2 \mathrm{CaO}_{a q}$, según el siguiente esquema de reacción (r17):

$2\left(\mathrm{SiO}_{2} \cdot \mathrm{Al}_{2} \mathrm{O}_{3}\right)+7 \mathrm{CaO}+\mathrm{xH}_{2} \mathrm{O}=2\left(\mathrm{SiO}_{2} \cdot \mathrm{Al}_{2} \mathrm{O}_{3} \cdot 2 \mathrm{CaO}\right.$ aq $)+2 \mathrm{SiO}_{2} \cdot 3 \mathrm{CaO}$ aq

Y como conclusión se indicó que la interacción química en medio acuoso, entre las arcillas activadas térmicamente y la cal apagada, es un proceso lento, que se desarrolla además en tres fases que son las siguientes:

- La primera fase en la que se forma una disolución saturada de hidróxido de calcio.

- La segunda fase comprende un proceso de "adsorción" de hidróxido de calcio por la arcilla activada térmicamente (metacaolín).

- La tercera fase consiste en una reacción química entre el metacaolín y el $\mathrm{Ca}(\mathrm{OH})_{2}$ (probablemente con la "adsorbida" al principio), expresada por la reacción química mencionada antes (r17).

La composición química de los productos de la reacción puzolánica con el $\mathrm{Ca}(\mathrm{OH})_{2}$ en medio acuoso, sobre todo, los que contienen alúmina, depende de los siguientes factores:

- la relación global sílice/alúmina de la puzolana,

- el contenido de su parte vítrea, pero referida a la relación sílice/alúmina,

- la presencia o ausencia de álcalis, y en caso de estar éstos presentes, con su proporción en el sistema reaccionante,

- la cantidad de fase líquida,

- la concentración de cal en ella,

- la temperatura, etc.

Cabe destacar que las dos fases alumínicas predominantes son $\mathrm{C}_{4} \mathrm{AH}_{\times}$y $\mathrm{C}_{2} \mathrm{ASH} 8$ (gehlenita). La primera es hexagonal pero a elevada temperatura pasa a $\mathrm{C}_{3} \mathrm{AH}_{6}$ cúbica, y se forma preferentemente a partir de puzolanas con vidrio escaso en alúmina y de zeolitas analcíticas, y en medios muy concentrados en portlandita. Mientras que la segunda se forma con concentraciones de cal menores, aunque finalmente se genera, de una forma $u$ otra, una mezcla de proporciones de una forma u otra en función de la concentración en cal Calleja, (1969; 1988). Así, la formación de $\mathrm{C}_{2} \mathrm{ASH} \mathrm{H}_{8}$ a bajas relaciones agua/puzolana, puede ser debida a una disminución de la concentración de la cal en la fase líquida en tales condiciones, a causa de la fuerte basicidad producida por los álcalis liberados. En el caso del metacaolín, la fase predominante es $\mathrm{C}_{2} \mathrm{ASH}$, aún en presencia de cal en exceso lo que no explica su ausencia en los morteros puzolánicos a temperatura ordinaria, y 
la razón, según el autor, puede ser de tipo físico, por la dificultad de difusión de los iones calcio en un medio con escasa fase líquida muy concentrada en álcalis, lo que impide los procesos normales de disolución y cristalización. También parece formarse el aluminato cúbico $\mathrm{C}_{3} \mathrm{AH}_{6}$ estable a concentraciones de cal de $1.08 \mathrm{~g} / \mathrm{l}$, pues por encima de dichas concentraciones se forma el $\mathrm{C}_{4} \mathrm{AH}_{13}$ pseudo-hexagonal.

Por otra parte, y según los estudios de Murat y cols. (1983) sobre el sistema metacaolín$\mathrm{Ca}(\mathrm{OH}) 2$-agua en distintas condiciones, relacionadas todas ellas con las características del cemento tales como el curado, la relación agua/conglomerante, la relación metacaolín $/ \mathrm{Ca}(\mathrm{OH}) 2$, la posibilidad de utilizar arena y su influencia en el proceso de fraguado y endurecimiento y la subsiguiente ganancia de resistencias mecánicas, y aplicando las técnicas de DRX y TG para identificar los hidratos formados, se confirmó la presencia de: $\mathrm{C}_{2} \mathrm{ASH} 8$ (gehlenita) y C-S-H, con pequeñas cantidades de $\mathrm{C}_{4} \mathrm{AH}_{13}$. También dichos autores propusieron el siguiente esquema de las reacciones de hidratación (r18, r19, r20) "simultáneas" (en nomenclatura de cementos):

$$
\mathrm{AS}_{2}+6 \mathrm{CH}+9 \mathrm{H}=\mathrm{C}_{4} \mathrm{AH}_{13}+2 \mathrm{CSH}
$$

(metacaolínita)+(cal)+(agua)=(aluminato tetracálcico hidratado)+(tobermorita) C-S-H

$$
\mathrm{AS}_{2}+5 \mathrm{CH}+3 \mathrm{H}=\mathrm{C}_{3} \mathrm{AH}_{6}+2 \mathrm{CSH}
$$

(metacaolínita)+(cal)+(agua)=(aluminato tricálcico hidratado)+(tobermorita) C-S-H

$$
\mathrm{AS}_{2}+3 \mathrm{CH}+6 \mathrm{H}=\mathrm{C}_{2} \mathrm{AH}_{8}+\mathrm{CSH}
$$

$($ metacaolínita $)+($ cal $)+($ agua $)=($ gehlenita hidratada $)+($ tobermorita $)$ C-S-H

La relación en peso de $\mathrm{AS}_{2} / \mathrm{CH}$ ha sido respectivamente $0.5,0.6$ y 1.0, con la necesidad de 1 mol de portlandita por cada mol de metacaolínita para alcanzar el $100 \%$ de hidratación teórica, originando todos los hidratos mencionados (con la excepción para la tobermorita que pudiera ser del tipo I o II (Taylor, 1997). No obstante, siempre se deben de tener en consideración para los resultados finales tanto el tamaño de partícula, como el estado de cristalización y sus posibles impurezas.

Por otro lado, estudiado el curso de la reacción química del caolín activado (metacaolín), ésta indicó que, tanto su estructura como la composición de las partes reactivas son igual de importantes, pese a que la relación sílice/alúmina es mayor para el metacaolín que lo es para la gehlenita $\left(\mathrm{C}_{2} \mathrm{ASH}\right)$, la cual se origina como producto de reacción predominante por disponer de alúmina en condiciones de reacción, incluso cuando existiera exceso de portlandita en el medio acuoso. Aun así, estas consideraciones no explican por qué no se forma dicho producto en morteros curados a temperatura ambiente, lo cual bien pudiera estar relacionado con el mecanismo implicado en su formación.

Pero centrándose ahora en la parte aluminica, $\mathrm{Al}_{2} \mathrm{O}_{3}{ }^{\mathrm{r}}$, del metacaolín (y de todas las puzolanas en general) exclusivamente, parece ser que, según Calleja, al igual que pudiera ocurrir para la parte silícica, $\mathrm{SiO}_{2}{ }^{\mathrm{r}}$, los productos de reacción que se pueden formar dependen en gran parte del contenido de cal en el sistema, es decir, si la cal está en abundancia, se formará $\mathrm{Al}_{2} \mathrm{O}_{3} \cdot 3 \mathrm{CaO}_{a q}$, pero, en caso contrario, se originaría $\mathrm{Al}_{2} \mathrm{O}_{3} \cdot 2 \mathrm{CaO}_{\text {aq }}$ para finalmente transformarse ambos en $\mathrm{Al}_{2} \mathrm{O}_{3} \cdot 3 \mathrm{CaO} \cdot 6 \mathrm{H}_{2} \mathrm{O}$ estable. 
Estas últimas condiciones quedan expuestas a su debido ajuste lo que supuestamente debe ocurrir tras el tratamiento térmico del caolín a $700^{\circ} \mathrm{C}$ durante 2 horas y subsiguiente ataque básico de la portlandita gracias a la reacción puzolánica. Y es que el hecho de la descomposición de su estructura cristalina tras el calentamiento programado, permite pensar en la probable existencia de los "únicos productos resultantes" que refieren Murat y col. (1983), en los cuales los cationes respectivos $\mathrm{Si}^{4+}$ y Al ${ }^{3+}$ se corresponden a formas más o menos conjuntas de $\mathrm{SiO}_{4} \mathrm{H}^{3-}$ y $\mathrm{Al}_{2} \mathrm{O}_{4} \mathrm{H}^{4-}$, respectivamente. Dichas formas necesitarán protones para su neutralización, los cuales les son aportados fácilmente por los cationes $\mathrm{H}^{+}$del agua (rehidratación), y también por cationes alcalinos y/o alcalino-térreos (en este caso, el $\mathrm{Ca}^{2+} \mathrm{del} \mathrm{Ca}(\mathrm{OH})_{2}$ y de la portlandita) cuya fuerza de atracción puede ser de tal grado que acabe separándolas en mayor o menor medida en sus formas cálcicas correspondientes (el mecanismo de la reacción puzolánica).

Algunas de las hipótesis sobre los diversos modos de activación, incluso el básico de la portlandita y actuación cementante subsiguiente mediante la correspondiente fijación de $\mathrm{Ca}(\mathrm{OH})_{2}$ (reacción puzolánica), pueden ser representadas, según Way y col. (1982), por algunas posibles reacciones químicas (r1.21, r1.22 y r1.23) tales como:

$$
\begin{aligned}
& \equiv \mathrm{Si}-\mathrm{O}-\mathrm{Si} \equiv+\mathrm{OH}^{-} \rightarrow \equiv \mathrm{Si}-\mathrm{OH}+{ }^{-} \mathrm{O}-\mathrm{Si} \equiv \\
& \mathrm{n}\left(\equiv \mathrm{Si}-\mathrm{O}_{4}\right)=\mathrm{Al}^{-} \ldots . . \mathrm{M}^{\mathrm{n}+}(\text { alcalino } / \text { alcalinoté rreo })+4 \mathrm{OH}^{-} \rightarrow \mathrm{n}\left(\equiv \mathrm{Si}-\mathrm{O}_{4}{ }^{-}\right)+\mathrm{M}^{\mathrm{n}+}+\mathrm{n}\left[\mathrm{Al}(\mathrm{OH})_{4}\left(\mathrm{H}_{2} \mathrm{O}\right)_{2}\right]^{-} \\
& \left(\equiv \mathrm{Si}-\mathrm{O}_{4}\right)+\mathrm{n}\left[\mathrm{Al}(\mathrm{OH})_{4}\left(\mathrm{H}_{2} \mathrm{O}\right)_{2}\right]^{-}+4 \mathrm{Ca}(\mathrm{OH})_{2}+\mathrm{aq} \rightarrow\left(\equiv \mathrm{Si}-\mathrm{O}_{4}\right) \mathrm{Ca}_{2}+0.5 \mathrm{Ca}_{4} \mathrm{Al}_{2}(\mathrm{OH})_{0.25} \cdot 19 \mathrm{H}_{2} \mathrm{O}+5(\mathrm{OH})^{-}
\end{aligned}
$$

La mencionada no separación individualizada referida (en la red del caolín previamente distorsionada por el calor) de los tetraedros de $\mathrm{Al}^{3+}$ de coordinación 4 (termodinámicamente inestables), también octaedros de coordinación 6 con exceso de carga negativa (igualmente inestables), o bien tetraedros de origen octaédrico, efectuada por ataque básico de la portlandita debe producirse rápidamente, y más aún, cuando en el medio hay presencia de $\mathrm{CaSO}_{4}$, (en forma de anhidrita, hemihidrato o yeso, suficiente para originar ettringita (Talero, 2008, 2009; 2011, Talero y Delgado, 2007). Esta última reacción química se producirá con mucha rapidez en todos los casos de puzolanas naturales y artificiales caracterizados por sus contenidos apreciables de alúmina reactiva, $\mathrm{Al}_{2} \mathrm{O}_{3}{ }^{\mathrm{r}}$, en su composición química.

\section{I.2.6.2.- Cenizas volantes.}

En el año 1835 las fábricas de cemento empezaron a utilizar como combustible el carbón pulverizado, cuyos inquemados habían de tenerse en cuenta en la dosificación adecuada del "crudo" cuya cocción a temperatura apropiada, origina el clínker Portland.

Pero centrándonos en las cenizas volantes como adiciones activas al $\mathrm{CP}$, las más utilizadas de todas son las de las centrales termoeléctricas que emplean carbón pulverizado como combustible, de cuyos inquemados se separan las fracciones más finas - las cenizas volantes-, provenientes de los gases de combustión, por separación mecánica o precipitación electrostática.

Como se ha citado con anterioridad, la norma ASTM C 618 diferencia dos clases de cenizas volantes: las cenizas volantes clase $\mathrm{F}$ y las cenizas volantes clase $\mathrm{C}$. Las clase $\mathrm{F}$ tienen propiedades puzolánicas y proceden de la combustión de carbones antracíticos o bituminosos. En cambio, la 
clase C, además de poseer propiedades puzolánicas, poseen también ciertas propiedades cementíceas, es decir, hidráulicas, y proceden de la combustión de lignitos o carbones subbituminosos. Y según dicha norma, las dos clases de cenizas volantes pueden ser añadidas al hormigón en planta, aunque de diferente manera: las cenizas clase F, puzolánicas nada más, suelen sustituir parcialmente el CP del hormigón, porque al reaccionar con la portlandita de su hidratación generan productos de hidratación semejantes a los del propio $\mathrm{CP}$, aunque de origen puzolánico. En cambio, las cenizas volantes de la clase C, puzolánicas e hidráulicas, suelen adicionarse, en cambio, en sustitución del árido fino del hormigón.

Muchos autores aconsejan la utilización de las cenizas volantes como adición al CP (Dunstan, 1986; Mehta, 1986; Malhotra, 1991), ya que, según ellos, mejoran las prestaciones de los conglomerantes resultantes frente al ataque del anión sulfato, respecto al CP puro. Otros autores, en cambio (Grzymek, 1980), aconsejan su uso por su contenido en sílice reactiva. Por otro lado, Bensted (1988) demostró mediante sus investigaciones, cómo la resistencia de un CP resistente a los sulfatos disminuía al añadirle determinada ceniza volante. Por este motivo, las normas europeas y británicas tales como las UNE EN 206 y BS 8500-1 no permiten el uso de cenizas volantes a cementos Portland resistentes a los sulfatos cuando se requieren elevadas resistencias a los mismos.

También Irassar y cols. (1990; 1991; 1996) demostraron, a escala de laboratorio, que las resistencias sulfáticas de los cementos con las cenizas volantes clase $\mathrm{F}$, ensayados conforme al método Koch y Steinegger (Koch y col. 1960), disminuían apreciablemente por lo que los hormigones fabricados con las mismas sufrieron su degradación después de haber estado expuestos 2 años a aguas agresivas que contenían sulfatos. Además, este efecto negativo se produjo más intensivamente, a medida que el reemplazo de $\mathrm{CP}$ por dichas cenizas volantes fue mayor, por causa, según estos autores, de la mayor acción difusiva capilar de los sulfatos en estos hormigones. Gracias a estas investigaciones, se recomendó no utilizar este tipo de cementos en zonas de aguas sulfáticas que tengan una elevada evaporación y que puedan aumentar, por ello, la concentración de iones sulfato en dichas aguas, lo que provocaría mayor agresividad aún de las mismas.

\section{I.2.6.3.- Puzolanas naturales.}

Las puzolanas naturales son también materiales silíceos o silíceo-aluminosos en naturaleza, que se presentan como rocas o minerales, sin propiedades hidráulicas cementíceas por sí mismas, pero finamente molidas son capaces de reaccionar en medio acuoso y a temperatura ambiente, por medio de sus constituyentes ácidos — sílice y alúmina reactivas, principalmente-, con el hidróxido de calcio como tal o bien en forma de portlandita procedente de la hidratación del CP.

La mayoría de las puzolanas naturales son de origen volcánico y fueron los primeros materiales puzolánicos que empleó el ser humano en la construcción de antiguas estructuras de Egipto, Grecia, Roma y la India. Hace más de 2000 años los romanos utilizaron el material de tufas zeolíticas depositadas en las estribaciones del volcán Vesubio y, en concreto, en Pozzvali (Italia), lugar este al que estos materiales deben su denominación (Ramachandran, 1995).

Todas aquellas aplicaciones tan tempranas de las puzolanas naturales, de las que muchas de ellas, además, han perdurado hasta la fecha, demuestran que, en definitiva, son buenos materiales para fines constructivos. En el planeta tierra se disponen de ellos en la mayoría de 
terrenos post- o volcánicos. Lo que no significa, por otro lado, que su procedencia sea garantía de una buena actividad puzolánica, la cual debe de ser siempre evaluada por los métodos normalizados correspondientes para dicho propósito.

Estas puzolanas naturales son, por tanto, de origen volcánico, y se forman mediante los procesos eruptivos cuando el magma se ha enfriado bruscamente, estando constituidas principalmente por aluminatos y silicatos que muestran una textura amorfa y/o vítrea $y$, en definitiva, de estructura desordenada o no cristalina. En la mayoría de los casos, los materiales generados de este modo adquieren además una estructura porosa, lo que les confiere una superficie específica elevada.

Otras puzolanas naturales de tipo arcilloso presentan, por lo general, poca actividad puzolánica, sin embargo, algunas arcillas crudas y erosionadas del grupo de las esmectitas (filosilicatos) que se dividen en dos subgrupos: las dioctaédricas (montmorillonita, beidellita, nontronita) y las trioctaédricas (estevensita, hectorita, saponita), y que en España pueden encontrarse en Almería, muestran cierta actividad puzolánica, aunque no muy elevada, debido a la reacción de la cal con los silicatos de los tetraedros de las diferentes capas que contienen. Sin embargo y como se ha visto con anterioridad, las arcillas adquieren una mejor actividad puzolánica mediante tratamiento térmico (metacaolín) a temperaturas en el rango de $540-900^{\circ} \mathrm{C}$, lo que rompe sus enlaces químicos cristalinos dando, como resultado, una estructura amorfa y desordenada o no cristalina.

Otro tipo de puzolanas naturales son las zeolitas que resultan estar formadas por unas alteraciones, bajo condiciones hidrotermales, del vidrio volcánico, lo que, como consecuencia, hace posible su reacción química con la cal en medio acuoso y a temperatura ambiente.

En general, las puzolanas naturales se pueden clasificar por su principal componente que reacciona químicamente en medio acuoso con la cal y a temperatura ambiente, el cual puede ser: vidrios volcánicos (desordenada estructura vidriosa de alumino-silicatos con impurezas cristalinas como cuarzo, feldespato o mica), tufas o trasses volcánicas, así como diatomeas, y sus depósitos se pueden encontrar en todas las partes del mundo.

En cambio, las arcillas y los esquistos no se pueden considerar como puzolanas naturales, propiamente dichas, puesto que necesitan ser calcinadas antes de forma adecuada, para que así posean características puzolánicas, por cuyo motivo ambas tiene que ser consideradas, necesariamente, puzolanas artificiales.

\section{I.2.7.- Hidratación del cemento Portland en presencia de adiciones minerales activas \\ (puzolánicas) y/o no-activas (fíllers). Estimulación de la hidratación y sus tipos.}

La hidratación del $\mathrm{CP}$ en sistemas ternarios constituidos por adiciones minerales activas y/o no activas puede ser considerada desde diferentes grados de complejidad, (Figura I-17 y Figura I-18):

- $\quad \mathrm{CP}+$ Adición mineral activa (puzolánica), 


$$
\begin{aligned}
& \text { - } \mathrm{CP}+\text { Adición mineral no activa (filler), } \mathrm{y} \\
& \text { - } \quad \mathrm{CP}+\text { Adición mineral activa (puzolánica) + adición no activa (filler). }
\end{aligned}
$$

Todos estos materiales, una vez que forman parte de una mezcla única, provocan entre ellos diferentes interacciones de naturaleza físico-química, donde intervienen el tamaño y la forma de la partícula, su composición química, el contenido en fracción amorfa, vítrea y/o cristalina de la adición mineral, su naturaleza silícea o calcárea, su carácter químico ácido o básico y, si la adición mineral activa es puzolánica o siderúrgica o no es activa, entre otros muchos parámetros físicos y químicos. Dichas interacciones físico-químicas son significativas hasta tal punto y medida que llegan a provocar estimulaciones de la hidratación del CP con el que se han mezclado, con implicación directa y plena incluso en sus propias reacciones químicas de hidratación y/o reaccionar químicamente con sus productos de reacción generados, y entre todos ellos, con la portlandita y/o el $\mathrm{C}_{3} \mathrm{~A}$ especialmente.

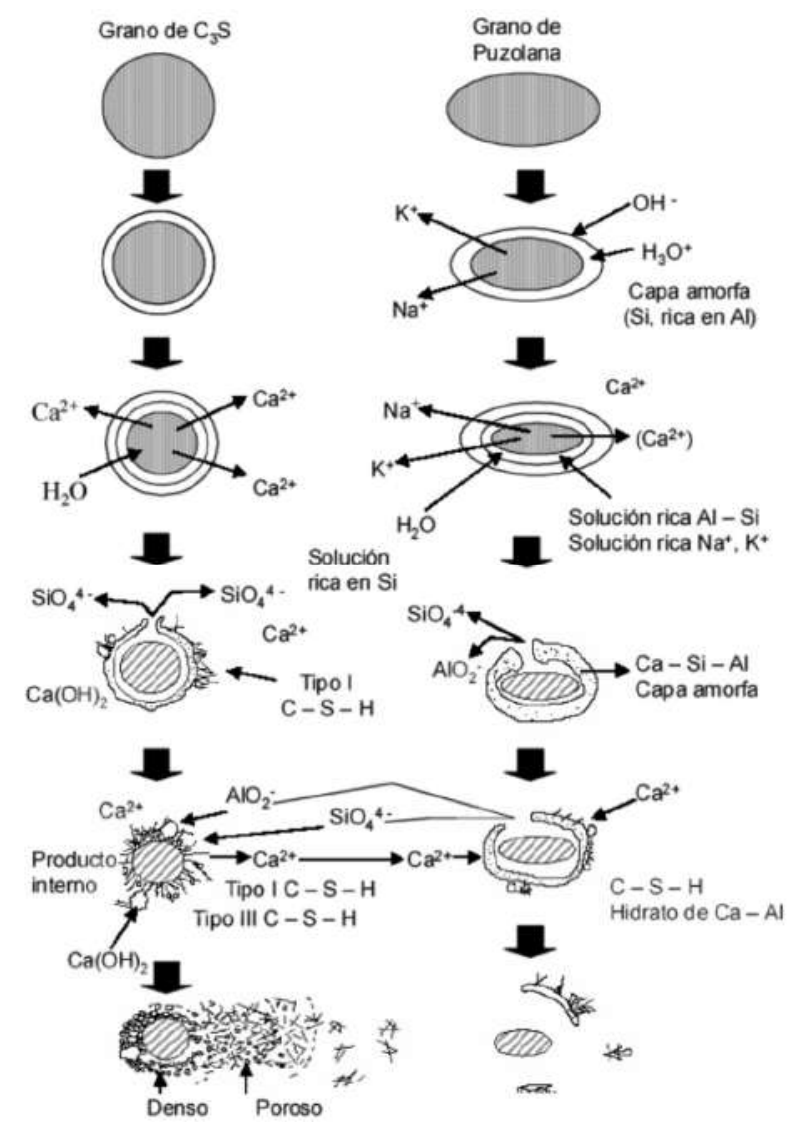

FIGURA I-17.- ESQUEMA DE LA HIDRATACIÓN DEL C3S EN PRESENCIA DE UNA PUZOLANA (MONOSI Y COL. 1986).

Finalmente se ha de destacar también que dicha estimulación de la hidratación que le provocan las adiciones minerales a la fracción del CP con el que se han mezclado, la pueden realizar por tres vías: por vía directa, no-directa e indirecta, pudiendo ser además esta última, promovida por una considerable actividad puzolánica previa desarrollada con mucha rapidez y a edades muy tempranas. Y si ésta última estimulación no se produce, ni de forma rápida ni de forma lenta, dicha 
estimulación de la hidratación del $\mathrm{CP}$ ha podido ser promovida nada más que por cualquier filler, y si es calizo más y mejor que si es silíceo. El fundamento físico-químico o químico-físico, según sea el caso, de cada estimulación mencionada, se describe a continuación, Tabla I-14.

La estimulación de la hidratación del CP por vía directa consiste en un mecanismo puramente físico, que se produce por el agua de amasado que inicialmente humedece la superficie de las partículas de la adición mineral que se le ha adicionado a dicho CP. Así, las partículas del $\mathrm{CP}$, una vez que se han hidratado y agotado por ello el agua de amasado que inicialmente las humectó, continúan hidratándose, pero esta vez, con el agua de amasado que habría humedecido al principio también y, a la par, la superficie de todas y cada una de las partículas de la adición mineral, ya sea ésta puzolánica o cristalina (es decir, ninguna de las dos es hidráulica per se, luego, no consumen el agua de amasado que las humedeció al inicio de su amasado con el CP). Lo que en cualquier caso y sin ninguna duda, le provoca una mayor hidratación a la fracción de $\mathrm{CP}$ con el que se había mezclado la puzolana, y, consiguientemente, un aumento considerable, a edades iniciales especialmente, de la concentración de portlandita en la fase líquida de su pasta cementante, habiendo sido originada además por una menor cantidad de dicho CP.

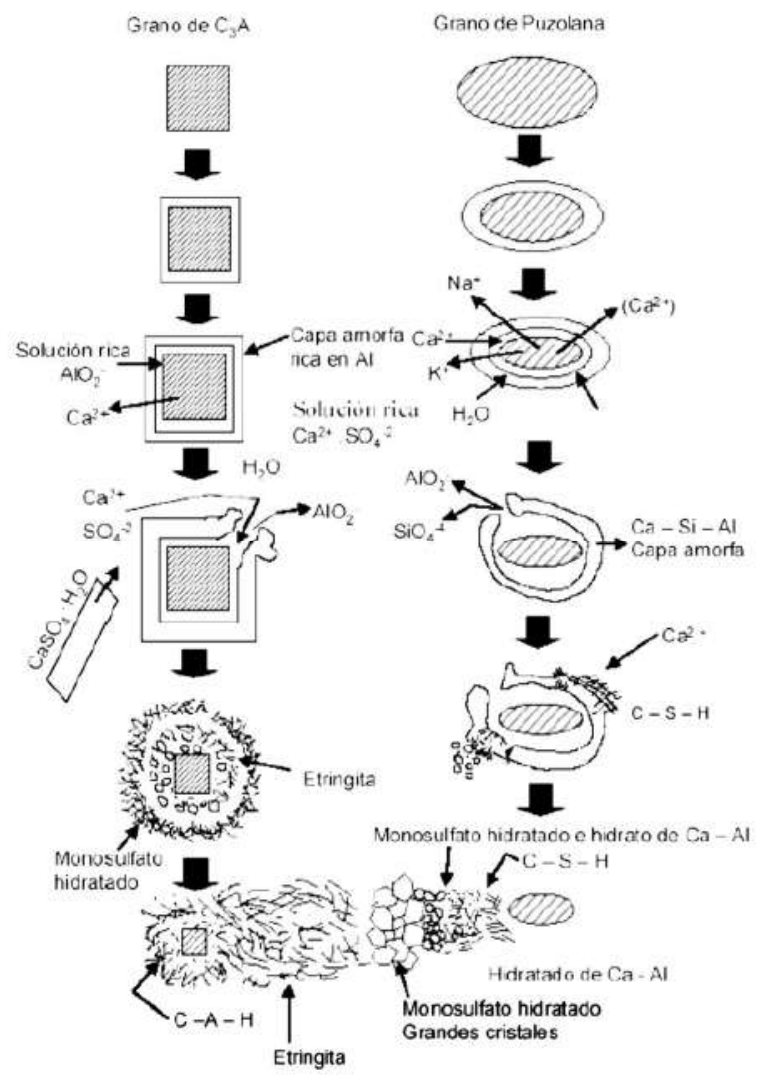

FIGURA I-18.- ESQUEMA DE LA HIDRATACIÓN DEL C3A EN PRESENCIA DE UNA PUZOLANA (MONOSI Y COL. 1986).

En cambio, la estimulación de la hidratación por vía no-directa: 
- es debida, en principio, a las cargas electrostáticas positivas y negativas adquiridas por las partículas de filler o de puzolana, durante el proceso de molienda o durante la etapa de amasado, y, a continuación,

TABLA I-14.- TIPOS DE ESTIMULACIÓN DE LA HIDRATACIÓN DEL CEMENTO PORTLAND POR LAS ADICIONES MINERALES PUZOLÁNICAS Y CRISTALINAS.

\begin{tabular}{|c|c|c|}
\hline $\begin{array}{c}\text { Tipo de } \\
\text { estimulación }\end{array}$ & $\begin{array}{l}\text { Agente promotor de la } \\
\text { estimulación }\end{array}$ & Efecto producido en el CP \\
\hline DIRECTA & $\begin{array}{c}\text { Adiciones minerales } \\
\text { puzolánicas activas y no activas }\end{array}$ & $\begin{array}{l}\text { Efecto de carácter físico nada más, promovido por } \\
\text { la humectación inicial de la superficie de las partículas } \\
\text { de las adiciones minerales, por el agua de amasado, la } \\
\text { cual promueve y origina finalmente una mayor } \\
\text { hidratación de la fracción de CP con el que se han } \\
\text { mezclado. } \\
\text { Aumento de la cantidad de calor de hidratación } \\
\text { originada por g de CP e incremento del contenido de } \\
\text { portlandita en la fase líquida, gracias a una mayor y } \\
\text { más intensa hidratación de los constituyentes del CP. }\end{array}$ \\
\hline $\begin{array}{l}\text { NO- } \\
\text { DIRECTA }\end{array}$ & $\begin{array}{c}\text { Adiciones minerales } \\
\text { puzolánicas activas y no activas }\end{array}$ & $\begin{array}{l}\text { Efecto de carácter químico-físico promovido al } \\
\text { principio del proceso de hidratación, por la carga } \\
\text { electroestática de las partículas de la adición mineral } \\
\text { (adquirida durante la molienda de su cemento y/o el } \\
\text { propio amasado), y posteriormente, debido al } \\
\text { desarrollo del potencial zeta generado conforme la } \\
\text { hidratación progresa. } \\
\text { Finalmente las partículas de la adición mineral } \\
\text { puzolánica actúan como centros de nucleación (la de } \\
\text { naturaleza silícea) o de precipitación (la de naturaleza } \\
\text { calcárea) para los cristales de portlandita, es decir, se } \\
\text { comportan como "cristales semillas" de cristales de } \\
\text { portlandita. }\end{array}$ \\
\hline INDIRECTA & $\begin{array}{l}\text { Adiciones puzolánicas de muy } \\
\text { elevada actividad, } \\
\text { principalmente las de carácter } \\
\text { químico alumínico o alumínico- } \\
\text { silícico, incluido } \\
\text { excepcionalmente el humo de } \\
\text { sílice, de carácter químico } \\
\text { silícico (actuación físico-química } \\
\text { gracias también a sus } \\
\text { características morfológicas } \\
\text { relacionadas con el muy } \\
\text { pequeño tamaño de sus } \\
\text { partículas esféricas) }\end{array}$ & $\begin{array}{l}\text { Incremento muy considerable y específico, que no } \\
\text { genérico, de la velocidad de hidratación del contenido } \\
\text { de } \mathrm{C}_{3} \mathrm{~A} \text {, que no del } \mathrm{C}_{3} \mathrm{~S} \text {, de la fracción del } \mathrm{CPO} \text { con el } \\
\text { que se ha mezclado la puzolana, promovido por la } \\
\text { muy elevada, temprana y rápida actividad puzolánica } \\
\text { desarrollada por su elevado contenido de } \mathrm{Al}_{2} \mathrm{O}_{3}{ }^{{ }^{-}} \text {, } \\
\text { especialmente. Lo que conlleva un incremento } \\
\text { considerable del calor de hidratación y del porcentaje } \\
\text { de agua químicamente enlazada, Figura } 1-17 \text { y Figura } \\
\text { 1-18; }\end{array}$ \\
\hline
\end{tabular}

- es debida al potencial Zeta especialmente, generado conforme progresa la hidratación del CP. Además, tanto las partículas de puzolana como las de filler silíceo pueden actuar como centros de nucleación de cristales de portlandita, mientras que si el fíller es calizo sus 
COMPORTAMIENTO SULFÁTICO Y MECÁNICO-RESISTENTE DE CEMENTOS PORTLAND CON ELEVADOS

partículas se comportan como centros de precipitación, es decir, como "cristales semilla" ("seed crystals") de dichos cristales de portlandita.

Finalmente, la estimulación por vía indirecta (Rahhal y col. 2007b; 2008; Talero y col. 2009b) está provocada por una actividad puzolánica muy significativa por elevada, rápida y temprana, a la edad de 2 días, e incluso a 1 día nada más, de la puzolana que se le ha añadido al CP. Lo que ineludiblemente provoca una disminución muy rápida y temprana también, de la concentración de portlandita en la fase líquida, la cual promueve, a su vez, una muy rápida, elevada y temprana también hidratación de la cantidad de $\mathrm{C}_{3} \mathrm{~A}$, que no de $\mathrm{C}_{3} \mathrm{~S}$, de la fracción del $\mathrm{CPO}$ con el que se ha mezclado la puzolana muy activa de carácter químico alumínico y alumínico-silícico, que no tanto, si su carácter químico es silícico, de acuerdo con Rahhal y col. (2009); Rahhal y cols. (2004; 2005; 2007a); Talero y col. (2009), e incluso silícico-alumínico (Rahhal y col. 2003a; 2003b; 2003c; 2004), motivo por el cual, dicha actividad puzolánica ha de ser considerada necesariamente y una vez más, más específica que genérica. Únicamente la puzolana silícica humo de sílice es capaz también de estimular por vía indirecta la hidratación más rápida del $\mathrm{C}_{3} \mathrm{~A}$ del $\mathrm{CPO}$, pero hasta las primeras 16 horas nada más, porque después es anti-específica, y tanto más anti-específica cuanto más progrese la hidratación selenitosa o no.

En definitiva, las partículas de las adiciones minerales activas suelen ser de menor tamaño que las del $\mathrm{CP}$, y humedecen su superficie al entrar en contacto con el agua de amasado. Y según sea su carácter químico, independientemente de que su estado físico sea vítreo y/o amorfo, y que además, estén constituidas por una pequeña o muy pequeña fracción cristalina, actúan como estimuladoras por vía directa de la hidratación de la fracción del CP con el que se han mezclado, mediante las moléculas de agua de amasado que humedecieron sus partículas inicialmente las cuales se las transmite sin más a las de CP aún anhidras, una vez que una gran parte de ellas ya se han hidratado con la cantidad de agua de amasado que las humedeció inicialmente a la par. A continuación, estimulan también dicha hidratación por vía no-directa. Y si además, dicha partícula de adición mineral es puzolánica tipo humo de sílice (con carácter químico silícico, según Talero, 1986) logra estimular también la hidratación del CP por vía indirecta, pero únicamente durante las primeras 16 h de hidratación inicial a lo sumo (Rahhal y col. 2003a; 2009). En cambio, si es metacaolín (con carácter químico alumínico, según Talero, (1986) logra estimular también la hidratación del CP por vía indirecta, pero desde el principio del ensayo y durante todo el periodo de vida útil previsto del hormigón, mortero o pasta del que forme parte.

Además y en el caso del calor de hidratación generado, este tipo de estimulación de la hidratación por vía indirecta viene acompañado por el desprendimiento de una extraordinaria cantidad de calor de hidratación muy elevada, sobre la que se tratará con más detalle en el apartado siguiente.

En definitiva, de todas las posibles adiciones puzolánicas silíceas en naturaleza y silícicas en carácter químico, únicamente el HS actúa físico-químicamente (por vía directa, no-directa e indirecta sobre todo, la cual por su intensidad y prontitud solapa a las dos vías primeras). En cambio, el resto de las silícicas y silícico-alumínicas, estimulan más al principio por vía directa y no-directa puesto que su actividad puzolánica es mucho menor, pero sobre todo, la manifiestan mucho más lentamente, con lo que finalmente actúan bastante más a modo de focos de disipación del calor de hidratación generado. Y si además son cenizas volantes o diatomeas, con más razón todavía si cabe. 


\section{I.3.- Comportamiento del cemento Portland con adiciones minerales inorgánicas frente a distintos medios agresivos.}

\section{I.3.1.- Frente al ataque del dióxido de carbono $\left(\mathrm{CO}_{2}\right)$ del aire. Carbonatación.}

Desde la aparición en el mercado de los cementos Portland con adiciones activas, en sustitución de los cementos Portland puros o tradicionales, en igualdad de condiciones y para idénticos usos constructivos, el proceso de carbonatación les está afectando en determinadas ocasiones y circunstancias, por reacciones químicas degenerativas. Y ello, a pesar de que paradójicamente la carbonatación haya constituido y constituya un medio de protección natural bastante eficaz de los hormigones de cemento Portland puro, siendo además el fundamento de su contrastada estabilidad y durabilidad ante el ataque del $\mathrm{CO}_{2}$ del aire. De aquí que no es deseable denominar a la acción natural de dicho $\mathrm{CO}_{2}$ del aire "ataque agresivo para el hormigón", ya que ello dependerá más de las características y composición del propio hormigón sobre el que actúe y del cemento que lo constituya, que de las del propio $\mathrm{CO}_{2}$ que son constantes para una condición determinada de humedad, presión y temperatura del aire. Este fenómeno de la carbonatación degrada a los hormigones de cemento Portland con adiciones activas (HCPA), en general, y con cenizas volantes, puzolanas naturales, arcillas activadas y similares, humo de sílice (en todas sus respectivas proporciones comunes), escorias siderúrgicas (en cantidades elevadas, especialmente) y "filler" (si es calizo, más aún), en particular. Y en ausencia de un curado hídrico adecuado, les afecta más todavía y aún con menores contenidos de las mismas.

El fundamento de la nocividad de la carbonatación de algunos HCPA se basa en que el dióxido de carbono, $\mathrm{CO}_{2}$, junto con la humedad, ambiental o no, penetra en la pasta hidratada de cemento por la red de poros, microporos, fisuras, microfisuras, e incluso, por la propia zona de transición árido-pasta, máxime si el árido es calizo, originando finalmente la carbonatación de la portlandita, $\mathrm{Ca}(\mathrm{OH})_{2}$, liberada en la hidratación de su fracción clínker Portland, y también, del resto de sus componentes sólidos, tales como el gel CSH, aluminatos, Fase AFt y/o AFm, etc. En los casos que el hormigón no posea adiciones, los propios del hormigón de cemento Portland (HCP), la carbonatación puede incluso dar por resultado una reducción de la porosidad del material favoreciendo además la formación de una capa protectora en la superficie del hormigón (Glasser y cols. 2007). Pero eso sólo ocurre si la fase líquida de la pasta cementante de dicho hormigón, está sobresaturada de portlandita, que una vez precipitada en la superficie en forma de placas hexagonales, por acción del $\mathrm{CO}_{2}$ del aire, se transforma en muy poco tiempo en calcita sintética la cual constituye en definitiva, una capa protectora.

En el caso contrario, si dicha fase líquida de la pasta cementante del hormigón no se encuentra en estado de sobresaturación en portlandita sino de subsaturación, no se producirá por secado precipitación alguna de portlandita, y sí, en cambio, su reacción química con el $\mathrm{CO}_{2}$ del aire disuelto para formar bicarbonato, $\mathrm{HCO}_{3}{ }^{-}$, y carbonato, $\mathrm{CO}_{3}^{2-}$, al ser el $\mathrm{pH}$ de dicha disolución muy inferior al de la disolución sobresatuarada de portlandita (aprox. de 12,3 a 12,5). Esta reacción, no sólo se limita a la superficie del hormigón, sino que penetra progresivamente hacia el interior por la red de poros. Esto se produce mayoritariamente por la presencia de adiciones puzolánicas en las cantidades que les son propias a cada tipo, o si las mezclas son muy pobres en cemento Portland 
COMPORTAMIENTO SULFÁTICO Y MECÁNICO-RESISTENTE DE CEMENTOS PORTLAND CON ELEVADOS

(grava-cemento, suelo-cemento, etc.). La carbonatación negativa provoca una modificación de la porosidad de la capa carbonatada que se traduce en un crecimiento de los poros capilares (20-350 nm) a expensas de los poros de pequeñas dimensiones que existen en el hormigón no carbonatado. Además, el proceso de descalcificación del gel CSH es mucho más severo ya que la relación Ca/Si de partida es mucho menor (Chen y cols. 2006). Asimismo, se observa una disminución de la resistencia mecánica a compresión de tales hormigones carbonatados y un incremento de su permeabilidad (Ranc. y col. 1989). En definitiva, en los HCPA la porosidad y la carbonatación varían en el mismo sentido, mientras que en los HCP no.

A continuación obsérvense en la Figura I-19 las diferencias morfológicas entre la capa protectora que se forma a partir de una disolución sobresaturada en portlandita y la que se forma a partir de una disolución subsaturada.
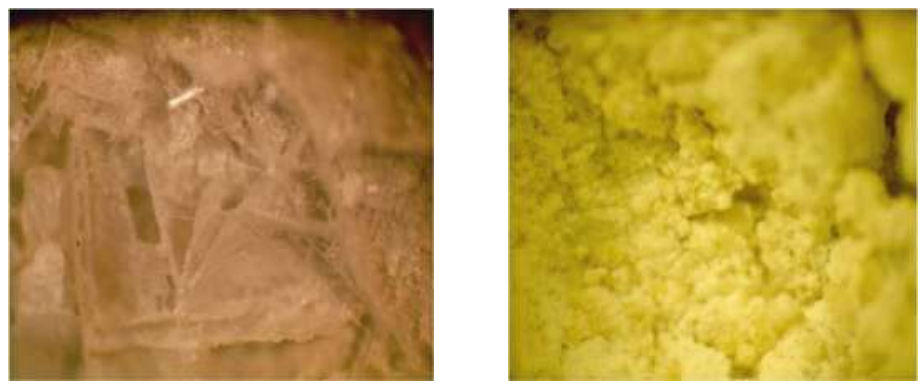

FIGURA I-19.- (A) CARBONATACIÓN POSITIVA: MACLAS ENTRELAZADAS Y COMPACTAS, DE LA PASTA DE UN CEM I. (B) CARBONATACIÓN NEGATIVA: GRÁNULOS DE CALCITA SINTÉTICA DE ASPECTO TERROSO, DESAGREGADOS Y DE TEXTURA ÍNTIMA GRANUDA, PROCEDENTES DE UN HORMIGÓN POBRE MUY CARBONATADO.

La reacción química de la portlandita con el $\mathrm{CO}_{2}$ del aire en condiciones de subsaturación dando por resultado finalmente bicarbonato de calcio, $\mathrm{Ca}\left(\mathrm{HCO}_{3}\right)_{2}$, se describe mediante la reacción química (r23) preferentemente. Dicho bicarbonato de calcio, como ya se ha venido diciendo, a diferencia de la forma carbonato, $\mathrm{CaCO}_{3}$, es muy soluble en agua, lo que facilita su pérdida por lixiviación, lo que a su vez depende de las condiciones ambientales.

Además, el bicarbonato de calcio disuelto en el agua de la fase líquida del hormigón puede migrar hacia la superficie del hormigón, por varios motivos. Estos son fundamentalmente, entre otros posibles, el calentamiento de la superficie por la acción de los rayos solares, y/o la difusión debido al gradiente de concentración. De este modo, el $\mathrm{Ca}\left(\mathrm{HCO}_{3}\right)_{2}$ acaba descomponiéndose en la superficie exterior al evaporarse el agua que lo disolvía debido a las condiciones higrométricas del aire exterior, la temperatura y/o el viento, con lo que finalmente, el bicarbonato de calcio se descompone en $\mathrm{CO}_{2}, \mathrm{H}_{2} \mathrm{O}$ y carbonato de calcio según la reacción química (r24):

$$
\begin{aligned}
& 2 \mathrm{H}_{2} \mathrm{CO}_{3}+\mathrm{Ca}(\mathrm{OH})_{2} \rightarrow \mathrm{Ca}\left(\mathrm{HCO}_{3}\right)_{2} \\
& \mathrm{Ca}\left(\mathrm{HCO}_{3}\right)_{2}+\mathrm{Calor} \rightarrow \mathrm{CaCO}_{3}+\mathrm{CO}_{2}+\mathrm{H}_{2} \mathrm{O}
\end{aligned}
$$

Estos mecanismos conducen a la formación de calcita y reducen la cantidad de iones calcio e iones hidroxilo de la disolución acuosa de los poros, lo cual a su vez, desencadena o provoca la disolución de más portlandita. Así, la formación de calcita en sustitución de portlandita reduce la porosidad del material ya que el volumen molecular de la calcita es mayor $\left(36,9 \mathrm{~cm}^{3} / \mathrm{mol}\right.$ comparado a $33,1 \mathrm{~cm}^{3} / \mathrm{mol}$ para el hidróxido de calcio, $\mathrm{CH}$ ). Recientemente, se ha aportado una 
evidencia experimental de la reducción de portlandita en favor de la calcita (Cultrone y cols. 2005; Rigo y cols. 2002). Además, y como se ha comentado, la carbonatación afecta a otros productos de hidratación del cemento diferentes de la portlandita, siendo el más importante de todos ellos el gel CSH; no sólo por tratarse del producto de hidratación mayoritario, sino por las consecuencias negativas que su carbonatación acarrea. La carbonatación de este producto químico causa una descalcificación progresiva del mismo para producir carbonato de calcio y gel de sílice (Slegers y col. 1976; Suzuki y cols. 1985; Kobayashi y col. 1994). Si bien, el carbonato de calcio obtenido a partir de este otro producto de hidratación, a diferencia del obtenido por la carbonatación de la portlandita, es en su mayor parte metaestable con escasa cristalinidad, e incluso amorfo (Thiery, 1992). La carbonatación del gel CSH produce retracción y pérdida de coherencia en la matriz del cemento. Se considera que este fenómeno ocurre una vez que se ha agotado la portlandita que localmente lo rodea, o cuando la carbonatación de ésta está ya muy impedida por la formación de carbonato de calcio en su superficie. Es decir, esto es equivalente a afirmar que los HCPA sufren antes la carbonatación del gel CSH que los $\mathrm{HCP}$, agravado además porque ya que el gel CSH de los HCPA posee una menor relación $\mathrm{Ca} / \mathrm{Si}$ su descalcificación será más rápida. Al igual que el gel CSH, la Fase AFm y la Fase AFt se carbonatan también. A este respecto ha sido demostrado que ambas fases se carbonatan produciendo carbonato de calcio, yeso e hidróxido de aluminio (Nishikawa y cols. 1992; Xiantuo y col. 1994; Zhou y col. 2000).

En definitiva, la influencia que tiene la presencia de adiciones puzolánicas en cualquier material de base cemento, que va a ser expuesto a un ambiente de carbonatación al aire, va a ser muy importante. Concretamente, por la actividad puzolánica que desarrollan los dos factores hidráulicos más importantes de cualquier puzolana, como son la $\mathrm{SiO}_{2}{ }^{\mathrm{r}-}$ y la $\mathrm{Al}_{2} \mathrm{O}_{3}{ }^{\mathrm{r}}$, por reacción directa con la portlandita generada fruto de la hidratación del clínker. Estos dos mismos factores hidráulicos y su actividad van a tener de la misma forma una clara influencia en cualquier material de base cemento, que va a ser expuesto a un ambiente de sulfatos, que será explicada convenientemente en los siguientes capítulos de esta Tesis Doctoral.

\section{I.3.2.- Frente a la reacción álcali-agregado.}

Para que se produzca la reacción árido-álcali $(R A A)$ en el $\mathrm{HCP}$, con y sin adiciones minerales, se necesitan tres condiciones que son las siguientes: que la cantidad de álcalis (iones alcalinos $\mathrm{Na}^{+}$y $\mathrm{K}^{+}$) en el cemento sea suficiente por elevada, áridos con componentes reactivos frente a los álcalis y la presencia de agua (Taylor, 1997). Los iones alcalinos pueden estar presentes en los cementos en forma de sales sulfáticas o estar enlazados con silicatos y/o aluminatos, aunque también pueden provenir del exterior, como por ejemplo, del rocío marino y del agua de mar propiamente dicha, que es lo más común.

Básicamente, este tipo de ataque químico se produce en las cuatro situaciones siguientes, cuyos fundamentos fisicoquímicos se explican a continuación:

1. Áridos silíceos reactivos tipo rocas opalinas, $\mathrm{SiO}_{2} \cdot \mathrm{H}_{2} \mathrm{O}$ : Las rocas de naturaleza silícea reactiva reaccionan con los álcalis $\left(\mathrm{Na}^{+} \mathrm{y} \mathrm{K} \mathrm{K}^{+}\right)$del cemento y/o de sus adiciones minerales y/o de los aditivos químicos dando lugar a la formación de geles de sílice que presentan una acción osmótica en presencia de agua y que, por adsorción de la misma en gran cantidad, aumentan de volumen provocando tensiones disruptivas internas para el hormigón del que 
forman parte. El esquema reactivo del proceso establecido por Plum y cols (1958) está representado por la siguiente reacción química (r26):

$$
a \mathrm{SiO}_{2} \cdot \mathrm{H}_{2} \mathrm{O}+b \mathrm{NaOH}+c \mathrm{Ca}(\mathrm{OH})_{2}+d \mathrm{H}_{2} \mathrm{O} \rightarrow n_{1} \mathrm{Na}_{2} \mathrm{O} \cdot n_{2} \mathrm{CaO} \cdot n_{3} \mathrm{SiO}_{2} \cdot n_{4} \mathrm{H}_{2} \mathrm{O}
$$

Los minerales y rocas susceptibles de provocar este fenómeno son las rocas opalinas, ciertas rocas volcánicas ácidas o intermedias (andesitas, riolitas, dacitas), algunas pizarras y filitas con elevado contenido de hidromicas y zeolitas del tipo heulandita, aunque algunas de ellas estando presentes en apreciables cantidades.

2. Áridos dolomíticos, $\mathrm{CaMg}\left(\mathrm{CO}_{3}\right)_{2}$ : Este tipo de áridos sufren el proceso de "desdolomitización" por reacción química con disoluciones alcalinas, produciendo la neoformación de brucita, $\mathrm{Mg}(\mathrm{OH})$, y una regeneración del hidróxido alcalino, lo que puede dar lugar a la continuidad del proceso, de acuerdo con las siguientes reacciones químicas (r27) y (r28):

$$
\begin{aligned}
& \mathrm{CaMg}\left(\mathrm{CO}_{3}\right)_{2}+2 \mathrm{NaOH} \rightarrow \mathrm{Mg}(\mathrm{OH})_{2}+\mathrm{CaCO}_{3}+\mathrm{Na}_{2} \mathrm{CO}_{3} \\
& \mathrm{Na}_{2} \mathrm{CO}_{3}+\mathrm{Ca}(\mathrm{OH})_{2} \rightarrow \mathrm{CaCO}_{3}+2 \mathrm{NaOH}
\end{aligned}
$$

La brucita, $\mathrm{Mg}(\mathrm{OH})_{2}$, puede aparecer en las zonas interfaciales de transición entre los áridos y la pasta o bien en el mismo árido, pudiendo reaccionar con la sílice alrededor del árido y formar un silicato de magnesio incoherente y no conglomerante. Por otra parte, la zona porosa que se crea alrededor del árido, por extracción de iones $\mathrm{Mg}^{2+}$, debilita la unión árido-pasta, sin que el proceso de desdolomitización provoque la aparición de geles expansivos. No obstante, las mencionadas reacciones químicas degradativas del árido dolomítico no se desarrollan por fortuna en todos los casos.

3. Árido feldespático, micáceo o granítico en reacción química con $\mathrm{Ca}(\mathrm{OH})_{2}$ : Este ataque químico puede dar lugar a formación de hidrogranates, alumino-silicatos de calcio hidratados, silicatos de calcio y alcalinos de $\mathrm{Na}^{+}$y K $\mathrm{K}^{+}$libres, que puede deteriorar la estructura interna del hormigón a través de su esqueleto granular (Soriano, 1988). Los factores que influyen en el posible deterioro son la composición mineralógica, el grado de alteración y tamaño del árido, la cantidad de portlandita de la fase intersticial del hormigón, la presencia de humedad, el tiempo y la temperatura.

4. Árido fino de origen arcilloso en reacción química con el agua de amasado, conservación o curado: Este ataque químico se produce en el caso de los áridos que pasan por el tamiz de 0,08 mm de luz de malla y que pueden reaccionar topoquímicamente en la fase intersticial del hormigón causando modificaciones en su comportamiento y durabilidad, dado que los materiales arcillosos poseen una estructura abierta, permiten la intrusión de las moléculas polares de agua, provocando variaciones de volumen que generan presiones disruptivas internas.

Los tres primeros tipos de ataque se pueden impedir sin más que disminuir lo más posible la presencia de portlandita en la fase líquida e intersticial del hormigón, utilizando para ello cementos puzolánicos o cementos del tipo CEM IV (Instrucción RC-16), recomendándose para los mismos el empleo de cualquier puzolana natural o artificial de carácter químico silícico-alumínico (Talero, 1993a; 1996) o silícico preferentemente (Martín Luengo, 1997; Talero, 1987; 1990; 1993a; 
1993b; 1996), tal como el humo de sílice y la nanosílice, las diatomeas y rocas opalinas, sin menoscabo de poder utilizar también las de carácter químico diferente como el alumínico-silícico, tal como la puzolana natural canaria, e incluso, el alumínico, tal como el metacaolín, aunque para el mismo fin protector que se busca, su cantidad adecuada, a igualdad de todo lo demás, será necesariamente diferente también. Lo que ineludiblemente le provocará, no obstante, su degradación ulterior por carbonatación a menos que se le proteja de su contacto con el aire y el agua.

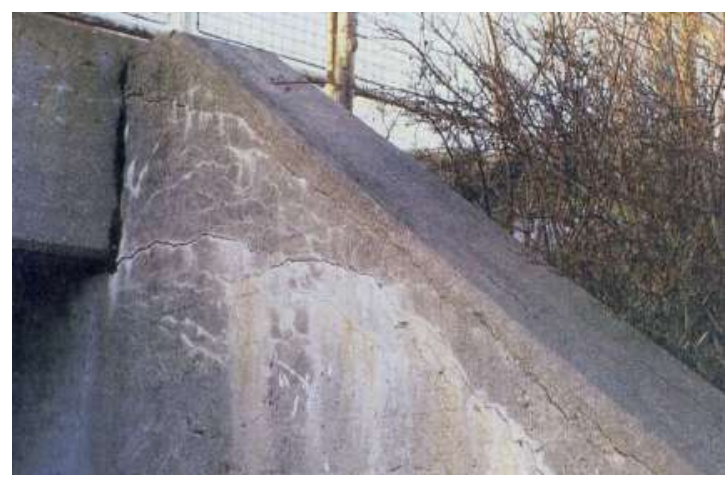

FIGURA I-20.- ATAQUE POR ÁRIDO SILÍCEO REACTIVO DE UN ESTRIBO DE PUENTE.

También es necesario significar, ya que afectan a los objetivos y conclusiones de esta Tesis Doctoral, que alguna de las soluciones propuestas para resolver la patología de reactividad álcaliagregado, son la utilización de cementos puzolánicos, o bien, el empleo de un cemento que tenga la característica de low-alkaly cement, pueden tener una influencia muy importante sobre la respuesta de este material frente al ataque químico agresivo de los sulfatos, como se podrá comprobar en los sucesivos capítulos de esta Tesis Doctoral.

\section{I.3.3.- Frente al ataque de los cloruros ( $\mathrm{Cl}$-). Rocío marino, sales de deshielo, etc.}

A modo de introducción, el ataque por los iones cloruro, $\mathrm{Cl}$, se produce sobre las armaduras de acero del hormigón. La acción de los cloruros produce la corrosión por picadura del acero, a diferencia de la corrosión generalizada que produce el ataque por carbonatación. Los diversos factores que favorecen el ataque por los iones cloruros en el hormigón son la temperatura, los recubrimientos de hormigón insuficientes, deficientes o escasos, porosos, permeables al aire y a la humedad.

El ataque por los iones cloruro debido a alguno de los componentes del hormigón es improbable, ya que existen límites máximos legales del contenido de iones cloruro en los mismos, lo cual reduce su presencia y, por ende, la posibilidad de ataque. Por ello, el ión cloruro debe penetrar desde el exterior hacia el interior del hormigón. El modo por el cual los iones cloruro penetran, se produce mediante diferentes mecanismos. El primero de ellos, el que se produce en obra real, y es el mecanismo por difusión pura o combinada con el de succión capilar del agua que los transporta. Finalmente, los iones se ubican finalmente en los poros interiores del hormigón, parcial 
COMPORTAMIENTO SULFÁTICO Y MECÁNICO-RESISTENTE DE CEMENTOS PORTLAND CON ELEVADOS CONTENIDOS DE PUZOLANAS (> 40\%): SU FUNDAMENTO QUÍMICO Y JUSTIFICACIÓN DE OTRAS CONSECUENCIAS POSIBLES

o totalmente llenos de agua, donde parte de estos aniones son fijados por algunos de los componentes del cemento mediante mecanismos químicos (reacción) y físicos (adsorción).

Una vez que los iones cloruros penetran en el hormigón, se ubican en su interior en diferentes estados, a saber:

- libres, es decir disueltos en la fase líquida de los poros del hormigón, pudiendo estar, o no, impedidos o dificultados físicamente para penetrar hasta llegar a las armaduras del hormigón,

- físicamente enlazados, es decir, atraídos mediante fuerzas de Van der Waals en la superficie de los poros, o

- químicamente enlazados, mediante reacción química con los compuestos de la hidratación del cemento Portland y/o de sus adiciones activas si éstas fueran adecuadas, y/o

- en un estado quimiadsorbido, tal y como el sugerido con el gel CSH del cemento.

De todos ellos, únicamente aquellos que se encuentran en estado libre pueden llegar a desencadenar el fenómeno electroquímico corrosivo sobre el acero de las armaduras del hormigón. En este caso también se produce un "perfil de concentración" decreciente desde la superficie al interior del hormigón, siendo mucho más evidente en el caso de los iones cloruro que en el de la carbonatación.

Los componentes de la hidratación del cemento Portland capaces de enlazar químicamente los iones cloruro son el aluminato tricálcico, $C_{3} A$, y el ferrito-aluminato tetracálcico, $C_{4} A F$, hidratados. Por reacción química con éstos se producen las sales: $3 \mathrm{CaO} \cdot \mathrm{Al}_{2} \mathrm{O}_{3} \cdot \mathrm{CaCl}_{2} \cdot 10 \mathrm{H}_{2} \mathrm{O}$ y $3 \mathrm{CaO} \cdot \mathrm{Fe}_{2} \mathrm{O}_{3} \cdot \mathrm{CaCl}_{2} \cdot 10 \mathrm{H}_{2} \mathrm{O}$, respectivamente, si bien al primero de ellos, el monocloroaluminato de calcio hidratado, denominado sal de Friedel (véase la Figura I-21), se le atribuye un mayor efecto en la reducción de la movilidad del anión cloruro (Lannegrand y cols. 2001; Jones y cols. 2003).
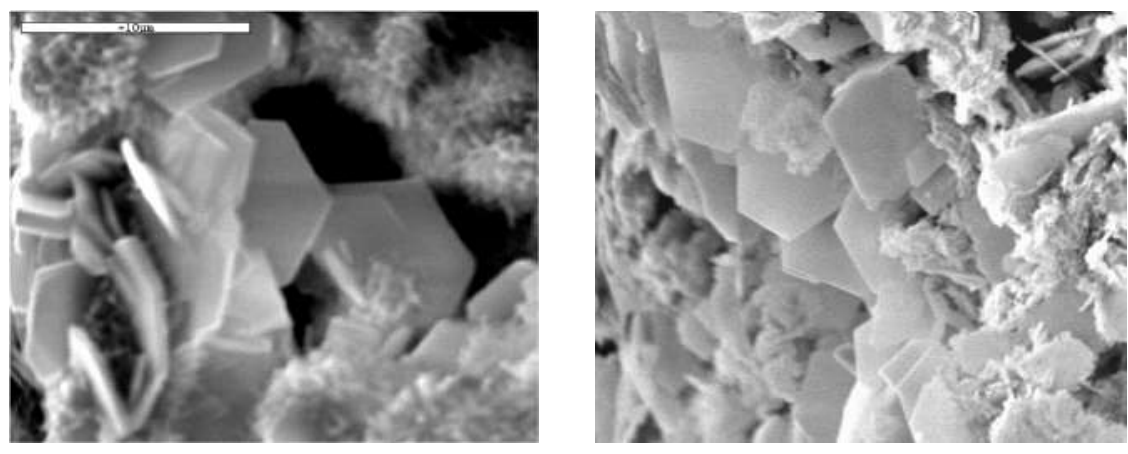

FIGURA I-21.- SAL DE FRIEDEL, MICROGRAFÍA DE MICROSCOPÍA ELECTRÓNICA DE BARRIDO; IZQUIERDA: MAGNIFICACIÓN (X1000). DERECHA: MAGNIFICACIÓN (X3500).

La sal de Friedel se puede formar a través de dos mecanismos o reacciones químicas diferentes (Lannegrand y cols. 2001; Jones y cols. 2003), a saber:

(a) el de la sustitución de los iones $\mathrm{OH}^{-}$en la Fase $\mathrm{AFm}$ por iones cloruro, $\mathrm{Cl}$, y

(b) el de captación de iones $\mathrm{Cl}^{-}$para su precipitación.

Y de acuerdo con Jones y cols. (2003) el mecanismo dominante es el (a), ya que por lo común, las mezclas de cemento Portland con determinadas puzolanas (aquéllas que poseen un 
carácter alumínico suficiente, aumentan en gran medida la relación de Fase AFm a Fase AFt, y por este motivo y a edades iniciales principalmente (hasta 50 días), el número de lugares o puntos de enlaces de iones $\mathrm{Cl}^{-}$aumenta también. En cambio a edades mayores, el mecanismo (b) o el de precipitación, llega a ser más importante. Todo lo cual significa que el mecanismo de intercambio iónico tiene inicialmente más importancia que el resto de los mecanismos o modelos citados, y es el que en definitiva, hace que el $p H$ de la fase líquida aumente, lo que proporciona de paso una mayor protección a las armaduras.

Seguidamente se exponen por orden, las reacciones químicas del anión cloruro, $\mathrm{Cl}$, con el aluminato tricálcico, $\mathrm{C}_{3} A$, del cemento Portland y con la alúmina reactiva, $\mathrm{Al}_{2} \mathrm{O}_{3^{r}}$, de las adiciones puzolánicas, para dar lugar todos ellos a la formación de la referida sal de Friedel. Tales reacciones químicas son las siguientes (r29 y r30):

$$
\begin{aligned}
& \mathrm{CaCl}_{2}+\mathrm{C}_{3} \mathrm{~A}+10 \mathrm{H}_{2} \mathrm{O} \rightarrow \mathrm{C}_{3} \mathrm{~A} \cdot \mathrm{CaCl}_{2} \cdot 10 \mathrm{H}_{2} \mathrm{O} \\
& \mathrm{CaCl}_{2}+\mathrm{Al}_{2} \mathrm{O}_{3}^{r-}+3 \mathrm{CaO}+10 \mathrm{H}_{2} \mathrm{O} \rightarrow \mathrm{C}_{3} \mathrm{~A} \cdot \mathrm{CaCl}_{2} \cdot 10 \mathrm{H}_{2} \mathrm{O}
\end{aligned}
$$

Como se puede ver, tanto la $\mathrm{Al}_{2} \mathrm{O}_{3}{ }^{r}$ de las puzolanas naturales y artificiales de carácter mayormente alumínico, forman dicha sal de Friedel al igual que la forma en las mismas condiciones el $C_{3} A$ del cemento Portland. No obstante, en el caso de los hormigones de cemento Portland con adiciones activas, las velocidades y reacciones de ambos procesos son diferentes, sucediendo lo mismo que en el caso del ataque de los iones sulfato con la formación de las correspondientes ettringitas. Dependiendo de la cantidad incorporada de tales adiciones activas, pueden llegar a inferir comportamientos y velocidades de reacción distintas del anión cloruro con el $C_{3} A$ que esté presente junto a aquellas. Por lo general, mayor velocidad que cuando ambos, cemento Portland y adición activa, se encontraban por separado. De este modo, habrá que tener muy en cuenta una vez más sus implicaciones en el correspondiente Efecto Sinérgico, ES, que también se genera en estos otros casos. Este $E S$, a diferencia del que se origina en el ataque de los iones sulfato que es muy perjudicial para el hormigón por ser muy expansivo y rápido, en el ataque de los iones cloruro resulta ser por el contrario, beneficioso para la matriz cementante porque el volumen molecular de la sal de Friedel es similar al de los aluminatos de calcio hidratados del cemento Portland, es decir, no es expansiva a diferencia de la ettringita de cualquier origen y etiología. Luego si no es expansiva, es colmatadora del sistema de poros, microporos y red de capilares del hormigón.

Además, otra de las particularidades beneficiosas de que se produzca la reacción de los iones cloruro con el cemento Portland con adiciones puzolánicas adecuadas, es la notable mayor rapidez de formación con la que se lleva a cabo la colmatación, así como la mayor cantidad total formada, que si ambos, cemento Portland y puzolana, formaran su sal de Friedel por separado (Mejia, 1997; Mejia y cols. 2000; 2003). Este otro Efecto Sinérgico beneficioso, se origina porque la velocidad de formación de la sal de Friedel de origen $\mathrm{Al}_{2} \mathrm{O}_{3^{r}}$ - de las puzolanas es mayor que la del $C_{3} A$ del cemento Portland, y en su co-precipitación, la elevada y rápida actividad puzolánica de aquélla en este otro medio con cloruros, provoca una mayor y más rápida hidratación de dicho $C_{3} A$ que cuando se encontraba sólo en el cemento Portland, es decir, por igual mecanismo de estimulación de su hidratación por vía indirecta que la que se le provoca a la fracción de cemento Portland en el caso del ataque de los iones sulfato (Talero, 2010) y del calor de hidratación ( $\underline{\text { Rahhal, }}$ 2002). 
Únicamente en el caso de que los iones cloruro provengan del cloruro de magnesio, $\mathrm{MgCl}_{2}$, el material hormigón se verá afectado, pero por el catión magnesio especialmente, que como se ha podido ver anteriormente, forma brucita, $\mathrm{Mg}(\mathrm{OH})_{2}$, al reaccionar con la portlandita, produciendo además intercambio catiónico con el calcio de las otras fases hidratadas del cemento.

Por todo ello, se ha puesto de manifiesto, de forma clara, el papel tan importante que pueden llegar a jugar también en este otro ataque agresivo de los cloruros a las armaduras del hormigón armado, las fracciones reactivas de dichas puzolanas, y más en concreto, la sílice reactiva, $\mathrm{SiO}_{2}{ }^{\mathrm{r}}$, y la alúmina reactiva, $\mathrm{Al}_{2} \mathrm{O}_{3^{\mathrm{r}}}$, especialmente, que las constituye en mayor o menor medida. $\mathrm{La}$ razón de tan importante papel estriba en que la $\mathrm{Al}_{2} \mathrm{O}_{3}{ }^{\mathrm{r}-}$ de las puzolanas posee también la capacidad de reaccionar químicamente, en medio acuoso, con la portlandita y el $\mathrm{NaCl}$, para originar sal de Friedel y de esta forma, promoviendo el "anti-ataque" de los cloruros a las armaduras del hormigón armado.

$\mathrm{La} \mathrm{SiO} 2^{\mathrm{r}}$, en cambio, no posee la capacidad de originar sal de Friedel como la $\mathrm{Al}_{2} \mathrm{O}_{3}{ }^{\mathrm{r}}$, aunque no por ello deja de ejercer su influencia en este otro ataque agresivo de los cloruros a las armaduras del hormigón armado, pero de forma no explícita nada más, si bien, en tiempos y formas distintas y con resultados finales totalmente diferentes por contrarios u opuestos, pero acordes, en cualquier caso, al tamaño medio y la morfología de sus partículas:

- si son del tipo diatomeas y similares, no poseen la misma capacidad estimuladora, por vía indirecta, de las reacciones de hidratación salina que la $\mathrm{Al}_{2} \mathrm{O}_{3}{ }^{\mathrm{r}-}$ promueve de forma explícita, pero si, en cambio, promueven físicamente merced a la elevada succión capilar de agua que ejercen sus partículas, denominadas frústulos, lo que facilita el ingreso muy rápido de los cloruros a las armaduras con las consecuencias perjudiciales pertinentes, y aunque finalmente lleguen a generar, como generan, geles C-S-H, la protección físico-química que los mismos pueden conferirle a las armaduras llegará siempre un poco tarde por no ser aún suficientes en cantidad, pero, en cambio,

- si son del tipo humo de sílice, la estimulación de la hidratación salina por vía indirecta, sí la pueden ejercer, pero únicamente y en el mejor de los casos, hasta las primeras 16 horas a lo sumo (Talero y col. 2009b), puesto que a partir de esa edad tan temprana deja de ejercerla (es decir, el tiempo que ha necesitado el humo de sílice para generar cantidad de gel CS-H suficiente para comenzar a actuar en sentido contrario o "protector" frente al ataque de los sulfatos y de los cloruros también, pero desde el punto de vista físico-químico especialmente); y tanto más deja de ejercerla cuanto más progresa la hidratación salina, es decir, cuanto mayor cantidad de gel C-S-H ha logrado generar, hasta el punto de llegar a tornarse en la opuesta, como se acaba de decir, por llegar a desestimularla, e incluso, a dificultarla e impedirla en su totalidad, ergo, termina por ser también "protectora", en las mismas circunstancias del ataque de los cloruros a las armaduras del hormigón armado como lo había sido frente al ataque de los sulfatos, es decir, es "anti-ataque de los cloruros", como lo es $\mathrm{Al}_{2} \mathrm{O}_{3}{ }^{\mathrm{r}}$, sólo que, a diferencia de esta última, su efecto "protector" de tipo físico continúa teniendo prioridad siempre.

\section{I.3.4.- Frente al ataque del agua de mar.}


El agua de mar es un reservorio inagotable de una disolución de sales cuyo pH está próximo a 7. Por consiguiente, se comportará como un ácido frente al hormigón. Esta agua contiene, entre otros, elevadas concentraciones de iones sodio y cloruro, y algo menores de iones magnesio, calcio, sulfato, potasio y bicarbonato. En la Tabla I-15 se muestra una composición promedio de las especies químicas disueltas en el mar. En este tipo de ataque químico agresivo los iones cloruro se ven coadyuvados en su ataque por los iones sulfato y por el catión magnesio, $\mathrm{Mg}^{2+}$, en el caso de que la estructura se encuentre sumergida completamente, y por la carbonatación si lo estuviera al aire o parcialmente sumergida. Esto hace que este ataque esté constituido simultáneamente por diversas reacciones químicas dependiendo de su origen y etiología.

TABLA I-15.- COMPOSICIÓN PROMEDIO DEL AGUA DE MAR.

\begin{tabular}{llc}
\hline Componente & Concentración (\%) \\
\hline Cloruro & $(\mathrm{Cl})$ & 55,0085 \\
Sodio & $\left(\mathrm{Na}^{+}\right)$ & 30,5935 \\
Sulfato & $\left(\mathrm{SO}_{4}^{2-}\right)$ & 7,7105 \\
Magnesio & $\left(\mathrm{Mg}^{2+}\right)$ & 3,6812 \\
Calcio & $\left(\mathrm{Ca}^{2+}\right)$ & 1,1740 \\
Potasio & $\left(\mathrm{K}^{+}\right)$ & 1,1342 \\
Bicarbonato & $\left(\mathrm{HCO}_{3}-\right)$ & 0,4079 \\
Bromuro & $\left(\mathrm{Br}^{-}\right)$ & 0,1890 \\
Ácido bórico & $\left(\mathrm{H}_{3} \mathrm{BO}_{3}\right)$ & 0,0756 \\
Estroncio & $\left(\mathrm{Sr}^{2+}\right)$ & 0,0219 \\
Flúor & $\left(\mathrm{F}^{-}\right)$ & 0,0037 \\
\hline \multicolumn{2}{c}{ TOTAL } & $\mathbf{1 0 0}$
\end{tabular}

No obstante, el deterioro en su conjunto no es tan rápido ni extremo como el ataque por los iones sulfato, aunque no por ello deja de ser lento y seguro en el tiempo. Y ello es debido, no sólo a que la cantidad de iones sulfato del agua de mar dista mucho de su saturación (lo que la diferencia de las aguas de los terrenos yesíferos y selenitosos que pueden llegar a acercarse bastante más a la saturación), sino que también y sobre todo, la formación previa de cloro-aluminatos de calcio hidratados, dificulta ulteriores ataques químicos agresivos de otras sales, entre ellas de los iones sulfato (Lannegrand y cols. 2001; Jones y cols. 2003), los cuales no por ello dejan de formar ettringita expansiva cuando deben y en la cantidad que deben en cada momento.

Y en cuanto al mecanismo de actuación del agua de mar sobre el hormigón, se puede decir que en el interior del hormigón, el agua de mar que rellena su red de poros, producirá la transformación de su microestructura. Así, se formarán aquellos compuestos más estables en el nuevo medio. De este modo, la calcita de la "piel" del hormigón se disuelve y se transforma en aragonito, que es el polimorfo de carbonato de calcio más estable en presencia de iones magnesio. Se estima que esta capa superficial de aragonito deja de ser continua después de tres meses en contacto con el agua de mar, aún así es capaz de producir la ralentización de la difusión de las especies iónicas hacia el interior del hormigón en las primeras semanas (Conejaud, 1980). Entre la superficie y el interior del hormigón se establece un elevado gradiente de $\mathrm{pH}$ (aprox. de entre $7 \mathrm{y}$ 13). Por encima de un valor de $\mathrm{pH}$ de 11, el hidróxido de magnesio es muy poco soluble, formándose una capa de brucita, $\mathrm{Mg}(\mathrm{OH})_{2}$, que se densifica un poco después a la misma velocidad que el aragonito. La capa de brucita formada es de espesor muy pequeño $(20$ a $50 \mu \mathrm{m})$ y se sitúa justo por encima de la de aragonito. Los productos de hidratación del cemento constitutivo del hormigón, serán consumidos progresivamente según sus productos de solubilidad. El primero de ellos será la portlandita, según la reacción química siguiente: 
COMPORTAMIENTO SULFÁTICO Y MECÁNICO-RESISTENTE DE CEMENTOS PORTLAND CON ELEVADOS

$$
\mathrm{Mg}^{2+}+\mathrm{Ca}(\mathrm{OH})_{2} \rightarrow \mathrm{Mg}(\mathrm{OH})_{2}+\mathrm{Ca}^{2+}
$$

Los iones calcio así liberados pueden entonces participar en la formación de diversos precipitados, por ejemplo: yeso, ettringita (el agua de mar aporta los iones sulfato) y/o sal de Friedel (el agua de mar aporta los iones cloruro). De nuevo puede encontrarse en este ejemplo una continuidad de los "engranajes químicos", y cómo la liberación de iones comunes, como el $\mathrm{Ca}^{2+}$, en diversas reacciones, posibilita que se sucedan otras. Después de la disolución de la portlandita, sigue la descalcificación del gel CSH, y así sucesivamente siguiendo el orden de los productos de solubilidad de los diferentes productos de hidratación. Después de un corto período de tiempo tras el que se establece el nuevo régimen estacionario, el interior del hormigón ha quedado casi completamente aislado del medio ambiente (Conjeaud, 1980). Se deduce que ninguno de los iones liberados por el ataque del ión magnesio escapa al agua de mar, y por tanto que todos los productos de reacción quedan atrapados en las capas superficiales. Por consiguiente, la resistencia del hormigón al agua de mar depende mucho más de la composición química del cemento que de la resistencia de las capas superficiales a la abrasión y a los desgastes mecánicos producidos por el entorno (la arena, la zona de marea), aunque dicha resistencia física deba también ser tenida muy en cuenta. No obstante, la porosidad juega un papel fundamental, al igual que en todos los ataques agresivos. Como ya había remarcado Le Chatelier, y al igual que en el ataque por los iones sulfato, se han de considerar con precaución y evitar aquellos procesos que conducen a la formación de cristales de grandes dimensiones, no en la superficie, sino en el seno de la pasta de cemento, ya que las fuerzas de crecimiento cristalino van a producir un hinchamiento destructivo. Es el caso de la ettringita y de los sulfoaluminatos análogos formados con los iones sulfato del agua de mar. De aquí que, análogamente al ataque por los iones sulfato, existan especificaciones relativas al contenido de $C_{3} A$ de los cementos resistentes al agua de mar, así como también, el de $\mathrm{Al}_{2} \mathrm{O}_{3}{ }^{r-}$ y $\mathrm{SiO}_{2}{ }^{r-}$, de las puzolanas.

\section{I.4.- Comportamiento del cemento Portland con adiciones minerales inorgánicas frente al ataque de los sulfatos $\left(\mathrm{SO}_{4}{ }^{2-}\right)$}

\section{I.4.1.- Introducción.}

El problema existente relacionado con el ataque de los cementos Portland por los iones sulfato, se abordó en un principio en EEUU tratando de disminuir cuantitativamente el contenido de $\mathrm{C}_{3} \mathrm{~A}$ procedente del cemento Portland, en el conjunto de la masa del hormigón. Con este objetivo parte de aquél se sustituía físicamente, hasta los límites máximos permisibles, por determinados materiales, generalmente inorgánicos, más ó menos rocosos y molidos, y de contenidos variable en silicatos. A dichos materiales se les denominó genéricamente adiciones, inertes ó activas; a su vez a estas últimas se las denominó de un modo general, con el término puzolanas ó escorias siderúrgicas.

En general los resultados que se obtuvieron vinieron a ser tan heterogéneos e inconexos, a veces, como las adiciones empleadas, habiéndolos de todos los gustos y cuantías, de tal modo que comprendían una gama que se extendía desde muy buenos a muy malos, y sobre todo con el natural apelativo genérico del momento de que "esta adición inerte ó aquella puzolana..., mejora la 
resistencia a los sulfatos de tal cemento... y aquella otra lo empeora...", es decir, sin pretenderlo se había desembocado en la "casuística".

Obviamente la ingeniería civil y la arquitectura, ambos campos prácticos fundamentales de utilización de todos estos materiales, no podían hacer recaer su responsabilidad y ejecutoria en la "casualidad" del buen ó mal comportamiento de tal ó cual adición con tal ó cual cemento Portland, dilucidado siempre, en su caso, merced a largas investigaciones previas, no carentes de metodología pragmática, y si por el contrario y como es lógico en la casualidad metodológica del mismo. Por todo lo cual, paralelamente a estas investigaciones y posiblemente por los resultados proporcionados por las mismas, se hizo imprescindible y necesario abordar además el problema, estudiando con detenimiento el comportamiento de una gran variedad de cementos Portland y más concretamente de sus correspondientes clínkeres, seleccionados por las cantidades respectivas de sus componentes fundamentales ("alita", "belita", "celita", "bronwmillerita" y "ferritas", más ó menos cristalinos), frente a la acción de los diversos sulfatos.

Fruto de todo ello fue la puesta en marcha de varias investigaciones (Miller, 1928, 1942; Wolochow, 1952; Santarelli, 1941) a veces solapadas en el tiempo con las anteriores, de la que se obtuvieron un gran número de resultados en las últimas décadas.

Por otra parte Kalousek, Porter y Benton (Kalousedy cols. 1972), señalaron que las limitaciones normalizadas actualmente sobre los contenidos porcentuales potenciales calculados de $\mathrm{C}_{3} \mathrm{~A}$ y $\mathrm{C}_{4} \mathrm{AF}+\mathrm{C}_{3} \mathrm{~A}$ de los cementos Portland de elevada resistencia al ataque de los iones sulfato (CEM IV/B) no son la única y mejor respuesta al problema del ataque sulfático, ya que según ellos, la esperanza de vida media ante un ataque sulfático, de algunos hormigones de elevada calidad preparados con tales cementos, es de menos de 50 años.

Estos fenómenos están también relacionados con:

- Las aseveraciones realizadas, mucho antes, por Santarelli (1941), en el sentido de que no se puede olvidar la posibilidad de ataque sulfático adicional, aunque más lento, de la fase "ferrítica", cuya composición es variable según la saturación de $\mathrm{Al}_{2} \mathrm{O}_{3}$ del $\mathrm{MF}, \% \mathrm{Al}_{2} \mathrm{O}_{3} /$ $\% \mathrm{Fe}_{2} \mathrm{O}_{3}$ y su proporción en el clínker.

- Lo afirmado por Thorwaldson (1952) de que las probetas carentes de $\mathrm{C}_{3} \mathrm{~A}$, en las que el $\mathrm{Al}^{3+}$ está, todo él, como $\mathrm{C}_{4} \mathrm{AF}$, fueron atacadas por disoluciones al $2 \%$ de $\mathrm{Na}_{2} \mathrm{SO}_{4}$ ó $\mathrm{MgSO}_{4}$, con intensidad menor de lo que lo fueron las probetas de mortero hechas con $\mathrm{C}_{3} \mathrm{~A}$ puro, pero mayor que sus homónimas de $\mathrm{C}_{3} \mathrm{~S}$ puro, $\mathrm{y}$

- Lo afirmado por Bogue (1959) de que probetas de mortero de cemento con 15\% de $\mathrm{C}_{4} \mathrm{AF}$, permanecieron más de 10 años en disolución de $\mathrm{NaSO}_{4}$, y no mostraron señal alguna de expansiones,, por el contrario y en contra de lo que cabría esperar, sus homónimas del $24 \%$ al $27 \%$ de $\mathrm{C}_{4} \mathrm{AF}$, se destruyeron a los 2 años.

Y volviendo de nuevo a la temática primitiva, se observa que como resultado de los trabajos llevados a cabo por entonces, se obtuvo la primera gran conclusión sobre la misma, circunscrita única y exclusivamente a los cementos Portland, y es que "la resistencia potencial de un cemento Portland al ataque de los iones sulfato era y es función inversa, principalmente, de su contenido de $C_{3} A$ ". Por cuya razón se hizo patente la gran vulnerabilidad de los cementos cuyos contenidos respectivos de $\mathrm{C}_{3} \mathrm{~A}$ y $\mathrm{C}_{4} \mathrm{AF}$ estuviesen por encima de unos límites que actualmente ya se encuentran como especificaciones y/o limitaciones diversas en los distintos países con tecnología avanzada. 
COMPORTAMIENTO SULFÁTICO Y MECÁNICO-RESISTENTE DE CEMENTOS PORTLAND CON ELEVADOS

Tales cementos, calificados genéricamente como "cementos Portland Resistentes a los Sulfatos", en España pasarían a denominarse, en principio, "cementos Portland Resistentes a las Aguas Selenitosas o Cementos PAS" (Pliego PCCH-64). En este sentido conviene señalar los trabajos previos realizados al efecto en el IETCC por Soria (1966). Posteriormente, y a partir de 1975, a tales cementos se les denominó "cementos Portland Resistentes al Yeso", PY (Pliego RC-75).

Estos cementos, clasificados siempre dentro de los cementos Portland, aunque diferenciados, como se verá, de ellos, se caracterizan en todos los países por tener limitados los contenidos porcentuales ponderales calculados de $\mathrm{C}_{3} \mathrm{~A}$ y $\mathrm{C}_{4} \mathrm{AF}$, solos o en coyunda, siendo para España el máximo del 5\% para el primero y el máximo del 22\% para la suma de ambos (Instrucción RC-16).

\section{I.4.2.- Tipos de ataque por los iones sulfato a los materiales de base cemento (SO $\left.{ }^{2-}\right)$.}

\section{I.4.2.1.- Ataque por el sulfato de calcio en forma de yeso, $\mathrm{CaSO}_{4} \cdot 2 \mathrm{H}_{2} \mathrm{O}$.}

Este tipo de ataque químico es el que se le produce en presencia de agua, a los elementos de hormigón en contacto con terrenos yesíferos y selenitosos, principalmente. Se debe entender, en el caso de los suelos, que el ataque del hormigón por los iones sulfato de los mismos se produce si éstos se movilizan por su disolución previa en el agua, teniendo lugar en uno u otro grado de intensidad -débil, medio o fuerte- según la concentración en sulfato que se alcance. Los efectos negativos de este ataque químico se producen con rapidez, y se traducen en agrietamiento y pérdida de resistencia mecánica, debido al gran incremento de volumen que se produce en la pasta endurecida del cemento constitutivo del hormigón.

Los efectos negativos de este ataque químico se producen con rapidez, y se traducen en agrietamiento y pérdida de resistencia mecánica, debido al gran incremento de volumen que se produce en la pasta endurecida del cemento constitutivo del hormigón.

Este ataque químico se produce mediante una serie de reacciones químicas expansivas entre determinadas fases y productos de hidratación del cemento Portland (con o sin adiciones puzolánicas y escorias siderúrgicas), y los aniones sulfato, $\mathrm{SO}_{4^{2-}}$. Fundamentalmente, estas reacciones químicas expansivas son la formación de monosulfoaluminato de calcio hidratado o Fase $A F m$, a partir del aluminato tricálcico, $C_{3} A$, del cemento Portland $(\mathrm{CP})$ o a partir de la alúmina reactiva, $\mathrm{Al}_{2} \mathrm{O}_{3^{r}}$, o alúmina tetra o penta-coordinada (Talero, 1986; Trusilewicz, y cols. 2012) de las adiciones puzolánicas (AP) (las de carácter alumínico o alumínico-silícico principalmente (Talero, 1986, Talero, 1993b; 1996; Talero y cols. 1999) o a partir del aluminato monocálcico vítreo, CA, de las escorias siderúrgicas. No obstante, tales fuentes de aluminato también originan el trisulfoaluminato de calcio hidratado o Fase AFt o ettringita, o "bacilo del cemento" (su estructura fue establecida en 1970 por Moore y col. (1970)), mucho más expansiva que el monosulfoaluminato. La Fase AFt se forma siempre antes que la Fase AFm, pudiéndose incluso mantener como tal si la cantidad de sulfatos presentes es al menos tres veces mayor que la de aluminatos, como así ocurre en el caso de las referidas aguas yesíferas o selenitosas, y transformándose total o parcialmente en Fase AFm en los casos contrarios. Éste es el motivo por el cual las aguas con sulfato de calcio son tan agresivas para el cemento Portland ordinario o común, es decir, para aquellos cementos que no poseen la característica SR. Adicionalmente, en estas condiciones de exceso de iones sulfato también se puede producir neo-formación de yeso a partir de la portlandita o a partir de elevadas concentraciones de 
$\mathrm{Ca}^{2+}$ provenientes de nuevos procesos de hidratación de las fases que permanecían anhidras, lo que también lleva aparejado un aumento relativo del volumen.

Las reacciones químicas de formación de ambos sulfoaluminatos y las relaciones de volumen con sus respectivos aluminatos originarios son las que se recogen a continuación:

$$
\begin{array}{lcc}
\text { CP-Fase AFm: } & \mathrm{C}_{3} \mathrm{~A}+\mathrm{CaSO}_{4} \cdot 2 \mathrm{H}_{2} \mathrm{O}+10 \mathrm{H}_{2} \mathrm{O} \rightarrow \mathrm{C}_{3} \mathrm{~A} \cdot \mathrm{CaSO}_{4} \cdot 12 \mathrm{H}_{2} \mathrm{O} \\
\text { Vol. Molar } & 88,8 & 319,1 \\
\text { Rel. Volumen } & 1 & 3,6 \\
\text { AP-Fase AFm: } & \mathrm{Al}_{2} \mathrm{O}_{3}^{r-}+3 \mathrm{CaO}+\mathrm{CaSO}_{4} \cdot 2 \mathrm{H}_{2} \mathrm{O}+10 \mathrm{H}_{2} \mathrm{O} \rightarrow \mathrm{C}_{3} \mathrm{~A} \cdot \mathrm{CaSO}_{4} \cdot 12 \mathrm{H}_{2} \mathrm{O}
\end{array}
$$

Vol. Molar

29,1 (Volumen molar del $\gamma-\mathrm{Al}_{2} \mathrm{O}_{3}$ )

319,1

Rel. Volumen

1

10,9

CP- Fase AFt: $\quad \mathrm{C}_{3} \mathrm{~A}+3 \mathrm{CaSO}_{4} \cdot 2 \mathrm{H}_{2} \mathrm{O}+25 \mathrm{H}_{2} \mathrm{O} \rightarrow \mathrm{C}_{3} \mathrm{~A} \cdot 3 \mathrm{CaSO}_{4} \cdot 31 \mathrm{H}_{2} \mathrm{O}$

$\begin{array}{ll}\text { Vol. Molar } \quad 88,8 & 714,7\end{array}$

Rel. Volumen 1

8,0

AP-Fase AFt $: \quad \mathrm{Al}_{2} \mathrm{O}_{3}^{r-}+3 \mathrm{CaO}+3 \mathrm{CaSO}_{4} \cdot 2 \mathrm{H}_{2} \mathrm{O}+25 \mathrm{H}_{2} \mathrm{O} \rightarrow \mathrm{C}_{3} \mathrm{~A} \cdot 3 \mathrm{CaSO}_{4} \cdot 31 \mathrm{H}_{2} \mathrm{O}$

Vol. Molar

29,1 (Volumen molar del $\gamma-\mathrm{Al}_{2} \mathrm{O}_{3}$ )

714,7

Rel. Volumen 1

28,3

En el caso de la reacciones (r33) y (35), las relaciones de volumen deben ser mayores aún, ya que se ha supuesto que el volumen molecular de la alúmina reactiva de las adiciones puzolánicas, $\mathrm{Al}_{2} \mathrm{O}_{3}{ }^{r-}$, es el de la $\gamma-\mathrm{Al}_{2} \mathrm{O}_{3}$, y con toda seguridad dicha suposición es errónea, ya que debe ser menor lógicamente. Por otra parte, se ha demostrado también que la velocidad de formación de la ettringita de este último origen, es decir, de la $\mathrm{Al}_{2} \mathrm{O}_{3}{ }^{{ }^{-}}$de las puzolanas, ya sean naturales o artificiales, es aproximadamente diez veces mayor que la de formación de la ettringita de origen $C_{3} A$ del cemento Portland, y en justa correspondencia, el tamaño de aquélla es alrededor de diez veces menor que el de ésta (Talero, 2002; 2003a; 2003b; 2005a; 2007; 2009). Véanse al efecto ambas ettringitas en las Figura I-22. La razón estriba en que la $\mathrm{Al}_{2} \mathrm{O}_{3}{ }^{r-}$ se encuentra en el estado físicoquímico ideal para que se lleve cabo dicha reacción química (r33), y del mismo modo la (r35). En cambio, el $C_{3} A$ de los cementos Portland se encontraría en situación diferente, es decir, en el estado físico-químico no ideal, o, al menos, en la forma menos ideal para obtener el mismo resultado. De aquí que la velocidad de formación de la ettringita de este origen sea sensiblemente menor. Consecuentemente, el $C_{4} A F$ forma ettringita mucho más lentamente todavía. Por todo ello, han venido a denominarse ettringita de rápida formación (ett-rf), ettringita de lenta formación (ett-lf) y ettringita de muy lenta formación (ett-vlf), respectivamente.

Pero es que además, en vista de que todas las adiciones activas, en general, y las puzolánicas, en particular, se utilizan habitualmente incorporadas al cemento Portland en fábrica o al hormigón en planta, cuando se lleva a cabo el ataque de los sulfatos, ya sea en el laboratorio o en obra real, dichos sulfatos reaccionan al mismo tiempo con la alúmina reactiva, $\mathrm{Al}_{2} \mathrm{O}_{3}{ }^{r^{-}}$de la 
COMPORTAMIENTO SULFÁTICO Y MECÁNICO-RESISTENTE DE CEMENTOS PORTLAND CON ELEVADOS CONTENIDOS DE PUZOLANAS (> 40\%): SU FUNDAMENTO QUÍMICO Y JUSTIFICACIÓN DE OTRAS CONSECUENCIAS POSIBLES

fracción puzolana y con el $C_{3} A$ de la fracción cemento Portland del cemento de mezcla correspondiente (Talero, 2010). De modo y manera que la formación conjunta de ambas ettringitas, ett-rf y ett-lf, en dicho medio sulfático común, no se realiza de una manera independiente sino interdependiente, combinada e interactiva entre las dos (Talero, 2005a; 2007; 2009). Además, cuanto más próximas entre sí se encuentren las partículas de $\mathrm{Al}_{2} \mathrm{O}_{3}{ }^{r^{-}}$y de $\mathrm{C}_{3} \mathrm{~A}$, caso de los cementos de mezcla cemento Portland/puzolana, con elevado porcentaje de sustitución, más interdependiente es su formación conjunta o co-precipitación. Esto significa que ambas ettringitas se forman en mayor o menor medida, aunque el producto de reacción final de dichos cementos de mezcla esté más próximo a la ett-rf que a la ett-lf, y al contrario, en el caso del cemento de mezcla de menor porcentaje de sustitución (Talero, 2005a; 2007; 2009).

(a)

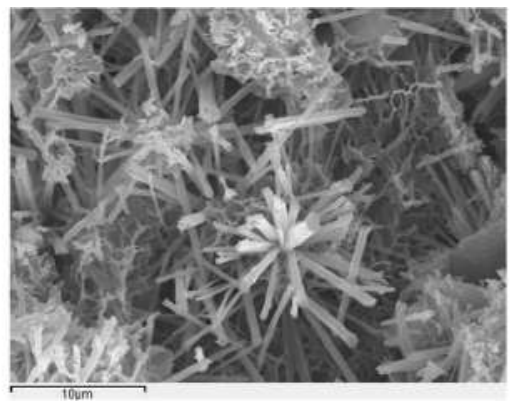

(b)

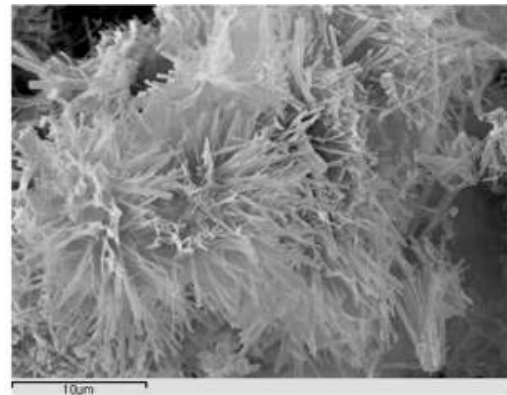

Figura I-22.- MICROFOTOGRAFÍAS DE MICROSCOPÍA ELECTRÓNICA DE BARRIDO (X1000); (A) ETTRINGITA DE LENTA FORMACIÓN, DE ORIGEN CEMENTO PORTLAND; (B) ETTRINGITA DE RÁPIDA FORMACIÓN DE ORIGEN PUZOLÁNICO.

El efecto expansivo resultante de esta interdependencia entre la ett-rf y ett-lf durante su coprecipitación conjunta en un medio sulfático común, es siempre más sinérgico que aditivo, por cuyo motivo ha sido denominado "Efecto Sinérgico Expansivo", ESE (Talero, 2010), cuya consecuencia final es que a igualdad de todo lo demás y tanto en el laboratorio como en la realidad, el ataque sulfático agresivo a tales cementos de mezcla (con tales puzolanas alumínicas y alumínico-silícicas principalmente) se lleva a cabo siempre más pronto que a su propio cemento Portland puro, siendo además este efecto tan deletéreo para el hormigón y tan rápido, que ha justificado también haberle podido denominar con fundamento "ataque rápido del yeso". Lógicamente y por el contrario, la formación de la ett-rf y la ett-vlf, o de origen $C_{4} A F$ del cemento Portland, no es combinada, sino independiente.

Por todo ello, se ha puesto de manifiesto, de forma clara, el papel tan importante que pueden llegar a jugar en el ataque de los sulfatos, las fracciones de sílice reactiva, $\mathrm{SiO}_{2}{ }^{\mathrm{r}-}$, y alúmina reactiva, $\mathrm{Al}_{2} \mathrm{O}_{3}{ }^{\mathrm{r}}$, especialmente, que forman parte de la composición de las adiciones puzolánicas en mayor o menor medida. Y tanto, si su estado físico es vítreo, caso de las cenizas volantes, el humo de sílice y las diatomeas, cuanto más si es amorfo, caso de los metacaolines y demás arcillas activadas, o si su estado físico es una mezcla aleatoria de ambos estados físicos, caso de la puzolana natural canaria, la cual incluso posee además una fracción apreciable zeolítica, que es cristalina, aunque también puzolánica, no obstante.

La razón de tan importante papel estriba en que la $\mathrm{Al}_{2} \mathrm{O}_{3}{ }^{r-}$ de las puzolanas posee la capacidad cierta de reaccionar químicamente, en medio acuoso, con la portlandita (y con la cal 
apagada) y los sulfatos, para originar también ettringita a mayor velocidad, y de menor tamaño, lógicamente, pero no por ello menos expansiva, sino todo lo contrario porque es más expansiva incluso, que la que forma el $\mathrm{C}_{3} \mathrm{~A}$ de los $\mathrm{CPO}$. Es decir, posee la capacidad cierta de participar de forma explícita en dicho ataque agresivo y promoverlo por ello, hasta el punto de poder acelerarlo y de forma muy notable incluso, por la estimulación de la hidratación selenitosa que le provoca al $\mathrm{C}_{3} \mathrm{~A}$, que no en cambio al $\mathrm{C}_{3} \mathrm{~S}$, de la fracción del $\mathrm{CPO}$ con el que se ha mezclado la puzolana, como consecuencia de la actividad puzolánica tan específica, por elevada, temprana y rápida que logra desarrollar previamente, desde el inicio de la hidratación. En definitiva, la $\mathrm{Al}_{2} \mathrm{O}_{3}{ }^{\mathrm{r}-}$ comienza siendo promotora del ataque de los sulfatos y termina siendo facilitadora del mismo, es decir, es "proataque" de los sulfatos.

$\mathrm{La} \mathrm{SiO}_{2}{ }^{\mathrm{r}-}$, en cambio, no posee la capacidad de originar ettringita como la $\mathrm{Al}_{2} \mathrm{O}_{3^{\mathrm{r}} \text {, aunque no }}$ por ello deja de ejercer, no obstante, su influencia también en dicho ataque agresivo, pero de forma implícita nada más. En función de las propiedades físicas de la puzolana los resultados finales, pueden llegar a ser totalmente diferentes por contrarios u opuestos, pero acordes, en cualquier caso, al tamaño medio y la morfología de sus partículas:

- si son del tipo diatomeas, rocas opalinas y similares, no poseen la misma capacidad estimuladora, por vía indirecta, de las reacciones de hidratación selenitosa que la $\mathrm{Al}_{2} \mathrm{O}_{3}{ }^{\mathrm{r}}$ promueve de forma explícita. En cambio, promueve el efecto protector de dilución física derivado del reemplazo, junto con el de dilución química de la portlandita originada inicialmente merced a la elevada succión capilar de agua de amasado y de cualquier otro tipo, que ejercen sus partículas, lo que, sin duda alguna, facilita el ingreso muy rápido de los sulfatos al interior del hormigón, el mortero o la pasta que las contiene. Finalmente llegan a generar geles C-S-H en cantidad suficiente para conferir la protección necesaria, aunque para entonces, la expansión que se ha producido, a igualdad de todo lo demás, sea algo mayor que la de su propio CPO puro, cuyas probetas continuarán expandiendo si aún hay cantidad de sulfatos en exceso; sin embargo, aquellas que contienen estas puzolanas, no porque habían dejado de expandir mucho antes (Talero 2012; 2013), puesto que habrían generado ya para entonces y pese a todo, cantidades de geles C-S-H suficientes y necesarios para impedir totalmente dicha expansión.

- si son del tipo humo de sílice, la estimulación de la hidratación selenitosa por vía indirecta sí la pueden ejercer (Talero 2012; 2013), pero únicamente y en el mejor de los casos, hasta las primeras 16 horas a lo sumo (Talero y col. 2009), puesto que a partir de esa edad tan temprana deja de ejercerla (es decir, el tiempo que ha necesitado el humo de sílice para generar cantidad de gel C-S-H suficiente para comenzar a actuar en sentido contrario o "protector" frente al ataque de los sulfatos, desde el punto de vista físico-químico). Además, tanto más deja de ejercerla cuanto más progresa la hidratación selenitosa, es decir, cuanto mayor cantidad de gel C-S-H ha logrado generar, hasta el punto de llegar a tornarse en la opuesta, por llegar a desestimularla e, incluso, a dificultarla e impedirla en su totalidad, ergo, termina por ser también "protectora", en las mismas circunstancias del ataque de los sulfatos. No obstante, la estimulación por vía directa también la debe de ejercer, y algo más allá incluso quizás de los 28 días de edad (Talero 2012; 2013), puesto que hasta esas edades dicho efecto "protector" ha sido menor con el aumento del porcentaje de reemplazo, mientras que a partir de esas edades fue mayor, y fue incluso bastante mayor que el de las 
COMPORTAMIENTO SULFÁTICO Y MECÁNICO-RESISTENTE DE CEMENTOS PORTLAND CON ELEVADOS

diatomeas visto con anterioridad, aunque en cualquier caso ambos fueron de tal magnitud que pudieron ser calificados de "anti-ataque de los sulfatos", es decir, todo lo contrario al calificativo que se le adscribiera antes a la $\mathrm{Al}_{2} \mathrm{O}_{3}{ }^{\mathrm{r}-}$ en las mismas circunstancias.

\section{I.4.2.2.- Ataque por el sulfato de magnesio, $\mathrm{MgSO}_{4}$.}

Este otro taque químico agresivo también se denomina "ataque del subsuelo de las zonas yesíferas" (caso de España). Y básicamente, es un ataque producido por disoluciones de $\mathrm{MgSO}_{4}$. Este otro tipo de sulfato agresivo en presencia de aguas subálveas, de escorrentía o de manantial, ataca a la pasta de cemento que compone el hormigón, siendo considerado, en general, como el más agresivo de todos los sulfatos para el hormigón de cemento debido a la acción agresiva simultánea de:

- el catión magnesio, $\mathrm{Mg}^{2+}$, por intercambio iónico con el Ca ${ }^{2+}$ (Talero, 1991; Talero 2005b), según la serie liófila o liotropa, de la portlandita y de los silicatos y aluminatos de calcio hidratados, produciendo su descalcificación, para formar brucita, $\mathrm{Mg}(\mathrm{OH})_{2}$, y las correspondientes sales de magnesio, que al no ser hidráulicas provocan pérdida de cohesión y resistencias mecánicas, siendo finalmente arrastradas por el agua, o permanecen in situ en el hormigón pero sin capacidad conglomerante, y

- los iones sulfato, $\mathrm{SO}_{4}{ }^{2-}$, a los aluminatos del cemento la cual se produce de modo similar a la originada por el yeso, dependiendo su grado de protagonismo de la concentración de $\mathrm{MgSO}_{4}$ de la disolución agresiva.

De este modo, y según sea la citada concentración de $\mathrm{MgSO}_{4}$, el ataque que produce al hormigón se puede catalogar como corrosión puramente sulfática, corrosión sulfoalumínico-selenitosa o corrosión magnésico-selenitosa; no obstante, si la concentración de $\mathrm{Mg}^{2+}$ es baja, la agresividad del agua en cuestión es escasa o nula, y por el contrario, si la concentración de $M g^{2+}$ es elevada, la agresividad del agua es también elevada o muy elevada.

A continuación se expone a título de ejemplo, la reacción del $\mathrm{MgSO}_{4}$ con la portlandita:

$$
\mathrm{Ca}(\mathrm{OH})_{2}+\mathrm{MgSO}_{4}+2 \mathrm{H}_{2} \mathrm{O} \rightarrow \mathrm{Mg}(\mathrm{OH})_{2}+\mathrm{CaSO}_{4} \cdot 2 \mathrm{H}_{2} \mathrm{O}
$$

Vol. Molar $\quad 31,0$

Rel. Volumen
1
74,2

2,2

Por último y para prevenir en cualquier caso este otro ataque sulfático agresivo, se han de utilizar también los mismos cementos prescritos para el caso del ataque del yeso, es decir, cementos que posean la característica SR. Y en el supuesto posible que contengan adiciones activas, éstas habrán de poseer las mismas características químicas que para el caso del referido ataque del yeso, sin menoscabo de tener que proporcionarle además al hormigón, en casos extremos de ataque, protección pasiva (adecuada dosificación, colocación y puesta en obra y curado hídrico con protección externa inclusive si es necesario), y protección activa incluso (eliminación del agua agresiva mediante descenso del nivel de la capa freática o su desecación electroosmótica, e incluso, neutralización química o bacteriológica de la misma). 


\section{I.4.2.3.- Ataque por el Sulfato de sodio, $\mathrm{Na}_{2} \mathrm{SO}_{4}$}

Este otro tipo de ataque sulfático agresivo se da por diversas regiones de América del Norte y del Sur. Nuevamente, es un ataque de los iones sulfato. Junto a éste se produce otro ataque, de menor importancia, el de intercambio iónico según la serie liófila o liotropa (Talero, 1991; Talero 2005b) entre el ión $\mathrm{Na}^{+}$y el $\mathrm{Ca}^{2+}$ en todas sus formas presentes en el hormigón, haciéndolas solubles en el agua cuando antes no lo eran, produciendo su descalcificación, y si las características químicofísicas del árido son favorables, además, reacción árido-álcali (Veronelli, 1979).

$$
\begin{array}{ccc}
\multicolumn{2}{c}{\mathrm{Ca}(\mathrm{OH})_{2}+\mathrm{Na}_{2} \mathrm{SO}_{4} \cdot 10 \mathrm{H}_{2} \mathrm{O} \rightarrow 2 \mathrm{NaOH}+\mathrm{CaSO}_{4} \cdot 2 \mathrm{H}_{2} \mathrm{O}+8 \mathrm{H}_{2} \mathrm{O}} \\
\text { Vol. Molar } & 31,0 & 74,2 \\
\text { Rel. Volumen } & 1 & 2,2
\end{array}
$$

Una vez formado el yeso, los aniones sulfato, originan con el cemento Portland puro o con adiciones, ettringita, al igual que en el caso del ataque por yeso únicamente. Por lo tanto, y en definitiva, como consecuencia de este tipo de ataque sulfático agresivo, la estructura de hormigón atacada no tendrá unas fisuraciones tan acusadas como en el ataque del yeso, aunque sí en cambio se habrá reblandecido lentamente con pérdidas notables de resistencias mecánicas en todos los casos. Finalmente, en todos aquellos casos en los que el árido sea además reactivo frente a los álcalis del cemento, este ataque sulfático podrá ir acompañado también por el de reactividad árido-álcali (Veronelli, 1979).

Este tipo de ataque sulfático agresivo se dificulta e incluso impide del mismo modo que el ataque del yeso, y en caso de severidad extrema, como el ataque del sulfato magnésico. Por último, el ataque del sulfato de potasio, $\mathrm{K}_{2} \mathrm{SO}_{4}$ es muy semejante al de $\mathrm{Na}_{2} \mathrm{SO}_{4}$.

\section{I.4.3.- Causas: formación de sulfato-aluminatos de calcio hidratados expansivos}

La interacción entre los cementos Portland y los iones sulfato a los que se ha hecho referencia con anterioridad, por su transcendencia tecnológica y/ó científica, ha sido y continúa siendo investigada, a nivel mundial, habiéndose encontrado que, generalmente, por la acción de los iones sulfato sobre los compuestos mineralógicos de hierro y aluminio del cemento Portland hidratado, y de un modo especial sobre la fase ferrítica, se forman unos compuestos que según $\mathrm{H}$. Kühl (1961) se clasifican en las categorías y tipos siguientes:

Categoría A: Las sales complejas de aluminato tricálcico:

Tipo I: $3 \mathrm{CaO} \cdot \mathrm{Al}_{2} \mathrm{O}_{3} \cdot 3 \mathrm{CaSO}_{4} \cdot 30$ ó $32 \mathrm{H}_{2} \mathrm{O}$

$\mathrm{C}_{3} \mathrm{~A} \cdot 3 \mathrm{CaSO}_{4} \cdot 30$ ó $32 \mathrm{H}_{2} \mathrm{O}$, ó bien $\mathrm{C}_{6} \mathrm{AS}_{3} \mathrm{H}_{30}$

$\mathrm{C}_{3} \mathrm{~A} \cdot \mathrm{CS}_{3} \cdot \mathrm{H} 30$ ó 32

Tipo II: $3 \mathrm{CaO} \cdot \mathrm{Al}_{2} \mathrm{O}_{3} \cdot \mathrm{CaSO}_{4} \cdot 12 \mathrm{H}_{2} \mathrm{O}$

$\mathrm{C}_{3} \mathrm{~A} \cdot \mathrm{CaSO}_{4} \cdot 12 \mathrm{H}_{2} \mathrm{O}$, ó bien, $\mathrm{C}_{4} \mathrm{ASH}_{12}$

\section{$\mathrm{C}_{3} \mathrm{~A} \cdot \mathrm{CSH}_{12}$}

Categoría B: las sales complejas de ferrito tricálcico: 
COMPORTAMIENTO SULFÁTICO Y MECÁNICO-RESISTENTE DE CEMENTOS PORTLAND CON ELEVADOS

Tipo I: $3 \mathrm{CaO} \cdot \mathrm{Fe}_{2} \mathrm{O}_{3} \cdot 3 \mathrm{CaSO}_{4} \cdot 32 \mathrm{H}_{2} \mathrm{O}$

Tipo II: $3 \mathrm{CaO} \cdot \mathrm{Fe}_{2} \mathrm{O}_{3} \cdot \mathrm{CaSO}_{4} \cdot 12 \mathrm{H}_{2} \mathrm{O}$

Las sales de la Categoría A se denominan "Fase AFt", las del Tipo I, y "Fase AFm" las del Tipo II, según sean las moléculas de sulfato de calcio que contengan respectivamente, y que se han citado con anterioridad en el apartado 1.3.4.3. Pese a ello, muchos otros investigadores las han venido denominando también de diferentes maneras, a saber:

Para el caso de la primera ó Tipo I, ó "Fase AFt": "Trisulfoaluminato Tricálcico Hidratado", ó "Trisulfoaluminato Hidratado", ó "Trisulfoaluminato" ó "Trisulfato", ó "Trisulfo", ó "Sulfoaluminato de calcio Hidratado: Alto en sulfato", ó "Trisulfato-aluminato Tricálcico Hidratado", aunque se la conoce comúnmente con el nombre de "Ettringita", ó "Sal de Candlot y Michaelis", ó "Bacilo del Cemento".

Para el caso de la segunda fase ó "Fase AFm": "Monosulfoaluminato Tricálcico Hidratado", ó "Monosulfoaluminato Hidrato" ó "Monosulfoaluminato", ó "Monosulfato" ó "Monosulfo", ó "Sulfoaluminato de Calcio Hidratado: Bajo en Sulfato", ó "Monosulfatoaluminato Tricálcico Hidratado"; a esta fase, a diferencia de la anterior, no se la conoce con nombre común alguno, por lo que a lo largo de este trabajo se la designará Fase AFm, ó simplemente AFm.

Y por último, para las sales de la Categoría B se sigue una denominación análoga.

La importancia de los mencionados tipos de sulfato-aluminatos de calcio hidratados, sales de la Categoría $A$, y en especial de la Ettringita, estriba en la influencia que ejerce sobre la hidratación de los cementos por los siguientes motivos:

- por provocar retraso en el tiempo de fraguado de aquellas pastas de cemento Portland que tienen un exceso de yeso,

- por ser causa y efecto de la desintegración del hormigón de cemento Portland por ataque sulfático,

- por ser el origen de las elevadas resistencias mecánicas a edades iniciales de los cementos sobresulfatados, $\mathrm{y}$

- por ser causa y efecto del autopretensado de hormigones de cemento expansivo, ya que estas fuerzas expansivas, controladas debidamente pueden utilizarse para desarrollar esfuerzos de compresión de valor cuantificable y determinado (Lossier, 1952).

De todos ellos, los dos últimos fenómenos se pueden catalogar de no nocivos ó beneficiosos, mientras que a los primeros, de perjudiciales ó dañinos, y de un modo especial el fenómeno segundo.

Por el contrario los sulfato-ferritos de calcio hidratados han sido menos investigados, presumiblemente por menor nocividad (Santarelli, 1941) para el hormigón de cemento Portland, pues en la bibliografía estudiada, no se han encontrado casos reales evidentes en donde se reseñan fenómenos nocivos inmediatos (que hayan tenido lugar en un período de tiempo de 30 ó 40 años), producidos por estos compuestos, y si sólo predicciones de vida útil para algunos hormigones de tal tipo de cemento Portland que los puede originar en gran cuantía (como eran los antiguos cementos PY españoles (Pliego RC-75), actuales SR de la Instrucción RC-16, y similares de otros 
países (-cemento Tipo V en EEUU-), de menos de 50 años, como han demostrado, tras sus investigaciones al respecto, Kalousek y cols. (1972).

En resumen, que dada la trascendencia e interés de los sulfato-aluminatos de calcio hidratados, se ha considerado conveniente estudiarlos con más detalle como se verá seguidamente, por su particular transcendencia en este trabajo.

\section{I.4.3.1 Ettringita ó "Fase AFt"}

De acuerdo con Dana (1932), la ettringita, ó Fase AFt, como mineral natural, se encontró por vez primera en 1847 en inclusiones calizas de lava cercanas a Ettringen y Mayen próximas a Coblenza, Renania, y consistían en diminutos cristales hexagonales coloreados. También se detectó acompañando a la afwillita en la zona de contacto entre calizas y doleritas en Scawt Hill, próximas a Larny County (Irlanda). Y del mismo modo aparece en las minas de Lucky, Tombstone, Cochise y County en Arizona (USA), como producto de alteración de silicatos y aluminatos de calcio y aluminio.

Michaelis (1892) atribuyó expresamente, por vez primera, el ataque sulfático de los hormigones de cemento Portland, a la formación y presencia de ettringita en su seno, por cuyo motivo la denominó "Bacilo del Cemento".

Posteriormente Lerch y cols. (1929), tras informar que Candlot (1890) la había preparado sintéticamente, en forma de esferulitas de algunos $\mathrm{mm}$ de diámetro, mezclando disoluciones saturadas de aluminato de calcio y sulfato de calcio, harían un estudio detallado del sistema para establecer como Kühl (1961), la existencia de dos compuestos, uno "alto en sulfato" -la ettringita- y otro "bajo en sulfato" -el AFm-, que se verá más adelante. Para ello prepararon igualmente ettringita en forma de finas agujas alargadas, las cuales a veces también formaban esferulitas.

Desde entonces la ettringita ha sido y continúa siendo objeto de estudios físico-químicos muy completos, realizados para conocer mejor sus posibles estructuras cristalinas, y también, para conocer el contenido exacto de moléculas de agua y para comprender mejor la causa exacta de su efecto expansivo perjudicial ó beneficioso, en su caso, etc. De aquí que no debe extrañar la abundancia bibliográfica que existe al respecto hasta nuestros días.

Así tenemos que Jones (1938), Kalousek (1941) y D'Ans y col. (1954) principalmente, exploraran el sistema cuaternario $\mathrm{CaSO}_{4}-\mathrm{CaO}-\mathrm{Al}_{2} \mathrm{O}_{3}-\mathrm{H}_{2} \mathrm{O}$ a $20^{\circ} \mathrm{C}$ y $25^{\circ} \mathrm{C}$, para que a continuación Eitel (1957) glosara tales trabajos aclarando algunos extremos y mejorando la representación gráfica del sistema, que se encuentra en la Figura I-23.

En una apreciación general se puede decir que la ettringita forma cristales hexagonales, circulares que se reúnen en agrupaciones estrelladas a modo de "erizo", siendo sus índices de refracción $\mathrm{w}=1.464, \varepsilon=1.458$, su carácter óptico y su densidad 1.73.

Dado que los cristales de ettringita preparados por Kalousek (1941) eran demasiado pequeños para que se pudiese estudiar por microscopio óptico, Midgley y col. (1971), los obtuvieron de tamaño superior (muchos de ellos de dimensiones superiores a $120 \mu \mathrm{m}$ de longitud y 2-3 $\mu \mathrm{m}$ de grosor), haciendo preparaciones adecuadas de cementos sobresulfatados, del mismo modo los detectarían Schwiete y cols. (1969), pero esta vez en forma de agujas muy pequeñas (de alrededor de $0.25 \mu \mathrm{m}$ de longitud y $0.05 \mu \mathrm{m}$ de diámetro). Igualmente Mehta (1969), informó que, en pastas de $\mathrm{C}_{4} \mathrm{~A}_{3} \mathrm{~S}-\mathrm{CS}-\mathrm{C}$ conteniendo una relación agua/sólido baja, la ettringita se formaba a modo 
de cortos prismas hexagonales con una relación grueso/longitud de 1/3, hecho que confirma en otro trabajo (Mehta, 1973) pues dichos prismas cristalinos eran de alrededor de $1 \mu \mathrm{m}$ de longitud y $1 / 4$ $\mu \mathrm{m}$ de grosor. Más adelante el mismo autor (Mehta, 1976a), utilizando diversas mezclas a base de $\mathrm{C}_{3} \mathrm{~A}$ ó $\mathrm{CA}$, por una parte, y yeso, anhidrita y $\mathrm{MgSO}_{4}$ por otra, y todo ello en presencia, ó no, de $\mathrm{Ca}(\mathrm{OH})_{2}$, llega a la conclusión de que sólo se formaban delgadas agujas y esferulitas de ettringita siempre que hubiera suficiente "espacio útil" para ello, y en su defecto, caso de tener una relación agua/sólidos aún menor, la ettringita adoptaba la forma de los cristales prismáticos hexagonales cortos citados anteriormente.
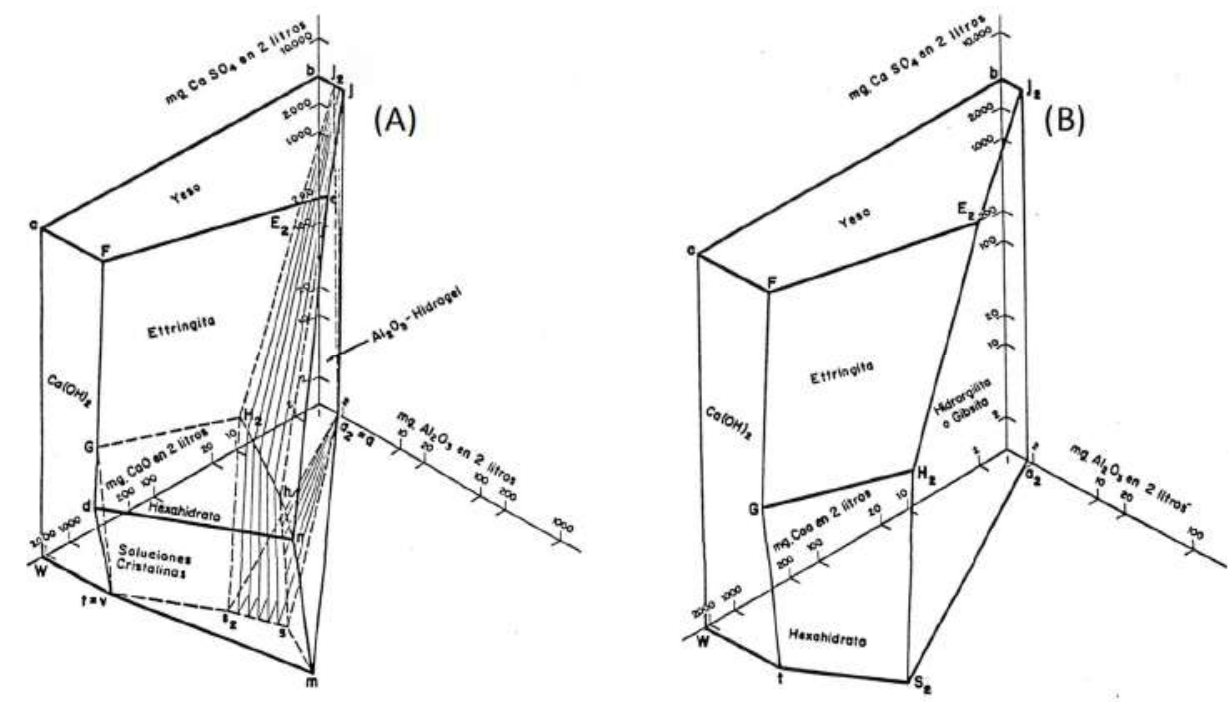

FIGURA I-23.- DIAGRAMA DE EITEL; (A) DIAGRAMA DE CRISTALIZACIÓN METAESTABLE PARA EL SISTEMA CaO$\mathrm{Al}_{2} \mathrm{O}_{3}-\mathrm{CaSO}_{4}-\mathrm{H}_{2} \mathrm{O}$ A $2 \mathrm{O}^{\circ} \mathrm{C}$; (B) DIAGRAMA DE CRISTALIZACIÓN ESTABLE PARA EL SISTEMA CaO-Al2 $\mathrm{O}_{3}-\mathrm{CaSO}_{4}-\mathrm{H}_{2} \mathrm{O}$ A $20^{\circ} \mathrm{C}$.

Y posteriormente el mismo autor (Mehta, 1983), utilizó la microscopia óptica y electrónica y nuevas mezclas distintas de los anteriores (CA-CaO-CaSO $4-\mathrm{H}_{2} \mathrm{O}, \mathrm{CA}, \mathrm{C}_{12} \mathrm{~A} 7, \mathrm{C}_{3} \mathrm{~A}-\mathrm{CaSO}_{4}-\mathrm{H}_{2} \mathrm{O}$, $\mathrm{C}_{2} \mathrm{AS}$, vidrio - $\mathrm{CaO}-\mathrm{CaSO}_{4}-\mathrm{H}_{2} \mathrm{O}, \mathrm{CAS}_{2}$ vidrio $-\mathrm{CaO}_{-}-\mathrm{CaSO}_{4}-\mathrm{H}_{2} \mathrm{O}$ pastas endurecidas, por autopretensado, de cemento de aluminato, ó cemento expansivo), para obtener la ettringita, teniendo en cuenta que en un medio saturado de $\mathrm{CaO}$, se forma la ettringita de pequeño tamaño, 
análoga a la que frecuentemente aparece en la superficie de la fase aluminato original; por el contrario, en un medio con una concentración de $\mathrm{CaO}$ por debajo de la saturación se forma la ettringita de mayor tamaño $y$, frecuentemente, a cierta distancia de la superficie de la fase aluminato original.

La ettringita hexaprismática de la pasta endurecida del cemento expansivo, al igual que la ettringita formada en un medio saturado de $\mathrm{CaO}$, muestra unas dimensiones de 0.1-0.2 x 0.5-1.0 $\mu \mathrm{m}$, mientras que la ettringita de la pasta de cemento aluminato, en un medio de contenido de $\mathrm{CaO}$ menor al de saturación, exhibe unas dimensiones de 0.5-1.0 x 4.0-6.0 $\mu \mathrm{m}$.

Igualmente ocurriría con el estudio y determinación del contenido exacto de moléculas de agua de la ettringita, que tras ser muy investigado y debatido durante varias décadas, y pese a las dos versiones estructurales propuestas que existen, dadas por Bezjak y col. (1966) y por Moore y col. (1968) e independientemente por Courtais y cols. (1968), los investigadores Skoblinskaya y col. (1975), demostraron empleando diversas técnicas instrumentales, que la ettringita, como fase sólida individualizada, incluye únicamente treinta moléculas de $\mathrm{H}_{2} \mathrm{O}$ en su composición y que el exceso de moléculas de agua no sólo está presente en los canales intercristalinos, según los datos de Moore y Taylor, sino que también queda absorbido en las superficies de los cristales defectuosos, así como que en el caso de la ettringita rehidratada, una parte de dicha agua en exceso puede estar condensada capilarmente.

Por último y respecto a la causa exacta del efecto ó mecanismo expansivo inherente a la misma, ocurre todo lo contrario que en las dos características anteriores, ya resueltas, es decir, que son muchas las hipótesis más ó menos empíricas ó fundamentadas sobre el verdadero y auténtico mecanismo ó mecanismos expansivos asociados con la formación de los sulfato-aluminatos de calcio hidratados en general y con la ettringita en particular, propuestas desde antaño hasta nuestros días, quedando por tanto, aún pendiente, su resolución definitiva. Cada uno de tales mecanismos, generalmente, han venido "clarificados" por su autor, merced a un modelo gráfico, ó símil explicativo más ó menos ingenioso, razonado y/o sofisticado, intentando con ello cada investigador, explicar los efectos citados al principio, y entre ellos tenemos los siguientes:

1ㅁ Mecanismo "Through-Solution", conocido también como "discurrir de la disolución a través del hormigón": Según esta hipótesis la fase sólida reaccionante entra en contacto con la disolución "caminando con la misma", antes de precipitar como un nuevo producto sólido distinto del original. Esta hipótesis ya fue promulgada en su tiempo por Lafuma (1929) y sus principales partidarios se encuentran; Chatterji y col. (1963a), Mehta (1969, 1973a, 1979), Collepardi y cols. (1978), Mikhail y cols. (1981), Bensted (1977), Teoreanu y col. (1982), Negro y col. (1983), etc.

$2^{\text {o }} \quad$ Mecanismo "sólido-líquido", conocido también como "topoquímico": según esta hipótesis, el sólido reacciona con el medio líquido que lo circunda y se convierte en un nuevo producto sólido distinto y más estable que el original, encargándose dicho medio líquido de recibir y/o suplir el material necesario donde se requiera para alcanzar el equilibrio de la reacción en cada lugar, de aquí que pueda tener lugar con ó sin disolución previa. Esta hipótesis, al igual que la anterior, fue promulgada por Le Chatelier y Lafuma, y actualmente entre sus principales partidarios se encuentran: Van Arkel (1956), Hansen (1962), Chatterji y col. (1963b), Mehta y col (1965) -este según Chatterji (1976) pero no según el propio autor (Mehta, 1976b), Teoreanu y col. (1982), Cohen y col. (1982), etc. No obstante recientemente Mehta se preguntaba si las observaciones experimentales apoyan el deseo generalizado de muchos investigadores de aceptar esta hipótesis, 
pues según este autor las formas estructurales y sus consecuencias que Taylor (1973) le atribuye al monosulfato-aluminato de calcio con $18 \mathrm{H}_{2} \mathrm{O}$, no son aplicables para el aluminato tetracálcico hidratado, ni para la ettringita.

3o $\quad$ Mecanismo de las "Presiones Osmóticas": Según esta hipótesis, se sugiere que los cambios de volumen de morteros y hormigones endurecidos por formación de ettringita expansiva, son similares a los que se originan en el hinchamiento de geles de arcilla. Entre los principales partidarios está Thorwaldson (1952).

4o Mecanismo de "Crecimiento Anisotrópico": Según esta hipótesis, el mecanismo en cuestión es similar al del fraguado del yeso de París, y pese a que el volumen total de sólidos y agua presentes disminuya, se arguye que el espacio efectivo adoptado por la masa de cristales de yeso entrelazados, se ve aumentado, aunque con ciertas cavidades en su interior. Esta hipótesis fue también promulgada por Le Chatelier (1919) y entre sus principales partidarios se encuentran Michaelis (1892) —aunque Bentur y col. (1975) le ponen objeciones-.

5o Mecanismo de la "Ettringita Coloidal": Según esta hipótesis, en este mecanismo existen tres fases ó estadios:

1a fase: En presencia de hidróxido de calcio, $\mathrm{CH}$, la naturaleza de la ettringita que se forma sería coloidal, no adoptando por tanto la forma de "largas varillas prismáticas hexagonales". Pues bien, sólo esta ettringita de tipo coloidal es capaz de originar grandes expansiones.

$2^{\underline{a}}$ fase: Para que la ettringita coloidal origine grandes expansiones habría de estar en contacto con una fuente externa de agua.

$3^{\text {a }}$ fase: La ettringita coloidal, de alta superficie específica, tiene una estructura cristalina peculiar, como propusieron Moore y col. (1968) con carga neta negativa, lo cual podría originar una atracción de moléculas de agua, que rodeando a la partícula de ettringita coloidal, originaría repulsiones inter-partículas, debido al potencial $\mathrm{Z}$, origen del efecto expansivo global.

Entre los principales partidarios están: Mehta (1973a, 1973b), Mehta y col. (1978) —en hipótesis-, Negro y col. (1982)].

6o- Mecanismo de "Crecimiento Cristalino por Presión": Según esta hipótesis está completamente demostrado que un cristal sometido a la acción de un peso y en una vasija que contenga una disolución sobresaturada del mismo, crece por todas sus caras, pero las aristas de su base tienden a crecer más rápidamente que el resto de sus caras. Tales cristales tienden a formar una pirámide escalonada cuya base tiene una forma cóncava.

Entre los principales partidarios están: Taber (1916), Kalousek y col. (1970). Esta hipótesis explica las observaciones de Chatterji (1974) y Seligman y col. (1964).

Pues bien, una vez realizado este estudio bibliográfico sobre los distintos mecanismos hipotéticos existentes, más ó menos fundamentados, cabe señalar en este sentido que:

1. La presencia de algún(os) autor(es) en dos ó más mecanismos simultanea ó sucesivamente, no tiene otro significado más que, 
- bien dichos mecanismos pueden ocurrir simultanea ó progresivamente, en mayor ó menor cuantía, a lo largo de las distintas fases del fraguado y endurecimiento de la pasta cementante correspondiente,

- bien que habiendo sido partidario(s) de un primer mecanismo, su(s) investigación(es) posterior( es) sobre el tema en cuestión, le(s) ha(n) hecho admitir, ó no, otro(s) mecanismo(s), siendo por tal motivo el de through-solution y el topoquímico los más controvertidos de todos.

2. A la vista de los trabajos, se puede aceptar que la presencia de los mencionados sulfatoaluminatos de calcio hidratados produce, a veces, fenómenos destructivos en multitud de obras civiles de hormigón.

Únicamente basta decir al respecto que en este campo concreto que afecta ó puede afectar al hormigón, se habla a veces de la existencia de una "ettringita primaria", ó "Tipo 1" ó "macrocristalina", colmatadora, origen y fuente de la creación de grandes resistencias, beneficiosas y no nociva a los efectos c) y d) citados con anterioridad en este apartado. Por otra parte, también se habla de una "ettringita secundaria", ó "Tipo 2", ó "microcristalina", de menor tamaño que la anterior, disruptiva, origen y fuente de pérdida de rigidez y resistencias mecánicas, perjudicial y nociva y adscrita a los efectos a) y b) citados en este apartado. Y el cómo, cuándo y dónde se forma ó puede formar cada una de ellas se justifica refiriendo que el producto de la reacción entre el $\mathrm{C}_{3} \mathrm{~A}$ y el yeso, es ettringita, la cual ocupa mayores volúmenes que la suma de los dos componentes originales de forma separada; no obstante si esta reacción llega a su final, dice el autor, ó se completa durante las primeras 24 horas de edad, a temperatura normal del laboratorio, el conjunto de la pasta cementante donde transcurre dicha reacción es lo suficientemente plástico como para "acomodar" el cambio de volumen y su efecto expansivo anejo, sin perjuicio ó daño alguno de todo el conjunto; de hecho, y según el autor, el cambio de volumen medido es mínimo (esta primera ettringita es la "primaria", ó "macrocristalina", ó beneficiosa). Por otra parte, si un exceso de iones sulfato, no consumidos en las primeras edades, de origen propio y/o ajeno, permanecen y/o acceden, respectivamente, a toda la pasta cementante después de las primeras 24 horas y por ende generalmente fraguada y endurecida, la expansión subsiguiente que originan con más $\mathrm{C}_{3} \mathrm{~A}$ sobrante, se debe igualmente a la formación de más ettringita (esta segunda ettringita es la "secundaria", ó "microcristalina", ó perjudicial).

Por el contrario, Mehta (1983) por otro, tras asignarle este último el calificativo de "microcristalina" a la ettringita "secundaria" ó "Tipo 2", con lo que obviamente calificaba, quizás sin proponérselo, de "macrocristalina" a la ettringita "primaria" ó "Tipo 1", han afirmado que esta última se forma en condiciones de baja concentración de $\mathrm{Ca}^{2+}$ del medio, menor que su valor de saturación, según los primeros, predominando, generalmente, según el segundo, en los procesos de hidratación de los cementos sobresulfatados y/o de rápido endurecimiento, los cuales están formados, en mayor ó menor grado, por $\mathrm{C}_{2} \mathrm{~S}, \mathrm{C}_{4} \mathrm{AS}, \mathrm{C}_{4} \mathrm{AF}$, y CS, produciéndose de este modo los efectos beneficiosos de todos conocidos y que caracterizan a tales tipos de cementos, por todo lo cual propondría finalmente el autor que tales tipos de "microcristales" de ettringita no son expansivos.

Asimismo, pero por idénticas razones opuestas los autores mencionados anteriormente calificarían de expansiva a la ettringita "microcristalina" que se forma en un medio de alta 
concentración de iones $\mathrm{OH}^{-}$ó lo que es lo mismo de concentración de $\mathrm{Ca}^{2+}$ idéntica a la de saturación, según aquellos.

Tales calificativos de perjudicial ó beneficiosa a la ettringita expansiva, ó no, respectivamente, dependen pues, según los autores, de las condiciones existentes en el entorno en el momento de la formación de cada una de ellas y entre las cuales se encuentran, la retracción, la rigidez ó dureza del sistema y la concentración respectiva de iones $\mathrm{OH}$ (o bien de $\mathrm{Ca}^{2+}$ ) y $\mathrm{SO}_{4}=$ en la disolución de contacto, habiendo observado Mehta experimentalmente que la ettringita "microcristalina" es capaz de absorber gran cantidad de agua sobre su superficie, originando con ello cambios considerables de volumen en toda la masa del hormigón con sus efectos perjudiciales correspondientes.

\section{I.4.3.2. Monosulfato-Aluminato de calcio hidratado o "fase AFm"}

En una apreciación general se puede decir que el monosulfato-aluminato de calcio hidratado, ó Fase AFm, forma placas hexagonales y agujas, cuyos índices de refracción son w=1.504, $\varepsilon=1.488$; su carácter óptico es negativo y su densidad es 1.95. Este compuesto forma solución sólida en placas también hexagonales con el $4 \mathrm{CaO} \cdot \mathrm{Al}_{2} \mathrm{O}_{12} \mathrm{H}_{2} \mathrm{O}$ ó $\mathrm{C}_{4} \mathrm{AH}_{12}$, que se parece mucho en la forma del cristal y en el diagrama de DRX, pero a diferencia de la ettringita no hay pruebas de que forme solución sólida con el monosulfato-ferrito correspondiente.

La importancia de este sulfato-aluminato de calcio hidratado estriba en que han sido dos, Chatterji y col. (1963a), los investigadores que conjuntamente le atribuyeron por vez primera la capacidad de crear expansión tras su formación y desarrollo posterior, en su caso, a partir de la hidratación previa de todas las fases alumínicas del cemento, las cuales, una vez como $\mathrm{C}_{4} \mathrm{AH}_{13}$, al estar expuestas a la acción de los iones sulfato, pasan a monosulfato-aluminato de calcio hidratado con doce moléculas de agua de constitución, ó fase AFm, fenómeno éste que se atribuye a un proceso de cambio de ión de tal modo que unión $\mathrm{SO}_{4}=$ sustituye a dos grupos $\mathrm{OH}^{-}$. Este paso puede ir acompañado, según algunos autores, por un primer aumento de volumen, dependiendo de la presencia ó ausencia del $\mathrm{Ca}(\mathrm{OH})_{2}$ necesario y suficiente para ello; a continuación y con un exceso de iones $\mathrm{SO}_{4}{ }^{-}$se puede producir un segundo aumento de volumen, superior al primero, al pasar el AFm a AFt ó ettringita, mediante el mecanismo hipotético de "Through-solution" antes citado.

\section{iii) Otros Compuestos}

Finalmente se ha de constatar que tras varias investigaciones, tanto con ensayos de laboratorio como en obra real, se han detectado por DRX, SEM, TEM y DSC, unos nuevos compuestos semejantes a los sulfato-aluminatos de calcio hidratados citados, que difieren de ellos en que todos o parte de los elementos $\mathrm{Al}$ presentes están sustituidos por $\mathrm{Si}$, así como también el anión sulfato, $\mathrm{SO}_{4}{ }^{\circ}$, principalmente por $\mathrm{CO}_{3}{ }^{\circ},(\mathrm{OH}-)$, etc.

Así entre 1961 y 1965 se demostró que el $\mathrm{Fe}_{2} \mathrm{O}_{3}$ puede entrar en la fase ettringita en lugar del $\mathrm{Al}_{2} \mathrm{O}_{3}$, hecho éste que Diamond y col. (1983) y Martín-Luengo (1997) mediante DRX por otro, no lo han podido confirmar, y el $\mathrm{Ca}(\mathrm{OH})_{2}$ en lugar de $\mathrm{CaSO}_{4}$, sin que se modifiquen las características de la ettringita que le son propias.

Más adelante, Laffaille y col (1970) descubren nuevos datos sobre la estructura cristalina de la thaumasita, los cuales en 1975 serían confirmados por Lukas (1976) y posteriormente por 
Lachaud (1979). Estos autores le adscribieron respectivamente a la thaumasita las siguientes fórmulas químicas:

$$
\begin{aligned}
& \mathrm{Ca}_{6}(\mathrm{Si})_{2}\left(\mathrm{CO}_{3}\right)_{2}\left(\mathrm{SO}_{4}\right)_{2} \cdot 22 \mathrm{H}_{2} \mathrm{O}=(\rho \cong 1.87), \\
& \mathrm{Ca}_{3}\left(\mathrm{SiO}_{3}\right)_{1.7-2.1}\left(\mathrm{SO}_{4}\right)_{1.2-0.7}\left(\mathrm{CO}_{3}\right)_{0.3-0.5} \cdot 15 \mathrm{H}_{2} \mathrm{O}, \mathrm{y} \\
& \mathrm{CaCO}_{3} \cdot \mathrm{CaSiO}_{3} \cdot \mathrm{CaSO}_{4} \cdot 15 \mathrm{H}_{2} \mathrm{O} .
\end{aligned}
$$

Por último, Diamond y col. (1983) estudian por microscopia electrónica (SEM y TEM) partículas individuales de ettingita que se encuentran en pastas de cemento adscritas morfológicamente todas ellas al grupo AFt "defectuoso" o ettringita "defectuosa"; tales deficiencias ligeras o mayores, en $\mathrm{Al}$ y/o azufre, pueden ser compensadas a la vez y paralelamente, según estos dos últimos autores, la primera por sustitución isomórfica del silicio y sorpresivamente no de hierro (en esto coinciden con lo apreciado al respecto posteriormente por Martín Luengo (1997) y la segunda, en forma del anión sulfato, $\mathrm{SO}_{4}{ }^{-}$, por dos hidróxidos, $2(\mathrm{OH})^{-}$, o por un carbonato, $\mathrm{CO}_{3}=$.

Todo ello pudiera quedar quizás justificado en base a las investigaciones de Moore sobre la clinkerización y productos resultantes tras el enfriamiento subsiguiente, y demuestra la posibilidad real de sustitución isomórfica, inversa a la isocuántica, del $\mathrm{Al}^{3+}$, del $\mathrm{C}_{3} \mathrm{~A}$, por $\mathrm{Si}^{4+}$ ó por $\mathrm{Fe}^{3+}$, para provocar desequilibrios termodinámicos en el cristal de origen, y si bien dicho autor no hizo ninguna referencia de lo que pudiera llegar a ocurrir de la hidratación selenitosa de dicho clínker los citados ensayos de laboratorio y obras reales han venido a confirmarnos tal posibilidad real de formación.

Finalmente cabe citar aquí también la Wodorfita descubierta por Lukas (1976) y que tiene de fórmula química $6 \mathrm{CaAl}_{1.5} \cdot\left(\mathrm{SO}_{4} \cdot \mathrm{SiO}_{3} \cdot \mathrm{CO}_{4}\right) \cdot(\mathrm{OH})_{10.5} \cdot 15 \mathrm{H}_{2} \mathrm{O}$ y la Jouravskita que tiene de fórmula química $\mathrm{Ca}\left[\mathrm{Al}(\mathrm{OH})_{6}\right]_{2}\left[\mathrm{SO}_{4}\right]_{3} \cdot 26 \mathrm{H}_{2} \mathrm{O}$.

\section{I.4.4.- Conclusiones obtenidas del estudio bibliográfico realizado sobre el ataque de los cementos Portland por los sulfatos.}

La gama total de los cementos Portland nos viene clasificada por igual en todos los países industrializados en función de su distinto grado de resistencia a los iones sulfato.

El contenido potencial de $\mathrm{C}_{3} \mathrm{~A}$ calculado, en \%, de un cemento Portland es determinante su papel sobre su resistencia, o no, al ataque de los iones sulfato y a otros ataques agresivos, habiendo surgido en la actualidad posibles dudas al respecto sobre la idea generalizada de pro-resistencia al citado ataque de los compuestos de hierro del clínker, correspondientes.

El entorno de variabilidad del contenido de $\mathrm{C}_{3} \mathrm{~A}$ calculado de los cementos Portland, desde los resistentes a los no resistentes a los iones sulfato, está comprendido entre $0 \%$ y el $15 \%$.

Como consecuencia de lo anterior no es de extrañar el encontrarnos actualmente en cualquier trabajo y/o cita afín, los cementos Portland empleados en el mismo, ya fueren ó no resistentes a los iones sulfato, ordenados de mayor a menor, ó viceversa, contenido porcentual correspondiente de $\mathrm{C}_{3} \mathrm{~A}$ calculado, no siendo, por el contrario de igual rango de importancia, aunque si interesante, el contenido porcentual correspondiente de $\mathrm{C}_{4} \mathrm{AF}, \mathrm{C}_{3} \mathrm{~S}$ y/o $\mathrm{C}_{2} \mathrm{~S}$, por este orden para igual fin. 
Cada país suele tener, entre otros, un valor "frontera", además de algún otro, del contenido porcentual de $\mathrm{C}_{3} \mathrm{~A}$ del cemento, que separa nítidamente los cementos Portland resistentes a los iones sulfato (SR), de los que no lo son, y que para España y el resto de la Unión Europea es actualmente es del $5 \%$.

Según todo lo anterior, a menor contenido potencial de $\mathrm{C}_{3} \mathrm{~A}$ de un cemento Portland, menor cantidad de ettringita expansiva podrá formar, menor expansión originará y mayor estabilidad de volumen, seguridad y larga vida útil, ante el ataque de aguas selenitosas, le proporcionará al hormigón con él preparado. Por ello el deber de un especialista en esta temática ante un problema general no cuantificado ni cualificable es aconsejar el empleo, uso y consumo de aquellos materiales que en esas ó parecidas condiciones selenitosas originen la menor expansión posible y por ende posean intrínsecamente el contenido mínimo porcentual de $\mathrm{C}_{3} \mathrm{~A}$, en valor absoluto ó relativo, para producirla.

La casuística inicial habida en los muchísimos ensayos previos llevados a cabo con cementos Portland desemboca en una generalidad, las conclusiones anteriores, que da como fruto finalmente una solución concreta: la fabricación y puesta a punto de un nuevo cemento (antiguo PY español (Pliego RC-75) actual SR (Intrucción RC-16) ó Tipo V en USA (ASTM C 150), para combatir el ataque sulfático y sus fatales consecuencias, el cual habrá de cumplir unas determinadas especificaciones al respecto.

Pese a todo lo anterior y a tenor de los trabajos llevados a cabo por Kalousek y cols. (1972), en los que cuestionan con fundamento, [...] que la vida útil de hormigones, confeccionados con cemento Portland de elevada resistencia al ataque de los iones sulfato, que están en contacto con aguas selenitosas, pueda ser superior a los 50 años, cabe preguntarse: ¿Podrá haber algún otro cemento, si no Portland solo, de mezcla, que pueda ser de resistencia más elevada aún que la de los propios Portland de elevada resistencia al ataque de los iones sulfato? Y en su caso de que los haya ¿Cómo influirá en dicha resistencia una notable cantidad -mayor del $40 \%$ en peso- de la adición puzolánica en la mezcla? Esto es, como se verá, uno de los objetivos de esta Memoria de Tesis Doctoral.

Finalmente lo que también expondremos serán las especificaciones existentes de algunos de estos tipos de cementos con adiciones puzolánicas. Tales especificaciones se encuentran en la Tabla I-1. En ella se pueden observar como los cementos puzolánicos tipo CEM IV/B de la Instrucción RC-16 no disponen de especificación alguna sobre RS ni sobre resistencia al agua de mar. Ello ha motivado la realización de este trabajo de Tesis Doctoral para obtenerlas, principalmente las de RS por su mayor peligrosidad, o en su defecto, algún método acelerado de ensayo y sus especificaciones para diferenciar en un corto espacio de tiempo aquellos cementos puzolánicos tipo CEM IV/B de la Instrucción RC-16 que sean de elevada RS de aquellos otros que no lo son tanto.

Tal y como ya demostrara Talero a propósito de la resistencia al ataque de los iones sulfato RS de los cementos Portland con adiciones puzolánicas (Talero, 1986) que en la misma influía en mayor o menor medida según los casos, tanto la RS de la fracción Portland como la RS de la fracción puzolana y puesto que las "Generalidades" respecto de la primera ya fueron tratadas con detalle por dicho autor en la MEMORIA de su Tesis Doctoral (Talero, 1986), no consideramos necesario repetirlas aquí y si en cambio las correspondientes a la fracción puzolana por razones obvias. 
No obstante y a pesar de lo cual, lo que si expondremos serán las conclusiones que obtuvo dicho autor de sus investigaciones, por ser punto de partida para nuestro trabajo. Dichas conclusiones fueron las siguientes:

Los cementos Portland con adición de materias puzolánicas únicamente hasta un $40 \%$ en peso, se comportaron de modo errático, y en fundamento contrapuesto, en sus resistencias ante el ataque de los iones sulfato (RS) y mecánicas a edades iniciales, RM, especialmente. La interpretación que cabe dar a estos resultados se fundamenta principalmente en los efectos que ejerce en el fraguado y endurecimiento, el estado de la alúmina tetra y penta coordinada aportada por la puzolana y por el cemento Portland (en éste formando parte del $\mathrm{C}_{3} \mathrm{~A}$ principalmente), y la mayor o menor reactividad de la sílice puzolánica.

Tomando como base la conclusión general anterior, se pueden perfeccionar las RM, a edades iniciales especialmente, o la RS, de un Cemento Portland, por la(s) Adición(es) Puzolánica(s), si la(s) misma(s) son compatibles, por su composición y estructura, con la composición del Cemento Portland de partida, para la consecución de cada objetivo anterior.

Las expansiones producidas por la formación de ettringita de origen puzolana(s) (de su $\mathrm{Al}_{2} \mathrm{O}_{3}{ }^{\mathrm{r}}$ ) y de origen cemento Portland (de su $\mathrm{C}_{3} \mathrm{~A}$ ) al formarse conjuntamente, son más que aditivas, SINÉRGICAS.

Se han establecido métodos tecnológicos apropiados y rápidos que permiten determinar de una forma sencilla y económica el EFECTO SINÉRGICO EXPANSIVO máximo ó adecuado, según sea el caso, y conocer las dosificaciones más convenientes -en cantidad y calidad de los componentes, cemento Portland, (ó clínker Portland en su caso), puzolana(s) y yeso- para obtener un cemento de mezcla, Portland más puzolana(s) únicamente, de características prefijadas.

\section{I.4.5.- Resistencia a los sulfatos de los Cementos con Adiciones Puzolánicas.}

\section{I.4.5.1.- Generalidades.}

Paralelamente a toda la gama de ensayos llevados a cabo, principalmente en USA, con los cementos Portland, se repetía lo mismo con los de Adiciones Puzolánicas correspondientes a estos cementos además de con otros comerciales, merced a la adición de una gran multiplicidad de materiales más ó menos puzolánicos, por aquello de minimizar los males a base de disminuir lo más posible la fracción Portland que era lo más susceptible al ataque de los sulfatos, y con ella la fracción $C_{3} A$ correspondiente, en toda la masa del hormigón.

Por todo ello Davis y cols. (1935) publicaron los resultados de un denso trabajo llevado a cabo al efecto, llegando a la conclusión de que al igual que ocurriese con los cementos Portland, los puzolánicos mostraban idéntico comportamiento casuístico, es decir, que ante el ataque sulfático unos se portaban mejor y otros peor.

Unos años después Tuthill (1956), tras llegar a idéntica conclusión exigiría, por vez primera, especificaciones precisas al respecto (al igual que ocurrió con los cementos Portland) tanto para los

cementos con adiciones puzolánicas como para las puzolanas y clínkeres correspondientes empleados en su preparación. 
Evidentemente no se dieron dichas especificaciones con anterioridad porque, entre otras cosas, y a diferencia de lo que ocurriese con los Portland, el problema era infinitamente más complejo al intervenir no sólo las características del clínker sino también las de las puzolanas.

Igualmente concluiría el autor que a diferencia de los Portland no resistentes a los sulfatos, cuya respuesta en tal sentido suele ser relativamente rápida, los puzolánicos necesitaban por lo general mayores períodos de tiempo de exposición sulfática que aquellos para igual fin.

Paralelamente en la antigua URSS, Baykov y col. (1936), referían haber comprobado que los cementos "Portland-puzolana", eran considerablemente más resistentes al ataque de las disoluciones sulfáticas sódicas ó cálcicas, que los cementos Portland ordinarios, no señalando los autores en este trabajo las características estructurales de los referidos cementos.

Años más tarde Kalousek y col. (1970), tras una investigación llevada a cabo al efecto con catorce cementos con adiciones puzolánicas, dos de ellos "de laboratorio", obtendría la misma conclusión anterior, es decir, que unos cementos puzolánicos resistian el ataque del ión sulfato (los que llevaban como puzolana tierra de Santorin ó vidrio vitrificado altamente silícico), y otros no (los que llevaban como puzolana diversos materiales, más ó menos arcillosos, calcinados).

Más tarde, Blanks (1948) tras referir que las placas del ensayo Merriman (Garcia de Paredes, 1978) confeccionadas con cemento "Portland-puzolana" mostraban una resistencia sulfática superior, afirmaría que merced a combinaciones convenientes de cemento Portland y puzolanas "apropiadas"..., impartían al hormigón muchas de las cualidades pretendidas y deseadas, para finalmente reconocer y admitir la existencia de factores desconocidos, total ó parcialmente, del problema en cuestión.

Por otra parte y casi por las mismas fechas, se celebró en San Francisco (EEUU) el Simposio: SYMPOSIUM ON USE POZZOLANIC MATERIALS IN MORTARS AND CONCRETES, First Pacific Area National Meeting, patrocinado por la International Standard Organization (1949). Entre los participantes se obtienen las siguientes conclusiones:

Cuando se usan puzolanas como sustituyentes de cemento Portland, tipo I y II de la ASTM, se mejora la resistencia a la acción de las aguas sulfáticas y en el caso particular de Portland con altos contenidos de $\mathrm{C}_{3} \mathrm{~A}$, dicha mejoría es aún más notable.

Que como ocurriere con los cementos Portland, aunque quizás por las mismas y/o diferentes causas, unos cementos puzolánicos resistían el ataque sulfático y otros no, existiendo por lo general, para el caso de los primeros, una relación directa entre el contenido de puzolana y la mejoría en resistencia sulfática subsiguiente, en comparación con el Portland sin adición de puzolana ó Portland matriz.

Por último Blanks (1948) concluía tras sus trabajos que sólo determinadas combinaciones Portland X (a base del tipo I, II ó III ASTM) con puzolana Z proporcionaban a la pasta, mortero u hormigón correspondientes, la tan anhelada resistencia a los sulfatos, desconociéndose las causas de tal evento. En este sentido y sólo a ese tipo de puzolana que mejoraba la resistencia a los sulfatos de Portland tipo I, II ó III correspondiente.

De nuevo Tuthill (1956) incidirá, en lo mismo, empezando a señalar, al igual que Bogue (1929), que todos los cementos con adiciones puzolánicas que mostraban buen comportamiento ante el ataque sulfático, tenían de común como puzolana, materiales más bien silícicos, vítreos y 
activos, como tierra de diatomeas, rocas opalinas y similares. Esta mejoría en resistencia al ataque sulfático que tan específicos materiales proporcionaban a sus fracciones Portland acompañantes respectivas, serviría de estímulo para perseverar en estos trabajos a fin de que, dada la similitud de calificación de otros afines, hacerlos extensibles a todas las puzolanas en exclusividad; de aquí que algunos investigadores empezaron a denominarlas con el apelativo genérico y simple, que denota un todo único, de "la puzolana" ó simplemente "puzolana" y con ellos y de igual modo a los cementos con adiciones puzolánicas y sus buenas propiedades al respecto al decir de muchos.

En tal sentido y en el colmo de las generalizaciones, Turriziani y col. (1952) recuerdan los resultados de los estudios más recientes llevados a cabo por ellos, sobre la naturaleza de los productos de reacción entre la cal y "la puzolana" y los de la hidratación del clínker Portland, en relación con la comprobada resistencia química de los cementos con adiciones puzolánicas.

Pese a ello y aún en la línea primitiva, seguían obteniéndose resultados por otros investigadores, que confirmaban una vez más lo conocido hasta entonces. No obstante sí hemos de hacer notar que a partir de aquí, y una vez que se consiguió calificar a los cementos Portland "de elevada resistencia, o no, a las aguas selenitosas", las puzolanas se empezaron a utilizar en el sentido de averiguar si su presencia junto a aquellos les mejoraba -aumentaba o empeorabadisminuía-, dicha resistencia sulfática original.

Por aquel entonces Chapelle (1958) en Francia, lleva a cabo un completo trabajo en el que tras demostrar, en contra de la opinión generalizada, hasta el momento, que el ataque selenitoso "sulfo-cálcico" le llama el autor- a las puzolanas, ampliado a las escorias de alto horno, era un hecho constatable, llega a preparar por vez primera mezclas ternarias, cemento-puzolana-escoria.

Posteriormente Turriziani y col. (1956) convendrían una vez más, tras sus trabajos en la influencia altamente positiva sobre resistencias a los sulfatos, que producían las puzolanas ricas en sílice reactiva añadidas cemento Portland, residiendo en ello, principalmente, la causa de la alta resistencia sulfática de los cementos con adiciones puzolánicas.

Por otra parte, Calleja (1966) señala que la "combinación consistente en conglomerantes puzolánicos hechos con clínkeres, de por si estables, frente a los agresivos selenitosos, y puzolanas, —lo que en Italia se denominaban cementos férrico-puzolánicos—, es excelente para la consecución del fin que con ellos se persigue", llegando incluso el autor a generalizar que "la personalidad de los cementos con adiciones puzolánicas, en este aspecto de las ventajas, es tal, que les permite aliarse con otros conglomerantes, que a su vez poseen características propias y excelentes de durabilidad frente a sulfatos (yeso, aguas selenitosas, sumándose sus acciones), basando el autor la explicación de ese buen comportamiento de los cementos con adiciones puzolánicas en la puzolana presente.

A continuación, Soria (1967) manifestaba en un trabajo premiado que "los cementos con adiciones puzolánicas y siderúrgicos se consideraban como los conglomerantes sancionados por la práctica como resistentes a las aguas sulfatadas", y de ello el autor se hace partícipe al afirmar siguiendo la línea de Turriziani (1956), Ramachandran y cols. (1964) y Grzymek y cols. (1980) que "su mayor durabilidad, que el Portland ordinario, sólo se cumple cuando han tenido lugar los fenómenos secundarios de la hidratación que motivan un desarrollo en el endurecimiento y una formación de fase amorfa tales que impidan la penetración del medio agresivo en la masa y sus consecuencias destructivas ulteriores". 
A la vez de Luxán (1967), partidario del término genérico "puzolana", trataba de demostrar el por qué "la puzolana evita la disgregación del hormigón en terrenos yesíferos" y por ello indica que "a su juicio, la coyunda PAS-PUZOLANA, proporcionaría cementos de alta resistencia a las aguas selenitosas".

De nuevo Calleja (1968) en un estudio -también premiado-, más completo y compendiador del tema y siguiendo, en principio, la línea de Tuthill, Bogue, Turriziani, Río, etc., señala que "los conglomerantes hidraúlicos a base de clínker Portland y puzolana altamente rica en sílice reactiva, resisten particularmente, y mejor que otros, los ataques de aguas agresivas naturales", y en otro pasaje de su trabajo confirmaría de nuevo la ya clásica dicotomía existente en este tema, al referir que "para algunos, la adición de puzolana perjudica a los cementos de contenido elevado de óxido férrico (bajo módulo de fundentes), tales como los cementos Ferrari, Kühl y/o antiguos PAS-PUZ españoles, mientras para otros, las puzolanas mejoran incluso la resistencia química de estos cementos". No obstante y para el autor "son en realidad más abundantes y razonables las opiniones que se inclinan, desde el punto de vista de la durabilidad para los sulfatos, por cementos constituidos por buenas puzolanas naturales y clinkeres intrínsecamente resistentes a aguas y suelos selenitosos o sulfatados con lo cual se revalorizan los antiguos PAS-PUZ españoles".

Por último y finalmente el autor participa de la clásica teoría al referir que "las ventajas de las puzolanas en los cementos con adiciones puzolánicas residen en la estabilidad de éstos frente a la expansión por sulfatos y en la durabilidad de los mismos frente a ataques por aguas y suelos selenitosos".

Parte de algunos de estos trabajos y conclusiones se encuentran compendiados por Biczok (1972), el cual en alguno de los pasajes cuanta al respecto que según W.W. Kind, los cementos con adiciones puzolánicas (considerados por el autor como un todo único y homogéneo) y siderúrgicas, son totalmente resistentes a las disoluciones de $\mathrm{CaSO}_{4} \mathrm{y} \mathrm{MgSO}_{4}$ de determinada concentración y a las de $\mathrm{Na}_{2} \mathrm{SO}_{4}$ lo son también, siempre que contengan una cantidad suficiente -mínimo 25\%- de materias ácidas e hidráulicamente activas. Por otra parte, afirma que las investigaciones de cementos Portland con bajo contenido de alúmina expuestos a las disoluciones de sulfatos, muestran que la resistencia al ataque sulfático de los cementos Portland "sulfato-resistentes" es inferior a la de los cementos con adiciones puzolánicas y siderúrgicas, aunque superior a la de los Portland normales.

Siguiendo en esta línea Mehta y col. (1982) encontraron que la adición de tras ó puzolana, mejoraba la durabilidad de los hormigones de cemento Portland, de aquí que, por parecido motivo, Kind y Kalousek recomendaran que para aplicaciones de resistencia a los sulfatos era de interés la reducción del contenido de $\mathrm{Ca}(\mathrm{OH})_{2}$, libre ó disponible de los cementos Portland hidratados mediante la adición de materiales con sílice reactiva tales como las puzolanas, las cuales son capaces de convertir el $\mathrm{Ca}(\mathrm{OH})_{2}$ en silicatos cálcicos hidratados, explicando esto incidentalmente el por qué los cementos Portland bajos en $\mathrm{C}_{3} \mathrm{~A}$, los cementos con adiciones puzolánicas y los cementos Portland con escoria de alto horno se aconsejen con frecuencia para aplicarlos en hormigones resistentes a los sulfatos.

Casi al mismo tiempo, Mather (1978) afirmaría, coincidiendo con los resultados de Turriziani, Rio, Celani, Angeletti, etc., que los cementos con adiciones puzolánicas que resisten 
elevadísimas concentraciones de sulfatos, similares a las del drástico ensayo de L-A (Blondiau, 1961), son aquellos cuya puzolana tiene un elevado contenido de sílice reactiva.

Y una vez más Calleja (1969) incidiría en lo mismo, basándose para ello "en la menor reserva alcalina de las pastas de cemento puzolánico que en relación con la durabilidad hace que los hormigones confeccionados con tales cementos tengan una resistencia notablemente mayor frente a los ataques químicos producidos por aguas puras, ácidas, carbónicas agresivas e incluso selenitosas y marinas...", hasta tal punto que más adelante el autor refiere que los cementos resistentes, en distinta medida, a los ataques por sulfatos pueden ser de varios tipos y clases, estando dentro de los Portland, los de bajo contenido de $\mathrm{C}_{3} \mathrm{~A}$ y $\mathrm{C}_{4} \mathrm{AF}$, pero no siendo, no obstante, los cementos más genuinamente resistentes al ataque por sulfatos, en general, los de tipo Portland, sino los que contienen escorias y los puzolánicos, llegando a ser, según el autor, éstos últimos "inclusive eficaces frente a ataques por yesos", de ahí que invitara, al igual que M. de Luxán B., "al técnico encargado de su puesta en obra, su uso y consumo -el cual ya de por sí tenía una cierta prevención contra el empleo de cementos distintos del Portland "puro", unas veces por ser la práctica habitual, y otras por temor, no siempre fundado, a fraudes-, a que empleara tanto los siderúrgicos como los puzolánicos "serios"... y "de garantía"..., por ser de fiar... para tal fin".

Más tarde Mather (1978) informaba que unos cementos puzolánicos, resistían más el ataque sulfático que otros, habiendo preparado todos ellos a base de una gama variable de puzolanas -en este caso cenizas volante- y cementos Portland. Por el contrario, Grzymek y cols. (1980) son abiertos partidarios de los cementos con adiciones puzolánicas tras sus trabajos al respecto siguiendo la línea, sin proponérselo, de Tuthill, Bogue, Turriziani, etc., de emplear puzolanas con sílice reactiva, tipo diatomita, etc.

En posteriores investigaciones estudios, Bensted (1988) refiere como la resistencia de un cemento Portland resistente a los sulfatos, se ve alterada y cambiada de signo y por ende disminuida, al añadirle determinada ceniza volante, con lo que los puzolánicos correspondientes no se comportaban como su Portland original.

Y, tras él, Samanta y col. (1982) continúan abundando en lo mismo al citar, generalizando, que estudiada ampliamente la química de las puzolanas, se ha establecido que la sustitución parcial de cemento Portland por puzolana, aumenta la resistencia de los morteros correspondientes al ataque por aguas sulfáticas.

Y ahí no queda el tema pues esta idea llegaría a plasmarse en el Reino Unido como normativa -la SfB, Df, UDC 691.32, DIGEST 90, feb.1968, BUILDING RESEARCH STATION, Digest 90 (Second Series): "Concrete in Sulphate-Bearing Soils and Groundwaters", Apartado Tipos de Cemento-, que dice: "la inclusión de puzolana también mejora ó aumenta la sulfato-resistencia de los cementos Portland ordinarios".

Y tampoco se pueden dejar de citar los comentarios de Sorensen (1982) a raíz de sus trabajos en esta línea, que indican el efecto beneficioso de las puzolanas, y en particular las artificiales, cenizas volantes, sobre el comportamiento de los cementos Portland ante el ataque sulfático, para acabar generalizando que tales resultados están en la línea de los existentes en la bibliografía sobre la "buena imagen" de que gozan mundialmente los cementos puzolánicos ante el citado ataque agresivo. 
Y por último, se hace necesario citar también, las opiniones de Bradbury (1982) sobre los cementos con adiciones puzolánicas fabricados con las puzolanas artificiales, cenizas volantes. Este autor reconoce que los cementos puzolánicos no se venden comercialmente como resistentes al ataque sulfático aún cuando se sabe, según el autor, que poseen tales buenas propiedades, antisulfatos, y hasta tal punto que, tras sus ensayos, las equipara a las que genuinamente poseen los cementos Portland resistentes al ataque de los iones sulfato, (antiguos PY españoles hoy SR), siempre y cuando el contenido de iones sulfato del agua agresiva respectiva no exceda del que poseen normalmente las aguas subálveas correspondientes, superando, por ende, a los Portland en todos los casos, no así a los equivalentes PY españoles hoy SR para el caso de una elevada y normal concentración de iones sulfato en el agua agresiva.

Por todo ello se piensa que estas citas han servido lo suficiente para el fin propuesto: mostrar con claridad la situación real de esta temática y que a la vista de los trabajos realizados y las conclusiones obtenidas en materia de cementos con adiciones puzolánicas no es otra que la existencia de dos "frentes", uno, a favor, y otro, en contra del empleo, y uso indiscriminado de los cementos con adiciones puzolánicas y/o de las puzolanas, frente a las aguas sulfáticas, en general, y selenitosas en particular, basándose para ello normalmente en las conclusiones sobre sus respectivos trabajos muy particulares y casuísticos y/u opiniones personales, generalmente no contrastadas al respecto.

En el caso más numeroso, el de los investigadores "a favor", nacidos, como decíamos, al amparo de los buenos resultados obtenidos con sus puzolanas "particulares" al caso, en especial las eminentemente "silícicas", como ópalos y diatomeas, éstos solían extender y generalizar la conclusión del buen comportamiento de éstas al resto de las puzolanas, cual si las mismas se trataren de un "TODO ÚNICO, HOMOGÉNEO E INDIVISIBLE".

Asimismo, se ha considerado que los cementos con adiciones puzolánicas no han tenido nunca en la normativa española especificaciones sobre su resistencia, ó no, a los sulfatos hasta el Pliego RC-88, y ello con base en las investigaciones realizadas y finalizadas dos años antes de la aparición de dicho Pliego, por R. Talero, las cuales fueron objeto de su Tesis Doctoral (Talero, 1986) realizada en el Instituto "Eduardo Torroja". Entre sus numerosas conclusiones podemos extraer que pueden existir cementos Tipo II y IV, según la denominación de dicho Pliego, de Elevada, Moderada ó Nula resistencia a los sulfatos, lo cual fue determinante para enunciar las condiciones específicas de resistencia a los sulfatos en dicho Pliego, extrañando en cambio que los cementos Mixtos ó Tipo V de dicho Pliego no tuvieran ningún tipo de especificaciones al respecto, lo cual dio motivo para estudiar este tema en la presente Memoria de Tesis Doctoral, a fin de tratar el mismo de un modo más causístico que casuístico, merced a una hipótesis de trabajo a la que corresponde, como veremos, un planeamiento generalizado del mismo.

Toda esta discusión sobre tan importante tema quedaría zanjada definitivamente por Talero (1986) mediante una densa investigación realizada años atrás para este fin, y como resultado de la misma obtuvo estos dos importantes consejos prácticos:

Según la conclusión general $1^{\underline{a}}$ anterior todos los cementos Portland con puzolana únicamente hasta un $40 \%$ en peso de esta última, no se pueden calificar de elevada o moderada resistencia al ataque de los iones sulfato, en general y de calcio (yeso), en particular, existiendo entre los mismos similar grado de variabilidad de comportamiento, elevado, moderado y escaso y 
aplicable aún dentro de cada grupo citado, ante dicho ataque, al igual que ocurriere entre los Portland. Por lo tanto y desde el punto de vista del ataque sulfático agresivo, a aquellos no se les podrá considerar en adelante como un todo único, homogéneo e indivisible, ni aconsejarse directa o indirectamente su uso indiscriminado ante el mismo, por lo que previamente y antes de su puesta en obra se les deberá o tendrá, según el grado de agresividad del medio, que determinar su grado de adecuación correspondiente mediante algún método acelerado de ensayo adecuado para tal fin, y

Según la conclusión general segunda y desde el punto de vista de la RS y/o RM a edades iniciales, el vasto mundo de las puzolanas debería clasificarse no en función de sus orígenes, sino en función de sus posibilidades respectivas de utilización más adecuada. Y puesto que la misma va a depender en cierta medida de su constitución físico-química, fundamentalmente en forma reactiva, es decir, $\mathrm{SiO}_{2}{ }^{\mathrm{r}-}, \mathrm{Al}_{2} \mathrm{O}_{3^{\mathrm{r}-}}$ y $\mathrm{Fe}_{2} \mathrm{O}_{3^{\mathrm{r}}-9}$.

Finalmente y volviendo a su principal característica expuesta al inicio de este apartado, deseamos añadir que en ocasiones la acción facilitadora del ataque sulfático propiciado a los cementos Portland por este tipo de puzolanas, es de tal magnitud que acorta peligrosamente la durabilidad de los hormigones y morteros correspondientes preparados con las mismas. Y ello con base al EFECTO SINÉRGICO EXPANSIVO originado ante dicho ataque agresivo por la ettringita de "rápida formación" o de origen puzolana alumínica y la ettringita de "lenta formación" o de origen $\mathrm{C}_{3} \mathrm{~A}$ del cemento Portland, que se forman conjuntamente o en su caso potenciado el efecto expansivo resultante acortando peligrosamente y en definitiva la durabilidad de las estructuras de hormigón preparadas con las mismas.

Por último y respecto del resto de los ataques agresivos potenciales, naturales o artificiales (agua de mar, carbonatación, árido-álcali, cloruros, hielo-deshielo, abrasión, etc.) para los cementos con adiciones activas, del comportamiento de estos tipos de puzolanas o sus "híbridos" ante el ataque del yeso, se puede deducir el comportamiento más probable de cada una de ellas ante cada uno de los mismos.

\section{I.4.5.2.- Efecto protector ó "Anti-Sulfato" de las Puzolanas a los Cementos Portland: causas probables y discrepancias posibles.}

El creciente desarrollo mundial de los cementos con puzolanas debido al problema energético así como también a los buenos resultados que han obtenido algunos notables investigadores del ramo, en la aplicación de tales conglomerantes, no ha ido acompañado por un avance paralelo en nuestros conocimientos sobre el mecanismo de la acción puzolánica y su efecto protector "anti-sulfatos" (al decir de aquéllos), correspondiente.

Por esta razón el estudio de las transformaciones a través de las cuales al cemento Portland asociado con la puzolana, se hace resistente al ataque químico de las aguas agresivas naturales, particularmente para España y por razones obvias, las selenitosas, constituye todavía un problema de notable interés, no solo tecnológico, sino también científico, por sus indudables trascendencias económicas y sociales, que a nivel mundial pueden tener estos tipos de conglomerantes hidráulicos.

\footnotetext{
${ }^{9}$ Véase el apartado 1.4.4.4 de esta MEMORIA de Tesis Doctoral..
} 
De aquí que después Kalousek y cols. (1972) y más recientemente Mehta (1983) comentaran que: "Aún no se conoce el mecanismo exacto por el cual las reacciones puzolánicas contribuyen a las resistencias mecánicas y sulfáticas (durabilidad) de morteros y hormigones".

De todo lo cual y a continuación, se van a detallar las distintas hipótesis existentes hasta nuestros días, las cuales tratan de dar una posible explicación a la creencia generalizada del efecto protector de las puzolanas resistencia potencial al ataque de los iones sulfato ó efecto "anti-sulfato" en los cementos puzolánicos.

Así Lafuma (1929) sugiere que la combinación entre un compuesto hidratado insoluble del cemento en el estado sólido y una sustancia en disolución origina siempre expansión, pero si el compuesto del cemento pasa a la disolución, reacciona y luego precipita, no se produce expansión; en otras palabras, cuando la solubilidad del compuesto reaccionante del cemento es muy pequeña, los productos de reacción se producen "in situ" y los cristales formados ejercen un empuje contra los sólidos de su alrededor, por el contrario cuando la solubilidad es mayor, hay cierta difusión y los productos de reacción se depositan en los espacios libres disponibles. Es sabido igualmente que la solubilidad del aluminato tetracálcico hidratado es muy pequeña en disoluciones saturadas de cal, y la del hexahidrato cúbico lo es también hasta en disoluciones de cal medio saturadas, por ello la fijación de la cal por reacción con la puzolana da compuestos que están en presencia de disoluciones con pequeña concentración en cal y por tanto se producen las condiciones señaladas por Lafuma para que la formación de sulfato-aluminatos de calcio hidratados no sea expansiva.

Posteriormente Blondiau (1961) aportaría una experiencia, a nuestro juicio no definitiva, en favor de esta teoría, a saber: Un cemento puzolánico completamente hidratado, en el que la concentración de cal es aproximadamente $0.89 \mathrm{~g} \mathrm{CaO} / \mathrm{l}$, se le amasa con yeso, según el ensayo L-A que veremos con más detalle más adelante, y sólo se origina una pequeña expansión, ocurriendo todo lo contrario, en condiciones similares, pero con el cemento puzolánico anhidro.

Además, Flint y col. (1934), proponían la teoría de que ello se debe, como en el caso de la sustitución del $\mathrm{C}_{3} \mathrm{~A}$ por $\mathrm{C}_{2} \mathrm{AF}$, ó de $\mathrm{C}_{3} \mathrm{~A}$ cristalino por fase vítrea, ó de mayor tiempo de curado, a la formación de hidrogranates que contienen cal, sílice, alúmina y óxido férrico, y que son de por sí resistentes. Para Franklin, y en el caso de las puzolanas, le parece raro, pero Thorvaldson (1952) lo admite con carácter general.

Después López Ruiz (1955a, 1955b) daría más de una explicación al respecto, así tenemos: $1^{\underline{a}}$ explicación: Al silicato bicálcico hidratado con agua y $\mathrm{pH}$ - 11.74 le ocurre:

$2\left(2 \mathrm{CaO} \bullet \mathrm{SiO} \bullet 4 \mathrm{H}_{2} \mathrm{O}\right)+\mathrm{nH}_{2} \mathrm{O} \rightarrow 3 \mathrm{CaO} \bullet 2 \mathrm{SiO} \bullet \mathrm{nH}_{2} \mathrm{O}+\mathrm{Ca}(\mathrm{OH})_{2}$

y si se continúa la disolución, a un $\mathrm{pH}$ de 11.55 hay otro paso de hidrólisis:

$3\left(\mathrm{CaO} \bullet 2 \mathrm{SiO} \bullet \mathrm{nH}_{2} \mathrm{O}\right)+\mathrm{H}_{2} \mathrm{O} \rightarrow 2\left(\mathrm{CaO} \bullet \mathrm{SiO} \bullet \mathrm{nH}_{2} \mathrm{O}\right)+\mathrm{Ca}(\mathrm{OH})_{2}$

y el silicato monocálcico, a su vez, cuando se alcanza un $\mathrm{pH}$ de valor 7 , tiende a descomponerse en $\mathrm{Ca}(\mathrm{OH})_{2}$ y $\mathrm{SiO}_{2}$. De todo lo cual se deduce, según el autor, que "la reacción del $\mathrm{Ca}(\mathrm{OH})_{2}$ libre, con la sílice y la alúmina, sólo en el caso de que formen algún compuesto desconocido estable sílicoalumínico-cálcico, podría interpretar ó dar una explicación a la resistencia de los cementos puzolánicos frente a los citados agresivos". De otra forma hay que admitir, y es lo 
más probable, a juicio del autor, que la estabilidad se debe a las condiciones especiales que concurran en la formación de los compuestos cálcicos.

$2^{\text {a }}$ explicación: Es muy probable que en la estabilidad de los cementos puzolánicos desempeñe un papel esencial la mayor compacidad del producto fraguado.

No obstante y a pesar de todo ello, "el autor reconoce que con estas explicaciones no se da una razón exacta y por ende satisfactoria de la resistencia que las puzolanas le confieren a los cementos puzolánicos contra el ataque de las aguas selenitosas". Pese a todo lo cual y tras admitir sólo parcialmente la teoría de Lafuma, concluye el autor, en que es muy probable que en el ataque por los sulfatos la formación de "sulfoaluminato", pueda considerarse como la primera causa de la destrucción y entonces la influencia de la puzolana podría atribuirse:

- ya a la formación de una superficie protectora de compuestos puzolana-cal,

- ya a la formación de geles por y para la descomposición de los "sulfoaluminatos",

- ya al modo de formarse el "sulfoaluminato" como sugería Lafuma.

Después Bogue (1929) señalaría que el sulfato-aluminato de calcio hidratado se forma más rápidamente en disolución de alta concentración de $\mathrm{Ca}(\mathrm{OH})_{2}$ y ya que la desintegración de los cementos en disoluciones sulfáticas es debida principalmente a la formación de aquella sal, la presencia de "SiO 2 activa", según el autor, retardará la formación del sulfato-aluminato, retrasándose y evitándose con ello la desintegración de la estructura de hormigón de cemento Portland.

Paralelamente Tuthill (1956) indicaría que lo propuesto por Bogue implica que la "sílice activa" ó "puzolana", según el autor, son útiles para reducir la severidad del ataque sulfático al combinarse ambas con $\mathrm{Ca}(\mathrm{OH})_{2}$ y formar compuestos más insolubles.

A continuación Turriziani y col. (1957) mencionan que la resistencia a los sulfatos de los cementos puzolánicos es debida al modo particular de conformación estructural de la pasta de cemento puzolánico (teoría de la acción impedidora de los geles de neoformación provenientes de la puzolana y la cal), coa ligada, en calidad y cantidad, de cualquier modo, a la presencia de la sílice reactiva, $\mathrm{SiO}_{2^{\mathrm{r}}}$, que la partícula vítrea del material puzolánico, es decir, que al aparecer, la "calidad" del gel protector es función de una determinada "cantidad" presente de sílice reactiva, $\mathrm{SiO}_{2^{2}}$, que en palabras de los autores significa que dicho efecto protector de la puzolana reside, ó bien en la menor cantidad de "alúmina solubilizable" de la puzolana por parte del $\mathrm{Ca}(\mathrm{OH})_{2}$ en presencia de $\mathrm{SiO}_{2}{ }^{\mathrm{r}}$ ó bien en la menor "sulfatación" de los aluminatos presentes en cada caso, por el impedimento que a tal fin suponen los geles y su "calidad" en función de la "cantidad" de $\mathrm{SiO}_{2}{ }^{\mathrm{r}}$, como dijimos anteriormente.

Un año después Chapelle (1958) demuestra la posibilidad real de ataque "sulfo-cálcico" de minerales silico-alumínicos. Para que dicho ataque tenga lugar con disolución previa del mineral atacado, es necesario que la coordinación del $\mathrm{Al}$ sea 4, por el contrario cuando dicha coordinación del $\mathrm{Al}$ es 6 el ataque "sulfo-cálcico" del material se produce sin disolución previa y los morteros fabricados son atacados y destruidos. Finalmente y cuando la coordinación del Al es 4 y 6, el autor no pudo establecer reglas precisas que correlacionen la estabilidad e inalterabilidad del material y las condiciones en las que se opera según el citado ataque "sulfo-cálcico".

Así mismo este autor refiere que la cal necesaria en el ataque "sulfo-cálcico" puede: 
- estar presente bajo la forma de $\mathrm{Ca}(\mathrm{OH})_{2}$,

- resultar de una reacción de hidratación de los silicatos de calcio anhidros del cemento Portland,

- estar presente total ó parcialmente bajo forma amorfa no ionizable (ejemplo: la escoria de alto horno).

No obstante, y al decir del autor, en el supuesto de este último caso, el ataque "sulfo-cálcico" disminuye de intensidad, de tal manera que:

- Los silicatos conteniendo aluminio en coordinación 4 no son atacados,

- idem., en coordinación 4 y 6 son atacados con disolución previa del mineral,

- idem., en coordinación 6 son atacados sin disolución previa.

Seguidamente Polivka y col. (1961) recomiendan, al igual que Barba (1968) en España diez años después, la necesidad de hacer un estudio físico-químico del mecanismo por el cual las puzolanas mejoran, entre otros, la resistencia de los cementos Portland al ataque de los sulfatos.

En este sentido, Malquori y col. (1936) expondría su punto de vista al respecto, que a juicio de Calleja (1968) es el más completo, para lo cual por una parte considera que la tobermorita formada por reacción puzolánica tiene una relación C/S menor que la del cemento Portland y que, además, por su carácter de pseudogel, rellena los microporos de la pasta y recubre y protege las fases vulnerables al ataque, impartiendo ambos hechos mayor compacidad, impermeabilidad y durabilidad a los conglomerantes; y por otra parte considera que, si bien las puzolanas no son específicamente resistentes a los sulfatos, como dejan menos cal sin combinar, hacen fallar las condiciones favorables para la formación y estabilidad de los "sulfo-aluminatos" expansivos y con ello confieren indirectamente a la pasta una mayor resistencia al ataque por sulfatos.

De nuevo Turriziani y Río (1957), participando en mayor ó menor grado de esta idea anterior de Malquori, afirman que la distinta "cantidad" de geles de silicatos de calcio hidratados con distinta estructura y composición, da lugar a una diferente distribución de fases, en la cual ven estos autores la razón de la mayor durabilidad de los cementos puzolánicos frente a los Portland, puesto que consideran que no existen apenas diferencias cualitativas entre ambos tipos de cementos que pudieran servir de explicación. Igualmente estos autores para explicar la mayor resistencia química y el mejor comportamiento de los cementos puzolánicos hechos a base de clínker de baja relación A/F y de puzolanas muy ricas en sílice frente a disoluciones agresivas de sulfatos, se basan también en la protección que confieren las puzolanas al cemento sometido a la acción de las aguas selenitosas, que explican, por una acción de recubrimiento por compuestos de puzolana-cal ó por geles hidratados procedentes de la descomposición de vidrios compuestos, cuya acción se ejerce sobre los constituyentes vulnerables al ataque. Tales recubrimientos son los que impiden la difusión iónica y las reacciones de intercambio entre las fases de la pasta y las disoluciones agresivas; del mismo modo les ha servido para explicar la no equivalencia entre la alúmina (se puede decir que muy activada) del clínker, generalmente en forma de $\mathrm{C}_{3} \mathrm{~A}$ en su mayor parte, y la alúmina reactiva, $\mathrm{Al}_{2} \mathrm{O}_{3}{ }^{\mathrm{r}-}$ de la puzolana en cuanto a la susceptibilidad de las pastas de cemento puzolánico frente a los sulfatos, fenómeno que más adelante confirmaría experimentalmente Kurdowski y col. (1981) con los cementos expansivos. 
Esta falta de equivalencia no se puede explicar suponiendo que la alúmina de la puzolana no da lugar a $\mathrm{C}_{4} \mathrm{AH}_{13}$, pues este hidrato se forma de hecho.

Para dichos autores, ambas explicaciones residen en que las puzolanas, ricas en sílice, ésta y la alúmina, se encuentran muy entremezcladas en el vidrio, de manera que los productos de reacción alúmina-cal se forman, en medio de los productos de reacción sílice-cal, protegidos por éstos que son más abundantes. Por tanto y en definitiva parece que la resistencia química de los cementos puzolánicos, a juicio de estos autores, puede depender, aparte de la mayor ó menor facilidad por otros conceptos, de la cantidad y naturaleza ("calidad") de la fase vítrea de las puzolanas y de la relación S/A activas de los cementos, debiendo ser el valor de dicha relación próximo a 6 para que los mismos puedan resistir al severo ensayo de L-A (Blondiau, 1961) de modo comparable a como lo hacen los cementos aluminosos y sobresulfatados.

Seguidamente Río y cols. (1961) como consecuencia de los trabajos realizados llegan a las siguientes conclusiones:

- Tanto el cemento Portland como el puzolánico, hidratados, tienen parecida e incluso la misma composición química,

- El cemento Portland hidratado tiene más $\mathrm{Ca}(\mathrm{OH})_{2}$ que el correspondiente puzolánico,

- Esto hace que al parecer la tobermorita del cemento Portland está rodeada por una disolución saturada de $\mathrm{Ca}(\mathrm{OH})_{2}$ y la del puzolánico no,

- Todo ello no justifica el distinto comportamiento, en la práctica, de los dos cementos citados, Portland y puzolánico,

- De donde se deduce que probablemente la mayor resistencia química de los cementos puzolánicos dependa no sólo de las distintas fases presentes en las pastas hidratadas, sino también de una distinta proporción cuantitativa, que da a la pasta dura una particular estructura resistente.

Esta última conclusión, al decir de los autores, viene confirmada por lo investigado al respecto para terminar probando que la causa principal de la especial resistencia química de las pastas puzolánicas, según ellos, se debe a la mayor impermeabilidad y sobre todo a la notable acción protectora que sobre las fases presentes ejercen los geles neoformados, obstaculizando la difusión de los iones y los intercambios con las disoluciones de contacto. No obstante y aún siendo, como dicen los autores, la resistencia química función de los geles neoformados, reconocen los mismos, tras una investigación complementaria, que:

- La sílice reactiva, $\mathrm{SiO}_{2}{ }^{\mathrm{r}}$, ejerce una buena y notable influencia para que los cementos puzolánicos correspondientes sean resistentes al yeso.

- La sílice reactiva, $\mathrm{SiO}_{2}{ }^{\mathrm{r}}$, de la puzolana que ellos emplearon, presenta, al reaccionar con $\mathrm{Ca}(\mathrm{OH})_{2}$, una velocidad de reacción netamente superior a la correspondiente de la alúmina reactiva, $\mathrm{Al}_{2} \mathrm{O}_{3}{ }^{\mathrm{r}}$, con el fin de impedir ó al menos reducir sensiblemente la solubilización de la alúmina reactiva $\mathrm{Al}_{2} \mathrm{O}_{3}$, , de la puzolana al contacto con la cal.

- Los geles de silicato cálcico hidratado neoformados ejercen una notable acción protectora ya sea limitando la cantidad de alúmina presente que haya podido reaccionar con el 
$\mathrm{Ca}(\mathrm{OH})_{2}$, ya sea disminuyendo la susceptibilidad, a los sulfatos, de los aluminatos que se puedan formar.

Sin perder esta línea, a continuación Turriziani y col. (1957), tras sus trabajos afines confirmarían como conclusión de los mismos lo dicho por los anteriores, es decir, que la sílice reactiva, $\mathrm{SiO}_{2}{ }^{\mathrm{r}}$, del material puzolánico que emplearon, presenta en sus "confrontaciones" con el $\mathrm{Ca}(\mathrm{OH}) 2$, una velocidad de reacción netamente superior a la de la alúmina correspondiente de dicho material puzolánico, precisando los autores más aún, "y es que el objeto ó fin de aquella era y es impedir, ó al menos frenar sensiblemente, la solubilización de ésta, y luego, en un cemento puzolánico, la formación ó producción de un aluminato de neoformación".

Finalmente y al objeto de poder controlar si la menor "sulfatación" en el ensayo de Anstett, presentada por los cementos de alta proporción de $\mathrm{SiO}_{2} / \mathrm{Al}_{2} \mathrm{O}_{3}{ }^{\mathrm{r}-}$ fuera debida no tanto a la acción protectora de la sílice, cuanto, por efecto de la "disolución" ó mejor "dispersión", a un menor contenido de aluminatos, los autores piensan finalmente que no es el efecto "diluyente" ó "dispersante", sino más bien que la presencia de mucha sílice reactiva, $\mathrm{SiO}_{2}{ }^{\mathrm{r}}$, de la puzolana presente origina una menor "sulfatación" de los aluminatos correspondientes. Igualmente demuestran los autores que, al parecer, la presencia de sílice reactiva $-\mathrm{SiO}_{2}{ }^{\mathrm{r}-}$ provoca descomposición de la ettringita y/ó Fase AFm presentes, lo que Taylor (1990) posteriormente refirió como "hidrolizar los sulfoaluminatos presentes". Y del mismo modo Calleja (1968) referiría en relación con el tema que no sólo se evita el ataque sobre la portlandita (lo que la puzolana consigue), sino también el ataque de los sulfatos (aguas y suelos selenitosos) a los aluminatos hidratados del cemento.

Paralelamente y una vez más en España, dado el gran interés que este tema tenía y sigue teniendo en nuestro país, de Luxán (1967) se haría partícipe de todas estas ideas al afirmar que en presencia de un exceso de cal los aluminatos son insolubles y entonces el sulfato del yeso, después de penetrar por difusión en el interior, actúa sobre el aluminato sólido y produce la destrucción; sin embargo cuando no hay más que la de una disolución muy diluida, por la hidrólisis de los silicatos, al haberse combinado parte de ella con los elementos activos de una puzolana, la acción de los sulfatos se produce sobre el aluminato disuelto y en este caso la formación de "sulfatoaluminatos", aumenta la compacidad con estos compuestos ya, no expansivos, con lo que la puzolana evita la destrucción del cemento.

A su vez Soria (1967) coincidiendo con algunos autores de los citados y al particularizar para un cemento PAS-PUZ, afirmaría igualmente, siguiendo la línea de Calleja, que al emplear un clínker PAS, actual I-0 y I/SR, MR, se anula o al menos se atenúa notablemente, la posibilidad de agresión por medios sulfatados, en las primeras edades del conglomerante -ausencia de $\mathrm{C}_{3} \mathrm{~A}-$, más tarde, continúa el autor, la fijación de cal por parte de la puzolana, coloca al conglomerante en una región del sistema $\mathrm{CaO}-\mathrm{CaSO}_{4}-\mathrm{Al}_{2} \mathrm{O}_{3}-\mathrm{H}_{2} \mathrm{O}$, en la cual, debido a la mayor solubilidad ocasionada por la baja concentración de calcio, se requieren concentraciones muy altas de sulfato de calcio para que el conjunto se traslade a la zona peligrosa de existencia de la ettringita -"sulfoaluminato expansivo"-. De igual modo, nos comenta el autor, debe tenerse en cuenta que a medida que avanza la edad del conglomerante, también colaboran en la durabilidad los nuevos productos creados por la puzolana que impiden el acceso, por su impermeabilidad, del medio agresivo. 
Y para el conjunto, y siguiendo la línea de Calleja, el autor refiere que el dualismo PASPuzolanas atenúa notablemente la acción del ión sulfato, ya que junto a la falta de $\mathrm{C}_{3} \mathrm{~A}$ del clínker, que sería susceptible de ataque en las primeras edades, surge una bajada o descenso de $\mathrm{pH}$ del medio líquido por efecto puzolánico de la puzolana, manteniendo por debajo del límite la basicidad que corresponde a la formación de "sulfoaluminatos" expansivos.

No obstante hemos de reseñar que este autor y para el caso de los citados cementos PASPUZ, actuales I-0 y I/SR,MR con puzolana (Tipos II-Z, II-C, IV y V), expuestos a los sulfatos, admite sin más con otros autores:

- La posibilidad de ataque, aunque lento de la fase ferrítica, y

- La reactividad de la alúmina presente en casi todas las puzolanas naturales y artificiales que puede conducir a la formación de ettringita expansiva.

Después sería Biczok (1972) el que justificaría la "buena fama" al caso de los cementos puzolánicos, basándose en que en este tipo de cementos no puede formarse sulfato-aluminato de calcio hidratado, con lo que debido a la escasa cantidad de "portlandita" liberada durante la hidratación, no puede formarse sulfato de calcio hidratado en cantidades considerables.

También es de destacar en este caso que, contrariamente a lo expuesto al respecto, por la "escuela italiana" referente a la necesidad de que el cociente S/A supere el valor de 6, el autor narra que puzolanas artificiales eminentemente alumínicas, tales como el metacaolín (componente principal de las arcillas caoliníticas calcinadas y activas), fijan la portlandita liberada en la hidratación del cemento Portland reduciendo con ello la posibilidad de formación de aluminato tricálcico hidratado perjudicial, con lo cual no debe de extrañarnos, al decir del autor, que el empleo de hormigón de cemento de arcillas activadas en ambientes agresivos sea recomendado por el Instituto Soviético de Química que realizó los ensayos previos.

Igualmente Lea (1956) tras revisar su primitiva hipótesis, la actualiza haciéndose partícipe de la nueva teoría existente sobre la acción protectora de los geles de neoformación, particularizado en el C-S-H formado entre la puzolana y la cal, la cual se deposita como un manto o cubierta impermeable sobre las superficies de las distintas fases en las que encuentra o puede encontrar el ión $\mathrm{Al}^{3+}$, e igualmente sugiere, sin más, la existencia de alguna otra inactivación del $\mathrm{Al}_{2} \mathrm{O}_{3}$ de la puzolana, tal como la sustitución de $\mathrm{Al}^{3+}$ en la estructura del C-S-H, que puede tener, a juicio del autor, un efecto similar al anterior.

De igual modo se harían partícipes de Kalousek y cols. (1972), para reconocer, no obstante y una vez más, que el mecanismo por el cual la puzolana disminuye o protege del ataque sulfático no se conoce completamente.

Más adelante Mehta y col. (1982) participarían de la ya clásica línea o idea que caracteriza este tema, al referir que las recomendaciones para fabricar cementos resistentes a los sulfatos, se basan en reducir el contenido disponible de $\mathrm{Ca}(\mathrm{OH})_{2}$ de los cementos Portland hidratados mediante la adición de materiales con "sílice activa", tales como las puzolanas, los cuales son capaces de convertir dicho $\mathrm{Ca}(\mathrm{OH})_{2}$ en silicatos de calcio hidratados. Obsérvese como estos autores, al igual que los italianos, hacen extensible a todas las puzolanas, (creemos que por considerarlas como un TODO), las buenas cualidades de resistencia al ataque de los iones sulfato que pragmáticamente vienen demostrándose única y exclusivamente para las eminentemente "silícicas" (con elevado contenido de sílice reactiva, $\mathrm{SiO}_{2}{ }^{\mathrm{r}}$ ). 
Seguidamente de Luxán (1967) comenta del mismo modo en su Tesis Doctoral, que el incorporar de puzolana al cemento Portland tiene como fin principal fijar la cal liberada de su hidratación, creando compuestos hidráulicamente insolubles y estables, y aumentando tanto la resistencia mecánica como química, -generalizando aquí la autora al igual que otros investigadoresdel producto resultante, pasando a insertar en el mismo todas las ventajas de este tipo de cementos. No obstante y al igual que ocurriera con Soria, Biczok, etc., esta autora junto con Soria (1967), y en respuesta a Bensted (1977), admitiría, que entre la muchas consideraciones que se deben tener en cuenta en la creación y puesta a punto de un ensayo de "sulfato-resistencia" al afecto, estaba, entre otras, el contenido porcentual de "alúmina activa" en la puzolana.

Paralelamente Bensted (1988) destacaría la importancia que tiene el tipo de clínker usado para establecer los beneficios de una puzolana, pues mientras que para un clínker de cemento Portland ordinario, la puzolana generalmente resulta satisfactoria, para un clínker de cemento Portland resistente a los sulfatos no lo es tanto. Normalmente por supuesto, -continúa el autor-, un clínker resistente a los sulfatos, no se usaría con una puzolana, ya que el del clínker Portland ordinario con la puzolana añadida daría propiedades de resistencia a los sulfatos; así por ejemplo con una puzolana artificial, como por ejemplo, una ceniza volante, el grado de resistencia a los sulfatos aumenta del cemento Portland ordinario al Portland resistente a los sulfatos pasando por este orden por el puzolánico de matriz P y matriz P-Y correspondientes. En otras palabras, la resistencia a los sulfatos de un cemento P-Y, dice el autor, se ve generalmente disminuida al incorporarle tal puzolana, silenciándose que la del Portland correspondiente se ve aumentada.

Dicho autor refiere también que la puzolana al fijar cal se vuelve inerte teniendo a actuar de este modo más como un "filler" causante de la pérdidas de resistencias mecánicas subsiguientes, y en función de este filler se originan menos uniones o enlaces con la puzolana de donde resulta esa mayor porosidad que la que hubiese desarrollado normalmente, dando como resultado todo ello una disminución en resistencia a los sulfatos por debajo de la del cemento P-Y solo ó matriz.

Años más tarde, este mismo autor insistiría en su misma idea de considerar que toda puzolana, tras su reacción puzolánica subsiguiente, acaba finalmente como un "filler", siendo por ende nociva. Por el contrario Calleja [206], tras la reunión mantenida con Talero en la que éste de informe de las conclusiones que detuviera de sus investigaciones afines previas a la presente TD, empieza a admitir que una puzolana ejerce "acciones-positivas-diversas" tales como que,

- una puzolana determinada (siempre la misma) puede dar, en idénticas condiciones, resultados diferentes en varios aspectos - incluso buenos en unos casos y malos en otros con distintos clínker Portland;

- un clínker Portland determinado (siempre el mismo) puede dar, en las mismas condiciones resultados distintos en varios aspectos - incluso buenos en unos casos y malos en otros con diferentes puzolanas;

- una o varias puzolanas con uno o varios clinkeres, en condiciones iguales o distintas, pueden dar, en aspectos diferentes, resultados de cualquier signo y magnitud.

Y a continuación afirma que "para que la fijación de cal tenga lugar con amplitud y eficacia, la puzolana debe ser lo más activa posible, dependiendo de la actividad total ๑otras cosas aparte® del contenido global de sílice y alúmina, y la actividad a corto plazo del contenido de alúmina principalmente; con el mismo fin el clínker Portland debe poseer, como ya se indicó, un alto grado 
de saturación de cal y un elevado módulo silícico, es decir, un elevado contenido total de silicatos, y en particular el tricálcico, y un contenido bajo de aluminato tricálcico y tanto menor esté cuanto mayor sea el contenido de alúmina de la puzolana".

Más tarde Grzymek (1999) continúa en la misma idea primitiva y casuística al afirmar que la positiva influencia de la diatomita se debe a la reacción puzolánica que se origina con el $\mathrm{Ca}(\mathrm{OH})_{2}$ liberado de la hidratación del cemento Portland, con la formación subsiguiente de silicatos cálcicos hidratados de baja basicidad resistentes a la corrosión, disminuyendo así el contenido de $\mathrm{Ca}(\mathrm{OH})_{2}$ en el medio, con lo que previene la formación en su caso de grandes cantidades de yeso y además de ettringita. Así y a diferencia de otros investigadores, llevan a efecto un trabajo en esta materia que tras aportar más datos al respecto, no por ello deja de ser casuístico, alejándose de este modo de un tratamiento y estudio global, conjuntado, armónico y metodológico del mismo.

De idéntico modo, o sea, experimentalmente, y al mismo tiempo, Uchikawa y cols (1995) estudian la influencia de la puzolana en la velocidad de hidratación del $\mathrm{C}_{3} \mathrm{~A}$, con y sin yeso presente y obtiene como conclusiones fundamentales entre otras, para el fin de este trabajo:

- En el sistema "puzolana - $\mathrm{C}_{3} \mathrm{~A}-\mathrm{CaSO}_{4} \bullet 2 \mathrm{H}_{2} \mathrm{O}$ ", con indiferencia de la presencia de $\mathrm{Ca}(\mathrm{OH})_{2}$, la hidratación inicial del $\mathrm{C}_{3} \mathrm{~A}$ y la formación de ettrigita y "monosulfato" (Fase AFm), fueron aceleradas por la adición de la puzolana.

- La puzolana tiende a rebajar o disminuir el grado de hidratación del $\mathrm{C}_{3} \mathrm{~A}$ a edades más avanzadas.

- Los tipos y clases de productos de reacción formados, así como su cuantía respectiva se producen en función de la composición de la puzolana, así la alta en sílice da C-S-H y la rica en álcalis $\mathrm{C}_{3} \mathrm{AH} 6$.

Últimamente Mehta (1999) relacionando la calidad y cantidad de durabilidad química de un conglomerante hidráulico hidratado con la distribución del tamaño de poro en la pasta endurecida correspondiente, llegaría a afirmar que al parecer los grandes poros son los responsables de las bajas resistencias y en general, baja durabilidad, mientras que los pequeños poros, como consecuencia de las reacciones puzolánicas, juegan un papel muy importante en el aumento de resistencias mecánicas, impermeabilidad y durabilidad química.

Y ya en la actualidad Samanta y col. (1982) atribuyen el aumento de resistencia a los sulfatos que sufren los cementos Portland, a la adición de puzolanas por:

- la disminución o ausencia de portlandita del medio por su fijación por la puzolana.

- la sugerencia de que, en presencia de puzolana, el monosulfato-aluminato formado no expansivo -al decir de los autores-, se origina predominantemente antes que la ettringita forma expansiva-.

- la inhibición del proceso corrosivo debido a la formación rápida de yeso, en su caso.

- la creación o formación de los productos de reacción en forma de gel, los cuales impiden ulteriores penetraciones de la disolución corrosiva, y particularmente más aún a la capa de C-S-H, gel de tobermorita, que recubre y protege a los aluminatos vulnerables (aluminato tetracálcico hidratado), como sugirió Steopoe.

- la teoría de Lafuma. 
COMPORTAMIENTO SULFÁTICO Y MECÁNICO-RESISTENTE DE CEMENTOS PORTLAND CON ELEVADOS

Finalmente y como consecuencia del estudio efectuado a partir de la bibliografía reseñada, se han obtenido las siguientes conclusiones:

1. Es de destacar que, de origen, tanto los planteamientos de los problemas como sus soluciones respectivas continúan siendo más casuísticos, particulares e inconexos, que causísticos, generales y globales. No obstante dichos planteamientos así como sus explicaciones y/o soluciones correspondientes, se hacen de tal modo, que los buenos resultados que se obtienen con determinadas y concretas puzolanas y/o cementos puzolánicos, fácilmente puedan hacerse extensibles y/o extrapolables, por el lector o sector tecnológico, principalmente, al resto o totalidad de las puzolanas y/o cementos puzolánicos, ya que ambos, puzolanas y/o cementos puzolánicos, los suelen considerar como sendos TODOS ÚNICOS separados respectivos.

2. Contrasta bastante, en determinados trabajos, la fuerza y unidad de criterio común inicial, con las a veces puntualizaciones y observaciones, más recientes, en contra.

3. Es igualmente notorio y coincidente que aparente y casuística mente, los "buenos resultados obtenidos" en TODOS los trabajos que se han realizado sobre esta temática tengan, por lo general, de común la presencia de puzolana "silícica" (aquella que posee un elevado contenido de sílice reactiva, $\mathrm{SiO}_{2}{ }^{\mathrm{r}}$ ).

4. Cabe pensar que pese al buen comportamiento de las mismas, en ambientes sulfáticos, presentado, intencionadamente o no, por muchos investigadores, existen, no obstante, algunos casos notables que las cuestionan, sin haberse dado las explicaciones que avalen tales comportamientos discrepantes.

5. Es de destacar que muchos de los autores citados proponen que por lo general, una de las causas de la no formación de sulfato-aluminatos de calcio hidratados expansivos y por ende del efecto "protector" ó "antisulfato" de las puzolanas ante el ataque sulfático, es la baja concentración de portlandita, $\mathrm{Ca}(\mathrm{OH})_{2}$, del medio líquido, por fijación de la misma por las puzolanas por efecto puzolánico, lo cual lleva implícito un descenso de iones sulfato y aluminato en el mismo. No obstante, hemos de decir que esta idea está en franca discordancia con lo que dicen al respecto Jones, Kalousek, D'Ans y Eick y lo confirmado por Eitel, y es que pese a que haya baja o muy baja concentración de $\mathrm{Ca}(\mathrm{OH})_{2}$ se forman sulfato-aluminatos de calcio hidratados expansivos.

6. También son notables las explicaciones que se dan al efecto protector de la sílice reactiva, $\mathrm{SiO}_{2}{ }^{\mathrm{r}}$, presente en gran cantidad en determinadas puzolanas y su extrapolación a todas ellas por contenerla en mayor o menor cuantía, dado que los geles, más o menos tobermoríticos, que forman actúan:

- protegiendo sin más, siempre que sean geles de neoformación, ó

- protegiendo como "manta protectora" sobre los aluminatos expansivos, siendo la "calidad" de la misma función de la "cantidad" de sílice reactiva, $\mathrm{SiO} 2 \mathrm{r}-$, presente, ó

- "hidrolizando" y descomponiendo los sulfato-aluminatos expansivos que se pudieren formar, ó 
- impidiendo la solubilización de la alúmina por problemas de velocidad de hidratación y subsiguiente mayor coeficiente de reparto en favor de los silicatos, ó

- protegiendo siempre y cuando la coordinación de los aluminatos "acompañantes" sea 4, ó

- protegiendo, siempre y cuando el cociente S/A tenga un determinado valor, ó

- protegiendo al disminuir la susceptibilidad de los aluminatos, que se puedan formar, a los iones sulfato.

7. A estas hipótesis anteriores hay que añadir que casi todos los investigadores están de acuerdo en que dada la mayor superficie específica de las puzolanas, su presencia en pastas, morteros y/u hormigones, les proporciona mayor compacidad a todo el conjunto, la cual actúa como elemento protector de "primer grado", pues de todos es conocido el viejo axioma cementero referente a la mayor durabilidad de un hormigón compacto de cemento Portland no apropiado, sobre la correspondiente de otro hormigón poroso de cemento Portland apropiado.

8. Hemos de destacar también, la existencia de bastantes trabajos sobre el empleo de las puzolanas "silícicas", no pudiéndose decir otro tanto de las puzolanas "férricas" (aquellas que poseen un elevado contenido de óxido férrico reactivo, $\mathrm{Fe}^{2} \mathrm{O}^{3 r-}$, pues a diferencia de lo que ocurriere con los cementos Portland férricos (anteriores I-0 y I/SR y MR españoles), no se ha encontrado trabajo alguno sobre el uso específico de éstas últimas.

\section{I.4.6.- Las Adiciones Puzolánicas y sus Cementos: Caracterización y Control de su Durabilidad derivadas antes de su puesta en obra. Necesidad de Métodos Acelerados de Ensayo para tales fines.}

En este apartado se reseñan y estudian aquellos trabajos recopilados en la bibliografía, en donde se estudian métodos de ensayo o técnicas de trabajo existentes para determinar en períodos cortos de tiempo, el comportamiento más probable en la realidad de los cementos Portland y Portland con puzolanas, en su caso, frente a disoluciones de sulfatos procedentes de distintas sales.

Así en el Symposium de Estocolmo (Suecia), año 1938, y tras las discusiones habidas entre Thorvaldson, Crichton y Hakason, como consecuencia de la comunicación presentada por Lea (1956) sobre "La Química de las Puzolanas" el primero manifestó haber intentado evaluar el comportamiento de las puzolanas mediante su resistencia a las disoluciones de sulfatos, pero concluiría que los efectos secundarios producidos por otras variables eran demasiado grandes para permitir una valoración y subsiguiente clasificación reproducibles. Esto sería posteriormente recogido y comunicado, por su interés, por Moran y col. (1949) en el Simposio norteamericano sobre puzolanas celebrado en Octubre de 1949 en San Francisco, California.

La importancia de este tema era incuestionable, buena prueba de ello fue la realización del Simposio monográfico antes citado, donde autores tales como Davis y col. (1935) afirmaron que "la composición química de una puzolana no da indicio alguno para deducir su poder de combinación con la cal", hecho este discutido durante largo tiempo, haciéndose por ello necesario el desarrollo 
y puesta a punto de un método acelerado de ensayo satisfactorio que empleado con facilidad y fiabilidad, pueda ser seguro para evaluar una puzolana y su durabilidad derivada para el hormigón o mortero del que forme parte, dentro de un período de tiempo razonablemente corto. Y se podría añadir que idénticamente debe de ocurrir para conocer y prever con prontitud, su comportamiento real en un medio sulfático.

El mismo autor reconocía que durante varios años el Sponsoring Committe on Blended Cements de la ASTM, Comité C-1, sobre cementos tuvo y continúa teniendo, como única meta de su trabajo, y desde punto de vista del comportamiento real de tales cementos al ataque sulfático (Mather, 1978), la consecución y puesta a punto de una adecuada especificación para cementos puzolánicos, ya que en base a los conocimientos que se poseían, no existían por entonces,

- ni los métodos acelerados de ensayo de respuesta rápida para predecir el comportamiento real de una puzolana y/o su cemento puzolánico en el hormigón o mortero del que entre a formar parte y en especial y como decimos, del sometido a la acción de los diferentes medios naturales agresivos que le son más propios, como pueden ser: los sulfatos, los cloruros (yeso y sulfato magnésico mayormente en España), el agua de mar y la carbonatación,

- ni las especificaciones correspondientes.

Hoy día si existen tanto métodos acelerados de ensayo como especificaciones para tales cementos con adiciones puzolánicas tipo CEM IV/B ó cementos con escorias de alto horno tipo CEM III/A ó cementos con escorias de alto horno tipo CEM III/B de la Instrucción RC-16 mediante las cuales y en cuanto a métodos acelerados de ensayo se refiere se puede predecir el comportamiento real de dichos cementos, pudiendo citar,

- a cargo de Talero (1986): Los métodos: L-A adaptado, ASTM C452-68 adaptado, IET/RT-86: $\Delta \mathrm{L}$ e IET/RT-86: RMF, y

- a cargo de Mather, (1984): El método ASTM C1012-87.

El primero utiliza yeso como sulfato agresivo en todos ellos, y el segundo sulfato sódico (y sulfato magnésico en su caso). Del segundo cabe decir que según Talero puede que no tenga la debida fiabilidad puesto que al tenerle que exigir en su caso al cemento con adición puzolánica correspondiente, un determinado nivel de resistencias mecánicas en mortero normalizado ASTM C105, antes de su enfrentamiento a los diferentes tipos de disoluciones sulfáticas agresivas antes señaladas, para lo cual se han de curar en agua sus probetas correspondientes un variable número de días, resultará que para entonces y en tal caso, unas puzolanas habrían sido curadas hídricamente -presumiblemente las "silícicas" tipo diatomeas y rocas opalinas y las "sílicoaluminosas" según Talero (1986)- y otras no -presumiblemente las "alumínicas" y las "aluminosilícicas". Por este motivo el punto de partida de todas las puzolanas no es común y consiguientemente su respuesta puede que no sea comparable ni transportable a la realidad puesto que en la realidad la práctica común era y es no curar hídricamente sus hormigones y morteros.

Por todo ello los métodos adaptados citados antes, parecen más adecuados, ya que o todos los cementos puzolánicos se curan hídricamente un número de días común, caso del método L-A adaptado, o no se curan hídricamente, caso de los métodos ASTM C452 adaptado.

En este trabajo se utilizó el primero o sea el método Le Chatelier-Anstett (Blondiau, 1961), por las razones Generales y Particulares que se verán seguidamente: 
1. Por tener el sulfato de calcio dihidrato ó piedra de yeso ó algez, $\mathrm{CaSO}_{4} \bullet 2 \mathrm{H}_{2} \mathrm{O}$, como agresivo sulfático, siendo éste a la vez constituyente fundamental de la España yesífera. Por ello las conclusiones que se obtuvieran podrían ser íntegramente aplicables a la ya clásica problemática nacional: Las aguas selenitosas y los terrenos yesíferos.

2. Por la investigación científica y/o técnica que con él se pueda realizar ya que los sulfato-aluminatos de calcio hidratados expansivos que se forman, proceden de la reacción en medio acuoso del agresivo $\mathrm{CaSO}_{4} \bullet 2 \mathrm{H}_{2} \mathrm{O}$, y los compuestos hidratados del cemento.

3. Por haber sido calificado dicho método por los investigadores como drástico ó muy severo (Turriziani, 1957), ya que el hormigón en obra ni remotamente se encontrará, al decir de todos los autores, con una concentración de sulfatos tan elevadísima como la que emplea el método en cuestión. Por lo que a fuerza de ser excesivamente severo y ante la falta del método patrón idea, hemos creído conveniente emplearlo como de referencia.

4. Porque, aunque dicho método fue creado para los cementos Portland, con el tiempo sería utilizado por los investigadores italianos (Turriziani, 1957), precisamente por su excesiva severidad, para evaluar sus cementos puzolánicos, dada la importancia y trascendencia nacionales e internacionales de sus respuestas técnica y comercial para la industria italiana del ramo.

5. Porque los métodos acelerados de ensayo para valorar la resistencia de los cementos al ataque de los sulfatos, basados en la inmersión de barras de mortero pobre en diversas disoluciones sulfáticas, han mostrado, a diferencia del elegido en este trabajo (pasta hidratada), una escasa reproducibilidad ínter-laboratorios.

6. Porque este método utiliza como parámetro el incremento de variaciones dimensionales, incremento porcentual de diámetro, $\Delta \varnothing(\%)$, para calificar a los cementos Portland de elevada resistencia, ó no, al ataque de los iones sulfato, en general, y de calcio (yeso) en particular.

7. Porque posee las características necesarias para considerarle un buen método acelerado de ensayo, tales como: Validez, Precisión, Simplicidad, Agilidad y Facilidad de Manejo, Rapidez de Respuesta, Selectividad, Repetibilidad y bajo coste. Adicionalmente se caracteriza por su aporte de $\mathrm{SO}_{3}$ suficiente ( $15.5 \%$ ) para poder pasar a ettringita hasta un $17.44 \%$ de C3A, de donde cabe deducir que este método actúa con un exceso de yeso sobre la necesidad real, con aquellos cementos Portland cuyo contenido de $\mathrm{C}_{3} \mathrm{~A}$ es inferior al $17.44 \%$, ó sea prácticamente todos los cementos Portland, y porque originariamente se aplicaba a los cementos Portland, y en la actualidad está bastante circunscrito tanto a los cementos Portland como a los cementos con adiciones puzolánicas, según los investigadores italianos que lo utilizaran al efecto.

8. Por haber servido este método de contraste, convirtiéndose con el tiempo, por su excesiva severidad, como método de referencia para muchos investigadores considerandolo como tal por razones de seguridad absoluta ante los resultados de su diagnóstico.

9. Porque este método, según Jaspers $(1968 ; 1970)$, parece ser el método acelerado de ensayo más apropiado para diferenciar, desde el punto de vista de resistencia al ataque de los sulfatos, según el autor, a los cementos Portland metalúrgicos, puzolánicos y sobresulfatados. 
COMPORTAMIENTO SULFÁTICO Y MECÁNICO-RESISTENTE DE CEMENTOS PORTLAND CON ELEVADOS CONTENIDOS DE PUZOLANAS (> 40\%): SU FUNDAMENTO QUÍMICO Y JUSTIFICACIÓN DE OTRAS CONSECUENCIAS POSIBLES

10. Porque la operatoria de este método de ensayo, se adapta completamente a las máximas y mejores condiciones de curado hídrico que en determinadas ocasiones les son exigibles a los hormigones en la práctica real antes de entrar en servicio y por lo tanto en contacto, en su caso, con las disoluciones sulfáticas agresivas. 
ANEXO II 

Puesto que esta investigación, objeto de Tesis Doctoral, es la continuación de la Tesis Doctoral titulada "Contribución al Estudio Analítico y Físico-Químico del Sistema: Cementos Portland-Puzolanas-Yeso", ( $\underline{\text { Talero, 1986) }}$, para la consecución de los Objetivos citados en el Capítulo 4 de esta Memoria resulta imprescindible y necesario referirnos a las Conclusiones Generales que dicho autor obtuvo entonces y que constituyen el Anexo II de la Memoria de esta Tesis Doctoral:

1a. Los cementos Portland con adición de materiales puzolánicos únicamente hasta un $40 \%$ en peso, se comportan de modo errático y en fundamento contrapuesto, en sus resistencias ante el ataque de los iones sulfato (RS) y mecánicas a edades iniciales (RM) especialmente. La interpretación que cabe dar a estos resultados se fundamenta principalmente en los efectos que ejercen en el fraguado y endurecimiento, el estado de las alúminas aportadas por la Puzolana (en esta formando parte de la alúmina reactiva, $\mathrm{Al}_{2} \mathrm{O}_{3}{ }^{r-}$, vítrea y/o amorfa) y por el cemento Portland (en éste formando parte del $\mathrm{C}_{3} \mathrm{~A}$ principalmente) y a la mayor o menor reactividad de la sílice puzolánica.

2ạ. Tomando como base la conclusión general anterior, se pueden perfeccionar las RM, a edades iniciales especialmente, o la RS de un cemento Portland por las Adición(es) Puzolánica(s) si 
la(s) misma(s) es(son) compatible(s), por su composición química y estructura física, con la composición química del cemento Portland de partida para la consecución de cada objetivo anterior.

33. Las expansiones producidas por formación de ettringita de origen Puzolana(s) (de $\mathrm{su} \mathrm{Al}_{2} \mathrm{O}_{3}{ }^{\mathrm{r}-}$ ) y de origen cemento Portland (de su $\mathrm{C}_{3} \mathrm{~A}$ ) al formarse conjuntamente en medio sulfático común, son más que Aditivas, Sinergicas.

Se han establecido métodos tecnológicos apropiados y rápidos que permiten determinar de una forma sencilla y económica, el Efecto Sinérgico Expansivo máximo o adecuado, en cada caso, y conocer las dosificaciones más convenientes en calidad y cantidad de los componentes: cemento Portland (o clinker Portland en su caso), Puzolana y Yeso, para obtener cementos de mezcla, Portland más Puzolana únicamente, de características prefijadas.

Dichas conclusiones generales habían sido obtenidas por dicho autor con base en el comportamiento que habían mostrado frente al ataque de los sulfatos en el ensayo de Le Chatelier-Ansttet (L-A) y en los ensayos ASTM C452 e Híbrido-1, las puzolanas naturales y artificiales que había seleccionado antes con el fundamento debido, para conseguir los Objetivos que se había marcado y obtener las conclusiones generales que esperaba obtener. Y dicho comportamiento se puede ver con toda claridad en las Figuras II-1, II-2., II-3., II-4. y II-5., pero no sin antes tener que precisar al respecto de dichas puzolanas que:

1. En la Consideración previa I.3. 9a del Preámbulo, dicho autor escribió lo siguiente: "A lo largo de la numerosa bibliografía consultada sobre esta temática del comportamiento de estos conglomerantes hidráulicos en medios sulfáticos, se han encontrado, en multitud de ocasiones, los términos "activo" o "reactivo" referidos por lo general indistintamente o comúnmente, según investigadores, a la parte diversa constitutiva de la puzolana, distinta de la cristalina, la cual o cuales, junto con esta última, suelen confirmarlas en mayor o menor medida.

Por ello y aun no siendo objetivo, entre otros, de este trabajo de investigación el definirla(s), precisarla(s) y/o cuantificarla(s) en ningún caso, energética y/o físicamente con exactitud -tema éste de gran interés cuyo estudio cae dentro de otras especialidades o ramas muy concretas y específicas de las ciencias físico-químicas-, se desea dejar constancia de que pese a no ser partidario de la común interpretación y/o adscripción de ambos, $\mathrm{SiO}_{2}{ }^{r-}, \mathrm{Al}_{2} \mathrm{O}_{3^{r-}}$ y $\mathrm{Fe}_{2} \mathrm{O}_{3^{r-}}$, y, $\mathrm{SiO}_{a^{a^{r}}}, \mathrm{Al}_{2} \mathrm{O}_{3^{a-}}$ y $\mathrm{Fe}_{2} \mathrm{O}_{3^{a}}$, a un mismo concepto y/o estadio de energía y si, en cambio, de lo contrario, a lo largo de esta MEMORIA ambos términos se simbolizarán o representarán mediante la siguiente fórmula común para cada uno: $\mathrm{SiO}_{2^{r}}, \mathrm{Al}_{2} \mathrm{O}_{3}{ }^{r-}$ y $\mathrm{Fe}_{2} \mathrm{O}_{3^{r}}$, respectivamente, $y$ todo ello con base en razones de facilidad, comodidad y brevedad expositiva dado que no afecta en nada a los fines y objetivos pretendidos del presente trabajo de investigación."

Es decir el autor no incluyó, entre los Objetivos de su referida investigación, determinar la estructura atómica precisa de la $\mathrm{SiO}_{2}{ }^{\mathrm{r}-}$, de la $\mathrm{Al}_{2} \mathrm{O}_{3}{ }^{\mathrm{r}-}$ ni del $\mathrm{Fe}_{2} \mathrm{O}_{3}{ }^{\mathrm{r}-}$ de la fracción vítrea y/o amorfa de las puzolanas naturales ni artificiales, y especialmente la de la $\mathrm{Al}_{2} \mathrm{O}_{3}{ }^{\mathrm{r}}$, muy a pesar de que esta última fuera de las tres la que verificó, como esperaba y en contra de lo que se 
pensaba en toda la comunidad internacional incluida España, que tenía la capacidad de formar también ettringita por ataque de los sulfatos a temperatura ambiente con cal apagada y/o portlandita mediante también, a la par que la formaba, como ya era sabido desde hacía tiempo, el $\mathrm{C}_{3} \mathrm{~A}$ del CPO, y tanto en el Laboratorio como, sobre todo, en obra real. Ya estuviera mezclada la puzolana inadecuada con un CPO ó con un CPRS hasta un 40\% de reemplazo nada más, o sin estarlo, es decir, mezclada en solitario $\mathrm{y}$, como se acaba de decir, con cal apagada $\left[=\mathrm{Ca}(\mathrm{OH})_{2}\right]$, yeso y agua. Aunque estando mezclada con él, el resultado final era mucho peor que sin estarlo, puesto que el ataque sulfático se produce con mucha mayor intensidad, rapidez y virulencia, en suma, hasta el punto de que el Efecto Expansivo resultante era y es, como se ha dicho antes en la 3ª Conclusión General que obtuvo, más que Aditivo, Sinérgico (Talero, 1986) acortando así, por ello, la durabilidad prevista del hormigón o del mortero, y además muy considerablemente incluso.

(Trusilewicz y cols., 2012) demostraron que la fracción vítrea y/o amorfa de las puzolanas naturales y artificiales era y es, en realidad, el Aluminio tetra- y/o penta-coordinado (Moya y cols., 1988) más una pequeña fracción de $\chi$-alúmina metaestable (Trusilewicz y cols., 2012), aunque algún que otro autor aboga más bien por la $\kappa$-alúmina . Sin embargo R. Talero como ha logrado demostrar antes, todo ese Aluminio en presencia de cal apagada (ya sea como tal o como portlandita) y agua forma, a temperatura ambiente los siguientes productos de hodratación:

1.1. En presencia de sulfatos, ettringita de rápida formación que Talero simbolizó ett$r f$ para diferenciarla así de la ettringita de lenta formación o de origen $\mathrm{C}_{3} \mathrm{~A}$ del $\mathrm{CPO}$, que era le única que se conocía en todo el mundo hasta entonces y que la simbolizó, por el contrario, ett-lf, (Martin-Luengo (1992), ; Rahhal y col. (2014); Talero (1992, 1996, 2002, 2003a, 2003b, 2005a, 2005b; 2005c, 2005d, 2005e 2007, 2008, 2009, 2010, 2011b); Talero y col. (1991, 1994); Talero y cols. $(1999,2016))$.

1.2. En presencia de cloruros, sal de Friedel de rápida formación también o $s F-r f$ para diferenciarla así igualmente de la sal de Friedel de lenta formación o de origen C3A del CPO que la simbolizó, por el contrario, sF-lf, (Mejía (1997); Mejía y col. (1995, 1997); Mejía y cols. (2003, Talero (2012); Talero y col. (2012); Talero y cols. (2011)), y

1.3. En presencia de agua nada más: desprendimientos de cantidades de calor de hidratación inapropiadas por demasiados elevadas de sus pastas recién fraguadas y endurecidas (Rahhal (2002); Rahhal y col. (2008); Talero y col. (2007b, 2009b)) y/o por el comportamiento reológico inapropiado también de dichas pastas pero en estado fresco (Irassar y cols. (2014); Pedrajas (2015); Rahhal y cols. (2014); Talero (2017)) al podérseles producir fenómenos de exudación no deseados de agua con el aditivo químico disuelto y/o de segregación de sus demás componentes granulares durante su amasado, transporte, vaciado, colocación y puesta en obra y vibrado en el caso de que se trate de hormigón convencional cuanto más si es auto-compacto. 
2. En la 5 $5^{a}$ Conclusión de la Parte Operatoria Previa de la Memoria de Talero (1986) dicho autor escribió lo siguiente: "La cantidad de ettringita formada (dependiendo de su intensidad de pico $2 \theta=9,8^{\circ}$ ) de origen Puzolana, bien sola o en coyunda con el cemento Portland matriz PY6 (con un contenido potencial de $C_{3} A$ del $0 \%$ )guarda una relación directa con el contenido de $\mathrm{Al}_{2} \mathrm{O}_{3}(\%)$ de la misma, puesto que las clasificaciones que se obtendrían, de mayor a menor contenido por este orden, son prácticamente coincidentes y, en especial, las de las edades fundamentales del ensayo de: 1, 7, 14,21, 28, y 730 días (véase la Tabla 11) con la que se obtendrían en función de dicho contenido total de $\mathrm{Al}_{2} \mathrm{O}_{3}(\%)$ respectivo, de mayor a menor contenido, si bien dicha relación directa es sólo circunstancial". Puesto que, en realidad y puesto que dicha ettringita, según el Capítulo IV.5.2. y los resultados alli obtenidos de los cementos PUZ al efecto preparados y ensayados, ha de provenir necesariamente no de su referido contenido total de $\mathrm{Al}_{2} \mathrm{O}_{3}(\%)$ sino únicamente de la que es reactiva ó $\mathrm{Al}_{2} \mathrm{O}_{3^{r-}}$ (\%) de la puzolana, la clasificación que se debería de obtener de tales Puzolanas ensayadas en función de su respectivo contenido estimado de $\mathrm{Al}_{2} \mathrm{O}_{3} \mathrm{r}-(\%)$, habría de ser la siguiente: M1 > C > A $>\mathrm{O}>\mathrm{D}$ (véase además la Deducción XI.8ª), debiendo de ser además la ligera diferencia de contenido de $\mathrm{Al}_{2} \mathrm{O}_{3}{ }^{\mathrm{r}}$ (\%) encontrada entre las Puzolanas $\mathrm{A}$ y $\mathrm{O}$ cuali y cuantitativas.

Talero (1986) logró demostrar, mediante análisis semi-cuantitativo de DRX nada más, todo lo referido en la precisión 1.1 y verificarlo después con probetas de pasta y de mortero selenitoso, en mayor o menor grado pero siempre agresivo, hasta el punto de que de la cantidad total estimada de $\boldsymbol{e t t}$-rf formada por cada puzolana en exclusiva con cal apagada, yeso y agua, y, por otra parte, con un CPRS (el PY6 con $0 \% \mathrm{C}_{3} \mathrm{~A}$ que se va a utilizar también en esta investigación) en proporción de reemplazo 70/30 y 7\% $\mathrm{SO}_{3}$ cada uno:

- Pudo deducir y con gran precisión además, que el metacaolín que utilizó entonces (que fue el mismo que se ha vuelto a utilizar ahora en esta otra investigación objeto de esta nueva Tesis Doctoral) era el que mayor cantidad estimada de ett-rf había formado de las cinco puzolanas que ensayó y analizó a la par con él, lo que le permitió a su vez

- Poder predecir sin más que su correspondiente contenido estimado de $\mathrm{Al}_{2} \mathrm{O}_{3}{ }^{\mathrm{r}}$ (\%) tenía que ser el mayor de las cinco, seguido por el de la puzolana natural canaria, $\mathrm{C}$, y por las de Almagro (A) y Olot (O), puesto que no había aún método químico analítico cuantitativo normalizado alguno. Talero en el 2017, (Talero, 2017) realizó el diseño y puesta punto de un nuevo método de análisis químico por vía húmeda (NMAQVH). Lo que le ha permitido poder verificar finalmente dicha predicción de entonces, puesto que los contenidos de $\mathrm{Al}_{2} \mathrm{O}_{3}{ }^{\mathrm{r}-}(\%)$ de cada una de las puzolanas anteriores determinados mediante su NMAQVH mencionado, fueron los siguientes: $\mathbf{M}(14,86 \%)>\mathbf{C}(11,41 \%)>\mathbf{A}(7,70 \%)>\mathbf{O}(5,37 \%)>\mathbf{D}(0 \%)$, es decir, totalmente concidentes con los estimados entonces (año 1986) mediante análisis semi-cuantitativo por DRX, y

3. En la Consideración previa I.3. 10 d) del Preambulo dicho autor escribió lo siguiente también: "Porque la práctica real ha sancionado y demostrado que la mezcla puzolánica más extrema, o cemento 
puzolánico con mayor contenido, en peso, de Puzolana, que cumple generalmente con todas las especificaciones nacionales e internacionales y sea cual fuere la Puzolana, suele ser la 60\%/40\%, es decir, la 60/40, aunque sólo alguna(s) de ellas, deducibles, como se verá, de las conclusiones de este trabajo, proporcione(n) lo especificado al respecto en mayor porcentaje de adición puzolánica aún, el $45 \%, 50 \%, 55 \%, \ldots$, etc., en peso, pero generalmente aquella(s) suele(n) ser caso(s) aislado(s) y, por tanto, ni general(es) ni común(es)."

Es decir mediante esta consideración previa, dicho autor justificó y sentó ya entonces las bases de esta nueva investigación objeto de esta nueva Tesis Doctoral. Puesto que si nos fijamos con atención en las Figuras II-1, II-2, II-3, II-4, y II.5, se podrá observar que, sea cual fuere la familia de cementos de mezcla Portland con elevado (el P1 y P2 en este caso) o nulo (el PY6 en este caso también) contenido potencial de $\mathrm{C}_{3} \mathrm{~A}(\%) /$ Puzolana natural o artificial con considerable a más o menos apreciable contenido de $\mathrm{Al}_{2} \mathrm{O}_{3}{ }^{\mathrm{r}-}(\%)$ (la M, CV10, C, A, O y CV19, en dicho orden de mayor a menor contenido) que se considere, el cemento de mezcla 60/40 ó cemento Puzolánico tipo CEM IV/B fue el que mejor comportamiento mostró siempre, aún dentro de lo malo incluso, frente al ataque de los sulfatos. Independientemente de que su CP matriz tuviera elevado, moderado o nulo contenido potencial de $\mathrm{C}_{3} \mathrm{~A}(\%)$ y de que dicho cemento Puzolánico 60/40 fuera de elevada, moderada o escasa resistencia a los sulfatos (SR) porque toda su familia lo era total (ninguno de los 3 cementos de mezcla de la "familia" era SRC caso, por ejemplo, de las familias P1/M, P2/M, P1/C y P2/C) o parcialmente (todas las demás familias).Ya fuera:

- porque el contenido potencial de $\mathrm{C}_{3} \mathrm{~A}$ del $\mathrm{CPO}$ con el que se mezcló la puzolana era elevado. y/o

- porque el contenido de $\mathrm{Al}_{2} \mathrm{O}_{3}{ }^{\mathrm{r}-}(\%)$ de la puzolana que los constituía era considerable, como así lo era el del metacaolín $\mathrm{M}$, el de la puzolana natural canaria $\mathrm{C}$ y el de la ceniza volante CV10, o bastante apreciable, caso de la puzolana natural peninsular A, caso de los cementos de mezcla 80/20 y 70/30 de las familias P1(14,11\%C3A) y P2(11,09\%C3A)/M, C, A y O y de las "familias" PY6(0\%C3A)/CV10, PY6/M,/C,/CV10 y /A, respectivamente, habiéndose producido además en estas dos últimas "familias"de la $\mathrm{C}$ y de la $\mathrm{M}$ mayormente con el CPO P1 y P2, un Efecto Sinérgico Expansivo (ESE), de menor o mayor intensidad, respectivamente, entre la ett-rf formada por la $\mathrm{Al}_{2} \mathrm{O}_{3}{ }^{\mathrm{r}-}$ de la puzolana de turno y la ett-lf formada por el $\mathrm{C}_{3} \mathrm{~A}$ del CPO P1 ó del P2 en este caso con el que se mezcló, pero de resultado muy negativo en cualquier caso, porque el efecto expansivo total resultante fue mucho más intenso además de muy rápido, es decir, se produjo en muy poco tiempo, siendo, no obstante y además, lo más destacable de dicho crecimiento de volumen tan considerable y espectacular de las probetas en tan corto espacio de tiempo (en los 7 primeros días tan sólo), que el mismo fue proporcional al contenido de $\mathrm{Al}_{2} \mathrm{O}_{3}{ }^{\mathrm{r}-}(\%)$ de la puzolana, de $\mathrm{C} 3 \mathrm{~A}(\%)$ del CPO con el que se mezcló y del porcentaje de reemplazo de la una por el otro, es decir, el del correspondiente cemento Puzolánico P1/M 60/40 en este último caso. Para no dejar de ser espectacular conforme la hidratación selenitosa progresó pero por el motivo totalmente contrario $\mathrm{u}$ opuesto. Ya que, tanto en proporción absoluta como relativa, su 
referida probeta L-A 60/40 fue la que menos aumentó de volumen durante el transcurso de las demás edades del ensayo incluida la de su finalización a la edad de 2 años, y aún posteriormente, mientras que las probetas L-A de sus correspondientes cementos de mezcla "hermanos" P1/M 70/30 y 80/20 continuaron, en cambio, aumentando de volumen con el progreso de su respectiva hidratación selenitosa. Y según dicho autor, la razón no es otra que la estimulación de la hidratación selenitosa que sufre por vía indirecta (Rahhal, 2009) el contenido de $C_{3} A$, que no en cambio el de $C_{3} S$, de la fracción del CPO P1 y la del P2 con el que se mezcló la puzolana en cada caso, por la muy elevada, temprana y rápida actividad puzolánica que logra generar y desarrollar el considerable contenido de $\mathrm{Al}_{2} \mathrm{O}_{3}{ }^{\mathrm{r}^{-}}$ (\%) de la puzolana (el metacaolín M en este caso) desde el instante mismo de ponerse en contacto cada uno de los materiales sólidos implicados con el agua, lo que le justificó a dicho autor poder decir que su actividad puzolánica era y es más específica que genérica. Para más detalle y mayor justificación, véanse las Figuras II-6, II-7, II-8, II-9, II-10 y II-11 en las que se ha representado gráficamente dicha actividad puzolánica determinada mediante el ensayo de Frattini a las edades de 1, 2, 7, 14, 28 y 60 días, a cada una de las puzolanas ensayadas mencionadas (excepto la D por ser totalmente ajena, por fundamento químico, al tema de esta investigación objeto de esta nueva Tesis Doctoral) mezcladas con el CPO P1 en las proporciones porcentuales de reemplazo 80/20, 70/30 y 60/40. Además, dicha estimulación de la hidratación selenitosa por vía indirecta es de tal magnitud, rapidez e intensidad también que logra solapar o enmascarar incluso la que debió de haber sufrido antes también por vía directa (Talero, 2012b) y no-directa (Talero, 2013).
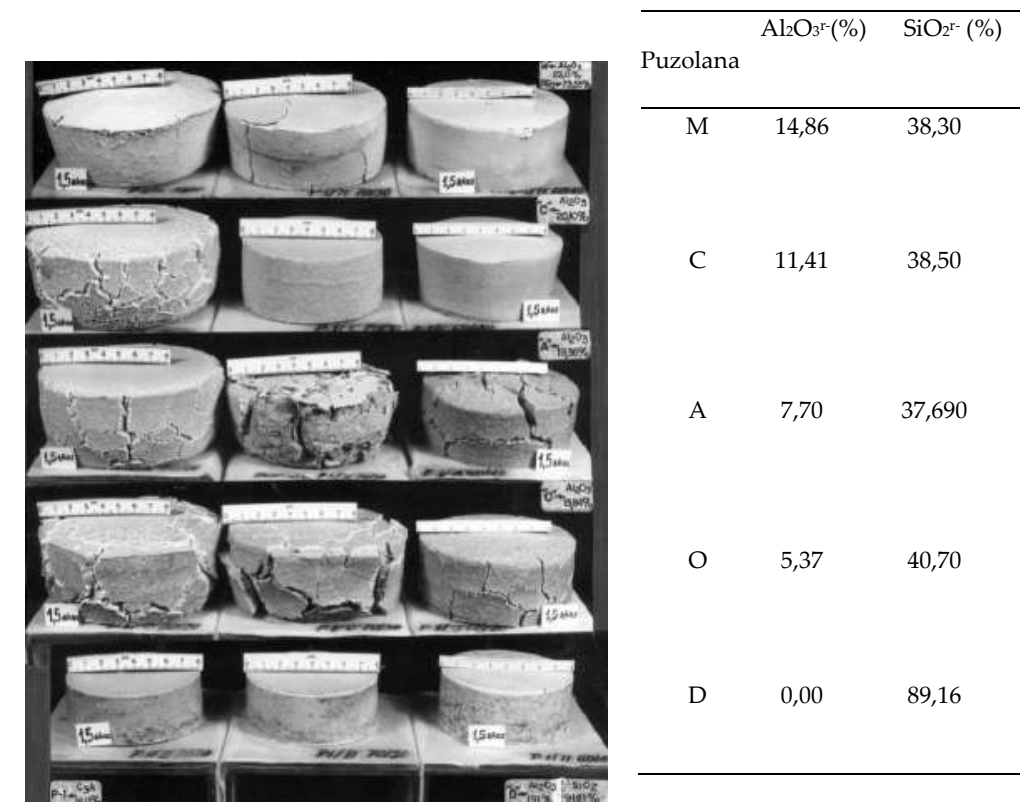

FigURA II-1. PROBETAS L-A DEL CPO P1 $\left(14,11 \% C_{3} A\right)$ CON LAS PUZOLANAS NATURALES C, A, O Y D 
(DIATOMEA PURIFICADA Y CALCINADA) Y LA ARTIFICIAL M (METACAOLÍN CON $\approx 50 \%$ DE IMPUREZAS DE CUARZO) EN LAS PROPORCIONES PORCENTUALES 80/20, 70/30 Y 60/40.

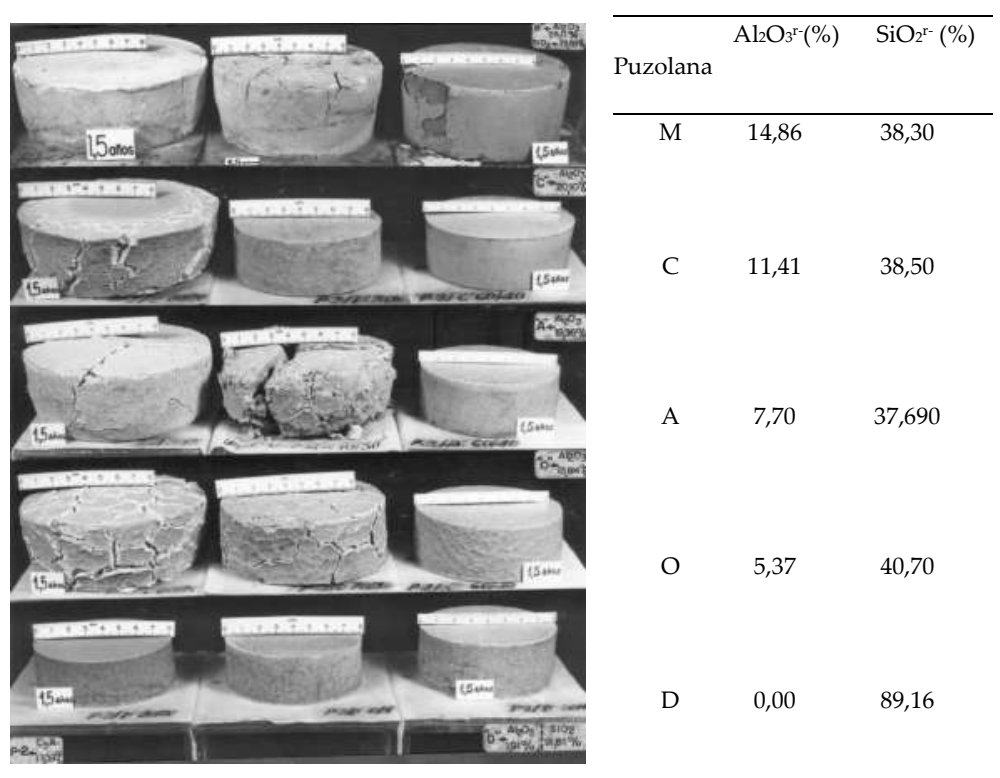

Figura II-2. Probetas L-A DEL CPO P2 (11,09\% C3A) CON LAS PUZOLANAS NATURALES C, A, O Y D (DIATOMEA PURIFICADA Y CALCINADA) Y LA ARTIFICIAL M (METACAOLÍN CON $\approx 50 \%$ DE IMPUREZAS DE CUARZO) EN LAS PROPORCIONES PORCENTUALES 80/20, 70/30 Y 60/40.

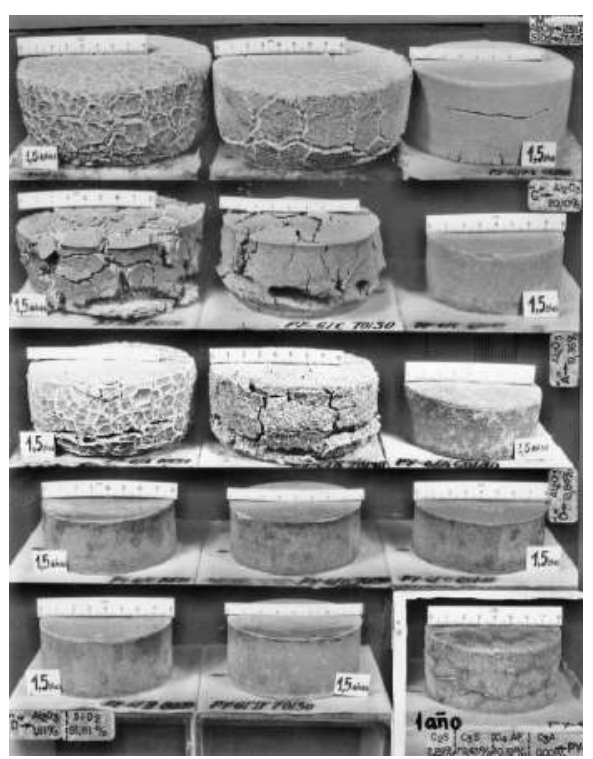

\begin{tabular}{ccc}
\hline Puzolana & $\mathrm{Al}_{2} \mathrm{O}^{r^{r}}(\%)$ & $\mathrm{SiO}_{2}{ }^{\mathrm{r}}(\%)$ \\
\hline $\mathrm{M}$ & 14,86 & 38,30 \\
$\mathrm{C}$ & 11,41 & 38,50 \\
& & \\
A & 7,70 & 37,690 \\
& & \\
O & 5,37 & 40,70 \\
& & \\
D & 0,00 & 89,16 \\
& & \\
\hline
\end{tabular}


COMPORTAMIENTO SULFÁTICO Y MECÁNICO-RESISTENTE DE CEMENTOS PORTLAND CON ELEVADOS CONTENIDOS DE PUZOLANAS ( $>40 \%$ ): SU FUNDAMENTO QUÍMICO Y JUSTIFICACIÓN DE OTRAS CONSECUENCIAS POSIBLES

Figura II-3. PROBETAS L-A DEL CPRS PY6 $\left(0 \% C_{3} A\right)$ CON LAS PUZOLANAS NATURALES C, A, O Y D (DIATOMEA PURIFICADA Y CALCINADA) Y LA ARTIFICIAL M (METACAOLÍN CON $\approx 50 \%$ DE IMPUREZAS DE CUARZO) EN LAS PROPORCIONES PORCENTUALES 80/20, 70/30 Y 60/40.

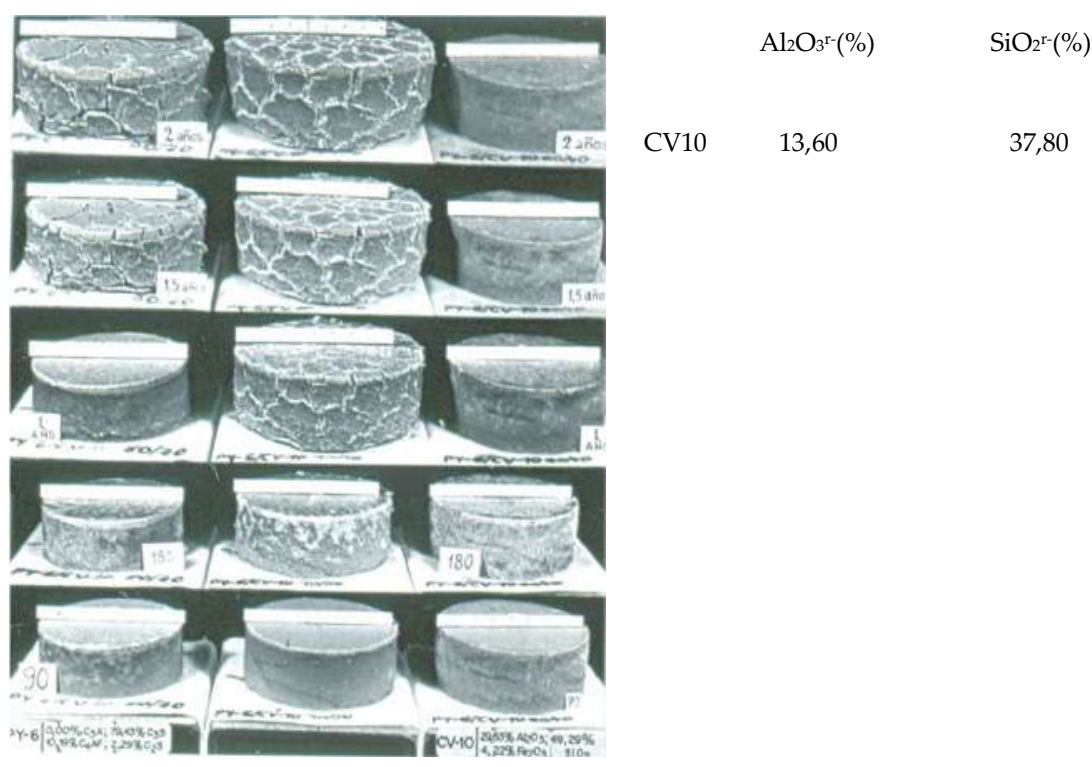

Figura II-4. PROBETAS L-A DEL CPRS PY6 ( $0 \%$ C3A) CON LA CENIZA VOLANTE CV10 EN LAS PROPORCIONES PORCENTUALES 80/20, 70/30 Y 60/40.

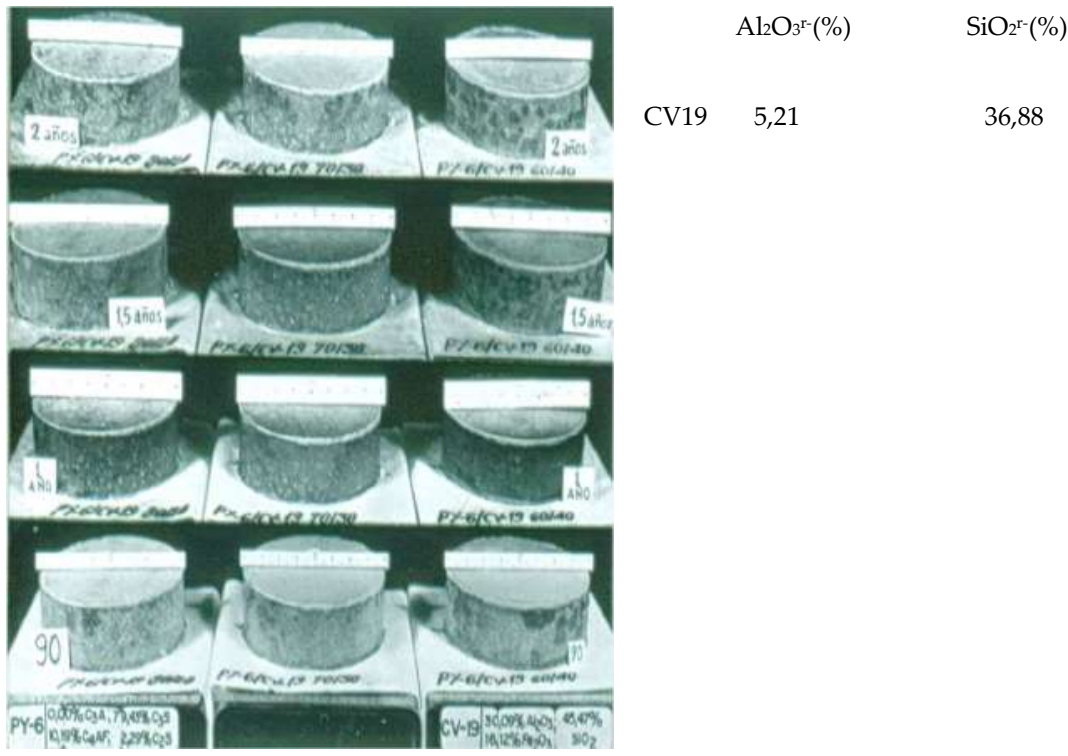

Figura II-5. PROBETAS L-A DEL CPRS PY6 (0\% C3A) CON LA CENIZA VOLANTE CV19 EN LAS 
PROPORCIONES PORCENTUALES 80/20, 70/30 Y 60/40.

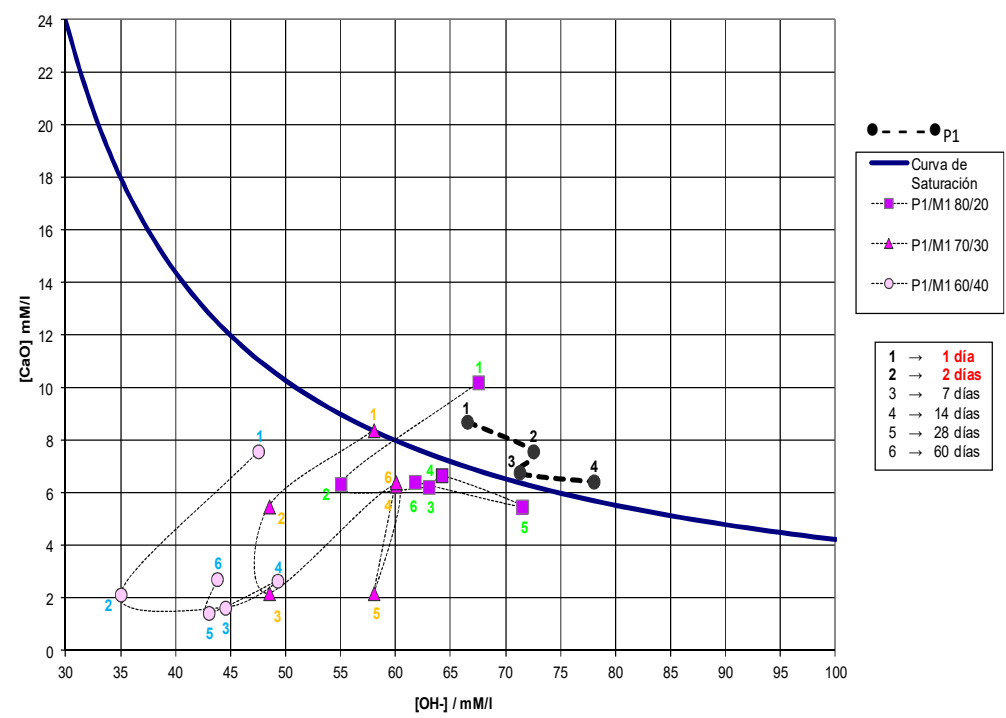

FIGURA II-6. ENSAYO DE FRATTINI: ACTIVIDAD PUZOLÁNICA GENERADA Y DESARROLLA POR EL METACAOLÍN M CON EL CPO P1 EN LAS PROPORCIONES PORCENTUALES DE REEMPLAZO 80/20, 70/30 Y 60/40. EDADES: 1, 2, 7, 14, 28 Y 60 DÍAS. OBSÉRVESE QUE EL CEMENTO PUZOLÁNICO P1/M 60/40 CUMPLE EL ENSAYO CLARAMENTE A LA EDAD DE 1 DÍA Y SU CEMENTO PUZOLÁNICO "HERMANO" 70/30 TAMBIÉN PERO NO, EN CAMBIO, SU OTRO CEMENTO DE MEZCLA “HERMANO” 80/20.

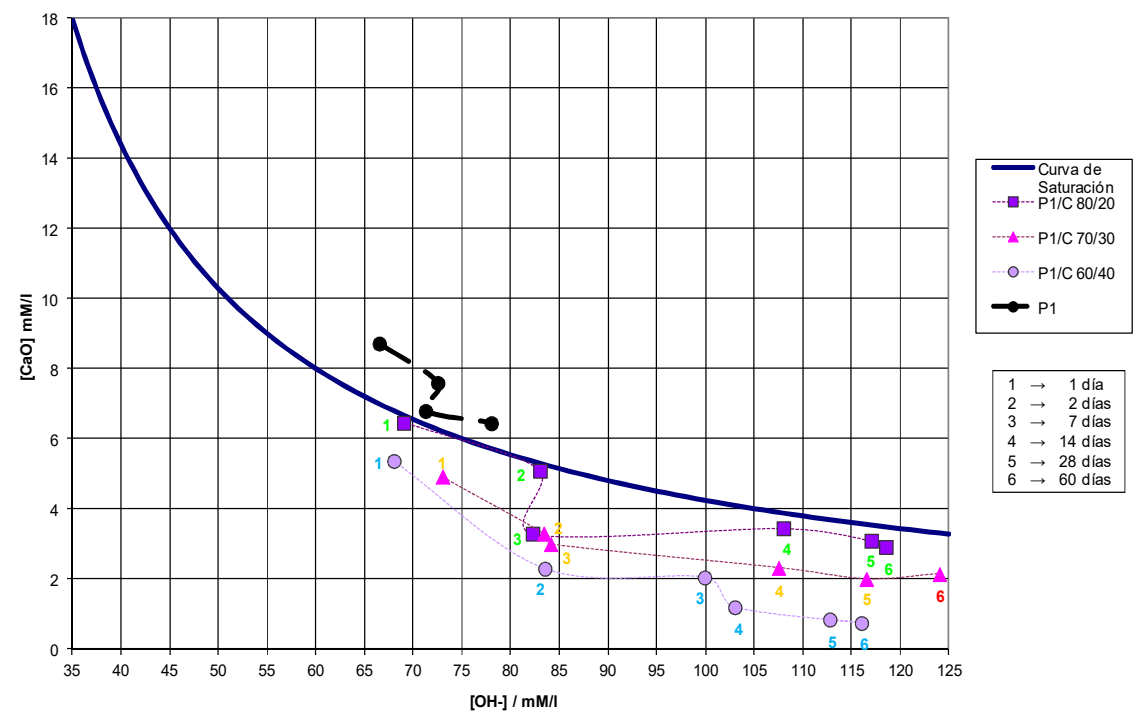

FIGURA II-7. ENSAYO DE FRATTINI: ACTIVIDAD PUZOLÁNICA GENERADA Y DESARROLLA POR LA PUZOLANA NATURAL C CON EL CPO P1 EN LAS PROPORCIONES PORCENTUALES DE REEMPLAZO 80/20, 70/30 Y 60/40. EDADES: 1, 2, 7, 14, 28 Y 60 DÍAS. OBSÉRVESE QUE LOS 
COMPORTAMIENTO SULFÁTICO Y MECÁNICO-RESISTENTE DE CEMENTOS PORTLAND CON ELEVADOS CONTENIDOS DE PUZOLANAS (>40\%): SU FUNDAMENTO QUÍMICO Y JUSTIFICACIÓN DE OTRAS CONSECUENCIAS POSIBLES

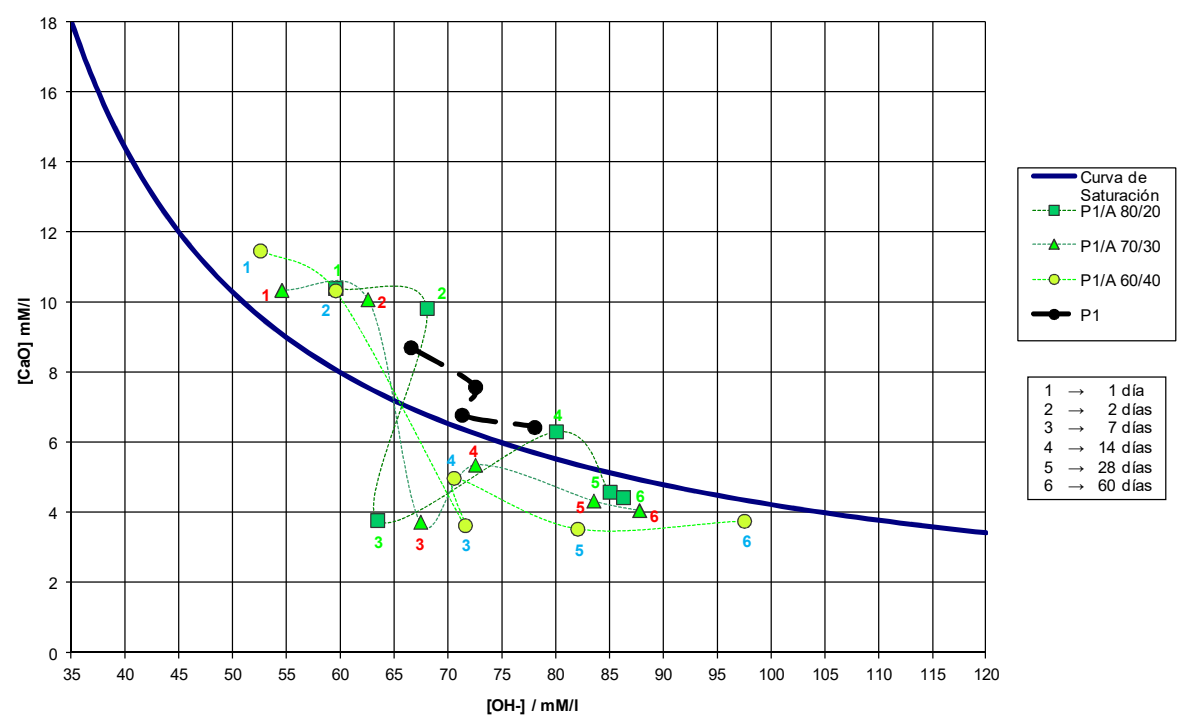

TRES CEMENTOS DE MEZCLA CUMPLIERON EL ENSAYO CON MENOR O MAYOR CLARIDAD, RESPECTIVAMENTE, DESDE LA EDAD DE 1 DÍA.

FigURA II-8. ENSAYO DE FRATTINI: ACTIVIDAD PUZOLÁNICA GENERADA Y DESARROLLADA POR LA PUZOLANA NATURAL A CON EL CPO P1 EN LAS PROPORCIONE SPOCENTUALES DE REEMPLAZO 80/20, 70/30 Y 60/40. EDADES: 1, 2, 7, 14, 28 Y 60 DÍAS. OBSÉRVESE QUE LOS TRES CEMENTOS DE MEZCLA CUMPLIERON EL ENSAYO CLARAMENTE DESDE LA EDAD DE 7 DÍAS EN ADELANTE PERO NO ANTES.

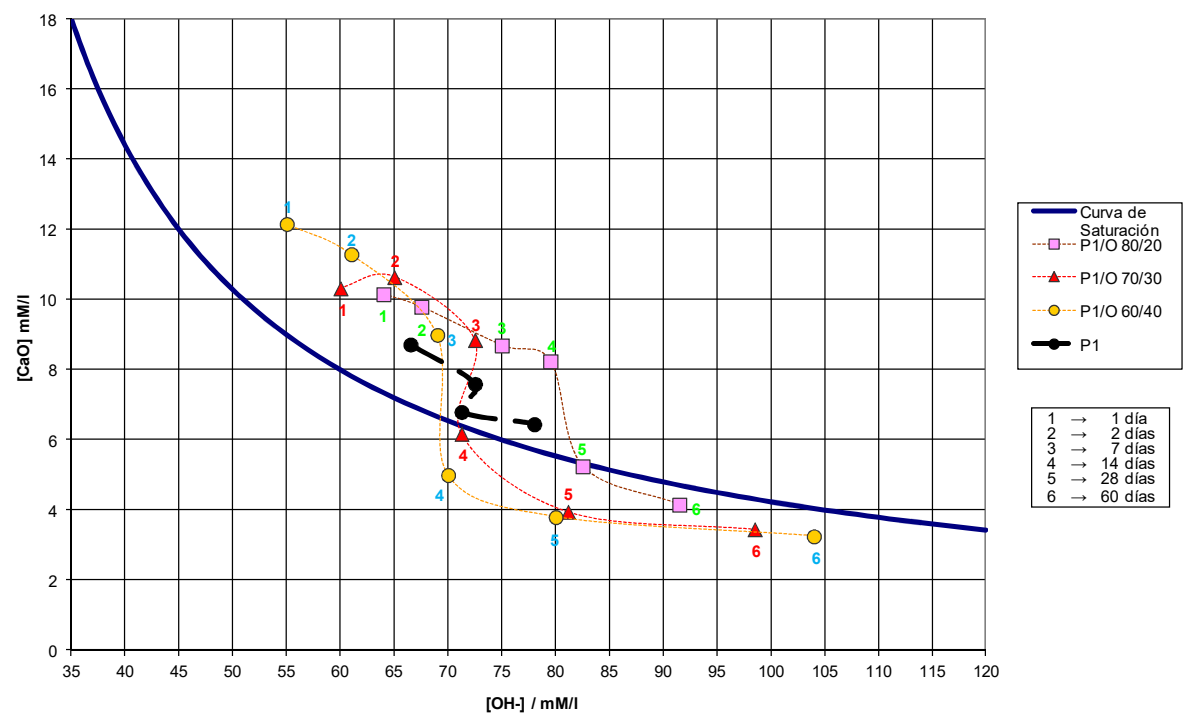

FigURA II-9. ENSAYO DE FRATTINI: ACTIVIDAD PUZOLÁNICA GENERADA Y DESARROLLA POR LA PUZOLANA NATURAL O CON EL CPO P1 EN LAS PROPORCIONES PORCENTUALES DE REEMPLAZO 80/20, 70/30 Y 60/40. EDADES: 1, 2, 7, 14, 28 Y 60 DÍAS. OBSÉRVESE QUE LOS CEMENTOS PUZOLÁNICOS P1/O 70/30 Y 60/40 CUMPLIERON EL ENSAYO CLARAMENTE DESDE LA EDAD DE 14 DÍAS EN ADELANTE PERO NO ANTES, MIENTRAS QUE SU CEMENTO DE MEZCLA "HERMANO" 80/20 LO EMPEZÓ A CUMPLIR A LA EDAD DE 28 DÍAS Y NO SIN DIFICULTAD. 


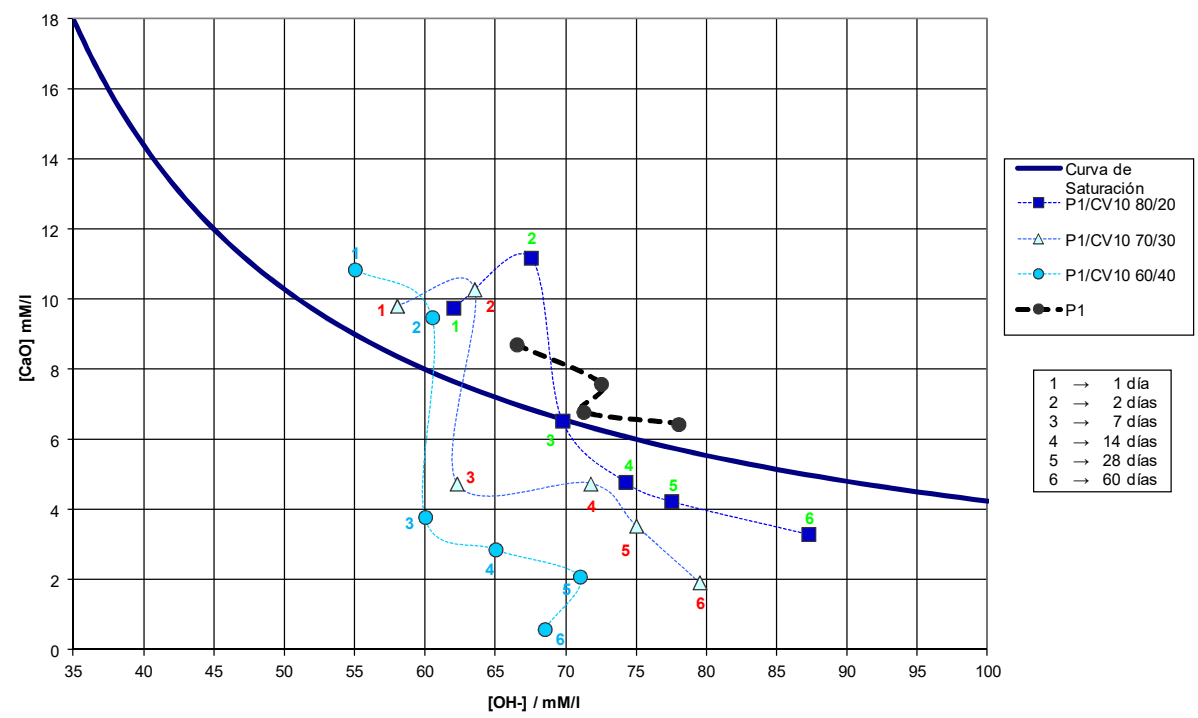

FIGURA II.10. ENSAYO DE FRATTINI: ACTIVIDAD PUZOLÁNICA GENERADA Y DESARROLLA POR LA CENIZA VOLANTE CV10 CON EL CPO P1 EN LAS PROPORCIONES PORCENTUALES DE REEMPLAZO 80/20, 70/30 Y 60/40. EDADES: 1, 2, 7, 14, 28 Y 60 DÍAS. OBSÉRVESE QUE LOS TRES CEMENTOS DE MEZCLA P1/CV10 80/20, 70/30 Y 60/40 CUMPLIERON EL ENSAYO CLARAMENTE DESDE LA EDAD DE 7 DÍAS EN ADELANTE PERO NO ANTES.

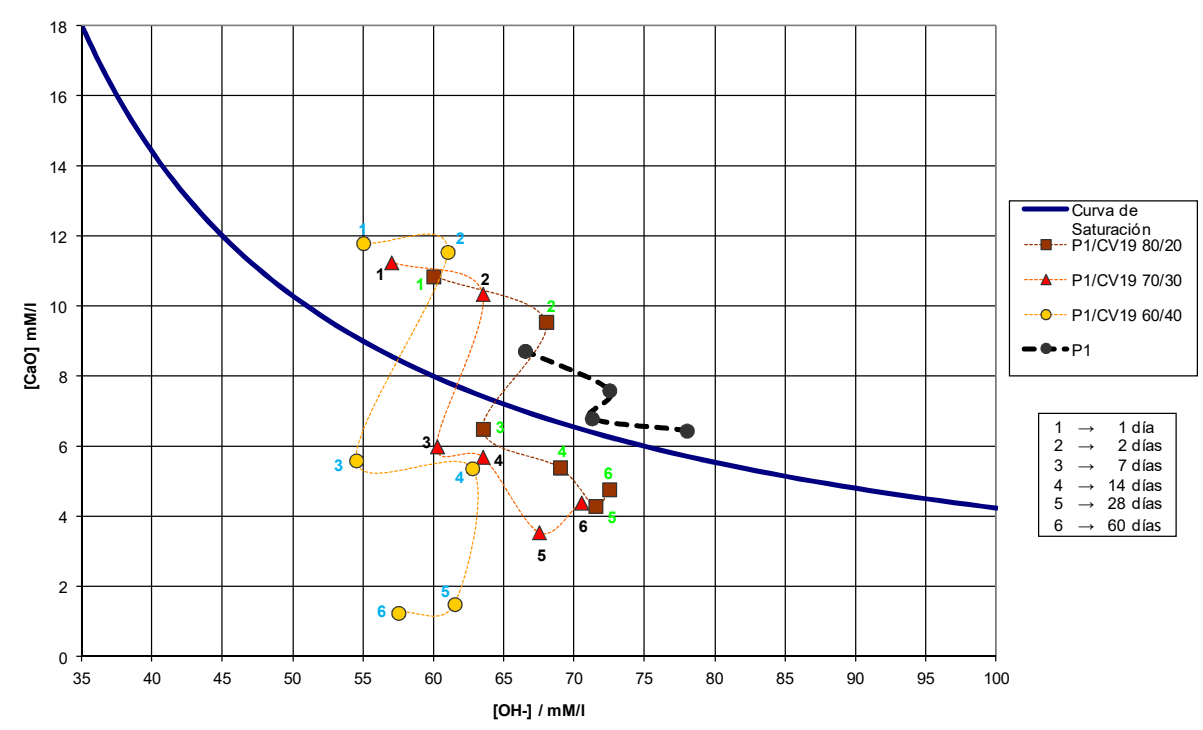

FIGURA II-11. ENSAYO DE FRATTINI: ACTIVIDAD PUZOLÁNICA GENERADA Y DESARROLLA POR LA CENIZA VOLANTE CV19 CON EL CPO P1 EN LAS PROPORCIONES PORCENTUALES DE REEMPLAZO 80/20, 70/30 Y 60/40. EDADES: 1, 2, 7, 14, 28 Y 60 DÍAS. OBSÉRVESE QUE LOS TRES CEMENTOS DE MEZCLA P1/CV19 80/20, 70/30 Y 60/40 CUMPLIERON EL ENSAYO CLARAMENTE DESDE LA EDAD DE 7 DÍAS EN ADELANTE PERO NO ANTES. 
Por consiguiente y de acuerdo con todo lo anterior pero, sobre todo, con todo lo escrito en el Capítulo 1 sobre el denodado esfuerzo que los fabricantes de cemento vienen realizando, de un tiempo a esta parte, para combatir de manera eficaz y contundente el «Efecto Invernadero», las cuestiones o preguntas que, con el fundamento debido, caben plantearse o formularse ahora a la vista de que todos los cementos Puzolánicos 60/40 de todas y cada una de las puzolanas naturales y artificiales que ensayó R. Talero (la M, C, A, O, D, CV10 y CV19, es decir, las mismas que se utilizarán una vez más en esta nueva investigación objeto de Tesis Doctoral también) mezcladas, por separado y en exclusiva, con todos y cada uno de los CP que utilizó también (el P1, P2, P31, PY4 y PY6, es decir, los mismos que se utilizarán una vez más en esta nueva investigación objeto de Tesis Doctoral también) fueron los que mostraron el mejor comportamiento, dentro del mal, buen o sólo regular comportamiento que mostró su correspondiente "familia" total o sólo parcial, frente al ataque de los sulfatos del ensayo L-A, son las siguientes:

\section{$1^{1}$. ¿Qué es lo que tienen de común todos los referidos cementos Puzolánicos $60 / 40 \ldots$ ?}

Respuesta: Que su contenido de CP (ya sea CPO o CPRS) era y es el menor de los tres cementos de mezcla de su correspondiente "familia", es decir, el que menor cantidad de portlandita pudo generar y poner a disposición de la fase líquida de cada probeta L-A con el transcurso del ensayo. O dicho de otro modo, tanto menos cantidad de portlandita pudo generar y poner a disposición de la fase líquida dicho cemento Puzolánico 60/40 de cada "familia" cuanto menos progresó el ataque sulfático. Y no tanto porque no la pudiera generar cuanto más porque era el cemento Puzolánico que poseía mayor cantidad de reemplazo de puzolana " $\mathrm{Z}$ " por $\mathrm{CP}, 40 \%$, la que habría podido y pudo generar y desarrollar finalmente mayor cantidad de actividad puzolánica con el transcurso de dicho ensayo L-A aunque su "calidad" fuera la misma en los tres cementos de mezcla de cada "familia". Lo que, en cualquier caso, conllevaría indefectiblemente más pronto (caso de la puzolana natural $\mathrm{C}$ en este caso, y artificiales tipo metacaolín M y similares) o más tarde (caso de las cenizas volantes principalmente) la disminución mayor o menor de su concentración de portlandita (expresada como $[\mathrm{CaO}] \downarrow$ ) en dicha fase líquida de su correspondiente probeta L-A, acorde además con su mayor o menor contenido de $\mathrm{Al}_{2} \mathrm{O}_{3}{ }^{\mathrm{r}}(\%)$ especialmente, para dificultar así por este motivo y en mayor o menor medida, respectivamente, la formación de toda la cantidad de ett-rf que su correspondiente contenido mencionado de $\mathrm{Al}_{2} \mathrm{O}_{3}{ }^{r}-(\%)$ habría sido capaz de formar en el caso de sus correspondientes cementos de mezcla "hermanos" 80/20 y 70/30 o condición más favorable para poder formarla toda ella.

\section{$2^{2}$. De acuerdo con la respuesta anterior ¿Cómo deberá de ser entonces, presumiblemente, el comportamiento frente al ataque de los sulfatos cuando el reemplazo de puzolana natural o artificial por CP (CPO o CPRS) supere el $40 \%$...?}

Respuesta: De acuerdo con lo dicho al final de la Respuesta de la pregunta anterior, presumiblemente mejor, aún en el supuesto de que la puzolana haya sido, en realidad, la principal y única "culpable" del mal comportamiento mostrado por su cemento de mezcla, en cualquier caso, cuando su reemplazo no superó el $40 \%$, y tanto peor fue su comportamiento al 
final del ensayo L-A, cuanto menor fue su porcentaje de reemplazo por $\mathrm{CP}$ y, al contrario. $\mathrm{Y}$ todo ello porque su contenido de $\mathrm{Al}_{2} \mathrm{O}_{3}{ }^{\mathrm{r}-}(\%)$ era considerable o bastante apreciable, caso, por ejemplo, del metacaolín M (14,86\%), de la ceniza volante CV10 (13,60\%) y de las puzolanas naturales A $(7,70 \%)$ y C (11,41\%) muy especialmente (Rahhal y col., 2005).

\section{3ạ. Y ¿Por qué razón deberá de ser entonces mejor su comportamiento...?}

Respuesta: Porque a la vista de los resultados obtenidos en el ensayo de Frattini (Figs. 3-6. a 311.) de cada uno de los cementos de mezcla de la "familia" de cada puzolana anterior, en cualquier caso y una vez más, en la fase líquida de la probeta L-A de su correspondiente cemento de mezcla 50/50, 40/60, 30/70, 20/80, etc. se deberá de disponer de menor concentración proporcional aún de portlandita ó [CaO] desde el principio al final del ensayo y tanto menor cuanto más progrese dicho ensayo y mayor haya sido el porcentaje de reemplazo de CP por puzolana que tan necesaria resulta ser para la formación de toda la cantidad de ett-rf que cada puzolana " $Z$ " es capaz de formar:

- por sí misma, de origen su propio contenido total de $\mathrm{Al}_{2} \mathrm{O}_{3}{ }^{\mathrm{r}-}(\%)$,

- e inducida, es decir, de origen el contenido de $\mathrm{C}_{3} \mathrm{~A}(\%)$ que la fracción del $\mathrm{CPO}$ con la que se mezcló aportó a la mezcla, al que logra estimular por vía directa (Talero, 2012b) y no-directa (Talero, 2013) e indirecta (Rahhal y cols., 2009) sobre todo, a hidratarse sulfáticamente también más y más rápidamente (o sea, a mucha más velocidad e intensidad, en definitiva, que sin la puzolana, es decir, cuando se trataba de dicho CPO puro) pero, en cualquier caso, la estimulación por esta última vía (Rahhal y cols., 2009) la realiza la puzolana " $Z$ " en medida proporcional a la cantidad de actividad puzolánica específica que no genérica (Mejía y cols. (2000); Pedrajas (2016); Talero (2011a, 2011b); Talero y cols. (2009)) generada y desarrollada antes por la fracción de su correspondiente contenido de $\mathrm{Al}_{2} \mathrm{O}_{3}{ }^{\mathrm{r}}-(\%)$ mencionado que aportó a su cemento de mezcla.

Por lo que, en defecto suficiente de portlandita en la fase líquida de su probeta L-A porque dicha actividad puzolánica ha sido considerable, no se deberá de formar toda ella sino mucha menor cantidad de ett-rf que la que, en realidad, debería y podría formar en condiciones más favorables: mucha menor cantidad de reemplazo de puzolana " $Z$ " por CP. De aquí que el comportamiento en RS de cada cemento de mezcla anterior deberá de ser mejor todavía con el aumento mencionado del porcentaje de reemplazo de puzolana " $Z$ " por CP mientras que en resistencias mecánicas a Compresión (RMC) y Flexotracción (RMF) especialmente y frente a la carbonatación negativa, deberá de producirse todo lo contrario u opuesto: peor lógicamente. Lo que sin duda alguna no dejará de ser un problema, por otra parte, y muy serio, por cierto (una vez que se verifique mediante esta nueva investigación objeto de Tesis Doctoral también), para poder realizar determinadas construcciones con este tipo de cementos de mezcla con tan elevados porcentajes de reemplazo de puzolana " $\mathrm{Z}$ ” por $\mathrm{CP}$.

\section{4⿳一巛工 . ¿Cómo se podrían verificar entonces, las hipótesis de comportamiento anteriores...?}

Respuesta: Se encuentra incluida en la Respuesta de la pregunta siguiente y última. 


\section{5 a Por último y teniendo en cuenta ahora la fabricación de cemento y el «Efecto Invernadero»} ¿Cómo se podría volver entonces a poner de manifiesto el mal comportamiento de la Puzolana " $\mathrm{Z}$ " frente al ataque de los sulfatos sin necesidad de tener que echar mano de cantidades de reemplazo por CP (CPO y CPRS) menores del $40 \%$ ?

Respuestas a estas dos últimas preguntas: Las respuestas a estas dos útlimas preguntas en la que se han compendiado y sintetizado los Objetivos de esta investigación vistos en el Capítulo 2, se da a lo largo del epígrafe 3.1. Fundamentos Teóricos no sin antes haber tenido en cuenta las siguientes tesis, o mejor AXIOMAS, e hipótesis de trabajo de R. Talero solo o en colaboración con otros autores y que son las siguientes:

1a. No se admite la creencia y el aserto generalizados existente sobre este tema hasta el año 1986 en casi toda la comunidad científica especializada incluida la española, de que la citada "fijación de cal" por parte de la puzolana, justificada por su actividad puzolánica, coloca al conglomerante en un medio de menor concentración de hidróxido de calcio con lo que y al decir de muchos investigadores de entonces, incluidos una vez más los españoles, se impediría y evitaría así la formación de sulfo-aluminatos de calcio hidratados o al menos si se formaban que su inata expansividad no fuese tan expansiva ni nociva. $Y$ a tal efecto cabe citar aquí que Uchikawa y Uchida (Uchikawa y col., 1974) demostraron que en el sistema "puzolana- $\mathrm{C}_{3} \mathrm{~A}-$ yeso", independientemente de la presencia o no de hidróxido de calcio en la hidratación inicial del $C_{3} A$, la formación de ettringita y Fase AFm se vio acelerada por la adición de puzolana, lo que nos alentó aún más para aceptar y establecer esta hipótesis de trabajo en cuanto a que ineludiblemente se forman en mayor o menor medida según Eitel (1957), habiéndolo confirmado además Talero (1986) experimentalmente quién además demostró que la ettringita de origen $\mathrm{Al}_{2} \mathrm{O}_{3}{ }^{\mathrm{r}-}$ de la puzolana no sólo se formaba y se forma a mucha mayor velocidad que la de origen $\mathrm{C}_{3} \mathrm{~A}$ del $\mathrm{CP}$ con el que se mezcló (unas $\approx 10$ veces mayor, razón por la cual a aquélla la denominó ettringita de rápida formación y la simbolizó ett-rf para diferenciarla así de la de este otro origen $\mathrm{C}_{3} \mathrm{~A}$ del $\mathrm{CPO}$ que la denominó ettringita de lenta formación y la simbolizó ett-lf, teniendo que ser además, como así lo era lógicamente, el tamaño de aquélla $\approx 10$ veces menor, (Martin-Luengo (1992), ; Rahhal y col. (2014); Talero (1992, 1996, 2002, 2003a, 2003b, 2005a, 2005b; 2005c, 2005d, 2005e 2007, 2008, 2009, 2010, 2011b); Talero y col. (1991, 1994); Talero y cols. $(1999,2016))$ sino que además aceleraba bastante la hidratación selenitosa o sulfática de este último y, más concretamente, la de su referido contenido de $\mathrm{C}_{3} \mathrm{~A}(\%)$ aportado a la mezcla, que no, en cambio, la de su correspondiente contenido de $\mathrm{C}_{3} \mathrm{~S}$ de la fracción del CPO con la que se mezcló la puzolana. Lo que justificó que dicho autor considerase que la actividad puzolánica de la $\mathrm{Al}_{2} \mathrm{O}_{3}{ }^{\mathrm{r}-}$ de la puzolana era y es más específica que genérica y que la formación conjunta de ambos tipos de ettringita en un medio sulfático común -co-preciìtación- llevaba y lleva siempre explícita e implícitamente aparejado un Efecto Expansivo que más que Aditivo era y es Sinérgico, (Martin-Luengo (1992), Rahhal y col. (2014); Talero (1992, 1996, 2002, 2003a, 2003b, 2005a, 2005b; 2005c, 2005d, 2005e 2007, 2008, 2009, 2010, 2011b); Talero y col. (1991, 1994); Talero y cols. (1999, 2016)). Todo ello sería confirmado además años más tarde por el mismo autor, solo o en colaboración, frente al 
ataque de los cloruros y con resultado positivo en este otro caso (Mejía (1997); Mejía y col. (1995, 1997); Mejía y cols. (2003, Talero (2012); Talero y col. (2012); Talero y cols. (2011)), y por partida doble también junto a V. Rahhal mediante el calor de hidratación (Rahhal (2002); Rahhal y col. (2008); Talero y col. (2007b, 2009b)), y junto a C. Pedrajas y V. Rahhal igualmente, pero mediante el comportamiento reológico de sus pastas frescas (Irassar y cols. (2014); Pedrajas (2015); Rahhal y cols. (2014); Talero (2017)) aunque con resultado dispar y fundamento químico contrapuesto.

$2^{\mathbf{a}}$. R. Talero ha comprobado y confirmado experimentalmente también en el Laboratorio que la ettringita de origen $\mathrm{C}_{3} \mathrm{~A}$ del $\mathrm{CPO}$ o ett-lf se forma fundamentalmente en disoluciones saturadas de portlandita (Talero, 1986). Y del mismo modo ha demostrado además que la de origen $\mathrm{Al}_{2} \mathrm{O}_{3}{ }^{\mathrm{r}-}$ de una puzolana natural o artificial o $e t t-r f$, se forma igualmente en semejantes o iguales circunstancias formando parte la puzolana de un cemento puzolánico o Tipo CEM IV/A y IV/B, e incluso de un CP con puzolanas oTipo CEM II/A-P, II/B-P, II/A-V y II/B-V, respectivamente, aún a pesar de que la concentración de portlandita de la fase líquida de sus pastas deje de ser concentrada más pronto que tarde, respectivamente también, porque su carácter químico es más alumínico que silícico, según dicho autor, y a pesar de que sea silicea y aluminosa en naturaleza según la norma ASTM C618 y aunque, en cualquier caso, su "reserva alcalina" (más apropiado es denominarle su "reserva portlandítica") sea bastante menor que la de los cementos Portland puros como lo es así la del último cemento puzolánico mencionado, el IV/B. Y a tal efecto hay que recordar lo que Eitel (1957) precisaba de los datos aportados en este sentido por D'Ans y col. (1954), según los cuales, para que se produzca reacción química entre los aluminatos de cualquier origen cementiceo o no solubles en agua y el sulfato de calcio, no es indispensable una elevada concentración de hidróxido de calcio, $\uparrow\left[\mathrm{Ca}(\mathrm{OH})_{2}\right]$, ni de portlandita lo que es propio de la fase líquida de las pastas endurecidas de los cementos puzolánicos mencionados, entre algunos otros $\mathrm{CP}$ con puzolanas. Y más propio lo será aún, lógicamente, la de la fase líquida de la pasta de aquellos otros cementos con mayor contenido aún de puzolana en exclusiva que dichos cementos puzolánicos Tipo CEM IV/B (Ref. Instrucción RC-16), de acuerdo con los resultados del ensayo de Frattini de las Figuras II.6. a II.11.

3a. De acuerdo, por tanto, con lo dicho al inicio de la tesis anterior, la segunda, se admite por probado experimentalmente también por R. Talero solo y en colaboración con otros autores, que la cantidad de sulfato-aluminatos de calcio hidratados expansivos, tipo ett-lf en este caso, formados es función directa del contenido potencial o real de $\mathrm{C}_{3} \mathrm{~A}(\%)$ del cemento Portland enfrentado al ataque del yeso, sea o no resistente al ataque de los sulfatos, no afectando en su comportamiento final el estado más o menos cristalino (cúbico, monoclínico u ortorrómbico) y/o más o menos vítreo de aquél.

4. De acuerdo igualmente y, por tanto, con lo dicho en el resto de la segunda tesis o AXIOMA, se admite asimismo por demostrado experimentalmente pero esta vez sólo por Talero (1992, 1996, 2002, 2003a, 2003b, 2005a, 2005b; 2005c, 2005d, 2005e 2007, 2008, 2009, 2010, 2011b), que el Aluminio tetra-y/o penta-coordinado (Moya y cols., 1988) más el que se encuentre en forma 
de $\chi-\mathrm{Al}_{2} \mathrm{O}_{3}$ metaestable (Trusilewicz y cols., 2012) de una puzolana natural o artificial, o alúmina reactiva sin más, $\mathrm{Al}_{2} \mathrm{O}_{3}{ }^{\mathrm{r}}$, todo él, puede formar también sulfato-aluminatos de calcio hidratados expansivos cuando concurran las condiciones físico-químicas necesarias y suficientes para ello, las cuales suelen coincidir con las existentes en los hormigones tradicionales de cementos puzolánicos cuanto más de cementos Portland con puzolanas, sea o no resistente al ataque de los iones sulfato su fracción Portland. Por consiguiente, al existir también una relación directa entre ambos: contenido de $\mathrm{Al}_{2} \mathrm{O}_{3} \mathrm{r}-(\%)$ de la puzolana $>>$ cantidad de ettringita de rápida formación o ett-rf originada por dicha puzolana con cal apagada (o con portlandita), yeso y agua, la cantidad de esta última es a su vez inversa a sus correspondientes contenidos de sílice reactiva, $\mathrm{SiO}_{2}{ }^{\mathrm{r}}$, y/u óxido férrico reactivo, $\mathrm{Fe}_{2} \mathrm{O}_{3}{ }^{\mathrm{r}-}$.

5a. Desde el punto de vista de la formación de ettringita, se admite con Turriziani y col. (1957)," Kurdowski y col. (1981), Mehta y col. (1982), la no equivalencia cuando se sustituyen equi molecularmente, del aluminato tricálcico, $\mathrm{C}_{3} \mathrm{~A}$, del clínker de cemento Portland y la alúmina reactiva, $\mathrm{Al}_{2} \mathrm{O}_{3}{ }^{\mathrm{r}}$, de una puzolana. Puesto que como se ha dicho antes en la tesis primera, la velocidad de formación de sus respectivas ettringitas es muy diferente y su expansividad resultante también (Martin-Luengo (1992); Rahhal y col. (2014); Talero (1992, 1996, 2002, 2003a, 2003b, 2005a, 2005b; 2005c, 2005d, 2005e 2007, 2008, 2009, 2010, 2011b); Talero y col. (1991, 1994); Talero y cols. $(1999,2016))$. Tanto en solitario cuanto mucho más cuando ambas ettringitas de cada origen se forman en un medio sulfático común-co-precipitación-porque originan un ESE de mayor o menor magnitud, pero acorde, en cualquier caso, con cada uno de dichos contenidos de efectos tremendamente negativos frente al ataque de los sulfatos a la pasta de cemento, pero, en cambio, muy positivos frente al ataque de los cloruros en exclusiva a las armaduras. Además, mientras que el $\mathrm{C}_{3} \mathrm{~A}$ es una especie química sintética concreta, precisa y específica: la sal aluminato tricálcico, $\mathrm{Al}_{2} \mathrm{O}_{3} \cdot 3 \mathrm{CaO}$, cuyo estado físico puede ser más o menos cristalino (cúbico, monoclínico u ortorrómbico) y/o más o menos vítreo, su peso molecular es $270,20 \mathrm{~g}$, su volumen molecular es $88,80 \mathrm{~cm}^{3}$ y su densidad es $3,040 \mathrm{~g} / \mathrm{cm}^{3}$ (Taylor, 1997), la $\mathrm{Al}_{2} \mathrm{O}_{3}{ }^{\mathrm{r}}$-de cualquier puzolana natural o artificialno lo es, por lo que no tiene ni puede tener nunca peso molecular alguno dada la enorme imprecisión de su estado físico que ni es totalmente vítreo ni tampoco totalmente cristalino sino una mezcla aleatoria de ambos, aunque predominando siempre el primero, el vítreo (en su doble versión de vítreo propiamente dicho o amorfo) sobre el segundo, el cristalino. Lo que, no obstante, no impide poder realizar cálculos estequiométricos con ella frente a los referidos ataques, por separado y en exclusiva, de los sulfatos y de los cloruros, o de ambos conjuntamente (del agua de mar) o sin ellos, es decir, sólo con agua destilada o potable, haciendo sin más que su peso molecular se asemeje al de la alúmina, $\mathrm{Al}_{2} \mathrm{O}_{3}$, en cualquiera de sus formas cristalinas: $\alpha-$ (corindón), $\beta-$ ó $\gamma$ - (Jones, 1938). 